Deutsch - typologisch 


\section{Institut für deutsche Sprache Jahrbuch 1995}




\section{Deutsch - typologisch}

Herausgegeben von

Ewald Lang und Gisela Zifonun

$\mathrm{W}$
$\mathrm{DE}$
$\mathrm{G}$

Walter de Gruyter · Berlin · New York 1996 


\section{Redaktion: Franz Josef Berens}

(0) Gedruckt auf säurefreiem Papier, das die US-ANSI-Norm über Haltbarkeit erfüllt.

Die Deutsche Bibliothek - CIP-Einheitsaufnahme

Institut für Deutsche Sprache 〈Mannheim〉:

Jahrbuch ... / Institut für Deutsche Sprache. - Berlin ; New York : de Gruyter.

Früher Schriftenreihe

ISSN 0537-7900

1995. Deutsch-typologisch. - 1996

Deutsch - typologisch / hrsg. von Ewald Lang und Gisela

Zifonun. - Berlin ; New York : de Gruyter, 1996

(Jahrbuch ...; 1995)

ISBN 3-11-014983-4

NE: Lang, Ewald [Hrsg.]

(C) Copyright 1996 by Walter de Gruyter \& Co., D-10785 Berlin

Dieses Werk einschließlich aller seiner Teile ist urheberrechtlich geschützt. Jede Verwertung außerhalb der engen Grenzen des Urheberrechtsgesetzes ist ohne Zustimmung des Verlages unzulässig und strafbar. Das gilt insbesondere für Vervielfältigungen, Übersetzungen, Mikroverfilmungen und die Einspeicherung und Verarbeitung in elektronischen Systemen.

Printed in Germany

Druck: Werner Hildebrand, Berlin

Buchbinderische Verarbeitung: Lüderitz \& Bauer-GmbH, Berlin 


\section{INHALT}

Gerhard Stickel: Eröffnung der Jahrestagung 1995

Einstiege und Zugänge

Ewald Lang: Das Deutsche im typologischen Spektrum.

Einführung in den Band

Bernard Comrie: Sprache und Sprachen: Universalien und Typologie

Ekkehard König: Kontrastive Grammatik und Typologie

V2 und Satzklammer und ihre Folgen

für die übrige Grammatik

Beatrice Primus: Dependenz und Serialisierung: das Deutsche im Sprachvergleich

Christer Platzack: Germanic Verb Second Languages

Brigitta Haftka: „Deutsch ist eine V/2-Sprache mit Verbendstellung und freier Wortfolge."

Chris Wilder: V2-Effekte: Wortstellungen und Ellipsen

Negation auf Wanderschaft

Barbara Lenz: Negationsverstärkung und Jespersens Zyklus im Deutschen und in anderen europäischen Sprachen

Karin Donhauser: Negationssyntax in der deutschen Sprachgeschichte: Grammatikalisierung oder Degrammatikalisierung?

Elke Hentschel: Negation in Interrogation und Exklamation 
Typenbestimmung in lexikalischen Feldern

Veronika Ehrich: Verbbedeutung und Verbgrammatik:

Transportverben im Deutschen

Susan Olsen: Partikelverben im deutsch-englischen Vergleich

Joachim Grabowski / Petra Weiß: Das Präpositioneninventar 289 als Determinante des Verstehens von Raumpräpositionen:

vor und hinter in fünf Sprachen

Ewald Lang: Lexikalisierung und Wortfeldstruktur - typologisch 312 betrachtet. Räumliche Dimensionsausdrücke als Fallstudie

\section{Grammatikalisierung und ,Mischtyp”}

Östen Dahl: Das Tempussystem des Deutschen im typologischen 359 Vergleich

John Ole Askedal: Überlegungen zum Deutschen als sprachtypologischem "Mischtyp"

Ulrich Engel / Ewa Geller: Das Verb in seinem Umfeld.

Die deutsche Standardsprache im Licht des Schwäbischen, des Jiddischen und des Polnischen

Pronomina: stark, schwach oder klitisch

Michal Starke: Germanische und romanische Pronomina:

405 stark - schwach - klitisch

Werner Abraham: Personalpronomina, Klitiktypologie und die Struktur des 'Mittelfeldes'

\section{Morphologische Variation}

Klaus-Michael Köpcke / David Zubin: Prinzipien für die Genuszuweisung im Deutschen

Wolfgang Ullrich Wurzel: Morphologischer Strukturwandel: Typologische Entwicklungen im Deutschen 
Phonologie und Graphie

T. Alan Hall: Silben- und Morphemstruktur in der Phonologie 553 des Deutschen

Ursula Kleinhenz: Zur Typologie phonologischer Domänen $\quad 569$

Kai Alter: Der Zusammenhang von Akzentuierung und 585

Phrasierung im Sprachvergleich

Peter Eisenberg: Zur Typologie der Alphabetschriften: 615

Das Deutsche und die Reform seiner Orthographie

Anschriften der Autoren

Das Institut für deutsche Sprache im Jahre 1995

Anhang: Rede des Hugo-Moser-Preisträgers Dr. Helmuth Feilke 697 



\section{GERHARD STICKEL}

\section{Eröffnung der Jahrestagung 1995}

Meine sehr verehrten Damen und Herren, verehrte Kolleginnen und Kollegen!

Zur Jahrestagung 1995 des Instituts für deutsche Sprache heiße ich Sie alle herzlich willkommen. Gesondert begrüßen möchte ich zunächst den Hausherrn, den Rektor der Universität Mannheim. Ich danke Ihnen, Magnifizenz, im Namen von uns allen dafür, daß wir diesmal in Ihrem Schlob tagen dürfen. Noch im letzten Jahr hat der Wissenschaftsrat wieder betont, wie wichtig die Zusammenarbeit zwischen auBeruniversitären Forschungseinrichtungen und den Hochschulen ist. Die Universität Mannheim und das IDS können in dieser Hinsicht auf eine Vielzahl erfolgreicher Formen der Kooperation in Forschung und Lehre hinweisen. Daß wir hier in der Aula der Universität versammelt sind, macht dies auf sinnfällige Weise deutlich.

Mit besonderem Dank begrüBe ich auch Herrn Direktor Roschy, den Vorsitzenden unseres Förderkreises. Dieser Verein von Freunden des IDS unterstützt die Tagung wieder einmal mit einer sehr praktischen Zuwendung. Ich nutze die Gelegenheit für den Hinweis, daB der Freundeskreis des IDS noch einige wenige Plätze für neue Mitglieder zu vergeben hat. Soweit die Werbeeinblendung!

Dies ist die 31. Jahrestagung des Instituts für deutsche Sprache. Die unauffallige Primzahl 31 hat keinerlei Symbolwert und gibt auch für numierologische Betrachtungen nichts her. Dennoch ist euch diese Tagung ein besonderes Ereignis, und zwar wegen ihres Themas „Deutsch - typologisch".

Wir sind in der letzten Zeit von Journalisten und anderen sprachinteressierten Mitbürgern gefragt worden, warum das IDS für diese Jahrestagung ein so linguistisch-technisches Gebiet wie die Sprachtypologie ausgewählt hat. Warum sollte eine Forschungseinrichtung, deren Namen schon den Forschungsgegenstand auf nur eine Sprache beschränkt, sich mit typologischen Fragen beschäftigen, die nicht auf einzelne Sprachen, sondern auf die „Verschiedenheiten des menschlichen Sprachbaues” (W. v. Humboldt), die Vielfalt der verschiedenen Sprachen gerichtet sind? Die naheliegende Antwort ist, daß wir über den typologischen Vergleich mit anderen Sprachen Neues über die deutsche Sprache herausfinden möchten oder doch wenigstens das Deutsche in vergleichender Beleuchtung stellenweise etwas deutlicher zu erkennen hoffen als bisher. Das Motiv 
ist ähnlich wie bei den verschiedenen kontrastiv-linguistischen Projekten, an denen im IDS gearbeitet worden ist und bei denen jeweils das Deutsche mit einer anderen Sprache verglichen wurde. Auch bei diesen Forschungen ging es unter der generellen Aufgabenstellung des IDS darum, eine kontrastreiche AuBensicht auf das Deutsche zu gewinnen, und dabei Eigenschaften dieser Sprache als relative Besonderheiten zu sehen, die in der Binnensicht der reinen Muttersprachenlinguistik oft nur als unauffallige Selbstverständlichkeiten erscheinen.

$\mathrm{DaB}$ auch die Beschreibung einer einzelnen Sprache implizit stets vergleichend ist oder sein sollte, ist schon oft gesagt und geschrieben worden. In den Beiträgen zu dieser Tagung soll dies für das Deutsche explizit geschehen. Damit sollen Teilantworten auf die Frage gegeben werden, was denn am Deutschen so besonders ist, das heißt, welche Eigenschaften für das Deutsche im Vergleich zu anderen Sprachen charakteristisch sind.

Bei den ersten Vorüberlegungen zu dieser Tagung hat der Berliner Kollege Ewald Lang ein mir besonders einleuchtendes Bild gebraucht. Bei der typologischen Beschreibung des Deutschen gehe es darum, meinte Lang, eine Art Phantombild dieser Sprache zu erstellen. So wie bei der kriminalistischen Arbeit ein Bild des Verdächtigen durch die Auswahl aus typischen Nasen, Haaransätzen, Augen, Kinnformen und anderen physiognomischen Merkmalen schrittweise bis zur Erkennbarkeit rekonstruiert wird, sucht die typologische Beschreibung einer Sprache durch die Analyse klassifizierungsgeeigneter Eigenschaften wie Satzstellung, Wortmorphologie, die formale Ausprägung grundlegender Bedeutungskategorien und andere das charakteristische Profil dieser Sprache zu ermitteln.

Zum Hintergrund der typologischen Beschreibung des Deutschen gehört ausgesprochen oder unausgesprochen stets auch die Feststellung, da 3 die deutsche Sprache in vieler Hinsicht gerade nichts Besonderes ist, $\mathrm{da} B$ sie viele ihrer Eigenschaften mit anderen Sprachen teilt. Nach den Ergebnissen der modernen Universalienforschung und der Allgemeinen Grammatik gehen die Gemeinsamkeiten erheblich weiter, als daß man im Deutschen wie in anderen Sprachen mit bestimmten Öffnungen im Kopf bedeutungstragende Geräusche produziert bzw. rezipiert. Die Charakteristik des Deutschen ergibt sich aus der Verteilung von relativen Besonderheiten und Gemeinsamkeiten mit mehr oder weniger vielen anderen Sprachen. Hierzu werden wir in den folgenden Vorträgen mehr und Genaueres erfahren.

Ich hoffe, es wird zumindest aus einigen der Beiträge auch erkennbar, $\mathrm{da} ß$ es bei dieser Tagung nicht ausschließlich um innerlinguistische Theoriefragen geht. In der vergleichenden Außensicht auf die deutsche Sprache 
entsprechen die typologischen Forschungen der Grundsituation des Lehrund Lerngebiets Deutsch als Fremdsprache, und sie sind damit sicherlich auch hilfreich für die Sprachreflexion im muttersprachlichen Unterricht, vom Germanistikstudium ganz zu schweigen.

Angesichts des Themas war eine Zusammenarbeit mit Vertretern der Allgemeinen Linguistik schon bei der Tagungsvorbereitung naheliegend. Anders als in früheren Jahren ist die Vorbereitung dieser Tagung in einer wirklichen Kooperation von zwei Forschungsinstituten geleistet worden, dem IDS und dem Forschungsschwerpunkt Allgemeine Sprachwissenschaft, Typologie und Universalienforschung, Berlin. Genau genommen haben auch diesmal nicht die Institute kooperiert, sondern Menschen. Es waren vor allem meine Institutskollegin Gisela Zifonun und der schon genannte Berliner Kollege Ewald Lang. Was im übrigen die Berliner Beteiligung an den Vorträgen angeht, so läßt eine Durchsicht des Programms die Befürchtung aufkommen, daB in der Berliner Linguistik zur Zeit nur wenig passiert, weil ein Großteil der Berliner Linguisten in Mannheim ist und an dieser Tagung mitarbeitet. Allen Referenten, ob aus Berlin oder den wenigen anderen Herkunftsorten, möchte ich herzlich für die Bereitschaft danken, zu dieser Tagung beizutragen.

Mit dem Wunsch, daß wir in diesen drei Tagen in Vorträgen und Diskussionsbeiträgen Neues und Wichtiges lernen mögen, eröffne ich die Jahrestagung 1995. 

Einstiege und Zugänge 



\section{Das Deutsche im typologischen Spektrum}

\section{Einführung in den Band}

\section{Deutsch - typologisch. Warum und wozu?}

Nach einem Rundblick auf die Wissenschaftslandschaft in der Germanistik und in den sich zunehmend verzweigenden anderen sprachwissenschaftlichen Disziplinen erwies sich die Themenwahl zur Jahrestagung 1995 als ebenso naheliegend und einleuchtend in der Sache wie werbend und anregend in der Absicht. Das Deutsche ist vielfältig und gründlich unter kontrastiven Gesichtspunkten analysiert und dokumentiert worden, aber es war von germanistischer Seite her bislang kaum Gegenstand typologischer Betrachtung. Umgekehrt ist die typologische Forschung selbst eher am zwischensprachlichen Vergleich von ausgewählten Schlüsselphänomenen interessiert, so daB das Deutsche dort zwar häufig vorkommt, aber meist nur in selektiven Ausschnitten.

Angesichts dieser Sachlage haben sich Mitarbeiter des Instituts für deutsche Sprache (IDS) und des Berliner Forschungsschwerpunkts "Allgemeine Sprachwissenschaft, Typologie und Universalienforschung" $(\text { FAS })^{1}$ zusammengetan und den Versuch verabredet, unter dem Thema "Deutsch - typologisch" eine neue Sicht auf die Struktur des Deutschen insgesamt zu ermitteln und wenigstens in Ausschnitten auch zu vermitteln. In den Blick zu nehmen für das Tagungsprogramm und die hier abgedruckten Beiträge sind zunächst die Prämissen des Unternehmens, nämlich die Rahmenbedingungen, innerhalb derer die Beschreibung einer einzelnen Sprache und die typologische Betrachtungsweise von Sprachen als unterschiedliche Zugänge innerhalb eines durch Universalien definierten Konzepts von "Sprache" zueinander in Beziehung zu setzen sind. Es geht dabei vornehmlich um folgende intradisziplinäre und methodische Zusammenhänge, zu deren Bewußtmachung grundsätzlich jeder der Aufsätze auf seine eigene Weise beiträgt:

1 Der FAS ist eine 1992 auf Empfehlung des Wissenschaftsrats gegründete außeruniversitāre Forschungseinrichtung, die bis Ende 1995 von der Förderungsgesellschaft Wissenschaftliche Neuvorhaben mbH München, einer Tochter der Max-Planck-Gesellschaft, getragen wird und ab 1996 als geisteswissenschaftliches Zentrum (gemeinsam finanziert vom Land Berlin und der DFG) weitergeführt wird. Der Name des FAS ist sein Programm; vgl. das Kurzportrāt im SPRACHREPORT 1/1995. 
(1) Typologie und Universalien stehen im Konnex. Die Universalien definieren zum einen den Bereich der invarianten, d.h. der notwendigen und der unmöglichen, zum anderen den Bereich der variierenden, d.h. der möglichen, aber nicht notwendigen Struktureigenschaften von "(natürlicher) Sprache" (in Abgrenzung gegen nicht-menschliche Kommunikationssysteme einerseits und künstliche Zeichensysteme andererseits). Aufgabe der Sprachtypologie ist es, den Variationsbereich von "Sprache” anhand der Vielfalt seiner Belegungen durch die auf der Erde existierenden und in stetem Wandel begriffenen Sprachen zu erforschen und daraus rekurrierende, die Struktur von Sprachen nach Typen sortierende Charakteristica zu gewinnen.

(2) Die typologischen Merkmale bilden ein Raster grammatischer Optionen, das die Struktur einer Sprache über verschiedene Ebenen hinweg bestimmt, was sich u.a. in der thematischen Gruppierung der Beiträge im Band manifestiert. Für jede Sprache kann daher letztlich so etwas wie ein typologisches Gesamtporträt entworfen werden. Dies für das Deutsche zu konturieren, ist der gemeinsame Nenner aller Beiträge, wenngleich die Ausmalung des Porträts noch lange Zeit beanspruchen dürfte. Aber schon mit dem heute verfügbaren Raster ist nicht nur jede einzelne Sprache für bestimmte Parameter oder Konstruktionstypen im Spektrum der Sprachen einzuordnen (die Beiträge des Bandes diskutieren gerade die hierfür nötigen Vergleichsinstanzen), es sind auch die diversen Ausprägungen einer Sprache - hier also der deutschen - im Variationsbereich ihrer Dialekte und historischen Stadien lokalisierbar (vgl. speziell dazu die Beiträge von K. Donhauser, U. Engel/E. Geller, W. U. Wurzel und $\mathrm{E}$. Hentschel).

(3) Das so verstandene typologische Raster bildet einen geeigneten Rah$m e n$, in den kontrastive Studien einzubetten sind (Grundsätzliches dazu im Beitrag von E. König, speziellere Analysen u.a. in den Beiträgen von S. Olsen, V. Ehrich, J. Grabowski/P. WeiB), aus dem praktische Folgerungen für Deutsch als Fremdsprache zu ziehen sind (hier sei auf einen etwa zeitgleich erscheinenden Sammelband verwiesen ${ }^{2}$ ) und mithilfe dessen gerade auch dem muttersprachlichen Germanisten im Studium und danach wichtige Einsichten zu vermitteln sind.

2 Handwerker, Brigitte (Hg.) (1995): Fremde Sprache Deutsch. Grammatische Beschreibung - Erwerbsverläufe - Lehrmethodik. Tübingen. (Tübinger Beiträge zur Linguistik 409). 


\section{Programm und Beiträge}

Themenwahl und Vortragsangebot der IDS-Jahrestagung 1995 verstanden sich somit als Plädoyer für die typologische Betrachtungsweise im Rahmen von (1) bis (3) - exemplifiziert anhand der deutschen Sprache, die zu den am intensivsten untersuchten und am ausführlichsten dokumentierten Sprachen zählt und die bei aller Vielfalt der Interessen und Aspekte alle Teilnehmer der Tagung oder Leser des Jahrbuchs als Gegenstand und Medium verbindet. Ziel der Tagung und der hier z.T. stark überarbeiteten Beiträge ist zum einen die Präsentation neuer Fakten über die Struktur und die Verwendung des Deutschen auf der deskriptiven Ebene, zum anderen und vor allem aber die Vorstellung einer Sehweise, die das Deutsche auf eine jeweilige Vergleichsebene mit anderen Sprachen bringt und somit seine spezifischen, seine typisierbaren und seine generellen Struktureigenschaften in ein neues Licht rückt.

Was damit beabsichtigt war und - wie der Band zeigt - in einem erheblichen Ausmaß auch erreicht wurde, ist die Erzeugung von Aha-Effekten. Für germanistische Muttersprachler erscheint bislang Selbstverständliches unter einer typologischen Perspektive heilsam verfremdet - man schaue nur in die Beiträge über Wortstellung (B. Haftka, C. Wilder), Pronomina (M. Starke, W. Abraham), Genus (K.-M. Köpcke/D. Zubin) oder Orthographie (P. Eisenberg). Für den Auslandsgermanisten läßt sich manche als "typisch Deutsch" beleumdete Spezialität dieser Sprache (Mark Twain ${ }^{3}$ läßt grüßen!) aus typologischer Sicht auf erhellende Weise einordnen - man lese etwa die Beiträge zu Satzklammer (U. Engel/E. Geller, J. O. Askedal), Partikelverben (S. Olsen) oder Fugenelementen (N. Fuhrhop). Dem Typologen bietet der hier unternommene Versuch, eine einzelne gut untersuchte Sprache auf allen Ebenen der Strukturbildung kritisch zu mustern, Einblicke in unbeachtet gebliebene Zusammenhänge zwischen den strukturellen Optionen, die das grammatische Porträt einer Sprache ausmachen - dazu mehr in Abschnitt 5.

Weil die hier in Auswahlen vorgeführte typologische Betrachtungsweise mit ihrer Fokussierung auf das Deutsche so viele Aspekte umfaßt und zugleich so viele in ihren Interessen durchaus unterschiedliche Adressaten erreichen soll, ist eine kurze Einführung in die Lektüre des Bandes wohl angebracht. Auf ein das Inhaltsverzeichnis mehr oder minder para-

3 Mark Twains berūhmte Satire "The awful German language/Die schreckliche deutsche Sprache" (etwa in der preiswerten Ausgabe des Verlags Sindlinger-Burchartz, Frickenhausen 1993) im Seminar referieren zu lassen, ist ein probates Mittel, um Studenten der Germanistik im AnschluB daran für die typologische Betrachtungsweise zu interessieren. 
phrasierendes Vorwort wird verzichtet zugunsten von Abstracts, die den Beiträgen vorangestellt sind. Die Gruppierung der Beiträge nach thematischen Schwerpunkten gibt gewiB eine erste Orientierung, dennoch ist die in herkömmlicher Terminologie formulierte sachbezogene Einteilung nur eine Zugangshilfe - die eigentlichen Meriten der typologischen $\mathrm{Be}-$ trachtungsweise liegen in der Diversifikation der Vergleichsinstanzen quer durch die Ebenen sprachlicher Strukturbildung und in der Vernetzung der dabei erhobenen Befunde.

Um dem vornehmlich mit dem Deutschen befaBten Leser die zahlreichen Facetten von „Deutsch - typologisch” zu erschlieBen, werden im folgenden anhand bestimmter Leitfragen einige denkbare Routen durch die Beiträge des Bandes empfohlen, die unterschiedlichen Zugangsinteressen entsprechen.

\section{Wie betreibt man Typologie?}

Jegliche Wissenschaft, also auch die Sprachtypologie, beginnt mit der Klassifizierung von Befunden, aber sie kann dabei nicht stehenbleiben. Das damit umrissene Problem betrifft in unserem Falle die Eruierung geeigneter Vergleichskriterien und die Interpretation der aus ihnen zu gewinnenden Resultate. Wir finden im Band Bemühungen zur Präzisierung von Vergleichskriterien, zur Erweiterung des Inventars der für den Vergleich herangezogenen Parameter und auch zur Validität der jeweils erhebbaren Befunde.

Mehrere Beiträge des Bandes diskutieren den wissenschaftshistorisch zu verzeichnenden Übergang von den klassischen pauschalen Typisierungen (etwa den primär morphologisch basierten Typzuweisungen "isolierend", "agglutinierend", "fusionierend/flektierend" oder den Greenbergschen "basic word order types" gemäß der Abfolge von Subjekt, Objekt, Verb) zu wesentlich feiner differenzierten und weiter verzweigten Vergleichsinstanzen: B. Comrie plädiert vor diesem Hintergrund für eine konstruktionsbezogene Typologie; W. U. Wurzel zeigt, daB die klassischen morphologischen Typzuweisungen aufs Deutsche nicht disjunkt anwendbar sind, sondern daB sich die Charakteristik der deutschen Flexion diachron und synchron gerade aus einer anteilig spezifizierbaren Mischung derselben ergibt. Die Beiträge zur Negation überprüfen Jespersens Zyklus als typologisches Kriterium und kommen ebenfalls zu nötigen Differenzierungen: etwa bezüglich der Interaktion von Negationsverstärkung und Wortstellungstypologie (B. Lenz) oder bezüglich der perspektivischen Verkürzung, die der Zyklus induziert, wenn man ihn als einfache Erklärungsschablone für die diachrone Syntax der Negation des Deutschen anlegt ( $K$. Donhauser). 
Die meisten Beiträge bringen Argumente für die Erweiterung und Komplettierung der $\mathbf{z}$ wischensprachlichen Vergleichsbasis und für die Diversifikation des Kriterieninventars, um so das in (2) erwähnte Raster von Optionen zu verfeinern. In der Tat ist die typologische Betrachtungsweise prinzipiell auf jeder Ebene grammatischer Strukturbildung anzuwenden, nur sind viele Domänen diesbezüglich noch wenig erschlossen.

Als wichtige Vorstöße in dieser Richtung sind die Beiträge zur Phonologie zu betrachten: T.A. Hall demonstriert die Rolle von Silbe vs. Morphem als Domänèn phonotaktischer Bedingungen, U. Kleinhenz diskutiert den Status der phonologischen Phrase, und K. Alter illustriert durch experimentelle Befunde den Zusammenhang von Akzentplacierung und prosodischer Phrasierung. Eines der zentralen Themen der theoretischen Diskussion der letzten Jahre ist die Argumentstruktur lexikalischer Einheiten, d.h. das lexikalisch verankerte Scharnier zwischen morphosyntaktischer und semantischer Strukturbildung. Die Aufsätze von B. Primus, S. Olsen und V. Ehrich belegen, daB und wie die Beschaffenheit der Argumentstruktur von Verben typologische Signifikanz gewinnt. Als Versuche, die typologische Vergleichsbasis um zunächst nur sehr indirekt erschließbare Domänen wie Lexikalisierung (was wird wie in einem Wort semantisch codiert?) und Wortfeldstruktur (wie ordnen sich die lexikalisierten Einheiten zu einem Feld?) zu erweitern, dürfen die Beiträge u.a. von V. Ehrich, J. Grabowski/P. Weiß und E. Lang gelten.

Typologie ist nicht einfach ein Schüttelsieb mit unterschiedlichen Durchlaßöffnungen, sondern eine ständige Bemühung um Strukturvergleiche auf einer zweiten Stufe, nämlich um die Sortierung von Übereinstimmungen und Differenzen, die man in der Strukturbildung der verglichenen Sprachen, also auf der ersten Stufe, ausfindig gemacht hat. Nicht jeder Unterschied zwischen zwei Sprachen ist als typologisch relevant qualifizierbar (wie B. Comrie zeigt) und nicht alle typologisch einschlägigen Parameter haben dasselbe Gewicht (wie u.a. W. U. Wurzel, B. Haftka, C. Platzack, Ö. Dahl, T.A. Hall, P. Eisenberg für ganz verschiedene Bereiche der Grammatik illustrieren). Daher partizipiert die typologische Betrachtungsweise nicht nur rezeptiv (im Sinne der Übernahme theoretischer Vorgaben als Vergleichsinstanzen), sondern in zunehmendem Maße auch aktiv an der linguistischen Theoriediskussion (im Sinne der crosslinguistischen Überprüfung theoretischer Konzepte auf ihre generelle Gültigkeit und ihre typologische Aussagefähigkeit hin). Auch dafür finden sich im Band deutliche Spuren, insonderheit in den Beiträgen zu V2 und Satzklammer sowie zur Phonologie.

Theoretische Kontroversen stehen hier nicht im Zentrum, deshalb sprechen wir auch modellneutral von "typologischer Betrachtungsweise". 
Aber wegen des in (1) erläuterten Zusammenhangs von Typologie und Universalien gilt grundsätzlich, daß jeder, der sich mit der linguistischen Beschreibung einer Sprache befaßt, möglicherweise intuitiv und unreflektiert, aber von der Sache her unabdingbar als Typologe agiert. In diesem Sinne will der Band den primär mit dem Deutschen befaBten Lesern nicht neue Vorgehensrezepte andienen, sondern ihnen eher verdeutlichen, was sie (zumindest implizit) ständig praktizieren. Auch dies ein wichtiger Aspekt des Vorhabens, eine neue Sicht zu vermitteln.

\section{Was heißt „Deutsch als Mischtyp”?}

Nicht allein in den entsprechend rubrizierten Beiträge von Ö. Dahl, J. O. Askedal und U. Engel/E. Geller, sondern in fast allen Beiträgen wird das Deutsche unter der jeweiligen typologischen Optik als „Mischtyp” ausgewiesen. Wer auf holzschnittartige Einteilungen à la "flektierend", „V1, V2, VLetzt" und "freie Wortfolge" gefaBt war, könnte angesichts der zahlreichen Auskünfte über den Mischcharakter des Deutschen am Nutzen der typologischen Betrachtungsweise zweifeln.

Nun, „Mischtyp” ist hier nicht etwa das Verlegenheitsetikett für die Resultate einer Analyse, die vor einer unübersichtlichen Gemengelage kapituliert hat, sondern "Mischtyp” ist eine nach Domänen und Parametern jeweils exakt ausbuchstabierte Charakterisierung. Angesichts der detailliert vorgeführten Befunde ist "Mischtyp" genau die zutreffende Bezeichnung: sie verrät die nötige Umsicht gegenüber vorschnellen Einordnungen, und sie umfaßt die erklärte Absicht zu weitergehender Differenzierung. Tatsächlich besteht der hauptsächliche Erkenntnisgewinn der Beiträge des Bandes gerade im differenzierten Nachweis für die folgende generelle Aussage: das Spezifische des Deutschen besteht gerade in seiner jeweiligen Mischcharakteristik. Dies ist alles andere als trivial. Denn es sind die unter dem Label "Mischtyp" anteilig spezifizierten Struktureigenschaften, die synchron den jeweiligen Platz des Deutschen im Spektrum der Sprachen zu bestimmen und diesen Platz diachron als Resultat von Sprachwandel zu erklären gestatten und so die Puzzlesteine liefern für ein schrittweise auszufertigendes Gesamtporträt. Zur Illustration drei Beispiele aus ganz unterschiedlichen Bereichen:

Syntax: Im Hinblick auf die klassischen "basic word order types" hat sich schon sehr früh die Diskussion am Deutschen als "Mischtyp” (Hauptsatz SVO, Nebensatz SOV) entzündet und mittlerweile eine ganze Forschungsrichtung zu „V2-Phänomenen” begründet. Die Lokalisierung von "Deutsch als Mischtyp" zwischen Verbzweit- und Verbletzt-Sprache in Termen neuester Theorieentwicklung (etwa im „minimalistischen Programm") bildet auch den Angelpunkt für mehrere in diesem Band vorge- 
legte Beiträge. B. Haftka nimmt gängige, aber widersprüchliche typologische Einordnungen des Deutschen zum Ausgangspunkt, um mit einigen wenigen Annahmen über "scrambling" und "checking" den Mischtyp so auszubuchstabieren: Deutsch ist eine abgeleitete V2-Sprache mit zugrundeliegender SOV-Reihenfolge und flexibler, aber keineswegs ungeregelter Wortfolge. Ebenso folgt C. Platzack in seinem Beitrag über die germanischen V2-Sprachen dem auch für das Deutsche gültigen SymmetriePrinzip, dab das finite Verb im Hauptsatz stets dieselbe Position einnimmt, sieht jedoch für die typologische Variation in der Vorfeldbesetzung andere Mechanismen vor. C. Wilder schlieBlich ordnet die sog. V2Effekte bezüglich der Grammatik der Ellipse (etwa Deutsch vs. Englisch) als Resultat unabhängiger einzelsprachlicher Optionen innerhalb von sprachübergreifend wirksamen Prinzipien der Ellipsen-Bildung ein.

Diachronie: Wenn, wie in (1) oben festgestellt, die Typologie die Aufgabe hat, den kontingenten Variationsbereich sprachlicher Ausdrucksbildung zwischen „Notwendig" und „Unmöglich" zu strukturieren, dann legt sie natürlich auch die jeweiligen Spielräume für historische Veränderungen fest. Nun aber ist die diachrone Abfolge der Zustände einer Sprache keineswegs einfach als sequentielle Rückprojektion ihrer synchronen Koordinaten in die Sprachgeschichte zu erfassen, und wieder ist es die ausbuchstabierte Charakterisierung als „Mischtyp”, die einem solchen KurzschluB vorbeugt, wie die Beiträge von W. U. Wurzel zur Flexion und K. Donhauser zur Negation verdeutlichen.

Wortfeldstruktur: Daß sich selbst in einem generell zum Grundwortschatz gehörigen und durch Universalien hinreichend prädeterminierten Wortfeld wie dem der Ausdrücke für räumliche Dimensionen Partitionstypen unterscheiden lassen, zeigt der Aufsatz von E. Lang. Wieder erscheint hierbei das Deutsche als anteilig spezifizierter "Mischtyp" zwischen proportionsbasierter und betrachterbasierter Dimensionszuweisung. Genau dies aber ist die Basis, von der aus sprachspezifische Mehrdeutigkeiten, Lücken und Inferenzen erklärt werden können. Hier zeigt sich erneut, daß die Charakteristik "Mischtyp" gekoppelt ist mit einer exakten Angabe der Ingredienzen.

Schieblich ist eine begründete Kennzeichnung als "Mischtyp” auch der geeignete Ausgangspunkt, um das Deutsche in areallinguistischen Bezügen (vgl. die Beiträge von Ö. Dahl und E. König) und Interferenzprozessen (dazu u.a. E. Lang und U. Engel/E. Geller) zu positionieren. 
5. Was bringt die Typologie für die Grammatikschreibung?

Eine deutsche Grammatik, die dem hier als Zielbild entworfenen typologischen Gesamtporträt die nötige Grundierung verleihen könnte, gibt es noch nicht und es wird sie, trotz einiger beeindruckender Leistungen $^{4}$ auf dem Wege dahin, in nächster Zeit kaum als einheitliches Opus zwischen zwei Buchdeckeln geben können. Der Grund ist ebenfalls aus dem vorliegenden Band ablesbar: in dem Maße, wie unsere differenzierte Kenntnis über die typologisch relevanten Vergleichsinstanzen wächst, wächst auch die Kenntnis unserer Unkenntnis: stets liegen Sondierungstiefe und Darstellungsbreite im Widerstreit, und kompromißlerische Gesamtbeschreibungen werden zu Recht gescheut. Der unmittelbare Wert der typologischen Betrachtungsweise für die Grammatikdarstellung beruht - jenseits der in Abschnitt 3 erwähnten kritischen Funktion für die Theoriebildung und den Modellvergleich - in der Sichtbarmachung von bislang wenig beachteten Zusammenhängen zwischen den Strukturbildungsdomänen, genauer: in der Einsicht in die Funktionsweise von sog. Schnittstellen und in der Aufdeckung von Korrelationen zwischen bestimmten Parameterwerten innerhalb einer Sprache als typologisches Indiz. Hier ein Beispiel für einen solchen Zusammenhang $\mathbf{z w i s c h e n ~ W o r t s t r u k t u r ~ u n d ~ P h r a s e n s t r u k t u r : ~}$

S. Olsen leitet den handfesten Unterschied zwischen höchst produktiver Präfixverb-Bildung im Deutschen und vergleichsweise marginaler im Englischen ebenso wie die Unterschiede in der Argumentvererbung bei ansonsten vergleichbaren Partikelverben aus den unterschiedlichen Entwicklungslinien ab, die die beiden Sprachen vom gemeinsamen germanischen SOV aus genommen haben (Mittelenglisch wird SVO, das Deutsche bewahrt SOV und nimmt SVO im Hauptsatz dazu), und aus den damit induzierten Differenzen in der Köpfigkeit (im Englischen sind Phrasen kopfinitial, Wortstrukturen kopffinal, im Deutschen harmoniert

4 Hier ist nicht der Ort, auf zwei ganz unterschiedliche jüngere Werke, deren Titel für sich selbst sprechen, genauer einzugehen, aber sie verdienen im vorliegenden Kontext vorrangige Erwähnung: Abraham, Werner (1995): Deutsche Syntax im Sprachenvergleich. Grundlegung einer typologischen Syntax des Deutschen. Tübingen. (= Studien zur deutschen Grammatik 41); Glinz, Hans (1994): Grammatiken im Vergleich. Deutsch - Französisch - Englisch - Latein. Formen - Bedeutungen - Verstehen. Tübingen. (= Reihe Germanistische Linguistik 136). Nicht explizit typologisch ist die von Gisela Zifonun, Ludger Hoffmann, Bruno Strecker u.a. im IdS gerade fertiggestellte zweibāndige "Grammatik der deutschen Sprache” (Berlin/New York 1996) ausgerichtet. Als breit angelegte Gesamtdarstellung trāgt sie allein schon durch ihre Detailliertheit dazu bei, das typologische Portrāt des Deutschen zu vervollständigen. 
die Form des Partikelverbs mit der Rechtsköpfigkeit der Wortstruktur). - AbschlieBend eine mögliche Leseroute durch den Band, wie sie sich aus dem Verfolg von Zusammenhängen ergeben kann:

Jeder, der Deutsch als Fremdsprache lernen muB, nimmt die Genuszuweisungen für die Nomina als arbiträre Liste wahr und - etwa im Vergleich zum Englischen - als zusätzlichen Lernaufwand in Kauf. Nun zeigt der Beitrag von K.-M. Köpcke/D. Zubin, daB die Genuszuweisung im Deutschen - wiederum in einem arbeitsteiligen Mischverfahren aus phonologischen, morphologischen und semantischen Prinzipien - durchaus motiviert ist. Von da aus ist es nur ein kleiner Schritt, um zu sehen, daB die unterschiedliche Realisierung der Kategorie Genus im Deutschen (wo es für alle Nomina obligat zu spezifizieren ist) gegenüber dem Englischen (wo nur im Pronominalsystem noch Reste erhalten sind) nicht einfach unter Morphologie abzubuchen ist, sondern z.B. via Kongruenz auch syntaktische Folgeerscheinungen zeitigt: im Deutschen und Englischen ist wegen neutralisierter Genusmarkierung im Plural zulässig meine Onkel und Tanten/my uncles and aunts, im Singular aber gestattet eben nur das Englische die entsprechende Ellipse: $m y$ aunt and uncle/ ${ }^{*}$ meine Tante und Onkel/*mein Onkel und Tante, und damit sind wir bei den von $\mathrm{C}$. Wilder diskutierten generellen Ellipse-Prinzipien mit sprachspezifischer Anwendungssteuerung. Die genusspezifizierten (Personal-)Pronomina er/sie/es im Deutschen und he/she/it im Englischen (und ihre Gegenstücke in vielen anderen Sprachen) zeigen indes noch eine weitere syntaktische Involvierung: sie zerfallen nach ihrem Verhalten bezüglich Topikalisierung, Koordinierbarkeit etc. in die syntaktisch definierten Subgruppen "stark - schwach - klitisch" (M. Starke) und determinieren gemäß dieser Differenzierung in erheblichem MaBe u.a. die möglichen Besetzungen des "Mittelfeldes" (W. Abraham). Pronominal mehrfach besetzte Mittelfelder hinwiederum fallen dadurch auf, daB gegenüber ihrer Besetzung mit vollen NP "die relative Abfolge der pronominalen Argumente eigenen Regeln zu folgen scheint" (B. Primus) ...

So kommt man zwanglos und gleich über mehrere Anmarschwege vom Genus zur Syntax. Kurzum: die typologische Betrachtungsweise fungiert für die Grammatikschreibung des Deutschen als ständiger Impulsgeber für die Unterscheidung von Zusammenhängen und Indikator für den $\mathrm{Zu}$ sammenhang von Unterschieden. 


\title{
BERNARD COMRIE
}

\section{Sprache und Sprachen: Universalien und Typologie}

\begin{abstract}
Die Sprachtypologie hat sich bisher im allgemeinen mit der Typologisierung von Sprachen beschäftigt, z.B. im Versuch, die Gesamtstruktur einer Sprache nach ihrer morphologischen Struktur oder nach ihrer Wortfolge zu charakterisieren. Seit neuerem neigen viele Typologen eher dazu, Konstruktionen anstatt Sprachen zu typologisieren. Diese Möglichkeit wird anhand von vier Konstruktionen erläutert, die Kontraste zwischen dem Deutschen und anderen Sprachen aufweisen: Kasusmarkierung nominaler Prādikate, Tough Movement, Relativsātze und Nominalsātze, Tempus und Aspekt. Die Typologisierung einer Sprache sollte also nicht, oder wenigstens nicht nur, als die Charakterisierung der Gesamtsprache betrachtet werden, sondern eher als die Charakterisierung der verschiedenen Konstruktionen, die diese Sprache umfaßt.
\end{abstract}

Wenn Nichttypologen an die Sprachtypologie denken, denken sie meistens an ein Unternehmen, bei dem man Sprachen typologisiert und klassifiziert. ${ }^{1}$ Eine Sprache wird also als agglutinerend oder isolierend klassifiziert, als OV-Sprache (rechtsköpfig) oder VO-Sprache (linksköpfig), als Sprache mit oder ohne Pro-Drop, als konfigurationell oder nichtkonfigurationell. Obwohl die Termini nur auf gewisse Aspekte der Struktur der Sprache hinweisen - auf ihre morphologische Struktur, auf ihre Wortstellung usw. - steckt öfters die Erwartung dahinter, daß diese typologischen Unterschiede größere Bedeutung für die allgemeine Struktur der gegebenen Sprache haben.

In diesem Aufsatz möchte ich eine Kritik anbringen. Obwohl ich die Leistungen der mehr oder weniger holistischen Sprachtypologie keineswegs unterschätzen will, glaube ich, daB es wichtig ist, nicht nur Sprachen, sondern auch Konstruktionen zu typologisieren. An Hand von vier Beispielen werde ich zu zeigen versuchen, daB man in einigen Fällen mit der Typologisierung einer Konstruktion zufrieden sein muB, obwohl es andere Fälle gibt, wo man doch an größere Zusammenhänge zwischen logisch unabhängigen Merkmalen denken kann.

1 Eine frühere Version dieses Aufsatzes wurde im März 1995 bei der 31. Jahrestagung des Instituts für deutsche Sprache vorgetragen. Ich bin allen Diskussionsteilnehmern für ihre Anmerkungen dankbar. 


\section{Kasusmarkierung nominaler Prädikate}

In vielen Sprachen der Welt kommt eine Kopulakonstruktion vor, in der sowohl das Subjekt als auch das nominale Prädikat im Nominativ stehen. Ein Beispiel dafür ist der lateinische Satz (1).

(1) Verae amicitiae sempiternae sunt. echt.NOM Freundschaften.NOM ewig.NOM sind 'Echte Freundschaften sind ewig.'

Bei der Analyse dieses Satzes entsteht ein Problem. Sollte man den Nominativ des nominalen Prädikats als einen Fall von Rektion - die Kopula regiert den Nominativ - oder aber als einen Fall von Kongruenz - das nominale Prädikat stimmt mit dem Subjekt im Kasus überein - betrachten? Beide Analysen können die Struktur von (1) beschreiben.

Die allgemeine Sprachtheorie muB die Möglichkeit zulassen, daB eine Kopula ein nominales Prädikat regiert, da es Sprachen gibt, wo das nominale Prädikat in einem obliquen Kasus steht, obwohl das Subjekt im Nominativ steht. Ein Beispiel dafür ist das Polnische, wie in Satz (2).

(2) Ten chtopiec jest moim uczniem.

dieser.NoM Junge.NOM ist mein.INS Schüler.INS

'Dieser Junge ist mein Schüler.'

Die allgemeine Sprachtheorie muß aber auch mit der Möglichkeit rechnen, daß eine Sprache Kongruenz zwischen nominalem Prädikat und Subjekt verlangt, da es Sprachen gibt wie zum Beispiel das Lateinische, die gerade diese Möglichkeit aufweisen. In der AcI-Konstruktion in (3) muB das Prädikat, da sein Subjekt im Akkusativ steht, auch im Akkusativ stehen. In (4) gilt das gleiche fïr den Dativ. ${ }^{2}$

(3) Creditur Pythagorae auditorem fuisse Numam.

es.wird.geglaubt Pythagoras.GEN Zuhörer.AKK gewesen.sein

Numa.AKK

'Man glaubt, daß Numa ein Zuhörer von Pythagoras war.'

(4) Mihi neglegenti esse non licet.

ich.DAT nachlässig.DAT sein nicht es.ist.erlaubt

'Es ist mir nicht erlaubt, nachlässig zu sein.'

2 Beispiel (4) ist eigentlich etwas komplixierter, da der Dativ hier nicht buchstäblich Subjekt des infinitivischen Satzes ist, sondern eher mit dem nicht ausgedrückten Subjekt dieses Satzes koreferent ist. Das allgemeine Prinzip, daß das nominale Prädikat seinen Kasus durch Kongruenz bekommt, bleibt aber gültig. 
Man sollte nicht denken, daß solche Beispiele nur in toten Sprachen vorkommen, da das Neuisländische fast das gleiche Muster darbietet. In (5) stehen sowohl das Subjekt der Kopula als auch das nominale Prädikat im Nominativ, in (6) stehen beide im Akkusativ.

(5) Strákarnir voru kitladir.

die.Jungen.NOM wurden gekitzelt.NOM

'Die Jungen wurden gekitzelt.'

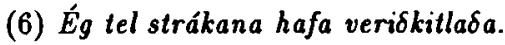

ich glaube die.Jungen.AKK haben worden gekitzelt.AKK

'Ich glaube, daB die Jungen gekitzelt worden sind.'

Hängt dieser Unterschied zwischen Rektion und Kongruenz nominaler Prädikate mit anderen Unterschieden zwischen diesen Sprachen zusammen? Ich glaube, die Antwort muß negativ sein, obwohl die Begründung dafür Daten aus zwei weiteren Sprachen verlangt, unter ihnen das Deutsche.

Wir wenden uns aber zuerst dem Finnischen zu. In Hauptsätzen und finiten Nebensätzen stehen sowohl das Subjekt als auch das nominale Prädikat im Nominativ, wie zum Beispiel in (7). ${ }^{3}$ Außer finiten Nebensätzen, wie zum Beispiel in (8a), hat das Finnische auch nichtfinite Nebensätze, wie zum Beispiel in (8b). In nichtfiniten Nebensätzen dieser Art steht das Subjekt im Genitiv, also sinun 'du.GEN' in (8b).

(7) Kirja on valkoinen.

Buch.NOM ist weiB.NOM

'Das Buch ist weiB.'

(8a) Tiedän, että sinä olet Helsingissä.

ich.weiß daB du.NOM bist Helsinki.LoK

(8b) Tiedän sinun olevan Helsingissä.

ich.weiß du.GEN seiend Helsinki.LOK

'Ich weiB, daß du in Helsinki bist.'

Wie verhält sich nun ein nominales Prädikat in einem finnischen nichtfiniten Nebensatz? Die Antwort fällt nicht nur für verschiedene Idiolekte des Finnischen unterschiedlich aus, sondern hängt auch von der lexikalischen

3 Im Finnischen gibt es auch die Möglichkeit, nominale Prädikate in den Partitiv zu setzen, was ein Beispiel für die Rektion nominaler Prädikate darstellt. Für unsere Zwecke ist aber nur die Möglichkeit des Nominativs des nominalen Prädikats wichtig. 
Wahl des nominalen Prädikats ab. Bei Adjektiven der morphologischen Klasse, die einen Nominativ auf -inen und einen Genitiv auf - isen hat, ist die bei weitem bevorzugte Form der Nominativ, wie im Beispiel (9).

(9) Tiedän kirjan olevan valkoinen/*?valkoisen. ich.weiB Buch.GEN seiend weiB.NOM/GEN 'Ich weiB, daB das Buch weiB ist.'

Im Fall des Adjektivs heikko 'schwach' wird aber der Genitiv viel leichter akzeptiert, einige Sprecher bevorzugen sogar den Genitiv bei diesem Adjektiv.

(10) Tiedān kirjan olevan heikko/heikon. ich.weiB Buch.GEN seiend schwach.NOM/GEN 'Ich weiB, daB das Buch schwach ist.'

Eine ähnliche Variation findet man auch im Deutschen, obwohl hier die Variation eher verschiedene chronologische Stufen der Sprache betrifft. In einem Satz wie (11) bevorzugt die heutige Sprache den Nominativ des nominalen Prädikats, und einige Sprecher lehnen den Akkusativ sogar ab, während der Akkusativ in früheren Sprachstadien die Regel war (Drosdowski 1984, S. 658).

(11) Laß mich dein Freund (NOM)/deinen Freund (AKK) sein.

Wenn eine einzige Sprache Variation zwischen zwei typologischen $\mathrm{Mu}$ stern zulassen kann, kann dieser Unterschied kein tiefgehender typologischer Parameter sein. Solche Beispiele beweisen, daB die Untersuchung zwischensprachlicher Unterschiede auch mit Fällen rechnen muB, wo ein eindeutiger struktureller Unterschied nicht mit anderen Unterschieden korreliert.

\section{Tough Movement}

Der Ausdruck Tough Movement ist auch in der deutschsprachigen Literatur geläufig für Sätze wie (12a)-(12b) im Englischen und Deutschen. ${ }^{4}$ Hauptmerkmal der Konstruktion ist, daB das Subjekt des Hauptsatzes eine direkte semantische Beziehung zum Infinitiv hat, und zwar sich so verhält, als wäre es das Objekt des Infinitivs. Man vergleiche (13a)(13b), wo diese Nominalphrase tatsächlich als direktes Objekt des Infinitivs auftaucht.

4 Dieses Kapitel stützt sich auf Comrie/Matthews (1990). Erst während der Jahrestagung des Instituts für deutsche Sprache habe ich zwei wichtige neuere Beiträge zur Analyse von Tough Movement kennengelernt: Blosen et al. (1987) und Demske-Neumann (1994). 
(12a) This problem is easy to solve.

(12b) Dieses Problem ist leicht zu losen.

(13a) It is easy to solve this problem.

(13b) Es ist leicht, dieses Problem zu lösen.

Auf den ersten Blick sehen die deutsche und die englische Konstruktion sehr ähnlich aus. Wenn man sie weiter untersucht, stellt man jedoch fest, daß es doch erhebliche Unterschiede gibt. Einer dieser Unterschiede taucht auf, sobald man die Konstruktion nicht prädikativ, sondern attributiv gebrauchen will. Im Englischen ist das Adjektiv Kopf der Konstruktion, die aus Adjektiv und Infinitiv besteht, und deshalb hat die attributive Konstruktion, wie zum Beispiel in (14a), das Adjektiv in attributiver Stelle, wobei der Infinitiv seine abhängige Stelle behält. Im Deutschen dagegen erscheint gerade der Infinitiv, allerdings in die Form des Gerundivums umgewandelt, als Kopf der attributiven Konstruktion - erkennbar zum Beispiel an der flektierten Form des Gerundivums. Die Entsprechung des englischen Adjektivs bleibt unflektiert, was eher eine Analyse als Adverb denn als Adjektiv nahelegt. Diese Analyse wird weiter von der Beobachtung unterstützt, daB dieses Adverb weggelassen werden kann, wie zum Beispiel in (15), also keine unentbehrliche Konstituente der Konstruktion ist. Dies weist eher auf ein Adverb als auf ein Adjektiv hin.

(14a) an easy problem to solve

(14b) *ein leichtes Problem zu lösen

(14c) ein leicht zu lösendes Problem

(15) Dieses Problem wäre zu lösen.

Die Verteilung der beiden Konstruktionen, des englischen Typs und des deutschen Typs, unter den germanischen Sprachen ist interessant. Schwedisch und, nach Blosen et al. (1987), Dänisch ähneln bis in die Einzelheiten dem Englischen. Im schwedischen Satz (16) ist svär 'schwer' ein Adjektiv. Im Schwedischen stimmen prädikative Adjektive mit ihrem Subjekt in Numerus und Genus überein, deshalb steht das Adjektiv in (16) im Singular, in (17) aber im Plural.

(16) Boken är svär att läsa.

'Das Buch ist schwer zu lesen.'

(17) Böckerna är svåra att läsa.

'Die Bücher sind schwer zu lesen.' 
In (18) findet man ein attributiv gebrauchtes Adjektiv als Kopf der attributiven Konstruktion, genau wie im englischen Beispiel (14a).

(18) en svär bok att läsa

'ein schwer zu lesendes Buch'

Niederländisch scheint beide Konstruktionen zu besitzen, wobei der deutsche Typ mit dem Infinitiv ohne om 'um' vorkommt, der englische Typ mit dem Infinitiv mit om.

(19a) Die man is moeilijk tevreden te stellen.

(19b) ? Die man is moeilijk om tevreden te stellen.

'Jener Mann ist schwer zufriedenzustellen.'

Der Unterschied zwischen den beiden niederländischen Konstruktionen läßt sich an Hand des attributiven Gebrauchs feststellen. Die Konstruktion (20a) entspricht genau der des Deutschen, mit dem einzigen Unterschied, daB das Niederländische den Infinitiv behält, ohne ihn in ein Partizip zu verwandeln. Die Konstruktion (20b) entspricht genau der des Englischen; man beachte zum Beispiel die flektierte Form des Adjektives moeijlijk 'schwer'. 6

(20a) een moeilijk tevreden te stellen man

(20b) een moeilijke man om tevreden te stellen

'ein schwer zufriedenzustellender Mann'

Die Verteilung der Konstruktionstypen unter den germanischen Sprachen scheint ziemlich willkürlich zu sein. Die slavischen Sprachen, hier durch das Russische vertreten, unterscheiden sich aber etwas grundsätzlicher von den germanischen Typen. Auf den ersten Blick gibt es kein Tough Movement im Russischen. Der russische Satz (21) entspricht

5 Die b-Version von (19) wird von einigen Sprechern in der Standardsprache zugunsten der a-Version vermieden. Das hängt anscheinend mit der Tatsache zusammen, daß die Nicht-Standardsprache dazu neigt, die Sphäre des Infinitives mit om ständig zu erweitern. Das führt in der Standardsprache zu einer negativen Reaktion gegen diejenigen Varianten mit om, die nur durch die Anwesenheit von om von synonymen Ausdrucksweisen unterschieden werden. Die negative Reaktion erstreckt sich nicht auf den attributiven Gebrauch, da es hier weitere Unterschiede als die Anwesenheit bzw. Abwesenheit von om gibt.

6 Der niederländische Infinitiv, im Gegensatz zum deutschen Partizip, ist im allgemeinen nicht flektierbar, deshalb kann man Flektion nicht als Kriterium gebrauchen, um zu prüfen, ob der Infinitiv Kopf der Konstruktion ist. Allerdings lassen einige Infinitive Flektion zu, z.B. de te voorziene problemen 'die zu erwartenden Probleme'. 
dem deutschen und englischen Beispiel (13); die Konstruktion ist unpersönlich, das Adjektiv steht also im Neutrum, und das Wort knigu 'Buch' steht im Akkusativ als direktes Objekt des Infinitivs. Eine buchstäbliche Übersetzung von (12) ist aber völlig unannehmbar im Russischen. Der ungrammatische Satz (22) bietet kniga als Subjekt dar, im Nominativ und mit dem kongruierenden Adjektiv im Femininum, da das russische Wort kniga grammatisch Femininum ist.

(21) Legko čitat'ètu knigu.

leicht.NT lesen dies- Buch.AKK

'Es ist leicht, dieses Buch zu lesen.'

(22) *Èta kniga legka čitat'.

dies- Buch.NOM leicht.F lesen

Eine gute Entsprechung des germanischen (12) im Russischen bietet Beispiel (23), wo die grammatischen Relationen im Vergleich zu (21) unverändert bleiben - die Konstruktion ist unpersönlich, weshalb das Adjektiv im Neutrum und das direkte Objekt knigu im Akkusativ stehen. Das Objekt wird aber vorangestellt, was durch die syntaktisch freie Wortfolge des Russischen zugelassen ist und die Thematisierung widerspiegelt, die in den germanischen Sprachen durch Tough Movement erfolgt. Das hängt mit einer allgemeinen Eigenschaft des Russischen (und anderer slavischer Sprachen) zusammen: Thematisierung erfolgt eher durch Wortstellungsveränderungen als durch Veränderungen der Satzglieder.

(23) Ėtu knigu legko citat' .

dies- Buch.AKK leicht.NT lesen

Im Russischen gibt es aber Sätze wie zum Beispiel (24), die diesem typologischen Unterschied anscheinend widersprechen. Hier steht kniga im Nominativ, das Adjektiv ist feminin, allerdings gebraucht man anstatt des Infinitivs das Verbalnomen mit der Präposition dlja 'für'.

(24) Ėta kniga legka dlja čtenija.

dies- Buch.Nom leicht.F für Lesen

Sobald man solche Beispiele weiter untersucht, ergibt sich, daß sie keineswegs syntaktische Entsprechungen der germanischen Konstruktionen sind, obwohl solche russischen Beispiele unter gewissen Umständen als pragmatische Entsprechungen der germanischen Konstruktionen dienen können. Ein wichtiges Merkmal der germanischen Konstruktionen, sowohl des deutschen wie des englischen Typs, ist, daB es zwar eine direkte semantische Beziehung zwischen der Nominalphrase im Nominativ und 
dem Infinitiv gibt, aber keine notwendige semantische Beziehung zwischen dieser Nominalphrase und dem Adverb bzw. Adjektiv. Man kann zum Beispiel sagen das Brot ist leicht zu schneiden, oder auf englisch the bread is easy to cut, obwohl die ÄuBerungen das Brot ist leicht oder the bread is easy kaum interpretierbar sind, wenigstens im gleichen Sinn. Im Russischen ist die Konstruktion (24) nur dann möglich, wenn der einfachere Konstruktionstyp èta kniga legka 'dieses Buch ist leicht' möglich ist. Bei (24) ist die einfachere Konstruktion möglich, weshalb die erweiterte Konstruktion auch zugelassen ist. Da der einfache Satz ètot xleb legok 'dieses Brot ist leicht' unannehmbar ist, wird auch der erweiterte Satz (25) abgelehnt.

(25) * Ètot xleb legok dlja rezanija.

dies- Brot.NOM leicht.M für Schneiden

'Dieses Brot ist leicht zu schneiden.'

Interessant ist, daB (26) völlig annehmbar ist, obwohl eine buchstäbliche Entsprechung im Deutschen unmöglich wäre: ${ }^{*}$ Dieses Zimmer ist angenehm zu schlafen. Die Möglichkeit des einfachen èta komnata prijatna 'dieses Zimmer ist angenehm' läßt auch (26) zu. Im allgemeinen kann man sagen, daß diese russische Konstruktion eine einfache Konstruktion mit einem Subjekt und einem prädikativen Adjektiv ist, wobei der Satz mit einem fakultativen adverbialen Präpositionalgefüge erweitert ist, also etwa 'dieses Buch ist leicht in Bezug auf Lesen'.

(26) Ėta komnata prijatna dlja sna.

dies- Zimmer.NOM angenehm.F für Schlaf

'Dieses Zimmer ist angenehm zum Schlafen.'

Das alles hängt mit der Abneigung des Russischen gegen produktive satzgliedverändernde Regeln (bzw. ihre Entsprechungen in anderen grammatischen Terminologien) zusammen.

\section{Relativsätze und Nominalsätze}

Der deutsche Relativsatz ist in seiner allgemeinen Struktur ein Paradebeispiel für den in Europa am meisten verbreiteten Relativsatztyp. Deutsche Relativsätze werden von einem Relativpronomen eingeleitet, das zwei wichtige Eigenschaften besitzt: Erstens, das Pronomen wird vorangestellt, auch wenn es ein Satzglied vertritt, wie zum Beispiel ein direktes Objekt, das normalerweise nach dem Verb stehen würde. Zweitens, das Relativpronomen hat ein morphologisches Kasusmerkmal, welches, zusammen mit Präpositionen, die syntaktische bzw. semantische Rolle des Relativpronomens innerhalb des Relativsatzes ausdrückt. In (27) zum Beispiel ist das Relativpronomen zwar vorangestellt, der Akku- 
sativ (ohne Präposition) läßt aber erkennen, daß es sich um ein direktes Objekt handelt.

\section{(27) der Band, [den ich - kaufle]}

In diesem Typ von Relativsätzen kann man in ziemlich konkreter Weise von einer Leerstelle reden, in (27) und späteren Beispielen durch einen Strich dargestellt. Im Deutschen ist es im allgemeinen nicht möglich, Argument-Satzglieder einfach wegzulassen, man vergleiche die Ungrammatikalität der dritten Version in Beispiel (28) mit den Versionen, in denen direkte Objekt durch eine Nominalphrase mit lexikalischem Kopf oder durch ein Pronomen vertreten ist.

(28) Ich kaufte den Band/ihn/*0.

Diese Eigenschaften der Relativpronomenkonstruktion führen zu weiteren Beobachtungen. Wenn das Relativpronomen vorangestellt ist, entsteht die Frage, ob es Beschränkungen für diese Bewegung gibt. ${ }^{7}$ Es gibt sie. Im Schriftdeutschen sind die Beschränkungen sogar sehr streng. Es ist zum Beispiel unmöglich, eine Konstituente eines Nebensatzes voranzustellen, was durch die Ungrammatikalität von (29a) gezeigt wird.

(29a) *der Band, [den er sagt, [daß ich - kaufte]] (29b) der Band, [von dem er sagt -, daß ich ihn kaufte]

Die grammatische Entsprechung ist (29b), wo die Leerstelle im Hauptsatz der Relativkonstruktion liegt (vgl. er sagt von dem Band, daß ich ihn kaufle). Obwohl einige Dialekte des Deutschen sowie das Englische und andere germanische Sprachen lockere Beschränkungen haben, gibt es trotzdem Beschränkungen in jeder dieser Sprachen. Keine von ihnen würde zum Beispiel die buchstäbliche Übersetzung des japanischen Beispiels (35) (s. unten) zulassen.

Die Eigenschaften des europäischen Relativsatzes - europäisch, da dieser Typ in Europa, und nur in Europa, verbreitet ist - weisen auf einen klaren Unterschied hin zwischen Relativsätzen und Ergänzungssätzen mit einem substantivischen Kopf wie (30). Nur der Relativsatz hat eine Leerstelle; dagegen sind in (30) alle Argumente des Verbs im Nebensatz vorhanden.

7 Falls man die prozessuale Terminologie nicht verwenden will, kann man das Problem auch anders formulieren: Welche Einschränkungen gibt es für die Beziehung zwischen einem Relativpronomen und der entsprechenden Leerstelle, oder sogar zwischen dem Relativpronomen und dem entsprechenden Satzglied in einem Hauptsatz? Die Hauptlinie der Argumentation hāngt also nicht von den Einzelheiten unterschiedlicher beschreibender Techniken ab. 
(30) die Tatsache, daß ich den Band kaufte

Der Nebensatz in (30) kann nur durch die unveränderliche Konjunktion daß eingeleitet werden, im Gegensatz zum flektierbaren Relativpronomen, das Relativsätze einleitet. Die Konstruktion (30) entspricht genau der Ergänzungskonstruktion mit einem verbalen Kopf, wie zum Beispiel in (31).

(31) Er weiß, daß ich den Band kaufte.

Wie oben gesagt, ist der Relativsatztyp, der ein Relativpronomen gebraucht, ziemlich selten unter den Sprachen der Welt, nur in Europa kommt er massenhaft vor, sogar in nichtindogermanischen Sprachen Europas, was sicher arealtypologische Beziehungen widerspiegelt. Weit verbreiteter unter den Sprachen der Welt ist der japanische Typ (33), den man im Vergleich zum einfachen Satz (32) analysieren kann. Innerhalb des Relativsatzes, der durch eckige Klammern hervorgehoben ist, gibt es keinen expliziten Hinweis auf den Kopf der Relativkonstruktion (hier: 'das Buch'). Der Relativsatz hat mehr oder weniger die Struktur eines Hauptsatzes; der einzige Unterschied zwischen (32) und dem Relativsatz von (33) liegt in der Anwesenheit bzw. der Abwesenheit des Substantivs hon 'book'.

(32) Gakusei ga hon o katta.

Student NOM Buch AKK kaufte

'Der Student kaufte das Buch.'

(33) [gakusei ga katta] hon

Student Nom kaufte Buch

'das Buch, das der Student - kaufte.'

Es gibt zwei Richtungen, die man bei der Beschreibung dieser Unterschiede $z$ wischen dem Deutschen und dem Japanischen verfolgen kann; und beide sind in der Literatur vertreten. So kann man behaupten, daB die Unterschiede oberflächlich sind und daß japanische Relativsätze auf mehr oder weniger dieselbe Weise wie deutsche Relativsätze zu analysieren sind. Ich vertrete die entgegensetzte Richtung, und zwar, daB die Unterschiede $z$ wischen den beiden Sprachtypen tiefgehend und auBerdem mit anderen grammatischen Unterschieden verknüpft sind. ${ }^{8}$

Als erste zusätzliche Beobachtung können wir feststellen, daß das Japanische sogenannte Nullanaphern zuläBt, wie zum Beispiel in (34), welches

8 Diese Analyse des japanischen Relativsatzes wird ausführlicher von Matsumoto (1988) entwickelt. Für eine Anwendung auf eine weitere Sprache des ost-/südostasiatischen Areals s. Comrie/Horie (1995). 
die normale Entsprechung eines deutschen Satzes mit einem unbetonten Pronomen darstellt.

(34) Gakusei ga katta.

Student NOM kaufte

'Der Student kaufte es.'

Da das Japanische Nullanaphern zuläBt, ist es viel schwieriger, oder sogar unmöglich, ein Plädoyer zugunsten der Anwesenheit von Leerstellen zu entwickeln. Der Relativsatz von (33) ist ein wohlgeformter einfacher Satz der japanischen Sprache. Eine mögliche Analyse wäre, daß die japanische Konstruktion (33) ganz einfach aus einem Substantiv und einem attributiven Nebensatz besteht und daB die japanische Grammatik nichts weiter über das Verhältnis zwischen den beiden Konstituenten sagt. Die genauere Angabe dieses Verhältnisses ist eher pragmatisch: Man muB ein pragmatisch plausibles Verhältnis finden. Wir kommen gleich auf einige Folgen dieser Analyse zurück.

Wenn es aber so ist, gibt es keine Voranstellung oder andere „Bewegung” in der japanischen Konstruktion. Und wenn es keine Voranstellung gibt, kann es selbstverständlich auch keine syntaktischen Einschränkungen für diese Voranstellung geben. In der Tat gibt es Beispiele japanischer Relativsätze, deren buchstäbliche Übersetzung in eine europäische Sprache völlig unmöglich wäre, wie zum Beispiel Satz (35).

[[Kawaigatte.ita] hito ga nakunatta] inu ga maiban eki made kainusi o mukae.ni kita.

hielt Mann NOM starb Hund NOM jeden.Abend Bahnhof zu Herr AKK um.zu.grüBen kam

'*Der Hund, den der Mann, der - hielt, starb, kam jeden Abend zum Bahnhof, um seinen Herrn zu grüßen.'

Der Sinn des Satzes ist, daß ein Mann einen Hund hielt. Dieser Mann ist gestorben. Trotzdem kommt der Hund jeden Abend zum Bahnhof, um den Mann zu grüßen. Wichtig dabei ist, daB jeder Japaner in diesem Satz die Geschichte des treuen Hundes Hatschiko erkennt, der so berühmt in Japan ist, daß sein Standbild vor dem Bahnhof Schibuja in Tokio steht. Alle pragmatischen Bedingungen für eine erfolgreiche Interpretation sind also erfüllt.

Wenn die oben skizzierte Analyse des japanischen Relativsatzes zutrifft, würde man erwarten, daß diese sehr locker strukturierte Konstruktion noch weitere Interpretationsmöglichkeiten hat. Die Unterschiede, die das Deutsche oder das Englische zwischen Relativsätzen wie (27) und Ergänzungssätzen mit substantivischem Kopf wie (30) aufweisen, exi- 
stieren nicht im Japanischen. Beispiel (36) hat dieselbe Struktur wie (33) - ein substantivischer Kopf mit einem attributiven Nebensatz insbesondere wenn man auf die Annahme einer Leerstelle im Falle des Relativsatzes verzichtet.

(36) [gakusei ga hon o katta] zizitu

Student NOM Buch AKK kaufte Tatsache

'die Tatsache, daß der Student das Buch kaufte'

Wichtig dabei ist, daB die Struktur von (36) keineswegs den normalen japanischen Ergänzungskonstruktionen mit verbalem Kopf entspricht. Man vergleiche zum Beispiel (37), wo der Nebensatz explizit durch no oder koto nominalisiert werden muB, um als Ergänzungssatz zu fungieren.

(37) [Gakusei ga hon o katta] no/koto o siranakatta.

Student NOM Buch AKK kaufte NMS AKK nicht.wuBte

'Ich wuBte nicht, daB der Student das Buch gekauft hatte.'

Relativsätze und Ergänzungssätze erschöpfen ferner keineswegs den Umfang der Interpretationen, die diese Konstruktion charakterisieren. Beispiel (38) gehört zu keiner dieser beiden Interpretationsmöglichkeiten, ist trotzdem völlig grammatisch und leicht interpretierbar im Japanischen. Eine wortgetreue deutsche Übersetzung wäre zum Beispiel 'der Laut, daß jemand an der Tür klopft'.

(38) [dareka ga doa o tataku] oto jemand NOM Tür AкK klopft Laut

'der Laut von jemand, der an der Tür klopft'

Der Unterschied $\mathrm{zwischen} \mathrm{deutschen} \mathrm{und} \mathrm{japanischen} \mathrm{Relativsätzen} \mathrm{ist}$ sogar oberflächlich ziemlich erheblich. Wenn man aber diese Unterschiede auf dem Hintergrund anderer Unterschiede zwischen den beiden Sprachen betrachtet, so sieht man, daB einige dieser Unterschiede - wie zum Beispiel, Relativsatztyp und Nullanapher - doch miteinander verknüpft sind, d.h., es gibt einige zwischensprachliche Unterschiede, die als Teile eines allgemeineren typologischen Porträts der gegebenen Sprachen betrachtet werden können.

\section{Tempus-Aspekt}

Als letztes Beispiel möchte ich kurz das Zusammenwirken von Semantik und Pragmatik innerhalb von Tempus-Aspekt-Systemen berühren. Es kommt oft vor, daß die eine Sprache eine grammatische Opposition im Tempus-Aspekt-System hat, die in der anderen Sprache fehlt. Im Deutschen gibt es zum Beispiel ein Plusquamperfekt, das unter gewis- 
sen Umständen feine semantische Nuancen ausdrücken kann. In einer Erzählung spiegelt eine Reihe von Verben im Imperfekt normalerweise die chronologische Reihe der Ereignisse wider, wie zum Beispiel in (39), wo man normalerweise folgern würde, daß der Sprecher ankam, bevor sein Freund wegging.

(39) Ich kam an. Mein Freund ging weg.

Das Plusquamperfekt weist auf ein Ereignis, das vor der Bezugszeit - in einer Erzählung, normalerweise das gerade geschilderte Ereignis - stattfindet, was dazu führt, daß Anordnung in der Erzählung und chronologische Reihenfolge nicht unbedingt übereinstimmen. Bei (40) würde man annehmen, daB ich ankam, nachdem mein Freund wegging.

(40) Ich kam an. Mein Freund war weggegangen.

Im Russischen gibt es kein Plusquamperfekt. Was das Tempus-AspektSystem betrift, so ist die einzige Entsprechung das Präteritum, vor allem des perfektivischen Aspekts. Die russische Satzfolge (41), wie ihre deutsche Entsprechung (39), legt nahe, daB der Sprecher ankam, bevor sein Freund wegging. Wie drückt man das Gegenteil im Russischen aus, wo es kein Plusquamperfekt gibt?

(41) Ja prišel. Moj drug ušel.

Ein einfacher Ausweg ist, den Unterschied statt grammatisch lexikalisch auszudrücken. Russisch hat ein Adverb uže 'schon', und in (42) drückt dieses Adverb aus, daB der Zustand der Abwesenheit des Freundes des Sprechers gültig war, als der Sprecher ankam, d.h., daB der Sprecher erst dann kam, als sein Freund schon weg war.

(42) Ja prišel. Moj drug uže ušel.

ich kam.an mein Freund schon ging.weg

Um den Eindruck zu vermeiden, es sei immer das Deutsche, das reichere grammatische Möglichkeiten als das Russische aufweist, wenden wir uns zuletzt einem Beispiel für das umgekehrte Verhältnis zu. Im Russischen erstreckt sich die grammatische Opposition zwischen Perfektiv und Imperfektiv auf fast alle Verben, und diese grammatische Opposition fehlt im Deutschen. Im Russischen wird die Opposition in Beispielen wie (43) sehr erfolgreich ausgenutzt. Der Imperfektiv des Verbs umirat' 'sterben' kann die Vorstadien des Todes ausdrücken, d.h. die Stadien, die normalerweise, nicht aber unbedingt zum Tod führen. Der Perfektiv schließt den Tod unbedingt mit ein. Beispiel (43) sagt also, da $B$ jemand die Vorstadien des Sterbens erlitten hat, trotzdem aber genesen ist. 
(43) On umiral, no ne umer.

er starb.IPFV aber nicht starb.PFV

'Er lag im Sterben, starb aber nicht.'

Eine wörtliche Übersetzung ins Deutsche, wo diese grammatische Opposition fehlt, würde zu einem Widerspruch führen: 'Er starb, aber er starb nicht.' Deshalb muB man zu lexikalischen MaBnahmen greifen, wie zum Beispiel zum Ausdruck im Sterben liegen, der explizit auf die Vorstadien des Sterbens hinweist. ${ }^{9}$

\section{Zusammenfassung}

An Hand von vier Beispielen habe ich zu zeigen versucht, daB es einerseits isolierte Unterschiede zwischen Sprachen gibt, die in keinen größeren typologischen Zusammenhang gehören, obwohl sie natürlich wichtig sind, wenn man ein vollständiges Bild der zwischensprachlichen Variation gewinnen will. Andererseits gibt es Gebiete, wo verschiedene logisch unabhängige Unterschiede doch miteinander verknüpft zu sein scheinen, öfters auf Weisen, die in der bisherigen Sprachtypologie kaum berührt worden sind.

\section{Literatur}

Blosen, Hans/Bærentsen, Per/Dittmer, Ernst/Pedersen, Bendt/Fors, Harald (1987): schwer und schwierig in der Bedeutung 'difficilis'. Ein Modellfall für die Beschreibung synonymer Adjektive. Heidelberg. (Germanische Bibliothek: Reihe 4, Untersuchungen).

Comrie, Bernard (1989): On identifying future tenses. In: Abraham, Werner/Janssen, Theo (Hg.): Tempus-Aspekt-Modus. Die lexikalischen und grammatischen Formen in den germanischen Sprachen. Tübingen. (Linguistische Arbeiten 237). S. 52-63.

Comrie, Bernard/Horie, Kaoru (1995): Complement clauses versus relative clauses: some Khmer evidence. In: Abraham, Werner/Givón, T./Thompson, Sandra A. (Hg.): Discourse grammar and typology. Papers in honor of John W.M. Verhaar. Amsterdam. (Studies in Language Companion Series 27). S. 65-75.

Comrie, Bernard/Matthews, Stephen (1990): Prolegomena to a typology of Tough Movement. In: Croft, William/Denning, Keith/Kemmer, Suzanne (Hg.): Studies in typology and diachrony for Joseph H. Greenberg. Amsterdam. (Typological Studies in Language 20). S. 43-56.

Demske-Neumann, Ulrike (1994): Modales Passiv und Tough Movement. Zur strukturellen Kausalität eines syntaktischen Wandels im Deutschen und Englischen. Tübingen. (Linguistische Arbeiten 326).

9 Für eine andere Anwendung dieser Ideen auf das Deutsche (neben anderen Sprachen) s. Comrie (1989). 
Drosdowski, Gūnter (Hg.) (1984): Duden Grammatik der deutschen Gegenwartssprache. 4. Auflage. Mannheim.

Matsumoto, Yoshiko (1988): Semantics and pragmatics of noun-modifying constructions in Japanese. In: Axmaker, Shelley/Jaisser, Annie/Singmaster, Helen (Hg.): Papers from the Fourteenth Meeting of the Berkeley Linguistic Society. Berkeley, CA. S. 166-175. 


\title{
EKKEHARD KÖNIG
}

\section{Kontrastive Grammatik und Typologie}

\begin{abstract}
Dem traditionellen Programm der kontrastiven Linguistik (effektivere Gestaltung von Fremdsprachenunterricht auf der Grundlage eines systematischen Vergleichs zwischen Muttersprache und zu erlernender Fremdsprache) wird eine Konzeption gegenübergestellt, die kontrastive Linguistik als Grenzfall eines typologischen Vergleichs auffaft. Nach einer Diskussion der besonderen Möglichkeiten, die ein auf zwei Sprachen beschränkter typologischer Vergleich bietet (Feinkörnigkeit, Zahl der Parameter, Umfang des Vergleichs), wird ein Gesamtbild der typischen Eigenschaften des Deutschen im Vergleich zu den germanischen und zu den europäischen Sprachen insgesamt entworfen. Basis dieser 'Charakterologie' ist eine umfassende Auswertung der kontrastiven Untersuchungen zum Deutschen sowie der relevanten typologischen Literatur.
\end{abstract}

\section{Kontrastive Grammatik: Programm und Wirklichkeit}

Das Programm der kontrastiven Linguistik wurde in den sechziger Jahren aus dem Bestreben heraus entwickelt, den Fremdsprachenunterricht durch einen systematischen Vergleich von Muttersprache und zu erlernender Fremdsprache effektiver zu gestalten. Ausgangspunkte dieses Programms waren die Annahmen, daß jede Fremdsprache auf der Grundlage der bereits erworbenen Muttersprache gelernt wird und daß Gemeinsamkeiten zwischen Mutter- und Fremdsprache den LernprozeB erleichtern (positiver Transfer), Unterschiede diesen LernprozeB jedoch erschweren (Interferenz). Durch einen Vergleich zwischen Muttersprache und zu erlernender Fremdsprache hoftte man, Fehler vorhersagen und erklären sowie Strategien zu ihrer Vermeidung entwickeln zu können. Insbesondere im Bereich der Lautstruktur einer Sprache hat dieses Programm durchaus ein großes $\mathrm{MaB}$ an Plausibilität und führte somit auch zu einigen Erfolgen. Da jedoch bei der Umsetzung dieses Programms vielfach übersehen wurde, daß die Beziehungen zwischen bereits beherrschter Muttersprache und zu erlernender Fremdsprache nur einer der Faktoren sind, die beim Prozeß des Fremdsprachenerwerbs eine Rolle spielen (cf. Wienold 1973), mußten die hochgesteckten Erwartungen bezüglich der praktischen Implikationen des Sprachvergleichs enttäuscht werden. Viele Anhänger der o.g. Programmatik wandten sich daraufhin der empirischen Beschäftigung mit dem lernersprachlichen Verhalten in den verschiedenen Phasen des Fremdspracherwerbs zu, d.h. der Fehleranalyse (vertikalen kontrastiven Analyse) oder der Analyse von Interimsspra- 
che und von approximativen Systemen. Andere sprachen sich dafür aus, die kontrastive Linguistik von ihrer ursprünglichen $\mathbf{Z}$ weckbestimmung zu lösen und einfach als neuen $Z$ weig der vergleichenden Sprachwissenschaft zu definieren, gleichsam als Grenzfall eines typologischen Vergleichs. Ziel einer so verstandenen kontrastiven Linguistik ist ein umfassender Vergleich zweier Sprachen, der allerdings nur dann sinnvoll ist, wenn er Muster und Regelhaftigkeit der Variation sichtbar macht, die einer Analyse jeder der beiden Sprachen für sich allein weitgehend verschlossen bleiben. Ein solcher Vergleich ist grundsätzlich nicht gerichtet und wird erst bei bestimmten praktischen Interessen zu einem gerichteten Vergleich zwischen Ausgangs- und Zielsprache (Übersetzungswissenschaft), zwischen Erst- und Zweitsprache (Sprachkontaktforschung) oder Mutterund Fremdsprache (Fremdsprachenunterricht).

In dem vorliegenden Beitrag wird dieses zuletzt genannte Programm näher ausgeführt. Möglichkeiten einer intensiven Zusammenarbeit und Interaktion zwischen Typologie, dem systematischen Vergleich vieler Sprachen entlang weniger Parameter der Variation, und der kontrastiven Linguistik, einem feinkörnigen Vergleich zweier Sprachen entlang vieler Parameter der Variation, werden aufgezeigt und diskutiert. Der größte Teil des Aufsatzes ist der Frage gewidmet, inwieweit kontrastive Analysen 2 wischen dem Deutschen und anderen Sprachen (insbesondere europäischen Sprachen) neues Licht auf das Deutsche geworfen und einen Beitrag zur Charakterisierung des Deutschen als Sprachtyp geliefert haben. Andererseits ist es auch interessant zu sehen, wie das Fehlen jeder vergleichenden Perspektive zu unverständlichen Idiosynkrasien in der Terminologie und zu Problemen in der Analyse einer Einzelsprache führt.

\section{Kontrastive Grammatik als Grenzfall der Typologie \\ 1.1 Möglichkeiten}

Wenn kontrastive Sprachanalysen nicht mehr allein mit der Zielsetzung verbunden werden, neue Fundamente für die Planung und Steuerung von Fremdsprachenunterricht zu liefern, müssen sie sich anderen Anforderungen stellen und anderen Kriterien der Relevanz und Adäquatheit genügen. Eine elementare Anforderung dieser Art ist die Erwartung, daB durch kontrastive Analysen das Spezifische einer Einzelsprache sichtbar wird. Ein Blick in die umfangreiche Literatur zum Deutschen als einer der kontrastierten Sprachen zeigt, wie schwierig diese Zielsetzung zu verwirklichen ist. Immerhin finden sich aber in der relevanten Literatur selbst für so intensiv beschriebene Sprachen wie das Deutsche und Eng- 
lische immer wieder neue Beobachtungen, die erst durch den Vergleich in den Blickpunkt rücken. Drei Beispiele seien hier genannt:

(i) Nur in deutschen Imperativsätzen ist die Erststellung des Verbs obligatorisch. Im Englischen sind Adverbiale (u.a. der Art und Weise) vor dem Verb zulässig und in Instruktionstexten sogar üblich:

(1) a. Mischen Sie gründlich den Sand, Zement und Kies ...

b. Thoroughly mix the sand, cement and gravel together ...

(ii) Infinitivkonstruktionen, in denen das mitverstandene Subjekt von einem unspezifizierten Objekt des Hauptsatzes kontrolliert wird, sind im Deutschen mit einer großen Zahl von Verben möglich (z.B. anordnen, befehlen, bitten, drängen, empfehlen, erlauben, raten etc.), im Englischen jedoch weitgehend ausgeschlossen (cf. Rohdenburg 1990, 1991; Panther 1994):

(2) a. Wer hat erlaubt, den Firmenwagen zu benutzen?

b. Sie drängte, die Gefangenen zu befreien.

(iii) Rekursion von Präpositionalphrasen ist im Deutschen wesentlich üblicher als im Englischen. Im Englischen erscheinen an der Stelle einer deutschen Präposition häufig Partizipien: ${ }^{1}$

(3) a. Die Antwort auf die Frage an den Menschen von heute...

b. The answer to the question facing modern man ...

Zu den elementaren Erwartungen an den Ertrag einer kontrastiven Analyse gehört auch die, daß diese Perspektive völlig idiosynkratische Terminologie zu vermeiden hilft. In der grammatikographischen Tradition jeder Einzelphilologie gibt es Termini, die für einen Vergleich selbst mit eng verwandten Sprachen völlig ungeeignet sind. $\mathrm{Zu}$ diesen Termini gehört z.B. im Deutschen die Bezeichnung 'Pertinenzdativ' für eine Verwendung des sog. 'freien Dativs', in der dieser Kasus den Besitzer von Körperteilen ('externen Possessor') kennzeichnet, die von der durch das Verb ausgedrückten Handlung betroffen werden:

(4) Paul massierte ihr den Rücken.

Wegen der völlig anderen Bedeutung von pertinence im Englischen und Französischen ist ein Terminus wie 'possessiver Dativ' für eine vergleichende Analyse unbedingt vorzuziehen. Ein weiteres Beispiel für Terminologie, die zu stark an der grammatikographischen Tradition der Germanistik und den Verhältnissen der deutschen Sprache orientiert zu sein

1 Weitere Informationen zu den genannten Phänomenen sind in Rohdenburg (1990), (1991) zu finden. 
scheint, ist die Differenzierung zwischen 'Vorgangspassiv' und 'Zustandspassiv':

(5) a. Das Essen wird zubereitet.

b. Das Essen ist zubereitet.

Eine parallele Differenzierung ist in vielen Sprachen nicht zu finden. $\mathrm{Zu}$ dem wird, wie Nedjalkov (1988) gezeigt hat, oft übersehen, daB es im Deutschen neben dem 'Zustandspassiv' auch ein 'Zustandsaktiv' (subjective resultative) gibt:

(6) a. Die Äpfel sind allmählich/vor einer Woche verfault. (Perfekt)

b. Die Apfel sind ganz/seit einer Woche verfault. ('Zustandsaktiv')

Nedjalkov subsumiert sowohl das 'Zustandspassiv' (objective resultative), als auch das Zustandsaktiv (subjective resultative) unter die Kategorie des Resultativs, die sich für sprachvergleichende Analysen, ebenso wie für die historische Analyse des Perfekts (Resultativ > Perfekt) als wesentlich relevanter erwiesen hat. SchlieBlich kann man noch den Terminus 'Gerund' als Beispiel für den Gebrauch eines Terminus für sehr unterschiedliche Erscheinungen in der Grammatikographietradition verschiedener Philologien erwähnen. Mit diesem Terminus bezeichnet man im Deutschen und Englischen die Nominalisierung von Sätzen oder Verbalphrasen in Argumentpositionen. Die für die Beschreibung von romanischen Sprachen verwandten Termini 'gerundio' und 'gérondif' werden dagegen für die Bezeichnung von adverbialen Partizipien (Konverben) verwendet. Auch zu solchen elementaren terminologischen Klärungen können kontrastive Analysen einen wesentlichen Beitrag liefern.

Ein zentrales Problem jeder typologischen Analyse ist es, eine ausreichende Breite und eine gewisse Tiefe oder Feinkörnigkeit der Analyse miteinander zu verbinden. Diese beiden Anforderungen sind nur sehr schwer miteinander $z u$ vereinbaren und im allgemeinen gilt, daß die Breite der Analyse umgekehrt proportional ist zu ihrer Tiefe und umgekehrt. Eine Beschränkung des Vergleichs auf zwei Sprachen, wie sie für kontrastive Analysen charakteristisch ist, schafft hier besondere Möglichkeiten für die Tiefe oder Feinkörnigkeit des Vergleichs. Anstatt eine Vielzahl von Sprachen entlang eines oder weniger Parameter (z.B. lineare Abfolge von S, V und $\mathrm{O}$, Kodierung von grammatischen Relationen, Silbenstruktur etc.) zu vergleichen, werden durch einen kontrastiven Vergleich zwei oder drei Sprachen in Bezug auf viele Parameter miteinander verglichen. Durch diesen Verzicht auf grobe Breite des Vergleichs ist es möglich, Verbindungen zwischen einzelnen Unterschieden herzustellen und Verallgemeinerungen zu treffen, die einzelne Unterschiede als Manifestationen einiger weniger fundamentaler Unterschiede einordnen. 
Insbesondere für die Sprachen Deutsch und Englisch gibt es mehrere Versuche, diese besonderen Möglichkeiten eines kontrastiven Vergleichs zu erkunden (cf. Hawkins 1986; Rohdenburg 1990, 1991, Abraham 1995). In Hawkins (1986) z.B. werden eine Fülle von Kontrasten in verschiedenen grammatischen Domänen unter den folgenden allgemeinen Kontrast subsumiert:

(7) Im Deutschen besteht eine engere Korrespondenz zwischen Oberflächenstruktur und Bedeutung als im Englischen:

- Im Englischen manifestieren Oberflächenstrukturen mehr Vagheit oder Ambiguität.

- Im Englischen besteht weniger Übereinstimmung zwischen syntaktisch definierten Teilsätzen und semantischen Propositionen.

- Das Deutsche weist einen engeren Zusammenhang zwischen Oberflächenstruktur und semantischen Repräsentationen auf.

Die spezifischen Kontraste, auf denen diese Verallgemeinerungen beruhen, sind u.a. die reichere Flexionsmorphologie des Deutschen, die spezifischeren Selektionsbeschränkungen vieler Verben im Deutschen gegenüber dem Englischen, die größere Freiheit der Wortstellung des Deutschen und die geringere Beschränkung von Extraktionen im Englischen gegenüber dem Deutschen. Aufgrund von verschiedenen kritischen Reaktionen auf sein Buch (cf. Rohdenburg 1990, 1991) hat Hawkins in einer neueren Veröffentlichung (Hawkins 1992) seine Globalcharakterisierung deutsch-englischer Kontraste modifiziert. Als klare Manifestationen des o.g. generellen Unterschieds in der Entsprechung zwischen Form und Bedeutung in den beiden Sprachen sieht er jetzt vor allem die Phänomene 'temporäre Ambiguität' (cf. (8)), 'Grenzüberschreitung von Argumenten' (cf. (9)), sowie die Frage der Differenzierung von Argumenten durch Zuordnung zu grammatischen Relationen (cf. (10)):

(8) a. The candidate expected to win lost.

b. Der Kandidat, von dem ein Sieg erwartet worden war, verlor.

(9) a. Literature is boring to study.

b. Es ist langweilig, Literatur zu studieren.

(10) a. My guitar broke a string mid-song.

b. An meiner Guitarre riß mitten im Lied eine Saite.

Im Deutschen sind temporäre Ambiguitäten, wie wir sie in (8) finden, und die durch Bewegungstransformationen erzeugten Grenzüberschreitungen von Argumenten des Typs (9)a. seltener als im Englischen. Andererseits werden im Deutschen unterschiedliche thematische Rollen wesentlich konsequenter durch morphologische Kodierung unterschieden 
als im Englischen. Nach der von Hawkins (1992) geäußerten Auffassung sind es letztlich die zugrundeliegende Position des Verbs im Deutschen (SOV) sowie bestimmte Prinzipien der Sprachverarbeitung, die den Schlüssel zum Verständnis der genannten Unterschiede enthalten. Umfassende Vergleiche dieser Art sind ein Schritt zur Verwirklichung des Programms von V. Mathesius, eine Charakterologie für eine Sprache zu entwickeln, und insbesondere des Programms einer holistischen Typologie, wie es z.B. Georg von der Gabelentz formuliert hat (cf. Plank 1986).

Die besonderen Möglichkeiten einer auf zwei Sprachen beschränkten, aber dafür umfassenden vergleichenden Analyse zeigen sich auch darin, $\mathrm{da} B$ interessante und wesentliche Parameter typologischer Variation im AnschluB an kontrastive Analysen entwickelt worden sind. Im AnschluB an Arbeiten von G. Rohdenburg hat z.B. F. Plank (1983) die Art der Abbildung von thematischen Rollen auf grammatische Relationen als relevanten Parameter typologischer Variation vorgeschlagen. Plank unterscheidet $\mathrm{zwischen}$ transparenter und funktionaler Kodierung von grammatischen Relationen und zeigt, daB das Deutsche (transparente Kodierung) und Englische (funktionale Kodierung) extrem unterschiedliche Positionen auf diesem Parameter einnehmen. Im Englischen können sehr verschiedene thematische Rollen als Subjekte kodiert werden, wie die Beispiele in (10) und (11) zeigen:

(11) a. Tomorrow will be cloudy.

b. This advert will sell us a lot of dog food.

c. This hotel forbids dogs.

Dagegen fehlt im Englischen völlig eine paradigmatische Differenzierung von Objekten durch Kasus, wie wir sie im Deutschen finden. Das Englische kennt lediglich eine syntagmatische Differenzierung von Objekten, d.h., nur wenn mehr als ein Objekt auftaucht, erfolgt eine Differenzierung durch Wortstellung (He sent me a postcard) oder durch Präpositionen (He gave the book to me). Alle Objekte von zweistelligen Verben werden dagegen identisch kodiert und behandelt. Charakteristisch für das Deutsche ist dagegen eine mehr oder weniger konsistente Identifikation von thematischen Rollen durch grammatische Relationen. Nicht-agentivische Subjekte sind im Deutschen selten und Objekte werden paradigmatisch als Akkusativ-, Dativ- und Genitivobjekte differenziert. Die wesentlich strengeren Restriktionen, die im Deutschen für die Bildung von Passivsätzen mit werden und abgeleiteten Subjekten ${ }^{2}$ bestehen (Sätze mit

2 Daneben sind im Deutschen allerdings auch subjektlose Passivkonstruktionen unabhängig von der Valenz des jeweiligen Verbs zulässig. 
agentivischen Subjekten, zweiwertige Verben mit kasusindizierten Objekten), die Zulässigkeit von subjektlosen Sätzen, sowie die Kennzeichnung der Objektposition durch ein Reflexivpronomen in der sog. 'middle voice' sind weitere Manifestationen dieses generelleren Unterschieds in der Kodierung von thematischen Rollen durch grammatische Relationen in den beiden Sprachen:

(12) a. Paul wird von seinen Eltern unterstützt/*geholfen.

b. Mich friert./ Mir graust vor dir.

c. Dieses Buch liest sich sehr spannend.

In Müller-Gotama (1994) wird die Relevanz dieses Parameters der Variation für eine größere Stichprobe von Sprachen nachgewiesen. Die von Van Valin entwickelte Unterscheidung zwischen 'role-dominated' und 'reference-dominated languages' (cf. Van Valin 1993) ist mit der oben skizzierten Unterscheidung eng verwandt. ${ }^{3}$

Aufgrund der herausragenden Rolle amerikanischer Sprachwissenschaftler/innen war die Theoriediskussion in der Sprachwissenschaft besonders eng mit der Analyse der englischen Sprache verknüpft. Die Rolle des Englischen als Ausgangspunkt und Fokus der Analyse sowie als bevorzugter Exemplifikationsgegenstand für alle möglichen Phänomene und Bereiche führte oft zu der unglücklichen Tendenz, andere Sprachen als eine Art 'verbogenes Englisch' (distorted English) zu betrachten. Wenn man jedoch von vornherein alle Phänomene unter einer vergleichenden oder kontrastiven Perspektive betrachtet, wird deutlich, daB das Englische als Ausgangspunkt und Demonstrationsobjekt für die Analyse bestimmter Phänomene wenig geeignet ist, weil bestimmte Unterscheidungen im Englischen entweder überhaupt nicht zu finden oder aufgrund aktueller Prozessse des Wandels nicht klar erkennbar sind. Dies gilt z.B. für die Untersuchung von Reflexivität und die Analyse der sog. 'emphatischen Reflexiva' wie dt. selbst. Die folgenden Beispiele zeigen, daß im Englischen eine Reihe von Unterscheidungen nicht sichtbar sind, die im Deutschen deutlich getroffen werden. Englisch himself hat völlig unterschiedliche Entsprechungen in den folgenden vier Beispielen:

3 Ein interessanter Versuch, eine Reihe von Kontrasten zwischen dem Englischen und Deutschen auf einen generellen Unterschied bzw. Parameter zurūckzuführen ist auch in Doherty (1993) zu finden: M. Doherty sieht eine Reihe von typischen Kontrasten zwischen englisch-deutschen Ūbersetzungen als Reflex der durchgāngigen Rechtsverzweigung der Satzstruktur im Englischen gegenüber der Linksverzweigung in der Struktur deutscher Sătze an. 
(13) a. The director himself will look into this problem.

b. Der Direktor selbst wird sich um dieses Problem kümmern.

(14) a. The director regarded himself in the mirror.

b. Der Direktor betrachtete sich im Spiegel.

(15) a. He was reluctant to admit even to himself that he had no more moves left.

b. Er zögerte, auch nur sich selbst einzugestehen, daß ...

(16) a. I think Bob sees himself in her. He sees something that reminds him of himself.

b. ... Er sieht etwas, was ihn an ihn selbst erinnert.

Das System der Anaphern (dt. sich), d.h. der Geltungsbereich der Bindungsprinzipien, ist im Englischen nur sehr schwer vom System zum Ausdruck von Diskursprominenz (dt. selbst) zu trennen, und genau diese Tatsache ist zum großen Teil für die Konfusion verantwortlich, die in der Literatur zu den sog. emphatischen Reflexiva zu beobachten ist. Das Altenglische hatte keine Reflexivpronomina, und im Laufe der geschichtlichen Entwicklung des Englischen wurden solche reflexiven Anaphern aus einer Kombination von Personalpronomina und sog. 'emphatischen Reflexiva' entwickelt (her + self $>$ herself). Diese Formen sind im Englischen nur schwach grammatikalisiert und werden zudem auch als Ausdruck von Diskursprominenz analog zu deutsch selbst verwendet. Somit wären das Deutsche oder die skandinavischen Sprachen, die diese beiden Systeme deutlich unterscheiden, ein wesentlich geeigneterer Ausgangspunkt für die Analyse von Reflexivität und die 'emphatischen Reflexiva' (cf. König 1991; Primus 1992; Baker 1995). Interessante lexikalische Differenzierungen in diesem Bereich (cf. norw. selveste, selve, selv) machen insbesondere die skandinavischen Sprachen zu einem idealen Ausgangspunkt für die Analyse von 'emphatischen Reflexiva'.

Andererseits ist das Deutsche nicht gerade repräsentativ für lexikalische Unterscheidungen, die im System der Indefinitpronomina für die Sprachen der Welt oder auch nur die europäischen Sprachen typisch sind (cf. Haspelmath, erscheint). Im Deutschen ist mit dem formalen Kontrast $\mathrm{zwischen}$ jemand und irgend jemand oder etwas und irgend etwas, der ohnehin nur für Personen und Sachen getroffen werden kann, nur in wenigen Kontexten ein deutlicher Bedeutungsunterschied verbunden. Systematische Differenzierungen wie die zwischen some und any im Englischen oder zwischen - to und -nibud' im Russischen fehlen im Deutschen völlig:

(17) a. someone - somewhere - some time - something ...

b. anyone - anywhere - any time - anything ... 
(18) a. čto-to - kto-to - gde-to ...

b. čto-nibud' - kto-nibud' - gde-nibud'...

Beispiele wie diese zeigen, wie sinnvoll und nützlich es ist, die Analyse einer Einzelsprache mit einer vergleichenden Perspektive zu verbinden. Eine solche Perspektive verhilft einer einzelsprachlichen Analyse zu einer Orientierung im Raum des Möglichen und des für die Sprachen der Welt Typischen.

\subsection{Grenzen}

Ein auf zwei oder wenige Sprachen begrenzter Vergleich hat zwar seine besonderen Möglichkeiten, muß aber letztlich an einem umfassenden Vergleich orientiert bleiben, damit voreilige Schlüsse vermieden werden können, die aufgrund der verengten Perspektive naheliegend sind. Insbesondere Aussagen über Zusammenhänge und Korrelationen 2 wischen variierenden Eigenschaften bedürfen der Untermauerung durch eine breite und möglichst repräsentative Stichprobe von Sprachen. Häufig werden jedoch solche Hypothesen auf der Basis von wenigen Sprachen entwickelt und schon durch eng verwandte oder benachbarte Sprachen in Frage gestellt oder sogar deutlich widerlegt. Drei Beispiele sollen die Problematik eines zu schmalen Fundaments für Aussagen über Korrelationen und Zusammenhänge verdeutlichen.

Das Deutsche besitzt im Gegensatz zum Englischen und Französischen ein reichhaltiges Inventar von Modal-oder Abtönungspartikeln ( $\mathrm{mal}, \mathrm{ja}$, doch, eben, etwa, denn ...). Der SchluB allerdings, daB die Verfügbarkeit einer solchen Klasse von Indikatoren für den Stärkegrad einer Äußerung bzw. für den relevanten Kontext der Verarbeitung einer ÄuBerung (cf. König 1991, S. 180ff.) etwas mit der Verbstellung oder speziell mit einem durch Verbstellung identifizierten Mittelfeld zu tun hat (cf. Abraham $1991 ; 1995)$, ist äuBerst problematisch. Für den größten Teil der skandinavischen Sprachen läßt sich diese Annahme noch vertreten, da hier unterschiedliche topologische Felder, einschlieflich eines Nexusfeldes, unterschieden werden können. Völlig unplausibel ist diese Annahme jedoch für das Jiddische oder Isländische, die auch in Nebensätzen die Abfolge SVO haben, ebenso wie für das Finnische. Alle drei der genannten Sprachen haben ein mehr oder weniger differenziertes Inventar an Modalpartikeln.

Ein weiteres Beispiel für einen übereilten und unzulänglich abgesicherten Schluß ist die Annahme, das Deutsche habe deshalb kein Preposition Stranding (im Gegensatz zum Englischen), sondern lediglich Postposition Stranding, weil es Kasus von rechts nach links zuweise (Bayer 1990): 
(19) a. What are you looking at?

b. Wem hast du das zuliebe getan?

Zweifel an dieser Korrelationsaussage und damit an der Erklärung werfen wiederum allein schon andere germanische Sprachen auf. Im Afrikaans finden wir Verbzweitstellung im Hauptsatz und SOV im Nebensatz, ebenso wie im Deutschen, aber auch sowohl Preposition Stranding als auch Postposition Stranding.

Das dritte Beispiel betriftt Konstruktionen mit externen Possessoren des folgenden Typs:

(20) a. Mir zittern die Knie.

b. Paula massierte Paul den Rücken.

Im Deutschen, wie in vielen anderen Sprachen, werden bei Handlungen, die Körperteile betreffen, die Possessoren nicht mit dem Possessum zusammen in der gleichen Phrase kodiert, sondern als separate Satzglieder ('externe Possessoren'). Strukturen des Typs (20) stellen ein notorisches Problem in der Analyse der Valenz oder Argumentstruktur der entsprechenden Verben dar, weil nicht ganz klar ist, ob man die Possessoren zur Valenz des Verbs rechnen oder als Pseudo-Aktanten betrachten soll. Dieses in den europäischen Sprachen weitverbreitete Strukturmuster ist jedoch im Englischen und in den keltischen Sprachen nicht zu finden:

(21) a. My knees are shaking.

b. I scratch your back ...

Die Beobachtung dieser Kontraste im Englischen und Französischen und eine spezifische Analyse des bestimmten Artikels in Konstruktionen des Typs (20), nach der der Artikel in Konstruktionen dieses Typs nicht ein token sondern einen Typ bezeichnet, veranlassen Vergnaud/Zubizarreta (1992) zu der Annahme, daß externe Possessoren in solchen Sprachen nicht möglich sind, in denen der bestimmte Artikel invariant ist. ${ }^{4}$ Diese Hypothese wird - wie schon erwähnt - durch das Englische und die keltischen Sprachen gestützt, ist aber für das Hebräische, das Maltesische und Baskische nicht haltbar.

4 Die Argumente für diese Analyse lassen sich etwa wie folgt zusammenfassen: In Konstruktionen mit externen Possessoren wird der bestimmte Artikel als Expletiv verwendet und bezeichnet nicht ein token, sondern den Typ eines Körperteils. In diesen Fällen ist der bestimmte Artikel daher nicht durch semantische Interpretation (als Bezeichnung eines tokens) lizenziert, sondern durch morphologische Interpretation, d.h., er muB mit dem folgenden Nomen in Numerus, Genus, Kasus etc. kongruieren. 
Beispiele wie diese zeigen, daß Aussagen über Zusammenhänge und Korrelationen nicht auf die schmale Basis eines Vergleichs zwischen zwei oder drei Sprachen gestellt werden können, sondern die breite Basis eines typologischen Vergleichs erfordern. Eine solche breite Basis ist zudem auch erforderlich, um Beobachtungen über Kontraste zwischen zwei Sprachen in einen größeren Zusammenhang einzuordnen und zu verstehen. Die Beobachtung, daB im gesprochenen Deutsch das Perfekt als Erzähltempus dem Past Tense des Englischen weitgehend entspricht, ist ohne den weiteren Horizont einer typologischen Untersuchung wenig aussagekräftig. Erst urnfassendere Vergleiche, wie die von Dahl (1985) und Bybee/Dahl (1989), zeigen, daß die Innovation im Deutschen liegt, daß das Perfekt in vielen Sprachen die Funktionen des Präteritums übernimmt und das Präteritum sogar verdrängt. Im Jiddischen und im Afrikaans ist dieser Prozeß der Verdrängung des Präteritums weitgehend abgeschlossen. In diesem größeren Zusammenhang werden auch bestimmte Innovationen in Varianten des Deutschen verständlich: Die Entwicklung eines doppelten Perfekts, das auch im Jiddischen und im Afrikaans zu finden ist, ist die Folge des Verlusts einer Präteritumsform für das Hilfsverb haben (cf. (22)), und das sog. doppelte Plusquamperfekt (cf. (23)) kann als Zwischenschritt in dieser Entwicklung angesehen werden:

(22) Als ich angekommen bin, hat er seine Arbeit schon beendet gehabt. (23) Ich hatte mit ihm gesprochen gehabt.

\section{Zur typologischen Charakterisierung des Deutschen}

\subsection{Das Deutsche als typischer Vertreter der germanischen Sprachen}

Nach der Diskussion der Anforderungen an kontrastive Analysen, ihrer Möglichkeiten und Grenzen sowie der Notwendigkeit ihrer Einbettung in den größeren Zusammenhang der Sprachtypologie, können wir die verfügbaren kontrastiven Studien zum Deutschen und anderen Sprachen $^{5}$ mit der zentralen Frage dieser Jahrestagung konfrontieren, d.h. mit der Frage nach ihrem Beitrag zum Entwurf eines typologischen Gesamtportraits für das Deutsche. Eines der Ergebnisse, die sich aus dieser Kontrastierung des Deutschen mit anderen Sprachen ergeben, ist die

5 Neben den bereits genannten Arbeiten zum Deutschen und Englischen sind z.B. Blumenthal (1987) für das Sprachenpaar Deutsch-Französisch, Kaneko/Stickel (1983) für das Sprachenpaar Deutsch-Japanisch, Cartagena/Gauger (1989) für das Sprachenpaar Spanisch-Deutsch, Engel/Mrazovic (1986) für das Sprachenpaar Deutsch-Serbisch/Kroatisch und Engel et al. (1993) für das Sprachenpaar Deutsch-Rumänisch zu nennen. 
Charakterisierung und Einstufung des Deutschen als typischer Vertreter der germanischen Sprachen. ${ }^{6}$

Viele, wenn nicht sogar die überwiegende Mehrzahl der Eigenschaften, die wir aufgrund unseres heutigen Wissens über die Sprachen der Welt als typisch für die Familie der germanischen Sprachen ansehen, sind im Deutschen zu finden. Eine repräsentative Auswahl von diesen Eigenschaften wird in der folgenden Liste gegeben, die in dem darauf folgenden Text näher kommentiert wird:

(24) Das Deutsche als typischer Vertreter der germanischen Sprachen

\begin{tabular}{|c|c|}
\hline $\begin{array}{l}\text { - Morpho- } \\
\text { logie: }\end{array}$ & 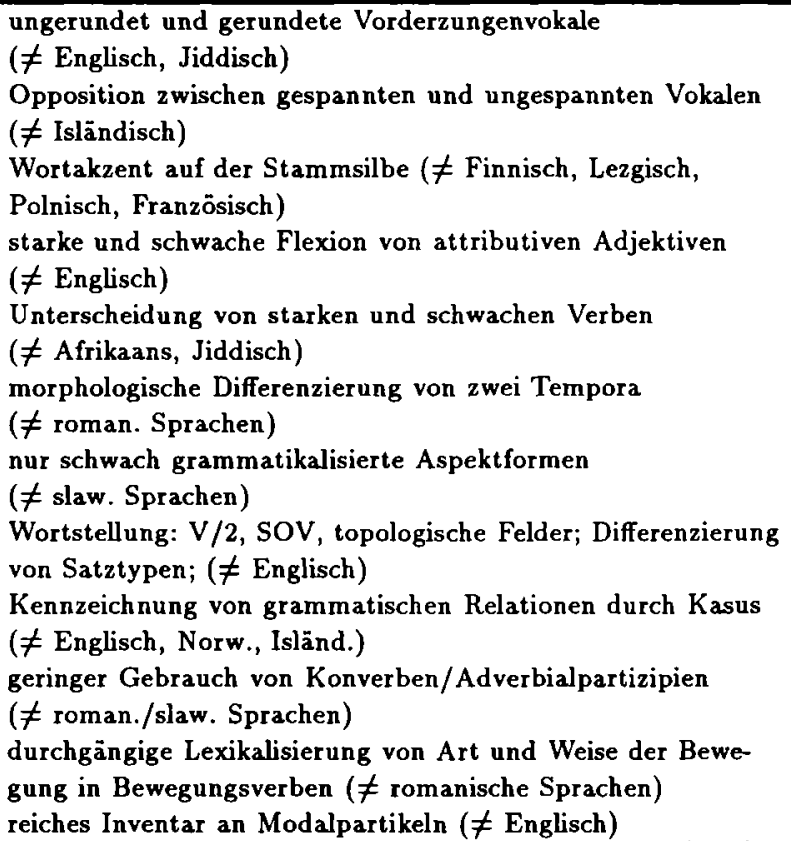 \\
\hline
\end{tabular}

Charakteristisch für das segmentale Inventar von germanischen Sprachen ist u.a. die Opposition zwischen ungerundeten und gerundeten Vorderzungenvokalen (z.B. Kissen - küssen; lesen - lösen). Mit Ausnahme des Englischen und des Jiddischen, die vermutlich durch Sprachkontakt ihre

6 Eine neuere Zusammenstellung von strukturellen Skizzen aller germanischen Sprachen, einschlieblich ihrer wichtigsten historischen Stufen, ist in König/van der Auwera (1994) zu finden. 
gerundeten Vorderzungenvokale verloren haben, ist dieser Kontrast noch in allen germanischen Sprachen zu finden. Ein charakteristischer Zug der Vokalsysteme dieser Sprachen ist auch die Unterscheidung von Vokalpaaren durch die Opposition 'gespannt - ungespannt' (z.B. bieten - bitten; fühlen - füllen), wobei allerdings in manchen Fällen lediglich ein quantitativer und kein qualitativer Kontrast in der phonetischen Realisierung besteht (z.B. Saat - satt). Die Assoziierung des Wortakzents mit der Stammsilbe ist ein Kennzeichen des heimischen Kernwortschatzes der germanischen Sprachen und unterscheidet diese Sprachen deutlich von Sprachen, in denen der Wortakzent auf eine bestimmte Silbe fallt, auf die erste wie in den finno-ugrischen Sprachen, auf die zweite wie im Lezgischen, auf die vorletzte wie im Polnischen oder auf die letzte wie im Französischen.

Typische Eigenschaften der germanischen Sprachen in der Morphologie sind die Unterscheidung zwischen starken und schwachen Verben, sowie die Unterscheidung zwischen starker und schwacher Flexion von attributiven Adjektiven (z.B. ein starker Tee - der starke Tee). Beide Oppositionen sind im Deutsche erhalten, während z.B. das Afrikaans kaum noch starke Verben benutzt und die Unterscheidung zwischen starker und schwacher Adjektivflexion in vielen germanischen Sprachen auf wenige Mitglieder der Paradigmen beschränkt ist. Wie in allen anderen germanischen Sprachen ist auch im Deutschen die Klasse der starken (unregelmäßigen) Verben eine geschlossene Klasse, die zudem allmählich reduziert wird (z.B. schallen - schallte; backen - backte). Eine typische Erscheinung der germanischen Sprachen ist auch die Unterscheidung von lediglich zwei morphologisch differenzierten Tempora (Präsens - Präteritum). Diese Opposition ist ein Reflex des ursprünglichen Tempussystems aller germanischen Sprachen. Die anderen Tempusunterscheidungen, die heute in vielen germanischen Sprachen zu finden sind (Perfekt, Plusquamperfekt, Futur) wurden allerdings auch weitgehend parallel ausgebildet und grammatikalisiert. Die Entwicklung vom Perfekt zum narrativen Tempus ist dagegen nur in einem Teil der germanischen Sprachen zu beobachten. Im Deutschen ist dieser Prozeb noch in vollem Gang, während er im Jiddischen völlig und im Afrikaans weitgehend abgeschlossen ist. In den zuletzt genannten Sprachen ist das Präteritum durch das Perfekt (fast) völlig verdrängt worden. An die Stelle des Plusquamperfekts ist ein 'doppeltes Perfekt' getreten, da auch für das Hilfsverb haben keine Präteritumsform mehr gebräuchlich ist. Als weiteren typischen Zug des Tempus- und Aspektsystems der germanischen Sprachen kann man auch die nur schwache Ausbildung (Grammatikalisierung) von Aspektunterscheidungen ansehen. Stark grammatikalisierte Aspektunterscheidungen sind lediglich im Englischen (Progressivform - 
einfache Form) zu finden. Anfänge, die in Richtung einer ähnlichen Differenzierung weisen (dt. ich war am Lesen), kann man zwar auch in allen anderen germanischen Sprachen finden, diese Bildungen sind jedoch noch vielen Restriktionen (Transitivität, Aktionsart, Tempus) unterworfen. ${ }^{7}$

Ein typischer Vertreter der germanischen Sprachen ist das Deutsche auch in Bezug auf die Stellung des Verbs. Die Zweitstellung des finiten Verbs im Hauptsatz gehört zu den markanten Eigenschaften dieser Sprachfamilie. Daneben ist auch die Endstellung von Verben in eingebetteten Sätzen (SOV) oder zumindest die Differenzierung von topologischen Feldern aufgrund der Wortstellung ein markanter Zug der meisten germanischen Sprachen und ihrer früheren historischen Stufen. Ausnahmen sind hier das Englische, das Isländische, das Färöische und das Jiddische. Die Differenzierung von Satztypen (Satzmodi) durch Wortstellung gehört ebenfalls zu den Eigenschaften, die das Deutsche als typischen Vertreter der germanischen Sprachen ausweisen. Insbesondere die Unterscheidung zwischen Deklarativ- und Interrogativsätzen wird in den germanischen Sprachen durch die Reihenfolge von Subjekt bzw. Topik und Verb getroffen. Weitaus häufigere Strategien der Bildung von Interrogativsätzen in den Sprachen der Welt sind die Verwendung von Partikeln (z.B. -ko/ $-k \tilde{o}$ im Finnischen, $l i j \mathrm{im}$ Russischen) oder die Disjunktion.

Die ausschließliche Kodierung von grammatischen Relationen (Subjekt, Objekt) durch Kasus ist eine Eigenschaft, die das Deutsche mit keiner anderen modernen germanischen Sprache teilt, wohl aber mit deren historischen Vorstufen. Auch im Altisländischen und im Altenglischen wird das Subjekt jeweils im Nominativ kodiert, bzw. der im Nominativ kodierte Aktant ist das Subjekt. Es ist dieser konservative Zug gegenüber den anderen germanischen Sprachen, in denen grammatische Relationen fast ausschließlich durch die Wortstellung angezeigt werden, der hier zu der durchaus problematischen Aufnahme dieser Eigenschaft in die Tabelle (24) führte. Vom synchronen Standpunkt aus betrachtet ist es eine Eigenschaft, die das Deutsche mit einigen slawischen Sprachen, mit einigen finno-ugrischen Sprachen, mit dem modernen Griechisch, dem Türkischen, Baskischen und dem Albanischen in Europa teilt. Absolut charakteristisch für germanische Sprachen ist dagegen der geringe Gebrauch,

$7 \mathrm{Zu}$ den neueren Entwicklungen im Aspektsystem des Deutschen könnte man auch die Entwicklung der aspektuellen Kategorie des Absentivs zählen:

(i) Er ist einkaufen/Bier holen/schwimmen ...

Die durch solche Sātze ausgedrückte aspektuelle Bedeutung ist der einer Progressivform vergleichbar, hat jedoch die zusātzliche Implikation, daß die durch das Subjekt bezeichnete Person nicht am Ort des Sprechers ist (cf. de Groot (erscheint)). 
den das Deutsche von adverbialen Partizipialkonstruktionen ('Konverben') macht. Der Gebrauch solcher Konverben ist im Deutschen, wie in den meisten anderen germanischen Sprachen, starken Beschränkungen unterworfen. Ausnahmen bilden hier lediglich das Jiddische und vor allem das Englische (cf. Pusch 1980; Haspelmath/König 1995):

(25) a. Not knowing the picture, he bought it.

b. Da er das Bild nicht kannte, kaufte er es.

Mit der Charakterisierung des Deutschen als typischen Vertreter der germanischen Sprachen ist natürlich nicht die Behauptung verbunden, das Deutsche folge in allen seinen Eigenschaften dem Muster der Mehrheit der germanischen Sprachen. In einigen seiner Eigenschaften ist das Deutsche durchaus in einer Minderheitenposition. Auslautverhärtung finden wir neben dem Deutschen nur noch im Niederländischen und im Afrikaans. Andererseits findet sich diese Eigenschaft auch in slawischen Sprachen, wie dem Russischen und Polnischen. ${ }^{8}$ Die wesentlichen Kasusunterscheidungen für Nomina der älteren germanischen Sprachstufen sind nur noch im Deutschen, Isländischen und Jiddischen bewahrt worden, und eine morphologische Differenzierung zwischen Indikativ und Konjunktiv ist heute nur noch in zwei modernen 'Dialekten' des Germanischen zu finden, dem Isländischen und dem Deutschen. Insgesamt hat das Deutsche wesentlich mehr von den ursprünglichen Flexionsunterscheidungen der alten Sprachstufen bewahrt als alle anderen germanischen Sprachen, mit Ausnahme des Isländischen. Schließlich finden sich im Deutschen natürlich auch einige Eigenschaften, die in keiner anderen germanischen Sprache, wohl aber in anderen europäischen Sprachen zu finden sind. Ein interessantes Beispiel dieser Art ist die Fusion von Präpositionen und definiten Artikeln (am, zum, beim, ans, zur, ins etc.). Eine ähnliche Erscheinung ist auch im Französischen zu finden $(d e+l e$ $>d u ; \dot{a}+l e>a u)$. Im Unterschied zu den französischen Beispielen, wo diese Fusion obligatorisch ist, gibt es im Deutschen einen interessanten semantischen Kontrast zwischen Fällen mit Fusion und Fällen ohne Fusion ( $a$ n dem vs. am). Eine genaue Klärung dieses Kontrastes steht wohl noch aus, ganz grob kann man jedoch sagen, daB in den Fällen keine Fusion erfolgt, in denen die Definitheit durch den vorausgehenden Ko-text bedingt ist, während in Fällen der Skriptdefinitheit, d.h. der Bedingtheit von Definitheit durch allgemeines Hintergrundwissen, Fusion zu beobachten ist.

8 Im Gegensatz zum Russischen und Polnischen tritt die Auslautverhärtung im Deutschen nicht am Wortende, sondern am Silbenrand auf. 
(26) a. Plötzlich kamen wir an ein Tor. An dem Tor stand ein Soldat.

b. Wo ist Peter? - Er steht dort am Tor.

2.2 Das Deutsche als typischer Vertreter des Standard Average European

Dem von B.L. Whorf (1962) geprägten Begriff Standard Average European $(S A E)$ liegt die Intuition zugrunde, da $B$ durch den Vergleich von europäischen Sprachen mit dem völlig Fremden, d.h. mit Sprachen wie dem Hopi, wesentliche Gemeinsamkeiten unter den Mitgliedern eines Kernbereichs der europäischen Sprachen deutlich sichtbar werden, die bei einem auf Europa beschränkten Vergleich kaum zu erkennen sind. Im Rahmen des Forschungsprojekts "Typology of Languages in Europe” (EUROTYP) wurde dieser Begriff bei der Charakterisierung arealer Phänomene wieder aufgegriffen und erwies sich durchaus als sinnvoll und nützlich. Es zeigte sich bei verschiedenen Teilprojekten, dab nicht nur der gesamteuropäische Sprachraum durch bestimmte Erscheinungen charakterisiert werden kann, sondern daß darüber hinaus auch für einen Kernbereich von europäischen Sprachen bestimmte Eigenschaften charakteristisch sind. Als für ganz Europa charakteristische Phänomene könnte man etwa die Opposition zwischen bestimmten und unbestimmten Artikeln, die weitgehende Akkusativität in der Kodierung grammatischer Relationen, die subjektlosen Infinitive als häufige Strategie der Komplementierung, eine Präferenz für finite Subordination und die Möglichkeit der koordinativen Verknüpfung von Phrasen aller Art (hier und heute, auch und gerade weil etc.) ansehen. Daneben gibt es jedoch auch einige Erscheinungen, die lediglich für einen Kernbereich von europäischen Sprachen charakteristisch sind, aber kaum in der Peripherie zu finden sind. Eine solche Erscheinung ist z.B. die Kodierung des externen Possessors im Dativ, die in nahezu allen europäischen Sprachen mit Ausnahme des Englischen, der keltischen Sprachen, und der skandinavischen Sprachen zu finden ist (cf. König/Haspelmath, erscheint). Die folgenden Beispiele, ebenso wie schon die Beispiele in (20), verdeutlichen diese Erscheinung für das Deutsche:

(27) a. Du hast mir den Arm gebrochen.

b. Er putzte sich die Nase.

c. Du bist mir auf das Kleid getreten.

Im Englischen, ebenso wie in den keltischen Sprachen, werden die Possessoren in den entsprechenden Strukturen als Possessivpronomina oder Genitivattribute in der gleichen Phrase wie das Possessum, d.h. also als interne Possessoren, ausgedrückt: 
(28) a. You broke my arm.

b. He blew his nose.

c. You stepped on my dress.

Externe Possessoren sind im Englischen nur dann möglich, wenn das Possessum in einer Präpositionalphrase ausgedrückt wird:

(29) a. He kissed her on the cheek.

b. She took me by the hand.

In den skandinavischen Sprachen werden, wie das folgende schwedische Beispiel zeigt, externe Possessoren durch den Superessiv, d.h. durch eine Präpositionalphrase mit der lokativen Präposition på 'auf', kodiert:

(30) a. Nägon bröt armen på honom.

'Jemand hat ihm den Arm gebrochen'

b. Han darrade pa handen.

'Ihm zitterte die Hand'

Es ist somit die Peripherie des europäischen Sprachraums im Nordwesten (Englisch, Keltisch), im Norden (skandinavische Sprachen) und zum Teil im Osten (Russisch), die externe Possessoren entweder völlig ausschließt oder durch Lokalkasus (Superessiv, Adessiv) kodiert.

Eine weitere Erscheinung, die das Deutsche mit einem Kernbereich der europäischen Sprachen verbindet, ist das Fehlen von kausativen Verben, die durch produktive morphologische Prozesse von inchoativen Verben abgeleitet werden (cf. Haspelmath 1993). Verbpaare dieser Art sind z.B. im Arabischen und im Finnischen zu finden:

(31) a. (arab.) darasa 'lernen' - darrasa 'lehren'

b. (finn.) herätä 'aufwachen' - herättä 'wecken'

Für das Deutsche, ebenso wie für andere Beispiele des SAE, ist die umgekehrte Ableitungsrichtung, von kausativen zu inchoativen (antikausativen) Verben, der wesentliche, produktive ProzeB (offnen - sich offnen; sammeln - sich sammeln). Beispielpaare des Typs sinken - senken, schmilzen - schmelzen, sitzen - setzen, springen - sprengen widersprechen der eben gemachten Aussage nur scheinbar, da es sich um einen auf wenige lexikalische Elemente beschränkten, im Deutschen nicht produktiven ProzeB handelt.

Als für das SAE typische areale Erscheinung kann man zudem noch die Kodierung des Aquativs (z.B. so alt wie) durch Demonstrativ-und Relativadverbien nennen (Haspelmath/Buchholz, erscheint): 
(32) a. (dt.) so ADJ wie

b. (russ.) tak ADJ kak

c. (lat.) tam ADJ quam

$\mathrm{d}$. aber: (engl.) as ADJ as

Schließlich gehören noch eine Reihe von Eigenschaften, die mit der Form und Stellung von adverbialen Konjunktionen zusammenhängen, zu den Charakteristika, die den arealen Begriff Standard Average European mit Sinn erfüllen: die satzeinleitende Stellung von adverbialen Konjunktionen, die Finitheit und variable Stellung der entsprechenden Adverbialsätze, die Bildung von adverbialen Konjunktionen durch Inkorporierung von Adpositionen, Interrogativpronomina und Komplementierern, die Verfügbarkeit eines großen Inventars von Konjunktionen im semantischen Bereich 'Konditionalität', 'Kausalität' und 'Konzessivität' etc. Eine detaillierte Diskussion dieser Eigenschaften und ihrer arealen Beschränkungen ist in Kortmann (erscheint) zu finden.

\subsection{Typologische Charakterisierung des Lexikons}

Der typologische Vergleich von Sprachen war bisher im wesentlichen auf Phonologie, Syntax und Morphologie beschränkt, während Lexikon und sprachliche Interaktion weitgehend ausgeklammert blieben. Bescheidene Anfänge in der Einbeziehung des Lexikons in einen kontrastiven oder typologischen Vergleich waren erst in den letzten Jahren möglich, als man davon abging, das Lexikon lediglich als eine Ansammlung von idiosynkratischen Eigenschaften zu betrachten. Den ersten überzeugenden Versuch einer Ausweitung der typologischen Perspektive auf das Lexikon kann man wohl in der Untersuchung von L. Talmy (1985) über die Lexikalisierungsmuster bei Bewegungsverben sehen. Talmy unterscheidet fünf Komponenten, die bei Bewegungsverben lexikalisiert sein können: die Tatsache der Bewegung (Motion), die bewegte Entität oder Figur (Figure), die Richtung der Bewegung ( $P$ ath), den Hintergrund, auf dem etwas bewegt wird (Ground), sowie die Art und Weise bzw. die Ursache der Bewegung (Manner/Cause). Je nachdem, was in einer Sprache systematisch in den Bewegungsverben ausgedrückt wird, lassen sich nun verschiedene Typen unterscheiden. In den germanischen Sprachen wird zusammen mit der Tatsache der Bewegung fast ausnahmslos auch ihre Art und Weise lexikalisiert (2.B. rollen, kriechen, gehen, fahren, springen, schwimmen etc.). Wenn darüber hinaus die Richtung der Bewegung ausgedrückt wird, geschieht dies meist durch ein separates Morphem (Affix, Adverb). In den romanischen Sprachen, ebenso wie im Japanischen und Koreanischen wird neben der Tatsache der Bewegung typischerweise auch die Richtung der Bewegung, nicht aber ihre Art und Weise aus- 
gedrückt (frz. sortir, partir, passer, monter, entrer, quitter, surgir etc.). Eine durchgängige gemeinsame Lexikalisierung von Tatsache der Bewegung und bewegter Entität weist Talmy schlieBlich für das Atsugewi nach. In den europäische Sprachen ist dieses Lexikalisierungsmuster dagegen sehr selten und nur bei Verben wie regnen oder spucken zu finden.

Innerhalb dieser Typologie ist das Deutsche ein typischer Vertreter der Sprachen, in denen die Tatsache der Bewegung durchgängig mit ihrer Art und Weise lexikalisiert wird. ${ }^{9}$ AuBer dem Verb kommen gibt es nur sehr wenige Fälle, in denen eine Richtung (hier: zum Orientierungszentrum) aber keine Art und Weise ausgedrückt wird, während das Englische durchaus eine Reihe von Entlehnungen dieser Art aus dem Französischen übernommen hat. So drückt z.B. die Übersetzung von enter als 'betreten', oder von go als 'gehen', zusätzlich die Art und Weise der Bewegung ('zu FuB') aus. Aus diesem Grund ist eine solche Übersetzung in Fällen wie den folgenden ausgeschlossen:

(33) a. The thought never entered my mind.

b. This should have never entered into the discussion.

c. I'll go crazy.

d. I have to go to London.

Interessante Anregungen für einen systematischen Vergleich des lexikalischen Inventars von Sprachen kamen in den letzten Jahren insbesondere von kontrastiven Analysen. Auf der Grundlage eines umfassenden Vergleichs der Selektionsbeschränkungen von transitiven Verben im Deutschen und Englischen hat z.B. F. Plank (1984) auf ein Phänomen aufmerksam gemacht, das für das Deutsche charakteristisch ist, aber im Englischen weitgehend fehlt. Im Deutschen werden bedeutungsähnliche Verben (meist durch trennbare Präfixe) häufig nach bestimmten Eigenschaften der folgenden Objekte differenziert. "Semantische Kongruenz" (semantic agreement) nennt Plank dieses Phänomen, dessen Relevanz er an verschiedenen Wortfeldern und Verbgruppen demonstriert. So gibt es z.B. im Englischen für den Vorgang des Bekleidens und Entkleidens nur das reversive Verbpaar put on - take off, das keinerlei Selektionsbeschränkungen bezüglich des durch das Objekt ausgedrückten Kleidungsstückes aufweist. Neben dem genannten Wortpaar könnte man auch noch das leicht archaische Paar don - doff nennen, das in der Bedeutung 'to put on/take off with a purpose' verwendet wird:

9 Einige der relevanten Verben haben allerdings im Laufe der geschichtlichen Entwicklung eine Verengung auf eine bestimmte Art und Weise hin erfahren. Im Althochdeutschen bedeutete faran z.B. noch 'sich bewegen', ohne auf eine bestinmte Art und Weise der Bewegung festgelegt zu sein. 
(34) a. He donned a crash helmet.

b. He doffed his hat.

Im Deutschen hängt dagegen die Auswahl eines speziellen Verbs unter mehreren Möglichkeiten (anziehen, aufsetzen, umbinden, anstecken, umlegen etc.) jeweils von der Position des Kleidungsstückes und seinem Kontakt mit dem Körper ab:

(35) a. to put on one's glasses - die Brille aufsetzen

b. to to put on one's jacket - die Jacke anziehen

c. to put on a tie - eine Krawatte umbinden

d. to put on a ring - einen Ring anstecken etc.

Weitere Beispiele für den erwähnten generellen Unterschied zwischen dem Deutschen und Englischen finden sich im Wortfeld „Kochen” oder etwa bei den Verben mit effizierten gegenüber solchen mit affizierten Objekten. Auch hier unterscheidet das Deutsche in vielen Fällen zwei Verben je nach Art des Objekts:

(36) a. to paint a picture - ein Bild malen

b. to paint the wall - die Wand anmalen

Leichter als bei den offenen lexikalischen Klassen der Nomen, Verben und Adjektive lassen sich bei den relativ geschlossenen Klassen der Funktionswörter umfassende Vergleiche durchführen und Kontraste aufdecken. Wie bereits erwähnt gibt es im Englischen keine Entsprechungen zu den Modalpartikeln des Deutschen ( $j a$, doch, denn, etwa, eben, wohl etc.). Das Fehlen solcher Ausdrücke ist eine der zahlreichen Eigenschaften, die das Englische zu einem völlig untypischen Repräsentanten der germanischen Sprachen machen. Auch die Klasse der Fokuspartikeln ist im Englischen im Vergleich zum Deutschen sehr begrenzt (cf. König 1991). So gibt es im Englischen z.B. keine Entsprechung für die Verwendung von noch und schon als Fokuspartikeln, und es fehlt eine Differenzierung der Art, wie sie im Deutschen zwischen nur und erst getroffen wird. Besonders deutlich läßt sich die unterschiedliche Ausdifferenzierung der lexikalischen Teilklasse der Fokuspartikeln an der Tatsache demonstrieren, $\mathrm{da} ß$ für die äußerst vielseitige englische Partikel even im Deutschen eine große Zahl von Entsprechungen zur Verfügung stehen und je nach bestimmten Eigenschaften von Fokus und Skopus gewählt werden müssen:

(37) a. Even giants started from small beginnings.

b. Selbst Riesen haben einmal klein angefangen.

(38) a. He even drove very fast.

b. Er ist sogar sehr schnell gefahren. 
(39) a. The situation is serious, even dangerous.

b. Die Situation ist ernst, ja sogar gefährlich.

(40) a. He did not even say hello.

b. Er hat uns nicht einmal begrüßt.

(41) a. I refuse to even talk to him.

b. Ich weigere mich, mit ihn auch nur zu sprechen.

(42) a. Even the attempt is punishable.

b. Schon der Versuch ist strafbar.

(43) a. Even as they were negotiating ...

b. Noch während sie verhandelten ...

Ein besonders reiches Betätigungsfeld für kontrastive Beobachtungen zum Lexikon ist natürlich die Wortbildung. Eine Besonderheit des Deutschen in diesem Bereich ist die Ableitung von Diminutivformen von Verben (köcheln, hüsteln, tänzeln, lächeln, kränkeln, trōpfeln, streicheln). Was die Kontrastierung von Strategien der verbalen Interaktion anbelangt, so gibt es einige interessante Ansätze zu kontrastiven Vergleichen von Ausdrucksmitteln und Strategien der Höflichkeit, zur Verwendung von Sprechakten und zum Zusammenhang zwischen kulturellen Werten und Maximen der verbalen Interaktion (Wierzbicka 1991; BlumKulka/Kaspar 1993), auf die hier jedoch nicht näher eingegangen werden soll.

\section{Zusammenfassung}

Ziel des vorausgegangenen Ausführungen war es, Möglichkeiten und Grenzen einer kontrastiven Linguistik zu diskutieren, die sich als Grenzfall eines typologischen Vergleichs versteht. Die besonderen Möglichkeiten eines solchen auf zwei Sprachen beschränkten Vergleichs bestehen im Umfang und in der Feinkörnigkeit des Vergleichs. Um vorschnelle und unzulängliche Verallgemeinerungen zu vermeiden, muß sich ein kontrastiver Vergleich jedoch stets an einem umfassenderen, typologischen Vergleich orientieren. In dem Maße, in dem eine kontrastive Analyse auf eine präzise Erfassung von Kontrasten und auf weitgehende Verallgemeinerungen abzielt, wird sie sich allerdings auch von dem ursprünglichen Programm der kontrastiven Linguistik entfernen. Im Zusammenhang mit der Diskussion dieser Möglichkeiten und Grenzen einer kontrastiven Linguistik wurde gleichzeitig eine Bestandsaufnahme bezüglich des Beitrags vorgenommen, den kontrastive und typologische Vergleiche der letzten Jahre zur Charakterisierung des Deutschen als Sprachtyp geliefert haben. 


\section{Literatur}

Abraham, Werner (1991): Discourse Particles. Amsterdam.

Abraham, Werner (1995): Deutsche Syntax im Sprachvergleich. Tübingen.

Baker, Carl L. (1995): Locally free reflexives, contrast, and discourse prominence. In: Language 71, S. 63-101.

Bayer, Josef (1990): Directionality of Government and Logical Form: A Study of Focusing Particles and Wh-scope. Habilitationsschrift Universitāt Konstanz.

Blum-Kulka, Shoshana/Kaspar, Gabriele (Hg.) (1993): Interlanguage Pragmatics. Oxford.

Blumenthal, Peter (1987): Sprachvergleich Deutsch-Französisch. Tübingen.

Bybee, Joan/Dahl, Östen (1989): The creation of tense and aspect systems in the languages of the world. In: Studies in Language 13, S. 51-103.

Cartagena, Nelson/Gauger Hans Martin (1989): Vergleichende Grammatik Spanisch - Deutsch. 2 Bände. Mannheim/Wien/Zürich.

de Groot, Caspar (erscheint): The Absentive. In: Dahl, Östen (Hg.): Tense and Aspect in the Languages of Europe. Berlin.

Dahl, Östen (1985): Tense and Aspect Systems. Oxford.

Doherty, Monika (1993): Parametrisierte Perspektive. In: Zeitschrift für Sprachwissenschaft 12, S. 3-38.

Engel, Ulrich/Mrazovic, Pavica (Hg.) (1986): Kontrastive Grammatik DeutschSerbokroatisch. München.

Engel, Ulrich et al. (Hg.) (1993): Kontrastive Grammatik Deutsch-Rumänisch. Heidelberg.

Gnutzmann, Claus (Hg.) (1990): Kontrastive Linguistik. Bern.

Haspelmath, Martin (1993): More on the typology of inchoative/causative verb alternations. In: Comrie, Bernard/Polinsky, Maria (Hg.): Causatives and Transitivity. Amsterdam. S. 87-120.

Haspelmath, Martin/König, Ekkehard (Hg.) (1995): Converbs in CrossLinguistic Perspective. Berlin.

Haspelmath, Martin (erscheint): Indefinite Pronouns. Oxford.

Haspelmath, Martin/Buchholz, Oda (erscheint): Equality and similarity in the languages of Europe. In: van der Auwera, Johan ( $\mathrm{Hg}$.): Adverbial Constructions in the Languages of Europe. Berlin.

Hawkins, John (1986): A Comparative Typology of English and German: Unifying the Contrasts. London.

Hawkins, John (1992): A performance approach to English/German contrasts. In: Mair/Markus (Hg.), S. 115-136.

Kaneko, Tohru/Stickel, Gerhard (1983ff.): Deutsch und Japanisch im Kontrast. 3 Bände. Heidelberg.

König, Ekkehard (1991): The Meaning of Focus Particles: A Comparative Perspective. London. 
König, Ekkehard (1993): Contrastive linguistics: Language comparison or language pedagogy? In: Seeber, Hans Ulrich/Gōbel, Walter (Hg.): Proceedings des Anglistentages 1992 Stuttgart. Tübingen. S. 289-302.

König, Ekkehard/van der Auwera, Johan (Hg.) (1994): The Germanic Languages. London.

König, Ekkehard/Haspelmath, Martin (erscheint): Les constructions à possesseur externe dans les langues de L'Europe. In: Feuillet, Jack ( $\mathrm{Hg}$.): Actance et valence dans les langues de l'Europe. Berlin.

Kortmann, Bernd (erscheint): Adverbial Subordinators in the Languages of Europe. Berlin.

Mair, Christian/Markus, Manfred (Hg.) (1992): New Departures in Contrastive Linguistics. 2 Bde. Innsbruck.

Müller-Gotama, Franz (1994): Grammatical Relations. A Cross-linguistic Perspective on their Syntax and Semantics. Berlin.

Nedjalkov, Vladimir P. (1988): Resultative, Passive, and Perfect in German. In: Nedjalkov, Vladimir P. (Hg.): Typology of Resultative Constructions. Amsterdam. S. 411-432.

Panther, Klaus-Uwe (1994): Kontrollphänomene im Englischen und Deutschen aus semantisch-pragmatischer Perspektive. Tübingen.

Plank, Frans (1983): Transparent versus functional encoding of grammatical relations: a parameter for syntactic change and typology. In: Linguistische Berichte 86, S. 1-13.

Plank, Frans (1984): Verbs and objects in semantic agreement. In: Journal of Semantics 3, S. 305-360.

Plank, Frans (Hg.) (1986): Folia Linguistica XX. (Special Issue Typology).

Primus, Beatrice (1992): Selbst - Variants of a scala adverb in German. In: Jacobs, Joachim (Hg.): Informationsstruktur und Grammatik. Opladen. S. 54-88.

Pusch, Luise (1980): Kontrastive Untersuchungen zum italienischen 'gerundio'. Tübingen.

Rohdenburg, Günter (1990): Aspekte einer vergleichenden Typologie des Englischen und des Deutschen. Kritische Anmerkungen zu einem Buch von John A. Hawkins. In: Gnutzmann (Hg.), S. 133-152.

Rohdenburg, Günter (1991): Weitere Betrachtungen zu einer vergleichenden Typologie des Englischen und Deutschen. Universität Duisburg: L.A.U.D.

Rohdenburg, Günter (1995): Cognitive complexity and increased grammatical explicitness in English. Erscheint in Cognitive Linguistics.

Talmy, Leonard (1985): Lexicalization Patterns: Semantic Structure and Lexical Forms. In: Shopen, Timothy (Hg.): Language Typology and Syntactic Description Bd III. Cambridge. S. 57-149.

Van Valin, Robert D. Jr. (Hg.) (1993): Advances in Role and Reference Grammar. Amsterdam. 
Vergnaud, Jean-Roger/Zubizarreta Marie-Louise (1992): The definite determiner and the inalienable constructions in French and English. In: Linguistic Inquiry 23, S. 595-652.

Whorf, Benjamin Lee (1962): Language, Thought and Reality. New York/London.

Wienold, Götz (1973): Die Erlernbarkeit der Sprachen. München.

Wierzbicka, Anna (1991): Cross-cultural Pragmatics. The Semantics of Human Interaction. Berlin. 


\section{V2 und Satzklammer}

und ihre Folgen für die übrige Grammatik 



\title{
BEATRICE PRIMUS
}

\section{Dependenz und Serialisierung: das Deutsche im Sprachvergleich}

\begin{abstract}
Die vorliegende Arbeit untersucht grammatische Serialisierungsfaktoren und geht auf die semantische Rolle und die Rektion der Verbargumente nāher ein. Das sind zwei unabhāngige Faktoren der Wortstellung, die zwar gemeinsam auf einen allgemeinen multifaktoriellen Dependenzbegriff zurückgeführt, aber nicht voneinander abgeleitet werden können. Die wortstellungsrelevante Hierarchie von semantischen Rollen kann als Spezialfall semantischer Dependenzasymmetrien ausgewiesen werden. Auf der Grundlage dieses Dependenzbegriffs wird ein allgemeines Serialisierungsprinzip aufgestellt, das mehrere in der Forschung diskutierte Prinzipien zusammenfaBt. Die beiden Parameter der Dependenz können bei der Determination der Abfolge der Verbargumente in Abhăngigkeit vom verblexemspezifischen Konstruktionstyp gegeneinander konkurrieren oder miteinander koalieren. Diese Interaktion wird im Rahmen eines Wettbewerbsmodells der Serialisierung präsentiert. Über die koalierende vs. konkurrierende Interaktion wird die konstruktionsspezifische festere vs. freiere Stellung der Verbargumente im Deutschen und im Sprachvergleich erklärt. Im sprachvergleichenden Teil werden ditransitive Konstruktionen mit Rezipient und Patiens in 50 europäischen Sprachen untersucht.
\end{abstract}

\section{Präferenzregeln im Wettbewerb}

Die relative Abfolge der Verbargumente im Deutschen und in anderen Sprachen wird nicht durch strikte Grammatikregeln, sondern durch Präferenz- bzw. Markiertheitsregeln determiniert. Dies erkennt man in den folgenden deutschen Beispielen daran, daß die Abfolge in (1b) nicht absolut ungrammatisch ist:

(1a) ${ }^{1}$ hierbei legte Herr von Schröder die Hand aufs Herz. (TM, S. 21)

(1b) ${ }^{4}$ hierbei legte die Hand Herr von Schröder aufs Herz.

$\mathrm{Da}$ die Abfolge Akkusativobjekt - Subjekt markiert ist, beweist nicht nur ihre deutlich geringere Akzeptabilität ${ }^{1}$, sondern auch ihre deutlich geringere Texthäufigkeit. So beträgt die Häufigkeit der markierten Abfolge definites Akkusativobjekt - definites Subjekt relativ zur unmar-

1 Vgl. die Ergebnisse der Akzeptabilitätsbefragungen in Connolly (1987) und Primus (1994). Die Zahlen vor den Beispielen in (1a)-(2b) zeigen lediglich die ungefähre relative Akzeptabilität dieser Sätze: $(1 a)>(2 a)>(2 b)>(1 b)$. 
kierten Abfolge nur 0,6\% im Mannheimer Korpus, das Hoberg (1981) untersucht hat.

Die Abfolge Akkusativobjekt - Subjekt kann verwendet werden, wenn sie einer anderen, z.B. pragmatischen Präferenzregel genügt. Eine solche Präferenz ist, vorerwähnte oder nicht-fokussierte Information vor nicht-vorerwähnte oder fokussierte Information zu stellen. ${ }^{2}$ Die Wirkung dieser pragmatischen Präferenz erkennt man, wenn man eine leicht abgewandelte Variante von (1) als Antwort auf eine W-Frage nach dem Subjekt auffaBt. Vgl. (2):

Wer durfte denn die Hand aufs Herz der Großherzogin legen?

(2a) ${ }^{2}$ Ich glaube, daß nur Herr von Schröder die Hand aufs Herz der Großherzogin legen durfie.

(2b) ${ }^{3}$ Ich glaube, daß die Hand aufs Herz der Großherzogin nur Herr von Schröder legen durfte.

Die Interaktion zweier Präferenzregeln, einer grammatischen und einer pragmatischen, führt dazu, daB im Textkontext des Romans (2b) akzeptabler ist als (1b). Solche Akzeptabilitätsdifferenzen deuten darauf hin, daß die Abfolgeregeln des Deutschen kumulativ operieren. M.a.W versuchen Sprecher des Deutschen alle Präferenzregeln zu befolgen. Diese Ansicht über die Interaktion von Abfolgeregeln hat u.a. Reis (1987) treffend als "Wettbewerbsmodell" bezeichnet. Die vorliegende Arbeit versteht sich als weiterer Beitrag zur Präzisierung des Wettbewerbsmodells der Serialisierung. ${ }^{3}$

Charakteristisch für das hier angenommene Wettbewerbsmodell ist, daß es einen absoluten Begriff der Grundabfolge ablehnt. Weil im Deutschen und in vielen anderen Sprachen mehrere Serialisierungsfaktoren operieren, kann es keine absolut unmarkierte Abfolge geben, sondern immer nur eine unmarkierte Abfolge relativ zu einer bestimmten Präferenzregel mit genau einem determinierenden Faktor bzw. Parameter. Diese Annahme, die in (3') präzisiert wird, ist ein Spezialfall einer vielerorts vertretenen Grundannahme der Markiertheitstheorie, die in (3) erscheint:

(3) Markiertheitsbewertungen sind strikt lokal, d.h. sie gelten nur relativ zu genau einem determinierenden Parameter.

2 Die Formulierung dieser pragmatischen Präferenz beansprucht nicht, beschreibungsgenau und explanativ adäquat zu sein, sondern soll lediglich zur Veranschaulichung der Interaktion mehrerer Präferenzregeln beitragen.

3 Vgl. z.B. auch Uszkoreit (1986), Jacobs (1988) und Dietrich (1994). 
(3') Die Abfolge $\mathrm{z}$ weier Konstituenten $<\mathrm{X}, \mathrm{Y}>$ ist unmarkiert relativ zu $P$ genau dann, wenn $<X, Y>$ eine Serialisierungsregel hinsichtlich genau eines Parameters $P$ befolgt ( $<Y, X>$ heißt markierte Abfolge relativ zu $\mathbf{P}$ ).

Diese Auffassung vom Serialisierungsmodul einer Sprache steht im Gegensatz zur Ansicht vieler Sprachwissenschaftler, die von genau einer unmarkierten Abfolge (d.h. der Grundabfolge) einer Sprache ausgehen, so z.B. für das Deutsche Lenerz (1977a), Hoberg (1981), Grewendorf/Sternefeld (1990), Haftka (1994), Rosengren (1994). In generativgrammatischen Arbeiten wird die durch syntaktische Funktionen determinierte Abfolge als Grundabfolge postuliert, während andere Abfolgen durch Transformationen, z.B. Scrambling, von der Grundabfolge abgeleitet werden. In sprachtypologischen Ansätzen ist die Annahme genau einer Grundabfolge der Verbargumente in einer Sprache die Mehrheitsmeinung, die man z.B. bei Greenberg (1963), Mallinson/Blake (1981), Hawkins (1983) und Siewierska (1988) findet. Im Rahmen solcher Ansätze ist nur die Abfolge in (1a) und (2a) die Grundabfolge. Unter dieser Annahme kann man nicht ohne weiteres erklären, warum die Abfolge in (2b) im angegebenen Kontext ähnlich gut akzeptiert wird wie (1a) im Textkontext des Romans.

Wie lassen sich in einem Wettbewerbsmodell die Akzeptabilitätsunterschiede in (1a), (1b), (2a) und (2b) datengerecht und einfach formulieren? (1a), die beste Variante im Textkontext des Romans, weist eine grammatisch und pragmatisch unmarkierte Abfolge auf. In (1b), der schlechtesten, von Thomas Mann nicht gewählten Variante, liegt eine sowohl grammatisch als auch pragmatisch markierte Abfolge vor. (2a) zeigt eine grammatisch unmarkierte, aber pragmatisch markierte Abfolge, (2b) eine grammatisch markierte, aber pragmatisch unmarkierte $A$ bfolge. Die Tatsache, daß viele, aber nicht notwendigerweise alle Sprecher des Deutschen (2a) gegenüber (2b) bevorzugen, deutet darauf hin, daB Sprecher des Deutschen Präferenzen unterschiedlich gewichten und dabei die grammatische Präferenz den Ausschlag gibt. ${ }^{4}$ Die gewichtete Interaktion der beiden Serialisierungsfaktoren führt also zum Akzeptabilitätsgefälle, das durch die Zahlen vor den jeweiligen Beispielen angedeutet wurde: $(1 \mathrm{a})>(2 \mathrm{a})>(2 \mathrm{~b})>(1 \mathrm{~b})$.

4 Vgl. Jacobs (1988) zur Präzisierung dieser Auffassung. Die Postulierung unterschiedlich gewichteter Präferenzregeln ist nicht unproblematisch, und es ist daher erstrebenswert, die unterschiedliche Gewichtung als Folgeerscheinung anderer Gesetze zu erklären. Vgl. für einen Versuch im Hinblick auf pragmatische Präferenzen Primus (1994). 
Erwähnenswert ist auch folgende Beobachtung im Kontext einer WFrage nach dem Subjekt wie in (2): jede der beiden theoretisch möglichen Abfolgen von Subjekt und Objekt befolgt eine Präferenz und mißachtet eine andere, weil hier die grammatische und die pragmatische Präferenz in Konkurrenz zueinander stehen. Das Resultat ist eine Wortstellungsfreiheit von Subjekt und Objekt im Kontext einer W-Frage nach dem Subjekt, die im Textkontext des Romans für das Subjekt und Objekt in (1) nicht gegeben ist. Im Textkontext von (1) besteht zwischen der grammatischen und der pragmatischen Präferenz eine Koalition. Bei einer Koalition aller Präferenzen entsteht im Deutschen der Eindruck einer festen Wortstellung. Das liegt daran, daB in einem solchen Fall die markierte Abfolge keine Motivation hat.

Zusammenfassend läßt sich feststellen, daß man im Rahmen des Wettbewerbsmodells nicht nur nachweisbare Akzeptabilitätsunterschiede datengerecht erfassen, sondern auch Unterschiede der Wortstellungsfreiheit erklären kann.

Ich werde im folgenden zeigen, daß im Deutschen und in anderen Sprachen zwei verschiedene grammatische Serialisierungsfaktoren angenommen werden müssen, so daß schon auf der grammatischen Ebene die Annahme genau einer Grundabfolge problematisch ist. Die Eigenständigkeit dieser Parameter führt dazu, daß konglomerate Begriffe wie Subjekt, direktes Objekt und indirektes Objekt eher hinderlich als nützlich sind. Probleme im Zusammenhang mit der Verbstellung und pragmatische Faktoren werden ausgeklammert. ${ }^{5}$

\section{Semantische Dependenz}

2.1 Die Ableitung der wortstellungsrelevanten Hierarchie von semantischen Rollen

Ausgangspunkt der folgenden Überlegungen zum rollensemantischen Serialisierungsparameter bildet der Ansatz von Dowty (1991), der hier in einigen wesentlichen Aspekten modifiziert wird.

Die rollensemantische Struktur eines Prädikats abstrahiert von der Verblexembedeutung diejenigen grundlegenderen relationalen Komponenten, die für den syntaktischen Valenzrahmen des Prädikats relevant sind. Es handelt sich bei diesen relationalen Komponenten um Prädikate wie Kontrolle, Verursachung, Wahrnehmung, Aktivität bzw. Bewegung und

5 Pragmatische Faktoren wurden von der Autorin dieses Beitrags in anderen bereits publizierten Arbeiten eingehender untersucht, vgl. Primus (1993) und (1994). 
Besitz. Im folgenden werden solche Prädikate „rollensemantische Basisprädikate" genannt, und die Relation zwischen einem rollensemantischen Basisprädikat und einer bestimmten semantischen Argumentstelle wird als "Basisrolle" bezeichnet.

Durch bestimmte Basisprädikate determinierte Basisrollen stehen in einem engeren semantischen Zusammenhang und bilden einen multifaktoriellen und somit graduierbaren Prototypenbegriff, den Dowty ProtoRolle nennt. Die Basisrollen, die die Agens-Proto-Rolle charakterisieren, erscheinen in (4):

(4a) CONTROL $(x, \ldots) \quad x$ kontrolliert/Kontrolleur

(4b) CAUSE $(x, \ldots) \quad x$ verursacht/Verursacher

(4c) $\operatorname{MOVE}(x, \ldots) \quad x$ ist physisch aktiv/Bewegungsträger

(4d) $\operatorname{EXPER}(x, \ldots) \quad x$ nimmt wahr bzw. hat eine psychische Einstellung/Wahrnehmer (engl. experiencer)

(4e) POSSESS $(x, \ldots) \quad x$ verfügt über etwas/Besitzer

Die linke Spalte führt die agentivischen Basisprädikate ein, während in der rechten Spalte die Bezeichnungen für die entsprechenden Basisrollen erscheinen.

(4a)-(4d) enthalten Basisprädikate und Basisrollen, die bei Dowty (1991), aber auch in vielen anderen Ansätzen im Zusammenhang mit dem Agensbegriff diskutiert wurden. Statt Willkürlichkeit oder Intentionalität habe ich Kontrolle gewählt, weil diese Agenseigenschaft mehr als Willkürlichkeit umfassen soll. Kontrolle impliziert auch bestimmte Fähigkeiten oder Verantwortung von seiten des Handelnden (vgl. Rayfield (1977) und Thalberg (1972)). Es muß jedoch betont werden, daß der Unterschied $\mathbf{z w i s c h e n ~ K o n t r o l l e ~ i m ~ w e i t e r e n ~ S i n n ~ u n d ~ W i l l k u ̈ r l i c h k e i t ~ i m ~}$ engeren Sinn für die Serialisierungsdaten nicht unmittelbar relevant ist. Bewegung wird ebenfalls sehr allgemein aufgefaßt und soll jede Form von physischer Veränderung oder Aktivität und nicht nur den Ortswechsel bzw. die Fortbewegung eines Partizipanten erfassen. EXPER erfaBt nicht nur sensorische oder geistige Zustände wie bei sehen und denken, sondern auch psychische Einstellungen wie bei gefallen, mißfallen, nützen oder schaden. Das Besitzprädikat in (4e) kommt bei Dowty nicht vor und soll nicht nur Besitz im engeren Sinn, sondern jede Form von Verfügbarkeit erfassen. Die Einführung von Wahrnehmern und Besitzern als agen- 
tivische Rollen findet man seltener in der Literatur und muB deshalb besonders hervorgehoben werden.

Die Liste der agensrelevanten Basisprädikate in (4) mag nicht vollständig sein, aber sie enthält die wichtigsten Begriffe. Es ist für das Folgende wichtig festzuhalten, daß sich die Formulierung der folgenden Prinzipien und Definitionen nicht ändert, wenn man zusätzliche Basisprädikate einführt.

Ähnlich wie in Dowtys Arbeiten (z.B. Dowty (1979)) werden auch in dieser Arbeit Basisprädikate im Rahmen von Bedeutungspostulaten eingesetzt. Bedeutungspostulate geben Bestandteile von Lexembedeutungen wieder und stellen keine Paraphrasen von Lexembedeutungen dar, was durch eine unilaterale Implikationsrelation zum Ausdruck gebracht wird. Vgl. (5), wo nur eine rudimentäre, alle irrelevanten Details vernachlässigende Repräsentation angeboten wird:

(5a) Peter gab dem Kind den Apfel.

$\forall \mathrm{x} \forall \mathrm{y} \forall \mathrm{z}[\mathrm{GEB}(\mathrm{x}, \mathrm{y}, \mathrm{z}) \rightarrow$

CONTROL $(x, \operatorname{BECOME}(\operatorname{POSSESS}(y, z)) \& \operatorname{MOVE}(x, z))]$

(5b) Peter nahm dem Kind den Apfel.

$\forall \mathrm{x} \forall \mathrm{y} \forall \mathrm{z}[\mathrm{NEHM}(\mathrm{x}, \mathrm{y}, \mathrm{z}) \rightarrow$

CONTROL $(x, \operatorname{BECOME}(\neg \operatorname{POSSESS}(y, z)) \& \operatorname{MOVE}(x, z))]$

(5c) Peter erzählte dem Kind ein Märchen.

$\forall \mathbf{x} \forall \mathbf{y} \forall \mathbf{z}$ [ERZ ̈̈HL $(x, y, z) \rightarrow$

CONTROL(x, BECOME(EXPER $(y, z)) \& \operatorname{MOVE}(x))]$

(5d) Peter zeigte dem Kind sein neues Auto.

$\forall \mathrm{x} \forall \mathrm{y} \forall \mathrm{z}[\mathrm{ZEIG}(\mathrm{x}, \mathrm{y}, \mathrm{z}) \rightarrow \operatorname{CONTROL}(\mathrm{x}, \operatorname{BECOME}(\operatorname{EXPER}(\mathrm{y}, \mathrm{z}))$ \& $\operatorname{MOVE}(\mathbf{x}))]$

(5e) Der Junge tötete den Vogel.

$\forall x \forall y[T O ̈ T(x, y) \rightarrow \operatorname{CAUSE}(x, \operatorname{BECOME}(\operatorname{DEAD}(y))$

\& $\operatorname{MOVE}(\mathbf{x}, \mathbf{y}))]$

(5f) Dem Jungen gefiel der Film.

$\forall x \forall y[\operatorname{GEFALL}(x, y) \rightarrow \operatorname{EXPER}(x, y)]$

(5g) Peter hat ein neues Auto.

$\forall \mathbf{x} \forall \mathbf{y}[\operatorname{HAB}(x, y) \rightarrow \operatorname{POSSESS}(x, y)]$ 
(5h) Der Junge ähnelt seinem Vater. $\ddot{A} \operatorname{HNEL}(x, y)$

BECOME wird ähnlich wie bei Dowty (1979) verwendet und soll zum Ausdruck bringen, daB der vom unmittelbar folgenden Prädikat bezeichnete Sachverhalt erst am Ende des vom Verblexem bezeichneten Vorgangs zutrifft.

Die semantische Rolle des Arguments $x$ fallt in (5a)-(5h) unter das Proto-Agenskonzept. In (5a)-(5d) kontrolliert $x^{6}$ die vom Verb denotierte Situation. Daraus folgt für prototypische Handlungsverben wie die in (5a)-(5d), daf $x$ die vom Verb bezeichnete Situation verursacht und sich auch ihrer wesentlichen Aspekte bewuBt ist. ${ }^{7}$ In (5a) kontrolliert $x$ ein Ereignis, in welchem $y$ in den Besitz von $z$ kommt. In (5b) kontrolliert $x$ ein Ereignis, in welchem $y$ den Besitz über $z$ verliert. In (5c) kontrolliert $x$ ein Ereignis, in welchem y zum Wahrnehmer von $z$ wird. Die Verben erzählen in (5c) und zeigen in (5d) unterscheiden sich durch den Parameter der akustischen vs. optischen Wahrnehmung. In (5e) entspricht dem ersten Argument von töten ein Verursacher, wobei Kontrolle und Wahrnehmung nicht ausgeschlossene, aber auch nicht notwendige Bedeutungsbestandteile sind. In (5a)-(5e) ist $x$ auch in Bewegung, also an der Situation physisch aktiv beteiligt. In (5a)-(5b) und (5e) manipuliert $x$ dabei auch einen weiteren Partizipanten unmittelbar oder mittels eines Instruments. In (5f) hat $x$ nur eine psychische Einstellung, während in $(5 \mathrm{~g}) \times$ nur über etwas verfügt. Besonders hervorheben muB man die rollensemantische Struktur in (5h), die in diesem Modell zugelassen ist. Das Verblexem ähneln selegiert kein Basisprädikat aus der Liste (4) und somit auch keine semantische Rolle im traditionellen Sinn. Alle semantischen Argumente, die in den Beispielen mit $\mathbf{x}$ bezeichnet wurden, fallen unter den Prototypenbegriff der Agentivität, obwohl ein Verb wie geben, sagen oder zeigen, mehr Agenseigenschaften an x zuweist, als das Verb gefallen, haben oder gar ähneln.

Die bisherigen Ausführungen bewegen sich trotz geringfügiger Modifikationen noch im Rahmen, den Dowty (1991) abgesteckt hat. Das ändert sich mit der Rekonstruktion der Unterscheidung $\mathrm{z}$ wischen Proto-Agens und Proto-Patiens. Dowty versucht, den Unterschied zwischen ProtoAgens und Proto-Patiens dadurch zu erfassen, daß er dem Proto-Patiens Basisprädikate zuordnet, die möglichst verschieden sind von denen des

6 In verkürzter Redeweise wird $x$ mit seinem Denotat gleichgesetzt.

7 Vgl. über diesen Zusammenhang von Kontrolle, Kausalität und Wahrnehmung Thalberg (1972), von Wright (1974) und Primus (1995a). 
Proto-Agens: sukzessive telische Affiziertheit im Sinne Krifkas (1989), Unbeweglichkeit oder Zustandsveränderung. Aber schon bei Dowtys kausaler Affiziertheit und der Zustandsveränderung durch Bewegung zeigt es sich, daB der Unterschied $z$ wischen Agens und Patiens im Grunde genommen nicht durch den Inhalt der Basisprädikate entsteht, denn Kausalität und Bewegung kommen auch agentivischen Rollen zu. Der grundlegende Unterschied zwischen Proto-Agens und Proto-Patiens muB daher woanders liegen.

Bei der Rekonstruktion des Unterschieds zwischen Agens und Patiens muß man beachten, daB es zwei Typen von rollensemantischer Information gibt: zum einen den Inhalt und die Zahl der einer Argumentstelle zugewiesenen Basisprädikate, zum anderen die Strukturposition der Argumente in der Rollenstruktur eines Verbs oder Satzes. Ich gehe davon aus, $\mathrm{da} B$ der hier relevante Unterschied 2 wischen Agens und Patiens durch die Position der entsprechenden semantischen Argumente in der rollensemantischen Struktur eines Prädikats entsteht und nicht dadurch, daß sie Argumente verschiedener rollensemantischer Basisprädikate sind. ${ }^{8}$

Es stellt sich nun die Frage, welche kognitiv-semantische Interpretation die Reihenfolge der Argumente in der rollensemantischen Struktur eines Prädikats hat. Die Reihenfolge der Argumente bildet die relativen rollensemantischen Abhängigkeiten zwischen den semantischen Argumenten eines Prädikats ab. Eine plausible Erklärung ist meiner Annahme nach die, daB die kognitive Verarbeitung des Begriffs des Verursachers, Wahrnehmers oder Sich-Bewegenden unabhängig erfolgen kann vom Begriff des Verursachten, Wahrgenommenen oder Bewegten, aber nicht umgekehrt. Das, was Linguisten als prototypisches Patiens oder Thema auffassen, also das Verursachte, Wahrgenommene oder Bewegte, können wir nur mit Rückgriff darauf interpretieren, wie sich der Verursacher, Wahrnehmer oder Sich-Bewegende in der vom Verb denotierten Situation verhält. In diesem Sinne hat die kognitive Verarbeitung einer agentivischen Rolle Priorität über die kognitive Verarbeitung einer Patiensrolle. Rollensemantische Abhängigkeit verstehe ich als Spezialfall des allgemeinen Dependenzbegriffs, der laut Mehrheitsmeinung wie in (6) bestimmt wird:

$8 \mathrm{DaB}$ die Position eines Arguments in der rollensemantischen Struktur eines Prādikats für seine oberflächensyntaktische Strukturposition relevant ist, wird oft behauptet, z.B. von Jackendoff (1987), (1991) und Grimshaw (1990). Dennoch wird der Agensbegriff in den erwähnten Arbeiten nicht ausschließlich strukturell definiert, sondern mit Hilfe einer inh altlichen Kausalitătskomponente von anderen agensverwandten Rollen wie Wahrnehmer oder Bewegungsträger und von patiensähnlichen Rollen abgegrenzt. 
(6) $\mathrm{Y}$ ist abhängig von $\mathrm{X}$ genau dann, wenn $\mathrm{X}$ ohne $\mathrm{Y}$, aber $\mathrm{Y}$ nicht ohne $X$ vorkommen bzw. interpretiert werden kann.

In syntaktischer Hinsicht ist eine Konstituente $Y$ abhängig von einer Konstituente $X$ in einer bestimmten Konstruktion genau dann, wenn $X$ ohne $\mathrm{Y}$, aber $\mathrm{Y}$ nicht ohne $\mathrm{X}$ in dieser Konstruktion vorkommen kann. In semantischer Hinsicht besagt (6), daß X ohne $Y$, aber $Y$ nicht ohne $\mathrm{X}$ interpretierbar ist. $^{9}$

Die hier vertretene Auffassung von Proto-Patiens kann auf der Grundlage der bisherigen Ausführungen wie in (7) präzisiert werden:

(7) Ein beliebiges semantisches Argument $x$ fungiert als Proto-Patiens eines rollensemantischen Basisprädikats $P$ genau dann, wenn $P$ eine von $x$ verschiedene Argumentposition hat, die $x$ vorangeht, sonst fallt die Rolle von $x$ unter Proto-Agens.

Bei semantisch intransitiven Verben gibt es keine zweiten Argumente, wenn man leere Argumentpositionen ausschlieBt. Bei Verbot leerer Argumentstellen können sich intransitive Verben entweder durch den Inhalt bzw. die Zahl der Basisprädikate oder durch eine Präsenz bzw. Absenz einer semantischen Dependenzrelation zum Verb voneinander unterscheiden, aber nicht durch die Besetzung verschiedener Argumentstellen. ${ }^{10}$ Dagegen nimmt z.B. Grimshaw (1990) tiefer eingebettete Positionen bei semantisch einstelligen Verben an, so daß die erste Position leer bleibt.

(7) läßt diesen Fall zu. Es hängt davon ab, wie man den Begriff der Argumentposition in (7) einschränkt.

Semantische Abhängigkeiten sind transitiv. Bei dreistelligen Verben wie in (5a)-(5d) entsteht eine Hierarchie von Abhängigkeiten. Das mittlere Argument $y$ in (5a)-(5d) hat hybride semantisch-strukturelle Eigenschaf-

${ }^{9}$ Diese Annahme ist möglicherweise zu stark. Fūr unsere Zwecke reicht die Abschwächung, daß $Y$ mit Rückgriff auf $X$ leichter oder schneller interpretiert werden kann als ohne Rückgriff auf $X$.

10 DaB sich sogenannte 'unergative' intransitive Verben (z.B. arbeiten, lachen) von 'ergativen' Verben (z.B. wegfahren, verblühen) durch die semantische Dependenzrelation zwischen Verb und Argument unterscheiden, wird in Primus (1995a, Kap. 6.6) gezeigt. Es ist in diesem Zusammenhang erwăhnenswert, daB die 'semantische Verbnähe', die zu inkorporationsāhnlichen Erscheinungen führt, von der semantischen Dependenz zwischen $z$ wei Koargumenten unterschieden werden muB, auch wenn die zwei Phänomene letztlich auf dasselbe dependenzbasierte Prinzip zurückgeführt werden kōnnen. 
ten. ${ }^{11}$ Einerseits ist $\mathbf{y}$ das erste Argument des Basisprädikats POSSESS oder EXPER und fungiert somit relativ zu z als Proto-Agens. Andererseits ist $\mathbf{y}$ in der CONTROL-Prädikation ein zweites Argument relativ zu $x$ und somit von diesem semantisch abhängig. Relativ zu $x$ fungiert $y$ als Proto-Patiens. Argumente mit dieser Kombination von strukturellen Proto-Agens- und Proto-Patiens-Eigenschaften fasse ich unter Proto-Rezipient zusammen. Auch ein Benefaktiv wie in Peter strickt seiner Frau einen Pulli hat eine Besitzerlesart: Peter intendiert durch sein Stricken, daB seine Frau über einen Pulli verfügt. In einer anderen Lesart des Benefaktivs strickt Peter einen Pulli anstatt seiner Frau, die somit die Rolle eines potentiellen, aber nicht realisierten Agens übernimmt. Solche Eigenschaften von Benefaktiven fallen unter das Proto-Agens-Konzept. Aber andererseits setzen Benefaktive immer einen Verursacher und aktiv Beteiligten voraus (vgl. Fillmore (1968), Dik (1978)) und sind somit von diesem semantisch abhängig. Hinsichtlich ihrer hybriden rollensemantischen Dependenzeigenschaften fallen Benefaktive unter das Konzept des Proto-Rezipienten.

Auf der Grundlage der relativen rollensemantischen Abhängigkeiten zwischen den semantischen Koargumenten eines Prädikats entsteht folgende Hierarchie von Proto-Rollen (angezeigt durch ' ... $<\Theta \ldots$...):

(8) Proto-Agens (A) $<\Theta$ Proto-Rezipient (R) $<\Theta$ Proto-Patiens (P)

Die Abkürzungen für die jeweiligen Proto-Rollen erscheinen in Klammern.

Während die Hierarchie (8) im vorliegenden Ansatz eine Folgeerscheinung der rollensemantischen Dependenzen zwischen den Koargumenten eines Prädikats ist, wird sie in mehreren Arbeiten zur deutschen Wortstellung postuliert, so z.B. bei Lange (1978), Uszkoreit (1986), Connolly (1987), Jacobs (1988) und Kefer (1989). Unterschiede zwischen den zitierten Autoren sowie zwischen den zitierten Autoren und der hier vertretenen Hierarchie (8) entstehen dadurch, daß die Auffassungen über semantische Rollen divergieren. Der auffälligste Unterschied betrifft die Einordnung des Wahrnehmers (engl. experiencer), der in den zitierten Ansätzen explizit ausgeschlossen oder auf einer Stufe mit dem Rezipienten oder Benefaktiven gesetzt wird. Die Relevanz der Hierarchie (8) für die Wortstellung und für andere sprachliche Phänomene wurde auch in sprachvergleichenden oder sprachtypologischen Ansätzen erkannt (vgl. z.B. Fillmore (1968), Jackendoff (1972) und Givón (1984)).

11 Die Tatsache, daß hybride Rollen und somit Kategorienüberlappung zugelassen ist, ist ein weiterer Vorteil der prototypensemantischen Konzeption von Proto-Rollen. 
Das strukturell-topologische Prinzip, das diesen Dependenzparameter der Argumentabfolge erfaft, ist in (9) formuliert:

(9) Wenn ein Ausdruck Y bezüglich eines Parameters P von einem Ausdruck $X$ abhängt, dann sind $X$ und $Y$ in der syntaktischen Struktur im unmarkierten Fall so plaziert, daB X Y vorangeht (oder X Y asymmetrisch c-kommandiert).

Die topologische Präzedenzrelation wird in (9) um die strukturelle Relation des c-Kommandos ergänzt. Für die Zwecke der vorliegenden Arbeit reicht die einfachste Definition von c-Kommando aus: Ein Knoten $X$ c-kommandiert einen Knoten $Y$, wenn $X$ und $Y$ einander nicht dominieren und der erste verzweigende Knoten, der $X$ dominiert, auch $Y$ dominiert. Die Präzedenzrelation und die c-Kommando-Relation determinieren $z$ wei voneinander unabhängige Ordnungsrelationen zwischen zwei Ausdrücken. Allerdings gilt für das Deutsche, daB X Y vorangeht genau dann, wenn $X$ Y c-kommandiert unter der plausiblen und jüngstens mehrheitlich vertretenen Annahme, daB die Grundstellung des finiten Verbs am rechten Satzrand ist. Mit Ausnahme des Albanischen, das im Abschnitt 5 dieser Arbeit erwähnt und in einer anderen Arbeit (Primus (1995b)) eingehender diskutiert wurde, spielt die c-KommandoBeschränkung für die folgenden Ausführungen keine wesentliche Rolle. Deshalb wurde sie in (9) in Klammern gesetzt. ${ }^{12}$

Für die hier behandelten rollensemantisch determinierten Abfolgen gilt ein Spezialfall von (9), der in (9') formuliert wird:

(9') Wenn ein Verbargument $Y$ von einem anderen Koargument $X$ rollensemantisch abhängig ist, dann sind $X$ und $Y$ in der syntaktischen Struktur im unmarkierten Fall so plaziert, daB X Y vorangeht (oder $\mathrm{X} \mathrm{Y}$ asymmetrisch c-kommandiert).

Das Prinzip (9') erfaßt zum Beispiel die Präferenz, die Rollenhierarchie (8) durch die syntaktische Abfolge der Verbargumente ikonisch abzubilden. Rollensemantische Abhängigkeit determiniert eine Abfolge von Verbargumenten, die im folgenden entsprechend der strikt lokalen, relationalen Markiertheitsauffassung und aufgrund des determinierenden Parameters "rollensemantisch unmarkiert” genannt wird. Rollensemantisch unmarkierte Abfolgen zeigen die Beispiele (1a), (2a) und (5a)-(5h).

Die Reichweite des Prinzips (9) ist sehr groß. Es erfaßt u.a. folgende attestierte universelle Präferenzen:

$12 \mathrm{Vgl}$. die eingehendere Diskussion des Verhältnisses zwischen der topologischen Präzedenzrelation und der strukturellen c-Kommando-Relation in Primus (1995a, Kap. 5 und 6) sowie (1995b). 
(a) Ein Antezedens c-kommandiert seine Anapher (z.B. ein referenzidentisches Reflexivpronomen) asymmetrisch oder geht ihr voran (vgl. z.B. Langacker (1969), Reinhart (1983)).

(b) Ein Modifikator oder ein quantifizierter Ausdruck c-kommandiert seinen semantischen Bereich asymmetrisch oder geht ihm voran (vgl. z.B. Jacobs (1988), Pafel (1993)).

(c) Ein referentiell unabhängiges Argument (z.B. ein Satztopik im Sinne Reinharts (1981)) c-kommandiert ein referentiell abhängiges Argument asymmetrisch oder geht ihm voran (vgl. z.B. Gundel (1988), Primus (1993)).

Die Wirkung der Anapherbeschränkung (a) im Deutschen wurde vielerorts besprochen (vgl. z.B. Primus (1989)) und wird hier in (10) illustriert:

(10a) weil ich die Kinder sich selbst überließ

(10b) ' weil ich sich' selbst die Kinder' überließ

$\mathrm{DaB}$ die Abfolge in (10b) tatsächlich anaphersemantisch markiert ist, zeigt das Beispielpaar (11) ohne Anapher, das eine freiere Abfolge der relevanten Argumente aufweist:

(11a) weil ich die Kinder der Mutter überließ

(11b) weil ich der Mutter die Kinder überließ

Angewandt auf quantifikationssemantische Dependenz ergibt (9) die in (b) formulierte Präferenz. Die Wirkung dieser Präferenz zeigt ein Textbeleg aus meinem Korpus, der die Quantoren niemand und irgendwelches enthält:

(12a) Es steht ganz fest, daß niemanden irgendwelches Verschulden trifft. (TM, S. 31)

(12b) ?? Es steht ganz fest, daß irgendwelches Verschulden niemanden trifft.

'Es gibt niemanden, den irgendein Verschulden trifft'

Im Textkontext des Romans ist die intendierte Lesart 'es gibt niemanden, den irgendein Verschulden trifft'. Das bedeutet, daB das Nominativargument irgendwelches Verschulden relativ zum Akkusativargument niemanden, in dessen semantischem Bereich es sich befindet, interpretiert wird. Das ergibt die Abfolge in (12a), die quantifikationssemantisch unmarkiert, aber rollensemantisch markiert ist. Die von Thomas Mann intendierte Lesart ist bei der rollensemantisch unmarkierten Abfolge in (12b) so gut wie ausgeschlossen. 


\subsection{Der erweiterte rollensemantische Dependenzbegriff}

Semantische Abhängigkeiten entstehen nicht nur bei den in (4) eingeführten Basisprädikaten und bei den in der Rollenhierarchie (8) genannten Rollen. Eine semantische Abhängigkeit besteht auch zwischen den Argumenten von ähneln in (5h). Das erste Argument von ähneln fungiert als Bezugspunkt des Vergleichs, so daB das zweite Argument relativ zum ersten Argument interpretiert wird. Das erkennt man auch daran, da $B$ das zweite Argument eine de dicto Lesart haben kann, während das erste Argument nur eine de re Lesart aufweist.

(5h) belegt außerdem die Unabhängigkeit der hier vertretenen rollensemantischen Parameter: eine semantische Abhängigkeit zwischen zwei Argumenten kann auch ohne die in (4) eingeführten rollensemantischen Inhalte entstehen. Abhängigkeiten, die traditionelle semantische Rollen betreffen, sind nur ein Spezialfall rollensemantischer Abhängigkeiten.

Ich möchte im folgenden weitere Evidenz für die Annahme liefern, daB für die Abfolge der Verbargumente die Strukturposition eines Arguments in der semantischen Repräsentation eines Verbs bzw. Satzes relevant ist und nicht der spezifische Inhalt eines semantischen Basisprädikats und die daran geknüpften traditionellen semantischen Rollen. Darauf deuten Verben hin, deren Bedeutung keines der oben genannten Basisprädikate inkludiert und deren Argumente keine traditionelle semantische Rolle tragen. Neben dem Verb ähneln in (5h) gibt es eine reichliche Auswahl von rollensemantisch unterspezifizierten Verben. Vgl. einige Beispiele in (13), in denen nicht das gesamte Bedeutungspostulat, sondern nur eine rudimentäre rollensemantische Struktur angeboten wird:

(13a) daß sich ein Teil des Wasserstoffes in schwerere Elemente verwandell (HH, S. 18) CHANGE(STATE1(x), STATE2(x))

(13b) daß der Urzustand der Materie aus den allereinfachsten Bausteinen bestanden hat (HH, S. 18)

WHOLE-PART $(x, y)$

(13c) Die Naturwissenschaft gleicht einem gewaltigen Kreuzworträtsel. (HH, S. 10) $\operatorname{GLEICH}(x, y)$

(13d) als Columbus Amerika fand (HH, S. 10) $\operatorname{FIND}(\mathbf{x}, \mathbf{y})$

(13e) weil aus diesem Prinzip weitere Gesetze folgen $\mathrm{x} \Rightarrow \mathrm{y}$ 
(13f) Auch die Natur kann aus einem gewaltigen Ball von Wasserstoff und Helium lediglich eine Sonne schaffen. (HH, S. 23) CAUSE(x, Change(STATE1(y), STATE2(y)))

(13h) weil dem Erdinneren schwefelhaltige Gase entweichen WHOLE-PART $(x, y)$

Die Verben in (13) haben Argumente, die keine in der einschlägigen Forschung etablierte semantische Rolle tragen. Bis auf das hier irrelevante Argument $x$ in (13f) sind sie weder Verursacher noch Verursachte, weder Wahrnehmer noch Wahrgenommene, weder sich bewegende, noch bewegte Mitspieler. Aber auch solche Verben haben eine semantische Valenzstruktur, durch die semantische Dependenzen entstehen. So setzt in (13a) der Endzustand 2 einen Anfangszustand 1 temporal und kausal voraus. In (13b) kann die semantische Funktion des Teils bzw. Inhalts nur relativ zum Ganzen interpretiert werden. Das erste Argument von gleichen in (13c) fungiert als Bezugspunkt des Vergleichs, so daB das zweite Argument relativ zum ersten Argument interpretiert wird (vgl. auch (5h)). Bei einem Finden-Ereignis (vgl. (13d)) kann man y nur dann als das Gefundene interpretieren, wenn man $x$ verifiziert und feststellt, daß das Verhalten von $x$ der Rolle des Finders entspricht. Die semantische Asymmetrie zwischen Antezedens und Konsequens einer Folgerungsrelation wie in (13e) zeigt sich sowohl in ihren Bezeichnungen als auch in der Abfolge dieser Argumente in der angegebenen standardlogischen Notation. In (13f) haben wir dieselbe relevante rollensemantische Teilstruktur wie in (13a), in (13h) dieselbe rollensemantische Struktur wie in (13b).

In all diesen Fällen determiniert das in der Rollenstruktur vorangehende Argument die semantische Interpretation des nachfolgenden Arguments und nicht umgekehrt. Wenn man für alle Verben, die keine traditionellen Rollen selegieren, weitere semantische Rollen einführt, so würde das Inventar der semantischen Rollen ins Uferlose expandieren. Das würde mit sich ziehen, daB auch die rollensemantische Abfolgeregel des Deutschen durch viel mehr semantische Rollen ergänzt werden müBte. Der rollensemantische Parameter des Prinzips (9) erfaßt jedoch solche Fälle und weist die in (13a)-(13h) gezeigten Abfolgen als rollensemantisch unmarkiert aus.

Das Prinzip (9) erklärt aber einige Besonderheiten der relativen Abfolge von Verbargumenten im Deutschen nicht. Eine erste in der Literatur häufig diskutierte Besonderheit ist, $\mathrm{da} B$ die Stellung mancher Nominativargumente fester ist als die Stellung anderer Nominativargumente, was 
ein Vergleich zwischen (1) einerseits und (14)-(15) andererseits demonstriert: ${ }^{13}$

(14a) Allerdings schienen auch diese Ausführungen die Psychologin nicht besonders zu interessieren. (EH, S. 15)

(14b) Allerdings schienen die Psychologin auch diese Ausführungen nicht besonders $\mathrm{zu}$ interessieren.

(15a) Da der Firma Z. enge Geschäftsbeziehungen zu Siemens nachgesagt werden (SZ)

(15b) Da enge Geschäftsbeziehungen zu Siemens der Firma Z. nachgesagt werden

Eine zweite u.a. von Gadler (1980) und Reis (1987) beobachtete Besonderheit ist, daB die relative Abfolge zweier Objekte relativ frei ist. Vgl. (16):

(16a) um Charles diesen Anblick zu ersparen (EH, S. 5)

(16b) um diesen Anblick Charles zu ersparen

Die Abfolge Akkusativobjekt-Dativobjekt ist bei zwei definiten Argumenten (wie in (16b)) mit $40 \%$ fast so häufig wie die umgekehrte Abfolge im Mannheimer Korpus (vgl. Hoberg (1981)). In pragmatisch kontrollierten Akzeptabilitätstests läßt sich eine Präferenz für die Abfolge Dativargument-Akkusativargument nicht nachweisen (vgl. Gadler $(1980))$.

Eine dritte Besonderheit betrift die relative Abfolge pronominaler Verbargumente. (17)-(19) sind die pronominalen Varianten von (14)-(16), wobei in (17) auch das Genus des Akkusativs verändert wurde, um den wortstellungsrelevanten Kasusunterschied sichtbar zu machen:

(17a) Allerdings schienen sie ihn nicht besonders zu interessieren.

(17b) "? Allerdings schienen ihn sie nicht besonders zu interessieren.

(18a) ?? Da ihr sie nachgesagt werden

(18b) Da sie ihr nachgesagt werden

(19a) ${ }^{? ?}$ um ihm ihn zu ersparen ${ }^{14}$

(19b) $u m$ ihn ihm zu ersparen

${ }^{13} \mathrm{Vgl}$. die Ergebnisse der Akzeptabilitätstests mit ähnlichen Verben in Primus (1994).

14 Diese Abfolge ist möglich, wenn man das Akkusativpronomen klitisch an das Dativpronomen anfügt (vgl. (23a) weiter unten). 
Die relative Abfolge der pronominalen Argumente scheint eigenen Regeln zu folgen.

All diese Phänomene deuten auf die Wortstellungsrelevanz der syntaktischen Funktion eines Verbarguments hin. Bei diesem Serialisierungsfaktor handelt es sich nicht um ein beliebig definierbares Konzept von syntaktischer Funktion, sondern um den Kasus oder die Präposition, die ein Prädikat seinen Argumenten zuweist. Diese formale Valenzrelation bezeichnet man als Rektion. Ihr widmet sich der nun folgende 3 . Abschnitt.

\section{Rektionsdependenz}

Eine wichtige Annahme des vorliegenden Ansatzes ist, da $B$ auch morphologische Kasussysteme hierarchisch organisiert sind und daB sich auch diese Hierarchie in der relativen Abfolge der Argumente widerspiegelt. Die relevante Hierarchie von Formfunktionen ist (20):

(20) Nominativargument <m Akkusativ-/Ergativargument <m Dativargument $<m$ andere oblique (adpositionale) Argumente

(20) ordnet nicht kategoriale Einheiten, also kasusmarkierte Nominalphrasen beliebiger Funktion, sondern funktionale Konzepte, d.h. regierte Argumente verbaler Prädikate.

Die Relevanz der Hierarchie (20) in der Grammatik des Deutschen ist mindestens für folgende Phänomene gut belegbar: Reflexivierung (vgl. Primus (1989)), diachronischer Kasusabbau (vgl. Primus (1987)), Kasuserwerb (vgl. Primus/Lindner (1994)). Die Wortstellungsrelevanz der Hierarchie (20) wird in erster Linie durch die relativen Rektionsdependenzen in (21) etabliert:

(21) Für beliebige Sprachen S, beliebige hierarchisch angeordnete Formfunktionen in $S$ und beliebige verbale Prädikate in $S$ gilt im unmarkierten Fall:

(a) Die Selektion einer rangniedrigeren Formfunktion impliziert asymmetrisch die Selektion (mindestens) einer ranghöheren Formfunktion.

(b) Je höher die Formfunktion auf der Hierarchie von $\mathrm{S}$ rangiert, um so mehr verbale Prädikate selegieren sie.

Die Wirkung der Rektionsdependenzen zwischen den ersten drei Kasusfunktionen in der Hierarchie zeigt (22). Die Verbliste ist Mater (1971) entnommen. 
(22)

$$
\begin{array}{llll}
<\text { Kasus } x, \ldots> & (17.500) \rightarrow & <\text { Nom, ... } & (17.500) 100 \% \\
<\text { Dat, ... } & (5.460) \rightarrow & <\text { Nom, Akk, Dat } & (5100) 93 \% \\
<\text { Akk, .. } & (9.740) \rightarrow & <\text { Nom, Akk, Dat> } & (5100) 52 \%
\end{array}
$$

Die erste Zeile in (22) zeigt, daB jedes Verb mit mindestens einem Kasusargument mit überaus großer statistischer Dominanz den Nominativ für dieses Argument selegiert. M.a.W. kann ein Akkusativ im syntaktischen Valenzrahmen eines Verbs nicht ohne Nominativ vorkommen, aber ein Nominativ kann ohne Akkusativ vorkommen. In der Liste von Mater gilt das für alle Verben (100\%). Die zweite Zeile zeigt, daß jedes Verb mit einem Dativargument mit überaus großer statistischer Dominanz auch ein Akkusativ- und ein Nominativargument selegiert. Bei Mater sind es 93\% der Verben. Die Umkehrung in der dritten Zeile ergibt mit $52 \%$ keine statistische Dominanz: Von der Präsenz eines Akkusativarguments im Valenzrahmen eines Verbs kann man nicht ein Dativargument erwarten. Nicht berücksichtigt wurden die Verben mit Genitivargumenten, die mit weniger als $1 \%$ des Gesamtbestandes für die Statistik in (22) nicht repräsentativ sind.

Die Kasushierarchie (20) ist wortstellungsrelevant im Deutschen und in anderen Sprachen, und zwar aufgrund der Tatsache, dab sie die relativen Rektionsdependenzen zwischen zwei Koargumenten genau widerspiegelt. Angewandt auf Rektionsdependenz ergibt das allgemeine dependenzbasierte Wortstellungsprinzip (9) eine Präferenz, die Kasushierarchie (20) auf die oberflächensyntaktische Abfolge der Argumente ikonisch abzubilden. Diesen Spezialfall von (9) formuliert (9"):

(9") Wenn ein Verbargument $Y$ von einem Koargument $X$ rektionsabhängig ist, dann sind $\mathrm{X}$ und $\mathrm{Y}$ in der syntaktischen Struktur im unmarkierten Fall so plaziert, daB X Y vorangeht (oder $\mathrm{X} \mathrm{Y}$ asymmetrisch c-kommandiert).

Aufgrund des determinierenden Faktors wird eine durch (9") als unmarkiert ausgewiesene Abfolge als "formfunktional unmarkiert" bezeichnet. Eine Motivation für das Prinzip (9") könnte darin liegen, daB einige Kasusformen im Deutschen und in anderen Sprachen zusammengefallen sind. In solchen Fällen kann die Wortstellung zur Disambiguierung und somit rascheren Verarbeitung der Kasusfunktion dienen. Eine zusätzliche verwandte Motivation für das Prinzip (9"), die auch für Sprachen mit geringem Kasussynkretismus gilt, könnte sein, daß (9") eine beschleunigte Sprachverarbeitung des morphologischen Kasusrahmens eines Prädikats garantiert. $\mathrm{Zu}$ dieser Annahme passen die folgenden vier Beobachtungen. Der in (20) angegebenen Reihenfolge der Kasus entspricht (a) die in (22) erfaBte Rektionsdependenz zwischen den Kasus des Deutschen, 
(b) die Reihenfolge des Kasuserwerbs, (c) eine abnehmende statistische Häufigkeit der Kasus und (d) eine steigende Allomorphiekomplexität der Kasusformen. Es ist also in mehreren Hinsichten optimal, dem Hörer die Kasusargumente in der in (20) etablierten Reihenfolge zu präsentieren.

Im Hinblick auf die Kodierung rollensemantischer Information muB folgende Beobachtung besonders hervorgehoben werden (vgl. dazu eingehender Primus (1995a, Kap. 4 und 6): semantische Abhängigkeiten werden bevorzugt strukturell-topologisch kodiert, die unterschiedliche Zahl und der Inhalt von Basisprädikaten werden bevorzugt durch $\mathrm{Ka}$ sus kodiert. Die Unabhängigkeit dieser rollensemantischen Parameter erklärt auch, warum Rezipient und Patiens bei kanonischen ditransitiven Verben im Deutschen und in vielen anderen Sprachen morphologisch kontra-ikonisch zur semantischen Hierarchie (8) kodiert werden. Morphologisch ergative Konstruktionen sowie Konstruktionen mit nicht-nominativischem Zustandsträger gehören ebenfalls zu den kontraikonisch kodierenden Konstruktionstypen. ${ }^{15}$

Die Wirkung der Präferenz (9") zeigt sich ohne Interferenz von seiten rollensemantischer Dependenzen ${ }^{16}$ bei der Abfolge der sogenannten 'schwachen' Pronomina im Deutschen. Zu dieser Klasse gehören die Personal- und Reflexivpronomina. Relevante Daten wurden in (17)(19) präsentiert. Eine von der Kasushierarchie abweichende Abfolge ist möglich, wenn das zweite Pronomen an das erste Pronomen klitisiert wird, wie in (23): ${ }^{17}$

(23a) da habe ich dir'n falsch geschildert

(23b) Er ließ sich's versichern.

Die starke Klitisierungstendenz des Pronomens es erklärt möglicherweise, warum es bei zwei Akkusativpronomina immer vorangehen muß

15 Dowty hat weder der Unabhängigkeit der beiden rollensemantischen Parameter noch der Unabhängigkeit der beiden Kodierungssysteme Beachtung geschenkt. Letzteres sieht man daran, daß er mit diesbezūglich undifferenzierten Begriffen wie Subjekt und Objekt arbeitet. Sein Argumentselektionsprinzip basiert auf der unterschiedlichen Zahl der Basisprädikate, die einer Argumentstelle zugewiesen wird. Deshalb triftt sein Prinzip nur für die Kasuskodierung korrekte Prognosen.

16 Dieses Faktum ist selbst erklärungsbedürftig. Eine Beobachtung, die zu seiner Erklärung beitragen könnte, ist, daß die 'schwachen' Pronomina im Deutschen außerhalb der Satzdomäne der anderen Argumenttypen plaziert sind (vgl. Lenerz (1994)).

17 Vgl. Lenerz (1994) zur Unterscheidung zwischen 'schwachen' Pronomina und Klitika. 
oder nur in klitisierter Form nachgestellt werden darf (vgl. Hofmann (1994, S. 53)): wir lassen es ihn spüren/wir lassen ihn's spüren/?" wir lassen ihn es spüren.

Zusammenfassend kann man festhalten, daB die Stellungsbesonderheiten der 'schwachen' Pronomina daher rühren, dab sich bei ihnen der rollensemantische Serialisierungsparameter nicht bemerkbar macht. Daraus resultieren folgende Unterschiede zum topologischen Verhalten von Verbargumenten, die nominal oder als 'starke' Pronomina realisiert werden: (a) keine Aufspaltung der Nominativargumente in solche mit freierer und solche mit festerer Stellung, (b) eine Präferenz für die Abfolge Akkusativvor-Dativ und (c) eine relativ feste Abfolge, weil es für die Umkehrung der kasusdeterminierten Abfolge keine rollensemantische Motivation gibt. Die formfunktional unmarkierte Abfolge kann jedoch ähnlich wie bei nominalen Argumenten für pragmatische Zwecke umgekehrt werden unter der Voraussetzung, daB das entsprechende Pronomen einen Satzakzent tragen kann.

\section{Konkurrenz und Koalition der Serialisierungsparameter im Deutschen: festere und freiere Abfolgen}

Ich möchte nun im folgenden 4 . Abschnitt zeigen, daB dieselbe Hierarchie von Formfunktionen, die für die relative Abfolge von Personalpronomina angenommen werden muB, auch für nominale Argumente im Deutschen wortstellungsrelevant ist. Außerdem möchte ich zeigen, daß der Wechsel zwischen freier und fester Serialisierung durch die Interaktion zwischen Rektionsdependenz und semantischer Dependenz einfach erklärt werden kann.

Ich fange mit den festeren Abfolgen an. Eine festere Abfolge ergibt sich von selbst bei Koargumenten, die rollensemantisch und kasusfunktional kongruente Abhängigkeiten aufweisen. Diese Koalition von Faktoren finden wir beim stellungsfesteren Nominativargument in (1), weil das Verb legen in der vorgegebenen Valenzvariante ein agentivisches Nominativargument und ein akkusativisches Patiensargument selegiert. Dasselbe gilt für die Nominativargumente in (5a)-(5e).

Entgegen der Annahme von Lenerz (1977b), Uszkoreit (1986) und Jacobs (1988) ist ein Nominativargument, dem kein willkürlich handelndes Agens entspricht, stellungsfest, wenn es in der rollensemantischen Struktur des Prädikats vor seinen Koargumenten erscheint. Wie aus den Ausführungen im Abschnitt 2.2 weiter oben ersichtlich wurde, trägt ein solches Nominativargument nicht notwendigerweise die traditionelle, auf willkürlich Handelnde eingeschränkte Rolle des Agens. Nominativargu- 
mente, denen kein Agens im engeren Sinn entspricht, die aber im vorliegenden Modell die Bedingungen für eine festere Abfolge erfüllen, zeigen die Beispiele in (5g)-(5h) weiter oben sowie (24)-(25):

(24a) daß Joseph $K$. das Geld von einem Schweizer Konto erhallen habe

(24b) ${ }^{? ?}$ daß das Geld Joseph K. von einem Schweizer Konto erhalten habe

(25a) bei dem die Beteiligten der Profitsucht verfielen (SZ)

(25b) ?? bei dem der Profitsucht die Beteiligten verfielen

Das Nominativargument in (24a) fungiert als Besitzer, d.h. als erstes Argument einer POSSESS-Prädikation und steht vor dem akkusativischen Besitzobjekt. DaB die von-Phrase nicht als Agens fungiert, wurde von vielen Linguisten festgestellt (vgl. ausführlicher Kunze (1991)). Das Nominativargument in (25a) fungiert als Träger einer psychischen Einstellung und steht vor einem akkusativischen Einstellungsobjekt. Die Abfolge in den Sätzen (24b) und (25b) hat keine grammatische Motivation, wodurch der Eindruck der festeren Wortstellung entsteht. Natürlich sind (24b) und (25b) akzeptabel, wenn sie einer pragmatischen Präferenz genügen, was weiter oben am Beispiel (2) gezeigt wurde. Das ist der Grund, warum ich von relativ fester Abfolge spreche. Die pragmatische Reparaturmöglichkeit werde ich im folgenden nicht mehr erwähnen, weil sie immer gegeben ist und nicht direkt für die hier diskutierten Fallunterscheidungen verantwortlich ist.

Weitere relativ feste Abfolgen betreffen rollensemantische Dependenzen, die durch traditionelle semantische Rollen nicht erfaBt werden. Die relative Abfolge der Argumente solcher Verben hat Lötscher (1981) eingehender besprochen. Die rollensemantische Struktur solcher Verben wurde in (13) dargestellt. Bei den Verben in (13a)-(13d) entspricht der rollensemantischen Dependenz auch eine koalierende Rektionsdependenz, so daß die illustrierten Abfolgen relativ fest sind, was der Leser selbst überprüfen kann. Eine grammatische Motivation für eine andere als die in (13a)-(13d) illustrierte Abfolge gibt es nicht. Lötscher listet für solche Verben verschiedene disparate Abfolgeregeln auf. Dieser Vorschlag ist ein guter Beginn, aber keine befriedigende Lösung des Problems, weil er die im vorliegenden Beitrag nachgewiesene gemeinsame semantische Eigenschaft solcher und ähnlich gelagerter Fälle nicht erfaßt.

Eine andere Konstellation mit gleichem Wortstellungseffekt liegt bei zwei gleichwertigen Formfunktionen vor, wie in (26)-(27): 
(26a) Der Lateinlehrer fragt den Schüler die Vokabeln ab.

(26b) ?? Der Lateinlehrer fragt die Vokabeln den Schüler ab.

(27a) Der Lateinlehrer läßt den Schüler die Vokabeln aufsagen. (27b) " Der Lateinlehrer läßt die Vokabeln den Schüler aufsagen.

(26) und (27) inkludieren die rollensemantische Information, daB der Lateinlehrer ein Ereignis bewirkt, in welchem der Schüler die Vokabeln hört bzw. mitteilt. Relativ zu den Vokabeln fungiert also der Schüler als Wahrnehmer bzw. Dicendi-Agens. Aufgrund der rollensemantischen Dependenzen ist die in (26a) und (27a) angegebene relative Abfolge der beiden Akkusativargumente zu erwarten. $\mathrm{Da}$ die Umkehrung dieser Abfolge wie in (26b) und (27b) weder rollensemantisch noch kasusfunktional motiviert ist, ist sie ohne pragmatische Reparatur nicht akzeptabel.

Bei einer Koalition der grammatischen Serialisierungsparameter kann man folgendes Ergebnis festhalten. Diejenigen Nominativargumente sind relativ stellungsfest, bei denen ein Abweichen von der kasusdeterminierten Abfolge keine rollensemantische Motivation hätte. Ähnliches gilt für die kasusfunktional determinierte Abfolge 'schwacher' Pronomina, weil der rollensemantische Parameter ausfällt. Die rollensemantisch determinierte Abfolge zweier Akkusativargumente ist ebenfalls relativ fest, weil ein Abweichen von ihr keine kasusfunktionale Motivation hätte. Der Koalitionsfall der grammatischen Serialisierungsparameter und die daraus resultierende Wortstellungsrigidität entsteht im Deutschen bei drei Typen von Konstruktionen: beim ikonisch kodierenden Konstruktionstyp und trivialerweise durch Ausfall eines Parameters beim kasusfunktional neutralisierten Konstruktionstyp und bei der rollensemantisch neutralisierten Abfolge 'schwacher' Pronomina.

Es gibt im Deutschen aber auch Konstruktionen, in denen die rollensemantischen und kasusfunktionalen Abhängigkeiten zweier Koargumente inkongruent sind. Das führt zu einer Konkurrenz zwischen rollensemantischer und formfunktionaler Dependenz. Diese Situation findet man in den Belegen in (14)-(16). In (14a) haben wir beim Verb interessieren den Zustandsträger vor dem Zustandsobjekt aber Akkusativ vor Nominativ. Folglich gibt es eine formfunktionale Motivation für die Umkehrung dieser Abfolge zu Nominativ vor Akkusativ, wie in (14b). $\mathrm{Zu}$ diesem Verbtyp gehört auch gefallen in (5f).

Eine grammatisch freie Wortstellung liegt auch in (13e)-(13g) weiter oben vor. In (13e) erscheint das logische Antezedens als regierte Präpositionalphrase, und das Konsequens steht im Nominativ. Die semantisch motivierte Abfolge Antezedens-Konsequens kann aus formfunktio- 
nalen Gründen umgekehrt werden. In (13f) und (13g) kann von der illustrierten rollensemantisch unmarkierten Abfolge ebenfalls aus formfunktionalen Gründen abgewichen werden. Kasusfunktional determinierte "Minimalpaare" mit identischer Rollenstruktur bilden (13a) und (13f) einerseits und (13b) und (13g) andererseits. Die freiere Abfolge in den kontra-ikonischen Konstruktionen (13f) und (13g) kontrastiert mit der festeren Abfolge in (13a) bzw. (13b), wo eine ikonische formfunktionale Kodierung vorliegt.

Ähnlich gelagert sind auch die Fälle (15) und (16), die zu den rollensemantisch kanonischen ditransitiven Konstruktionen zählen. In diesen Konstruktionen geht das Dativargument dem Akkusativargument in der rollensemantischen Struktur des Satzes voran, was in (5a)-(5d) gezeigt wurde. Wenn im Passiv das Akkusativargument im Nominativ erscheint, wie in (15), so ändern sich die relativen kasusfunktionalen Abhängigkeiten zwischen den beiden Argumenten nicht. Die Inkongruenz zwischen rollensemantischer und formfunktionaler Dependenz erklärt die freie Abfolge solcher Argumente. ${ }^{18}$

Im folgenden möchte ich auf problematischere Fälle eingehen. Es ist fraglich, ob es semantisch in jeder Hinsicht gleichwertige Argumente gibt, weil referentiell-semantisch in der Regel das erste Argument als Bezugskonstituente für alle nachfolgenden Argumente gewählt wird, aber es gibt einige Verben bzw. verbale Konstruktionen, die rollensemantisch symmetrisch beteiligte Argumente selegieren (vgl. auch Dowty (1991)). Ein Beispiel bietet (28):

(28a) daß die Entstehungsgeschichte der Erde sehr eng mit der Entstehungsgeschichte der Sonne verknüpft ist (HH, S. 11)

(28b) ?? daß mit der Entstehungsgeschichte der Sonne sehr eng die Entstehungsgeschichte der Erde verknüpft ist

Es gibt für die Umkehrung der kasusfunktional determinierten Abfolge in (28a) keine rollensemantische Motivation und somit liegt wie erwartet eine relativ feste Abfolge vor.

Schwieriger zu beurteilen ist die rollensemantische Symmetrie der Objektpaare in (29):

(29a) weil er den Kollegen seiner Familie vorstellte

(29b) weil er seine Wünsche der neuen Situation anpaßte

18 Die formfunktionalen Dependenzen zwischen Rezipient und Patiens āndern sich beim bekommen-Passiv (weil der Junge das Fahrrad geschenkt bekommt). Im vorliegenden Ansatz wird korrekt vorhergesagt, daB in dieser Konstruktion eine festere Abfolge Rezipient vor Patiens vorliegt. 
(29c) weil er die jüngeren Mitarbeiter den älteren Kollegen gleichstellte (29d) weil er roten Wein dunklem Bier vorzieht

Unter der Annahme, daB die Objektpaare in (29) partiell symmetrisch beteiligte Mitspieler bezeichnen, erklärt sich im vorliegenden Modell die zugegebenermaßen sehr schwach ausgeprägte Präferenz für die Abfolge Akkusativ-vor-Dativ von selbst: es gibt für die Dativ-Akkusativ-Abfolge keine hinreichende rollensemantische Motivation. Diese Motivation ist nur bei den semantisch kanonischen ditransitiven Verben, die in (5a)(5d) illustriert wurden, gegeben. Die Rezipienten in (5a)-(5d) zeichnen sich durch eine eindeutige rollensemantische Asymmetrie gegenüber den Patiensargumenten aus.

Dativargumente, deren Rolle ebenfalls nicht zu den kanonischen ProtoRezipienten gezählt werden kann, zeigen die Beispiele $(30 \mathrm{a}, \mathrm{b})$ :

(30a) weil er das Buch (x) dem Regal (y) entnahm (30b) weil er die Blumen (x) der Kälte (y) auslieferte (30c) $\operatorname{LOC}(x, \operatorname{REG}(y))$

(30c) stellt die lokale rollensemantische Struktur dar, an denen die zwei Objekte in (30a, b) beteiligt sind, wie sie von Bierwisch (1988) und Lang (1991) mit besonderem Augenmerk auf lokale Präpositionen vorgeschlagen wurde. REG erfaßt näher spezifierbare Regionen der Lokalisierung wie z.B. Fläche, Innenraum usw. Für diese Lesart von $(30 a, b)$ sprechen Paraphrasen wie 'er nahm das Buch aus dem Regal' und 'er bewirkte, daß die Blumen in der Kälte waren'. Die in (30) illustrierten Verben haben aber auch andere Lesarten, in denen die rollensemantischen Dependenzen $z$ wischen den fraglichen Argumenten anders ausfallen, wie (31) zeigt:

(31a) weil er diesen Worten (y) eine Drohung (x) entnahm WHOLE-PART $(\mathbf{y}, \mathbf{x})$

(31b) weil er den Kunden (y) die Ware (x) auslieferte $\operatorname{POSSESS}(y, x)$

(30) und (31) verdeutlichen, daB es eine Reihe von Verben gibt, die bezüglich der rollensemantischen Dependenzen $z$ weier Koargumente mehrere Optionen zulassen.

Es ist außerdem damit zu rechnen, daß die rollensemantischen Dependenzen unterspezifizierter Argumente lexemspezifisch ausfallen können oder durch morphologische derivationelle Prozesse verändert werden können. $\mathrm{Zu}$ dieser lexemspezifischen Restklasse von Verben mit leicht bevorzugter Akkusativ-Dativ-Abfolge, die beim jetzigen Stand der Forschung rollen- 
semantisch nicht befriedigend erklärt werden kann, gehören die Verben überlassen und übergeben.

\section{Konkurrenz und Koalition der Serialisierungsparameter in den ditransitiven Konstruktionen europäischer Sprachen}

Wie anhand deutscher Daten gezeigt werden konnte, sind formfunktionale Dependenzen und rollensemantische Dependenzen in einigen Konstruktionen ikonisch und in anderen Konstruktionen kontra-ikonisch aufeinander abgebildet. Für den ikonisch abbildenden Konstruktionstyp trifft der hier vorgestellte Ansatz die Prognose, daß die Abfolge der Argumente solcher Verben innerhalb eines Sprachsystems relativ fest und im Sprachvergleich konstant ist. Dieser Sachverhalt erklärt sich von selbst dadurch, daß es keinen alternativen grammatischen Wortstellungsfaktor gibt, der eine andere Abfolge motiviert. Für den kontra-ikonisch abbildenden Konstruktionstyp trifft der hier vorgestellte Ansatz die Prognose, daß die Abfolge der Argumente solcher Verben innerhalb eines Sprachsystems relativ frei und im Sprachvergleich variabel ist. Dieser Sachverhalt erklärt sich von selbst dadurch, daß jede Abfolge zweier kontraikonisch kodierter Argumente einer grammatischen Serialisierungspräferenz genügt.

In diesem Abschnitt sollen die Beobachtungen zum Deutschen durch sprachtypologische Daten ergänzt werden. Die Einbettung einer detaillierteren einzelsprachlichen Analyse in eine sprachtypologische Perspektive ist sowohl für germanistische als auch für sprachtypologische Fragestellungen von Nutzen. Für den germanistisch Interessierten wird dieser Abschnitt zeigen, daß das allgemeine dependenzbasierte Prinzip (9) keine sprachspezifische Serialisierungsregel des Deutschen, sondern ein universelles Präferenzgesetz ist. Für den sprachtypologisch wie für den germanistisch Interessierten sind die im folgenden dargestellten Mechanismen der Sprachvariation von besonderem Interesse.

Unter der Annahme des universellen Prinzips (9) ist Sprachvariation hinsichtlich der hier diskutierten wortstellungsrelevanten Dependenzparameter zu erwarten. Es gibt Sprachen, in denen beide grammatische Parameter 'neutralisiert' sind und stattdessen diskursbasierte Dependenzen eine besonders starke Wirkung zeigen. Solche Sprachen zeichnen sich durch eine rollensemantisch und kasusfunktional absolut freie Abfolge aller Verbargumenten aus. Kiss (1995) nennt solche Sprachen diskurskonfigurationell. Zu diesen Sprachen zählen Baskisch, Finnisch, Georgisch, Lazisch, Rumänisch, Ungarisch und Türkisch. Die 'Neutralisation' des rollensemantischen Parameters bei gleichzeitiger Relevanz des 
formfunktionalen Parameters zeigt sich in der Abfolge der 'schwachen' Pronomina im Deutschen. Auch beim kasusfunktionalen Parameter ist mit erheblicher Sprachvariation zu rechnen, denn zur 'Neutralisation' dieses Parameters kommen Variationsfaktoren hinzu, die die Zahl der wortstellungsrelevanten Kasusdistinktionen oder das Verhältnis zwischen semantischer Rolle und Kasusfunktion betreffen. Ich werde mich im folgenden auf den kasusfunktionalen Parameter in seiner Interaktion mit dem rollensemantischen Parameter konzentrieren und habe dafür rollensemantisch kanonische ditransitive Konstruktionen (d.h. Rollenstrukturen wie in (5a)-(5d)) gewählt. ${ }^{19}$

Ich habe im Rahmen des EUROTYP-Programms zur Typologie der europäischen Sprachen die relative Abfolge von Proto-Rezipient und ProtoPatiens in 50 Sprachen untersucht (vgl. Primus (1995b)). Dieser Abschnitt faßt die Ergebnisse dieser Untersuchung zusammen.

Ich beginne mit den Sprachen, die rollensemantisch kanonische ditransitive Verben wie im Deutschen mittels Kasus formal voneinander unterscheiden, wobei das Proto-Patiens und der Proto-Rezipient kontraikonisch kodiert werden. Im folgenden wird dies als Kodierungstyp 2 abgekürzt. Vgl. (32):

(32a) On dal bratu knigi $\quad$ (Weißrussisch) ${ }^{20}$

er gab Bruder-DAT Bücher-ACC

'Er gab (seinem/einem) Bruder (die) Bücher.'
Dao je bratu knjigu
(Serbo-Kroatisch)
gab AUX Bruder-DAT Bücher-ACC
'Er gab (seinem/einem) Bruder (die) Bücher.'

(33) faßt die relative Abfolge von Proto-Rezipient (R) und Proto-Patiens

(P) für alle Sprachen aus meiner Stichprobe, die den Kodierungstyp 2 aufweisen, zusammen:

(33) 1. <R, P> leicht bevorzugt (15 Sprachen): Artschinisch, Deutsch, Inguschisch, Kaschubisch, Lettisch, Litauisch, Ober-Sorbisch, Polnisch, Russisch, Serbo-Kroatisch, Slowakisch, Slovenisch, Tschechisch, Ukrainisch, Weißrussisch.

19 Die Auffassung, daf geben, nehmen, erzählen und zeigen rollensemantisch kanonische ditransitive Verben sind, vertritt in seiner sprachtypologischen Untersuchung auch Blansitt (1973).

20 Interlinearübersetzungen erscheinen nur bei weniger bekannten Sprachen oder wenn die Formfunktion zur Diskussion steht. Die Beispiele wurden durch Informantenbefragungen eruiert. 
2. $<\mathrm{P}, \mathrm{R}>$ leicht bevorzugt (1 Sprache): Albanisch, vgl. Primus (1995b)

3. Keine Präferenz (12 Sprachen): Awarisch, Altgriechisch, Beschitinisch, Darginisch, Estnisch, Finnisch, Latein, Lezgisch, Rumänisch, Tzesisch, Udmurtisch, Ungarisch.

$<\mathrm{R}$, P> leicht bevorzugt wegen diskurskonfigurationeller Faktoren (4 Sprachen): Baskisch, Georgisch, Lazisch, Türkisch.

4. Feste Abfolge von R und P: keine Sprache

Für den Kodierungstyp 2 gibt es keine andere feste oder unmarkierte Abfolge in meiner Sprachenstichprobe. Mit Ausnahme des Albanischen, auf das ich in einer anderen Arbeit (1995b) näher eingehe, wird in 15 Sprachen (darunter auch das Deutsche) die Abfolge $\langle R, P\rangle$ leicht bevorzugt. Diese leichte Präferenz für die $<R, P>-A b f o l g e$ charakterisiert kasusmarkierende Sprachen: sie findet sich nämlich bei keinem anderen Kodierungstyp in meiner Stichprobe.

Keine klare Präferenz zeigen 12 weitere Sprachen unter Punkt 3, wobei sich darunter einige diskurskonfigurationelle Sprachen mit grammatisch absolut freier Argumentabfolge befinden wie z.B. Finnisch, Rumänisch und Ungarisch. In 4 weiteren diskurskonfigurationellen Sprachen entsteht eine Präferenz für $<R, P>$ nachweislich durch die Tatsache, da $B$ ein Proto-Patiens als unmarkierter, verbnah plazierter Assertionsfokus fungiert. Die relative Abfolge von $R$ und $P$ ist in diesen Sprachen ebenfalls grammatisch frei. Sprachen mit grammatisch freier Wortstellung wie das Türkische und Georgische unterscheiden sich von Sprachen mit scheinbar freier Stellung von $R$ und $P$ wie das Deutsche u.a. darin, daß sie für alle Verben und alle Argumenttypen eine grammatisch freie Abfolge aufweisen. Es ist damit zu rechnen, daB sich bei genaueren einzelsprachlichen Analysen Verschiebungen innerhalb der Gruppen 1 und 3 ergeben.

Solche Korrekturen beeinträchtigen die auffälligsten Ergebnisse nicht, und diese erscheinen unter 2 und 4 in (33): bei diesem Kodierungstyp ist eine Präferenz für die $<\mathrm{P}, \mathrm{R}>$-Abfolge selten und eine feste Abfolge nicht attestiert.

Für diese sprachvergleichenden Befunde bietet sich dieselbe Erklärung an, wie für die deutschen Daten: Der Kodierungstyp 2 führt zu einer kontra-ikonischen ditransitiven Konstruktion, was das Verhältnis zwischen rollensemantischer Dependenz und Rektionsdependenz betrifft. Es überrascht somit nicht, daß sich bei diesem Kodierungstyp keine festen Abfolgen durch einzelsprachliche Grammatikalisierungsprozesse entwickeln konnten. DaB bei einer Konkurrenz zwischen kasusfunktionaler Dependenz und rollensemantischer Dependenz der rollensemantische 
Faktor in der Performanz vorrangig behandelt wird, ist nicht überraschend, weil rollensemantische Dependenzen bei der (De)kodierung einer ÄuBerung wichtiger sind. Deshalb gibt es, wenn überhaupt, nur eine leichte Präferenz für $<R, P>-A b f o l g e n$ in dieser Gruppe von Sprachen.

Betrachten wir nun die Abfolge von Proto-Rezipient und Proto-Patiens in Sprachen, die diese Rollen kasusfunktional nicht voneinander differenzieren. In meiner Abkürzung ist das Kodierungstyp 1. Vgl. (34):
(34a) $Z_{i j}$ gaf Johan
sie gab Johann-OBJ ein Buch-OBJ
(Niederländisch)
(34b) *Zij gaf een boek Johan.
'Sie gab Johann ein Buch'

Den sprachvergleichenden Überblick für den Kodierungstyp 1 bietet (35):

(35) Feste Abfolge <R, P> (7 Sprachen): Dänisch, Englisch, Friesisch, Niederländisch, Norwegisch, Schwedisch

Anderer Kodierungstyp: Isländisch (2), nur bei einigen Verben

Andere feste oder bevorzugte Abfolge von $R$ und P: keine Sprache

Eine feste Stellung von Rezipient und Patiens gibt es mit Ausnahme einiger isländischer Verben nur bei diesem Kodierungstyp, und für alle Konstruktionen dieses Kodierungstyps ist die feste Abfolge $<R, P\rangle$. Für den Konstruktionstyp 1 gibt es keine andere feste oder präferierte Abfolge in meiner Sprachenstichprobe. Meine Erklärung für diese Befunde ist dieselbe wie beim doppelten Akkusativ im Deutschen (vgl. (26)). Eine Umkehrung der Abfolge $<\mathbf{R}, \mathbf{P}>$ kann grammatisch nur durch die Kasushierarchie motiviert werden. Fehlt diese Motivation, weil es keine Kasusunterschiede (bzw. keine wortstellungsrelevanten Kasusunterschiede) gibt, so fehlt auch die Umkehrungsoption.

Die Relevanz der Kasushierarchie für die Erklärung der Sprachvariation in diesem Bereich zeigt sich auch bei der eingehenderen Analyse einiger mit dem Deutschen verwandter Sprachen. Das Niederländische besitzt nur zwei wortstellungsrelevante Kasuskategorien, den Nominativ und einen weiteren Kasus, den ich Objektiv nenne. Diese Unterscheidung ist nur noch in der Flexion der Pronomina und einiger Substantive overt. Fangen wir mit der relativen Abfolge von Nominativ- und Objektivargumenten an. Vgl. (36):
(36a) Het meisje sloeg de jongen. das Mädchen-NOM schlug den Jungen-OBJ
(36b) "De jongen sloeg het meisje.
(36c) *Sloeg de jongen het meisje? 
Bei dieser ikonischen Kodierung hat die Umkehrung der Abfolge in (36a) keine grammatische Motivation und ist somit wie im Deutschen besonders markiert (vgl. (36b)). In Ja/Nein-Fragen mit Verberststellung wie in (36c) ist sie im Niederländischen sogar blockiert.

Ein Vergleich zwischen (34) und (36) hilft, die Wortstellungsrelevanz der Kasusfunktionen im Rahmen des Wettbewerbsmodells besser zu beurteilen. In (36) entsteht die feste Abfolge wegen der ikonischen Kasuskodierung, in (34) wegen der Absenz jeglicher Kasusdistinktion. In beiden Fällen gibt es keine kasusfunktionale Motivation für die Umkehrung der rollensemantisch determinierten Abfolge.

Betrachten wir nun kontra-ikonisch kasusmarkierende Konstruktionen, die Passivkonstruktion in (37) und die Zustandskonstruktion in (38):

(37a) Mijn oom is de urn geschonken.

meinem Onkel-OBJ ist die Urne-NOM geschenkt (worden)

(37b) De urn is mijn oom geschonken.

(37c) Is mijn oom de urn geschonken?

(37d) Is de urn mijn oom geschonken?

(38a) Jouw vader bevalt mijn boek.

deinem Vater-OBJ gefält mein Buch-NOM

(38b) Mijn boek bevalt jouw vader.

(38c) Bevalt jouw vader mijn boek?

(38d) Bevalt mijn boek jouw vader?

In solchen Fällen gibt es eine kasusfunktionale Motivation für die Umkehrung der rollensemantisch determinierten Abfolge (37a, c) und (38a, c). Die kasusdeterminierten Abfolgen sind (37b, d) und (38b, d). Alle Abfolgen sind grammatisch motiviert und folglich in etwa gleich akzeptabel.

Im Gegensatz zum Niederländischen und Deutschen haben das Englische und die festlandskandinavischen Sprachen, also Dänisch, Schwedisch und Norwegisch, keine syntaktisch relevanten Kasuskategorien mehr. Dabei ist die Annahme Chomskys (1981) plausibel, daß in diesen Sprachen die Kasuskategorien Nominativ vs. Objektiv von bestimmten strukturellen Positionen ableitbar und somit in diesem Sinn syntaktisch irrelevant sind. Bei Chomsky ist diese strukturelle Kasuszuweisung postuliert, im vorliegenden Ansatz ist sie auf der Basis der Kasushierarchie (20) durch das universelle Prinzip (9) insoweit erklärt, als (9) und (20) durch viele andere Phänomene unabhängig motiviert sind. 
Für solche Sprachen trifft der vorliegende Ansatz drei korrekte Prognosen. Die erste Prognose betrifft die feste Stellung von nominativischem Agens und objektivischem Patiens. Vgl. (39):

(39a) The girl ate the cake.

(39b) ?? The cake the girl ate.

$(39 \mathrm{c}){ }^{*}$ Did the cake eat the girl?

Die zweite Prognose sagt zutreffenderweise eine feste Stellung von objektivischem Rezipienten und objektivischem Patiens voraus. Vgl. (40):

(40a) She gave John a book.

(40b) * She gave a book John.

Die dritte Prognose betrifft Passivkonstruktionen und Konstruktionen mit objektivischem Zustandsträger. Aufgrund der sprachspezifischen, strukturell determinierten Kasuszuweisung muB das Nominativargument unabhängig von seiner rollensemantischen Funktion in einer bestimmten satzinitialen strukturellen Position („Subjektposition”) stehen. Vgl. (41) und (42):

(41a) He was given her.

(41b) *Her was given he.

(42a) This matter annoys me.

(42b) * Me annoys this matter.

Es gibt einen weiteren Konstruktionstyp, im welchem die Wirkung der Formfunktion auf die Abfolge von $\mathbf{R}$ und $\mathbf{P}$ im Sprachvergleich deutlich wird. Beim Kodierungstyp 3 wird $R$ durch eine Adposition und $P$ nominal, mit oder ohne overtem Kasus, kodiert. Bei diesem Kodierungstyp haben wir wieder eine kontra-ikonische Konstruktion. Beispiele für diesen Kodierungstyp und für die leicht bevorzugte Abfolge in der jeweiligen Sprache erscheinen in (43).

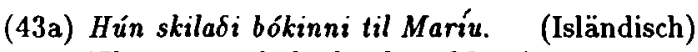

'She returned the book to Mary'

(43b) Ho scritto una lettera a Carlo. (Italienisch) 'I wrote a letter to Carlo'

(43c) Jien nibghat l-ittra lil Alan. (Maltesisch) I send the-letter to Alan 'I send the letter to Alan' 
(43d) Dadox knigata na profesora. (Bulgarisch) gave the-book to the-teacher 'gave the book to the teacher'

(43e) Thug mé ull don ghasúr sin inné. (Irisch) gave I apple to-the boy that yesterday 'I gave an apple to that boy yesterday'

Für die Beispiele in (43) wurden englischsprachige Übersetzungen angeboten, weil das Englische für jedes illustrierte Verb eine genau entsprechende Konstruktion mit präpositionalem Proto-Rezipienten zur Verfügung stellt.

Den sprachvergleichenden Befund für den Kodierungstyp 3 faBt (44) zusammen:

(44) 1. <P, R> leicht bevorzugt (18 Sprachen): Bulgarisch, Dänisch, Deutsch, Englisch, Französisch, Friesisch, Isländisch, Irisch, Italienisch, Katalanisch, Makedonisch, Maltesisch, Neugriechisch, Niederländisch, Norwegisch, Spanisch, Schwedisch, Walisisch.

2. Keine Präferenz (1 Sprache): Bretonisch

3. $<R, P>$ (feste oder unmarkierte Abfolge): keine Sprache

4. Feste Stellung von $P$ und $R$ : keine Sprache

Für Konstruktionen des Typs 3 gibt es keine andere feste oder unmarkierte Abfolge in meiner Sprachenstichprobe. Sprachen, die sowohl in (44) als auch in (33) oder (35) erscheinen, haben zwei Konstruktionen für R und P: John gave Mary the book/a book to Mary; Hans schickte dieser Fima einen Brief/einen Brief an diese Firma.

Der Kodierungstyp 3 führt wie der Kodierungstyp 2 zu einer kontraikonischen ditransitiven Konstruktion, was das Verhältnis zwischen rollensemantischer Dependenz und Rektionsdependenz betrifft. Es überrascht somit nicht, daß sich bei diesem Kodierungstyp keine festen Abfolgen durch einzelsprachliche Grammatikalisierungsprozesse entwickeln konnten.

Es gibt dennoch einen Unterschied zwischen den Befunden beim Kodierungstyp 2 und denen beim Kodierungstyp 3. Wenn es eine leichte Präferenz für eine bestimmte Abfolge beim Kodierungstyp 3 gibt, so ist das die formfunktional motivierte $<P, R>-A b f o l g e$. Dafür ist der einzige Unterschied zwischen Kodierungstyp 2 und 3 verantwortlich und dieser besteht in der Konstituentenlänge, ein wortstellungsrelevanter Faktor, der von Behaghel (1923) über Lenerz (1977a) bis Hawkins (1990), (1994) immer wieder Beachtung erfahren hat. Beim Kodierungstyp 3 entsteht zwischen den fraglichen Argumenten ein systematischer Gewichtsunter- 
schied, da der Rezipient wegen der Präposition auch bei einer minimalen kategorialen Füllung länger ist als das nominale Patiens. Das Gewichtsprinzip der Wortstellung favorisiert daher für alle in (44) aufgeführten Sprachen die Abfolge $<P, R>$. Zu dieser Annahme paBt die Beobachtung, $\mathrm{da} B$ eine Umkehrung der $\langle\mathrm{P}, \mathrm{R}\rangle-\mathrm{Abfolge} \mathrm{zu}<\mathrm{R}, \mathrm{P}\rangle$ möglich ist, wenn das Patiens länger als der Rezipient ist. Vgl. (45):

(45a) She gave to John the book I bought yesterday.

(45b) Ho scritto a Carlo una lettera di cinque pagine.

'I wrote to Carlo a letter of five pages'

Zum Abschluß der sprachvergleichenden Betrachtungen sei noch erwähnt, daB sich die Variationsmöglichkeiten der Abfolge von Patiens und Rezipient in ditransitiven Konstruktionen kaum ändern, wenn man auch Sprachen auferhalb Europas heranzieht, was aus der Arbeit von Blansitt (1973) leicht rekonstruiert werden kann, aber hier aus Platzgründen nicht nachgewiesen werden konnte.

\section{Schlußbemerkungen}

Die von mir präsentierten deutschen und sprachvergleichenden Daten belegen, daB die beiden diskutierten Parameter der Dependenz, rollensemantische Dependenz und Rektionsdependenz, bei der Determination der Abfolge der Argumente in Abhängigkeit vom verblexemspezifischen Konstruktionstyp gegeneinander konkurrieren oder miteinander koalieren können.

Der Koalitionsfall kann bei mehreren Konstruktionstypen eintreten: beim ikonisch kodierenden Konstruktionstyp, beim kasusfunktional neutralisierten Konstruktionstyp und beim rollensemantisch neutralisierten Konstruktionstyp. Für den Koalitionsfall trifft der hier vorgestellte Ansatz die im Laufe der Arbeit bestätigte Prognose, daB die Abfolge der Verbargumente innerhalb eines Sprachsystems, z.B. des Deutschen, relativ fest und im Sprachvergleich konstant ist. Bei oberflächlicher Betrachtung scheint sich eine aus einem Koalitionsfall resultierende Abfolge nur nach dem Parameter der rollensemantischen Dependenz zu richten (insoweit der rollensemantische Parameter selbst nicht neutralisiert ist, was bei den 'schwachen' Pronomina des Deutschen der Fall ist).

Der Konkurrenzfall tritt nur bei kontra-ikonisch kodierenden Konstruktionen ein. Im Sprachvergleich entsteht im Konkurrenzfall eine größere Variation, was die leicht präferierte Abfolge betrifft. Feste Abfolgen sind nicht zu erwarten und konnten für den untersuchten Datenbereich tatsächlich nicht gefunden werden. Innerhalb eines Sprachsystems, z.B. des Deutschen, entsteht im Konkurrenzfall der Eindruck der Wortstel- 
lungsfreiheit. Es handelt sich dabei um eine Scheinfreiheit, weil in solchen Konstruktionen jede Abfolge genau einen grammatischen Serialisierungsparameter befolgt und somit grammatisch determiniert ist.

\section{Literatur}

Textquellen

$\mathrm{EH}=$ Eva Heller. Beim nächsten Mann wird alles anders. Frankfurt a.M., Fischer Taschenbuch Verlag 1987.

HH = Heinz Haber. Unser blauer Planet. Stuttgart, Deutsche Verlags-Anstalt 1965.

TM = Thomas Mann. Königliche Hoheit. Berlin, Fischer Verlag 1955.

SZ = Sūddeutsche Zeitung v. 19.11.1991: Die krummen Touren der Biedermänner.

\section{Zitierte wissenschaftliche Literatur}

Behaghel, Otto (1923): Deutsche Syntax. Eine geschichtliche Darstellung. 4. Bd. Heidelberg.

Bierwisch, Manfred (1988): On the grammar of local prepositions. In: Bierwisch, Manfred/Motsch, Wolfgang/Zimmermann, Ilse (Hg.): Syntax, Semantik und Lexikon. Berlin. S. 1-66.

Blansitt, Edward L. (1973): Bitransitive clauses. In: Working Papers on Language Universals 13, S. 1-26.

Chomsky, Noam (1981): Lectures on government and binding. Dordrecht.

Connolly, Leon A. (1987): Case Grammar and word order in German: the case for place by case. In: Studies in Language 11, S. 129-161.

Dietrich, Rainer (1994): Wettbewerb - aber wie? In: Haftka (Hg.), S. 33-48.

Dik, Simon C. (1978): Functional Grammar. Amsterdam.

Dowty, David R. (1979): Word meaning and Montague Grammar. Dordrecht.

Dowty, David R. (1991): Thematic proto-roles and argument selection. In: Language 67, S. 547-619.

Fillmore, Charles J. (1968): The case for case. In: Bach, Emmon/Harms, R. (Hg.): Universals in linguistic theory. New York. S. 1-90.

Gadler, Hanspeter (1980): Die Akzeptabilität der Abfolge nominaler Satzglieder im Deutschen. In: Grazer Linguistische Studien 11/12, S. 54-85.

Givón, Talmy (1984): Syntax: A functional typological introduction. 1. Bd. Amsterdam.

Greenberg, Joseph H. (1963): Some universals of grammar with particular reference to the order of meaningful elements. In: ders. (Hg.): Universals of language. Cambridge, Mass. S. 58-90.

Grewendorf, Günther/Sternefeld, Wolfgang (1990): Scrambling theories. In: ders. (Hg.): Scrambling and barriers. Amsterdam. S. 3-40. 
Grimshaw, Jane (1990): Argument structure. Cambridge, Mass.

Gundel, Jeanette (1988): Universals of topic-comment structure. In: Hammond, Michael/Moravcsik, Edith A./Wirth, Jessica R. (Hg.): Studies in Syntactic typology. Amsterdam. S. 209-244.

Haftka, Brigitta (Hg.) (1994): Was determiniert Wortstellungsvariation? Berlin.

Haftka, Brigitta (1994): Wie positioniere ich meine Position? Überlegungen zu funktionalen Phrasen im deutschen Mittelfeld. In: dies. (Hg.), S. 139-160.

Hawkins, John A. (1983): Word order universals. New York.

Hawkins, John A. (1990): A parsing theory of word order universals. In: Linguistic Inquiry 21, S. 223-261.

Hawkins, John A. (1994): A performance theory of order and constituency. Cambridge.

Hoberg, Ursula (1981): Die Wortstellung in der geschriebenen deutschen Gegenwartssprache. München.

Hofmann, Ute (1994): Zur Topologie im Mittelfeld: pronominale und nominale Satzglieder. Tübingen.

Jackendoff, Ray (1972): Semantic interpretation in generative grammar. Cambridge, Mass.

Jackendoff, Ray (1987): The status of thematic relations in linguistic theory. In: Linguistic Inquiry 18, S. 369-411.

Jackendoff, Ray (1991): Semantic structures. Cambridge, Mass.

Jacobs, Joachim (1988): Probleme der freien Wortstellung im Deutschen. In: Sprache und Pragmatik 5, S. 8-37.

Jacobs, Joachim/Stechow, von Arnim/Sternefeld, Wolfgang/Vennemann, Theo (Hg.) (1993): Syntax. Ein internationales Handbuch zeitgenōssischer Forschung. Berlin.

Kefer, Michel (1989): Satzgliedstellung und Satzstruktur im Deutschen. Tübingen.

Kiss, Katalin E. (1995): Discourse-configurationality in the languages of Europe. In: Siewierska $(\mathrm{Hg}$.$) , i.E.$

Krifka, Manfred (1989): Nominalreferenz und Zeitkonstitution: Zur Semantik von Massentermen, Pluraltermen und Aktionsarten. München.

Kunze, Jürgen (1991): Kasusrelationen und semantische Emphase. Berlin.

Lang, Ewald (1991): A two-level approach to projective prepositions. In: Rauh, Gisa (Hg.): Approaches to prepositions. Tübingen. S. 127-167.

Langacker, Ronald W. (1969): On pronominalization and the chain of command. In: Reibel, D.A./Shane, S.A. (Hg.): Modern studies in English. Englewood Cliffs. S. 160-187.

Lange, Klaus-Peter (1978): 'Subjekt-Inversion' im Mittelfeld des deutschen Satzes. In: Deutsche Sprache 6, S. 193-202.

Lenerz, Jürgen (1977a): Zur Abfolge nominaler Satzglieder im Deutschen. Tübingen. 
Lenerz, Jūrgen (1977b): Zum Einfluß von „Agens” auf die Wortstellung des Deutschen. In: Viethen, H.W. et al. (Hg.): Grammatik und interdisziplinäre Bereiche der Linguistik. Akten des 11. Linguistischen Kolloquiums Aachen 1976. Tübingen. S. 133-142.

Lenerz, Jūrgen (1994): Pronomenprobleme. In: Haftka (Hg.), S. 161-174.

Lötscher, Andreas (1981): Abfolgeregeln für Ergänzungen ìm Mittelfeld. In: Deutsche Sprache 9, S. 44-60.

Mallinson, Graham/Blake, Barry J. (1981): Language typology. Amsterdam.

Mater, Erich (1971): Deutsche Verben. 6. Bd. Leipzig.

Pafel, Jürgen (1993): Skopus und Wortstellung. In: Jacobs et al. (Hg.), S. $867-880$.

Primus, Beatrice (1987): Grammatische Hierarchien. München.

Primus, Beatrice (1989): Parameter der Herrschaft: Reflexivpronomina im Deutschen. In: Zeitschrift für Sprachwissenschaft 8, S. 53-88.

Primus, Beatrice (1993): Word order and information structure: a performancebased account of topic positions and focus positions. In: Jacobs et al. (Hg.), S. 880-896.

Primus, Beatrice (1994): Grammatik und Performanz: Faktoren der Wortstellungsvariation im Mittelfeld. In: Sprache und Pragmatik 32, S. 39-86.

Primus, Beatrice (1995a): Cases and thematic roles: Ergative, accusative, active. Ms. 350 Seiten. München.

Primus, Beatrice (1995b): The relative order of recipient and patient in the languages of Europe. In: Siewierska (Hg.), i.E.

Primus, Beatrice/Lindner, Katrin (1994): Variation in grammar and language acquisition. In: Tracy, Rosemarie/Lattey, Elsa (Hg.): How tolerant is universal grammar? Essays on language learnability and language variation. Tübingen. S. 185-204.

Rayfield, David (1977): Handlung. In: Meggle, Georg (Hg.): Analytische Handlungstheorie. 1. Bd. Frankfurt a.M. S. 69-88.

Reinhart, Tanya (1981): Pragmatics and linguistics: An analysis of sentence topics. In: Philosophica 27, S. 53-94.

Reinhart, Tanya (1983): Anaphora and semantic interpretation. London.

Reis, Marga (1987): Die Stellung der Verbargumente im Deutschen. Stilūbungen zum Grammatik-Pragmatik-Verhältnis. In: Rosengren, Inger ( $\mathrm{Hg}_{\mathrm{g}}$ ): Sprache und Pragmatik. Lunder Symposium 1986. Stockholm. S. 139177.

Rosengren, Inger (1994): Scrambling - was ist das? In: Haftka (Hg.), S. 175196.

Siewierska, Anna (1988): Word order rules. London.

Siewierska, Anna (Hg.) (1995): Word order in the languages of Europe. Berlin. (Im Erscheinen)

Thalberg, Irving (1972): Enigmas of agency. Studies in the philosophy of human action. London. 
Uszkoreit, Hans J. (1986): Constraints on order. In: Linguistics 24, S. 883-906. Wright, Georg Henrik von (1974): Erklären und Verstehen. Frankfurt a.M. 


\title{
CHRISTER PLATZACK
}

\section{Germanic Verb Second Languages}

Attract vs. Repel: On Optionality, A-bar Movement and the Symmetrical/Asymmetrical Verb Second Hypothesis*

\begin{abstract}
Im 'Minimalistischen Programm' (Chomsky 1995) werden A-Bewegungen ('Amovements', d.h. N-Hebung, V-Hebung usw.) und A'-Bewegungen ('A-barmovements', d.h. Extraposition, VP-Adjunktion, 'scrambling' usw.) als sehr ungleichwertige Operationen behandelt. Der vorliegende Aufsatz untersucht die distinkten Eigenschaften von A-Bewegungen und A'-Bewegungen anhand von drei Gruppen von Argumenten, nämlich Topikalisierung (Abschnitt 2), Verschiebung schwacher Pronomina (Abschnitt 3) und Verb-Zweit unter der Symmetrie-Annahme (Abschnitt 4). Die Konklusionen daraus sind, daß die hier vertretene Analyse eine Möglichkeit bietet, A-Bewegungen und A'Bewegungen zu unterscheiden, ohne letztere aus dem Zustāndigkeitsbereich der Grammatik zu verbannen.
\end{abstract}

\section{Introduction}

Within the Minimalist program (Chomsky 1995) movement is taken to be attraction of features by corresponding features in functional categories. This theory offers profound prospects for describing the core computational properties of the language faculty like V-raising and N-raising, agreement, and generally the kind of processes subsumed under A-movement. The behavior of operations like extraposition, right-node raising, VP-adjunction, scrambling and other types of A-bar-movements are not readily incorporated, however. Chomsky (1995, ch. 4, section 7.3.) even

- Der Aufsatz greift in die aktuelle Diskussion innerhalb des 'Minimalistischen Programms' ein und kann daher u.a. auch als günstiger Einstieg in die Hintergrundsliteratur und die metaphernreiche Terminologie dieser Modellversion dienen. Wir haben uns daher entschlossen, den englischen Originaltext des Tagungsvortrags beizubehalten. (Anmerkung der Herausgeber)

In preparing this paper I have benefitted from discussions with Lars-Olof Delsing, Cecilia Falk, Gunlög Josefsson and Inger Rosengren. I have also got valuable comments by the audience of a workshop organized in August 1994 held in honour of professor Inger Rosengren, as well as by the audiencies of the 10th Comparative Germanic Syntax workshop in Brussels, January 1995, and the conference Grammar in Focus, Lund University, February 1995. The usual disclaimers apply, of course. 
suggests that such rearrangements are not the subject-matter of the Minimalist program.

It is undeniable that A-movement and A-bar-movement have different properties. Whereas A-movement is local in nature (it is commonly assumed that no instance of A-movement can cross the boundary of a tensed clause, for instance), no such restriction holds in general for Abar-movement. Furthermore, as is evident from the success of the Relativized Minimality condition of Rizzi (1990), these two types of movement result in different types of chains. However, to exclude the study of Abar movement from grammar proper (i.e. saying that A-bar movement is not explicable in terms of the computational system of the I-grammar) seems to me to be an unnecessarily drastic way to handle a problematic set of cases.

In this paper I will defend the thesis that there is a theoretically based difference between A-movement and A-bar-movement, which is the basis for the different properties of these two types of movement. Whereas I will follow Chomsky (1995) in describing A-movement as the result of Attract $F$, where $F$ is an abstract feature, I will claim that A-bar movement should be described as Repel F. Attraction takes place in order to check features, covertly if the attracting feature is weak, overtly otherwise (pied piping the phrase associated with the attracted feature in the latter case). Repel F, on the other hand, is not a case of feature checking. Assuming theoretically that any element in the clause can be marked [Repel F], this element is forced to move out of the domain hosting $F$ (the maximal projection of the functional head containing F). Repel F must presumably always be applied prior to Spell-Out.

I will provide three sets of arguments for the proposed distinction between A-movement and A-bar movement. In section two I will demonstrate that, applied to Topicalization, my approach has several virtues compared to a checking account. Section three is about a more local instance of A-bar-movement, the displacement of weak pronouns: as will be shown, an analysis in terms of Repel $F$ seems preferable in such cases as well. ${ }^{1}$

1 There is no consensus today regarding the status of pronoun displacement; with respect to Scandinavian Object Shift (see section 3 below), the movement involved has been claimed to be A-movement, A-bar-movement, Head movement or PF-movement. See Holmberg/Platzack (1995, p. 145ff.) for an overview. Unless there is a one-to-one relation between Attract/Repel and type of movement, the exact classification of the movement involved in pronoun displacement has no consequences for my discussion. 
Finally, in section four, I will approach verb second, demonstrating that the Repel-analyses of Topicalization and weak pronouns favour the symmetrical verb second hypothesis (the finite verb always moves to $\mathrm{C}^{\circ}$ ) over the asymmetrical one (the finite verb is in Agrs ${ }^{\circ}$ in subject first clauses, in $\mathrm{C}^{\circ}$ otherwise). In section five I conclude that although the approach taken here can be seen as uneconomical, introducing another reason for movement in addition to attraction, it has certain virtues due to offering a possibility to keep A-movement and A-bar-movement apart without having to take the drastic step of expelling A-bar-movement from grammar proper.

\section{Topicalization}

\subsection{Introduction}

In this section I will claim that Topicalization is triggered by the presence of a feature incompatible at Spell-Out with the highest A-projection; for convenience I will simply call this feature "A". Prior to Spell-Out, an element marked [Repel A] must move to the first available node outside the highest A-position.

From a functional perspective, Topicalization can be described in terms of dichotomies like Theme-Rheme, Topic-Comment, FocusPresupposition, or Given-New; how to interpret the division of a particular sentence is determined by the context. From the point of view of grammar, the interpretation of the fronting in terms of information structure is less salient compared to the fronting per se: whatever contextual reason we may find to front a phrase, grammar must provide us with the possibility to perform such a fronting. This is accomplished if we assume that a marker [Repel A] may be added to any one of the phrases within the clause. The description of Topicalization in terms of Repel A is outlined in 2.2. Subsection 2.3 is about Narrative Inversion, and subsection 2.4 about Topic-Drop, both constructions being of importance for the comparison of my account of Topicalization with approaches in terms of attraction.

\section{$2.2 \quad$ Topicalization as a result of [Repel A]}

According to the theory presented here, the German sentence (1), where the direct object is topicalized, is derived as outlined in (2): 
(1) Dieses Buch las er gerne.

(2) $[\mathrm{CP}[\mathrm{C} \cdot$ las] $[$ AgrsP er .... dieses Buch gerne] $] \rightarrow$ [Repel A]

[CP dieses Buch

The direct object dieses Buch 'this book' is marked [Repel A]. Hence, this phrase must be moved out of the domain of A-positions prior to Spell-Out. Taking the highest A-position to be AgrsP, the phrase marked [Repel A] must move to the first available position in front of AgrsP; a restriction like Shortest Movement prevents the phrase to move anywhere else. In a structure like (3), where the finite verb has moved to $\mathrm{C}^{\circ}$, SpecCP is available as a landing site for the repelled phrase.

Alternatively, we may envisage the possibility that the finite verb is still in $\mathrm{Agrs}^{\circ}$, as in (4), i.e. its finiteness feature has not yet been checked:

(3) [AgrsP er las....dieses Buch]

[Repel A]

In this case there is no C-projection, and as a consequence there is no available landing site for the repelled phrase. ${ }^{2} \mathrm{~A}$ theoretical possibility in such a case is to generate an empty functional head in front of AgrsP: let us call this head $\mu^{\circ}$, following a suggestion by Johnson (1991). Spec- $\mu \mathrm{P}$ would then be available for the repelled phrase, as illustrated in (4):

(4) $\left[\mu \mathrm{P}\right.$ dieses Buch $\left[_{\mu}{ }^{\circ} \mathrm{e}\right]\left[\right.$ AgrsP er las .... $\left.\left.\mathrm{t}_{\mathrm{i}}\right]\right]$

Verb second apparently forces verb movement to $\mu^{\circ}$. However, since $\mu \cdot$ does not carry any features of its own, it cannot attract the verb. Only if the verb is attracted by a higher head does it have to pass through $\mu^{\circ}$. In a framework assuming a symmetrical analysis of verb second, according to which $\mathrm{C}^{\bullet}$ hosts a strong finiteness feature to be checked against a corresponding feature of the finite verb (see section four below $)^{3}$, the presence of a finite verb in the structure forces the generation of CP. Hence, also when (4) is generated to provide a landing site for the repelled phrase, a C-projection must be created on top of

2 Following Kayne (1994) I take adjunction to a phrase with a specifier to be impossible, hence the phrase to be topicalized cannot adjoin to AgrsP.

3 Another possible way is to lexicalize the strong finiteness feature in $\mathrm{C}^{\circ}$ with an expletive complementizer like that; , see Law (1991) for such a suggestion. Taking lexicalization to make strong features weak (see Groat 1995), the raising of the finite verb to $\mathrm{C}^{\circ}$ is now postponed till after PF. 
$\mu \mathrm{P}$, giving us (5), where the verb has moved from $\mathrm{Agrs}^{\circ}$ to $\mathrm{C}{ }^{\circ}$ in order to check the finiteness feature:

(5) $\left[\mathrm{CP}\left[\mathrm{C} \cdot \operatorname{las}_{\mathrm{v}}\right] \mu \mathrm{P}\right.$ dieses Buch ${ }_{\mathrm{i}}\left[\mu^{\circ} t_{\mathrm{v}}\right]\left[\right.$ AgraP $_{\text {er }} t_{\mathrm{v}} \ldots \mathrm{t}_{i}$ gerne $]$

This derivation is ruled out by economy principles. The structure in (5) was created in order to take care of both the finiteness feature of the verb, and the marking of dieses Buch with [Repel A]. However, the structure given in (2) offers a more efficient way to perform the same things, hence (5) is a less economical description, and consequently must be blocked. It is in accordance with this account that the word order of (5) is ungrammatical:

(6) * Las dieses Buch er gerne.

The description of Topicalization just outlined directly accounts for the absence of embedded clauses introduced by Topic + that. The domain to escape by a phrase marked [Repel $A$ ] must be the one delimited by the highest A-position, blocking cases like Swedish (7).

(7) *Han beklagade [aldrig att han kommer hit].

'he regretted never that he comes here'

Note that my account predicts that Topic + that is possible in case we have a that-clause which is independently used. In Swedish, that-clauses can be used without any matrix as exclamations: it is in accordance with my description that Topicalization is possible in such cases, see (8) below:

(8) Aldrig att han kommer hit!

'never that he comes here'

In the next subsection I will discuss Narrative Inversion, a construction which might be problematic for a description where Topicalization is the result of overt attraction of a strong feature.

\subsection{Narrative Inversion}

A description where Topicalization is triggered by a strong Topic feature in $\mathrm{C}^{\bullet}$ has problems explaining why cases like (7) are bad. If Topicalization is an instance of Attract F, (see Zwart 1993, p. 243 and Wilder/Cavar 1994, p. 69 for checking accounts compatible with such a description) there must be a feature in $\mathrm{C}^{\circ}$ which attracts a feature in the fronted element. Following standard procedures within the Minimalist program, this feature should be strong or weak, i.e. languages would potentially differ with respect to overt Topicalization. It has been taken as a defining feature of verb second languages that there must be some 
element in front of the finite verb, hence presumably there is a strong Topic feature in $\mathrm{C}^{\circ}$ in these languages. Under this scenario the presence of a construction like Narrative Inversion is problematic, since it is not obvious that this construction involves any movement. The Dutch example in (9) is taken from Zwart (1993, p. 201):
(9) 1. Afijn, ik naar die vent toe 'so I to that guy went. PRT'
(Zwart 1993, p. 201):

2. Begint-ie me toch 'starts-he me MODAL So I went over to this guy, een verhaal op te hangen a story on to hang' and he starts to tell me a (you would not believe it) (crazy) story

Zwart (1993, p. 201-205) claims that the finite verb in main clauses is in $\mathrm{C}^{\circ}$ in V2-languages except in subject first clauses, where it is in Agrs ${ }^{\circ}$, immediately following the subject in Spec-AgrsP (the asymmetrical hypothesis of verb second, see section 4). This analysis predicts (Zwart 1993, p. 202) that there is a triggering element in Spec-CP in cases of Narrative Inversion - otherwise the theory must be supplemented with the ad hoc assumption that $\mathrm{C}^{\circ}$ hosts a particular strong $\mathrm{V}$-feature only in this construction. To avoid such a construction particular solution, Zwart describes Narrative Inversion as containing an empty operator in Spec-CP. Elaborating upon a suggestion by Cardinaletti (1990) regarding Topic-Drop, Zwart furthermore assumes this operator to bind a pronominal variable. Just like the empty operator in the Topic-Drop constructions, this operator is assumed to indicate contiguity.

Whereas the operator analysis is the only natural one given the asymmetrical V2 hypothesis of Zwart (1993), the symmetrical V2 hypothesis and the approach to Topicalization in terms of [Repel A], that I am advocating here, clearly favour an analysis where there is nothing in front of $\mathrm{C}^{\circ}$ in Narrative Inversion constructions: Narrative Inversion is what we get in main clauses when there is no element marked [Repel A]. According to the symmetrical V2 hypothesis, there is always a strong $V$-feature in $\mathrm{C}^{\circ}$, hence fronting of the verb in the absence of something in Spec-CP is in no way an ad hoc solution in this approach.

4 Swedish examples with Narrative Inversion have been discussed e.g. by Platzack (1987) and by Dahlbāck/Vamling (1983), from which the following example is taken:

(i) Så låg han bara dār. Kom hon in dãr, kände han igen henne, började han darra...

'then lay he only there. Came she in there, recognized he her, began he to-tremble ...' 
Comparing my approach to Zwart's, the two analyses assign the following structures, respectively, to the Dutch example given in (9.2) above (only the leftmost part of the structure is indicated).

(10) Zwart's account of Narrative Inversion

$\left[\mathrm{CP} O \mathrm{p}_{\mathrm{i}}\left[\mathrm{c} \cdot \text { begint-ie me toch een verhaal op te hangen } \mathrm{pro}_{\mathrm{i}}\right]\right]^{5}$

(11) My account of Narrative Inversion

[c - Begint-ie me toch een verhaal op te hangen]

As is immediately clear, the analysis in (11) is more economical than the one in (10). However, we cannot just compare two analyses of a single example (or type of examples) to determine which solution is the most economical one; to do this we must of course consider the involved assumptions in a broader perspective. Nevertheless, given the symmetrical V2-hypothesis and the approach to A-bar-movement advocated in the present paper, there is no need to assume any hidden material in a construction with Narrative Inversion.

The two approaches to Narrative Inversion make different predictions with regard to the relation between this construction and Topic-Drop: whereas my analysis is compatible with a description where Topic-Drop and Narrative Inversion have different structures (Topic-Drop differs from Narrative Inversion in involving movement of an element to SpecCP), Zwart's analysis predicts Topic-Drop and Narrative Inversion to be instances of the same process: in both cases there is an empty operator in Spec-CP binding a small pro. This difference is illustrated in (12):

(12) a. Zwart's account of (object) Topic-Drop (after Cardinaletti 1990) [CP Op $p_{i}\left[\mathrm{c} \cdot \operatorname{vet}\left[\right.\right.$ AgrsP jag inte $\left.\left.\left.p r_{i}\right]\right]\right] \quad(=10)$ know I not

b. My account of Topic-Drop [CP proi $\left[\mathrm{c} \cdot \operatorname{vet}\left[\mathrm{AgrsP}_{\mathrm{jag}}\right.\right.$ inte $\left.\left.\left.\mathrm{t}_{\mathrm{i}}\right]\right]\right]$

Zwart's account appears to be more economical than mine: he is able to reduce two constructions to one. However, it is not clear to me that there is a factual basis for reducing Narrative Inversion to a subcase of TopicDrop: there is no real argumentation in Zwart (1993) for this description, only his observation that both constructions indicate continuity with the preceding discourse. Although this observation is correct, its value as an

5 Remember that Zwart (1993) uses Cardinaletti's analysis, which incorporates Cinque's (1990) idea that the operator is binding a small pro. The exact position of this small pro bound by $O p$ is unclear to me. For the discussion here, the exact position of small pro in (10) is of no importance. 
argument for assigning Narrative Inversion and Topic-Drop the same structural description may be doubted.

The value of the continuity argument is weakened by the fact that the operator analysis of Topic-Drop does not pertain to all instances of this construction: Cardinaletti (1990) argues that constructions with object Topic-Drop are structured differently compared to constructions with subject Topic-Drop, as illustrated in (13):

(13) a. Habe ich gestern gekauft.

b. Op; habe ich gestern pro; gekauft.

c. Habe es gestern gekauft.

d. pro habe $t_{i}$ es gestern gekauft

Whereas object Topic-Drop involves an operator in Spec-CP binding small pro, subject Topic-Drop involves the fronting of small pro to SpecCP (or, given the asymmetrical analysis of Zwart (1993), to Spec-AgrsP).

Zwart's account predicts a certain similarity between Narrative Inversion and cases with object Topic-Drop, whereas no similarity is predicted with respect to subject Topic-Drop. Since both subject Topic-Drop and object Topic-Drop indicate continuity with the preceding context, it is clear that Zwart's observation that Narrative Inversion also indicates such continuity cannot be a strong argument: if Cardinaletti is right there are obviously constructions with a continuity interpretation that do not contain an empty operator in Spec-CP. Hence the economy argument for reducing Narrative Inversion to a subcase of Topic-Drop cannot be considered a strong one.

So far I have tried to show that Zwart's account of Narrative Inversion is not necessarily the correct one. Under my description, there is no need to assume the presence of an empty operator in Spec-CP in Narrative Inversion constructions: as a matter of fact, I claim that there is no Spec-CP in this case. Such a description is possible in a grammar where Topicalization is triggered by [Repel A], as mentioned above, whereas it leads to an ad hoc solution in case Topicalization is triggered by a strong feature in $\mathrm{C}^{\circ}$.

Narrative inversion is not the only construction where it seems feasible to assume the lack of Spec-CP: also that-clauses are of this type. As mentioned in connection with example (8) above it is a problem for descriptions that assume the obligatory presence of Spec-CP to account for the fact that this position is not an appropriate landing site for topicalized elements in that-clauses. In my account, however, the structure of ordinary that-clauses and the structure of main clauses with Narrative 
Inversion are considered to be identical: both constructions are headed by a specifier-less CP, indicating that neither the main clause with Narrative Inversion, nor the ordinary embedded that-clause, has the twopart structure typical of root clauses. Consequently they should have the same pragmatic interpretation in terms of topic-comment, theme-rheme etc. Discussing Narrative Inversion in German, Önnerfors (forthcoming) comes to the conclusion that clauses with Narrative Inversion are emphasizing their full-comment interpretation. It seems to me that the same interpretation can be given to that-clauses; to make the comparison as simple as possible, consider the use as exclamatives of the Swedish attclauses in (14):

(14) a. Att han ska vara så djäkla dum! 'that he shall be so bloody stupid'

b. Att han inte kan lugna sig! 'that he not can calm himself (=calm down)'

c. Att du alltid ska behöva skrika sả! 'that you always shall have-to shout so'

d. Att det aldrig kan bli vackert väder! 'that it never can be nice weather'

As already mentioned in connection with the discussion of (9) above, in such cases there is an alternative construction, in which an adverbial of the embedded clause is repelled:

(15) a. Inte att han kan lugna sig! 'not that he can calm down'

b. Alltid att du ska behöva skrika så! 'always that you shall have-to shout so'

c. Aldrig att det kan bli vackert väder! 'never that it can be nice weather'

My description automatically accounts for the occurrence of examples like (15): in the absence of a matrix clause, an element marked [Repel A] within the that-clause must be outside the highest A-projection. SpecCP is available as a landing site. Note, however, that my description does not explain why only adverbials may be fronted in cases like this.

\subsection{Topic-drop as a general fronting of small pro}

In this subsection I will try to show that Cardinaletti (1990) is not necessarily on the right track when she argues for different analyses of subject and object Topic-Drop. I will provide support for an analysis where both subject and object Topic-Drop are the result of the fronting of small pro. Since Cardinaletti (1990) provides good reasons to assume 
subject Topic-Drop to be an instance of small pro fronting, I will here inspect her arguments for giving another analysis of object Topic-Drop and demonstrate that these arguments are not compelling.

The analysis of object Topic-Drop that I am envisaging is given in (16); compare with Cardinaletti's account in (13b):

(16) $p r o$ habe ich gestern $t_{i}$ gekauft

Such a description would be in line with the analysis of Topicalization that I am advocating here. Contrary to Cardinaletti's proposal, TopicDrop could then be generalized as involving small pro marked [Repel A]. Below I will try to show that the arguments Cardinaletti (1990) gives for distinguishing subject and object Topic-Drop are not water tight.

There are several properties of object Topic-Drop which are captured by both descriptions. Cardinaletti mentions the following ones; for details, see Cardinaletti (1990):

1. No null argument is possible when Spec-CP is filled by another element, either lexical (a topicalized phrase or a wh-element), or empty (question-operator). Furthermore, only one null element of this kind is possible per sentence, indicating that there is a single position involved (Spec-CP). ${ }^{6}$

2. Object Topic-Drop obeys island constraints, like other cases of fronting to Spec-CP. ${ }^{7}$

3. Only NPs are possible to drop, although movement to Spec-CP is not restricted to NPs. Since small pro is an NP, not a PP, for instance, this fact is compatible with the small pro analysis of object Topic-Drop. ${ }^{8}$

6 Compare (ia) with (ib), both examples are taken from Cardinaletti 1990, (her examples (2a) and (3a)):

(i) a. Habe ich gestern gekauft.

b. *Gestern habe ich gekauft. (OK: Gestern habe ich es gekauft.)

7 Consider the following example violating Complex NP Constraint (Cardinaletti 1990, her example (8a)).

(i) *Glaube ich an die Möglichkeit zu sehen.

8 The following illustration is taken from Cardinaletti (1990, p. 79):

(i) Speaker A: Hast du auf Hans gewartet?

Speaker B: *Habe ich lange gewartet.

(OK: Auf ihn habe ich lange gewartet.) 
4. The null object cannot be coreferential with the subject of the clause, i.e. there seems to be a kind of strong cross over effect. ${ }^{9}$

5. Object Topic-Drop allows parasitic gaps. ${ }^{10}$

Let us now turn to the properties of object Topic-Drop that according to Cardinaletti (1990) are incompatible with the small pro approach, and which therefore constitute the basis for her assumption that object Topic-Drop is structurally different from subject Topic-Drop. Firstly, she notices that whereas successive cyclic wh- and XP-movement to Spec$\mathrm{CP}$ are possible, the supposed movement of an empty small pro from an embedded clause leads to ungrammaticallity (in this presentation, all German examples are from Cardinaletti's paper, unless otherwise stated):

(17) a. Den Professor $i$ sagt Hans $t_{i}$ hat (habe) er $t_{i}$ gesehen.

b. *Sagt Hans hat (habe) er gesehen.

(18) a. Den Hans $s_{i}$ glaube ich $t_{i}$ daß er $t_{i}$ gesehen hat.

b. *Glaube ich $\mathrm{da} \beta$ er gesehen hat.

Secondly, whereas extraction out of infinitive clauses of overt elements is possible both from a preverbal clause and a postverbal clause, object Topic-Drop is possible only if the infinitive clause is preverbal:

(19) a. *Habe ich beschlossen zu kaufen.

b. Habe ich zu kaufen beschlossen.

Thirdly, the null object cannot be a pronoun of the 1st and 2nd person; such a restriction is not found with overt fronting:

(20) Speaker A: Habe ich dich gestört?

Speaker B: Mich hast du sehr gestört.

Speaker B: *Hast du sehr gestört.

These differences between object Topic-Drop and overt fronting to SpecCP are compelling for the small pro hypothesis, but not impossible to overcome. Consider first the fact that not all types of extractions are

9 Compare (i) with (ii), both examples taken from Cardinaletti (1990), her examples (20) and (21):

(i) *Liebt er sehr. (ii) *Wen liebt er

10 The following example has number (22) in Cardinaletti (1990):

(i) a. Habe ich [ohne zu erkennen] gesehen

b. Habe ich [ohne zu kaufen] gelesen 
possible. Note that object Topic-Drop in a case like (18b) is possible in other V2-languages. (21) gives a Swedish example:

(21) Tror jag inte att han känner.

'believe I not that he knows'

Swedish allows two different word orders for constructions like (17a) with overt Topicalization:

(22) a. Den flickan, sa han, hade han kysst.

'that girl said he had he kissed'

b. Den flickan sa han han hade kysst.

'that girl said he he had kissed'

In (22a), sa han 'said he' is clearly parenthetical. (22b) illustrates the case where the complementizer is not visible (complementizer deletion is possible in Swedish in argument clauses). Note that only the word order in (23b) is compatible with object Topic-Drop:

(23) a. * Sa han hade han kysst.

'said he had he kissed'

b. Sa han han hade kysst.

'said he he had kissed'

The only possible word order in German is the one corresponding to the parenthetical interpretation in Swedish (22a/23a). In these cases, Topic-Drop is impossible in both languages, maybe as a consequence of a restriction on parentheticals that they cannot be sentence initial. It is to be noted that Reis (1994) offers further support for the assumption that cases like (17a) do not involve fronting but parentheticals.

The proposed analysis does not explain why object Topic-Drop out of the daß-clause in (18b) is prohibited, and why German differs from Swedish in this respect. However, since extraction out of embedded clauses is more restricted in German than in Swedish, I believe the solution will be found as soon as we understand this restriction properly. Like the restriction illustrated in (19), to which there is no Swedish counterpart, the OV/VO distinction between German and Swedish is probably of importance.

Consider finally the restriction illustrated in (20), showing that the null object in German cannot be a pronoun of 1st or 2nd person. In Swedish, on the other hand, there is no such restriction: the null object can be of any person, see Mörnsjö (1996). Cardinaletti's description cannot account for the Swedish facts, since the operator in Spec-CP in her description is only compatible with 3rd person NPs. The small pro analysis, 
on the other hand, can account for both the German and the Swedish facts. It is well-known that languages may differ with respect to the possible interpretation of small pro: e.g. Frisian and Bavarian only allow null subject small pro of $2 \mathrm{nd}$ person, and the Swedish dialect Älvdalsmälet only allows null subject small pro of 1st plural and 2nd plural. Hence it should be possible to argue for some language particular interpretation of small pro to be involved also with respect to object Topic-Drop.

Concluding, the arguments for a distinction between subject and object Topic-Drop presented in Cardinaletti (1990) are not as strong as they may seem to be when only German is taken into consideration. As I have shown, the analysis presented here, with fronting of small pro in both subject and object Topic-Drop, is more economical and hence preferrable. In addition, this is the natural analysis in a framework where Topicalization is triggered by [Repel A].

\section{Weak pronouns}

\subsection{Introduction}

Like Romance and the other Germanic languages, the Scandinavian languages, i.e. Danish, Faroese, Icelandic, Norwegian and Swedish, display the difference between strong and deficient pronouns proposed by Cardinaletti/Starke (1994) and Starke (this volume), deficient pronouns being either weak or clitics. A pronoun is considered strong when it can be conjoined, stressed or modified. Weak pronouns are morphologically identical to strong pronouns but pronounced unstressed; furthermore they cannot be conjoined or modified. The clitic pronouns are morphologically different from the strong pronouns, in addition to not being able to be stressed, conjoined, and/or modified. Compare Swedish henne 'her' (3sg fem objective case) which is used both as strong and as weak pronoun (as a weak pronoun it is often pronounced [anə]), whereas its clitic counterpart is ' $\boldsymbol{n} \boldsymbol{a}$, pronounced [(ə)na], obviously not a phonetically reduced form of henne.

According to Cardinaletti/Starke (1994) and Starke (this volume), weak pronouns must occur in a position different from the position of the strong pronouns. Whether or not they are right in claiming that Weak Pronoun Demotion is obligatory will be discussed in section 3.4 below; here it is enough to note the fact that weak pronouns may occur in positions where we do not find strong pronouns or full DPs. I will claim that Weak Pronoun Demotion is triggered by a marker [Repel Case], discussing weak subject pronouns in section 3.2 and weak object pronouns in section 3.3 . 
It is to be noted that I am not the first one who is envisaging a description of Weak Pronoun Demotion in terms of repellence, although - to the best of my knowledge - no one has used the term Repel. Diesing/Jellinek (1993), for instance, argue that Object Shift (the demotion of a weak object pronoun, see section 3.3 below) is movement out of the existential closure of the clause. Similarly, Rosengren (1993) claims that Scrambling involves movement of a phrase out of the Focus domain. Both descriptions have been of importance for the account presented here.

\subsection{Subject pronouns}

The behavior of Mainland Scandinavian weak subject pronouns in inverted structures indicates that such pronouns occupy a position different from the position taken by DP-subjects and strong subject pronouns. The following Swedish examples show that a weak subject pronoun following the finite verb must be adjacent to the verb, whereas a DP-subject and a strong subject pronoun may be separated from the verb by one or several adverbials. To the best of my knowledge, these facts were first discussed within a generative framework in Platzack (1986, p. 43-46). ${ }^{11}$

(24) a. Har verkligen Kalle / HAN / *'n gjort det här?

'has really Kalle / he (strong) / he (weak) done this here'

b. Igår köpte inte Erik / HAN / *'n en ny bil.

'yesterday bought not Erik / he (strong) / he (weak) a new car'

In embedded clauses, adverbials may occur between the complementizer and a DP-subject or strong subject pronoun, but not between the complementizer and a weak subject pronoun:

(25) a. Hon undrade om verkligen Kalle / HAN / *'n hade köpt boken. 'she asked if really Kalle / he (strong) / he (weak) had bought book-the'

b. Det är märkligt att inte Erik / HAN / *'n

har köpt en ny bil.

'it is curious that not Erik / he (strong) / he (weak)

has bought a new car'

These facts indicate that a weak subject pronoun is not in the same position as a strong subject pronoun or a DP subject. Assuming the latter ones to be in Spec-AgrsP, the weak subject pronoun must be in a higher

11 In the examples I have indicated the weak pronoun with a reduced spelling, 'n for han 'he', d'n for den 'it' (common gender). In written Swedish, there is no spelling difference between strong and weak personal pronouns, as already mentioned. 
position, outside of AgrsP. A way to account for this placement of the weak subject pronoun is to assume a description where the weak subject pronoun is marked [Repel Case]: since AgrsP is the highest functional projection for checking Case, this description forces the weak subject pronoun to move out of AgrsP, presumably to Spec- $\mu$ P. See the discussion in section 4.2 below and the introduction of the $\mu$ in connection with example (4) above.

\subsection{Weak Object Pronouns}

A description in terms of [Repel Case] will account for the placement of a weak subject pronoun outside of AgrsP as I have just shown. With respect to weak object pronouns, it is not immediately clear that they are always placed outside of their relevant Case position, i.e. Spec-AgroP. As a matter of fact, Cardinaletti/Starke (1994) claim that weak pronouns actually occupy the Case position, which would mean that a weak object pronoun in VO-languages like the Scandinavian ones are in Spec-AgroP. Since AgroP is outside of NegP in Scandinavian, this description immediately accounts for the observation that weak object pronouns in these languages are in front of the negation at Spell-Out (Object Shift), whereas strong object pronouns and DP objects are left behind the negation at Spell-Out, as illustrated by the Swedish examples in (26):

(26) a. Han köpte d'n inte. 'he bought it (weak) not' He did not buy it.

b. *Han köpte DEN / boken inte. 'he bought it (strong) book-the not'

c. Han köpte inte DEN / boken. 'he bought not it (strong) / book-the' He did not buy it / the book.

Although I do not have examples which undoubtedly tell us that weak object pronouns in front of the negation are in a position outside of AgroP, there are data pointing in that direction. Consider the Swedish examples in (27), illustrating the position of a weak object pronoun in a case where both sentence adverbials and the negation are involved: ${ }^{12}$

(27) a. Han köpte d'n förmodligen faktiskt inte.

'he bought it probably actually not'

12 Only the word order (27a) is possible in Danish and Norwegian, only Swedish has the full set of possibilities. See Hellan/Platzack (1995) for an overview of the distribution of weak pronouns in Mainland Scandinavian. 
b. Han köpte förmodligen d'n faktiskt inte.

c. Han köpte formodligen faktiskt d'n inte.

As these examples show, a weak object pronoun may occur in front of all middle field adverbials, including the negation, or in between such adverbials, the only restriction being that it precedes the negation, which is usually the last one of the adverbials in the middle field (see Holm 1991). Unless we are willing to assume that AgroP may precede not only the negation, but also optionally one or several sentence adverbials, these examples suggest a position for the weak object pronoun outside of AgroP. ${ }^{13}$

With respect to Object Shift, Johnson (1991) has suggested that shifted objects occupy a particular position, i.e. Spec- $\mu P^{14}$ I have already introduced the technical possibility to generate an empty $\mu$-projection in section 2.2 above. Let us assume that the $\mu \mathrm{P}$ involved in Object Shift is localized somewhere between TP and AgroP. As mentioned in 2.2, since $\mu$ ' does not carry any features, it cannot attract the verb - only if the verb is attracted to a higher position does it have to go through $\mu^{\circ}$, as a consequence of the Shortest Distance requirement.

With $\mu^{\circ}$ created, its Spec-position may serve as a landing site for the weak object pronoun, which due to its marker [Repel Case] must be outside of AgroP. ${ }^{15}$ Hence a description in terms of Repel forces us to assume the possibility to create "empty" phrases like $\mu$ P. Note however that such phrases are not allowed unless their heads are filled (by a trace) at Spell-Out. ${ }^{16}$ This will explain e.g. why Object Shift is possible only

13 The same type of argument can be levelled against the suggestion in Diesing/Jelinek (1993) that the Object Shifted pronoun has moved to an Aspectual node - once again the different word orders illustrated in (48) indicate that the landing site of the pronoun is not a fixed one, hence presumably not determined by some abstract feature of the verb.

14 Johnson (1991) discusses the status of this projection, suggesting a connection with AgroP, whereas Diesing/Jelinek (1993) suggest that $\mu \mathrm{P}$ is AspP (aspect phrase); in both cases $\mu$ would be an $A$-position. Although I use Johnson's term, I consider $\mu$ to be an A-bar-position.

15 Another possibility would be to assume that the weak object pronoun cliticizes to $\mu^{\circ}$, much in line with the suggestion in Josefsson (1994). Under this analysis, it is unclear why the pronoun cannot raise with the verb to $C^{\bullet}$, where it would precede the finite verb (assuming Kayne's (1994) restriction that only left adjunction is available).

16 In section 2.2 I claimed that there may be a phrase $\mu \mathrm{P}$ between $\mathrm{CP}$ and AgrsP, also in embedded clauses. If overt movement through $\mu^{\circ}$ is a necessary condition for its presence, we have to assume an analysis where the 
in case the verb has moved to a higher position; compare (26a) with the Swedish example in (28a), which is ungrammatical:

(28) a. *Han hade $d$ 'n inte köpt. 'he had it (weak) not bought'

b. Han hade inte köpt $d$ 'n / den / boken. 'he had not bought it (weak) /it (strong) /book-the'

\subsection{Weak pronouns in situ}

Weak pronouns undergo Object Shift only when the verb has left VP (or AgroP, actually), see Holmberg (1984, 1986). As a consequence, there is no Object Shift in Mainland Scandinavian in cases with auxiliaries (see (28) above), in embedded clauses, or in control infinitives; the following examples are all Swedish:

(29) a. *Han kunde henne/det inte förstå.

'he could her / it not understand'

b. Han kunde inte förstå henne / det.

'he could not understand her/ it'

(30) a. *Det är konstigt att han henne / det inte förstod.

'it is peculiar that he her / it not understood'

b. Det är konstigt att han inte forstod henne / det.

'It is peculiar that he did not understand her / it'

(31) a. *Han lovade att den inte läsa.

'he promised to it not read'

b. Han lovade att inte läsa den.

'he promised to not read it'

He promised not to read it.

Note that Object Shift is possible in cases like (30) and (31) in languages like Icelandic, where the tensed verb leaves VP in embedded clauses and the infinitive leaves VP in control infinitives. On the other hand, there is no movement of the main verb in Icelandic in cases with auxiliaries, and consequently Object Shift is blocked in such constructions.

(32) a. Ég veit að Jón las hana ekki.

'I know that John read her not'

I know that John did not read it.

complementizer is generated in $\mathrm{Agrs}^{\circ}$, subsequently moved to $\mathrm{C}^{\circ}$ to check the finiteness feature. 
b. Hann lofað i að lesa hana ekki.

'he promised to read her not'

He promised not to read it.

c. *Jón hefir hana ekki lesið.

John has her not read

d. Jón hefir ekki lesiơ hana.

John has not read her

The restriction on Object Shift to contexts where the verb has moved out of VP (AgroP) is somewhat problematic for the account in Cardinaletti/Starke (1994), according to which a deficient (including weak) pronoun cannot occur at Spell-Out in its base position. They are therefore forced to assume some kind of vacuous movement of the object pronouns in cases like (29)-(33). Of course, such a description is possible but - to the best of my knowledge - there is no way to support it empirically.

According to the theory presented above, weak pronouns are marked [Repel Case]. If the presence of this marker is a necessary property of weak pronouns, my description would erroneously predict that the ungrammatical cases of (29)-(33) are well-formed - the pronoun has to repel AgroP at Spell-Out. ${ }^{17}$ Consequently, we must assume a weak pronoun to be optionally marked [Repel Case]. In this way the marker [Repel Case] behaves as the marker [Repel A], which is also optional in nature, see section 2 above.

If the option [Repel Case] is picked for cases like (29)-(33), the pronoun is forced to leave AgroP. Creating a $\mu \mathrm{P}$ outside of AgroP will give us a landing site for the weak object pronoun. However, since there is no overt movement of the verb, the head $\mu^{\circ}$ will remain empty, leading to a crashed derivation. Since the pronoun cannot remain in situ, being marked [Repel Case], there is no way to save the derivation.

In the absence of a Repel-feature, there is no problem: Procrastinate will block the movement of the pronoun prior to Spell-Out, deriving the well-formed cases of (29)-(33) with the weak pronoun in situ. Having

17 Naturally we could envisage some hitherto not mentioned mechanism with the same effect as movement (compare the possibility in many languages to express the focus of a clause either by moving it to a particular Focus position, or prosodically marking it as the focus), but to the best of my knowledge there is no empirical support (at least not any specific prosody) for such a description. 
introduced the possibility that weak pronouns do not have to be marked [Repel Case], we predict that also the pronoun in a Swedish example like (34) may be weak:

(34) Mannen köpte inte den. 'man-the bought not it' The man did not buy it.

It has been claimed, e.g. in Holmberg $(1986,1991)$, that the pronoun in such a case is necessarily interpreted as strong. On the other hand, Josefsson (1994) is of the opinion that the pronoun might be weak: it might e.g. be phonologically reduced, as in (35):

(35) a. Han köpte inte'n.

'he bought not it (reduced form')

b. Han såg inte'na.

'he saw not her (reduced form),18

If Cardinaletti/Starke (1994, p. 12) are right in claiming that only deficient pronouns may prosodically restructure, the pronouns in (35) must be weak. Hence examples like (35) show that weak pronouns do not have to undergo Object Shift, even in contexts where this is the most natural option.

\section{Verb Second}

\subsection{Introduction}

Both within the Principle-and-Parameter approach to syntax and within the Minimalist approach, there are essentially two competing analyses of verb second: the symmetrical analysis, going back to den Besten (1977), the essential claim of which is that the finite verb always goes to $\mathrm{C}^{\circ}$ in main clauses, and the asymmetrical approach of Travis (1984), according to which the verb moves to $\mathrm{C}^{-}$in all cases except in subject-first main clauses, where the CP-level is lacking. The proponents of the symmetrical account have generalized verb movement to $\mathrm{C}^{\circ}$ in all main clauses, but on the other hand they have to provide a special mechanism for getting the subject to the position in front of the finite verb in subject initial clauses. No special mechanism of this kind is needed under the asymmetrical account - however, under this account the finite verb has two different

18 As mentioned in section 3.1. the form ' $n a$ is not a reduced form of the full oblique form henne 'her', but a particular weak oblique form, presumably a reduction of the old accusative hana 'her', which has been lost in its full form for about 500 years. 
positions in main clauses, $\mathrm{Agrs}^{\circ}$ (or $\mathrm{I}^{\circ}$ ) in subject first clauses, $\mathrm{C}^{\circ}$ in other cases.

Travis' (1984) reason to adopt the asymmetrical analysis of verb second is the existence of a difference between subject-first main clauses and other main clauses in the Germanic V2-languages: neither German nor Dutch accept a weak object pronoun in first position, although a weak subject pronoun is permitted. The relevant opposition is given in (36) and (37):

(36) a. $\mathrm{Ze} / \mathrm{Zij}$

'they (weak/strong)

b. ${ }^{*} \mathrm{Ze}$

ken ik niet.

'they (weak) know I not'

c. Hen ken ik niet.

'they (strong) know I not' komen. (Dutch, Zwart 1994, p. 5) come'

(37) a. Es hat das Brot gegessen.

(German, Travis 1991, p. 359)

b. *Es haben die Kinder gegessen. (es = the bread)

As in Dutch, there is a weak/strong opposition in German: replacing es with the stressed form das makes (37b) grammatical:

(38) Das haben die Kinder gegessen.

Not all pronouns behave the same way. As Vikner/Schwartz (forthcoming) show, there is no morphological difference between the weak and strong forms of e.g. German er/ihn 'he/him' and sie/sie 'she/her', hence no subject-object asymmetry with these pronouns. The same holds for Scandinavian, where an asymmetry like (36) and (37) is found only with a set of phonetically reduced pronouns. See Vikner/Schwartz (forthcoming) for examples.

It is clear that an asymmetric analysis of V2 elegantly accounts for subject-object asymmetries as the ones illustrated above. Under a symmetrical analysis of V2, there is no obvious reason why such an asymmetry should exist, although it is possible to account for the factual asymmetry in various ways (see Vikner/Schwartz (forthcoming) for a review).

However, since the difference between the symmetric and the asymmetric analyses of verb second is manifested mainly in the different analyses of fronted weak pronouns (see 4.3 for a discussion of some other alleged factual differences between the two approaches), it is obvious that the asymmetrical approach would lose much of its appeal if it is possible to show that this difference follows as a consequence of the nature of the 
pronouns, and hence does not necessarily have anything to do with verb second per se. The following discussion intends to demonstrate that this is the case.

\subsection{The subject-object asymmetry with weak pronouns}

The main problem with the symmetrical account of verb second, according to Travis (1984) and Zwart (1993), among others, is the inability, without further proviso, to account for the subject-object asymmetry with respect to fronted weak pronouns: weak subject pronouns, but not weak object pronouns, may introduce the main clause. However, given the analysis of Weak Pronoun Demotion in terms of [Repel Case], as outlined above, and the assumption that weak pronouns cannot be topicalized, i.e. they cannot be marked [Repel $A$ ], this factual difference is directly compatible with a symmetrical analysis of verb second. Let us first consider the possibility to front a weak subject pronoun.

Assume the derivation of a main clause where a weak subject pronoun has been overtly attracted to Spec-AgrsP, checking for Case, and the finite verb is in $\mathrm{Agrs}^{\circ}$, where it has checked for $\phi$-features. According to the symmetrical analysis of verb second, the finite verb still has its finiteness feature to check; furthermore, since this feature is checked against the finiteness feature of $\mathrm{C}^{\circ}$, which is strong in verb second languages, this checking must take place prior to Spell-Out.

There are two possibilities, both of which may provide well-formed derivations. Recall that the weak pronoun, marked [Repel Case], has to get out of AgrsP. Under the first scenario, a phrase $\mu \mathrm{P}$ is generated on top of AgrsP: remember that this is possible only if the verb is attracted to a higher position, forcing it to pass through $\mu^{\circ}$ on its way to $\mathrm{C}^{\circ}$. We now have a landing site for the weak subject pronoun outside of AgrsP, namely Spec- $\mu \mathrm{P}$. If the clause contains an element marked [Repel A], this element is moved to Spec-CP, as illustrated above. See the analysis in (39).

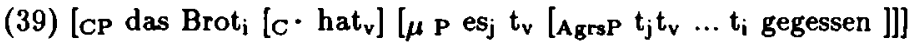

Under the second scenario, there is no $\mu \mathrm{P}$ on top of AgrsP. In this case AgrsP is the complement of $\mathrm{C}^{*}$. A weak subject pronoun in Spec-AgrsP, marked [Repel Case], has to move to the first available position outside of AgrsP, i.e. Spec-CP, as illustrated in (40):

(40) [CP es [ [C. hat $\left.{ }_{v}\right]\left[\right.$ AgrsP $_{i} t_{i} t_{v} \ldots$ das Brot gegessen ]] 
This analysis is compatible with the fact that no other element can be moved to Spec-CP: an example like (41) is not well-formed: ${ }^{19}$

(41) *Das Brot es hat gegessen.

Thus under the second scenario, no element of the clause may be marked [Repel A]. As the analysis outlined demonstrates, it is a coincidence that Spec-CP is available both for phrases marked [Repel A] and for phrases marked [Repel Case]. Since there is just one position, only one of these options may be picked for the fronted element. Presumably, weak pronouns cannot be marked [Repel $\mathrm{A}$ ], hence there is actually only one option.

Consider now the case of weak object pronouns. These pronouns are Case checked in Spec-AgroP, i.e. the marker [Repel Case] forces them to be outside of AgroP. The shortest possible movement is movement to Spec$\mu \mathrm{P}$, as discussed above. There is no way to get from AgroP to Spec-CP by a short move. Hence, there is only one position for weak object pronouns, assuming, as above, that deficient pronouns may not be marked [Repel A]. Consequently, my analysis accounts for the asymmetry with respect to the possibility of fronting weak subject pronouns, and the inability to front weak object pronouns, without giving up the symmetrical analysis of verb second.

4.3 Zwart's arguments for distinguishing between Topicalization and subject first clauses

Whereas I have shown that my analysis in terms of [Repel Case] makes it possible to account for examples like (36) and (37) with the symmetrical hypothesis of verb second, this naturally does not a priori disqualify an asymmetric account of verb second: there might be other empirical virtues of this approach. However, the arguments that $Z$ wart (1993) gives for his asymmetric analysis of verb second are not wholly compelling, as the following discussion will show.

According to the asymmetric V2-analysis, subject first V2 sentences are AgrsPs, hence something else than V2-sentences with Topicalization.

19 The same restriction is found in West Flemish, where clitic ze 'she' in first position cannot be preceded by a topicalized phrase. See (i), taken from Haegeman (1991), example (26b):

(i) * Morgen ze werkt zie.

'tomorrow she (clitic) works she'

See Haegeman for a discussion of the ambivalent status of the clitic pronoun as head or maximal projection. No such ambivalency is needed in the description proposed here. 
Zwart (1993, p. 243-254) gives four arguments for this assumption (in addition to the asymmetry between subject and object weak pronouns). The first argument is based on a difference found in Dutch with respect to the 2nd person ending in subject-first clauses and in clauses where something else has been fronted:

(42) a. Jij kent $/{ }^{*}$ ken dat boek.

'you know that book'

b. Dat boek ken $/{ }^{*}$ kent jij.

'that book know you'

That book you know.

According to $\mathrm{Zwart}$, the short form is used when $\mathrm{V}$ is in $\mathrm{C}^{\circ}$, as an indication of Agrs-to-C movement. The long form is used otherwise; hence in (42a) with subject-first and only the long form available, the verb is not in $\mathrm{C}^{\circ}$. A problem for this analysis is why not both endings are possible in (42a): after all, also subjects can be topicalized.

Zwart approaches this problem in Zwart (1993, p. 183, fn. 8), and also in Zwart (1994, p. 31-33). His solution, which is pretty technical, involves a separation of the licensing of the features of the phrase and of the checking of the $\mathrm{N}$-features of the head. As he himself contends, it is not clear whether there is independent support for such extensions of the analysis. Presently, it can be concluded that $\mathrm{Zwart}$ has envisaged a way to solve the problem, although the consequences have not yet been investigated. Thus, we can conclude that the argument based on the facts in (42) is at best unsufficient.

Zwart's second argument involves examples like (43):

(43) a. Jan kent ('nog altijd) 't niet.

'John knows still always it not'

John (*still) doesn't know it.

b. Toch kent (nog altijd) Jan ( ${ }^{*}$ nog altijd) 't niet

'yet knows still always John still always it not'

Yet John still doesn't know it.

The verb and the clitic are adjacent in (43a), and the subject and the clitic are adjacent in (43b). According to Zwart (1993, p. 245), this is accounted for if the subject is in Spec-AgrsP in both cases, whereas the verb is in $\mathrm{Agrs}^{\circ}$ in (43a), in $\mathrm{C}^{\circ}$ in (43b). Under the symmetrical analysis, where the verb moves to $\mathrm{C}^{\circ}$ in both (43a) and (43b), it is not clear, according to $\mathrm{Zwart}$, how the subject can undo the requirement that the verb and the clitic must be adjacent. 
There are several things unclear with this argument. First of all it is not obvious where the clitic is situated. From (43b) we can see that adverbials may not intervene between Spec-AgrsP and the clitic, whereas adverbials are allowed between $\mathrm{C}^{\circ}$ and Spec-AgrsP. Under the asymmetrical analysis, (43a) furthermore indicates that adverbials may not intervene between $\mathrm{Agrs}{ }^{\circ}$ and the clitic. I do not understand, frankly, why this should be an argument for the asymmetrical analysis. Furthermore, this argument can be criticized in the same way as the first argument: since subjects may be topicalized, one possible reading of (43a) is that the subject is topicalized, and then there should not be any difference between (43a) and (43b).

Zwart's third argument is actually not an argument. According to Zwart (1993, p. 246), the symmetrical hypothesis predicts that Topicalization should be possible wherever subject placement is possible, given that subject placement and Topicalization are the same processes. He then procedes to show that Topicalization in embedded clauses is severely limited, compared to subject first embedded clauses. But this is not, as far as I can see, an argument against the symmetrical hypothesis: proponents of symmetric V2 do not claim that the subject is in Spec-CP in embedded clauses - on the contrary, like proponents of asymmetric V2, they assume the subject to be in Spec-AgrsP in ordinary embedded clauses. Hence this argument is a non-argument.

The fourth argument has to do with subject deletion under coordination. Zwart (1993, p. 252) assumes that "an element in the second clause of a coordinate structure can only delete under identity with an element in the first clause if the two elements are in the same structural position". Since the asymmetrical analysis of V2 claims that the subject is in the same structural position when it is clause initial as when it occurs after the verb in inversion, this analysis predicts the correctness of the following four word orders:

(44) a. subject-finite - XX and topic-finite - subject gap - YY

b. topic - finite - subject - XX and subject gap - finite - YY

c. topic - finite - subject - XX and topic - finite - subject gap - YY

d. subject - finite - XX and subject gap - finite - YY

The word order of (44d) is correctly predicted to be well-formed also by the symmetrical V2 hypothesis. The word order of (44a), on the other hand, is predicted to be ungrammatical by the symmetrical hypothesis, but well-formed by the asymmetrical one. Surprisingly, Zwart (1993) 
does not discuss (44a). However, we immediately note that this word order is impossible in Swedish, as illustrated in (45):

(45) *Det här tåget fortsätter som intercitytåg till Lund

'this here train continues as intercity train to Lund

och sedan stannar _ bara i Eslöv.

and then stops only in Eslöv'

Hence with respect to (44a), the symmetrical hypothesis, but not the asymmetrical one, makes the correct prediction.

Consider next the word order of (44b), first described in a generative framework by Höhle (1983). This word order is found at least in Dutch, German and Swedish; see also the discussion in Heycock/Kroch (1994):

a. In Mainz fährt Karl abends los und_kommt morgens in Bonn an.

b. Bagaget satte han ner på golvet och _ sprang direkt till utgången. 'luggage-the put he down on floor-the and _ ran directly to exit-the'

He put the luggage on the floor and ran directly to the exit.

In this case, the asymmetrical hypothesis, but not the symmetrical one, appears to make the correct prediction. Note however that there is no indication in these examples of the exact position of the deleted subject in the second conjunct: there could just as well be a gap in the position after the verb as before the verb; if the gap is after the verb we have something similar to Narrative Inversion in the second conjunct. If this is the correct analysis, the occurrence of the structure is predicted by the symmetrical hypothesis.

The fourth word order, illustrated in (44c), is not well-formed in Swedish, as shown by the example in (47). Since the gap is in the same structural position as its antecedent under both the symmetrical and the asymmetrical hypotheses of V2, both hypotheses make the wrong prediction:

(47) *Igår tog han tåget till Lund och där köpte _ en ny bil. 'yesterday took he train-the to Lund and there bought _ a new car' He took the train to Lund yesterday and bought a new car there.

As the discussion has shown, the observed distribution of subject gaps in coordinations does not seem to provide arguments for either of the two V2-hypotheses. Alternatively, we may doubt the validity of the condition for deletion assumed by Zwart, i.e. that an element in the second conjunct can only delete under identity with an element in the first conjunct if the two elements are in the same structural position. 
Concluding, the arguments provided by Zwart (1993) for choosing the asymmetrical analysis of verb second over the symmetrical analysis are at best unclear, and we need more information about various predictions before being able to evaluate them. In the absence of the support of the subject-object asymmetry with respect to initial weak pronouns, I cannot see any good reason to select the asymmetrical analysis over the symmetrical one.

\section{Conclusion and discussion}

Beginning with the observation that Topicalization is a process that does not fit in nicely with a theory where movement is confined to instances of Attract $F$ ( $F$ for feature), I have proposed an alternative account in terms of Repd F: an element marked [Repel A] (A for A-positions) is forced to find a place outside the A-positions, i.e. in front of AgrsP. A similar account may be used for weak pronouns - I claim here that weak pronouns are marked [Repel Case], forcing them to find positions outside of AgroP, and AgrsP, depending on their status as object or subject, respectively.

The analysis of Topicalization as Repel $\mathbf{A}$ is compatible with the symmetrical V2-hypothesis, according to which the finite verb always raises to $\mathrm{C}^{\circ}$ in main clauses in V2 languages, presumably attracted by a strong finiteness feature in $\mathrm{C}^{\circ}$. This hypothesis is indirectly supported by my account of weak pronouns - the strongest argument for the asymmetrical V2-hypothesis is the observation that weak subject pronouns, but not weak object pronouns, may topicalize, which has been taken as indicating a structural difference between main clauses beginning with the subject and main clauses where some other element is in first position. However, given the marking of weak pronouns as [Repel Case], this asymmetry is shown to be a consequence of the nature of these pronouns, hence not an argument for asymmetric V2. As I have attempted to show, also other arguments launched for the asymmetrical V2 hypothesis turn out to be inconclusive. Thus, the present study supports the symmetrical V2 hypothesis over the asymmetrical one.

Concluding, the proposal that A-bar-movement is triggered by a marker [Repel F] attached to some element in the string is an uneconomical description from one point of view, as it introduces a second trigger for movement besides Attract F. However, since A-bar-movement is different in nature from A-movement, attempts to generalize over the two types of movement may well be in error. This is not to say that the approach in terms of Repel $F$ is necessarily the correct one. However, as I have shown in this paper, several seemingly disparate properties of Topicalization 
and deficient pronoun demotion are accounted for under the proposed description, supporting the hypothesis that Repel $\mathbf{F}$ may actually be an option to be considered seriously. If this approach can be successfully applied also to other constructions containing A-bar-movement, it would offer an alternative to Chomsky's suggestion that several kinds of A-barrelated constructions cannot be accounted for within the computational system.

\section{References}

Cardinaletti, Anna (1990): Subject/object asymmetries in German null-topic constructions and the status of SpecCP. In: Mascaró, J./Nespor, M. (eds.): Grammar in Progress. Dordrecht. p. 75-84.

Cardinaletti, Anna/Starke, Michal (1994): The Typology of Structural Deficiency. On the Three Grammatical Classes. FAS-Papers in Linguistics 1. Berlin 1995, p. 1-55. [to appear also in: van Riemsdijk, Henk (ed.): Clitics in the Languages of Europe. Berlin.]

Chomsky, Noam (1993): A Minimalist Program for Linguistic Theory. In: Hale, K./Keyser, S.J. The View from Building 20. Essays in Linguistics in Honor of Sylvain Bromberger. Cambridge, Mass./London. p.1-52.

Chomsky, Noam (1995): The Minimalist Program. Cambridge, Mass.

Cinque, Giuglio (1990): Types of A-bar Dependencies. Cambridge, Mass./ London.

Dahlbäck, H./Vamling, K. (1983): "Tog han då foto" - ett syntaktiskt fenomen i malmöitiskt talspråk. Unpublished ms., Department of Linguistics, University of Lund. [Took he then a-picture - a syntactic phenomenon in Swedish spoken in the city Malmoe]

den Besten, Hans (1977): On the Interaction of Root Transformations and Lexical Deletive Rules. Ms., MIT and University of Amsterdam. Also published in den Besten (1989), p. 14-100.

den Besten, Hans (1989): Studies in West Germanic Syntax. PhD diss., University of Tilburg.

Diesing, Molly/Jellinek, E. (1993): The syntax and semantics of Object Shift. (= Working Papers in Scandinavian Syntax 51).

Groat, E. (1995): English Expletives: A Minimalist Approach. In: Linguistic Inquiry 26, p. 354-365.

Haegeman, Liliane (1991): Subject clitics and clitic doubling in West Flemish. In: van Riemsdijk, H./Rizzi, L. (eds.): Clitics and their hosts: EUROTYP Working Papers. Theme group 8: Clitics. p. 99-154.

Hellan, Lars/Platzack, Christer (1995): Pronouns in Scandinavian Languages: an Overview. In: Working Papers in Scandinavian Dyntax 56, p. 47-69. Forthcoming in: van Riemsdijk, H. (ed.): Clitics in the Languages of Europe. Berlin.

Heycock, C./Kroch, Anthony (1994): Verb movement and coordination in a dynamic theory of licensing. In: The Linguistic Review 11, p. 257-283. 
Höhle, Tilman (1983): Subjektslūcken in Koordinationen. Ms., University of Cologne.

Holm, L. (1991): Satsadverbial eller sättsadverbial? In: Telander, M. et al. (eds.): Svenskans beskrivning 18, Lund. p. 172-180. [Sentence adjunct or verbal adjunct?]

Holmberg, Anders (1984): On certain clitic-like elements in Swedish. In: Working Papers in Scandinavian Syntax 13, p. 1-31.

Holmberg, Anders (1986): Word Order and Syntactic Features in the Scandinavian Languages and English. PhD Diss., University of Stockholm.

Holmberg, Anders (1991): The Distribution of Scandinavian Weak Pronouns. In: van Riemsdijk, H./Rizzi, L. (eds.): Clitics and their hosts. EUROTYP Working Papers. Theme group 8: Clitics. p. 155-173.

Holmberg, Anders/Platzack, Christer (1995): The Role of Inflection in Scandinavian Syntax. New York and Oxford.

Johnson, K. (1991): Object Positions. In: Natural Language and Linguistic Theory 9 , p. 577-636.

Josefsson, Gunlōg (1994): Object Shift and Weak Pronouns in Swedish. In: Hellan, L. (ed.): Clitics in Germanic and Slavic. EUROTYP Working Papers. Theme group 8: Clitics. p. 51-82. [also published in Working Papers in Scandinavian Syntax 49: p. 59-94.]

Kayne, Richard S. (1994): The Antisymmetry of Syntax. Cambridge, Mass./ London.

Law, Paul (1991): Verb movement, expletive replacement, and head government. In: The Linguistic Review 8, p. 253-285.

Mörnsjö, M. (1996): Konstextuell betingad strylening av fundamentsledet. [Topic-Drop in Swedish]. Unpublished ms, Department of Scandinavian languages, Lund University.

Önnerfors, Olaf (forthcoming): On narrative declarative V1-sentences in German. To appear in: Swan, T./Westvik-Jansen, O. Modality in Germanic Languages. Proceedings of the IXth Troms $\varnothing$ International Symposium on Language 1993. Berlin.

Platzack, Christer (1986): The Position of the Finite verb in Swedish. In: Haider, H./Prinzhorn, M. (eds.): Verb Second Phenomena in Germanic Languages. Dordrecht. p. 27-47.

Platzack, Christer (1987): The Case of Narrative Inversion in Swedish and Icelandic. In: Working Papers in Scandinavian Syntax 31, p. 9-14.

Platzack, Christer (1994): Syntactic differences in the Comp-domain: Mainland Scandinavian evidence for Split Comp. In: Glow Newsletter 32, p. 46-47.

Reis, Marga (1994): Extractions from Verb-Second Clauses in German? Unpublished ms, University of Tübingen. To appear in: Lutz, U./Pafel, J. (eds.): On Extraction and Extraposition in German. Amsterdam.

Riemsdijk, Henk van (1978): A Case Study in Syntactic Markedness. Lisse.

Rizzi, Luigi (1990): Relativized Minimality. Cambridge, Mass./London. 
Rosengren, Inger (1993): Wahlfreiheit mit Konsequenzen - Scrambling, Topikalisierung und FHG im Dienste der Informationsstrukturierung. In: Reis, M. (ed.): Wortstellung und Informationsstruktur. Tübingen. p. 251-312.

Starke, Michal (this volume): Germanische und romanische Pronomina: stark - schwach - klitisch.

Travis, Lisa (1984): Parameters and Effects of Word Order Variation. PhD diss., MIT.

Travis, Lisa (1991): Parameters of Phrase Structure and V2 Phenomena. In: Fiengo, R. (ed.): Principles and Parameters in Comparative Grammar. Cambridge, Mass./London. p. 339-364.

Vikner, Sten/Schwartz, Bonnie (forthcoming): The Verb Always Leaves IP in V2 Clauses. To appear in: Belletti, A./Rizzi, L. (eds.), Parameters and Functional Heads. Essays in Comparative Syntax. New York/Oxford.

Wilder, Chris/Ćavar, Damir (1994): Word order variation, verb movement, and economy principles. In: Studia Linguistica 48, p. 46-86.

Zwart, Jan-Wouter (1993): Dutch Syntax. A Minimalist Approach. PhD diss., Dept. of General Linguistics, Groningen University.

Zwart, Jan-Wouter (1994): The Minimalist Program and German Syntax. A Reply to Gärtner and Steinbach. In: Working Papers in Scandinavian Syntax 54, p. 1-41. 


\title{
BRIGITTA HAFTKA
}

\section{"Deutsch ist eine V/2-Sprache mit Verbendstellung und freier Wortfolge."}

\author{
Abstract \\ Der Titel des Beitrags vereinigt häufige typologische Einordnungen des Deut- \\ schen, die, wenn sie nicht interpretiert werden, einander widersprechen: \\ 1. Deutsch ist eine $S(u b j e k t) O(b j e k t) V(e r b)-S p r a c h e / e i n e ~ O V-S p r a c h e$. \\ 2. Deutsch ist eine der germanischen Verbzweitsprachen. \\ 3. Deutsch ist eine Sprache mit freier Wortstellung. \\ 4. Deutsch ist eine Scramblingsprache.
}

Im ersten Teil gehe ich zunāchst auf die beiden Einordungen, die die Verbposition betreffen, ein und zeige, daB die dem eingeleiteten Nebensatz entsprechende SOV- oder OV-Reihenfolge bei Annahme eines nach links regierenden Verbs im Deutschen sinnvollerweise als grundlegend angesehen werden kann, während die den germanischen Verbzweitsprachen eigene Anordnung des finiten Verbs nach einer maximalen Konstituente als abgeleitet betrachtet werden muß. Im zweiten Teil wird gezeigt, wie die sich aus der Vergabe der semantischen Rollen (Thetarollen) des Verbs nach links ergebende hierarchische Struktur auf die lineare Folge im Mittelfeld deutscher Sätze abgebildet wird und wie man sich Umordnungen dieser Reihenfolge (oft als Scrambling bezeichnet) bei Berücksichtigung von Skopusverhältnissen (z.B. der Negation/Affirmation) sowie von Kontextbedingungen und speziellen Topikalisierungen vorstellen kann und wieso sie eingeschränkt - also nicht völlig frei - sind.

1. (S)OV-Sprache vs. V/2-Sprache

Wenn beide Kennzeichen gleichzeitig gelten sollen, kann das nur folgendermaßen verstanden werden: Wir wissen, daß das finite Verb im Deutschen, speziell im deklarativen Hauptsatz normalerweise immer einer maximalen Phrase (XP) folgt. Dies kann sowohl das Subjekt sein:

(1) [DPManche Linguisten] lieben Nonsens.

als auch jede andere maximale Phrase:

(2) [DPNonsens] hat Vater schon immer geliebt.

(3) [PPSeit seiner Kindheit [PP in den Bergen des Harzes]] wandert er gern.

einschließlich von verbalen Projektionen und Sätzen: 
(4) [VP-f;zuIm Harx zu wandern] macht Spaß.

(5) [VP-f Mannheim besuchen] wollte er schon lange.

(6) [ $\mathrm{CP}$ Daß wir unsere Kollegen hier wiedersehen], ist ein besonderes Vergnügen.

Diese Tatsache wird als Test dafür verwendet, ob eine sprachliche Sequenz eine maximale Phrase ist oder nicht. Was vor dem finiten Verb stehen kann, ist eine maximale Phrase:

(7) a. [AdvP Auf] steigt der Strahl und fallend gieft er voll der Marmorschale Rund ... (C.F. Meyer, Der Römische Brunnen)

b. [AP [DPSeiner Mutter] ähnlich] war Peter schon immer.

Auch im uneingeleiteten abhängigen Satz steht das finite Verb an zweiter Stelle:

(8) Er meinte, [DP Nonsens] habe Vater schon immer geliebt.

Das gilt auch für $w$-Phrasen, die in $w$-Interrogativsätzen ebenfalls dem finiten Verb vorangehen:

(9) [AdvP Wo] tagen heute die Linguisten?

(10) [PP Von wem] wurde die Tagung eröffnet?

(11) [DP Wessen Vorlesung] hat euch gefallen?

Im Gegensatz zu diesen Verbzweit-Sätzen steht das finite Verb in den eingeleiteten abhängigen Sätzen (12-19) an letzter Stelle:

Er meinte,

(12) daß manche Linguisten Nonsens lieben.

(13) daß Vater schon immer Berge geliebt hat.

(14) daß er seit seiner Kindheit Nonsens geliebt haben soll.

Ich weiß nicht,

(15) ob er schon lange Mannheim besuchen wollte.

(16) a. ob der Strahl aufsteigt.

b. ob Peter schon immer seiner Mutter ähnlich war.

(17) wo heute die Linguisten tagen.

(18) von wem die Tagung eröffnet wurde.

(19) wessen Vorlesung euch gefallen hat.

Warum wird nun davon ausgegangen, daß das Deutsche eine SOV- oder OV-Sprache sei, wenn doch diese Endposition des finiten Verbs meist nur in abhängigen Sätzen vorkommt? Dazu betrachten wir die Struktur der Verbalphrase im Satz (20): 


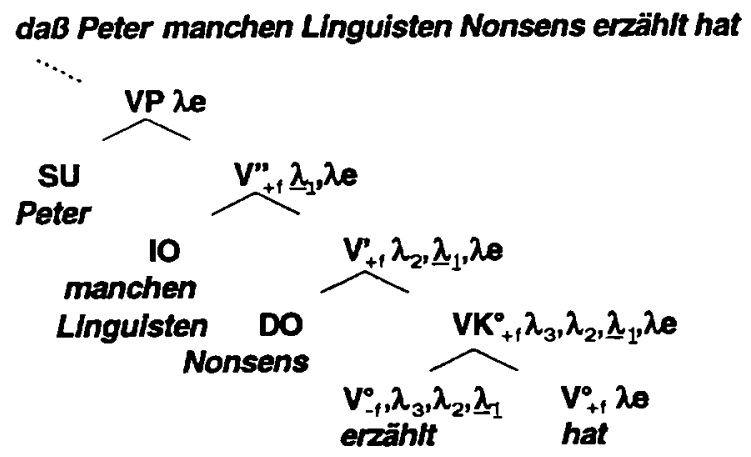

(S)

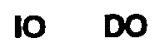

Wie (20) zeigt, steht das finite Auxiliar $\left[\mathrm{V}^{*}+\mathrm{f}\right.$ hat $]$ im Verbendsatz innerhalb seiner Verbalphrase, genauer innerhalb seines Verbkomplexes $\left[V^{\circ}+f\right.$ erzählt hat]. Der Verbkomplex (VK $\left.{ }^{\circ}\right)$ „erbt” - grob gesagt - neben den formalen Eigenschaften auch die referentielle Argumentstelle $\lambda$ e vom finiten Auxiliar und die Subkategorisierungseigenschaften, semantischen Rollen oder Theta-Rollen $\left(\lambda_{3}, \lambda_{2}, \lambda_{1}\right)$ vom Partizip Perfekt des Hauptverbs. Dies ergibt - nach Bierwisch (1990) - die Argumentstruktur des Verbkomplexes.

Die interne Theta-Rolle $\lambda_{3}$ wird vom $\mathrm{VK}^{\circ}$ an seine unmittelbar vorangehende Nachbarkonstituente, die DP Nonsens, vergeben. Mit der Vergabe dieser Thetarolle $\lambda_{3}$ an die als Thema fungierende DP ist der strukturelle Akkusativ verbunden. Das heißt, die DP fungiert als direktes Objekt (DO). Nimmt man nun an, daß der Verbkomplex durch die Vergabe dieser Thetarolle zu V' projiziert, so erhält man eine erste Projektionsstufe des Verbs, die wiederum die Theta-Rolle $\lambda_{2}$ an die als Adressat fungierende DP manchen Linguisten vergibt. Diese von V' vergebene interne Thetarolle, die hier mit dem Dativ verbunden ist, ist das indirekte Objekt (IO).

In manchen generativen Überlegungen ist damit die Verbalphrase abgeschlossen. Deshalb bezeichnet man die verbliebene mit dem Nominativ verbundene Thetarolle für das Agens $\lambda_{1}$ im Gegensatz zu den internen Thetarollen für die Objekte als externe Thetarolle. In neueren Phrasenstrukturmodellen wird häufig die externe Thetarolle an die im Spezifizierer der VP stehende SU-DP vergeben. Durch die Vergabe der externen 
Thetarolle projiziert V' (oder, je nach dem, wie man sich die VP-Struktur bei mehr als einem Objekt vorstellt, $V^{\prime 1}$ ) zur maximalen Verbalphrase VP.

VP hat nun noch die referentielle Argumentstelle, die, wie Ilse Zimmermann zeigt, „durch einen Operator zu spezifizieren ist, der den Referenztyp des betreffenden Syntagmas festlegt" (Zimmermann 1991, S. 4). Dies geschieht jedoch erst in einer späteren Stufe der Ableitung des Satzes.

Wenn das Verb nun im deutschen Nebensatz seine Thetarollen in der beschriebenen Weise nach links vergibt (s.(21)),

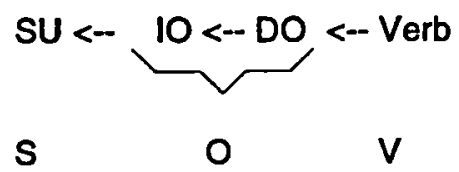

so ist es sinnvoll, anzunehmen, daß das Verb im Deutschen nach links $\Theta$-regiert, daß also den verschiedenen Reihenfolgen im deutschen Satz eine Reihenfolge SOV innerhalb der VP zugrundeliegt. ${ }^{2}$

Die normale Aussagesatz-Verbstellung $\mathrm{V} / 2$ ist dann als Abwandlung dieser Grundreihenfolge zu beschreiben, d.h. man muß eine Verschiebung des finiten Verbs aus seiner die hierarchische Struktur spiegelnden Endposition in eine Position nach der ersten maximalen Phrase und, wie die einleitenden Beispiele zeigen, nicht einfach nach dem Subjekt annehmen.

In der generativen Grammatik wird in verschiedenen Variationen angenommen, daB das finite Verb als Head der Verbalphrase (VP) seine morphologischen Merkmale im Head einer die VP dominierenden funktionalen Kategorie INFL (I) bzw. der Unterkategorien von INFL: Subjekt-

1 Auf die VP-Schalen von Larson (1988) soll hier nicht eingegangen werden.

2 Im Rahmen der generativen Grammatik wird zur Zeit heftig darüber debattiert, wie eine universelle Phrasenstruktur aussehen sollte. Vorausgesetzt, daß der Kopf einer Phrase ein Komplement und einen Spezifizierer haben kann,

- so wird nach der hier favorisierten Auffassung angenommen, daß deren Anordnung sprachspezifisch parametrisiert ist. Für das Deutsche gilt dann eine weitere Differenzierung nach sog. verbalen oder nominalen Kategorien:

+V-Kategorien (Verb, Adjektiv) $\Theta$-regieren ihre Komplemente nach links

$+\mathrm{N}$-Kategorien (Substantiv, Präposition) $\Theta$-regieren ihre Komplemente nach rechts 
und Objekt-Kongruenz (Agreement), Tempus (Tense) usw. abholen oder neuerdings (vgl. Chomsky 1992) spätestens in der LF-Komponente überprüfen oder checken muB. Das bedeutet, daß das finite Verb sukzessive an die jeweiligen Headpositionen adjungiert wird und auf diese Weise in eine Position links von der VP gelangt, nämlich nach $I^{\circ}$ (= AGRS). Beschränkt wird diese Bewegung durch den sog. HeadMovement-Constraint, der besagt, daB Heads - also $\mathrm{X}^{\circ}$-Kategorien - nur in eine $\mathrm{Y}^{\circ}$-Position verschoben werden dürfen, d.h. in die Head-Position einer hierarchisch höheren Kategorie. Betrachten wir die INFL-Phrase der Einfachheit halber hier als Blackbox, berücksichtigen wir also hier nicht die einzelnen Unterkategorien, so kann man sich diese Verbbewegung vorstellen wie in (22):

a.

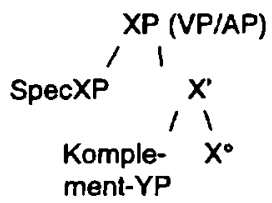

b.

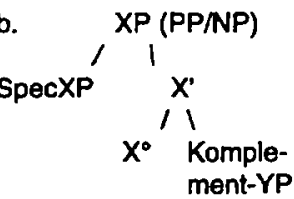

- Nach der anderen Auffassung (Kayne u. a.) gibt es nur eine universelle Phrasenstruktur, in der der Spezifizierer stets links und das Komplement stets rechts vom Kopf steht.

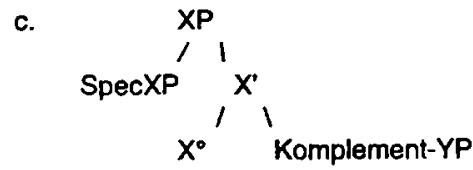

Im ersteren Falle ist die $\Theta$-Rektionsrichtung des Kopfes innerhalb einer angenommenen VP-Struktur parametrisiert und damit typologisch relevant. Im zweiten Falle wäre die Rektionsrichtung des Verbs typologisch irrelevant. Die Struktur der VP wäre in allen Sprachen gleich. Die typologische Einordnung des Deutschen müßte von Oberflācheneigenschaften der Sätze abgelesen werden.

Siehe zu den Auswirkungen einer solchen universellen Phrasenstrukturannahme für die Beschreibung des Deutschen z.B. auch die Diskussion in Donati/Tomaselli (1995) und in C.M. Schmidt (1995). 


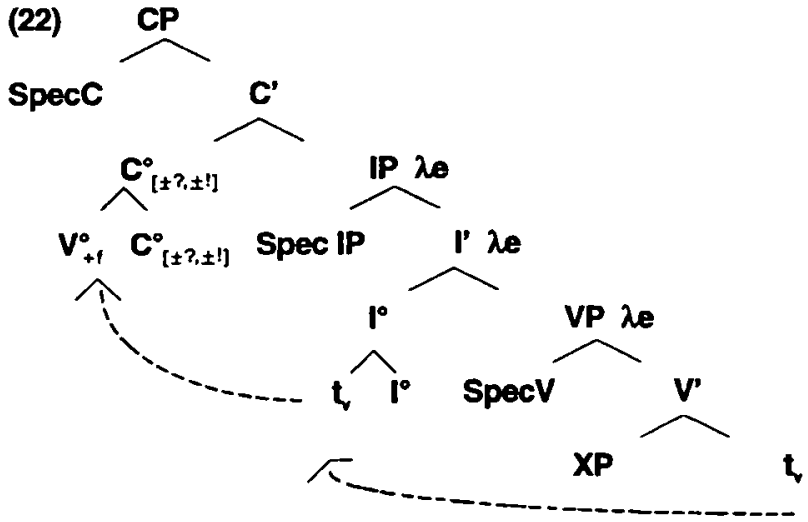

Nimmt man unter simplifizierender Vernachlässigung der Differenzhypothese $^{3}$ an, daß der Satz immer eine COMP-Phrase (CP) ist und daB in $C^{*}$ der an die Position des finiten Verbs gekoppelte Referenztyp des Satzes (Deklarativsatz, Interrogativsatz usw.) codiert ist, so wird die oben schon genannte referentielle Argumentstelle durch den Operator in $\mathrm{C}^{\circ}$ gebunden. Im Komplementsatz ist dies der Komplementierer daß oder $o b$.

Ist in $\mathrm{C}^{\circ}$ ein Satztyp codiert (z.B. durch $\left.[+?,-!]\right)$, der die oberflächensichtbare Anordnung des finiten Verbs in der zweiten Position versus in der ersten Position erfordert, so muß das Verb sich aus seiner $\mathrm{V}^{\circ}$ Position über die INFL-Head-Positionen in die höchste Head-Position, also in das lexikalisch leere $\mathrm{C}^{\bullet}$ bewegen und an dieses adjungieren. Dadurch wäre - stark vereinfacht - die Satztypcharakteristik z.B. eines Entscheidungsinterrogativsatzes gesichert:

(23) a. $\left[\mathrm{CP} / \mathrm{C}^{\prime}\left[\mathrm{C}^{*}\right.\right.$ Lieben $\left[\mathrm{C}^{*} \mathrm{I}_{+}\right.$?;-!] 0$] \mathrm{IP}_{\mathrm{IP}}\left[\mathrm{I}^{\prime} t_{\mathrm{v}} / \mathrm{VP}\right.$ manche Linguisten $[\mathrm{v}$ ' Nonsens $t[\mathrm{v}] J]]]]]]$ ?

3 Die hybride Differenzhypothese (2. Alternative), wie sie von Brandt et al. (1992) vertreten wird, besagt, daB

- Verb-letzt-Deklarativsātze und Verb-letzt-w-Interrogativsätze CP/IPs,

- Verb-zweit-Deklarativsätze und Verb-zweit-w-Interrogativsätze IPs,

- Verb-letzt-Entscheidungsinterrogativsātze $C^{1} / I^{1}$,

- Verb-erst-Deklarativsätze und Verb-erst-Entscheidungsinterrogativsātze $\mathrm{I}^{1}$ sind. 
Für V/2-Sätze muß mindestens und höchstens eine Phrase aus VP in die Spezifiziererposition der CP, also in eine Position vor das finite Verb gebracht werden.

Gibt es eine $w$-Phrase im Satz und ist $\mathrm{C}^{\bullet}$ als interrogativ [+?,-!] ausgezeichnet, so verlangt die Spezifizierer-Head-Kongruenz, daB diese $w$ Phrase in die Spezifizierer-Position der COMP-Phrase wandert (24):

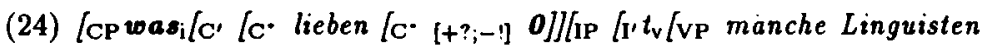
$\left.\left.\left[\mathrm{v}, t_{\mathrm{i}} t_{\mathrm{v}} J\right] J\right] J\right]$ ?

Ist $C^{*}$ dagegen als deklarativ $[-?,-!]$ ausgezeichnet, so verlangt die Spezifizierer-Head-Kongruenz, daB entweder eine - $w$-Phrase, d.h. eine maximale Phrase, die kein Fragewort enthält, nach Spec-CP verschoben wird, siehe (25) mit der Baumstruktur (26) und die Beispiele (1-8):

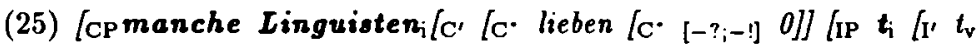
[vP $t_{i}\left[v^{\prime}\right.$ Nonsens $\left.\left.\left.\left.\left.t_{v}\right] J\right]\right]\right]\right]$
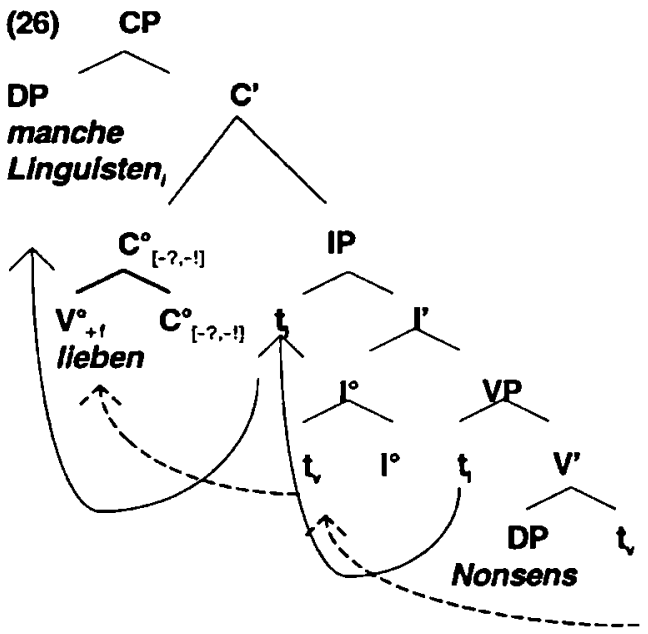

oder daß in SpecCP wie in (27) ein expletives ES eingesetzt wird, s.u.:

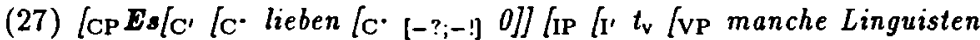
$\left[\mathrm{v}\right.$ Nonsens $t_{\mathrm{v}}$ [J]J]]

Diese Linksverschiebungen des finiten Verbs nach $\mathrm{C}^{\circ}$ und der maximalen Phrase nach SpecCP finden natürlich nur unter der Voraussetzung 
statt, daß $\mathrm{C}^{\bullet}$ zwar Satzmodus-Merkmale enthält, die aber lexikalisch unausgedrückt ( 0 ) bleiben. Das ist auch der Fall bei den uneingeleiteten abhängigen Sätzen, wie z.B. in unserem obigen Beispiel (8):

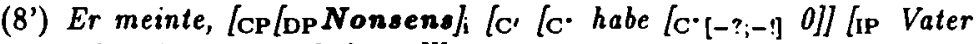
schon immer $t_{\mathrm{i}}$ geliebt $\left.t_{\mathrm{v}} \mathrm{Jl}\right]$

Steht in $\mathrm{C}^{\bullet}$ ein Komplementierer, also eine Konjunktion daß oder $o b$ wie in unseren Beispielen (12) - (16), so charakterisiert der Komplementierer den folgenden Satz als deklarativ oder interrogativ, und die Spezifiziererposition bleibt in der Standardsprache obligatorisch unbesetzt:

(12') [ $\mathrm{CP} / \mathrm{C}^{\prime}\left[\mathrm{C}^{\cdot}[-? ;-!]\right.$ daß] [IP manche Linguisten Nonsens lieben]]]

Ich gehe hier nicht auf die zahlreichen Besonderheiten ein, die mit der Besetzung der $\mathrm{C}^{\circ}$ - und der SpecCP-Position verbunden sind. Mehr darüber s. Haftka (1993) sowie Brandt/Reis/Rosengren/Zimmermann (BRRZ) (1992), die eine wichtige Alternative zu dieser hier nur angedeuteten traditionelleren Auffassung bieten (Differenzhypothese, s. Anm. 3)).

Man sieht, daB bei Annahme von projizierenden funktionalen Kategorien oberhalb der Verbalphrase, deren Head- und Spezifizierer-Merkmale die Veränderung der Verbposition und die Linksverschiebung einer XP veranlassen, relativ gut zu erklären ist, welches Verhältnis zwischen SOV und V/2-Stellung besteht, daB es sich dabei also um zwei verschiedene Ebenen handelt:

- (S)OV betrifft die Basisanordnung in der VP. Man findet dafür in der typologischen Literatur (vgl. Hawkins 1983, S. 230) auch Kleinschreibung: (s)ov, die als Hinweis auf die dargestellte Problematik zu deuten ist.

- $V / 2$ und auch $V / 1$ sind in einem solchen generativen Modell Derivationsergebnisse. Die Besetzung des lexikalisch leeren $\mathrm{C}^{*}$ durch das finite Verb und die angedeuteten Spezifizierer-HeadKongruenz-Eigenschaften müssen sprachspezifisch parametrisiert sein. Das heiBt, die Verschiebung des Verbs in die V/2- oder V/1Position hat, da sie ja in der Oberflächenstruktur des Satzes sichtbar ist, vor der Eingabe der derivierten Struktur in die Phonologische Komponente der Grammatik zu erfolgen. 


\section{Freie Wortstellung vs. „Scrambling”-Sprache}

Zwei weitere typologische Einordnungen des Deutschen lauten:

3. Deutsch ist eine Sprache mit freier Wortstellung.

4. Deutsch ist eine Scramblingsprache.

Satz 3, der behauptet, Deutsch habe eine freie Wortstellung, und Satz 4, der Deutsch als eine Sprache mit „durcheinandergebrachter” (= gescrambelter) Anordnung der Konstituenten charakterisiert, scheinen sich im Ergebnis zunächst nicht zu widersprechen, nur daß Satz 4 möglicherweise eine geordnete Grundreihenfolge voraussetzt, während Satz 3 nicht unbedingt eine solche Voraussetzung macht. Dies allerdings ist wichtig für die Deskription der deutschen Wortstellung. Die Abfolge von Subjekt, Objekt(en) und Adverbialen ist zwar nicht so streng geregelt wie im Englischen ${ }^{4}$, diese "Freiheit” ist aber durchaus strengen Regeln unterworfen.

Um das zu zeigen, gehen wir zurück zu unserer Struktur der VP: Mit der Vergabe der Argumentstellen des Verbs an die Komplemente und an das Subjekt ist ein Gerüst für den Satz, genauer für die Verbalphrase entstanden, das auf den verschiedenen Stufen durch adverbiale Modifikatoren erweitert werden kann. Dies geschieht normalerweise durch Adjunktion. Der Einfachheit halber nehme ich hier an, dab Modifikatoren an die verschiedenen V-Projektionsstufen basis-adjungiert werden können, in (28) also an V' die modale Adverbialbestimmung [Pp mit viel Humor] und an VP z.B. das Frequenzadverbiale [AdvP ofi]. Eine Anmerkung: Von den Modifikatoren zu unterscheiden ist z.B. die direktive adverbiale PP [PP vor die Nase]: deren direktive Präposition vor wird vom Verbkomplex [gesetzt hat] subkategorisiert, und sie vergibt ihrerseits ihre interne Thetarolle (Direktivum) an die DP [DPdie Nase]. Die PP ist also ein Komplement des Verbs, da ihr Head P vom Verb subkategorisiert ist, sie hat aber selbst keinen Argumentstatus.

4 Das Deutsche kann auf die Kennzeichnung der syntaktischen Funktion der Argumentphrasen als Subjekt (SU), indirektes Objekt (IO) oder direktes Objekt (DO) durch feste Positionen weitgehend verzichten, weil es eine ausreichende Substantiv- und vor allem Artikelflexion hat, die es ermöglicht, den Kasus einer DP auch in derivierter Position zu identifizieren. Bei Eigennamen ohne Artikel muß jedoch oft eine SU-IO-DO-Reihenfolge eingehalten werden, um Mißverstāndnissen vorzubeugen, vgl. Dann hat Hans Franz Maria vorgestellt. 


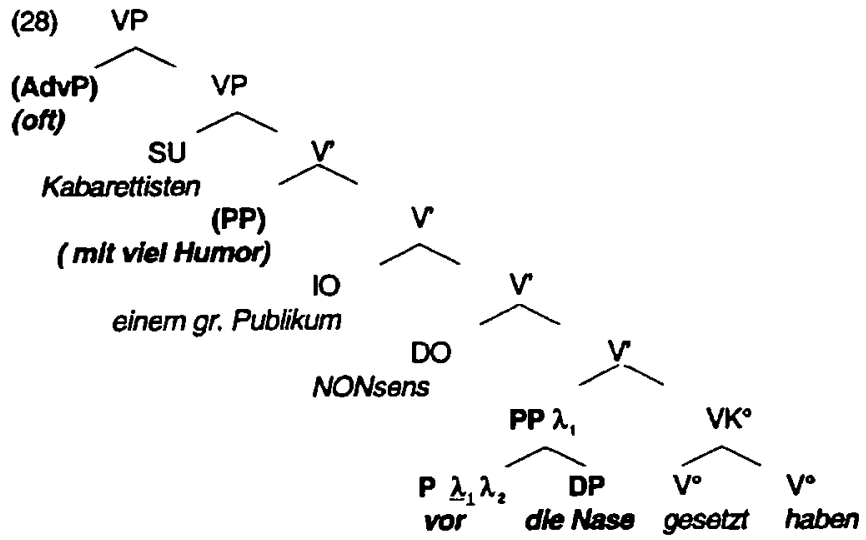

Wir haben also nun einen Sachverhalt, dergestalt daß

(29) oft Kabarettisten mit viel Humor einem großen Publikum Nonsens vor die Nase gesetzt haben.

Damit ist noch nichts darüber gesagt, ob dieser Sachverhalt bejaht oder verneint werden soll, ob er also im Skopus eines Negations- oder Affirmationsoperators stehen, ihm also folgen muß. In syntaktischen Termen ausgedrückt, bedeutet das, daß der Negations- oder Affirmationsoperator die VP c-kommandiert. ${ }^{5}$ Der Affirmationsoperator ist entweder phonetisch stumm oder wird durch eine Partikel (wie z.B. wohl, aber auch kaum) bzw. eine Partikelkombination (wie $2 . B$. $\left[\left[\mathrm{Pt}^{\cdot} \cdot \operatorname{sehr}\left[\mathrm{Pt}^{\cdot} \cdot\right.\right.\right.$ wohl $]$ ) lexikalisiert. Der Negationsoperator ist entweder ebenfalls durch eine Partikel wie nicht ausgedrückt, oder er ist in eine nie-oder kein-Phrase (keiner, niemand) integriert. Nimmt man an, daß der die negierende oder affirmierende Position zum Sachverhalt angebende Operator, wenn er leer ist oder durch eine Partikel lexikalisiert ist, als eine minimale Kategorie $\left(\mathrm{X}^{\circ}\right.$-Kategorie) zu einer maximalen Phrase projiziert, so ergibt sich die Positionsphrase (30).

5 x c-kommandiert nach Chomsky (1986) y, gdw.:

i. $x$ y nicht dominiert und

ii. wenn jedes $\mathrm{z}$, das $\mathrm{x}$ dominiert, auch $\mathrm{y}$ dominiert. 


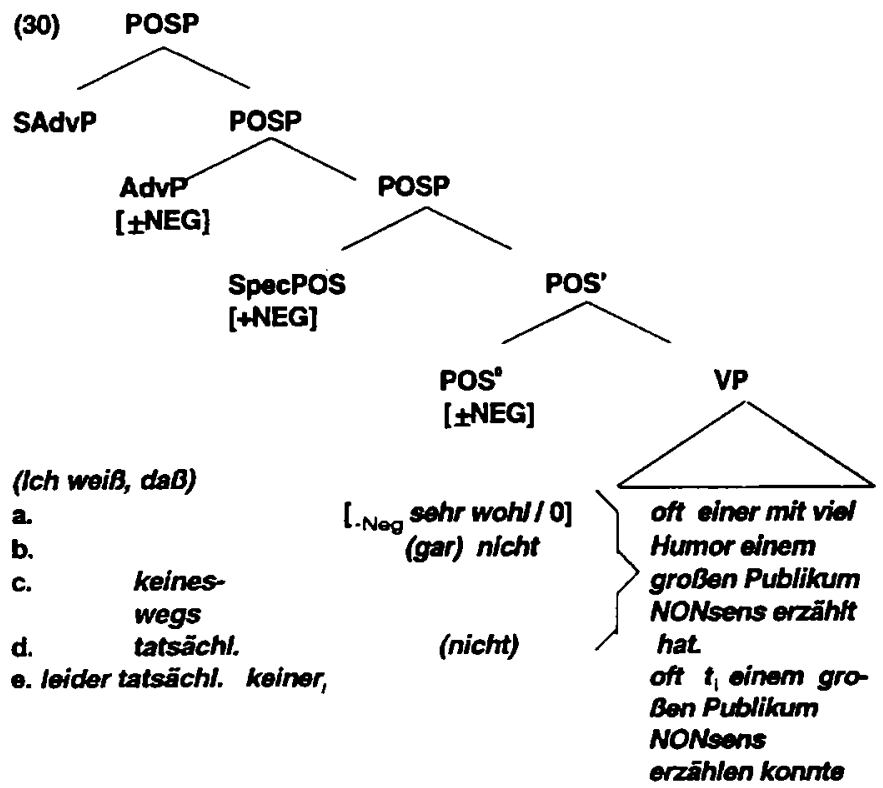

Ist die negierte Phrase eines der Elemente aus VP, so muß sie, soll die gesamte Proposition negiert sein, die VP verlassen, damit ihr [+NEG]Merkmal den Rest der VP in ihren Skopus nehmen kann, vgl. das keiner in (30e), das in die Spezifiziererposition der funktionalen Kategorie POSP oberhalb der VP wandern muß, vgl. die unterschiedlichen Skopusverhältnisse in (30e) und (30e'):

(30) e. daß leider tatsächlich keiner $r_{\mathrm{i}}\left[\mathrm{vp}\right.$ oft $t_{\mathrm{i}}$ einem großen Publikum NONsens erzählt hat]

'daß tatsächlich für keinen gilt, daß er oft einem großen Publikum Nonsens erzählt hat'

e'. daß leider tatsächlich [vpoft keiner einem großen Publikum Nonsens erzählen konnte]

'daß tatsächlich gilt, daß oft keiner einem großen Publikum Nonsens erzählen konnte'

Die die Negation oder Affirmation der Proposition modifizierenden Positionsadverbialia (tatsächlich, keinesfalls, keineswegs ...) werden an die Positionsphrase basis-adjungiert (30c-e). 
Nimmt man nun eine VP-Struktur wie (29) - ergänzt durch eine POSP wie (30) - an, so ergibt sich eine direkt der hierarchischen Struktur entsprechende Reihenfolge, die ich als Grundreihenfolge bezeichne. In solch einer Positionsphrase wird der Hauptakzent des Satzes dem syntaktisch zu bestimmenden Fokusexponenten zugewiesen, in (30) der am tiefsten eingebetteten subkategorisierten lexikalischen Nachbarkonstituente des Verbkomplexes ${ }^{6}$, nämlich NONsens.

Dieselbe Reihenfolge wird auch von definiten Substantiven eingehalten, die Bekanntes, aber nicht unmittelbar vorher schon einmal Erwähntes bezeichnen, also zum Fokusbereich gehören:

(31) (Ich habe gehört,)

daß (gestern die Chefin des Hauses charmant dem Publikum den jungen AUtor vorstellte]

Weitere wichtige Veränderungen dieser Grundreihenfolge - neben der Linksverschiebung einer negierten Phrase nach SpecPOS - ergeben sich bei der Anpassung eines Satzes an den Diskurs. Diese Anpassung ist im Deutschen und Niederländischen mit Linksverschiebungen von in der VP generierten Konstituenten innerhalb des Mittelfeldes verbunden, die man häufig alle oder nur teilweise als Scrambling bezeichnet, wobei Scrambling meist mit Adjunktion gleichgesetzt wird. Ich will hier nicht auf (mehr oder weniger kontrastive) Umordnungen mit lediglich informationsstrukturellen Konsequenzen eingehen, die nach Rosengren innerhalb der VP stattfinden und nach ihrer Meinung die einzig legitimen Scramblingfälle sind. In einem Syntaxmodell, das nach Chomsky (1992) nur Checking formaler Merkmale als Motiv für Bewegung zuläBt, habe ich dafür in Haftka (1994) eine Kontrastfokusphrase ${ }^{7}$ angesetzt, die der POSP übergeordnet ist und eine Spezifiziererposition für eine zwischen dem Satzadverbiale und der Negation/Affirmation anzuordnende sekundär betonte maximale Phrase zur Verfügung stellt:

(32) daß /FOCcP natürlich /FOCcP einem seRIÖsen Publikum / FOCc $^{\prime}$

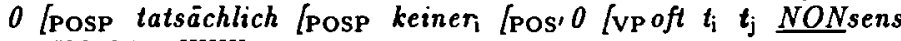
erzählt hätte]J]J]J]

6 Auf die Festlegung des grammatisch zu definierenden Fokusexponenten im Satz kann hier nicht eingegangen werden. $\mathrm{Vgl}$. dazu unter vielen anderen B. Haftka in: Grundzüge einer deutschen Grammatik (1981, S. 741-751), W. Abraham (1992), Rosengren (1994).

7 Die Kontrastfokusphrase ist an die Annahme gebunden, daB neben morphologischen Merkmalen (wie AGR(eement), T(ense)) auch das frei zugewiesene Kontrastfokus-Merkmal in einer entspechenden Spezifiziererposition gecheckt werden $k a n n / m u f$. 
So entsteht die für solche Sätze typische Hutkontur (Kapitälchen (sekundärer) - unterstrichene Großbuchstaben (primärer Akzent)).

An die Kontrastfokusphrase wird das Satzadverbiale basis-adjungiert, das auf diese Weise die gesamte affirmierte oder negierte Proposition subjektiv bewertend in seinen Skopus nimmt, s. (30e). Ist kein Kontrastfokusmerkmal und damit auch keine Kontrastfokusphrase im Satz vorhanden, so kann man annehmen, dab das Satzadverbiale an POSP adjungiert wird, worauf wir uns hier der Übersichtlichkeit halber beschränken wollen.

Ein anderer Komplex von Linksverschiebungen aus der VP betriftt diejenigen maximalen Phrasen, die auf Individuen referieren, die im unmittelbar vorangehenden Kontext oder in der Gesprächssituation schon "gegeben" sind, und deshalb als für den Hörer bewuBtseinspräsent und in diesem hörerbezogenen (Molnár (1991)) Sinne als „thematisch" angesehen werden. Solche Umordnungen können dazu führen, daB die POSP, vom Verb und von den Adverbialen abgesehen, teilweise oder völlig lexikalisch entleert wird. Die verschobenen Konstituenten hinterlassen an ihrer ursprünglichen Position koindizierte Spuren $\left(t_{i}, t_{j}\right)$ :

(33) Ich habe gehört,

a. daß die Chefin den Leuten $n_{\mathrm{j}}$ [angeblich [gestern $t_{\mathrm{i}}$ charmant $t_{\mathrm{j}}$ den jungen AUtor vorstellte]]

b. daß die Chefin diesen Mann $n_{\mathrm{i}}$ [angeblich [gestern $t_{\mathrm{i}}$ charmant dem PUBlikum $t_{\mathrm{k}}$ vorstellte]]

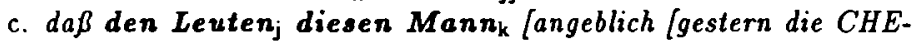
fin des Hauses $\mathrm{t}_{\mathrm{j}} \mathrm{t}_{\mathrm{k}}$ vorstellte]]

d. daß die Chefin $n_{\mathrm{i}}$ den Leuten diesen Mann $_{\mathrm{k}}$ [angeblich [gestern $\mathrm{t}_{\mathrm{i}} \mathrm{t}_{\mathrm{j}} \mathrm{t}_{\mathrm{k}}$ charmant VORstellte]]

Auch unbetonte Personal- oder Demonstrativpronomen müssen über das Satzadverbiale "gehoben" werden, also links vom Satzadverbiale stehen, vgl. $(33 e, f)$ :

(33) e. daß sie ihnen den $_{\mathrm{k}}$ [angeblich [gestern $t_{\mathrm{i}}$ charmant $t_{\mathrm{j}} t_{\mathrm{k}}$ VORstellte]]

f. daß ihnen den $n_{\mathrm{k}}$ langeblich [gestern die Chefin des Hauses charmant $t_{\mathrm{j}} t_{\mathrm{k}}$ VORstellte]]

gegenüber dem ungrammatischen (33e'):

(33) $\mathrm{e}^{\prime} .{ }^{*} \mathrm{da \beta}$ [angeblich [gestern sie charmant ihnen den vorstellte]]

Die Syntaxdeskription muB nun folgender Tatsache Rechnung tragen: Die Reihenfolge der unbetonten Konstituenten links vom Satzadver- 
biale/links von Modalpartikeln wie $j a / d o c h$ ist nicht beliebig, sondern wortform- und kasusabhängig, das heißt, es gibt eine Präzedenzhierarchie für gescrambelte Phrasen, links vom Satzadverbiale, die - sehr grob gesagt, - darauf hinausläuft, daß sich hier ebenfalls die Reihenfolge SU - IO - DO ergibt, auBer wenn es sich um Personalpronomen handelt, für die SU - DO - IO gilt.

Auf die Einzelheiten, wie diese Zusammenhänge beschrieben werden können, will ich hier nicht eingehen. Zwei Ansätze aber will ich nennen:

- Die der Vorstellung vom Deutschen als einer Scramblingsprache am nächsten kommende Alternative wäre eine Adjunktion an IP. Bei dieser Annahme kommt man nicht umhin, Filter zu formulieren, die sichern, daB die genannte Präzedenzhierarchie eingehalten wird ( $\mathrm{vgl}$. dazu das Filtersystem in Haftka 1988a, b).

- Die andere Alternative wäre, daB (wie in (34)) die verschiedenen Unterkategorien von INFL (SU-Kongruenz, IO-Kongruenz, DOKongruenz, Tempus), die als funktionale Kategorien zu maximalen Phrasen projizieren, Spezifizierer-Positionen für die oberflächensichtbare Kasusüberprüfung zur Verfügung stellen. ${ }^{8}$ Das würde bedeuten, daß Kasusüberprüfung nur für solche DPs oberflächensichtbar ist, die vor einem (möglichen) Satzadverbiale und damit vor der Positionsphrase und vor an die VP adjungierten Adverbialen stehen müssen, weil sie auf Vorerwähntes referieren und nicht im Skopus der Negation/Affirmation erscheinen dürfen, wenn sie nicht kontrastiv interpretiert werden sollen (Haftka 1994, 1995).

8 Die Annahme der Kongruenz- oder Agreement-Phrasen geschieht hier in Anlehnung an die Checking-Theorie des Minimalistischen Programms von Chomsky (1992), wobei es allerdings kaum empirische Evidenz dafür gibt, daß es im Deutschen neben dem overten Agreement-Checking bei diesen unbetonten vorerwähnten Phrasen auch noch ein verdecktes Checking der Kasusmerkmale aller anderen Argument-DPs auf dem Wege zur LF gibt. Das heißt, hier wird - Haftka $(1994,1995)$ wieder aufnehmend - nur versucht, die angeblich universellen Agreement-Spezifizierer für die Beschreibung der Reihenfolgerestriktionen gescrambelter Phrasen zu nutzen und zu zeigen, wo die Grenzen dieses Verfahrens liegen. 


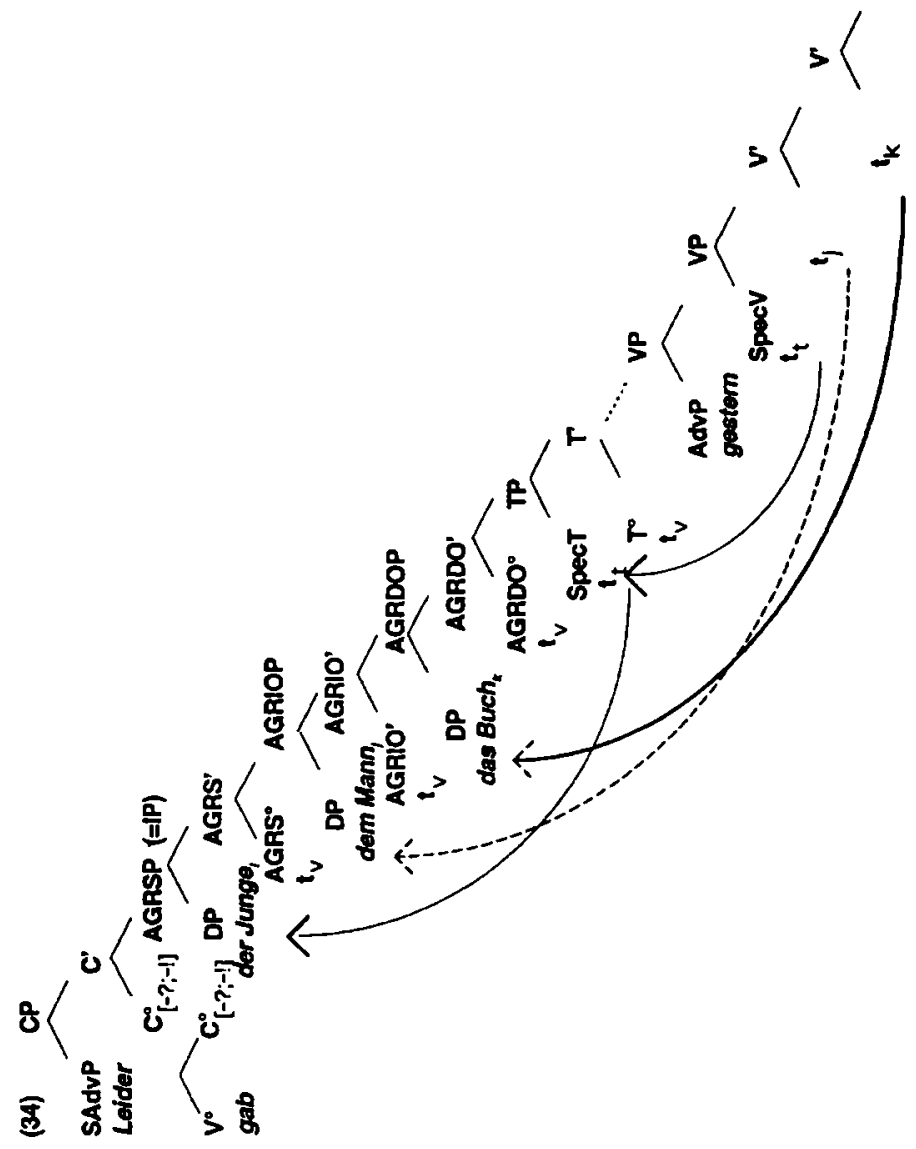


Rechnet man das durch, so bleibt auch dabei ein Problem offen, nämlich die idiosynkratisch feste Reihenfolge: akkusativisches Personalpronomen vor dativischem (35):

(35) a. daß $d u_{\mathrm{i}} i h n_{\mathrm{k}} i h m_{\mathrm{j}} \mathrm{t}_{\mathrm{i}}$ leider gestern $\mathrm{t}_{\mathrm{i}} \mathrm{t}_{\mathrm{j}} \mathrm{t}_{\mathrm{k}}$ GABst

b. daß $d u_{\mathrm{i}}$ dem $_{\mathrm{j}}$ das $_{\mathrm{k}} \mathrm{t}_{\mathrm{i}}$ leider gestern $\mathrm{t}_{\mathrm{i}} \mathrm{t}_{\mathrm{j}} \mathrm{t}_{\mathrm{k}}$ GABst

gegenüber der normalen Reihenfolge Dativ vor Akkusativ im Falle der Demonstrativpronomen (35b) und der definiten Nomina (34). Nimmt man einen Checking-Mechanismus wie in (34) an, so müBte das indirekte Objekt immer vor dem direkten Objekt erscheinen. Möglicherweise ist die DO-IO-Anordnung der Objekte ebenso wie die Klitisierung z.B. an $d a \beta$ in $(36 \mathrm{a})$ oder an $d u$ in $(36 \mathrm{~b})$

(36) a. dasses ihm sicher einer gegeben hat

b. daß du's ihm sicher gegeben hast

jedoch ein phonologischer ProzeB, der durch Prinzipien der PFKomponente abgedeckt wäre, also keinen Einwand gegen die Checkingtheorie darstellen müßte. ${ }^{9}$

Ich verwende hier für diese Linksverschiebungen im Mittelfeld nicht den Begriff „Scrambling”, weil es sich in dem angenommenen Modell nicht um Adjunktion etwa an IP handelt.

Nach meinen Beobachtungen (seit Haftka 1988) gibt es noch eine weitere Möglichkeit, die Grundreihenfolge SOV innerhalb der Verbalphrase zu verändern. Unter anderem kann dies auch dadurch geschehen, daB eine der Phrasen als Topik ausgezeichnet ist, d.h. als Gegenstand, über den bzw. als Situation, über die etwas ausgesagt werden soll. Das ist zwar häufig das Subjekt des Satzes ${ }^{10}$, kann aber auch eines der Objekte oder, wie ich annehme, auch eine der auf eine Situation referierenden adverbialen Phrasen (Temporale, Kausale ...) sein, unabhängig davon, ob das

$9 \mathrm{Vgl}$. auch H. Wegener (1985). In der Diskussion nach diesem Vortrag wies W. Abraham mich auf seinen interessanten Erklārungsansatz in Abraham (1995, S. 517) hin, der davon ausgeht, daB unbetonte Personalpronomina klitischen Charakter haben: „Der strukturelle Akkusativ steht dem CLTräger, vermittelt durch das funktionale Kongruenzmerkmal (AGR-O), nāher als der lexikalische Dativ". Eine Annahme, die aber bezogen auf (34) weitere Zusatzannahmen erfordert.

10 Statistiken, die ganze Texte untersuchen, kommen meist auf ca. $60 \%$ aller Sätze, die mit dem Subjekt beginnen. Ich kann solche Angaben aus einer eigenen unveröffentlichten statistischen Untersuchung aus den 60er Jahren (Novellen und Zeitungstexte aus der Goethezeit und der Gegenwart) bestätigen. 
Bezeichnete kontextuell oder situativ bewußtseinspräsent ist oder nicht. Eine solche Phrase, die einen Gegenstand/eine Situation bezeichnet, über den/die etwas ausgesagt werden soll und die deshalb das Merkmal [+Topik] erhält ( = „sachbezogene Ebene” bei Molnár 1991) kann zwischen $d a \beta$ oder dem Verb einerseits und den vorerwähnten Phrasen links vom Satzadverbiale andererseits erscheinen.

Wenn in einem syntaktischen Modell Verschiebungen von maximalen Phrasen immer nur dadurch zustande kommen, daB ein Spezifizierermerkmal einer funktionalen Kategorie das gleiche Merkmal hat wie die jeweilige Phrase, dann folgt aus der Tatsache, daB in einer Sprache eine Phrase mit einem bestimmten Merkmal wie z.B. Topik immer eine bestimmte Position einnimmt, daB dort die Spezifiziererposition sein muB, in der dieses Merkmal überprüft werden muB. Das heißt, zwischen $\mathrm{C}^{\circ}$ und IP/ AGRSP müssen wir eine Topikphrase annehmen. 


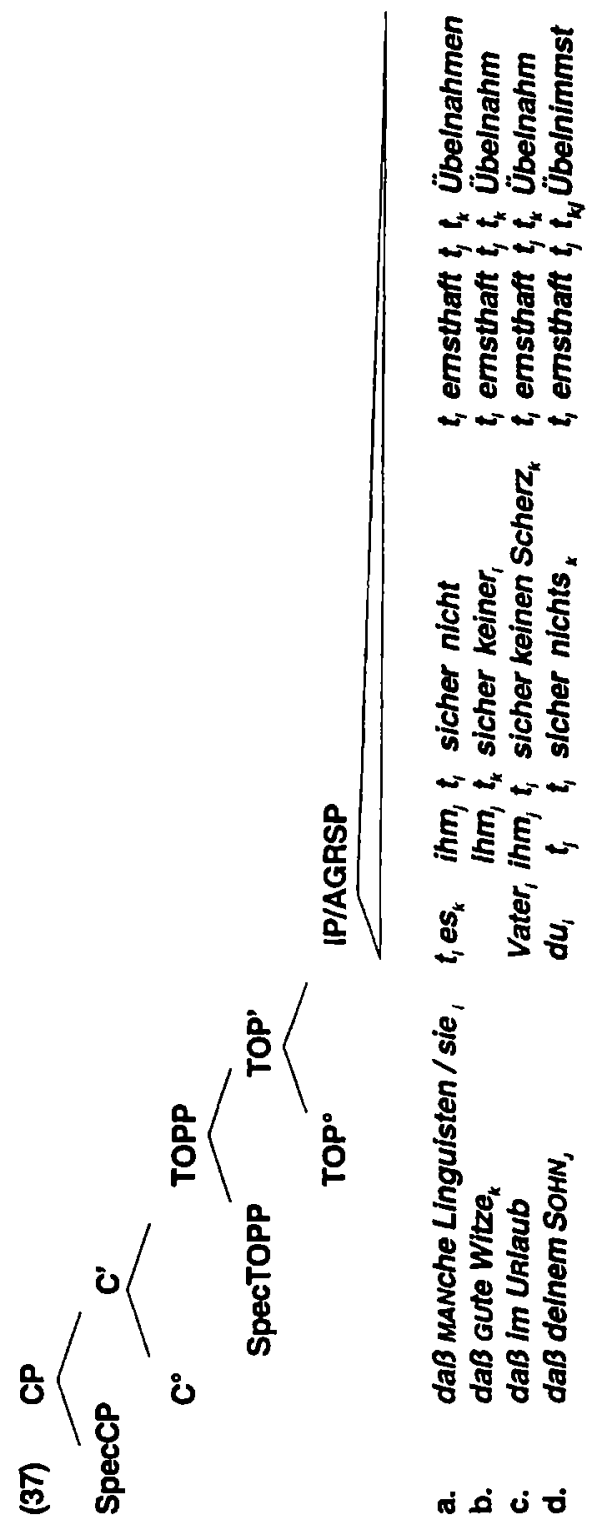


Das Topik ist immer dann sekundär betont, wenn es auf etwas referiert, das nicht unmittelbar vorerwähnt ist, vgl. in (37a): manche Linguisten mit Hutkontur vs, sie ohne diese Kontur.

Von der Topik-Position ausgeschlossen ist per definitionem stets die Phrase, die den Hauptakzent des Satzes trägt, also der Fokusexponent:

\section{*daß MUT Vater ihm zugesprochen hat}

Die Annahme, daß hier nur eine Position für eine Phrase zur Verfügung steht, entspricht dem empirischen Befund, daB vor den auf Vorerwähntes referierenden Phrasen normalerweise vom Hörer nur eine Phrase als Topik akzeptiert wird, s. (39-41):

(39) ? daß gestern manche Linguisten $t_{\mathrm{i}} e s_{\mathrm{k}}$ ihm $m_{\mathrm{j}} t_{\mathrm{i}}$ sicher nicht $t_{\mathrm{i}}$ ernsthaft $t_{\mathrm{j}} t_{\mathrm{k}}$ übelnahmen

(40) ? daß seitdem gute Witze $t_{k}$ ih $m_{j} t_{k}$ sicher keiner $t_{i}$ ernsthaft $t_{\mathrm{j}} t_{\mathrm{k}} \ddot{u}$ belnahm

(41) ? daß im Urlaub Vater $t_{\mathrm{i}}$ ih $m_{\mathrm{j}} t_{\mathrm{i}}$ sicher keinen Scher $z_{\mathrm{k}} t_{\mathrm{i}}$ ernsthaft $t_{\mathrm{j}} t_{\mathrm{k}}$ übelnahm

In deklarativen Verbzweit-Sätzen wandert nun im möglicherweise topikprominenten Deutschen die als Topik markierte Phrase in die als Vorfeld bekannte Position vor das finite Verb, d.h. in die Spezifiziererposition von CP, vgl. (42-44), es sei denn diese Position ist durch die den Hauptakzent des Satzes tragende maximale Phrase, die nie Topik sein kann, besetzt wie in (45):

(42) Viele Linguisten $n_{\mathrm{i}} /$ sie $_{\mathrm{i}}$ nahmen $t_{\mathrm{i}}$ es ${ }_{\mathrm{k}}$ ihm $\mathrm{m}_{\mathrm{j}} t_{\mathrm{i}}$ sicher nicht $t_{\mathrm{i}}$ ernsthaft $t_{\mathrm{j}} t_{\mathrm{k}}$ Übel

(43) Gute Witze nahm ihm $_{\mathrm{j}} t_{\mathrm{k}}$ sicher KEIner $t_{\mathrm{i}}$ ernsthaft $t_{\mathrm{j}} t_{\mathrm{k}}$ übel

(44) Im Urlaub nahm Vater, ihm $t_{\mathrm{j}} t_{\mathrm{i}}$ sicher KEInen Scher $z_{\mathrm{k}} t_{\mathrm{i}}$ ernsthaft $t_{\mathrm{j}} t_{\mathrm{k}}$ übel

(45) MUT hat Vater ihm zugesprochen

Ist weder die den Hauptakzent des Satzes tragende maximale Phrase in SpecCP angeordnet, noch eine Topikphrase vorhanden, dann wird häufig wie in (46) ein expletives $E S$ eingesetzt: ${ }^{11}$

(46) Es nahmen [AGROPihm $m_{\mathrm{j}}$ sicher [vP viele Linguisten $t_{\mathrm{j}}$ so manche Äußerung übel]]

11 Daneben gibt es (sicher häufiger in der gesprochenen Sprache) auch oft als narrativ bezeichnete deklarative V/1-Sătze vom Typ „Kam ein Hase zum Apotheker...” , „Hat (doch) gestern Anton Fritz getroffen und ...” usw. 
$\mathrm{Da} B$ dieses expletive Element für ein leeres Topik steht, beweist die geringere Grammatikalität von Sätzen wie (47)-(49), wo ein vorhandenes Topik nicht in die SpecCP-Position, also ins Vorfeld, verschoben worden ist:

(47) ? Es nahmen viele Linguisten $t_{\mathrm{i}} i h m_{\mathrm{j}}$ den Scher $z_{\mathrm{k}} t_{\mathrm{i}}$ sicher $t_{\mathrm{i}}$ ernsthaft $t_{\mathrm{j}} t_{\mathrm{k}}$ übel $t_{\mathrm{v}}$

(48) ? Es nahm gute Witze $t_{\mathrm{k}} t_{\mathrm{k}}$ ihm $m_{\mathrm{j}}$ sicher keiner $t_{\mathrm{i}}$ ernsthaft $t_{\mathrm{j}} t_{\mathrm{k}}$ übel $t_{\mathrm{v}}$

(49) ?? Es nahm im Urlaub Vater ${ }_{1} m_{\mathrm{j}} t_{\mathrm{i}}$ sicher keinen Scherz $\mathrm{z}_{\mathrm{k}} t_{\mathrm{i}}$ ernsthaft $t_{\mathrm{j}} t_{\mathrm{k}}$ übel $t_{\mathrm{v}}$

und die Ungrammatikalität von (50), wo das prototypische Topik, nämlich das pronominale Subjekt, nicht nach SpecCP ins Vorfeld gewandert ist:

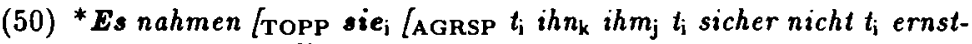
haft $t_{\mathrm{j}} t_{\mathrm{k}}$ übel $\left.t_{\mathrm{v}}\right]$

Im Deutschen können also durchaus viele statistisch mögliche Reihenfolgen von Subjekt- und Objektkonstituenten auch tatsächlich vorkommen, deren Anordnung unterliegt aber trotzdem strengen Restriktionen, ist also keineswegs frei im Sinne von beliebig. Deshalb komme ich zu dem meinen Titel einschränkenden SchluB: Deutsch ist eine abgeleitete V/2Sprache mit zugrundeliegender SOV-Reihenfolge. Die scheinbare Freiheit der Wortstellung ist streng restringiert.

\section{Literatur}

Abraham, W. (1992): Structural Properties of Information Packaging in German and in Universal Grammar. Erscheint in: Kiss, K.E. (ed.): Focus Languages. Oxford.

Abraham, W. (1995): Deutsche Syntax im Sprachenvergleich. Grundlegung einer typologischen Syntax des Deutschen. Tübingen. (= Studien zur deutschen Grammatik 41).

Brandt, M./Reis, M./Rosengren, I./Zimmermann, I. (BRRZ ) (1992): Satz, Satztyp und Illokution. In: Rosengren, Inger ( $\mathrm{Hg}_{\text {. }}$ ): Satz und Illokution. Bd.1. Tübingen. S. 1-90. (= Linguistische Arbeiten 278).

Bierwisch, M. (1990): Verb Cluster Formation as a Morphological Process. In: Yearbook of morphology 3, S. 173-199.

Chomsky, N. (1986): Barriers. Cambridge/Mass. MIT Press.

Chomsky, N. (1992): A Minimalist Program for Linguistic Theory. MIT Occasional Papers in Linguistics 1. Cambridge/Mass.

Donati, C./Tomaselli, A. (1995): Language Types and Generative Grammar: A Review of Some Consequences of the Universal VO Hypothesis. Ms. 
Haftka, B. (1981, 1984): Reihenfolgebeziehungen im Satz (Topologie). Kap. 4. In: Heidolph, K. E./Flämig, W./Motsch, W. (Hg.), S. 702-764.

Haftka, B. (1988a): Linksverschiebungen. Ein Beitrag zur Konfigurationalitāt des Deutschen. In: Bierwisch, M./Motsch, W./Zimmermann, I. (Hg.) (1988): Syntax, Semantik und Lexikon. Berlin. S. 89-146. (= studia grammatica XXIX).

Haftka, B. (1988b): Ob vielleicht tatsächlich nicht gern reist? In: Lang, E. (Hg.) (1988): Studien zum Satzmodus I. Berlin. S. 25-58. (= Linguistische Studien des ZISW der AdW der DDR R. A, 177).

Haftka, B. (1993): Topologische Felder und Versetzungsphänomene. In: Syntax. Ein internationales Handbuch zeitgenōssischer Forschung. Berlin/New York. S. 846-867.

Haftka, B. (Hg.) (1994): Was determiniert Wortstellungsvariation? Opladen.

Haftka, B. (1994): Wie positioniere ich meine Position? In: Haftka, B. (Hg.) (1994), S. 139-160.

Haftka, B. (1995): Syntactic Positions for Topic and Contrastive Focus in the German Middlefield. Vortrag bei der AG Fokus-Hintergrund-Gliederung bei der DGfS-Jahrestagung in Gōttingen. 1.-3. Mãrz 1995.

Hawkins, J. A. (1990): Word order universals. New York.

Heidolph, K.E./Flāmig, W./Motsch, W. (Hg.) (1981, 1984): Grundzüge einer deutschen Grammatik. Berlin.

Kayne, R. (1994): The Antisymmetry of Syntax. MIT Press.

Larson, R. (1988): On the Double Object Construction. In: Linguistic Inquiry 19, S. 335-391.

Molnár, V. (1991): Das TOPIC im Deutschen und im Ungarischen. Stockholm. (= Lunder Germanistische Forschungen 58).

Rosengren, I. (1994): Scrambling - was ist das? In: Haftka, (Hg.) (1994), S. 175-196.

Schmidt, C. M.(1995): Satzstruktur und Verbbewegung. Eine minimalistische Analyse zur internen Syntax der IP (INFLection-Phrase) im Deutschen. Tübingen. (= Linguistische Arbeiten 327).

Wegener, H. (1985): Der Dativ im heutigen Deutsch. Tübingen. (= Studien zur deutschen Grammatik 28).

Zimmermann, I. (1991): Die Syntax der Substantivgruppe. Weiterentwicklung der X'-Theorie. In: Zimmermann, I. (Hg.) (1991): Syntax und Semantik der Substantivgruppe. Berlin. S. 1-32. (= Studia grammatica XXXIII). 


\title{
CHRIS WILDER
}

\section{V2-Effekte: Wortstellungen und Ellipsen*}

\begin{abstract}
Verschiedene Sprachen, wie auch verschiedene Konstruktionen in den einzelnen Sprachen, weisen divergente und z.T. sehr komplexe elliptische Muster auf. Auf den ersten Blick scheinen komplexe Beschreibungen durch sprach- und konstruktionspezifische Ellipseregeln erforderlich zu sein. Dies wird anhand kontrastierender Möglichkeiten zur Objektellipse in Koordinationen sowie in unabhängigen elliptischen Sātzen (z.B. elliptischen Antworten) des Deutschen und des Englischen verdeutlicht. Bei nāherem Hinschauen stellt sich jedoch heraus, daß die unterschiedlichen Ellipsemöglichkeiten mit unterschiedlichen Wortstellungsmustern korrelieren. So kōnnen die syntaktischen Determinanten der Wortstellungsmuster, die ohnehin notwendige sprach- und konstruktionsspezifische Annahmen darstellen, verwendet werden für die Erklärung von variierenden Ellipsemöglichkeiten, ohne daß auf spracheigene Ellipseregeln zurückgegriffen werden muß. Diese These wird exemplarisch bewiesen an dem Zusammenwirken der invarianten Tilgungsregeln (Vorwärts- und Rückwärtstilgung) mit zwei Wortstellungsparametern (V2-Parameter und VO/OV-Parameter), die für die unterschiedlichen Konstituentenabfolgen des Deutschen und des Englischen verantwortlich sind.
\end{abstract}

\section{Einleitung}

Es ist selbstverständlich, daß eine universalgrammatische Theorie neben universellen Prinzipien auch sprachspezifische Regeln einräumen muß, um überhaupt in der Lage zu sein, die offensichtlichen Fakten der zwischensprachlichen Variation (z.B. Wortstellungsvariation) zu erfassen. Solche sprachspezifischen Regeln werden im Prinzipien-und-ParameterAnsatz als allgemeine Regeln (Prinzipien) konzipiert, die Optionen (Parameter) offenlassen, unter denen die einzelnen Sprachen auswählen können. Ein solcher Parameter, der im folgenden von Belang sein wird, ist der "VO/OV-Parameter”. Er bestimmt, ob in einer Sprache bei kanonischer Wortfolge das Hauptverb seinem Objekt-NP folgt (wie im Deutschen) oder vorangeht (wie im Englischen).

Der Unterschied zwischen VO- und OV-Sprachen kann durch die Annahme zum Ausdruck gebracht werden, daB deutsche und englische Satzstrukturen jeweils von unterschiedlichen Phrasenstrukturregeln determi-

* Ich danke Ewald Lang fũr die gründliche Durchsicht des Manuskripts. 
niert sind, wobei die (hier zu Illustrationszwecken sehr vereinfachten) Regeln jeweils der Grammatik der Einzelsprache zuzuordnen sind:
(1) a. $\quad \mathrm{VP} \rightarrow \mathrm{V} \mathrm{NP}$
(Engl.)
b. $\quad \mathrm{VP} \rightarrow \mathrm{NP}$ V
(Deutsch)

Beide Regeln besagen, daB NP und V zusammen eine Konstituente (VP) bulden; die Sprachen unterscheiden sich lediglich in der linearen Anordnung von NP und $V$ in der betreffenden Regel. Für jede Sprache gilt jedoch eine eigene Regel - das beiden Sprachen "Gemeinsame" wird so nicht zum Ausdruck gebracht.

Die beiden Regeln können zu einer einzigen „universell geltenden”, "parametrisierten" Regel (hier wieder vereinfacht) zusammengefaßt werden, wobei der offen gelassene „Parameter" - rechts/links - von Sprache zu Sprache verschieden "gesetzt" werden kann:

(2) VP besteht aus V und NP, wobei V rechts (Dt.)/links (Engl.) von NP steht

Nun gilt für beide Sprachen (ex hypothest für jede Sprache) diese eine Regel, und es müssen nicht für jede einzelsprachliche Grammatik gesonderte Regeln angegeben werden. Das "Spezifische", worin die enzelsprachlichen Grammatiken sich unterscheiden - die lineare Anordnung - wird als solches beschrieben, ohne daf die Beschreibung von gemeinsamen Eigenschaften als solche verloren ginge.

Ein zweiter Parameter, mit dem wir im folgenden zu tun haben werden, Ist der „V2-Parameter” Damit sind diejenigen Faktoren gemeint, die die verschiedenen Stellungseigenschaften von finiten Verben z.B. im Englischen und im Deutschen determinieren. Aus diesem Parameter soll u.a. folgen, (i) daß in deutschen Hauptsätzen finite Verben entweder die erste oder die zweite Position einnehmen (wo sie dann auch meist vor statt hinter dem Objekt stehen), nicht aber in Nebensätzen; und (ii) daß in englischen deklarativen Hauptsätzen finite Verben diese Stellungseigenschaft nicht aufweisen, in interrogativen Hauptsätzen aber schon.

Zusammen sind der "V2-Parameter” und der „VO/OV-Parameter” für die wichtigsten Verbstellungsunterschiede zwischen Deutsch und Englisch verantwortlich. Hier sind Festlegungen über die genauere Natur dieser beiden Wortstellungsparameter nicht von Belang - wichtig sind vielmehr die verschiedenen Strukturen und Wortfolgemuster, die durch sie determiniert werden. 
Das eigentliche Thema dieses Beitrags bilden Ellipsen, insbesondere zwischensprachlich unterschiedliche Ellipsemöglichkeiten, wie die in (3) - (6) illustrierten:

a. The hare, he sought and caught.
b. $\quad$ Den Hasen suchte er und fing.

a. Wenn er den Hasen jagt und fängt, ...

b. * If he hunts the hare and catches,...

(5) a. Was soll ich mit dem Bier machen?

b. In den Kühlschrank stellen.

(6) a. What should I do with the beer?

b. * Put in the fridge

In den Koordinationsbeispielen (3) und (4) ist das zweite Konjunkt jeweils elliptisch - zumindest das direkte Objekt (the hare / den Hasen) ist ausgelassen worden - mit unterschiedlichen Effekten, was die Grammatikalität des Beispiels in der jeweiligen Sprache betrifft. Die Antworten (5b) und (6b) sind ebenfalls elliptische Sätze mit Objektauslassung (das Bier / the beer), die denselben Kontrast aufweisen. Die Kontraste in (3) und (4) sowie die zwischen (5) und (6) könnten als Evidenz für die Notwendigkeit sprachspezifischer Ellipseregeln gedeutet werden. Darüber hinaus korrelieren die kontrastierenden Möglichkeiten bzgl. der Objektauslassung innerhalb der jeweiligen Sprachen - (3a) vs. (4b), (3b) vs. (4a) - auch mit unterschiedlichen grammatischen Konstruktionen (etwa Hauptsatz vs. Nebensatz), was zu der Annahme verleiten könnte, daß hier für die einzelnen Sprachen verschiedene, an einzelne grammatische Konstruktionen gebundene Ellipseregeln aufzustellen seien.

Im folgenden wird gezeigt, daß für diese Beispiele keine sprachbzw. konstruktionsspezifischen Ellipseregeln aufgestellt werden müssen: alle Kontraste lassen sich auf der Basis einer gemeinsamen, nichtparametrisierten (evtl. universellen) Ellipseregel erklären. Dem durch (3)-(6) erweckten Anschein zum Trotz zählt die betreffende Ellipseregel nicht zu den parametrisierten Regeln der Universalgrammatik. Diese Regel wird unten "Vorwärtstilgung" genannt - sie erfaßt das als Forward Conjunction Reduction bekannte Phänomen sowie einige andere Ellipsetypen. Die vorliegende Fallstudie unterstützt die folgende allgemeinere These: 
(7) (i) Prinzipien, die Ellipsen steuern, gelten sprachübergreifend (universell).

(ii) Unterschiede ergeben sich aus dem Zusammenwirken dieser Prinzipien mit unabhängigen Spezifika einzelsprachlicher Grammatiken.

Wesentlich ist dabei die Beobachtung, daB Unterschiede in Ellipsemöglichkeiten mit unterschiedlichen Wortstellungsmustern korrelieren. Das bedeutet, daß die syntaktischen Determinanten der Wortstellungsmuster, die völlig unabhängig von Ellipseerscheinungen notwendige sprachspezifische Annahmen darstellen, dann ausgebeutet werden können zur Erklärung von variierenden Ellipsemöglichkeiten, ohne da $\beta$ auf spracheigene Ellipseregeln zurückgegriffen werden muf.

Andererseits müssen jedoch verschiedene Ellipseregeln unterschieden werden: Rückwärtsellipsen (solche, die Lücken erzeugen, die links von den sie identifizierenden Wörtern stehen) weisen nicht eliminierbare Unterschiede zu den Vorwärtstilgungen auf. Im Laufe der Diskussion wird auf das Wesen dieser verschiedenen Ellipseregeln näher eingegangen, und es wird insbesonders für das Deutsche gezeigt, wie sie mit unabhängigen Wortstellungsfaktoren (insbesonders Verbstellungsfaktoren) interagieren, um eine breite Palette von elliptischen Satzmustern zu bestimmen.

\section{Ellipse und Syntax}

\section{$2.1 \quad$ Topic Drop}

Eine Hauptbeschäftigung theoretischer Linguisten ist die Suche nach Generalisierungen, die in Form von Regeln (z.B. Wortfolgeregeln) in die Grammatik eingebaut werden sollen. Die Methodik beruht auf Idealisierung und Introspektion: Man bereinigt die Daten, indem man z.B., nur vollständige Sätze betrachtet und unvollständige ÄuBerungen außer Acht läßt - die gesuchten Generalisierungen (mögliche vs. unmögliche Wortfolgen usw.) werden dann aus den 'bereinigten' Daten gewonnen. Die Intuition bietet eine unerläßliche Datenquelle: Ein externer Datenkorpus (Äußerungen) könnte lediglich eine Untermenge der wohlgeformten Satzmuster belegen und darüber hinaus „unreine” Daten enthalten. Um korrekte Generalisierungen zu gewährleisten, werden durch Intuition gewonnene Informationen darüber benötigt, was nicht wohlgeformt ist, genauso wie darüber, was wohlgeformt sein könnte. Die solchermaBen durch Beobachtung und Introspektion gewonnenen Generalisierungen bilden dann die Fakten, für die eine Theorie eine Erklärung liefern soll. 
Dabei werden fragmentarische Ausdrücke wie $(8 b, c)$ des öfteren ausgeschlossen (allerdings bilden gerade diese Beispiele ein inzwischen gut untersuchtes Phänomen, das sog. Topic-Drop-siehe u.a. Haegeman (1990), Platzack (in diesem Band)): ${ }^{1}$
a. Das habe ich schon beschrieben.
b. _habe ich schon beschrieben.
c. - habe das schon beschrieben.

Grammatikalitätsurteile können auch über solche fragmentarischen Ausdrücke gefällt werden. Wir wissen z.B., daß (8b) und (8c) zulässige Auslassungen enthalten, konstruierte Beispiele mit Subjekt- und Objektauslassungen wie in (9) aber sind ungrammatisch:

(9) a. * ich habe - schon beschrieben.

b. * das habe ..- schon beschrieben.

c. * - habe _ schon beschrieben.

Im Prinzip können auch für Ellipsen grammatiktheoretische Erklärungen gesucht werden. In der Tat ist Ellipse ein Phänomen, das im hohen Maße durch grammatische (syntaktische und phonologische) Faktoren bedingt ist.

Wir können das, was schon über vollständige Sätze bekannt ist, verwenden, um über die Analyse von elliptischen Ausdrücken zu entscheiden. In $(8 b, c)$ steht das finite Verb an erster Stelle; sonst stehen finite Verben nur in Entscheidungsfragen und bestimmten Konditionalsatztypen in erster Position. Die Sätze in $(8 \mathrm{~b}, \mathrm{c})$ sind jedoch weder Fragen noch Konditionalsätze, sondern haben übliche Deklarativsatzbedeutung. Wenn wir davon ausgehen, daB das ausgelassene Satzglied „in erster Position steht”, dann lassen sich diese Sätze den normalen V2-Deklarativsätzen zuordnen.

Angesichts der Möglichkeit der Objekt- bzw. Subjektauslassung in (8) fragt man sich, was die Auslassungen in (9) unmöglich macht. Durch Vergleich der beiden Paradigmen kann eine vorläufige Generalisierung in Form einer "Auslassungsregel" aufgestellt werden:

1 Die gängigen Analysen von Topic Drop gehen wie hier - und aus āhnlichen Grūnden - davon aus, daß diese Sātze syntaktisch vollständig sind. Sie werden aber nicht wie übliche Ellipsen als $F$ älle von phonologischer Tilgung behandelt, sondern es wird ein spezielles Element (null Topic bzw. null Operator) postuliert, das die erste Position in diesen Sätzen besetzt. Das Vorkommen dieses Elements wird per Stipulation auf die prā-finite Position (Spec,CP) von V2-Sätzen beschrānkt. Unter diesen Annahmen erübrigt sich die hier angedeutete Möglichkeit, diesen Satztyp als Spezialfall eines allgemeineren Ellipsephänomens zu behandeln. 
(10) Nur Satzglieder, die in prä-finiter Position stehen, dürfen ausgelassen werden.

Die Ungrammatikalität der Ausdrücke in (9) ließe sich dann als Verstoß gegen (10) erklären. Es gibt vor dem Finitum Platz nur für ein Satzglied. Wenn diese prä-finite Position schon besetzt ist $(9 \mathrm{a}, \mathrm{b})$, kann das ausgelassene Satzglied dort nicht stehen. Wie (9c) zeigt, konkurrieren auch ausgelassene Konstituenten um die Position vor dem Finitum.

Was heißt es, zu sagen, daß ein ausgelassenes Satzglied nur in präfiniter Position stehen darf? Machen wir den Unterschied zwischen phonologischer Kette (lineare Folge von Wortformen) und syntaktischer Repräsentation (hierarchische Struktur in Form eines Baumdiagramms bzw. Klammerrepräsentation), dann gibt es darauf zwei mögliche Antworten:

(11) a. das Fehlen einer Teilkonstituente im syntaktischen Baum

b. das Fehlen eines Teils der phonologischen Kette (die syntaktische Struktur ist vollständig)

Diese Alternativen machen verschiedene Aussagen über die Beziehung zwischen elliptischen Konstruktionen und den entsprechenden vollständigen (nicht-elliptischen) Sätzen. Nach (11a) ist der oberffächliche Unterschied $z$ wischen dem elliptischen und dem vollständigen Satz - daB bei ersterem an der entsprechenden Stelle in der phonologischen Kette nichts steht - ein Reflex unterschiedlicher syntaktischer Strukturen: dem elliptischen Satz liegt eine syntaktisch „defektive” Struktur zugrunde. Unter (11b) ist die syntaktische Struktur des elliptischen Satzes komplett, so da $\beta$ der elliptische Ausdruck und sein vollständiges Pendant im wesentlichen syntaktisch identisch sind. Was dem elliptischen Satz fehlt, ist nur ein Teil der entsprechenden phonologischen Repräsentation, der getilgt worden ist.

Ich halte (11b) für den geeigneteren Ansatz. Wenn in (8b,c) die 'ausgelassene' Konstituente nur in der phonologischen Repräsentation fehlt, sind dann syntaktisch gesehen diese Beispiele vollständige V2-Sätze (12b) - es ist nur an der fraglichen Stelle Material aus der phonologischen Repräsentation getilgt worden und wird nicht ausgesprochen (symbolisiert durch gestrichene Teile):
a. [habe das schon beschrieben]
b. [[ich] [habe das schon beschrieben]]

Nur so können Aussagen wie "das ausgelassene Satzglied steht in erster Position” oder "ausgelassene Konstituenten konkurrieren um die Position vor dem Finitum" sinnvoll gedeutet werden. Wenn man für diese 
Beispiele (11a) zugrunde legen würde, hätten solche Ausdrücke eine syntaktische Struktur wie (12a), in der es keine Position vor dem Finitum gäbe, um die nicht-vorhandene Konstituenten konkurrieren könnten usw.

Die in (12b) illustrierte Art von phonologischer Tilgung ist als syntaktisch bedingt durch eine Generalisierung erfa8bar, die sich auf syntaktische Begriffe stützt: „In einem finiten Satz darf nur in prä-finiter Position getilgt werden". Es wird sich herausstellen, daB dies bloß einen Spezialfall eines allgemeineren Prinzips bildet, das eine Vielzahl von weiteren Fällen erfaßt.

\subsection{Elliptische Antworten}

Kann ein finites Verb getilgt werden? Was passiert, wenn das finite Verb getilgt wird? Fragmentarische Ausdrücke kommen auch als Antworten auf Fragen vor - z.B. (13), (14). Es gibt gute Gründe, auch für solche elliptische Ausdrücke vollständige Satzstrukturen wie in (15) anzunehmen (vgl. u.a. Klein 1993, Schwabe 1994):

a. Was hat er gemacht?

b. Sich gewaschen.

a. Wer hat wem geholfen?

b. Maria, dem kleinen, Hans, den anderen.

a. [erch gewaschen]

b. [Maria dem kleinen

So können wir direkt aus der syntaktischen Repräsentation der Antwort (14b) erklären, warum die Wörter des Ausdrucks dem kleinen für den Dativ flektiert sind bzw. sein müssen. Das - hier phonologisch getilgte Verb helfen verlangt den Dativ an seinem grammatischen Objekt. Würde man davon ausgehen, daB die syntaktische Repräsentation des Ausdrucks (14b) gar kein Verb enthält, müßte man die Rektionsbedingungen des Verbs in der vorangegangenen Frage für den obligatorisch vorhandenen Dativ in der Antwort direkt verantwortlich machen. Dies würde der Hypothese gleichkommen, daB die Rektionsdomäne eines Verbs sich auf eine NP außerhalb des eigenen Satzes erstrecken könnte.

Die Annahme eines (phonologisch getilgten) Subjekts in der syntaktischen Repräsentation von (13b) erlaubt die Aufrechterhaltung einer generellen Aussage über die Distribution des Reflexivpronomens sich etwa, daB dieses ein Subjekt in der 3. Person im gleichen Satz verlangt. Wäre in (13b) kein syntaktisches Subjekt vorhanden, müBte man, um erklären zu können, warum die Antwort (13b) sich als Antwort auf (13a), 
nicht aber auf (16a) eignet, die Domäne dieser Aussage auf die Subjekte benachbarter Sätze ausdehnen.
a. Was hast du gemacht?
b. \# Er hat sich gewaschen.
c. \# Sich gewaschen.

Mit dem Tilgungsansatz ergibt sich, daß sich (13b) genausowenig wie (16b) als Antwort auf (16a) eignet, und aus demselben Grund (in der Regel kann eine Frage mit einem Subjekt in der 2. Person nicht mit einem Satz mit einem Subjekt in der 3. Person beantwortet werden).

Die Schlubfolgerung ist also, daB ein finites Verben getilgt werden kann. Dann wird es auch möglich, weitere post-finite Satzglieder zu tilgen, z.B. geholfen in (14b). DaB diese Art der Ellipse - wie Topic drop - der Bedingung (10) unterliegt, zeigt (17). Wird in einer elliptischen Antwort das finite Verb nicht getilgt, kann nichts getilgt werden, was hinter diesem steht (17b). Wieder kann post-finites Material (das Partizip gekommen) nur getilgt werden, wenn das Finitum auch getilgt wird (17c).
a. Wer ist gekommen?
b. * Peter ist
c. Peter

Man kann (10) also zu (18) erweitern:

(18) In einem finiten Satz darf nur die in prä-finiter Position stehende Konstituente getilgt werden, es sei denn, das finite Verb selbst ist getilgt worden

Die letztlich richtige Generalisierung ist noch allgemeiner: wir kommen darauf zurück.

\subsection{Kontrast Deutsch/Englisch}

Auch das Englische erlaubt Ellipse am linken Rand von Hauptsätzen. So kann z.B. die Entscheidungsfrage (19a) die Form (19b) annehmen mit Ellipse des Auxiliars, oder (19c) - mit Tilgung von Auxiliar und Subjektpronomen. Alleinige Auslassung des Subjekts ist allerdings nicht möglich (19d):
a. Did you see anyone?
b. You see anyone?
c. See anyone?
d. * Did see anyone? 
Die Möglichkeit zur Vergangenheitsinterpretation spricht dafür, daß den elliptischen Varianten $(19 \mathrm{~b}, \mathrm{c})$ eine syntaktische Repräsentation zugrunde liegt, die die Vergangenheitsform des finiten Auxiliars (did) enthält. Die Beispiele $(19 \mathrm{~b}, \mathrm{c})$ lassen auschlieBlich eine Interpretation als eine direkte Entscheidungsfrage zu, was sich ebenfalls erklären läßt, wenn ihnen eine vollständige syntaktische Repräsentation mit Auxiliarinversion zugrunde gelegt wird: ${ }^{2}$
a. Did you see anyone?
b. Did you see anyone?
c. * Did you see anyone?

Wie im Deutschen können - wenn das finite Verb nicht getilgt ist keine weitere Konstituenten ausgelassen werden, vgl. (20c). Die Generalisierung in (18) scheint also auch für das Englische zu geiten.

Es gibt einen Unterschied zwischen Englisch und Deutsch, der sich am besten anhand von Frage-Antwort-Paaren (vgl. (5)-(6)) zeigen läBt, wobei der abweichende Ausdruck (22b) mit der möglichen Antwort Put it (the beer) in the fridge zu kontrastieren ist:
a. Was soll ich mit dem Bier machen?
b. In den Kühlschrank stellen.
c. [dusollst das Bief in den Kühlschrank stellen]
a. What should I do with the beer?
b. * Put in the fridge
c. * [ut in the fridge]

Im Englischen ist - im Gegensatz zum Deutschen - die Auslassung des Objekts nicht möglich. Es entsteht der Eindruck, daß für die Bedingungen, die die Form von elliptischen Antworten steuern, sprachspezifische Unterschiede eingeräumt werden müssen.

Fragmentarische Ausdrücke dieser Art bilden auch Teilsätze (Konjunkte) in Koordinationen (vgl. (3)-(4)). Bei Koordinationen wird das Phänomen, daß ein Ausdruck (unterstrichen in (23)-(24)) gleichzeitig Teil von

2 (19b,c) können auch eine Lesart wie Do you see anyone? bekommen, d.h. diese elliptischen Varianten können auch durch die Tilgung des Hilfsverbs im Präsens entstehen. Die Interpretation der elliptischen Beispiele als Entscheidungsfragen und nicht als Deklarative wird durch das Vorhandensein des Polaritätsausdrucks anyone erzwungen. Wohlgeformte Beispiele dieser Art sind - wahrscheinlich durch die mangels linguistischer Antezedenten eingeschränkten Möglichkeiten zur Wiederauffindung des getilgten Materials - äußerst beschränkt. Weitere Diskussion findet sich bei Haegeman (1990), Klein (1993), Schwabe (1994), Wilder (1995). 
mehreren Konjunkten zu sein scheint, als das Ergebnis einer Ellipse angesehen: in einem Konjunkt unterliegt eine dem unterstrichenen Ausdruck entsprechenden Konstituente der phonologischen Tilgung. ${ }^{3}$
a. The hare, he sought and caught.
b. * Den Hasen suchte er und fing.
a. Wenn er den Hasen jagt und fängt, ...
b. * If he hunts the hare and catches, ...

Die Kontraste in (23) und (24) legen nahe, daB auch für die Koordinationsellipse für verschiedene Sprachen unterschiedliche Möglichkeiten anzunehmen sind. Ich werde hingegen dafür plädieren, daB Elidierungsprozesse in den beiden Sprachen durch identische allgemeine Bedingungen gesteuert werden.

Der Kontrast in (24) ist offenbar mit dem in (21) vs. (22) verwandt. In beiden Fällen wird ein direktes Objekt von Ellipse betroffen. Für (24) läßt sich das zweite Konjunkt wie (25) repräsentieren: ${ }^{4}$

$$
\text { a. }{ }^{*} \quad \ldots \text { und [and [ catches fängt] }
$$

In beiden Bereichen - bei elliptischen Antworten wie bei Koordinationsellipsen - sollte der $\mathbf{z w i s c h e n s p r a c h l i c h e ~ K o n t r a s t ~ a u f ~ d e n s e l b e n ~}$ Faktor zurückgeführt werden: diejenige Eigenschaft des Englischen, die (22b/22c) unmöglich macht, macht auch (24b/25b) unmöglich - während das Deutsche diese Eigenschaft nicht aufweist. Die Eigenschaft könnte als spezifische Klausel einer allgemeinen Ellipseregel - d.h. in Form einer „parametrisierten Ellipseregel” - formuliert werden, etwa wie in (26):

(26) Ein direktes Objekt darf (dt.)/darf nicht (engl.) von Ellipse betroften werden.

Verschiedene Indizien sprechen jedoch dafür, daB die Annahme von parametrisierten Ellipseregeln nicht nur nicht notwendig ist (man kommt ohne Parametrisierung von Ellipseregeln aus), sondern sogar falsch wäre (mit parametrisierten Ellipseregeln würden abstraktere Generalisierungen verschenkt werden).

3 Ich gehe davon aus, dab die Konjunkte in diesen Beispielen als vollstāndige Sätze zu analysieren sind, d.h. als CP und nicht etwa als VP. Siehe auch Abschnitt 5. sowie Wilder (1994), (1995).

4 Beim Auswahl solcher Beispiele muB auf die Möglichkeit einer „intransitiven Verwendung" des Verbs im 2. Konjunkt geachtet werden: vgl. He roasted the hare and ate (it) vs. He roasted the hare and devoured *(it). 
Der Kontrast in (25) fallt mit einem unabhängigen Unterschied zwischen den beiden Sprachen zusammen, nämlich mit dem Wortfolgeparameter (VO/OV-Parameter). Eine invariante Ellipseregel, die sich direkt auf Wortstellungsfaktoren bezieht, kann mit den unabhängig gegebenen Wortfolgeunterschieden interagieren, um die zwischensprachlichen Kontraste zu ergeben. (26) kann daher durch eine nicht-parametrisierte Ellipseregel ersetzt werden, die sich auf Verbpositionen bezieht:

Ein Satzglied darf nicht getilgt werden, wenn es hinter einem (nicht-getilgten) Verb steht.

Dieser Alternative birgt noch weitere Vorteile in sich. Die Bedingung (18), die sich allein auf finite Verben bezieht, wird von (27), die sich auch auf nicht-finite Verben bezieht, mit erfaBt. Mit der Annahme von (27) kann also auf (18) verzichtet werden: die Effekte von (18) ergeben sich als Sonderfall der allgemeineren Formulierung.

Der Ansatz wird weiter durch die Tatsache unterstützt, daß Variationen in der Konstituentenabfolge innerhalb einer Sprache zu veränderten Ellipsemöglichkeiten führen. Im Englischen führt die Voranstellung des Objekts in eine prä-verbale Position dazu, daB das Objekt dann doch ausgelassen werden kann, ohne da $B$ das regierende Verb mitgetilgt werden muß. Genau dies ist im zweiten Konjunkt des englischen Beispiels (23a) der Fall: ${ }^{5}$

$$
\text { [the hare, he sought] and [tought] }
$$

Eine Erklärung für die Ungrammatikalität des deutschen Beispiels (23b) liegt jetzt auf der Hand: Gleichzeitig wird der Kontrast zwischen (23b) und dem entsprechenden englischen Beispiel (23a) einerseits und dem deutschen Nebensatz (24a) andererseits verständlich. Wie in (28) gezeigt, sind hier zwei Konstituenten - Objekt und Subjekt - getilgt worden. Das gleiche gilt für (23b) und (24a):

(29) * [den Hasen suchte er] und [ fing ] $(=23 \mathrm{~b})$

[wenn er den Hasen sucht] und [ fägt] $(=24 a)$

5 Diese Art der Auslassung ist im Englischen in alleinstehenden Sätzen nicht möglich. Es kann kein vorangestelltes ("topikalisiertes”) Objekt unter Bezug auf einen nicht explizit vorhandenen „Diskurs-Referenten” ausgelassen werden - m.a.W., Topic Drop ist im Englischen - im Gegensatz zum Deutschen - nicht möglich. Der Grund für diese Beschränkung ist nicht bekannt - vgl. Haegeman (1990), Wilder (1995). 
Der Unterschied ergibt sich aus der Position des finiten Verbs: das zweite Konjunkt von (23b/29) ist ein V2-Satz, dessen Verb nicht getilgt worden ist. Es kann also höchstens eine phrasale Konstituente getilgt werden, nämlich die, die vor dem Finitum steht - vgl. (9c) oben. Unter der Annahme, dab das getilgte Objekt in der prä-verbalen Position steht, steht das getilgte Subjekt hinter dem Verb: das Beispiel scheitert somit an der unzulässigen Tilgung des Subjekts. Der Kontrast von (29) mit (28) und (30) folgt also direkt aus unabhängigen Verbstellungsfaktoren. (28) ist möglich, weil im Englischen bei Topikalisierung des Objekts kein V2Effekt (d.h. keine Subjekt-Auxiliar-Inversion) auftritt - das finite Verb wird nicht dem Subjekt vorangestellt. (30) ist möglich, weil das finite Verb in deutschen Nebensätzen an satzfinaler Stelle - also nicht vor dem getilgten Subjekt - steht.

Im nächsten Abschnitt wird die syntaktische Beschreibung dieser Wortstellungsunterschiede präzisiert bei Hervorhebung der Annahmen, von denen in der anschlieBenden Diskussion Gebrauch gemacht wird. In Abschnitt 3. werden dann mehrere Ellipsetypen vorgestellt und ihre Hauptmerkmale notiert. Es ist wichtig, daB die hier relevante Regel „Vorwärtstilgung” - von anderen Typen klar abgegrenzt werden kann, damit die einschlägigen Generalisierungen aus den Daten ersichtlich werden. Anschließend wird ein Vorschlag zur Präzisierung der Generalisierung in (27) gemacht.

\section{Wortstellungsparameter}

Der erste hier wichtige Parameter ist der OV/VO Parameter. Er bestimmt, daß im Deutschen das Objekt vor den Verben steht (abgesehen vom Finitum in V2-Sätzen), während im Englischen das Objekt hinter dem Verb steht, außer wenn das Objekt z.B. als Topikphrase oder Fragewort an die Satzspitze gestellt wird. Der zweite - der V2Parameter - unterscheidet zwischen Sprachen, die in Hauptsätzen eine generalisierte Zweit-Stellung für finite Verben aufweisen (V2-Sprachen wie dem Deutschen), und Nicht-V2-Sprachen wie dem Englischen. Der Unterschied zwischen Englisch und Deutsch zeigt sich vor allem in deklarativen Hauptsätzen, wo im Deutschen finite Verben nur an zweiter Stelle stehen, im Englischen aber auch an dritter (vierter usw.) Stelle.

Wortfolgeunterschiede zeigen sich in den phonologischen Ketten. Bestimmt werden sie jedoch durch Unterschiede in den hierarchischen/ linearen Beziehungen unter Konstituenten in den syntaktischen Repräsentationen. "Wortfolgeparameter" sind also mithilfe von Relationen zwischen Konstituenten in Baumstrukturen zu beschreiben. Vorausgesetzt wird hier eine Beschreibung der Satzstruktur finiter Sätze wie in (31). 
(31) a. Deutsch (V2/Obj-V):

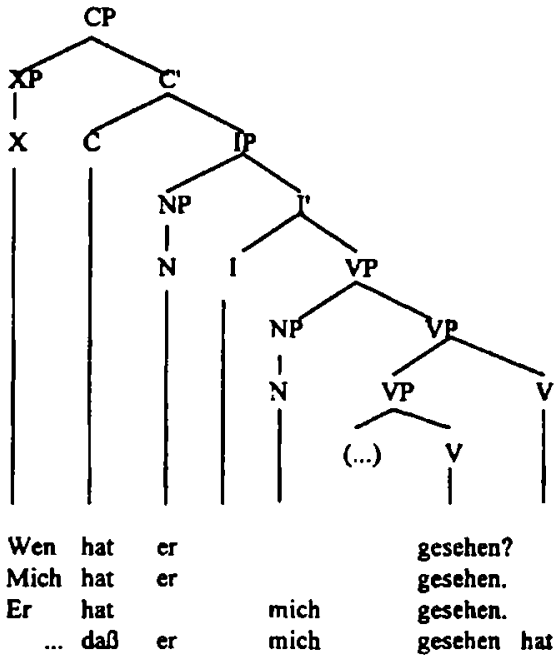

b. Englisch (V2 / V-Obj):

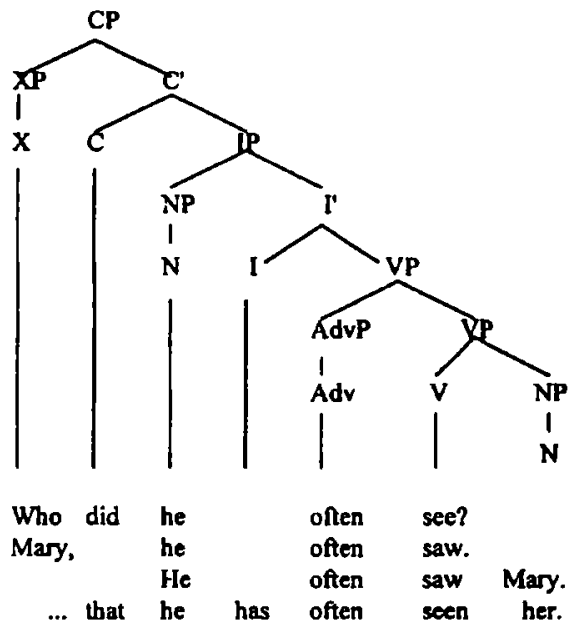


Die Position $C$, die in deutschen Nebensätzen die satzeinleitenden Konjunktionen $d a \beta, a b$ usw. enthält, wird in Hauptsätzen durch das finite Verb besetzt (31a). In englischen Nebensätzen (31b) wird C durch that, if usw. besetzt. Englisch weist eine „beschränkte" V2-Eigenschaft auf, da in direkten Fragesätzen das finite Hilfsverb in C steht. Der Unterschied zum Deutschen zeigt sich in deklarativen Hauptsätzen: C bleibt „leer”, das finite Verb steht in V (Hauptverben) bzw. I (Hilfsverben).

Der OV/VO-Parameter kommt durch die Anordnung der VP-internen Konstituenten zum Ausdruck. Im Deutschen folgt der Kopf „V" anderen VP-Konstituenten: das Hauptverb steht rechts von seinem Komplement (2.B. direkten Objekt); das Hilfsverb steht rechts von seinem Komplement (VP des Hauptverbs). Im Englischen hingegen steht jedes verbale Element vor seinen Komplementen.

Für Deutsch wird eine IP (INFL-Phrase) angesetzt, wobei der Kopf dem Komplement (oberste VP) vorangeht (siehe hierzu u.a. Zwart (1993)). An sich spielt diese Annahme hier keine besondere Rolle: wichtig ist nur, daß das finite Hauptverb bzw. Hilfsverb in Nebensätzen - im Unterschied zum finiten Hilfsverb des Englischen - nicht die I-Position, sondern eine Position in VP innehat.

Eine zusätzliche Annahme, die im folgenden eine wichtige Rolle spielt, betrifft die hierarchische Position des direkten Objekts. Im Einklang mit vielen anderen Autoren gehe ich davon aus, daB prä-verbale Objekte im Deutschen Positionen auBerhalb der VP besetzen können. Dafür spricht u.a., daB ein nicht-finites Verb alleine die satzinitiale Position vor dem Finitum besetzen kann, wobei das Objekt im Mittelfeld bleibt. In dieser Position darf nur eine phrasale Konstituente stehen - das Objekt mub daher außerhalb der minimalen das Verb enthaltenden Phrase (=VP) stehen:
a. Gesehen habe ich den Film nicht
b. [CP[VP $t_{\mathrm{NP}}$ gesehen] habe [IP ich den Film nicht $t_{\mathrm{VP}}$ ]]

Eine entsprechende Konstruktion ist im Englischen nicht möglich: das Verb kann nicht vorangestellt werden, ohne daB sein Objekt mit vorangestellt wird. Die minimale phrasale Konstituente, die das Verb enthält (VP), enthält auch das Objekt:
a. * Seen, I haven't the film
b. Seen the film, I haven't
c. [CP[VP seen the film] C [IP I haven't t]] 
Die vom deutschen direkten Objekt eingenommene Position könnte eine "Spec-Position" oder die Position einer "Adjunktion" an eine "INFL"Projektion sein (vgl. u.a. Müller/Sternefeld (1993), Zwart (1993)).

Diese Annahme hat zur Folge, daB die Asymmetrie zwischen Deutsch und Englisch bzgl. der linearen Anordnung des Verbs und seines $\mathrm{Ob}$ jekts mit einer hierarchischen Asymmetrie einhergeht. In deutschen OVSätzen steht das prä-verbale Objekt "höher” in der Struktur als V d.h. das Objekt ist nicht Schwester von V, sondern von einer höheren Konstituente, die V enthält. Das englische postverbale Objekt ist nicht "höher" als V, da die beiden Schwesterkonstituenten sind. In deutschen V2-Sätzen steht das Objekt im Mittelfeld auch "niedriger” als das finite Verb, jedoch höher als alle nicht-finiten Verben. Diese hierarchische Relation "höher/niedriger als" kommt durch den Begriff "c-Kommando" zum Ausdruck - mehr dazu in Abschnitt 4. unten.

\section{Ellipse}

Fehlendes phonologisches Material in einer Ellipsestelle $\mathrm{E}$ wird durch ein Antezedens A mit identischem Inhalt, das in einer bestimmten lokalen Beziehung zu $E$ steht, lizensiert. In Koordinationen, wo $E$ in einem Konjunkt $\mathrm{K}$ enthalten ist, steht $A$ in einem benachbarten Konjunkt $\mathrm{K}$ '. Nach der Richtung der Beziehung lassen sich zwei Haupttypen feststellen:

$$
\begin{aligned}
& \text { a. Vorwärtstilgung: } \quad\left[\begin{array}{llllllll}
\mathbf{K}^{\prime} & \ldots & \mathbf{A} & \ldots & \mathbf{K}^{\prime}
\end{array}\right] \&\left[\begin{array}{lllll}
\mathbf{K} & \ldots & \mathbf{E} & \ldots & \mathbf{K}
\end{array}\right] \\
& \text { b. Rückwärtstilgung: }\left[\begin{array}{lllll}
K & \ldots & E & \ldots & K
\end{array}\right] \quad \&\left[\begin{array}{llllll}
K^{\prime} & \ldots & A & \ldots & K^{\prime}
\end{array}\right]
\end{aligned}
$$

Hinsichtlich der Stellung von $A$ und $E$ in $\mathrm{K}$ bzw. $K$ ' scheinen dies spiegelbildliche Operationen zu sein: bei Vorwärtstilgung wird an der „linken Peripherie” getilgt, bei Rückwärtstilgung an der „rechten Peripherie”:

(35) a. Vorwärts: A und E sind linksperiphere Wortketten in K' bzw. K

b. [Hans hat Maria gestern angerufen] und [Hans-hat Maria heute besucht]

(36) a. Rückwärts: $E$ und $A$ sind rechtsperiphere Wortketten in K bzw. K'

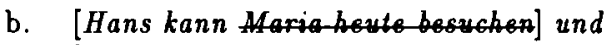
[Fritz muß Maria heute besuchen] 
Der Eindruck von Symmetrie ist jedoch nicht richtig. In Vorwärtsabhängigkeiten müssen $\mathrm{E}$ und $\mathrm{A}$ nicht strikt (im linearen Sinne) peripher sein - in der sog. Gapping-Konstruktion (37) entstehen Lücken in medialer Stellung in nicht-initialen Konjunkten:

$$
\begin{aligned}
& \text { [Hans hat das Buch ausgeliehen] und [Fritz _- zurückgebracht] } \\
& \text { Vorwärts }
\end{aligned}
$$

\section{* [Hans _- ausgeliehen] und [Fritz hat das Buch zurückgebracht] Rückwarts}

Bei näherem Hinschauen bestätigt sich, daß mit der Richtung der Ellipse eine Reihe weiterer Asymmetrien verknüpft sind (siehe z.B. Wesche 1995, Wilder 1994, 1995).

Im folgenden geht es primär um die Vorwärtstilgung. Die im Abschnitt 2 besprochenen Ellipsetypen, die Koordinationsellipsen wie auch die unabhängigen Ellipsetypen (elliptische Antworten usw.), haben wesentliche Eigenschaften gemeinsam. Dieser Sachverhalt läBt sich dadurch erklären, $\mathrm{da} B$ sie durch den gleichen ProzeB - hier Vorwärtstilgung genannt - zustandekommen. Um Vorwärtstilgungen von den anderen Typen abgrenzen zu können, werden jetzt Rückwärts-, Vorwärts- und weitere Ellipsetypen in einigen wesentlichen Eigenschaften verglichen. Die wichtigsten Kontraste 2 wischen Vorwärts- und Rückwärtstilgungen betreffen (i) die Stellung der Ellipse $\mathrm{E}$ im Konjunkt $\mathrm{K}$ (bzw. im unabhängigen Satz): ob eine Ellipse in "medialer" Stellung auftreten kann oder nicht (vgl. (37), (38)); (ii) den syntaktischen Status der elidierten Wortketten: während „Vorwärts-Lücken" nur syntaktischen Konstituenten bestimmter Art entsprechen dürfen, kommen „Rückwärts-Lücken” durch aus syntaktischer Sicht beliebig zusammengesetzte Wortketten zustande.

\subsection{Rückwärtstilgung}

Für Rückwärtstilgung ist (36) ungefähr richtig - es gibt keine nichtperiphere Rückwärtstilgungen. Die Tatsache, daß das "Antezedens" an der rechten Peripherie von $K^{\prime}$ stehen muB, kann als eine Art „Parallelismusbedingung” für die Wiederauffindung des Inhalts der Ellipse verstanden werden: $A$ muB genau dort in $K^{\prime}$ stehen, wo $E$ in $A$ steht. Wo $E$ in $K$ überhaupt stehen darf, ist dann Sache unabhängiger Bedingungen.

Die Tilgungsregel kann nur unter Bezug auf wohlgeformte Wortfolgen in entsprechenden nicht-elliptischen Ausdrücken formuliert werden. Was „peripher” besagt, läßt sich als Abhängigkeit zwischen Tilgungsstellen formulieren: ob ein Wort $\mathrm{X}$ getilgt werden kann, hängt davon ab, ob alle 
Wörter $Y$, die in der normalen Wortfolge rechts von X (in $\mathrm{K}$ ) stehen, auch getilgt werden. Die Tatsache, daf nur am rechten $R$ and von $K$ getilgt werden darf, ergibt sich dann von selbst.

Peripheriebedingung (Rückwärtstilgung):

Ein Wort $X$ in $K$ kann nur dann getilgt werden, wenn jedes

Wort $Y$, das rechts von $X$ in $K$ steht, auch getilgt wird

In deutschen Nebensätzen beispielsweise hängt die Tilgung des Partizips $(=X)$ von der Tilgung des Finitums $(=Y)$ ab. Beispiele wie (40c), in denen das Hauptverb allein getilgt wird, sind nicht möglich. In der Hauptsatzwortfolge (40d) beobachten wir eine solche Abhängigkeit nicht: bei vorhandenem Finitum kann das nicht-finite Verb getilgt werden.

(40) a. ... daß er mich angerufen, und daß sie dich besucht hat.

[daß er mich angerufen und [daß sie dich besucht hat]

b. $\quad . . d a \beta$ er mich, und daß sie dich besucht hat.

[daß er mich und [daß sie dich besucht hat]

c. * ... daß er mich hat, und daß sie dich besucht haben.

* [daß er mich besuch hat und [daß sie dich besucht haben]

d. Er hat mich und sie hat dich besucht.

[er hat mich und

[sie haben dich besucht]

Der Grund für die Asymmetrie ist leicht zu sehen: aufgrund der V2-Regel nimmt das Finitum in Hauptsätzen eine Position ein, in der es für die Tilgung des Partizips nicht mehr relevant ist. Das Beispiel illustriert den allgemeineren Punkt, daß die Peripheriebedingung für Rückwärtstilgung lediglich unter Bezug auf die unabhängig gegebenen Anordnungen von Worteinheiten $\mathrm{X}$ und $\mathrm{Y}$ definierbar ist, ganz ohne Bezug auf den syntak- 
tischen Status von $\mathrm{X}$ und $\mathrm{Y}^{6}{ }^{6}$ Anders sieht es bei den Vorwärtstilgungen aus.

Ein weiterer Unterschied zwischen Rückwärts- und Vorwärtstilgungen betrifft die Tatsache, daB bei Rückwärtsellipsen $\mathbf{E}$ und $\mathbf{A}$ syntaktisch nicht unbedingt kompletten Hauptkonstituenten (Satzgliedern) entsprechen müssen. In (41a) wird beispielsweise neben dem Hauptverb auch der Verbkomplex des Relativsatzes zum Objekt ausgelassen; das Umgekehrte kommt bei Vorwärtsellipse überhaupt nicht in Frage:

(41) a. [ich hatte den Brief, den Maria und [du hattest den Brief, den Josef gelesen hat, geschrieben] b. * $\frac{[\text { der Brief, den Maria gelesen hat, wurde vernichtet }] \text { und }}{\text { [deschickt hat, ging verloren }]}$

Ellipsen nach diesem Muster kommen auch in nicht-koordinierten Strukturen vor:

(42) a. Es scheint so, als ob jeder, der die rote _ auch die grüne Scheibe qetroffen hat

b. Dem Sohn ein Fahrrad - heißt auch der Tochter ein Dreirad kaufen zu müssen

Solche Beispiele weisen auf ein Problem bei der Bestimmung der Domänen K, K' für Ellipsen hin, auf das hier nicht weiter eingegangen wird (für weitere Diskussion, siehe Williams (1990), Wilder (1995)). Beispiele dieser Art unterstreichen die rein auf Wortketten bezogene Natur der Rückwärtsellipse: Man braucht anscheinend bloß zwei benachbarte phonologische Ketten miteinander zu vergleichen - sind sie am rechten Rand identisch, dann darf der identische Teil der ersten Kette wegfallen.

\subsection{Nicht-gerichtete Ellipsetypen}

Bevor ich auf Vorwärtstilgung zu sprechen komme, eine Zwischenbemerkung zu einigen weiteren Ellipsetypen, die in Koordinationen auftreten, und die von den Rückwärts- und von den Vorwärtstilgungen zu unterscheiden sind. Im Englischen kann unter gewissen Bedingungen ein Hauptverb zusammen mit seinen Komplementen ausfallen, z.B. bei der sog. VP-Ellipsekonstruktion (43). $\mathrm{Zu}$ den Bedingungen gehört, daB ein (meist finites) Hilfsverb zurückbleibt, das gewissermaßen die Stelle der Ellipse markiert.

6 Angesichts der Möglichkeit zur Tilgung von Teilen von Wörtern - vgl. Sie sucht den Ein- und er sucht den Ausgang - müfte diese Formulierung entsprechend modifiziert werden. 
(43) a. John might have [seen someone], but Mary hasn't [ - ].

b. Mary hasn't [ - ], but John might have [seen someone].

In etwa analog zur englischen VP-Ellipse ist die „NP-Ellipsekonstruktion” des Deutschen (44). Hier handelt es sich um den Wegfall eines Substantivs mit seinen Ergänzungen, wobei ein Determinierer, Quantor oder dergl. zurückbleibt. ${ }^{\text {? }}$

(44) a. Hans hat [zwei Bilder von mir] gemacht, aber Maria wollte nur [eins _] haben.

b. Mary hat nur [eins _] gemacht, aber Hans will [zwei Bilder von mir] haben.

Diese Konstruktionen stellen ebenso wie die bislang besprochenen Ellipsearten eine Herausforderung für die Thesen in (7) dar, zumal das Deutsche (wie viele andere Sprachen) die VP-Ellipse nicht kennt (zumindest nicht in dem AusmaB wie das Englische), die NP-Ellipse andererseits im Englischen viel beschränkter ist als im Deutschen: ${ }^{8}$

(45) a. *Hans mag jemanden gesehen haben, Maria hat aber nicht (vgl. (43a))

b. Peter bought a red car and Paul a blue *(one) (vgl. (45c))

c. Peter hat ein rotes Auto gekauft und Paul ein blaues -

Eine erfolgreiche Reduktion dieser Erscheinungen auf das Zusammenspiel von universellen Ellipseprozessen mit einzelsprachlichen Spezifika im Sinne von (7) steht bislang aus.

7 Von der DP-Hypothese (vgl. Haider (1988) u.a.) ausgehend kann man in diesem Fall von Auslassung des NP-Komplements von D sprechen, in Analogie zur Tilgung des VP-Komplements von INFL.

8 Es treten gelegentlich auch im Deutschen - unter noch ungeklärten Bedingungen - VP-Ellipsen auf, meist in umgangssprachlichen Registern und eher bei Modalverb- als bei periphrastischen Tempuskonstruktionen:

(i) Wir müssen nicht da hinfahren, und ich glaube nicht, daß ich _- will.

(ii) Obwohl wir nicht _- müssen, hören wir uns doch lieber die Vorlesung an.

Häufig wird jedoch eine Konstruktion mit pro-prädikativem es unausweichlich:

(iii) Maria wird sich in dich verknallen, aber ich werde *(es) nicht.

(iv) Wir sind in unseren Bemühungen gescheitert, und die anderen sind *(es) auch. 
Die Konstruktionen (43)-(45) sind in einer anderen Hinsicht relevant. $\mathrm{DaB}$ sie in initialen wie auch in finalen Konjunkten auftreten können, zeigt, daß sie analytisch von Rückwärts- und Vorwärtstilgungen zu trennen sind. Des weiteren ist es erforderlich, bei der Betrachtung von Vorwärts- und Rückwärtstilgungen auf die Möglichkeit von VP- und NP-Ellipse zu achten, denn beide können Lücken erzeugen, die aufgrund ihrer Stellung im Konjunkt mit echten Vorwärts- bzw. Rückwärtslücken verwechselt werden können.

So können wir z.B. NP-Ellipse dadurch von Rückwärtstilgung von N unterscheiden, daB bei ersterer ein übriggebliebener unbestimmter Artikel im Neutrum die starke Flexion aufweisen muB (vgl. (46c)).

(46) a. Hans hat ein -- und

Maria hat kein Bild von mir qesehen

Rückwärtstilgung/*NP-Ellipse

b. * Hans hat nur ein _- gesehen, aber

Maria hat mehr als ein Bild von mir gemacht

* NP-Ellipse/*Rückwärtstilgung

c. Hans hat nur eins _- gesehen, aber

Maria hat mehr als ein Bild von mir gemacht.

NP-Ellipse/*Rückwärtstilgung

Eine Ellipse in nicht-satzfinaler Stellung macht die für NP-Ellipsen charakteristische starke Flexion erforderlich. Falls die starke Flexion nicht vorhanden ist (46a), kann es sich nur um eine Rückwärtstilgung handeln. (46b) kann nicht durch Rückwärtstilgung entstanden sein, da die Ellipse nicht am rechten Rande des Konjunktes steht. Setzt man aber, wie in (46c), die starke Flexion ein, wird das Beispiel grammatisch - also handelt es sich um eine NP-Ellipse.

\subsection{Vorwärtstilgung}

Bei den Vorwärtstilgungen werden in der Regel drei Haupttypen unterschieden: linksperiphere Auslassungen (35b), mediale Auslassungen (Gapping - (37)) sowie Fälle, bei denen nur ein Satzglied übrigbleibt (sog. Bare Argument Ellipsis - (47)):

(47) a. Josef trinkt Wein zum Mittag, und [Maria (auch)]

b. Josef trinkt Wein zum Mittag, aber [kein Bier]

Letztere lassen sich als Extremfäle von Vorwärtstilgung in einem sententialen Konjunkt analysieren: 
(48) a. Josef trinkt Wein zum Mittag, und [[Maria] (auch)]

b. Josef trinkt Wein zum Mittag, aber [Lef [kein Bier] Tum [tittog]

\subsubsection{Die „Hauptkonstituentenbedingung”}

Alle drei Typen von Vorwärtstilgung reagieren in einer Weise auf syntaktische Konstituenz, wie sie bei Rückwärtstilgung nicht gegeben ist - es könnnen nur komplette Hauptkonstituenten von Vorwärtstilgung betroffen werden: ${ }^{9}$

(49) Hauptkonstituentenbedingung (Vorwärtsellipse):

E entspricht nur kompletten syntaktischen Hauptkonstituenten in $\mathrm{K}$

Ich sehe hier vom Versuch einer formalen Definition des Begriffs "Hauptkonstituente" ("Satzglied”, engl. major constituent) ab - vgl. aber Chao (1988, Kap 2); informell läßt er sich wie folgt charakterisieren: Die phonologische Kette eines Satzes ist zerlegbar in eine Sequenz von Hauptkonstituenten bestehend aus (i) dem Hauptprädikat (meistens ein Vollverb), (ii) seinen Argumenten (Subjekt, Objekt(e), präpositionalen und satzartigen Ergänzungen, usw.), (iii) Modifikatoren des Satzes bzw. des Prädikates (adverbiale Ergänzungen), und (iv) funktionalen Elementen (Kopula- sowie Hilfsverben, Komplementierer, usw.), soweit diese in (ii) und (iii) nicht enthalten sind.

Die Hauptglieder eines Satzes teilen sich im Hinblick auf ihren X'theoretischen Projektionsstatus in zwei Gruppen auf: Konstituenten mit dem Status von Köpfen („minimale Projektionen” i.S. der X'-Projektion) - V, I, und C, d.h. (i) und (iv); und phrasale Konstituenten („maximale Projektionen"): Subjekt, Komplemente von V und adverbiale Ergänzungen, d.h. (ii) und (iii). „Zwischenprojektionen” (Gruppierungen, die zwar Konstituentenstatus haben, die jedoch weder "maximale” noch "minimale" Projektionen sind) zählen nicht zur Klasse der Hauptkonstituenten. Beispiele wie (50) ließen sich zwar als Ergebnis der Tilgung einer einzelnen elidierten C'-Konstituente analysieren:

(50) a. Zum Mittag trinkt er Wein und

... und [K [zum Abend] [C' [rinkd] [ef] [Woin]]]

9 Die Hauptkonstituentenbedingung ist bisher als Bedingung für die nichtgetilgten Reste in elliptischen Konstruktionen formuliert worden: „Reste haben major constituents zu sein" (vgl. Hankamer (1979), Neijt (1979), Chao (1988)). 
b. Wann hat er es gemacht und wie?

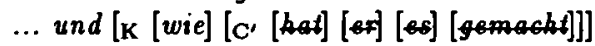

Sie könnten aber auch eine Sequenz aus adjazenten Tilgungstellen darstellen: z.B. ein Kopf $\mathrm{C}^{\circ}$ (trinkt) neben zwei Phrasen (Subjekt und Objekt) in (50a). Das simultane Auftreten von mehreren Vorwärtsellipsen in einem Konjunkt muß ohnehin berücksichtigt werden, um diskontinuierliche Ellipsen zu erfassen, die sich aus mehreren Konstituenten zusammensetzen (Kopf und Phrase in (51a)), wie auch, um einzelne Lücken erfassen zu können, denen keine einzelne syntaktische Konstituente entspricht (51b):

(51) a. Josef trank Bier gestern und Maria, Wein. ... und [K [Maria] [

b. Josef trinkt Bier zum Mittag, und Wein zum Abend.

… und [K [W [ Wein zum Abend] $\mathrm{K}$ ]

Damit wird das aus (50) entstehende Motiv, die Klasse der möglichen Tilgungsziele auf $\mathrm{Zwischenprojektionen} \mathrm{zu} \mathrm{erweitern,} \mathrm{hinfällig.}$

Verwandte Überlegungen betreffen die Frage, ob die phrasalen Projektionen der Hauptkonstituenten mit Kopfstatus (C, I, V) selbst auch als Hauptkonstituenten gelten sollen. Immer wo eine solche Konstituente (z.B. IP) in einer Ellipse enthalten ist, läBt sie sich auch als Sequenz von einzelnen Tilgungen ( $\mathrm{I}^{\circ}+\mathrm{V}^{\circ}+$ dazugehörigen phrasalen Satelliten) analysieren. Ich ziehe die "konservativere" Theorie vor, in der die maximalen Projektionen von I und V, und Zwischenprojektionen generell, nicht zur Klasse der Hauptkonstituenten eines Satzes zählen.

Wenn nur ganze Hauptkonstituenten von Vorwärtstilgung betroffen werden können, dann können auch nur ganze Hauptkonstituenten von der Tilgung "hinterlassen" werden. Oft bleibt eine einzelne Konstituente übrig (Bare Argument Ellipsis), es kann aber auch eine Reihe von mehreren Hauptkonstituenten zurückbleiben (Gapping). Die Wirkung von (49) zeigt sich z.B. in (52). Weder bei Gapping noch bei Bare Argument Ellipsis ist die Tilgung eines Teils eines nominalen Satzglieds möglich $(52 a, b)$. Die Auslassung eines Objektnomens zusammen mit einem Teil seines Relativsatzes (52c) - vgl. (41) oben - führt ebenfalls zu starker Ungrammatikalität:

(52) a. * Josef hat drei Männer gesehen, und [[Maria] tat [ Frauen] ] 


\section{b. * Drei Männer sind gekommen, und [[ Frauen] (auch) ] \\ c. * [der Brief, den Maria gelesen hat, wurde vernichtet] und [ geschickt hat, ging verloren]}

Derselbe Effekt läBt sich bei unabhängigen Ellipsen nachweisen. Auf die Frage (53a) kann (53b) als elliptische Antwort dienen, nicht aber (53c): ${ }^{10}$

(53) a. Was fährt er für einen Wagen?

b. [einen schnellen Wagen]]

c. * [or [ [ [ schnellen Wagen]]

(54) a. Mit wem gehst du dorthin?

b. [mit dir]

c. * [ gohe [mit dir]

Diese Überlegungen genügen, um erstens festzustellen, daß sich Vorwärtsvon Rückwärtsellipse bzgl. (49) unterscheidet, und zweitens, daß diese Bedingung nicht nur für Vorwärtsellipse in Koordinationen gilt, sondern auch für die im Abschnitt 2. besprochenen nichtkoordinativen Ellipsetypen (z.B. elliptische Antworten).

\subsubsection{Peripherie, Mediale Ellipsen und „Kopfbedingung”}

Der Konstrast in (41) (vgl. auch (52c)) zeigt schon, daB die Einhaltung der Peripheriebedingung (35a) allein nicht ausreicht, um eine Vorwärtsellipse zu ermöglichen. Auch das Vorkommen von medialen Ellipsen bei Vorwärtsabhängigkeiten zeigt, daB die Peripheriebedingung für $\mathrm{E}$ nicht rein linear bestimmt werden kann. Es ist aber auch nicht so, da $B$ beliebige Ellipsen, sofern sie die Hauptkonstituentenbedingung (49) erfüllen, möglich sind. Ein repräsentatives Minimalpaar bilden die Beispiele in (55):

(55) a. [Josef trinkt Wein zum Mittag] und [Maria zum Abendbrot]

b. * [Josef liebt Rotwein] und [Maria verabscheut

Nicht-initiale (mediale usw.) Tilgungen in Vorwärts-Richtung dürfen nur hinter gewissen Wörtern vorkommen. Das finite Verb verabscheut in (55b) blockiert mediale Ellipse, das Subjektnomen Maria in (55a) nicht.

10 Die Tilgung von "Wagen" in (i) ist als ein Fall von NP-Ellipse (und nicht von Vorwärtstilgung) hier nicht relevant:

(i) [ feinen schnellen 
An diesem Punkt kehren wir zur Bedingung (27) (Abschnitt 2. oben) zurück. Dort hieß es, daB ein Satzglied nicht getilgt werden kann, wenn es hinter einem Verb steht:

$$
\text { E darf nicht hinter nicht-getilgtem } X \text { stehen, wobei } X=V
$$

Nun ist (56) in zweierlei Hinsicht nicht ganz richtig. Zum einen ist die Beziehung zwischen E und X nicht als lineare Präzedenz ("hinter ... X") zu formulieren, vielmehr muß sie ausschließlich unter Bezug auf hierarchische Strukturbegriffe ausbuchstabiert werden. Dies zeigt sich sofort daran, daB (56) nur dann zur Geltung kommen darf, wenn X (das nichtgetilgte Verb) zum selben Satz wie $E$ gehört, d.h. nicht in einer phrasalen Konstituente enthalten ist. Das Verb verabscheut im Relativsatz zu die Frau in (57) blockiert z.B. nicht die Tilgung der hinter ihm stehenden Wörter trinkt Wein:

$$
\begin{aligned}
& \text { [Josef trinkt Wein zum Mittag] und } \\
& \text { [[die Frau, die er verabscheut,] }
\end{aligned}
$$

Es gibt auch Fälle, in denen eine Vorwärtsellipse durch ein nicht getilgtes Element X, das hinter der Ellipsestelle steht, blockiert wird: d.h. Fälle, wo $\mathrm{E}$,nicht vor $\mathrm{X}$ stehen darf”. So ist z.B. in deutschen Nebensätzen die Tilgung eines nicht-finiten Verbs nur dann möglich, wenn das ihm folgende finite Verb ebenfalls getilgt wird:

(58) a. * ... daß Hans mich besuchen möchte und dich wird ... und [af dich wird]

b. ... daß Hans mich besuchen möchte und dich nicht ... und [ dich nicht ]

Die hierarchische Beziehung $z$ wischen Ellipsestelle $\mathrm{E}$ und „blockierendem Element" $X$, die diese Unterschiede korrekt erfaBt, ist c-Kommando.

Zum anderen ist $\mathrm{X}$ in (56) nicht ausschlieblich mit $\mathrm{V}$ zu identifizieren. Auch Wörter anderer Kategorien blockieren Vorwärtsellipsen, z.B. satzeinleitende Konjunktionen (=C):

(59) a. [daß Josef Wein trinkt] und [daf Maria Bier trinkt] b. * [daß Josef Wein trinkt] und [daß Maria Bier

Die Klasse der Elemente, die Vorwärtsellipsen blockieren, läßt sich rein hierarchisch erfassen: Kopf-Konstituenten (V, C usw.) blockieren, phrasale Konstituenten (NP, PP usw.) nicht. Der Unterschied zwischen Maria und verabscheut in (55) korreliert mit deren jeweiligem phrasenstrukturellen Status. 
Wir ersetzen daher (56) durch die "Kopf-Bedingung” (60):

(60) Kopf-Bedingung (Vorwärtsellipse):

$E$ wird von keiner nicht-getilgten Kopf-Konstituente in $\mathrm{K}$ ckommandiert

(60) macht die Tilgung einer Konstituente $Y$ von der Tilgung von anderen Konstituenten $\mathrm{X}$ abhängig. Nur „Y c-kommandierenden” KopfKnoten $\left(\mathrm{N}^{*}, \mathrm{C}{ }^{*}\right.$, usw) sind relevante Kandidaten für ${ }_{n} \mathrm{X}^{n}$. $\mathrm{c}$-Kommando ist eine strukturelle Beziehung, definiert zwischen Konstituenten (=Knoten in einem Baum): Ein Knoten c-kommandiert alle seine Schwesterknoten sowie alle Knoten, die in diesen enthalten sind (alle Töchter der Schwester):

(61) $\mathrm{X}$ c-kommandiert $\mathrm{Y}$ gdw. (i) $\mathrm{Y}$ ist eine Schwester von $\mathrm{X}$

(ii) $Y$ ist eine Tochter einer Schwester von $\mathrm{X}$

Um die c-Kommando-Beziehung zu bestimmen, muß man die hierarchischen Beziehungen im Baum untersuchen. In (62), das das 2. Konjunkt von $(55 a, b)$ darstellt, hat der N-Knoten (Maria) keine Schwester. Es gibt also keine weiteren Knoten, die von diesem $\mathrm{N}$ c-kommandiert sind; insbesondere ist $\mathrm{N}$ (Wein) nicht von $\mathrm{N}$ (Maria) c-kommandiert. Dieses Wort ist - wie alle anderen Wörter, die zu phrasalen Hauptkonstituenten gehören - gemäß (60) für die Tilgbarkeit von weiteren „untergeordneten" Hauptkonstituenten irrelevant. 
(62)

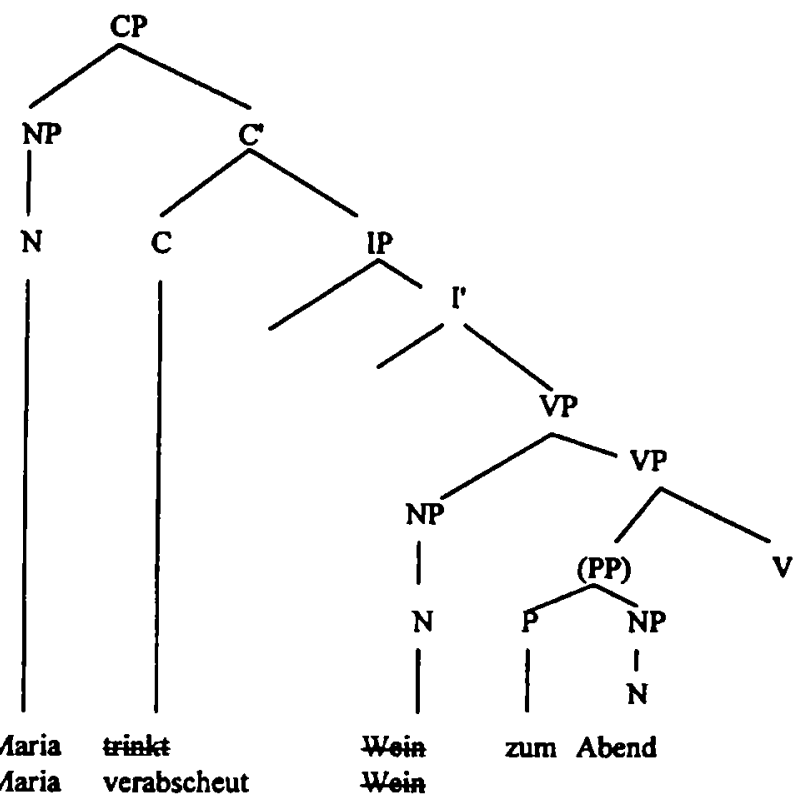

In (62a) befindet sich das finite Verb (trinkt) in C. Das C-Element hat eine Schwesterkonstituente - nämlich IP, und c-kommandiert somit alles, was in IP enthalten ist (alle Töchter von IP), inklusive $\mathbf{N}=$ Wein. Der Inhalt von C (das Verb) gilt jedoch als "getilgt". Da keine weitere (nichtgetilgte) Kopfkonstituente das Objektnomen (Wein) c-kommandiert, ist die Tilgung von Wein gemäß (60) zulässig. In (62b) hingegen ist der Inhalt von C - das finite Verb verabscheut - nicht getilgt. Da das Nomen (Wein) sich in diesem Fall im c-Kommandobereich eines nicht-getilgten Kopfes befindet, läßt (60) die Tilgung von Wein nicht zu.

Die Kopf-Bedingung faßt mediale Ellipsen (Gapping) mit linksperipheren Ellipsen zusammen. In V2-Sätzen sind Konstituenten rechts von $V$ von $V$ c-kommandiert und können nur dann ausgelassen werden, wenn das Verb mitgetilgt wird. Dies ist die grundsätzliche Generalisierung, was Gapping betrifft. Konstituenten links vom Verb sind nicht von diesem c-kommandiert und können auch unabhängig vom Verb getilgt werden (linksperiphere Ellipse).

Gapping wird oft als ein selbständiges Phänomen betrachtet, das direkt von der Tilgung finiter Verben abhängt - eine Sichtweise, die z.T. da- 
durch entsteht, daB nur V2-Sätze in Betracht gezogen werden. Daß dies nicht richtig ist, zeigt die Tatsache, daB in Nebensätzen mediale Ellipsen auch dann vorkommen, wenn das Finitum nicht getilgt ist:

(63) a. ... daß Hans ein Buch gekauft hat und ihr schenken will.

b. ... und [af ihr schenken will]

Bei Nebensatzwortfolge stehen phrasale Konstituenten im Mittelfeld (Subjekt, Objekte) auBerhalb des c-Kommando-Bereiches des finiten Verbs, können also auch dann getilgt werden, wenn das finite Verb selbst nicht getilgt wird, ohne daB dabei ein VerstoB gegen die Kopfbedingung (60) entsteht. In (63) erzeugt die Tilgung des Akkusativobjekts eine mediale Lücke zwischen Dativobjekt und Verb. Das Dativobjekt ckommandiert zwar die Lücke, gilt als phrasale Konstituente gemäß (60) jedoch nicht als "Blockierer”. ${ }^{11}$

Dieses Beispiel kann man direkt mit einem V2-Satz vergleichen, in dem das nach $\mathrm{C}$ angehobene finite Verb die Objekt-NP c-kommandiert:

$$
\begin{aligned}
& \text { * [Hans hat ein Buch gekauft] und [Han will ihr Buch } \\
& \text { schenken] }
\end{aligned}
$$

(64) exemplifiziert wieder den scheinbaren Zusammenhang $\mathrm{zwischen} \mathrm{me-}$ dialer Tilgung und Tilgung des finiten Verbs: der Vergleich mit (63) unterstützt die Verallgemeinerung, die mit der Kopfbedingung ausgedrückt wird. Die Tatsache, daß in deutschen Hauptsätzen Phrasentilgung im Mittelfeld von der Tilgung des finiten Verbs abhängt, ergibt sich jetzt als Nebenprodukt des Zusammenwirkens des allgemeineren Prinzips (60) mit den Spezifika der deutschen Wortstellungsregeln.

Beispiele wie (63) und (64) lassen sich auch mit Nebensätzen vom Typ (65) vergleichen, in deren zweitem Konjunkt ebenfalls ein nicht-getilgter Kopf ( $d a \beta$ in $C)$ genau wie das vorangestellte Finitum in (64) die Tilgung von Phrasen in seinem c-Kommando-Bereich (d.h. im Mittelfeld) verhindert:

$$
\begin{aligned}
& \text { * [daß Hans ein Buch gekauft hat] und [daß ihr } \\
& \text { schenken will] }
\end{aligned}
$$

Nebensätze mit nicht-getilgtem Komplementierer unterscheiden sich von Hauptsätzen mit nicht-getilgtem Finitum in C darin, daB im ersten Fall überhaupt keine Vorwärtsellipse zugelassen wird (66a), während im zweiten eine phrasale Konstituente ausgelassen werden kann (66b):

11 Es ist streng genommen auch möglich, daß die Ellipse in (63) keine „mediale Lücke” ist, jedoch nur dann, wenn für das 2. Konjunkt eine unplausible Konstituentenabfolge: ein Buch ihr schenken - angenommen wird. 
(66) a. * [daß Hans ein Buch gekauft hat] und [daß es ihr schenken will]

b. [Hans hat ein Buch gekauft hat] und will es ihr schenken]

Der Kontrast folgt aus der unabhängigen Wortstellungsasymmetrie zwischen Haupt- und Nebensätzen: in Hauptsätzen ist eine phrasale Konstituente in der Position vor $\mathrm{C}$ (auBerhalb des c-Kommando-Bereichs von C) zulässig, in deklarativen Nebensätzen nicht.

Dieser Ansatz wirft auch neues Licht auf eine Asymmetrie in der Tilgbarkeit von finiten Verben in deutschen Nebensätzen. Unter der Annahme, daß Gapping eine selbstständige Regel ist, die die Tilgung von finiten Verben (evtl. zusammen mit weiteren Konstituenten) bewirkt, lieben sich Beispiele vom Typ (67) als Fälle von Gapping ansehen (vgl. die Diskussion über backwards Gapping bei Ross (1970)):

(67) a. [daß Maria gekommen [daß Hans gegangen ist]

b. [daß Maria das Buch und [daß Hans die Blumen bringen soll]

c. [daß Maria mir Blald und [daß Hans dir Blumen schenken sold]

Diese Beispiele sind aus zwei Gründen von üblichen Gapping-Sätzen zu differenzieren. Erstens enthalten sie Rückwärtsellipsen, während echtes Gapping im Sinne einer „medialen Lücke" nur bei Vorwärtsellipse vorkommt. Zweitens erfolgen die Tilgungen in (67) bei Vorhandensein eines nicht-getilgten Komplementierers (daß), was bei Vorwärtsellipse auch die alleinige Tilgung des finiten Verbs blockiert (68b):

(68) a. [daß Maria gekommen ist] und [daß Hans gegangen ist] Rückwärts

b. * [daß Maria gekommen ist] und [daß Hans gegangen ist] Vorwärts

Daher sind die Beispiele (67) als normale Fälle von Rückwärtstilgung einzuordnen. Die Asymmetrie bzgl. der Tilgbarkeit des finiten Verbs und anderer Konstituenten bei vorhandenem Komplementierer erklärt sich einfach daraus, daß Rückwärtstilgung der Kopfbedingung (60) nicht unterliegt. Eine Gapping-Regel braucht es nicht mehr: „Vorwärts-Gapping” entpuppt sich als Spezialfall von Vorwärtstilgung, einem allgemeineren 
Prozeß, der u.a. durch (60) geregelt wird; „Rückwärts-Gapping” ist als Rückwärtstilgung aufzufassen, als linear arbeitender ProzeB, der bei finaler Verbstellung natürlich auch das finite Verb als erstes erwischt.

Wesentlich bei der Erklärung des asymmetrischen Verhaltens des finiten Verbs bei Vorwärtstilgung im Deutschen - in Zweitstellung verhindert es die Tilgung von Phrasen im Mittelfeld; in Endposition nicht - ist die Annahme, daB Mittelfeldkonstituenten außerhalb des c-KommandoBereichs der satzfinalen Verbposition stehen (bzw. stehen können). Phrasale Konstituenten unterliegen optionalen Verschiebungen nach links sog. Scrambling - wobei sie außer Reichweite des Verbs gelangen. Wenn Mittelfeldkonstituenten Scrambling unterliegen können, wird ihre Tilgbarkeit nicht vom finalen Verb beeinfluBt. Eine VP kann jedoch nicht im Mittelfeld verschoben werden (vgl. Grewendorf/Sabel 1994 für ausführliche Diskussion), was sich an der Immobilität des nicht-finiten Verbs bei periphrastischem Tempus in Nebensätzen zeigt:

(69) a. ... daß Hans dich nicht [t besuchen] möchte

b. *... daß Hans dich [ $t$ besuchen] nicht $t$ möchte

Dies hat zur Folge, daß eine nicht-finite VP im Mittelfeld nie außerhalb des c-Kommando-Bereichs des finalen finiten Verbs steht. Wir erwarten also, daB ein finites Hilfsverb die Tilgung einer nicht-finiten VP blockiert, was sich in (70) bestätigt: ${ }^{12}$

(70) a. *.. daß Hans mich besuchen möchte und dich wird.

* [daß Hans mich besuchen möchte] und [do dich [[ wird]]

b. ... daß Hans mich besuchen möchte und dich nicht.

[daß Hans mich besuchen möchte] und [daß Hons dich nicht [[buchen] ] ̈̈chte]]

12 Falls Beispiele wie (i) für akzeptabel gehalten werden, bilden sie ein Problem, da die nicht-finite VP im 2. Konjunkt bei nicht-getilgtem finiten Modalverb getilgt worden ist.

(i) daß Hans mich besuchen kann und will

Ein mōglicher Ausweg wāre, die VP-Lücke als Ergebnis einer zusătzlichen VP-Ellipse (ii-b) zu analysieren (vgl. auch Fußnote 8).

(ii) a. ... und [daß Handich [lvP - besuchen] will Vorwärtstilgung

b. ... und [def Hawich [[VP - will] VP-Ellipse 
Obwohl Scrambling von nicht-finiten Verbphrasen nicht möglich ist, können sie topikalisiert, d.h. ins Vorfeld verschoben werden (71a). Dies ist der einzige Fall, wo solche VPs nicht im c-Kommando-Bereich des finiten Hilfsverbs stehen, und auch - wie prognostiziert - der einzige Fall, wo Vorwärtstilgung der VP bei nicht-getilgtem finiten Hilfsverb möglich ist (71b):

(71) a. Thomas Mann lesen will jeder t $t_{\mathrm{VP}}$

b. Thomas Mann lesen will jeder und kann keiner.

c. [Thomas Mann lesen will jeder $t_{\mathrm{VP}}$ ] und [Than kanner $t_{\mathrm{VP}}$ ]

Der Vergleich mit dem Englischen, der in Abschnitt 2 durchgeführt wurde, läBt sich nun unter der Annahme der Kopfbedingung - jetzt als sprachübergreifendes Prinzip verstanden - erweitern. Der wesentliche Unterschied zum Deutschen besteht darin, daB englische Objekte von V in VP c-kommandiert werden. Folglich kann das Objekt nur dann getilgt werden, wenn das Hauptverb selbst mitgetilgt wird - vgl. (72), (73):

* [John bought a book] and [Lave to her]

[John bought a book for me today] and [Lon for her yesterday]

b. [John bought a book for me] and [Mary for her]

(73a) weist eine periphere Lücke auf (Tilgung von Subjekt, V und Objekt). Wenn das Verb getilgt worden ist, entsteht auch die Möglichkeit für Gapping: in (73b) sind Verb und Objekt getilgt worden, Subjekt und weitere VP-Konstituenten bleiben - das Subjekt c-kommandiert zwar Verb- und Objektellipsen, als phrasale Konstituente blockiert es jedoch die Tilgung nicht.

Ein Subjekt kann in Nebensätzen getilgt werden, solange die einleitende Konjunktion auch getilgt wurde. Nicht-getilgtes that in $\mathrm{C}$ blockiert die Tilgung von Konstituenten in IP (Subjekt, Verb, Objekt usw) in allen Kombinationen:

$$
\begin{aligned}
& \text { *.. that John has bought a book and [that will give it } \\
& \text { to her] }
\end{aligned}
$$




\section{b. *... that John bought a book for me and [that Mary bought} abok for her]

Parallel dazu zeigt sich die Wirkung der Kopfbedingung bei Hilfsverbvoranstellung in Fragesätzen - Subjektellipse ist bei nicht-getilgtem vorangestelltem Verb (75b) nicht möglich:

(75) a. [The students must leave] and [ may not return]

b. * [Must the students leave] or [may stay] ?

Zusammenfassend läßt sich bestätigen, daß die Kopfbedingung eine Erklärung für Asymmetrien bei Vorwärtstilgungen sowohl zwischen Sprachen als auch zwischen Konstruktionen innerhalb einzelner Sprachen liefern kann. Darüber hinaus zeigt sich die Wirkung dieser Bedingung in elliptischen Ausdrücken, die keine expliziten Antezedenten im selben Satz aufweisen. Sowohl elliptische Antworten als auch "gekürzte Hauptsätze” können als Produkte von „Vorwärtstilgungen” aufgefaßt werden. Das „Antezedens” befindet sich in diesen Fällen im vorangehenden Diskurs - bei elliptischen Antworten, als Teil der Frage, die sie beantworten; bei "gekürzten Hauptsätzen” als salientes Diskurs-Topik. Bei Koordinationen gilt das vorangehende Konjunkt als Spezialfall von „vorangehendem Diskurs".

\section{Asymmetrische Koordination}

Die vorangegangene Diskussion geht von der Prämisse aus, daß Koordinationsellipsen als Ergebnis von phonologischen Tilgungen in satzartigen Konjunkten zu behandeln sind. Eine wesentliche Rolle spielt dabei die Annahme, daB die Stellung von „getilgten" Konstituenten in satzartigen Konjunkten vollständig durch Wortfolgeregeln determiniert wird. Die Möglichkeiten zur Tilgung der einen oder anderen Konstituente hängen dann von den allgemeinen Bedingungen für die Ellipseregeln ab, die auf der Basis von unabhängig bestimmten Konstituentenstrukturen sowie den sich daraus ergebenden Wortfolgen operieren.

Zu diesem Ansatz gibt es eine Alternative, die von der Annahme ausgeht, daB Koordinationen schon in der syntaktischen Struktur aus "kleinen Konjunkten" bestehen (und nicht erst durch phonologische Tilgung zustandekommen). Die Beispiele in (76), die hier als elliptische Satzverknüpfungen wie in (77) analysiert werden, erhalten in diesem Alternativansatz eine syntaktische Analyse wie in (78):

(76) a. Der Jäger ging in den Wald und fing einen Hasen.

b. Er wird mich anrufen und dich besuchen.

c. Er kauft und liest die Zeitung. 
(77) a. [[der Jäger ging in den Wald] und [ fing einen Hasen]] Vorwärts

b. [[er wird mich anrufen] und [ dich besuchen]] Vorwärts

c. [[er kauft diond und [e liest die Zeitung]]

Rückwärts

Vorwärts

(78) a. Der Jäger [[ging in den Wald] und [fing einen Hasen]]

b. Er wird [[mich anrufen] und [dich besuchen]]

c. Er $[[$ kauffl] und [liest $]]$ die Zeitung

Die unterstrichenen Wörter befinden sich in (77) innerhalb eines Konjunkts und kontrollieren eine Ellipse im anderen Konjunkt. In (78) dagegen werden sie als syntaktisch nur einmal vorhandenes Material behandelt, das sich außerhalb der Koordinationsdomäne befindet. Diese Konstituenten sind dann für beide Konjunkte gemeinsam relevant, indem sie gleichzeitig mit beiden Konjunkten grammatische Beziehungen eingehen: Das Subjekt in (78a) z.B. kongruiert mit zwei finiten Verben - mit einem in jedem Konjunkt.

Diese Alternative erlaubt es anscheinend, zumindest für Koordinationen, auf den Mechanismus der phonologischen Tilgung zu verzichten. Im folgenden werden Argumente skizziert, die die Notwendigkeit von Tilgungsregeln für Koordinationsellipsephänomene nachweisen und somit gegen den Ansatz (78) sprechen.

Wie aus (77)-(78) hervorgeht, bringen die beiden Alternativen unterschiedliche Annahmen über den syntaktischen Status von Konjunkten mit sich. Der Tilgungsansatz geht davon aus, daß Konjunkte generell vollständige Sätze sind (zumindest, was die hier angeführten Beispiele betrifft), während der Ansatz (78) die weniger restriktive Annahme macht, da $B$ syntaktische Konstituenten aller Arten koordinativ verknüpft werden können:

(79) Konjunkte sind syntaktische Konstituenten

Es läßt sich leicht nachweisen, daß (79) nicht ausreicht, um Rückwärtstilgung überflüssig zu machen. Rückwärtsellipsen entsprechen in diesem Ansatz die Fälle, in denen "gemeinsames Material" den (kleinen) syntaktischen Konjunkten folgt, während die Wortketten, die in der Tilgungsanalyse sozusagen als "Satzreste” zurückbleiben, als „kleine Konjunkte” analysiert werden. In vielen Beispielen entspricht dieser Rest jedoch kei- 
ner syntaktischen Konstituente und kann daher nach (79) kein Konjunkt sein:

(80) a. Peter glaubt, daß Maria, und Hans glaubt, daß Nina, am schnellsten fertig wird

b. * [Peter glaubt, daß M.] und [Hans glaubt, daß N.] $\underline{a m}$ schnellsten fertig wird

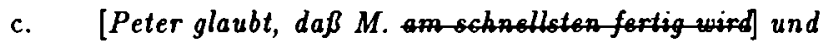
[Hans glaubt, daß $N$. am schnellsten fertig wird]

Die minimale Analyse, die mit (79) verträglich ist, ist (80c), die dann die Annahme einer Rückwärtstilgungsoperation, wie sie oben beschrieben wurde, erforderlich macht. ${ }^{13}$

Ein Argument für die Notwendigkeit einer Vorwärtstilgungsoperation läßt sich aus der Existenz von sog. asymmetrischen Koordinationen herleiten:

(81) a. In den Wald ging der Jäger und fing einen Hasen

b. Gestern ist Maria einkaufen gegangen und hat sich einen Pullover gekauft

Für übliche Vorwärtsellipsen werden Strukturen angesetzt, in denen gemeinsame Konstituenten links von den kleinen syntaktischen Konjunkten stehen (vgl. (77)). In (81) aber erscheint die gemeinsame Konstituente nicht links von dem ersten Konjunkt, sondern ist in diesem enthalten. Das finite Verb, das jeweils links vom Subjekt steht, gehört nicht zu dem gemeinsamen externen Kontext, sondern muB in beiden Fällen dem ersten Konjunkt zugerechnet werden. Beispiele dieser Art können nicht ohne zusätzliche und sonst unbegründete Annahmen mit einem Ansatz, der ohne Vorwärtstilgung arbeitet, verträglich gemacht werden:

13 Manchmal wird versucht, solche Beispiele über eine Bewegungstransformation (Right Node Raising) zu analysieren, wobei die Kette am schnellsten fertig wird, die ja eine Konstituente (vielleicht eine Zwischenprojektion von INFL, d.h. I') bildet, nach rechts aus beiden Konjunkten angehoben worden ist:

(i) [[Peter glaubt, daß M. t] und [Hans glaubt, daß N.t]] [1' am schnellsten fertig wird]

Es gibt keinerlei unabhāngige Evidenz für eine derartige Bewegungsregel, die I'-Konstituenten aus Nebensätzen nach rechts anhebt. Vgl. Wilder (1995) für weitere Diskussion. 
die Annahme von "kleinen Konjunkten” vermag nicht alle Instanzen von Vorwärtstilgung zu ersetzen. ${ }^{14}$

Im Tilgungsansatz ergeben sich die wesentlichen Eigenschaften dieses Satztyps ohne zusätzliche Annahmen.
a. [In den Wald ging der Jäger] und [ding einen Hasen]
Vorwärts
b. [Gestern ist Maria einkaufen gegangen] und [ hat sich einen Pullover gekauft] Vorwärts

Die asymmetrische Natur von Beispielen wie (81) erweist sich als Asymmetrie im syntaktischen Status der Konjunkte: verknüpft werden ein V2Satz mit topikalisierter Konstituente im Vorfeld und ein subjekt-initialer V2-Deklarativsatz (d.h. ein Satz ohne topikalisierte Phrase im Vorfeld). Im zweiten Konjunkt wird das Subjekt jeweils unter Identität mit der entsprechenden Konstituente im vorangehenden Konjunkt getilgt. Die Tilgung genügt allen bisher diskutierten Bedingungen für Vorwärtstilgung: das Antezedens befindet sich im vorangehenden Konjunkt, die Ellipsestelle entspricht einem Satzglied, und sie befindet sich nicht im c-Kommando-Bereich eines nicht-getilgten Kopfes in ihrem Konjunkt. Ist die prä-verbale Position des zweiten Konjunktes besetzt, wird diese Art der Subjekt-Ellipse unmöglich:

(83) * Gestern ist Maria einkaufen gegangen und heute hat sich einen Pullover gekaufi.

* [gestern ist Maria einkaufen gegangen] und [heute hat sich einen Pullover gekauft]

Aus der V2-Bedingung folgt, daß die Subjekt-Lücke in (83) sich in postverbaler Position befindet; die Tilgung verletzt also die Kopfbedingung $(60)$.

Eine weitere Asymmetrie-Eigenschaft dieser Beispiele betrifft die jeweilige Position der Ellipse und des Antezedens: ein post-verbales Subjekt lizensiert die Tilgung eines prä-verbalen Subjekts. Diese asymmetrische Stellung ist bei Objekt-Tilgung nicht möglich - ein Objekt im Vorfeld im zweiten Konjunkt kann nicht unter Identität mit einem post-verbalen Objekt im ersten Konjunkt getilgt werden, obwohl diese Ellipse den bis-

14 Siehe Zwart (1991), Wilder (1994), (1995). Versuche, bei solchen Beispielen ohne Vorwärtstilgung auszukommen, finden sich in Höhle (1990), Heycock/Kroch (1994). 
her diskutierten Voraussetzungen (einschl. der Kopfbedingung) genügen würde.

(84) a. * Der Jäger hat den Hasen gesucht und hat er auch gefangen.

$$
\begin{aligned}
& \text { b. * }[\text { der Jäger hat den Hasen gesucht }] \text { und }\left[\begin{array}{l}
\text {-TOP hat er } \\
\text { auch gefangen }
\end{array}\right. \\
& \text { +TOP }
\end{aligned}
$$

Wie kann der Kontrast zwischen (81) und (84) erklärt werden? Tilgungsoperationen unterliegen im allgemeinen zwei Arten von Bedingungen: (i) solchen, die regeln, wo die Ellipse stehen kann (unabhängig von der Beziehung zum Antezedens); (ii) solchen, die festlegen, wie die Relation der Ellipse zum Antezedens sein muB. Die Kopfbedingung fallt unter (i). Unter (ii) fallen Identitätsbedingungen, die - im Falle von Vorwärtstilgung - vorschreiben, daB die grammatische Funktion des Antezedens und die der getilgten Konstituente identisch sein müssen. Ein Objekt kann auch unter formaler Identität mit dem Subjekt - nicht dessen Tilgung lizensieren; und umgekehrt.

Ich schlage vor, den Kontrast zwischen (81) und (84) an einer Asymmetrie $\mathbf{z}$ wischen prä-verbalen Subjekten und prä-verbalen Objekten festzumachen, die sich dann bei der für Vorwärtstilgung erforderlichen Identität bemerkbar macht. Diese Asymmetrie läßt sich wie folgt formulieren:

(85) a. Eine Phrase im Vorfeld, die nicht Subjekt ist, erhält ein Merkmal [+TOP]

b. Ein prä-verbales Subjekt erhält nicht notwendigerweise [+TOP]

c. Keine weitere Phrase (z.B. im Mittelfeld) erhält [+TOP]

Nehmen wir zusätzlich an, daB Antezedens und Ellipse bzgl. des Merkmals [TOP] übereinstimmen müssen, um bei der Vorwärtstilgung als „identisch” zu gelten. Dann ergibt sich daraus die Asymmetrie. Aus (85a) und (85c) folgt für (84), daB das Objekt im Mittelfeld im ersten Konjunkt nicht identisch ist mit dem Objekt im Vorfeld im zweiten Konjunkt: die Ellipse scheitert also an der Identitätsbedingung. Aus (85b) und (85c) folgt für (81), dab das Subjekt im Vorfeld mit dem Subjekt im Mittelfeld im ersten Konjunkt identisch sein kann: solange das prä-verbale Subjekt kein [+TOP]-Merkmal erhält, ist die Vorwärtstilgung möglich. ${ }^{15}$

15 Der Kontrast zwischen (81) und (84) korreliert mit einer weiteren Asymmetrie zwischen prä-verbalen Subjekten und prä-verbalen Objekten in V2Sätzen - nāmlich, daß das schwache Pronomen es im Vorfeld nur als Subjekt vorkommen kann:
(i) Es hat das Gras gegessen
(ii) * Es hat der Esel gegessen 
Weitere asymmetrische Beispiele lassen sich konstruieren - z.B. aus der Verbindung einer W-Frage mit einem Subjekt-initialen Deklarativsatz (86):

(86) a. *Wen hat Maria besucht und hat mich angerufen?

b. * [wen hat Maria besucht] und [Aaria hat mich angerufen]

Obwohl dieses Beispiel den Bedingungen für Vorwärtsellipse genügt, bildet es keinen akzeptablen Satz. Dies läBt sich möglicherweise erklären mit Bezug auf Faktoren, die unabhängig bestimmen, was sich womit koordinativ verknüpfen läßt, denn Konstituentenfragen lassen sich generell nicht mit Deklarativsätzen (auch nicht-elliptischen) verbinden (87):

* Wen hat Maria besucht und Peter hat mich angerufen?

Andererseits ist manches Beispiel dieser Art (mit Subjektellipse) nicht so schlecht:

(88) a. Wann ist Maria einkaufen gegangen und hat sich einen Pullover gekauft?

b. * [wann ist Maria einkaufen gegangen] und [arat sich han Pullover gekaufl]

c. [wann ist Maria einkaufen gegangen] und [Aaria hat sich einen Pullover gekauft]

Im Rahmen des hier vertretenen Ansatzes muß dieses Beispiel als Koordination von einer direkten W-Frage mit einem subjektinitialen Deklarativsatz analysiert werden (88c) ${ }^{16}$ Würde das Beispiel als Ergebnis der Koordination zweier W-Fragen analysiert, ergäbe sich eine Struktur, in der die Tilgung des Subjekts dann die Kopfbedingung verletzen würde (88b).

Die Korrelation läßt sich herleiten mit der Annahme, daß sich es mit dem Merkmal [+TOP] nicht verträgt.

16 Semantisch gesehen ist (88) jedoch eher als eine komplexe Frage zu betrachten, in der der Inhalt des zweiten Konjunkts im Skopus des Frageworts liegt. Der Satz wird verwendet, um nach dem Zeitpunkt eines komplexen Ereignisses 20 fragen, das den Inhalt des zweiten Konjunkts mit einbezieht, wobei impliziert wird, daB es einen Zeitpunkt gibt, zu dem ein aus Einkaufen-Gehen und einen-Pullover-Kaufen bestehendes Ereignis stattfindet. Āhnliche Überlegungen gelten auch für (81) und (89). 
Ähnlich verhält es sich mit Beispielen des Typs (89a), sofern sie akzeptabel sind. Das Beispiel besteht aus einer verbinitialen Entscheidungsfrage und einem finiten Konjunkt mit Subjektellipse: $:^{17}$

(89) a. Ist er in die Schule gegangen und hat die Arbeit geschrieben?

b. * [ist er in die Schule gegangen] und [hat die Arbeit geschrieben]

c. [ist er in die Schule gegangen und [ hat die Arbeit geschrieben]

Hartmann (1994, S. 9) setzt hierfür eine Analyse an, in der zwei Entscheidungsfragen miteinander verknüpft werden, wobei die Subjekt-Lücke im zweiten Konjunkt rechts vom finiten Verb steht (89b). Nur die Analyse von (89a) als asymmetrische Verknüpfung von Entscheidungsfrage und subjektinitialem Deklarativ (89c) ist mit der Kopfbedingung vereinbar.

\section{Schlußwort}

Im Vorangehenden ist an einer Reihe verschiedener Beispiele dargestellt worden, wie vermutlich universale, nicht-parametrisierte Tilgungsregeln mit unabhängig gegebenen Konstituentenstrukturen und Wortfolgen interagieren, um die vielfältigen Muster der möglichen (und unmöglichen) elliptischen Konstruktionen zu ergeben. Klare Erfolge für die Thesen in (7) sind für Rückwärtstilgung mithilfe der Peripheriebedingung (39) erzielbar, wie auch für Vorwärtstilgung mithilfe der Hauptkonstituentenbedingung (49) und der Kopfbedingung (60). Die letztgenannte Bedingung erweist sich als besonders ertragreich, indem sie es erlaubt, (i) mit einer Tilgungsregel sowohl linksperiphere wie auch mediale Ellipsen zu erfassen; (ii) dabei zwei speziellere Regeln (Forward Conjunction Reduction und Gapping) durch eine allgemeinere zu ersetzen; und (iii) die in Abschnitt 2. besprochenen $z$ wischensprachlichen Unterschiede hinsichtlich der Objekttilgung auf die Effekte der in Abschnitt 3. besprochenen Wortstellungsparameter zurückzuführen.

Probleme bleiben (natürlich). Um eins hier abschlieBend zu erwähnen (weitere finden im Text und in FuBnoten Erwähnung): es ist in Abschnitt 2. angedeutet worden, daB das im Deutschen vorkommende Phänomen Topic Drop auch als Fall von Vorwärtstilgung (mit implizitem Antezedens) erfasst werden kann - die Effekte der Kopfbedingung sind ja klar ersichtlich. Es bleibt dann aber die Frage, warum diese Art der Ellipse

17 Das Englische läßt für analoge Beispiele (vgl. (75b)) offenbar eine solche "asymmetrische" Analyse nicht zu. 
beispielsweise im Englischen überhaupt nicht möglich ist - d.h. warum ich statt that, I have solved already unter keinen Umständen *I have solved already (bei mitverstandenem Objekt-Topik) äuBern darf.

\section{Literatur}

Chao, Wynn (1988): On Ellipsis. New York.

Grewendorf, Günther/Sabel, Joachim (1994): Long Scrambling and Incorporation. In: Linguistic Inquiry 25, S. 263-308.

Haegeman, L. (1990): Non-overt subjects in diary contexts. In: Mascaró, Juan/Nespor, Marina (eds.): Grammar in Progress. Dordrecht. S. 167174.

Haider, Hubert (1988): Die Struktur der deutschen Nominalphrase. In: Zeitschrift für Sprach wissenschaft 7, S. 32-59.

Hankamer, Jorge (1979): Deletion in Coordinate Structures. New York.

Hartmann, Katharina (1994): Zur Koordination von V-2 Sätzen. In: Zeitschrift für Sprachwissenschaft 13, S. 3-19.

Heycock, Caroline/Kroch, Anthony (1994): Verb Movement and Coordination in a Dynamic Theory of Licensing. In: The Linguistic Review 11, S. 257-283.

Höhle, Tilman (1990): Assumptions about asymmetric coordination in German. In: Mascaró, Juan/Nespor, Marina (eds.): Grammar in Progress. Dordrecht. S. 221-235.

Klein, W. (1993): Ellipse. In: Jacobs, Joachim/von Stechow, Arnim/Sternefeld, Wolfgang/Vennemann, Theo ( $\mathrm{Hg}$.): Syntax: ein internationales Handbuch zur zeitgenōssischen Forschung. Berlin. Bd. 1, S. 763-799.

Müller, Gereon/Sternefeld, Wolfgang (1993): Improper Movement and Unambiguous Binding. In: Linguistic Inquiry 24, S. 461-507.

Neijt, Anneke (1979): Gapping. Dordrecht.

Platzack, Christer (in diesem Band): Germanic Verb Second Languages. Attract vs. Repel: On Optionality, A-bar Movement and the Symmetrical/Asymmetrical Verb Second Hypothesis.

Ross, John (1970): Gapping and the Order of Constituents. In: Bierwisch, Manfred/Heidolph, Karl Erich (eds.): Progress in Linguistics. The Hague. S. 249-259.

Schwabe, Kerstin (1994): Syntax und Semantik situativer Ellipsen. Tübingen.

Wesche, Birgit (1995): Symmetric Coordination. Tübingen.

Wilder, Chris (1994): Coordination, ATB and Ellipsis. In: Groninger Arbeiten zur Germanistischen Linguistik 37, S. 291-331.

Wilder, Chris (1995): Some Properties of Ellipsis in Coordination. In: Geneva Generative Papers 2, S. 23-61.

Williams, Edwin (1990): The ATB Theory of Parasitic Gaps. In: The Linguistic Review 6, S. 265-279. 
Zwart, C. Jan-Wouter (1991): Subject deletion in Dutch: a difference between subjects and topics. In: Kas, Michael/Reuland, Eric/Vet, Co (eds.): Language and Cognition 1. University of Groningen. S. 333-350.

Zwart, C. Jan-Wouter (1993): Dutch Syntax. PhD Dissertation, Universitāt Groningen. 
Negation auf Wanderschaft 



\title{
Negationsverstärkung und Jespersens Zyklus im Deutschen und in anderen europäischen Sprachen
}

\begin{abstract}
Im Zentrum meiner Ausführungen steht ein Phānomen, das unter dem Stichwort „Jespersens Zyklus” ein Begriff geworden ist, nämlich die in vielen Sprachen zu konstatierende zyklisch auftretende Verstärkung von āuferlich zu schwach gewordenen Negationswörtern. (Ich spreche in Anlehnung an Jacobs (1991) von "Negationstrāgern”.) Im Abschnitt 1 werde ich das Phānomen "Jespersens Zyklus” anhand einiger Beispiele vorstellen und dann einige Aspekte behandeln, die im Kontext dieses Phānomens eine Rolle spielen: Negationsverstärkung (Abschnitt 2), Stellung der Negationstrāger (Abschnitt 3) und Areallinguistische Ausprāgungen (Abschnitt 4).
\end{abstract}

\section{Jespersens Zyklus}

Mit „Jespersens Zyklus" wird ein Phänomen bezeichnet, welches Jespersen selbst folgendermaßen beschrieben hat:

(1) (a) "The original negative adverb is first weakened, then found insufficient and therefore strengthened, generally through some additional word, and this in its turn may be felt as the negative proper and may then in course of time be subject to the same development as the original word." (Jespersen 1917, S. 4)

Horn bringt „Jespersens Zyklus” auf einen kurzen Nenner:

(1) (b) „Jesperen's Cycle - the repeated pattern of successive weakening and restrengthening of the negative marker." (Horn 1989, S. 446)

Jespersens prototypisches und oft zitiertes Beispiel ist die Entwicklung des französischen Negationsträgers (ne) pas, dessen Entwicklung im Lateinischen seinen Ausgang nahm:

(2) 1. lat. ne dico

2. non dico ( $\ll$ ne oenum dico)

3. frz. jeo ne di

4. je ne dis pas

5. je dis pas

Die lateinische Negationsform hieß ursprünglich ne, wurde dann zu non verstärkt, was eine Zusammenziehung und Verschleifung von ne oenum 
(= nicht eines) darstellt (oenum ist die alte Form von unum). Aus dem Lateinischen haben sich alle romanischen Sprachen entwickelt, so auch das Französische. Im Altfranzösischen nun hatte sich das lateinische non wieder abgeschwächt zu ne, welches dann im Laufe der Zeit seinerseits wieder verstärkt wurde, nämlich durch pas (=ne pas). Und dieses pas, das wörtlich ja „Schritt” bedeutet, also selbst ursprünglich keinerlei Negation beinhaltet, tritt in der heutigen französischen Alltagssprache häufig schon ohne ne auf (siehe Stufe 5 in (2)), es übernimmt allein die Negationsfunktion und -bedeutung; der Verstärker wird also zum Negationsträger. Einen deutlichen Hinweis darauf, daB pas im Gegenwartsfranzösischen als der eigentliche Negationsträger fungiert, gibt eine von Ramat (1987, S. 181) erwähnte Untersuchung, derzufolge französische Kleinkinder beim Spracherwerb als erste Negationsform pas bilden.

Vermutlich wird irgendwann das ne ganz verschwinden, so wie es heute schon in verschiedenen Wendungen der Fall ist:
Pas du tout!
Überhaupt nicht!
Pourquoi pas?
Warum nicht?

In anderen Fällen jedoch ist ne noch immer obligatorisch, wie etwa in den folgenden Wendungen:

(b) Ne pas fumer! Ne pas marcher sur la pelouse!
Nicht rauchen!

Nicht über den Rasen laufen!

Möglicherweise spielt hier das Vorhandensein eines Verbs eine Rolle. Verbnegation ist meist Satznegation, d.h. im Skopus der Negation befindet sich nicht nur das Verb, sondern der ganze Satz. Deshalb ist die Beziehung zwischen Verb und Negationsträger von besonderer Bedeutung und es ist kein Zufall, daß bei den in der Literatur angeführten Beispielen für Jespersens Zyklus meist Verbnegation im Zentrum der Betrachtung steht. Ich werde später auf diesen Punkt zurückkommen.

Jespersens Zyklus läBt sich auch in vielen anderen Sprachen nachweisen. Im Englischen etwa ging die Entwicklung vom altenglischen Negationsträger ne zunächst über Verstärkung im Frühmittelenglischen (ne not), dann Abschwächung durch Verlust des ursprünglichen Negationselementes im späten Mittelenglischen (nur noch not) zu WiederVerstärkung im Neuenglischen (do not):

(4) englisch (nach Jespersen 1917: S. 9ff.)
1. ae.
ic ne secge
2. frühme.
$I$ ne seye not
3. spätme. I say not 
4. ne. I do not say

$5 . \quad I$ don't say

6. [aj dn sæj]

Im Verlaufe der neuenglischen Sprachperiode läBt sich nun wieder eine Abschwächung feststellen: do not wird zu don't zusammengezogen und in der Alltagssprache heute noch weiter verschliffen (siehe Stufe 6 in (4)). Jespersens Zyklus folgend wird die nächste Stufe vermutlich wieder eine Verstärkung des reduzierten Wortkörpers durch ein zusätzliches Wort sein.

Im Deutschen (vgl. (5a)) verlief die Entwicklung vom althochdeutschen ni über Abschwächung des Wortkörpers im Frühmittelhochdeutschen (der volle Endsilbenvokal [i] wurde zu [a] >ne oder auch en), dann Verstärkung durch niht bis zu Wieder-Abschwächung im Neuhochdeutschen, wo ne ganz wegfiel und nicht alleiniger Negationsträger wurde. Ganz ähnlich verlief die Entwicklung im Niederländischen (vgl. (5b)), das seinen Ursprung im Altniederfränkischen hat (vgl. Hutterer 1990, S. 263):

(5) (a) deutsch
1. ahd.
ni $V$
2. frühmhd.
ne/en $V$
3. mhd.
ne/en $V$ niht
4. nhd.
$\checkmark$ nicht

(b) niederländisch
1. anfrk.
en $V$
2. $\mathrm{mnl}$.
en $V$ niet
3. nnl.
$\checkmark$ niet

Auch in den nordgermanischen Sprachen haben sich die Negationsträger Jespersens Zyklus gemäß entwickelt:

(6) norwegisch (nach Jespersen 1917, S. 8f.).
1. Haraldr ne veit
2. ne veit-at Haraldr
ne $V$
3. veit- fit at Haraldr
ne $V$ eigi/ekki
$\checkmark$ ikke

Im Altnordischen war ne der alleinige Negationsträger, im Norwegischen wurde er dann durch- at verstärkt. Später verschwand der ursprüngliche Negationsträger ne und -at allein übernahm dessen Funktion und Bedeutung. - at findet sich vor allem in poetischen Texten, in Prosatexten trat eigi oder ekki als Verstärker und späterer alleiniger Negationsträger 
auf, im heutigen Norwegisch heift er ikke und hat Entsprechungen in allen anderen nordgermanischen Sprachen:

(7) schwedisch icke / dänisch ikke / isländisch ekki / färöisch ikki

Alle diese Formen waren ursprünglich Verstärker des aus dem Altnordischen ererbten Negationsträgers ne, der in allen nordgermanischen Sprachen jedoch schon früh obligatorisch verschwand. Mit diesem alten Negationsträger ne verschwand auch der für indoeuropäische Negationswörter typische initiale Nasallaut, vgl. etwa in (8a) die Entsprechungen von nicht in verschiedenen germanischen, romanischen, keltischen und slawischen Sprachen; alle beginnen mit Nasal, in indoeuropäischen Sprachen typischerweise mit [n]. Auch in vielen nicht-indoeuropäischen Sprachen beginnen Negationswörter mit Nasallaut, mit [n] oder auch mit [m], vgl. etwa (8b):

(a) serbkr. ne portug. não rumän. nu got. ni russ. ne span. no bulg. ne altsächs. ne poln. nie ital. non irisch $n a$ aleman. $n i$ niederld. niet afrikaan. nie niederdt. nich

(b) ungarisch nem armenisch mi koreanisch $m a$ türkisch me

Weshalb Negationswörter so oft mit einem Nasallaut beginnen, auch darüber macht sich Jespersen Gedanken und kommt zu folgender Erklärung: Negationspartikeln waren ursprünglich primitive Interjektionen, die Abscheu ausdrückten, gepaart mit einer Geste des Naserümpfens, und durch die Kontraktion der Nasenmuskeln beim Naserümpfen kam die Nasalität der Äußerung zustande:

(9) (a) "... the old negative ne, which I take to be ... a primitive interjection of disgust, accompanied by the facial gesture of contracting the muscles of the nose ... This natural origin will account for the fact that negatives beginning with nasals $(n, m)$ are found in many languages outside the Indo-European family." (Jespersen 1917, S. 6f.)

Wir mögen heute über derartige Erklärungsversuche die Nase rümpfen. Doch zu Beginn unseres Jahrhunderts lag Jespersen damit durchaus im Trend seiner Zeit, den Ursprung menschlicher Sprache mit Gestik und Mimik in Verbindung zu bringen; vgl etwa Uhl 1906:

(9) (b) „Wir haben uns nun vorzustellen, daß jeder Sprachlaut ursprünglich mit einer entsprechenden Körperbewegung oder Körperhaltung verbunden war. Das eine kann eigentlich ohne das andere gar nicht gedacht werden." (Uhl 1906, S. 4) 
Doch zurück zur Negationsverstärkung, die oft genug der Grund dafür war, daß der ursprüngliche Negationsträger mit initialem Nasal ganz verschwand und durch ein Wort ersetzt wurde, das ursprünglich gar kein Negationsträger war.

\section{Negationsverstärkung}

Negationsverstärkung kann auf unterschiedliche Weise geschehen. Die negationsverstärkenden Elemente, um die es bei der Diskussion über Jespersens Zyklus geht, verstärken die ä u B e r e Form, den Wortkörper des ursprünglichen Negationsträgers, wenn dieser allein als zu schwach angesehen wird. Es handelt sich bei Jespersens Zyklus nicht darum, die Negation inhaltlich mit Nachdruck zu versehen, dies wäre ein andersgeartetes Phänomen; inhaltliche Negationsverstärkung kann im Deutschen etwa mit folgenden Wendungen geschehen:

(10) (a) nicht im geringsten

(b) nicht einen Pfifferling

(c) nicht die Bohne

(d) nicht ums Verrecken

Derartige Ergänzungen fügen zur Negationbedeutung einen verstärkenden Bedeutungsbestandteil hinzu; die Ausdrücke in (10) kann man mit überhaupt nicht, ganz und gar nicht paraphrasieren. Jedoch ist ihre Verwendung kontextuell stark eingeschränkt vg. (11):

Das interessiert mich nicht die Bohne

Das ist nicht einen Pfifferling wert

? Das ist nicht die Bohne wert

? Das interessiert mich nicht einen Pfifferling

(b) Das stört mich nicht im geringsten

Das mache ich nicht ums Verrecken

? Das stört mich nicht ums Verrecken

? Das mache ich nicht im geringsten

Die negationsverstärkenden Wendungen haben zwar dieselbe Funktion und Bedeutung, sind aber in den einschlägigen Kontexten nicht gegeneinander austauschbar. Ein weiteres Charakteristikum dieser inhaltlich verstärkenden Phrasen besteht darin, daB es sich um "Negative Polaritäts-Elemente" (NPEs) handelt, d.h. sie sind nur im Kontext von Negation akzeptabel. Vgl. die Sätze in (12) ohne Negation: 
(12) (a) ? Das interessiert mich im geringsten

(b) ? Das ist einen Pfifferling wert

(c) ? Das interessiert mich die Bohne

(d) ? Das werde ich ums Verrecken tun

Die Funktion dieser Phrasen ist auf Verstärkung von Negation beschränkt.

Auch in älteren Sprachstufen des Deutschen finden sich schon solche Phrasen, die die Negation inhaltlich verstärken, etwa die Wendungen in (13) (entnommen aus Schützeichel 1981, Paul 1920 und Moser/Schröbler 1969):

ahd. ni trophen/drof

mhd. niht ein blat/strô/bast/hâr niht eine bône

Die Wendung nicht die Bohne ist offensichtlich keine neuzeitliche Errungenschaft. Auch im Alt- und Mittelhochdeutschen ging es darum, mit derartigen Ausdrücken die Negation inhaltlich mit Nachdruck zu versehen.

Anders ist es bei den Negationsverstärkern, die im Rahmen von Jespersens Zyklus eine Rolle spielen; hier handelt es sich um Ausdrücke, die die äubere Form eines Negationsträgers stärken. Ausdrücke wie pas im Französischen, do im Englischen oder ekki im Norwegischen verlieren in negationsverstärkender Funktion ihre Eigenbedeutung, sie werden „desemantisiert". Sie gehen mit dem ursprünglichen Negationsträger eine Verbindung ein, deren Bedeutung die einfache Negation ist.

Das gilt auch dann, wenn das verstärkende Element seinem Ursprung nach selbst schon ein Negationsträger ist, wie etwa das deutsche niht oder das englische not, hier nochmal aufgeführt in (14):

(14) mhd. ne $V \underline{\text { niht }}$

me. ne $V \underline{\text { not }}$

Beide Formen, niht und not, gehen - wie übrigens auch das niederländische niet - auf die gemeingermanische Form ni io wiht zurück, die nicht ein Ding, nicht ein Wesen bedeutet und im Gotischen als ni waiht belegt ist. Im Deutschen und Englischen verlief die Entwicklung wie in (15c und d) angeführt: 
(15) (a) germ. ni io wiht (= nicht ein Ding / Wesen)

(b) got. ni waiht

(c) dt. niowiht $\gg$ niwiht $\gg$ niht

(d) engl. nowiht $>$ nought $>$ not

In Verstärkerfunktion werden auch niht und not desemantisiert und bilden jeweils mit ne gemeinsam e i n e $n$, wenn auch morphosyntaktisch diskontinuierlichen, Negationsträger. In solchen Fällen sprechen wir von „pleonastischer” Negation. Behaghel spricht von Negations- „Häufungen” und konstatiert (Hervorhebung von mir. BL):

(16) „Für alle diese Häufungen gilt bis in die neueste Zeit hinein die Regel, daB der Satz verneinend bleibt; die Verneinungen heben sich nicht gegenseitig auf; man kann aber auch im allgemeinen $n$ i c h t sagen, daB sie einer Verstärkung d es A u sd r u c k s dienen." (Behaghel 1924, S. 80)

Verstärkt wird, wie Behaghel ganz richtig bemerkt, nicht „der Ausdruck", d.h. die Bedeutung, verstärkt wird nur die äußere Form.

niht verstärkte im Mittelhochdeutschen und Frühneuhochdeutschen nicht nur den einfachen Negationsträger ne, sondern auch komplexe $\mathrm{Ne}-$ gationsträger. Mit der Unterscheidung „einfacher vs. komplexer Negationsträger" beziehe ich mich auf Jacobs (1991), er differenziert folgendermaßen: ein semantisch einfacher Negationsträger beinhaltet nur einen einzigen Bedeutungsbestandteil, nämlich NEGATION, ein semantisch komplexer Negationsträger beinhaltet außer NEGATION noch weitere Bedeutungsbestandteile. Semantisch komplexe Negationsträger sind im Deutschen beispielsweise Pronomina und Adverbien wie niemand, nichts, niemals, nirgendwo. Betrachten wir fürs Mittelhochdeutsche und Frühneuhochdeutsche die Beispiele in (17) (entnommen aus Moser/Schröbler (1969) und Paul (1920)):

(17) mhd. swelch hêrre nieman niht versaget

waz ob er hie heime iu niemer mêre niht gewirret ich gehort bi minen tagen nie selhes niht gesagen

frnhd. wem niemand nicht gefällt nichts gutes war es freilich nicht arm ist er aber nimmer nicht

Pleonastische Negation gibt es im heutigen Standarddeutschen nicht. Wenn zwei Negationsträger auftreten, so wird keiner von beiden desemantisiert, beide behalten ihre Negationsbedeutung und die ÄuBerung wird affirmativ verstanden, die Negationen heben sich gegenseitig auf. 
So etwa in den Sätzen in (18), die als korrektive Erwiderungen auf vorhergehende Behauptungen geäußert werden könnten:

(18) Kein Student hat nichts gelesen (= Jeder Student hat etwas gelesen) Karl strebt nicht nach nichts (= Karl strebt sehr wohl nach etwas)

Solcherart aufhebende Negation gab es bis in die frühneuhochdeutsche Sprachepoche hinein überhaupt nicht, ich zitiere Behaghel:

(19) (a) „DaB mehrere Verneinungen sich gegenseitig aufheben, ist erst Errungenschaft der neueren Schriftsprache." (Behaghel 1924, S. 80)

Laut Behaghel hat sich die deutsche Standardsprache damit weit von der "volkstümlichen Rede" entfernt. Er schreibt:

(19) (b) „Da die Doppelung in einem großen Teil der heutigen Mundarten noch lebendig ist, so kann die Zurückdrängung in der Schriftsprache nicht das Ergebnis einer bodenständigen Entwicklung sein. Sie ist vielmehr die Folge der Schulung am Lateinischen, und die Stellung der nhd. Schriftdenkmäler hängt $a b$ von ihrer größeren oder geringeren Entfernung von der volkstümlichen Rede." (Behaghel 1924, S. 81f.)

Pleonastische Negation findet sich, wie auch Behaghel konstatiert, heutzutage noch in einigen regionalen Varianten des Deutschen, wie etwa dem Bairischen und dem Zürichdeutschen, vgl. die Beispiele in (20) (das bairische entnommen aus Zehetner (1985), das zürichdeutsche aus Weber (1987)):

(20) bairisch Koan bessan weasd ned finddn

((K)einen besseren wirst du nicht finden)

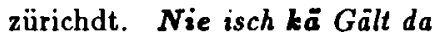

(Nie ist (kein) Geld da)

Allerdings ist diese diskontinuierliche Negation gewissen Beschränkungen unterworfen hinsichtlich der Funktion des negierten Elementes im Satz: im Bairischen ist pleonastische Negation nur akzeptabel, wenn das Objekt negiert wird, bei Subjektnegation ist der Satz unakzeptabel, vgl. die Sätze in (21):

(21) (a) Da Loisl hot neamats net g'seng

(Der Alois hat niemanden (nicht) gesehen) 
(b) Neamats hot an Loisl g'seng

(Niemand hat den Alois gesehen)

* Neamats hot an Loisl net g'seng

Ist niemand Objekt, wie in (a), so ist ein verstärkender Negationsträger möglich, ist niemand hingegen Subjekt des Satzes, wie in (b), dann wird der Satz durch einen zusätzlichen Negationsträger unakzeptabel.

Die Gründe für diese Subjekt/Objekt-Asymmetrie wurden gelegentlich erörtert. In Bayer (1988) wurde etwa eine Erklärung durch das universell geltende Empty Category Principle (ECP) im Rahmen der Prinzipien-Parameter-Theorie (PPT) diskutiert. In Lenz (1989) wurde anhand von Sätzen mit pleonastischer Negation aus verschiedenen Sprachen, Sprachstufen und Dialekten gezeigt, daB zuviele Daten gegen eine solche Begründung sprechen.

Ich fasse kurz zusammen:

- In vielen Sprachen läßt sich folgende Entwicklung nachweisen: ein Negationsträger wird seiner äußeren Form nach geschwächt und deshalb durch eine zusätzliche Wortform verstärkt, schlieBlich verschwindet er ganz, der Verstärker wird zum alleinigen Negationsträger und die Entwicklung beginnt von vorn.

- Von besonderem Interesse sind bei derartigen Entwicklungen diejenigen Stadien, in denen das ursprüngliche Negationswort und sein Verstärker gemeinsam auftreten und $\mathrm{e}$ i $\mathrm{n}$ e $\mathrm{n}$ - morphosyntaktisch diskontinuierlichen - Negationsträger bilden; der Verstärker hat seine Eigenbedeutung verloren, er wurde desemantisiert.

- Dies gilt auch für solche Verstärker, die ihrem Ursprung nach selbst Negationsträger sind: sie heben nicht die Bedeutung des ersten $\mathrm{Ne}-$ gationswortes auf, sondern bilden mit diesem zusammen eine semantische Einheit.

Abschwächung und evtl. Wieder-Verstärkung von Wortkörpern beschränkt sich natürlich nicht auf Negationsträger, sondern es handelt sich dabei um eine generelle Erscheinung in der Entwicklungsgeschichte von Sprachen überhaupt: Wenn ein Wortkörper, der eine wichtige Bedeutung trägt, zu schwach wird, um dieser Bedeutung gerecht zu werden, wird er entweder verschwinden und durch einen anderen ersetzt oder er wird äußerlich verstärkt. Ein typisches Beispiel für ersteres ist die Ersetzung des klassisch-lateinischen rus durch vulgärlateinisches campania, welches die Grundlage der entsprechenden Lexeme in den romanischen Sprachen wurde, während rus ausstarb (vgl. (22)). Die andere Möglich- 
keit, die Verstärkung von Wortkörpern, kann auf ganz unterschiedliche Weise geschehen; beispielsweise durch Anhängung eines Diminutivsuffixes, welches dabei seine Diminutivbedeutung verliert, also desemantisiert wird und lediglich zur Verstärkung des Wortkörpers dient; ganz systematisch geschah solches etwa im Vulgärlateinischen: so wurde (vgl. (23)) aus sol soliculum (und daraus später frz. soleil), aus agnus wurde agnellus (und daraus später frz. agneau):

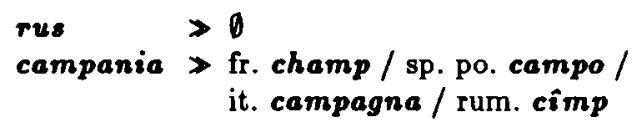

(23) sol

$>$ soliculum $>$ soleil

agnus $>$ agnellus $>$ agneau

Die lateinisch-französische Sprachgeschichte weist noch viele weitere Fälle dieser Art auf. In den nach-lateinischen Stadien zeigt sich auch hier dann wieder eine Abschwächung der jeweiligen Wortkörper. Doch zurück zu den Negationsträgern.

\section{Stellung der Negationsträger}

Bisher standen Abschwächung und Wieder-Verstärkung von Negationswörtern im Zentrum meiner Ausführungen. Wenn wir die Entwicklung der Negationsträger in den verschiedenen Sprachen betrachten (etwa die Beispiele in (2), (4), (5) und (6) oben), so stellen wir fest, daß sich im Laufe der jeweiligen Entwicklung nicht nur die äußere Form, sondern auch die $\mathrm{S}$ t e ll u $\mathrm{n} g$ der Negationsträger ändert, und zwar speziell ihre Stellung relativ zum finiten Verb. Schon die wenigen hier angeführten Beispiele zeigen, daB man von drei Stellungsvarianten ausgehen kann, die mit einer gewissen Regelhaftigkeit einander ablösen:
1. NEG $V$
präverbale Negation
2. NEG $V$ NEG diskontinuierliche Negation
3. $\quad V N E G$ postverbale Negation

Im ersten Stadium steht der Negationsträger vor dem finiten Verb, im zweiten Stadium gibt es diskontinuierlich verteilte Negationsträger, die sich die Negationsbedeutung teilen, im dritten Stadium gibt es einen Negationsträger hinter dem finiten Verb. Und dieser tendiert nun dazu, in die präverbale Position zu wandern, so daß die Ausgangsposition 1 wiederhergestellt wird.

Die Entwicklung im Englischen zeigt deutlich diese zyklische Bewegung des Negationsträgers von präverbal über diskontinuierlich zu postverbal und wieder zu präverbal (vgl. (25) und auch (4)): 


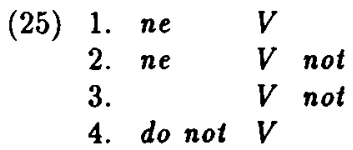

Präverbales $n e$ - diskontinuierliches ne not-postverbales not - präverbales not, verstärkt durch do.

Wie Lehmann (1978, S. 104) anführt, sind aus frühneuenglischer Zeit auch einzelne Sätze mit präverbalem not ohne do belegt - eine Konstruktion, die im Gegenwartsenglischen mit anderen Negationsträgern noch möglich ist, etwa mit never:

\section{I never went to London}

Die Verstärkung des Negationsträgers innerhalb der präverbalen Position - wie im Englischen durch do und im Lateinischen durch oenum (hier nochmals aufgeführt in (27)) - ist nicht der nächste Zyklusschritt, sondern dient dazu, den Negationsträger möglichst lange innerhalb der präverbalen Position zu erhalten und eine zu schnelle Abschwächung und somit den nächsten Zyklusschritt, den der Diskontinuität, zu vermeiden:

$\begin{array}{llll}\text { (27) engl. } & & \text { lat. } & \\ \text { not } & V & \text { ne } & V \\ \text { do not } & V & \text { ne oenum } & V \\ \text { don't } & V & \text { non } & V\end{array}$

Ich beziehe mich damit auf die Ausführungen in Jespersen (1917), Bernini (1987) und Horn (1989), ohne hier im Detail darauf eingehen zu können. Der entscheidende Punkt ist, daB der präverbalen Stellung des Negationsträgers eine besondere Bedeutung zukommt. Sie scheint in den indoeuropäischen Sprachen die ursprüngliche zu sein und führt die zyklische Entwicklung in den einzelnen Sprachen offensichtlich immer wieder zu dieser Stellung zurück.

Die präverbale Stellung des Negationsträgers scheint auch die universell vorherrschende zu sein. Wie Bernini (1987) ausführt, sind nichtpräverbale, d.h. postverbale und diskontinuierliche, Negationsträger in den Sprachen der Welt nicht sehr zahlreich. Interessanterweise konzentriert sich ihr Vorkommen im Bereich der romanischen, germanischen und keltischen Sprachen; daneben treten sie gehäuft nur noch in einigen afrikanischen Sprachgruppen auf.

Schon Jespersen (1917, S. 5) stellte fest, daB präverbale Stellung des Negationsträgers wesentlich häufiger vorkommt als nicht-präverbale, er spricht von einer „natürlichen Tendenz, das Negationswort als erstes zu 
plazieren". Horn (1989, S. 446) formuliert mit Bezug auf Jespersen das "Neg First Principle”, das er allerdings weiter faft und damit auch solche Konstruktionen einbezieht, in denen der Negationsskopus sich auf nichtverbale Elemente beschränkt; er spricht von der „Vorliebe der Negation, ihrem Fokus voranzugehen", vgl. (28), dazu einige Beispiele aus dem Gegenwartsdeutschen in (29):

(28) Neg First Principle: the preference for negation to precede its focus (Horn 1989, S. 446)

(29) Sie kommt nicht heute (sondern morgen)

[vs. Sie kommt heute nicht]

Er liest nicht das Buch (sondern die Zeitung)

[vs. Er liest das Buch nicht]

Nicht Petra schlaft (sondern Maria)

[vs. Petra schläft nicht]

In den Sätzen links steht jeweils nur der unterstrichene Ausdruck im Skopus der Negation, es handelt ich um replazive oder kontrastierende $\mathrm{Ne}$ gation, die eine angeschlossene sondern-Phrase erfordert. In den Sätzen rechts in eckigen Klammern hingegen umfaBt der Negationsskopus den gesamten Restsatz; es handelt sich um das, was in der älteren Literatur meist als "Verbnegation" bezeichnet wird, angemessener ist der Terminus "Satznegation".

Negationen, die keine Satznegationen sind, werden in der Literatur recht unterschiedlich behandelt. Es würde zu weit und zu unnötiger Verwirrung führen, sie hier in die Betrachtungen miteinzubeziehen. Ich beschränke mich deshalb weiterhin auf Verb- bzw. Satznegation.

Versuche, die Position der Negationsträger mit bestimmten typologischen Satzmustern in Verbindung zu bringen, waren nicht sehr erfolgreich, da es zu viele Gegenbeispiele für die jeweils postulierten Zuordnungen gibt. Wenn man das Deutsche und die skandinavischen Sprachen betrachtet, dann scheint eine solche Zuordnung von Negationsposition und Satzmuster zunächst naheliegend. So wie im Deutschen unterscheiden sich auch in den skandinavischen Sprachen Matrix- und Konstituentensätze durch die unterschiedliche Position des finiten Verbs: in Matrixsätzen liegt im unmarkierten Falle SVO-Stellung vor (Subjekt-VerbObjekt), in Konstituentensätzen SOV-Stellung (Subjekt-Objekt-Verb). Entsprechend unterscheidet sich auch die Position des Negationsträgers: bei SVO-Stellung steht er postverbal, bei SOV-Stellung präverbal, vgl. die Sätze in (30) (das norwegische Beispiel wurde entnommen aus Sandvei $(1956$, S. 169)): 
SVO: postverbal

dt. Ich glaube dem Mann nicht

norw. Jeg tror ikke mannen
SOV: präverbal

(daB) tch dem Mann nicht glaube

(at) jeg ikke tror mannen

Diese im Deutschen und Skandinavischen beobachtbare Zuordnung läßt sich jedoch nicht generalisieren, schon in der verwandten englischen Sprache bestätigt sie sich nicht, vgl. (31):
SVO: präverbal
SVO: präverbal
engl. I don't believe the man (that) I don't believe the man

Hier liegt sowohl im Matrix-als auch im Konstituentensatz SVO-Stellung vor und in beiden Fällen präverbale Negation. Es hat verschiedene Versuche gegeben, unter Berücksichtigung zusätzlicher Faktoren plausible Generalisierungen zu finden, etwa Vennemann (1974), Lehmann (1978) und Bernini (1987), doch bleiben viele Fragen offen. Ramat bringt den Stand der Dinge auf einen kurzen Nenner:

(32) "We must accept for the moment ... that it is dangerous to relate NEG (discontinuous or simple) to a typology of word order in a simplistic and schematic way." (Ramat 1987, S. 185)

Für das hier zu behandelnde Thema ist dieses Problem von nur marginaler Bedeutung, Horn äußert sich diesbezüglich folgendermaBen:

(33) "Word order is not a crucial factor (or at least not the crucial factor) in motivating Jespersen's cycle." (Horn 1987, S. 457)

Auslöser für Jespersens Zyklus ist stets ein zu schwach gewordener Negationsträger, der nach formaler Verstärkung verlangt, um seiner Funktion gerecht zu werden.

\section{Areallinguistische Ausprägungen}

Jespersens Zyklus beschreibt einen diachronen Ablauf in der jeweiligen Entwicklungsgeschichte einer bestimmten Sprache: von einem präverbalen über ein diskontinuierliches und ein postverbales wieder zum präverbalen Stadium. Die einzelnen Stadien sowie ihre zeitlichen Ausdehnungen sind von Sprache zu Sprache verschieden. Im Deutschen und Englischen beispielsweise lief die Entwicklung über Jahrhunderte parallel: in altenglischer/altdeutscher Zeit präverbale Negation, im Mittelalter diskontinurerliche Negation, seit dem Übergang zur Neuzeit postverbale Negation. Das Deutsche ist seitdem in diesem Stadium stehengeblieben, das Englische hat schon vor Jahrhunderten den nächsten Schritt zur präverbalen Negation vollzogen. Im Französischen hat sich das seit den ältesten Tex- 
ten belegte präverbale Stadium zeitgleich mit dem Altdeutschen und Altenglischen bis in die mittlere Sprachepoche hinein erhalten; das darauf folgende Stadium diskontinuierlicher Negation blieb jedoch weitaus länger erhalten als in den beiden anderen Sprachen; erst in unserem Jahrhundert deutet sich ein Übergang zum postverbalen Stadium an. Alle drei Sprachen hatten vor gut tausend Jahren dieselbe Ausgangsposition, nämlich präverbale Negation, heute befindet sich jede von den Dreien in einem anderen Stadium: Französisch diskontinuierlich mit Tendenz zu postverbal, Deutsch seit langem postverbal und Englisch bereits wieder präverbal.

Mit diesem synchron so uneinheitlichen Zustand befassen sich drei italienische Sprachwissenschaftler mit jeweils unterschiedlicher Schwerpunktsetzung: Molinelli (1987) untersucht die Situation in den heutigen romanischen Sprachen unter Einbeziehung vieler regionaler Varianten und konstatiert ein areales typologisches Kontinuum. Bernini (1987) analysiert die heutige Situation der germanischen Sprachen, ohne auf regionale Varianten einzugehen und konstatiert ein Kontinuum, das an das romanische Kontinuum anschließt. Und Ramat (1987) befaßt sich mit der gegenseitigen Beeinflussung der beiden Kontinua.

Ich fasse die Ergebnisse ihrer Untersuchungen kurz zusammen. Präverbale Negation weisen im romanischen Sprachraum synchron folgende Sprachen auf: Portugiesisch, Spanisch, Italienisch, Rumänisch und OstRomansch (Romansch wird laut Crystal (1987, S. 442) von ca. 50.000 Menschen im Schweizer Kanton Graubünden gesprochen), vgl dazu die Beispielsätze in (34), entnommen aus Molinelli (1987, S. 166):

$\begin{array}{ll}\text { Portugiesisch } & \text { Não venho } \\ \text { Spanisch } & \text { No vengo } \\ \text { Italienisch } & \text { Non vengo } \\ \text { Rumänisch } & \text { Nu vin } \\ \text { Ost-Romansch } & \text { Riconun avaiva mamma }\end{array}$

Diskontinuierliche Negation findet sich außer im Französischen noch im Catalanischen, im Zentral-Romansch und im Ladinischen (das laut Crystal (1987, S. 440) noch etwa 20.000 Menschen in Südtirol sprechen), Beispiele in (35):

(35) Französisch

Catalanisch

Zentral-Romansch

Ladinisch
Je ne viens pas

No te'l deixarà pas

Ke co nu fatschi britch

Ne ste pa a davei festidi de nos 
Postverbale Negation konstatiert Molinelli im Provençalischen, im WestRomansch und im Lombardischen, Beispiele in (36):

\section{(36) Pro}

$\begin{array}{ll}\text { Provençalisch } & \text { Voli pas } \\ \text { West-Romansch } & \text { Kwela diuna play a mi buk } \\ \text { Lombardisch } & \text { Dormi nô }\end{array}$

Auf einen kurzen Nenner gebracht: präverbale Negation findet sich im südlichen und diskontinuierliche im zentralen und nördlichen romanischen Sprachgebiet, postverbale Negation konzentriert sich im Zentrum, kommt jedoch in keiner der nationalen Standardsprachen vor.

Ein Phänomen, das bei der Betrachtung der Daten in (34) bis (36) ins Auge fällt, auf das Molinelli jedoch nicht weiter eingeht, ist die starke Differenzierung im relativ kleinen Romansch-Sprachgebiet mit insgesamt nur etwa 50.000 Sprechern: im Osten präverbale, im Zentrum diskontinuierliche und im Westen postverbale Negation. Berninis (1987) Untersuchung des germanischen Sprachraums ist insofern unvollständig, als er die regionalen deutschen Varianten mit pleonastischer Negation völlig außer Betracht läBt. Er unterscheidet:

1. Sprachen mit präverbaler Negation wie das Englische (Berninis Beispielsatz in (37)).

2. Sprachen mit postverbaler Negation und Bindung des Negationsträgers ans Verbsyntagma, wie die nordgermanischen Sprachen, wobei er nur die Matrixsatz-Struktur zugrundelegt (seine Beispielsätze in (38)).

3. Sprachen mit postverbaler Negation in Matrixsatz-Konstruktionen, die darüberhinaus noch "rhematische" Negation zulassen, er meint damit Sätze wie in (29) (nicht das Buch, nicht heute, nicht Petra) und Sätze mit wortinterner Negation wie deutsch kein, niederländisch/afrikaans geen und jiddisch keyn (seine Beispielsätze in (39)). Jiddisch und Afrikaans weisen hier diskontinuierliche Negation auf. Auch im Bereich des Niederländischen gibt es einzelne regionale Varianten mit diskontinuierlicher Negation, beispielsweise im Raum Utrecht.

(37) Englisch I do not care

(38) Isländisch pad veit eg ekki

Norwegisch eg sâ ham ikke

Dänisch Jeg ved at han ikke har penge

Schwedisch Han kunde icke komma 
(39)
Deutsch Er kannte keine Regeln
Jiddisch Im darf men keyn finger in moyl nit araynleygn
Afrikaans Daar is geen kos in die kas nie

Bernini konstatiert ein germanisches Kontinuum mit Englisch und seiner präverbalen Negation am einen Ende, den "kontinentalen" germanischen Sprachen mit "rhematischer" Negation am anderen Ende und den nordgermanischen Sprachen mit verbsyntagma-gebundenen Negationsträgern in der mittleren Position.

Im Hinblick auf Jespersens Zyklus sind Berninis „kontinentale” Sprachen als Gruppe jedoch uninteressant. Das Deutsche gehört aufgrund seiner postverbalen Negation in V2-Sätzen in dieselbe Gruppe wie die skandinavischen Sprachen. Afrikaans und Jiddisch sowie einige deutsche und niederländische Dialekte mit diskontinuierlicher Negation bilden eine Gruppe für sich.

Das romanische und das germanische Kontinuum treffen sich da, wo die Sprachen diskontinuierliche Negation aufweisen. Eine verbindende Position zwischen den beiden Kontinua sieht Bernini auch in den keltischen Sprachen, die ebenfalls diskontinuierliche Negation aufweisen (vgl. die Beispiele in (40)); er betrachtet diskontinuierliche Negation als "Zwischenstadium" in der Negationsentwicklung:

(40) Bretonisch Ne lavaro ket kement-se

Walisisch Nid ydyw'r tad ddim yn qweithio yn y siop

Ramat (1987) geht der Frage nach, ob die streckenweise sehr ähnliche Negations-Entwicklung in den romanischen und germanischen Sprachen auf gegenseitige Beeinflussung schließen läßt. Gemeinsamer Ausgangspunkt war die indoeuropäische Negationspartikel ${ }^{*} n e$, deren Wortkörper schwach war und schon früh zur Klitisierung neigte, siehe etwa lateinisch non (entstanden aus ne oenum). Die zyklische Schwächung und Verstärkung des Negationsträgers verlief in den einzelnen Sprachen vermutlich unabhängig voneinander, streckenweise mag es jedoch gegenseitige Beeinflussungen gegeben haben, historische Kontakte zwischen romanischen und germanischen Populationen sind hinreichend bekannt. Gemeinsam ist den Sprachen beider Zweige die zyklische Änderung der Negationsposition im Laufe der Jahrhunderte und die Tatsache, daB sich synchron nicht-präverbale Negationen gerade in ihren Gebieten häufen, während in fast allen übrigen Sprachgebieten der Welt präverbale Negation vorherrscht. 
Zusammenfassend läßt sich festhalten:

Die drei diachron zu beobachtenden, einander zyklisch ablösenden Negations-Stadien lassen sich im romanisch-germanischen Sprachgebiet auch synchron nachweisen. Wahrscheinlicher Ausgangspunkt der Negation in allen Sprachen dieses Gebietes war die indoeuropäische Negationspartikel *ne in präverbaler Position. Die Entwicklung der einzelnen Spachen verlief unterschiedlich bezüglich der zeitlichen Ausdehnung der drei Negations-Stadien, woraus die Uneinheitlichkeit der heutigen Situation resultiert. Die Verteilung der einzelnen Negationstypen läßt jedoch areale Konzentrierungen erkennen. Grob betrachtet - ausgehend von V2Konstruktionen und dialektale Varianten außer acht lassend - ergibt sich folgende Verteilung: im Westen und Süden präverbale Negation, im westlichen Zentrum diskontnuierliche Negation, im Norden und im östlichen Zentrum postverbale Negation:

$\begin{array}{lll}\text { präverbal: } & \text { Westen: } & \text { englisch } \\ \text { Süden: } & \begin{array}{l}\text { portugiesisch, spanisch, } \\ \text { italienisch, rumänisch }\end{array} \\ \text { diskontin.: } & \text { Westl. Zentrum: } & \text { französisch, catalanisch } \\ \text { postverbal: } & \text { Norden: } & \text { skandinavisch } \\ & \text { Östl. Zentrum: } & \text { deutsch }\end{array}$

Diese gegenwärtig zu konstatierende Situation betrifft einen punktuellen Querschnitt. Sie sollte jedoch nicht darüber hinwegtäuschen, daß die Negationsträger auch weiterhin auf Wanderschaft sein werden.

\section{Literatur}

Bayer, Josef (1988): ECP und Logische Form: Eine Anmerkung zur doppelten Negation im Bairischen. Ms. MPI Nijmegen.

Behaghel, Otto (1924): Deutsche Syntax. Band 2. Heidelberg.

Bernini, Giuliano (1987): Germanic and (Gallo-)Romance negation: an area typology. In: Ramat, P. (ed.): Linguistic Typology. Berlin etc. S. 172178.

Crystal, David (1987): The Cambridge Encyclopedia of Language. Cambridge.

Horn, Laurence R. (1989): A Natural History of Negation. Chicago etc.

Hutterer, Claus Jürgen (1990): Die germanischen Sprachen. 3. Auflage. Wiesbaden.

Jacobs, Joachim (1991): Negation. In: Stechow, A. v./Wunderlich, D. (Hg.): Semantik. Berlin etc. S. 560-596.

Jespersen, Otto (1917): Negation in English and Other Languages. Historiskfilologiske Meddelelser 1,5. Kopenhagen. 2. Auflage 1966. 
Lehmann, Winfried P. (1978): Changes in the Negative Sentence Pattern in German. In: Hartmann, D. et al. (Hg.): Sprache in Gegenwart und Geschichte. Köln etc.

Lenz, Barbara (1989): Subjekt/Objekt-Asymmetrien bei doppelter Negation. Ms. Universitāt Wuppertal.

Molinelli, Piera (1987): The current situation as regards discontinuous negation in the Romance languages. In: Ramat, P. (ed.): Linguistic Typology. Berlin etc. S. 165-172.

Moser, Hugo/Ingeborg Schröbler (1969): Mittelhochdeutsche Grammatik. Tübingen.

Paul, Hermann (1920): Deutsche Grammatik. Band IV. Halle a.d.S.

Ramat, Paolo (1987): The diachronic perspective and typology. In: Ramat, $P$. (ed.): Linguistic Typology. Berlin etc. S. 178-187.

Sandvei, Marius (1956): Norwegische Konversations-Grammatik. 3. Auflage. Heidelberg.

Schūtzeichel, Rudolf (1981): Althochdeutsches Wörterbuch. 3. Auflage. Tübingen.

Uhl, Wilhelm (1906): Entstehung und Entwicklung unserer Muttersprache. Leipzig.

Vennemann, Theo (1974): Theoretical Word Order Studies: Results and Problems. In: Papiere zur Linguistik 7, S. 5-25.

Weber, Albert (1987): Zürichdeutsche Grammatik. 3. Auflage. Zürich.

Zehetner, Ludwig (1985): Das bairische Dialektbuch. Mūnchen. 


\title{
KARIN DONHAUSER
}

\section{Negationssyntax in der deutschen Sprachgeschichte: Grammatikalisierung oder Degrammatikalisierung?*}

\begin{abstract}
Die Diskussion um die Entwicklung der Negation im Deutschen hat durch den Bezug auf das sprachtypologische Modell des Jespersen-Zyklus eine perspektivische Einengung erfahren, durch die zentrale Aspekte dieser Entwicklung, die Diversifikation der Negationskennzeichnung vom Althochdeutschen zum Neuhochdeutschen und der Stellenwert der Phänomene der Mehrfachnegation, weitgehend ausgeblendet bzw. unzutreffend bewertet wurden. Erweitert man die Untersuchungsperspektive in diesen beiden Bereichen, so ergibt sich nicht nur ein wesentlich differenzierteres Bild der historischen Entwicklung des Deutschen, sondern man wirft zugleich einen Blick hinter die Kulissen des Jespersen-Zyklus, d.h., man erhält Einblick in strukturelle Optionen für die Realisierung der Kategorie Negation innerhalb der Grammatik, die im Rahmen typologischer Überlegungen zu berūcksichtigen sind.
\end{abstract}

\section{Problemstellung: Von Jespersens Zyklus zur Negationssyntax des Deutschen}

Die Entwicklung der Negation oder - genauer gesagt - des Negationsausdrucks im Deutschen ist in den vergangenen Jahrzehnten dominant unter einer Perspektive betrachtet worden, nämlich mit Fokus auf die Herausbildung des "verbalen Negators" nicht, die bereits von Jespersen (1917) als Beispiel für seine Vorstellung von der zyklischen Erneuerung der Negationskennzeichnung angeführt wird. Dieser Prozeß, der im Deutschen mit einer Positionsveränderung verbunden ist, wird im allgemeinen in folgender Weise schematisiert und beschrieben:

* Die Überlegungen, die in diesem Aufsatz kondensiert prāsentiert werden, habe ich in den Jahren 1992 und 1993 in Vorträgen an den Universitäten Passau, Osnabrück, Berlin und Jena (DGfS-Tagung) ausführlich vorgestellt. Diese Vorträge sind bislang nicht publiziert. - Wertvolle Unterstützung bei der Fertigstellung dieses Manuskriptes verdanke ich Frau Koyka Stoyanova (Berlin), die die Glossierung der alt- und mittelhochdeutschen Belege besorgt hat. 
(1) Schema 1:

$\begin{array}{llll}\text { Phase I } & n \imath & +V_{\text {fin }} \\ \text { Phase II } & n \imath & +V_{\text {fin }}+(n \imath w \imath h t) \\ \text { Phase III } & e n / n \imath+V_{\text {fin }}+n \imath h t \\ \text { Phase IV } & (n e) & +V_{\text {fin }}+n \imath c h t \\ \text { Phase V } & & +V_{\text {fin }}+n \imath c h t\end{array}$

Er beginnt in spätalthochdeutscher Zeit. Dort tritt zu der aus dem Germanischen überkommenen Negationspartikel $n \imath$ (Phase I), die im allgemeinen prä-finit, d.h. unmittelbar vor dem finiten Verb plaziert ist, immer häufiger die ursprünglich wohl als adverbıaler Akkusativ zu deutende Form niwiht ('nicht-etwas') oder nzowiht ('nicht-irgendetwas'), die ihrerseits in post-finiter Stellung erscheint und die von Jespersen funktional als Negationsverstärker analog zu nhd nicht die Bohne, nicht ein $b_{2} \beta$ chen etc. gedeutet wird (Phase II). Die Setzung dieses Negationsverstärkers wird im Mittelhochdeutschen zunehmend obligatorisch (Phase III), die Negationskennzeichnung geht auf nıcht über und verlagert sıch weg von der tonschwachen Partikel ne, die dann im Frühneuhochdeutschen ihrerseits nur noch fakultativ gesetzt wird (Phase IV) Nach dem 16. Jahrhundert ist sie nicht mehr belegt

Die Fokussierung auf diesen Entwicklungsgang, der in der neueren Forschung vorrangig unter wortstellungstypologischen Gesichtspunkten (vgl Jacobs $1982, \mathrm{~S} 415 \mathrm{ff}$ und die dort referierte Literatur) diskutiert wurde und der lokal als Grammatikalisıerungsprozeß zu werten ist, beinhaltet jedoch zwei gravierende perspektıvische Verzerrungen, die das Verständnis der Negationsentwicklung im Deutschen nachhaltig beeinträchtigt haben

Die erste perspektıvısche Verzerrung betrifft den Status der Mehrfachnegation $1 \mathrm{~m}$ Deutschen, die im Kontext von Schema 1 als reine Transitionserscheinung gedeutet wird In diesem Sinne charakterisieren z B Pensel (1981) und noch deutlicher Qian (1987) den Entwicklungsablauf bei den Veränderungen der Negationskennzeichnung im Deutschen als Übergang von einem mononegativen System der Negationskennzeichnung zu einem anderen, der durch ein zwischengelagertes polynegatıves System vermittelt wird. Diese Verallgemeinerung von Schema 1 ist in zweierlei Hinsicht unzutreffend

Erstens, sie ignoriert das bereits im 19. Jahrhundert erarbeltete Wissen über das Negationssystem des Althochdeutschen, das von Anfang an außerhalb der noch wenig verbreiteten Doppelkennzeichnung der Nega- 
tion durch ni ... niwiht regulär auch andere Instanzen einer Mehrfachkennzeichnung negativer Sätze vorsieht:

Ther heilant ni gab iru nihhein antuurti (T 85,3) der Heiland NEG gab ihr NEG-ein Antwort

Kombiniert werden dabei die prä-finite Negationspartikel $n i$, deren Setzung im Althochdeutschen im allgemeinen obligatorisch ist, und die „negative" Form von Indefinitpronomina (z.B. nihhein), die ihrerseits morphologisch transparent - durch die Verbindung der Negationspartikel ni mit dem Indefinitpronomen gebildet werden. Diese zusätzliche Negationskennzeichnung am Indefinitum ist im Althochdeutschen zwar allem Anschein nach nur optional und nicht obligatorisch; dennoch kann das Negationssystem des Althochdeutschen vor diesem Hintergrund kaum pauschal als mononegativ klassifiziert und beschrieben werden.

Zweitens, die Aussage, das Negationssystem des Neuhochdeutschen sei mononegativ, gilt nur für die Standardvarietät des geschriebenen Deutsch. Im Nonstandard, in den Dialekten und ebenso im standardsprachnahen gesprochenen Deutsch, sind Mehrfachkennzeichnungen der Negation auch im Neuhochdeutschen möglich, wenn nicht sogar geläufig:

Ja sogd da Doogda, merkens ihnen, vor den sechs Wochen darf keine alte Frau kein Kind nicht anschauen. (DuH 79)

\section{Keine Macht für niemand.}

Die Mehrfachnegation ist demnach definitiv nicht per se ein Charakteristikum der mittelhochdeutschen Übergangsphase, sondern sie ist eine durchgehend präsente Strukturoption, die als solche offenbar nicht an die Veränderungen in der Realisierung der Negationskennzeichnung gebunden ist.

Die zweite perspektivische Verzerrung, die mit der Generalisierung von Schema 1 verbunden ist, ergibt sich unmittelbar aus der ausschließlichen Fokussierung auf die Negationspartikel nicht. Dabei wird ausgeblendet, daß die Partikel nicht im Neuhochdeutschen nicht die einzige Möglichkeit darstellt, einen Satz als negativ zu markieren. Das Neuhochdeutsche verfügt vielmehr über ein ganzes Sample von Negationswörtern (nichts, niemand, nie, nirgends, kein, keinesfalls, ...) mit eigenständiger negativer Kraft und mit jeweils charakteristischen Einsatzbereichen, die über den Wortartstatus und/oder zusätzliche Bedeutungkomponenten geregelt sind. So kann etwa die Negationspartikel nicht als Ausdruck der 
Satznegation nur dann verwendet werden, wenn im Satz keine Indefinita vorkommen bzw. wenn die Indefinita auberhalb des Skopus der Negation liegen.

Ich habe niemanden gesehen.

'Es ist nicht der Fall, daß ich jemanden gesehen habe.'

(5b) Ich habe jemanden nicht gesehen.

'Es gibt jemanden, den ich nicht gesehen habe.'

\#'Es ist nicht der Fall, daB ich jemanden gesehen habe.'

Im Althochdeutschen dagegen ist die Setzung von $n i$ in der Regel durchwegs obligatorisch: $n i$ erscheint auch dann, wenn im Satz Indefinita vorhanden sind, die sich im Skopus der Negation befinden.

(6) Gibot, thaz sie firnamin, ouh wiht mit in ni namin (O III 14,89)

(er) gebot, daB sie beachteten und etwas mit ihnen NEG nahmen

'er gebot, daß sie das beachteten und nichts mit sich nahmen' \#'er gebot, ... und etwas nicht mit sich nahmen'

Die mit ni gebildeten „negativen" Indefinita, die etymologisch einem Teil der Negationswörter des Neuhochdeutschen zugrunde liegen, haben im Althochdeutschen in der Regel noch keine selbständige negative Kraft. Sie fungieren dominant als "polarity items", d.h., sie bilden additive, nicht alternative Kennzeichnungsinstanzen der Negation im Althochdeutschen, die zudem nicht obligatorisch, sondern nur fakultativ zum Einsatz kommen.

Vergleicht man in dieser Weise die Gesamtsystematik des Negationsausdrucks im Alt- und im Neuhochdeutschen, so wird deutlich, daß die Funktionen des althochdeutschen Negators $n i$ im Neuhochdeutschen nicht einfach auf die Negationspartikel nicht übergehen, sondern der Funktionsbereich von ahd. $n i$ ist im Neuhochdeutschen verteilt auf eine ganze Gruppe von Negationswörtern mit unterschiedlichem syntaktischkategorialen Status, die zudem auch verschiedene Stellungseigenschaften haben. Der in Schema 1 modellierte Übergang von ahd. ni zu nhd. nicht ist demnach kein isoliert zu betrachtendes Phänomen, sondern er steht in einem größeren Entwicklungszusammenhang, der im Sinne von Schema 2 vorrangig dadurch gekennzeichnet erscheint, daß die morphologische und syntaktische Homogenität des Negationsausdrucks verloren geht: 
(7) Schema:

\begin{tabular}{l|l} 
AHD & NHD \\
ni ... (ni+Indef.) & $\begin{array}{l}\text { nicht } \\
\text { nichts } \\
\text { niemand } \\
\text { nirgends } \\
\text { nie } \\
\text { niemals } \\
\text { kein } \\
\text { keinesfalls } \\
\ldots\end{array}$ \\
\hline
\end{tabular}

Die sprachhistorische Interpretation dieses Diversifikationsprozesses erfordert einen deutlich erweiterten Untersuchungsansatz, und zwar sowohl im Hinblick auf die zu analysierenden sprachhistorischen Datensätze als auch in bezug auf den grammatiktheoretischen Rahmen der Untersuchung, der mit Blick auf Art und Umfang der zu interpretierenden Phänomene im größeren Kontext einer Negationssyntax des Deutschen zu definieren ist. Die moderne Forschung offeriert hierzu für das Neuhochdeutsche zwei grundsätzlich verschiedene Modelle, die in folgender Weise zu charakterisieren sind:

1) ein transformationalistisches Modell:

Dieses erklärt die in Schema 2 aufgeführten Negationswörter des Neuhochdeutschen in gleicher Weise als Realisierungsinstanzen einer abstrakten syntaktischen Kategorie NEG (moderne Grammatiker sprechen in diesem Zusammenhang von einer funktionalen Kategorie), die unter bestimmten Bedingungen an im Satz vorkommende Indefinita attrahiert und mit diesen verschmolzen wird. Unterbleibt diese Attraktion, dann erscheint in der Oberflächenstruktur die Partikel nicht, die als unmittelbare Realisierung von NEG zu betrachten ist (vgl. Kürschner 1983).

2) ein lexikalistisches Modell:

Dieses sieht die Satznegation NEG im Neuhochdeutschen als Teil der lexikalischen Bedeutung der in Frage stehenden Wörter. Die Auswahl und Positionierung des Kennzeichnungsmittels richtet sich nach den Skopusverhältnissen im Satz, wobei die negativen Indefinitpronomina die Stellungsbeschränkungen des in diesem Analyserahmen meist als Satzadverbiale klassifizierten Negators nicht kompensieren (vgl. Jacobs 1982). 
Diese beiden Modelle, die für das Neuhochdeutsche bis heute kontrovers diskutiert werden, werfen in jeweils spezifischer Weise Licht auf Art und Umfang der grammatischen Veränderungen, die dem in Schema 2 skizzierten Diversifikationsprozeß zugrunde liegen: Nach dem transformationalistischen Modell, das ohne weiteres auch auf das Althochdeutsche zu übertragen ist, beruhen die zwischen dem Alt- und dem Neuhochdeutschen zu beobachtenden Unterschiede im Negationsausdruck aller Wahrscheinlichkeit nach auf eher geringfügigen Differenzen im Bereich der syntaktischen Regelstruktur, auf einer Positionsveränderung der funktionalen Kategorie NEG innerhalb des Strukturbaums und auf der unterschiedlichen inhaltlichen Ausgestaltung einer „Zusatzregel”, die im Althochdeutschen wohl nicht als obligatorische Attraktionsregel, sondern als fakultative Kopier- oder Kongruenzregel zu fassen ist. Die Übernahme des lexikalistischen Modells für das Neuhochdeutsche dagegen impliziert eine grundlegendere Umstrukturierung im Negationssystem, da der Befund zum Althochdeutschen eine lexikalische Deutung der Negation dort wenig wahrscheinlich macht. In diesem Fall ergibt sich ein Veränderungsszenario, das als Degrammatikalisierung oder Lexikalisierung zu charakterisieren ist: das abstrakte Merkmal NEG verlagert sich von der Syntax in das Lexikon und definiert dort ein Wortfeld, das in einer spezifischen Weise wortartübergreifend organisiert ist.

Den sich hier abzeichnenden Interpretationsmöglichkeiten soll nun im folgenden in einer diachronen Studie etwas genauer nachgegangen werden, und zwar auf einer erweiterten Datenbasis, die nicht auf den ,verbalen Negator” beschränkt bleibt, sondern die die Entwicklung der „nominalen Negatoren" miteinschließt. Mein Interesse gilt dabei zunächst der Verlaufsstruktur der mit Schema 2 anvisierten Entwicklung, die bislang nur über ihre Eckpunkte beschrieben ist, und sodann einigen Beobachtungen zum Phänomen der Mehrfachnegation, die bei der Kalkulation der Negationsentwicklung im Deutschen mitberücksichtigt werden müssen.

\section{Ausgewählte Aspekte der Negationsentwicklung vom Althochdeutschen zum Neuhochdeutschen}

\subsection{Zur Verlaufsstruktur der Entwicklung}

Wie in Abschnitt 1 bereits näher erläutert, handelt es sich bei der Herausbildung von nhd. nicht nach allgemeiner Auffassung um einen mehrere Jahrhunderte umgreifenden, mehrstufigen Prozeß, dessen entscheidende Phase - die Verlagerung der Negationskennzeichnung auf den ursprünglichen Negationsverstärker - im Bereich des Mittelhochdeutschen anzusiedeln ist. Diese Vorstellung und die damit verbundene zeitliche Lo- 
kalisierung beruhen auf der Analysearbeit der Sprachhistoriker des 19. und frühen 20. Jahrhunderts, die die zentralen alt- und mittelhochdeutschen Textdokumente entweder vollständig oder zumindest in größeren Abschnitten ausgewertet haben. Ergebnis dieser Arbeit ist der im folgenden spezifizierte Befund, der synoptisch bei Behaghel (1924) zusammengetragen ist: Demnach findet sich vor Mitte des 11. Jahrhunderts im Althochdeutschen bestenfalls ein Hinweis für die Verwendung von niht bzw. niwiht als Negationsverstärker, nämlich die folgende Stelle aus dem Evangelienbuch Otfrids von Weissenburg, die Behaghel (1918, S. 230 und 1924, S. 70) neben zwei Stellen aus dem altsächsischen Heliand (H 5120 und $H$ 5471) als Erstbeleg für diesen Gebrauch von niwiht anführt:

ni zaweta imo es niawiht (O II 5,12)

NEG gelang ihm dessen NEG-etwas

Dabei wird zawen, das nur bei Otfrid belegt ist, von Behaghel als zweiwertiges Verb mit Dativ- und Genitivrektion interpretiert, was mit Blick auf die bei Kelle (1881, S. 722) aufgeführte gesamte Beleglage vertretbar, aber auch nicht zwingend erscheint. In allen anderen Belegen, in denen $n i$ und niwiht in Kombination miteinander auftreten, fungiert niwiht - so jedenfalls Behaghel - eindeutig nicht als adverbialer Negationsverstärker, sondern als Indefinitpronomen in Subjekts- oder Objektsfunktion, - eine Funktion, in der es als Vorläufer von nhd. nichts und nicht als Vorläufer von nhd. nicht zu betrachten ist. Der Gebrauch von niwiht als Negationsverstärker in Kombination mit ahd. ni wird daher für diese frühe Phase der deutschen Sprachgeschichte sicher zurecht als marginal betrachtet.

Diese Belegsituation, die für das 8. und 9. Jahrhundert charakteristisch ist, ändert sich um 1050 mit Notker III von St. Gallen, in dessen Werken das adverbielle, negationsverstärkende niht erstmals in größerem Umfang zu belegen ist. Behaghel zählt auf den ersten 100 Seiten von Notkers Psalmen immerhin bereits 8 Belege, die in ihrer Mehrzahl eindeutig als Instanzen des „verstärkenden” niht zu interpretieren sind:

(9) Ih ne habo niêht in gemeitun sô uilo geuueinôt. (N II 16,11) ich NEG-habe NEG grundlos so viel geweint

(10) Siê nechedent niêht. uuiêo mali christiani tuont. (N II 99,25) sie NEG-sprechen NEG wie schlechte Christen tun

Bei Williram ist - so Behaghel (1924, S. 70f.) - „die Anwendung von nicht bei der Verneinung des Verbs bereits grundsätzlich durchgeführt ... Von nun an ist niht neben en das Regelmäßige" mit einigen spezifischen Ausnahmen wie z.B. den Modalverben, die bis ins Frühneuhochdeutsche hinein dominant nur mit proklitischem en- negiert werden. Diese Regu- 
laritätsannahme, die im allgemeinen generell für das Mittelhochdeutsche übernommen wird, gilt bestenfalls bis in die Mitte des 13. Jahrhunderts. $\mathrm{Ab}$ dann mehren sich die Fälle von selbständig gebrauchtem nicht - man vergleiche dazu die zeitlich nicht weit auseinander liegenden Handschriften $\mathbf{A}$ und $\mathbf{B}$ des Nibelungenliedes.

(11a) des engerte niht her Sivrit (NL 43,4-Hs.B, Mitte 13. Jh.) dessen NEG-begehrte NEG Herr Siegfried

(11b) des gerte niht Sifrit (NL 43,4-Hs.A, 2. Hälfte 13. Jh.) dessen begehrte NEG Siegfried

Dies gilt vor allem für oberdeutsche Texte wie z.B. die Urkunden der Stadt Basel, die bereits in der Zeit von 1278 bis 1290 nur mehr ein Beispiel für die Verbindung von $e^{n-}$ und $n i h t$ aufweisen. In Texten anderer Provenienz wird $n$ iht in bestimmten Konstellationen noch länger von $n e$ bzw. en- begleitet, z.T. bis hinein ins 16 . Jahrhundert, das abgesehen von einigen dialektalen Besonderheiten (Behaghel 1918, S. 247) als maximale Vorkommensgrenze zu betrachten ist (Ebert/Reichman/Solms/Wegera 1993, S. 426). Die Verselbständigung von nicht als "verbaler Negator” ist aber wohl auch für nicht-oberdeutsche Texte wesentlich früher anzusetzen, spätestens im 15. Jahrhundert, in dem auf breiter Front Frequenzrückgänge bei der Setzung von ne/en- beobachtet werden (Pensel 1981, S. 306f.). - Soweit die nähere Aufschlüsselung des sprachistorischen Befundes, der dem in Schema 1 gefaßten Verlaufsprotokoll der Entwicklung von nhd. nicht zugrunde liegt.

Die oben angeführten Analysen der Sprachhistoriker des späten 19. Jahrhunderts geben in der gleichen Weise allerdings auch Einblick in den Werdegang der nominalen Negatoren, der vor allem in Hinblick auf die zeitliche Lokalisierung in charakteristischer Weise von dem des „verbalen Negators" abweicht. Dabei ergeben sich mindestens zwei Gruppen von "nominalen Negatoren”, die auch von ihrer morphologischen Struktur voneinander zu unterscheiden sind:

1) die mit ni gebildeten und auch noch neuhochdeutsch mit $n$ - anlautenden Negatoren wie niemand, nirgends, nichts, nie usw. und

2) der Negator kein und die von ihm abgeleiteten Bildungen wie keineswegs, keinesfalls usw., die keinen Reflex der althochdeutschen Negationspartikel in sich tragen.

Die Verselbständigung dieser beiden Gruppen von Negationswörtern läuft in keinem Fall unmittelbar parallel zur Entwicklung des verbalen Negators. Sie erfolgt vielmehr allem Anschein nach mit einer jeweils charakteristischen zeitlichen Verschiebung, wobei Gruppe 1 durch einen 
Vorlauf, Gruppe 2 dagegen durch einen leichten Nachlauf zu der Entwicklung des verbalen Negators gekennzeichnet erscheint. Grundlage für die Annahme eines solchen Vorlaufs im Falle der Gruppe 1 sind die sehr umfassend angelegten Untersuchungen zum Althochdeutschen, die - wie wir oben gesehen haben - für negationsverstärkendes niwiht nur einen zudem strittigen Beleg ausweisen. Ganz anders ist die Situation bei den nominalen Elementen der Gruppe 1. Sie alle sind im Althochdeutschen in der Kombination mit $n i$ gut ausgewiesen, ja sie erscheinen durchwegs bereits althochdeutsch auch allein in negierender Funktion so 2.B. in folgenden Belegen, die alle zweifelsfrei als negiert zu interpretieren sind:

(12) thaz imo fisg nihhein infloh (O V 14,23)

daB ihm Fisch NEG-ein entging

(13) nioman sententi sina hant in phluog inti uuidarscouuonti ist gifuoglih gotes rihhe (T 51,4)

NEG-jemand legend seine Hand an (den) Pflug und zurūckschauend ist geeignet Gottes Reich

(14) nio in altere araugta sih so in Israhel $(\mathrm{T} 61,6)$

NEG-je jemals (es) ereignete sich so in Israel

Dieser Entwicklungsvorsprung ist auch in vielen mittelhochdeutschen Texten noch durchaus erhalten, insofern als die nominalen Negatoren auch dort häufiger als das adverbiale nicht allein als Negationsträger erscheinen. Diese Differenzen nivellieren sich jedoch offenbar gegen Ende des 13. Jahrhunderts. Jedenfalls nimmt Behaghel (1924, S. 74) aufgrund seiner Untersuchungen an, daB der Verlust des $e n$ - in den Fällen, „wo sich niht neben $e n$-gestellt hat, ... Hand in Hand mit dem Untergang des enneben verneinten nicht-verbalen Gliedern (nieman, nehein usw.)" geht, d.h., für die letzte Phase des Verselbständigungsprozesses ist - zumindest beim derzeitigen Stand der Forschung - von einem Gleichlauf zwischen dem verbalen Negator und einem Teil der nominalen Negatoren auszugehen. Die nominalen Negatoren der Gruppe 2 (kein, keinesfalls usw.) dagegen haben durchgehend einen deutlichen Nachlauf zur Entwicklung des verbalen Negators. Dies gilt zunächst für die Entwicklung des „negativen Indefinitartikels" kein, der im Unterschied zu dem auch formal als negativ gekennzeichneten nihhein bis ins 16. Jahrhundert (Pensel 1981, S.321f., Ebert/Reichmann/Solms/Wegera 1993, S. 320) hinein auch in positiver Bedeutung ('irgendein') zu belegen ist - allerdings dominant in ganz spezifischen Kontexten: in nicht-affirmativen Sätzen

(15) waer er mir keine wile bi, er lieze sine untugend durch mich (Trist. 11628, zit. n. Paul/Wiehl/Grosse 1989, S. 379) wäre er irgendeine Weile bei mir er ließe ab (von) seiner Untugend durch mich 
bzw. in Verbindung mit der Komparation:

(16) mein gotlich hertze ist mer zu dir geneiget denn zu keinem menschen (A. Langmann 25, zit. n. Ebert/Reichmann/Solms/ Wegera 1993, S. 320)

mein göttliches Herz ist mehr zu dir geneigt als zu irgendeinem Menschen

Daneben erscheint kein in seiner Vorform dehein von Anfang an ebenso wie nihhein in negativen Sätzen,

(17) ezn gereit nie mit schilte dehein riter als volkommen

(Iw. 1458/59, zit. n. Paul/Wiehl/Grosse 1989, S. 379)

es-NEG ritt NEG-je mit (einem) Schild (NEG-)irgendein Ritter so

vollkommen

allerdings zunächst nicht mit eigenständiger negativer Kraft, wie sie für nihhein schon für das Althochdeutschen belegt ist. Die ersten Belege für die Verwendung von kein als selbständiger Negator datieren vielmehr aus dem 12. und 13. Jahrhundert (Paul/Wiehl/Grosse 1989, S. 379), also in etwa in den zeitlichen Bereich, in dem auch der verbale Negator nicht mit selbständiger negativer Kraft zu beobachten ist.

(18) man sol deheiniu wafen tragen in den sal (NL 1745,2)

man soll NEG-irgendwelche Waffen tragen in den Saal

Kein bleibt jedoch - wie insbesondere die Untersuchung von Pensel (1981) ausweist - in seiner Entwicklung im folgenden deutlich zurück: es findet sich bis ins 16. Jahrhundert hinein überdurchschnittlich häufig in Verbindung mit anderen Negationswörtern, vor allem in Verbindung mit nicht - eine Kombination, die auch noch heute im Nonstandard und in vielen Dialekten die mit Abstand geläufigste Form der Mehrfachkennzeichnung negativer Sätze darstellt.

(19) Frau Mutter / es bedarf hier keines Looses nicht. Das Recht der Erstgeburth / das Hertze / das mir bricht für das gemeine Heil $/$ bestimmen mir die Würde. (34)

(20) Do hejft koa Betn nimma, do ghört a Fuhr Mist hi, Mesner. (BW 16)

Dem entspricht, daß die von kein abgeleiteten Negationswörter wie keinesfalls, keineswegs usw. ihrerseits noch einmal jüngere Erscheinungen darstellen. Die einschlägigen Handbücher (vgl. DWB 1873, S. 493ff.) datieren ihr Auftreten ins 14. (keineswegs) bzw. 18. (keinesfalls) Jahrhundert, also in eine Zeit, in der die wesentlichen Umstrukturierungsprozesse im deutschen Negationssystem mit Sicherheit bereits abgeschlossen sind. 
Wir erhalten demnach unter Verwendung der seit dem 19. Jahrhundert vorliegenden Untersuchungsergebnisse ein gegenüber Schema 1 erweitertes Verlaufsprotokoll der in Frage stehenden Entwicklung, wonach in dem in Schema 2 anvisierten Gesamtprozeß drei, vielleicht sogar vier Teilentwicklungen $z u$ unterscheiden sind, die leicht phasenverschoben gegeneinander ablaufen:

Schema 3:

TE 1: Die Verselbständigung der nominalen Negatoren aus Gruppe 1

(selbständige Verwendung belegbar ab 8. Jh.)

TE 2: Die Verselbständigung des verbalen Negators nicht (selbständige Verwendung belegbar ab 12. Jh)

TE 3: Die Verselbständigung des Negators kein (selbständige Verwendung belegbar ab 13. Jh.)

TE 4: Die Verselbständigung weiterer Negationselemente auf der Basis von TE 3

Die Identifikation dieses Ablaufmusters beinhaltet folgende Festlegungen in bezug auf die sprachhistorische Interpretation des Entwicklungsganges: Erstens, die absolute Chronologie der Ereignisse läßt Zweifel aufkommen, ob bzw. inwieweit die unter Fokussierung auf TE 2 geläufige Erklärung, der Niedergang des althochdeutschen Negators $n i$ sei bedingt durch die Tonschwäche und dadurch forcierte Klitisierung dieses Elements im Mittelhochdeutschen, für die Gesamtentwicklung übernommen werden kann. TE 1 jedenfalls setzt ein zu einem Zeitpunkt, in dem die Abschwächungsprozesse bei der ursprünglichen Negationspartikel $n i$ noch nicht graphisch zu greifen sind.

Zweitens, die ermittelte relative Chronologie TE 1 vor TE 2 schlieBt aus, daß die in Schema 2 illustrierte Diversifikation der Negationskennzeichnung ausgelöst wird durch die positionelle Verlagerung der funktionalen Kategorie NEG, die nach Maßgabe des transformationalistischen Modells mit dem Wechsel von ahd. ni zu nhd. nicht (TE 2) verbunden ist. Letzteres ist nicht per se ein Argument gegen eine Interpretation der Gesamtentwicklung im Kontext des transformationellen Modells, es bedeutet zunächst lediglich eine Festlegung in bezug auf die Reihenfolge der unter Maßgabe dieses Modells anzusetzenden Regelveränderungen (Attraktionsregel vor Strukturregel mit Effekt der Dislozierung von NEG).

Diese Reihenfolge, die innerhalb des Modells erst noch zu motivieren wäre, spiegelt sich in den vorliegenden Daten allerdings nicht mit der vom Modell her zu erwartenden Deutlichkeit, vielmehr suggerieren die Daten 
einen wesentlich diffuseren Prozeßablauf, in dem selbständiger und nichtselbständiger Gebrauch der nominalen Negatoren und selbständiger bzw. nicht-selbständiger Gebrauch von nicht (in nicht-nominaler Funktion) für einen längeren Zeitabschnitt nebeneinanderstehen. Möglicherweise resultiert dieser Eindruck aus der Lückenhaftigkeit bzw. der noch unzureichenden Durchdringung der zur Verfügung stehenden Daten. Im Kontext des lexikalistischen Modells wäre ein solches Erscheinungsbild aber nicht nur möglich, sondern in Verbindung mit dem dort anvisierten DegrammatikalisierungsprozeB sogar zu erwarten, da die Umstrukturierung von einem grammatischen in ein lexikalisches System der Negationseinführung die Etablierung der lexikalischen Negationsträger bereits voraussetzt. Dies schließt die Möglichkeit ein, daß beide Systeme für eine gewisse Zeit nebeneinander existieren - eine Annahme, die mit dem oben skizzierten Erscheinungsbild des Alt- und Mittelhochdeutschen sehr gut $\mathrm{zu}$ vereinbaren ist.

Die „Negationswörter” des Mittelhochdeutschen wären demnach als strukturell ambig zu interpretieren, und zwar sowohl als „polarity items” (wenn sie mit $n e$ bzw. en-verbunden sind) wie auch als selbständige Negationsträger (wenn sie alleine im Satz vorkommen). Die zuletzt genannte Option besteht erwartungsgemäß zunächst nur für solche "polarity items", deren morphologische Struktur die Inkorporation des Merkmals NEG identifizierbar macht. Die Einbeziehung von kein (TE 3) demgegenüber setzt voraus, daB sich das lexikalische System der Negationskennzeichnung bereits vom grammatischen abgelöst hat bzw. daß das grammatische System der Negationskennzeichnung zu diesem Zeitpunkt bereits aufgegeben ist. Spätere Neubildungen wie keineswegs oder keinesfalls (TE 4) orientieren sich daher nicht notwendig am grammatisch bestimmten Bildungsprinzip des Alt- und Mittelhochdeutschen: sie erfolgen ohne Rückgriff auf das grammatische Negationsmorphem ne bzw. $e n$ - und sie entwickeln sich unabhängig von den "positiven Indefinita”, insofern als eineswegs und einesfalls als lexikalische Einheiten auch zum Zeitpunkt der Entstehung von keinesfalls und keineswegs nicht zu belegen sind.

Die Analyse der Verlaufsstruktur der Negationsentwicklung im Deutschen ergibt demnach einige positive Argumente für die Übernahme des lexikalistischen Ansatzes, eine Interpretation im Rahmen der transformalistischen Analyse ist aber auf dieser Basis ebenfalls nicht definitiv auszuschließen. 


\subsection{Beobachtungen zur Mehrfachnegation im Deutschen}

Betrachten wir vor diesem Hintergrund nun eine weitere Gruppe von Daten zur Negationsentwicklung des Deutschen, die in den gängigen Analysen ebenfalls kaum Beachtung gefunden haben, nämlich Veränderungen in Struktur und Interpretation von Sätzen, die mehrere Negationskennzeichnungen aufweisen. Wie eingangs bereits dargelegt, handelt es sich dabei um eine durchgehende Strukturoption des Deutschen, die im Regelfall keine Auswirkung auf die negative Interpretation des Satzes hat; d.h. es handelt sich um Instanzen einer Mehrfachkennzeichnung bzw. um die Einführung von Bedeutungselementen, die im allgemeinen bei der Bedeutungskalkulation von Sätzen nicht gegeneinander zu verrechnen sind. Diese Aussage gilt im Prinzip für alle Sprachstufen des Deutschen, für das Neuhochdeutsche allerdings mit der Einschränkung, daß Sätze wie die folgenden nicht als standardsprachlich akzeptiert werden:

Aber ich habe kein Geld nicht gehabt.

'Aber ich hatte kein Geld.'

Sätze dieses Typs erlauben aber auch unter standardsprachlichen Bedingungen keine Verrechnung der Negationen; d.h. sie sind im Rahmen der Standardsprache schlicht und einfach nicht interpretierbar.

Das in dieser Weise nahezu durchgängige Phänomen der Mehrfachnegation spricht auf den ersten Blick deutlich für eine transformationalistische Anlage der Negationssyntax des Deutschen, die mit der funktionalen Kategorie NEG nur eine semantisch interpretierbare Negationsinstanz innerhalb der Syntax vorsieht, die an der Oberflächenstruktur aber je nach Regelanlage u.U. mehrfach in Erscheinung tritt. Auch das lexikalistische Modell, nach dem Satznegationen voneinander unabhängig durch einzelne Lexeme eingeführt werden, ist durchaus offen für das Phänomen der Mehrfachkennzeichnung, es impliziert seinerseits aber zumindest die Möglichkeit einer Verrechnung, nämlich dann, wenn beide Negationsträger eigene Skopusbereiche definieren, die aufeinander zu beziehen sind.

Dies deckt sich mit der Beobachtung, daß die Negationswörter des Neuhochdeutschen sowohl in der Standardsprache wie auch in den Dialekten im Sinne der sich aufhebenden Negation gegeneinander zu verrechnen sind, wenn der zweite Negator in spezifischer Weise betont wird:

(23a) Ich habe niemandem NICHTS gegeben. (Standard)

(23b) I hob neamads NIX gem. (Bair.)

$\cong$ 'ich habe jedem etwas gegeben' 
Diese Betonung definiert einen eigenständigen Skopusbereich, auf den dann der andere Negator bezogen wird.

Beispiele dieser Art finden sich auch über das Neuhochdeutsche hinaus in älteren Sprachstufen des Deutschen,

(24) nicht nymmer hab die Zuversicht nach lobelicher wirde - nymmer bichte nicht (Altd. Museum II,223, zit. n. Behaghel 1918, S. 244)

(25) er wiss gerade so Viel, als Niemand ohne seinen Schaden nicht wissen kann (Wieland 22,56, zit. n. Behaghel 1918, S. 244)

allem Anschein nach aber erst ab dem 14. Jahrhundert, für das das DWB (Bd. V, Sp. 468) folgenden Beleg ausweist:

(26) irn ist niht dekeiner, ir ist maniger und einer an blindtheit sô verfizzen (Trist. 17779ff.)

ihrer-NEG ist NEG NEG-irgendeiner, ihrer ist (sind) mancheiner (viele) so auf Blindheit bedacht

Für das Althochdeutsche und das frühe Mittelhochdeutsche dagegen nennt die Literatur keine einschlägigen Belege.

Bestätigt sich diese Verteilung, dann spricht dies für die Degrammatikalisierungshypothese und damit für die Annahme einer umfassenderen Umstrukturierung im deutschen Negationssystem, wobei der Gleichlauf der zeitlichen Terminierung dieses Prozesses mit den unter 2.1 genannten Veränderungen mit der gebotenen Vorsicht als zusätzliche Bestätigung gewertet werden kann.

\section{Die Negation auf Wanderschaft? \\ Von der Negationssyntax des Deutschen zu Jespersens Zyklus}

Fassen wir diese Überlegungen zusammen, dann müßte deutlich geworden sein, daß die durch die Fixierung auf Schema 1 erfolgte perspektivische Einschränkung der sprachhistorischen Datenbasis für das Verständnis der Negationsentwicklung im Deutschen gravierend ist. Sie verdeckt die syntaktische und semantische Komplexität der zu interpretierenden Phänomene und damit den grammatischen Tiefgang der Problemstellung, die hier unter Bezugnahme auf an der Gegenwartssprache entwickelte Modelle einer Negationssyntax des Deutschen illustriert und diskutiert wurde. Die dabei vorgetragenen Überlegungen erlauben einen ersten Blick hinter die Kulissen von Jespersens Zyklus und zeigen die Negation auf Wanderschaft nicht nur auf dem planen Gelände der Oberflächenstruktur, sondern im mehrdimensionalen Areal der Gramma- 
tik - als Kletterer im Strukturbaum der Syntax oder vielleicht sogar als Wanderer zwischen den Welten, der vom syntaktischen zum lexikalischen Teilmodul der Grammatik überwechselt. Voraussetzung für die Entscheidung zwischen diesen beiden Optionen, die bei genauerer Analyse u.U. noch um zusätzliche Modelle zu erweitern wären, ist nicht zuletzt die Ergänzung und Vertiefung der im 19. Jahrhundert erarbeiteten sprachhistorischen Datenbasis, die interpretatorischen Anforderungen und Standards einer modernen historischen Linguistik derzeit nur z.T. Rechnung trägt.

\section{Literatur}

WB = Der Bayerwald, H. 4/1989.

DuH = Haller, Reinhard (1977): Von Druden und Hexen. Sagen aus dem Bayerischen Wald. Grafenau.

DWB = Grimm, Jacob/Grimm, Wilhelm (1873/89): Deusches Wörterbuch. Bd. 5 und 7. Leipzig.

$\mathrm{N}=$ Piper, Paul (Hg.) (1882/83): Die schriften Notkers und seiner Schule, Bd. 1 und 2. Tübingen.

NL = Batts, Michael S. (Hg.) (1971): Das Nibelungenlied. Paralleldruck der Handschriften $\mathrm{A}, \mathrm{B}$ und $\mathrm{C}$ nebst Lesarten der übrigen Handschriften. Tübingen.

$\mathrm{O}=$ Erdmann, Oskar (1973): Otfrids Evangelienbuch. 6. Aufl., besorgt von Ludwig Wolff. (Altdeutsche Textbibliothek Bd. 49).

$\mathrm{S}=$ Daniel Caspar von Lohenstein: Sophonisbe Hrsg. v. Rolf Tarot, Stuttgart 1970.

$\mathrm{T}=$ Sievers, Eduard (Hg.) (1892): Tatian. Lateinisch und altdeutsch mit ausführlichem Glossar. 2., überarbeitete Auflage. Paderborn. (Bibliothek der ältesten deutschen Literatur-Denkmāler, Bd. 5).

Trist $=$ Marold, Karl (Hg.) (1969): Gottfried von Strabburg: Tristan. 3. Abdruck mit einem durch $F$. Rankes Kollationen erweiterten und verbesserten Apparat besorgt und mit einem Nachwort versehen von W. Schröder. Berlin.

\section{Monographien und Aufsätze}

Adamzik, Kirsten (1987): Probleme der Negation im Deutschen. Studien zur zeitgenössischen Grammatikographie. Münster. (Studium Sprachwissenschaft. Beihefte. 10).

Behaghel, Otto (1918): Die Verneinung in den deutschen Sprachen. In: Wiss. Beihefte zur Zeitschrift des ailg. Dt. Sprachvereins, 5. Reihe, 38/40, S. 225-252. 
Behaghel, Otto (1924): Deutsche Syntax. Eine geschichtliche Darstellung. Bd. II: Die Wortklassen und Wortformen. Heidelberg. (Nachdruck Heidelberg 1989).

Coombs, Y. M. (1976): A Semantic Syntax of Grammatical Negation in the Older Germanic Dialects. Göppingen. (Göppinger Arbeiten zur Germanistik 177).

Dittmar, H. (1874): Über die altdeutsche Negation $n e$ in abhängigen Sätzen. In: ZfdPh, Ergānzungsband, S. 183-318.

Eroms, Hans-Werner (1993): Der indefinite Nominalnegator kein im Deutschen. In: Vuillaume, Marcel (Hg.): Studien zur Syntax und Semantik der Nominalgruppe. Tübingen. S. 1-18.

Grimm, Jacob (1890): Deutsche Grammatik. 3. Teil besorgt durch G. Roethe u. E. Schröder. Gūtersloh. (Nachdruck Hildesheim 1967).

Harweg, Roland (1979): Sind negative Behauptungssätze immer Verneinungen? In: ZGL 7, S. 279-303.

Jacobs, Joachim (1982): Syntax und Semantik der Negation im Deutschen. München. (Studien zur theoretischen Linguistik 1).

Jespersen, Otto (1917): Negation in English and Other Languages. Kopenhagen. (Historisk-filologiske Meddelelser I,5).

Kelle, Johann (1881): Otfrids von Weifenburg Evangelienbuch. Bd. 3: Glossar der Sprache Otfrids. Aalen. (Neudruck Aalen 1963).

Kürschner, Wilfried (1983): Studien zur Negation im Deutschen. Tübingen. (Studien zur deutschen Grammatik 12).

Lehmann, Winfried P. (1978): Changes in the Negative Sentence Pattern in German. In: D. Hartmann/Linke, H./Ludwig, O. (Hg.): Sprache in Gegenwart und Geschichte. FS. H. M. Heinrichs. Köln/Wien. S. 94-109.

Mensing, Otto (1891): Untersuchungen über die Syntax der Concessivsätze im Alt- und Mittelhochdeutschen. Diss. Kiel.

Mourek, Vaclav E. (1902): Über die Negation im Mittelhochdeutschen. (Sitzungsber. d. Böhm Gesellsch. d. Wissensch.)

Paul, Hermann (1989): Mittelhochdeutsche Grammatik. 23. Aufl. neu bearb. von Peter Wiehl/Siegfried Grosse. Tübingen.

Pensel, Franzjosef (1981): Die Satznegation. In: Kettmann, Gerhard/Schildt, Joachim (Hg.): Zur Ausbildung der Norm der deutschen Literatursprache auf der syntaktischen Ebene (1470-1730). Der Einfachsatz. 2. unveränd. Aufl. Berlin. S. 287-326.

Qian, Minru (1987): Untersuchungen zur Negation in der deutschen Gegenwartsprache. Eine mikro- und makrostrukturelle Analyse. Heidelberg.

Reichmann, Oskar/Wegera, Klaus-Peter (Hg.) (1993): Frühneuhochdeutsche Grammatik. Von Robert Peter Ebert, Oskar Reichmann, Hans-Joachim Solms und Klaus-Peter Wegera. Tübingen.

Stickel, Gerhard (1970): Untersuchungen zur Negation im Deutschen. Braunschweig. (Schriften zur Linguistik 1). 
Zingerle, I. V. (1862): Über die bildliche Verstärkung der Negation bei mittelhochdeutschen Dichtern. In: Sitzungsberichte der philos.-hist. Classe der kaiserlichen Akademie der Wissenschaften zu Wien 39, S. 414-477. 


\title{
ELKE HENTSCHEL
}

\section{Negation in Interrogation und Exklamation}

\begin{abstract}
Der Beitrag beschäftigt sich mit negierten Interrogationen des Typs Guck mal dort drüben, ist das nicht $U d o$ ?, die als Vergewisserungsfragen verwendet werden, sowie mit negierten W-Interrogationen zum Ausdruck des Erstaunens, wie sie in Was es nicht alles gibt! vorliegen. Es wird gezeigt, daß beide Äuferungstypen weit über das Deutsche und die indoeuropäischen Sprachen hinaus verbreitet sind, so dab sich die weit verbreitete Ansicht, daf nicht in solchen Fällen als Modalpartikel anzusehen sei, nicht halten läßt, sondern andere, sprachübergreifend gültige Interpretationen des Phänomens gefunden werden mūssen. Angesichts der Befunde in Falle des negierten Ausrufs wird darüber hinaus dafür plädiert, diachronische Faktoren in die Untersuchung mit aufzunehmen.
\end{abstract}

\section{Negierte Interrogation}

Warum sagt man: Guck mal da drüben, ist das nicht Udo?, wenn man der Meinung ist, daB es sich höchstwahrscheinlich um Udo handelt (und eben gerade nicht, wenn man vermutet, daB er es nicht ist)? Das nicht, das in diesem oft als "Vergewisserungsfrage" bezeichneten Satztyp auftritt, wird meist als Modal- oder Abtönungspartikel aufgefaßt (cf. z.B. Blanken 1983, Helbig 1988, Thurmair 1989, BrauBe 1994). In vieler Hinsicht verhält es sich tatsächlich anders als das nicht der „normalen” (meist als „propositional" bezeichneten) Negation. Als äuBeres Unterscheidungsmerkmal wird oft angeführt, daB propositionales nicht im Gegensatz zu nicht-propositionalem stets betont sei. Dagegen muB allerdings eingewandt werden, daB durchaus abweichende Betonungen vorkommen, ohne daß sich am Bezug der Negation etwas ändern müBte, cf. z.B. Bist du IMMER noch nicht satt? (propositionale Negation, Betonung auf immer). Es gilt aber die umgekehrte Regel: nicht-propositionales nicht kann nicht betont werden.

Interessanter als der Betonungsunterschied ist die bisher kaum beachtete Tatsache, daf die grammatischen Regeln für die Fusion von nicht und unbestimmtem Artikel oder Nullartikel zu kein-in den Fällen der nichtpropositionalen Negation nicht wirksam werden. Cf. z.B. die folgenden Sätze: 
Ich habe keine Lust.

*Ich habe nicht Lust.

Wieso kommst du nicht mit ins Kino? Hast du keine Lust?

Wieso kommst du nicht mit ins Kino? ${ }^{*}$ Hast du nicht Lust?

vs.

Hast du nicht Lust, mit ins Kino zu kommen?

Ebenso:

Ich habe kein Auto.

*Ich habe nicht ein Auto.

Hast du kein Auto?

vs.

Hast du nicht ein Auto? (Nur Vergewisserungsfrage)

etc.

Auch die anderen Kontraktionen der Negation mit einem indefiniten Element, wie sie in nie(mals), nirgends, nirgendwo, niemand vorliegen, lassen sich nicht in Vergewisserungsfragen verwenden. Cf. z.B.:

Hast du nie(mals) geraucht?

Hast du nicht mal geraucht?

(Vergewisserungsfrage)

Wachsen hier nirgends Pilze?

Wachsen hier nicht irgendwo Pilze? (Vergewisserungsfrage)

Hat niemand angerufen?

Hat nicht jemand angerufen?

(Vergewisserungsfrage)

Die unterschiedlichen Funktionen der Negation schlagen sich also in der Morphologie nieder.

Negierte Vergewisserungsfragen dieses Typs sind nicht auf das Deutsche beschränkt; dies zeigen die Ergebnisse einer empirischen Untersuchung von bisher 46 Sprachen, davon 24 indoeuropäische (germanische, romanische, slawische und auch weiter östliche indoeuropäische Sprachen von Farsi über Bengali bis Singhalesisch) und 22 nicht-indoeuropäische. Unter den nicht-indoeuropäischen Sprachen sind drei europäische aus zwei Familien (Finnisch, Ungarisch/Georgisch); auBerhalb Europas wurden untersucht: $z$ wei semitische Sprachen, sechs schwarzafrikanische Sprachen aus verschiedenen Sprachfamilien, drei Turksprachen und eine südamerikanische sowie $\mathrm{zwei}$ nordamerikanische Indianersprachen; außerdem Chinesisch, Indonesisch, Japanisch, Koreanisch, Tagalog. Nur zwei Sprachen aus diesem Sample, nämlich die beiden nordamerikanischen Indianersprachen Apache und Navajo (zwei nahe verwandte polysynthetische Sprachen aus der athapaskischen Sprachfamilie) kennen 
eine solche Verwendung der Negation nicht, obgleich sie grundsätzlich eine gleichzeitige Verwendung von Negation und Interrogation zulassen; ${ }^{1}$ diese wird aber ausschlieBlich propositional verstanden. Aus diesen $\mathrm{Be}$ funden folgt, daß es sich um ein universelles, logisch erklärbares Phänomen und nicht um eine spezielle deutsche Partikel handeln muB.

Um zu erklären, wie dieses Phänomen zustandekommt, müssen zunächst drei Ebenen der Satzbedeutung unterschieden werden:

- die propositionale Bedeutung oder Proposition, die sich aus den lexikalischen Elementen eines Satzes zusammensetzt und die in Maja kommt/Kommt Maja?/Maja komm! etc. identisch bleibt.

- der Satzmodus; in den obigen drei Beispielsätzen liegen drei verschiedene Satzmodi vor (Assertion, Interrogation, Imperativ).

- die illokutive Bedeutung, die bekanntlich häufig, aber keineswegs immer mit der Funktion des Satzmodus übereinstimmt; keine Übereinstimmung zwischen Satzmodus und Illokution liegt beispielsweise dann vor, wenn Interrogationen als Aufforderungen benutzt werden (cf. z.B. Hilfst du mir mal eben?).

Eine logische Erklärung für die Funktionsweise negierter Interrogationen kann sich nur aus dem Zusammenwirken der Bedeutung des Satzmodus Interrogation und der Negation ergeben. Wenn die Negation nicht auf den propositionalen Gehalt bezogen wird, sondern auf den Satzmodus, dann läBt sich ein solcher Satz leicht formalisiert beschreiben als

NEG (INTERR (p))

wobei NEG für Negation, INTERR für Interrogation und $p$ für Proposition stehen soll. Mit anderen Worten: Eine Proposition wird in die Form einer Interrogation gekleidet. Da unter neutralen Bedingungen die Antworten "Ja" und "Nein", also das Zutreffen und das NichtZutreffen der Proposition, ungefähr gleich wahrscheinlich sind, erfährt die Äußerung durch den Interrogativmodus eine starke Einschränkung ihrer Wahrheits- oder, da es hier nicht um formale Logik geht, vielleicht besser: ihrer Gültigkeitsbedingungen; die Proposition trifft sozusagen nur noch mit einer Wahrscheinlichkeit von $50 \%$ zu. Nun kommt die Negation hinzu. Wenn sie nicht auf die Proposition, sondern auf den Satzmodus bezogen wird, dann wird durch sie die soeben beschränkte Einschränkung der Gültigkeitsbedingungen verändert, denn es ist ja dann gerade die

1 Ich danke B. Comrie für den Hinweis auf Sprachen, in denen die gleichzeitige Verwendung von Negation und Interrogation ausgeschlossen ist. Dieser Sprachtyp kann natūrlich schon aufgrund dieser strukturellen Einschränkung keine negierten Vergewisserungsfragen bilden. 
gültigskeitseinschränkende Einwirkung des Satzmodus auf die Proposition, die negiert wird. Dadurch entsteht die positive Tendenz der Frage.

Zugleich läßt sich auch zeigen, daB es im Gegensatz zu den Annahmen Meibauers (1990, S. 463) nicht sinnvoll ist, die Funktion der Negation auf die pragmatische Ebene zu beziehen. Pragmatisch gesehen ist eine Äußerung wie "Ist das nicht Udo?" ganz genauso eine Frage wie die ÄuBerung „Bist du denn immer noch nicht satt?”. Es wird in beiden Fällen eine Antwort erwartet, und diese Antwort ist für die fragende Person wichtig, um ihre Annahmen zu bestätigen oder notfalls zu falsifizieren. Es mag zwar durchaus richtig sein, daB die Entscheidung über die propositionale resp. nicht-propositionale Zuordnung der Negation (also ihr Bezug auf die Proposition resp. ihren Bezug auf den Satzmodus) in Einzelfällen ausschlieBlich aufgrund pragmatischer Gegebenheiten gefällt werden kann; damit ist die Funktionsweise einer Konstruktion, die sich in so vielen verschiedenen Sprachen in immer der gleichen Weise findet, aber noch lange nicht erklärt.

\section{Negierte Exklamationen}

Neben den Interrogativsätzen des Typs Entscheidungsfrage gibt es auch die des Typs W-Frage (auch Bestimmungsfrage, Pronominalfrage, Ergänzungsfrage, Satzteilfrage genannt). Dieser Formtyp mit einleitendem Interrogativum - Pronomen oder Proadverb - kann als selbständiger Satz ${ }^{2}$ nicht nur zum Zwecke der Interrogation, sondern auch zum Zwecke der Exklamation benutzt werden, cf. z.B.:

\section{Wie kalt es ist!}

Näf $(1987$, S. 143) unterscheidet dabei 14 verschiedene Typen von WExklamationssätzen, die man folgendermaßen systematisieren könnte:

Die sieben folgenden Satztypen können jeweils mit Zweitstellung oder mit Endstellung des finiten Verbs (bei Näf: ${ }_{n}$ Personalform") auftreten. Es gibt dann drei Typen mit einleitendem wie, und zwar (in Klammern ausgeführte Beispielsätze nach Näf (1987)):

2 Als unselbständige Sātze kōnnen Sätze mit einleitendem Interrogativum die unterschiedlichsten syntaktischen und semantischen Funktionen wahrnehmen. Als indirekte Fragesātze stehen sie in Subjekt- oder Objekt-Position; als Relativsätze bilden sie Attribute, als konzessive Konditionalsātze (unter obligatorischem Zusatz von a $\mathrm{c} \mathrm{h}$ und/oder i m m e r, cf. was du auch sagst/was auch immer du sagst ... /was immer du sagst ...) Adverbialbestimmungen. 
- mit Verb

(Wie bist du gewachsen/Wie du gewachsen bist)

- mit prädikativem Adjektiv

(Wie bist du groß geworden/Wie du groß geworden bist!)

- mit direkt auf wie folgendem Adjektiv

(Wie groß bist du geworden/Wie groß du geworden bist?)

ferner zwei Typen mit was:

- mit Verb (Was hast du dich verändert/Was du dich verändert hast!)

- mit prädikativem Adjektiv

(Was bist du groß geworden!/Was du groß geworden bist!)

und zwei mit was für ein:

- mit Aufspaltung der Wortfolge von was für ein (Was ist das für ein riesiger Kerl!/Was das für ein riesiger Kerl ist!)

- ohne Aufspaltung der Wortfolge von was für ein

(Was für ein riesiger Kerl ist das/Was für ein riesiger Kerl das ist!)

Diese detaillierte Auflistung ist aber nur scheinbar vollständig. Ergänzen müBte man sie zunächst noch um die - wenn auch archaisch wirkende Verwendung von welch- und welch ein wie in

Welche Schönheit! Welche Prachl!

Welch ein $Z u$ fall!

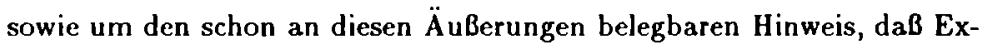
klamationen des wie-, was für ein- und welch-Typs besonders häufig elliptisch geäußert werden; cf. auch:

Was für ein Mistwetter!

Wie nett!

Zu Recht weist Näf (1987, S. 147f.) darauf hin, daß was in Exklamativsätzen in Funktion und Bedeutung mit wie übereinstimmen kann. DaB dies aber nicht notwendig immer der Fall ist und daß es zudem noch weitere Typen von W-Exklamativen gibt, zeigen Beispielsätze wie die folgenden:

Was du alles weißt!

Wer alles gekommen ist!

Wen die so kennl!

Wo du schon überall warst! 
Rosengren (1992, S. 281) schlieBt aus solchen Beispielen, daß ${ }_{\eta}$ alle wPhrasentypen vorzukommen (scheinen)", ${ }^{3}$ wobei "bestimmte w-Phrasen ... in der Regel zusammen mit alles (wie, was, wer, wo, womit) auf(treten)."

Interessant ist der Nachweis, daB die Zweitstellung des Finitums in dem von Näf untersuchten Corpus, den Grimmschen Kinder- und Hausmärchen, gegenüber der Endstellung eindeutig überwiegt. Insofern scheint es sich bei der Endstellung also um eine neuere Entwicklung zu handeln. Da sie eindeutig fakultativ ist, kann sie zumindest nicht zur zentralen Grundlage der Interpretation von exklamativen W-Sätzen gemacht werden.

Der Satzmodus der W-Interrogation scheint nun abermals über das Deutsche hinaus auch generell besonders gut dafür geeignet zu sein, Erstaunen auszudrücken, cf. z.B. das folgende vielsprachige Staunen über Schönheit:

dt. Wie schön du bist!

engl. How beautiful you are!

franz. Quelle jolie femme il a épousée! ${ }^{4}$

russ. Kakaja krasata!

serb. Śta je lepa!

türk. Ne güzelsin!

etc.

Auch dies ist bereits ein sehr interessantes Phänomen, denn offenbar kann man die Erklärung für die Bevorzugung dieses Satztyps zum Ausdruck des Staunens nicht einzelsprachlich und auch nicht auf indoeuropäische Sprachen beschränkt geben, sondern es muß sich um ein universales Phänomen handeln. Es scheint generell möglich zu sein, die Verwunderung über die Eigenschaften eines Objektes mit der Frage nach eben diesen Eigenschaften auszudrücken - womit so etwas wie 'mir fehlen die Worte' auf Satzebene geäußert wird. Eine Erklärung in dieser Richtung ist sicher einleuchtend. Warum aber ist es zusätzlich möglich, eine Negation zu verwenden, ohne daB dadurch über einen negativen Sachverhalt gestaunt würde? Cf.:

Was es nicht alles gibt!

Was du nicht alles erlebt hast!

3 Problematisch ist dabei allerdings die Auffassung, auch bei den Sätzen Warum der immer so früh aufsteht! und Wieso der immer zu spät kommt! handle es sich um Exklamationen.

4 Beispiel nach Grevisse (1986, S. 665). 
Im Deutschen unterscheiden sich solche W-Exklamationen normalerweise durch ihre Satzstellung von "echten” Interrogationen. Außerdem treten sie typischerweise, wie in den obigen Beispielen, mit dem Allquantor allauf. Diese letztere Beobachtung hat eine ganze Reihe von Autorinnen und Autoren zu der Annahme verführt, daB dies eine zwingende Bedingung für diese Art von Negation sei. Dabei schwanken die Angaben, die über diese Gebrauchsbeschränkung gemacht werden, $\mathbf{z w i s c h e n ~ d e m ~}$ strikten "In wh-exclamatory sentences nicht is bound to alles" (Meibauer 1991, S. 463) resp. „Für diesen Typ ist das Vorkommens von alles nach nicht obligatorisch (BrauBe 1994, S. 121) und dem etwas vager formulierten „In den Exklamativsätzen ist nicht immer mit einem allquantifizierenden Ausdruck wie alles verbunden (...) (Thurmair 1989, S. 160). Nun sind solche Kombinationen in der Tat häufig; aber sie sind keineswegs zwingend, wie die folgenden Beispiele zeigen:

\section{In wieviel Not hat nicht der gnädige Gott über dir Flügel gebreitet! Was du nicht sagst!}

Was du nicht sagst! wurde gelegentlich (Meibauer 1990, S. 461) als ausschlieblich ironische Bemerkung sowie mit dem Hinweis, das positive $\mathrm{Ge}-$ genstück Was du sagst! sei nicht möglich, aus dem Untersuchungsbereich herausgenommen. Der Satz muB aber nicht notwendig ironisch geäußert werden, sondern kann auch schlicht Erstaunen über etwas ausdrücken, was das Gegenüber gesagt hat. Mit seiner Ausklammerung ist zudem das Problem noch lange nicht gelöst; auch die archaische Wendung In wieviel Not hat nicht der gnädige Gott über dir Flügel gebreitet!(aus dem Choral "Lobet den Herren") ist ja durchaus noch synchron verständlich; und damit nicht genug: sie weist auch keine Stellungsunterschiede zu einer „echten” W-Interrogation auf. Angesichts solcher Befunde erhebt sich also die naheliegende Frage: wie funktionieren solche Äußerungen wirklich, und gibt es sie auch in anderen Sprachen?

Auch hier wurden weitere indoeuropäische wie außerindoeuropäische Sprachen zum Vergleich herangezogen. Nachweisen lieB sich bisher ein ganz genauso wie im Deutschen strukturiertes, von Quantoren durchweg offenbar völlig unabhängiges Verfahren zum Ausdruck des Erstaunens über einen positiven Sachverhalt mithilfe einer negierten W-Frage in 20 Sprachen, davon 13 indoeuropäische und sieben nicht-indoeuropäische. Dieser Befund bedeutet, daB es sich abermals um ein mit logischen Mitteln erklärbares allgemeines Verfahren handeln muB. Abermals läBt sich das Zusammenwirken von Interrogation und Negation durchaus logisch erklären. W-Interrogationen haben allerdings andere Wahrheits- oder Geltungsbedingungen als Interrogationen des Typs Entscheidungsfrage: während im letzteren Fall die gesamte Proposition zur Disposition ge- 
stellt wird, wird in ersterem nur ein einzelnes Element innerhalb einer als gültig vorausgesetzten Proposition als offene Variable gesetzt. Wenn die Negation wie im vorgenannten Fall auf den Satzmodus bezogen wird, so entsteht wiederum eine formale Frage, die als Nicht-Interrogation gekennzeichnet ist. Es ist klar, daB der Unterschied zwischen der negierten und der nicht-negierten Interrogation hier nicht so stark ist wie bei Entscheidungsfragen. Die Gültigkeitsbedingungen der Proposition werden durch diesen Interrogationstyp nicht eingeschränkt, und der Modus kann auch ohne zusätzliche Markierung als Ausruf fungieren; Negationen sind folglich fakultativ.

Interessant ist nun, daB die Möglichkeit einer solchen Verwendung der negierten W-Frage weder von der Sprachfamilien-Zugehörigkeit noch von regionalen Faktoren abzuhängen scheint: was z.B. im Französischen und Italienischen möglich ist, geht im Portugiesischen anscheinend nicht; im Finnischen sind negierte W-Fragen dieses Typs nicht möglich, wohl aber im Ungarischen; und während das Tartarische diese Konstruktion zuläßt, ist sie im Türkeitürkischen ausgeschlossen. Wenn man aber die Angaben einiger Informanten berücksichtigt, denen zufolge negierte Exklamationen etwa im Dänischen oder Norwegischen "mostly by older speakers" 5 getätigt werden, und dabei zugleich im Auge behält, daB das Vorhandensein oder Fehlen der Negation in diesem speziellen Satztyp keinen Bedeutungsunterschied bewirkt, so liegt die Überlegung nahe, daB es sich hier um ein diachronisch zu betrachtendes Phänomen handelt. Vermutlich lassen die meisten Sprachen diese Konstruktion im Prinzip zu, aber ob von der Möglichkeit der Markierung durch eine Negation Gebrauch gemacht wird oder nicht, ist historischen Schwankungen unterworfen, die möglicherweise ganz ähnlich verlaufen wie die verschiedenen Markierungen der Negation selbst in Jespersens Zyklus (cf. Jespersen 1966). ${ }^{6}$ In dem Maße, in dem die W-Interrogation bereits durch andere Mittel - im Deutschen etwa durch die Endstellung des Verbs - als Ausruf kenntlich gemacht ist, steigt vermutlich auch die Tendenz, die zusätzliche Markierung durch den Negator fallenzulassen. Zugleich zeigen die vorliegenden Befunde und Überlegungen, daß es äußerst sinnvoll sein kann,

5 Persōnliche Auskunft von G. Andersen.

6 Hierfür spricht auch die Tatsache, daß sich gelegentlich auch für Sprachen, in denen die Mehrheit der Befragten bisher das Vorhandensein negierter Exklamationen ausgeschlossen hat, einzelne Äußerungen finden lassen, die diesem Schema doch entsprechen; cf. z.B. spanisch: ; Cuanto no tendre que sufrir hasta conseguirlo! (für diesen Hinweis danke ich C. Sanz, Georgetown) oder englisch: What I didn't do to get that report finished on time! (für diesen Hinweis danke ich K. Stanley, Piedmont). 
auch bei typologischen Untersuchungen diachronische Faktoren mit zu berücksichtigen.

\section{Literatur:}

Blanken, Gerhard (1983): Bestātigungsfragen mit nicht und doch. In: Deutsche Sprache 11, S. 250-326.

Braufe, Ursula (1994): Lexikalische Funktionen der Synsemantika. Tübingen. (Forschungsberichte des Instituts für deutsche Sprache 71).

Grevisse, Maurice (1986): Le bon usage. Grammaire française avec des remarques sur la langue française d'aujourd'hui. 11.éd., revue. Paris etc.

Helbig, Gerhard (1988): Lexikon deutscher Partikeln. Leipzig.

Hentschel, Elke (1986): Ist das nicht interessant? Zur Funktion verneinter Fragen. In: Schlieben-Lange, Brigitte (Hg.): Sprache und Wissen. Göttingen. S. 73-86. (Zeitschrift für Literaturwissensch aft und Linguistik 64).

Jespersen, Otto (1966): Negation in English and other languages. 2. Aufl. (1. Auff.: 1917). Kopenhagen. (Historisk-Filologiske Meddelelser udviget af Det Kongelige Danske Videnskabernes Selskab, Bind 1, nr. 5).

Meibauer, Jōrg (1990): Sentence mood, lexical categorial filling, and nonpropositional nicht in German. In: Linguistische Berichte 130, S. 441465.

Meibauer, Jörg (1991): Existenzimplikaturen bei rhetorischen w-Fragen. In: Reis, Marga/Rosengren, Inger ( $\mathrm{Hg}$.): Fragesātze und Fragen. Referate anläplich der 12. Jahrestagung der Deutschen Gesellschaft für Sprachwissenschaft, Saarbrūcken 1990. Tübingen. S. 223-242.

Năf, Anton (1987): Gibt es Exklamativsätze? In: Meibauer, Jörg (Hg.): Satzmodus zwischen Grammatik und Pragmatik. Referate anläblich der 8. Jarestagung der Deutschen Gesellschaft für Sprachwissenschaft Heidelberg 1986. Tübingen. S. 140-161.

Rosengren, Inger (1992): Zur Grammatik und Pragmatik der Exklamation. In: Rosengren, Inger ( $\mathrm{Hg}$.): Satz und Illokution. Tübingen. S. 263-306.

Thurmair, Maria (1989): Modalpartikeln und ihre Kombinationen. Tübingen. 


\section{Typenbestimmung}

in lexikalischen Feldern 



\title{
Verbbedeutung und Verbgrammatik: Transportverben im Deutschen
}

\begin{abstract}
In diesem Aufsatz behandele ich die komplexe Bedeutung morphologisch einfacher Verben. Im Mittelpunkt steht der Zusammenhang zwischen der lexikalischen Bedeutung eines Verbs und den grammatischen Realisierungen, in denen es auftreten kann. Unter semantisch-lexikalischen Gesichtspunkten betrachte ich die thematischen Rollen der Verbargumente (AGENS, PATIENS), die Aktionsarten der Verben (ZUSTAND, PROZESS, EREIGNIS) sowie die Frage, ob die Art und Weise der Durchführung einer Handlung in der Bedeutung eines Verbs spezifiziert ist (manner vs. non-manner-Verben). Unter grammatischen Gesichtspunkten gehe ich ein auf das Problem der Auxiliarselektion (haben vs. sein) bei den komplexen Vergangenheitstempora und auf das Variationspotential der jeweiligen Verb-Argumentstruktur (Argumentalternation und Argumentreduktion). Typologisch gesehen spielt die Tatsache, daß Transportverben im Deutschen die Komponente der Ortsverānderung und die Komponente der Bewegungsart in der Bedeutung eines einfachen Verbstammes bündeln, für die Analyse eine zentrale Rolle.
\end{abstract}

Du glaubst zu schieben, und du wirst geschoben. (Mephisto)

\section{Vorbemerkungen - Zum Status des Lexikons in der Grammatik}

Der Status lexikalischer Information in der Grammatik ist - unabhängig von dem jeweils adoptierten Forschungsparadigma - zwischen „Lexikalisten” und „Nicht-Lexikalisten” umstritten und gilt als Prüfstein für die Reichweite syntaktischer respektive lexikalischer Regeln. In der Kontroverse zwischen den Vertretern der Standardtheorie und der Generativen Semantik in den frühen siebziger Jahren kristallisierte sich die Debatte um die Frage, wie morphologisch komplexe Formen (z.B. Nominalisierungen) und semantisch komplexe Wörter (z.B. kill) herzuleiten sind - als unzerlegbare Einheiten des Lexikons mit idiosynkratischer Bedeutung oder als das Ergebnis von syntaktischen Operationen. Die beiden Grundpositionen stehen einander immer noch gegenüber. Aller- 
dings haben sich nicht nur die grammatischen Strukturformate geändert, die den Bezugsrahmen der Auseinandersetzung bilden, auch der Begriff "Lexikalismus" hat sich gewandelt: Während in der Debatte der siebziger Jahre die lexikalistische Position durch die Auffassung gekennzeichnet war, daB das Lexikon eine Liste phonologisch ausbuchstabierter Worteinträge und ihrer idiosynkratischen Bedeutungen sei, hat sich im Gefolge des Lexikalistischen Funktionalismus über die Paradigmengrenzen hinweg die Einsicht durchgesetzt, daß das Lexikon eine innere Architektur aufweist, die es erlaubt, komplexe Wortbedeutungen durch systematische Operationen lexikalisch herzuleiten.

Lexikalistisch orientierte Studien dieses neueren Typs bewegen sich im Spannungsfeld zwischen universalistischen Annahmen über die Struktur möglicher Wörter in allen Sprachen und einzelsprachlichen Untersuchungen zur Struktur tatsächlicher Wörter in bestimmten Sprachen. Typologische Untersuchungen nehmen in diesem Spannungsfeld eine Mittelstellung ein, indem sie Sprachen mit übereinstimmender Lexikonarchitektur unterhalb der Ebene universaler Festlegungen einem gemeinsamen lexikologischen Typ zuordnen. Entscheidende Anstöße zu einer lexikologischen Typologie haben die Arbeiten von Talmy (1985) gegeben. Talmy betrachtet darin die Bündelung (conflation) verschiedener Komponenten der Wortbedeutung in einem atomaren Wortstamm und faßt Sprachen nach der Zugehörigkeit zu bestimmten conflation-types zusammen. So zeichnen sich etwa die germanischen Sprachen nach Talmy dadurch aus, daB sie bei Bewegungsverben die Komponente der Fortbewegung (motion) und die Komponente der Bewegungsart (manner) in einem einzigen Wortstamm bündeln (Beispiele: rutschen, gleiten, kriechen, krabbeln etc.), während sie URSPRUNG, WEG und ZIEL der Fortbewegung mithilfe von präpositionalen "Satelliten"-Phrasen (ins Wasser gleiten, durch den Turnel kriechen) explizit machen. Romanische Sprachen bündeln in Verben wie span. salir und entrar demgegenüber URSPRUNG und WEG bzw. WEG und ZIEL, Ortsveränderung und Bewegungsart vermögen sie nicht in einem einfachen Verbstamm zu bündeln; Sätze wie Der Wagen rollt in den Graben sind daher in direkter Übersetzung im Spanischen oder im Französischen nicht möglich und müssen periphrastisch konstruiert werden.

Als ein wesentlicher Parameter lexikologischer Typologien gilt die Eigenschaft der Unakkusativität bzw. Unergativität von Verben (Perlmutter 1978, Levin/Rappaport 1991a). Als "unakkusativ" werden dabei Intransitiva wie ankommen, sinken, verschwinden klassifiziert. Diese Verben lassen es zu, daf das Partizip der Vergangenheit (angekommen, gesunken, verschwunden) als Attribut zur Subjekt-NP verwendet wird 
(Das angekommene Paket, das gesunkene Schiff, die verschwundenen Gelder). Ihr Partizip verhält sich damit zu der attribuierten SubjektNP genauso wie das Partizip transitiver Verben zu einer attribuierten Objekt-NP (Das gestohlene Paket, das versenkte Schiff, die verschwendeten Gelder). Unter der Unakkusativitätshypothese wird deshalb angenommen, daB die Subjekt-NP unakkusativer Verben dieselbe Thetarolle (THEMA) realisiert wie die Objekt-NP transitiver Verben und daher syntaktisch aus der Position des direkten Objekts herzuleiten ist. ${ }^{1}$ Den unakkusativen Intransitiva mit THEMA-Subjekt stehen die unergativen Intransitiva mit AGENS-Subjekt (z.B. tanzen, lachen, klatschen) gegenüber. Diese Verben teilen mit transitiven AGENS-Verben die Eigenschaft der Passivierbarkeit (Es wurde getanzt, es wurde gelacht, es wurde geklatscht), sie verbieten die attributive Verwendung des Partizips der Vergangenheit ( Die getanzte Braut, *das gelachte Publikum). ${ }^{2}$

In neueren Arbeiten zur Struktur der Verbbedeutung (z.B. Levin/Rappaport 1989, Levin 1993, Jackendoff 1990, Grimshaw 1991) spielt die Unergativ/Unakkusativ-Unterscheidung eine zentrale Rolle. Diese Arbeiten thematisieren vor allem den Zusammenhang von Wortsemantik und Syntax. Sie gehen davon aus, daB selbst feinste Nuancierungen der semantischen Struktur eines Wortes in seinem grammatischen Verhalten ihren Niederschlag finden. Attribuierbarkeit und Passivierbarkeit bilden in diesem Zusammenhang nur einen Ausschnitt aus dem Potential grammatischer Realisierungsvarianten. Reflexivierung, Nominalisierung, die Bildung von Resultativkonstruktionen und das gesamte Spektrum möglicher Variationen der Argumentstruktur werden in diese Studien einbezogen. In der psycholinguistischen Literatur, vor allem zum Spracherwerb, hat man im AnschluB an solche Studien danach gefragt, ob der Erwerb der Bedeutung dem Erwerb des syntaktischen Wissens logisch und zeitlich vorausgeht ("semantic bootstrapping", vertreten u.a. von Pinker 1989), oder ob umgekehrt das grammatische Verhalten eines Verbs für das sprachlernende Kind den Schlüssel zur Rekonstruktion seiner Bedeutung bildet ("syntactic bootstrapping”, vertreten z.B. von Gleitman 1990, Landau/Gleitman 1985, Naigles 1990). Für eine systematische Untersuchung, in der es nicht um Prozesse geht, weder um den des Spracherwerbs, noch um den der Sprachverarbeitung, spielt die

1 „Unakkusativ" heißen diese Verben deshalb, weil ihr Objekt wegen der fehlenden Subjekt-Phrase (nach Burzios Gesetz) keine Akkusativmarkierung annehmen kann und daher in Nominativsprachen an der Satzoberfläche durch den Nominativ zu realisieren ist.

2 Durch Beispiele wie (25-27) unten wird diese Feststellung allerdings eingeschrānkt. 
Frage nach der zeitlichen Ordnung des Zugriffs auf die Ebenen der Wortbedeutung und der Syntax keine Rolle; es genügt, wenn sich überhaupt ein systematischer Zusammenhang zwischen der Bedeutung eines Verbs und dem Potential syntaktischer Realisierungen, in denen es vorkommen kann, aufzeigen läßt. Diesem Zusammenhang will ich im folgenden nachgehen. Dabei beschränke ich mich auf die Auxiliarselektion bei den komplexen Vergangenheitstempora (haben vs. sein) einerseits sowie auf Veränderungen der Argumentstruktur durch Argumentalternation und Argumentreduktion andererseits.

$\mathrm{DaB}$ es hinsichtlich dieser Eigenschaften Unterschiede schon zwischen etymologisch verwandten Wörtern und/oder typologisch verwandten Sprachen gibt, mögen die folgenden Betrachtungen illustrieren:

\section{Auxiliarselektion}

Das Deutsche gehört bekanntlich zu den Sprachen, die bei der Bildung der komplexen Vergangenheitstempora zwischen haben- und seinselegierenden Verben bzw. Verbphrasen differenzieren (1). Es unterscheidet sich in dieser Hinsicht vom Englischen, das nur die have-Form kennt (2).

(1) Jonathan ist gerannt/hat getrampelt/ist in das Blumenbeet getrampelt.

(2) Jonathan has run/has stamped/has stamped into the flower bed.

Das Französische, das Italienische oder das Niederländische besitzen ebenfalls zwei Formen, weisen diese aber teilweise anders zu als das Deutsche. Dies wirft die Frage auf, ob die betreffenden Verben in diesen Sprachen andere Bedeutungen haben, oder ob - bei Übereinstimmung in der Bedeutung - andere Kriterien für die Auxiliarselektion gelten, mit der Folge, daB die verglichenen Sprachen verschiedenen lexikalischen Strukturtypen zuzuordnen wären.

\section{Argumentalternation}

Im Englischen gibt es ein umfangreiches Inventar von Inchoativ/Kausativpaaren (wie open, close, fill, empty etc.), die formal allein durch die Transitiv/Intransitiv-Opposition gekennzeichnet sind (3). Im Deutschen müssen die entsprechenden Verben in inchoativer Bedeutung reflexiviert sein (4):

(3) a Jonathan opened the door./The door opened $\left({ }^{*}\right.$ itself $)$.

$\mathrm{b}$ Jonathan filled the tank with gas./The tank filled $\left({ }^{*}\right.$ itself) with gas. 
(4) a Jonathan öffnete die Tür./Die Tür öffnete sich (*öffnete). Jonathan füllte den Tank mit Benzin./Der Tank füllte sich (* füllte) mit Benzin.

Engl. fill und pour verbieten die Alternation von ZIEL- und MITTELPhrase, fill kann nur das ZIEL, pour nur das MITTEL zum Objekt machen (5), irn Deutschen ist die Alternation für füllen zulässig ( $6 \mathrm{a}, \mathrm{b})$, bei den Partikelverben ist sie verbreitet $(7 a, b)$, teilweise bei obligatorischer Reduktion des MITTEL-Arguments (7c, d).

(5) a Jonathan filled the pot with coffee.

b * Jonathan filled coffee into the pot.

c Jonathan poured coffee into the pot.

d John poured the pot with coffee.

(6) a Jonathan füllte die Kanne mit Kaffee.

b Jonathan füllte den Kaffee in die Tasse.

c Jonathan goß den Kaffee in die Kanne.

d *Jonathan goß die Kanne mit Kaffee.

(7) a Jonathan goß den Kaffee/die Tassen ein.

b Jonathan goß die Milch/die Kanne aus.

c Jonathan fegte die Krümel vom Tisch ab.

d Jonathan fegte den Tisch (*von den Krümeln) ab.

Sind die englischen und die deutschen Verben nur scheinbar bedeutungsgleich, bündeln sie unterschiedliche Bedeutungskomponenten in ihrer semantischen Struktur (i)? Gelten bei übereinstimmender Verbbedeutung für Variationen der Argumentstruktur im Englischen und im Deutschen grundsätzlich unterschiedliche Regeln (ii)? Oder handelt es sich hier einfach um arbiträre Unterschiede, die zu den idiosynkratischen Bestandteilen lexikalischer Information gehören (iii)? Eine positive Antwort auf (i) würde das Englische und das Deutsche im Bereich der Lexikonarchitektur typologisch unterscheiden, eine positive Antwort auf (ii) im Bereich der Grammatik (vgl. dazu den Beitrag von Olsen in diesem Band).

\section{Argumentreduktion}

$\mathrm{Zu}$ den klassischen Problemzonen der Valenztheorie gehört die Weglaßbarkeit von Objektphrasen. Bestimmte Verben (eines der Standardbeispiele ist essen) erlauben es, das direkte Objekt zu unterdrücken $(8 \mathrm{a}, \mathrm{b})$, andere verbieten dies $(9 a, b)$. 
(8) a Jonathan ißt eine Suppe.

b Jonathan ißt

(9) a Jonathan verzehrt seinen Proviant.

b *Jonathan verzehrt

In der intransitiven Variante (8b) ist der Bezug auf ein (indefinites) Objekt aber implizit mitgegeben (Wer iBt, iBt etwas). Prädikatenlogische Repräsentationen geben den Bezug auf das implizite Objekt daher durch existentielle Bindung wieder:

(10) b' ヨy [Ess (Jonathan, y)]

$\mathrm{DaB}$ eine solche Repräsentation nicht alle impliziten Argumente erfassen kann, zeigen Verben wie backen mit einer kreativen (11) und einer kausativen Bedeutungsvariante (12). Nur in der kreativen Lesart kann das Objekt unterdrückt werden (11b), aber genau diese Variante läBt sich nicht durch existentielle Bindung repräsentieren, da der Kuchen, den Hans backt, beim Backen erst entsteht. ${ }^{3}$

(11) a Jonathan backt einen Kuchen.

b Jonathan backt

c * *x [back (Jonathan, x)]

(12) a Jonathan backt eine Forelle.

b *Jonathan backt

Das implizite Argument kann in der Redesituation deiktisch verankert sein (z.B. wenn Eva (13a) äuBert, während sie Adam den Apfel reicht) oder sich auf ein in der Rede selbst eingeführtes Antezedens zurückbeziehen (anaphorische Verankerung, (13b)). In diesen Fällen ist das implizite Argument nicht durch existentielle Bindung darstellbar, denn Adam iBt nicht irgendeinen, sondern den ihm von Eva gereichten Apfel. Das implizite Argument muß daher durch eine freie Variable dargestellt werden, für die im Kontext eine geeignete Belegung zu suchen ist. Transitive Verben wie verzehren verbieten die Unterdrückung der Objektphrase al-

3 Ein anderes Problem der existentiellen Bindung impliziter Argumente betrifft den Skopus des Existenzquantors in Sätzen wie Alle essen oder Hans hat den ganzen Tag gegessen. Mit weitem Skopus ((Es gibt etwas, das alle essen bzw. Es gibt etwas, das Hans den ganzen Tag ißt) repräsentiert, wūrden diese Sätze besagen, daß alle dasselbe essen bzw. daß Hans den ganzen Tag dasselbe ift. Für Verben wie essen wäre also der Existenzquantor auf engen Skopus zu beschränken, eine Beschränkung, die für ziehen oder lesen (Alle ziehen (denselben Karren) oder Hans hat den ganzen Tag (dasselbe Buch gelesen) nicht gilt. 
lerdings auch dann, wenn ein geeigneter Kontext für die deiktische oder anaphorische Verankerung zur Verfügung steht (13c).

(13) a

b Eva reichte Andam einen Apfel und er aß

c Eva reichte Adam einen Apfel, und er verzehrte

Auch hinsichtlich der Optionalität von Argumenten gibt es Unterschiede zwischen dem Englischen und dem Deutschen. Während etwa für das deutsche Verb gießen die explizite Realisierung von URSPRUNG, WEG oder ZIEL obligatorisch ist, können sie im Englischen deiktisch verankert werden und damit implizit bleiben: An einer gedeckten Kaffeetafel ist (15b) im Englischen möglich, die deutsche Entsprechung (14b) muß demgegenüber als abweichend gelten.

(14) a Wer wird den Kaffee in die Tassen gießen?

b ${ }^{*}$ Wer wird den Kaffee gießen?

(15) a Who is going to pour the coffee into the cups?

$\mathrm{b}$ Who is going to pour the coffee ?

Das Deutsche verlangt in solchen Fällen die Verwendung eines Partikelverbs (16).

(16) a Wer wird den Kaffee eingießen?

b * Who is going to pour the coffee in?

Ich beschränke mich in diesem Aufsatz auf das Deutsche und greife als eine konzeptuell klar abgrenzbare Teilklasse der Basisverbstämme die Transportverben heraus. Im Mittelpunkt der Erörterung steht das Problem der Argumentreduktion. Ich werde zu zeigen versuchen, daB die WeglaBbarkeit der Argumente eines Verbs durch seine lexikalische Bedeutung determiniert ist und also nicht zu seinen idiosynkratischen Eigenschaften gehört.

\section{Semantische Klassifikationsdimensionen}

\subsection{Thematische Rollen}

Die Bedeutung der Transportverben läßt sich in allgemeiner Weise so charakterisieren:

(17) Ein Transport ist ein Vorgang, bei dem ein AGENS (x) auf ein PATIENS $(y)$ einwirkt, so daf $y$ ausgehend von seinem URSPRUNGSort (u) längs eines WEGES $(w)$ seinen Ort kontinuierlich ändert und schließlich zu dem ZIELort (z) gelangt. 
Die Variablen $\mathrm{x}, \mathrm{y}, \mathrm{u}, \mathrm{w}$ und $\mathrm{z}$ repräsentieren die Argumente des Verbs. AGENS, PATIENS, URSPRUNG, WEG und ZIEL charakterisieren die thematischen Rollen der Argumente, d.h. sie geben an, in welcher Weise die von den Argumentvariablen bezeichneten Individuen an dem durch das Verb bezeichneten Vorgang beteiligt sind. Der Begriff "Argument" ist verwandt, aber nicht identisch, mit dem valenztheoretischen Begriff der "Stelle" bzw. der Ergänzung. Argumente repräsentieren Initiator oder Auslöser, NutznieBer oder Opfer eines Geschehens auf der Ebene der lexikalischen Form. Ergänzungen, die eine Verbstelle besetzen, kodifizieren Argumente auf der Ebene der syntaktischen Form. Aus der Valenztheorie ist die Unterscheidung zwischen Ergänzungen und Angaben bekannt. Auch diese Unterscheidung betrifft die syntaktische Form. Für die Abgrenzung zwischen Ergänzungen und Angaben gibt es bekanntlich keine eindeutigen Kriterien (cf. Steinitz 1969, Vater 1978, 1981). Versuche, Optionalität als Entscheidungskriterium zu etablieren, müssen als gescheitert gelten; erfolgversprechender scheint eine multidimensionale Gewichtung verschiedener Merkmale (Jacobs 1994). Nach allgemein akzeptierter Auffassung ist AGENS die Rolle des willentlichen Verursachers einer Handlung, THEMA die Rolle des Objekts, das durch die im Verb ausgedrückte Handlung eine Zustandsveränderung erfährt (bzw. im Falle der Transportverben eine Ortsveränderung). Dieser Auffassung gemäß realisieren die Tasche und die Kundin in (18) gleichermaßen die THEMA-Rolle.

(18) Jonathan trägt die Tasche/die Kundin ins Auto.

Im Gefolge der Fillmoreschen Kasustheorie hat man ausgiebig darüber nachgedacht, ob zwischen THEMA als dem unbelebten Objekt und PATIENS oder BENEFAKTIV als dem belebten Teilhaber oder Nutznießer einer Handlung unterschieden werden muB. $\mathrm{DaB}$ eine solche Unterscheidung durchaus Sinn macht, läßt sich an Konstruktionen mit lassen demonstrieren:

(19) a Die Kundin läßt sich von Jonathan ins Auto tragen.

b *Die Tasche laßft sich von Jonathan ins Auto tragen.

Unter Hinweis auf das Verhalten bei Passivierung in Beispielen wie (20) kann man ähnlich auch für die Differenzierung zweier Verursacherrollen argumentieren, der Rolle des belebten und der Rolle des unbelebten Verursachers. (Jackendoff 1983, 1990 unterscheidet in diesem Sinne zwischen AGENT und ACTOR):

(20) a Die Tasche wurde von dem Jungen in den fünften Stock getragen.

b ?Die Tasche wurde von dem Fahrstuhl in den fünften Stock getragen. 
Die Diskussion solcher und ähnlicher Beispiele in den frühen siebziger Jahren hat freilich gezeigt, daß es schnell zu einer Rolleninflation kommt, wenn jede Bedeutungsnuancierung die Etablierung einer weiteren Rolle rechtfertigt. Vermieden oder jedenfalls eingedämmt werden kann eine solch inflationäre Rollenvermehrung, wenn man von der Vorstellung Abschied nimmt, daB ein Argument in einer bestimmten Rolle alle definierenden Eigenschaften dieser Rolle besitzen muB. Einem Vorschlag von Dowty (1992) folgend, nehme ich stattdessen an, daB man die Argumente eines Verbs danach gewichten kann, ob sie mehr ProtoAgens-Eigenschaften oder mehr Proto-Patiens-Eigenschaften realisieren. Proto-Agens- und Proto-Patiens-Eigenschaften sind nach Dowty die folgenden:

(21) Proto-Agens:

- WILLENTLICHKEIT: Arg. ist willentlicher Partizipant der Handlung.

- EMPFINDUNGS-/WAHRNEHMUNGSFÄHIGKEIT: Arg. ist an der Handlung als empfindungs- und/oder wahrnehmungsfähiges Individuum beteiligt.

- VERURSACHUNG: Arg. ist Verursacher einer Zustandsveränderung bei einem anderen Partizipanten der Handlung.

- BEWEGUNG: Arg. ist relativ zu einem anderen Partizipanten in Bewegung.

- UNABHẢ NGIGE EXISTENZ: Arg. existiert unabhängig von der Handlung.

(22) Proto-Patiens:

- ZUSTANDSVERÄNDERUNG: Arg. wird durch die Handlung einer Zustandsveränderung unterworfen.

- INKREMENTALITÄT: Die Zustandsveränderung ist inkrementell, d.h., der Zustand von Arg. verändert sich fortlaufend in der Zeit.

- KAUSALE AFFIZIERUNG: Die Zustandsveränderung von Arg. wird durch Einwirkung eines anderen Partizipanten der Handlung herbeigeführt.

- NICHT-BEWEGUNG: Arg. ist relativ zu einem anderen Partizipanten stationär.

- ABHÄNGIGE EXISTENZ: Arg. existiert nicht unabhängig von der Handlung. 
Wenn im folgenden von der PATIENSrolle bei Transportverben die Rede ist, dann besagt dies, daB PATIENS bei allen Transportverben die ersten drei, aber nicht die letzten beiden Eigenschaften der Proto-Patiens-Rolle besitzt.

\section{$2.2 \quad$ Aktionsarten}

Traditionell sind unter dem Stichwort „Aktionsarten” Phaseneigenschaften von Verben wie Ingressivität, Inchoativität, Kontinuativität, Egressivität oder Iterativität betrachtet worden. In der jüngeren Aktionsartendiskussion stehen dagegen die sog. Vendler-/Dowtyklassen mit der (letztlich auf die Kategorienlehre des Aristoteles zurückgehenden) Unterscheidung von Sachverhaltskategorien wie activities, states, accomplishments und achievements im Mittelpunkt (Vendler 1967, Dowty 1979). In der Aktionsartenliteratur ist wenig danach gefragt worden, ob Phasenkategorien und Sachverhaltskategorien verschiedene Aktionalitätsdimensionen bilden oder ob es sich hier bloB um verschiedene Terminologien handelt. In meinen eigenen Arbeiten zur Aktionalitätsproblematik (Ullmer-Ehrich 1977, Ehrich 1992) habe ich den zweiten Standpunkt vertreten und Ingressiva wie Egressiva unterschiedslos den ("resultativen” oder "terminativen”) Ereignisverben zugerechnet. Die Kritik an einer solchen Gleichsetzung in einer frühen Arbeit von R. Steinitz (1981) nötigt zu einer Revision dieser Auffassung. Steinitz betrachtet in dieser Arbeit Ingressiva auf los- und Egressiva auf aus- (losschreien, losschreiben, loslaufen, austoben, ausweinen, ausschlafen). Diese Verben genügen den beiden von Steinitz geforderten Kriterien für Aktionsarten, erstens dem formalen Kriterium, indem sie das jeweilige Basisverb morphologisch verändern, und zweitens dem semantischen Kriterium, indem sie die Grundbedeutung des Basisverbs modifizieren. Steinitz zeigt, daB einige der klassischen Tests für die Aktionsartenzuweisung, wie sie außer von Vendler selbst für das Deutsche z.B. von Andersson (1972) in die Diskussion eingebracht wurden, für die Abgrenzung etwa der Aktivitäts- und Zustandsverben von den ingressiven oder egressiven Ereignisverben nicht brauchbar sind. Zwar stimmen ingressive Verben auf los(23b) im Hinblick auf die Kombinierbarkeit mit durativen Begrenzungsadverbialen mit den Ereignisverben (Vendlers „accomplishments” und „achievements") überein (23c), was dafür spricht, sie derselben Gruppe zuzuordnen, bei den aus-Verben gibt es in dieser Hinsicht jedoch Unter- 
schiede: Die nicht-reflexiven Varianten (24b) verhalten sich anders als die reflexiven $(24 c){ }^{4}$

(23) a Das Kind hat stundenlang geschrieen.

b *Das Kind hat stundenlang losgeschrieen.

c ${ }^{*}$ Das Kind ist stundenlang hingefallen.

(24) a Das Kind hat stundenlang getobt.

b ${ }^{*}$ Das Kind hat stundenlang ausgetobt.

c Das Kind hat sich stundenlang ausgetobt.

Partizipialattribute sind von intransitiven Ereignisverben (25a), nicht aber von los-Verben (25b) möglich, während sie für aus-Verben mindestens akzeptabel scheinen $(25 \mathrm{c})$.

(25) a Das hingefallene Kind

b *Das losgeschrieene Kind

c Das ausgetobte Kind

(25c) mag man auf die reflexive Variante von austoben zurückführen. Dies spricht dann allerdings dagegen, die Aktionalitätsmerkmale der Verben als allein ausschlaggebend für die Attribuierbarkeit des Partizips anzusehen und legt nahe, die thematischen Rollen der Verbargumente mit einzubeziehen. Daß die thematische Rolle (PROTO-PATIENS) über die Attribuierbarkeit des Partizips (mit)entscheidet, zeigen Beispiele wie (26), die sich bei übereinstimmenden Phasenkategoriemerkmalen hinsichtlich der thematischen Rollen ihrer Argumente unterscheiden: (26a) und (26b) mit AGENS-Subjekt verbieten, (26c) mit PROTO-PATIENS-Subjekt erlaubt die Attribuierung des Partizips. Allerdings sind die thematischen Rollen nicht allein entscheidend. Die Verben in (27) haben übereinstimmend ein AGENS-Subjekt und unterscheiden sich untereinander nur hinsichtlich ihrer Aktionalitätsmerkmale (PROZESS vs. EREIGNIS). Das Ereignisverb ausbrechen läßt den attributiven Gebrauch des Partizips zu, das ProzeBverb rennen verbietet dies.

(26) a Das Kind hat losgebrüllt. ${ }^{*}$ Das losgebrillte Kind

b Die Wettkämpfer sind losgelaufen./?Die losgelaufenen Wettkämpfer

c Der Bus ist losgefahren./Der losgefahrene Bus

4 Dies mag ein Hinweis darauf sein, daß aus-neben einer egressiven Lesart in austoben eine exhaustive Lesart in sich austoben hat. Auf diesen Punkt kann ich hier jedoch nicht näher eingehen. 
(27) a Die Häflinge sind gerannt./ ${ }^{*}$ Die gerannten Häflinge

b Die Häflinge sind ausgebrochen./Die ausgebrochenen Häftlinge

$\mathrm{Da}$ es in diesem Aufsatz um Basis-Transportverben geht, werde ich im folgenden die Phasen-Aktionalitätsmerkmale vernachlässigen und mich auf Sachverhaltskategorien beschränken. Neben EIGENSCHAFTEN wie blond/geizig sein, auf die ich hier nicht eingehen will, unterscheide ich ZUSTANDE wie brillen und sitzen, PROZESSE wie laufen und wachsen sowie EREIGNISSE wie ausbrechen und anwachsen. ${ }^{5}$ In allen drei Kategorien können Intransitiva entweder ein PROTO-AGENS oder ein PROTO-PATIENS-Subjekt haben. Brüllen, laufen und ausbrechen etwa haben ein PROTO-AGENS-, sitzen, wachsen und anwachsen ein PROTO-PATIENS-Subjekt.

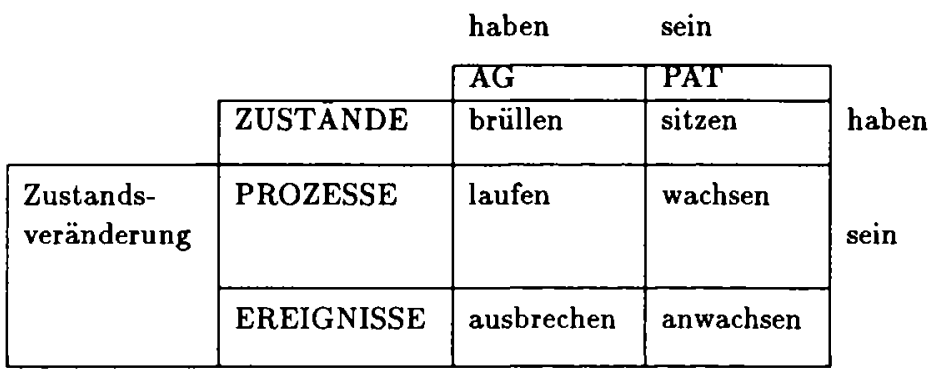

Tab. 1: Sachverhaltskategorien, Thematische Rollen, Auxiliarselektion

Zustände mit PROTO-AGENS-Subjekt sind dynamische, Zustände mit PROTO-PATIENS-Subjekt statische Zustände. Brüllen und sitzen beziehen sich auf ein zeitlich offenes Geschehen, sie sind nicht auf einen definiten Endzustand bezogen und involvieren nicht einmal eine Veränderung in der Zeit. Im Prinzip kann man nicht nur beliebig lange brüllen, sondern auch mit gleichbleibender Intensität. Zustände sind insofern zeitlich offen und stabil. Prozesse teilen mit Zuständen das Merkmal der zeitlichen Offenheit, man kann beliebig lange laufen oder wachsen, ohne ein definitives Endstadium zu erreichen. In einer an Vendler orientierten Klassifikation werden Verben wie laufen und brüllen daher derselben Kategorie (den Aktivitäten) zugeordnet. Prozesse involvieren aber notwendig eine kontinuierliche Veränderung in der Zeit. Mit jedem Schritt, den man läuft, und mit jedem Zentimeter, den man wächst, ist eine Ortsveränderung bzw. eine Größenveränderung verbunden. Prozesse sind

5 Interessanterweise gibt es im Deutschen kaum intransitive Basis-Ereignisverben mit AGENS-Subjekt. Die meisten Verben dieser Kategorie sind Partikelverben. 
insofern Zustandsveränderungen. Diese Eigenschaft teilen sie mit Ereignissen. Allerdings sind Ereignisse anders als Prozesse zeitlich nicht offen, sondern auf einen definitiven Endzustand bezogen, sie lassen sich daher nicht mit durativen Begrenzungsadverbialen verbinden (28).

(28) a Das Kind hat stundenlang gebrïlt

b Die Häflinge sind stundenlang gerannt.

c ${ }^{*}$ Die Häflinge sind stundenlang ausgebrochen.

M.a.W., ZUSTÄNDE sind zeitlich offen und stabil [+o, +s], PROZESSE sind zeitlich offen und nicht-stabil [+o, $-s]$, EREIGNISSE sind zeitlich geschlossen und nicht-stabil [-o, -s].

In der germanistischen und indogermanistischen Philologie weiB man spätestens seit Brugmann, daB die haben/sein-Selektion bei intransitiven Verben mit den Aktionsarten zusammenhängt (vgl. dazu H. Paul 1917, Dal 1952). Diese alte Erkenntnis ist in jüngerer Zeit im Zusammenhang mit der Unakkusativitätshypothese wiederbelebt worden. Als ein zentraler Parameter, der unakkusative Verben gegenüber unergativen auszeichnet, gilt gemeinhin die Selektion von sein bei den komplexen Vergangenheitstempora. Ausschlaggebend für die Selektion von sein ist nach der Unakkusativitätshypothese die thematische Rolle des Subjekts: Verben mit THEMA- oder (PROTO-) PATIENS-Subjekt selegieren sein, Verben mit AGENS-Subjekt haben: Diese Version der Unakkusativitätshypothese stützt sich vor allem auf die Betrachtung romanischer Sprachen. Für die germanischen Sprachen ist in jüngerer Zeit die ausschlaggebende Rolle der Aktionalitätsmerkmale hervorgehoben worden. Aktionalität gilt neuerdings als weiterer Parameter für Unakkusativität (bzw. „Ergativität” (Abraham 1993)). Dazu ist zu bemerken, daß Aktionalität und Rollenzugehörigkeit grundlegend verschiedene semantische Dimensionen ausmachen. Aktionalitätsmerkmale betreffen die temporalen Eigenschaften der Verbhandlung, Rollenmerkmale die Beteiligungsmodalität, also die Art, in der die Argumente (genauer gesagt, ihre Referenten) an der Verbhandlung teilhaben. Für die haben/seinSelektion bzw. für die Attribuierbarkeit des Partizips spielt keine dieser Dimensionen die alleinausschlaggebende Rolle, vielmehr wirken beide zusammen. Im Deutschen sind (abgesehen natürlich von den transitiven Verben, die grundsätzlich haben selegieren) nur die Zustandsverben mit PROTO-AGENS-Subjekt eindeutig haben-selegierend (Tab.1). Bei den Zustandsverben mit PROTO-PATIENS-Subjekt konkurrieren haben und sein (ich bin gesessen/ich habe gesessen). Prozeb- und Ereignisverben mit PROTO-PATIENS-Subjekt selegieren ausnahmslos sein. Dagegen gibt es bei den Prozebverben mit PROTO-AGENS wiederum 
eine haben/sein-Konkurrenz (Wir sind/haben gelaufen, geschwommen, geritten etc.).

Bei intransitiven Verben der Zustandsveränderung (ProzeB- und Ereignisverben) ist es jeweils das Subjekt, das die Zustandsveränderung durchmacht. Transitive Verben der Zustandsveränderung fallen in drei Teilklassen, solche wie heiraten, bei denen beide Argumente (Jonathan und Maria) eine Veränderung erfahren (29 a), Verben wie verletzen, bei denen die Veränderung auf das als Objekt realisierte PROTO-PATIENS beschränkt ist (29b) und schließlich Verben wie vergessen, bei denen die Veränderung nur das PROTO-AGENS (Maria) betrifft (29 c).

(29) a Maria heiratet Jonathan.

b Maria verletzt Jonathan.

c Maria vergißt Jonathan.

Im Bereich der Transportverben, um die es hier geht, kann man entsprechend unterscheiden $\mathrm{zwischen}$ solchen Verben, bei denen allein PATIENS eine Ortsveränderung durchmacht (notiert als OV-PAT) und solchen, bei denen AGENS zusammen mit PATIENS seinen Ort ändert (notiert als OV-AG):

(30) a Hans wirft den Ball aufs Dach. (OV-PAT)

b Hans trägt den Ball aufs Dach. (OV-AG)

2.3 Die Art und Weise der Handlungsdurchführung: manner- vs. nonmanner-Verben

Bestimmte Verben enthalten in ihrer lexikalischen Bedeutung eine Charakterisierung der Handlungsdurchführung, andere sind in dieser Hinsicht unbestimmt. Besonders augenfällig ist dies bei den Verben der Ortsveränderung. Schleichen, kriechen, trippeln, tänzeln kennzeichnen die Bewegungsart, kommen, ausbrechen, fliehen lassen sie unbestimmt. Den Kontrast zwischen manner- und non-manner-Verben gibt es aber auch in anderen semantischen Domänen, z.B. bei den Konsumverben (essen vs. mümmeln, kauen, schlingen; lesen vs. schmökern, vgl. dazu Tschernitschek 1993), bei den Wahrnehmungsverben (gucken vs. spähen, starren, glotzen) oder den Reinigungsverben (säubern vs. fegen, wischen, schrubben, moppen). In diesem Aufsatz, in dem es um transitive Transportverben geht, interessiert neben dem Kontrast $\mathrm{zwischen}$ manner- und non-manner-Verben vor allem die Frage, ob das Verb die Bewegungsart des AGENS- oder die des PATIENS-Arguments hervorhebt. Schubsen etwa kennzeichnet die Handlungsart des AGENS (notiert als M-AG), in (31a) ist es Jonathan, der schubst, und nicht der Ball. Demgegenüber 
hebt kullern die Bewegungsart von PATIENS hervor (notiert als MPAT), in (31b) kullert der Ball und nicht Jonathan.

(31) a Jonathan schubst den Ball in den Teich./ ${ }^{*}$ Der Ball schubst in den Teich. (M-AG)

b Jonathan kullert den Ball in den Teich./Der Ball kullert in den Teich. (M-PAT)

\section{Transportverben}

\subsection{Subklassifikation der Transportverben}

Im folgenden werden die Transportverben nach MaBgabe der oben eingeführten semantischen Klassifikationsdimensionen in Gruppen unterteilt. Schieben und rollen gehören zu den PROZESS-Verben ${ }^{6}$, werfen und schleudern zu den EREIGNIS-Verben. ${ }^{7}$

Hinsichtlich des Merkmals der Ortsveränderung unterscheiden sich Verben, die eine Ortsveränderung nur von PATIENS involvieren (OVPAT: schaufeln, tröpfeln, werfen, schleudern, stapeln, gießen), von Verben, bei denen AGENS zusammen mit PATIENS seinen Ort ändern kann oder muB (OV-AG: schieben, rollen, bringen, tragen). Verben mit AGENS-spezifischer manner-Komponente (M-AG: schieben, schaufeln, werfen) stehen in Kontrast zu Verben mit PATIENS-spezifischer manner-Komponente (M-PAT: rollen, tröpfeln, schleudern). Verben wie stapeln haben ebenfalls eine manner-Komponente, die jedoch nicht die Bewegungsart betrifft, sondern die aus der Verbhandlung resultierende Positionsmodalität von PATIENS (notiert als PM-PAT). Bringen, tragen und gießen schließlich enthalten keine manner-Spezifizierung.

6 Mit explizitem ZIEL-Argument beziehen sich auch schieben und rollen auf Ereignisse. Verben wie werfen und schleudern haben aber auch ohne ZIELArgument nur eine EREIGNIS-Lesart.

7 Ich betrachte die Verben nur in ihrer aufgefūhrten Lesart als Transportverben. Schleudern hat auch eine Interpretation als reines Körperbewegungsverb, z.B. Jonathan schleudert die Arme hoch. 


\begin{tabular}{|l|l|l|l|}
\cline { 2 - 3 } \multicolumn{1}{c|}{} & \multicolumn{1}{l|}{ OV-AG } & \multicolumn{1}{c|}{ OV-PAT } & \multicolumn{1}{|l}{} \\
\hline PROZESS & $\begin{array}{l}\text { schieben } \\
\text { rollen }\end{array}$ & $\begin{array}{l}\text { schaufeln } \\
\text { tröpfeln }\end{array}$ & $\begin{array}{l}\text { M-AG } \\
\text { M-PAT }\end{array}$ \\
\hline EREIGNIS & $\begin{array}{l}\text { werfen } \\
\text { schleudern } \\
\text { knallen } \\
\text { stapeln }\end{array}$ & $\begin{array}{l}\text { M-AG } \\
\text { M-PAT }\end{array}$ \\
& PM-PAT \\
\hline & $\begin{array}{l}\text { bringen } \\
\text { tragen }\end{array}$ & gieBen & \\
\hline
\end{tabular}

Tab. 2: Transportverben im Deutschen

In der folgenden Liste (32-43) sind die Transportverben in verschiedene Teilklassen gruppiert, das erste Verb stammt jeweils aus Tab. 2, die ihm folgenden Verben gehören zur selben Teilklasse und zeigen dieselben semantischen und syntaktischen Eigenschaften.

(32) schieben, schubsen, treiben, zerren, ziehen; (AGENS als Antrieb oder als AnstoB).

(33) a schleppen, puckeln; (AGENS als Vehikel)

b karren, kutschen, kutschieren, schippern; (Instrument als Vehikel)

c paddeln, rudern, radeln, reiten; (Instrument als Vehikel, Körperbewegung von AGENS)

(34) schaufeln, fegen, harken, hebeln, loffeln, pumpen, schippen, schneiden, schöpfen; (AGENS gibt AnstoB mit Hilfe eines Instruments)

(35) werfen, kicken, köpfen, treten, stoßen, schnipsen, spucken, heben, wuchten, stemmen; (AGENS als AnstoB)

(36) rollen, kugeln, kullern, schleifen; (AGENS als Antrieb oder als AnstoB)

(37) tröpfeln, tropfen, träufeln, streuseln; (AGENS als AnstoB) 
schleudern, spritzen, sprühen; (AGENS als AnstoB)

(39) knallen, schmettern, rumpeln, klatschen;

(Geräusch-Emissions-Verben)

(40) stapeln, breiten, kleben, schichten, stopfen, türmen; (Resultierende Positionsmodalität)

(41) gießen, streuen, schütten; (AGENS als AnstoB)

(42) a bringen, holen; (AGENS als Antrieb)

b schicken; (AGENS als AnstoB

\section{tragen; (AGENS als Antrieb)}

Die Verben (32-35) spezifizieren die Bewegungsart von AGENS (M-AGVerben), die Verben (36-38) kennzeichnen die Bewegungsart von PATIENS (M-PAT-Verben). Bei den Verben der Gruppen (33), (36) und (42a) kann die Ortsveränderung von PATIENS durch AGENS in Gang gehalten werden (ANTRIEBS-Verben), bei den Verben der Gruppen (34), (35) und (37-39) wird sie von AGENS in Gang gesetzt (ANSTOSSVerben). ${ }^{8}$ Die Verben der Gruppen (32) und (36) lassen dabei die ANTRIEBS- ebenso wie die ANSTOSS-Lesart zu: Wer sein Fahrrad nach Hause schiebt, gelangt selbst nach Hause (AGENS als ANTRIEB), wer einen Geldschein in die Tasche schiebt, behält seine Ausgangsposition bei (AGENS als ANSTOSS). Wer den Käse zum Bahnhof rollt, geht mit (ANTRIEB), wer ein Geldstück über den Tisch rollt, nicht (ANSTOSS). Der Unterschied zwischen ANTRIEBS- und ANSTOSS-Verben fält im übrigen nicht zusarmmen mit der Unterscheidung zwischen EREIGNISund PROZESS-Verben, bringen, holen sind EREIGNIS-, aber keine ANSTOSS-Verben. Bei den Verben der Gruppe (33) ist zu differenzieren zwischen Verben, bei denen AGENS selbst als Vehikel des Transports fungiert (33a), und solchen, bei denen AGENS ein Instrument als Vehikel benutzt und zusätzlich eigene Körperkraft mobilisiert (33c) oder nicht (33b). Morphologisch sind die Instrument- und Vehikelverben als Konversionsbildungen gekennzeichnet. Die Verben der Gruppe (34) beziehen sich auf Transporte, bei denen ein Instrument benutzt wird. Mor-

8 Jackendoff (1990) spricht von „inception of motion” und unterscheidet zwischen entraining und launching als Subfunktionen einer allgemeinen CAUSE-Funktion. 
phologisch sind sie ebenfalls als Konversionen gekennzeichnet. Bei diesen Verben, ebenso wie bei denen der Gruppe (35) und (37-39), wechselt nur PATIENS seinen Ort. Den ANSTOSS-Verben mit PATIENS-spezifischer Bewegungsart (38) entsprechen die Geräusch-Emissions-Verben (39). Sie sind primär nicht auf Transportereignisse bezogen, in Kombination mit ZIEL-Phrasen nehmen sie aber eine sekundäre Transportlesart an und heben in dieser Lesart das Geräusch hervor, das bei dem Transport von PATIENS ausgeht. Zu den ANSTOSS-Verben gehören auch Verben wie gießen und schütten (41). Anders als die meistens anderen ANSTOSSVerben geben sie weder einer AGENS- noch einer PATIENS-spezifischen Handlungsart Ausdruck, sie kennzeichnen lediglich die Bewegungsrichtung des Transports und involvieren Beschränkungen über den Aggregatzustand des Transportguts.

Bringen, holen und schicken (42) sind deiktische Verben, URSPRUNG und ZIEL werden hier relativ zu einem kontextuell gegebenen Referenzpunkt $\mathrm{R}_{\mathrm{L}}$ identifiziert. Bei bringen haben AGENS und PATIENS denselben von ZIEL verschiedenen URSPRUNG, $R_{L}$ kann mit ZIEL identisch sein (Der Briefträger brachte die Post) oder mit URSPRUNG (Jonathan brachte die Briefe zum Postamt). Im Englischen sind diese beiden Fälle unterschiedlich lexikalisiert, der erste wird durch bring wiedergegeben, der zweite durch take. (The postman brought the mail/Jonathan took the letters to the post-office.) Bei holen nimmt AGENS einen Transportweg, der von seinem URSPRUNG $U_{A G}$ über den davon verschiedenen URSPRUNG von PATIENS U UAT zum Ausgangspunkt $U_{\text {AG }}$ zurückführt. $R_{L}$ fällt dabei mit $U_{A G}$ zusammen und ist wie dieser identisch mit ZIEL. Bei schicken teilen AGENS und PATIENS denselben URSPRUNG, aber nur PATIENS gelangt zu dem mit $R_{L}$ identischen ZIEL. Das Verb tragen steht in seiner Kategorie allein. Von den hier aufgeführten Transportverben ist es das einzige, bei dem die Ortsveränderung von AGENS und PATIENS optional ist. (Man kann einen Rucksack tragen, ohne sich von der Stelle zu bewegen, z.B. beim Warten an einer Bushaltestelle.) Tragen gehört zu den Verben, bei denen AGENS selbst als Vehikel fungiert. Falls also tragen einen Ortswechsel von PATIENS zum Ausdruck bringt, so ist damit notwendig auch ein Ortswechsel von AGENS verbunden. Die Vehikeleigenschaft teilt tragen mit puckeln und schleppen, anders als diese gibt tragen jedoch keiner AGENS-spezifische Handlungsart Ausdruck.

\subsection{Die lexikalische Repräsentation von Transportverben}

Mit der lexikalischen Repräsentation von Verben beschäftigt sich eine Vielzahl neuerer Arbeiten, auf die ich hier im einzelnen nicht eingehen kann. Gemeinsam ist den verschiedenen Ansätzen eine (teilweise uneinge- 
standene) Affinität zu Vorstellungen der Generativen Semantik. Mit dieser teilen sie insbesondere das Konzept der lexikalischen Dekomposition, die Annahme also, daB Wortbedeutungen komplex sind und in mehrere elementare Prädikat/Argument-Strukturen zerlegt werden müssen. Mit der Dekompositionshypothese verbindet sich der universalistische Anspruch, daB verschiedene Einzelsprachen in ihrem Lexikon von denselben atomaren Prädikaten Gebrauch machen, diese aber in unterschiedlicher Weise bündeln (s.o. die Diskussion von Talmy).

Thematische Rollen (AGENS, PATIENS etc.) werden in einigen Analyseformaten (z.B. Jackendoff 1990) indirekt eingeführt, und zwar durch Rekurs auf die Argumentstellen der atomaren Basisprädikate. Dieser Konzeption schlieBe ich mich hier an. Für die Repräsentation der Transportverben genügen ACT, AFFECT, GO, BE AT, CAUSE und BECOME als Basisprädikate:

(44) ACT

AFFECT $(x, y)$

GO $\quad(x, w)$

BE AT $\quad(x, z)$

CAUSE ([p], [q])

BECOME [BE AT $(x, y)]_{z}$
„X ist tätig"

"x wirkt auf $y$ ein"

"x geht einen Weg w"

"x befindet sich am Ort z"

"[p] verursacht [q]"

"x gerät in einen Zustand $z "$

Das erste Argument von AFFECT ist (ebenso wie das Argument von ACT) ein PROTO-AGENS, das zweite ein PROTO-PATIENS ${ }^{9}$, GO und BE AT haben ein PROTO-PATIENS als erstes Argument, GO hat einen WEG, BE AT einen ORT als zweites. Das Wegargument kann als Strecke $[u, z]$ mit $u$ als URSPRUNG und $z$ als ZIEL repräsentiert werden. Von dieser Repräsentation mache ich immer dann Gebrauch, wenn der Transport ZIEL-bezogen ist (wie in Jonathan schiebt das Rad in den Teich).

Das zweite Argument von AFFECT und das erste von GO spielen dieselbe thematische Rolle (PROTO-PATIENS), wobei AFFECT und GO

9 Jackendoff (1990) etabliert zwei verschiedene Strānge (tiers), auf denen die thematischen Rollen definiert werden, den action tier mit dem Basis-Prädikat AFFECT und den thematic tier mit den Basis-Prädikaten CAUSE, GO, GOTO. Ein gegebener Individuenausdruck kann auf dem action tier als zweites Argument von AFFECT ein PATIENS sein und auf dem thematic tier als erstes Argument von GO oder GOTO ein THEMA. Jackendoff weicht damit von der landläufigen Auffassung ab, daß der Referent einer NP in genau einer thematischen Rolle vorkommt. In einem Ansatz mit PROTO-Rollen à la Dowty, wie ich ihn hier vertrete, kann auf die Unterscheidung zwischen PATIENS und THEMA verzichtet werden. 
allerdings verschiedene PROTO-PATIENS-Eigenschaften hervorheben, AFFECT die Eigenschaft der kausalen Affizierung, GO den Aspekt der Zustandsveränderung (s.o.(22)). CAUSE nimmt EREIGNISSE, PROZESSE oder ZUSTÄNDE, kurz Situationen, als Argumente. ${ }^{10}$ Das erste Argument von CAUSE repräsentiert die Ursache [p], das zweite die resultierende Wirkung [q]. [p] und [q] sind Situationsvariable, sie beziehen sich auf den Sachverhalt, dem in einer Proposition p bzw. q Ausdruck gegeben wird. Auch das inchoative Prädikat BECOME nimmt ein Situationsargument, genauer ein Zustandsargument, welches durch BE AT mit seinem PATIENS-Argument repräsentiert wird.

Intransitive Verben in unergativer Verwendung (lachen) haben ein einstelliges ACT-Prädikat mit AGENS als einzigem Argument (45a). Unakkusative Intransitiva (sinken) gehen auf ein AFFECT-Prädikat mit PATIENS als einzigem Argument und in zweiter Position zurück (45b). Intransitive Prozeßverben (laufen) mit einer Ortsveränderungskomponente haben ein einstelliges ACT-Prädikat und ein durch CAUSE verbundenes GO-Prädikat (45c):

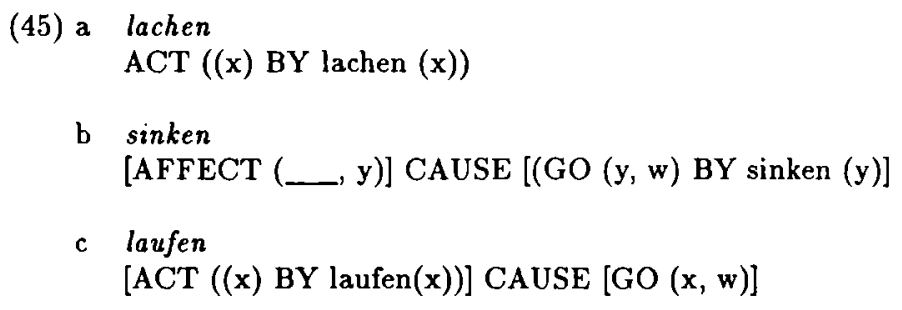

Bei Verben mit AGENS-spezifischer manner-Komponente (schieben) wird diese als eine BY-Phrase dem AFFECT-Prädikat lexikalisch subordiniert (46), bei Verben mit PATIENS-spezifischer manner-Komponente (rollen) erscheint die BY-Phrase in Subordination zu dem GO-Prädikat (47). Die Unterscheidung $z$ wischen ANTRIEBs-Verben (schieben, rollen) und ANSTOSS-Verben (werfen, schleudern) kann durch eine entsprechende Differenzierung des AFFECT-Prädikats dargestellt werden (48, 49).

10 In diesem Punkt weiche ich von der verbreiteten Auffassung ab, wonach CAUSE ein AGENS-Argument zu einem EREIGNIS-Argument in Beziehung setzt. Der Grund dafür ist philosophischer Natur: „Verursachung” wird seit Hume als Beziehung zwischen Ereignissen definiert. (Vgl. zu den Problemen der Kausalanalyse Lewis (1973) und Dowty (1979)). 
(46) schieben

[AFFECT $_{\text {ANTRIEB }}((x, y)$ BY schieben $(x))$ ] CAUSE [GO $\left.(y, w)\right]$

(47) rollen

$\left.\operatorname{lafFECT}_{\text {ANTREB }}(x, y)\right]$ CAUSE [GO $((y, w)$ BY rollen $\left.(y))\right]$

(48) werfen

[AFFECT ANSToss $_{\text {( }}(\mathbf{x}, \mathbf{y})$ BY werfen $\left.\left.(x)\right)\right]$ CAUSE [GO $\left.(y, w)\right]$

(49) schleudern $^{11}$

[AFFECT ANSTOSs $((x, y)]$ CAUSE [GO $((y, w)$ BY schleudern $(y))]$

Vehikelverben wie karren oder rudern haben in ihrer semantischen Repräsentation kein PATIENS-Argument. Es ist nämlich durchaus vorstellbar, daB jemand rudert, ohne etwas anderes als sich und sein Boot zu transportieren (50). Das PATIENS-Argument in Sätzen wie Jonathan rudert die Gäste über den See, das zu dem Verb transitivierend hinzutreten kann, ist ein optionales Argument, das weder hinzutreten muB, noch mitverstanden wird, wenn das Verb intransitiv verwendet ist. In diesern Sinne ist das optionale PATIENS zu unterscheiden vom impliziten PATIENS, welches, auch wenn es an der Satzoberfläche unterdrückt wird, konzeptuell mitgegeben ist.

Für Vehikelverben wie karren und kutschieren ist ebenso wie für Anstoßverben vom Typ schaufeln oder loffeln ein zusätzliches Prädikat USE einzuführen, das ein INSTRUMENT als zweites Argument nimmt (50, 51).

11 In den Repräsentationen (45-57) habe ich die Argumente der atomaren Basisprādikate durch freie Variablen indiziert. Dabei ist allerdings nicht sichergestellt, daß zwei Vorkommen desselben Argumentausdrucks $x$ sich auf denselben Referenten beziehen. Eine Möglichkeit, dies zu gewährleisten, ist die Indizierung durch Subscripte $x_{i} x_{j} x_{k}$, eine andere die Bindung durch den Lambda-Operator (Bierwisch 1983).

(58) schieben

$\lambda w \lambda y \lambda x[[\operatorname{AFFECT}((x, y)$ BY schieben(x))] CAUSE [GO $(y, w)]]$

Die Lambda-Abstraktion wird von links nach rechts abgearbeitet, d.h., der am weitesten links stehende Abstraktor bindet das am tiefsten eingebettete Argument, der am weitesten rechts stehende Abstraktor bindet das externe Argument, das bei Verben schließlich als Subjekt zu realisieren ist. Aus Gründen der einfacheren Lesbarkeit habe ich hier auf Indizierung bzw. Bindung der Variablen durch Lambda verzichtet. Als Notationskonvention nehme ich an, daB jeder Argumentname für genau einen Referenten steht. 
(50) karren

[ACT ((x) BY (USE $(x, m)) \&$ Karren $(m))]$ CAUSE [GO $(x, w)]$

(51) schaufeln

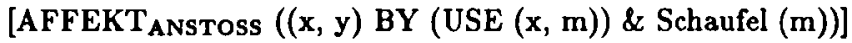
CAUSE [GO $(y, w)]$

Verben, die die resultierende Positionsmodalität kennzeichnen, (stapeln, türmen), ordnen die manner-Komponente dem BE-Prädikat der Resultatsituation unter (52).

(52) stapeln

[AFFECT $(x, y)$ ] CAUSE [BECOME [BE AT $((y, z)$ BY stapel $(y))$ ]]

Bei Verben, die weder eine AGENS- noch eine PATIENS-spezifische manner-Komponente haben ( $g$ ießen, tragen), wird BY direkt dem übergeordeten CAUSE-Prädikat zugeordnet. Gießen ist ZIEL-bezogen und hat daher $[u, z]$ als zweites Argument von GO (53). Tragen ist in seiner lexikalischen Struktur weder ZIEL- noch WEG-bezogen (s.o.). Es hat lediglich ein AFFECT-Prädikat mit dem Index ANTRIEB. Die Indizierung garantiert, daß eine optionale WEG- und/oder ZIEL-Phrase hinzutreten kann (54).

(53) gießen

$([\operatorname{AFFECT}(x, y)]$ CAUSE $[G O(y,<u, z>)])$ BY $\operatorname{gießen}(x)$

(54) tragen

$\operatorname{AFFECT}_{\text {ANTRIEB }}(x, y)$

Bringen, holen, schicken unterscheiden sich in ihrer semantischen Repräsentation durch die Zuordnung des Referenzortes $R_{L}$ zu URSPRUNG und ZIEL (55-57).

$$
\text { bringen }
$$

[AFFECT $\left._{\text {ANTRIEB }}(x, y)\right]$ CAUSE [GO $\left.(y,<u, z>)\right]$ BY [GO $(x,\langle u, z>)]$

a $\quad \mathrm{R}_{\mathrm{L}}=\mathrm{z}$ und $\mathrm{R}_{\mathrm{L}} \neq \mathrm{u}$ (engl. bring)

b $\quad \mathbf{R}_{\mathrm{L}}=\mathrm{u}$ und $\mathrm{R}_{\mathrm{L}} \neq \mathrm{z}$ (engl. take)

(56) holen

[AFFECT $\left._{\text {ANTRIEB }}(x, y)\right]$ CAUSE [GO $\left.(y,<w, z>)\right]$ BY $[\mathrm{GO}(\mathrm{x},<\mathrm{u}, \mathrm{w}>)]$

$\mathbf{R}_{\mathrm{L}}=\mathrm{u}=\mathrm{z}, \mathbf{R}_{\mathrm{L}} \neq \mathrm{w}$ 
schicken

[AFFECT $\left._{\text {ANSTOSS }}(\mathrm{x}, \mathrm{y})\right]$ CAUSE [GO $(\mathrm{y},\langle\mathrm{u}, \mathrm{z}>)]$

$\mathbf{R}_{\mathrm{L}}=\mathbf{z}, \mathbf{R}_{\mathbf{L}} \neq \mathrm{u}$

Die Repräsentationen (46-57) enthalten keinen Aufschlub darüber, ob AGENS seinen Ort zusammen mit PATIENS wechselt oder nicht. (Das GO-Prädikat bezieht sich immer nur auf das PATIENS-Argument y). Der Grund dafür ist, daB M-AG-Verben nicht notwendig einen Ortswechsel von AGENS involvieren. (58) wird man so verstehen, daB PATIENS auf seinem WEG von AGENS begleitet wird, in (59) behält PATIENS seinen Ausgangsort dagegen bei.

(58) a Jonathan schiebt das Auto zur Tankstelle.

b Jonathan zieht die Kuh auf die Weide.

c Jonathan rollt den Teppich ins Wohnzimmer.

(59) a Jonathan schiebt das Geld in die Hosentasche.

b Jonathan zieht die Taschentücher aus dem Hut.

c Jonathan rollt die Münzen über den Tisch.

Die unterschiedlichen Interpretationen für (58) und (59) beruhen auf alltäglichem Erfahrungswissen. Lexikalisches Wissen sagt uns lediglich folgendes:

(60) ANTRIEBSverben können (aber müssen nicht) auf Transportvorgänge referieren, bei denen AGENS zusammen mit PATIENS seinen Ort wechselt. ANSTOSSverben beziehen sich auf Transporte, bei denen ausschlieBlich PATIENS seinen Ort wechselt.

Die für die Interpretation von (58) und (59) herangezogene Alltagserfahrung spielt auf der Ebene der lexikalischen Bedeutung keine Rolle. Sie trägt das zur vollen Interpretation eines Verbs notwendige Kontextwissen bei, wird aber erst auf der Ebene enzyklopädischen Faktenwissens wirksam.

Es ist nicht immer klar (und wird zumeist auch nicht diskutiert), ob es sich bei den angenommenen Prädikat/Argument-Strukturen einer lexikalischen Zerlegung lediglich um Einheiten einer semantischen Rekonstruktionssprache handelt oder ob ihnen ein psychologisch realistischer Status im mentalen Lexikon zukommt. Die Frage nach der psychologischen Realität von Dekompositionsstrukturen hat wie alle psycholinguistischen Fragen zwei Aspekte. Der eine betrifft den mentalen Kode, in dem die Bedeutungsinformation repräsentiert ist, der andere die Prozeßcharakteristiken des lexikalischen Zugriffs beim Sprechen und beim Verstehen. Die zu letzterem Punkt verfügbaren empirischen Ar- 
beiten weisen in entgegengesetzte Richtungen. Roelofs (1992) stellt die Evidenzen CONTRA Dekomposition zusammen, Bierwisch/Schreuder (1992) gehen vor allem auf die PRO-Argumente ein. Die ContraEvidenzen haben alle mit dem Zeitverlauf des Zugriffs zu tun. Es gibt keinen empirisch nachweisbaren Zusammenhang $z$ wischen ansteigender semantischer Komplexität eines Wortes und ansteigendem Zeitverbrauch für den Zugriff auf das betreffende Wort. Allerdings besagen selbst eindeutig negative Evidenzen hinsichtlich der ProzeBcharakteristiken des Zugriffs nichts über den Repräsentationskode des mentalen Lexikons. Die lexikalische Information kann durchaus in Dekompositionskomplexen repräsentiert sein und gleichwohl beim Sprechen und Verstehen holistisch abgerufen werden. Während die Frage nach den ProzeBcharakteristiken durch Experimente zwar noch nicht entschieden, aber grundsätzlich doch entscheidbar ist, bildet für die Frage nach den Repräsentationseigenschaften die linguistische Analyse selbst die eigentliche empirische Grundlage: Wenn sich zeigen läßt, daß grundlegende lexikalische Operationen über verschiedene Einzelsprachen hinweg durch Rekurs auf vergleichbare Dekompositionsstrukturen rekonstruierbar sind, so mag dies zumindest als ein wichtiges Indiz dafür gelten, daB die betreffenden Strukturen im mentalen Lexikon ein psychologisches Äquivalent haben.

\subsection{Veränderungen der Argumentstruktur bei Transportverben}

In diesem Abschnitt geht es um Veränderungen der grundlegenden Argumentstruktur von Transportverben. Es wird gefragt, wann die verschiedenen Argumente der Basisstruktur ihre Rolle vertauschen (Argumentalternation) bzw. unter welchen Bedingungen ein Argument unterdrückt werden kann (Argumentreduktion). Ich gehe diesen Fragen nacheinander für AGENS, PATIENS und WEG/ZIEL nach. Dabei möchte ich zeigen, daB die oben (Abs. 3.1) dargestellten Bedeutungseigenschaften verschiedener Subklassen von Verben für das Argumentverhalten entscheidend sind.

\subsubsection{AGENS/PATIENS-Alternation}

Das AGENS-Argument eines Transportverbs kann mit dem PATIENSArgument koindiziert sein. AGENS und PATIENS sind dann referenzidentisch und PATIENS wird entweder unterdrückt oder als Reflexivpronomen realisiert. 
(61) a Jonathan ${ }_{\mathrm{i}}$ schiebt []$_{\mathrm{i}}$ in die Schule. (... sich)

b Jonathan $n_{\mathrm{i}}$ fegt []$_{\mathrm{i}}$ um die Ecke. $\left({ }^{*}\right.$... sich)

c Die Demonstranten $n_{\mathrm{i}}$ ziehen [ ] $]_{\mathrm{i}}$ durch die Stadt. (*... sich)

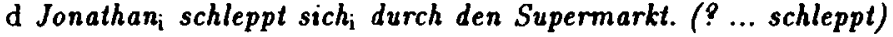

(62) a Jonathan stemmt sich auf die Mauer. (* stemmt)

b Jonathan $n_{\mathrm{i}}$ wirft sich wütend auf den Teppich. (* wirft)

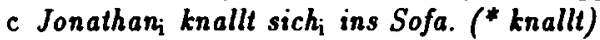

d Jonathan $n_{\mathrm{i}}$ schaufelt sich $_{\mathrm{i}}$ durch die Menge. (? schaufelt)

Diese Form der Alternation ist beschränkt auf manner-Verben. Bei MAG-Verben sind reflexive oder nicht-reflexive Varianten möglich. Bei MPAT-Verben ist die Reflexivierung obligatorisch. Zwar ist (62c) ohne Reflexivum grammatisch, in dieser Variante ist das Subjekt jedoch nicht mehr AGENS des Geschehens, sondern PATIENS. Bringen, tragen oder gießen, die die Handlungsart nicht kennzeichnen, können nicht nach dem Muster von (61) (62) alternieren:

(63) a * Jonathan bringt (sich) in die Schule.

b ? Die Menge gießt sich über den Roten Platz.

c * Jonathan trägt sich auf den Speicher.

Es ist klar, daf die Beispiele in (61) auf metaphorischer Umdeutung der betreffenden Verben beruhen. Von der Ausgangsbedeutung bleiben die manner-Komponente und die Komponente der Fortbewegung erhalten. Letztere bezieht sich allerdings auf die Fortbewegung von AGENS, deswegen ist in der semantischen Repräsentation PATIENS (erstes Argument von GO) identisch mit AGENS (erstes Argument von AFFECT).

(64) a schieben (intransitive Variante)

[AFFECT $((x, y)$ BY schieben $(x))$ ] CAUSE [GO $(x, w)]$

$\mathrm{b}$ rollen (reflexive Variante)

[AFFECT $(x, x)$ ] CAUSE [GO $((x, w)$ BY rollen $(x))$ ]

Die Repräsentationen für schieben und rollen unterscheiden sich hier dadurch, daB die zweite Argumentstelle von AFFECT bei schieben leer ist (und daher kein Reflexivum erfordert), während rollen die erste und die zweite Argumentstelle von AFFECT mit referenzidentischen Argumenten besetzt, so daB die PATIENSstelle reflexiv realisiert werden muB. Jonathan schiebt, schleppt, fegt, knallt, rudert, schaufelt (sich) ... besagt soviel wie Er geht, als ob er etwas schiebt/schleppt/wirft/knallt bzw. Er geht mit rudernden, schaufelnden Armbewegungen. In all diesen Wendungen wird die Bewegungsart von AGENS hervorgehoben. Es ist daher 
nicht verwunderlich, daB nur manner-Verben diese Realisierungsvariante zulassen.

\subsubsection{AGENS-Reduktion}

Manner-Verben mit PATIENS-spezifischer Handlungskennzeichnung erlauben nicht nur die Besetzung der PATIENS-Stelle durch ein mit AGENS identisches Argument, sondern auch die Unterdrückung von AGENS, die betreffenden Verben kommen dann in ihrer unakkusativen Variante vor (65). DaB M-AG-Verben (vom Typ ziehen) nicht in dieser Weise verwendbar sind, ist leicht zu erklären. Die Verben in (65) kennzeichnen die Bewegungsart von PATIENS, M-AG-Verben heben demgegenüber die Bewegungsart von AGENS hervor. Aus genau diesem Grunde kann AGENS bei diesen Verben nicht unterdrückt werden.

(65) a Das Abendkleid schleift durch die Pfütze.

b Das Fahrrad rollt in den Graben.

c Der Bleistift kullert vom Tisch.

(66) a "Das Abendkleid zieht in den Ballsaal.

b "Das Fahrrad schiebt in den Graben.

c *Der Bleistift schubst vom Tisch.

Die unakkusative Variante von rollen unterscheidet sich in ihrer semantischen Repräsentation von der transitiven Variante nur dadurch, daB die erste Argumentstelle von AFFECT leer bleibt:

$$
\begin{aligned}
& \text { rollen (unakkusativ) } \\
& \text { [AFFECT (-, y)] CAUSE [GO (y, w) BY rollen (y)] }
\end{aligned}
$$

Die reflexiven und die unakkusativen Varianten der M-PAT-Verben (Typ rollen) stehen zueinander in deutlichem Kontrast. In der reflexiven Variante hat das AGENS-Subjekt Kontrolle über seine eigene Körperbewegung $(68 \mathrm{a}, \mathrm{b})$, in der unakkusativen Variante wird das Subjekt als PATIENS eines Geschehens konzeptualisiert, das es nicht kontrollieren kann $(68 \mathrm{c}, \mathrm{d})$.

(68) a Der Junge rollt sich aus dem Bett.

b * Der Tote rollt sich aus dem Bett.

c Der Junge rollt aus dem Bett.

d Der Tote rollt aus dem Bett.

Da M-AG-Verben keine unakkusativen Varianten haben, ist der Kontrast reflexiv/nicht-reflexiv bei diesen Verben nicht funktional, in der Version 
mit koindizierten AGENS und PATIENS gehört Reflexivierung daher zu den beliebigen idiosynkratischen Eigenschaften der M-AG-Verben.

\subsubsection{Reduktion des PATIENS-Arguments}

M-AG-Verben, die eine AGENSspezifische Handlungsart kennzeichnen (Typ schieben, schaufeln), erlauben die Unterdrückung des PATIENS, M-PAT-Verben mit PATIENS-spezifischer Handlungskennzeichnung (Typ rollen, knallen) lassen dies ebensowenig zu wie Verben ohne manner-Komponente (Typ bringen) (69-71).

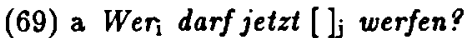

b Jonathan $n_{\mathrm{i}}$ steht vor dem Haus und schaufelt []$_{\mathrm{j}}$ wie ein Besessener.

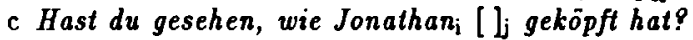

d Sieh mal, wie der Postbote [ ] $_{\mathrm{j}}$ schleppt!

(70) a * Wer darf jetzt []$_{j}$ rollen?

b * Jonathan ${ }_{\mathrm{j}}$ ist im Garten und wälzt []$_{\mathrm{j}}$ wie ein Besessener.

c * Hast du gesehen, wie Jonathan [ ] $_{j}$ getröpfelt hat?

$\mathrm{d} *$ Sieh mal, wie der Postbote $\mathrm{e}_{\mathrm{i}}\left[\mathrm{j}_{\mathrm{j}}\right.$ schleudert.

(71) a * Wir brauchen Milch $h_{\mathrm{j}}$ Wer, muß jetzt []$_{\mathrm{j}}$ holen?

b * Schau mal, der Postbote $e_{\mathrm{i}}$ kommt und bringt [ ]j.

c * Der Tramper, steht an der Straße und trägt [ ]j.

Es macht dabei nichts aus, daß das unterdrückte PATIENS-Argument ohne weiteres aus dem Kontextwissen rekonstruiert werden kann (wie in (71a, b)). Allerdings kann PATIENS auch bei M-AG-Verben nicht unter allen Umständen implizit bleiben, sondern nur dann, wenn AGENS beim Transport selbst einen Ortswechsel durchmacht. Aus diesem Grund verhalten sich Verben wie zerren und schieben in den Sätzen (72) und (73) unterschiedlich.

(72) a Die Mutter, wollte nach Hause, aber das Kind zerrle []$_{j} z u m$ Eissalon.

b Jonathan $n_{\mathrm{i}}$ lud sich den Sack auf und puckelte [ $]_{\mathrm{j}}$ in den Keller.

c Das Auto saf im Schlamm fest, und Jonathan $n_{\mathrm{j}}$ schob [ ] bis es $\mathrm{j}_{\mathrm{j}}$ freikam.

(73) a * Jonathan $n_{\mathrm{i}}$ brauchte dringend eine Münze $e_{\mathrm{j}}$ und zerrte []$_{\mathrm{j}}$ aus der Manteltasche.

b * Der Sachbearbeiter $;$ nahm die Kaffeetasse $\mathrm{j}_{\mathrm{j}}$ und schob [ ] in die Schreibtischschublade.

c *Der Prinz wartete schon und Rapunzel $\mathrm{i}_{\mathrm{j}}$ zog [ $]_{\mathrm{j}}$ nach oben. 
Eine weitere Einschränkung für die Unterdrückung von PATIENS betrifft die gleichzeitige Realisierung von WEG oder ZIEL. Verben wie schaufeln, die eine AGENS-spezifische Handlungsart kennzeichnen, bei denen wie bei allen Anstoßverben aber nur PATIENS seinen Ort wechselt, lassen die Unterdrückung von PATIENS nämlich nur dann zu, wenn auch WEG/ZIEL implizit bleiben. Deswegen ist nur (74a), nicht aber (74b) wohlgeformt.

(74) a Jonathan schaufelt schon den ganzen Morgen.

b * Jonathan schaufelt schon den ganzen Morgen in den Keller.

\subsubsection{Die Unterdrückung von WEG/ZIEL}

WEG und ZIEL werden syntaktisch als Lokaladverbiale realisiert, weshalb man sie landläufig als „Adjunkte” oder „Angaben” klassifiziert. Weglaßbarkeit kann für die Zuweisung des Adjunktstatus dann aber kein definierendes Merkmal sein, denn WEG/ZIEL sind bei Transportverben keineswegs unter allen Umständen weglaßbar. Verben, die eine Richtung spezifizieren wie gießen, schütten, wuchten verlangen, daB WEG oder ZIEL explizit gemacht werden (75). Nur wenn einem emphatischen Kontrast Ausdruck gegeben werden soll, kann bei Verben des Typs gießen die WEG/ZIEL-Phrase unterdrückt werden (76).

(75) a * Jonathan goß den Sekt [in die Gläser].

b * Jonathan schüttete die Möhren [in den Topf].

c * Jonathan wuchtete die Koffer [ins Gepäcknetz].

(76) a Du sollst den Sekt gießen, nicht tröpfeln!

Die deiktischen Verben des bringen-Typs, bei denen der kontextuell eingeführte Referenzort $\mathbf{R}_{\mathbf{L}}$ mit dem ZIEL-Ort zusammenfällt, lassen demgegenüber die Unterdrückung von WEG/ZIEL zu (77). Die M-AG/MPAT-Verben des schieben- und rollen-Typs erlauben dies nur, wenn - wie in den Beispielen (72) - auch das PATIENS-Argument implizit bleibt. Ist PATIENS dagegen explizit gemacht, so muß auch WEG/ZIEL an der Satzoberfläche realisiert werden (78).

(77) a Alle warteten unterm Tannenbaum, Endlich brachte jemand die Geschenke [ ] .

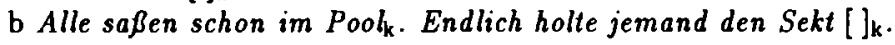

(78) a * Alle warteten unterm Tannenbaum $m_{\mathrm{k}}$. Endlich schob jemand die Geschenke [ ]

b * Alle saßen schon im Pool . Endlich goß jemand den Sekt [ $]_{k}$. 
In (78) etabliert der Kontext ein Antezedens für die anaphorische Verankerung von ZIEL, trotzdem kann die ZIEL-Phrase nicht einfach unterdrückt werden. Dies macht wiederum deutlich, daB die Bedingungen für die Unterdrückung eines konzeptuell gegebenen Arguments nicht allein durch Eigenschaften der Textstruktur festgelegt werden.

Insgesamt lassen sich die Bedingungen für Veränderungen der Argumentstruktur bei Transportverben wie folgt zusammenfassen:

(79) a AGENS kann mit PATIENS koindiziert sein bei allen manner-Verben (M-AG/M-PAT-Verben).

a1 MAG-AG-Verben kommen als reflexive oder als nicht-reflexive Formen vor.

a2 M-PAT-Verben sind obligatorisch reflexiv.

b M-PAT-Verben kommen in einer unakkusativen Variante mit implizitem AGENS vor.

b1 Die unakkusative Realisierung ist obligatorisch nicht-reflexiv.

(80) a PATIENS kann implizit bleiben bei M-AG-Verben.

b Tritt ein ZIEL oder WEG-Argument hinzu, kann PATIENS nur implizit bleiben, wenn AG einen Ortswechsel durchmacht.

(81) a ZIEL/WEG kann implizit bleiben bei deiktischen Verben und bei manner-Verben (M-AG/PAT).

b Nur bei deiktischen Verben kann ZIEL/WEG anaphorisch verankert werden.

Abschließend ist die Frage zu stellen, warum die Argumente eines Verbs unterdrückt werden, wenn sie doch als implizite Argumente "mitverstanden" sind. Ein Geschehen, an dem zwei oder mehr Mitspieler beteiligt sind (ein "transitives Geschehen"), ist unter verschiedenen Perspektiven konzeptualisierbar. Alle Mitspieler können gleichgewichtig in den Blick kommen (in diesem Fall werden alle Argumente des Verbs an der Satzoberfläche realisiert), es ist aber auch möglich, daB ein Mitspieler wie durch einen zoom aus dem Gesamtbild herausgelöst wird, so dab die anderen im Hintergrund verschwimmen. In diesem Fall wird nur das Argument explizit gemacht, das die hervorgehobene Rolle spielt, und die anderen Argumente bleiben implizit. Welche Perspektive ein Sprecher jeweils einnimmt, hängt von seiner Mitteilungsintention ab und gehört damit zu pragmatischen Faktoren, die hier nicht behandelt werden können. Die obige Analyse hat aber deutlich gemacht, daß jede Klasse von Verben ihr eigenes Potential von möglichen Perspektivierungen eröffnet. Das AGENS-Argument eines transitiven Verbs kann (durch Unterdrückung des PATIENS) nur dann in den Vordergrund gerückt 
werden, wenn das betreffende Verb schon in seiner lexikalischen Bedeutung das AGENS hervorhebt, indem es die Handlungsart von AGENS kennzeichnet (M-AG-Verben des Typs ziehen, schaufeln) und/oder einer Zustandsveränderung von AGENS Ausdruck gibt (OV-AG-Verben bzw. Antriebsverben). Umgekehrt kann das PATIENS-Argument nur dann herausgelöst werden, wenn das Verb in seiner lexikalischen Bedeutung die Handlungsart des PATIENS hervorhebt (M-PAT-Verben). Ist ein Verb gegenüber den Handlungsarten von AGENS oder PATIENS neutral (wie die Verben des bringen/holen-Typs), so lassen sich AGENS oder PATIENS mit diesem Verb auch nicht aus dem Gesamtgeschehen herauslösen.

Auch wenn der Diskurskontext ein Antezedens für die Verankerung eines impliziten Arguments zur Verfügung stellt, können die lexikalischen Bedingungen für die Weglaßbarkeit nicht auBer Kraft gesetzt werden. Die Erklärung dafür ist in den Bedingungen für die Wahrnehmung von Transporthandlungen zu suchen. $\mathrm{Ob} \mathbf{x}$ etwas zieht oder schiebt, ob $\mathrm{x}$ schaufelt oder dribbelt, ob y rollt oder schleift, das sieht man an der Fortbewegungsart von $x$ bzw. $y$. Dagegen kann man einem Transport nicht ansehen, ob etwas geholt wird oder gebracht. Dazu müssen URSPRUNG und ZIEL von AGENS und PATIENS bekannt sein. Was von einer Handlung wahrnehmbar ist und wie verschiedene Handlungsarten sich in der Wahrnehmung unterscheiden, gehört zu unserem empirischen Faktenwissen. In den Transportverben des Deutschen ist dieses Faktenwissen in der Unterscheidung von AGENS- und PATIENS-spezifischen manner-Verben lexikalisiert.

\section{SchluBbetrachtung}

Ich habe in diesem Aufsatz einen kleinen Ausschnitt aus dem Verblexikon des Deutschen unter verschiedenen typologischem Aspekten (Bündelung von Komponenten der Verbbedeutung, Unakkusativität/Unergativität, Aktionalität) betrachtet. Zwei Gesichtspunkte erwiesen sich für die Klassifikation der Transportverben als zentral: Die AGENS-/PATIENSspezifische Kennzeichnung der Bewegungsart (M-AG/M-PAT-Verben) und die Kennzeichnung der Ortsveränderung, die entweder nur PATIENS betrifft (OV-PAT- bzw. ANSTOSS-Verben) oder auch AGENS mit einschlieBt (OV-AG- bzw. ANTRIEBS-Verben). Die Bündelung dieser Bedeutungskomponenten eröffnet für jedes Transportverb ein Potential an Perspektiven, unter denen eine komplexe bzw. "transitive" Situation gesehen werden kann: AGENS-zentriert bei M-AG- und OV-AG-Verben, PATIENS-zentriert bei M-PAT- und OV-PAT-Verben. Das Argumentverhalten der betrachteten Verben (Argumentalternation und Argumentreduktion) wird durch dieses lexikalisch festgelegte Perspektivenpoten- 
tial eingeschränkt. Es ist damit weder idiosynkratisch noch durch rein pragmatisch zu explizierende Kontextbedingungen determiniert.

\section{Literatur}

Abraham, Werner (1993): Ergativa sind Terminativa. In: Zeitschrift für Sprachwissenschaft 12 (2), S. 157-184.

Andersson, Sven-Gunnar (1972): Aktionalitāt im Deutschen. Eine Untersuchung unter Vergleich mit dem russischen Aspektsystem. Bd. I: Die Kategorien Aspekt und Aktionsart im Russischen und im Deutschen. Uppsala: Studia Germanistica Upsaliensia 10.

Bierwisch, Manfred (1983): Semantische und konzeptuelle Relationen lexikalischer Einheiten. In: Rư̌iłka, Rudolf/Motsch, Wolfgang (Hg.): Untersuchungen zur Semantik. Berlin. (studia grammatica XXII). S. 61-99.

Bierwisch, Manfred/Schreuder, Robert (1992): From concepts to lexical items. In: Cognition 42, S. 23-60.

Dal, Ingerid (1952): Kurze deutsche Syntax auf historischer Grundlage. Tübingen.

Dowty, David R. (1979): Word Meaning and Montague Grammar. Dordrecht.

Dowty, David R. (1992): Thematic proto-roles and argument selection. In: Language 67, S. 547-619.

Ehrich, Veronika (1992): Hier und Jetzt. Studien zur lokalen und temporalen Deixıs Im Deutschen. Tübingen

Gleitman, Leila R. (1990): The structural source of verb meanings. In. Language Acquisition 1, S. 3-55.

Grimshaw, Janet (1991): Argument Structure. Cambridge, Mass.

Jackendoff, Ray (1983): Semantics and Cognition. Cambridge, Mass.

Jackendoff, Ray (1990): Semantic Structures. Cambridge, Mass.

Jacobs, Joachim (1994): Kontra Valenz. Trier

Landau, Barbara/Gleitman, Leila R. (1985): Language and Experience. Cambridge, MA.

Levin, Beth (1993): English Verb Classes and Alternations. A preliminary investigation. Chicago

Levin, Beth/Rapoport, T R. (1988): Lexical Subordination. In. Papers from the 24th Regional Meeting of the Chicago Linguistic Society, S. 275-289.

Levin, Beth/Rappaport, T.R. (1989): Approaches to Unaccusative Mismatches. Proceedings of the 19th Annual Meeting of the North-Eastern Linguistics Society, S. 314-328.

Levin, Beth/Rappaport, Hovav, Malka (1991): The Lexical Semantics of Verbs of Motion. In: Roca, I. (ed.): Thematic Structure: Its Role in Grammar. Berlin, S. 247-269.

Levin, Beth/Rappaport Hovav, Malka (1991b): Wiping the slate clean: A lexical semantic exploration. In: Cognition 41, S. 123-151. 
Lewis, David (1973): Causation. In: Journal of Philosophy 70, S. 556-567.

Naigles, Letitia (1990): Children use syntax to learn verb meanings. In: Journal of Child Language 17, S. 357-374.

Paul, Hermann (1917): Deutsche Grammatik II. Tübingen.

Perlmutter, David M. (1978): Impersonal Passives and the Unaccusative Hypothesis. In: Berkeley Linguistics Society 4, S. 157-189.

Pinker, Steven (1989): Learnability and Cognition. The Acquisition of Argument Structure. Cambridge, Mass.

Pustejovsky, James (1991): The Syntax of Event Structure. In: Cognition 41.

Pustejovsky, James/Busa, Federica (1994): Unaccusativity and Event Composition. In: Bertinetto, P.M. (Hg.): Generative Approaches to Tense and Aspect. Amsterdam.

Roelofs, Aardie (1992): A spreading-activation theory of lemma retrieval in speaking. In: Cognition 42, S. 107-142.

Steinitz, Renate (1969): Adverbialsyntax. Berlin. (studia grammatica X).

Steinitz, Renate (1981): Der Status der Kategorie „Aktionsart” in der Grammatik (oder: Gibt es Aktionsarten im Deutschen?) Linguistische Studien 76. Berlin: Akademie der Wissenschaften der DDR. (Reihe A Arbeitsberichte).

Steinitz, Renate (1992): „Modern”: Argumentstruktur, „Traditionell”: Valenz - Versuch eines Brückenschlags. In: Linguistische Berichte 137, S. 33-44.

Talmy, Leonard (1985): Lexicalization patterns: semantic structures in lexical forms. In: Shopen, T. (Hg.) Language Typology and Syntactic Description, Vol. 3: Grammatical Categories and the Lexicon. Cambridge, UK. S. 57-149.

Tschernitschek, Christel (1993): Ūberlegungen zur Argumentstruktur von Konsumverben. Magisterarbeit Seminar für Allgemeine Sprachwissenschaft der Universitāt Tübingen.

Ullmer-Ehrich, Veronika (1977): Zur Syntax und Semantik von Substantivierungen im Deutschen. Kronberg.

Van Valin, Robert D. Jr. (1990): Semantic Parameters of Split Ergativity. In: Language 66, S. 221-260.

Vater, Heinz (1978): Probleme der Verbvalenz. In: Leuvense Bijdragen 67, S. 267-308.

Vater, Heinz (1981): Valenz. In: Radden, Gūnter/Dirven, René (Hg.): Kasusgrammatik und Fremdsprachenunterricht. Trier. S. 217-235.

Vendler, Zeno (1967): Verbs and Times. In: Vendler, Zeno (1967): Linguistics in Philosophy. Ithaca. S. 122-146. 


\title{
SUSAN OLSEN
}

\section{Partikelverben im deutsch-englischen Vergleich*}

\begin{abstract}
Nach einer knappen Abgrenzung von Partikelverben vs. Präfixverben werden in den Abschnitten 2 und 3 beide Arten der Verbbildung im Deutschen miteinander kontrastiert. In Abschnitt 4 wird auf das Phānomen der Argument vererbung bei Partikelverbbildung näher eingegangen. Dies führt in Abschnitt 5 zu einer vorlāufigen Bilanz der Ergebnisse für das Deutsche, die im zweiten Teil des Aufsatzes mit Partikelverbbildungen im Englischen verglichen werden. Die Diskussion in den Abschnitten 6 und 7 demonstriert, wie die formalen Unterschiede zwischen den beiden Sprachen im Bereich der Partikelverbbildung in typologischen Unterschieden verankert sind, die sich im Laufe der Sprachgeschichte des Englischen herausgebildet haben. Das Phänomen der Argumentvererbung kommt in Abschnitt 8 erneut zur Sprache, wo Unterschiede zwischen den beiden Sprachen thematisiert werden. In 9 werden schlieblich die Ergebnisse der Gesamtuntersuchung zusammengefaft.
\end{abstract}

\section{Formale Abgrenzung der Partikelverben von Präfixverben}

Thematischer Gegenstand dieses Aufsatzes ist die Bildung komplexer Verben mit Hilfe präpositionaler Relationen. In der deutschen Gegenwartssprache treffen wir auf $\mathrm{z}$ wei formal voneinander abzugrenzende $\mathrm{Ty}-$ pen komplexer Verben: ${ }^{1}$ Präfixverben wie in (1)

(1a) Er beschreibt die Tafel mit Formeln.

(1b) Sie entnimmt dem Paffotoautomaten die Fotos.

(1c) Er überklebt die Wunde mit einem Pflaster.

(1d) Ste umhängten das Rednerpult mit Fahnen.

(1e) Sze durchzog die Handarbeit mit goldenen Fäden.

und Partikelverben wie in (2).

(2a) Sie sprüht ein Pflegemsttel auf.

(2b) Sie bauen einen Seatenflügel an.

(2c) Er kıppte die Asche aus.

* Fūr Anregungen möchte ich Anette Dralle, Ewald Lang, Marga Reis, Renate Steinitz, Dieter Wunderlich und Ilse Zimmermann danken.

1 Für eine detailliertere Diskussion dieser formalen Typen vgl. Stiebels/Wunderlich (1994). 
(2d) Er riß das Blatt $\underline{a b}$.

(2e) Sie forderten ein vergleichendes Gutachten ein.

Die Verbalpräfixe bilden eine kleine und geschlossene Klasse, die aus den gebundenen Elementen be-, ent-, er-, ver- und zer- sowie den fünf selbständigen Präpositionen durch, hinter, über, um und unter besteht. ${ }^{2}$ Die Klasse der Verbpartikeln dagegen ist größer. Sie umfaßt Präpositionaladverbien wie ab, an, aus, ein, hinab, heraus usw.

Was im Verständnis dieser Diskussion Partikeln von Präfixen formal unterscheidet, ist ihre Trennbarbeit vom Verbstamm: Partikeln sind trennbare Elemente, Präfixe nicht. Bei der Festlegung des Begriffs „Partikelverb” darf nicht übersehen werden, daß die Präpositionalpräfixe durch, hinter, über, um und unter auch Partikelverbkonstruktionen eingehen. Neben den festen Bildungen in (1c-e) treten unfeste wie in (3) auf.

(3a) Die Milch schwappt über.

(3b) Sie leiten den Verkehr $\underline{u m}$.

(3c) Sie zieht den Faden durch.

(3d) Schieb doch einen Bierdeckel unter!

\section{Präpositionsinkorporation (PI) bei Präfixverben}

Historisch gesehen gehen auch die heutigen Präfixe auf ursprünglich frei auftretende Präpositionalelemente zurück wie got. bi, us, af und and, die zunächst in einer unfesten Beziehung zum Verb gestanden und sich erst im Laufe der Sprachentwicklung zu unselbständigen Elementen entwickelt haben, die dem Verbstamm vorausgehen. Daraus wird klar, da $B$ beide Klassen komplexer Verben auf einem ProzeB der engen Assoziation eines präpositionalen Elements mit dem Verb basieren. Da Präfixund Partikelverben in dieser Hinsicht eine gemeinsame Genese haben und von daher ein identisches wortstrukturelles Verhalten zu erwarten wäre, stellt sich die Frage, ob die in der heutigen Sprache streng gehandhabte formale Abgrenzung der beiden Verbtypen voneinander durch eine weitere funktionale oder semantische Eigenschaft unterstützt wird.

${ }^{2}$ Vgl. hierzu Wunderlich (1987). 
Charakteristisch für die präfixalen Muster in (1) ist das Phänomen der Argumentvererbung ${ }^{3}$, das durch die Kontraste in (4) und (5) veranschaulicht wird.

(4a) Er schreibt Formeln an die Tafel.

(4b) Er beschreibt die Tafel mit Formeln.

(5a) Er klebt Tesa über den Riß.

(5b) Er $\underline{u}$ berklebt den Riß mit Tesa.

Überklében wird aus kleben abgeleitet, indem das Komplement von über zum direkten Objekt des Präfixverbs wird. Das ursprünglich direkte Objekt Tesa verliert dabei seinen Status als direktes Objekt und wird durch eine oblique Präposition ( $m i t$ ) neu angeschlossen. Dieses (sog. 'Applikativ'-)Muster läßt sich lexikalisch mittels funktionaler Komposition erklären, wie im folgenden zu zeigen ist. Die Bedeutungsrepräsentationen in $(6 \mathrm{a}, \mathrm{b})$ sind - inklusive der Klammernotation - an die in Wunderlich (1991) und (1994) entwickelte Semantik von Präpositionen und Verben angelehnt.

Kleben ist ein kausatives Positionsverb, das eine Situation (wofür die Situationsvariable s steht) denotiert, in der ein Agens $\mathbf{x}$ bewirkt, daB ein Thema $\mathbf{y}$ in eine neue Lokation $\mathbf{P}$ gebracht wird. Die Dekompositionsstruktur des Verbs umfaßt m.a.W. eine direktionale Komponente als Teil der verbalen Bedeutung (intuitiv gesprochen: man klebt etwas irgendwohin).

Die Semantische Form (= SF) des Verbs wird in der Notationsweise der Kategorialgrammatik festgehalten, die als Basiskategorien die Kategorien 0 (= Propositionen) und 1 (= Individuen) hat. Aus den Basiskategorien setzen sich Funktorkategorien je nach ihrer kombinatorischen Potenz zusammen. Das SF-Prädikat KLEB beispielsweise gehört der Kategorie $0 / 1 / 1$ an, $P$ der Kategorie $0 / 1$ und \& der Kategorie 0/0/0.

3 Baker (1988), von dem der Begriff Präpositionsinkorporation ausging, versteht den ProzeB so, daß der Kopf einer präpositionalen Ergänzung zum Verb mittels Kopfbewegung in der Syntax an das regierende Verb adjungiert wird. Die syntaktische Inkorporation einer Prāposition dient dazu, die Rektionsdomāne des Basisverbs zu erweitern, so daß das komplexe (Applikativ-) Verb nach der Inkorporation in die ursprüngliche Rektionsdomäne der Präposition hineinregiert und somit imstande ist, ihr Objekt zu seinem strukturellen (applizierten) Objekt zu machen. Im Gegensatz dazu wird hier der Standpunkt vertreten, daß eine präpositionale Relation in ein Verb schon im Lexikon mittels funktionaler Komposition inkorporiert wird mit der Konsequenz, daB das komplexe Verb lexikalisch ein neues internes Objekt von der präpositionalen Relation erbt. 
Die SF selbst ist eine offene Formel der Kategorie 0. Diejenigen Argumente der Formel, die in der Syntax wirksam sind, werden durch Lambda-Abstraktoren gebunden, die vor die semantische Formel geschrieben werden. Die Lambda-Operatoren wandeln die SF-Proposition in ein n-stelliges Prädikat um und enkodieren so die Argumentstruktur des Lexems. ${ }^{4}$

(6) Lexikoneinträge

(6a) kleb-: $[+\mathrm{V},-\mathrm{N}]$

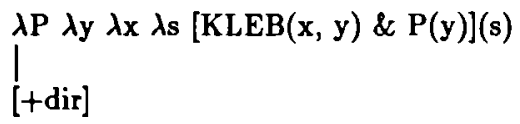

(6b)

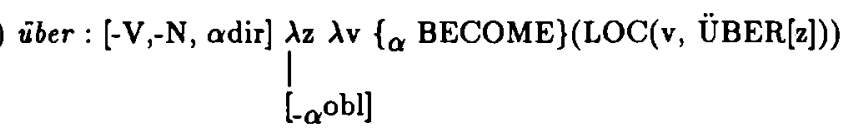

Die lokale bzw. direktionale Präposition über in (6b) verfügt über zwei Argumente - ein internes $z$ und ein externes $\mathbf{v}$ - und denotiert eine Relation, die darin besteht, daB das externe Argument $\mathbf{v}$ innerhalb der ÜBER-Region (kategorisiert als 1/1) des Relatums z lokalisiert wird. Die geschweiften Klammern um das BECOME-Prädikat repräsentieren seine Fakultativität: Wenn BECOME vorhanden ist, so handelt es sich um die direktionale Lesart der Präposition, die eine Änderung in der Lokalisierung von $\mathbf{v}$ beinhaltet. In diesem Fall instantiiert der lambdaOperator $\lambda z$ das Merkmal [-obl], das mit Akkusativ assoziiert wird. Fehlt das BECOME-Prädikat, so ist von der statischen (nicht-direktionalen) Variante auszugehen. Der entsprechende Lambda-Operator wird in diesem Fall mit dem Merkmal [+obl] adressiert, das als Dativ realisiert wird. Durch die Möglichkeit, die Lambda-Operatoren auf diese Weise mit grammatischen Merkmalen auszustatten, können sie als Aufhänger für

4 Vgl. hierzu Bierwisch (1989), Maienborn (1990) und (1995), Wunderlich (1994) und Kaufmann (1995). Wunderlich (1994) und Kaufmann (1995) argumentieren, daB die Kausalrelation CAUSE ( $x$, BECOME (P)) nicht in der Semantischen Form (=SF) dieses Verbs explizit erscheinen mub, da sie aus allgemeinen Prinzipien folgt. Da ein lexikalisches Verb eine kohärente Situation denotiert, wird automatisch eine kausale Beziehung ergänzt, wenn zwei Konjunkte seiner SF nicht zeitgleiche Ereignisse beinhalten. Im Falle von kleben steht der Prädikätsausdruck $\mathbf{P}$ für ein direktionales Adverbial, das eine punktuelle Transition (den Übergang von $\neg \mathbf{P}$ zu P) impliziert, was nicht mit der (ausgedehnten) Aktivität KLEB zeitgleich sein kann. In der Terminologie von Wunderlich (1994) stellen aus diesem Grund Verben wie kleben implizite kausative Verben dar. 
die Theta-Information des Lexems dienen. Das kausative Positionsverb kleben wählt nun aufgrund des implizit vorhandenen Prädikats CAUSE (vgl. hierzu Anm. 4) die direktionale Variante (= [-obl]) von über.

Die von über denotierte präpositionale Relation kann mittels funktionaler Komposition an der geeigneten Stelle in der Bedeutung von kleben (nämlich für die Prädikatsvariable P) durch Lambda-Konversion eingesetzt werden. Funktionale Komposition stellt eine kombinatorische Operation der Kategorialgrammatik dar, die die Sättigung einer Argumentposition eines Funktors durch einen Ausdruck, der selbst noch ungesättigte Argumente hat, erlaubt. Diese Operation wird in (7a) schematisch angedeutet. Aus der SF von kleben in (6a) erkennt man, daß dieses Verb ein prädikatives Argument (= die Variable $P$ ) vom Typ $0 / 1$ verlangt. Da die Präpositionalrelation über vom Typ $0 / 1 / 1$ ist, muB sie um ein Argument reduziert werden, bevor sie an der P-Stelle der SF von kleben eingesetzt werden kann. Die interne Argumentstelle $\mathrm{z}$ wird an $k l e b e n$ vererbt. Das Schema in (7b) veranschaulicht die dafür verantwortlichen Schritte: Ein Funktor der Kategorie 0/1/1/(0/1) wird mit einem Funktor der Kategorie 0/1/1 verbunden, indem das niedrigste Argument 1 des $z$ weiten Funktors auf den ersten Funktor vererbt wird, wobei ein neuer Funktor der Kategorie 0/1/1/1 entsteht.

\section{(7) a. Funktionale Komposition: $\quad \underline{\alpha} / \beta \quad \beta / y \rightarrow \underline{\alpha / \gamma}$}

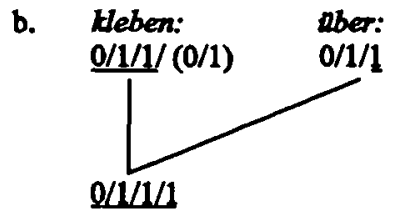

(7c) unten zeigt nun die Integration der Bedeutung von über in die Verbbedeutung mittels Lambda-Konversion. Auf diese Weise entsteht die kompositionelle Bedeutung des komplexen Verbs. Das interne Argument von über $(=\mathrm{z})$ wurde auf die Argumentstruktur von überkleben vererbt, wo es als niedrigster Lambda-Operator erscheint. Dabei wurde das externe Argument der Präposition mit dem internen Objekt des Basisverbs identifiziert. Die interne Struktur des Präfixverbs überkleben wird im Baum (7d) gezeigt. Die Variable s (der Kategorie 1) steht für eine Situation, z.B. ein Ereignis, das die Proposition instantiiert.

(7) c. überkleb-:

$\lambda \mathrm{z} \lambda \mathrm{y} \lambda \mathrm{x} \lambda \mathrm{s}[\operatorname{KLEB}(\mathrm{x}, \mathrm{y}) \&$ BECOME (LOC $(\mathrm{y}, \ddot{\mathrm{UBER}}[\mathrm{z}]))](\mathrm{s})$ 
Anders als Bierwisch (1989), der eine Konstante INST der Kategorie $0 / 0 / 1$ annimmt, die eine Instantiierung der SF-Proposition durch die referentielle Variable des Verbs bewirkt (e in der Konfiguration [e INST ...]), geht Wunderlich von einer gleichwertigen impliziten Konstante aus, die eine Instantiierung der verbalen Proposition durch die Variable s erlaubt. Auf die Explizierung der Instantiierungskonstante in der SF eines Verbs kann nach Wunderlich verzichtet werden, weil sie völlig regelmäBig und daher aufgrund der Variablen s stets vorhersagbar ist.

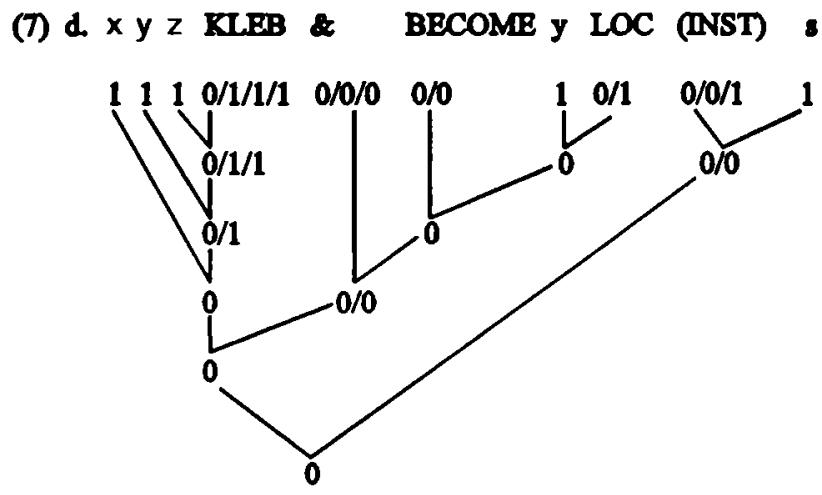

\section{Präpositionsinkorporation (PI) bei Partikelverben}

Da Partikeln ebenso wie Präfixe zum größten Teil auf präpositionalen Relationen basieren, ergibt sich die Frage, ob im Falle eines Partikelverbs die präpositionale Relation auf ähnliche Weise in die Verbbedeutung integriert wird. Der Punkt, auf den es mir hier in erster Linie ankommt, ist, zu zeigen, daß Argument vererbung in der oben illustrierten Form für trennbare Partikelverben nicht charakteristisch ist. Die präpositionale Bedeutung wird im Falle der Partikelverben nicht in der zweistelligen Form inkorporiert, die für Präfixverben typisch ist, sondern hauptsächlich in 'intransitiver' (oder 'adverbieller') Form. Insbesondere kommt es bei Partikelverben charakteristischerweise nicht zu einer Argumentvererbung wie in (5b), wo das Komplement der Präposition das direkte Objekt des Basisverbs verdrängt. Dies wird durch die Partikelverben in (8) verdeutlicht.

(8a) Sie montiert den Feuerlöscher an. (z.B. an die Wand) (8b) Ich lege eine Folie auf. (auf den Projektor) 
(8c) Sie graben die Kartoffeln aus.

(8d) Er goß die Soße über. (aus der Erde)

(über den Braten)

Diese Beispiele sprechen dafür, daB eine zweistellige präpositionale Relation schon im Lexikon zu einer einstelligen 'Partikel' abgeleitet wird, bevor sie in die Verbbedeutung inkorporiert wird. Auf der Grundlage des präpositionalen Eintrags für auf in (9a) wird die Partikel in (9b) abgeleitet, indem die zweite Variable existentiell gebunden wird. Der Partikeleintrag ist dabei zu verstehen als ein Eintrag, der aus dem Basiseintrag (= BLE im Sinne von Bierwisch (1989)) im Lexikon abgeleitet wird und den Status eines virtuellen Lexikoneintrags (= VLE, vgl. Bierwisch (1989)) aufweist. Aus der Bedeutung 'v wird lokalisiert innerhalb der AUF-Region eines $z$ ' wird die Bedeutung gewonnen 'es gibt ein $z$, innerhalb dessen AUF-Region $\mathbf{v}$ lokalisiert wird'.

(9a) auf: $[-\mathrm{V},-\mathrm{N},+\operatorname{dir}] \lambda \mathrm{z} \lambda \mathrm{v}[\mathrm{BECOME}(\mathrm{LOC}(\mathrm{v}, \mathrm{AUF}[\mathrm{z}]))]$<smiles>C[Te]</smiles>

(9b) Partikelbildung: $\lambda v \exists z$ [BECOME(LOC(v, AUF[z]))]

Nun kann eine solche Partikelbedeutung in die Bedeutung geeigneter Verben eingebunden werden. Als kausatives Positionsverb selegiert legen (aufgrund des impliziten CAUSE-Prädikats, vgl. Anm. 4) die direktionale Variante der Präposition auf. Der kompositionale Aufbau der komplexen Verbbedeutung auflegen geschieht auf der Grundlage des Eintrags in (10a) mittels funktionaler Applikation, wie in (10c) gezeigt wird.

(10a) leg -: $[+\mathrm{V},-\mathrm{N}] \lambda \mathrm{P} \lambda \mathrm{y} \lambda \mathrm{x} \lambda \mathrm{s}[\mathrm{LEG}(\mathrm{x}, \mathrm{y}) \& \mathrm{P}(\mathrm{y})](\mathrm{s})$<smiles>[AlH2]</smiles>

(10b) auf: [Part] $\lambda v \lambda z$ [BECOME(LOC(v, AUF[z]))]

(10c) aufleg: $[+\mathrm{V},-\mathrm{N}] \lambda \mathrm{y} \lambda \mathrm{x} \lambda \mathrm{s}[\mathrm{zz}[\operatorname{LEG}(\mathrm{x}, \mathrm{y}) \&$ $\operatorname{BECOME}(\operatorname{LOC}(y, \operatorname{AUF}[z]))]](s)$

Die Prädikatsstelle $\mathbf{P}$ von legen wird durch die Partikelbedeutung vollständig gesättigt, so daß es nicht zu einer Argumentvererbung kommt, wie das Resultat in (10c) zeigt. Auflegen ist ein zweistelliges Verb, in dem die direktionale Komponente von legen lexikalisch durch auf gesättigt wird. Da die Präpositionalbedeutung im Falle des Präfixes in (7) zweistellig ist, kann sie, wie in (7b) explizit dargestellt, nur über funktionale Komposition mit der Verbbedeutung verbunden werden. 
Funktionale Applikation stellt nun den kombinatorischen ProzeB dar, der einen Funktor auf sein Argument anwendet. In diesem Fall kann die Partikelbedeutung, da sie ja einstellig ist, direkt für die Prädikatsvariable $\mathbf{P}$ in der Bedeutung des Verbs per funktionaler Applikation eingesetzt werden. Ihre Wirkungsweise wird in (11a) vereinfacht angedeutet. Der Baum in (11b) zeigt die interne Struktur des komplexen Partikelverbs auflegen, die in der SF von (10c) implizit vorhanden ist.

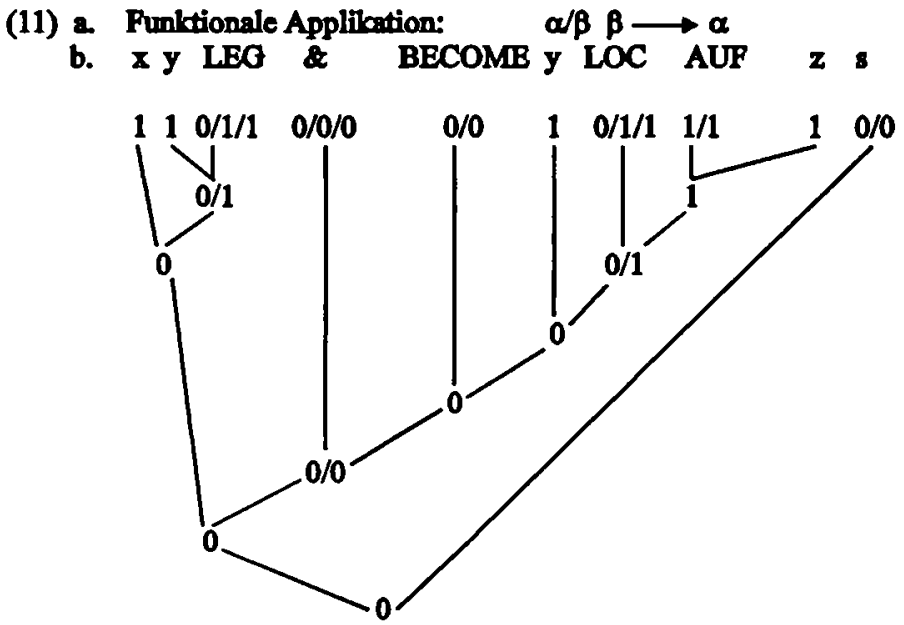

$\mathrm{DaB}$ diese Analyse richtig ist, bestätigt in interessanter Weise die Klasse der fünf Präpositionen, die sowohl Präfix- wie auch Partikelverben ableiten. In ihrer Präfixvariante weisen sie Argumentvererbung auf,

(12a) Die Mücken fliegen um die Kerze.

(12b) Die Mücken umfliegen die Kerze.

während sie in ihrer Partikelvariante das Präpositional-Relatum implizit lassen:

(12c) Sie band eine Schürze um. (etwa: um ihre Taille)

Was wir allerdings im Gegensatz zur Argumentvererbung bei Partikelverben häufig antreffen, ist, daß die Partikelbedeutung, die ein implizites (d.h. existentiell gebundenes) Argument beinhaltet, durch eine vollständige Präpositionalphrase mit semantisch kongruenter Präposition syntaktisch wiederaufgegriffen werden kann. Diese Konstruktion wird in (13) exemplifiziert. 
(13a) Sie bügelt ein Stickmuster (auf den Kissenbezug) auf.

(13b) Sie will ein Pflegemittel (auf die Schuhe) aufsprayen/aufsprühen.

(13c) Sie versucht, (auf eine Bluse) ein Monogramm aufzusticken.

(13d) Wir müssen noch die Glasur (auf den Kuchen) aufiragen.

(13e) Die Stadt läßt eine neue Teerschicht (auf die Straße) aufwalzen.

(13f) Sie leimt die abgebrochenen Figürchen wieder (an die Vase) an.

Die Präpositionalphrase (auf den Kissenbezug usw.) dient dazu, das zunächst implizit gelassene Argument der Partikel explizit zum Ausdruck zu bringen. Das bei der Partikelbildung lexikalisch unterdrückte Präpositional-Relatum erscheint explizit in der Syntax als Argument einer kongruenten Präposition. ${ }^{5}$

\section{4. (Beschränkte) Argumentvererbung bei Partikelverben?}

Die vorangegangene Diskussion ergab, daB Präpositionsinkorporation bei Präfixverben mittels funktionaler Komposition, bei Partikelverben mittels funktionaler Applikation erfolgt mit der Konsequenz, daB sich das präpositionale Relatum bei Präfixverben als ein Objekt an das abgeleitete Verb vererbt, während es bei Partikelverben implizit bleibt. Daraus ergibt sich die Frage, ob die Vererbung eines präpositionalen Komplements auf ein Partikelverb grundsätzlich ausgeschlossen ist. Es ist fraglich, ob die Inkorporation der vollen (d.h. zweistelligen) präpositionalen Relation bei Partikelverben tatsächlich in nennenswertem Umfang vorkommt. Die Beispiele in (14) illustrieren einige der wenigen Fälle, in denen die Partikel auf ihr Objekt tatsächlich durchbringt.

(14a) Der Vertreter hat dem Mann ein Abo aufgedrängt.

(14b) um den Kälbern das Zeichen der Ranch aufzubrennen.

(14c) Du hast dem Maultier zu viele Lasten aufgepackt.

Auch im System der an-Verben lassen sich im beschränkten Maße ähnliche Fälle finden.

(15a) Man trug ihm den Vorsitz an.

(15b) Sie werben sich grundsätzlich nur Gleichgesinnte an.

(15c) die Bücher, die ich mir angeschleppt habe.

Ein Blick zurück in die Sprachgeschichte lehrt uns, wie es zu dieser Konfiguration gekommen ist. Die Kombination aus einem Simplexverb plus

5 Wie diese Analyse formal zu implementieren wäre, kann an dieser Stelle nicht weiter ausgeführt werden, vgl. aber Olsen (1995b). 
einem präpositionalen Akkusativ wurde im Ahd. als ein doppelter Akkusativ realisiert, vgl. (16). ${ }^{6}$

(16a) blias er sie ana then selbon heilegon geist (Otfrid $5,11,9$ ) blies er sie an den heiligen Geist ('er blies den heiligen Geist in sie')

(16b) er tod sih anauuentit (Otfrid 1,15,34) er den Tod sich an wendet ('er wendet sich dem Tod zu')

Im Laufe der Zeit wurde diese Konstruktion systematisch abgebaut, indem der zweite Akkusativ in einen Dativ umgewandelt wurde. Die Tatsache, daB dieser Dativ dem Nominativ-Wechsel beim bekommen-Passiv unterliegt, deutet darauf hin, daB er in diesem Sprachstadium als struktureller Kasus des Verbs zu deuten ist und nicht mehr durch eine Präposition regiert wird:

(17) Der Mann bekommt ein Abo aufgedrängt. vs. (14a) Der Vertreter hat dem Mann ein Abo aufgedrängt.

Charakteristikum der exzeptionellen Dativ-Vererbung bei Partikelverben ist, daB das Komplement der Präposition nicht als direktes Objekt vererbt wird wie bei den Präfixverben, sondern zusätzlich zum direkten Objekt als Dativ-Objekt des Verbs erscheint. Diese Dativmarkierung ist interessant, weil sie offensichtlich einen Weg eröffnet, der es erlaubt, die bei Partikelverbbildung übliche Unterdrückung des präpositionalen Relatums zu umgehen. Dadurch ähnelt diese Konstruktion der Präfixbildung. Andererseits bewahrt die Dativ-Vererbung gerade das typische Charakteristikum der Partikelverbbildung, nämlich, daß das direkte Objekt des Basisverbs diesen Status nicht verliert. Dies wird in (18) nochmals verdeutlicht. Ausgehend von Sie wickelte eine breite Schärpe um die Puppe wird die Partikelkonstruktion gebildet: Sie wickelte der Puppe eine breite Schärpe um, wo Schärpe in beiden Fällen Objekt des Verbs ist.

(18a) Sie wickelte eine breite Schärpe um die Puppe. DO (18b) Sie wickelte der Puppe eine breite Schärpe um. DO

Demgegenüber findet beim vergleichbaren Präfixverb in (19) eine Herabstufung im grammatischen Status des direkten Objekts zu einem obliquen Objekt statt, das nicht länger als strukturelles Argument des Verbs gilt, sondern ein eigenes Regens (die Präposition mit) fordert.

(19) Sie umwickelte die Puppe mit einer breiten Schärpe. DO > PO

Auf der Grundlage der Semantik der beteiligten Lexeme in (20a und b) erhalten wir über funktionale Komposition die Repräsentation in (20c),

6 Für eine detailliertere Diskussion hierzu vgl. Müller (1948). 
die in diesem Fall beiden Verbkonstruktionen, sowohl der Präfixverblkonstruktion umwickeln als auch der Partikelverbkonstruktion umwickeln mit Dativvererbung zugrundeliegt. Dieser Eintrag hat den Status eines virtuellen Lexikoneintrags (= VLE, vgl. Bierwisch (1989)) und stellt die gemeinsame zugrundeliegende semantische und grammatische Information als Default-Information für beide Verbformen bereit.

(20a) wickel -: $[+\mathrm{V},-\mathrm{N}] \lambda \mathrm{P} \lambda \mathrm{y} \lambda \mathrm{x} \lambda \mathrm{s}[\mathrm{WICKL}(\mathrm{x}, \mathrm{y}) \& \mathrm{P}(\mathrm{y})](\mathrm{s})$ [-obl]

(20b) um: $[-\mathrm{V},-\mathrm{N}] \lambda \mathrm{z} \lambda \mathrm{v}[\operatorname{BECOME}(\operatorname{LOC}(\mathrm{v}, \operatorname{EXT}[\mathrm{z}]) \& \operatorname{ENCL}(\mathrm{D}[\mathrm{u}], \mathrm{z}))]^{7}$ [-obl]

(20c) $\lambda z \lambda y \lambda x \lambda s[\operatorname{WICKL}(x, y) \& \operatorname{BECOME}(\operatorname{LOC}(y, \operatorname{EXT}[z])$

$\& \operatorname{ENCL}(D[y], z))](s)$

Das präpositionale Relatum (die Variable z) wird dem komplexen Verb vererbt. Im Falle des Partikelverbs umwickeln wird nun der Kasusrahmen um einen strukturellen Dativ erweitert, wie in (21a) angedeutet. ${ }^{8}$

(21a) $\lambda z \quad \lambda y \quad \lambda x \quad \lambda s[W I C K L(x, y) \& \operatorname{BECOME}(\operatorname{LOC}(y, \operatorname{EXT}[\mathrm{z}])$ $\& \operatorname{ENCL}(D[y], z))](s)$

dat acc nom

(21b) $\lambda z \quad \lambda y \quad \lambda x \quad \lambda s[\operatorname{WICKL}(x, y) \& \operatorname{BECOME}(\operatorname{LOC}(y, \operatorname{EXT}[z])$ $\& \operatorname{ENCL}(\mathrm{D}[\mathrm{u}], \mathrm{z}))](\mathrm{s})$

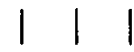

acc * nom

Beim Präfixverb umwickeln andererseits behält das Verb den Kasusrahmen des Simplexverbs bei ohne eine solche Kasuserweiterung. Da umwickeln also nach wie vor lediglich über zwei Kasus (Nominativ und Akkusativ) verfügt, ist es nicht in der Lage, alle drei Argumente mit Kasus zu versehen. Ein solches Kasusdefizit, bei dem zwei interne Argumente eines komplexen Verbs um denselben Kasus konkurrieren (hier den Akkusativ), führt nach der Hypothese der Priorität der affixalen Be-

7 Die Semantik der Präposition um entstammt Wunderlich (1993). Sie besagt, daß $u$ in der proximalen externen Region eines $v$ lokalisiert wird, wobei eine Dimension von $\mathbf{u} \mathbf{v}$ umgibt.

8 Das Situationsargument des Verbs erhält nicht auf dieselbe Art und Weise wie die anderen verbalen Rollen eine thematische Rolle, sondern dient dazu, die vom Verb denotierte Proposition in einer Situation referentiell zu verankern. 
deutung in (22) stets dazu, daß das präpositionale Objekt (z) gegenüber dem verbalen Objekt $(y)$ bei der Kasuszuweisung Vorrang hat.

(22) Hypothese der Priorität der affixalen Bedeutung

Reichen die Kasusmerkmale eines komplexen Verbs nicht aus, um alle seine Thetarollen mit Kasus zu versehen, so haben die Argumente des Affixes bei der Zuweisung der vorhandenen Merkmale Vorrang.

Die Hypothese, daB das Affix Priorität bei der Realisierung seiner Argumente erhält, habe ich in Olsen (1994) angeboten als Erklärung für die Veränderung bei den grammatischen Funktionen, die mit der Argumentvererbung bei Präfixverben einhergeht. In (21b) bleibt $\lambda y$ ohne verbalen Kasus, so daB ein neues Regens erforderlich wird. In Olsen (1995a) wird gezeigt, daB die Präposition mit mit ihrer Pertinenzsemantik (v HAB z) geeignet ist, in den Applikativkonstruktionen die Aufgabe eines Regens zu übernehmen.

Empirisch gesehen kann also ein ursprüngliches Argument eines Basisverbs wie $\lambda y$ in (21b) unterdrückt werden, wenn dieses Verb einer präpositionalen Affigierung unterzogen wird. Die affixalen Argumente erhalten bei der Realisierung der verbalen Argumente Präferenz. Warum sollte dies so sein? Die Antwort auf diese Frage liegt auf der Hand: Das ursprüngliche Objekt gehört zum Basisverb und ist auf der Grundlage der im Lexikoneintrag enkodierten semantischen Repräsentation dieses Verbs eindeutig rekonstruierbar. Bei der Anfügung eines Präfixes an einen lexikalisch gegebenen Verbstamm andererseits geht es nicht mehr um das ursprüngliche Lexem, sondern um eine derivationelle Abwandlung der Verbbedeutung. Fehlt das Argument des Affixes, so kann die durch das Präfix denotierte präpositionale Relation nicht zur Geltung kommen. Es liegt im Wesen einer Ableitung, daB ein neues Wort mit neuen Eigenschaften geschaffen wird.

Argumentvererbung mit Dativ ist in den wenigen Fällen, die tatsächlich bei Partikelverben vorkommen, starken Beschränkungen unterworfen, die ganz offensichtlich mit den Restriktionen zusammenhängen, die dem Dativ als strukturellem Kasus in der Gegenwartssprache anhaften. Tauschen wir das Beispiel in (18) und (19) gegen (23) aus, in dem ein unbelebtes anstelle eines belebten Präpositionalobjekts vorkommt, so ist das Partikelverb mit Dativvererbung schon sehr fragwürdig, wie (23c) zeigt, vgl. Wunderlich (1983).

(23a) Sie legen Blumen um das Grab.

(23b) Sie umlegen das Grab mit Blumen.

(23c) *Sie legen dem Grab Blumen um. 
Das Präfixverb in (23b) dagegen bleibt unverändert in seiner Grammatikalität.

In dieser Hinsicht macht Wunderlich (1983) eine interessante Beobachtung. Er vergleicht Sätze wie in (24) miteinander und zeigt, daf die Form des Verbs von der Stereotypizität des präpositionalen Komplements abzuhängen scheint.

(24a) Der Rhein flutet über seine Ufer.

(24b) Der Rhein flutet über die Felder/die Gärten/die Straßen.

(25a) Der Rhein flutet über.

(25b) ?Der Rhein überflutet seine Ufer.

(25c) Der Rhein überflutet die Felder/die Gärten/die Straßen.

Die Präposition über in (24a) enthält ein stereotypisches Komplement für den Kontext fiuten, während das Komplement in (24b) pragmatisch gesehen weniger erwartbar ist. Das stereotypische Komplement in (24a) ergibt das Partikelverb in (25a), während das Präfixverb in (25b) abwegig wirkt. Präfixverben sind dagegen bildbar bei nicht-stereotypischen präpositionalen Komplementen wie in (25c). ${ }^{9}$

Im Hinblick auf die vorangegangene Diskussion kann dieser Umstand folgendermaßen gedeutet werden: Wird in einer bestimmten Situation eine präpositionale Relation gewählt, die als internes Argument ein semantisch nicht prädiktables Denotat hat, so wird diese Relation in ihrer vollständigen Ausführung mittels funktionaler Komposition in die Verbbedeutung integriert. Funktionale Komposition bewirkt, daB das interne Argument der Relation auf das neue Verb vererbt und in sein Thetaraster als zu realisierendes Objekt aufgenommen wird. Auf diese

9 Weitere Beispiele sind (i), (ii) und (iii). Da Arnim am Bodensee lebt(e), stellt See in (ia) ein Objekt dar, das aufgrund von Weltwissen aus dem Kontext leicht ergänzbar ist. Für das Objekt in (ib) (Hasen) gilt dies dagegen nicht. Insofern ist das Partikelverb in (ii) ableitbar, bei dem See implizit gelassen wird, wāhrend das Präfixverb mit Argumentvererbung in diesem Fall abweichend ist.

(ia) Arnim fährt über den See.

(ib) Arnim fährt über den Hasen.

(iia) Arnim fährt über.

(iib)??Arnim überfährt den See.

Da man (auch Arnim) andererseits nicht typischerweise Hasen überfährt, wird in (iii) das Prāfixverb gewählt, wo Hasen explizit zur Realisierung kommt.

(iii) Arnim überfährt den Hasen.

(iiib) ?? Arnim fährt über. 
Weise entsteht ein Präfixverb. Deckt sich andererseits der Inhalt der internen Stelle der präpositionalen Relation mit Information, die entweder der verbalen Bedeutung oder aber der pragmatischen Situation entnommen werden kann, so wird diese Stelle ihrer Redundanz wegen im Lexikon existentiell geschlossen mit der Folge, daB sie nicht vererbt wird. In diesem Fall wird ein Partikelverb abgeleitet. Die Arbeitsteilung funktionale Komposition vs. Applikation geht einher mit einem formalen Unterschied: Präfixale Elemente sind formal gesehen unselbständige Morpheme, Partikel dagegen stellen (lexikalische) Prädikate dar und tauchen in der Syntax scheinbar selbständig (d.h. getrennt vom Verbstamm) auf.

\section{Vorläufige Bilanz}

Überleitend zu einem Vergleich mit der Partikelverbbildung im Englischen läBt sich zusammenfassend festhalten, daB ein Präfix im Deutschen in dem Sinne präpositional ist, daB es zwei Argumente in die Konstruktion einbringt. Eine Partikel dagegen ist adverbial, indem das interne Argument implizit bleibt. Allein die Partikel stellt also ein wohlgeformtes Prädikat dar. Obwohl es nach wie vor rätselhaft ist, warum ein lexikalischer Stamm wie die Verbindung Partikel + Verb syntaktisch bei gewissen Konstruktionen wie z.B. Verbzweitstellung trennbar sein kann, kommt diese Eigenschaft allein dem einwertigen Prädikat (d.h. der Partikel) zu, niemals dem zweiwertigen Präfix.

Dennoch sieht die Sprachstruktur des Deutschen zwei Wege vor, um das implizit gelassene Relatum der Partikel syntaktisch zum Ausdruck zu bringen. Es kann einerseits mit Hilfe einer präpositionalen Explikation realisiert werden, oder aber es wird über eine fakultative Realisierung im Dativ ergänzt:

(26a) Sie trug Feuchtigkeitscreme (auf ihre Haut) auf.

(26b) Sie trug (ihrer Haut) Feuchtigkeitscreme auf.

In der obigen Darstellung habe ich mich bemüht, ein kohärentes Bild der komplexen Verbbildung im Deutschen zu skizzieren. Es muB betont werden, daB diese Analyse nicht auf alle einzelnen Präfix- und Partikelverben zutrift, die im Wortschatz des Deutschen vorhanden sind. Präfix- und Partikelverbsysteme stellen sehr komplexe Geflechte dar, die viele Einflüsse teilweise sehr heterogener Art reflektieren. Ich habe mir hier lediglich im Sinne einer linguistischen Analyse zum Ziel gesetzt, die produktive Regularität der kompositionellen Bildungen zu charakterisieren. Die aufgezeigte Kompositionalität, die durch die Verbindung eines Bewegungsverbs mit einer direktionalen Präpositionalrelation er- 
zeugt wird, dient als Ausgangspunkt für die einzelnen Systeme und stellt einen Maßstab dar, mittels dessen Idiosynkrasie im System erkannt und gemessen werden kann. ${ }^{10}$

So wird es nicht überraschen, daB, wie im folgenden zu zeigen ist, die eben skizzierte Analyse der Partikelverben im Deutschen fast unverändert auf Partikelverben im Englischen übertragen werden kann. Auch im Englischen besteht die Partikelverbbildung aus der Inkorporation einer einstelligen präpositionalen Relation. Wo formale Unterschiede auftreten, gehen sie in interessanter Weise auf typologische Unterschiede zwischen beiden Sprachen zurück.

\section{Typologischer Vergleich der Satzstruktur}

Deutsch und Englisch haben als germanische Sprachen in ihren ältesten Sprachstadien zunächst die SOV-Struktur ihres gemeinsamen Ahnen geerbt. Das Mittelenglische wandelte sich dann zu einer SVO-Sprache, was eine deutliche Auswirkung auf die Struktur von Partikelverben in dieser Sprache hatte, die ab diesem Zeitpunkt produktiv werden. ${ }^{11}$ Der Vergleich mit dem Deutschen ist v.a. deswegen aufschluBreich, weil das Deutsche die SOV-Grundabfolge des Germanischen bewahrt hat. Diese ältere Struktur wird allerdings in der modernen Sprache durch das Verbzweitphänomen ergänzt: Das finite Verb steht im Hauptsatz an der zweiten Stelle. Typische Satzstrukturen der beiden Sprachen werden in (27) genauer gezeigt.

10 Für eine eingehendere Diskussion dieser Thematik sei auf Olsen (1995) verwiesen.

11 Kennedy (1920) skizziert die folgende Entwicklung des Partikelverbs (nach ihm: Verb-Adverb-Kombination) im Englischen. Im Altenglischen herrschte die untrennbare Kombination (Präfixverbkonstruktion) deutlich vor, die trennbare Kombination (Partikelverbkonstruktion) war selten belegt. In der mittelenglischen Literatur konkurrieren dann zunächst entlehnte untrennbare Verbkombinationen aus dem Romanischen mit dem heimischen Präfixverb. Die heimische Partikelverbkonstruktion ist im Ggs. dazu auch im frühen Me. kaum vertreten. Erst im $15 \mathrm{Jh}$. tritt sie stärker hervor und zwar hauptsächlich in den weniger formalen Literaturstilen. Kennedy schlieBt aus seinen Auszāhlungen, daß das romanische Präfixverb als mittelengl. Lehnkonstruktion einen zweifachen Effekt auf die entlehnende Sprache ausübte: Es diente einerseits dazu, das heimische Präfixverb zu verdrängen und bremste zugleich das Aufkommen des heimischen Partikelverbs deutlich ab. In der Literatur des 17 . und 18. Jh. gerät das untrennbare romanische Verb zunehmend in Konkurrenz mit dem heimischen Partikelverb. Insbesondere in Literatur weniger hohen Niveaus (elisabethanische Komödien vs. etwa die Bibel) gewinnt das heimische Partikelverb schlieBlich die Oberhand. 
(27a) En: [IP She will [vp sew the sleeve on the dress]] (27b) Dt: [CPSie wird ${ }_{\mathrm{i}}$ [vp $\mathrm{t}_{\mathrm{j}}$ den Ärmel an das Kleid nähen $\mathrm{t}_{\mathrm{j}}$ ]]

Im heutigen Englisch steht das lexikalische Hauptverb am Anfang der Verbalphrase. Auxiliare werden in der Kopfposition der höheren funktionalen Kategorie (= IP) erzeugt. Der Verbkomplex im Deutschen befindet sich dagegen in VP-finaler Position, wobei ein finites Verb im Hauptsatz aus der Endstellung in die höchste funktionale Kopfposition (hier: C) bewegt wird. Eine weitere Konstituente füllt die vorangehende Spezifizierer-Position der CP aus.

In beiden Sprachen steht ein direktionales Prädikat nach den indirekten und direkten Objekten. Im frühesten Englischen und Deutschen stand dieses Element unmittelbar vor dem Verb in Endstellung. Das Deutsche bewahrt diese Abfolge im Nebensatz, wie (28b) mit annähen zeigt. Die ältere Abfolge Präpositionalelement + Verb wird aber im Englischen durch die Grammatikalisierung der VP-initialen Positionierung des Verbs zu Verb + Partikel geändert, vgl. to sew on in (28a).

(28a) She will [vpsew on the sleeve].

(28b) Sie wird [vpden Ármel annähen].

Als Innovation weicht also die neue Kopfposition innerhalb der VP sowie die Form der dadurch beeinfluBten Partikelverben (VO bzw. Verb + Partikel) im Englischen von den entsprechenden Strukturen im Deutschen ab. Aber auch innerhalb des Englischen selbst entsteht durch die neue VO-Struktur eine Divergenz zwischen der kopfinitialen phrasalen Struktur und der konservativeren kopffinalen Wortstruktur. Demgegenüber harmoniert die Form des Partikelverbs im Deutschen mit der Rechtsköpfigkeit der Wortstruktur in dieser Sprache.

In Folge ihrer regulären Bildungsweise gehen deutsche Partikelverben in alle produktiven derivationellen Prozesse ein, die für Verbstämme definiert sind. (29) zeigt, daB sich die produktiven Suffixe wie -er, -bar, -ung anstandslos mit einfachen wie komplexen Verbstämmen verbinden.

(29) Abnutzer, abnutzbar, Abnutzung; Ausbilder, ausbildbar, Ausbildung

Diese Situation läßt sich aufgrund der morphologisch irregulären Bildungsweise der Partikelverben im Englischen nicht dokumentieren. Die Linksköpfigkeit der Partikelverben erschwert ihre Verwendung als Basen für produktive derivationelle Prozesse. Obwohl die Suffixe -er, -ee, -able auf Verben spezialisiert sind und sogar Präfixverben als Basen zulassen, verweigern sie sich einer Verbindung mit Partikelverben, vgl. (30a) mit (30b): 
(30a) refill 'wieder füllen'; debug 'entwanzen' refiller, refillee, refillable; debuger, debugee, debugable

(30b) show off 'sich brüsten', vote in 'beschließen' * shower off, * showee off, * showable-off, * voter in, *votee in, *voteable-in

(30c) *show offer, ?? show-off-ee, ?show-off-able

Marginale Bildungen wie in (30c), die gelegentlich in der Umgangsprache auftauchen, zeigen, daB die Blockade gegen suffixale Derivationen damit zusammenhängt, daß die lexikalischen Eigenschaften der Suffixe bei Partikelverben mit wohl etablierten Prinzipien der Wortstruktur in Widerstreit geraten. Ein Suffix fügt sich in Einklang mit dem Kopfprinzip rechts in der Wortstruktur an einen selegierten Stamm an. Der von diesen Suffixen selegierte Verbkopf bildet bei englischen Partikelverben (im Gegensatz zu deutschen Partikelverben und zu englischen Präfixverben) den linken Bestandteil des komplexen Verbstamms. Dies hat zur Folge, daB ein, gemessen an seinen lexikalischen Forderungen legitim angefügtes Suffix mitten im Wort erscheint wie in (30b) und nicht als rechte Konstituente, wie die formalen Prinzipien der Suffigierung verlangen. Die Bildungen in (30c) entstehen, indem die Selektionseigenschaften der Suffixe gelockert werden zugunsten der Aufrechterhaltung der festen Rechtspositionierung des Suffixes. Weil diese Derivationsweise die Selektionseigenschaften der Suffixe verletzt, werden ihre Produkte als Verlegenheitslösungen empfunden. Die Folge dieser komplexen Situation ist, daß weder (30b) noch (30c) eine produktiv auszuschöpfende Möglichkeit des Englischen darstellt.

Als echte lexikalische Stämme zeigen sich Partikelverben im Englischen am deutlichsten, wenn der Kopffaktor nicht störend wirkt, was sowohl bei präfixalen Bildungen wie in (30a) als auch bei deverbaler Konversion zum Nomen der Fall ist. Letztere sind in der Gegenwartssprache sogar sehr produktiv, vgl. (31).

(31) a bailout, breakthrough, carryout, comeback, handout, kickoff, patchup, putdown, setup, showdown, spinoff, takeover, turnout, turnover

'Rettung, Durchbruch, Ausfuhr, Comeback, Aushändigung, AnstoB, Zusammenflicken, Abweisung, Errichtung, Auseinandersetzung, Abfallprodukt, Übernahme, Herstellung, Umsatz'

Die in (30) aufgezeigte Irregularität von Partikelverben im Englischen ist kein Argurnent gegen den Status der Verbindung Verb+Partikel als 
lexikalischen Stamm. Die obige Diskussion zeigt, daß ihre Eigenschaften durchaus mit der Theorie konform sind, die sie als irregulär charakterisiert.

\section{Stellung der Partikel im Englischen vs. Deutschen}

In Einklang mit dem Ergebnis der vorangegangenen Diskussion wird im folgenden von dem Leitgedanken ausgegangen, daB Partikelverben im Englischen genauso wie im Deutschen lexikalische Stämme darstellen. Wenn diese Annahme richtig ist, so teilt der verbale Bestandteil der Partikelverben im Englischen mit seinem deutschen Gegenstück die kuriose Eigenschaft, von der zugehörigen Partikel abtrenn- und wegbewegbar zu sein. Das Paradebeispiel im Deutschen ist die Voranstellung des finiten Verbs bei Verbzweitstellung, die den Verbstamm von der Partikel trennt und die Partikel in Endstellung strandet.

(32) Sie näht $\mathrm{t}_{\mathrm{i}}$ [vp den Ärmel an $\mathrm{t}_{\mathrm{i}}$ ]

Das Englische weist im Bereich der Partikelverben als Gegenstück dazu das Paradigma in (33) auf. Dabei gehe ich, wie eingangs betont, von der Annahme aus, da $B$ das englische Partikelverb als lexikalische Einheit in Einklang mit der SVO-Struktur dieser Sprache VP-initial erzeugt wird, so daB die Struktur in (33a) primär und die diskontinuierliche Form in (33b) davon abgeleitet sein muB.

(33a) She [vp [v sewed on] the sleeve]

(33b) She sewed the sleeve on.

Wenn die Partikel im Englischen das formale Gegenstück zu Partikeln in den anderen germanischen Sprachen ist, so ist zu erwarten, daB sie das Hauptcharakteristikum der Partikel in diesen Sprachen teilt, nämlich ihre Positionsfestigkeit. Im Deutschen und Niederländischen beispielsweise sitzt die Partikel ganz fest in der rechten Satzklammer und ist aus dieser Position nicht wegbewegbar. ${ }^{12}$ Dieses grammatische Faktum

${ }^{12}$ Im Deutschen und Niederländischen trennen Verbbewegungsprozesse wie Verbzweit den Verbstamm von der Partikel, was die Partikel in Endstellung strandet:

(ia) Jan ruft $t_{1}$ [vp das Mädchen an $\mathrm{t}_{\mathrm{i}}$ ].

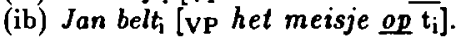

Die Partikel kann nur mit dem Verbstamm zusammen aus dieser Position herausbewegt werden, da sie alleine keine selbständige syntaktische Konstituente darstellt. Dies zeigt deutlich das Phänomen der Topikalisierung im Deutschen:

(iia) [Anrufen sollst [VP du sie nicht $\mathrm{t}_{\mathrm{i}}$ ].

(iib) ${ }^{*}\left[\mathrm{An}_{\mathrm{i}}\right]$ sollst [VP du sie nicht $\mathrm{t}_{\mathrm{i}}$ rufen].

Bei Verbanhebung im Niederländischen besteht die Option, daß entweder 
wird im Englischen oft dadurch verdunkelt, daß das Englische eine Bewegungsregel besitzt, die thematische Objekte voranstellt. Sie macht sich typischerweise bei pronominalen Objekten bemerkbar, wo sie fast obligatorisch wirkt, vgl. (34).

(34a) She sewed it on.

(34b) * She sewed on it.

$\mathrm{Da} \beta$ sie nicht obligatorisch ist, sondern mit der Thematizität des Objekts zu tun hat, zeigen Pronomen, die fokussiert werden können wie in (35). ${ }^{13}$

(35a) Am I supposed to check off mysélf?

'Soll ich mich etwa selbst abhaken?'

(35b) The lights won't pick up this.

'Die Scheinwerfer werden dies nicht beleuchten.'

Da das Objektpronomen in (35) nicht thematisch ist, unterliegt es der Bewegungsregel nicht und verbleibt in seiner Grundstellung. In dieses Bild paBt, daB eine nicht-pronominale Nominalphrase als direktes Objekt nur vorangestellt werden kann, wenn sie thematisch ist wie in (36a).

(36a) She sewed the sleeve on.

(36b) ??She sewed the sleeve with lace around the cuff on.

'Sie nähte den Ärmel mit der Spitze um die Manschette an.'

(36c) She sewed on the sleeve with lace around the cuff.

Die Erweiterung der einfachen definiten Nominalphrase durch Modifikatoren wie in (36b) hat den Effekt, daB der Informationswert der Phrase vergrößert wird, was automatisch zu einer Fokussierung der Phrase führt. Folglich ist die Voranstellung nicht adäquat und die Phrase bleibt in ihrer Grundstellung, vgl. (36c).

Das Beispiel in (37) belegt, daB diese Bewegungsanalyse durchaus plausibel ist. In (37a) wird ein ECM-Komplement Pete to be a fool unter einem Partikelverb eingebettet. Das Subjekt wird aus dem Infinitiv herausbewegt und in Einklang mit den bisherigen Annahmen vor die Partikel der Matrix-VP gestellt, wie (37b) zeigt. Die Voranstellung der Subjekts-NP ist im Beispiel (37c), das ein pronominales Subjekt enthält, im gleichen

der Verbstamm allein nachgestellt wird oder das ganze Verb. In (iiia) wird das komplexe Verb als Ganzheit nach rechts angehoben, in (iiib) nur der Verbstamm. Im letzteren Fall bleibt die Partikel in ihrer satzfinalen Grundstellung.

(iiia) dat Jan het meisje $\mathrm{t}_{\mathrm{i}}$ wil [opbellen $\mathrm{n}_{\mathrm{i}}$ ].

(iiib) dat Jan het meisje op $\mathrm{t}_{\mathrm{i}}$ wil [bellen $\mathrm{n}_{\mathrm{i}}$.

13 Vgl. Bolinger (1971), dem diese Beispiele (s. S. 40) entnommen sind. 
Sinne obligatorisch wie bei der einfachen Konstruktion (34a), wie (37d, e) zeigen. In (37e) unterbleibt wie in den Beispielen (35) die Voranstellung, weil das Pronomen fokussiert ist.

(37a) He made out [IP Pete to be a fool].

'Er gab an, daB Peter ein Narr sei.'

(37b) He made Pete $e_{i}$ out [IPt $t_{i}$ to be a fool].

(37c) *He made out [IP him to be a fool].

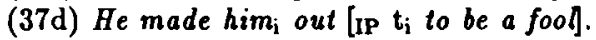

(37e) He made out [IP mé/himself to be a fool].

Es lassen sich drei weitere Argumente anführen für die hier vertretene Analyse, daB die Grundstellung im Englischen so beschaffen ist, daB die Basiseinheit Verb + Partikel ihren Platz vor dem direkten Objekt hat. Erstens lä8t nur diese Abfolge in (38) die Nominalisierung des Partikelverbs als Gerundium zu (vgl. Fraser 1976, S. 3).

(38a) the denting in of his car fender

'Einbeulen des Autokotflügels'

(38b) *the denting of his car fender in

Zweitens ist bekannt, daB eine bewegte Phrase eine Insel für weitere Extraktionen darstellt. Sie toleriert keine weitere Bewegung aus sich heraus. Nach meiner Analyse befindet sich das direkte Objekt in (39a \& b) in seiner Basisposition, während es in (39c \& d) der Partikel vorangestellt wurde. Wh-Extraktion des Adjunkts from his wife's office ist nur möglich aus der Grundposition in $(39 a, b)$.

(39) John filled out the forms from his wife's office.

'Hans füllte die Formulare vom Büro seiner Frau aus.'

(39a) Which office did John fill out the forms from?

(39b) From which office did John fill out the forms?

(39c) * Which office did John fill the forms from out?

(39d) ?? From which office did John fill the forms out? ${ }^{14}$

Dieses Ergebnis bestätigt sich in den weiteren Beispielen in (40).

(40) John totaled up the bills for the books.

'Hans addierte die Rechnungen für die Bücher zusammen.'

(40a) Which books did John total up the bills for?

(40b) For which books did John total up the bills?

(40c) * Which books did John total the bills for up?

(40d) ?? For which books did John total the bills up?

14 Nicht intendiert ist hier die Lesart, in der from which office die Situation des Formularausfüllens modifiziert. 
Zu diesen Argumenten kommt schlieBlich hinzu, daß kurze Adverbien (u.a. right) nur vor die Partikel in Endstellung einfügbar sind, wo sie dem direkten Objekt folgen. Sie dürfen nie die Einheit Verb + Partikel am Anfang der VP unterbrechen.

(41a) Sally poured the coffee right out.

'Sally goB den Kaffee sofort aus.'

(41b) * Sally poured right out the coffee.

Alle drei oben angeführten Argumente stellen Indizien dafür dar, daB die Verbindung Verb+Partikel zusammen vor dem direkten Objekt im Englischen am Anfang der VP erzeugt wird, und zwar in SVO-Stellung spiegelbildlich zu den SOV-Verhältnissen im Deutschen. Die davon abweichende Folge Verb + direktes Objekt + Partikel stellt eine abgeleitete Konstruktion dar, bei der die Partikel eine Positionsfestigkeit ähnlich der in den anderen germanischen Sprachen aufweist. Es ist das Objekt, das sich um die Partikel bewegt. ${ }^{15}$

\section{Argumentvererbung im Englischen}

Das Applikativmuster ist im Englischen im Gegensatz zum Deutschen nicht an ein Präfixmuster gebunden: Die alten germanischen Präfixe beund en-sowie with- (vgl. (42a)) sind nicht länger produktiv. Under- und over-in (42b) sind zwar produktiv, kommen aber in der heutigen Sprache

15 Genauer gesagt lege ich den Sätzen (33) und (34) folgende Analyse zugrunde, die auf der von Larson (1988) entwickelten und von Haider (1993) erneut aufs Deutsche und Englische angewandten 'Schalenkonzeption' der Verbphrase basiert:

(i)

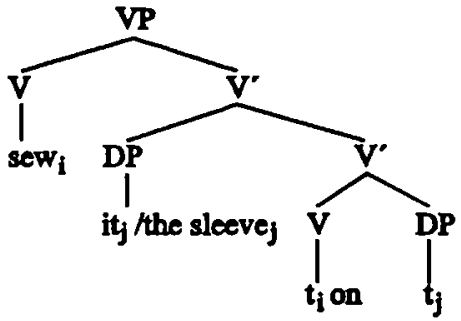

Die thematischen Phrasen it bzw. the sleeve werden in der VP vorangestellt, was wiederum erzwingt, daB auch der Verbstamm angehoben wird, da das Verb im Englischen seine Argumente nur nach rechts lizenziert. 
in einer skalaren Bedeutung vor, die für Argumentvererbung nicht von Belang ist. ${ }^{16}$ Die produktiven Verbalpräfixe de-, un- und re- in (42c) weisen schlieBlich keine Argumentvererbung auf, da sie (in der heutigen Sprache) nicht mit einer präpositionalen Relation assoziiert werden.

(42a) befriend, enslave, withstand 'als Freund behandeln, versklaven, widerstehen'

(42b) undervalue, overestimate 'unterschätzen, überschātzen'

(42c) debug, unwrap, rewind 'entwanzen, auspacken, aufziehen'

Die Veränderung der grammatischen Relationen, die für die präfixalen be- und ent- Muster im Deutschen charakteristisch sind, erscheint im Englischen ohne die Hilfe eines Präfixes. ${ }^{17}$

(43a) John sprayed/smeared/spread paint on the wall. 'Hans sprühte Farbe auf die Wand.'

(43b) John sprayed/smeared/spread the wall with paint.

Der Bereich der Partikelverben ist also ein Bereich, wo Ähnlichkeiten zwischen den beiden Sprachen hinsichtlich des Phänomens der Argumentvererbung auftreten könnten. Im Englischen wie im Deutschen basieren Partikelverben auf einer einwertigen präpositionalen Relation, die in eine dafür geeignete Verbbedeutung mittels funktionaler Applikation inkorporiert wird.

(44a) He pulled off the tablecloth. (etwa: off the table) 'Er zog die Tischdecke ab.'

(44b) She put on her engagement ring. (on her finger)

'Sie steckte ihren Verlobungsring an.'

(44c) They sent in their annual report. (in to someone) 'Sie schickten den Jahresbericht ein.'

(44d) He banged down the piano lid. (down on the piano top)

'Er knallte den Klavierdeckel runter.'

(44e) She held up the sign.

'Sie hielt das Schild hoch.'

(44f) They voted through the bill. (through congress)

'Sie verabschiedeten das Gesetz.'

16 Dies ist das Thema von Risch (1994).

17 Für eine detailliertere Diskussion dieser grammatischen Erscheinung im Englischen und Deutschen s. Olsen (1995a). 
Interessant ist, daß die zwei Möglichkeiten, die im Deutschen vorhanden sind, um das lexikalisch implizit gelassene Argument der Partikel syntaktisch zum Ausdruck zu bringen, im Englischen nicht gegeben sind. Sie werden beide durch die neuen typologischen Gegebenheiten im Englischen unterdrückt.

Da das heutige Englisch nicht mehr über morphologische Kasusmarkierung verfügt, ist nicht zu erwarten, daB Argumentvererbung des präpositionalen Objekts mit dativischem AnschluB auftritt. Die Beispielsätze (45b, d) zeigen, dab diese Konstruktion in der Tat nicht möglich ist.

(45a) He pulled the tablecloth off (the table). >

(45b) ${ }^{*} \mathrm{He}$ pulled the table the tablecloth off.

(45c) She put the parka on (the child).

(45d) *She put the child the parka on.

Auch die Möglichkeit, das implizit gelassene Objekt der Präposition durch eine zusätzliche kongruente Präpositionalphrase zu explizieren, scheint sich im Englischen nicht gehalten zu haben. Die anvisierte Konstruktion entstammt dem Germanischen und ist im heutigen Deutschen durchaus noch produktiv. ${ }^{18}$ Daß das Englische diese Konstruktion nicht bewahrt hat, scheint eine Auswirkung der neuen SVO-Struktur zu sein.

18 Die explizierende Prāpositionalphrase ist - genauer gesagt - nicht nur in den germanischen Sprachen etabliert, sondern auch im Lateinischen. In (i) werden Beispiele aus dem Gotischen (vgl. de la Cruz (1972, S. 87 u. 89)) angeführt, in (ii) ein Beispiel aus dem Althochdeutschen (vgl. Curme (1914, S. 333)) und in (iii) drei aus dem Lateinischen (vgl. Müller (1948, S. 343 u. 349)). Nach Curme ist diese, in seiner Terminologie, 'Mischkonstruktion' aus dem Englischen und Skandinavischen verschwunden.

(ia) Alluh auk ufhnaiwida uf fotuns imma (I Cor. 15,26) For he hath put all things under his feet

(ib) Hwaiwa inn galaith in gard gudis (Luk.6,4)

How he went into the house of God

(ii) Giang mit krîste er tho fon in in thaz spráhhus in (Otfrid $4,23,30$ ) 'Er ging mit Christus von ihnen in das Richthaus.'

(iiia) tu praeibis antefaciem domini thu forafeuris fora truhtines annuzzi (Got.Übers.)

(iiib) turbe inruerent in eum thie menigi anafielun in inan

(iiic) accesserunt ad eum zuogiengun zi imo 
Die Konstruktionen in (46) sind im Englischen nicht distinkt von der Konstruktion in (47) mit einem einfachen Verb und einer Präpositionalphrase. Daher sind sie völlig redundant und werden durch die einfachere Konstruktion ersetzt. Die scheinbare Abwesenheit einer präpositionalen Explikation im Englischen ist daher wohl darauf zurückzuführen, daB durch die VO-Struktur dieser Sprache die Kombination Partikelverb plus präpositionale Explikation durch ein einfaches Verb mit einer Präpositionalphrase ohne Verlust abgedeckt werden kann, wie in (47) veranschaulicht.

(46a) He pulled off the tablecloth - off the table.

(46b) He pulled the tablecloth off - off the table.

He pulled the tablecloth off the table.

Bolinger (1971, S. 31) weist allerdings im Zusammenhang mit seiner Kategorie adpreps ${ }^{19}$ auf Konstruktionen hin, die scheinbar beides zulassen, eine (intransitive) Partikel und eine kongruente präpositionale Explikation. Aus den Partikelverbkonstruktionen in (48a) und (48c) lassen sich nach Bolinger Relativsätze konstruieren, die das Präpositionalobjekt zum Bezugsnomen haben, was die Präposition am Satzende notwendigerweise stranden läßt. In diesem Fall kann die Folge Verb + kongruente Partikel vor der Präpositionalphrase erscheinen. Die Ergebnisse in (48b) und (48d) wirken nach meinem Sprachgefühl äußerst marginal.

(48a) He crossed over the bridge.

'Er überquerte die Brūcke.'

(48b) Is that the bridge that was crossed óver over?

(48c) He climbed up the pole.

'Er kletterte auf den Pfahl.'

(48d) Is that the pole that was climbed up up?

Wenn man Bolingers Beobachtung allerdings auf transitive Fälle ausdehnt, so wird klar, daB die Verdeutlichung des impliziten Inhalts der Partikel durch eine präpositionale Explikation in der Tat möglich ist. Interessanterweise ist dies aber nur in strukturellen Varianten ohne vorangestellte Nominalphrase erlaubt, die im Sinne dieses Aufsatzes die Basisabfolge darstellt.

(49a) Is that the windshield that he pulled off the sticker off?

'Ist das die Windschutzscheibe, von der er den Aufkleber abzog?'

19 Diese Kategorie umfaßt bei Bolinger (1971, Kap. 2) Elemente, die gleichzeitig in der Funktion als Präposition und Adverb vorkommen wie beispielsweise in in dem Satz: He came to the water and jumped in (the water). 
(49a') *Is that the windshield that he pulled the sticker off off?

(49b) Is this the table that he handed around the document around?

'Ist dies der Tisch, um den er das Dokument herumreichte?'

(49b') *Is this the table that he handed the document around around?

Konstruktionen wie in (49) scheinen mir strengen Restriktionen zu unterliegen. Zum einen scheinen sie nur in der konkret-direktionalen Bedeutung der Präposition möglich, weshalb das Beispiel (50) ausgeschlossen ist.

(50a) ? Was it the latest session of congress that they voted through the bill through?

'War es in der letzten Sitzung des Kongresses, daß sie die Gesetzesvorlage beschlossen?'

(50b) * Was it the latest session of congress that they voted the bill through through?

Zum zweiten setzt eine präpositionale Explikation voraus, daß dieselbe (einfache) morphologische Form sowohl die Partikel als auch die Präposition instantiieren kann. Diese Bedingung schränkt die Möglichkeiten deswegen radikal ein, weil einfache Präpositionen im Englischen (im Gegensatz zum Deutschen, das über eine Akkusativ-Dativ-Distinktion verfügt) selten alleine imstande sind, Direktionalität zu signalisieren. Oft wird zu diesem Zweck eine komplexe morphologische Form benötigt, vgl. in/into, on/onto. Wenn keine im Sinne von Bolinger (1971, S. 31ff.) fusionierte Form lexikalisiert ist, tritt eine zusammengesetzte Form auf down/down on, off/off of, out/out of, over/over to. Wie die Sätze in (51) zeigen, gehen einfache und komplexe Formen im Englischen eine Arbeitsteilung ein der Art, daB die einfache Form immer die Partikel darstellt und die komplexe Variante immer die Präposition.

(51a) John brought in dinner to his wife.

Part

'Hans brachte das Abendessen zu seiner Frau hinein.'

(51b) John brought dinner in to his wife.

Part

(51c) John brought dinner [into the living room].

Präp

'Hans brachte das Abendessen in das Wohnzimmer hinein.'

(51d) *John brought into dinner the living room.

Präp

Insofern liegt immer dann, wenn die morphologisch komplexe Form gewählt wird, eine Konstruktion Verb + Präpositionalphrase vor - vgl. (52a) und (52b), die die Partikelverb-Konstruktion mit präpositionaler Explikation ersetzt, wie die Ungrammatikalität von (52c) und (52d) beweist. 
(52a) He chased the cat off (of) the lawn.

'Er jagte die Katze vom Rasen.'

(52b) Was it the neighbor's lawn he chased the cat off of?

(52c) * Was it the neighbor's lawn he chased off the cat off?

(52d) *Was it the neighbor's lawn he chased the cat off off?

\section{Konklusionen}

Das Hauptergebnis dieses Aufsatzes ist, daB Partikelverbbildung in beiden Sprachen grundsätzlich denselben lexikalischen Prinzipien unterliegt. Aus der vorangegangenen Diskussion wurde klar, daB die formalen Unterschiede zwischen dem Deutschen und dem Englischen in diesem Bereich durch Divergenzen, die sich im Laufe der englischen Sprachgeschichte herausgebildet haben, mafigeblich geprägt sind.

Seit dem Mittelenglischen werden syntaktische Phrasen kopfinitial gebildet. Diese typologische Eigenschaft führte zur Ausbildung von Partikelverben in der (fürs Germanische unregelmäBigen) Form Verb + Partikel, die gegen die Rechtsköpfigkeit der Wortstruktur verstöBt. Konsequenz dieses Sprachwandels ist, daB Partikelverben im Englischen für kopfbasierte derivationelle Prozesse nicht zugänglich sind. Mit dem Abbau der alten germanischen Präfixe verlor das Englische darüber hinaus die Möglichkeit, das Applikativmuster von (1), (4) und (5) morphologisch zu enkodieren. Dieses Muster lebt zwar im Englischen - wie (39) zeigt - weiter fort, da es aber durch morphologisch einfache Verben getragen wird, unterliegt es nicht im gleichen MaBe wie ein affixales Muster der Reihenbildung. Insofern ist es weniger transparent als im Deutschen, wo es präfixal (und zwar mit Hilfe von be-, ent-, um- etc.) signalisiert wird. Obwohl die Partikelverbbildung im heutigen Englisch wie im heutigen Deutsch denselben Prinzipien unterliegt, hat das Englische durch den Verlust von morphologischem Kasus die Möglichkeit der Dativvererbung eingebüßt. Was die Möglichkeit angeht, das nicht-vererbte (implizit gelassene) Argument der Partikel durch eine kongruente Präpositionalphrase zu explizieren, so zeigt das von Bolinger beobachtete Phänomen in (48), daß diese Möglichkeit im Englischen grundsätzlich vorhanden ist, obwohl sie durch die formale Redundanz dieser Konstruktion in einer Sprache, die eine Verb + Partikel und P + O-Abfolge hat, grundsätzlich durch ein einfaches Verb + Präpositionalphrase verdrängt wird. Die latente Möglichkeit, die kongruente Partikel zu realisieren, kommt lediglich in gewissen Konstruktionen zum Vorschein, in denen das Objekt der Präposition extrahiert wird und die Partikel ihre konkret direktionale Bedeutung bewahrt. 


\section{Literatur}

Baker, Mark (1988): Incorporation: A Theory of Grammatical Function Changing. Chicago.

Bierwisch, Manfred (1989): Event Nominalizations. In: Motsch, Wolfgang (Hg.) (1989): Wortstruktur und Satzstruktur. Berlin. S.1-73.

Bolinger, Dwight (1971): The Phrasal Verb in English. Cambridge, Mass.

Curme, George (1914): The Development of Verbal Compounds in Germanic. In: Beiträge zur Geschichte der deutschen Sprache und Literatur 39, S. 320-361.

de la Cruz, Juan (1972): The Origins of the Germanic Phrasal Verb. In: Indogermanische Forschungen 77, S. 73-79.

Fraser, Bruce (1976): The Verb-Particle Combination in English. New York.

Haider, Hubert (1993): Deutsche Syntax - Generativ. Tübingen.

Höhle, Tilman (1982): Explikationen für 'normale Betonung' und 'normale Wortstellung'. In: Abraham, Werner (Hg.) (1982): Satzglieder im Deutschen. Tübingen, S. 75-153.

Kayne, Richard (1985): Principles of Particle Constructions. In: Guéron, Jacqueline/Obenauer, Hans-Georg/Pollock, Jean-Yves (Hg.) (1985): Grammatical Representation. Dordrecht. S.101-140.

Kaufmann, Ingrid (1995): Konzeptuelle Grundlagen semantischer Dekompositionsstrukturen. Tübingen.

Kennedy, Arthur (1920): The Modern English Verb-Adverb Combination. Language and Literature vol.1, no.1. Stanford.

Larson, Richard (1988): On the Double Object Construction. In: Linguistic Inquiry 19, S. 335-391.

Maienborn, Claudia (1990): Position und Bewegung: Zur Semantik lokaler Verben. IWBS Report 138. Stuttgart.

Maienborn, Claudia (1995): Situation und Lokation. Zur Bedeutung lokaler Adjunkte von Verbalprojektionen. Tübingen.

Müller, Gertraud (1948): Die ahd. Partikelkomposita. In: Beiträge zur Geschichte der deutschen Sprache und Literatur 70, S. 332-350.

Olsen, Susan (1994): Alternative grammatische Realisierungen lokativer Komplemente. (Erscheint in:) Papiere zur Linguistik.

Olsen, Susan (1995): Über Präfix- und Partikelverbsysteme. (Erscheint in:) Simeckova, Alena (Hg.) (1995): Wortbildung - Theorie und Anwendung. Universität Prag.

Olsen, Susan (1995a): Lokativalternation im Deutschen und Englischen. In: Zeitschrift für Sprachwissenschaft 13, S. 201-235.

Olsen, Susan (1995b): Zum Status der Kategorie Verbpartikel. (Erscheint in:) Beiträge zur Geschichte der deutschen Sprache und Literatur.

Risch, Gabriela (1994): Verbpräfigierung des Deutschen: Skalierungsverben mit über- und unter-. Dissertation, Universität Stuttgart. 
Stiebels, Barbara/Wunderlich, Dieter (1994): Morphology Feeds Syntax: The Case of Particle Verbs. In: Linguistics 32, S. 913-968.

Wunderlich, Dieter (1983): On the Compositionality of German Prefix Verbs. In: Bäuerle, Rainer et al. (Hg.) (1983): Meaning, Use, and Interpretation of Language. Berlin. S. 452-465.

Wunderlich, Dieter (1987): An Investigation of Lexical Composition: The Case of German be-Verbs. In: Linguistics 25, S. 283-331.

Wunderlich, Dieter (1991): How Do Prepositional Phrases Fit Into Compositional Syntax and Semantics? In: Linguistics 29, S. 591-621.

Wunderlich, Dieter (1993): On German um: Semantic and Conceptual Aspects. In: Linguistics 31, S. 111-133.

Wunderlich, Dieter (1994): CAUSE and the Structure of Verbs. Ms. Universitāt Düsseldorf. 


\title{
JOACHIM GRABOWSKI / PETRA WEISS
}

\section{Das Präpositioneninventar als Determinante des Ver- stehens von Raumpräpositionen: vor und hinter in fünf Sprachen}

\begin{abstract}
Die Frage der Verwendung und des Verstehens von Richtungsprāpositionen und der Beschaffenheit korrespondierender Raumkonzeptionen wird in Psychologie und Linguistik spätestens seit Miller und Johnson-Laird's Language and Perception (1976) und der Gegenüberstellung der deiktischen und der intrinsischen Raumauffassung intensiv diskutiert. Dabei wurde unter anderem der Einfluß des Diskurskontexts (Ehrich), der Statik vs. Dynamik der Situation (Wunderlich), des individuellen kognitiven Stils (Levelt) und der Richtungseigenschaften des Bezugsobjekts (Miller) auf die Wahl eines räumlichen Bezugssystems untersucht, ohne daf insgesamt eine zufriedenstellende Bestimmung erreicht werden konnte.
\end{abstract}

Am Beispiel der Prāpositionen der 1. Horizontalen im System der sekundāren Raumdeixis wird anhand einer Experimentalserie im Deutschen, Franzōsischen, Italienischen, Niederländischen und Englischen gezeigt, daß bei der hörerseitigen Identifikation eines Teilraums auf der Basis einer Lokalisationsāußerung psychologische, psycholinguistische, linguistisch-semantische und sprachtypologische Faktoren spezifisch interagieren: (1) die variable Gerichtetheit des Bezugsobjekts; (2) die verwendete Präposition; (3) die soziale Situation, in der eine Lokalisationsāußerung produziert wird; sowie (4) das Präpositioneninventar der verwendeten Einzelsprache, vor allem das Verhältnis der răumlichen zu den zeitlichen Ausdrücken. Insbesondere mit den Faktoren (3) und (4) wird ein Determinationsgrad der hörerseitigen Teilraumwahl erzielt, der die in der Literatur dokumentierten Zusammenhangsannahmen übertrifft. Dennoch bleibt in allen untersuchten Sprachen ein Rest an kommunikativer Unschärfe; an welchen Stellen diese Unschärfen auftreten, hängt jedoch vom jeweiligen Präpositioneninventar ab.

\footnotetext{
Warum sitzt man eigentlich hinter seiner Schreibmaschine, aber vor seinem Computer?
}

\section{Problemeingrenzung}

Der Raum ist eine grundlegende Erfahrungsqualität des Menschen (Gosztonyi 1976). Insofern erscheint es nur natürlich, daß Menschen auch oft über räumliche Gegebenheiten kommunizieren (vgl. allgemein Vater 
1991). Der vorliegende Aufsatz handelt von der sprachlichen Verständigung über einen sehr einfachen Fall einer räumlichen Gegebenheit: Ein Objekt befindet sich an einem Ort oder soll sich an einem Ort befinden. Unter einem Objekt seien dabei im weitesten Sinne alle materiellen Gegebenheiten in der Welt verstanden, also Lebewesen und konkrete Gegenstände. Die Einschränkung auf Objekte - gegenüber den ebenfalls lokalisierbaren Zuständen und Ereignissen (Jackendoff 1983) - erfolgt dabei lediglich aus Vereinfachungsgründen.

Wenn in der Kommunikation die räumliche Lage eines Objektes angegeben wird, kann dies im wesentlichen $z$ wei Gründe haben (Herrmann/Grabowski 1994): (1) Der Sprecher will das Objekt hervorheben und damit ins BewuBtsein des Kommunikationspartners rücken. Dies kann dadurch erfolgen, daB der Sprecher durch Angabe der (variabel spezifizierten) Objektklasse, der das Objekt angehört, durch Angabe mehr oder weniger spezifizierender Attribute des Objektes oder eben durch die Angabe des Ortes, an dem sich das Objekt befindet, auf das besagte Objekt referiert. Unter diesem Ziel des Sprechers steht das Lokalisieren somit äquifunktional neben dem Benennen und dem Beschreiben von Objekten. (2) Oder der Sprecher will einen Ort hervorheben, an dem sich das in Frage stehende Objekt befindet, befinden soll, befunden hat, noch nie befunden hat, befinden wird, auf keinen Fall befinden soll etc.

Welchem kommunikativen Zweck die Angabe der räumlichen Lage eines Objektes in der jeweils konkreten Situation auch dient: Das gemeinsame Kennzeichen von lokalisierenden Äußerungen besteht darin, daß das Zielobjekt oder der Zielort in eine räumliche Beziehung zu einem anderen Objekt (dem Bezugsobjekt oder Relatum) beziehungsweise zu dem Ort, den das Relatum einnimmt, gesetzt wird. (Zur hier nicht weiter zu vertiefenden Frage, ob eigentlich Objekte oder ob Örter die Argumentstellen von Lokalisationsrelationen besetzen, vgl. Habel 1989.)

Als geeignetes sprachliches Mittel für die Angabe von räumlichen Relationen zwischen Objekten finden vor allem Präpositionen Verwendung. Raumpräpositionen lassen sich danach unterteilen, ob sie sich auf die topologische (zum Beispiel in, bei) oder auf die dimensionale Struktur des Raumes (zum Beispiel vor, neben, über) beziehen (vgl. Jackendoff/Landau 1991; Klein 1994; Landau/Jackendoff 1993). Präpositionen wie beispielsweise auf können auch spezifische Verbindungen topologischer und dimensionaler Eigenschaften des Raumes thematisieren. Wir beschränken uns bei den folgenden Erörterungen auf dimensionale Präpositionen (Richtungspräpositionen, projektive Präpositionen; vgl. Herskovits 1986; Retz-Schmidt 1988) und bewegen uns somit im Bereich der sekundären Raumdeixis (Ehrich 1985). Die nachfolgend berichteten 
Untersuchungen betreffen Raumrelationen auf der 1. Horizontalen, der Sagittalen; soweit es das Deutsche betriftt, behandeln wir also die Verwendung der Präpositionen vor und hinter. Der sprachliche Ausdruck räumlicher Relationen auf der 2. Horizontalen (rechts von, links von) ist jedoch implizit mitbehandelt, wogegen für die Vertikale einige Sonderbetrachtungen erforderlich wären (vgl. Friederici 1989; Levelt 1984, 1986).

Wir erläutern zunächst (Abschnitt 2), warum bei der Interpretation der Präpositionen der 1. Horizontalen (beziehungsweise bei der Interpretation von Äußerungen, die entsprechende Präpositionalphrasen enthalten) Mehrdeutigkeit auftreten kann. Dann (Abschnitt 3) skizzieren wir einige schon vorliegende Versuche, angesichts dieses Ambiguitätspotentials beschreibende und erklärende Ordnung zu schaffen, das heißt anzugeben, unter welchen Bedingungen die Präpositionen in welcher Weise verwendet werden. An Hand eigener experimenteller Untersuchungen wird dargestellt (Abschnitt 4), daß die genannten Interpretationsprobleme im Deutschen tatsächlich bestehen und daB es mindestens drei Faktoren sind, die das Verstehen von vor und hinter determinieren, die zusammengenommen aber immer noch keine vollständige Vorhersage des interpretierenden Hörerverhaltens ermöglichen. Wir führen die Hypothese an (Abschnitt 5), daß ein Teil der bestehenden Mehrdeutigkeit darauf zurückzuführen ist, daß das Deutsche im Hinblick auf sein Präpositioneninventar zu einem bestimmten Typ von Sprachen gehört, und zeigen an Hand weiterer Untersuchungen, daß diese Annahme berechtigt ist und welche Einschränkungen und Erweiterungen sich daraus für eine einzelsprachenübergreifende Theorie der Determination der Verwendung von Richtungspräpositionen ergeben.

\section{Das Problem: Bezugssysteme des dimensionalen Lokalisierens}

Klein (1994, S. 165) nennt drei Voraussetzungen, die erfüllt sein müssen, damit raumbezogene ÄuBerungen 'funktionieren' können, das heißt, damit der Hörer aufgrund der Äußerung denjenigen Referenten ausmachen kann, auf den die Äußerung nach der Intention des Sprechers referieren soll: (1) Die Kommunizierenden müssen über eine hinreichend ähnliche Raumauffassung verfügen. (2) Sie müssen die Bedeutung der verwendeten Ausdrücke kennen. (3) Sie müssen 'allerlei Kontextinformation' heranziehen, um die Äußerung geeignet interpretieren zu können. Wir behandeln die Frage der Verwendung und der potentiellen Mehrdeutigkeit von vor und hinter im folgenden unter dem drittgenannten Aspekt der Kontextinformation und skizzieren die unter (1) und (2) genannten 
Voraussetzungen nur, ohne auf die damit verbundenen Probleme einzugehen.

Was die Raumauffassung des Menschen betrifft, so kann man annehmen, daB Objekte Örter einnehmen, für die eine topologische und eine dimensionale Struktur definiert ist. Man kann diese Raumauffassung anthropomorph begründen, den Menschen also als die primäre raumstrukturierende und raumdimensionierende Origo betrachten (vgl. Grabowski, in Vorb.):

(i) Der Mensch nimmt einen bestimmten Ort ein, an dem sich kein anderes Objekt befinden kann, es sei denn, es ist in ihm (= Inklusionsrelation). (ii) Andere Objekte beziehungsweise die Örter, die sie einnehmen, können unmittelbar an den Menschen angrenzen (= Kontaktrelation). (iii) Um den Menschen herum gibt es weiterhin eine Umgebung oder eine Region im Sinne eines Bereichs, den der Mensch von dem eingenommenen Ort aus manipulieren kann. Diese drei Bestimmungsstücke bilden die topologische Struktur des Raumes; sie erlauben die Unterscheidung von in beziehungsweise innerhalb und nicht in beziehungsweise außerhalb (qua (i)), von an, an ... dran und nicht an (qua (ii)) sowie von (nahe) bei und nicht bei beziehungsweise fern von (qua (iii)). Man beachte, daß die topologische Struktur zunächst einmal beliebigdimensional definiert ist.

Die dimensionale Struktur des Raumes ergibt sich bei Hinzuziehung zweier weiterer Annahmen: (iv) Die menschliche Raumauffassung ist dreidimensional. (v) Dabei handelt es sich jedoch nicht um einen Euklidischen Raum mit beliebigem Ursprung und beliebiger, zweifach orthogonaler Achsenorientierung und -polarisierung; vielmehr ergeben sich sowohl die Orientierung als auch die Polarität der drei Achsen aus den menschlichen Körperasymmetrien: Die Vertikale ist die Kopf-Fuß-Achse, wobei der Kopf den oberen, die Füße den unteren Pol bilden. Die 1. Horizontale verläuft durch Brust und Rücken, wobei der positive Pol (vorne) in Richtung des bevorzugten Einzugsbereichs der Wahrnehmungsorgane zeigt. Die 2. Horizontale schließlich ergibt sich orthogonal zu diesen beiden Achsen. Die asymmetrische Polarität dieser Achse ist umstritten; immerhin sind links und rechts jedoch durch die Händigkeit und die Lage der unpaarigen Organe unterschieden. An Hand der Orientierung und der Polarität der raumdimensionierenden Achsen kann man die Region eines Menschen in Teilräume aufgliedern und somit den VOR-, HINTER-, ÜBER-, UNTER-, RECHTS-VON- und LINKS-VON-Teilraum spezifzieren. 
Die dergestalt egozentrisch abgeleiteten Kennzeichen der menschlichen Raumauffassung können dann auch auf andere Menschen und andere Objekte übertragen werden; darauf kommen wir weiter unten ausführlich zurück.

Die sprachlichen Ausdrücke, die die dimensionalen Teilräume bezeichnen, nennt man das System der sekundären Raumdeixis (vgl. Ehrich 1985; wir beschränken uns hier auf die präpositionalen Ausdrücke). Ihre semantische Beschreibung erfolgt traditionell mit Hilfe einer Lokalisierungsfunktion, die unter Voraussetzung der dimensionalen Teilraumgliederung und unter Ausnutzung der topologischen Inklusion das Objekt, dessen räumliche Lage bezeichnet wird, in dem jeweiligen Teilraum des Relatums lokalisiert (Wunderlich/Herweg 1991). Vor dem Relatum bedeutet somit in dem Vor-Raum des Relatums beziehungsweise in dem Teilraum, der an die Vorderseite des Relatums angrenzt, wobei die Vorderseite des Relatums diejenige Seite ist, die in Richtung des positiven Pols der 1. Horizontalen zeigt. Entsprechend lassen sich die Bedeutungen von hinter, über, unter, links von und rechts von bestimmen. Wir teilen diese semantische Auffassung nicht, sondern halten es aus unterschiedlichen Gründen für vorteilhafter, den invarianten Bedeutungsanteil von Richtungspräpositionen im Zusammenhang mit der perzeptuellen Zugänglichkeit von Objekten und nicht über die Inklusion in seitenadjazenten Teilräumen zu rekonstruieren (Grabowski in Vorb.). Für das Folgende können wir es aber dabei belassen; es ist festzuhalten, daß das Verstehen der betreffenden Richtungspräpositionen und die damit verbundene Identifikation des intendierten Teilraums die Identifikation der entsprechenden Seiten des Relatums voraussetzt.

Beim Menschen als primärer raumdimensionierender Origo sind Vorderseite, Rückseite etc. aufgrund der erwähnten Körperasymmetrien problemlos bestimmbar. Andererseits ist Ego aber in vielen Fällen kein allzu verläßlicher Kandidat für die Verankerung von räumlichen Relationen $z$ wischen Objekten. Wir haben nämlich - neben unserer Egozentrik auch die Vorstellung einer räumlich stabilen Objektwelt, durch die wir uns hindurchbewegen. Mit dieser Bewegung durch die Welt ändert sich fortwährend unsere Position und die relative Orientierung unserer egozentrischen Raumachsen, vor allem in der Ebene: Mit einer Drehung des Körpers kann das, was gerade noch vor mir war, nun rechts von mir sein. Es kommt noch hinzu, daß wir wissen, daß jeder andere Mensch ebenfalls eine von sich aus egozentrische, von mir aus alterozentrische raumdimensionierende Origo konstitutiert. Deshalb ist es sinnvoll, die Raumangabe von Objekten nicht nur an meiner egozentrischen Origo zu verankern, sondern Objekte auch in Relation zu anderen - in ihrer 
Raumlage und -orientierung mutmaßlich zeitstabileren - Objekten zu lokalisieren. Dazu müssen aber - wenn wir uns jetzt wieder auf die 1 . Horizontale beschränken - die Vorder- und Hinterseite des Bezugsobjekts bestimmt werden. Das Problem besteht nun darin, daß es (a) mehrere Prinzipien gibt, nach denen einem Objekt eine Vorderseite zugeschrieben werden kann, daB (b) diese Prinzipien in einigen Fällen konkurrieren können, und daß man (c) der raumbezogenen Außerung in der Regel nicht ansehen kann, welches Prinzip gewählt wurde.

Die beiden Grundprinzipien, nach denen Menschen Objekten Vorderund Rückseiten zuschreiben, die die dimensionale Lokalisierung in Relation zu diesen Objekten erlauben, sind das extrinsische und das intrinsische Bezugssystem (vgl. hierzu und zum Folgenden CarlsonRadvansky/Irwin 1993; Ehrich 1985; Grabowski 1994; Levelt 1986; Retz-Schmidt 1988) beziehungsweise die merkmalsfundierte vs. nichtmerkmalsfundierte Gerichtetheit von Objekten (Herrmann 1990). Im intrinsischen Bezugssystem bezieht sich der Sprecher auf die Raumdimensionierung an Hand der inhärenten räumlichen Eigenschaften und Achsenasymmetrien des Bezugsobjekts; diese liegen, wie oben beschrieben, beim Menschen und anderen automobilen Lebewesen vor, aber auch bei Objekten, die der Mensch in charakteristischer Orientierung benutzt, wie beispielsweise Autos und allgemein Fahrzeuge, Kleidungsstücke, Uhren, Schränke und Schreibtische. Im extrinsischen Bezugssystem erfolgt die Frontattribution durch den aktuellen Situationskontext. Dies kann auf verschiedene Art erfolgen (Wunderlich 1982); ein besonderer und in der Literatur dem intrinsischen Lokalisieren bevorzugt gegenübergestellter Fall des extrinsischen Systems ist das deiktische System, in dem die Position und Orientierung des Sprechers beziehungsweise des Betrachters zur Bestimmung der Vorderseite herangezogen wird. In unserer Kultur erfolgt dies nach dem Prinzip des 'canonical encounter' (Clark 1973) beziehungsweise der 'facing strategy': Der dem Betrachter zugewandten Seite eines Objektes wird dessen Front zugeschrieben. (In anderen Kulturen (Hill 1982) und in unserer Kultur in anderen extrinsischen Systemen, beispielsweise bei sich bewegenden Relata, kann auch die 'aligning strategy' zum Tragen kommen, bei der die dem Betrachter abgewandte Objektseite als Front interpretiert wird.) Abbildung 1 zeigt die Verwendung von vor und hinter im deiktischen und im intrinsischen Bezugssystem. 

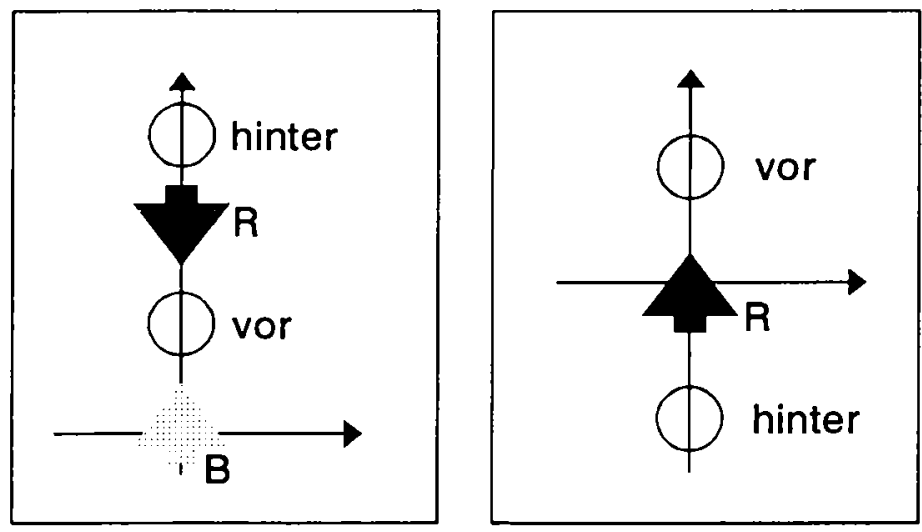

Abb. 1: Vor und hinter im deiktischen (links) und intrinsischen (rechts) Bezugssystem. Im deiktischen Fall induziert der Betrachter (B) die Front des Relatums (R) und damit dessen Gerichtetheit auf der 1. Horizontalen durch Gegenüberposition.

Formal läßt sich die Verwendung von vor und hinter in beiden Referenzsystemen im Bild einer Euklidischen Überformung des Raumes fassen (vgl. Grabowski 1994; Klein 1994). Im deiktischen System bildet der Beobachter beziehungsweise der Sprecher den Ursprung $O$ eines Koordinatensystems, seine Blickrichtung spannt den positiven Ordinatenabschnitt auf mit $\mathrm{y}(\mathrm{O})=0$. Sei $\mathrm{L}$ das lokalisierte Objekt und $\mathrm{R}$ das Relatum mit $y(L)>0$ und $y(R)>0$; das heißt, daB die in Beziehung gesetzten Instanzen in 'Blickrichtung' der Origo liegen. Dann ist $L$ vor $R$, wenn $y(L)$ $<y(R)$. L ist hinter $R$, wenn $y(L)>y(R)$. Im intrinsischen System bildet das Relatum $R$ die Origo mit $y(R)=0$. L ist vor $R$, wenn $y(L)>0$. L ist hinter $R$, wenn $y(L)<0$. Bei dieser formalen Beschreibung ist außer acht gelassen, wieweit die Verwendung von vor und hinter gegenüber seitlichen Abweichungen tolerant ist, also bei welchen Verhältnissen von $y(L)$ $-y(R)$ und $x(L)-x(R)$ (beziehungsweise der Beträge dieser Differenzen) $L$ noch vor/hinter $R$ und nicht links oder rechts vor/hinter $R$ oder schon links oder rechts von $\mathrm{R}$ lokalisiert wird.

Das Problem der Mehrdeutigkeit ergibt sich nun daraus, daß das deiktische Bezugssystem natürlich auch bei intrinsisch gerichteten Relata angewandt werden kann, wobei sich für vor und hinter gerade gegensätzliche Interpretationen ergeben. Die Sprache stellt zwar Mittel bereit, das verwendete Bezugssystem eindeutig zu markieren: Äußerungen der Art Von mir aus gesehen ... beziehungsweise Von dir aus gesehen ... können 
nur deiktisch, die Wendungen ... zur Linken ... oder ... an der Vorderseite ... können nur intrinsisch verstanden werden. Im kommunikativen Alltag verzichten Sprecher aber fast ausnahmslos darauf, diese Mittel einzusetzen (Grabowski/Miller, 1995), so daB Lokalisationen mit intrinsisch gerichteten Bezugsobjekten in aller Regel mehrdeutig sind. Diese Ambiguität illustriert Abbildung 2, in der die räumliche Lage jeder der beiden Katzen sowohl durch den Satz Die Katze ist vor dem Kabrio. als auch durch den Satz Die Katze ist links vom Kabrio. zutreffend beschrieben werden kann.

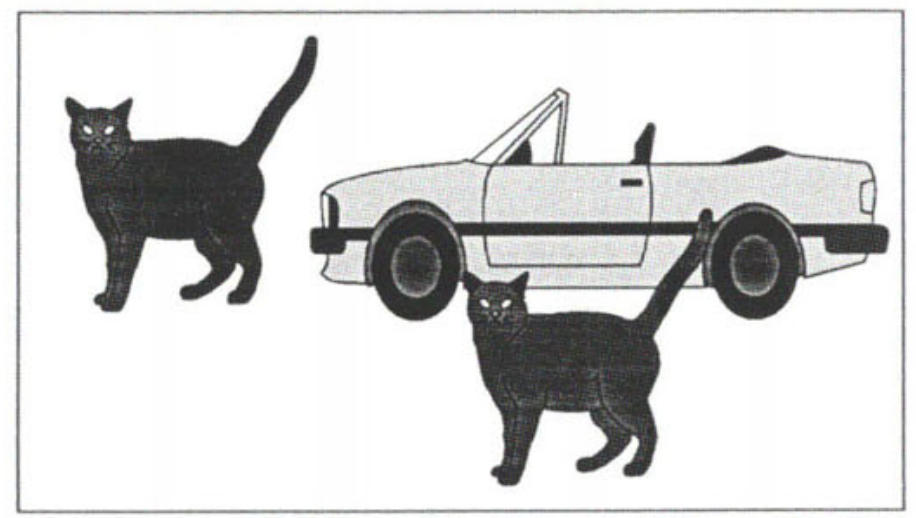

Abb. 2: Die Katze ist vor dem Kabrio. - Die Katze ist links vom Kabrio.

\section{Determinanten der Bezugssystemwahl}

Es stellt sich nun die Frage, unter welchen Bedingungen welches System verwendet wird beziehungsweise unter welchen Bedingungen Hörer Lokalisationsäußerungen auf die eine oder andere Art interpretieren. Wir skizzieren dazu, ohne Anspruch auf Vollständigkeit, vier Ansätze, die uns wesentlich erscheinen (vgl. Grabowski 1994; Weiß 1993).

Nach Miller/Johnson-Laird (1976) (vgl. auch Abkarian 1982) dominiert die intrinsische Perspektive generell die deiktische, wann immer ein Relatum als inhärent gerichtet wahrgenommen wird. Das Zutreffen dieser Annahme setzt jedoch voraus, daB in einer Kultur- und Sprachgemeinschaft Übereinstimmung herrscht, welche Objekte (gegebenenfalls in welchen Situationen) als gerichtet wahrgenommen werden. Angesichts der vielfachen Möglichkeiten situativer, nicht-merkmalsfundierter Frontzuschreibungen (vgl. Herrmann 1990) muB das generelle Vorliegen dieser 
Voraussetzung bezweifelt werden. Es kommt hinzu, daB selbst im Falle des mehr oder weniger eindeutigen Vorliegens objektimmanenter Gerichtetheit die polare Orientierung der Objektachse wechseln kann. In der kanonischen Orientierung des Kirchgängers bildet, solange er sich außerhalb der Kirche befindet, das Portal die Vorderseite der Kirche, der Altar steht hinten. Befindet man sich jedoch in kanonischer (Sitz-) Position in der Kirche, so ist jetzt der Altar vorne und das Portal hinten. Kirchen haben also zwei intrinsische Vorder- und Rückseiten. Insgesamt werden wir jedoch zeigen (s. unten Abschnitt 5), daB die Annahme der intrinsischen Präferenz die Verhältnisse im Englischen bei Relatumobjekten mit eindeutiger intrinsischer Orientierung (und Polarität) weitgehend zutreffend beschreibt.

Ehrich (1985) zeigt am Beispiel von Zimmerbeschreibungen, daß die Integration einzelner Objektkonstellationen innerhalb größerer räumlicher Arrangements besonders dann gelingt, wenn eine im Diskurs einmal gewählte Strategie beibehalten wird (vgl. auch Linde/Labov 1975; von Stutterheim/Carroll 1993). Oft treten Raumreferenzen jedoch nicht, wie es bei Wohnungsbeschreibungen oder Wegeinstruktionen der Fall ist, im lokalisierenden Diskurskontext auf, sondern stehen allein oder in nicht raumreferentiellen Zusammenhängen, so daß sich der Hörer bei seiner Interpretation nicht an vorangegangenen Bezugssystemwahlen orientieren kann.

Wunderlich (1981) weist darauf hin, daB der - durch die Verwendung statischer oder dynamischer Verben vermittelte - statische vs. dynamische Charakter der Situation, in der lokalisiert wird, die Interpretation präpositionaler Objektrelationen beeinflußt. Äußerungen, die Bewegungsverben enthalten (zum Beispiel Die Lampe soll rechts neben das Sofa gestellt werden.), werden eher deiktisch, Äußerungen mit statischen Verben (Die Lampe soll rechts neben dem Sofa stehen.) eher intrinsisch interpretiert. Es handelt sich dabei jedoch nicht um einen deterministischen Zusammenhang, vielmehr liegen die übereinstimmenden Präferenzen im Bereich von 70 bis 80 Prozent.

Levelt (1982) weist auf individuelle Präferenzen und Stile bei der Wahl des deiktischen oder intrinsischen Bezugssystems hin. Eigene Untersuchungen zeigen jedoch, daß uneinheitliche Interpretationen sowohl zwischen Individuen als auch innerhalb desselben Individuums vorkommen (Grabowski, i. Vorb.; vgl. auch Bürkle/Nirmaier/Herrmann 1986). Zudem erscheint die Annahme individueller Stile auch nicht plausibel: Wenn jemand einen solchen Stil ausgebildet hat, dann ist anzunehmen, da $\beta$ die bevorzugte Lokalisationsstrategie sowohl die Interpretation als auch die eigene Äußerungsproduktion betrifft. Wir suchen uns unsere 
Kommunikationspartner nun aber nicht nach ihrem Stil räumlicher Referenz heraus; raumbezogene Kommunikation muß $z$ wischen beliebigen Partnern gelingen. Wären die 'Deiktiker' und die 'Intrinsiker' in der Population gleichverteilt, so läge maximale kommunikative Unsicherheit vor - nur bei durchschnittlich 50 Prozent aller deiktisch oder intrinsisch faßbaren Lokalisationsäußerungen, also mit Zufallserwartung, würde der Hörer die Sprecherintention erfolgreich nachvollziehen. Überwiegt jedoch andererseits einer der Stile in der Population, so fragt man sich, warum die Angehörigen der kleineren Gruppe ihre raumreferentielle Strategie angesichts ihrer überwiegenden kommunikativen Mißerfolge als Stil kultivieren. Generell neigen Versuchspersonen bei wiederholter ähnlicher Aufgabenstellung zur Ausbildung gleichbleibender Reaktionsmuster, die dispositionelle Verhaltensstabilität vortäuschen können.

Die genannten und weitere Ansätze tragen jeweils einen Aspekt zur Vorhersage deiktischer vs. intrinsischer Interpretationen bei; insgesamt ist die Frage der Determination der Verwendung von Richtungspräpositionen jedoch weder umfassend noch zufriedenstellend geklärt. In den nachfolgend beschriebenen Untersuchungen wird zunächst gezeigt, daß und unter welchen Bedingungen im Deutschen nicht unerhebliche Ambiguität bei der Interpretation von vor und hinter besteht, und es wird erläutert, wie weit die empirisch-experimentelle Berücksichtigung einer Reihe von Einflußfaktoren zur Klärung des Problems beitragen kann.

\section{Experimente zur Interpretation von vor und hinter}

Betrachten wir folgendes Beispiel (Abbildung 3), das auch bei Vater (1991) und bei Ruhrberg/Rutz (1990) als mehrdeutige Situation angeführt wird und das wir für die nachfolgend dargestellten Untersuchungen verwendeten (vgl. zum Folgenden auch Grabowski 1994; Grabowski/Herrmann/Weiß 1993): Ein Fahrer und ein Beifahrer befinden sich in einem Auto auf der rechten Fahrbahnseite. In sichtbarer Entfernung sind am rechten Straßenrand mehrere Parkbuchten eingelassen; in der mittleren Bucht befindet sich ein Objekt. Der Beifahrer fordert den Fahrer auf, vor oder hinter diesem Objekt zu parken; das Objekt dient somit als Relatum der Lokalisationsäußerung. 


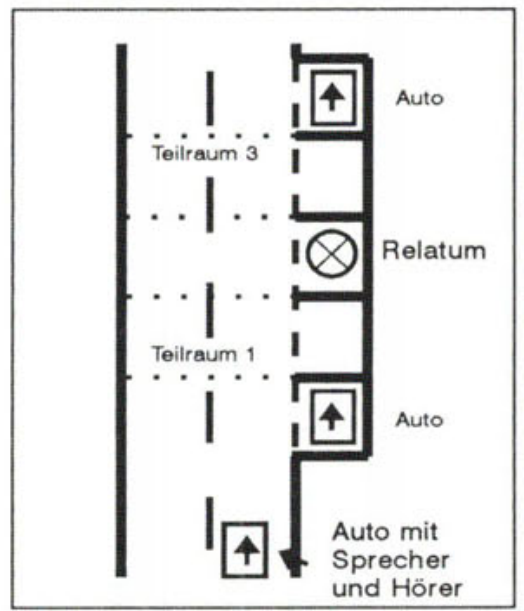

Abb. 3: Modellszenario zur Untersuchung der Verwendung von vor und hinter.

Die folgenden Erläuterungen zur Versuchsdurchführung gelten für alle berichteten Experimentalvarianten: Die Versuchspersonen standen vor einem ca. $60 \times 40 \mathrm{~cm}$ großen Modellszenario, das wie Abbildung 3 beschaffen war, wobei sich in der mittleren Parkbucht das jeweils kritische Relatum befand: im intrinsisch gerichteten Fall ein gelber VW Käfer, im ungerichteten Fall ein Baum. Nach der von der Versuchsleiterin jeweils mündlich vorgetragenen Instruktion bewegten die Teilnehmer das Modellauto in den Teilraum, der ihrer Interpretation der Lokalisationsäußerung entspricht. Die Untersuchung erfolgte im Einzeldurchgang. Die Versuchspersonen wurden bei ihrer Anwerbung mit der Frage angesprochen, ob sie einen Führerschein besäßen; deshalb nahmen sie an, daß die Untersuchung ein Verkehrsproblem behandelt. Kein Teilnehmer äußerte die Hypothese, es würden Fragen der Lokalisation behandelt. Diese lokalisationsbezogene Naivität kann jedoch nur für einen experimentellen Durchgang erhalten werden, deshalb wurde für jede Person nur ein Meßwert (gewählter Teilraum bei gegebener Instruktion) erhoben.

Wir haben das Grundmuster unseres Modellszenarios in eine private, informelle Situation eingebettet. Die Instruktion lautete: „Stell dir vor, du hast nach einer Party einem Freund angeboten, ihn nach Hause zu fahren. Du weißt aber nicht, wo er wohnt. Er sagt: Laß mich bitte vor [hinter] dem gelben Käfer [dem Baum] aussteigen. Wo würdest du mit dem Auto anhalten?" 
Nach der im vorangegangenen Abschnitt skizzierten Literaturlage läBt sich allenfalls erwarten, daB bei ungerichtetem Relatum (Baum) deiktisch (das heißt vor als Teilraum 1, hinter als Teilraum 9), bei gerichtetem Relatum (gelber Käfer) intrinsisch (das heiBt vor als Teilraum 3, hinter als Teilraum 1) interpretiert wird, wobei nur im letztgenannten Fall potentielle Mehrdeutigkeit besteht. Tabelle 1 zeigt die Ergebnisse.

\begin{tabular}{|l|c|c|}
\hline & \multicolumn{2}{|c|}{ Teilraum } \\
Baum & 1 & 3 \\
\hline "vor" & 20 & 0 \\
"hinter" & 3 & 17 \\
\hline Gesamt & 23 & 17 \\
\hline
\end{tabular}

\begin{tabular}{|l|c|c|}
\hline gelber & \multicolumn{2}{|c|}{ Teilraum } \\
Käfer & 1 & 3 \\
\hline "vor" & 24 & 15 \\
"hinter" & 23 & 17 \\
\hline Gesamt & 47 & 32 \\
\hline
\end{tabular}

Tab. 1: Teilraumwahlen als Interpretationen von vor und hinter in der Nachhauseweg-Situation bei ungerichtetem (links: Baum) und gerichtetem (rechts: gelber Kăfer) Relatum.

Bei ungerichtetem Relatum wird erwartungsgemäß überwiegend deiktisch interpretiert, während die Interpretationen im Falle des intrinsisch gerichteten Relatums völlig uneinheitlich ausfallen. Hier differenzieren die Präpositionen vor und hinter nicht zwischen den Teilräumen, es besteht Ambiguität. Anders formuliert: Der Sprecher kann mit der Wahl seiner Präposition das Hörerverhalten nicht in intendierter Weise beeinflussen. Zusammengenommen zeigt sich, daß die variable intrinsische Gerichtetheit des Relatums, wie erwartet, tatsächlich eine Determinante der Interpretation von vor und hinter darstellt.

Es finden sich in diesen und den nachfolgenden Ergebnissen immer wieder Fälle, in denen auch in Relation zu dem ungerichteten Baum nichtdeiktische Interpretationen vorgenommen werden. Hierbei dürfte es sich um extrinsische Interpretationen handeln, bei denen dem Baum durch die Gesamtgerichtetheit des Straßensettings eine in Fahrtrichtung weisende Vorderseite zugeschrieben wird.

Eine Anmerkung zur inferenzstatistischen Befundauswertung: Die Urteile über mehrdeutige vs. eindeutige Fälle, also darüber, ob die beiden Richtungspräpositionen in einer Situation $z$ wischen den beiden Teilräumen differenzieren, beruhen auf quantitativen Analysen der Reaktionshäufigkeiten mit Hilfe des Fisher-Tests. Dabei handelt es sich um 
die zweidimensionale Erweiterung des Binomial-Tests; eine signifikante, das heißt statistisch bedeutsame Differenzierung der Teilräume anhand der Präpositionen liegt anschaulich dann vor, wenn sich die überwiegende Zahl der Fälle in einer Situation in den beiden Zellen einer der beiden Diagonalen der Ergebnistabellen befindet (vgl. Siegel 1987).

Wir haben in einem nächsten Schritt die Charakteristika der Situation verändert, in der die raumbezogene Kommunikation erfolgt. Handelte es sich bei der Nachhauseweg-Situation um eine informelle, eher private Situation, so wurde die Produktion und Interpretation der Lokalisationsäußerung nun in einen formalen, institutionalisierten Kontext eingebunden: Die Versuchspersonen erhielten im Rahmen ihrer praktischen Führerscheinprüfung vom Fahrprüfer die Anweisung, vor oder hinter dem Bezugsobjekt zu parken. Die Ergebnisse zeigt Tabelle 2.

\begin{tabular}{|l|c|c|}
\hline & \multicolumn{2}{|c|}{ Teilraum } \\
Baum & 1 & 3 \\
\hline "vor" & 8 & 2 \\
"hinter" & 7 & 3 \\
\hline Gesamt & 15 & 5 \\
\hline
\end{tabular}

\begin{tabular}{|l|r|r|}
\hline gelber & \multicolumn{2}{|c|}{ Teilraum } \\
Käfer & 1 & 3 \\
\hline "vor" & 3 & 17 \\
"hinter" & 17 & 3 \\
\hline Gesamt & 20 & 20 \\
\hline
\end{tabular}

Tab. 2: Teilraumwahlen als Interpretation von vor und hinter in der Fahrprüfung-Situation bei ungerichtetem (links: Baum) und gerichtetem (rechts: gelber Käfer) Relatum.

Hier kehren sich die Eindeutigkeits- beziehungsweise Ambiguitätsverhältnisse im Vergleich zur Nachhauseweg-Situation um: Wiederum stellt sich die Gerichtetheit des Relatums als wichtige Determinante der Interpretation heraus, doch wird nun bei gerichtetem Relatum überwiegend intrinsisch interpretiert, während die Teilraumwahlen bei ungerichtetem Relatum völlig uneinheitlich ausfallen, so daß der Sprecher durch die Wahl einer der beiden Präpositionen das Hörerverhalten nicht lenken und somit nicht zwischen den Teilräumen differenzieren kann. Alle genannten Befunde wurden mehrfach repliziert und können als stabil und gesichert gelten.

Betrachtet man zusammenfassend die Situation im Deutschen (Tabelle 3 ), so ist festzustellen, daB die Interpretation von vor und hinter zumindest die Berücksichtigung der Wechselwirkung $\mathbf{z}$ wischen der sozialen 
Situation, in der sich Sprecher und Hörer befinden, und der vorhandenen oder nicht vorhandenen Gerichtetheit des Relatums erfordert.

\begin{tabular}{|l|l|l|}
\hline \multirow{2}{*}{ Situation } & \multicolumn{2}{|c|}{ Relatum } \\
\cline { 2 - 3 } Nachhauseweg & gerichtet & ungerichtet \\
\hline Fahrprüfung & $\begin{array}{c}\text { eindeutig } \\
\text { (intrinsisch) }\end{array}$ & mehrdeutig \\
\hline (deiktisch)
\end{tabular}

Tab. 3: Soziale Situation und Gerichtetheit des Relatums als Determinanten der Interpretation von vor und hinter im Deutschen.

Man kann diesen Befund - post hoc - damit erklären, daß Menschen unseres Kulturkreises in einer institutionalisierten, formalen Situation einen neutralen Bezugspunkt, eine nicht an die veränderliche Position der Interaktanten gebundene Verankerung - und damit den intrinsischen Referenzrahmen - bevorzugen und als Hörer auch erwarten, in einem informellen Kontext dagegen eher die beteiligten (in unserer Situation gleichgerichteten und an gleichem Ort positionierten) Personen - und damit das deiktische System - als Bezugspunkt präferieren. Der ungerichtete Baum in der Nachhauseweg-Situation und der gerichtete gelbe Käfer in der Fahrprüfung-Situation passen zu diesen Anforderungen; die Interpretationen fallen eindeutig aus. In der Nachhauseweg-Situation konfligiert die intrinsische Gerichtetheit des gelben Käfers jedoch mit der deiktischen Präferenz, so daß sich wahlweise deiktische oder intrinsische Interpretationen ergeben. In der Fahrprüfung-Situation konfligiert die Ungerichtetheit des Baumes mit der Präferenz nicht-personaler Verankerung der Raumrelation, die dadurch möglich wird, daß dem Baum im extrinsischen Bezugsrahmen eine 'objektive' Orientierung zugeschrieben wird. Hier kommt hinzu, daß die Interpretationen von vor und hinter nicht symmetrisch sind: vor wird öfter deiktisch, hinter öfter intrinsisch verstanden. 
Wir haben in weiteren, hier nicht berichteten Experimenten geprüft (Grabowski, i. Vorb.; Weiß 1993), daB die Uneinheitlichkeit der Interpretationen nicht lediglich daher rührt, daB es den Versuchspersonen in den vorgegebenen Situationen nicht so genau darauf ankommt, an welcher Stelle sie mit ihrem Auto anhalten.

Zwei ergänzende Befunde: Bringt man das gerichtete Relatum (den gelben Käfer) in der Nachhauseweg-Situation aus der Fahrtrichtung (es genügen schon $30^{\circ}$ ), verschwindet der Konflikt, und es ergeben sich einheitliche deiktische Interpretationen (Tabelle 4).

\begin{tabular}{|l|c|c|}
\hline & \multicolumn{2}{|c|}{ Teilraum } \\
& 1 & 3 \\
\hline "vor" & 10 & 0 \\
"hinter" & 0 & 9 \\
\hline Gesamt & 10 & 9 \\
\hline
\end{tabular}

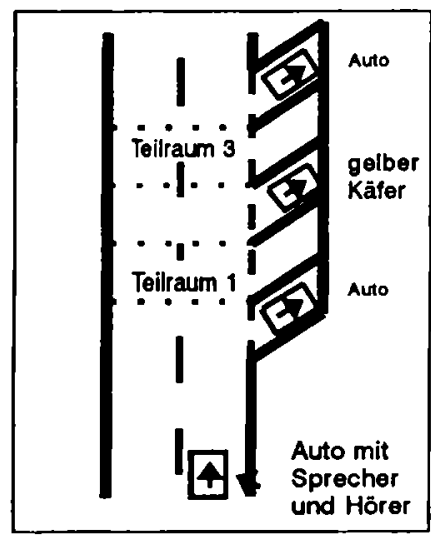

Tab. 4: Teilraumwahlen bei Aufhebung der Ko-Dimensionierung von Fahrtrichtung und intrinsischer Gerichtetheit des Relatums.

Dasselbe gilt, wenn man den deiktisch-intrinsischen Interpretationskonflikt durch die gegengerichtete Orientierung des gerichteten Relatums aufhebt, weil dann beide Interpretationssysteme übereinstimmen (Tabelle 5). 


\begin{tabular}{|l|c|r|}
\hline & \multicolumn{2}{|c|}{ Teilraum } \\
& 1 & 3 \\
\hline "vor" & 8 & 2 \\
"hinter" & 0 & 10 \\
\hline Gesamt & 8 & 12 \\
\hline
\end{tabular}

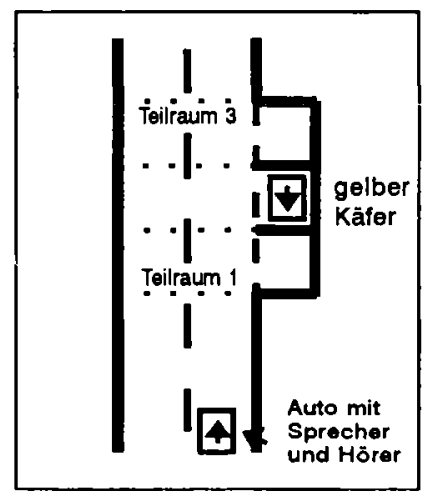

Tab. 5: Teilraumwahlen bei Gegenrichtung des Relatums (intrinsische und deiktische Interpretationen stimmen überein).

\section{Das Präpositioneninventar als Interpretationsdetermi- nante}

Die Berücksichtigung der Determinanten „soziale Situation” und „Gerichtetheit des Relatums" erlauben die Vorhersage der Interpretation von vor und hinter nur in bestimmten Wechselwirkungsbedingungen. Lassen sich weiterführende Bedingungsfaktoren angeben? Dazu betrachten wir das Verhältnis zwischen räumlicher Referenz und temporaler Referenz. Es gibt vielfältige Hinweise und detaillierte linguistische Analysen zu deren Verknüpfung (zum Beispiel Ehrich 1989; Wunderlich 1985). Da die verwendete Experimentalsituation in ihrer Dynamik festgelegt ist, kann die räumliche Ordnung auch durch zeitliche Metaphern ausgedrückt werden. Der dem Sprecher und Hörer nächstgelegene Teilraum 1 ist zugleich der Teilraum, der als erstes erreicht wird und der damit vor dem anderen erreicht wird; entsprechend 'kommt' Teilraum 3 nach Teilraum 1. Im Deutschen sind nun die präpositionalen Wortformen für die unmarkierten Pole der räumlichen wie der zeitlichen sekundären Deixis identisch, sie lauten beide vor. Für die markierten Pole ist dies mit hinter und nach ersichtlich nicht der Fall. Es ist deshalb zu fragen, ob ein Teil der beobachteten Ambiguität vielleicht gar nicht den Konflikt zwischen deiktischem und intrinsischem Lokalisationssystem widerspiegelt, sondern aus temporalen Interpretationen der Sprecheräußerung resultiert, zumindest soweit es die Verwendung von vor betrifft.

Wie kann man diese Hypothese prüfen? Sprachen unterscheiden sich danach, wieviele unterschiedliche Ausdrücke (Wortformen im nicht- 
flexionsmorphologischen Sinne) sie für die Präpositionen der 1. Horizontalen der sekundären Raumdeixis und der temporalen Deixis zur Verfügung stellen. Genauer gesagt unterscheiden sie sich dahingehend, ob es Präpositionen der sekundären Raumdeixis gibt, die nicht wortformidentisch mit zeitlichen Präpositionen sind. Es geht nicht darum, das Bedeutungs- oder Verwendungspotential dieser Präpositionen erschöpfend zu beschreiben. Auch ist nicht tangiert, daß temporale Metaphern in aller Regel für den Ausdruck räumlicher Gegebenheiten herangezogen werden können. Das einzige hier interessierende Charakteristikum betrifft die Frage, ob es in einer Sprache Richtungspräpositionen gibt, die nicht zugleich als temporale Präpositionen verstanden werden können.

Man kann diese sprachtypologische Hypothese prüfen, indem man die Verwendung der Richtungspräpositionen in Sprachen untersucht, deren Präpositionensystem sich von dem des Deutschen unterscheidet. Maximal kann eine Sprache im hier interessierenden Zusammenhang vier unterschiedliche Wortformen bereitstellen; dies ist beispielsweise im Französischen (devant/derrière, avant/après), im Italienischen (davanti/dietro, prima/dopo) und im Englischen (in front of/behind, before/after) der Fall. Wir nennen diese Sprachen Vier-PräpositionenSprachen. Das Deutsche ist mit den Wortformen vor, hinter und nach eine Drei-Präpositionen-Sprache wie auch das Niederländische (voor, achter, na). Zu den Zwei-Präpositionen-Sprachen gehört Latein, in dem mit ante und post die polaren Ausprägungen des räumlichen wie des zeitlichen Systems bezeichnet werden. Uns ist keine Ein-PräpositionenSprache bekannt, in der mit nur einem Ausdruck weder zwischen dem räumlichen und zeitlichen System noch zwischen den Polen dieser Dimensionen unterschieden würde.

Um zu zeigen, daß es sich um einen typologische Einflußfaktor und nicht lediglich um ein einzelsprachliches Phänomen handelt, müssen je Sprachtyp mehr als eine Sprache berücksichtigt werden. Wir haben die in Abschnitt 4 referierten experimentellen Untersuchungen im Deutschen deshalb in den Sprachen Niederländisch, Französisch, Italienisch und Englisch durchgeführt und damit Drei-Präpositionen-Sprachen und Vier-Präpositionen-Sprachen einander gegenübergestellt (Tabelle 6). Die Instruktionen an die Versuchspersonen wurden in die jeweilige Sprache übersetzt; statt vor und hinter wurden die jeweiligen Präpositionen der sekundären Raumdeixis verwendet, die in Tabelle 6 in den beiden linken Zellen jedes Vierfelderschemas aufgeführt sind. Versuchsleiter waren 
Muttersprachler der jeweiligen Sprache; die Untersuchungen wurden an Universitäten des jeweiligen Auslands durchgeführt (s. unten Abschnitt 7).

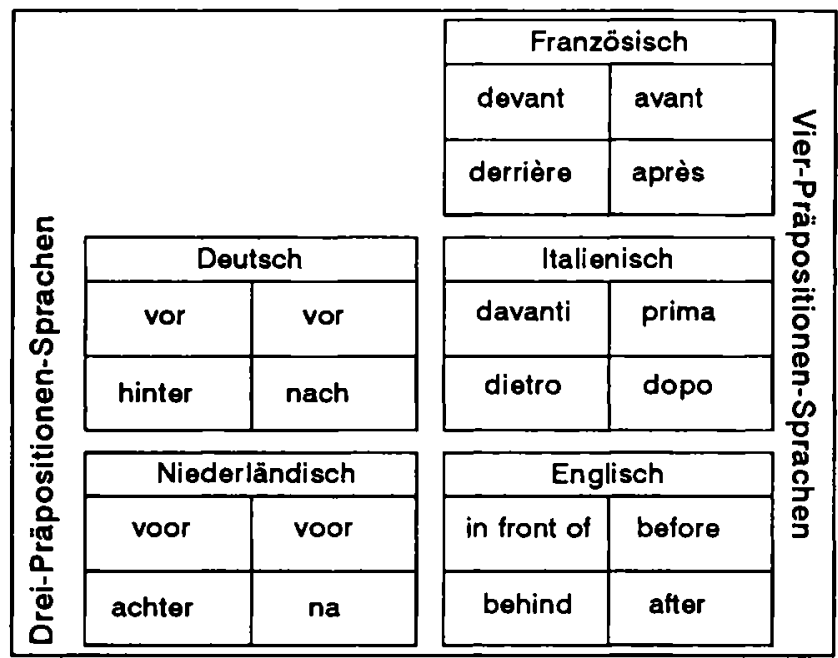

Tab. 6: Das Präpositioneninventar der sekundãren Raumdeixis (1. Horizontale: linke Spalte der Vierfelderschemata) und der sekundären temporalen Deixis (rechte Spalte der Vierfelderschemata) der fünf untersuchten Sprachen.

Wir berichten die erhaltenen Ergebnisse nicht im einzelnen, sondern fassen sie hinsichtlich der sich ergebenden Eindeutigkeiten und Mehrdeutigkeiten zusammen (Tabelle 7). 


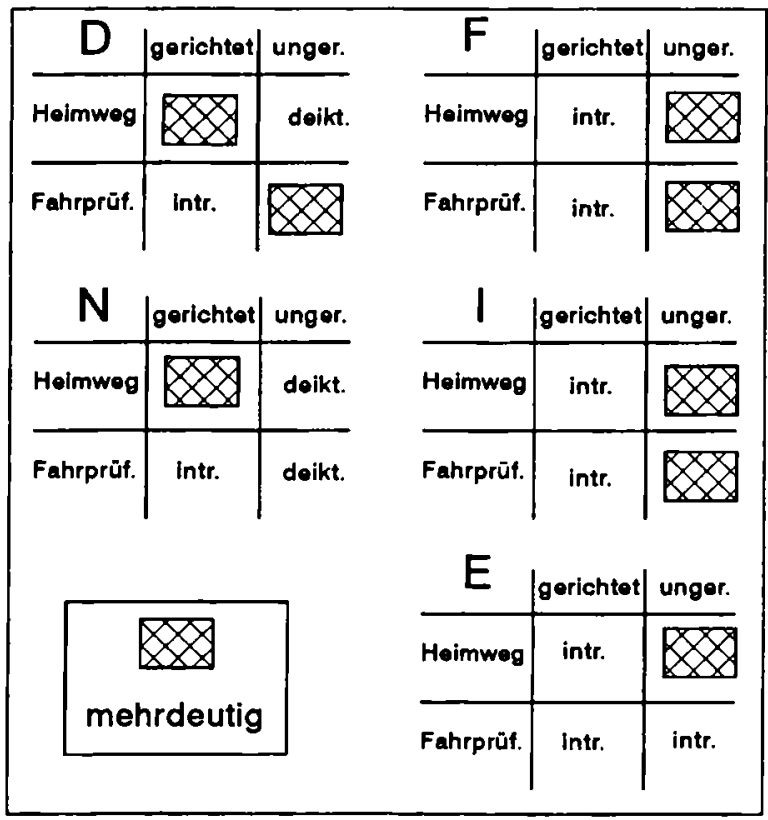

Tab. 7: Die Interpretation von Richtungspräpositionen der 1. Horizontalen in Abhāngigkeit von der sozialen Kommunikationssituation, der Gerichtetheit des Relatums und dem Sprachtyp. Die mehrdeutigen Bedingungsfalle sind durch Schraffur angegeben; intr. bedeutet einheitliche intrinsische Interprelation, deikt. bedeutet einheitliche deiktische Interpretation. D = Deutsch, N $=$ Niederländisch, $\mathrm{F}=$ Französisch, $\mathrm{I}=$ Italienisch, $\mathrm{E}=$ Englisch.

Es zeigt sich, daß sich die Interpretationen der Richtungspräpositionen einerseits im Deutschen und Niederländischen und andererseits im Französischen, Italienischen und Englischen untereinander sehr ähnlich verhalten. In den Drei-Präpositionen-Sprachen liegt jeweils eine Wechselwirkung $z$ wischen der sozialen Situation und den Richtungseigenschaften des Relatums vor. In den Vier-Präpositionen-Sprachen ist hingegen die Gerichtetheit des Relatums der entscheidende Faktor; im Bezug zu einem ungerichteten Relatum werden die Präpositionen der 1. Horizontalen, zumindest in der hier untersuchten dynamischen Situation, generell uneinheitlich interpretiert. In diesen Sprachen ist die Struktur des Präpositioneninventars sozusagen auf die Verwendung im Zusammenhang mit intrinsisch gerichteten Relata angelegt. 
Gleichwohl lassen sich die beobachteten Mehrdeutigkeiten nicht darauf zurückführen, daB die Versuchsteilnehmer Äußerungen interpretieren mußten, die sie selber in den gegebenen Situationen nicht verwenden würden. Wir haben im Deutschen und im Englischen identische Experimente aus der Sprachproduktionsperspektive durchgeführt, in denen der intendierte Teilraum vorgegeben wurde und die Teilnehmer in der Rolle des Beifahrers die Aufforderung an den Hörer/Fahrer, an Hand derer er den intendierten Teilraum identifizieren sollte, selber produzierten (Grabowski 1994; Grabowski/Miller 1995). Hier zeigte sich, daB unter allen Bedingungen über 50 Prozent der Versuchspersonen ÄuBerungen genau der Art produzierten, die den von uns gewählten Instruktionen in den Experimenten zur Interpretation entspricht, nämlich einfache Präpositionalphrasen mit vor oder hinter und der Bezeichnung für das jeweilige Relatum als Nominalphrase. Sprecher verwenden demnach bei der Lokalisation genau die Äußerungen, die sie als Hörer nicht eindeutig interpretieren können; sie sind sich der möglichen Mehrdeutigkeit und der alternativen räumlichen Bezugssysteme - die sie perfekt zu beherrschen und anzuwenden wissen - nicht bewußt. Selbst angesichts der alltäglichen kommunikativen Unschärfen sind sie von der Eindeutigkeit ihrer Sprachverwendung überzeugt (vgl. auch Buhl 1995). Dagegen kommen Teilnehmer unserer Untersuchungen manchmal noch nach Monaten zu uns und berichten, sie hätten nun ihre raumreferentielle Unschuld verloren und seien sich, wann immer sich etwas vor etwas anderem befindet, der Tatsache bewußt, daß es sich zugleich auch dahinter befindet. So gesehen waren unsere Experimente - unbeabsichtigt - auch ein Beitrag zur Sprachaufklärung.

\section{Resümee}

Die folgenden drei Schlußfolgerungen erscheinen uns wesentlich:

1. Die Präferenz des intrinsischen Systems bei gerichteten Relata wird in der anglo-amerikanischen Forschung oft behauptet. Sie scheint für den Sprachtyp, dem das Englische angehört, auch zuzutreffen. Es handelt sich jedoch nicht um ein generelles Prinzip. Für das Deutsche sind diese theoretischen Vorstellungen nur begrenzt tauglich, weil der Einfluß des in einer Sprache zur Verfügung stehenden Präpositioneninventars auf die Interpretation von Richtungspräpositionen übersehen wurde.

2. $\mathrm{Zu}$ der in der Literatur bereits diskutierten Gerichtetheit des Relatums kommen, zumindest für die hier untersuchte Situationscharakteristik, als weitere Determinanten der Verwendung von Richtungspräpositionen die Art der sozialen Situation, in der eine Lo- 
kalisationsäußerung steht, und das Präpositioneninventar, das die jeweilige Einzelsprache zur Verfügung stellt, hinzu.

3. In allen untersuchten Sprachen treten an systematischen Stellen Mehrdeutigkeiten auf. Es ist also keine der Sprachen insgesamt besser für eine eindeutige präpositionale Referenz auf räumliche Relationen geeignet. Je nach Präpositioneninventar gelingt die Kommunikation jedoch in unterschiedlichen Fällen unterschiedlich gut.

\section{Danksagung}

Die Experimente im Ausland wurden durch die Gastfreundschaft und kollegiale Unterstützung von Wolfgang Klein und Ursula Brinkmann (Nijmegen), Michel Fayol und Béatrice Bourdin (Dijon), Bianca de Bernardi (Verona) sowie George Miller und Christiane Fellbaum (Princeton) ermöglicht; Irene ter Haar, Alexa Heintze, Emanuela Antolini und Shari Landes haben als jeweilige Native Speakers geduldig und zuverlässig Versuchspersonen instruiert. Die Untersuchungen im Englischen wurden durch ein Forschungsstipendium der Deutschen Forschungsmeinschaft an den Erstautor unterstützt. Gisela Zifonun verdanken wir Vorschläge für die Verbesserung einer früheren Fassung dieses Textes.

\section{Literaturverzeichnis}

Abkarian, G.G. (1982): Comprehension of deictic locatives: the object „behind" it. In: Journal of Psycholinguistic Research 11, S. 229-245.

Bürkle, B./Nirmaier, H./Herrmann, Th. (1986): „Von dir aus ...” Zur hörerbezogenen lokalen Referenz. Mannheim: Universität, Lehrstuhl Psychologie III. (Arbeiten der Forschergruppe „Sprechen und Sprachverstehen im sozialen Kontext" Heidelberg/Mannheim, Bericht Nr. 10).

Buhl, H.M. (1995): Zur Blickpunktbezogenheit sprachlicher Lokalisationen: Der Genese-Effekt. Unveröffentl. Dissertation, Universität Mannheim.

Carlson-Radvansky, L.A./Irwin, D.E. (1993): Frames of reference in vision and language: Where is above? In: Cognition 46, S. 223-244.

Clark, H.H. (1973): Space, time, semantics, and the child. In: Moore, T.E. (ed.): Cognitive development and the acquisition of language. New York. S. 27-63.

Ehrich, V. (1985): Zur Linguistik und Psycholinguistik der sekundären Raumdeixis. In: Schweizer, H. $(\mathrm{Hg}$.): Sprache und Raum. Psychologische und linguistische Aspekte der Aneignung und Verarbeitung von Räumlichkeit. Stuttgart. S. 130-161.

Ehrich, V. (1989): Die temporale Festlegung lokaler Referenz. In: Habel, Ch./Herweg, M./Rehkämper, K. (Hg.): Raumkonzepte in Verstehensprozessen: Interdisziplinäre Beiträge zu Sprache und Raum. Tübingen. S. 1-16. 
Friederici, A.D. (1989): Raumreferenz unter extremen perzeptuellen Bedingungen: Perzeption, Repräsentation und sprachliche Abbildung. In: Habel, Ch./Herweg, M./Rehkämper, K. (Hg.): Raumkonzepte in Verstehensprozessen: Interdisziplināre Beiträge zu Sprache und Raum. Tübingen. S. 17-36.

Gosztonyi, A. (1976): Der Raum. Geschichte seiner Probleme in Philosophie und Wissenschaften. Freiburg.

Grabowski, J. (1994): Kommunikative Unschärfen - Zur Rezeption und Produktion von Richtungspräpositionen am Beispiel von "vor” und „hinter”. In: Kornadt, H.-J./Grabowski, J./Mangold-Allwinn, R. (Hg.): Sprache und Kognition: Perspektiven moderner Sprachpsychologie. Heidelberg. S. 183208.

Grabowski, J. (in Vorb.): Die Raumauffassung des Menschen und ihr Ausdruck in der Sprache: Determinanten der Verwendung dimensionaler Präpositionen. Habilitationsschrift, Universitāt Mannheim.

Grabowski, J./Herrmann, Th./WeiB, P. (1993): Wenn „vor” gleich „hinter” ist - zur multiplen Determination des Verstehens von Richtungspräpositionen. In: Kognitionswissenschaft 3, S. 171-183.

Grabowski, J./Miller, G.A. (1995): Factors affecting production and comprehension of spatial prepositions: a comparison of German and American English. Mannheim. (Arbeiten der Forschungsgruppe „Sprache und Kognition". Bericht Nr. 56).

Habel, Ch. (1989): „zwischen”-Bericht. In: Habel, Ch./Herweg, M./Rehkämper, K. (Hg.): Raumkonzepte in Verstehensprozessen: Interdisziplinäre Beiträge zu Sprache und Raum. Tübingen. S. 37-69.

Herrmann, Th. (1990): Vor, hinter, rechts und links: das 6H-Modell. Psychologische Studien zum sprachlichen Lokalisieren. In: Zeitschrift für Literaturwissenschaft und Linguistik 78, S. 117-140.

Herrmann, Th./Grabowski, J. (1994): Sprechen: Psychologie der Sprachproduktion. Heidelberg.

Herskovits, A. (1986): Language and spatial cognition. An interdisciplinary study of the prepositions in English. Cambridge.

Hill, C.A. (1982): Up/down, front/back, left/right. A contrastive study of Hausa and English. In: Weissenborn, J./Klein, W. (eds.): Here and there. Cross-linguistic studies on deixis and demonstration. Amsterdam. S. 1342.

Jackendoff, R.S. (1983): Semantics and Cognition. Cambridge.

Jackendoff, R.S./Landau, B. (1991): Spatial language and spatial cognition. In: Napoli, D.J./Kegl, J.A. (eds.): Bridges between psychology and linguistics: A Swarthmore Festschrift for Lila Gleitman. Hillsdale. S. 145-169.

Klein, W. (1994): Keine Känguruhs zur Linken - Über die Variabilitāt von Raumvorstellungen und ihren Ausdruck in der Sprache. In: Kornadt, H.J./Grabowski, J./Mangold-Allwinn, R. (Hg.): Sprache und Kognition: Perspektiven moderner Sprachpsychologie. Heidelberg. S. 163-182.

Landau, B./Jackendoff, R.S. (1993): „What” and „where” in spatial language and spatial cognition. In: Behavioral and Brain Sciences 16, S. 217-265. 
Levelt, W.J.M. (1982): Cognitive styles in the use of spatial direction terms. In Jarvella, R.J./Klein, W. (eds.): Speech, place, and action. Studies in deixis and related topics. Chichester. S. 251-268.

Levelt, W.J.M. (1984): Some perceptual limitations on talking about space. In: van Doorn, A.J./van de Grind, W.A./Koenderink, J.J. (eds.): Limits in perception. Essays in honour of Maarten A. Bouman. Utrecht. S. 323-358.

Levelt, W.J.M. (1986): Zur sprachlichen Abbildung des Raumes: Deiktische und intrinsische Perspektive. In: Bosshardt, H.-G. (Hg.): Perspektiven auf Sprache. Interdisziplinäre Beiträge zum Gedenken an Hans Hörmann. Berlin. S. 187-211.

Linde, C./Labov, W. (1975): Spatial networks as a site for the study of language and thought. In: Language 51, S. 924-939.

Miller, G.A./Johnson-Laird, Ph. N. (1976): Language and Perception. Cambridge.

Retz-Schmidt, G. (1988): Various views on spatial prepositions. In: Al Magazine 9, S. 95-105.

Ruhrberg, P./Rutz, H. (1990): Rāumliches Wissen und Semantik im Kontext der Generierung von Wegbeschreibungen. In: Freksa, C./Habel, Ch. (Hg.): Repräsentation und Verarbeitung räumlichen Wissens. Berlin. S. 235-249.

Siegel, S. (1987): Nichtparametrische statistische Methoden. 3. Aufl. Eschborn.

Stutterheim, Ch. von/Carroll, M. (1993): Raumkonzepte in Produktionsprozessen. In: Kognitionswissenschaft 3, S. 70-82.

Vater, H. (1991): Einfūhrung in die Raum-Linguistik 2. Aufl. Hürth-Efferen. (KLAGE Kölner Linguistische Arbeiten - Germanistik; 24).

Weiß, P. (1993): Psychologische und sprachtypologische Determinanten der Rezeption und Interpretation von "vor" und "hinter". Unveröffentl. Diplomarbeit. Mannheim: Universität, Lehrstuhl Psychologie III.

Wunderlich, D. (1981): Linguistic strategies. In: Coulmas, F. (ed.): A Festschrift for native speaker. The Hague. S. 279-296.

Wunderlich, D. (1982): Sprache und Raum. Studium Linguistik, Heft 12/13, S. 1-19 und S. 37-59.

Wunderlich, D. (1985): Raum, Zeit und das Lexikon. In: Schweizer, H. (Hg.): Sprache und Raum. Psychologische und linguistische Aspekte der Aneignung und Verarbeitung von Räumlichkeit. Stuttgart. S. 66-89.

Wunderlich, D./Herweg, M. (1991): Lokale und Direktionale. In: von Stechow, A./Wunderlich, D. (Hg.): Semantik. Ein internationales Handbuch der zeitgenössischen Forschung. Berlin. S. 758-785. 


\title{
EWALD LANG
}

\section{Lexikalisierung und Wortfeldstruktur - typologisch betrachtet}

\author{
Räumliche Dimensionsausdrücke als Fallstudie*
}

\begin{abstract}
Der Zusammenhang von Lexikalisierung und Wortfeldstruktur ergibt sich aus den Bedingungen, wie bestimmte semantische Komponenten in Wörtern codiert sind und wie sich diese als varïerende Belegungen einer "general formal structure” zu einem Wortfeld gruppieren. Kap. 2 führt in die für das Fallbeispiel nötigen semantischen und konzeptuellen Grundlagen der räumlichen Dimensionsauszeichnung (DA) ein, liefert die Begründung des einschlägigen Inventars an Komponenten (Parametern) und erläutert deren Verträglichkeit untereinander. Kap. 3 diskutiert einige die Wortfeldstruktur beschrānkende semantische und lexikalische Universalien für Dimensionsausdrücke. Kap. 4.1 erlăutert die innerhalb dieses Spielraums möglichen Partitionierungen des Wortfelds nach Proportions- vs. Betrachterbasiertheit der DA, Kap. 4.2 belegt die sich daraus ergebenden Grundtypen, Kap. 4.3 bringt eine skalierte Feineinteilung der dem Mischtyp zugehörigen Sprachen, beide werden gestūtzt durch jeweils prädizierbare Mehrdeutigkeiten, Lücken und Inferenzen. Kap. 5 illustriert die typ-verschiedenen Wortfeldstrukturen bezüglich lexikalischer Abdeckung und formuliert einen Ausblick.
\end{abstract}

\section{Einführung}

\section{$1.0 \quad$ Fragestellung}

Die neuere typologische Forschung hat - und das zeigt auch der vorliegende Band - grammatische Strukturbildung vornehmlich anhand ausgewählter und gut isolierbarer Vergleichsinstanzen und domänenspezifischer Parameterbelegungen untersucht: Inventare von Grundeinheiten, Typen von Grundwortstellung, lokale Konfigurationsbildung, morphologische Kategorienmarkierung etc. Typologie wird aber besonders in-

* Ich danke Paul Kay (Berkeley) für nützliche Hinweise zur Anlage der Tests und zur methodischen Absicherung der Befunde. Für die Beschaffung oder Überprüfung von fremdsprachigen Daten habe ich vielen zu danken: ByongRae Ryu [Koreanisch], Horst D. Gasde, Chen Xuan [Chinesisch], Joanna Blaszczak, Walter Duda [Polnisch], Svetlana Poljakova, Vladimir Klimonov [Russisch], Marcela Adamiková [Slovakisch]. Anregende Ideen verdanke ich der Lektüre von Zubin/Choi (1984) und Zubin/Svorou (1984). 
teressant, wenn sie sich die Systematisierung von Variationsbereichen des sprachlichen Ausdrucks vornimmt, die durch das Zusammenwirken mehrerer Domänen grammatischerer Strukturbildung determiniert sind. Den zweifellos komplexesten Bereich dieser Art stellt das Lexikon einer Sprache dar, dessen interne Architektur nicht nur durch die Bündelung phonologischer, morphologischer, syntaktischer und semantischer Information in Form von lexikalischen Einträgen, sondern auch durch die systematische Vernetzung dieser Einträge nach ihrer Zugehörigkeit zu entsprechenden Wortschatzgruppen, darunter auch die traditionell „Wortfeld" genannten, bestimmt ist.

Der mit diesem Beitrag thematisierte Zusammenhang von Lexikalisierung ( ${ }_{n}$ Welche semantische Information wird wie in einem Wort verpackt ?") und Wortfeldstruktur ("Wie ordnen sich die lexikalischen Packungen zu einem Feld?") und seiner eventuell typologisch variierenden Ausprägung betrifft genau diese beiden Aspekte der Lexikonarchitektur. Freilich liegt die Frage nach dem Zusammenhang als solche nicht auf der Hand, vielmehr entwickelt sich ihre Formulierung - etwa bezogen auf unsere Fallstudie zu den Dimensionsausdrücken - erst anhand von Teilfragen, die sich im Anschluß an empirische Beobachtungen etwa folgender Art stellen:

(1) Im Dt. und Engl. können sich dick - dünn bzw. thick - thin auf die dritte Achse oder den Durchmesser fester Objekte, die Stärke von Belägen, die Konsistenz von Flüssigkeiten, die Dichte von Substanzen u.a.m. beziehen. Im Chin. und Russ. sind die Entsprechungen hingegen lexikalisch feiner differenziert (Transkription vereinfacht):

(a) hòu - bó (dritte Achse), cu - $x \grave{i}$ (Durchmesser), mi-xi (Dichte), nóng - xi (Konsistenz) u.a.

(b) tolstyj - tonkij (dritte Achse), tuchnyj - xudoshchavyj (Durchmesser), gustoj - redkij (Dichte), plotnyj - zhidkij (Konsistenz) u.a.

Frage: Ist diese Verteilung in der Lexikalisierung zufällig oder ableitbar aus einer allgemeiner zu fassenden Charakteristik der Struktur von Wortfeldern?

(2) Im Dt. kann tief in bestimmten Kontexten antonymisch zu hoch verwendet werden und ist dann synonym zu niedrig, in anderen Sprachen jedoch ist in diesen Kontexten nur das entsprechende lexikalische Antonym zum Ausdruck für Höhe zulässig: 
(a) Das Flugzeug fliegt höher // niedriger / tiefer als der Ballon

(b) L'avion vole plus haut // plus bas / "plus profond que le ballon

(c) The plane flies higher // lower / *deeper than the balloon

(d) Nèi jià feiji fei de bì nèi ge qiquí yào gāo // di / *shēn

Frage: LäBt sich dieses offenbare Spezifikum des Deutschen in einer Theorie der Antonymbildung unterbringen und läßt sich eine solche wiederum mit der Explikation der Struktur von Wortfeldern verbinden?

Verglichen mit der reichen Literatur über typisierbare Unterschiede in den Sprachen hinsichtlich ihrer Phonologie, Morphologie und Syntax steht die Typologie der Lexikalisierung und der damit verbundenen Strukturierung lexikalischer Felder noch ziemlich in den Anfängen - vgl. Lehrer (1992) und König (in diesem Band). Die Gründe dafür mögen u.a. darin zu suchen sein, daB wir es bei einem solchen Vergleich mit komplexen Befunden zu tun haben, deren Vergleichsbasis wenigstens drei Domänen sprachlicher Strukturbildung und die damit verbundenen analytischen Grundannahmen involviert. Ich werde die drei ineinandergreifenden Strukturierungsaspekte kurz skizzieren und mit Beispielen illustrieren.

\subsection{Semantische Dekomposition}

Der erste Aspekt besteht in der Bedeutungsstruktur von Wörtern und beruht auf der Akzeptierung der Annahme, daß Wörter - zumindest in den sog. lexikalischen Hauptkategorien - keine semantisch unanalysierbaren Ganzheiten darstellen, sondern eine interne Bedeutungsstruktur aufweisen, die je nach theoretischem Rahmen als Liste von Merkmalen, als Konfiguration aus Komponenten oder als Bündel von Bedeutungspostulaten repräsentierbar ist. Ohne weitere Diskussion über die (theoretisch durchaus triftigen) Unterschiede zwischen diesen Repräsentationsalternativen lege ich hier die Auffassung zugrunde, daß die Bedeutung einer lexikalischen Einheit $\mathrm{dek}$ ompon i r b a r ist in formal kategorisierte und substantiell motivierte $B$ a u s e ine (forthin notiert als KOMPONENTEN), die letztlich als Elemente eines begrenzten Inventars universeller semantischer Primes zu legitimiern sind. Die Details hierzu werden im Abschnitt 2.2 ausgebreitet. 


\section{$1.2 \quad$ Lexikalisierung}

Die zweite Aspekt betrifft den Variationsbereich, innerhalb dessen die oben genannten KOMPONENTEN einzeln oder in typisierbaren Konfigurationen lexika lis ch abgedeck t oder - präziser $\mathrm{l}$ e $\mathrm{xi} \mathrm{k}$ a l i s i e r t werden. Hier etabliert Lehrer (1992, S. 249) eine neue Forschungsrichtung - „By lexical typology I refer to the characteristic ways in which language lexicalizes concepts; that is, packages material into words." - und verweist auf den typisierbaren Unterschied, ob in Ausdrücken für physische Krafteinwirkung das benutzte INSTRUMENT (Körperteil) le $\mathrm{xik}$ a lis $\mathbf{c h}$ in $\mathbf{k}$ orporier t wird (wie in den engl. Verben und Nomina kick, punch, slap) oder s y $\mathrm{n}$ $\mathrm{tag} \mathrm{m}$ a $\mathrm{t}$ i s $\mathrm{ch}$ explizie $\mathrm{t}$ wird (wie in den frz. Verbalkonstruktionen bzw. Nomina (donner un) coup de pied, coup de poing, coup de main (à qn).

Weitere einschlägige Beispiele stammen aus der kontrastiven Linguistik, etwa für Differenzen im Wortfeld der Verben des An- und Ablegens von Kleidungsstücken oder des Anbringens bzw. Entfernens von Teilen eines Ganzen (bei Artefakten). So ist das Engl. hier ziemlich sparsam und abstrakt, jedenfalls u $\mathrm{n} \mathrm{spe} \mathrm{zif} \mathrm{i} \mathrm{s} \mathrm{ch}$ - vgl. die Auswahl in (3) nach König (in diesem Band) bzw. in (4) nach Macheiner (1995, S. 335), während die entsprechenden Verben im Dt. $n$ a ch semantischen Komponenten wie GESTALT, POSITION und (Art von) KONTAKT des Kleidungsstücks am Körper bzw. des Teils am Ganzen $s$ p e $z$ if i z i e r t l e x i k a li$s$ i e $r$ sind und so das betreffende Wortfeld anreichern und strukturieren:

(3) to put on/off

one's glasses/hat - die Brille/den Hut aufsetzen/abnehmen, absetzen

one's jacket/skirt - die Jacke/den Rock anziehen/ausziehen, ablegen

a belt/a tie - einen Gürtel/Schlips umbinden/umlegen, ablegen

a ring/a medal - einen Ring/einen Orden anstecken/abstreifen, ablegen

(4) to remove

the spark plugs - die Zündkerzen herausdrehen

the plug leads - die Zündkabel abziehen

the filler cap - die Verschlußklappe aufdrehen 
the bolts - die Schrauben lösen

the lid

- den Deckel abnehmen

etc.

Nun sind dies vorerst nur nützliche Auswahldaten, aber die oben erwähnten Verfahren der lexikalischen Abdeckung von semantischen KOMPONENTEN (lexikalisch inkorporiert, komponentenweise differenziert, syntagmatisch expliziert etc.) geben zumindest die Richtung an, in der nach Typisierungsmöglichkeiten zu suchen ist. Wortfelder, deren Umfang und Struktur hier als intuitiv unproblematisch vorausgesetzt werden, sind unter dem Blickwinkel der "Lexical typology” mehr der Lieferant für Lexikalisierungsaspekte, ihre Struktur an sich ist jedoch nicht primärer Gegenstand der Analyse. Dies bringt den dritten Strukturierungsaspekt ins Spiel.

\subsection{Wortfelder}

Unzweifelhaft läßt sich der Wortschatz einer Sprache in Gruppen gliedern, wobei die unter "Wortfeld", „lexical field" oder "semantic field" bekannten Gruppierungsbefunde empirisch ebenso evident sind wie theoretisch klärungsbedürftig (vgl. Lutzeier (Hg.) 1993, sowie Lutzeier 1995 und die dort angegebene Literatur), vor allem hinsichtlich der Frage, ob und wie die ebenfalls gruppenbildenden Sinnrelationen, d.h. Inkompatibilität, (Ko-) Hyponymie, Antonymie u.a., für die Struktur eines Wortfeldes konstitutiv sind und wie sie darin theoretisch zu rekonstruieren sind.

Auf dem Hintergrund der Annahmen über Dekomposition und Lexikalisierung liegt es nahe, den Zusammenhang $\mathbf{z}$ wischen der Struktur eines Wortfeldes und der Bedeutungsstruktur einzelner Wörter - in Analogie zur Morphologie - als den zwischen einem Paradigma und seinen einzelnen Belegungsinstanzen (für die durch KOMPONENTEN definierten Slots) zu sehen. Die Probleme dabei bestehen in der Spezifikation der formalen Struktur des „Paradigmas”. Adrienne Lehrer hat es schon (1974, S. 66) und bis heute gültig so formuliert:

"Lexical items belong to the same semantic field, provided the same general formal structure of the readings remains, although the number or content of the markers may differ or the selection restrictions may differ. <...> However, whether a sufficiently clear analysis of „some general formal structure" can be given, remains to be seen, especially in the case of lexical items with relatively simple formal structure." 
Bisher haben sich lediglich (a) g le i che $\mathrm{s}$ y $\mathrm{ntak} \mathrm{tis} \mathrm{che} \mathrm{Ka}$ ate gorie und (b) gemeinsamer fundierender Asp e $k$ t als haltbare Kriterien für die Zugehörigkeit lexikalischer Einheiten zu einem Wortfeld erwiesen.

Die hier durch 1.1 - 1.3 eingenommene Perspektive - von den KOMPONENTEN über ihre auswahlweise Lexikalisierung in Wörtern zu deren Anordnung in Wortfeldern - ist bisher heuristisch und methodisch eher in umgekehrter Blickrichtung wirksam geworden: die Betrachtung von Wortfeldern und Lexikalisierungsdifferenzen war meist der Ausgangspunkt, um semantische Distinktionen zu ermitteln, daraus Komponenten (oder Merkmale) zu extrahieren und dann erstere durch letztere deskriptiv dingfest zu machen. Die folgende Fallstudie - ein erster Zwischenbericht aus dem größer angelegten Projekt „Basic Dimension Terms" (vgl. Lang 1995b) - will den Konnex der drei genannten Strukturbildungsaspekte anhand eines exemplarisch geeigneten Wortfeldes illustrieren und zugleich zeigen, wie sich dabei universelle Strukturannahmen und typologische Exploartion wechselseitig befördern.

Was macht die räumlichen Dimensionsausdrücke zu einem exemplarischen Wortfeld? Ihr gemeinsamer Fundierungsaspekt, die Auszeichnung räumlicher Dimensionen, ist durch den semantisch codierten Rekurs auf die perzeptiven Grundlagen der Raumorientierung bestimmt - dies macht ihre Analyse ergiebig für die Ermittlung formal kategorisierter und substantiell motivierter Bausteine eines universellen Inventars - (vgl. 1.1); sie bilden daher einen Ausschnitt aus dem Grundwortschatz jeder Sprache und sind vorrangige Kandidaten für lexikalische Primäreinheiten - nämlich nach Lehrer $(1974$, S. 66) „lexical items with relatively simple formal structure" (vgl. 1.2); ihr grammatisches Verhalten ist in hohem Ausmaße gleichartig, so daß ihre "general formal structure” als konstitutives Element eines Wortfelds präzise erfaBbar ist und damit zugleich den Variationsspielraum ihrer Verteilung im Wortfeld vorzeichnet.

\section{Grundlagen der Dimensionsauszeichnung (DA)}

\subsection{Der Ansatz im Überblick}

In einer Reihe neuerer Studien (Bierwisch/Lang (eds.) 1989; Lang 1990 a,b; Lang 1995 b; Lang/Carstensen/Simmons 1991) wurde gezeigt, daß die Grammatik der Dimensionsauszeichnung (DA), d.h. die Bedingungen, nach denen natürliche Sprachen räumliche Dimensionen auswählen und lexikalisch encodieren, zumindest die B e s t a nd t e il e (I) - (IV) in ihrem mehrere Ebenen umgreifenden Fundierungszus am m enhang gemäß (V) umfaßt: 
(I) A chsenbasierte Dimensionierung. Die DA ist nicht primär durch die Projektion des Körperschemas auf die räumliche Umgebung bestimmt (wie das u.a. Herskovits 1986 annimmt), sondern durch zwei unabhängige, aber interagierende Kategorisierungsraster für Achsen, genannt Primärer Orientierungsraum (POR) und In härentes Proportions s h e ma (IPS), die - auf je eigene Weise in der perzeptiven Grundausstattung des Menschen verankert - die für die DA relevanten Identifizierungskriterien für RaumAchsen und Objekt-Achsen liefern.

L a ge - und Gestalteigenschaften. Die DA räumlicher Objekte beruht darauf, dab bestimmte Achsenabmessungen eines gegebenen Objekts nach ihrer Koinzidenz mit einer der Achsen aus POR und/oder IPS als D i m e $n$ s i o $n$ e $n$ ausgezeichnet und entsprechend lexikalisch belegt werden. So wird im Dt. z.B. eine Achse d eines Objekts $\mathbf{x}$

(a) als Höhe von $x$ bzw. als Tiefe von $x$ ausgezeichnet, wenn $\mathrm{d}$ mit der Vertikalen bzw. der Betrachterachse des POR koinzidiert und/oder

(b) als Länge von $x$ oder als Dicke von $x$, wenn $\mathrm{d}$ mit der Maximalen bzw. der Substanzachse des IPS koinzidiert.

Es ist offensichtlich, daB die DA von Objektachsen nach IPS gemäß (b) sich auf die $G$ es $\mathrm{t}$ a l t e i g e $\mathrm{n} \mathbf{s} \mathrm{h}$ a f $\mathrm{t}$ e $n$, die nach POR gemäB (a) sich auf die $\mathrm{L}$ a g e e i g e $\mathrm{n} \mathbf{s} \mathrm{ch}$ a f t e n eines Objekts $x$ bezieht.

(III) P a r a m e t e r. Die DA erfolgt mithilfe einer begrenzten Menge von Dimensionsauszeichnungsparametern (DAP), die resultierend aus den perzeptiv fundierten Achsensystemen POR und IPS über ihre konzeptuelle Kategorisierung das Inventar potentieller semantischer KOMPONENTEN bilden, das für die Lexikalisierung des Bezugs auf räumliche Dimensionen zur Verfügung steht. Wegen seiner - konzeptuell vermittelten - Fundierung in der perzeptiven Grundausstattung des Menschen ist das Inventar der DAP die geeignete Basis, um linguistische Universalitätsannahmen zu formulieren und Befunde zwischensprachlicher Variation zu bewerten.

(IV) Schnittstelle von semantischer Struktur und konzeptueller Interpretation. Die Grammatik der DA umfaBt die Spezifikation der Bedingungen, nach denen mithilfe sprachlicher Ausdrücke räumliche Objekte bezüglich ihrer primären und/oder kontextuell induzierten Dimensionen ausgezeichnet werden. So etwa ist bezüglich ein und derselben Objektachse d der Aus- 
druck (a) die Stange ist $9 m$ lang eine primäre Auszeichnung der Maximalen des Objekts unabhängig von seiner Lage, der Ausdruck (b) die Stange ist $9 \mathrm{~m}$ hoch hingegen eine kontextuelle Spezifikation der Maximalen bezüglich der Lage des Objekts, und es gilt, daB (a) aus (b) ableitbar ist. Ersetzt man hier die Stange z.B. durch die Mauer, dann können die Ausdrücke lang und hoch nicht dieselbe Objektachse $d$ identifizieren und die Inferenz von (b) auf (a) gilt nicht.

Die systematische Erfassung solcher Zusammenhänge in der Grammatik der DA erfordert generelle Verfahren, die der Interaktion von "word knowledge" und "world knowledge" angemessen - d.h. bezüglich der betreffenden Ausdrücke ohne die Annahme inflationärer Polysemie, aber mit einer klaren Trennung von le $x$ ik a lis $c h$ fixierter Bedeut ung und k ontextueller Anwendung - Rechnung tragen. Das dafür entwickelte sog. Z w e i-S t u f e n-M od ell der semantischen Interpretation (vgl. u.a. Bierwisch/Lang (eds.) 1989; Lang 1990a, b; Lang 1994; Lang 1995b) mag als Versuch gelten, der Unterscheidung wie der Überschneidung von sprachgebundenem lexikalischsemantischem Wissen und nicht-sprachgebundenem konzeptuellen Weltwissen in kontrollierter Form beizukommen. Das Modell sieht dafür zwei Repräsentationsformate, nämlich Semantische Form (SF) und Konzeptuelle Ebene (CS), sowie diverse Abbildungen zwischen ihnen vor - Details in der genannten Literatur.

(V) Fundierungszusammenhang von (I) - (IV). Abb. 1 unten (zitiert aus Lang 1995b) zeigt drei unterscheidbare Ebenen der Repräsentation und Verarbeitung räumlicher Information und die daraus zu gewinnenden Dimensionsauszeichnungsparameter (DAP) im Zusammenhang. Die Perzeptive Ebene ist durch die sensorische Wahrnehmung physikalischer Parameter bestimmt, hier vornehmlich solcher, die sich aus der Wirkung der Schwerkraft ableiten. Die Konze ptuelle Ebene ist bestimmt durch die verhaltensrelevante Kategorisierung perzeptiver Information, d.h. perzeptive Unterschiede werden nur in dem Maße konzeptualisiert und eventuell auch lexikalisiert, wie sie für unser Alltagsverständnis vom Raum benötigt werden. Auf dieser Ebene liefern die beiden achsenbezogenen Kategorisierungsraster IPS und POR das Inventar von Parametern (DAP), das der sprachlich codierten DA semantisch zugrunde liegt. Bei der linguistischen Analyse von Dimensionsausdrücken figurieren die DAP - unter völliger Wahrung ihres konzeptuellen Gehalts - in zweierlei Repräsentationsformaten:

(a) als Einträge in sog. Objektschemata (OS), d.h. als Elemente der gedächtnisfixierten oder der aktualen kontextuell spezifizierten, mithin 
begrifflichen Repräsentation räumlicher Objekte (= Konzeptuelle Ebene in Abb. 1)

(b) als semantische KOMPONENTEN in der SF von Dimensionsausdrücken (und Bezeichnungen von räumlichen Objekten, die wir hier aber nicht diskutieren), d.h. als das Material "which language packages into words" (= Semantische Ebene in Abb. 1).

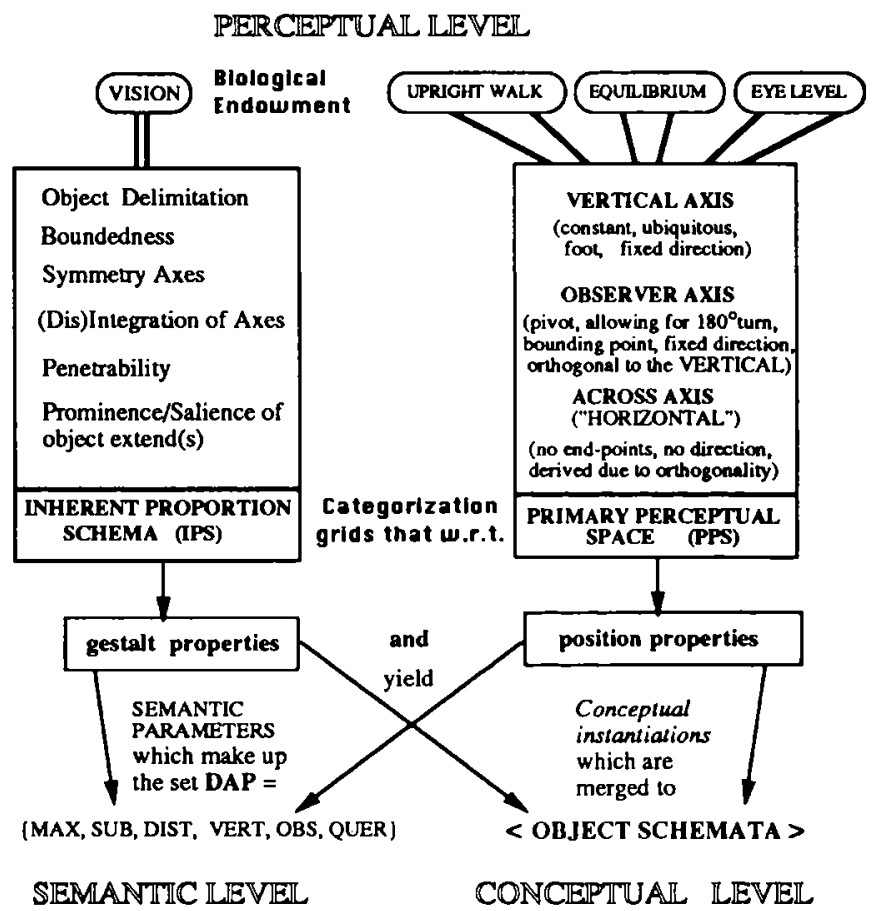

Abb. 1: Fundierung und Ausgliederung der Parameter für die Dimensionsauszeichnung

Im Kontrast zu anderen Ansätzen in der Literatur sind für den hier vertretenen linguistischen Ansatz zwei Annahmen unverzichtbar. E rste n s, es gibt keine direkten Verbindungen zwischen Perzeption und Lexikalisierung, vielmehr wird der unbestreitbare Konnex zwischen beiden Bereichen phylo-, onto- und aktualgenetisch und daher auch in der Diachronie und Synchronie der Versprachlichung stets über die kon- 
zeptuelle Kategorisierung vermittelt und gesteuert. $Z$ w e i t e $n \mathbf{s}$, die als semantische Bausteine in SF figurierenden DAP sind zwar aus demselben Stoff wie die Einträge in den OS der Konzeptuellen Ebene, stellen aber nur eine designierte Teilmenge davon dar: $\{D A P$ in SF $\} \subseteq\{$ Einträge in OS\}, designiert durch ihre Encodierung in sprachliche Ausdrücke. Wir benutzen zur Kennzeichnung des Unterschieds die typographische Konvention KAPITÄLCHEN vs. Kursiv. Die so postulierte Unterscheidung zwischen semantischen und konzeptuellen Elementen entspricht dem unstrittigen Befund, daB nicht alles, was konzeptuell kategorisiert ist, auch lexikalisiert wird, und sie eröffnet und begrenzt zugleich damit auch den uns hier interessierenden Variationsbereich für Lexikalisierungen.

\subsection{Die Auszeichnungsparameter}

2.2.1 Der primäre Orientierungra um (POR), unser internes Modell des externen Raums, wird durch drei Achsen gebildet, die Vertikale, die Betrachter-Achse und die sog. Horizontale oder besser: die Quer-Achse. Jede der Achsen hat ihre spezifischen, aus der unterschiedlichen Verankerung im Perzeptionsapparat stammenden Eigenschaften, alle zusammen bestimmen wesentlich die Art und Weise, wie wir die räumliche Umgebung begrifflich repräsentieren und sprachlich encodieren. Es sind diese drei Achsen des POR, mithilfe derer

(5) (a) Objekten eine Lage und/oder ein Ort im Raum zugewiesen wird

(b) Objekte inbezug auf andere Objekte lokalisiert werden

(c) Objekten Bewegung (= Änderung der Lage und/oder des Ortes) zugeschrieben wird

Als Illustration diene die räumliche Situation in Abb. 2 mit der Auswahl von sprachlichen Ausdrücken (6), deren Bedeutung jeweils einen Bezug auf die Vertikale nach $(5)(a-c)$ enthält. 


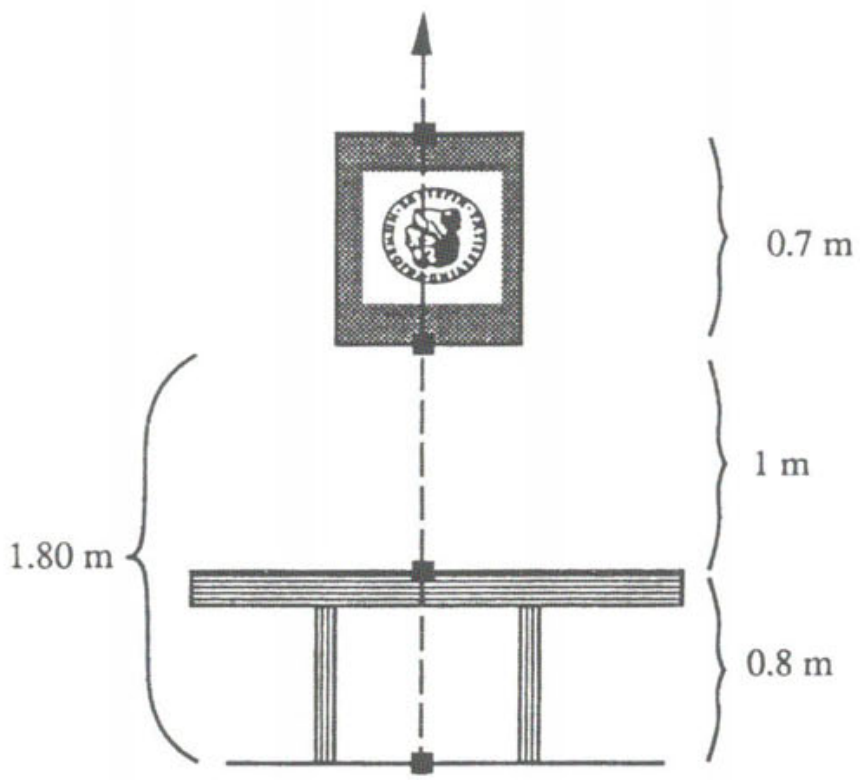

Abb. 2: Die Vertikale als Orientierungsachse

(6) Der Tisch ist $0.8 \mathrm{~m}$ hoch / hat eine öhe von $0.8 \mathrm{~m} /$ [Lage] steht / steht normal

Das Plakat ist $0.7 \mathrm{~m}$ hoch / hat eine Höhe von $0.7 \mathrm{~m} /$ hängt / hängt verkehrtrum

Das Plakat ist $1.8 \mathrm{~m}$ hoch / in einer Höhe von $1.8 \mathrm{~m}$ [Ort]

Der Tisch ist unter dem Plakat / unterhalb des Plakats [Lokalisierung]

Das Plakat ist $1 \mathrm{~m}$ über dem Tisch / $1 \mathrm{~m}$ höher als der Tisch

Das Plakat ist am Tisch ausgerichtet /

mit dem Kopf nach unten gehängt

[Lageänderung]

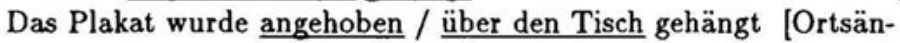
derung]

Alle u n ter st ri chen e n Ausdrücke in (6) enthalten in ihrer lexikalischen Bedeutung einen Bezug auf die Vertikale des POR, der in der semantischen Repräsentation (SF) dieser Ausdrücke als Parameter 
VERT figuriert, wobei die Art seiner Verpackung und Einpassung u.a. von der syntaktischen Kategorie des Ausdrucks abhängt (zu Dimensionsadjektiven vgl. Lang 1989, zu Positionsverben vgl. Maienborn 1990a,b, 1995; Lang, Carstensen, Simmons 1991; zu den einschlägigen Präpositionen - vgl. Lang 1991, 1993). Natürlich enthalten auch die kursiven Ausdrücke, d.h. die Objektbezeichnungen Tisch und Plakat, einen semantischen Bezug auf die Vertikale des POR. So gehört es zu unserem Begriff „Tisch” (und entsprechend zur Bedeutung des Wortes Tisch), $\mathrm{da} B$ ein solches Objekt eine ausgezeichnete Achse d hat, die mit der Vertikalen des umgebenenden Raum übereinstimmt und so die kanonische Ober- und Unterseite eines Tisches sowie dessen kanonische Lage im Raum bestimmen. Ein Plakat (Bild etc.) hat hingegen eine inhärente Orientierung, dergestalt, daB es eine Achse d umfaßt, die - abhängig vom Dargestellten - als inhärente Höhe bzw. Oben-Unten-Achse ausgezeichnet ist, unabhängig von der Vertikalen und von der aktuellen Lage des Objekts im Raum.

Analoges gilt für den Bezug auf die $\mathrm{B}$ e $\mathrm{t} \mathbf{r} \mathbf{a} \mathrm{ch} \mathbf{t}$ e $\mathbf{r}-\mathbf{A} \mathrm{ch}$ s e des POR, für die Rolle des semantischen Parameters OBS in der Bedeutung von Ausdrücken wie tief, vor, hinten etc., für die kanonische (FluB, Schrank) vs. inhärente (Loch, Wunde) Perspektivierung von Objekten und ihre Repräsentation - ich verweise auf Lang/Carstensen/Simmons (1991).

Anzumerken ist jedoch, daB die dritte Achse des POR, die sog. Horizontale oder Quer-Achse, keine eigenständige Kategorisierung von Objekten (etwa bezüglich kanonischer oder inhärenter "Horizontalität” oder "Transversalität") bewirkt. Der Grund: wir haben keine organische Ausstattung für die eigenständige Identifizierung der Quer-Achse, vielmehr wird diese stets relativ zu einer anderen unabhängig identifizierbaren Achse bestimmt. Aufgrund ihrer unterschiedlichen Verankerung im Perzeptionssystem (kurz in Abb. 1, ausführlicher in Lang 1989) haben die Achsen des POR unterschiedliche Eigenschaften und entsprechend distinkte Funktionen innerhalb unseres internen Modells des äußeren Raums. Sehr gerafft:

(7) Die Vertikale, konstituiert aus der organismischen Reaktion auf die Gravitation, stellt eine u b i q u it ä r e und $\mathrm{k}$ on $\mathrm{s}$ a $n \mathrm{t} e$ Orientierungsachse dar. Sie ist physikalisch und konzeptuell die p r om ine n teste und daher innerhalb des POR die $\mathrm{d}$ o $\mathrm{m}$ in a $\mathrm{nt}$ e Achse: die anderen Achsen definieren sich relativ zur Vertikalen. 
(8) Die B e t r a cht e r a c h s e ist bestimmt durch die B l i c kr i c h t u $\mathrm{g}$ eines (potentiellen oder aktuellen) Betrachters. Daher ist sie $z$ we i f $\mathrm{ch}$ b e w e g l i c h:

(a) sie ist - anders als die schwerkraftbasierte Vertikale - nicht im physikalischen Raum verankert, sondern durch den beweglichen und sich bewegenden menschlichen Interpreten des physikalischen Raums induziert;

(b) sie hat einen anatomisch bedingten Drehpunkt, der Drehungen bis $180^{\circ}$ in zwei Richtungen erlaubt.

Im unmarkierten Fall, der durch die Augenlage des Betrachters im aufrechten Gang gegeben ist, ist die Betrachterachse orthogonal $\left(\nless 90^{\circ}\right.$ ) zur Vertikalen. Der andere relevante Fall ist der, wo Betrachterachse und Vertikale in $\nless 180^{\circ}$ zueinander, also parallel, aber in entgegengesetzter Richtung laufen. Die Betrachterchse ist die Quelle der Tiefenwahrnehmung.

(9) Die Quer-A ch s e gründet sich nicht auf perzeptive Primärinformation, ihre Identifizierung ist abhängig von der der beiden anderen Achsen. Die Quer-Achse ist definiert durch ihre Orthogonalität zur Vertikalen und zur Betrachterachse.

Die Achsen des POR liefern die als jeweilige Achsen-Identifizierungsbedingungen fungierenden semantischen Parameter VERT, OBS und QUER, die für die DA unmittelbar einschlägig sind. In Abschnitt 4 werden wir sehen, daB die unterschiedlichen Eigenschaften der in (7) - (9) charakterisierten Achsen unmittelbare Auswirkungen für die Bestimmung des Bereichs von universeller und typologisch variierender Lexikalisierung haben.

2.2.2 Die Achsen, die aus dem I n här en $\mathbf{t}$ e n P r o portion s$\mathrm{s} \mathrm{ch} \mathrm{e} \mathrm{m} \mathrm{a}$ (IPS) resultieren, beziehen sich auf relevante Gestalteigenschaften von Objekten wie Begrenztheit oder nicht, Dimensionalität (1D, 2D, 3D), Symmetrieachsen, Achsenproportion (z.B. ob ein Objekt eine $\mathrm{M}$ a x i m a le aufweist, worauf sich u.a. die Bedeutung von Ausdrücken wie lang, kurz, entlang, long, tall, short, along etc. bezieht), ob eine Objektachse den Durchblick gewährt ( $D$ is t a n z ) oder verwehrt ( $\mathrm{Substanz}$ ). Die Achsen des IPS liefern die ebenfalls als Achsen-Identifizierungsbedingungen fungierenden semantischen Parameter MAX, SUB, DIST und QUER.

2.2.3 D a s I n ve $\mathbf{n}$ t a r d e r D A P. Die Interaktion der beiden Kategorisierungsraster POR und IPS liefert zum einen das für DA einschlägige Inventar von semantischen Parametern (DAP), zum anderen 
das Inventar sämtlicher konzeptuell zulässigen Objektschemata (OS), das die gesamte Bandbreite der Dimensions-, Lage- und Beweglichkeitseigenschaften räumlicher Objekte umfaBt. Der so bestimmte "catalogus mundi" möglicher räumlicher Objekte ist in Lang/Carstensen/Simmons (1991) im Detail dargestellt und braucht daher hier nicht aufgeblättert zu werden.

Kurz charakterisiert werden sollen indes die semantischen Parameter des für die DA zuständigen Inventars (ausgenommen den holistisch determinierten Parameter SIZE für dt. groß - klein - vgl. Lang 1989), und zwar mit dem Hinweis, daB MAX, VERT etc. nicht bloße Etiketten, sondern kategorisierte Bausteine mit einer klaren innertheoretischen Interpretation darstellen. In vereinfachter Diktion beinhalten die jeweiligen DAP folgende

(10) I dentifizier ung bedingungen:

MAX identifiziert die maximale desintegrierte Achse d eines Objekts $x$, was voraussetzt, daB g e $n$ a $u$ e i $n$ e solche Achse bei $x$ verfügbar ist (daher sind z.B. lang, kurz nicht anwendbar auf Bälle, Kreise, Quadrate etc.).

SUB identifiziert eine nicht-maximale dritte (dickes Brett, dünne Scheibe) oder integrierte Objektachse (z.B. den Durchmesser wie in dicke Stange, dünner Faden). ${ }^{1}$

DIST identifiziert eine Objektachse, die als Innendurchmesser eines Hohlkörpers begriffen wird. Obwohl SUB und DIST geometrisch gesehen dieselbe Art Abmessung betreffen können, beruhen sie auf perzeptiv gegensätzlichen Eigenschaften, nämlich Durchblick verwehrend vs. Durchblick gewährend. So bezieht sich SUB auf Achsen massiver Objekte, DIST auf Achsen konkaver oder hohler Objekte.

VERT identifiziert genau diejenige desintegrierte Achse d eines Objekts $\mathbf{x}$, die mit der Vertikalen des umgebenden Raum koinzidiert.

OBS identifiziert eine desintegrierte nicht-minimale Objektachse, die mit der Betrachterachse koinzidiert - zu zusätzlichen Selektionsbeschränkungen siehe 4.2 unten.

1 SUB liegt darüberhinaus einer Reihe von nicht-achsenbasierten Dimensionszuweisungen zugrunde, etwa bezogen auf Konsistenz oder Dichte. Die davon betroffenen Lexikalisierungsdifferenzen wurden in (1) auswahlweise illustriert. 
QUER identifiziert eine desintegrierte Objektachse, die nicht bereits durch die Parameter MAX, SUB, VERT oder OBS identifiziert ist. QUER und DIST können sich auf dieselbe Achse beziehen, wobei DIST zusätzlich spezifiziert ist für (Innen-)Abstand.

Man beachte, daB QUER (und mit der genannten Zusatzbedingung auch DIST) - da ihnen primäre Identifizierbarkeit abgeht - in beiden Kategorisierungsrastern eine Art $L \ddot{u}$ c $k$ e $n$ f ü l l e r darstellen: in POR deckt QUER Horizontalität insofern ab, als es sich auf Objektachsen bezieht, die weder durch VERT noch durch OBS identifiziert sind; in IPS ergänzt es MAX und SUB, indem es Achsen identifiziert, die durch diese Parameter nicht identifizierbar sind. Kurzum: QUER liegt im Überlappungsbereich von POR und IPS und bildet so eine Quelle für Mehrdeutigkeit und Variation in der lexikalischen Abdeckung bzw.der Lexikalisierung - vgl. 4.2 unten.

2.2.4 D A P u n d Wortfeld s t r u k u r. Um von den DAP zu den zu Wortfeldern gruppierten sprachlichen Ausdrücken zu kommen, bedarf es zunächst der von Lehrer geforderten "general formal structure", die das dem Wortfeld zugrunde liegende Paradigma bestimmt - vgl. Abschnitt 1.3 oben und auch die von V. Ehrich (in diesem Band) vorgeschlagenenen Repräsentationsschemata für Transportverben. Als semantische KOMPONENTEN sind die einzelnen DAP in kategorienspezifische - d.h. für Positionsverben, Präpositionen oder Dimensionsausdrücke jeweils verschiedene - komplexere Bedeutungsstrukturen verpackt. Die relevante Gemeinsamkeit von Dimensionsausdrücken (Adjektiven und ihren Nominalisierungen) besteht darin, daB ihre Lexikoneinträge auf der SF-Ebene alle dem folgenden $R$ e $p$ ä se $n$ t a $t$ i o $\mathrm{s} \mathrm{s} \mathrm{ch} \mathrm{e} \mathrm{m} \mathrm{a} \mathrm{genügen:}$

(11) $\lambda \mathrm{c} \lambda \mathrm{x} \quad$ [QANT [DIM $\mathrm{x}]=\left[\begin{array}{lll}\mathbf{v} & \pm & \mathrm{c}\end{array}\right]$

Mit dem Hinweis auf Lang (1989) und Bierwisch/Lang (eds.) (1989) vernachlässigen wir alle Details zu den für Graduierung (QUANT) und Vergleich ( $[[\mathrm{x}]=[\mathrm{v} \pm \mathrm{c}]]$ ) zuständigen Komponenten und beschränken uns auf die als Variable für die einschlägigen DAP figurierende Komponente DIM. ${ }^{2}$ Mit der aus (11) und der jeweiligen kategorialen Information (Adjektiv, Nomen) nun gewonnenen "general formal structure"

2 Wir begrenzen den Bereich der Variablen DIM hier auf Werte aus der Domäne Raum. Als generelles Strukturschema ist (11) jedoch auch gültig für Dimensionsausdrücke aus anderen ontologischen Domänen wie Gewicht (schwer, leicht), Temperatur (warm, kalt), Alter (alt, jung), Preis (teuer, billig). 
sind strikte Bedingungen für die $F$ e l d z u g e hö $\mathrm{r}$ g k e i t eines Wortes fixiert. Sie beinhalten u.a. folgende Anforderungen:

(12) Ein Ausdruck A der Kategorie K gehört nur dann zum Wortfeld der K-Lexikalisierungen von DIM, wenn

(a) A mit MaBphrasen kombinierbar ist

(b) A regulär komparierbar ist

(c) A ein konträres lexikalisches Antonym A' besitzt

(d) A und A' im Komparativ reguläre Konversen bilden

Bezogen aufs Deutsche werden durch (12)(a)-(d) Ausdrücke wie riesig oder flach aussortiert, durch (c) wird die Antonymie-Relation präzisiert (vgl. Lang 1995a), durch (c) und (d) werden die Distanzausdrücke hoch (springen), tief (tauchen), weit (werfen) von den gleichlautenden Dimensionsausdrücken separiert - ausführlich dazu Lang (1989), (1995a). Nach der in (11) und (12) fixierten Eingrenzung betrachten wir nun die Frage, wie die Elemente der Menge

$$
\text { DIM }=\{\text { MAX, SUB, DIST, QUER, VERT, OBS }\}
$$

arbeitsteilig oder in Kombination lexikalisiert werden und damit die Struktur des resultierenden Wortfelds bestimmen. Dazu bedarf es noch eines Blicks auf ihre konzeptuelle Verträglichkeit.

\subsection{Verträglichkeitsbedingungen}

2.3.1 Par a m et erko m bin a tionen. Die Annahme, daß das Inventar DIM aus der I $\mathbf{n}$ e $\mathbf{r}$ a $\mathbf{k}$ t i o $\mathbf{n}$ der beiden Achsensysteme POR und IPS resultiert, trägt dem Umstand Rechnung, daß eine Objektachse häufig nicht durch einen einzelnen Parameter, sondern durch eine Kombination von Parametern aus POR und IPS als Dimension ausgezeichnet wird. Solche Kombinationen kommen auf der semantischen und der konzeptuellen Ebene vor, hier ein paar Beispiele:

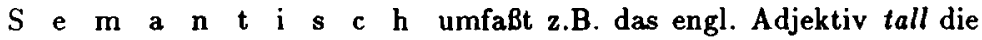
(asymmetrische) Konjunktion von MAX und VERT, wobei die Tatsache, daß als Antonym zu tall das Adjektiv short fungiert (nicht etwa low oder ein eigenes), darauf hinweist, daß tall eine Objektachse als die Maximale identifiziert, die zudem noch spezifiziert ist durch ihre Koinzidenz mit der Vertikalen.

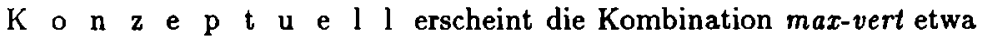
im OS für "Baum” oder „Turm”, was besagt: (i) daB diese Objekte eine kanonische Orientierung bezüglich der Vertikalen besitzen, (ii) daß diese Orientierung sich auf die Maximale bezieht. AuBer in dieser gedächtnisfixierten Form kommt die Kombination max-vert auch als Resultat 
kontextueller Spezifikation vor. So enthält das primäre OS für „Stange” nur den Eintrag max, was ausreicht, um etwa den Ausdruck die Stange ist $3 m$ lang regulär zu interpretieren. Die Interpretation von die Stange ist $3 \mathrm{~m}$ hoch oder the pole is $9 \mathrm{~m}$ tall/high indes versieht das aktuelle OS für "Stange" mit einer kontextuell induzierten Spezifikation bezüglich der Vertikalen, die zu einem Eintrag max-vert führt.

Dies nur als Beispiel dafür, wie im Rahmen der DA Gestalteigenschaften (MAX) in Lageeigenschaften (VERT) überführt werden. Die Tatsache, daß dies in umgekehrter Richtung (Lage- in Gestalteigenschaften zu verwandeln) nicht geht, liefert zusätzliche Evidenz für unsere Analyse von engl. tall wie für die asymmetrische Beziehung zwischen IPS und POR überhaupt.

2.3.2 Verträglichkeit unter den Parametern. Die hier zu vertretende Annahme lautet, daB die Gesamtheit konzeptuell möglicher OS ebenso wie der Spielraum zulässiger Dimensionsauszeichnungen und Lagevariationen von Objekten (gleichviel, ob primär oder kontextuell induziert) durch einige wenige Verträglichkeitsbedingungen bestimmt sind, die festlegen, welche Kombination von Achsenidentifizierungsbedingungen - also von DAP - vorkommen und damit auch lexikalisiert werden können. Unter der in (10) angesetzen Interpretation der DAP erhalten wir 14 mögliche Kombinationen in drei Gruppen:

(14) (a) einzelne Parameter:

MAX, VERT, OBS, QUER, DIST, SUB

(b) zulässige Kombinationen (beruhend auf kompatiblen Achseneigenschaften):

MAX-VERT, QUER-MAX, QUER-DIST, MAX-OBS, VERT-OBS $\left(\nless 180^{\circ}\right)$

(c) unzulässige Kombinationen (beruhend auf inkompatiblen Achseneigenschaften):

*MAX-SUB, *DIST-SUB, *OBS-SUB, *OBS-VERT $\left(\nless 0^{\circ}\right)$

Man beachte, daß eine Kombination aus Parametern - wie oben anhand von engl. tall illustriert - keine einfache Konjunktion, sondern einen strukturierten Komplex aus einem fundierenden Parameter (linker Teil) und einem spezifikatorischen (rechter Teil) darstellt. Die Kombination VERT-OBS in (14)(b) ist bei Lexikalisierung selektional beschränkt auf konkave Objekte, die einerseits kanonisch an der Vertikalen orientiert sind und zugleich spezifiziert sind durch eine kanonische (FluB, Graben) oder kontextuell induzierte (Topf) Perspektive in Gegenrichtung. Die Kombinationen *MAX-SUB, *DIST-SUB, *OBS-SUB in (14)(c) sind aufgrund von perzeptiv unverträglichen Eigenschaften ausgeschlos- 
sen, die Kombination *OBS-VERT $\left(\nless 0^{\circ}\right.$ ) ist zwar perzeptiv durchaus verträglich (Blick nach oben), aber offenbar konzeptuell irrelevant. ${ }^{3}$

Als Lexikalisierungskandidaten verbleiben somit die 11 Parameter(kombinationen) in (14)(a-b).

\section{Semantische und lexikalische Universalien für Dimensionsausdrücke}

\subsection{Ausgangsannahmen}

Im Rahmen des oben schon erwähnten Zwei-Stufen-Modells der semantischen Interpretation wird der Status semantischer Universalien wie in (15) und ihre Rolle in der Theoriebildung durch Anforderungen wie (16) - (18) bestimmt.

(15) Semantische Universalien sind generelle Aussagen darüber, wie semantische Komponenten (oder Konfigurationen daraus) in lexikalisch kategorisierte, morphosyntaktisch spezifizierbare, somit kompositionell paßfähige Einheiten encodiert werden, aus denen sich Phrasen- und Satzstrukturen aufbauen.

Wir beschränken uns hier auf die unterstrichenen Teile in (15) und unterwerfen ihre theoretische Ausbuchstabierung den folgenden Anforderungen:

(16) Semantische Universalien müssen zur Aufhellung der Unterscheidung wie der Interaktion von sprachlich codierter Bedeutung und kontextueller Information beitragen.

(17) Semantische Universalien müssen die Basis liefern, um (a) Ambiguität, Polysemie, Unspezifiziertheit zu unterscheiden sowie (b) Lücken und (c) verschiedene Typen von Inferenz zu erklären.

3 Als Beleg für die lexikalische Aussparung dieser semantisch möglichen Kombination mag das folgende Zitat aus einer TV-Sendung aus Cape Canaveral gelten:

(i) Die Rakete steigt in die Höhe und verschwindet in der Tiefe des Alls

Die Tatsache, daß der Flugweg der Rakete eine gerade Strecke bildet (die mit der Vertikalen und der parallelen Blickrichtung des Betrachters koinzidiert), kann semantisch und lexikalisch nicht durch eine Einheit abgedeckt werden, sondern muB - mit einem Wechsel des Bezugssystems - auf zwei Einheiten (Höhe, Tiefe) verteilt werden. 
(18) Semantische Universalien, die konstatieren, welche (Kombinationen von) Komponenten lexikalisiert („packaged into categorized lexical items and this way put into grammatical structure formation") werden, sollten sich so weit wie möglich auf unabhängige Erklärungen stützen.

Auf diesem Hintergrund können wir nun probehalber einige Universalien formulieren.

\subsection{Was wird wie lexikalisiert?}

Angesichts der entscheidenden Rolle der in 2.3.2 erläuterten Verträglichkeitsbedingungen legt (14) eine universelle Einschränkung wie (19) nahe, die wir in zwei Versionen bieten:

(19) Nur zulässige Kombinationen von Parametern aus DIM werden lexikalisiert

Es gibt keine lexikalischen Einheiten, die simultan die Identifizierung von Achsen gemäB MAX-SUB, DIST-SUB, OBS-SUB oder OBS-VERT beinhalten

Die auf den ersten Blick trivial erscheinende Feststellung über systematische lexikalische Lücken hat aber durchaus nicht-triviale Implikationen für die Lexikalisierung, z.B. die, daB Parameter, die sich auf wechselseitig inkompatible Achseneigenschaften beziehen, separat lexikalisiert werden:

(20) Wenn MAX, SUB, DIST, OBS als semantische Komponenten in Einheiten ein und desselben Wortfeldes figurieren, dann sind diese Einheiten lexikalisch distinkt.

Zwei weitere (mutmaßliche) Universalien beziehen sich auf die jeweils prominenten Achsen aus IPS und POR. Die erste Feststellung - wiederum in zwei Versionen - lautet:

(21) Die prominenten Achsen aus IPS und POR werden separat lexikalisiert

In einem Wortfeld von Dimensionsausdrücken gibt es zumindest distinkte Ausdrücke für MAX und SUB wie auch für VERT und OBS.

Anders als (20), das ein Korollar zu (19) darstellt, ist (21) eine unabhängige Feststellung. Sie postuliert separate Lexikalisierung von MAX (aus IPS) und VERT und OBS (aus POR) und QUER (evtl. aus beiden) trotz der Tatsache, daß die Achseneigenschaften, auf die sich die jewei- 
ligen Parameter beziehen, paarweise kompatibel sind, wie die zulässigen Kombinationen in (14)(b) zeigen. (21) ist eine Hypothese über prominenzbasierte minimale Distinktheit innerhalb des Wortfeldes der Dimensionsausdrücke, und als solche durchaus im Einklang mit dem Befund, $\mathrm{da} B$ das Englische MAX (long, short), VERT (high, low) und MAXVERT (tall) separat lexikalisiert, wie auch mit der Möglichkeit, daß es Sprachen gibt, die OBS (im $\nless 90^{\circ}$ zu VERT) und VERT-OBS $\left(\nless 180^{\circ}\right)$ in distinkte Wörter verpacken.

Die Festellung (22) ist eine vorläufige Annahme über den Zusammenhang von konzeptueller Salienz und Codierung in lexikalischen „primes” (d.h. in wortstrukturellen Basiswörtern).

(22) Dimensionsausdrücke für MAX, VERT, OBS sind lexikalische "primes"

Nun mag (22) trivial erscheinen, wo doch in dem guten Dutzend bisher im Projekt untersuchter Sprachen die Dimensionsausdrücke stets zum jeweiligen Kernlexikon gehören. Dennoch ist (22) zum einen ein Kriterium, um Ausdrücke wie länglich, gigantisch, quadratisch ergänzend zu (11) und (12) auszusortieren, zum anderen ist es eine Herausforderung, crosslinguistisch nach Gegenbeispielen zu fahnden. Zusammen bestimmen (U-1) - (U-3), was im Wortfeld der Dimensionsausdrücke minimal lexikalisiert ist und damit auch den Bereich möglicher Variation.

\section{Typologische Variation in der Wortfeldstruktur der Dimensionsausdrücke}

\subsection{Ausgangslage}

4.1.1 M e h r Kom pon ente n a ls Wört e r. Unter Berücksichtigung der in Kap. 2 gegebenen Erläuterungen läßt sich das Inventar der für die Lexikalisierung verfügbaren Parameter zunächst wie in Abb. 3 veranschaulichen. Die Schraffur kennzeichnet die Herkunft der Parameter aus IPS bzw. POR, Doppelschraffur folglich kombinierte Herkunft, fehlende Schraffur bei QUER und DIST deren in Abschnitt 2.2.3 diskutierte Lückenfüller-Funktion bezüglich IPS und POR. Umrandete Parameter sind gemäß (U-2, U-3) Kandidaten für distinkte primäre Lexikalisierung. 


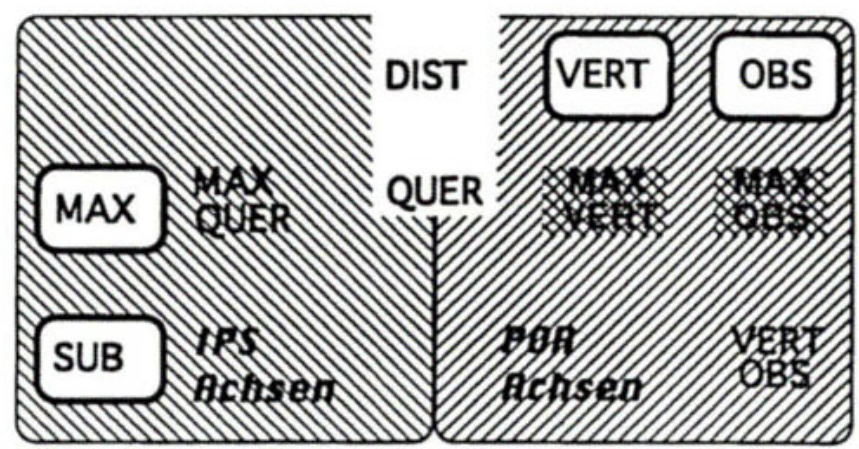

Abb.3: Inventar semantischer Komponenten für räumliche Dimensionsausdrücke

Theoretisch reicht das Inventar in Abb. 3 für 11 potentielle Dimensionsausdrücke (lexikalische Antonyme nicht mitgezählt), andererseits gibt es den robusten empirischen Befund, daB in den untersuchten Sprachen die Zahl der nach (12) ausgegliederten Dimensionsausdrücke zwischen 5 und 8 rangiert (lexikalische Antonyme nicht einberechnet). Also gibt es keine eins-zu-eins Abbildung zwischen Komponenten und Dimensionsausdrücken, sondern offenbar ein „few-many-mapping”. Wir stehen somit vor der Frage, welche Dimensionsausdrücke welche Teilmengen des Inventars abdecken, genauer: wie das Inventar bezüglich seiner lexikalischen Abdeckung partitioniert ist. Tatsächlich unterscheiden sich Sprachen danach, wie das Inventar der Komponenten lexikalisch aufgeteilt ist. Die Suche nach rekurrierenden Aufteilungsmustern und Versuchen zu ihrer Erklärung ist somit ein VorstoB in die Typologie der Wortfeldstruktur.

4.1.2 Determinanten des Variat ions bereich s. Wenn wir die als Universalien gedachten Feststellungen in (21) und (22), daß MAX, SUB, VERT, OBS distinkt und als „primes” lexikalisiert werden, als gültig betrachten (und die Befunde sprechen bisher nicht dagegen), dann ist die mögliche Variation in der lexikalischen Abdeckung auf den Bereich der restlichen Parameter eingeschränkt. Die Frage ist: Was bestimmt die Grenzen für die lexikalische Partition?

Die Trennlinie zwischen POR und IPS ist es offenbar nicht, denn es gibt - wie aus Abb. 3 zu ersehen - zwei Bereiche, die einer so simplen Aufteilung widersprechen. 
Erstens: Die zulässigen Kombinationen MAX-VERT und MAX-OBS umfassen Parameter aus beiden Rastern (Doppelschraffur in Abb. 3), und weil es lexikalische „primes” gibt, die solche Kombinationen abdecken (wie engl. tall), verläuft die Partitionierung nicht notwendig nach der Herkunft der Parameter aus POR vs. IPS.

Zweitens: Parameter wie QUER (und DIST), die als Lückenfüller innerhalb und zwischen beiden Rastern ohnehin perzeptiv unterbestimmt sind (vgl. 2.2.3), geben auch keine gute Grenzmarkierung für Lexikalisierungbereiche ab. Im Gegenteil, die Daten aus den untersuchten Sprachen zeigen, daß QUER und DIST offenbar wegen dieser Unterbestimmtheit gerade einen Bereich des Wortfeldes der Dimensionsausdrücke bilden, bezüglich dessen lexikalischer Abdeckung sich die Sprachen erkennbar unterscheiden.

Aus den bisher aus ca. 15 Sprachen erhobenen Daten (die bier natürlich nicht reproduziert, sondern nur durch Beispiele illustriert werden können) lassen sich d r e i $D$ e $t$ e r $m$ i n a n t e n für die lexikalische Aufteilung des Wortfeldes der Dimensionsausdrücke extrahieren. Zwei sind als Strategien der Dimensionsauszeichnung in erster Näherung (genauer in 4.3) so zu umschreiben:

Proportionsbasierte Strategie:

Das relative AusmaB von zwei Objektabmessungen a, b, also ob a $>\mathbf{b}$ oder $\mathbf{b}>\mathbf{a}$, entscheidet über die Dimensionszuweisung an a und $\mathbf{b}$.

(24) B e trachter basierte Strategie:

Die Bedingung, ob $\mathbf{a}=$ OBS, $\mathbf{b}=$ QUER zu OBS (oder umgekehrt) entscheidet über die Dimensionszuweisung an $\mathbf{a}$ und $\mathbf{b}$.

Unabhängig von (23) und (24) wirkt sich die in 2.2 .1 erläuterte Dominanz der Vertikalen als Orientierungsachse in Gestalt eines wie folgt umschreibbaren Prinzips aus:

Die Vertikale gewinnt:

Wenn eine (desintegrierte) Objektachse a mit der Vertikalen des umgebenden Raums koinzidiert, dann bestimmt dies die Dimensionszuweisung an $\mathbf{a}$.

Zur Illustration stelle man sich einen Schreibtisch mit den Abmessungen $\mathbf{a}=2 \mathrm{~m}, \mathbf{b}=1 \mathrm{~m}, \mathbf{c}=0.80 \mathrm{~m}$ vor. Wie auch immer die Achsenverteilungen sein mögen, das Prinzip in (25) pickt die kanonische Oben-Unten Abmessung heraus (sagen wir c) und reserviert sie für eine Identifizierung mit dem Ausdruck, der VERT lexikalisiert, im Dt. also er ist $0.80 \mathrm{~m}$ hoch / hat eine Höhe von $0.80 \mathrm{~m}$. Wenn die verbleibenden 
Abmessungen a, b identifiziert werden durch er ist $2 m$ lang und $1 m$ breit, dann ist (23) wirksam; wenn durch er ist $2 m$ breit und $1 m$ tief, dann ist (24) wirksam. In der Tat bedienen sich das Dt., Engl. und weitere Sprachen beider Strategien (was sich als typologisch relevantes Kennzeichen erweist - vgl. Abschnitt 4.2 unten), aber grundsätzlich nicht simultan innerhalb einer Konstruktion: ${ }^{*} E r$ ist $2 m$ breit und $1 m$ breit ist klar abweichend. Die Unakzeptabilität solcher Ausdrücke bringt eine generelle Distinktheitsbedingung für koordinierte Konstruktionen ins Spiel (vgl. Lang 1984), die spezialisiert auf Dimensionsausdrücke so lautet:

E i n z i g k e i t s b e s c h r än $k$ u $n$. Innerhalb ein und desselben komplexen Ausdrucks zur gleichrangigen Identifizierung distinkter Objektachsen a, b, c darf ein Dimensionsausdruck A nur einmal vorkommen.

Mit den in (19) - (22) und (23) - (26) genannten Determinanten ist der Variationsbereich für die lexikalische Partition des Wortfeldes der Dimensionsausdrücke soweit eingegrenzt, daB wir Datenmaterial nach rekurrierenden Mustern auswerten und diese typologisch einordnen können. Aus Platzgründen kann dies hier nur in illustrativen Auswahlen geschehen.

\subsection{Typologische Grobeinteilung und Ermittlungsverfahren}

4.2.1 P a r t i t i on i e r u n g s t y pen. Beginnen wir mit der lexikalischen Abdeckung der in 2.2.3 erwähnten Lückenfüller-Parameter QUER und DIST und den damit zusammenhängenden Effekten auf die übrige Wortfeldstruktur. Die im Projekt untersuchten Sprachen unterscheiden sich danach, ob der Teilbereich des Wortfeldes, der QUER lexikalisch abdeckt

\author{
der proportionsbasierten \\ Strategie (23) folgt \\ der betrachterbasierten \\ Strategie (24) folgt \\ einer Verschmelzung \\ beider Strategien folgt
}

(Chinesisch (Mandarin)) oder

(Koreanisch) oder

(Dt., Engl., Franz.,

Russ. u.a.).

Wohlgemerkt, (27)(a-b) lassen sehr wohl zu, daß sich in einer Sprache die beiden Strategien auf disjunkte Teile des Wortfeldes der Dimensionsausdrücke beziehen (Koreanisch ist dafür ein Belegfall), der springende Punkt bei (27)(c) ist, daß sich beide Strategien auf dieselben lexikalischen Einheiten beziehen - wie anhand von Dt. breit in 4.1.2 oben illustriert. Dabei lassen sich, wie in Abschnitt 4.3 unten ausgeführt wird, die unter $(27)(c)$ angegebenen Sprachen noch nach dem jeweiligen Anteil von 
Proportions- bzw. Betrachterbasiertheit skalieren: Dt. ist die Nummer 1 bezüglich Betrachterbasiertheit, Russ. die Nummer 1 bezüglich Proportionsbasiertheit, Engl., Franz., Poln., Slovak. liegen dazwischen.

4.2.2 E r m it t l ung s verfahre $\mathrm{n}$. Die Datenerhebung im Projekt erfolgt (wie bei allen verwandten Untersuchungen z.B. Dirven/Taylor (1988), Durrell (1988a, b), Lafrenz (1983), Lang (1989), (1990a), Spang-Hanssen (1990), Svorou (1987), Zubin/Choi (1984), Zubin/Svorou (1984)) durch Elizitierungstests, meist Aufgaben zur Benennung von Objektabmessungen. Anders als bei den Erhebungen anderer Autoren ist das „experimental design” im Projekt jedoch bewuBt so angelegt, daB dabei der Unterschied von primärer und kontextuell induzierter Dimensionsauszeichung (Beispiel $9 m$ lange/hohe Stange in 2.1 (IV) oben) systematisch eruierbar wird, um bei der semantischen Analyse als Indiz für die Trennung von lexikalisch fixierter Bedeutung vs. kontextueller Anwendung der Dimensionsausdrücke zu dienen. AuBerdem werden die erhobenen Befunde bezüglich ihrer semantischen Relevanz den in (12) und (15) - (18) formulierten Anforderungen unterworfen. Ich führe hier zwei aus den im Projekt benutzten Elizitierungstests mit repräsentativen Daten vor. Einen in 4.2.3, um damit die typologische Grobeinteilung gemäB (27)(a-c), den anderen in 4.3, um die typologische Feineinteilung innerhalb von $(27)(c)$ zu belegen, aber beide, um sie semantisch unter den genannten Anforderungen (12) und (15) - (18) zu rechtfertigen.

4.2.3 Die lexikalis che A b d e ckung von Q UER. Als illustrativ und ergiebig hat sich der folgende Test erwiesen, bei dem die Vpn gebeten wurden, anhand von $A b b$. 4 die Abmessungen $a, b$, c eines Bretts mit verschiedenen Lageeigenschaften in den räumlichen Situationen (I) - (III) dimensional (adjektivisch oder nominal) zu benennen. Den Vpn waren als plausible konstante Ausmaße des Bretts mitgeteilt worden: $a=1 \mathrm{~m}, \mathrm{~b}=30 \mathrm{~cm}, \mathrm{c}=3 \mathrm{~cm}$. Die in (28) - (29) aufgelisteten Benennungsresultate werden anschließend, die in (30) - (32) in 4.2 .7 kommentiert und gedeutet. 
III
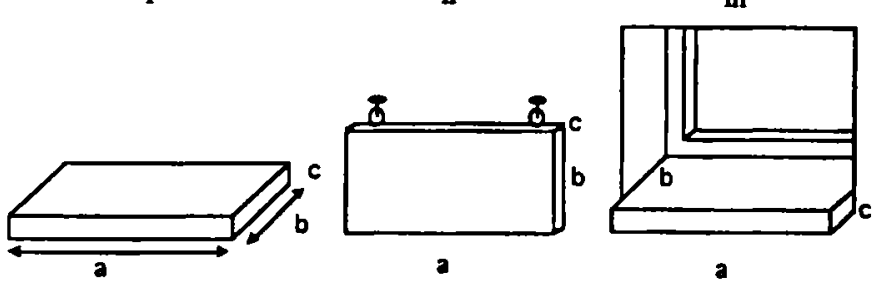

a

Abb. 4: Benennung von Objektachsen: Brett
Dt. $\quad a=$ lang
$a=$ breit
$a=$ breit
b $=$ breit
b $=$ hoch
$\mathrm{b}=$ tief
$c=$ dick
$c=$ dick
$c=$ dick

(29) Engl. a = long
$a=$ wide
$\mathrm{b}=$ high
$c=$ thick

$a=$ wide

$\mathrm{b}=$ wide

$\mathrm{b}=$ deep

$\mathrm{c}=$ thick

$c=$ thick

(30)
Chin. $\mathrm{a}=$ cháng
$a=$ cháng $/{ }^{*} k u a ̄ n$
$\mathrm{a}=$ cháng $/{ }^{*}$ kuān
$\mathrm{b}=\mathrm{kuān}$
$\mathrm{b}=\mathbf{g} \overline{\mathbf{a}} \mathbf{0}$
$\mathrm{b}=\mathrm{kuān} /{ }^{*}$ shēn
$c=$ hòu
$c=$ hòu
$\mathrm{c}=$ hòu

(31) Koreanisch
(A) $a=$ selo
$a=$ selo
$a=$ selo
$\mathrm{b}=$ kalo
$\mathrm{b}=$ nophi/kalo
b = kalo
$\mathrm{c}=$ khuki
$\mathrm{c}=$ khuki
$\mathrm{c}=\mathrm{khuki}$
$\mathrm{b}=$ selo
$c=$ khuki
(B) $\mathrm{a}=$ kalo
$\mathrm{a}=$ kalo
$\mathrm{a}=$ kalo
$\mathrm{b}=$ selo/nophi
$\mathbf{b}=$ selo
$c=$ khuki
$\mathrm{c}=$ khuki
$\mathrm{b}=$ phok
$c=$ khuki
(C) $\mathbf{a}=$ kili
$a=$ kili
$a=$ kili
$\mathrm{b}=$ nophi
b $=$ phok $/$ kiphi
$c=$ khuki
$c=$ khuki
$a=d \operatorname{lin} a /$ shirina
$a=d$ lina $/ *$ shirina
$\mathrm{b}=$ shirina
$\mathrm{b}=$ vysota
$\mathrm{b}=$ shirina $/{ }^{*}$ glubina
$c=$ tolshchina
$c=$ tolshchina
$\mathrm{c}=$ tolshchina

(32) Russ. $a=$ dlina

Als erstes fältt auf, daß die Benennung der dritten Abmessung $c$ in den Sprachen gegenüber den Lagevarianten (I) - (III) konstant bleibt. Dies entspricht den Vorgaben über die Encodierung des Parameters SUB in 
(10), (14), (19) und (21). Bei den Abmessungen a und b hingegen beobachten wir Wechsel in der Benennung, die offenbar (i) durch die jeweilige Lage des Bretts bedingt sind, (ii) AufschluB darüber geben, wie der Parameter QUER lexikalisch abgedeckt wird.

4.2.4 D t. u n d E $\mathrm{ng}$ l. Betrachten wir diesbezüglich zunächst die uns vertrauten, aber hinsichtlich der Zuweisungsstrategie gemischten, also kritischer Prüfung doppelt bedürftigen Sprachen in (28) und (29), und zwar unter dem Blickwinkel: was besagen die Verteilungsdaten von breit/wide über die durch sie lexikalisch abgedeckten Parameter?

Im Hinblick auf die in (14) und Abb. 3 aufgeführten 10 Parameter(kombinationen) ist als erstes festzuhalten, daB breit/wide den Einzelparameter QUER abdecken können - wie in (28/29)(I), aber auch die Parameterkombination MAX-QUER - wie in (28/29)(II) und (III). Als nächstes vergegenwärtigen wir uns, daß der Parameter QUER keine unabhängige perzeptive Fundierung hat, sondern wie in (10) formuliert, stets die durch MAX, SUB, VERT, OBS gelassene Lücke füllt. Für breit/wide (als Encodierung von QUER) heißt das, die Benennung einer Objektabmessung d durch breit/wide erfolgt stets i $n$ Relation $z$ u einer unabhängig identifizierbaren Objektabmessung d'. Die Bedingungen für die Wahl von $d$ und d' zeigt ein Blick auf die Daten in (28/29) bezüglich (I) - (III).

In (I) folgt die Zuweisung von $\mathbf{a}=$ lang/long, $\mathbf{b}=$ breit $/$ wide der proportionbasierten Strategie (23), d.h. QUER in breit/wide wird zugewiesen in Relation zu einer Achse d', die als Maximale (d.h. d' $=\mathbf{a}=\mathbf{M A X}$ ) durch lang/long identifiziert wird. Das Vorkommen von lang/long ist nach der Universalienannahme (21) ein sicheres Indiz dafür, daß Maximalität die definierende Eigenschaft der betreffenden Objektachse ist. In (II) folgt die Zuweisung von $\mathbf{a}=$ hoch/high dem Prinzip (25) "die Vertikale gewinnt" und liefert somit ebenfalls eine Achse d' $=\mathbf{b}=$ VERT), in Relation zu welcher QUER bestimmt werden kann, somit $\mathbf{a}=$ breit/wide. Nach welcher Strategie? Wenn a in (II) proportionsbasiert benannt würde, müßte gelten $\mathbf{a}=$ lang/long, was zwar nicht völlig ausgeschlossen ist, aber von den Vpn in Kombination mit $\mathbf{b}=$ hoch $/$ high abgelehnt wird. Somit folgt die Zuweisung von $\mathbf{a}=b \mathrm{reit} / \mathrm{wide}$ in (II), wo breit/wide die Parameterkombination MAX-QUER lexikalisch abdecken, der betrachterbasierten Strategie (24). Dies ergibt sich aus der Orthogonalität der Achsen des POR zueinander (OBS im $\nless 90^{\circ}$ zu VERT, QUER im $\nless 90^{\circ}$ zu OBS), wie in (7) - (9) erläutert. In (III) folgt die Zuweisung $\mathbf{a}=$ breit $/$ wide, $\mathbf{b}=$ tief/deep ebenfalls der betrachterbasierten Strategie (24). Das Vorkommen von tief/deep ist nach (21) ein sicheres Indiz für Betrachterbasiertheit. 
Wir können nun zwei Feststellungen über die lexikalische Abdeckung von QUER durch breit/wide im entsprechenden Wortfeld der dt. und engl. Dimensionsausdrücke treffen und anschließend in 4.2.5 eine wichtige semantische Frage klären.

(33) (a) In Relation zu d' = MAX werden breit/wide proportionsbasiert zugewiesen und decken dann allein den Parameter QUER ab;

(b) in Relation zu d' = VERT oder d' = OBS werden breit/wide betrachterbasiert zugewiesen und können dann auch die Parameterkombination MAX-QUER abdecken.

4.2.5 Die lexikalis che Bedeutung von breit/wide. Besagt (33) nun, daB breit/wide eine Lexikalisierung sowohl von QUER allein als auch von der Kombination MAX-QUER darstellen und somit echt polysem ist? Nein. Die in breit/wide lexikalisch fixierte, d.h. im strengen Sinne le $\mathrm{xik}$ a lis i e r t e Bedeutungskomponente ist nur QUER, wohl aber kann breit/wide kontextuell bedingt - vgl. (33) (b) auf die Kombination MAX-QUER angewandt werden. Wie breit/wide weisen auch andere Dimensionsausdrücke die Eigenschaft auf, daß sie - falls der entsprechende Kontext gegeben ist - in einem über die in ihnen lexikalisch codierten Identifizierungsparameter hinausreichenden Bereich anwendbar sind. Die erweiterte Anwendung - wie von QUER in breit/wide auf MAX-QUER - ist wiederum grundsätzlich durch die Verträglichkeitsbedingungen in (14) geregelt. Ob der Grund für die Erweiterung des Anwendungsbereichs eines lexikalisierten Parameters in einer systematischen Bezeichnungslücke, d.h. im Fehlen eines eigenen Wortes ${ }^{4}$, zu suchen ist, kann letztlich nur durch spezielle diachronische Studien beantwortet werden. Ein dt.-engl. Vergleich spricht jedoch dafür: so sind im Dt. breit - schmal Lexikalisierungen von QUER, weit - eng von DIST, während im Engl. die fehlende Belegung von DIST eine echte lexikalische Lücke bildet, so daB wide - narrow als Lexikalisierungen von QUER kontextuell qua Verträglichkeit auch auf QUER-DIST anwendbar sind.

Die semantisch wichtige Unterscheidung von lexikalisch fixierter Bedeutung und kontextuell gesteuerter Anwendung (eine Facette der Unterscheidung von semantischer vs. konzeptueller Ebene in 2.1) wird durch die A n to $\mathrm{n}$ me $\mathrm{n} b \mathrm{ild} \mathbf{u} \mathrm{n}$ und das Inferenzverhalten

4 Am ehesten wäre engl. broad ein Kandidat für eine Lexikalisierung von MAX-QUER, aber broad verhält sich bezüglich der Feldzugehörigkeit nach (12) ziemlich idiosynkratisch: es nimmt keine Maßphrasen: ${ }^{*}$ the board is $1 \mathrm{~m}$ broad, wohl aber the board is $1 \mathrm{~m}$ in bredth, und es bildet keine Wh-Phrasen ( ${ }^{*}$ How broad is the board?). 
gestützt. $\mathrm{Zu}$ Inferenzen mehr in 3.2.6, zu Antonymie hier nur zwei Bemerkungen.

Erstens, wenn die $V$ pn mit zwei bezüglich a unterschiedlich dimensionierten Brettern in (II) oder (III) konfrontiert werden, wo breit/wide also QUER-MAX abdecken, akzeptieren sie etwa Das linke Brett ist breiter als das rechte, vermeiden aber bei der Konverse das lexikalische Antonym schmal bzw. narrow und weichen aus auf das rechte Brett ist weniger breit/kürzer als das linke (bzw. the right board is less wide // shorter than the left one). Dies entspricht auffallend dem Befund bei tall (das eine Lexikalisierung von MAX-VERT darstellt), als dessen Antonym ebenfalls nur das lexikalische Antonym des fundierenden Parameters MAX, nämlich short fungieren kann.

Zweitens, die Bedingung, daB die lexikalisierten Komponenten die gemeinsame Basis für die Antonymbildung darstellen, ermöglicht die klärende Unterscheidung zwischen lexikalischer Antonymie (z.B. hoch - niedrig) und kontextuell induzierter Antonymie (hoch - flach, tief flach, hoch - tief - vgl. auch (2)), über die im IdS-Jahrbuch 1993 (Lang 1995a) ausführlich diskutiert wurde. Die bei letzterer zu beobachtenden "Antonymgabeln" sind Resultat der kontextuell bedingten erweiteren Anwendung von Dimensionsausdrücken.

F a $z$ i $t$ : Wir haben bei der Rekonstruktion der Wortfeldstruktur der Dimensionsausdrücke unter dem Gesichtspunkt der lexikalischen Abdeckung somit folgende Befunde zu berücksichtigen:

(34) (a) die eigentliche Lexikalisierung von einzelnen oder kombinierten DAP;

(b) die kontextuell bedingte erweitere Anwendung dieser Lexikalisierungen auf damit verträgliche DAP(-Kombinationen).

(c) lexikalische Lücken (wie im Engl. bezüglich DIST, im Dt. bezüglich MAX-VERT)

(d) Anwendungslücken von Lexikalisierungen (vgl. 4.3.3 unten).

4.2.6 Ko $\mathrm{K} \mathrm{te} \mathrm{xt} \mathrm{be} \mathrm{d} \mathrm{in} \mathrm{g} \mathrm{ung} \mathrm{e} \mathrm{n.} \mathrm{Der} \mathrm{Test} \mathrm{in} \mathrm{Abb.} 4$ ist deshalb so ergiebig, weil er ein Brett in drei Situationen mit zunehmender Integration in die räumliche Umgebung zeigt, von den reinen Gestalteigenschaften des Bretts an sich in (I) (lang, breit) über die vertikale Orientierung in (II) (breit, hoch) und die Integration in ein räumliches Makro-Objekt (Fensternische), von dem das Brett die spezifikatorischen Auszeichnungen (breit, tief) erbt. In dieser Hinsicht geben die eruierten Benennungsvarianten darüber AufschluB, wie kontextabhängig die $\mathrm{Zu}-$ weisung von Dimensionsausdrücken ist bzw. umgekehrt, was die jeweili- 
gen Dimensionsausdrücke an kontextueller Spezifikation einbringen. Der letztgenannte Aspekt verdeutlicht bezüglich des Inferenzverhaltens der Dimensionsausdrücke im Kontext noch einmal die in 4.2.5 verfochtene Unterscheidung von lexikalischer Bedeutung und kontextuell bedingter Anwendung. Hierzu zwei bemerkenswerte Befunde:

Erstens, die in 4.2.4 und 4.2.5 erläuterten Zuweisungsbedingung für breit/wide gelten für sprachliche wie nicht-sprachliche Kontexte gleichermaBen. Was in Abb. 4 durch nicht-sprachliche Kontextinformation geboten wurde, kann ebenso durch sprachliche in Sätzen wie (35) geliefert werden, die - gemäB den Einzigkeitsbedingung (27) - dieselbe Information bezüglich d' bereitstellen, die für die Zuweisung von breit/wide an d nötig ist:

Das Brett ist lang und breit genug, aber zu dünn The board is long and wide enough but too thin [d' = MAX, b = QUER wie in Abb. 4 (I)]

Das Brett ist breit und hoch genug, aber zu dünn The board is wide and high enough but too thin [d' = VERT, a = MAX-QUER wie in Abb. 4 (II)]

Das Brett ist breit und tief genug, aber zu dünn The board is wide and deep enough but too thin [d' = OBS, a = MAX-QUER wie in Abb. 4 (III)]

Dies macht erneut klar, daß die in der sonstigen Literatur häufig zu findende Polysemieannahme für breit/wide semantisch kaum gerechtfertigt ist, sondern die hier vertretene Auffassung, für breit/wide $\mathrm{e}$ in e durch QUER repräsentierte lexikalische Bedeutung (die allerdings, wie gezeigt, inhärent relational ist) zu postulieren und entsprechende kontextuelle Anwendungsbedingungen zu formulieren, den Fakten eher gerecht wird.

Zweitens, der Test mit dem Brett bringt zuverlässige Daten über die inferenziellen Beziehungen $\mathbf{z w i s c h e n}$ den Gestalteigenschaften und den Lageeigenschaften von Objekten. Vgl.:

(36) (a) Das Brett ist $1 \mathrm{~m}$ breit, $30 \mathrm{~cm}$ tief

$\rightarrow$ Das Brett ist $1 \mathrm{~m}$ lang, $30 \mathrm{~cm}$ breit

(b) The board is $1 \mathrm{~m}$ wide, $30 \mathrm{~cm}$ high

$\rightarrow$ The board is $1 \mathrm{~m}$ long, $30 \mathrm{~cm}$ wide

(c) Das Brett ist $1 \mathrm{~m}$ lang, $30 \mathrm{~cm}$ breit + Das Brett ist $1 \mathrm{~m}$ breit, $30 \mathrm{~cm}$ hoch $/$ tief 
Dies zeigt, daB die inhärenten Gestalteigenschaften eines Objekts gültig aus seinen kontextuell induzierten Lageeigenschaften gefolgert werden können, aber nicht umgekehrt. Die diesen Inferenzen zugrunde liegende Operation ist die der De-Spezifizierung (vgl. Lang, Carstensen, Simmons (1991)), die wiederum beweist, daB aus der kontextuell bedingten Anwendung eines Dimensionsausdrucks wie breit/wide auf MAX-QUER in (36) (a-b) auf dessen lexikalische Bedeutung QUER geschlossen werden kann, nicht aber umgekehrt, wie in (36) (c) zeigt.

SchlieBlich ist Abb. 4 auch noch gut als "diagnostic" für die aufgrund der Strategienmischung gemäB (27) (c) zu erwartende Mehrdeutigkeit von breit/wide. So zeigt sich nicht nur, daB ohne einschlägigen sprachlichen oder nicht-sprachlichen Kontext ein Satz wie

(37) Das Brett ist $50 \mathrm{~cm}$ breit/The board is $0.5 \mathrm{~m}$ wide/in width

$m$ e $h$ r d e $u$ t $i \quad g$ ist bezüglich der Abmessung, auf die sich breit/wide beziehen, sondern auch, dab wir den Spielraum und die Quelle der verschiedenen Zuweisungsmöglichkeiten für breit/wide exakt aufzählen können. Wohlgemerkt: diese Mehrdeutigkeit ist nicht zu verwechseln mit Polysemie, vielmehr zu vergleichen der referentiellen Unterbestimmtheit von anaphorischen Pronomina, die auch eine fixierte lexikalische Bedeutung haben, aber nur kontextabhängig referieren. ${ }^{5}$

Wenn nun die Mehrdeutigkeit von breit/wide eine Folge der Tatsache ist, daß Dt. und Engl. bezüglich der lexikalischen Abdeckung zum "gemischten" Typ gehören, dann sollte man erwarten, daß die Sprachen vom rein proportionsbasierten Typ diesbezüglich keine Mehrdeutigkeiten aufweisen, und das ist in der Tat so.

4.2.7 C h in es is ch und Kore a $n$ is c h. Die Daten in (30) - bitte zurückblättern! - weisen das Chin. als klar proportionsbasiert aus, die Abmessung a wird konstant mit cháng benannt, das ausschließlich MAX lexikalisiert, während $\mathbf{b}$ in (I) und (III) für $k u a \bar{n} n$ reserviert ist, das seinerseits - anders als breit/wide - strikt beschränkt ist auf die Lexikalisierung von QUER in Relation zu d'= MAX und somit für die Abmessung a und für eine Anwendung auf MAX-QUER grundsätzlich ausscheidet. In (30) (II) folgt die Zuweisung $\mathbf{b}=g \overline{\mathbf{a}} o$ dem Prinzip (25) "die Vertikale gewinnt", was mit der proportionsbasierten Zuweisung von $\mathrm{a}=$ cháng/ ${ }^{*} k u \bar{a} n$ in (II) nicht interferiert, somit (25) als unabhängiges Prinzip bestätigt.

5 Eine ganz analoge Form von Mehrdeutigkeit besteht bei den von J. Grabowski/P. Weiß (in diesem Band) untersuchten Präpositionen vor und hinter bezüglich ihres deiktischen vs. intrinsischen Gebrauchs. 
Die Tatsache, daß $\mathbf{b}={ }^{*}$ shē $n$, das OBS lexikalisiert, für alle drei Situationen ausgeschlossen ist, belegt, daB das Chin. nicht über eine betrachterbasierte Strategie verfügt. Natürlich hat das Chin. eine primäre Lexikalisierung für den Parameter OBS, nämlich shēn, aber dies ist selektional beschränkt auf Abmessungen in konkaven oder hohlen Objekten und interagiert in keiner Weise mit der Zuweisung und lexikalischen Abdeckung von QUER. Die aus der Proportionsbasiertheit zu prädizierenden Eigenschaften von $k u \bar{a} n$ [QUER zu MAX] bezüglich Mehrdeutigkeit und Inferenzverhalten werden bestätigt. Anders als breit/wide in (37) ist kuān in (38) nicht mehrdeutig.

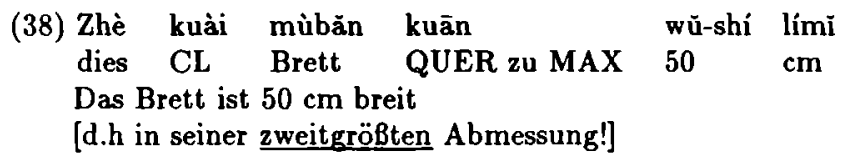

Und ebenso gibt es keine zu (36) (a-b) analogen gültigen Inferenzen, weil die Voraussetzung dafür, nämlich die betrachterbasierte Zuweisung von shē $n$ und Anwendung von kuān auf MAX-QUER im Chin. fehlen. Vgl.:

(39) (a) Zhè kuài mùbăn kuān $1 \mathrm{~m},{ }^{*}$ shēn $30 \mathrm{~cm}$

† Zhè kuài mùbăn cháng $1 \mathrm{~m}$, kuān $30 \mathrm{~cm}$

(b) Zhè kuài mùbăn *kuān $1 \mathrm{~m}$, gāo $30 \mathrm{~cm}$

† Zhè kuài mùbăn cháng $1 \mathrm{~m}$, kuān $30 \mathrm{~cm}$

(c) Zhè kuài mùbān cháng $1 \mathrm{~m}$, gāo $30 \mathrm{~cm}$

$\rightarrow$ Zhè kuài mùbăn cháng $1 \mathrm{~m}$, kuān $30 \mathrm{~cm}$

Das Koreanische ist reich an Dimensionsausdrücken, aber diese bilden disjunkte Subgruppen, von denen die mit kili und phok als Lexikalisierungen von MAX bzw. QUER dem Chin. cháng bzw. kuān ähnelt, indem sie proportionsbasiert zugewiesen wird - vgl. (31)(C). Die andere Subgruppe kalo und selo aber ist klar betrachterbasiert nach Zubin/Choi (1984, S. 337): "the spatial terms kalo and selo <... > pick out the edges of a surface which are across and in line with the observer's visual field, respectively, with no regard for the relative extension of these edges." Übersetzt in unsere Redeweise heiBt das, daB kalo und selo korrelativ zugewiesen werden, so daB kalo QUER abdeckt in Relation zu d' = OBS und selo OBS abdeckt in Relation zu d" = QUER. Um dies aus den Testdaten zu entnehmen, ist für (31) (A) und (B) die Blickrichtung des jeweiligen Betrachters längs bzw. quer zum Brett angesetzt. Bemerkenswert ist die komplementäre Verteilung von kalo und selo auf die Abmessungen $\mathbf{a}$ und $\mathbf{b}$ innerhalb von und zwischen den Datengruppen (A) und (B). Die zusätzliche Option für $b=$ nophi [VERT] in (A) bis (C) folgt unabhängig aus dem Prinzip (25) „die Vertikale gewinnt”. 
Bemerkenswert ist ferner, daB Ausdrücke aus beiden Subgruppen nicht miteinander in koordinativen Konstruktionen vorkommen können, was (a) die Disjunktheit der zugrunde liegenden Strategien verdeutlicht, (b) einen Hinweis auf die einzelsprachliche Verschärfung des Prinzips (26) zu einem Homogenitätsprinzip darstellt. Entsprechend verhält es sich mit der Mehrdeutigkeit, die Übersetzung von (37) in Ausdrücke der erstgenannten Subgruppe ist wie im Chin. eindeutig - vgl. (40), die in die Ausdrücke kalo und selo hingegen ist ohne Kontexthilfen absolut unterspezifiziert bezüglich ihrer Referenz auf $a$ und $\mathbf{b}-\mathrm{vgl}$. (41):

(40) Ku-nelphanci-nun DET.Brett.TOP

phoki QUER zu MAX.SUBJ

Das Brett ist $1 \mathrm{~m}$ breit

[d.h in seiner zweitgrößten Abmessung]

(41) Ku-nelphanci-nun selo-ka/kalo-ka

il meta ita.

DET.Brett.TOP OBS.SUBJ/QUER zu OBS.SUBJ $1 \mathrm{~m}$ DECL Das Brett ist $1 \mathrm{~m}$ lang, breit

Das Inferenzverhalten ist leicht vorhersagbar. Wenn durch Maßangaben die Proportionen erschließbar sind, dann gibt es gültige Inferenzen von Ausdrücken der zweiten auf die der ersten Subgruppe, d.h. von kontextuell induzierten Lageeigenschaften der Objekte auf ihre inhärenten Gestalteigenschaften, andersrum natürlich nicht. Vgl.:

(42) Ku-nelphanci-nun kalo-ka $1 \mathrm{~m}$, selo-ka $0.3 \mathrm{~m}$ ita.

$\rightarrow$ Ku-nelphanci-nun kili-ka $1 \mathrm{~m}$, phoki $0.3 \mathrm{~m}$ ita.

Das Brett ist in der Querachse $1 \mathrm{~m}$, in der Betrachterachse $0.30 \mathrm{~m}$.

$\rightarrow$ Das Brett ist $1 \mathrm{~m}$ lang, 0.30 breit.

Zum Russ., dessen Daten in (32) strukturell denen des Chin. sehr ähneln und mithin auf Proportionsbasiertheit verweisen, sind nur zwei Bemerkungen nötig. E r s t e $\mathrm{n} s$, anders als im Chin. ist shirina als Lexikalisierung von QUER nicht auf die Zuweisung in Relation zu d' = MAX beschränkt, sondern es kann auch in Relation zu d' = VERT zugewiesen werden, wie (32)(II) zeigt. Hier ist gemäB (25) b mit vysota [VERT] belegt, was Raum läBt, a entweder proportionsbasiert mit dlina [MAX] oder - "weniger gern" (so die VPn) - mit shirina [QUER] zu belegen. $\mathrm{Z}$ w e i t e $\mathrm{n} s$, wie im Chin., aber anders als im Dt. und Engl., ist die Lexikalisierung von OBS, glubina, selektional auf Abmessungen konkaver oder hohler Objekte beschränkt. Somit fallt OBS als relevante Achse d' für die Zuweisung von shirina [QUER] im Russ. aus.

Der letzte Punkt zeigt eine weitere Facette der crosslinguistischen Variation bezüglich des Wortfelds der Dimensionsausdrücke: Sprachen, die 
nach (22) dieselbe Anzahl von primären distinkten Lexikalisierungen von MAX, VERT, OBS aufweisen, können sich dennoch unterscheiden in den Selektionsbeschränkungen, die mit diesen Ausdrücken verbunden sind. Somit sollten wir Selektionsunterschiede auf die Liste der typologischen Parameter setzen.

\subsection{Typologische Feineinteilung und Interferenz}

Die in (27)(c) erwähnten Sprachen vom Misch-Typ (Dt., Engl., Russ.) sollen nun in ihrer Skalierung bezüglich proportionsbasierter oder betrachterbasierter Zuweisung eingeordnet und erläutert werden. Zugleich will ich einen zweiten Test vorführen und die aus den Daten zu entnehmende Feineinteilung auf einen Fall von sprachlicher Interferenz anwenden. Dazu müssen die in (23) und (24) bloß in erster Näherung formulierten Kennzeichen von Proportions- vs. Betrachterbasiertheit etwas detaillierter ausgeführt werden. Wir können uns dabei auf die in 4.2. diskutierten Daten stützen. Wir zerlegen die beiden Strategien in je vier "diagnostics", die zusammen oder eben in typologisch relevanten Auswahlen die lexikalischen Abdeckungsbereiche im Wortfeld der Dimensionsausdrücke einer Sprache L (so die Variable über den untersuchten Sprachen) bestimmen.

4.3.1 B e t r a c h t e r b a si e r t e S t r a t e gie. Ihr Einfluß auf die Struktur des Wortfelds der Dimensionsausdrücke in der Sprache L läßt sich nach folgenden Kriterien diagnostizieren:

(43) $0-1$

Die Ausdrücke, die OBS und/oder VERT in L lexikalisch abdecken, bestimmen den Abdeckungsbereich und die Interpretation der Ausdrücke in L, die QUER abdecken.

(44) O-2

Die Ausdrücke, die OBS in L lexikalisch abdecken, sind $n$ i $c$ h t selektional auf konkave oder hohle Objekte beschränkt.

(45) $\mathrm{O}-3$

Für eine spezifizierbare Klasse von Objekten gibt es bezüglich der Achse $d$ in $L$ eine Benennungsalternation von Ausdrücken, die VERT und VERT-OBS lexikalisch abdecken.

(46) $0-4$

In L kann die Vertikalitätsauszeichnung die Maximalitätsauszeichnung absorbieren, d.h. die Anwendung des Ausdrucks für VERT auf MAX-VERT verhindert die gesonderte Anwendung des Ausdrucks für MAX auf dasselbe Objekt. 
Einen Kommentar benötigten höchstens (O-3) und (O-4). Die Benennungsalternation ist am einfachsten anhand konkaver Objekte wie in (47) zu belegen, im Dt. aber - wie in (2) gezeigt - weit ausdehnbar auch auf andere Objekte und sogar Distanzen.

(47) Der Topf ist zu hoch, um ins Regal zu passen, aber nicht tief genug für die Pute

(O-4) bezieht sich auf die Alternative, die übrigbleibt, wenn „die Vertikale gewonnen hat". Die Absorption ist typisch für Dt.und Engl., vgl. die Auszeichnungen high, wide $\left({ }^{*} l o n g\right)$, deep für $b$ in (29) oder für einen $2 \mathrm{~m}$ hohen Eckschrank tall, wide, deep, wobei im Engl. tall die Absorption sogar lexikalisiert ist. Eine getrennte Vertikalitäts- und Maximalitätszuweisung für denselben Eckschrank findet sich im Chin. oder Russ. (vysota - dlina - shirina).

4.3.2 Proportions basierte $\mathrm{Str}$ a tegie. Die analogen, außer ( $\mathrm{P}-1)$ zu (O-1) bis (O-4) komplementären Kriterien für eine so determinierte Wortfeldstruktur der Dimensionsausdrücke lauten:

(48) P-1

Die Ausdrücke, die MAX in $L$ lexikalisch abdecken, bestimmen den Abdeckungsbereich und die Interpretation der Ausdrücke in L, die QUER abdecken.

(49) P-2

Die Ausdrücke, die OBS in L lexikalisch abdecken, sind selektional auf konkave oder hohle Objekte beschränkt.

(45) P-3

Falls vorhanden, ist eine Benennungsalternation von Ausdrücken, die VERT und VERT-OBS lexikalisch abdecken, auf eine enge Klasse von Objekten (Hohlkörper) begrenzt

(46) P-4

In L sind Vertikalitätsauszeichnung und Maximalitätsauszeichung stets separierbar.

Mit den Os und Ps können wir die Sprachen nun ziemich genau nach ihrem Mischungsverhältnis skalieren und darüberhinaus Mehrdeutigkeiten und Anwendungslücken erklären. Ich illustriere das anhand der Daten aus einem weiteren Test.

4.3.3 $\mathrm{St} \mathrm{u} \mathrm{f} \mathrm{e} \mathrm{-} \mathrm{t} \mathrm{r} \mathrm{e} \mathrm{p} \mathrm{p} \mathrm{a} \mathrm{u} \mathrm{f/t} \mathrm{r} \mathrm{e} \mathrm{p} \mathrm{p} \mathrm{a} \mathrm{b.} \mathrm{In} \mathrm{der} \mathrm{folgenden} \mathrm{Auf-}$ gabe sollten die Vpn die Abmessungen der ersten (schraffierten) Stufe einer Treppe und der Treppe insgesamt benennen, und zwar in zwei Versionen: (a) bei Bewegung treppauf, (b) bei Bewegung treppab. Der Test 
liefert Daten über die Bewegung als Kontextfaktor und über die dimensionale Teil-Ganzes-Erblichkeit zwischen Stufe und Treppe. Zunächst die Daten in Auswahl, dann die Erläuterungen.

(47) Chin.

$$
\begin{aligned}
& \mathrm{a}=\text { gāo [VERT] } \\
& \mathrm{b}=\text { cháng [MAX] } \\
& \mathrm{c}=\text { kuān [QUER zu MAX] }
\end{aligned}
$$

(48) Korean. a = nophi [VERT]

$\mathrm{b}=$ kalo

[QUER zu OBS]

$\mathrm{a}=$ kiphi [VERT-OBS]

$c=$ selo [OBS]

$\mathrm{b}=$ kalo [QUER zu OBS] $c=$ selo [OBS]

(49) Dt.

$$
\begin{aligned}
& \mathrm{a}=\text { hoch } \\
& \mathrm{b}=\text { breit } \\
& \mathrm{c}=\text { tief }
\end{aligned}
$$$$
\begin{aligned}
& a=\text { tief } \\
& b=\text { breit } \\
& c=? ? ?
\end{aligned}
$$

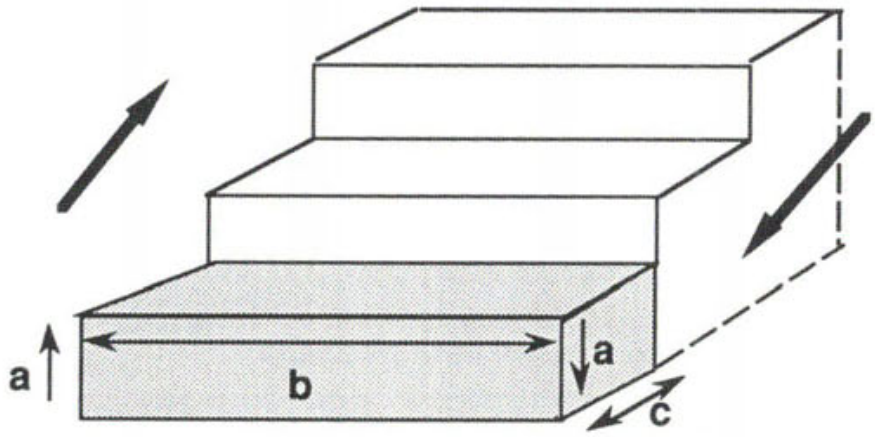

Abb. 5: Benennung von Objektabmessungen: Treppenstufe

(50) Russ.

$$
\begin{aligned}
& \mathrm{a}=\text { vysota [VERT] } \\
& \mathrm{b}=\text { dlina [MAX] /shirina [QUER zu VERT] } \\
& \mathrm{c}=\text { shirina }[\mathrm{QUER} \text { zu MAX] /??? }
\end{aligned}
$$

(51) Poln.

$$
\begin{array}{ll}
\mathrm{a}=\text { wysoki [VERT] } & \mathrm{a}=\text { glęboki [VERT-OBS] } \\
\mathrm{b}=\text { dlugi [MAX] } & \mathrm{b}=\text { dlugi [MAX] } \\
\mathrm{c}=\text { szeroki [QUER zu MAX] } \mathrm{c}=\text { szeroki [QUER zu MAX] }
\end{array}
$$


(52) Slovak.
$\mathrm{a}=$ vysoký [VERT]
$\mathrm{b}=$ dlhý
[MAX] /siroký [QUER] b = dlhý [MAX]
$c=$ široký [QUER] /hlboký [OBS] $c=$ široký [QUER zu MAX]

4.3.4 S k a 1 i e r u n g. Chin. (47) und Russ. (50) machen treppauf/treppab keinen Unterschied in der Benennung der Stufe, was die Proportionsbasiertheit beider unterstreicht. Wir können es durchprüfen, alle Ps sind im Chin. erfüllt:

P-1 (kuān wird nur relativ zu MAX zugewiesen); P-2 (Stufe ist kein konkaves Objekt); P-3 (keine Benennungsalternation bei nicht-konkaven Objekten); P-4 (Vertikalitäts- und Maximalitätsauszeichnung getrennt), und kein $O$. Russ. ist ähnlich, nur dab hier (O-1) ergänzend hinzukommt, nämlich daB QUER relativ zu VERT zugewiesen wird - was shirina in (50) für b erlaubt, dann aber für c eine Anwendungslücke aufreißt (???), weil glubina [OBS] selektional auf konkave Objekte beschränkt ist.

Kor. (48) erfüllt alle Os der Betrachterbasiertheit, was aber treppauf/treppab ebenfalls keinen Unterschied bezüglich $b$ und c bewirkt, wohl aber nutzt das Kor. die Benennungsalternative für a nach O-3. Eine Anwendungslücke kann hier nicht auftreten.

Dt. erfüllt O-1 bis O-3, wie man in (49) leicht sieht, aber auch O-4: wenn man sich die Stufe mit a als der Maximalen vorstellt, wird die Treppe zwar unbequem zu benutzen sein, aber die Auszeichnung bleibt treppauf diesselbe hoch - breit - tief. Wo aber rührt die Anwendungslücke im Dt. (49) her? Aus zwei unabhängigen, aber im Effekt konvergierenden Faktoren. E r s t e n s, tief deckt im Dt. OBS und OBS-VERT ab, letzteres ist die Basis für die Benennungsalternative in $\mathrm{O}-3$, ersteres führt dazu, daB O-1 und O-3 bezüglich tief interferieren - eine einzelsprachliche Option. Z w e i t e n s, treppab wird die Einzigkeitsbeschränkung (26) wirksam, indem sie verhindert, daB tief, wiewohl auf distinkte Abmessungen bezogen, zweimal auftritt - eine universelle Beschränkung, die sich erwartungsgemäß durchsetzt. So erklärt sich die Anwendungslücke im Dt., anders als die im Russ. in (50) mit $\mathbf{b}=$ shirina (vgl. oben).

4.3.5 In terfere $\mathrm{nz} z \mathrm{w}$ is c he $\mathrm{n} \mathrm{S}$ p r a c he $\mathrm{n}$. Die Daten in (49) - (51) sind besonders interessant, weil sie eine Feineinteilung innerhalb der slavischen Sprachen zeigen, die - trotz der gemeinslavischen Herkunft der Dimensionsausdrücke - in der Skalierung Russ. - Poln. Slovak. einen schrittweisen Übergang von Ps auf Os aufweisen und sich dem Dt. annähern. Die sich verändernde Arbeitsteilung zwischen Ps und Os läßt sich anhand der Daten so tabellieren: 
(52)

$\begin{array}{llllll}\text { Chin. } & \text { P-1 } & \text { P-2 } & \text { P-3 } & \text { P-4 } & \\ \text { Russ. } & \text { P-1 } & \text { P-2 } & \text { P-3 } & \text { P-4 } & \text { O-1 } \\ \text { Poln. } & \text { P-1 } & \text { P-2 } & \underline{\mathrm{O}-3} & \text { P-4 } & \text { O-1 } \\ \text { Slovak. } & \text { P-1 } & \underline{\mathrm{O}-2} & \underline{\mathrm{O}-3} & \mathrm{P}-4 & \mathrm{O}-1 \\ \text { Dt. } & \text { P-1 } & \underline{\mathrm{Q}-2} & \underline{\mathrm{O}-3} & \underline{\mathrm{Q}-4} & \mathrm{O}-1\end{array}$

Im Poln. wird P-3 durch O-3 ersetzt (oder ergänzt), jedenfalls läBt es die Benennungsalternative zum Zug kommen, der Rest bleibt wie im Russ. Im Slovak. indes wird zusätzlich P-2 durch O-2 ersetzt, was ein entscheidender Schritt zur Betrachterbasiertheit ist. Er beruht auf einer winzigen, doch effektvollen Veränderung: während im Russ. die Lexikalisierung von OBS, glubokij/glubina, selektional gemäB P-2 auf konkave und hohle Objekt beschränkt ist, ist für Slovak. hlboky/hl'bka - möglicherweise unter dem EinfluB des Dt. - diese Bedingung sehr gelockert und die Klasse der Objekte, die die Benennungsalternative zulassen, ist gewachsen.

Hier, am Beispiel von Ausdrucksinventaren mit erkennbar denselben historischen Wurzeln, zeigt sich erneut, daB Selektionsbeschränkungen unbedingt zu den relevanten Parametern einer „lexical typology” und einer Typologie der Wortfeldstruktur gehören.

4.3.6 T e i l - G a n z e s-I n f e r e n z e $\mathrm{n}$. Nur andeuten will ich zum SchluB, wie sich die in Ps und Os errechnete Feintypologie in der Vererbung der Dimensionsauszeichnungen von Stufe zu Treppe niederschlägt. Eine Konsequenz aus dem Prinzip (25) "die Vertikale gewinnt" ist, daß die Auszeichnung einer kanonischen Höhen-Abmessung vom Teil aufs Ganze und vom Ganzen auf die Teile vererblich ist. Hier ist kaum Variation zu erwarten:

(53) (a) The height of the staircase is composed of the heights of the steps

(b) Die Höhe der Treppe ergibt sich aus den Höhen der Stufen

(c) Vysota lestnicy sootvetstvuyet summe vysoty stupenej [Russ.]

(d) Wysokość schodów wynika z wysokości schodków [Poln.]

(e) Výška schodištă sa skladá zo sú čtu výšiek schodov [Slovak.]

Anders bei den Lexikalisierungen von OBS. Eine Vererblichkeit der Auszeichnungen ist nur vom Ganzen auf Teile möglich (etwa treppab in den Keller), und nur wenn 0-3 gilt, daher * für Russ., aber möglich im Poln. und Slovak. 
(54) (a) The depth of the staircase is composed of the depth of the stairs

(b) Die Tiefe der Treppe ergibt sich aus den Tiefen der Stufen

(c) *Glubina lestnicy sootvetstvuyet summe glubiny stupenej [Russ.]

(d) Glębokość schodów wynika z glębokości schodków [Poln.]

(e) Hl'bka schodištă sa skladá zo sú čtu hl'bok schodov [Slovak.]

Bei den Ausdrücken, die MAX und QUER lexikalisch abdecken, ist die Vererblichkeit der Dimensionsauszeichnungen klar vorhersagbar: bei proportionsbasierten Sprachen wie Russ. muß eine Bezeichnungsänderung erfolgen, bei betrachterbasierten können sie vererbt werden:

(55) (a) The width of the steps is equal to the width of the staircase

(b) Die Breite der Stufen ist gleich der Breite der Treppe

(c) Dlina stupenej sootvetstvuyet shirine lestnicy [Russ.] *Shirina stupenej sootvetst vuyet shirine lestnicy

5. Wortfeldstruktur - typologisch: Zusammenfassung und Ausblick

\section{$5.1 \quad$ Konklusionen}

In den vorangegangenen Abschnitten wurde versucht, die Struktur von Wortfeldern als Resultat verschiedener, teils disjunkter, teils überlappender Abdeckungsbereiche von lexikalischen Einheiten zu beschreiben, und die grobe Einteilung nach den zwei dabei erkennbaren Strategien proportionsbasiert vs. betrachterbasiert - im Detail auszubuchstabieren, anhand von Daten zu interpretieren und so zu gewissen Einsichten über Lexikalisierung, die Verpackung semantischer Komponenten in Wörtern und deren Anordnung zu einem Wortfeld zu gelangen.

Wenn wir nun das in Abschnitt 4.1.1 Abb. 3 gezeigte Inventar semantischer KOMPONENTEN für räumliche Dimensionsausdrücke mit einigen der bisher erzielten Ergebnisse auffüllen (wir nehmen nur vier Sprachen), so läßt sich die hier entworfene Typologie der Wortfeldstruktur wie folgt illustrieren. Abb. 6 zeigt zunächst die beiden mehr oder minder reinen Typen, nämlich die proportionsorientierte Partition des Wortfeldes im Chinesischen (Abb. 6a) und die betrachterbasierte im Koreanischen (Abb. 6b). In Abb. 7 die beiden "Mischtypen” Deutsch und Englisch. Die jeweilige Schraffur markiert den gesamten lexikalischen Abdeckungsbereich des kursiv gesetzen Dimensionsausdrucks (wir lassen polare Antonyme weg), innerhalb desselben kennzeichnet der fett umrandete Parameter dessen direkte Lexikalisierung, die von da aus sich erstreckende Schraffur kennzeichnet deren kontextuell erweiterten 
Anwendungsbereich. Doppelte Schraffur besagt entsprechend, daB eine Parameterkombination im Anwendungsbereich zweier primärer Lexikalisierungen liegt. Die Komplementarität der Kriterien für Proportionsbasiertheit (P-1) - (P-4) und Betrachterbasiertheit (O-1) - (O-4) läBt sich für die beiden dafür repräsentativen Sprachen ganz gut veranschaulichen. Es bedarf nur weniger Kommentare.

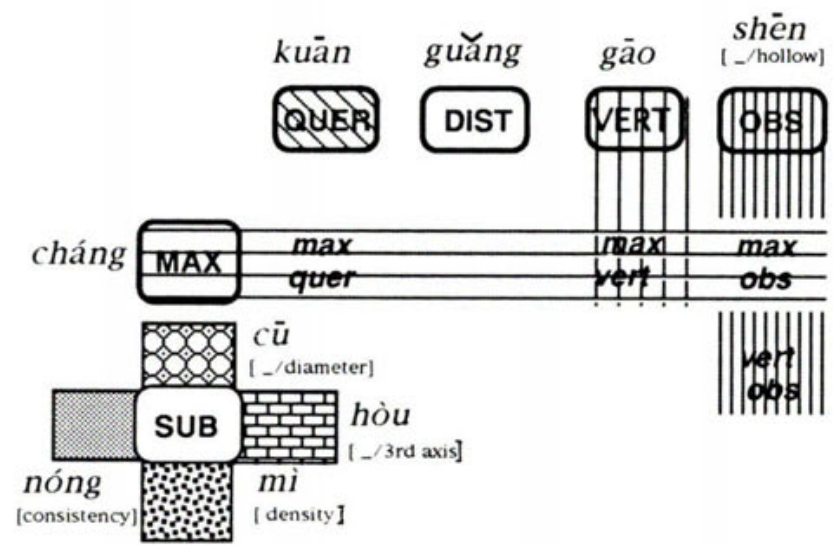

Abb. 6a: Chinesisch

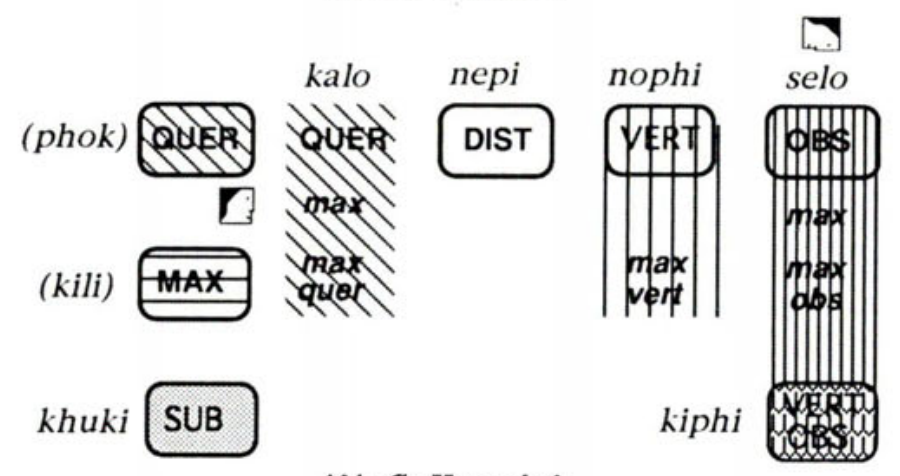

Abb. 6b: Koreanisch

Man sieht, daß im Chin. gemäß (P-1) die Lexikalisierung von QUER, nämlich $k u a \bar{n} n$ stets nur relativ zur Lexikalisierung von MAX, nämlich cháng, zugewiesen wird, während dieses wiederum alle Parameterkombinationen mit MAX als erweiterten Anwendungsbereich abdeckt. (P-2) und (P-3) sind durch die Selektionsbeschränkung [--/hollow] für shēn 
vermerkt. Im Kor. ist - wenn man von den beiden eingeklammerten proportionsbasierten Ausdrücken phok und kili, die sich wie Chin. kuān und cháng verhalten und ein eigenes Subfeld bilden, absieht - der lexikalische Abdeckungsbereich deutlich nach (O-1) - (O-4) strukturiert: MAX und die Parameterkombinationen mit MAX liegen im Anwendungsbereich von drei verschiedenen primären Lexikalisierungen, nämlich von nophi gemäß (O-4) und - je nach Betrachterposition - von kalo b2w. selo. Die primäre Lexikalisierung von OBS ist gemäB (O-2) nicht auf Hohlkörper eingeschränkt, dafür hat das Kor. mit kiphi eine eigene Lexikalisierung für VERT-OBS.

Der hier anhand von Chin. vs. Kor. unternommene Vergleich von proportionsbasierter und betrachterbasierter Wortfeldstruktur führt außerdem auf die eingangs unter (1) verzeichneten Beobachtungen und Fragen zurück und legt als Antwort eine universalienverdächtige Tendenz nahe. Offenbar besteht nämlich zwischen der lexikalischen Differenzierung des Parameters SUB in L und dem Typ des Wortfeldes nach Os und Ps folgender Zusammenhang: in Sprachen vom proportionsbasierten Typ stehen die Gestalteigenschaften der zu dimensionierenden Objekte im Vordergrund. Das entspricht dem Befund, daB solche Sprachen - in unserem Sample Chin. (vgl. Abb. 6a) und Russ. - den Bezug auf die Substanzachse ebenfalls nach Gestalteigenschaften (desintegriert oder nicht, Umfang, Dichte, Konsistenz) lexikalis ch differenzie r ter vornehmen, während die Sprachen vom betrachterbasierten Typ, wo nicht die Gestalteigenschaften, sondern die Lageeigenschaften der Objekte im Fokus stehen, hier offensichtlich abstrakter sind (vgl. Abb. 6b und Abb. 7). 

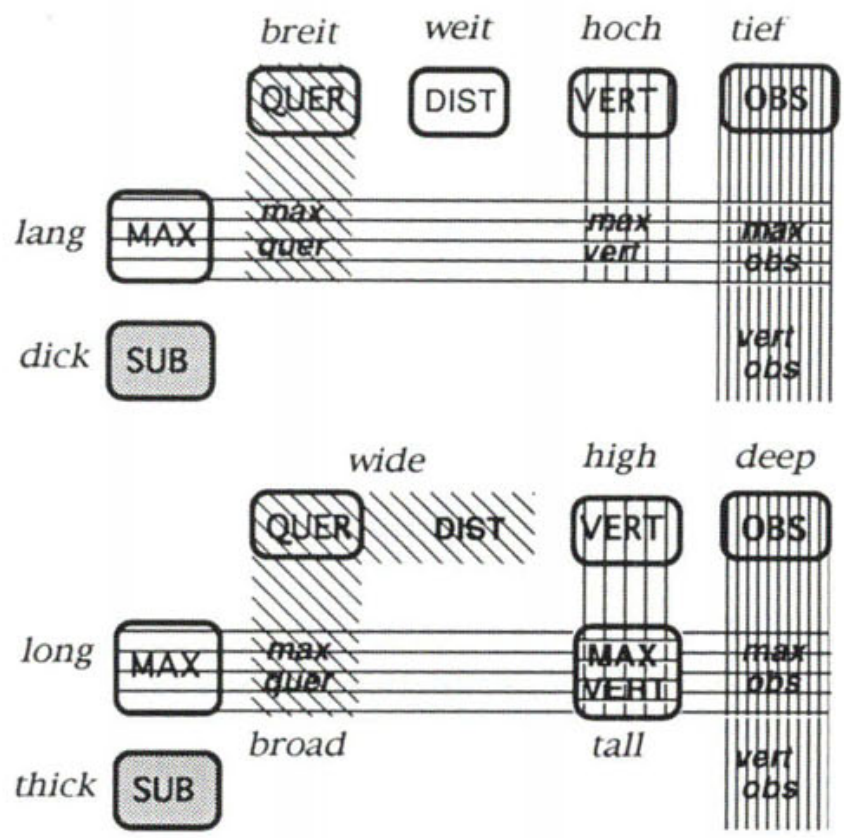

Abb. 7: Deutsch und Englisch

Der Mischtyp - (P-1) und (O-1) gelten zugleich - zeigt sich bei diesen beiden Sprachen in den Doppelschraffuren, die anzeigen, im Anwendungsbereich welcher primärer Lexikalisierungen die Kombinationen mit MAX liegen. Sie reflektieren genau die in den Abschnitten 4.2.5 - 4.2.6 über Kontextbedingungen und Inferenzen angeführten Daten. Sichtbar werden auch drei Differenzen zwischen dem dt. und dem engl. Wortfeld der Dimensionsausdrücke: im Dt. ist DIST lexikalisiert (weit - eng), im Engl. nicht, dafür hat Engl. tall als Lexikalisierung von MAX-VERT und evtl. als historisches Relikt mit idiosynkratischen Eigenschaften mit broad eine Lexikalisierung von MAX-QUER.

Einige weitere Unterschiede, darunter der schon eingangs in (2) angesprochene, werden in dieser zweidimensionalen Darstellung noch nicht sichtbar. Eine detailliertere Studie zu den Distanzausdrücken hoch - tief - weit könnte belegen, daß bezüglich des Kriteriums (O-3) (Benennungsalternative) das Dt. tatsächlich extrem ist. Die kontextuelle Antonymie von hoch - tief (hängen, fliegen) beruht darauf, daB im Dt. nicht nur die 
Blickrichtung des Betrachters (OBS) als Koordinate zur Lokalisierung eines entfernten Objekts fungiert, sondern daB - bei einer Konstellation VERT im $\nless 0^{\circ}$ zu OBS - der Betrachter seinen Standort in das zu lokalisierende Objekt projizieren und von dort „zurückblicken” kann, also VERT-OBS vom entfernten Objekt aus konstruiert.

\subsection{Ausblick}

Die in diesem Entwurf einer Typologie der Wortfeldstruktur formulierten Anforderungen halte ich für unverzichtbar, auch wenn sie bisher nur ausschnittweise eingelöst wurden, die getroffenen Annahmen bezüglich lexikalisch fixierter Bedeutung vs. kontextuell erweiterte Anwendung von (Dimensions-)Ausdrücken für zumindest plausibel. Beide zusammen bestimmen auch die Richtung, in der die Projektarbeit weitergeführt werden muß: die Typologie der Wortfeldstruktur der Dimensionsausdrücke muß sich auf mindestens drei weitere Bereich erstrecken: (a) die Morphosyntax der Komparation, (b) die Antonymbildung, (c) die möglichen Zusammenhängen zwischen dem (in Os und Ps auszurechenden) Typ der Wortfeldstruktur der Dimensionsausdrücke und der Wortfeldstruktur von Lokalisierungsausdrücken (etwa Präpositionen) bezüglich intrinsischer vs. deiktischer Seitenzuweisung (vor, hinter etc.), vgl. dazu J. Grabowski/P. WeiB (in diesem Band).

Auch unter der Rubrik „Universalien” bleibt flankierend dazu viel zu tun. Die Untersuchung der Lexikalisierung von OBS ist noch sehr oberflächlich. Wie z.B. erklärt sich der aus allen untersuchten Sprachen erhobene Befund, daß es zu den Lexikalisierungen von OBS kein polares lexikalisches Antonym gibt? Wir müssen tiefer gehen - in die Tiefenwahrnehmung und deren konzeptuelle Verarbeitung.

\section{Literatur}

Berlin, Brent/Kay, Paul (1969): Basic Color Terms. Berkeley.

Bierwisch, Manfred (1989): The Semantics of Gradation. In: Bierwisch, M./Lang, E. (eds.) (1989), S. 71-261.

Bierwisch, Manfred/Lang, Ewald (1989): Somewhat Longer - Much Deeper Further and Further. Epilogue to the Dimension Adjective Project. In: Bierwisch, M./Lang. E. (eds.) (1989), S. 471-514.

Bierwisch, Manfred/Lang, Ewald (eds.) (1989): Dimensional Adjectives: Grammatical Structure and Conceptual Interpretation. Berlin/Heidelberg/New York. (Springer Series in Language and Communication 26).

Dirven, René/Taylor, John (1988): The Conceptualisation of Vertical Space in English: The Case of Tall. In: Rudzka, Brygida (ed.): Topics in Cognitive Linguistics. Amsterdam/Philadelphia. S. 379-402. 
Durrell, Martin (1988a): $\mathrm{Zu}$ einigen deutschen und englischen Dimensionsadjektiven. Eine vergleichende Analyse. In: Munske, H. H. et al. (eds.): Deutscher Wortschatz. Lexikologische Studien. Berlin/New York. S. 93115.

Durrell, Martin (1988b): Some problems of contrastive lexical semantics. In: Hüllen, W./Schulze, R. (eds.): Understanding the lexicon. Meaning, Sense and World Knowledge in Lexical Semantics. Tübingen. S. 230241.

Ehrich, Veronika (1995): Verbbedeutung und Verbgrammatik: Transportverben im Deutschen. (in diesem Band)

Grabowski, Joachim/Weiß, Petra (1995): Das Präpositioneninventar als Determinante des Verstehens von Raumprāpositionen: vor und hinter in fünf Sprachen. (in diesem Band)

Herskovits, Anette (1986): Language and Cognition. An interdisciplinary study of the prepositions in English. Cambridge.

König, Ekkehard (1995): Kontrastive Grammatik und Typologie. (in diesem Band)

Lafrenz, Peter G. (1983): Zu den semantischen Strukturen der Dimensionsadjektive in der deutschen Gegenwartssprache. Göteborg. (Göteborger Germanistische Forschungen 24).

Lang, Ewald (1984): The Semantics of Coordination. Amsterdam/Philadelpia. (Studies in Language Companion Series 9).

Lang, Ewald (1989): The Semantics of Dimensional Designation of Spatial Objects. In: Bierwisch, M./Lang, E. (eds.) (1989), S. 263-417.

Lang, Ewald (1990a): Primary Perceptual Space and Inherent Proportion Schema. Journal of Semantics 7, 121-141.

Lang, Ewald (1990b): Sprachkenntnis, Objektwissen und rāumliches Schließen. Zeitschrift für Linguistik und Literaturwissenschaft 78, S. 59-97.

Lang, Ewald (1991): A two-level approach to projective prepositions. In: G. Rauh (ed.): Approaches to prepositions. Tübingen. S. 127-167.

Lang, Ewald (1993): The meaning of German projective prepositions: a twolevel approach. In: Zelinsky-Wibbelt, C. (ed.): The Semantics of Prepositions. From Mental Processing to Natural Processing. Berlin/New York. S. 249-291.

Lang, Ewald (1994): Semantische vs. konzeptuelle Struktur: Unterscheidung und Überschneidung. In: Schwarz, M. (ed.): Kognitive Semantik/Cognitive Semantics. Ergebnisse, Probleme, Perspektiven. Tübingen. S. 25-40.

Lang, Ewald (1995a):Das Spektrum der Antonymie. Semantische und konzeptuelle Strukturen im Lexikon und ihre Darstellung im Wörterbuch. In: Harras, G. (Hg.): Die Ordnung der Wörter. Berlin/New York. S. 30-98. (IdS-Jahrbuch 1993).

Lang, Ewald (1995b): Basic Dimension Terms: A first look at universal features and typological variation. In: FAS-Papers in Linguistics 1, S. 66-100. 
Lang, Ewald/Carstensen, Kai-Uwe/Simmons, Geoff (1991): Modelling Spatial Knowledge on a Linguistic Basis. Theory - Prototype - Integration. Berlin/Heidelberg/New York. (Lecture Notes in Artificial Intelligence Vol. 481).

Lehrer, Adrienne (1974): Semantic Fields and Lexical Structure. Amsterdam/London.

Lehrer, Adrienne (1992): A theory of vocabulary structure: Retrospectives and prospectives. In: Pütz, M. (ed.): Thirty Years of Linguistic Revolution. Philadelphia/Amsterdam. S. 243-256.

Lutzeier, Peter Rolf (Hg.) (1993): Studien zur Wortfeldtheorie. Studies in Lexical Field Theory. Tübingen 1993. (Linguistische Arbeiten 288).

Lutzeier, Peter Rolf (1995): Lexikalische Felder - was sie waren, was sie sind und was sie sein könnten. In: Harras, G. (Hg.): Die Ordnung der Wörter. Berlin/New York. S. 4-29. (IdS-Jahrbuch 1993).

Macheiner, Judith (1995): Übersetzen. Ein Vademecum. Frankfurt am Main.

Maienborn, Claudia (1990a): Lokale Verben und Präpositionen: Semantische und konzeptuelle Verarbeitung in LEU II. IBM Deutschland, Stuttgart. (IWBS Report 119).

Maienborn, Claudia (1990b): Position und Bewegung: Zur Semantik lokaler Verben. IBM Deutschland, Stuttgart. (IWBS-Report 138).

Maienborn, Claudia (1995): Situation und Lokation. Die Bedeutung lokaler Adjunkte von Verbalprojektionen. Diss. Phil. Hamburg 1993. [Erscheint 1995 in: Studien zur deutschen Grammatik, Tübingen]

Spang-Hanssen, Ebbe (1990): La sémantique des adjectifs spatiaux. In: Revue Romane 25, S. 292-309

Svorou, Soteria (1987): The semantics of spatial extension terms in Modern Greek. In: Buffalo Working Papers in Linguistics 87/01, S. 56-112.

Zubin, D.A./Choi, S. (1984): Orientation and gestalt: Conceptual organizing principles in the lexicalization of space. In: CLS-20. Parasession on lexical semantics. S. 333-345.

Zubin, D.A./Svorou, S. (1984): Perceptual schemata in the spatial lexicon: A cross-linguistic study. In: CLS-20. Parasession on lexical semantics. S. 346-358. 

Grammatikalisierung und „Mischtyp” 



\title{
ÖSTEN DAHL
}

\section{Das Tempussystem des Deutschen im typologischen Vergleich}

\begin{abstract}
Als grundlegende Analyseeinheit für das typologische Studium von Tempusund Aspektsystemen wird das 'Gramm' eingeführt - eine Kategorie, unter die zum Beispiel 'Progressiv' oder 'Perfektiv' fallen. Im typologischen Vergleich spielen übereinzelsprachliche Grammtypen eine Rolle. Bezüglich der Verteilung von Grammtypen lassen sich in den europäischen Sprachen bestimmte areale Tendenzen feststellen. Das deutsche Tempus- und Aspektsystem kann als relativ "arm" eingeordnet werden. Genauer analysiert werden das Perfekt und die Ausdrucksmöglichkeiten für Zukunft im Deutschen.
\end{abstract}

\section{Typologisches über Tempus und Aspekt}

Das typologische Studium von Tempus- und Aspektsystemen ist nicht so gut entwickelt wie z.B. die Wortfolgetypologie. Das hängt wohl damit zusammen, daß es sich in diesem Bereich um schwer vergleichbare, semantisch definierte Kategorien handelt. Doch sollten Arbeiten wie Friedrich (1974), Comrie (1976), (1985), Chung/Timberlake (1985), Ultan (1978) erwähnt werden.

Ende der siebziger Jahre habe ich eine datenorientierte Untersuchung von Tempus- und Aspektsystemen verschiedener Sprachen initiiert. Mit Hilfe eines Fragebogens von etwa 160 Sätzen, die aus dem Englischen in die jeweilige Sprachen übersetzt wurden, haben wir Materialien aus 64 Sprachen gesammelt, die eine Art „convenience sample” ausmachten. Zu derselben Zeit haben Joan Bybee und ihre Mitarbeiter Revere Perkins und William Pagliuca eine Untersuchung von morphologischen Verbkategorien in einer kontrollierten Auswahl von 50 Sprachen durchgeführt, mit Hilfe existierender grammatischer Beschreibungen als hauptsächlicher Informationsquelle. Die Ergebnisse dieser Projekte wurden gleichzeitig, aber unabhängig voneinander publiziert, in den Monographien Dahl (1985) bzw. Bybee (1985), und waren trotz der unterschiedlichen Methodologie, auffallend ähnlich. 1989 haben wir einen gemeinsamen Artikel verfaßt, in dem wir versuchten, unsere Ansätze zu integrieren. Vor kurzem haben Bybee, Perkins und Pagliuca ihre gemeinsame Arbeit in einer Monographie vorgelegt (Bybee et al. 1994). Dieses Buch ist zur Zeit das vollständigste und aktuellste Werk über Tempus, Aspekt und Modalität aus einer typologischen Perspektive. 


\section{"Gramme"}

Die grundlegende Analyseeinheit in Bybee/Dahl (1989) und Bybee et al. (1994) sind nicht die traditionellen Kategorien Tempus und Aspekt sondern, was wir grams, zu Deutsch "Gramme”, nennen d.h. Kategorien wie das Progressiv im Englischen, das Passé simple im Französischen usw. Begriffe wie Tempus, Modus und Aspekt sehen wir als Charakterisierungen zu dem semantischen Inhalt eines Gramms, oder lieber als Domäne, aus denen ihre Bedeutungen gewählt werden. Im typischen Fall sind sie aber nicht strukturell wesentliche Einheiten grammatischer Systeme. Viele, vielleicht die meisten Gramme verbinden in ihrer Semantik Elemente aus verschiedenen Domänen, und es ist eher die Regel als eine Ausnahme, daB Gramme, die traditionell unter einer Kategorie geführt worden sind, im Hinblick auf ihren Ausdruck sehr unterschiedlich sind.

Der Begriff Gramm ist auf der sprachspezifischen Ebene zu verstehen, d.h. ein Gramm gehört zur Grammatik einer bestimmten Sprache eher als zur allgemeinen Grammatiktheorie. Eine wichtige These unserer Arbeiten ist jedoch, daB Tempus- und Aspektgramme unter eine relativ begrenzte Zahl von übereinzelsprachlichen Typen fallen. In der universellen Grammatiktheorie ist also die grundlegende Einheit der übereinzelsprachliche Gramm-Typ, der in den individuellen Sprachen als Gramm manifestiert wird. Diese Grammtypen sollen nicht als absolute Einheiten - etwa als Buchstaben eines universalen Alphabets - verstanden werden, sondern als die statistisch wahrscheinlichsten Bündelungen von Eigenschaften im "grammatischen Raum" oder als vergleichmäBig stabile Punkte längs der Grammatikalisierungswege, die die Gramme in ihrer Entwicklung beschreiben. Die Grammtypen sind auch nicht „semantische Kategorien” oder "Begriffskategorien”. Freilich ist ein Grammtyp von seiner Semantik zusammengehalten, aber es ist doch wesentlich, daß ein Grammtyp nicht ein Begriff ist, sondern ein Typ von grammatischem Element, das auch im Hinblick auf seine Ausdruckseigenschaften charakterisiert werden kann: jeder Grammtyp hat eine typische Ausdrucksweise, die seiner Position in den Grammatikalisierungsprozessen entspricht.

Ich habe auch den Begriff Grammfamilie (gram family) eingeführt. Eine Grammfamilie ist eine Gruppe von Grammen, die in einem historischen Prozeß erstanden sind - entweder durch Erbe von einer gemeinsamen Ursprache oder durch Sprachkontakt. 


\section{Die Struktur eines typischen Tempus- und Aspektsystems}

In Figur 1 werden die wichtigsten Tempus- und Aspekt-Grammtypen dargestellt. Die Pfeile zeigen die möglichen Grammatikalisierungsprozesse.

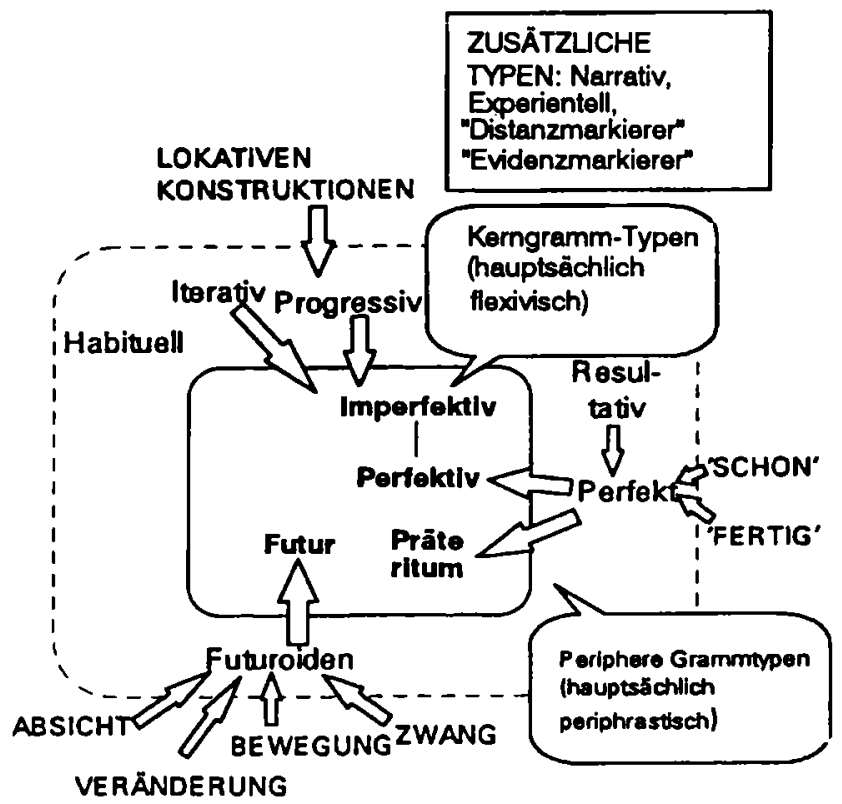

Figur 1. Hauptgrammtypen

Als Glieder des "harten Kerns” von Tempus- und Aspekt-Systemen finden wir nur wenige Grammtypen: Perfektiv:Imperfektiv, Präteritum („Past”) und Futur. Perfektiv:Imperfektiv ist in strukturalistischer Terminologie ausgedrückt eine „äquipollente Opposition”, wo beide Glieder markiert sein können.

Diese Opposition hat nicht nur eine aspektuelle, sondern auch eine temporale Bedeutung: Das Perfektiv wird allgemein auf die Vergangenheitsreferenz beschränkt. Der Grammtyp Präteritum wird oft nur mit dem Imperfektiv kombiniert (das "Imperfekt” der traditionellen Grammatik). Vier Arten von Realisationen der „Kerntypen” Perfektiv: Imperfektiv und Präteritum treten häufig auf. (Figur 2). 
Typ 0: Keino Kemgramme

(gewohnilch)
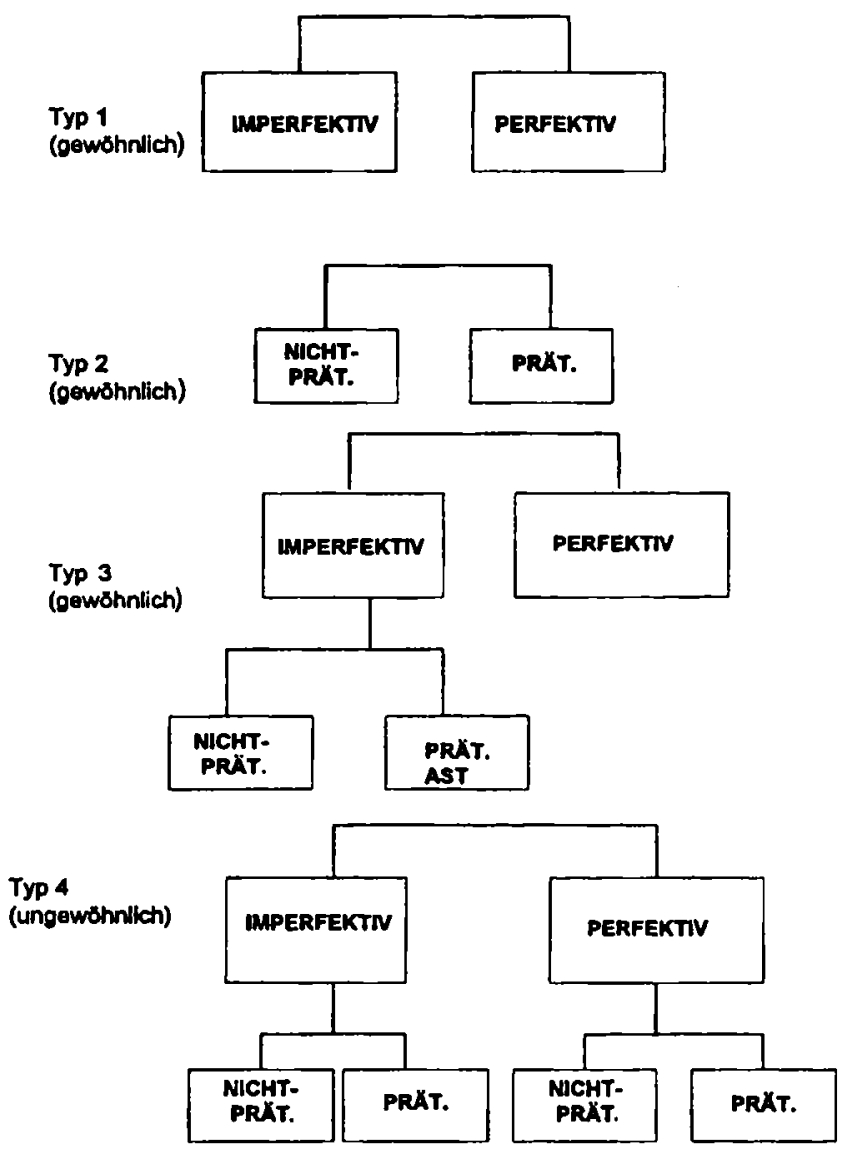

Figur 2. Systeme von Kerngrammen

An der Peripherie des Systems finden wir Grammtypen wie das Perfekt, das Progressiv und die ,jüngeren" Zukunftskonstruktionen (hier "Futuroiden" genannt), die alle normalerweise periphrastich (analytisch) ausgedrückt werden. Außerhalb des Systems sind einige der typischen lexikalischen Quellen der verschiedenen Grammtypen angegeben. 


\section{Areale Tendenzen}

Man kann in der Arealtypologie Erscheinungen auf wenigstens zwei Ebenen unterscheiden, die man die Mikro-Ebene und die Makro-Ebene nennen kann.

Die Mikro-Ebene ist das traditionelle Forschungsgebiet der arealen Linguistik, in der der Begriff "Sprachbund" zentral gewesen ist. Ein Sprachbund (das Wort wird auch in anderen Sprachen gebraucht) ist eine Gruppe von Sprachen, die geographisch benachbart, aber nicht notwendigerweise genetisch verwandt sind und die ähnliche grammatische Entwicklungen aufweisen. Man kann wohl sagen, daB Sprachbundphänomene in Grammatikalisierungsprozessen eher die Regel als eine Ausnahme sind - solche Prozesse verbreiten sich oft zu mehreren benachbarten Sprachen und schaffen dadurch Grammfamilien. Beispiele von solchen Grammfamilien finden wir in Figur 3, wo die wichtigsten Futurkonstruktionen in den europäischen Sprachen gezeigt werden.

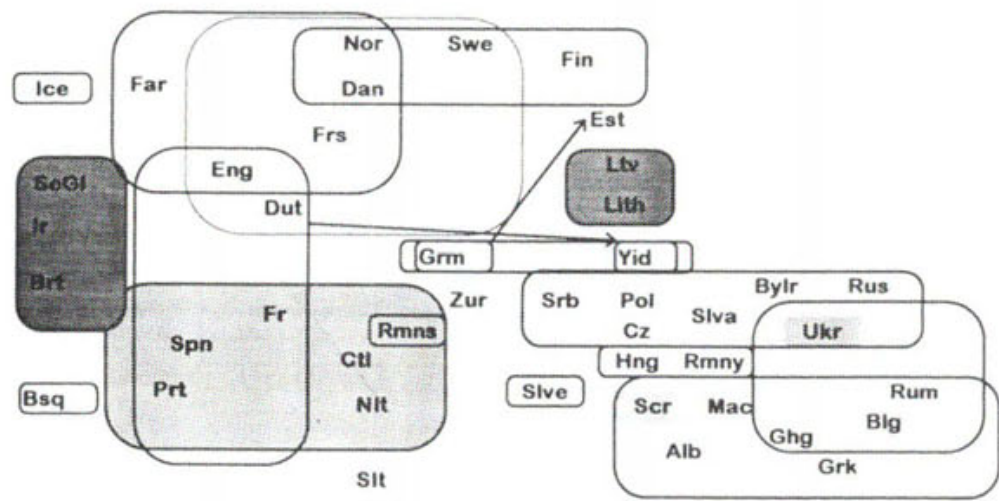

Figur 3. Grammfamilien in Europa, die Zukunftsreferenz ausdrücken. Synthetisch ausgedrückte Gramme sind grau grundiert.

Die Makro-Ebene behandelt statistische Tendenzen, die für Kontinente oder Teile von Kontinenten gelten. In der typologischen Forschung ist es jetzt klar geworden, daß die meisten grammatischen Phänomene geographisch nicht gleichmäBig verteilt sind. Das gilt z.B. für die Wortfolgetypen von Greenberg (SOV, SVO usw.), wie in den letzten Jahren gezeigt worden ist. Tempus- und Aspektsysteme sind in dieser Hinsicht keine Ausnahme. Die Grammtypen verteilen sich geographisch sehr ungleichmäßig: die arealen Einflüsse sind im Bereich der Grammatikalisierungsprozesse sehr stark. Letzten Endes sind natürlich die arealen Makro-Erscheinungen auf die Mikro-Ebene zurückzuführen. 
Figur 4 zeigt die Verteilung der Grammtypen Präteritum und Imperfektiv/Perfektiv in der Sprachenauswahl von Bybee et al. (1994). (Die Karte ist nicht skalenrecht.) Man sieht hier deutlich die Konzentrationen von Sprachen bestimmter Typen. Der Grammtyp Präteritum hat dabei eine besonders deutliche Verbreitung.

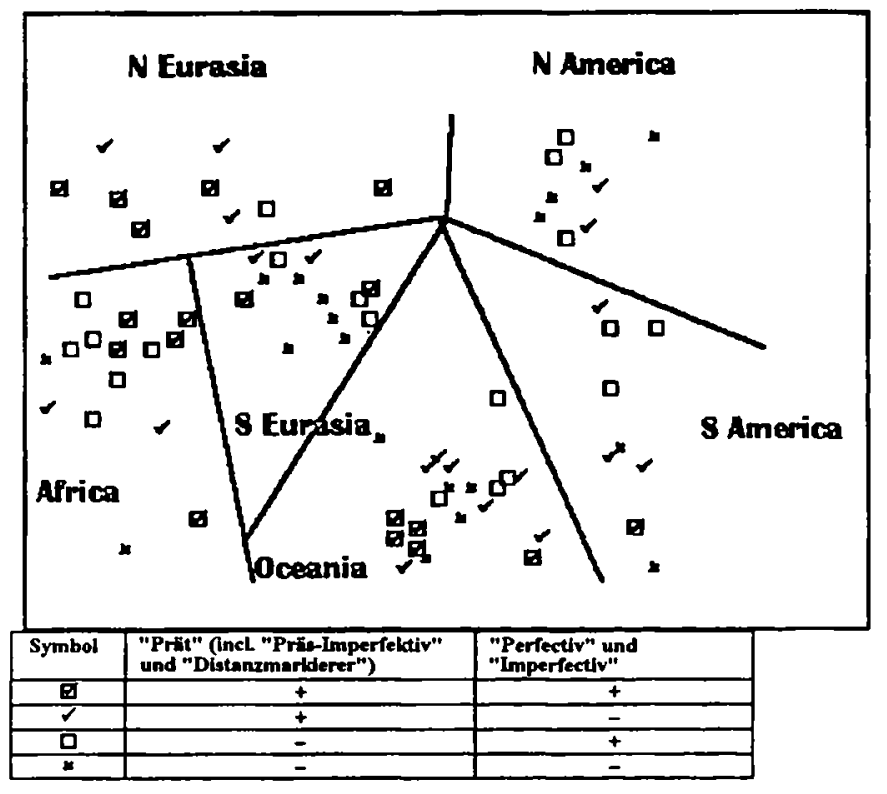

Figur 4. Verteilung der Hauptgrammtypen in der Auswahl von Bybee et al. 1994

In den europäischen Sprachen finden wir ganz bestimmte areale Tendenzen:

- Alle europäische Sprachen haben den Grammtyp Präteritum.

- Der Unterschied Perfektiv:Imperfektiv fehlt in vielen Sprachen, besonders in Nord-Europa.

- Das Perfekt kommt in den europäischen Sprachen sehr häufig vor; das „habeo-Perfekt” - d.h. ein Perfekt das auf einer possessiven Konstruktion basiert - findet man fast nur in diesem Weltteil. 
- In Nord-Europa ist auBerdem das Futur nur schwach grammatikalisiert oder fehlt überhaupt.

Für das Verstehen des deutschen Systems sind die zwei letzten Punkte von besonderer Bedeutung, und wir werden sie jetzt näher beleuchten.

\section{Das Perfekt in Europa}

Das Perfekt kommt in den europäischen Sprachen sehr häufig vor. Das "habeo-Perfekt" findet man fast nur in diesem Weltteil. In vielen Sprachen, z.B. im Deutschen, ist das Perfekt eine Mischung zwischen dem "habeo" und dem „esse"-Typ.

Das Perfekt ist in den peripheren Teilen Europas gut bewahrt.

Die Expansion des alten Perfekts in mehreren Sprachen des europäischen Zentralgebietes, auch im Deutschen, und der damit zusammenhängende "Präteritumschwund" in vielen Varianten des Deutschen ist ein klassischer Fall von Grammatikalisierung. Weil dieser Prozeb nicht überall gleichmäßig weit gegangen ist, bietet das „Kontinentalgermanische” eine Möglichkeit, die Grammatikalisierung „live” zu studieren.

Über die Semantik der Vergangenheitstempora im Deutschen ist sehr viel geschrieben worden. Die Literatur gibt einen Eindruck von Verwirrung, teils sogar von Verzweiflung.

Aus typologischer Sicht muß man die Situation im Hochdeutschen als ein typisches Übergangssystem charakterisieren. Solche Systeme lassen sich schlecht an das strukturalistische Ideal anpassen, aber sind aus der Perspektive der Grammatikalisierungstheorie heraus normal.

Die nicht vollgezogene Grammatikalisierung des Perfekts zu einem allgemeinen Präteritumtempus schafft eine eigenartige Konkurrenzsituation zwischen dem Perfekt und dem alten Präteritum, wo es eigentlich nicht möglich ist, die Wahl zwischen den beiden Grammen in einer einfachen Formel zu erfassen. Am besten können wir eine Reihe von Faktoren identifizieren, die die Wahl beeinflussen.

Latzel (1974), (1977) hat die Wahl zwischen den deutschen Vergangenheitstempora quantitativ studiert. Am interessantesten für unsere Zwecke sind vielleicht seine Daten über den Gebrauch von Perfekt und Präteritum in Todesanzeigen in verschiedenen Teilen Deutschlands, d.h. wo der Kontext konstant gehalten und die geographische Dimension variiert wird: 


$\begin{array}{lll} & \text { Perfekt (\%) } & \text { Präteritum (\%) } \\ \text { Süddeutsches Sprachgebiet } & 56 & 44 \\ \text { Rhein-Main-Gebiet } & 39 & 61 \\ \text { Niederdeutsches Sprachgebiet } & 29 & 81\end{array}$

Die Entwicklung von Perfekt zu Präteritum folgt in allgemeinen einem bestimmten Muster, wobei die letzten Kontexte, die davon berührt werden, die erzählenden/narrativen sind. Die Entwicklung im Deutschen ist ein gutes Beispiel dafür. DaB das Präteritum das bevorzugte Erzählungstempus im Deutschen ist, ist eine wohlgekannte Tatsache, die unter anderem der Ausgangspunkt der Tempus- und Aspekttheorie von H. Weinrich (1964) war. Nach der Meinung von Weinrich ist das Präteritum ein Tempus der „erzählten Welt”. Eine Variation desselben Themas ist die Unterscheidung zwischen dem Perfekt als ein "Isolations-Tempus" und dem Präteritum als ein „Ketten-Tempus”. Latzel (1974) kommt zu dem SchluB, daß es im Deutschen besondere Beschränkungen für den Gebrauch von Präteritum in Ein-Satz-Texten und in Einleitungssätzen zu längeren Texten gibt. Man könnte also eine Todesanzeige wie (a) oder (b) aber nicht wie (c) beginnen:
(a) Am ... starb unser Mitarbeiter Herr $X Y$
(b) Unser Mitarbeiter Herr $X Y$ ist gestorben
(c) Unser Mitarbeiter Herr XY starb

Mehrere Forscher haben vorgeschlagen, Fälle des „echten Perfekts” von Fällen des "Quasiperfekts" (mit der Terminologie von Fabricius-Hansen 1986) zu unterscheiden, wobei das „echte Perfekt” etwa dem englischen Perfekt entspricht. In einer extremen Version findet man diese These in Bäuerle (1979), wo behauptet wird, daß das deutsche Perfekt homonym sei, d.h. daß man es als zwei verschiedene Einheiten sehen muß, wobei die eine einfach eine von zwei Realisierungsmöglichkeiten der Kategorie Präteritum sei. Die Homonymiethese scheint nicht mit dem KontinuumCharakter der Unterscheidung zwischen den Vergangenheitstempora vereinbar zu sein. Die Unterscheidung von „echten” und "unechten” Fällen des Perfekts ist dagegen ganz kompatibel mit der Hypothese, daB das deutsche Perfekt sich in einem Übergangsstadium zwischen einem (typischen) Perfekt und einem allgemeinen Präteritum befindet.

Die germanischen Sprachen, in denen das Perfekt das Präteritum verdrängt hat, gliedern sich in zwei Typen. Im ersten (z.B. Afrikaans) ist die Präteritumform der Kopula (was/war) noch bewahrt. Im zweiten (z.B. Jiddisch) ist diese Form verlorengegangen: man verwendet auch hier das Perfekt. 
Im deutschen Sprachraum findet man Beispiele beider Typen: der erste im Süd-Osten, der zweite im Süd-Westen.

\section{Die Zukunft im Deutschen}

Die Zukunftsreferenz wird im Deutschen, besonders in der gesprochenen Sprache, verhältnismäBig oft nicht markiert. Statt dessen verwendet man das Präsens. Die werden-Konstruktion ist historisch gesehen relativ jung und ist noch nicht in alle Dialekte eingedrungen; so wird sie z.B. im Zürichdeutschen als fremd empfunden (Bickel 1992). In diesem Sinn ist das Deutsche ein Teil des "nordeuropäischen futurlosen Gebietes", das alle germanischen Sprachen (ausgenommen das Englische) und auch die Ostseefinnischen (Finnisch, Estnisch) umfaBt. Was diese Sprachen im Vergleich mit etwa dem Englischen und dem Französichen charakterisiert, ist die Abwesenheit einer grammatikalisierten, d.h. obligatorischen Markierung von Zukunftsreferenz in "reinen Voraussagen”. Im folgenden Satz aus unserem EUROTYP-Fragebogen wurden für das Deutsche sowohl das Präsens als auch die periphrastische Konstruktion mit werden ("Futur I") als Alternative gegeben: Morgen regnet es/wird es regnen. Im Englischen wäre es dagegen nicht möglich, das Präsens zu verwenden: It's going to rain/will rain tomorrow.

Das futurlose Gebiet war früher stärker ausgeprägt als heute: sowohl das Gotische wie auch das Altslawische hatten eigentlich keine systematischen, grammatischen Mittel, die Zukunft zu markieren.

\section{Die Armut des Deutschen}

In meinem Vortrag habe ich ein wenig provokativ gesagt, daB das deutsche Tempus- und Aspektsystem im allgemeinen recht arm ist. Das würde vor allem für die Dialekte gelten, wo der Präteritumschwund völlig durchgeführt worden ist und auch das werden-Futur nicht systematisch gebraucht wird. Man vergleiche z.B. das Bulgarische, wo ein deutscher Satz wie Er hat einen Brief geschrieben wenigstens zwölf Übersetzungen hat.

Dabei sollte man wohl hinzufügen, daß diese "Armut" nicht bedeutet, $\mathrm{da} B$ die deutsche Sprache weniger ausdrucksfähig ist. Es handelt sich ja hier darum, was grammatisch markiert wird, nicht um die allgemeine Ausdruckskraft der Sprache. 


\section{Literatur}

Bāuerle, Rainer (1979): Temporale Deixis - temporale Frage. Tübingen.

Bybee, Joan L. (1985): Morphology: a study of the relation between meaning and form. Amsterdam.

Bybee, Joan/Dahl, Ōsten (1989): The creation of tense and aspect systems in the languages of the world. In: Studies in Language 13, S. 51-103.

Bybee, Joan/Perkins, Revere/Pagliuca, William (1994): The Grammaticization of Tense, Aspect and Modality in the Languages of the World. Chicago.

Bickel, Balthasar (1992): The Marking of Future Time Reference in Züritūütsch. Future Time Reference in European Languages I. (EUROTYP Working Papers VI.2).

Chung, Sandra/Timberlake, Alan (1985): Tense, Aspect, and Mood. In: Shopen, Timothy (Hg.): Language Typology and Syntactic Description, I: Clause Structure. Cambridge. S. 202-258.

Comrie, B. (1976): Aspect. An Introduction to the Study of Verbal Aspect and Related Problems. Cambridge.

Comrie, B. (1985): Tense. Cambridge.

Csató, Eva (1992): On some theoretical and methodological problems of the typological study of tense-aspect categories. (EUROTYP Working Papers, Series VI, No. 1).

Dahl, Östen (1985): Tense and Aspect Systems. Oxford.

Fabricius-Hansen, Cathrine (1986): Tempus fugit. Düsseldorf.

Friedrich, P. (1974): On aspect theory and Homeric aspect. In: International Journal of American Linguistics. vol. 40, No. 4., Part 2, Memoir 28.

Gvozdanović, Jadranka/Janssen, Theo A.J.M., (Hg.) (1991): The function of tense in texts. Amsterdam.

Latzel, Sigbert (1974): Perfekt und Präteritum im Ein-Satz-Āusserungen der geschriebenen deutschen Sprache. In: Gelhaus, Hermann/Latzel, Sigbert (Hg.): Studien zum Tempusgebrauch im Deutschen. Tübingen. S. 173-274.

Latzel, Sigbert (1977): Die deutschen Tempora Perfekt und Präteritum. München.

Ultan, Russell (1978): The nature of future tenses. In: Greenberg, J. ( $\mathrm{Hg}$.): Universals of human language. Vol. 3. Word structure. Stanford. S. 82123.

Weinrich, Harald (1964): Tempus - besprochene und erzählte Welt. 2. Aufl. Stuttgart. 


\title{
JOHN OLE ASKEDAL
}

\section{Überlegungen zum Deutschen als sprachtypologischem „Mischtyp”}

\begin{abstract}
Ausgehend von einschlägigen typologischen Parametern (Verbstellung, Kasusmarkierung, analytische und synthetische Konstruktion) werden Aspekte einer allgemeinen morphosyntaktischen Charakterisierung des Deutschen zur Diskussion gestellt. Die deutschen Klammerbildungen werden unter dem Aspekt links- und rechtsverzweigender Serialisierung betrachtet. Es wird dabei erwogen, die Verbalklammer im Hauptsatz als die Überlagerung einer zugrundeliegenden Verbendstellung durch eine pragmatische Satzartenmarkierung anzusehen. Das Verhāltnis zwischen Morphologie und syntaktischen Regeln wird im Hinblick auf die „Konfigurationalitäts”-Diskussion erläutert. Sowohl bei Verbkonstruktionen als auch bei der Funktionskodierung im nominalen Bereich wird auf die Analytitizitāt/Synthetizităt-Unterscheidung Bezug genommen. Im Rahmen dieser Parameter erscheint das Deutsche als ein sprachtypologischer "Mischtyp”, der aber insgesamt durch weitgehende funktionale Konvergenz der typologisch unterschiedlichen Strukturen und Verfahren gekennzeichnet ist.
\end{abstract}

\section{Allgemeines}

Aus auslandsgermanistischer Sicht erscheint die Themenwahl der dies. jährigen IDS-Tagung „Deutsch - typologisch” in hohem Maße sinnvoll. Auch wer von mit dem Deutschen nahe verwandten Sprachen ausgeht, wie es beispielsweise die skandinavischen Sprachen angeblich sind, wird in Lehre und Forschung täglich mit kontrastiv-grammatischen Fragestellungen konfrontiert. Als kennzeichnender Unterschied zwischen kontrastiver Grammatik einerseits und Sprachtypologie andererseits wird - freilich etwas vereinfachend - angeführt, die kontrastive Grammatik vergleiche zwei (oder jedenfalls wenige) Sprachen im Hinblick auf viele Eigenschaften, während die allgemeine Sprachtypologie möglichst viele Sprachen auf eher wenige Eigenschaften hin untersuche (Gnutzmann 1990, S. 7; König 1990, S. 117, 129). Bei genauerem Hinsehen erweist sich aber die in der kontrastiven Grammatik gestellte Frage nach dem Tertium comparationis - einer für Muttersprache und Fremdsprache gleich gültigen gemeinsamen Vergleichsgrundlage - als eine Frage nach Parametern allgemeinerer, letzten Endes universeller Art, wie sie von der sprachtypologischen Forschung bereitgestellt werden. 
Wie die verschiedenen Vorträge auf dieser Tagung zeigen, ist die gegenwärtige Sprachtypologie kein monolithisches Unternehmen. Es stehen sich zwei Hauptrichtungen gegenüber: zum einen die generativistische, die von einer im Grunde kognitiv-psychologischen Parameterkonzeption mit Universalitätsanspruch ausgeht, und zum anderen die auf strukturalistisches Gedankengut zurückzuführende und durch die maßgeblichen Arbeiten von Joseph Greenberg (insbesondere 1966) angeregte Richtung, die pragmatisch-funktionale Erklärungen anstrebt und zunehmend semiotische Fragestellungen einbezieht. Die erstere Richtung ist weniger, die letztere, die sich in der Diskussion häufig als die Sprachtypologie schlechthin versteht und auch so verstanden wird, stärker „oberflächen" bezogen. Die letztere Richtung zeigt wohl die gröBere Affinität zu der Auslandsgermanisten vertrauten kontrastiv-grammatischen Sehweise (vgl. hierzu insbesondere den Titel und die Darstellung von Hawkins 1986). Ihr werden die typologischen Parameter entnommen, auf die im folgenden zur Veranschaulichung eingegangen wird.

Bei der typologischen Diskussion einer Einzelsprache kann auf zweierlei Art und Weise verfahren werden: Zum einen kann nach dem Nutzen der allgemeinen Sprachtypologie für die einzelsprachliche Beschreibung gefragt werden. Zum anderen kann man aber auch die Frage stellen, welche Eigenschaften der betreffenden Sprache bzw. welche Beiträge zu ihrer Erforschung sich für die allgemeine Sprachtypologie als besonders einschlägig erweisen. Im folgenden soll unter dem letzteren Aspekt kurz auf gewisse Aspekte der deutschen Morphosyntax hingewiesen werden, die einzeln und insgesamt geeignet sind, gängige Annahmen der allgemeinen Sprachtypologie zu ergänzen oder gar zu modifizieren.

\section{Wort-/Gliedstellung und Klammerbildung}

Die Endstellung von Verbformen und mit dem lexikalischen Vollverb semantisch und dependentiell eng zusammengehörenden Elementen (trennbare Vorsilben, Funktionsnomina, Bestandteile phraseologischer Fügungen) wird seit Drach (1940) als ein besonderes, für das Deutsche kennzeichnendes Konstruktionsmerkmal der „Klammer-" oder "Rahmenbildung" aufgefaßt, dem auf psychologischer Ebene auch eine informationssteuernde "Spannungs" funktion zugesprochen wird (vgl. z.B. Thurmair 1991, S. 182, 199; Weinrich 1993, S. 29f.; Gesichtspunkte dieser Art finden sich schon bei Adelung 1781, S. 510). Ohne irgendwelche psychologischen Implikationen anzustreben, wies der Däne Gunnar Bech (1955/57) sehr detailliert nach, wie das von ihm so benannte "verbale SchluBfeld" für die deutsche Satztopologie konstitutiv ist (vgl. insbesondere Bech 1955, S. 60-80). In der damaligen, von der Weis- 
gerberschen inhaltbezogenen Grammatik stark beeinfluBten deutschen Sprachgermanistik wurde zunächst nur mit deutlichem Vorbehalt von Bechs Untersuchungen Kenntnis genommen (Brinkmann 1957; Henzen 1959). Ihre Bedeutung wurde aber von der deutschen generativen Transformationsgrammatik (Bierwisch 1966, S. 176f.; Grewendorf 1987) und später auch im Rahmen der deutschen Rezeption von Greenberg (1966) gewürdigt. Es folgte eine intensive Diskussion über die deutsche Grundwortstellung - als (S)VO wie in Hauptsätzen oder (S)OV wie in $\mathrm{Ne}$ bensätzen -, die sich nun sowohl im generativen Lager als auch bei den nichtgenerativen Sprachtypologen weitgehend zugunsten der Verbendstellung entschieden zu haben scheint (Eisenberg 1994, S. 381f.).

Die Annahme einer zugrunde liegenden Verbendstellung im Deutschen gibt zum einen AnlaB, das Verhältnis von syntaktischer und pragmatischer Unmarkiertheit nochmals zu überdenken. Während im Bereich der selbständigen Sätze die Aussagesätze im Verhältnis zu Fragesätzen, Ausrufesätzen usw. ohne Zweifel illokutiv unmarkiert sind, haben die Nebensätze allgemein keine eigene illokutive Funktion (Lehmann 1988, S. 193). Vgl. z.B.:

(1) Sie hat das Buch schon gelesen.

(2) Hat sie das Buch schon gelesen?

(3a) Er weiß, daß sie das Buch schon gelesen hat.

(3b) Stimmt es, daß sie das Buch schon gelesen hat?

(3c) Sag ihm, daß sie das Buch schon gelesen hat!

Nebensätze wie (3) sind m.a.W. illokutiv merkmallos und gehen in Satzgefüge ein, deren illokutive Funktion durch den Obersatz festgelegt wird. Aussagesätze (1) und Entscheidungsfragesätze (2) sind illokutiv merkmalhaltig, aber von den beiden jeweils charakterisierenden Werten [+Assertion] und [+Frage] ist der erstere der weniger markierte. Daraus läBt sich folgern, daB im Deutschen die pragmatisch neutrale zugrunde liegende Verbendstellung in Hauptsätzen durch besondere pragmatische Markierungsfunktionen des finiten Verbs überlagert wird. Auf die gleiche Weise verhalten sich Niederländisch und Friesisch und - freilich topologisch etwas weniger deutlich markiert - Festlandskandinavisch (fakultativ auch Färöisch; vgl. insgesamt Askedal 1995, S. 97-101). Dafür vertreten im germanischen Raum Englisch und Isländisch den universalgrammatisch üblichen Fall der gleichen topologischen Strukturierung von Haupt- und Nebensätzen.

Zum anderen sind deutsche Klammerbildungserscheinungen von Interesse in Zusammenhang mit dem - freilich empirisch fragwürdigen Vennemannschen Prinzip der "natürlichen Serialisierung" (z.B. Ven- 
nemann 1973, S. 40-47) als durchgehender Modifikator-Kopf- oder Kopf-Modifikator-Abfolge und der sog. typologischen "Inkonsistenz" als Abweichung davon (Vennemann 1973, S. 32; vgl. dazu auch Abraham/Scherpenisse 1983, S. 294-300). Das Deutsche ist nun - wohl wie die meisten anderen Sprachen auch - offensichtlich insofern "inkonsistent”, als verschiedene Konstruktionen unterschiedliche Serialisierungsrichtung (als Modifikator-Kopf- oder Kopf-Modifikator-Abfolge) aufweisen. In folgenden Konstruktionen liegt Modifikator-Kopf-Abfolge (M-K) vor:

$M-K \quad 1$. Verbale SchluBfeldstruktur (mit grundlegender interner $V_{n}-V_{2}$ $\mathrm{V}_{1}$-Abfolge):

(4) als er den Brief zu schreiben versucht hatte

M-K 2. Entsprechende Voranstellung von Adjektivergänzungen:

(5) viel Geld wert, schwere Arbeit gewohnt

M-K 3. Flektierende Attribute vor Nomen:

(6) eine schōne Frau

M-K 4. Adverb/adverbialer Modifikator vor Adjektiv:

(7) sehr vorlaut

Kopf-Modifikator-Abfolge (K-M) liegt vor in folgenden Fällen:

K-M 1. (Überwiegend) Adposition (als Präposition) vor Regiertem

(8) an eine schöne Frau

K-M 2. Nomen vor nichtflektierendem Attribut:

(9) der Mann an der Ecke

(10) das Haus, das er verkaufen wollte

(11) der Wunsch, nach Argentinien zu emigrieren

(12) die Hoffnung, daß sie bald wieder zu ihm zurückkehrt

K-M 3. Vergleichsprädikat vor Vergleichsstandard:

(13) größer als sein Bruder

Das Deutsche besitzt vier hauptsächliche Arten der Klammerbildung (vgl. insgesamt auch Weinrich 1973, S. 29-70):

Kl 1. Die Nebensatzklammer aus Subjunktion und verbalem Schlubfeld: (14) weil er von diesem Tag an hart gearbeitet hatte

$\mathrm{Kl}$ 2. Die verbale Hauptsatzklammer in Aussagesätzen und Entscheidungsfragen: 
(15) Von diesem Tag an hatte er hart gearbeitet.

(16) Hatte er von diesem Tag an hart gearbeitet?

Kl 3. Die Nominalklammer aus Artikelwort und nominalem Kern:

(17) ein hart arbeitender Mensch

Kl 4. Die Präpositionalklammer - oder genauer: Adpositionalklammer - aus Präposition und Postposition oder postpositionaler adverbieller Partikel:

(18) oon diesem Tag an

Von diesen Klammerbildungen sind in den betreffenden Konstruktionen die Nebensatzklammer immer, und sowohl die Nominalklammer als auch die Hauptsatzklammer meistens vorhanden (zur statistischen Dominanz der Hauptsatzklammer in der gesprochenen Sprache gegenüber Sätzen ohne zweiten Klammerteil bzw. zur Produktivität dieser Art von Klammerbildung vgl. Thurmair 1991, S. 186, 193-198). Die Adpositionalklammer tritt vergleichsweise weniger häufig auf (jedoch ist bei den Präpositionsausdrücken in Rechnung zu stellen, daB sie am häufigsten eine Nominalklammer enthalten). An den deutschen Klammerbildungen ist des weiteren zu beobachten, daB sie in unterschiedlichem AusmaB konstruktionsinterne Kontinuierlichkeit oder Diskontinuierlichkeit aufweisen. Diskontinuierlich sind die Hauptsatzklammer mit getrenntem finitem und infinitem Verb (infiniten Verben) bzw, anderen hinteren Klammerteilen und die Adpositionalklammer mit getrenntem prä- und postpositionalem Bestandteil.

Die genannten vier deutschen Klammerkonstruktionen divergieren auch im Hinblick auf die Serialisierungsrichtung(en). Das Verhältnis zwischen Subjunktion und darauf folgendem Satzinhalt kann man als eine den Präpositionalgliedern vergleichbare Kopf-Modifikator-Abfolge auffassen (vgl. schon Blümel 1914, S. 180f.), während die Nominalklammer einen klaren Fall der Modifikator-Kopf-Abfolge darstellt. Die Hauptsatzklammer und die Adpositionalklammer sind bekanntlich beide Abfolgen vereinende "Umklammerungen".

Durch die Klammerbildungen werden Konstruktionsdomänen markiert, die weitgehend auch semantische Interpretationsdomänen sind. (Nur das für die Diskursgestaltung besonders wichtige Vorfeld der Aussagesätze scheint sich diesem Prinzip zu entziehen.) Dies wird in einschlägigen deutschen Darstellungen durch den eher psychologischen Ausdruck „Spannung” umschrieben (z.B. Weinrich 1993, S. 30). Für das Deutsche zeichnet sich hier ein Prinzip der Isomorphie von syntaktischen Konstruktions- und semantischen Interpretationsdomänen ab, 
an der die deutschen Klammerbildungen wesentlich - man könnte schon sagen: diagrammatisch-ikonisch - beteiligt sind. Diese Isomorphie kommt durch eine Konvergenz von Serialiserungskontinuierlichkeit und -diskontinuierlichkeit bzw. von verschiedenen konstruktionsinternen Serialisierungsrichtungen - in Vennemannscher Terminologie: Serialisierungsinkonsistenz - zustande. Insofern liegt es hier nahe, in der Serialisierungsinkonsistenz dennoch eine funktionale diagrammatische Konvergenz (Konsistenz) zu sehen.

In diesem Zusammenhang wäre noch zu erwähnen, daß das Deutsche im allgemeinen wenig Extraktion von Konstituenten aus Konstruktionen heraus erlaubt (Hawkins 1986, S. 87-114). Aus Präpositional- (und Postpositional-)gliedern kann anders als etwa im Englischen und in den skandinavischen Sprachen nicht herauspermutiert werden:

(19a) An die Zukunft dachte er nicht.

(19b) *Die Zukunft dachte er nicht an .

(19c) Norw.: Fremtiden tenkte han ikke på _.

Die Extraktion von Satzgliedern aus Nebensätzen begegnet im Deutschen eventuell nur als systemwidrige, kommunikativ motivierte Performanzerscheinung (Wunderlich 1980):

(20a) *Dieses Auto bedauert er sehr, daß er _ gekauft hat. (20b) Norw.: Denne bilen angrer han svert pa at han har kjøpt _.

Gelegentlich nicht ganz abzulehnen ist dafür die Extraktion von Satzgliedern aus extraponierten Infinitivkonstruktionen (Hawkins 1986, S. 88 f.), die keinen 1. Klammerteil aufweisen und noch dazu auf einer (universellen) Sententialitätsskala einen niedrigeren Platz einnehmen (Chr. Lehmann 1984, S. 168-173; 1988, S. 200); vgl. den Unterschied zwischen der kohärenten Konstruktion ohne Extraktion in (21a) und der inkohärenten Konstruktion in (21b) mit Extraktion aus der nachgestellten Infinitivkonstruktion:

(21a) Dieses Problem hat er dennoch nicht zu lösen versucht. (21b) Dieses Problem hat er dennoch nicht versucht_zu lösen.

Auch wenn die deutschen Extraktionsrestriktionen durch tiefensyntaktische Parameter motiviert sein mögen, ist unter oberflächensyntaktisch typologischem Aspekt eine starke Korrelation zwischen domänenmarkierender Klammerbildung einerseits und einer starken Abneigung gegen das Überschreiten von Konstruktionsgrenzen andererseits zu beobachten. 
Zum dritten sind die deutschen Klammerbildungen für die allgemeine linguistische Stilistik sowie für psychologische Sprachrezeptionstheorien von Interesse, da sie eine funktionalstilistisch unterschiedliche Streuung aufweisen. Es ist nachgewiesen worden, daB die Einrahmungen in der gesprochenen Sprache, aber auch in weniger anspruchsvollen schriftsprachlichen Textsorten zumeist wenig umfangreich sind und daher leicht zu überblicken und zu rezipieren, in fachsprachlicher und akademischer Prosa dagegen häufig erheblich umfangreicher sind (Thurmair 1991, S. 185-190, 191f., 198). Ähnliches gilt insbesondere auch für die sog. "erweiterten" vorangestellten Adjektiv- und Partizipialattribute, die in der gesprochenen Sprache sowie in belletristischen Texten im allgemeinen weniger üblich sind, in fachsprachlichen und wissenschaftlichen Texten aber häufig vorkommen (vgl. Weinrich 1993, S. 546; Thurmair 1991, S. 197) und dort einen erheblichen Umfang erreichen können:

(22) der im März 1976 völkerrechtlich in Kraft getretene Internationale Pakt

(23) das allgemein damit in Verbindung gebrachte wirtschaftliche Elend

(24) eine im kollektiven Gedächtnis der Deutschen glanzvoll vergoldete Vergangenheit

Praktisch bedeutet dies, daß unter bestimmten funktionalstilistischen Bedingungen in höherem $A$ usma $B$ von typologisch kennzeichnenden Modifikator-Kopf-Abfolgen Gebrauch gemacht wird als unter anderen.

\section{Kasusmorphologie, Satzgliedstellung und Konfigurationalität}

In Greenbergs (1966, S. 96) Universale 41 wird ein Zusammenhang zwischen Kasusmarkierung und Verbstellung postuliert, dem das Deutsche bei der Annahme zugrunde liegender Verbendstellung entspricht: „If in a language the verb follows both the nominal subject and nominal object as the dominant order, the language almost always has a case system." Daran schließt sich aus typologischer Perspektive die Frage an, inwieweit die Stellung der nichtverbalen Satzglieder (Ergänzungen und Angaben, allgemein Argumente zum Prädikat) eine sog. "freie" ist (wie dies gelegentlich für das sog. "Mittelfeld” angenommen wird; vgl. Eisenberg 1994, S. 383, und des weiteren den Beitrag von Haftka in diesem Band). Einerseits findet sich z.B. bei Engel (1970; 1988, S. 320-327) eine auf morphosyntaktischen Merkmalen basierende Beschreibung, deren weitgehende Gültigkeit durch Textuntersuchungen bestätigt werden kann (Zeman 1979, S. 14f. u.ö.). Andererseits können aber auch semantische Kategorien sowie eher pragmatische Bedingungen wie Empathie, Fokus- 
erscheinungen und Thema-Rhema-Gliederung die von Engel angenommene morphosyntaktische Normalabfolge sozusagen überspielen (Lenerz 1977; Lötscher 1981; Zemb 1978, S. 392-432). Insofern steht die Satzgliedstellung des Deutschen im Spannungsfeld zwischen Grammatikalisierung (Syntaktifizierung) und eigenständiger, semantisch-pragmatisch motivierter Funktionalität.

Ein wichtiges universalgrammatisches Thema ist der Zusammenhang von Morphologie und Syntax. Möglich ist, daB eine syntaktische Regel entweder nur mit einem oder mit zwei oder sogar mehr unterschiedlichen morphologischen Kasus korreliert ist (vgl. z.B. Collinge 1984, S. 19; Comrie 1983, S. 64-68). Der letztere Fall - d.h. die Zuordnung einer syntaktischen Regel zu zwei oder mehr Kasus - liegt bekanntlich in Sprachen mit Ergativ/Absolutiv-Markierung vor, in denen das ergativische Subjekt transitiver Verben und das absolutivische Subjekt intransitiver Verben sich trotz unterschiedlicher Kasusmarkierung normalerweise syntaktisch gleich verhalten (Anderson 1976; Comrie 1978, S. 336-350). Aus dem Bereich der germanischen Nominativ/Akkusativ-Sprachen wären in diesem Zusammenhang das Neuisländische und Färöische zu erwähnen, deren sog. „oblique" Subjekte im Dativ und Akkusativ (und im Isländischen ganz vereinzelt auch im Genitiv) gleiche syntaktische Eigenschaften wie die Nominativsubjekte aufweisen, denen sie stellungsmäßig entsprechen (vgl. jeweils Höskuldur Thráinsson 1994, S. 175f.; Barnes 1986). Demgegenüber sind im Deutschen die gleichen syntaktischen Regeln (in bezug auf Passivkonstruktionen, Imperativ- und Infinitivbildung, sog. "Anhebungs"-Konstruktionen, gewisse Koordinationserscheinungen) mit nur einem Kasus korreliert (Reis 1982, S. 185-198; ähnlich auch Wegener 1986, S. 21). Vgl. z.B. den Unterschied zwischen den folgenden isländischen (25) und deutschen (26) Beispielen für Infinitivbildung:

(25a) Mig (A) vantar ekki peninga (A).

(25b) Ég vonast til a $\delta_{-}$(A) vanta ekki peninga (A).

(26a) Mir (D) fehlt das Geld (N).

(26b) *Ich hoffe, _(D) das Geld (N) nicht zu fehlen.

(26c) Ich hoffe, daß mir (D) das Geld (N) nicht fehlt.

Vgl. weiter die unterschiedlichen Tilgungsmöglichkeiten bei Koordination im Isländischen (27) und im Deutschen (28): 
(27a) Honom (D) finst verkefnid (N) of bungt.

(27b) Hann (N) segist vera duglegur, en _ (D) finst verkefnio (N) of pungt.

$(28 \mathrm{a}){ }^{*} \operatorname{Er}(\mathrm{N})$ gilt als tüchtig, aber _ (D) kommt die Hausarbeit (N) zu schwer vor.

(28b) Er gilt (N) als tüchtig, aber ihm (D) kommt die Hausarbeit (N) zu schwer vor.

Deutsche Daten dieser Art sind für den Problembereich einschlägig, der in den 80er Jahren als "syntaktische Konfigurationalität" diskutiert wurde (vgl. Askedal 1993b). Wichtig ist in diesem Zusammenhang der Nachweis von Fanselow (1987, S. 32-48, 215-236), daB das Deutsche zum einen deutlich konfigurationale Züge aufweist, zum anderen aber auch im Hinblick auf gewisse andere Parameter weniger konfigurational ist. Daraus ergibt sich die allgemein interessante Folgerung, daB sog. „Konfigurationalität” - wie vieles andere in der Grammatik auch - eine gradiente Skala und keine starre dichotomische Taxonomie darstellt. Die fraglichen deutschen Daten aus dem Bereich syntaktischer Konstruktionen wird man in Zusammenhang mit dem oben angesprochenen Schillern deutscher Gliedstellungsregeln zwischen grammatikalisierter Festigkeit und pragmatisch-semantischer Motiviertheit sehen dürfen.

\section{Analytische und synthetische Konstruktion}

In der klassischen, morphologisch orientierten Sprachtypologie ist die Unterscheidung von synthetischer und analytischer Konstruktion wichtig (auch wenn sie nicht ganz einheitlich verstanden wird; Bally 1932, S. 25). Synthetische Konstruktion besagt bekanntlich Relationskodierung durch morphologische Markierung in Gestalt von Agglutination oder/und Flexion, während analytische Konstruktion als Abwesenheit morphologischer Markierung bei Zuhilfenahme grammatikalisierter Verknüpfungswörter zu verstehen ist (Abraham 1988, S. 38, 787f., 865f.; vgl. auch Askedal 1993a, S. 308-311, 316). Es begegnet ab und zu die Auffassung, das Deutsche sei aus diachronischer Sicht von einer eher synthetischen zu einer mehr analytischen Konstruktionsweise unterwegs, was sich insbesondere im Ersatz von Kasus durch präpositionale Ausdrucksweisen manifestiere. Diese These mag für große Teile des deutschen Dialektgebietes zutreffen (Dal 1971a; Russ 1990), ist aber für die deutsche Standardsprache, die hier vorrangig zur Diskussion steht, in dieser Form nicht aufrechtzuerhalten. 
Im verbalen Bereich ist im Verlauf der Sprachgeschichte eine Entwicklung zu verzeichnen, die sich als Zunahme von Konstruktionsanalytizität verstehen läßt. Das urgermanische Tempussystem bestand bekanntlich aus den beiden finiten Formen Präsens und Präteritum mit morphologischer Modusopposition zwischen Indikativ und Konjunktiv. Das Subsystem der infiniten Formen hatte vorwiegend nominalen Charakter: Die Partizipien wurden wie Adjektive flektiert (Ebert 1978, S. 57-64), und die Flexion des Infinitivs zeigt bis ins mittelalterliche Deutsch substantivische Züge (Dal 1966, S. 100). Im Gegenwartsdeutsch ist beim produktiven Konjugationstyp der schwachen Verben ein Großteil der morphologischen Konjunktivmarkierung verlorengegangen, was einen Verlust an Synthetizität bedeutet. Im Bereich der Verbkonstruktionen mit infinitem Verb finden sich drei nichtflektierende - im Sinne von Bech (1955, S. 1216) supinische - Formen ( $($-Infinitiv, zu-Infinitiv, sog. Perfektpartizip), die in Konstruktion mit Auxiliarverben bzw. auxiliarähnlichen Verben ein insgesamt sehr umfassendes System von aktivischen und passivischen Tempusformen und modalen Verbfügungen ausmachen; Eroms (1987, S. 75) spricht von einer allgemeineren Tendenz zur "Periphrastisierung” (vgl. z.B. auch Askedal 1982). In diesen Zusammenhang gehören wohl auch die sog. "würde-Umschreibungen" sowie die mehr oder weniger weitgehende Generalisierung des periphrastischen Perfekts. Damit geht in der Satztopologie die Herausbildung der deutschen Schlubfeldstrukturen einher (Härd 1981), deren synchronische Systematik bei Bech (1955, S. 60-80) ihre eindrucksvolle Darstellung gefunden hat.

Im Bereich der nominalen Kasus sieht dies etwas anders aus. Der Bestand der Kasus - Nominativ, Akkusativ, Dativ, Genitiv - im heutigen Deutsch ist praktisch der gleiche wie im Althochdeutschen und Gotischen (abgesehen vom nur relikthaften Instrumental bzw. Vokativ dieser beiden frühen germanischen Sprachstufen). Dafür hat sich eine funktionale Verschiebung vollzogen: Aus dem Genitiv ist weitgehend ein Kasus der nominalen Subordination geworden, und der Akkusativ und Dativ sind in hohem Maße auf die beiden Funktionen direktes bzw. indirektes Objekt spezialisiert worden. Im Bereich der Adverbialbestimmungen haben die Kasus, vor allem der Genitiv, gegenüber den Präpositionalgliedern an Bedeutung verloren. Diese unterschiedlich weit gehende, aber als diachronische Gesamttendenz unverkennbar vorhandene funktionale Vereinheitlichung wird man schwerlich generell als Kasusabbau bzw. Übergang zu mehr analytischer Konstruktionsweise abtun können.

Geändert hat sich dabei die Art der morphologischen Markierung der Kasus in der Nominalphrase. Für das Germanische und das Althochdeutsche kann man ohne wesentliche Vorbehalte ein Kongruenzsystem 
ansetzen, wie es z.B. sowohl in älteren als auch in neueren slawischen und romanischen Sprachen vorliegt. Über das Mittelhochdeutsche als Übergangsstadium mit zunehmender Formenneutralisierung macht sich im Neuhochdeutschen die Tendenz geltend, den Kasus einer Nominalphrase nicht mehr an allen Einzelwörtern, sondern vielmehr nur an einer oder höchstens zwei Stellen der gesamten Nominalphrase, vorzugsweise am konstruktionsinitialen Determinativ, morphologisch zu markieren (sog. "Monoflexion" oder "monoflexivische Kooperation", vgl. Dal 1971b, S. 241, Anm. 2 mit Hinweis auf Admoni; Weinrich 1993, S. 487; des weiteren auch Werner 1979). Man vgl. folgende Beispiele:

(29) die Wünsche des neuen Kunden $\neq$ der neuen Kunden

(30) Sie wollte den jungen Mann unterstützen. $\neq$ Sie wollte dem jungen Mann helfen.

Zweimalige Markierung liegt im Gen.Sg.M./N. und im Dat.Pl. gewisser Flexionsklassen vor:

(31) die Wünsche des jungen Mannes

(32) mit den alten Männern

Derartige morphologische Markierungsmuster bedeuten an sich auch keinen Kasusabbau bzw. Übergang zur Konstruktionsanalytizität, sondern stellen vielmehr ein ökonomischeres Verfahren der Kasusmarkierung dar. Übergänglichkeit zu konfigurationell-analytischen Markierungsverfahren bezeugen eher die Fälle, wo bei weitergehendem Kasussynkretismus Position bzw. Topologie eine syntaktisch disambiguierende Funktion hat. $\mathrm{Vgl}$. die folgenden Minimalpaare (bei vorausgesetzter Normalintonation):

(33) Er übermittelte den Gruß der Frau (attributiver Genitiv Sg.). $\neq$ Er übermittelte der Frau den Gruß (indirektes Objekt im Dativ Sg.)

(34) ... weil die junge Frau (Nominativsubjekt) die andere Dame (Akkusativobjekt) schon kannte. $\neq \ldots$ weil die andere Dame (Nominativsubjekt) die junge Frau (Akkusativobjekt) schon kannte.

Die in diesem Punkt besprochenen Züge des Deutschen dürften zeigen, daB nicht alle Bereiche eines grammatischen Systems sich typologisch gleich verhalten müssen: Der Bereich der Verbkonstruktionen weist im Deutschen deutlich analytische Züge auf, während der nominale Bereich noch weitgehend synthetisch ist. Dabei ist freilich die historisch ursprüngliche Kasusmarkierung durch Kongruenz einem neuen Prinzip der morphologischen Ökonomisierung von Konstruktionssynthetizität weitgehend gewichen. 


\section{Schluß}

Das Deutsche ist in seiner syntaktischen Basis eine Verbendstellungs(„SOV”-) Sprache, deren Grundabfolge durch eine universalgrammatisch seltene Satzartenmarkierung überlagert wird. In verschiedenen syntaktischen Kopf/Modifikator-Konstruktionen tragen unterschiedliche Serialisierungsrichtungen zur "Klammer"-Markierung syntaktischer Konstruktions- und semantischer Interpretationsdomänen bei, wodurch ein syntaktisch-semantisches Isomorphie-Prinzip sichtbar wird. Im nominalen Bereich zeigt das Deutsche strenge Bindung syntaktischer Regeln an die Kasusmorphologie, jedoch auch in nicht unbedeutendem AusmaB eher "konfigurationale" Züge. Ähnlich sind in Verbkonstruktionen und bei der Funktionskodierung im nominalen Bereich sowohl synthetische als auch analytische Verfahren zu beobachten. Insgesamt erscheint das Deutsche als ein sprachtypologischer "Mischtyp", in dem aber die typologisch unterschiedlichen - etwa „inkonsistenten” - Strukturen und Verfahren im Gesamtsystem deutlich funktionalisert sind. (Dabei sind freilich auch gewisse areale Beziehungen in Rechnung zu stellen; vgl. etwa Askedal 1989, 1995.)

\section{Literatur}

Abraham, Werner (1988): Terminologie zur neueren Linguistik. 2., völlig neu bearbeitete und erweiterte Aufl. Tübingen.

Abraham, Werner/Scherpenisse, Wim (1983): Zur Brauchbarkeit von Wortstellungstypologien mit Universalanspruch. In: Sprachwissenschaft 8, S. 291-355.

Adelung, Johann Christoph (1781): Deutsche Sprachlehre. Zum Gebrauche der Schulen in den Königlichen Preubischen Landen. Berlin.

Anderson, Stephen R. (1976): On the notion of subject in ergative languages. In: Li, Charles N. (Hg.) (1976): Subject and Topic. New York etc. S. 1-24.

Askedal, John Ole (1982): Zur semantischen Analyse deutscher Auxiliarkonstruktionen unter dem Aspekt der Unterscheidung von summativer und nicht-summativer Bedeutung. In: Deutsch als Fremdsprache 19, S. 159167.

Askedal, John Ole (1989): Typologische und areallinguistische Überlegungen zu den modernen germanischen Sprachen. In: Sprachwissenschaft 14, S. $440-466$.

Askedal, John Ole (1993a): Aspekte der Morphosyntax der modernen skandinavischen Sprachen vor dem Hintergrund der Sprachtypologie. In: Glienke, Bernhard/Marold, Edith et al. (Hg.) (1993): Arbeiten zur Skandinavistik. 10. Arbeitstagung der deutsch-sprachigen Skandinavistik 22.-27.9.1991 am Weißenhäuser Strand. Frankfurt am Main etc. S. 301-315. 
Askedal, John Ole (1993b): Configurationality in language typology and diachronic syntax: Evidence from Germanic. In: Norsk Lingvistisk Tidsskrift 11, S. 125-134.

Askedal, John Ole (1995): Geographical and Typological Description of Verbal Constructions in the Modern Germanic Languages. In: Askedal, John Ole/Bjorvand, Harald ( $\mathrm{Hg}$.) (1995): Drei Studien zum Germanischen in alter und neuer Zeit. Odense. S. 95-146. (NOWELE Supplement Vol. 13).

Bally, Charles (1932): Linguistique générale et linguistique française. Paris.

Barnes, Michael (1986): Subject, Nominative and Oblique Case in Faroese. In: Scripta Islandica 37, S. 13-46.

Bech, Gunnar (1955/57): Studien ūber das deutsche verbum infinitum. Bd. 1-2. Kopenhagen.

Bierwisch, Manfred (1966): Grammatik des deutschen Verbs. 4. Aufl. Berlin (DDR). (Studia Grammatica II).

Blümel, R. (1914): Einführung in die Syntax. Heidelberg.

Brinkmann, Hennig (1956/57): [Rezension zu Bech 1955/57]. In: Wirkendes Wort 7, S. 49-51, 373-374.

Collinge, N.E. (1984): How to Discover Direct Objects. In: Plank, Frans (Hg.) (1984): Objects. Towards a Theory of Grammatical Relations. New York etc. S. 9-27.

Comrie, Bernard (1978): Ergativity. In: Lehmann, Winfried P. (Hg.) (1978): Syntactic Typology. Studies in the Phenomenology of Language. Austin, Texas/London. S. 329-394.

Comrie, Bernard (1983): Language Universals and Linguistic Typology. Oxford.

Dal, Ingerid (1966): Kurze deutsche Syntax auf historischer Grundlage. 3., verb. Aufl. Tübingen.

$\mathrm{Dal}$, Ingerid (1971a): Systemerhaltende Tendenzen in hochdeutschen Mundarten. In: Dal, Ingerid (1971): Untersuchungen zur germanischen und deutschen Sprachgeschichte. Oslo etc. S. 171-180.

Dal, Ingerid (1971b): Ūber Kongruenz und Rektion im Deutschen. In: Dal, Ingerid (1971): Untersuchungen zur germanischen und deutschen Sprachgeschichte. Oslo etc. S. 239-247.

Drach, Erich (1940): Grundgedanken der deutschen Satzlehre. 3. Aufl. Frankfurt a.M.

Ebert, Robert P. (1978): Historische Syntax des Deutschen. Stuttgart. (Sammlung Metzler 167).

Eisenberg, Peter (1994): German. In: König, Ekkehard/van der Auwera, Johan (1994): The Germanic Languages. London/New York. S. 359-387.

Engel, Ulrich (1970): Regeln zur Wortstellung. In: Forschungsberichte des Instituts für deutsche Sprache 5, S. 3-148.

Engel, Ulrich (1988): Deutsche Grammatik. Heidelberg. 
Eroms, Hans-Werner (1987): Passiv und Passivfunktionen im Rahmen einer Dependenzgrammatik. In: Centre de Recherche en Linguistique Germanique (Nice) (Hg.) (1987): Das Passiv im Deutschen. Akten des Kolloquiums über das Passiv im Deutschen, Nizza 1986. Tübingen. S. 73-95. (Linguistische Arbeiten 183).

Fanselow, Gisbert (1987): Konfigurationalităt. Untersuchungen zur Universalgrammatik am Beispiel des Deutschen. Tübingen. (Studien zur deutschen Grammatik 29).

Gnutzmann, Claus (1990): Einleitung. In: Gnutzmann, Claus (Hg.) (1990): Kontrastive Linguistik. Frankfurt a.M. etc. S. 7-11.

Greenberg, Joseph H. (1966): Some Universals of Grammar with Particular Reference to the Order of Meaningful Elements. In: Greenberg, Joseph H. (Hg.) (1966): Universals of Language. 2nd Ed. Cambridge, Mass./London. S. 73-113.

Grewendorf, Günther (1987): Kohārenz und Restrukturierung. Zu verbalen Komplexen im Deutschen. In: Asbach-Schnitker, Brigitte/Roggenhofer, Johannes (Hg.) (1987): Neuere Forschungen zur Wortbildung und Historiographie der Linguistik. Festgabe für Herbert E. Brekle zum 50. Geburtstag. Tübingen. S. 123-144.

Haftka, Brigitta (in diesem Band): „Deutsch ist eine V/2-Sprache mit Verbendstellung und freier Wortfolge."

Hawkins, John A. (1986): A Comparative Typology of English and German. Unifying the Contrasts. London/Sydney.

Härd, John Evert (1981): Studien zur Struktur mehrgliedriger deutscher Nebensatzprädikate. Göteborg. (Göteborger germanistische Forschungen 21).

Henzen, Walter (1959): Eine Systematik der infiniten Verbalformen [Rezension zu Bech 1955/57]. In: Muttersprache 69, S. 115-127.

Höskuldur Thráinsson (1994): Icelandic. In: König, Ekkehard/van der Auwera, Johan (Hg.) (1994): The Germanic Languages. London/New York. S. 142189.

Kōnig, Ekkehard (1990): Kontrastive Linguistik als Komplement zur Typologie. In: Gnutzmann, Claus (Hg.) (1990): Kontrastive Linguistik. Frankfurt a.M. etc. S. 117-131.

Lehmann, Christian (1984): Der Relativsatz. Tübingen.

Lehmann, Christian (1988): Towards a Typology of Clause Linkage. In: Hajman, John/Thompson, Sandra A. (Hg.) (1988): Clause Combining in Grammar and Discourse. Amsterdam/Philadelphia. S. 181-225

Lenerz, Jūrgen (1977): Zur Abfolge nominaler Satzglieder im Deutschen. Tübingen. (Studien zur deutschen Grammatik 5).

Lötscher, Andreas (1981): Abfolgeregeln für Ergänzungen im Mittelfeld. In: Deutsche Sprache 9, S. 44-60.

Reis, Marga (1982): Zum Subjektbegriff im Deutschen. In: Abraham, Werner (Hg.) (1982): Satzglieder im Deutschen. Vorschläge zur syntaktischen, semantischen und pragmatischen Fundierung. Tübingen. S. 271-211. (Studien zur deutschen Grammatik 15). 
Russ, Charles V.J. (Hg.) (1990): The Dialects of Modern German. A Linguistic Survey. London.

Thurmair, Maria (1991): Warten auf das Verb: Die Gedächtnisrelevanz der Verbklammer im Deutschen. In: Wierlacher, Alois et al. (Hg.) (1991): Jahrbuch Deutsch als Fremdsprache. Band 17. München. S. 184-202.

Vennemann, Theo (1973): Explanation in Syntax. In: Kimball, J.P. (Hg.) (1973): Syntax and Semantics. Vol. 2. New York/London. S. 1-50.

Wegener, Heide (1986): Gibt es im Deutschen ein indirektes Objekt? In: Deutsche Sprache 14, S. 12-22.

Werner, Otmar (1979): Kongruenz wird zu Diskontinuitāt im Deutschen. In: Broganyi, Bela (Hg.) (1979): Studies in Diachronic, Synchronic, and Typological Linguistics. Festschrift für Oswald Szemerényi on the Occasion of his 65th Birthday. Part. II. Amsterdam. S. 959-988.

Weinrich, Harald (1993): Textgrammatik der deutschen Sprache. Mannheim etc.

Wunderlich, Dieter (1980): Diskontinuierliche Infinitivphrasen im Deutschen. Anmerkungen zu einem Aufsatz von Sigmund Kvam. In: Deutsche Sprache 8, S. 145-151.

Zeman, Jaromir (1979): Untersuchungen zur Satzgliedstellung im Nebensatz in der deutschen Sprache der Gegenwart. Brno.

Zemb, Jean Marie (1978): Vergleichende Grammatik Französisch-Deutsch. Teil 1. Mannheim etc. 


\title{
ULRICH ENGEL / EWA GELLER
}

\section{Das Verb in seinem Umfeld}

Die deutsche Standardsprache im Licht des Schwäbischen, des Jiddischen und des Polnischen

\begin{abstract}
Ein Vergleich mit drei benachbarten oder verwandten Sprachen soll die Konturen des Standarddeutschen deutlich machen. Die Konstrastierung erfolgt in folgenden Bereichen: 1. Die deutschen „Vergangenheitstempora” Prāteritum und Perfekt. Die Gegenūberstellung mehrerer deutscher Sätze und ihrer Entsprechungen/Ūbersetzungsäquivalente läßt erkennen, daß die genannten Tempora nicht nur zeitbezogene Informationen liefern. 2. Umfangreichere Verbalkomplexe im Nebensatz. Hier zeigt sich in den Vergleichssprachen eine "logischere" Wortstellung, die aber vermutlich auch im älteren Deutsch gültig war. Die heute als "typisch deutsch" erscheinende Topologie hat sich offenbar erst seit dem Mittelalter entwickelt. 3. Entscheidungsfragen werden im Standarddeutschen und auch im Schwābischen anders markiert als in den Vergleichssprachen Jiddisch und Polnisch: während hier neben der wohl weltweit charakteristischen Frage-Intonation einleitende Partikeln verwendet werden, bestimmen dort Intonation und Wortstellung ( Verb-Erst”) den Fragecharakter. Im Zusammenhang mit diesen grammatischen Fragen wird auch die Entstehungsgeschichte des Jiddischen noch einmal zur Diskussion gestellt.
\end{abstract}

\section{Vorbemerkungen}

Unser Beitrag zur Typologie des Deutschen - der deutschen Standardsprache in ihrer gegenwärtigen Form - gründet sich auf die Untersuchung einiger grammatischer Kategorien aus dem Umfeld des Verbs. Wir verstehen hier unter "Verb” den sogenannten Verbstamm, also das "nackte” Verb ohne affigierte oder infigierte Elemente. Damit gehören auch die Flexionselemente zum „Umfeld”, unter ihnen der Ablaut, der bei den starken Verben den Tempusbereich gliedern hilft. Bei der gebotenen Auswahl aus den in Frage kommenden Umfeldkategorien war die Versuchung stark, die valenzfundierten Elemente - Aktanten/Ergänzungen/Objekte u.a. - zu untersuchen. Wir haben dieser Versuchung widerstanden, weil 
diese Erscheinungen im wesentlichen bekannt, wohlbeschrieben und auch kaum strittig sind. ${ }^{1}$ So haben wir uns beschränkt auf die Untersuchung

- gewisser Erscheinungen aus dem Bereich der sog. Vergangenheitstempora,

- von Stellungserscheinungen in mehrgliedrigen Verbalkomplexen,

- der Möglichkeit, einen bestimmten Illokutionstyp durch die Verbstellung zu markieren.

Es handelt sich um Phänomene aus den Bereichen der Flexematik, der Satzsyntax und der Pragmatik.

Die Auswahl der Kontrastsprachen bedarf zusätzlicher Begründung. Zunächst: Wir haben drei Sprachen ausgewählt, die in besonders enger räumlicher Beziehung zum Deutschen stehen:

- das Schwäbische als einen der oberdeutschen Dialekte,

- das Jiddische als „Nahsprache” des Deutschen,

- das Polnische als östliche Nachbarsprache.

Diese zu vergleichenden Sprachen bilden ein einzigartiges räumliches und typologisches Kontinuum, wobei das Jiddische eine Zwischenstellung einnimmt. ${ }^{2}$ Als Extreme des Kontinuums fungieren eine germanische und eine westslawische Sprache.

Beim Jiddischen handelt es sich um das Ostjiddische als einzige heute noch lebendige Sprache des ehemals mittel- und osteuropäischen Judentums. Wir gehen dabei vom Standardjiddischen aus, wie es von Uriel Weinreich festgelegt wurde, lassen somit dialektale Unterschiede beiseite. Das Jiddische wird in der Germanistik gemeinhin immer noch als Varietät des Deutschen, gelegentlich gar als deutsche „Mundart” bezeichnet. Selbst wenn dies für das ausgestorbene Westjiddische stimmen sollte, muß dem Ostjiddischen mit seinem slawisch-germanischen Mischcharakter doch der Status einer völlig autonomen Sprache zugebilligt werden. ${ }^{3}$

1 Umstritten ist lediglich die Art der Kategorisierung der valenzabhängigen Elemente, auch ihre Gesamtmenge, kaum aber die zwischensprachlichen Kontraste im einzelnen.

2 Vgl. Timm (1986, S. 14).

3 Die Streitfrage, ob man es im Falle des Ostjiddischen mit einer stark slawisierten germanischen Sprache oder mit einer spāter germanisierten westslawischen Sprache zu tun habe, spielt für unsere folgenden Überlegungen keine Rolle und kann deshalb hier unerörtert bleiben. Vgl. dazu Wexler (1991), Wexler (1993) und Geller (1994). 
Das Schwäbische ist ein oberdeutscher, aus einer einstigen Stammessprache (dem Alemannischen) hervorgegangener Dialekt. Bei der Herausbildung der modernen deutschen Standardsprache, die im 18. Jahrhundert ihren Abschluß fand, ist das Schwäbische nicht zum Zuge gekommen, spielte infolgedessen als Schul- und Amtssprache keine Rolle mehr und vermochte auch keine nennenswerte Schriftlichkeit herauszubilden. Heute ist es, wie die übrigen deutschen Dialekte, dem regionalen Ausgleich, der Nivellierung und der Anpassung an die deutsche Standardsprache ausgesetzt und wird über kurz oder lang den modernen Formen des Verkehrs und der Kommunikation zum Opfer fallen. Noch ist es nicht soweit, noch lohnt es sich, auch durch die Brille des Schwäbischen das Standarddeutsche zu beleuchten. Zugrunde gelegt wurde das Ostschwäbische der Gegend um Aalen-Ellwangen-Bopfingen.

Die schwäbischen Beispiele wurden phonetisch transkribiert, wobei teilweise die IPA-Regelung zugrundegelegt wurde; in einer syntaktischen Untersuchung minder wichtige Feinheiten wie der Öffnungsgrad bestimmter Vokale wurden nicht berücksichtigt. Die jiddischen Beispiele wurden gemäß einer verbreiteten Tradition transliteriert. Es ergaben sich dabei einige Inkongruenzen (z.B. wurde der $z$-Laut im Schwäbischen anders wiedergegeben als im Jiddischen). Wir sind zuversichtlich, daß die Leser mit der Erschließung der "richtigen”, d.h. der von uns gemeinten Ausdrucksformen keine unüberwindlichen Schwierigkeiten haben werden.

\section{Flexemebene: Vergangenheitstempora}

Die deutschen "Tempora” sind in den vergangenen anderthalb Jahrzehnten detailliert und weitgehend überzeugend beschrieben worden. ${ }^{4}$ Daneben gibt es allerdings noch die extrem abweichende Tempuskonzeption von Harald Weinrich (seit 1964) und Ulrich Engels Auffassung, die Weinrich näher steht als den erstgenannten Autoren. Angesichts dieser Situation erscheint es durchaus gerechtfertigt, das deutsche Tempussystem aus typologischer Perspektive neu zu durchleuchten. Wir konzentrieren uns dabei auf die „Vergangenheitstempora”, speziell auf Präteritum und Perfekt im Deutschen und ihre Entsprechungen in den Vergleichssprachen.

Wir geben zunächst vier deutsche Sätze mit ihren jeweiligen Übersetzungen.

4 Vgl. vor allem Bäuerle (1979), Fabricius-Hansen (1986) und Ballweg (1988); zur kontrastiven Beschreibung vor allem Czochralski (1972). 
(1) dt. Ich vergaß, den Wagen zur Werkstatt zu bringen Das bereute ich sehr.

schw. i ho' vrgesa do wa:ga en d werkštat z breyat. des hopme saumäse ghait.

jidd. ' $\chi$ hob fargesn, dos ojto in warštat awektsufirn. dos hob $\chi \chi$ stark badojiert.

poln. Zapomniałem/zapominalem oddać/oddawać samochód do warsztatu. Bardzo tego żalowatem/pożalowatem.

(2) dt. Ich vergaß, den Wagen zur Werkstatt zu bringen. Das habe ich sehr bereut.

schw. I ho' vrgesa da waga en d werkštat z brejat. des hopme ghait.

jidd. ix hob fargesn, dos ojto in warštat awektsufirn. dos hob $i \chi$ štark badojert.

poln. Zapomniatem/zapominatem oddać/oddawać samochód do warszlatu. Bardzo tego pozalowalem.

Im zweiten Teil der deutschen Beispiele sind unterschiedliche Tempusformen verwendet: das Präteritum in (1), das Perfekt in (2). Die schwäbischen, jiddischen und polnischen Beispiele enthalten in diesen Teilen jeweils ein einziges Tempus: zweiteiliges Perfekt im Schwäbischen und im Jiddischen, einteiliges Präteritum im Polnischen. ${ }^{5}$ Das Gleiche zeigt sich in den folgenden Beispielpaaren:

(3) dt. Sie wollten den Namen wissen. Aber den sagte ich nicht. schw. se hont da no'ma wisa gwelt. abr den ho'ne ne gsaet.

jidd. zej hobn gewolt wisn dem nomen. ober ix hob im nit gezogt. poln. Chcieli znać nazwisko. Ale go nie mówitem/powiedziatem.

(4) dt. Sie wollten den Namen wissen. Aber den habe ich nicht gesagt. schw. se hont da no'ma wisa gwelt. abr den ho'ne ne gsaet.

5 Genau betrachtet ist das polnische Präteritum freilich auch eine Art Perfekt, weniger aus historischen Gründen (die Präteritalendungen sind aus einstigen Formen des Auxiliarverbs być 'sein' hervorgegangen und spāter agglutiniert worden) als wegen der relativen Selbstāndigkeit der "Endungen”, die im Satz prinzipiell (fast) frei verschiebbar und an nahezu beliebige Elemente anheftbar sind, vgl.:

Już dlugo na ciebie czekalem ...

Jużem dlugo na ciebie czekal.

Juź dlugom na ciebie czekal.

Juz dlugo ciebiem czekal.

Powiedziala, żem juz dlugo na ciebie czekal.

Aber diese strukturelle Eigenschaft des Tempusmarkers ist für unsere weiteren Betrachtungen nicht von Belang. 
jidd. zej hobn gewolt wisn dem nomen. ober $x$ hob im nit gezogt. poln. Chcieli znać nazwisko. Ale go nie powiedziatem.

Offenbar wird das Vergangene in den vier Sprachen unterschiedlich gegliedert. Wie kommt es, daß drei dieser Sprachen mit einem Tempus auskommen, ohne daf offenbar irgendein Informationsdefizit entstünde, ohne daB jedenfalls der Zeitwert der jeweiligen Sätze in irgendeiner Form mangelhaft erfaßt würde?

Es liegt nahe zu folgern, daB in den vier Sprachen Zeitgleiches jeweils unterschiedlich perspektiviert, auch unterschiedlich gewichtet wird, womit ein wesentlicher Teil der sprachlich übermittelten Information unübersetzbar bliebe. Man könnte weiter aus diesem Befund folgern, daß der Hauptunterschied zwischen den deutschen Tempora Perfekt und Präteritum gar nichts mit 'Zeit' zu tun habe, sondern anderswo zu suchen sei (dazu unten mehr). ${ }^{6}$ Aber die polnischen Übersetzungsäquivalente weisen, zunächst wenigstens, in eine andere Richtung. Zwar stimmen in den Beispielpaaren (1), (2) und (3), (4) die polnischen Tempusendungen jeweils überein. Aber zugleich werden Aspektdifferenzen sichtbar:

In (1) kann dem deutschen Präteritum (bereute) im Polnischen sowohl eine imperfektive Form ( $\dot{z} a l o w a l e m$ ) als auch eine perfektive Form (pozalowalem) entsprechen, und ebenso läßt sich in (3) das deutsche Präteritum (sagte) alternativ durch die Formen mówilem (imperfektiv) und powiedziatem (perfektiv) übersetzen.

Auch dem deutschen Perfekt in (2) (habe bereut) entsprechen alternativ die poln. Formen zalowalem (imperfektiv) und pozalowalem (perfektiv). Aber in (4) entspricht dem deutschen Perfekt (habe gesagt) nur eine poln. perfektive Form (powiedzialem).

Das bedeutet: Es besteht eine gewisse Tendenz, das deutsche Perfekt durch ein perfektives Verb wiederzugeben, während das deutsche Präteritum („Imperfekt”) den Übersetzer weniger festlegt, freilich die Wie-

6 Das Germanische kannte (wie das Indoeuropäische) eine Opposition Prāteritum:Perfekt, die jedoch dem Ausdruck der Aktionsart diente, vgl. Streitberg (1896, S. 276ff.), und im Zusammenhang damit die Relation zwischen Sachverhalt und Sprechzeit differenzierte, vgl. Kuryłowicz (1987). Diese ursprūngliche Opposition, die im Englischen am klarsten erhalten ist, wurde im Deutschen früh neutralisiert, was den "Prāteritumschwund” im Oberdeutschen und auch im Jiddischen zur Folge hatte. Im Slawischen existierte diese Opposition nicht, dafür gab es die Aspektopposition. Tempus- und Aspektdifferenzierung dieser Art kommen selten in einer Sprache zugleich vor. Die beiden Oppositionen sind durchaus heterogen. Aber es scheint enge Berūhrungszonen zu geben, speziell beim deutschen Perfekt (vgl. unten). 
dergabe durch ein imperfektives polnisches Verb prinzipiell offenhält. ${ }^{7}$ Das deutsche Perfekt hat, so scheint es, auch eine aspektuale Funktion, nämlich: es vermag die aspektual meist neutralen deutschen Verben als "perfektivisch", d.h. als "terminativ" o.ä. zu kennzeichnen. ${ }^{8}$ Ähnliches scheint Fourquet gemeint zu haben, als er zwei Bezugssysteme - das der Gegenwart und das der Vergangenheit - unterschied und lediglich dem (gegenwartsbezogenen) Perfekt 'Abgeschlossenheit' zusprach. ${ }^{9}$

Es soll gar nicht bestritten werden, daß sich aus isolierten Sätzen oder solchen - wie hier - mit Minikontexten nur mit Vorbehalt generalisierbare Schlüsse ziehen lassen. Dennoch lassen sich gewisse, offenkundig in den sprachlichen Fakten begründete $Z$ wänge nicht einfach wegdiskutieren. Dies nötigt uns freilich die Überlegung auf, ob die Weinrichsche „pragmatische" Interpretation von Perfekt vs. Präteritum nicht doch Aporien klären könnte, in denen wir uns ständig verfangen. Denn ein Vergleich der beiden deutschen Formulierungen zeigt, daB sich der empfindsame Leser von der originalen Fassung des letzten Satzes viel mehr, direkter, verpflichtender angesprochen fühlen müßte als von der pervertierten Fassung: das Perfekt zieht, unabhängig von jeglichem Zeitbezug, das Geschehen in den Vordergrund, in die Welt des zu Besprechenden, trägt es damit als für Schreiber und Leser belangvoll, unmittelbar, unabdingbar vor; das Präteritum rückt dagegen das Geschehen in den Hintergrund, hält es auf Distanz, macht es für die Gesprächsbeteiligten relativ belanglos.

Noch schwerer durchschaubar sind die Übersetzungsprozesse in einem Fall, wo es um die Beschreibung eines Geschehens geht, das für den imperfektiven Aspekt geradezu prädestiniert zu sein scheint. Die deutschen Sätze

Mein Großvater trank täglich nach dem Essen eine Tasse Kaffee. und

Mein Großvater hat täglich nach dem Essen eine Tasse Kaffee getrunken. werden, sofern der $z$ wischen beiden vorhandene Unterschied zum Ausdruck

7 Vor einer allzu simplen Parallelsetzung des deutschen Tempus mit dem slawischen Aspekt (z.B. Perfekt $\cong$ perfektiv) wird freilich zu Recht gewarnt, so Czochralski (1972, S. 25 et passim). Andererseits gibt Czochralski selbst zahlreiche Ūbersetzungsbeispiele, in denen sich dt. Perfekt und poln. perf. Aspekt, ebenso dt. Prăteritum und poln. imperf. Aspekt entsprechen.

8 Czochralskis epochales Standardwerk zu Tempus und Aspekt im Deutschen und im Polnischen gibt auffallenderweise keine semantische Definition des Aspekts und klammert damit das Problem aus, an dem sich Generationen von Slawisten und Linguisten die Zähne ausgebissen haben.

9 Fourquet (1970, S. 114, S. 126-128 et passim). 
gebracht werden soll - also etwa bei ausdrücklicher Gegenūberstellung -, im Polnischen folgendermaben wiedergegeben:

Mój dziadek pijal codziennie po jedzeniu filizanke kawy.

bzw.

Mój dziadek pil codziennie po jedzeniu filizanke kawy.

Im ersten Fall liegt also eine iterative, im zweiten Fall eine imperfektive Form vor. Perfektiv ist keine der beiden Formen. Der deutsche Tempusunterschied aber geht offenbar verloren.

So hat sich auf Grund des Vergleichs mit dem Polnischen gezeigt, daß die Vergangenheitstempora der deutschen Standardsprache durch Beiziehung aspektualer und "modaler" Kriterien eine verfeinerte Beschreibung erfahren können. Der Vergleich mit dem Jiddischen und dem Schwäbischen dürfte demgegenüber wenig hergeben. Beim Schwäbischen scheint in der Tat ein „Präteritumschwund" eingetreten zu sein, und zwar ersatzlos. Das Jiddische hingegen hat ein eigenes Aspektsystem entwickelt, das sich zwar an das der slawischen Sprachen anlehnt, aber doch deutlich eigene Formen zeigt. ${ }^{10}$ Wenn sich das Jiddische in den angeführten Fällen ähnlich wie oberdeutsche Mundarten zu verhalten scheint, so muB dahingestellt bleiben, ob dies als spätmittelalterliches Erbe anzusehen ist oder, wie neuerdings vermutet wird ${ }^{11}$, auf späteren EinfluB des Westjiddischen zurückgeht.

\section{Satzebene: Umfangreiche Verbalkomplexe}

Nehmen wir an, daB einem Mann verweigert wurde, sein Auto waschen zu lassen, sich aber später herausstellte, daß der vorgehabte Waschvorgang doch das Empfehlenswertere gewesen wäre. Diesen komplexen Sachverhalt kann man im Deutschen auf verschiedene Weise sprachlich wiedergeben, zum Beispiel in der soeben vorgetragenen, recht umständlichen Form, aber auch mit Hilfe der fünf Verben

haben sollen dürfen lassen waschen

Diese Verben lassen sich zu einem Verbalkomplex ordnen, und zwar nach verbindlichen Regeln: Dependenzbäume entsprechen hier vollkommen den hierarchischen Strukturen der GB-Theorie. Wir haben die Verben oben schon gemäB dieser Hierarchie (wie auch sonst?) angeordnet: links für oben, rechts für unten.

10 Zum Verbalaspekt im Jiddischen vgl. Schaechter (1951) und Mark (1978, S. $291 \mathrm{ff}$.).

11 So Wexler (1993). 
Aus der hierarchischen Struktur läßt sich die lineare Abfolge ableiten. Die Dependenzgrammatiker haben es dabei ganz einfach: indem sie den Dependenzast nach rechts „kippen”, erhalten sie, im Prinzip wenigstens, die Nebensatzfolge mit dem Hauptverb ganz links, dem finiten Verb ganz rechts, also eine der obigen Anordnung gerade entgegengesetzte Folge, zum Beispiel

waschen lassen dürfen sollen hätte

etwa in dem Satz

${ }^{*}$ Er meint, daß er seinen Wagen waschen lassen dürfen sollen hätte.

Der Stern soll hier andeuten, daB die meisten Sprecher des Deutschen diese Folge unerträglich finden werden. Es sind dazu verschiedentlich Zusatzregeln formuliert worden, ohne daB man sich völlig hätte einigen können ${ }^{12}$; die meisten dieser Regeln laufen darauf hinaus, daß bei so vielen Infinitiven ein Element oder mehrere, dann in umgekehrter Reihenfolge, nach links verschoben werden. Dann ergibt sich die folgende korrekte Formulierung, die zugleich mit ihren Übersetzungsäquivalenten angegeben wird:

(5) dt. (Er meint,) daß er hätte sollen den Wagen waschen lassen dürfen

schw. (dr moent,) das $r$ het solə defə də wa:ga wäs̆ losə jidd. (er mejnt,) az er wolt gezolt megn lozn wašn dos ojto poln. (Myśli), ze powinno mu byto być wolno kazać umyć samochód.

Was auftällt, ist die Tatsache, daB sich das Standarddeutsche und das Jiddische gerade entgegengesetzt verhalten: im Deutschen wird, wenn auch mit Korrekturen, der Dependenzast nach rechts, im Jiddischen nach links gekippt, er entspricht somit genau der eingangs angegebenen hierarchischen Abfolge von oben nach unten.

Das (freilich nur bedingt vergleichbare) Polnische zeigt eine mit der des Jiddischen übereinstimmende Folge. Das Schwäbische zeigt demgegenüber einen Zwischenzustand, freilich eher mit Tendenz zum JiddischPolnischen. Ein sehr alter Informant bestätigte denn auch, zögernd immerhin, daß die Formulierung

...das $r$ het solo defə do wa:gə losə wäša

12 S. dazu Engel (1991, S. 447), Engel (1994, S. 110), Heidolph (1984, S. 723f.), Haftka (1994). 
ebenfalls möglich und wohl die ältere sei.

Ein fast identisches Bild zeigen die Beispiele 6-9, freilich mit der Einschränkung, daß das Polnische die Perfektform des (hypothetischen) Konjunktiv II nicht eindeutig wiederzugeben vermag. Beim Schwäbischen werden jeweils zuerst die älteren, kaum mehr gebrauchten, dann die neueren Formen angegeben:

(6) dt. daß er den Wagen hätte sollen waschen lassen ${ }^{13}$ schw. das r het solo do wa:go loso wäso (neuer: das $r$ het solo do wa:go wäs̆s losa)

jidd. az er wolt gezolt losn was̆n dos ojto

poln. ze mialby/powinien byl kazać umyć samochód

(7) dt. daß sie ihn nicht alleine hätte sollen schwimmen gehen lassen. schw. das se an net aloe' het sola losa gañ šwema (neuer: das se an ned aloe' hed solo šwema gaja losa)

jidd. az zi wolt nit gezolt im lozn alejn gejn šwimen

poln. ze nie powinna byta pozwolić mu samemu pójść popływać

(8) dt. daß sie ihn nicht sollte daran haben erinnern müssen schw. das se an net sot han miasa dra' erennra

jidd. az zi wolt nit gedarft muzn (im wegn dem) dermonen (im wegn dem) $)^{14}$

poln. że nie powinna była musié́ (mu o tym) przypominać (mu o ty

(9) $\mathrm{dt}$. daß sie sollte davon benachrichtigt worden sein schw. das se hot solo drvo' emformiert woara sae'

jidd. az zi wolt gezoll wegn dem wern informirt/informirt wern ${ }^{15}$ poln. że powinna byla zostać o tym powiadomiona

Das Schwäbische zeigt in (9) insofern ein Sonderverhalten, als bei Auxiliarverben in Endstellung wohl eher die "deutsche" Abfolge gewählt

13 Die Stellung der nichtverbalen Elemente, die sich nach bestimmten Regeln $z$ wischen die Verbformen einschieben lassen, wird hier nicht weiter berücksichtigt.

14 Die jiddische Formulierung ist, ebenso übrigens wie die polnische, der deutschen Vorgabe nicht völlig àquivalent, weil es im Jiddischen keine Perfektform des Infinitivs mit Modalverben und im Polnischen keine Perfektform des Infinitivs gibt.

15 Auch hier besteht, wie poln., keine restlose Übersetzungsäquivalenz, weil es keine Perfektformen zum Infinitiv und zum Konjunktiv II gibt. 
wird.

Auch die folgenden Gegenüberstellungen bestätigen im ganzen das bisher gewonnene Bild (mit der Besonderheit, daB das Jiddische kein Perfekt des Infinitivs bei Modalverben zuläBt und das Polnische kein Perfekt für Infinitiv und Konjunktiv II kennt):

(10) dt. daß er getäuscht worden sein soll.

schw, das $r$ toišt wooro sae' sol 16

jidd. (az me zogt) az er iz geworn opgenart/opgenart geworn ${ }^{17}$

poln. (mówi sif) jakoby zosta zmylony

(11) dt. daß ich gefahren -worden sein soll

schw. das e sol sae' gfa:ra woวry (neuer: das e sol gfa:ro woəro sae') jidd. (az me zogt) az $\dot{\chi}$ bin geworn awekgefirt/awekgefirt geworn ${ }^{18}$ poln. (mówi się) jakobym zostata zawieziona

(12) dt. daß sie ihn soll kommen sehen haben schw. das se $n$ sol ho"koma säa (neuer: das se n sol koma säa ho') jidd. (az me zogt) az zi hot im gezen kumen poln. (że mówi się) jakoby zobaczyla go nadchodzqcego ${ }^{19}$

(13) $\mathrm{dt}$. daß sie ihn hätte kommen sehen sollen schw. das se $n$ het solo säa koma (neuer: das se n het sob koma säa) jidd. az si wolt gezolt im zen kumen poln. ze miałaby zobaczyć go nadchodzgcego

(14) dt. daß ich hätte getäuscht werden sollen schw. das e het sob weara taišt (neuer: het sob taišt weara)

16 Dies scheint eine moderne, „schriftnāhere” Form zu sein. Mein Informant hielt die Form das $r$ sol sae' woara taiłt für die ältere, die er allerdings nicht mehr gebraucht.

17 Die Übersetzbarkeit stōßt auch hier an ihre Grenzen. Das epistemisch gebrauchte sollen (dt. und schwäb.) wird im Jiddischen und im Polnischen durch einen entsprechenden Hypersatz wiedergegeben, wodurch sich die Struktur des Nebensatzes erheblich vereinfacht.

18 Auch hier und ebenso in Beispiel 12 zeigt sich, dab epistemischer Gebrauch des Modalverbs (sollen) durch eine periphrastische Konstruktion umgangen wird; und wieder gilt dasselbe für das Polnische.

19 Die Übersetzung kompliziert sich zusätzlich dadurch, daß anstelle der AcIKonstruktion im Polnischen eine Partizipialkonstruktion verwendet werden muB. 
jidd. $a z$ i Xwolt gezolt wern opgenart/opgenart wern poln. jakobym miala zostać zmylona

(15) dt. daß ich hätte gefahren werden sollen schw. das e het solo weara gfa:ra (neuer: het solo gfa:ro weary) jidd. az ixwolt gezolt wern awekgefirt/awekgefirt wern poln. jakobym miala zostać zawieziona

Alle Beispiele lassen erkennen, daB die Abfolge im Jiddischen in allen wesentlichen Punkten mit der Stellung im Polnischen übereinstimmt, mindestens übereinstimmen kann. Die Frage, ob das Polnische als Sprache der wichtigsten Gastgebernation hier als Substrat oder als Superstrat in Frage kommen könnte ${ }^{20}$, kann hier dahingestellt bleiben.

Das Verhalten des Schwäbischen muB nachdenklich stimmen. In seinen neueren Formulierungen ist es der deutschen Standardsprache recht ähnlich. Die älteren Abfolgen hingegen erinnern eher an Jiddisch und Polnisch, entsprechen also dem nach links gekippten Dependenzast. Nimmt man mittelhochdeutsche und frühneuhochdeutsche Texte hinzu, so läBt sich eine hierarchisch gesteuerte Folge (nach links gekippter Dependenzast) als ältere Form erschließen. Der Umschwung erfolgt im Verlauf eines halben Jahrtausends, Entscheidendes scheint sich im 16. Jahrhundert vollzogen zu haben. In Luthers früheren Texten (1520) werden Nebensatz-Verbalkomplexe meist noch mit dem Finitum eröffnet, in der Bibelübersetzung letzter Hand (1545) steht das Finitum eher an letzter Stelle. ${ }^{21}$ Härd hat gezeigt, wie die ältere hierarchisch bestimmte

20 Letzteres entspricht der immer noch herrschenden Auffassung, ersteres der von Paul Wexler und anderen formulierten These, daf die Menschen jūdischen Glaubens nach jahrhundertelanger Wanderung durch den Balkan in ihrer neuen osteuropäischen Heimat zunächst ein mit hebräischen Elementen durchsetztes Westslawisch (Sorbisch) gesprochen hätten, das erst in der Neuzeit in Anlehnung an das kulturell überlegene Westjudentum - damit das damals noch lebendige Westjiddische - „germanisiert" worden sei.

21 Streng genommen ist Luthers Verfahren differenzierter zu sehen. Zweigliedrige Verbalkomplexe folgen in der Bibel von 1545 ohnehin meist der neuhochdeutschen standardsprachlichen Regelung. Ausnahmen sind selten, 2.B. Ev. Johannis IV: Es kompt die zeit/das jr weder auff disem Berge/noch zu Jerusalem werdet den Vater anbeten ...Ich habe euch gesand zu schneiden/das jr nicht habt geerbeitet ...das er das wasser hatte zu wein gemacht ... sowie Ev. Johannis V: Denn es kompt die stunde/in welcher alle die in den Grebern sind/ werden seine stimme hören. Dagegen zeigen die (seltenen) dreigliedrigen Verbalkomplexe gewöhnlich Voranstellung des Finitums, während die restlichen Infinita wieder der standardsprachlichen Regelung folgen, z.B. Ev. Lucae: Darumb das du meinen 
Folge seit 1450, wenn auch mit zeitweiligen Schwankungen, allmählich in die heute standardsprachlich übliche übergeht. ${ }^{22}$ In noch frühere Epochen zurückgreifende Betrachtungen sind problematisch, weil es sich beim mittelhochdeutschen Schrifttum fast ausschlieBlich um Reimdichtungen handelt, zudem häufig um Übersetzungen; beides beeinfluBt die Wortstellung auf bisher noch unzureichend erforschte Weise. Eine Untersuchung von Teilen des Prosa-Lancelot, den die Forschung in die erste Hälfte des 13. Jahrhunderts verweist, läßt immerhin bei den dreigliedrigen Nebensatzkomplexen eine deutlich dominante hierarchisch orientierte Abfolge erkennen; Verbalkomplexe wie hett gesehen driben, hetten hören blasen, würt hören sagen überwiegen gegenüber solchen mit Endstellung des Finitums. ${ }^{23}$ In den Mundarten hat sich diese - stimmt man unserer und Härds Auffassung zu - ältere Abfolge noch weitergehend erhalten. ${ }^{24}$

Die neuhochdeutsche Standardsprache ist also, was die Stellung im Verbalkomplex betrifft, einen eigenen, völlig ungewöhnlichen Weg gegangen. Das Polnische hingegen folgt, wie sehr viele Sprachen, dem einfacheren und irgendwie auch „logischeren” Prinzip. Daß das Deutsche in Fällen besonders umfangreicher Verbalkomplexe das Finitum und andere Verbformen nach links rückt, ist bisher mit dem Streben nach Übersichtlichkeit, mit einer durch allzu viele aufeinanderfolgende Infinitive bewirkten Undurchschaubarkeit, die vermieden werden soll, begründet worden. Eine bessere Erklärung liefert möglicherweise der diachronische ProzeB, der eben in größeren Verbalkomplexen noch nicht völlig abgeschlossen ist: die hierarchisch höchststehenden Elemente folgen der alten, die tiefer hängenden Elemente der neuen Ordnung. Das Schwäbische folgt offenbar der standardsprachlichen Entwicklung mit deutlicher Verzögerung. Jüngere Sprecher, vor allem soweit sie zu städtischen Umgangssprachen übergegangen sind, verwenden fast ausschließlich die standardsprachli-

worten nicht gegleubet hast/welche sollen erfüllet werden zu jrer zeit. Und daselbst: Vnd sie wincketen seinem Vater/wie er jn wolt heißen lassen.

Vgl. Härd (1981, bes. S. 33ff.) Härd gewinnt seine Ergebnisse aus umfangreichen Corpusanalysen; die Interpretation der Daten erfolgt in kritischer Auseinandersetzung mit Hammarström.

23 Die ausfūhrlichen Ergebnisse dieser Untersuchung werden demnächst an anderer Stelle vorgelegt.

24 Aus diesen Beobachtungen erhellt jedenfalls, daß die vieldiskutierte Tendenz zur Endstellung des Finitums im Deutschen in Wahrheit als viel komplexerer Vorgang zu sehen ist: Man muB, um die Fakten richtig einzuordnen, die Folgeverhältnisse im gesamten Verbalkomplex untersuchen. 
che Abfolge.

Das (Ost-)Jiddische stimmt in diesen Dingen mit dem Polnischen und wohl auch mit dem älteren Deutsch überein. Wo liegen dann wohl die Wurzeln der jiddischen Stellungsregeln? Es kann weiter spekuliert und auch geforscht werden.

\section{Pragmatische Ebene: Entscheidungsfragen}

In Entscheidungsfragen (Satzfragen, Ja-Nein-Fragen) steht im Deutschen das finite Verb prototypisch in Spitzenstellung; anders ausgedrückt: das Finitum steht im linken Rahmenteil, und das Vorfeld ist leer:

(16) dt. Hat Anna die Bücher zurückgegeben?

Durch diese lineare Anordnung ist die Äußerung in der Regel eindeutig als Entscheidungsfrage markiert. „Interrogative Tonführung” tritt meist hinzu, wird in der Regel in normativen Darstellungen ${ }^{25}$ auch verlangt, ist aber nicht unbedingt erforderlich; die letztgenannte Äußerung würde auch mit terminaler Tonführung als Frage verstanden.

Die Frontstellung des Finitums ${ }^{26}$ in Entscheidungsfragen teilt das Deutsche mit einer Reihe von Sprachen, unter anderem mit dem Englischen und dem Französischen, die freilich zum Teil zusätzlich periphrastische Formen verwenden. Ganz anders verfahren die osteuropäischen Sprachen, aber auch das Jiddische, während das Schwäbische hier eindeutig dem Verfahren der deutschen Standardsprache folgt:

(16) jidd. tsi hot Xane di bixer opgegebn?

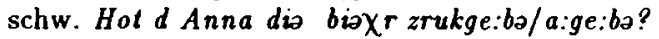

poln. Czy Anna oddala (te) ksiģziki?

Die „Fragepartikel”, eine für slawische Sprachen typische Erscheinung, hat das Jiddische offenbar - hier gibt es keine ernsthaften Meinungsunterschiede - vom Polnischen übernommen. ${ }^{27}$ Sie hat zur Folge, daB in der

25 Vgl. dazu Essen (1964).

26 Die traditionelle Grammatik spricht in diesen Fallen von "Inversion”. Wir halten den Terminus für gefährlich, weil er eine Normalitāt suggeriert, die so nicht existiert. In 60 bis $65 \%$ beliebiger Texte steht in Konstativsätzen das Subjekt an erster, das Finitum an zweiter Stelle: das ist ein ansehnlicher statistischer Wert, der aber unseres Erachtens für die Begründung einer „Normalstellung" nicht ausreicht, zumal wahlweise fast alle verschiebbaren Elemente diese Erststelle einnehmen können.

Es sollte freilich überlegt werden, ob frz. est-ce que, das vielfach noch als illokutiver Hypersatz interpretiert wird, in Wirklichkeit nicht schon zur 
Entscheidungsfrage - auch wenn hier das Finitum obligatorisch an die erste Stelle rückt ${ }^{28}$ - praktisch unbegrenzte Permutationsmöglichkeiten bestehen:

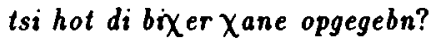

tsi hot opgegebn di bixer $\chi a n e ?$

tsi hot opgegebn $\chi$ ane di bixer?

Die Partikel tsi/czy reicht also im wesentlichen zur Kennzeichnung der Entscheidungsfrage aus, sie konkurriert in dieser Funktion allerdings im Polnischen wie im Jiddischen mit der interrogativen Intonation. So kann man - mit "Frageintonation" - auch sagen:

jidd. Xane hot di bixer opgegebn?

poln. Anna oddata ksigziki?

Zwar gibt es diese Möglichkeit formal auch im Standarddeutschen und im Schwäbischen:

dt. Anna hat die Bücher zurückgegeben?

schw. D Anna hot dio bioxr zruckge:bə/a:ge:bə?

Aber hier handelt es sich nicht mehr um offene Entscheidungsfragen, sondern um Rückfragen (Vergewisserungsfragen). ${ }^{29}$

Wie wenig gerade im Jiddischen und im Polnischen bei der Kennzeichnung der Entscheidungsfrage die Wortstellung eine Rolle spielt, zeigen die zahlreichen Permutationsmöglichkeiten, die am Fragecharakter der Äußerung überhaupt nichts ändern; man vergleiche

jidd. opgegebn hot $\chi$ ane di bixer?

(ohnehin unveränderlichen) Partikel geworden ist. Die von Isačenko 1959 in einer Diskussion aufgeworfene Frage, aus wievielen Wörtern est-ce que bestehe, läßt sich jedenfalls nicht einfach beantworten. Frz. Est-ce que tu viens? entspricht im übrigen dem poln. Czy idziesz? 'Kommst du mit?'.

28 Dies schreiben jedenfalls die gāngigen Grammatiken des Jiddischen vor. Die Jiddisch-Informanten, die für die vorliegende Untersuchung befragt wurden, können eine solche Regel nicht bestätigen, sind aber hierin - sie leben seit 50 Jahren in Warschau - möglicherweise durch das Polnische beeinflubt.

29 Dies unterscheidet das Deutsche offenbar von mehreren seiner Nachbarsprachen. Die frz. Äuberung Tu viens (avec)? (etwa am Ende einer Party an einen Mitgast gerichtet) ist eine reine Entscheidungsfrage. Die angemessene dt. Entsprechung wăre aber Kommst du mit? Die mit dem Frz. formal übereinstimmende Äußerung $D u$ kommst mit? wāre in dieser Situation nicht äquivalent, sie kōnnte allenfalls als Ausdruck starker Ūberraschung verwendet werden. 
di biXer hot Xane opgegebn?

poln. (Czy) Anna ksigziki oddala?

(Czy) oddala Anna ksigziki?

(Czy) ksigzki Anna oddata?

Diese Permutationen dienen allein der Fokusierung bestimmter Elemente.

Das Schwäbische verfügt in dieser Hinsicht, wie das Standarddeutsche, nur über beschränkte Möglichkeiten:

dt. Hat die Bücher Anna abgegeben?

schw. Hot dia bioxar d Anna zruckge:ba?

Frontstellung des infiniten Verbs ist im Deutschen und im Schwäbischen hier sowieso ausgeschlossen. Sie wäre nur möglich bei Überraschungsund bei Vergewisserungsfragen (Abgegeben hat Anna die Bücher? Zruckge:ba hot d Anna dia bia Xar?).

Die in den verschiedenen Sprachen vorhandenen Möglichkeiten sollen anhand zweier weiterer Entscheidungsfragen illustriert werden:

(17) dt. Sind diese Demonstrationen denn umsonst gewesen?

jidd. tsi zenen di demonstratsjes take gewen umsist/umzist gewen? schw. Senen dia demonštraziona omasušt gwest?

poln. Czy te demostracje byty zatem na darmo?

Im Jiddischen und im Polnischen gibt es zahlreiche Permutationsmöglichkeiten:

jidd. Take zenen di demonstracjes umzist gewen? (gewen umzist)

poln. Zatem na darmo byty te demonstracje?

jidd. Zenen take umzist gewen di demonstracjes?

poln. Byty zatem na darmo te demonstracje?

jidd. Zenen di demonstracjes take umzist gewen/gewen umzist?

poln. Byty te demonstracje zatem na darmo?

jidd. Umzist zenen take gewen di demonstracjes?

poln. Na darmo byty zatem te demonstracje?

jidd. Umzist take zenen gewen di demonstracjes?

poln. Na darmo zatem te demonstracje byty?

Das Standarddeutsche (kaum das Schwäbische) erlaubt nur Permutation der Abtönungspartikel denn:

dt. Sind denn diese Demonstrationen umsonst gewesen?

- eine Stellung, die im Schwäbischen (s.o.) ohnehin die reguläre ist. 
Ähnliches wird in den folgenden Beispielen deutlich, wo das Deutsche und das Schwäbische auf eine einzige Stellung festgelegt sind:

dt. Hat der Vater das wirklich nicht gewußt?

schw. hot dr baba des ärle $\chi$ ne gwist?

Im Jiddischen und im Polnischen gibt es dagegen wieder reiche Permutationsmöglichkeiten:

jidd. (tsi) hot der tate dos take ništ gewust?

poln. (Czy) ojciec naprawdę tego nie wiedziat?

jidd. Take hot der tate dos ništ gewust?

poln. (Czy) naprawde ojciec tego nie wiedzial?

jidd. Dos hot der tate take ništ gewust?

poln. Tego nie wiedzial ojciec naprawdę?

jidd. Dos hot der tate ništ gewust take?

poln. Tego ojciec nie wiedziat naprawde?

jidd. ništ gewust hot dos der tate take? (selten)

poln. Nie wiedzial tego ojciec naprawdę?

Nie wiedzial tego naprawdę ojciec? (seltener)

Nie wiedzial naprawdę tego ojciec? (selten)

Es bleibt festzuhalten, daB Polnisch und Jiddisch in Entscheidungsfragen die Folgeelemente wesentlich freier positionieren können als Standarddeutsch und Schwäbisch. Daß die beiden erstgenannten Sprachen über anderweitige Mittel verfügen, um die Entscheidungsfrage eindeutig zu charakterisieren, wäre nur eine dürftige Erklärung, denn über die interrogative Satzintonation verfügen Deutsch und Schwäbisch ja auch.

\section{Zusammenfassung}

In allen drei untersuchten Bereichen zeigt das (Standard-)Deutsche gegenüber den Vergleichssprachen eine weitgehend eigene Struktur.

Man mag sagen, nichts anderes sei zu erwarten gewesen, weil Tempus und Wortstellung im Deutschen anerkanntermafen anders geregelt sind als in vielen anderen Sprachen. Aber die Untersuchung hat für uns - die Autoren - doch manche Überraschungen ergeben.

Wenn im Bereich der Vergangenheitstempora das Deutsche gegenüber östlichen Sprachen als überdifferenziert galt, so muB mindestens dieser Gemeinplatz stark relativiert werden; das Zusammenwirken von Tempus, Aktionsarten und Aspekt läßt das Polnische (und andere slawische Sprachen) eher als ihrerseits feiner gegliedert erscheinen.

Was die Wortstellung betrift, so kamen wir gerade bei umfangreichen 
Verbalkomplexen mit dem Prinzip der umgekehrten Linearstruktur zu einem neuartigen Befund. In der Literatur haben wir darüber wenig gefunden, was auch nicht wunder nehmen kann, denn mit derart vielgliedrigen Komplexen hat man auch im Polnischen (und umso mehr im Jiddischen und im Schwäbischen) selten zu tun. Und im Bereich der Entscheidungsfragen zeigte sich, daB die Abfolge der Elemente in den vier Sprachen jeweils ganz unterschiedlichen Zwecken dient, allein im Deutschen jedenfalls bestimmte Illokutionen vereindeutigen kann.

Daneben fanden wir auch Anlab, die Struktur des Jiddischen und auch des Schwäbischen neu zu überdenken. DaB das Schwäbische sich, bei allen Unterschieden, als dem Standarddeutschen relativ ähnlich erwiesen hat, lediglich einen älteren Stand der Sprachentwicklung wiederzugeben scheint, mag dabei weniger überraschen. Aber die bisher kaum in Frage gestellte Hypothese von der Herkunft des Jiddischen aus spätmittelalterlichen deutschen Dialekten ist mindestens soweit erschüttert, daß man sich dieses Problems ernsthaft annehmen sollte. Heute steht hier Meinung gegen Meinung. Unsere Wissenschaft hat genug, übergenug, mit Scheinproblemen zu schaffen. Da kann man es schon als Fortschritt betrachten, wenn ein Problem, das bisher scheinbar keines war, als Forschungsgegenstand neu entdeckt wird.

\section{Literatur}

Ballweg, Joachim (1988): Die Semantik der deutschen Tempusformen. Eine indirekte Analyse im Rahmen einer temporal erweiterten Aussagelogik. Düsseldorf. (= Sprache der Gegenwart, Bd. 70).

Bäuerle, Rainer (1979): Temporale Deixis - temporale Frage. Zum propositionalen Gehalt deklarativer und interrogativer Sātze. Tübingen. (= Ergebnisse und Methoden moderner Sprachwissenschaft, Bd. 5).

Czochralski, Jan (1972): Verbalaspekt und Tempussystem im Deutschen und Polnischen. Eine konfrontative Darstellung. Warschau.

Engel, Ulrich (1991): Deutsche Grammatik. 2. Aufl., Heidelberg.

Engel, Ulrich (1994): Syntax der deutschen Gegenwartssprache. 3. Aufl. Berlin. (= Grundlagen der Germanistik, Bd. 22).

Essen, Otto von (1964): Grundzūge der hochdeutschen Satzintonation. Ratingen.

Fabricius-Hansen, Cathrine (1986): Tempus fugit. Über die Interpretation temporaler Strukturen im Deutschen. Düsseldorf. (= Sprache der Gegenwart, Bd. 64).

Fourquet, Jean (1971): Prolegomena zu einer deutschen Grammatik. 3. Aufl. Düsseldorf. (= Sprache der Gegenwart, Bd. 7).

Haftka, Brigitte (1994): Wann man angeblich soll das finite Verb voranstellen müssen. In: Steube, Anita/Zybatow, Gerhild (Hg.): Zur Satzwertigkeit 
von Infinitiven und Small Clauses. Tübingen. S. 155-171. (= Linguistische Arbeiten, Bd. 315).

Hammarstrōm, Emil (1923): Zur Stellung des Verbums in der deutschen Sprache. Studien in volkstümlicher Literatur und Urkundensprache der Übergangszeit vom Mittelhochdeutschen zum Neuhochdeutschen. Lund.

Härd, John Evert (1981): Studien zur Struktur mehrgliedriger deutscher Nebensatzprädikate. Diachronie und Synchronie. Göteborg. (= Gōteborger Germanistische Forschungen, Bd. 21).

Heidolph, Karl Erich et al. (1984): Grundzüge einer deutschen Grammatik. 2. A ufl., Berlin.

Kohrt, Manfred (1976): Koordinationsregelung und Verbstellung in einer generativen Grammatik des Deutschen. Tübingen.

Kohrt, Manfred (1979): Verbstellung und „doppelter Infinitiv” im Deutschen. In: Leuvense Bijdragen 68, S. 1-31.

Kuryłowicz, Jerzy (1987a): O rozwoju kategorii gramatycznych. Wyraczanie przeszłości i przyszlości. In: Studia Jǫzykoznawcze 1987, S. 118-140.

Kuryłowicz, Jerzy (1987b): Miejsce aspektu w systemie koniugacyjnym. In: Studia Jǫzykoznawcze 1987, S. 185-191.

Luther, Martin (1545): Die gantze Heilige Schrifft Deudsch. Darmstadt. (Sonderausgabe Wiss. Buchgesellschaft 1972).

Mark, Judl (1978): Gramatik fun der jidisěr klal-ş̆rach, New York.

Schaechter, M. (1951): Aktionen im Jiddischen: ein sprachwissenschaftlicher Beitrag zur Bedeutungslehre des Verbums. Wien (Diss.).

Streitberg, W. (1896): Urgermanische Grammatik. Einführung in das vergleichende Studium der altgermanischen Dialekte. Heidelberg.

Timm, E. (1986): Das Jiddische als Kontrastsprache bei der Erforschung des Frühneuhochdeutschen. In: ZGL 14, S. 1-22.

Weinrich, Harald (1971): Tempus - besprochene und erzählte Welt, 2. Aufl. Stuttgart. (= Sprache und Literatur, Bd. 16).

Wexler, Paul (1991): Yiddish - the fifteenth Slavic Language. A Study of Partial Language Shift from Judeo-Sorbian to German. In: Internat. Journal of Social Language, S. 9-150.

Wexler, P. (1993): The Ashkenazic Jews. A Slavo-Turkic People in Search of a Jewish Identity. Columbia. 



\section{Pronomina:}

stark, schwach oder klitisch 



\title{
MICHAL STARKE
}

\section{Germanische und romanische Pronomina: stark - schwach - klitisch}

\begin{abstract}
In Abschnitt 1 wird das System der Personalpronomina im Deutschen mit seiner scheinbar paradoxen Ausnahme es dargelegt und in Abschnitt 2.1 durch den Vergleich mit dem entsprechenden System im Italienischen einer plausiblen Erklärung zugeführt, die in die Annahme von drei Pronominalklassen stark - schwach - klitisch mündet. In 2.2 werden einige Voraussagen aus dieser Dreiteilung diskutiert, in 2.3 werden die Eigenschaften der drei Klassen von Pronomina auf ihre jeweiligen (teils defizienten) syntaktischen Projektionseigenschaften zurückgeführt. Die Grundthese lautet, daß die Dreiteilung stark - schwach - klitisch universell angelegt ist und sich die Einzelsprachen typologisch nur in der Auswahl der jeweils lexikalisierten Pronomina unterscheiden.
\end{abstract}

\section{Das deutsche Paradox}

Auf den ersten Blick scheint das System der Personalpronomina im Deutschen ziemlich banal zu sein. Anscheinend verhalten sich die Pronomina genau wie Nominalphrasen (NP), ob in Verb-Zweit-Sätzen in satzeinleitender Position (1) oder im Mittelfeld (2), ob als Subjekte, vgl. (1a) und (2a), oder als Objekte, vgl. (1b) und (2b):

(1) a. $\{$ Hans; $\boldsymbol{E} \boldsymbol{r}\}$ ist sehr nett

b. $\{$ Hans; Ihn $\}$ haben alle gesehen

(2) a. Heute ist $\{$ Hans; er $\}$ sehr nett

b. Alle haben $\{$ Hans; ihn $\}$ gesehen

Freilich weiß man schon lange, daß es in diesem sonst regelmäßigen und unauffalligen System eine seltsame Ausnahme gibt: das Pronomen es [3. Person, Singular, Neutrum]. Eine der „bizarren" Eigenheiten von es

1 Hier und im ganzen Aufsatz werden Klammer-Symbole wie folgt verwendet: (a) \{geschweifte Klammern\} zeigen ausschließende Alternativen an. Wenn mehrere Elemente innerhalb einer geschweiften Klammer stehen (vgl. (1)), dann sind sie unterschiedliche Optionen zur Belegung der betreffenden Position; wenn mehrere geschweifte Klammern innerhalb eines Ausdrucks vorkommen (vgl. (14)), dann kennzeichnen sie alternative Positionen für ein Element.

(b) [eckige Klammern] umschließen morphologische und semantische Merkmale.

(c) /Schrägstriche/ kennzeichnen Glossen zu fremdsprachigen Beispielen. 
besteht darin, daß es nicht koordinierbar ist - wiederum in all den schon illustrierten Positionen:

(3) a. \{Dieses Buch; ${ }^{*}$ Es $\}$ und diese Zeitungen sind sehr schön b. $\left\{\right.$ Dieses Buch; ${ }^{*}$ Es $\}$ und diese Zeitungen hat er gekauft

(4) a. ..., daß \{dieses Buch; *es\} und diese Zeitungen sehr schön sind b. ..., daß er \{dieses Buch; *es\} und die Zeitungen gekauft hat

Ebensowenig ist es modifizierbar/fokussierbar:

(5) Sogar \{dieses Buch; *es\} ist auf den Boden gefallen

Und schließlich hat es eine sehr eingeschränkte Distribution: es ist auf lokale verbnahe Positionen beschränkt, vgl. (6a) und (7a). Das heiBt, es kann nicht topikalisiert werden. Auch diese Beschränkung gilt sowohl für das Objektpronomen es, das nicht aus dem Mittelfeld heraus in die satzeinleitende Position einer Verb-Zweit-Konstruktion verschoben werden kann - vgl. (6b), als auch für das Subjektpronomen es, das nicht in einen höheren Teilsatz bewegt werden kann - vgl. (7b):

(6) a. Hans hat \{dieses Buch; es\} gestern gekauft

b. $\left\{\right.$ Dieses Buch; ${ }^{*}$ Es $\}$ hat Hans gestern gekauft

(7) a. $\{$ Dieses Buch; Es $\}$ ist sehr teuer

b. $\left\{\right.$ Dieses Buch; ${ }^{*}$ Es, $\}$ glaube ich, ist sehr teuer

Nichts davon trifft zu auf die übrigen Personalpronomina wie in (1) und (2), die sich in den genannten Hinsichten ganz wie NP verhalten:

(8) a. Er und sein Bruder sind sehr nett (Koordination)

b. Sogar er ist sehr nett (Modifikation/Fokussierung)

c. Er, glaube ich, ist sehr nett (nicht-lokal, Subjekt)

d. Ihn habe ich gesehen (nicht-lokal, Objekt)

Das Paradox, daß innerhalb vollkommener Normalität ein total befremdliches Element wie es auftritt, macht den besonderen Reiz des deutschen Systems der Personalpronomina aus und ist als solches ein Tatbestand, der sich bisher einer befriedigenden Erklärung entzogen hat.

Der nächstliegende Erklärungsansatz für die Lösung dieses Paradoxes versucht es mit verschiedenen „Klassen von Personalpronomina”. Bekanntlich kann in manchen Sprachen ein und dasselbe Merkmalsbündel [Person, Numerus, Genus, Kasus] auf zwei unterschiedliche Weisen realisiert werden. So etwa im Französischen, wo die Personalpronomina ganz systematisch zwei Realisierungen haben. Das Merkmalsbündel [3.Person, Singular, Feminin, Akkusativ] kann z.B. entweder als la oder als elle realisiert werden. 
Die Pronomina vom Typ la und die vom Typ elle haben deutlich verschiedene grammatische Eigenschaften, so daß es am günstigsten erscheint, zwei zugrunde liegende Klassen von Pronomina anzunehmen, nämlich klitische Pronomina und starke Pronomina. Die französischen Personalpronomina werden danach als in zwei Formen realisiert angenommen: in einer klitischen Form ( $l a)$ und in einer starken Form (elle).

Nun bietet es sich an, diese Differenzierung in Pronominalklassen auf das deutsche Paradox zu übertragen. Es könnte ja sein, daß sich es deshalb grammatisch so deutlich von den übrigen Personalpronomina im Deutschen abhebt, weil es zu einer anderen Klasse von Pronomina gehört. Diese Überlegung scheint aussichtsreich, nicht nur weil sie eine Handhabe für das Paradox bietet, sondern auch weil es eine deutliche Parallele zwischen der Unterscheidung klitische vs. starke Pronomina und der Unterscheidung es vs. übrige Personalpronomina gibt. Zum einen verhalten sich starke Pronomina exakt wie NP, und dies gilt auch für die meisten deutschen Personalpronomina, wie (1) - (2) zeigen. Zum anderen unterliegen klitische Pronomina Beschränkungen, die wiederum auffallend denen ähneln, die für das Pronomen es gelten. So etwa können klitische Pronomina weder koordiniert noch modifiziert/fokussiert werden, und sie müssen in enger lokaler Umgebung $z u$ ihrem jeweiligen Verb verbleiben. Dies sei hier anhand klitischer Pronomina aus dem Französischen und Slowakischen illustriert:

$$
\begin{aligned}
& \text { Jean le trouve gentil } \\
& \text { /Jean ihn findet nett / } \\
& \text { Jean findet ihn nett }
\end{aligned}
$$
a. *Jean le et son frère
/Jean ihn und seinen Bruder findet nett/
b. *Jean seulement le trouve gentil /Jean nur ihn findet nett /
c. $\left\{J e a n ; *^{*}\right.$ e $\}$, Marie croit que Pierre l'apprécie / Jean; ihn $\}$ Marie glaubt daß Pierre ihn-schätzt / \{Jean; Ihn\}, glaubt Marie, schätzt Pierre




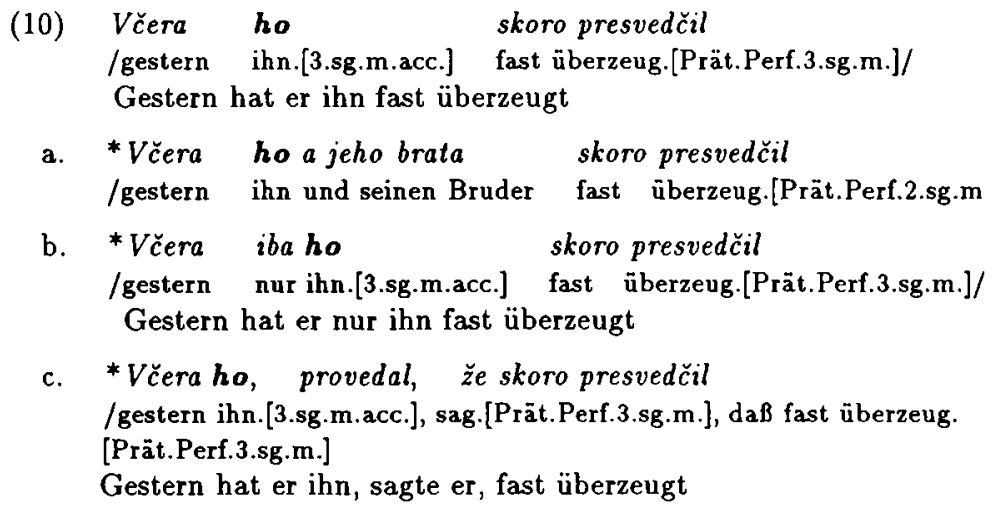

Das Paradox scheint somit aufgelöst: das seltsame Pronomen es ist einfach ein klitisches Personalpronomen, während die übrigen deutschen Personalpronomina starke Pronomina sind. Angesichts der großen Übereinstimmung $z$ wischen (3) - (6) einerseits und (9) - (10) andererseits macht dies auch durchaus Sinn. Zudem ist es eine unbestrittene und signifikante Tatsache, daß die klitischen Pronomina quer durch typologisch sehr unterschiedliche Sprachen gleiche grammatische Eigenschaften aufweisen, und die hier gezeigte Parallele zwischen es - il - ho erscheint dann nur als ein weiterer Belegfall für den generellen Parallelismus. Aber genau hier stoßen wir auf neue Probleme: in einigen Hinsichten verhält sich es nämlich nicht wie ein klitisches Personalpronomen, und dies ist angesichts der cross-linguistisch stabilen Uniformität der klitischen Pronomina ein gravierender Umstand. So etwa können - quer durch alle betreffenden Sprachen - nach Präpositionen keine Objektklitika, sondern nur starke Pronomina vorkommen. Das deutsche es aber kann dies doch und weicht darin klar von den Klitika ab: ${ }^{2}$

a. Je pars

Ich gehe

b. Išiel

/geh.[Prät.Imperf.1.sg.m.]

Ich bin $\mathrm{zu}$ ihm gegangen
Ich $\operatorname{kann}$

ohne es

$\left\{{ }^{*} l e ; l u i\right\}$

mit ihm

$\begin{array}{lcl}\text { som } & k & \left\{{ }^{*} \boldsymbol{m u} ; \text { nemu }\right. \\ \text { bin } & \mathrm{zu} & \mathrm{ihm} /\end{array}$

2 Die meisten deutschen Präpositionen verlangen anstelle von $\mathrm{P}+$ es eine $d a+$ P-Konstruktion (vgl. van Riemsdijk 1978). Dies ist ein unabhängiges Phänomen, das die Argumentation hier nicht berührt. 
Ein weiterer Unterschied zwischen es und den klitischen Pronomina besteht darin, daß alle bekannten Klitika jeweils nur in einer von zwei Positionen vorkommen: entweder adjazent zum Verb wie das französische le in (9), oder in der sog. „zweiten Stelle im Teilsatz" wie das slowakische ho in (10). Und dieses Muster zieht sich durch viele Sprachen. Das deutsche $e s$ jedoch verhält sich deutlich anders, indem es weder verb-adjazent ist noch als zweite Konstituente im Teilsatz erscheint:

..., [daß] [die Mutter] [dem Jungen] es jetzt gezeigt hat

Weitere Unterschiede zwischen es und den Klitika werden anhand des Subjektpronomens es in Abschnitt 2.2 erörtert. Das Paradox bleibt somit bestehen und erscheint vielleicht noch rätselhafter: die deutschen Personalpronomina sind durchweg starke Pronomina, nur mittendrin ist da dies seltsame Gebilde es, das irgendwie klitikartig, aber doch auch wieder kein echtes Klitikon ist.

Das Paradox und seine Gegenstücke in anderen germanischen Sprachen hat eine stattliche Reihe von Untersuchungen gezeitigt, etwa Haider (1984), Travis (1984), Jaspers (1989), Tomaselli (1990), A braham (1991), Cardinaletti/Roberts (1991), Holmberg (1991), Vikner/Schwartz (1991), Zwart (1991, 1993), Cardinaletti (1992), Haegeman (1992, 1993), Lenerz (1992), Tomaselli/Poletto (1992), Beerman (1993) - um nur einige zu nennen, aber es hat sich bislang einer Erklärung hartnäckig widersetzt.

\section{Die italienische Lösung}

\subsection{Parallelitätsbetrachtung}

Die entscheidende Beobachtung zur Auflösung des Paradoxes besteht darin, daß einige Sprachen, die reguläre starke und klitische Pronomina haben, ebenfalls so „seltsame" Pronomina haben, die sich weder wie klitische noch wie starke Pronomina verhalten. Dies gilt etwa für das Italienische - vgl. (14) mit Beispielen aus Cardinaletti (1991), aber auch für die französischen Objektpronomina in Imperativsätzen, vgl. Cardinaletti/Starke 1994, Anm. 32):

$$
\begin{aligned}
& \text { a. Non }\left\{^ { * } a \text { lui\} diró mai } \left\{{ }^{*} a \text { lui\} tutto }\{\text { a lui }\}\right.\right. \\
& \text { b. Non }\left\{{ }^{*} l o r o\right\} \text { diró mai }\{l o r o\} \text { tutto }\left\{{ }^{*} \text { loro }\right\} \\
& \text { c. Non }\{g l i\} \text { dirò mai }\left\{{ }^{*} g l i\right\} \text { tutto }\left\{^{*} g l i\right\} \\
& \text { /nicht ihm/ihnen/ihm sag.[Fut.1.sg] nie alles/ } \\
& \text { Niemals werde ich ihm/ihnen/ihm alles sagen }
\end{aligned}
$$

Das Pronomen gli /ihm/ in (14c) ist klitisch, und sämtliche pronominalen Klitika des Italienischen könnten an dieser Position auftreten. Offensichtlich ist das nicht-präpositionale Dativpronomen loro /ihnen/ in 
(14b) nicht klitisch: es unterliegt anderen Distributionsbedingungen. Andererseits ist loro aber ebenso offensichtlich kein starkes Pronomen wie etwa das präpositionale Pronomen a lui / ihm/ in (14a), das in einer Position steht, die auch eine NP einnehmen könnte. Somit ist loro als Pronomen ein eigenartiges Zwischending. ${ }^{3}$

Die Ähnlichkeit zwischen dem deutschen es und dem italienischen loro wird noch durch den Umstand verstärkt, daß loro dieselben klitikartigen Eigenschaften wie es hat. Es ist nicht koordinierbar - vgl. (15a), nicht modifizierbar/fokussierbar - vgl. (15b), und seine Bewegung aus der üblichen NP-Position heraus ist strikt lokal - vgl. (15c), wohingegen alle diese Konstruktionen mit starken Pronomina (oder vollen NP) möglich sind - vgl. (16):

(15) a. ${ }^{*}$ Non metterei

/nicht aufsetz.[Cond.1.sg]

il cappuccio

die Mütze

b. ${ }^{*}$ Non metterei

/nicht aufsetz.[Cond.1.sg]

c. ${ }^{*}$ Loro, non metterei

/Ihnen, nicht aufsetz.[Cond.1.sg] nie die Mütze/ mai loro e loro/ai mierei figli

nie ihnen und ihnen/meinen

Kindern a. Non metterei

/nicht aufsetz.[Cond.1.sg] b. Non metterei

/nicht aufsetz.[Cond.1.sg] mai solo loro il cappuccio

nie nur ihnen die Mütze/

mai il cappucio
nie die Mütze/ nie die Mütze ihm und Gianni/ Ich würde niemals nur ihm die Mütze aufsetzen

c. A lui, non metterei mai il cappuccio /Ihm, nicht aufsetz.[Cond.1.sg] nie die Mütze/ Ihm würde ich die Mütze niemals aufsetzen

Schließlich sind es und loro nicht den Adjazenz-Bedingungen unterworfen, ganz im Gegensatz zu den romanischen Klitika müssen sie nicht ad-

3 Die loro-Konstruktion ist klar zu trennen von "Doppelobjekt”-Konstruktionen, vgl. dazu die Diskussion in Cardinaletti (1991). 
jazent zum regierenden Verb stehen - vgl. (13) fürs Deutsche und (14b) fürs Italienische, und im Unterschied $z u$ anderen Klitika erscheinen sie nicht an der zweiten Position im Teilsatz.

Das deutsche Objektpronomen es und das italienische Dativpronomen loro verhalten sich somit strikt parallel. Ja, die Parallele geht sogar noch weiter: das Italienische hat seine Gegenstücke zum deutschen es. Neben dem starken Pronomen lui in (17a) verfügt das Italienische über klitikartige Pronomina wie egli in (17b). Egli steht im Kontrast zu den klitischen Subjekten in norditalienischen Dialekten (z.B. dem von Venedig), die verb-adjazent bleiben müssen - vgl. (17c):

\begin{tabular}{|c|c|c|c|c|c|}
\hline (17) a. & $\begin{array}{l}\boldsymbol{L} u \boldsymbol{i} \\
\left\{^{*} E g l i\right\} \\
\left\{{ }^{*} E l\right\} \\
/ \mathrm{er}\end{array}$ & $\begin{array}{l}\text { questo libro } \\
\text { queso libro } \\
\text { sto libro } \\
\text { dieses Buch }\end{array}$ & $\begin{array}{l}\{e g l i\} \\
\left\{{ }^{*} e l\right\} \\
\{e r\}\end{array}$ & $\begin{array}{l}\text { forse } \\
\text { i) forse } \\
\text { forse } \\
\text { vielleicht }\end{array}$ & $\begin{array}{c}\text { lo ha già letto } \\
\text { lo ha già letto } \\
\{\text { el\}lo ga za leto } \\
\text { \{er\}es hat schon gelesen/ }\end{array}$ \\
\hline
\end{tabular}

Er hat dieses Buch vielleicht schon gelesen

Pronomina wie egli verhalten sich exakt wie das deutsche Subjektpronomen es: sie sind weder koordinierbar noch modifizierbar/fokussierbar, ihr Bewegungsspielraum ist strikt lokal, und sie müssen nicht verb-adjazent sein.

Das italienische Paradigma zeigt somit klar, daß es drei Klassen von Pronomina gibt, und nicht etwa nur zwei. Neben starken und klitischen Pronomina gibt es einen dritten Typ, der auf keinen der beiden anderen Typen zu reduzieren und also zwischen stark und klitisch anzusiedeln ist. In Anlehnung an die für klitikartige germanische Pronomina übliche Terminologie (vgl. den Besten (1977, S. 25) und Koster (1978, S. 209)) nennen wir diese dritte Klasse von Pronomina schwache Personalpronomina. Um die starken Pronomina auszugliedern, reservieren wir den Terminus defiziente Pronomina für die Vereinigungsmenge der klitischen und schwachen Pronomina. Zur Motivierung dieses Terminus - vgl. Cardinaletti/Starke (1994).

Die Existenz einer dritten Klasse von Pronomina liefert nun eine prinzipelle Lösung für das deutsche Paradox. Wir haben oben gesehen, daß die Idee verschiedener „Klassen von Pronomina” der Lösung des Rätsels immerhin nahekommt (nämlich wenn es zu einer von den übrigen deutschen Personalpronomina verschiedenen Klasse gehören würde). Das Geheimnis bleibt aber dennoch eins, weil es keinen kohärenten Ansatz gibt, nach dem man es in eine der beiden Klassen - stark bzw. klitisch - einpassen könnte. Nun aber, da wir nach genauerem Hinsehen ein dritte Klasse von Pronomina entdeckt haben, ist die Situation ganz anders: es hat dieselben Eigenschaften wie italienisch loro und egli oder französisch il- 
vgl. (29a) unten - oder andere ähnliche Pronomina dieses dritten Typs. Damit verflüchtigt sich der Eindruck, daß das deutsche es eine höchst eigenwillige Ausnahme inmitten eines ganz normalen Systems darstellt.

Unter der neuen Sicht ist das deutsche Pronominalsystem nicht mehr rätselhaft, seltsam oder paradox. Vielmehr erscheint es nun als ganz normale Belegung des zugrundeliegenden dreiteiligen Systems der Personalpronomina. Anders gesagt, das deutsche Pronominalsystem ist genau wie sein italienisches Gegenstück. Wir können dies (mit einer kleinen Änderung, die in (25) unten erfolgt) folgendermaßen darstellen:

$$
\text { Italienisch }
$$

Deutsch

$\begin{array}{ccccc} & \text { [3.sg.m.dat] } & \text { [3.pl.dat] } & \text { [3.sg.m.acc] } & \text { [3.sg.n.acc] } \\ \text { klitisch } & \text { gli } & - & - & - \\ \text { schwach } & - & \text { loro } & - & \text { es } \\ \text { stark } & \text { alui } & \text { aloro } & i h n & -\end{array}$

Diese Dreiteilung ist keineswegs nur eine für Deutsch und Italienisch. Die Personalpronomina aller Sprachen, die wir bisher geprüft haben, ob Englisch, Französisch, Hebräisch oder Gun, lassen sich in dieses dreiteilige Muster einordnen - vgl. Cardinaletti/Starke (1994). Dies legt die Annahme nahe, daß die menschliche Sprache universell nur ein System von Personalpronomina vorgibt, wobei die Einzelsprachen sich lediglich darin unterscheiden, welche Klasse sie lexikalisieren.

\section{$2.2 \quad$ Einige Voraussagen aus dem System}

Das in (18) exemplifizierte System löst nicht nur das deutsche Paradox auf, es macht auch einige testbare Voraussagen: wenn Deutsch und Italienisch das zugrunde liegende Pronominalsystem gemeinsam haben, dann müßten die Eigenschaften des italienischen Systems auch im Deutschen nachweisbar sein. Und das sind sie in der Tat.

Voraussage Nr. 1: Referenz auf Personen

Ein besonders überraschender Zug von Personalpronomina ist es, daß einige nur auf Personen referieren können (das dafür in der Literatur übliche semantische Merkmal lautet [ \pm Menschlich], obwohl - da auch Bezeichnungen für Götter, Engel und Fabelwesen etc. darunterfallen [ \pm Person ] treffender wäre, aber dieses ist schon von der Morphologie besetzt - Anm. d. Übers.). Genauer gesagt, starke Pronomina können nur auf Personen referieren, während klitische und schwache Pronomina auf beliebige Entitäten referieren können. Im folgenden italienischen Beispiel (19) kann cappuccio entweder „Mütze” bedeuten (in diesem Falle sollte 
loro auf Personen referieren) oder "Füllfederkappe" (hierbei sollte loro nicht auf Personen referieren). Was wir feststellen können, ist, daB das defiziente (nicht-präpositionale) loro zwei Lesarten haben kann, daß aber die starke (präpositionale) Form a loro nur auf Personen, also nicht auf Füllfedern, referiert:

a. Non metterò mai loro cappuccio

b. Non metterò mai il cappuccio a loro

a. Ich werde ihnen nie die Mütze aufsetzen/die

[+ Menschl.] [- Menschl.]

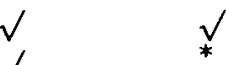

Füllfederkappe

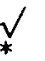

aufstecken

b. Ich werde ihnen nie die Mütze aufsetzen/*die Füllfederkappe

aufstecken

Diese Eigenschaft des Systems der Personalponomina ist umso überraschender, als sie genau so in vielen völlig unverwandten Sprachen auftritt - vgl. Cardinaletti/Starke (1994).

Wie erinnerlich können defiziente Pronomina nicht koordiniert werden. Das heißt, daß gerade diejenigen Personalpronomina, die auf nicht-menschliche Entitäten referieren können, nicht koordinierbar sind. Daraus folgt, daß koordinierte Personalpronomina sich nie auf nichtmenschliche Entitäten beziehen:

a. *Non metterò mai loro e loro il cappuccio

b. Non metterò mai il cappuccio loro e alle altre Ich werde ihnen und den anderen nie die Mütze/

[+ Menschl.] [- Menschl.]

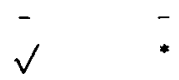

*die Füllerkappe aufsetzen

Wenn unsere Argumentation stimmt, daß das deutsche Pronominalsystem gar nicht so bizarr, sondern im Grunde identisch mit dem italienischen ist, dann müßten die in (19) und (20) illustrierten Beschränkungen auch fürs Deutsche gelten. Die erste Voraussage ist daher, daß koordinierte Personalpronomina im Deutschen nicht auf nicht-menschliche Entitäten referieren können, oder andersherum, daß deutsche Personalpronomina, die auf nicht-menschliche Entitäten referieren, nicht koordinierbar nicht.

Die Bewertung dieser Befunde ist sehr robust. Personalpronomina, die auf nicht-menschliche Entitäten referieren, widersetzen sich der Koordination: 
(21)

a. Maria hat ihn und den anderen eingeladen (ihn $=$ Karl)

b. *Maria hat ihn und den anderen repariert (ihn $=$ den Wagen)

$\begin{array}{lll}\text { a. } & \text { Er und sein Bruder sind sehr nett } & (\text { er }=\text { Karl }) \\ \text { b. } & * \text { Er und der daneben sind nicht verständlich }(\text { er }=\text { der Fahrplan })\end{array}$

Die Asymmetrie zwischen dem ihn in (21a), das koordinierbar ist, aber nicht auf nicht-menschliche Entitäten referieren kann, und dem ihn in (21b), das nicht koordinierbar ist, aber auf nicht-menschliche Entitäten referieren kann, folgt direkt aus dem zugrunde gelegten Pronominalsystem, nämlich unter der Annahme, daß ihn ambig ist zwischen einer schwachen Form (nicht-koordinierbar, Referenz auf nicht-menschliche Entitäten) und einer starken Form (koordinierbar, nur Referenz auf Personen).

Andererseits ist es das einzige schwache Pronomen im Deutschen, das kein Gegenstück in Gestalt eines starken Personalpronomens hat. Die anhand des Merkmals [ \pm Menschl.] sortierten Fakten liefern eine grundsätzliche Erklärung für die Abwesenheit eines starken Pronomens es im Deutschen: es kann keine starken Pronomina geben, die auf nicht-menschliche Entitäten referieren. ${ }^{4}$

Das Kriterium der (Nicht-)Koordinierbarkeit war nur ein Illustrationsfall für die Eigenschaften der schwachen Pronomina, aber natürlich treffen andere typische Eigenschaften ebenso zu. Da nur defiziente Pronomina auf nicht-menschliche Entitäten referieren können, sollten sich alle deutschen Pronomina, die auf nicht-menschliche Entitäten referieren, als defizient erweisen, und folglich alle Eigenschaften von es teilen, nicht nur die Nicht-Koordinierbarkeit. Und das tun sie auch.

Nehmen wir die Lokalitätsbeschränkung. In (6b) vs. (8d) oben wurde gezeigt, daß ihn nicht auf die verbnahe Position beschränkt ist. Aber sobald sich die Referenz von ihn zu [-Menschl.] verändert, wird die Bewegung von ihn lokal, d.h. auf verbnahe Positionen beschränkt, genau wie bei es - vgl. (23a) vs. (23b) und (23c). Derselbe Kontrast findet sich auch bei den Subjektpronomina in (24) - vgl. auch (7b) und (8c) oben:

4 Umgekehrt gibt es einige Fälle, wo es auf Personen referiert, etwa das Mädchen oder das Kind. Hier greift die prinzipielle Erklärung für die Abwesenheit eines starken Pronomens es natürlich nicht. Im Gegenteil, die Variation zwischen den Sprachen sollte sich u.a. darin zeigen, ob für diese Lesart von es ein starkes Personalpronomen existiert oder nicht. 
(23) a. Ihn, hat Maria gesagt, daß Hans schon eingeladen hat

b. ${ }^{*}$ Ihn, hat Maria gesagt, daß Hans schon gekauft hat

$$
(\text { ihn }=\text { den Freund) }
$$

c. ${ }^{*}$ Es, hat Maria gesagt, daß Hans schon gekauft hat

$$
(\text { ihn }=\text { den Wagen })
$$$$
(e s=\operatorname{das} A u t o)
$$

(24) a. Er, glaube ich, ist sehr nett

b. ${ }^{*} \boldsymbol{E} \boldsymbol{r}$, glaube ich, ist sehr teuer

$($ er $=$ sein Freund $)$

c. ${ }^{*}$ Es, glaube ich, ist sehr teuer

$(e r=\operatorname{der} Z u g)$

$(e s=\operatorname{das} A u t o)$

Dasselbe gilt für Modifizierung/Fokussierung. Eingangs hatten wir gezeigt, daß er modifiziert/fokussiert werden kann, was aber nur gilt, wenn er (ebenso das Akkusativpronomen ihn) sich auf Personen bezieht. ${ }^{5}$

Kurzum, die erste Menge von Voraussagen bestätigt klar die Hypothese, $\mathrm{da} ß$ das Deutsche die seinen Personalpronomina zugrunde liegende Syntax mit anderen Sprachen teilt. Genauer gesagt: (i) es ist innerhalb des deutschen Pronominalsystems keine Ausnahme, sondern sämtliche auf nicht-menschliche Entitäten referierenden Pronomina verhalten sich wie $e s$; (ii) es ist keine Ausnahme im Sprachsystem, vielmehr gibt es eine große Klasse von Pronomina (eben die schwachen, d.h. weder klitischen noch starken Pronomina), die sich wie es verhalten. Die Tabelle in (18) oben ist demnach wie folgt abzuändern:

$$
\text { Italienisch }
$$

\section{Deutsch}

$\begin{array}{ccccc} & \text { [3.sg.m.dat }] & {[3 . p l . d a t]} & {[3 . s g . m . a c c]} & {[3 . \text { sg.n.acc }]} \\ \text { klitisch } & \text { gli } & - & - & - \\ \text { schwach } & - & \text { loro } & \text { ihn } & \text { es } \\ \text { stark } & \text { a lui } & \text { a loro } & \text { ihn } & -\end{array}$

Voraussage Nr. 2: Maximale Projektion.

Wenn wir uns nun den abstrakteren Eigenschaften zuwenden, so zeigt sich ein syntaktischer Unterschied zwischen klitischen und schwachen Pronomina in ihrer Position in der Phrasenstruktur. Klitika verhalten sich wie Köpfe: wenn das Verb, d.h. ein Kopf, zu dem sie adjazent sind, wegbewegt wird, dann bewegen sie sich mit ihm:

5 Allerdings ist nicht jegliche Modifizierung für defiziente Pronomina ausgeschlossen. Sie können z.B. durch "floatende" Quantoren modifiziert werden:
(i) Ich
habe
sie gestern alle/beide gekauft
(ii) $\mathrm{Le}$
temo tutte/entrambe
/sie.[3.pl.acc] fürchte alle / beide/
Ich fürchte sie alle/beide 
(26) a. Se Gianni Pavesse organizzato con un certo anticipo, ... /wenn Gianni es.hätte organisiert im voraus, ... / Wenn Gianni es im voraus organisiert hätte, ...
b. L'avesse Gianni organizzato con un certo anticipo, ... /es.hätte Gianni organisiert im voraus, ... / Hätte es Gianni im voraus organisiert, ...

Dies ist Indiz dafür, daß das Klitikon buchstäblich an das Verb angeklebt ist, woraus wiederum folgt, daß es selbst ein Kopf ist.

Andererseits zeigt sich bei genauerer Betrachtung, daß das nicht-präpositionale Pronomen loro /ihnen/ die Position einer ganzen Phrase (XP) einnimmt - vgl. Cardinaletti/Starke (1993) zu Einzelheiten. Zu ähnlichen Folgerungen gelangen Kayne (1983) and Rizzi (1986) bezüglich defizienter pronominaler Subjekte im Französischen - vgl. (29a) unten, indem sie deren phrasalen Status als XP als Differenzpunkt zu den Subjektund Objektklitika in den norditalienischen Dialekten herausstellen.

Wenn unsere Annahme stimmt, daß im Deutschen das Pronomen es und die übrigen Personalpronomina in ihrer Referenz auf nicht-menschliche Entitäten klare Belegfälle für schwache Pronomina sind, dann müBten diese Pronomina Positionen besetzen, die für maximale Projektionen (XP) reserviert sind, und sie dürften sich nicht wie Köpfe verhalten. Dafür gibt es Belege sowohl aus der Stellung dieser Pronomina in VerbZweit-Sätzen wie auch aus ihrer Kombination mit Präpositionen:

(27) a. Es ist zu teuer

b. Er ist zu teuer (, dieser Zug)

(28) a. Ich kann ohne es nicht leben

b. (Dieser Zug ist sehr schnell,) ich könnte ohne ihn nicht pünktlich ankommen

In (27) besetzen die schwachen Pronomina die Spitzenposition in einem Verb-Zweit-Satz. Diese Sätze sind bekanntlich durchweg vom Typ [XP V ...], was gerade ihre Verb-Zweit-Eigenschaften bedingt. Daraus folgt, daß die schwachen Subjektpronomina eine XP-Position einnehmen - vgl. Cardinaletti/Starke (im Druck) für Argumente gegen alternative Annahmen. In (28) werden die schwachen deutschen Pronomina von einer Präposition regiert und nehmen innerhalb einer Präpositionalphrase (PP) wiederum eine Position ein, die für maximale Projektionen, also $\mathrm{XP}$, reserviert ist. 
Voraussage Nr. 3: Satzkoordination.

Da schwache Pronomina maximale Projektionen sind, verschmelzen sie nicht mit dem dazugehörigen Verb, da Klitika aber Köpfe sind, können sie in bestimmten Situationen mit dem Verb verschmelzen. Rizzi (1986) bemerkt, daß dies eine Erklärung für folgende Koordinationsasymmetrien liefert:

(29) a. Il travaille à son article et - - pense à ses problèmes Er arbeitet an seinem Aufsatz und - - denkt an seine Probleme

b. ${ }^{*}$ Jean le lavera soigneusement et-- remettra en place

c. Jean le lavera soigneusement et le remettra en place Jean wird $\{$ ihn, sie, es $\}$ sorgsam waschen und $(\{$ ihn, sie, es $\})$ wieder an seinen Platz legen

(29b) ist abweichend. Um den Satz akzeptabel zu machen, muß das klitische le wiederholt werden wie in (29c). Diese Asymmetrie folgt aus der Tatsache, daß es in (29b) keine Konstituente gibt, die zu koordinierenn wäre, d.h. keine Konstituente, die das Klitikon ausschließt, aber das Verb einschlieBt. In (29a) und (29c) hingegen gibt es eine solche Konstituente. Der Kontrast ist in (30) als Baumdiagramm dargestellt, wobei $\alpha$ den relevanten Knoten kennzeichnet:

a.

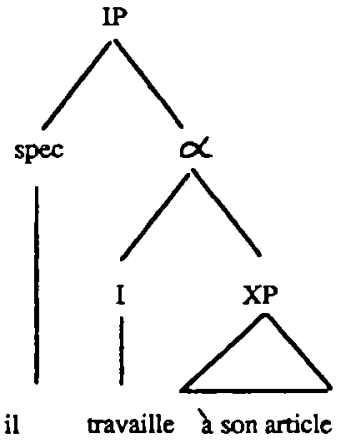

b.

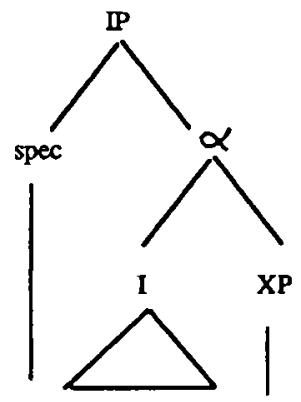

Jean le lavera soigneusement

Derselbe Kontrast findet sich, wenngleich noch subtiler, $\mathbf{z w i s c h e n}$ defizienten Subjekten vom egli-Typ im Standarditalienischen, die im zweiten Konjunkt wegfallen können, und den defizienten Subjekten in einigen norditalienischen Dialekten, die das nicht können: 


$$
\begin{aligned}
& \text { a. Egli canta e - balla benissimo (Standarditalienisch) } \\
& \text { Er singt und - - tanzt sehr gut } \\
& \text { b. }{ }^{*} \text { La canta e - - bala (Trentino) } \\
& \text { /Sie singt und - - } \operatorname{tanzt} /
\end{aligned}
$$

Hier gilt genau dieselbe Erklärung: egli ist ein schwaches Pronomen und daher in einer Specifier-Position - wie il in (30a) - und kann folglich im zweiten Konjunkt wegfallen. Hingegen ist la klitisch - wie le in (30b) und kann folglich im zweiten Konjunkt nicht wegfallen.

Nun, wenn es ein schwaches Pronomen ist, das die einleitende SpecifierPosition in einem Verb-Zweit-Satz besetzt, dann sollte es möglich sein, es (und andere defiziente deutsche Pronomina) im zweiten Konjunkt wegzulassen, ganz so wie französisch $i l$ und italienisch egli, aber im Gegensatz zu französisch le und norditalienisch la:

a. Es kostet viel und - schmeckt auch nicht gut (es = das Eis)

b. Er kostet viel und - schmeckt auch nicht gut (er = der Kuchen)

Wieder ist die Übereinstimmung wie erwartet. Sie bestätigt die Ähnlichkeit zwischen den germanischen und den romanischen Pronominalsystemen, spezieller noch, die Übereinstimmung der schwachen Pronomina wie deutsch es, französisch il und italienisch egli (als Subjekt) und loro (im Dativ).

\section{Voraussage Nr. 3: Feste Position}

Ein Charakteristicum defizienter Pronomina ist ihre feste Positionierung: sie können weder „außerhalb” ihrer Teilsätze, also topikalisiert oder disloziert, noch in ihrer grundlegenden thematischen Position vorkommen:

$$
\begin{aligned}
& \text { a. }\{\text { lui\}, questo libro, \{lui\} lo ha comprato }\{\text { lui }\} \\
& \left\{{ }^{*} \text { egli\}, questo libro, \{egli\}lo ha comprato }\left\{{ }^{*} \text { egli }\right\}\right. \\
& \text { /er, dieses Buch er es hat gekauft er/ }
\end{aligned}
$$

b. $\{$ a lui $\}$, Maria, $\{$ a lui $\}$ ha dato questo libro $\{$ a lui\} ieri $\{$ a lui $\}$ /ihm, Maria ihm hat gegeben dieses Buch ihm gestern ihm/

$$
\begin{aligned}
& \left\{{ }^{*} \text { loro }\right\}, \text { Maria, }\left\{{ }^{*} \text { loro }\right\} \text { ha dato }\{\text { loro }\} \text { questo libro }\left\{{ }^{*} \text { loro }\right\} \\
& \text { ieri }\left\{{ }^{*} \text { loro }\right\} \\
& \text { /ihnen, Maria, ihnen hat gegeben ihnen dieses Buch ihnen } \\
& \text { gestern/ ihnen/ }
\end{aligned}
$$

Die feste Position von schwachen Subjektpronomina ist ganz systematisch über - d.h. links von - der festen Position von schwachen Objektpronomina: 
(34) a. Egli ha dato loro questo libro

Er hat ihnen dieses Buch gegeben

b. Il a tout fait

Er hat alles getan

Die Distribution scheint somit die generell angenommene Verteilung von Elementen in den Konfigurationen spec-AgrS und spec-AgrO zu reflektieren, ein Faktum das am einfachsten so zu erfassen ist: „Schwache Pronomina werden nur in einer Konfiguration spec-Agr lizensiert, wo sie in einer lokalen Relation mit Kasusmerkmalen stehen." - vgl. die ausführliche Diskussion in Cardinaletti/Starke (1994).

Die Generalisierung über die Verteilung der schwachen Pronomina gilt auch für das Deutsche. Während volle NP im Mittelfeld ziemlich frei in ihrer Distribution sind, sind das Pronomen es und andere defiziente Pronomina fest placiert. Man vergleiche (35b) mit (36b), wo ihn $=$ den Parkschein:

$$
\begin{array}{r}
\text { a. ..., daß der Automat/das Gerät dem Kunden } \\
\text { den Parkschein doppelt berechnet hat } \\
\text { b. ..., daß den Parkschein dem Kunden der A utomat/ } \\
\text { das Gerät doppelt berechnet hat }
\end{array}
$$

(36) a. ..., daß er /es ihn dem Kunden doppelt berechnet hat

b. *..., daß ihn er / es dem Kunden doppelt berechnet hat

Ein schlagendes Argument für diese Verteilung ist die Tatsache, daß eine Folge von zwei es nur auf eine Weise interpretiert werden kann. Deutsche Sprecher können in (37a) das erste es nur als Subjekt und das zweite es nur als Objekt interpretieren, wohingegen die vollen NP in (37b) und (37c) viel freier in ihrer Abfolge sind:
a...., weil es es gegessen hat
b. ..., weil das Kind das Brot gegessen hat
c. ..., weil das Brot das Kind gegessen hat

Wieder verhalten sich die deutschen Personalpronomina wie erwartet, wenn man annimmt, $\mathrm{da} \beta$ das deutsche Pronominalsystem ähnlich wie seine romanischen Gegenstücke aufgebaut ist.

Voraussage Nr. 5: Wähle das am meisten reduzierte Pronomen!

In Sprachen, in denen defiziente und starke Personalpronomina eine unterschiedliche Morphologie aufweisen, könnte ein simpler Satz wie 
Hans beobachtet sie oder John watches her im Prinzip zwei Varianten besitzen, nämlich eine mit einer starken Pronominalform und eine mit einer defizienten. Nun zeigt sich aber, $d a B$ in solchen Sprachen immer nur eine von beiden möglich ist, nämlich die am meisten reduzierte:
a. Jean la regarde
b. *Jean regarde elle
Hans betrachtet sie

Dies schließt jedoch die Verwendung der starken Form nicht grundsätzlich aus, wie die folgenden Beispiele zeigen:
a. Jean regarde elle et son frère
Hans betrachtet sie und seinen Bruder
b. Jean regarde seulement elle
Hans betrachtet nur sie

\begin{abstract}
Allerdings kann die starke Variante der Pronomina nur dann verwendet werde, wenn die defiziente nicht zugänglich ist. Dies ist die knappste Formulierung eines generellen Prinzips, das besagt, daß stets die am meisten defiziente Form zu verwenden ist. Wenn eine klitische Form verfügbar ist, muß sie gewählt werden - vgl. (38). Wenn keine defiziente Form vorhanden ist, wird die starke Form (trivialerweise) zur am meisten defizienten Form und kann folglich verwendet werden - vgl. (39). An der Oberflächenstruktur ergibt sich daraus ein Paradigma, in dem ein Pronomen "weit links" erscheinen muß, außer wenn es koordiniert oder modifiziert ist, dann kann es auch "weiter rechts" auftreten - vgl. (38) und (39) oben.
\end{abstract}

Und wie steht's damit im Deutschen? Wenn das Pronominalsystem im Deutschen und Italienischen das gleiche ist, dann sollte das Auswahlprinzip auch in beiden Sprachen wirksam sein. Der Gleichklang der stark-schwach Paare (ihn - ihn, sie - sie) im Deutschen erschwert die Überprüfung. Man betrachte jedoch das folgende Paradigma:
(40) a. Ich habe
ihn gestern
eingeladen
b. Ich habe
gestern *ihn
eingeladen
c. Ich habe
gestern ihn und Maria eingeladen
d. Ich habe
gestern nur ihn
eingeladen

Auf den ersten Blick erscheint dieses Paradigma ziemlich willkürlich. Warum kann ihn in (40b) nicht nach dem Adverb stehen, wohl aber in (40c) und (40d), also in Kontexten, die im Italienischen ein starkes Pronomen erzwingen würden? Angesichts des Auswahlprinzips und der Tatsache, daß die Oberflächenform ihn mehrdeutig ist bezüglich einer schwa- 
chen und einer starken Lesart des Personalpronomens, werden diese Fakten beinahe trivial. Das schwache ihn wird bevorzugt gegenüber seinem starken Gegenstück ausgewählt, und das starke (post-adverbiale) Pronomen kann nur auftreten, wenn das schwache aus unabhängigen Gründen ausgeschlossen ist. Tatsächlich ist die Verteilung in (40) dieselbe wie in den romanischen Sprachen:

$$
\begin{aligned}
& \text { a. Ich habe }\{\boldsymbol{i} h \boldsymbol{n}\} \text { gestern }\left\{{ }^{*} \mathrm{ihn}\right\} \text { eingeladen } \\
& \text { a' Jean } \quad\{l a\} \text { regarde }\left\{{ }^{*} l a\right\} \\
& \text { b. Ich habe gestern ihn und Maria eingeladen } \\
& \text { b'. Jean regarde elle et son frère } \\
& \text { c. Ich habe gestern nurihn eingeladen } \\
& \text { c' Jean regarde seulement elle }
\end{aligned}
$$

Die Auflistung dieser Beispiele soll nicht implizieren, daß die Struktur der deutschen und der französischen Sätze übereinstimmt, es geht hier nur um die parallele Verteilung der Pronomina. (41) bestätigt erneut die grundlegende Ähnlichkeit der germanischen und romanischen Pronominalsysteme, speziell die Tatsache, daß auch das Deutsche verschiedene Klassen von Pronomina hat, deren Verteilung durch das Auswahlprinzip gesteuert wird.

Es gibt noch einen weiteren durch das Auswahlprinzip determinierten Phänomenbereich, an dem man die Übereinstimmung der germanischen und der romanischen Systeme illustrieren kann, nämlich die NomenPronomen-Asymmetrien. Da in den betreffenden Sprachen NP nicht in verschiedenen Varianten vorkommen (d.h. NP sind nur stark und besitzen keine schwachen oder klitischen Varianten), während Personalpromonina verschiedene Varianten aufweisen, liefert das Auswahlprinzip in den beiden Fällen unterschiedliche Ergebnisse. Bei Nomina erlaubt es stets die starke Form, die trivialerweise unter den zugänglichen Formen die am meisten reduzierte ist, bei Pronomina aber läßt es die starke Form nur in solchen Kontexten zu, die eine defiziente Form ausschließen (also bei Fokussierung etc.). Somit sollte es gewisse Kontexte geben, in denen starke NP auftreten können, aber nicht starke Pronomina, es sei denn, sie sind kontrastiert oder modifiziert etc. Dies läßt sich gut am Französischen veranschaulichen: während das Auswahlprinzip in (38b), hier wiederholt als (42a), das starke Pronomen ausschließt, impliziert es, daß in derselben Position eine NP vollkommen akzeptabel ist: 
(42) a.* Jean regarde elle

b. Jean regarde Marie

Jean betrachtet sie/ Marie

Damit haben wir ein zweites Paradigma, das die Wirksamkeit des Auswahlprinzips im Deutschen zeigt: das Auswahlprinzip verhindert ein starkes Pronomen in post-adverbialer Position - vgl. (41a) und (43a), aber es kann nicht verhindern, daß in dieser Position eine starke NP auftritt - vgl. (43b):

(43) a. Ich habe gestern *ihn eingeladen

b. Ich habe gestern Hans eingeladen

Diese Asymmetrie folgt unmittelbar aus dem Auswahlprinzip und liefert damit weitere Evidenz für die grundlegende Übereinstimmung der germanischen und romanischen Pronominalsysteme.

Die Paradigmen in (40) - (43) fallen direkt unter die minimale Annahme, $\mathrm{da} B$ das deutsche Pronominalsystem nicht etwa bizarr ist, sondern sich verhält wie alle übrigen Systeme, die wir kennen. Sie alle folgen aus einem einzigen Prinzip, das etwas vereinfacht lautet: „Wähle das jeweils defizienteste Pronomen". Dieses Prinzip hat seine unabhängige Motivierung in anderen Sprachen und kann möglicherweise aus allgemeineren Annahmen ableitet werden.

Die genannten Paradigmen haben auch einige wichtige Nebeneffekte. E r s t e n s, das schwache ihn kann [+ Menschl.] sein. Aber es gilt nicht, daß ein ihn mit [- Menschl.] schwach und ein $i h n$ mit [+ Menschl.] stark ist (was ja eine der bisherigen Deutungen war): die Verteilungsbeschränkungen in (41) und (43) beziehen sich auch auf ihn mit [+ Menschl.], was besagt, daß das schwache ihn sowohl für eine [+ Menschl.] wie auch für eine [- Menschl.] Interpretation zur Verfügung steht (wie das französische Klitikon le oder das italienische Klitikon lo). Das starke ihn jedoch ist nur [+ Menschl.] - genau wie die starken romanischen Pronomina.

$\mathrm{Z}$ we it e n s, die Verteilungsmuster zeigen, daß auch alle übrigen deutschen Objektpronomina eine schwache Form besitzen. So sind nicht nur die Pronomina der 3. Person ihn und sie mehrdeutig bezüglich schwacher und starker Form, sondern auch alle Pronomina der 1. und 2. Person. Dies hat man bisher nicht zu sehen vermocht, weil es für die Existenz einer schwachen Form keine morphologische Indikation gibt, und weil der Test mit der Referenz auf Personen (nur defiziente Formen können auf nicht-menschliche 
Entitäten referieren) für die Pronomina der 1. und 2. Person irrelevant ist. Nun aber zeigt sich, daß die Verteilungsmuster in (41) und (43) genauso für die Pronomina der 1. und 2. Person gelten:

$\left(41^{\prime} / 43^{\prime}\right)$

a. Hans hat $\{$ mich, dich $\}$ gestern $\left\{{ }^{*}\right.$ mich, ${ }^{*}$ dich $\}$ eingeladen

b. Hans hat gestern $\{$ mich, dich\} und Tom eingeladen

c. Hans hat gestern nur [mich, dich $\}$ eingeladen

Wenn wir nun die auf das Auswahlprinzip gestützte Erklärung für all diese Asymmetrien beibehalten wollen, so folgt daraus, daß die Personalpronomina der 1 . und 2. Person mehrdeutig sind bezüglich einer schwachen und einer starken Form.

Abschließend sei noch einmal betont, daß das Auswahlprinzip keineswegs als Elementarprinzip der Grammatik anzusehen ist, eine solche Auffassung wäre angesichts seines konstruktionsspezifischen Charakters sogar suspekt. Wir haben es hier lediglich als deskriptiv adäquate Generalisierung benutzt, um die Gemeinsamkeiten zwischen den germanischen und den romanischen Pronominalsystemen zu verdeutlichen und um zu erhärten, $\mathrm{da} \beta$ das Deutsche über schwache Pronomina verfügt. Wir sind jedoch davon überzeugt, daß das Auswahlprinzip ein Epiphänomen darstellt, das aus der Interaktion allgemeinerer Prinzipien abzuleiten ist vgl. Cardinaletti/Starke (1994) für eine ausführlichere Diskussion.

\subsection{Eigenschaften des zugrunde liegenden Systems}

Zusammenfassend läßt sich feststellen, daß sich alle Voraussagen erfüllt haben, die sich unter der Annahme einer grundlegenden Übereinstimmung zwischen den germanischen und den romanischen Pronominalsystemen (wobei es und die auf nicht-menschliche Entitäten referierenden Personalpronomina als schwache Pronomina gelten) formulieren lassen. Insgesamt bezeugen die Fakten bezüglich Referenz auf Personen, Auswahl unter Pronominalklassen, feste Positionierung in einem ansonsten recht liberalen Mittelfeld, Koordination mit tilgbaren Subjekten und Projektion von Pronomina als XP vs. $\mathrm{X}^{\circ}$ robust und hinreichend die Normalität des deutschen Pronominalsystems. Es gibt kein es-Paradoxon, oder aber das es-Paradoxon im Deutschen ist dasselbe wie das loroParadoxon oder das il-Paradoxon im Italienischen bzw. Französischen. All diese Paradoxa lösen sich auf angesichts der Verteilungsmuster, die auf die Existenz einer dritten Klasse von Pronomina verweisen.

Zum Abschluß ein kurzer Blick auf die strukturellen Quellen des zugrunde liegenden Systems der Personalpronomina. Die Kategorie der schwachen Pronomina steht irgendwie zwischen den starken und den 
klitischen Pronomina: mit den starken teilt sie die Eigenschaft, eine XPProjektion zu bilden (und andere Eigenschaften wie die mögliche Beibehaltung des Wortakzents), mit den klitischen hingegen teilt sie die Eigenschaft der Nicht-Koordinierbarkeit und der Nicht-Modifizierbarkeit. Dies ergibt das folgende Bild:

(44) a. Klitische Elemente sind defiziente $\mathrm{X}^{\circ}$-Projektionen.

b. Schwache Elemente sind defiziente XP-Projektionen.

c. Starke Elemente sind nicht-defiziente XP-Projektionen.

Nicht-defiziente Köpfe sind gewöhnlich nicht-klitische Köpfe, also Veiben, Nomina etc. Es verdient angemerkt zu werden, daß wir streng genommen durch das vorgeschlagene dreiteilige Pronominalsystem der Standardtheorie der Grammatik nichts hinzufügen. Die beiden für unsere Annahme zentralen Eigenschaften, nämlich XP vs. $X^{\circ}$ and Defizienz (= Nicht-Koordinierbarkeit, Nicht-Modifizierbarkeit etc.), sind Eigenschaften, auf die jede Grammatik, die sich auch nur minimal mit Klitika befaßt, zurückgreifen muß. Außerdem betrachtet jede Grammatik diese beiden Eigenschaften als unabhängig: es gibt Minimalpaare von Köpfen, von denen einer defizient ist, der andere nicht (z.B. viele Auxiliare in den slavischen Sprachen). Daher gibt es keine Kovariation zwischen Defizienz und $\mathrm{X}^{\circ}$-Projektion. Alle Theorien enthalten folglich den Begriff „schwaches Pronomen” als logische Möglichkeit. Um die Möglichkeit schwacher Pronomina tatsächlich auszuschließen, benötigte man einen Filter, der die Kombination der Eigenschaften XP-Projektion und Defizienz effektiv ausschließt. Solche Erwägungen sind wichtig, weil man bei einer oberflächlichen Betrachtung der angeführten Fakten den irrigen Eindruck gewinnen könnte, daß mit der Postulierung der schwachen Pronomina der Grammatiktheorie eine neue Einheit hinzugefügt würde.

Die "defizienten" Eigenschaften der Personalpronomina sind wie folgt verteilt (gezeigt wird nur eine Teilmenge der relevanten Eigenschaften, die sich über Morphologie, Phonologie und Semantik erstrecken): 


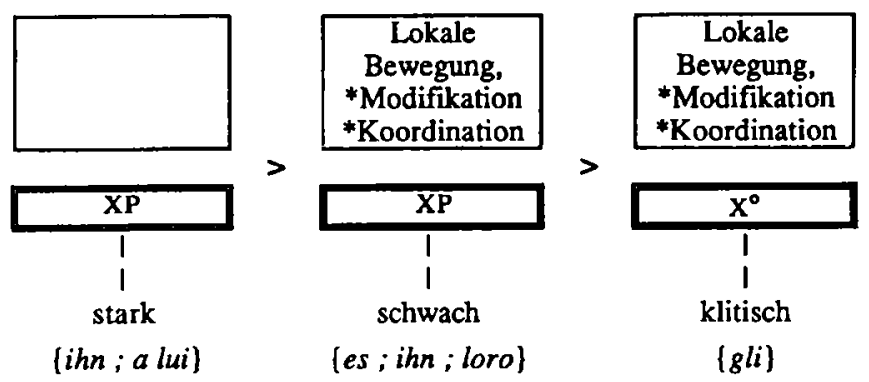

Schließlich sei angemerkt, daß die Beziehung stark $>$ schwach $>$ klitisch in (45) nicht allein auf den oben genannten Eigenschaften beruht, sondern auch in verschiedenen anderen Domänen sichtbar wird. So etwa besagt das Auswahlprinzip, das im Wesentlichen die Auswahl-Abfolge $\mathrm{zwischen}$ starken und defizienten Pronomina als stark $>$ defizient formuliert, natürlich auch, daB Klitika Vorrang haben vor schwachen Pronomina und schwache vor starken, also stark $>$ schwach $>$ klitisch.

Freilich ist dies nur ein skizzenhafter Abriß des zugrunde liegenden Systems der Personalpronomina, eine auf die Eigenschaften des Systems konzentrierte Diskussion findet sich Cardinaletti/Starke (1994). Hier ging es uns vornehmlich um den Nachweis, daß das deutsche Pronominalsystem nur paradox erscheint, wenn man die klare Dreiteilung des Systems nicht kennt. Daß alle Spuren des Rätsels verschwinden, sobald man das zugrunde liegende System herausgefunden hat, macht das vorgeschlagene System glaubwürdig.

In diesem Zusammenhang ist natürlich auch zu erwähnen, daß die oben gebrauchte Redeweise über die "Angleichung” des Deutschen an die italienische Lösung nur ein pädagogischer Kunstgriff ist. Die Analyse des Deutschen hängt in keiner Weise von der der romanischen Sprachen ab. Auch wenn die romanischen Sprachen nicht existierten, würden wir zu denselben Schlußfolgerungen gelangen. Wir hätten die Existenz einer dritten Klasse von Pronomina (und die Dreiteilung des zugrunde liegenden Systems) auch ausschließlich aus der Analyse deutscher Daten ableiten und die Ähnlichkeit zu anderen Sprachen nur als Konsequenz anführen können. In diesem Sinne ist das Deutsche, wie der Aufsatz 
zeigt, eine wichtige Belegquelle für Einsichten in die zugrunde liegende Dreiteilung stark - schwach - klitisch.

[autorisierte Übersetzung aus d. Engl.: Ewald Lang]

\section{Literatur}

Abraham, Werner (1991): Rektion und Abfolge pronominaler Satzglieder und ihrer klitischen Formen im Deutschen. In: Language and Cognition 1, S. 1-12.

Beermann, Dorothee (1993): Germanic pronouns. Unpublished manuscript, University of Tilburg.

den Besten, Hans (1977): On the Interaction of Root Transformations and Lexical deletive Rules. In: Groninger Arbeiten zur germanistischen Linguistik 20, S. 7-78.

Cardinaletti, Anna (1991): On pronoun movement: The Italian dative loro. In: Probus 3.2, S. 127-153.

Cardinaletti, Anna (1992): On cliticization in Germanic languages. In: Rivista di grammatica generativa 17, S. 65-99.

Cardinaletti, Anna/Roberts, Ian (1991): Clause structure and X-second. Erscheint in: Chao, W./Horrocks, G. (eds.) Levels of Representation. Dordrecht.

Cardinaletti, Anna/Starke, Michal (1993): The typology of structural deficiency. On the three grammatical classes. Paper presented at the 16 th GLOW Colloquium, Lund.

Cardinaletti, Anna/Starke, Michal (1994): The typology of structural deficiency. On the three grammatical classes. In: FAS-Papers in Linguistics 1. Berlin 1995, S. 1-55. [Erscheint auch in: Henk van Riemsdijk (ed.): EUROTYP Final Volume on Clitics, ESF, Berlin.]

Cardinaletti, Anna/Starke, Michal (in press): Deficient Pronouns: A View From Germanic. In: S. Epstein/Thrainsson, H. (eds.): Proceedings of the Harvard Comparative Germanic Syntax Workshop. Dordrecht.

Haegeman, Liliane (1992): The distribution of object pronouns in West Flemish. In: Rizzi, Luigi (ed.): Clitics in Romance and Germanic. In: EUROTYP Working Papers 3, S. 33-76.

Haegeman, Liliane (1993): Object clitics in West Flemish. In: GenGenP 1.1

Haider, Hubert (1984): Topic, focus and V-second. In: Groninger Arbeiten zur germanistischen Linguistik 25, S. 72-120

Holmberg, Anders (1991): The distribution of Scandinavian weak pronouns. In: Henk van Riemsdijk/Rizzi, Luigi (eds.): Clitics and Their Hosts. ESF Working Papers 3, S. 155-173.

Jaspers, D. (1989): A Head-Position for Dutch Clitics, or Wilma, Wim and Wackernagel. In: Jaspers, D. et al. (eds): Sentential Complementation and the Lexicon. Dordrecht. S. 241-252. 
Kayne, Richard S. (1983): Chains, Categories External to S, and French Complex Inversion. In: Natural Language and Linguistic Theory 1, S. 107-139.

Koster, Jan (1978): Locality Principles in Syntax. Dordrecht.

Lenerz, Jürgen (1992): Zur Syntax der Pronomina im Deutschen. In: Sprache und Pragmatik 29, S. 1-54.

van Riemsdijk, Henk (1978): A Case Study in Syntactic Markedness. Dordrecht.

Rizzi, Luigi (1986): On the status of subject clitics in Romance. In: Jaeggli, O./Silva-Corvalán, C. (eds.): Studies in Romance Linguistics. Dordrecht. S. 391-419.

Tomaselli, Alessandra (1990): COMP as a licensing head: An argument based on cliticization. In: Mascaró, Juan/Nespor, Marina (eds.): Grammar in Progress. Dordrecht. S. 433-445.

Tomaselli, Alessandra/Poletto, Cecilia (1992): Looking for clitics in Germanic languages: The case of Standard German. In: Rizzi, Luigi (ed.): Clitics in Romance and Germanic. EUROTYP Working Papers 3, S. 77-102.

Travis, Lisa (1984): Parameters and Effects of Word Order Variation. Ph.D. dissertation. MIT, Cambridge, MA.

Vikner, Sten/Schwartz, Bonnie (1991): The verb always leaves IP in V2 languages. Unpublished manuscript. Universität Stuttgart/Boston University. [Erscheint in: Belletti, Adriana/Rizzi, Luigi (eds.): Parameters and Functional Projections. Essays in Comparative Syntax, Oxford University Press].

Zwart, Jan-Wouter (1991): Clitics in Dutch: Evidence for the position of INFL. In: Groninger Arbeiten zur germanistischen Linguistik 33, S. 71-92.

Zwart, Jan-Wouter (1993): Dutch Syntax. A Minimalist Approach. Ph.D. dissertation, Universiteit te Groningen. 


\title{
Personalpronomina, Klitiktypologie und die Struktur des 'Mittelfeldes'
}

\author{
Wer in einer fremden Sprache schreibt, \\ der muß seine Denkungsart, wie ein Liebhaber, zu bequemen wissen. \\ Wer in seiner Muttersprache schreibt, \\ hat das Recht eines Ehmanns, \\ falls er dessen mächtig ist.
}

(Johann Georg Hamman, Versuch über eine akademische Frage)

\begin{abstract}
Personalpronomina und ihre reduzierten und klitischen Formen stehen an markanten Satzpositionen, die sich von der Position der koreferenten vollen Nomina grundsätzlich unterscheiden. Sie erscheinen allerdings in manchen Sprachen verbbezogen als Enklitika, in anderen als Proklitika. Es wird zuerst erwogen, diese enklitische bzw. proklitische Position von der grundlegenden Linearitätstypologie im greenbergschen Sinne (SVO und SOV/VSO) abhāngig zu machen. Wiewohl prinzipiell richtig zwingen klitische Pronomina im Skandinavischen sowie die Klitikstellung in Nichtdeklarativen zur Annahme, nach der ersten (rechtesten) thematischen Diskursposition im strukturellen Satzschema als Ort für die schwachen Pronominalformen zu suchen. Diese Annahme erscheint für eine Reihe von nichtverwandten Sprachen als haltbar. Im Blickpunkt stehen Sprachen aus den drei greenbergschen Haupttypen: SVO als V-mittelständigen Sprachen sowie SOV/VSO als V-randständige Sprachen. Je nachdem wie nichtdeklarative Sätze sich aus den zugrundegelegten Strukturen ableiten, erreicht das pronominale Klitikum eine enklitische oder eine postklitische Position, die sich dadurch auszeichnet, daß sie die rechteste diskursfunktionale Themaposition ist. Diese Einsicht macht die strukturelle Verschiebung der schwachen Pronomina systematisch ableit- und voraussagbar.
\end{abstract}

\section{Vorrede und Problematisierung}

Es ist auffallig, daß pronominale Klitika in jüngeren Arbeiten zur formalen Linguistik zu einem Dauerbrenner geworden sind. ${ }^{1}$ Dies hat beson-

1 So formte das vom Europarat geförderte linguistische Großforschungsprojekt Eurotyp einen eigenen Arbeitskreis zu diesem Thema; siehe Teilergebnisse in EUROTYP. PROGRAMME IN LANGUAGE TYPOLOGY. EUROPEAN SCIENCE FOUNDATION. Band 5: Clitic doubling and clitic groups sowie Band 6: Clitics: their origin, status, and position, jeweils herausgegeben von $H$. van Riemsdijk/L. Hellan (ohne Jahresangabe). 
dere Gründe. Wie sich zeigen wird, stehen diese phonologisch reduzierten Pronominalformen in anderen distributiven Zusammenhängen als ihre phonologisch starken Entsprechungen, so daB sich die Frage erhebt, wohin genau, d.h. an welchen strukturell vorgezeichneten Ort, die Klitika (CL) 'hinwandern' und vor allem was der Anlaß für diese Wanderung ist. Der vorliegende Aufsatz nimmt solche Fragen auf und diskutiert sie für eine Reihe verschiedener Sprachen, stets mit Blick auf die besondere Stellung des Deutschen, das solche reduzierte Pronomina mit eigenen Stellungseigenschaften ebenfalls hinreichend kennt. Folgende Feststellungen sind bereits erhärtet bzw. ergeben sich jeweils aus vorigem:

(i) Konservative Dialekte des Deutschen zeigen ausschlieBlich phonologisch reduzierte Formen bzw. klitische Entsprechungen (CL) der personalen Vollpronomina (Pron). Im besonderen gibt es keine Möglichkeit, Personalpronomina betont zu verwenden. Ist dies die ur- oder prototypische Funktion von CL? Worin ist diese Erscheinung begründet? Zur Feststellung, daß pronominale Klitika nicht in der Basisposition der koreferentiellen Objekte innerhalb von VP stehenbleiben können, vergleiche man die folgenden Beispiele aus dem modernen umgangssprachlichen Deutsch.

(1) a daß-s (= es, das Kind) dem Vater gefolgt hat

Träger = COMP (Konjunktion)

b Was hat-s dem Vater gegeben?

Träger $=$ finites $\mathrm{V}$

c Hat-n der Vater gesehen?

Träger $=$ finites $\mathrm{V}$

d ${ }^{*}$ daB dem Vater-s gefolgt hat

Träger ungleich COMP, nämlich Dativobjekt

e *Was hat dem Vater-s gegeben?

Träger ungleich finitem $V$, nämlich Dativobjekt

f *Hat dem Vater-s gefolgt?

Träger ungleich finitem $V$ (Dativ)

g *-n hat der Vater gesehen? (Satzspitze)

h S-ist einmal ein kleines Männchen gewesen. (Satzspitze) nur phonolog. Bedingg. (geringe Sonorităt) gegeben

i *R-hat einmal ein kleines Männchen gesehen. (Montafonerisch) schnellsprachl. R- bzw. 'r für $E r$ :

phonolog. Bedingg. alleine reicht nicht

Klitische Positionen (Positionen von 'pronominalen Klitika' = CL) sind eben nicht identisch mit den koreferenten NP-Positionen. Sie hängen 
zum einen, so wollen wir vorwegnehmen, von bestimmten 'Trägerkategorien' ab - das ist die phonologische Bedingung. Vgl. auch (1g), wo ja ein derartiger phonologischer Träger nicht gegeben ist im Vergleich zu (1c). Solche phonologischen Bedingungen alleine können aber die CLErscheinung nicht erklären, wie (1h, i) zeigen. Vielmehr hängen CLPositionen und ihre Verteilungscharakteristika weiter ebenso notwendig, aber darüber hinaus erst hinreichend, von bestimmten syntaktisch bestimmten Stellungen im Satz ab; vgl. wieder (1a-c) und (1d-f). Es wird zu zeigen sein, daß die syntaktische Bedingung durch alle hier untersuchten (idg.) Sprachen hin streng eingehalten wird, aber von typologischen Determinanten der jeweiligen zugrundeliegenden Satzstruktur abhängig ist.

(ii) Entgegen Wackernagels (1892) Generalisierung gibt es klitische Pronomina in Satzerstposition (vgl. Taylor 1993 zum Altgriechischen oder Eythórsson (1994) zu einer Reihe frühgermanischer Dialekte). Steht dies im Widerspruch zu (i)?

(iii) Die Frage danach, welcher grammatischen Kategorie der Klitikträger angehören muß, ist auf den ersten Blick verwirrend: in SOV-Sprachen müssen die Träger entweder finite (Hilfs-) Verben oder unterordnende Konjunktionen sein. Andere Kategorien sind ausgeschlossen. Vgl. (1ai). Jedoch: was sind die Gemeinsamkeiten zwischen finiten Verben und einbettenden Konjunktionen derart, daB sie diese Eigenschaft teilen können? Bei SVO-Sprachen sieht dies anders aus, da von Trägern im engeren Sinne bei den proklitischen Stellungen gar nicht gesprochen werden kann (Italienisch, Französisch) - bei den enklitischen wie im Rumänischen oder Italienischen hingegen wohl. Die Frage ist auch berechtigt, wieso denn CL im Romanischen (und allgemein in SVO-Sprachen) nicht an COMP wie im Deutschen herantreten. Spielt COMP im Romanischen keine so ausgezeichnete Rolle wie im Deutschen (genauer: beim Typus 'SOV+V-Zweit', den das Deutsche, Niederländische und Westfriesische ja mit der Scheidung zwischen abhängigem (SOV) und unabhängigem (V-Zweit) Satz darstellen)?

(iv) Pronominale Klitika (CL) sind unabhängig davon, ob sie spezifische, von den vollpronominalen Formen verschiedene phonologische Formen aufweisen, syntaktisch-positionell ausgezeichnet. Dies gilt für CL in beiden Sprachtypen: SOV ebenso wie SVO. Die syntaktischen Positionen von starken pronominalen Formen (Pron) und ihren klitischen Entsprechungen (CL) sind nicht identisch. 
(v) Unabhängig von der typologischen, greenbergschen Unterscheidung stehen $\mathrm{CL}$ ausschließlich links von ihren vollpronominalen Entsprechungen.

(vi) Wo Kasusunterscheidungen eine Rolle spielen wie im Deutschen, stehen Subjekt-CL immer links von Objekt-CL. Bei der DativAkkusativabfolge dreht sich die Abfolge um: NP-3+NP-4 $\neq$ CL-4+CL-3. Beide Erscheinungen erfordern eigene syntaktische Erklärungen.

(vii) Typologische Zugehörigkeiten alleine erlauben keine Voraussage darüber, ob CL auftreten. Das Serbokroatische und das Bulgarische z.B. erlauben sich den Luxus von CL-Gruppen (CL clusters) und CL-PronKopien, während das Russische überhaupt keine CL besitzt. Man vgl. auch den Unterschied zwischen Altgriechisch und Lateinisch: letzteres hat uns keine CL überliefert.

(viii) ALLGEMEINE THESE ZUR CL-TYPOLOGIE: Es wird hier zuerst die empirisch und kausal weiter plausibel zu machende Position verfolgt, daß die Stellung der klitischen Pronomina (CL) - sofern in einer Sprache überhaupt pronominale CL auftreten - typologisch bestimmt ist: V-interne Sprachen (SVO, OVS (?)) zeigen Proklitika, V-periphere Sprachen (SOV, VSO, VOS (?)) dagegen Enklitika.

(ix) Es wird sich allerdings zeigen, daß die allgemeine stellungstypologische These in (viii) nach bestimmten Details zu präzisieren und zu modifizieren ist und zwar folgendermaßen:

SPEZIELLE CL-THESE: Pronominale CL sind hochthematisch ('thematisch' als Diskurskategorie, in Opposition zu 'rhematisch'). Sie stehen demgemäß in jener thematischen Position, die den geringsten Abstand zu den koreferenten nominalen Entsprechungen aufweist. Im Szenario eines Verschiebungsmechanismus der CL aus der VP heraus nach links heißt dies, daB CL in der erstmöglichen thematischen Position stehen bleibt. Wir haben diese diskursstrukturelle Satzperiode, in die das thematische pronominale CL zu stehen kommt, FP ('Funktionalphrase') genannt und es weiterer empirischer Arbeit vorbehalten, diese vorerst diskursfunktionale Kategorie FP jeder Sprache extra auf die universalgrammatisch relevanten strukturellen Satzperioden abzubilden.

Mit dieser Präzisierung ist auch die Begründung gegeben (vgl. auch (x) unten): Klitische Pronomina rücken aus der Basisposition für die entsprechenden koreferentiellen NPs nach links heraus und $\mathrm{zwar}$ so weit nach links - entweder in das 'Mittelfeld' oder noch weiter über das finite Prädikat hinaus -, bis sie die erste mögliche Position im satzstrukturellen Diskursthemabereich, also den Bereich links von VP erreicht haben. Es ist unmittelbar deutlich, daß unter solchen Arbeitsprämissen ein 
nichttriviales, detailliert formalisiertes sowie eben dadurch einer empirischen Detailüberprüfung zugängliches Konzept einer satzsyntaktischen Struktur zugrundezulegen ist. Ganz konkret: es muß unmittelbar und einleuchtend verständlich werden, unter welchen Bedingungen die typologisch gröbere These in (viii) zugunsten von (ix) aufzugeben ist und wieso dann - d.h. unter welchen sehr spezifischen Zusatzkriterien, die sich aus dem Zusammenspiel zwischen diskursfunktionalen Kategorien wie Thema und Rhema und einer empirisch wohlbegründeten syntaktischen Untergliederung des Mittelfeldbegriffs ergeben - die These in (viii) doch noch sinnvoll bleibt.

(x) Wenn (viii) und (ix) empirisch haltbar sind, dann erhebt sich die Frage, wie sich diese deutlich unterschiedliche Verteilung zwischen pronominalen CL und deren koreferentiellen NPs begründet. Wie in (ix) angedeutet werden Argumente der Thema-Rhema-Verteilung ins Treffen geführt: je schwächer Pronomina, desto thematischer ist ihre Diskursleistung. Dies wirkt sich durch Verschiebung nach links in den satzstrukturellen Themabereich aus und führt zu folgendem Arbeitsprogramm:

(x.1) Für den Landeplatz der diskursfunktional motivierten CL-Linksverschiebung nimm an, daB CL nicht weiter als zur grammatischen Satzkategorie FP vorrückt.

(x.2) FP, Maximalprojektion mit kanonischer Projektionsgliederung (vornehmlich einem [Spez,P] mit $\mathrm{Spez}^{\circ}$ sowie einem Kopf, $\mathrm{F}^{\circ}$ ), ist der rechte Randknoten in einer universalgrammatischen Satzstruktur, dessen Kernbereich in der diskursthematischen Satzperiode liegt. Vgl. (34) unten.

(x.3) Weder ist FP hinsichtlich der kategorialen Alternative 'Argument/Adjunktion' festgelegt, noch ist CL von vornherein als XP, also als Maximalprojektion bestimmt. Beide Optionen sind nach einzelsprachlichen Distributionsdispositionen festzulegen. ${ }^{2}$

So weit zum Programm des Aufsatzes. Nun zur Ausführung. Zuerst diskutiere ich in Abschnitt 2 den kategorialen Status von Pronomina und ihren klitischen Formen, CL. In Abschnitt 3 stelle ich verschiedene Sprachen der drei Typen SVO, SOV und VSO mit ihren CL-Vertretungen vor. Abschnitt 4 gibt einen Überblick über distributionelle Gemeinsamkeiten und Unterschiede zwischen SVO- bzw. V-randständigen Sprachen. In 5 werden die diskursfunktionalen Satzperioden Thema und Rhema auf die universalgrammatische Satzstruktur abgebildet und der genaue syntak-

2 Fūrs Deutsche nehmen Abraham/Wiegel (1993) an, daß CL kategorienselektiv an Köpfe rechtsadjungieren (also enklitisch stehen). Aufgrund des Strukturerhaltungsprinzips folgt damit, daß CL als Nullprojektionen, also $\mathrm{N}^{\circ}$ bzw. $\mathrm{D}^{\circ}$ zu sehen sind. 
tische Ort von CL, schwachen Pronomina sowie starken Pronomina und Vollnomina festgelegt. In Abschnitt 6 gehe ich kurz auf eine rätselhafte Inversionserscheinung ein. In Abschnitt 7 wird die spezielle typologische CL-These anhand dreier Konstruktionstypen (Infinitiven, Imperativen und Gerundien) diskutiert. In Abschnitt 8 werden die unserer allgemeinen typologischen These scheinbar widersprechenden skandinavischen Sprachen auf ihre CL-Eigenschaften hin überprüft, was direkt zur speziellen CL-These in (ix) führt. Abschnitt 9 schafft einen abschließenden generellen Überblick.

\section{Syntaktische CL-Charakteristika bei SOV}

2.1 NP- (= Konstituenten-) Status, XP, oder Einzelwortstatus, $\mathrm{X}^{\circ}$ ?

Es ist für die Analyse nicht unerheblich, was der Projektionsstatus von starken, schwachen und CL-Pronomina ist. Man vgl. dazu die folgenden Selektionsbeschränkungen.

(2) *der er - außer st. Pronomina modifiziert durch einen Relativsatz: er, der-n gesehen hat

(3) *schöner er

(4) *er Mann

Daraus geht eindeutig hervor, daß der Wortartstatus der einer DP, nicht bloß einer NP ist. D.h. der er bzw. er Mann gehen deshalb nicht, weil er bereits den bestimmten Artikel (D) ebenso wie den N-Kopf soz. inkorporiert. Wie ist der janusköpfige Projektionsstatus aufzulösen? Es ist ja nicht vorstellbar, daß das Pronomen sowohl D wie auch $\mathrm{N}$-Kopf ist. Nun sind wir bei CL relativ sicher: das starke Pronomen ist von Maximalprojektionsstatus, also eine DP. ${ }^{3}$ Da sich CL andererseits an einen Kopf mit dem Status von $\mathrm{X}^{\circ}$ affigiert (COMP, V; man denke an die Konjunktionsflexion im Bairisch-Österreichischen), muß nach einem sehr allgemeinen Strukturerhaltungsprinzip CL von derselben Projektionsklasse sein: $\mathrm{X}^{\circ}$. Da es sowohl D-Referenz als auch Kopfstatus haben muB, ist es ein

3 nach herkōmmlicher Annahme mit folgender Struktur:<smiles>[Pb]</smiles>

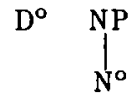


D-Kopf, also $\mathrm{D}^{\circ}{ }^{4}$ Dies trägt dem Umstand Rechnung, daß bei Enklitisierung wie im Deutschen Rechtsadjunktion vorliegt. Wenn jedoch, was sich nicht so leicht nachweisen lä8t, CL in einem eigenen Funktionsknoten innerhalb von IP steht, dann ergibt sich, sofern wir Verschiebung aus VP annehmen, ein Lizensierungsproblem: eine DP, verschoben aus VP heraus in die thematische Strukturperiode, kann nur in eine Kopfposition rücken, wenn auch die Spezifikatorstelle, die DP vertretende Stelle, besetzt ist. Daraus ergibt sich ein Lizensierungsproblem: wir nehmen - im üblichen formalen Jargon - an, daB die Spez-Stelle mit einem pro besetzt ist, das seinerseits (über Spez-Kopf-Rektion) das Kopf-CL lizensiert.

Diese strukturellen Vorgaben haben auch zwingende diskursfunktionale Folgen. Erstens sind nichtfokussierte bzw. nichtfokussierbare Elemente links von VP vom Thema-Hintergrund-Status. Vgl. zu Genauerem (34) unten. Zweitens ist der Projektionsstatus (vgl. die Diskussion zu (2)-(4)) ein kritischer Parameter: Maximalprojektionen (XP, somit in Sonderheit Artikelkonstituenten, DP bzw. [Spez, CP], die Satz-TOP-Position) sind definit und deshalb im allgemeinen referentiell spezifisch, eben auf keinen Fall referentiell unspezifisch und indefinit. Die Minimalprojektion $\mathrm{X}^{\circ}$, diejenige, in der wir Klitika identifiziert haben, muß aufgrund der prinzipiellen Spez-Kopf-Beziehung ebenfalls definit und referentiell spezifisch sein. Den Unterschied zwischen diesen beiden Positionen lokalisiere ich in der Fokussierbarkeit: DP (in Spez-TopP) kann immer Satzakzentträger sein, die dazugehörige $\mathrm{X}^{\circ}$-Position dagegen nie. Sie lassen sich aus diesem Grunde mit den beiden ersten diskursfunktionalen Perioden in (34) identifizieren: sie haben gemeinsam diskursfunktionale Themageltung, unterscheiden sich aber mittels der Kriterien 'Vordergrund' gegen 'Hintergrund'. Was den Spezifizitätscharakter von CL (und des NP-Subjekts) im besonderen ausmacht, sind die Merkmale der Person und des Numerus relativ zur Sprecherperson und somit auch der Personund Numeruskongruenz. Während starke Pronomina (die ja auch reinen DP-Charakter haben) selbst Identifikationen nach Person und Numerus erlauben, sind CL im D-Status (haben also Kopfcharakter bei DStatus, den sie mit starken Pronomina teilen), sind also wie alle Artikelwörter nicht nach Person identifiziert. Diese Identifikation muß durch einen Lizensierungsmechanismus erwirkt werden, der referentielle, also pragmatische Indizierung nach Personenreferenz erlaubt. Ich nehme an, daß eine solche Indizierung dem thematischen Vorfeld vorbehalten bleibt.

4 Cardinaletti (1994, S. 198) faßt dies in folgender 'flachen' Struktur: $\left.\right|_{D^{\circ}} ^{\mathrm{DP}}$ 
Somit muß jedes pronominale $C L$ in diesen diskursfunktionalen Bereich vorrücken. ${ }^{5}$ Und mit Kopfstatus als D(et(erminer)) ist ihm eine Kopfposition in 'TopP vorbehalten: CL kann nur so weit 'aufsteigen', bis es eine derartige Stelle erreicht hat, in der Thematizität in Ableitung von der Spezifizität bezügl. Person gesichert ist. Starke Pronomina haben diese Spezifizität in situ, also innerhalb von VP so wie NPs.

$\mathrm{DaB}$ CL nicht weiter steigen als bis zum erstmöglichen thematischen Kopfknoten, zeigen Verbkomplexe im Französischen sowie COMPHäufungen im Niederländischen und Deutschen.

(5) a Nous (*te) voulons te voir $\left({ }^{*}\right.$ te)

Frz. (nach Uriagereka 1995, S. 106: sein Beispiel (26))

b $\quad \ldots$ weil $<{ }^{\prime *} \mathbf{n}>$ daB $<$ 'n $>$ der Teufel geholt hat

bair.-österr. Dialekte

c $\quad \ldots$ voor $<{ }^{\prime *} t>$ dat $<$ 't $>$ iemand zag

ndl. Standard

vor daB es-CL jemand sah

Damit sind wichtige Korrelationen zwischen diskursfunktionalen Satzperioden und syntaktisch strukturellen Kategorien erkannt. Es zeigt sich einmal mehr, daß sich die strukturellen Abschnitte der Diskursfunktionen Thema und Rhema in Abhängigkeit von einer entsprechend leistungsfähigen Satzsyntax aus begründen lassen.

\section{Pronomina und ihre klitischen Formen in anderen Sprachen}

3.1 SVO-Sprachen. Romanische Beispiele (SVO):

FRANZÖSISCH (Kayne 1975):

(6) a *Marie ne connait que les

$\ldots{ }^{*}$ CL Pron-Form

M. NEG kennt außer sie

"Marie kennt nur sie"

b Marie les connait

CL in linksverschobener Stellung

5 Uriagereka (1995) nimmt, um eben dies zu erreichen, einen eigenen funktionalen Knoten, FP, über dem Flexionsknoten, IP (oder dessen Satelliten AgrS bzw. AgrO) an, der diese Attraktion auf CL ausübt. Es bleibt aber unklar, warum dieser funktionale Knoten gerade dort sitzt, wo er von Uriagereka hingesetzt wird - wenngleich er denselben Horizont anstrebt, wenn er sagt ,...F, the syntactic element interfacing with pragmatic indexicality." (Uriagereka 1995, S. 93) 
c Marie ne connait qu'eux $\ldots{ }^{*} \mathrm{CL}$, Pron-Form Pron bei rechtsläufiger Rektion

M. NEG kennt auBer euch

$d *$ Marie eux connait ... * Pron-Form in CL-Position

Natürlich ist $j e$ bereits klitisch, da es nur präverbal stehen kann. Postverbal, in Fokusposition, muB es ja durch eine Suppletivform vertreten $\operatorname{sein}(m o i)$.

ITALIENISCH (Cardinaletti 1994):

(7) a *Maria conosce ci

$\ldots{ }^{*} \mathrm{CL}$, Pron-Form

b Maria ci cognosce

$\mathrm{CL}$ in linksverschobener Stellung

c Maria cognosce noi

Pron bei rechtsläufiger Rektion

$d$ *Maria noi cognosce

... ${ }^{*}$ Pron-Form in CL-Position

RUMÄNISCH (Dobrovie-Sorin 1994, S. 70):

(8) a L-am rugat

... CL (Pron *il)

ihn=habe(-ich) gebeten

b*am il/o rugat

habe(-ich) ihn/sie gebeten

c baiatul pe care l-am vazut

der Junge P-den ihn=habe(-ich) gesehen

$\mathrm{DaB}$ allerdings das klitisch-pronominale Femininum als Objekt enklitsch und nicht proklitisch wie alle anderen schwachen Pronomina erscheint, läßt den Schluß zu, daß bei Klitisierung phonologische Prozesse von syntaktischen zu trennen sind. Dies ist angesichts des Sonderverhaltens von deutsch es bzw. 's sowie ndl. ' $t$ nicht überraschend. Siehe $(9 \mathrm{a}-\mathrm{c})$ - es handelt sich hierbei eben nicht um syntaktische CL, sondern um Schnellsprechformen ohne syntaktische Systematisierbarkeit.

(9) a Am rugat-o ... rumän. CL habe(-ich) gebeten=sie

b 's ist einmal/'s hat einst/?? $s$ ' atmet noch in TOP-Position: nur für expletives es, nie für es(N), sie(F)

c ' $t$ is nu eenmaal zo ndl. Expletivum, nie statt het(N)

Ebenso wie im Deutschen erscheint auch im Rumänischen die Konjunktion oder die Negationspartikel als phonologischer CL-Träger; man be- 
achte, daß dieser Umstand nicht an der syntaktischen Prokliseeigenschaft rüttelt:

(10) Nu stie ca-l/c-o/ca-i asteapta mama Nicht wei $B(-e r), d a B=i h n / d a \beta=s i e / d a B=s i e P L$ erwartet Mutter

Slawische Beispiele (Bulgarisch, Makedonisch, Serbokroatisch und Tschechisch, alle SVO; nach Dimitrova-Vulchanova 1993):

BULGARISCH

(11) a Ne si li mu ja dal knigata?

CL-Häufung nach der Generalisierung lï $A U X-C L+P R O N-C L$ NEG hast Q-PARTIKEL ihm es gegeben Buch-das?

b Ste mu go pratja kanonische Kasusabfolge: DAT + AKK werden ihm es schicken

c Knigata dali mu ja dadoxa? Buch-das ob ihm es gaben?

"Haben sie ihm dieses Buch wirklich gegeben?"

d Toj kaza, ce knigata sum mu ja bil dal er sagte daß Buch-das habe(ich) ihm es gehabt gegeben

e Toj kaza, ce na tebe knigata sum ja bil dal er sagte daß DIR Buch-das habe(ich) es gehabt gegeben

Wie (11d, e) zeigen, steht das nichtklitische Pronomen - im obigen Fall das emphatische na tebe "dir" - in einer anderen syntaktischen Position als CL.

\section{MAKEDONISCH}

(12) a Go vidov nego

CL-Dopplung (umggsprachl.)

ihn sah (ich) ihn

b Zima ja imase pritisnato Struga

Winter es hatte gepackt (die Stadt) Struga

c Jas sum mu gi zel parite ich habe ihm sie weggenommen Geld-das

d Ja vidov Marija/zenata sie sah(ich) Maria/Frau-die

e Daj mu go gib ihm es

\section{SERBOKROATISCH}

(13) a Ja mu ga zelim dati ich ihm es möchte geben 
b $\quad$ Taj < pesnik> mi je < pesnik> napiso knjigu dieser (Dichter) mir hat (Dichter) geschrieben Buch-ein

c Zelim da mu ga dam möchte(ich) zu ihm es gebe(ich) = 'ich möchte zum ihm es geb(e)' vgl. $z u m=\mathrm{g}=\mathrm{m}$ geben oder $z u m=8=n=$ unschädlich machen

\section{TSCHECHISCH}

(14) a Ma te Jan rad? hat dich Jan gerne?

b Nevidel jsem te cely den NEG=gesehen habe dich den ganzen Tag "Ich habe dich den ganzen Tag nicht gesehen"

c Nemel jsi ho urazet NEG=solltest haben ihn beleidigt

$\mathrm{Zu}$ beachten ist, daß Proklitizität im Slawischen, wie oben dargestellt, nicht mit Blick auf das finite Hilfsverb, sondern auf das (oft infinite) Vollverb gilt. Mit andern Worten: wo im Romanischen oberflächlich $\mathrm{CL}=$ $A U X+V$ gilt, setzt das Slawische, jetzt einmal von anderen Bedingungen ganz abgesehen, $A U X=\boldsymbol{C L}+V$. Dies soll als erste wesentliche Schärfung des am greenbergschen Typologieinventar orientierten Begriffsapparats gesehen werden: Pro- bzw. Enklitizität sind jedenfalls - und sehr wahrscheinlich nicht ausschließlich - mit Blick auf die syntaktische Periode zwischen finiten und infiniten Komponenten eines komplexen Prädikats zu bestimmen. Wir kommen noch ausführlich dazu.

Zum klitischen Status des Reflexivpronomens und seiner spezifischen Verwendung als Diatheseanzeiger, also in der Funktion eines Verbgenusmorphems im Deutschen und einer Reihe anderer Sprachen vgl. Abraham (1995a). Der klitische Status des 'diathetischen' Reflexivs mag nicht gleich ersichtlich sein. Sofern nicht durch das Intensivierpronomen verstärkt (und nur dann fokussierbar: sich selbst) sind sich und seine Vertreter der 1. und 2. Person stellungsbeschränkt und zwar im Sinne der Klitikrestriktionen auf die Position nach V bzw. COMP. Klitikstatus sollte sich aber auch im Romanischen durch Proklisis erweisen; dies bestätigt sich, etwa am Rumänischen (Dobrovie-Sorin 1994, S. 169ff.; vgl. auch Grosu 1994, Kap. 7 sowie Farkas/Zec 1995):

\section{RUMÄNISCH}

(15) a Nu se poate dormi cu atta zgomot nicht se kann schlafen bei all dem Lärm „Man kann bei all dem Lärm nicht schlafen” 
b S-a spus câ Ion e nebun

se $=$ hat gesagt daß Hans ist verrückt

"Man sagt..."

(15b) zeigt die orthographisch signalisierte Präinkorporation an den finiten Prädikatteil. In der Bedeutung ähnelt dies natürlich dem siimpersonale der italienischen Grammatik bzw. dem on dit des frz. Reflexivs (Abraham 1995a, S. 34-40; zu viel Genauerem dazu vgl. DobrovieSorin 1994, S. 175ff.). Wie sehr dieses deagentivierende Reflexiv bereits aus dem Pronominalparadigma herausgetreten ist und Verbeigenschaften wie Diathese anzeigt, läßt sich lebendig auch am Deutschen zeigen.

(16) a Es läßt sich Armen Almosen besser geben als Reichen.

b Es lassen sich Almosen Armen besser geben als Reichen. ${ }^{6}$

Die Objektvalenz ist in (16) voll abgesättigt, keinesfalls durch das Reflexiv mitübernommen. Wenn aber sich kasuslos ist, kann es nicht mehr Pronomen bzw. in einer nominalen Satzgliedfunktion sein (Kasusfilter). Zudem zeigt sich ja keine koreferentielle Bindung an ein Antezedens insofern tritt dieses 'denaturierte' Reflexiv auch aus anderen syntaktischsemantischen Zusammenhängen, in denen es sich sonst universalgrammatisch begründet. Die diathetische Funktion dieser Reflexivverwendung hängt offenbar damit zusammen, daß koreferentielle Reflexivität die Passivableitung blockiert (so Fanselow 1991, der diese Bedingung jedoch nicht weiter begründet): aus $X$ wäscht sich ist kein Passiv, etwa *Er/sich wird durch $X$ gewaschen abzuleiten. Dies ist keineswegs unmittelbar einsichtig, da ja die sonstige (und einzige) Passivbedingung im Deutschen, nämlich Agentivität des Prädikats wäscht vorliegt. ${ }^{7}$

6 Die beiden bedeutungsmäßig identischen Sätze haben unterschiedliche syntaktische Strukturen: (a) ohne Prädikatkongruenz mit dem referentiellen Subjekt hat ein strukturell höheres Expletivum es, also in CP, als (b), wo das subjektkongruierende Prädikat es tiefer, also in $\mathrm{AgrS}$, vorzusehen ist. Zu solchen Argumentationen vgl. Abraham (1992b).

7 Wenn wir davon ausgehen, daß Prinzip A der Bindungstheorie zur tieferen Begründung des Reflexivpronomens irgendwo erfüllt sein muß, dann muß dies in der Komponente der Logischen Form, LF, gegeben sein, jener Komponente, wo alle lexikalischen und morphologischen Elemente ihre volle funktionale und logisch-semantische Interpretation erhalten. Dies wäre so vorstellbar, daß das direkte Objekt an die Stelle des in Mittelkonstruktionen wie (16) notwendigen expletiven es rūckt und die Funktion des für die Bindungsbeziehung unverzichtbaren Antezedens übernimmt. Allerdings trāgt dieses Szenario im Deutschen deswegen nicht, weil es ja auch intransitive Mittelkonstruktionen gibt, wo also kein direktes Objekt für die Rekonstruktion des Antezedens in LF herhalten kann. Es bleibt somit nur die Bindung an die agentische Thetarolle, die ja in LF sichtbar wird. Damit wird aber 
3.2 Typologische Erweiterungen

\subsubsection{Modernes Arabisch und Hebräisch}

Das Arabische ist vom Typ SVO mit distributionellen VSO-Spuren; vgl. Fassi-Fehri (1993). Die Beispiele hier stammen aus Shlonsky (1994) ('=' notiert die CL-Bindung an den lexematischen Träger). Das moderne Hebräisch, wiewohl heute SVO, hat noch Spuren des alten VSO-Typs bewahrt.

(17) a [kaan bixayyt $]=$ ha (er) war nähend-3FS

'Er nähte es gerade' modernes palästinensisches Arabisch:[V-fin]=CL

b asaan-ha bitxayyt l-fistyaan... 'weil sie näht das Kleid' $\mathrm{COMP}=$ Subj-CL

c tmunot-eha tluyot al ha-kir Modernes Hebräisch Bild-3FS hängt an der-Wand Subj-NP=Poss-CL 'ihr Bild hängt an der Wand'

d xasavnu al-eha

Modernes Hebräisch

(wir) dachten an-3FS $\mathrm{P}=\mathrm{CL}$

'Wir dachten an sie'

(18) a VERB + OBJECT

fhim l-malme fhimt-ha

(Ich) verstand den Lehrer (Ich) verstehe sie

b N + POSSESSOR beet l-malme beet-ha

Haus der-Lehrer

Haus-ihr

'des Lehrers Haus'

c P + OBJECT min l-malme min-ha

von dem-Lehrer von-ihr

d CONJ + SUBJECT innu l-malme in-ha

das der-Lehrer das-sie

e QUANTIFIER+NP kull l-malmaat kull-hin

all die-Lehrer alle-sie

(19) a il mudarris fahhim-u li l-bint Kairoter Arabisch

der-Lehrer CAUS-verstehen-es dem-Mädchen

Objektpronominalisierung

umso mehr die verbmorphologische diathetische Leistung des klitischen Reflexivs sichtbar und begründet (so schon Abraham 1988a; ebenso Abraham 1994, Kap. 12). 
b il mudarris fahhim-ha l-dars der-Lehrer CAUS-verstehen-sie die Stunde nur ein einziges CL an V, das andere als PP innerhalb VP

c il mudarris fahhim-u laa-ha der-Lehrer CAUS-verstehen-es ihr $\quad \mathrm{V}+\mathrm{DO}-\mathrm{P}+\mathrm{IO}$

d *il mudarris fahhim-ha-u/u-ha der-Lehrer CAUS-verstehen-ihr-es/es-ihr

Kein Clustering: ${ }^{*} \mathrm{P}+\mathrm{IO}+\mathrm{DO}$

\subsubsection{Walisisch:}

Das Walisische ist wie alle keltischen Sprachen mit Ausnahme des Bretonischen, heute und in seinen historischen Vorstadien (Lewis/Pedersen 1937, S. 267ff.; Schafer 1995; Ternes 1970; Evans 1976: 179ff.; Thurneysen 1966, S. 327) streng und unkontrovers VSO, mit präverbalen Verbpartikeln, die die Satzart (affirmativ bzw. interrogativ) sowie Satznegation (vgl. hierzu besonders Ternes 1970 und Schafer 1995 fürs Bretonische) festlegen. Personalpronomina - und nur diese, nicht andere wie Possessivpronomina, die als Nominalpräfixe erscheinen, oder die erwähnten Satzartpartikel -, die klitisch ('abhängig', als grammatisch gebundenes Morphem) sowie frei vorkommen, standen und stehen als Suffixe (also 'enklitisch') oder infigiert (Lewis/Pedersen 1937, S. 193ft.; Mittelwalisisch: Evans 1976, S. 49f.). ${ }^{8}$ Subjektpronomina haben oft keine klitischen Vertreter, sondern werden nur durch die Kongruenzendung am Verb ausgedrückt (so auch Lewis/Pedersen 1937, S. 194; somit eingeschränkte 'pro-drop'Erscheinung). Es werden (nach Roberts/Shlonsky 1994) heute 16 unterschiedliche und weitgehend heterogene CL-Klassen verzeichnet, durchaus mit unterschiedlichen Stellungen zum Trägerlexem. Siehe zur Heterogenität (20).

Possessivpronomina unterschiedlicher syntaktischer Herkunft, freie Klitika der Klasse 1, erscheinen wie oben angedeutet unveränderlich proklitisch bzw. (in der Terminologie von Ternes (1970), allerdings auf das

8 Es ist nochmals zu betonen, daß es hier nur um die besondere Stellung der Personalpronomina und deren 'Herkunft' aus den koreferentiellen NPStellungen geht, nicht jedoch um eine unifizierende Erklärung der Stellung aller klitischen Morpheme, d.h. eine Beschreibung und Erklārung über alle unterschiedlichen Kategorien und Herkünfte hinweg. Damit verfällt im besonderen die Kritik von E. Ternes, der auf den proklitischen bzw. präfigalen Charakter der bretonischen Possessivpronomina und Verbpartikel verwies - welche Erscheinung ja gegen meine hypothetische typologische Verallgemeinerung zu sprechen schien. 
Bretonische beschränkt, 'präfigiert') mit Trägerkategorien wie N, V und CONJ:
a ei wraig9 seine Frau
b Mae Megan wedi ei weld 'M. hat ihn gesehen' ist $M$. nach seinem Sehen
c Dywedodd y bachgen ein bod wedi cyrraedd sagte der Junge unser Sein-Nach-Ankommen 'Der Junge sagte, daB wir angekommen sind'

Diese Präfixklasse von CL mit den spezifischen Selektionsbeschränkungen unterscheidet sich von den meisten der anderen $15 \mathrm{CL}-\mathrm{Klassen}$ grundlegend. (20) ähnelt dem traditionellen nominalen Gerundium. Man beachte, daB hierbei nicht wie im Satzverband Thema- und Rhemafunktionen zu unterscheiden sind, die als treibende funktionale Kraft für die CL-Positionen verantwortlich gemacht werden. Die Erscheinungen dieser Klasse bleiben weiter unberücksichtigt. Was uns hingegen brennend interessiert, ist, wie sich CL im freien Satzverband verhalten. Die Personalpronomina, Klasse 2, nun erscheinen in solchen syntaktischen Umgebungen und zwar als Kongruenzpronomina enklitisch als Suffixe oder als unfreie Suffixmorpheme, beim nichtzusammengesetzten Verb bzw. bei der Präposition (Lewis/Pedersen 1937, S. 282; Roberts/Shlonsky 1994, S. 3). ${ }^{10}$

Mae Emrys yn ei roi iddo

ist Emrys in seinem Geben=ihm Enklise; nie Traubenbildung

"Emrys gibt es ihm"

(22) a Roeddent hwy wedi clywed [PP yddint ennil y gadair]

waren=sie nach Hören für=sie Erringen den Lehrstuhl

P-Kongruenz

„Sie hatten gerade erfahren, daß sie den Lehrstuhl errungen hatten"

b Mae Emrys yn ei roi iddo

ist Emrys in seinem Geben es ihm keine Traubenbildung!

${ }^{9}$ Ich danke E. Ternes (Hamburg) für insistente Aufklärung.

10 Lewis/Pedersen (1937, S. 282) erwägen - das ist gegen den Hintergrund der Ausgangsthese, wonach SOV und VSO eine gemeinsame Strategie gegenüber schwachen Pronomina und $\mathrm{CL}$ entwickeln, nicht uninteressant -, daB aus dem Idg. ererbte Verbpersonalendungen den keltischen dermaßen ähnelten, daß sie in das neue System inkorporiert werden konnten. 
c Mae Megan wedi ei weld o/*Emrys ist Megan nach seinem Sehenihn $/{ }^{*}$ Emrys Beschränkung der Postposition zu $\mathrm{V}$ auf $\mathrm{CL}$

d Dywedodd bachgen ei bod hi/*Megan wedi cyrraedd sagte der Junge ihr Sein sie/*Megan nach Ankommen

In der folgenden Übersicht sind die wesentlichen Gemeinsamkeiten und Unterschiede der CL und sw. Pronomina im modernen Arabischen und Walisischen einander gegenübergestellt.

(23) CL-Status und distributionelle Eigenschaften (nach Roberts/ Shlonsky 1994, S. 4).

\begin{tabular}{|l|l|}
\hline WALISISCH & ARABISCH \\
\hline kein Clustering & $\begin{array}{l}\text { Clustering } \\
\text { ('Traubenbildung') }\end{array}$ \\
\hline kein schwaches & $\begin{array}{l}\text { schwaches } \\
\text { Nominativpronomen }\end{array}$ \\
\hline Wominativpronomen & $\begin{array}{l}\text { NP-Status } \\
\text { Kortstatus oder Affix } \\
\text { Kopfstatus, also Xo }\end{array}$ \\
\hline syntaktische Affigierung & $\begin{array}{l}\text { lexikalische Affigierung } \\
\text { (Inkorporation) }\end{array}$ \\
\hline
\end{tabular}

Das negative Merkmal bei 'Traubenbildung' scheint von Belang insofern, als sich darin der Status eines freien lexikalischen Morphems mit eigener lexikalischer Semantik und syntaktischen Selektionsbeschränkungen verrät; Traubenbildung dagegen hat mit morphologischer Affigierung zu tun, die nach allgemeiner Einsicht gegenüber kategorialen Selektionen weniger empfindlich ist. Es ist weiter für eine reine VSO-Sprache erwartbar, daß sich nur ein Subjektpronomen in CL-Enklise zeigt; das Arabische hat mit der Mischung aus VSO- und SVO-Merkmalen Raum für ein freies DP-Subjekt im Nominativ, der in [Spez, AgrS] lizensiert ist. Schlieblich ist die Enklitisierung im Arabischen insofern weiter fortgeschritten, als sich aus den enklitischen Positionen bereits durch Inkorporation Personalendungen am Verb ergeben haben. Damit zeigen sich in (22) Gemeinsamkeiten aus der gemeinsamen VSO-Geschichte der drei Sprachen ebenso wie Unterschiede aufgrund des modernen typologischen Wandels des Arabischen und Hebräischen.

\subsection{CL-Traubenbildung}

Zur CL-Traubenbildung im Deutschen und dazu, daß Trauben ('clusters') nicht disjungiert werden dürfen, vgl. (24). 
HOCHALEMANNISCH (MONTAFON)

(vgl. ausführlicher Abraham/Wiegel 1993)

(24) a *Gutsili hot-r göschtr-m ko:ft

b Gutsili hot-r-m göschtr ko:ft

Bonbons hat $=e r=i h m$ gestern gekauft

c *Gutsili hot göschtr-r-m ko:ft

(25) a (aftos) tu-to -dixni

(er) ihm-es-zeigt

b *(Ego) tu-sixna ta-exo dosi

(Ich) ihm oft ihnen habe gegeben

c *To-thelo na agoraso

es-will-(ich) SUBJUNCTIVE kaufe(-ich)

\subsection{Partielle Konjunktionskongruenz}

Nicht alle, nämlich nur die zweiten Personen im Singular und Plural, kongruieren mit der Verbpersonalendung und zwar regelhaft durch Kopierung der Verbflexion, in der ein Personsuffix steckt (so unter Wiederaufnahme älterer rein philologischer Beschreibungen bei Bayer 1994/85): (e)s, der alte Dual für den Plural $i h r, t(u)$ für den Singular. Wenn wir die Konjunktion in COMP nur als phonologischen Träger betrachten, den syntaktischen Ort aber unterhalb von COMP in $\mathrm{AgrS} \mathrm{bzw}$. AgrO annehmen (wie bereits in Abraham/Wiegel 1993; s. auch Abraham 1994: Kap. 11), erklärt sich der Zusammenfall von (i) klitischem Personalpronomen, (ii) Verbalsuffix in der syntaktischen Satzzweitstelle, in die ja das Verb rücken muB, sofern diese Stelle nicht durch eine Konjunktion besetzt ist, und (iii) der bestimmten, unverwechselbaren Stelle von CL (bei V oder bei COMP). Gleichzeitig spüren wir damit den janushaften Status von CL als Verbaffix und Personalpronomen auf, auf den ja in der traditionellen Indogermanistik schon immer hingewiesen wurde (Wackernagel 1892).

(26) a $\quad \ldots$ ob-t-s e:s kum-t-s

b ... wann-st (du) arbat-st

Dies sollte nicht zuletzt zweierlei zeigen: zum einen, daß die CLVerbaffixe (Verbinkorporationen und Restrukturierungen; vgl. DobrovieSorin 1994, S. 62) im Romanischen kein Einzelfall sind und daß sich solche Affigierungen eigens und gegen die allgemeine (greenbergsche) typologische Hypothese begründen (also spezifisch gegen 'SVO hat Proklise'); und zum andern, daß sich hier in statu nascendi vor unseren (freilich mundartlich gewieften) Augen ein Grammatikalisierungsprozeß 
anbahnt, der bisher nur in toten Sprachen mehr erschlossen als beobachtet wurde.

\section{Gemeinsamkeiten zwischen dem Romanischen und Germanischen: Pronominalklitika (CL)}

(27) CL \& schwache (atonische) Pronomina, nicht jedoch starke (tonische) Pronomina:

a nicht-fokussierbar (nicht nach $P$; nicht kontrastiv betonbar) ( $\neq$ tonische Pronomina)

b nicht modifizierbar (= Vollpronomina außer bei Relativsātzen)

c keine Konstituentenkoordination ( $\neq$ Vollpronomina)

d nicht in Satzspitzenposition (in Isolation?)

e haben den Status von N ('Kopfstatus'), nicht von NP (komplexen Konstituenten)

f morphonologisch reduziert (keine notwendige Bedingung)

g lassen sich nicht 'dislozieren' ('herausstellen')

(28) Eigenschaften (nur) von CL, im Unterschied zu stark-tonischen (nicht jedoch zu schwach-tonischen) Pronomina:

a morphologisch reduziert

b syntaktisch Köpfe (legen den Kategorienstatus des Komplexes fest)

c und nicht frei, d.h. kein Vorkommen in:

Positionen für koreferentielle NPs

in Isolation, innerhalb PPs, in Herausstellung, Spaltkonstruktionen

... Koordination, Modifikation, Kontrastfokus

d nicht notwendig [+animate] (Cardinaletti/Starke 1994)

(29) a

\begin{tabular}{|c|c|c|}
\hline & $\mathrm{XP}$ & frei \\
\hline $\begin{array}{l}\text { klitisch } \\
\text { (CL) }\end{array}$ & - & - \\
\hline $\begin{array}{l}\text { starkes } \\
\text { Pron }\end{array}$ & + & \\
\hline
\end{tabular}


(29) b

\begin{tabular}{|lll|}
\hline & -frei & + frei \\
\hline $\mathrm{XP}$ & $?$ & stark \\
\hline $\mathrm{X}^{\circ}$ & $\mathrm{CL}$ & $\begin{array}{l}\text { kanonische } \\
\text { Köpfe }\end{array}$ \\
\hline
\end{tabular}

Die Stellung starker pronominaler Elemente im Deutschen ist identisch mit der der koreferenten Objekte - diese stehen ohne spezielle Kontextverknüpfung rechts innerhalb von VP. Es ist wieder zu betonen, daß dies besser an Dialekten zu zeigen ist, da nur dort echte $C L$ vorkommen und somit die Stellungsunterschiede deutlich werden. Vgl. (30)-(33).

(30) Gebundene Prons in Spitzenstellung IN V-2

\begin{tabular}{|l|c|c|c|}
\hline & V-2-INITIAL & $\begin{array}{l}\text { FREI (z.B. IN } \\
\text { ISOLATION) }\end{array}$ & $\begin{array}{l}\text { NUR } \\
\text { MENSCHLICH }\end{array}$ \\
\hline $\begin{array}{l}e: r \text { 'er' } \\
\text { stark, tonisch }\end{array}$ & + & + & + \\
\hline $\begin{array}{l}\epsilon s \text { 'es' } \\
\text { schwach, atonisch }\end{array}$ & + & - & - \\
\hline$a-s / z$ 'er - es' CL & - & - & - \\
\hline
\end{tabular}

SÜDTIROLER DIALEKT

[eckige Klammern für strukturelle VP-Grenzen]

(31) a $\quad \ldots \mathrm{daB}=\mathbf{a} / \mathbf{r}$ immer [INTELLIGENT isch] $\mathrm{COMP}=\mathrm{CL}$

b ...?? daß e:r intelligent isch FOKUSSIERTES VOLLPRONOMEN

(32) a E:r isch immer [intelligent] PRONOMEN IN TOPIKPOSITION; FOKUSSIERT

b $\quad * a / r$ isch immer [intelligent] CL IN TOPIKPOSITION

(33) a Ich habe gestern [*sie/SIE getroffen] FOKUS AUF PRONOMEN IN VP

b Ich habe sie gestern [getroffen] SW. PRON AUSSERHALB/LINKS VON VP

c Ich habe gestern wirklich [SIE getroffen] 


\section{Thema-Rhema-Verteilung im (SOV-) Satz - topologische Felder}

\subsection{Integration der Diskurskategorien in die Satzstruktur}

Gehen wir von folgender, für eine Sprache wie das Deutsche weiter sicher unkontroverser diskursfunktionaler Struktur aus. Man beachte, da $B$ die Satzgliedzuordnungen zu den diskursfunktionalen Perioden nur sehr grob vorgenommen worden sind. Wohl sind bereits die Vorkommensbeschränkungen der CL angedeutet - mit der Unsicherheit in der Dimension 'Thema-Hintergrund' (?CL), die daher rührt, daß wir nicht wissen, wie sich diese diskursfunktionale Periode satzsyntaktisch im Detail strukturieren läßt.

\begin{tabular}{|l|l|l|l|l|}
\hline \multicolumn{5}{|c|}{ einfacher Satz } \\
\hline \multicolumn{3}{|c|}{ Thema/Topic } & \multicolumn{3}{c|}{ Rhema/Comment } \\
\hline Fokus & Hintergrund & & Fokus & Hintergrund \\
\hline ADVERB & FINITES V & & DO & (Nicht-) \\
& AUXILIAR & & PP & Finites V \\
& SUBORDINATOR & & NEG & \\
& ?CL & CL & ${ }^{*}$ CL & ${ }^{*}$ CL \\
\hline
\end{tabular}

Diese CL-Einreihung basiert auf zweierlei empirischen Vorgaben: einmal den Distributionseigenschaften, die wir bisher beobachtet haben (sowohl anhand der Literatur als auch hier in Beispielreihen vorgeführt); und zum andern auf der Einsicht, daB pronominale CL nur mit hohem diskursspezifischem, d.h. hochthematischem, referentiell vorgegebenem (in Uriagerekas Sinne 'spezifischem') Status verwendbar sind. ${ }^{11}$ Vgl. zum

11 Ich habe diese Einsicht nur in zwei Fällen in der linguistischen Literatur wiedergefunden: einmal explizit bei Givón (1976), das andere Mal implizit bei Uriagereka (1995, S. 90). Letzterer schreibt den Anlaß für den weiter in der Literatur unkontroversen 'Linksruck' von CL deren Spezifizitātsfunktion zu. Es bleibt aber völlig undiskutiert, ja es wird nicht einmal die Frage gestellt, warum Spezifizität nun außerhalb von VP angesiedelt ist. Nur zu vermuten ist, daB Uriagereka eigentlich an Spezifizität im diskursfunktionalen Sinne insofern denkt, als spezifische und definite NPs mit Satznormalakzent außerhalb von VP stehen, während nichtspezifische, indefinite NPs (Subjekte wie Objekte) ihren Basisplatz innerhalb von VP haben. Diese Opposition läßt sich aber diskursfunktional verallgemeinern als logisch-semantische Interpretation von CL und sw. Pronomina innerhalb des kontextsensitiv strukturierten Satzes: also als strukturelle Periode für Satzthema im Unterschied zum Satzrhema. Siehe zu Begründungs- 
Themastatus der klitischen Pronomina bereits Givón (1976). Im besonderen sind CL - das haben die Distributionstests eindeutig erwiesen nicht in VP, offenbar der Satzperiode besonderer diskursfunktionaler Unspezifizität, d.h. von hochrhematischem Status, anzusiedeln. Was die genauere Position in der zweiten diskursfunktionalen Periode mit den Klassemen 'Thema' und 'Hintergrund' anlangt, so läßt sich jedenfalls sagen, $\mathrm{daB}$ es um den Rechtsrandbereich, also den Übergangsbereich 2 wischen der zweiten und dritten Spalte gehen muB. Die genaue Position ist ohne eine leistungsfähigere Syntax nicht zu erheben.

ansātzen und vielschichtiger Nachweisführung Abraham (1992; 1994, Kap. 14; Abraham 1995a, b). Immerhin kann auch Uriagereka nicht anders als im Zusammenhang mit einer bestimmten, CL motivierenden Funktionskategorie im Satz an eine Diskursfunktion the speaker's point of view zu denken. Er spricht in diesem Zusammenhang von einem syntaktischen Element „interfacing with pragmatic indexicality” (Uriagereka 1995, S. 93). 
(35) Satzfeldtypologische Einordnung von CL, schwachen und starken Pronomina:

CL und sw. Pron. in der Themaperiode, st. Pron. ebenso wie Voll-NPs in der Rhemaperiode. Winkelklammern zu lesen als ,entweder $\langle A\rangle$ oder $<$ B $>$ (oder $<\mathrm{C}>$ )"

\begin{tabular}{|c|c|c|c|c|c|c|c|c|c|c|}
\hline \multirow{3}{*}{$\begin{array}{l}\frac{4}{3} \\
\frac{3}{2}\end{array}$} & 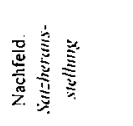 & 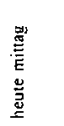 & & & & & 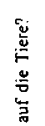 & 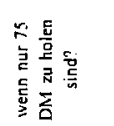 & 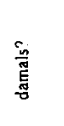 & \\
\hline & 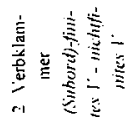 & 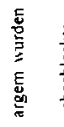 & 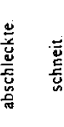 & 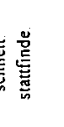 & $\begin{array}{l}\text { 总 } \\
\text { 兽 }\end{array}$ & 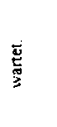 & $\begin{array}{l}\text { 愛 } \\
\text { 音 }\end{array}$ & & 总 & 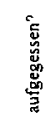 \\
\hline & 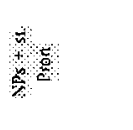 & 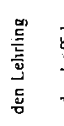 & & & $\begin{array}{l}\frac{2}{3} \\
\frac{5}{55} \\
\frac{5}{5} \\
\frac{5}{y}\end{array}$ & & 总 & & & \\
\hline \multirow{7}{*}{$\begin{array}{l} \\
\frac{1}{3} \\
\vdots\end{array}$} & 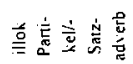 & 喜 & $\begin{array}{l}\overline{\mathrm{u}} \\
\overline{\mathrm{z}}\end{array}$ & 突 & & $\underline{\underline{\underline{z}}}$ & 言 & $\dot{\Delta}$ & 㔛 & $\overline{\mathrm{y}}$ \\
\hline & $\frac{8}{8}$ & 4 & औ & 8 & 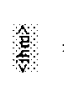 & & y & \$ & 3 & : \\
\hline & 8 & צ: & \% & 8 & ह & & $\beta$ & t & 8 & \\
\hline & 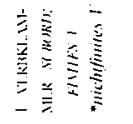 & $\because$ & 홈 8 & $8 \stackrel{\underline{\underline{E}}}{\Xi}$ & $\overline{\mathrm{u}}$ & & 豆 & 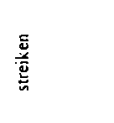 & $\underset{\underline{\underline{\underline{s}}}}{\underline{\underline{x}}}$ & 폰 \\
\hline & 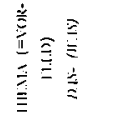 & $n$ & 离 & 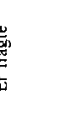 & 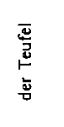 & 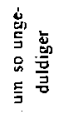 & & & & \\
\hline & 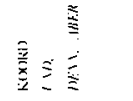 & 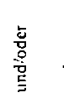 & 号 & & & & 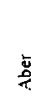 & 总 & & \\
\hline & 醇 & & & & & & & & & \\
\hline
\end{tabular}




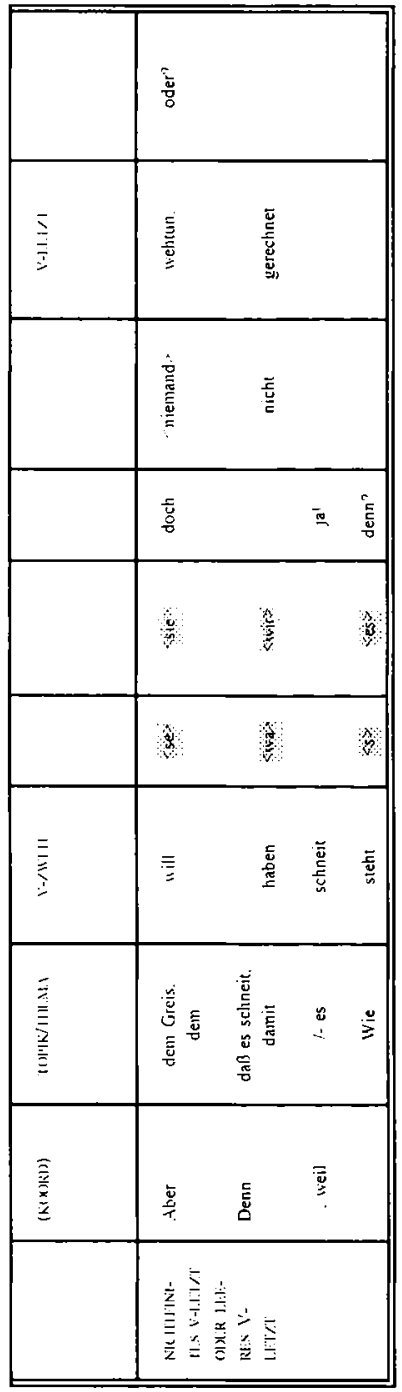




\section{Kasusunterschiede und lineare Nichtinvertierbarkeit}

Die Basisabfolge bei Objekten ist Dativ vor Akkusativ, bei schwachen Pronomina und CL jedoch Akkusativ vor Dativ. Die folgenden Abfolgebeschränkungen sind zu beobachten:

(36) a *Er hat ihm-DAT ihn-ACC überreicht \#(dem-DAT) Rotkäppchen den-ACC Korb

b * Sie will ihm-DAT es-ACC nicht sagen \#(dem-DAT) Rotkäppchen das-ACC Versteck

c ${ }^{*}$ Die Eltern wollten ihnen-DAT sie-ACC nicht lassen

(37) a ?Er hat ihr-n (DAT-ACC) überreicht

b ${ }^{*}$ Er will ihm-n nicht zeigen

c Sie will ihm-s nicht sagen

d 'Er hat ihr ihn überreicht

e ${ }^{*}$ Er will ihm ihn nicht zeigen

f *Sie will ihm es nicht sagen

Haegeman (1993) für das Westflämische und Vikner (1991) für die skandinavischen Sprachen zeigen, daß dieser Objektwechsel nicht auf das Deutsche beschränkt ist. Eine genauere Scheidung nach phonologischen Eigenschaften mag freilich ausweisen, daB hierbei auch nichtsyntaktische Bedingungen mitspielen - etwa daß Klitikkonsonanten mit schwacher Sonorität vor solchen mit höherer Sonorität stehen müssen (also /s/ vor $/ \mathrm{n} /, / \mathrm{n} /$ vor $/ \mathrm{m} / \mathrm{usw}$; vgl. $(37 \mathrm{~b}, \mathrm{c}))$. Freilich liegt hiermit eine gemischte, syntaktisch-phonologische Bedingungstraube vor. Sollten sich die Beobachtungen oben nicht als vollständig erweisen (so die Behauptung von Lenerz 1992) und zu gemischten Distributionen führen, dann ist nur der SchluB zu ziehen, daß schwache Pronomina infolge von phonologischen oder idiomatischen Merkmalen flach konfiguriert sind, also keinen strukturellen Lizensierungsbedingungen unterworfen sind. Auch im Frz. zeigen sich solche reversiblen Abfolgen - doch vgl. auch (38c-e), aber eben gegen (38f):

(38) a Je le lui dirai

ich es ihm sage-FUT

b Je te le dirai

ich dir es sage-FUT

c Gib-s ihm!

d Gib ihm-s!

e Er hat-s-m/n-m gemacht

f Er hat-m-s/*m-n gemacht 
Sollten jedoch die pronominalen syntaktischen Reversibilitätsverteilungen - eventuell neben phonologischen Nebenerscheinungen - allgemein haltbar sein, dann sind syntaktische Lösungen erforderlich. Diese Lösung ist komplex (Abraham/Wiegel 1993; Abraham 1994, S. 531ff.): sie geht davon aus, daB die Dativvalenz in einer Adjunktschale zu VP steht und daß somit der VP-interne Akkusativ über das Dativadjunkt nach links rückt, daß der Dativ als Linksadjunkt zur rhematischen VP andererseits stehen bleiben kann, da er eben nicht im Rhema-VP steht, das seinerseits nicht der diskursstrukturelle Ort für die fokusschwachen Thema-CL ist. Man beachte, daB die Datenbeobachtungen (nominale Dative vor Akkusativen, jedoch pronominal-klitische Akkusative vor Dativen, dies in weit über einzelne Sprachen hinausgehenden Beobachtungen, damit die Vorbehalte bei Lenerz 1992 entwertend) folgenden SchluB erzwingen: Dative stehen nach statistisch signifikanten Zählungen (Givón 1976, S. 160) in der Topikalisierungshierarchie deswegen höher, weil sie stärker referentiell-definit und durch die Eigenschaft [+menschlich] vertreten sind als Akkusative. Dies scheint mit ihrem prototypischen BENEFAKTStatus zusammenzuhängen und dies wiederum mit dem relativ stärkeren Anteil am Zustandekommen des Ereignisses der Satzprädikation. Nun ändert sich an diesen übergrammatischen Beziehungen natürlich nichts, wenn die Nomina durch Pronomina oder deren klitisch schwache Formen ersetzt sind. Trotzdem wechselt die Topikreihung so typisch und mit stark übereinzelsprachlicher Tendenz. Dies läßt nur die Folgerung zu, daß Pronomina und CL nicht mehr wie freie Lexeme im Satz den topikalisierungshierarchischen Bedingungen unterliegen, sondern in grammatische Bindungsprozesse eingebunden, soz. grammatikalisiert sind: eingebunden eben in Inkorporationsprozesse mit kategorialer Trägerabhängigkeit, wie morphologische Köpfe der Art, wie sie hier beschrieben wurden. Auf den minimalistischen Erklärungsrahmen bezogen könnte dieser Wechsel freilich bedeuten, daß der Akkusativ als struktureller Kasus zu einem funktionalen Knoten aufrücken muß, der Dativ als inhärenter Kasus dagegen VP-intern (oder VP-nahe) stehenbleibt. Ich diskutiere dieses Szenario hier nicht weiter (vgl, allgemein zur Kasuszuweisung im Rahmen der minimalistischen Syntax Abraham et al. (1996)).

\section{Enklise vs. Proklise, nichtdeklarative Konstruktions- typen und der Finitheitsparameter}

\subsection{Unterschiede}

Die allgemeine Stellungsthese zu CL in Abhängigkeit von den greenbergschen Abfolgetypen erfordert auf jeden Fall eine Präzisierung. Bereits auf ein paar wenige Sprachen beschränkt ergibt die CL-Verteilung nach 
bestimmten Konstruktionsbedingungen ein Bild, das aufs erste der allgemeinen typologisch begründeten These widerspricht. Dies betrifft die drei folgenden Konstruktionstypen: Imperative, Gerundien und Infinitive. Es zeigen sich folgende CL-Umgebungen bzw. Korrelationen (z.T. unter Rückgriff auf Daten bei Drachman 1994, Dobrovie-Sorin 1994 und Uriagereka 1995). Man vgl. (39).

\begin{tabular}{|l|l|l|l|}
\hline $\begin{array}{l}\text { Proklise bei finitem } \\
\text { Prädikat }\end{array}$ & Infinitiv & Imperativ & Gerundium \\
\hline Französisch & $\mathrm{CL}+\mathrm{V}$ & $\mathrm{V}+\mathrm{CL}$ & $\mathrm{V}+\mathrm{CL}$ \\
Italienisch & $\mathrm{CL}+\mathrm{V}$ & $\mathrm{V}+\mathrm{CL}$ & $\mathrm{V}+\mathrm{CL}$ \\
Spanisch & $\mathrm{V}+\mathrm{CL}$ & $\mathrm{V}+\mathrm{CL}$ & $\mathrm{V}+\mathrm{Cl}$ \\
Neugriechisch & $\mathrm{CL}+\mathrm{V}$ & $\mathrm{V}+\mathrm{CL}$ & $\mathrm{V}+\mathrm{CL}$ \\
Portug. unabhgg. Satz & $\mathrm{V}+\mathrm{CL}$ & $\mathrm{V}+\mathrm{CL}$ & $\mathrm{V}+\mathrm{CL}$ \\
Portug. abhgg. Satz & $\mathrm{CL}+\mathrm{V}$ & - & - \\
\hline Deutsch & $\mathrm{CL}+\mathrm{V}$ & $\mathrm{V}+\mathrm{CL}$ & $\mathrm{CL}+\mathrm{V}$ \\
\hline Enklise bei finitem Prädikat & Infinitiv & Imperativ & Gerundium \\
\hline
\end{tabular}

Ganz offensichtlich erfordern diese Daten eine feinkörnigere Analyse als das weniger feinkörnige greenbergsche Raster mittels $\mathrm{S}, \mathrm{V}$ und $\mathrm{O}$. Außerdem liefert diese tiefergehende syntaktische Analyse nicht nur den Schlüssel dazu, daß sich die allgemeinere These (unter dem gröberen greenbergschen Raster) halten läßt, sondern sie erhärtet auch den diskursfunktionalen Erklärhintergrund.

Die herausfallenden und erklärungsbedürftigen Abfolgen sind unten typographisch hervorgehoben: im spanischen Infinitiv wie in (40) im Vergleich zum übrigen romanischen, etwa im Französischen wie in (41), im unabhängigen Satz des Portugiesischen sowie im gesamten Deutschen als einzigem Vertreter des SOV/SVO-Typs (d.h. eines Typus mit relativ strenger V-letzt-Abfolge im abhängigen Satz und gleichzeitig ganz strenger V-zweit-Abfolge im unabhängigen Satz).

(40) a Lo oimos es hörten(-wir) „Wir hörten es"

b Para oirlo zu hören=es „es (zu) hören"

(41) a Tu le feras du es tun-FUT „Du wirst es tun"

b Elle va le faire sie geht es tun „Sie wird es tun" modernes Spanisch modernes Frz. 
(42) a

$$
\begin{aligned}
& \text { a Levá-lo-ei } \\
& \text { hebe(ich)=es=FUTURAUX } \\
& \text { b Mostra-no-los-á } \\
& \text { zeigen=uns=sie-FUTURAUX }
\end{aligned}
$$

europ. Portugiesisch

„Ich werde es heben"

Zum Portugiesischen habe ich hier nichts weiter zu sagen (dazu vgl. Rıvero 1988; Madeira 1992), auBer daß man sich durch scheinbar subjektlose Deklarative wie in $(42 a, b)$ oben nicht darüber hınwegtäuschen lassen darf, daB hier tatsächlich echte SVO-Strukturen vorliegen. Die pronominalen thematischen Subjekte sind ja flexivisch erkennbar. Freilıch sind keıne Proklitika beobachtbar, sind keine topıkalisierten phonologisch starken Morpheme vorhanden, die als Träger der CL fungieren könnten. Dies ist eine der syntaktisch strukturellen Einschränkungen, denen die allgemeine These zur typologischen Verteilung zwischen Prokhtika und Enklitika unterliegt. Die grammatische Alternative ist somit Inkorporation in die Verbflexion.

Im Deutschen wäre, gerechnet nur nach der SOV-Typologie, gerade en Stellungsspiegelbild zum Romanischen zu erwarten gewesen - das sıch mit den Abfolgen im Infinitıv und im Imperatıv jedoch nicht einstellt, ım Gerundıum dagegen ist dıe Abfolge 'erwartungsgemäß' splegelbildlıch zum Romanischen Was ist der tıefere Sinn dessen?

\section{Imperative}

Imperative verzeichnen im allgemeinen die folgenden Eigenschaften, sofern nicht bloß Sprechaktfunktion und nicht ein eigenes morphologisches Flexionsparadıgma den Imperativcharakter bestımmt (1) sie erscheinen nur in unabhängıgen Sätzen, (ii) sie haben demgemäß niemals eine einleitende Konjunktion (in COMP) oder ein anderes einleitendes Satzglied wie ein Adverb (in Sonderheit die Negationspartikel - im Deutschen wird gerade mit Negation gerne der Inıfinitıv verwendet. nıcht schlagen!, was erklärungsbedürftig ist); (iii) die Imperativformen stehen am absoluten Satzbeginn - vorabgehende NPs sind offenbar als Themata pendentia lınksherausgestellt. Den überzeugendsten Nachwels für die Top-Stellung des Imperatıvs liefern SOV-Sprachen wie das Deutsche, das Niederländische und das Westfriesische - erwarten wir doch nach der Zweitstellung des imperativischen Prädikats CL-Enklise, die sich auch ausnahmslos einstellt

In Strukturen mit V-Top-Stellung wie den Imperativen muß auch im Romanıschen das Verb in COMP stehen - 1m Gegensatz zu allen anderen Strukturen, wo es in IP steht ${ }^{13}$ Vgl (43) (Dobrovie-Sorm 1994, S 59f).

13 Im Deutschen dagegen steht das finite $V$ außer in Nebensätzen, wo COMP 
(43) a FRZ. regarde-le mit der Struktur [CoMP regarde $\left.e_{i}=l_{k}\right]\left[\begin{array}{ll}I P & t_{k} \\ t_{i}\end{array}\right]$

b RUM. da-i-l gib- ihm-ihn

trimite-mi-o

schick- mir-sie

Diese Imperativstrukturen werden wie gesagt deshalb eigens vermerkt, weil sie ja der zentralen, aber eben durch die zweite These strukturell spezifisch eingeschränkten Verallgemeinerung $z u$ widersprechen scheinen: bei strengem SVO stehen CL proklitisch. Wie wir sehen, bezieht sich dieser allgemeine Schluß auf SVO mit IP-Stellung von V (also der Verbstellung im deklarativen Satz), nicht jedoch auf Strukturen mit V in CP (dem Konjunktionsknoten), also einem Knoten über IP, dem Satzflexionsknoten (im Imperativ muB das Verb in die Satzspitzen-, die TOPPosition, um dort sowohl der Satzoperatoren- wie auch einer Fokusposition zu genügen). Der diskursfunktionale Grund für die Linksverrückung ist gleichwohl erfüllt: die pronominalen $C L$ sind in (43a-c) ja aus VP heraus nach links gerückt und stehen adjungiert an das finite Verb in COMP. Man sieht dies nur mit der oberflächlichen traditionellen Grammatikbrille nicht, weil die Klitika in gleicher Weise rechts von V stehen! Ein wichtiges Weiteres läßt sich aus (43a-c) oben ableiten: wenn die CL einzelne strukturelle Köpfe - etwa in $\mathrm{I}^{\circ}$ und in $\mathrm{C}^{\circ}$ - wären, dann könnte das Verb bei seinem Linksrücken in eine TOP-Position auch $\mathbf{z w i s c h e n}$ den beiden $\mathrm{CL}$ stehen bleiben. Das ist aber völlig ausgeschlossen. Damit liegt der Schluß nahe, daß die beiden $C L$ ins Verb inkorporiert sind. Dieser Schluß wird fürs Deutsche - und soviel ich sehe ausschließlich fürs Deutsche - auch gestützt durch die Kongruenzbeobachtungen für Konjunktionen (Bayer 1984/85; Abraham 1994, S. 521), also genau an der Kategorie, wo sich auch die CL adjungieren und wohin das finite Verb rücken muß, sofern diese Stelle nicht (wie im konjunktionseingeleiteten Nebensatz) durch eine Konjunktion besetzt ist. Solche scheinbaren Enklitika wie in (43a-c) haben also einen anderen Strukturaufbau als die normal beobachteten Proklitika. Vgl. (44) (nach Dobrovie-Sorin 1994, S. 61).

(44) a Ausgangsposition für SVO wie das Rumänische:

$$
\text { COMP ... [IP CL [IP V-I [vp tv ...]]] }
$$

durch die Konjunktion besetzt ist, vermutlich immer in COMP. Das sieht man nicht ohne weiteres. 
b proklitische Inkorporationsrestrukturierung ('restructuring incorporation'):

COMP ... [IP [I' CL V-I [vP tv ...]]]

c enklitische morphologische CL-Prädikateinschmelzung ('merger'):

[СомP V-I=CL [IP $t_{C L}\left[\right.$ IP $\left.\left.t_{V-I}\right]\right]$ ]

Proklitika sind trotz der unverrückbaren Adjazenz zum finiten $V$ freie Morpheme, in ihrer Selektionsposition dem Artikel vergleichbar; vgl. (44b). Enklitika dagegen haben worteingebundenen Charakter, sind somit unfrei, stärker verbkongruenzmorphologisch in ihrem Charakter. ${ }^{14}$ Soweit zu Imperativen, die sich quer durch alle Sprachen darin gleichen, daß das imperativfinite Verb als Satzoperator an die absolute fokussierende Satzspitze rücken muB und dabei CL auf jeden Fall in einer Themaposition landen läßt.

Gelegentliche Proklitika beim Imperativ sind entweder als herausgestellt (Thema pendens) oder als topikalisiert, also noch innerhalb des Satzgefüges, zu betrachten. Man vergleiche die beiden neugriech. mundartlichen Imperative (von Chios: $(45 \mathrm{a}, \mathrm{b})$ ) in derselben Bedeutung ${ }_{n} \mathrm{Halte}$ deinen Mund!" (nach Drachman 1994, S. 13). Die bedeutungsgleichen Entsprechungen des Standardgriechischen zeigen bloß die kanonische Proklise (vgl. $(45 c, d)$ ):

(45) a

$\begin{array}{lll}\text { a } & \begin{array}{l}\text { ta-loya-su ta-thu } \\ \text { die Worte-deine sie=halte }\end{array} & \text { Dialekt von Chios; Proklise(!) } \\ \text { b thun-ta ta-loya-su } & \text { Dialekt von Chios; Enklise } \\ & \text { halte=sie die Worte-deine } & \\ \text { c krata-ta ta-loya-su } & \text { Standardgriech.; Proklise } \\ \text { d } \quad \text { ta-loya-su ta-krata-k } & \end{array}$

Die Negationspartikel steht nie links vom (d.h. strukturell höher als das) Verb (Drachman 1994, S. 13). Da Neg andererseits strukturell höher als der funktionale Kongruenzknoten liegt, muß das imperativische Prädikat in COMP stehen.

\subsection{Gerundien}

Gerundien verhalten sich nach (39) in allen hier beobachteten Sprachen gerade umgekehrt, als man es nach der allgemeinen typologischen Stellungsthese (V-Randsprachen Enklise, V-Mittelsprachen Proklise) erwar-

14 Einen, wie mir scheint, ganz āhnlichen, nur in anderem Jargon ausgedrūckten Unterschied trifft auch Uriagereka (1995), indem er im Sinne der Minimalismustheorie $\mathrm{zwischen}$ starken und schwachen CL-attrahierenden Kategorien bzw. dem parametrischen Fehlen solcher Kategorien unterscheidet. 
ten würde: der romanische SVO-Typus zeigt Enklise, der deutsche SOVTypus dagegen Proklise. Zum Deutschen vgl. man:

(46) a zum's/es ihm mit einem Blumenstrauß Überreichen

b zum'n/ihn den Safe sauber aufbrechen Lassen

c zum ihm <'s/?es> mit einem Blumenstrauß <*'s/ ${ }^{*}$ es> Überreichen

d zum den Safe <*'n/*ihn> sauber <*'n/*ihn> aufbrechen Lassen

CL ist nur mit dem präpositionalen Träger $z u m$ verträglich. Wenn die nominale Verbform mit ihren Valenzen im VP-Status ist und die Adverbiale mit einem Blumenstrauß bzw. sauber linke VP-Grenzmarken darstellen, dann steht die Präposition zum im Satzflexionsknoten IP oder in COMP oder irgendwo dazwischen. Wenn wir davon ausgehen, daß Gerundien zumindest Aspekt, wenn nicht sogar Tempus (aber eben nicht Person und Numerus) ausdrücken, also in den IP-Knoten vorrücken, ohne AgrS zu erreichen, dann steht $C L$ in der deutschen Gerundialkonstruktion auf jeden Fall in der thematischen Satzperiode.

Ganz anders jedoch haben wir den anderen Gerundialtypus zu analysieren. Ich orientiere mich am Neugriechischen (Beispiele und Analyse nach Drachman 1994, S. 12f.).

\section{NEUGRIECHISCH (Drachman 1994, S. 12):}

a to grama-su, ematha oti i-Maria, diavanzondas-to, yelase dein Brief, ich hörte, daß die Maria lesend ihn

b ematha oti o-Petros fevgondas pire ta klidya mazi-tu ich erfuhr daß Peter weggehend nahm die Schlüssel mit sich

c * to grama-su, ematha oti i-Maria, diavanzondas-to yelase (kein Komma vor yelase!)

d Sie hat den ganzen Kaffee zum Trinken ausgeschüttet.

e Sie hat das Kind das ganze Flascherl, zum ti Austrinken gezwungen.

f Sie hat $\left.<^{*}{ }^{\prime} s_{i}\right\rangle^{15}$ das Kind $\left\langle * ' s_{i}\right\rangle\left\langle\right.$ das ganze Flascherl $\left.l_{i}\right\rangle$ zum $<$ 's $s_{\mathrm{i}}>$ Austrinken gezwungen.

Drachman nennt auch das adverbiale Konverb ohne Rektion in (b) 'Gerundium'. Wir beschränken uns hier auf die objektregierende Form in $(a, c)$ sowie das Deutsche in (d-f). (a, c) sowie (f) zeigen Objekt-CL. Im Deutschen weisen die Stellungsbeschränkungen nach (f) die PP-interne

15 Winkelklammern kodieren alternative Verwendung, also 'entweder - oder - oder ...'. 
Position des Objekts als Basisposition aus. Im hochnormalisierten Hochdeutschen gilt keine der Alternativen (zwischen $<>$ ) - um überhaupt zu Daten zu gelangen, muß man die gewachsene Umgangssprache bemühen. Zum Griechischen schließen wir, nur z.T. Drachman folgend, folgendes. $\mathrm{DaB}$ nur die Version mit Parenthese grammatisch ist, bestätigt nur die Position, daB nichtfinite Konstruktionen ein (unsichtbares) PROSubjekt mit Nullkasus (also nicht mit Nominativ!) haben müssen. Da in (c) das Subjekt i-Maria realisiert ist, ist gegen diese Bedingung verstoßen. Dies erklärt einerseits den Grammatikalisierungsunterschied zwischen (a) und (c). Andererseits zeigt die grammatische Parenthese deutlich, daß keine finite Konstruktion, im besonderen keine Satzflexionskategorie (Agr-Knoten) vorliegt. Damit ist diese Gerundialstruktur in (a) genauso ein adverbielles Konverb wie die in (b). Solchen tempus-, modus- und numeruslosen Strukturen lassen sich jedoch keine Diskursfunktionen wie Thema vs. Rhema zuordnen. Dann aber braucht CL das Rhemagebiet, nämlich die VP, auch nicht zu verlassen. Es bleibt folglich in seiner Grundposition unter Rechtsrektion, nämlich kanonisch rechts von V. Man prüfe anhand von (47), daß im Gerundium auch fürs Deutsche die unter Linksrektion gültige Position gilt. Da alle romanischen Sprachen für nicht V-topikalisierende Strukturen vom SVO-Typus (wo das Verb in IP bzw. dessen Subselektion AgrP steht, nicht in CP wie im Deutschen) sind, gilt durchgehend und völig erwartbar ' $V+C L$ '. Das deutsche präpositionale Gerundium mit ausschließlichem P-CL zeigt letztlich, daß kongruenzlose CP-Strukturen existieren - CL hängt sich an eine Kategorie an, die sonst COMP als CL-Träger vorbehalten ist. Und wenn man Gerundien nominalen Kategorialstatus zuspricht, dann zeigt ebendies, daf es nominale CP-Strukturen gibt - was freilich keinen logischen Semantiker (perseverierenden 'Lambdakonvertiten') überrascht.

Es bleibt darauf hinzuweisen, daß die beiden Enklisen für den Imperativ (ebenso wie den Interrogativ) und das Gerundium trotz gleicher Oberflächenposition auf völlig unterschiedliche Mechanismen zurückgehen; die einen, Imperativprädikate, haben nominativische pra-Subjekte und stehen an der Satzspitze; die anderen dagegen, Gerundien, haben kasuslose PRO-Subjekte (wie in Kontrollstrukturen unter Verben wie versprechen/raten/befehlen + Infinitiv) und stehen keineswegs an der Satzspitze - sie sind ja nichtfinit nach Person, Numerus und eventuell Tempus (sicher nicht jedoch nach Aspekt). Und letztlich ist zu beachten, daß die CL-Enklise quer durch alle Sprachen, in Sonderheit die der sonst proklitischen romanischen CL-Realisierer, auf eine Verbvorrückung über alle möglichen Landeplätze nach links zurückgeht - weiter als sonst in den romanischen Deklarativsätzen nötig ist. Somit ergibt sich eine the- 
matisch diskurskodierte Landestelle schon vor dem imperativisch-finiten V.

\subsection{Infinitive}

Mit 7.2-7.3 ist auch klar, inwiefern das oberflächlich gemeinsame Merkmal der Nichtfinitheit bei Gerundien und Infinitiven für den diametralen Unterschied (Enklise beim roman. Gerundium, Proklise beim Infinitiv mit Ausnahme des Spanischen) keinen erklärenden Status besitzt (d.h. über die allgemeine typologische These hinausgehen muB). Infinitive haben kein PRO, das ja wie bei der Kontrollkonstruktion regiert sein muB (Er versprach $\mathrm{PRO}_{\mathrm{i}}$ zu kommen). Ohne Subjekt und ohne Kongruenz besteht kein AnlaB für $V$, überhaupt aus seiner durch die Thetarollen bestimmten VP-Position in den Kongruenzknoten ins Mittelfeld zu rücken; es bleibt rechts von CL in V-Letztposition, wie es die Rektionsläufigkeit deutscher Verbaktanten vorschreibt (Abraham 1994, Kap. 1). Ob am Beginn des Infinitivkomplexes stehende CL-Formen in die syntaktische Argumentation miteinbezogen werden sollten, steht dahin: es wäre dann ein Subjekt-pro vorauszusetzen, das alleine thetasemantisch begründet ist und für die Lizensierung von CL herzuhalten hätte.

$$
\begin{array}{ll}
\text { a } & -\mathrm{s}-\mathrm{m} / \mathrm{n} \text { gern gebm } \\
& =\text { bairisch-österreichisch } \\
\text { b } & \text {-s den gern gebm } \\
& =\text { es dem gerne gegeben } \\
\text { c *den-s gebm } & \\
\text { d eam des } /{ }^{*} \text { es gebm }
\end{array}
$$

den „dem” bzw. des „das/es” ist die schwache Pronominalform, die in einer Vielzahl deutscher Dialekte das schwächste Glied im Paradigma, $e s$, dann vertritt, wenn dieses nicht als syntaktisches CL auftritt. ${ }^{16}$ Die Alternative wäre, den Status derartiger Formen ausschlieblich phonologisch, also als Schnellsprechformen festzulegen.

Syntaktische Subjektlosigkeit ist der Grund, weshalb die gleichermaßen rektionsrechtsläufigen romanischen SVO-Sprachen Gerundial- und Infinitiv-CL grundlegend asymmetrisch konstruieren. Wieso fält aber das Spanische mit $V+C L$ aus dem allgemeinen Infinitivbild der Romania heraus? Wir können im Augenblick nur so viel sagen, daB CL in span.

16 es kommt in der schwachen und der starken syntaktischen Verteilung nicht oft vor und wird in solchen Umgebungen im allgemeinen durch $d$-Formen ersetzt. Von schwäbischen Kollegen (U. Lutz/Tübingen) habe ich mir sagen lassen, daß man seinen Dialekt gerade aufgrund dieser Ausnahme erkennt. Zu dialektalen Varianten des Deutschen vgl. Abraham/Wiegel 1993. 
para oirlo verbinkorporiert ist und als Affix nur in Kopfstellung, also rechts vom Verbstamm stehen kann. Uriagereka (1988) bringt dies mit der Existenz eines parametrisch agierenden Funktionsknotens in Verbindung bzw. der Attraktionskraft dieser Funktion derart, daß ein freies CL-Morphem oder ein Verbaffix entsteht (s. auch Uriagereka 1995, S. 92ff.).

\subsection{Schlubfolgerung}

Der zentrale Schlüssel für die auseinanderlaufenden Positionen der pronominalen Klitika (CL) ist die Finitheit des Prädikats nach den Bestimmungsstücken Tempus, Subjektperson und Subjektnumerus bzw. die spezifische syntaktisch-semantische Funktion des CL-regierenden Prädikats. Beim Imperativ (ebenso wie beim Interrogativ, gleichgültig ob in der Wortfrage oder Satzentscheidungsfrage) muß das Prädikat in die Satzoperatorposition in CP rücken, um den spezifischen grammatikalisierten Imperativsprechakt zu lizensieren. Das imperativisch-finite V steht also strukturell höher als im einfachen Deklarativsatz, für den der Greenbergtypus SOV bzw. SVO ausgelegt ist (dies, so wissen wir alle, in Ermanglung einer detaillierteren und leistungsfähigeren Syntaxstruktur). In einer solchen Top-Position des V braucht aber auch bei SVO (dem Typus, dem alle der romanischen Sprachen in (39) angehören) CL nicht höher als bis eben außerhalb von VP (genauer in die strukturelle Dimension von IP oder AgrP) nach links zu verrücken. Somit bleibt die allgemeine, auf Deklarativstrukturen ausgelegte These unbeschadet: SVO zeigt Proklise. Im speziellen Imperativfall müßte man greenbergisch von VSO und damit von Enklise ausgehen - was ja mit der Hauptthese im Einklang ist.

8. Die germanisch-skandinavischen Sprachen vom SVOTypus mit Enklise - CL-Ausscherer?

Das Schwedische zeigt CL-Nachbindung, obwohl es vom SVO-Typus ist. Widerspricht dies unserer Generalisierung?

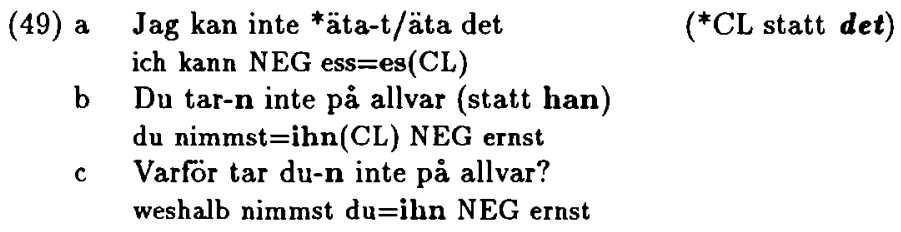


Das Schwedische stellt trotz seines unkontroversen SVO-Typus die schwachen und klitischen Pronomina postverbal (aber vor die Satznegation). Vgl. auch (50) fürs Norwegische.

(50) NORWEGISCH (Christensen-Koch 1985):
a Hun/*a har bodd her
${ }^{*} \mathrm{CL}$ in Satzspitzenstellung sie $/{ }^{*} \mathrm{CL}$ hat gewohnt hier
b Vi vet at ikke hun $/{ }^{*}$ a har bodd her ${ }^{*} \mathrm{CL}$ nach NEG wir wissen daf NEG sie hat gewohnt hier
c $\mathrm{Vi}$ vet at a ikke har bodd her CL im Mittelfeld, vor NEG

Ohne hier näher darauf eingehen zu können gehe ich davon aus, daB die Position des starken Satznegators eine strukturelle Grenze setzt. Im Keltischen (VSO) steht ein solches NEG, ket (als Partikellexem, nicht als proklitischer Satzaffirmator präverbal wie im Bretonischen), postverbal vor Objekten, Adverbien, Objektnebensätzen oder Prädikatspartizipien, jedenfalls aber vor dem Kongruenzkomplex, IP (vgl. neuerdings Schafer 1995, S. 161 et passim). Auch in den romanischen SVO-Sprachen steht die starke Neg-Partikel oft direkt vor den Objekten: man denke an pas direkt hinter dem finiten Verb im Frz., ohne daB sich ein anderes Satzglied $z$ wischen dieses NEG und das finite Verb drängen kann. Starkes NEG setzt zum finiten Prädikatsteil einerseits und zur Kette von Objekten andererseits eine enge Beziehung, allerdings in Abhängigkeit von der typischen Rektions- und Satzskopusrichtung: nach rechts bei SVO-Sprachen, nach links bei SOV. Man denke an das Deutsche, wo die NEG-Partikel nicht durch nichts von der V-letzt-Position getrennt werden kann und sich auf alle definiten Objekte links von NEG bezieht.

$$
\begin{aligned}
& \text { a weil <*nicht }>\text { er }<* \text { nicht }>\text { [vp [den Nachbarn <nicht }> \\
& \text { b-s-Skopus] ausstehen kann] } \\
& \text { b because he <*not }>\text { often does [s-Skopus }-><\text { not }><* \text { often }> \\
& \text { [vp participate at parties]] }
\end{aligned}
$$

Das Wesentliche ist, daß zwischen der unabhängigen und der abhängigen Satzstruktur eine auffallende Asymmetrie in dem Sinne besteht, daß sich im abhängigen Satz ein 'Mittelfeld' (nach Diderichsen (1962) ein eigenes 'Nexusfeld') öffnet, in das schwache Adverbien rücken können (Platzack 1988). In dieser strukturellen Periode landen CL in der erstmöglichen Stelle auf ihrer Suche nach einer Themaposition - durchaus im Sinne der speziellen CL-These in (ix), zusammengefaßt nochmals in (xv) unten. Eine solche Asymmetrie besteht in den anderen SVO-Sprachen, den romanischen Sprachen und dem Englischen, nicht; entsprechend muß CL 
über das finite Prädikat weiter nach links rücken. Man vgl. nochmals die norweg. Beispiele in (50).

\section{Schluß: Erklärung für die CL-Verschiebung vor dem Hintergrund von Diskursfunktion und Satztypologie}

(xi) Für strenge SVO-Sprachen, also Sprachen ohne stellungsfreies Subjekt ist die THEMATISCHSTE Position die des Subjekts. Jedes andere Satzglied links vom Subjekt steht außerhalb des einfachen Satzes (etwa als Thema pendens); andere Satzglieder als Subjekte sind vor dem finiten V oder AUX im allgemeinen nicht gestattet. Thematisches Material, sofern nicht selbst $S$, steht $z$ wischen $S$ und V. Es muB links von $V$ stehen, denn $\mathrm{V}+\mathrm{O}$ ist ja RHEMATISCH. Diese Situation führt zu PROKLISIS. Sie gilt für die romanischen SVO-Sprachen. Die kanonische phonologische Verschleifung mit dem finiten Verbträger spricht dafür, von einem Vorschritt zu Präfigierung zu sprechen. Ohne Zweifel ist die Proklise im Bretonischen - das ja eine keltische Sprache und ursprünglich vom Typus VSO ist - durch arealen Einfluß des Französischen (SVO) zu erklären.

(xii) Die Merkmalskombination [+stellungsfreies $\mathrm{S},+\mathrm{SVO}$ ] wie im Slawischen (sofern diese Sprachen die CL als Erscheinung überhaupt aufweisen; das Russische etwa hat keine pronominalen CL, wohl aber Nullsubjekte) erlaubt jedes Satzglied in der Topikposition. Auch in solchen Sprachen steht CL links von V, allerdings nicht in präfigaler Bindung (also als Morphem freier). Auch solche Sprachen zeigen jedoch PROKLISIS.

(xiii) Der SOV/SVO-Typus der kontinentalen westgermanischen Sprachen (Deutsch, Niederländisch, Westfriesisch, Jiddisch) sowie der ebenfalls V-randständige VSO-Typus des Walisischen hat eindeutig ENKLISE, unabhängig davon ob $\mathrm{S}$ stellungsfrei ist oder nicht. Er zeigt ENKLISE, weil die Position zwischen $V$ und $S$ die am weitesten linke bzw. vorderste ist, bis zu welcher ein THEMATISCHES Element aufsteigen kann in dem Bestreben, seine Diskursfunktion zu signalisieren. Beim Walisischen ist erwägbar, daB sein VSO aus einem früheren indoeuropäischen SOV (V[SO] aus [SO]V) stammt. Weiter sieht es so aus, als verhielte sich der VOS-Typus (nach dem Befund der australischen Eingeborenensprachen; vgl. Schachter 1976) wie VSO. Der exotische Typus ist jedenfalls SVO!

(xiv) Auch das Semitische (kairoter Umgangsarabisch, modernes Hebräisch) zeigt ENKLISE der pronominalen CL, jedoch mit bestimmten Unterschieden zum Walisischen. Diese Unterschiede sind auf den gemischten 
typologischen Status des modernen Arabischen und Hebräischen (SVO mit VSO-Optionen) zurückzuführen.

(xi)-(xiv) bestätigen die eingangs aufgestellte rein empirische allgemeine CL-Hypothese, daB die V-randständigen Sprachtypen ENKLISE, die Vmittelständigen dagegen PROKLISE aufweisen. Dies ist jedoch insofern zu korrigieren bzw. zu präzisieren, als es nichtdeklarative Satzbilder gibt, in denen auch die V-mittelständigen Sprachtypen CL-Enklise zeigen. Wir haben veranschaulicht, daß dies dann vorliegt, wenn die finite Prädikatkomponente in die Topikposition vorrückt. Andererseits gibt es den Vmittelständigen Typus wie die kontinentalskandinavischen Sprachen mit CL-Enklise (statt der für diesen Typus vorausgesagten Proklise). Dieser Umstand zwingt dazu, die allgemeine These zugunsten der spezielleren aufzugeben.

(xv) SPEZIELLERE CL-THESE: Pronominale CL sind hochthematisch. Sie stehen demgemäß in jener thematischen Position, die den geringsten Abstand zu den koreferenten nominalen Entsprechungen aufweist. Im Szenario eines Verschiebungsmechanismus der CL aus der VP heraus nach links heißt dies, daß CL in der erstmöglichen thematischen Position stehen bleibt. Wir haben diese diskursstrukturelle Satzperiode, in der das thematische pronominale CL zu stehen kommt, FP genannt und es weiterer empirischer Arbeit vorbehalten, diese vorerst diskursfunktionale Kategorie FP jeder Sprache extra auf die universalgrammatisch relevanten strukturellen Satzperioden abzubilden.

In den kontinentalskandinavischen V-mittelständigen Sprachen ist der Ort dieser diskursfunktionalen CL rechts vom finiten Prädikat. Diese FPPeriode unterscheidet sich distributionell so von der der romanischen Vmittelständigen Sprachen, da $B$ die in der Linksverrückung früheste thematische Bedingung bereits vor dem mittelständigen $V$, also in der Enklise, erfüllt ist. FP in den skandinavischen V-mittelständigen Sprachen liegt rechts vom finiten Satzprädikat, in den ebenfalls V-mittelständigen romanischen Sprachen dagegen links davon.

(xvi) Mit der Ausbildung von CL scheint ein gewisser Ausprägungsgrad der Kongruenzfunktion (nach Person und Numerus beim Verb) bei den CL-Trägern einherzugehen. Daraus folgt, daB AGR ausgeprägten, paradigmatisch hochidentifizierten Status hat. Das Englische hat kein solches hochentwickeltes Kongruenzparadigma, folglich kein pronominales CL. Auch wenn (zusätzlich) kasusidentifizierende Strukturpositionen für CL in Anspruch genommen werden (etwa bei Cardinaletti 1994, Abraham/Wiegel 1993, Abraham 1995), wird verständlich, daß das sowohl 
kongruenz- wie kasusfremde moderne Englische keine CL-Positionen bereitstellt.

Da im Altenglischen das Kongruenz- und Kasusparadigma noch ähnlich wie im Deutschen ausgebildet war, sollten syntaktische CL (und nicht nur phonologische wie in we're, they'll) vorkommen können. Eine der Schwierigkeiten bei toten Sprachen stellt die schreibsprachliche Überlieferung dar. Das moderne Griechische besitzt CL, wie wir dargestellt haben, das Altgriechische hingegen nicht, soweit wir dies beurteilen können - d.h. das Altgriechische verfügt nur über 'schwache Pronomina' (nach der bei Cardinaletti/Starke 1994 entwickelten Nomenklatur). Das Lateinische scheint bloß einen Personalpronomentypus zu besitzen, nämlich 'stark'. Sicheres verschließt sich uns bei alten Sprachen jedoch.

(xvii) Es ist nur natürlich, davon auszugehen, daB Null-CL-Sprachen ('pro-drop'-Sprachen) das Vorstadium der CL-Erscheinung kennen. Diese Annahme, so plausibel sie ist, wird einem aber durch verschiedene Sprachen schwer gemacht: etwa durch das Russische, das sehr wohl Nullprosubjekte kennt, uns aber in der Schriftsprache keinen CLAnhaltspunkt dafür zur Verfügung stellt. Dasselbe gilt für das Lateinische. Und: inwiefern erlaubt das Verbflexionsparadigma weniger eindeutige Verbkongruenzidentifikationen als das Italienische? Oder: wie läßt sich angesichts jedes Fehlens von verbaler Objektflexion die pro-dropErscheinung von Objekten in italienischen Dialekten erklären? Zwingen uns solche Einsichten dazu, den CL-Zwischenschritt auf dem Weg zu pronominalen Nullsubjekten aufzugeben? Oder fehlt in dieser Kalkulation ein Aspekt, den wir bisher völlig unterschlagen haben? Liegen hier einfach rein unsystematische pragmatische Auslöser zugrunde, die sich dann einfach konventionell - d.h. ohne tieferen typologischen Grund fixiert haben? ${ }^{17}$

17 Eine Erwägung in dieser Richtung ist folgendes wert. Man geht allgemein davon aus, daß pro-drop-Sprachen wie das Italienische, Rumānische, Portugiesische und Spanische, etwa im Unterschied zum Französischen hinreichend reich unterschiedene Verbkongruenzparadigmen aufweisen, um auf die Nennung des diskursfunktional schwachen Subjektpronomens verzichten zu können. $\mathrm{Vgl}$. die Übersicht in (i).

(i)

Französ. Deutsch Italien. Neugriech.

starke Pronomina schwache Pronomina CL pro-drop

$\begin{array}{llll}+ & + & + & - \\ - & + & + & + \\ + & +(-) & + & + \\ - & - & + & +\end{array}$


(xviii) Worin in den einzelnen CL-Sprachen auf jeden Fall Gemeinsamkeiten bestehen, sind die folgenden Stellungskriterien (zu (a)-(c) vgl. Dimitrova-Vulchanova 1993, S. 23):

(a) sie lassen als CL-Träger nur einen Vertreter einer spezifischen grammatischen Kategorie zu;

(b) sie ordnen CL einer bestimmten linearen Position zu, bleiben aber inbezug auf die kategoriale Zugehörigkeit des CL-Trägers neutral;

(c) sie ordnen CL in eine größere CL-Traube ein;

(d) der CL-Position in der Satzstruktur, die ja die erste (vom linken VP-Rand aus gezählte) erreichbare thematische Position ist, kommt unterschiedlicher kategorialer Status zu und zwar eine zwischen der TOP-Position und eben dem linken VP-Rand. ${ }^{18}$

Diese Annahme machen solche Sprachen noch plausibler, die sich aufgrund von Objektkongruenz in der Verbmorphologie diskursfunktional schwache Nullobjekte leisten: etwa das Ungarische. Freilich scheint eine solche verbale Objektflexion gar nicht nötig zu sein, wenn wir solchen Erscheinungen wie in italien. Dialekten Glauben schenken. Nun ist das Deutsche aber auf jeden Fall unter den Sprachen, die sich aufgrund ihres Verbkongruenzparadigmas Nullsubjekte leisten könnten: vgl. bin - bist - ist - sind - seid - sind bzw. $-e-(e) s t-(e) t-e n-(e) t-e n$. Das erlaubt eine fast $100 \%$ ige Identifikation nach Person und Numerus. Das Französische identifiziert sogar noch vollstāndiger. Trotzdem fehlen Nullrealisierungen. Einen Schlūssel scheinen die Umgangssprache und Dialekte $z u$ liefern. So kann man im Deutschen in Fragen und Ausrufen durchaus sagen: Bist (du) blöd!? Seid's (ihr/es) ganz gescheit?! Daß't/Wann'st nur aufpaßt!, in Notizen wie Bin um 5 zuhause/habe schon gegessen, Sind bald zurück sowie in Erzāhlanfängen wie in Ist einmal ein kleines Männchen gewesen, Hat einmal .... Natürlich gibt es auch hier Einschränkungen (so spielen diese Beispiele nie das gesamte Personparadigma durch); auch sehe ich von den mundartlichen Besonderheiten der Beispiele ab, ohne welche die Identifikation schlechter ginge. Es geht darum, daß die Subjektidentifikation eben auch ohne Subjektpronomen eindeutig wäre, sollte sich das Deutsche konventionell zur Nullrealisierung verstehen. Aber die Sprechergemeinschaft des Deutschen läßt sich diese Doppelidentifikation, 'diesen Luxus' eben nicht nehmen. Es ist durchaus zu erwägen, daß sich mit diesem Konservativismus - den ja z.B. eine so verwandte Sprachgemeinschaft wie die Niederländer nicht mit uns teilen - auch eine Typologie der Sprechergemeinschaften und der Sprachkultur erstellen ließe. Zu einem ersten Versuch in dieser Richtung vgl. Abraham (1995b).

18 Dimitrova-Vulchanova (1993) bestimmt diesen Ort fürs Slawische als kategorial offenen Satzknoten, der über der Negationskonstituente (die im Slawischen immer vorne steht) und der Moduskonstituente rangiert, die ihrerseits über dem Auxiliarkomplex und VP sitzt und zu dem sie für CL Rechtsadjunktion beobachtet. Uriagereka (1995) bestimmt diesen Ort rein 
Zwischen diesen vier Kriterien besteht keineswegs komplementäre Verteilung; vielmehr lassen sich verschiedene Kombinationen denken: etwa zwischen (a) (wie im Deutschen) und (b) (Wackernagelgeneralisierung). Das Deutsche beachtet ohne jeden Zweifel sowohl (a) wie auch (b). Ohne Zweifel wandeln sich Sprachen auch derart, daß sie vom einen Typus zum andern übergehen oder indem sie zwei Regelkriterien zulassen, die allerdings unterschiedlichen regional bestimmten Systemen entstammen. So beobachtet Dimitrova-Vulchanova (1993, S. 23) für das Makedonische Zugehörigkeit zu (c) (CL-Traubenbildung) wie auch (b), ersteres offenbar als Folge der analytischen Entwicklungen innerhalb des Balkansprachbundes (etwa bei Bulgarisch und Rumänisch). (b) im besonderen erlaubt die Verallgemeinerung, daB die strukturelle TOP-Position im Satz von jedem Satzglied eingenommen werden kann, solange sie nur entsprechende Textanknüpfungsfunktionen verkörpern kann. Dies ist ja, wie wir am Englischen leicht ablesen können, nicht in jedem Sprachtypus gegeben (im Englischen etwa kann nur das grammatische Subjekt in dieser TOP-Position stehen; eigene fokussierte Topikalisierungen müssen über Spaltkonstruktionen realisiert werden). Die Wackernagelposition, die vor allem für die alten idg. Sprachstadien beobachtet wurde (Wackernagel 1892), gilt mit Sicherheit für eine große Zahl moderner Sprachen nicht, selbst für das in vieler Hinsicht konservative Deutsch nicht (vgl. Taylor (1993) zum Altgriechischen, das schon aus der Wackernagelverallgemeinerung ausschert). Es wäre sinnvoll, der Frage nachzugehen, ob diese Wackernagelposition als tendenziell optimale CL-Position an bestimmte satzstrukturelle, typologische Eigenschaften geknüpft ist. Es ließe sich bei einer solchen Forschungsstrategie z.B. die Idee verfolgen, daß SOVTypus mit V-Zweit vorliegen muB. Man denke bei diesem Ausgangspunkt an die alten Stadien der romanischen Sprachen wie das Altfranzösische, -italienische, -spanische sowie Altenglisch mit der SOV-Struktur, das im Unterschied zum modernen Französischen CL enklitisch an seinen phonologischen Träger band (Adams 1987, Fontana 1993). DimitrovaVulchanova (1993, S. 23) beobachtet, daB das Makedonische dabei ist, (b) (= Wackernagelbedingung, d.h. rein lineare Festlegung ohne kategoriale Eindeutigkeit) zugunsten des areal beeinflußten (c) aufzugeben.

Allgemein hat sich wieder gezeigt, daß diskursfunktionale Kategorien wie Thema, Rhema, Vorder- und Hintergrund nicht nur direkte Entsprechungen in der syntaktischen Struktur haben, sondern daß sich ihr jeweiliger syntaktisch-struktureller Ort auf der Grundlage einer hinreichend stark differenzierenden und empirisch-distributionellen Eigen-

kategorial als FP, läßt aber nicht erkennen, worin eine allgemeine kontextuelle Identifikation dieser FP bestehen könnte. 
schaften Rechnung tragenden Unterscheidung festlegen läßt. Dies wurde hier vornehmlich fürs Deutsche vorgetragen; aber es besteht begründeter AnlaB, die diskurstechnische Struktur in (34) je nach den eigenen Distributionseigenschaften der einzelnen Sprachen ebenso satzsyntaktisch zu bestimmen.

Dies beschließt meine Ausführungen. ${ }^{19}$ Es sollte deutlich geworden sein, daB diese typologische Exerzitie - sofern ihr irgendein empirischer Wert zukommt - gezeigt hat, daB man typologisch ohne detaillierte Distributionskriterien einer Verallgemeinerung des CL-Ortes gar nicht nachhorchen kann, daB mit anderen Worten typologische Erörterungen auf der Basis der greenbergschen Unterscheidungen alleine zu keinem sinnvollen Ergebnis führen.

\section{Literatur}

Abraham, W. (1988a): Middle constructions in German. In: Groninger Arbeiten zur germanistischen Linguistik 28, S. 25-62.

Abraham, W. (1988b): Vorüberlegungen zur Syntax der Modalpartikeln. In: Linguistische Berichte 118, S. 443-465.

Abraham, W. (1993): Null subjects in the history of German: from IP to CP. In: Lingua 89/2-3, S. 117-142.

Abraham (1992a): The syntax of Thema and Rhema. In: Gilbers, D./ Looyenga, S. (eds.): Language and cognition II. Groningen Yearbook of Linguistics and Cognitive Research. Groningen. S. 1-18.

Abraham, W./Wiegel, A. (1993): Reduktionsformen und Kasussynkretismus bei deutschen und niederländischen Pronomina. In: Abraham, W./Bayer, J. (Hg.): Dialektsyntax. Opladen. S. 12-49.

Abraham, W. (1994): Deutsche Syntax im Sprachenvergleich. Grundlegung einer typologischen Syntax des Deutschen. Tübingen. (Studien zur deutschen Grammatik 41).

Abraham, W. (1995a): Middle constructions in West Germanic. In: Abraham, W./Givón, T./Thompson, S. (Hg.): Discourse grammar and typology. Amsterdam. S. 1-43.

19 Was hinter weiteren Idiosynkrasien wie CL-X-CL-Dopplungen oder CL-XNP-Kopien diskurskausal steht, bleibt im Moment hier ohne Erklārungsversuch (dazu z.B. Dobrovie-Sorin 1994 fürs Rumänische; Shlonsky 1995 fürs Westflämische). Es gilt auf jeden Fall, Argumentpositionen von Nichtargumentpositionen zu unterscheiden. Wahrscheinlich entzieht sich ein Erklärversuch auch dem hier angepeilten diskursfunktionalen Hintergrund, so daß solche Fragen hier gar nicht in erster Linie zu verfolgen sind. Man würde nur eben gerne einen tieferen Grund vermuten wollen, als der bloBe verallgemeinerte BeschreibungsprozeB auf der Grundlage einer rein formal begründeten Landeplatzproliferation herzugeben vermag. 
Abraham, W. (1995b): German cold and male - Dutch warm and female Considerations of a typology of national speaking communities. In: Shannon, Th. F./Snapper, J. (Hg.): Biannual Berkeley Studies in Dutch literature and linguistics. Berkeley, California. S. 171-210.

Abraham, W./Einstein, S./Trainusson, H./Zwart, C.J.W. (in Vorb.) (Hg.): Minimal Ideas. Amsterdam.

Adams, M. (1987): From Old French to the theory of pro-drop. In: Natural Language and Linguistic Theory 5,1, S. 1-33.

Bayer, J. (1984/85): COMP in Bavarian syntax. In: The Linguistic Review 3, S. 209-274.

Belletti, A. (1994): Case checking and clitic placement. Three issues on (Italian/Romance) clitics. In: Geneva Generative Papers 1993, vol. 1/2, S. 101-118.

Cardinaletti, A. (1994): On the internal structure of pronominal DPs. In: The Linguistic Review 11/3-4, S. 195-220.

Cardinaletti, A./Starke, M. (1994): The typology of pronouns. A view from Germanic. Paper Harvard.

Christensen-Koch, Ch. (1985): Subject clitics and A'-bound traces. In: Nordic Journal of Linguistics 8, S. 12-30.

Diderichsen, P. (1962): Elementaer Dansk grammatik. Kopenhagen.

Dimitrova-Vulchanova, M. (1993): Clitics in Slavic. In: Frondheim Working Papers in Linguistics 18, S. 1-50.

Dobrovie-Sorin, C. (1994): The syntax of Romanian. Comparative studies in Romance. Berlin/New York. (Studies in Generative Grammar 40).

Drachman, G. (1994): Some properties of clitics (with special reference to Modern Greek). FAS/Berlin-Vortrag 1994. Paper Univ. Salzburg.

Evans, D.S. (1976): A grammar of Middle Welsh. Dublin.

Ethyrsson, Th. (1994): Functional categories, cliticization, and verb movement in the early Germanic languages. Paper for the Ninth Comparative Syntax Workshop, Harvard University. January 5-6, 1994.

Fanselow, G. (1991): Minimale Syntax. Groningen. (Groninger Arbeiten der germanistischen Linguistik 32).

Farkas, D./Zec, D. (1995): Agreement and pronominal reference. In: G. Cinque/Guisti, G. (Hg.): Advances in Roumanian linguistics. Amsterdam. S. 83-102. (Linguistics Today 10).

Fassi-Fehri, A. (1993): Issues in the structure of Arabic clauses and words. Dordrecht.

Fontana, J.M. (1993): Phrase structure and the syntax of clitics in the history of Spanish. Dissertation Univ. Pennsylvania, Pittsburg.

Givón, T. (1976): Topic, pronoun, and grammatical agreement. In: Li, Ch. (Hg.): Subject and topic. New York, S. 151-188.

Grosu, A. (1994): Three studies in locality and case. London/New York. (Theoretical Linguistics). 
Haegeman, L. (1993): Some speculations on argument shift, clitics, and crossing in West-Flemish. In: Abraham, W./Bayer, J. (Hg.): Dialektsyntax. Opladen. S. 131-160.

Hendrick, R. (1988): Anaphora in Celtic and Universal Grammar. Dordrecht.

Holmberg, A. (1991): The distribution of Scandinavian weak pronouns. In: Riemsdijk, H.v./Rizzi, L. (Hg.): Clitics and their hosts. Univ. of Tilburg.

Kayne, R. (1975): French syntax. Dordrecht.

Lewis, H./Pedersen, H. (1937): A concise comparative Celtic grammar. Gōttingen.

Lenerz, J. (1992): Zur Syntax der Pronomina im Deutschen. Lund. (Sprache und Pragmatik. Arbeitsberichte 29).

Madeira, A. (1992): On clitic placement in European Portuguese. In: UCLWP 4, S. 95-122.

Platzack, Chr. (1988): The emergence of a word-order difference in Scandinavian subordinate clauses. In: Fakete, D./Laubitz, Z. (Hg.): McGill Working Papers in Linguistics: Special issue on Comparative Germanic Syntax, S. 215-238.

Progovac, L. (1993): Clitics in Serbo-Croatian: COMP as the second position. Paper Wayne State University, read at LSA Meeting at Boston (in Sept. 1994).

Rivero, M.-L. (1988): The structure of IP and V-movement in the languages of the Balkans. Paper Univ. Ottawa.

Roberts, I./Shlonsky, U. (1994): Pronominal enclisis in VSO languages. Paper Bangor/Maryland/Geneva. (GLOW presentation 1994, Vienna).

Schachter, Paul (1976): The subject in Philippine Languages: topic, actor, actor-topic, or none of the above. In: $\mathrm{Li}, \mathrm{Ch}$. ( $\mathrm{Hg}$.$) : Subject and topic.$ New York. S. 439-518.

Schafer, R. (1995): Negation and verb-second in breton. In: Natural Language and Linguistic Theory 13, S. 135-172.

Shlonsky, U. (1994): Semitic clitics. In: Geneva Generative Papers 2/1, S. 1-11. (LSA talk 1993).

Shlonsky, U. (1995): Agreement in COMP. In: The Linguistic Review 11/3-4, S. 351-376.

Taylor, A. (1993): A prosodic account of clitic positions in Ancient Greek. Paper Univ. Pennsylvania.

Ternes, E. (1970): Grammaire structural du Breton de l'lle de Groix. Heidelberg.

Thurneysen, R. (1966): A grammar of Old Irish. Dublin.

Uriagereka, J. (1988): On government. Dissertation University of Connecticut, Storrs.

Uriagereka, J. (1995): Aspects of the syntax of clitic placement in Western Romance. In: Linguistic Inquiry 26, 1, S. 79-124.

Vikner, St. (1991): Verb movement and the licensing of NP-positions in the Germanic languages. Dissertation Univ. Genf. 
Wackernagel, J. (1892): Über ein Gesetz der indogermanischen Wortstellung. In: Indogermanische Forschungen 1, S.333-436. 
Morphologische Variation 



\title{
KLAUS-MICHAEL KÖPCKE / DAVID ZUBIN
}

\section{Prinzipien für die Genuszuweisung im Deutschen}

\begin{abstract}
In dem Beitrag wird gegen die Arbitraritätsthese bei der Genuszuweisung im Deutschen argumentiert. Es wird davon ausgegangen, dab das Genus durch phonologische, morphologische und semantische Prinzipien motiviert wird. Solche Prinzipien werden exemplarisch vorgestellt. Es wird auch der $\mathrm{Nachweis} \mathrm{er-}$ bracht, daB die Kategorie Genus semantisch-pragmatisch zum Transport von Bedeutungen ausgenutzt wird. Schlieflich wird in dem Beitrag der Versuch unternommen, das Motivationsniveau für die Genuszuweisung im gesamten nominalen Lexikon zu bestimmen. Zu diesem Zweck wird auf den Begriff „Entropie” zurückgegriffen. Es stellt sich heraus, daB der ermittelte Entropiewert für das Gesamtsystem niedrig ist; d.h., daß der Grad der Ungewißheit für die Genuszuweisung im Deutschen insgesamt nur schwach ausgeprägt ist. Abschließend wird der Grad der Motiviertheit des Genussystems im Deutschen mit anderen nominalen Klassifikationssystemen und deren Motivierungsgrad verglichen.
\end{abstract}

\section{Das Problem}

Die Faszination, die von der Genuszuweisung im Deutschen ausgeht, und zwar für Kinder wie für Erwachsene, ist u.E. in dem sehr einprägsamen Liedchen der Sesamstraße aufgehoben. Da heißt es:

Der, die, das,

Wer, wie, was,

Wieso, weshalb, warum?

Wer nicht fragt, bleibt dumm.

Kinder lieben es, in Spielsituationen das Genus zuzuweisen. Erwachsene fragen sich, ob es nun der oder das Teil, der, die oder das Joghurt heiß, und sie sinnieren darüber, ob die Genusopposition bei der Tag und die Nacht oder die Sonne und der Mond motiviert ist und warum sich innerhalb eines situativen Zusammenhangs, wie etwa dem der Arbeit mit Küchenutensilien, kein einheitliches Genus etabliert hat; man denke an der Löffel, die Gabel und das Messer.

Manchmal bleibt es nicht bei der Faszination allein, etwa wenn 'Der Spiegel' den Ex-Bundespräsidenten Carstens dafür tadelt, die Kleinmut anstatt der Kleinmut gesagt zu haben. Gelegentlich wird die Genusunterscheidung auch für spezifische poetische Wirkungen ausgenutzt, etwa in der von Heinrich Heine beschriebenen Liebesaffäre zwischen einem Fichtenbaum (maskulin) und einer Palme (feminin): 
Ein Fichtenbaum steht einsam

Im Norden auf kahler Höh.

Ihn schläfert; mit weißer Decke

Umhüllen ihn Eis und Schnee.

Er träumt von einer Palme,

Die, fern im Morgenland,

Einsam und schweigend trauert

Auf brennender Felsenwand.

Übersetzungen dieses Gedichts in das Englische geraten langweilig, solche in das Russische, wo beide Bäume feminin klassifiziert sind, oder Französische, wo beide Bäume maskulin klassifiziert sind, erhalten eine etwas eigenartige Konnotation. In allen Fällen wird - und hierauf hat schon Roman Jakobson verwiesen - der von Heine intendierte erotische Beigeschmack verwischt oder völlig geopfert. Offenkundig aber weist der Ansatz der sexus-basierten Herangehensweise an die Genuskategorisation eine Reihe von Problemen auf: Zum einen ist bei dieser Sichtweise eine unkontrollierbar große Anzahl kontextuell stimulierter Bedeutungsvarianten vorauszusetzen, um das Genus eines jeden $\mathrm{x}$-beliebigen Segments des nominalen deutschen Lexikons zu erklären. Zum anderen ist überhaupt nicht klar, was kontextuelle Bedeutungsvarianten mit einer zugrundeliegenden Sexusbedeutung zu tun haben sollen.

Die Enttäuschung darüber, daß die Erwartung einer konsistenten und transparenten semantischen Motivierung der Genuszuweisung sich nicht bestätigen ließ, führte zu der zweiten Herangehensweise in der modernen grammatischen Theoriebildung, nämlich zu der Annahme, die spezifische Genuszuweisung eines Nomens sei arbiträr.

Das Problem, ob die Mitgliedschaft eines spezifischen Nomens konzeptuell motiviert ist oder arbiträr erfolgt, kann in der sprachwissenschaftlichen Forschung auf eine mittlerweile ganz beachtliche Tradition zurückblicken, vgl. etwa Royen (1929), Fodor (1959), Wienold (1967), Köpcke (1982), Claudi (1985) und Zubin/Köpcke (in Vorb.). Grimm (1831) verfolgte bei seinen Überlegungen zum Genus die Grundidee, daß dem grammatischen Geschlecht sprachhistorisch die Kategorie Sexus vorausgegangen sei. Als Ergebnis eines „gigantischen Metaphorisierungsprozesses” (Leiss 1994) wird ausgehend von Bezeichnungen für Menschen auch die gesamte unbelebte Welt sexualisiert.

„Das grammatische genus ist...eine in der phantasie der menschlichen sprache entsprungene ausdehnung des natürlichen auf alle und jede gegenstände.” (S. 345). „Das maskulinum scheint das frūhere, größere, festere, sprōdere, raschere, das thätige, bewegliche, zeugende; das femininum das spätere, kleinere, weichere, stillere, das leidende, empfan- 
gende; das neutrum das erzeugte stoffartige, generellere, unentwickelte, collektive." (Grimm 1831, S. 359)

Die Charakterisierung des Genus als metaphorische Ausdehnung von Geschlechtscharakteristika ist empirisch nicht haltbar, weder für das Deutsche noch für irgendeine andere indoeuropäische Genus-Sprache.

Die Position der Junggrammatiker auf die eher romantisierenden Überlegungen Grimms verfiel in das andere Extrem. Brugmann (1889) vertrat die Ansicht, daß Sexus von Genus abgeleitet worden ist und nicht umgekehrt und daB die Genuskategorisation, abgesehen von Geschlechtsunterscheidungen bei Bezeichnungen für Menschen jeglicher semantischer Basis entbehrt. Die Genuskategorien selbst würden ursprünglich auf die morpho-phonetische Form der Nomina zurückgehen. Viele dieser genusanzeigenden formalen Merkmale seien jedoch im Laufe der Jahrhunderte verlorengegangen.

Die Brugmannsche Position hat in der modernen Linguistik weite Anerkennung gefunden. Forschungen über die Kategorie Genus waren vor diesem Hintergrund dann auch meist auf morphologische und syntaktische Aspekte des Systems beschränkt, vgl. etwa Werner (1975), Hyman (1980) und Corbett (1988). In der modernen Linguistik werden nominale Klassifikationssysteme und insbesondere das Genus manchmal geradezu als paradigmatische Beispiele für die Arbitrarität der sprachlichen Struktur schlechthin analysiert.

Wir werden in diesem Aufsatz in partieller Übereinstimmung mit der Grimmschen Position versuchen zu zeigen, daß im nominalen Lexikon Wortfelder existieren, deren Genuszuweisung semantisch motiviert ist. Hierbei handelt es sich jedoch letztlich nicht um sexus-basierte Charakteristika. Neben den semantischen Mustern werden wir produktive formale Muster für die Genuszuweisung nachweisen. Schließlich wollen wir zeigen, daß im Lexikon Felder existieren, deren Genuszuweisung weder mit semantischen noch formal motivierten Mustern harmonieren. Insgesamt meinen wir beweisen zu können, daß die Genuszuweisung im Deutschen doch in bemerkenswertem Maße semantischen und formalen Organisationsprinzipien unterworfen ist. Dies wäre dann unsere Entgegnung auf die Brugmannsche Position, der sich auch heute noch viele „moderne” Linguisten verpflichtet fühlen.

\section{Prinzipien der Genuszuweisung}

\subsection{Formale Prinzipien}

Arbitrarität wird gemeinhin für die monomorphematischen Nomina angenommen. Für derivierte Nomina ist bekannt, daB mit den meisten 
Derivationssuffixen eine kategorische Genuszuweisung einhergeht; Femininum etwa bei -ung und -heit/keit, Maskulinum etwa bei -ling und Neutrum z.B. bei dem Zirkumfix ge-.-e. Die monomorphematischen Nomina sind noch einmal in polysyllabische und monosyllabische Nomina aufzuspalten. Bei den polysyllabischen Nomina korreliert eine spezifische Endung mit einer Genuszuweisung, etwa das auslautende Schwa mit dem Femininum (Typ Kurve) oder auslautendes -en mit dem Maskulinum (Typ Wagen) oder dem Neutrum, sofern Nullableitungen aus Infinitiven, also derivierte Nomina vorliegen (Typ das Essen). Das Problem reduziert sich damit gewissermaßen auf die Genuszuweisung zu den monosyllabischen Nomina.

Exemplarisch für formale genuszuweisende Prinzipien soll zunächst ein allgemeines Prinzip, das sogenannte Konsonantenhäufungsprinzip, vorgestellt werden. In AnschluB daran geht es um vier phonologische Prinzipien, die deutliche Korrelationen mit der Genuszuweisung aufweisen.

Das Konsonantenhäufungsprinzip besagt, daß mit steigender Konsonantenzahl im Onset und in der Koda eines monosyllabischen Nomens die Tendenz einer maskulinen Genuszuweisung zunimmt, vgl. auch $\mathrm{Zu}$ bin/Köpcke (1981) und Köpcke (1982). Tabelle 1 zeigt, daß der prozentuale Anteil der maskulin klassifizierten Nomina kontinuierlich mit zunehmender Konsonantenzahl in prävokalischer oder postvokalischer Position ansteigt.

Tabelle 1: Korrelation zwischen der Anzahl der Konsonanten und der Genuszuweisung bei monosyllabischen Nomina

\begin{tabular}{|l|l|c|l|l|}
\hline a) & Konsonaten & $\begin{array}{l}\text { Nomina } \\
\text { insgesamt }\end{array}$ & $\begin{array}{l}\text { davon Mask. } \\
\text { in Prozent }\end{array}$ & Beispiele \\
& 0 & 57 & 46 & Axt, Eis \\
& 1 & 853 & 59 & Mast, Tür \\
& 2 & 505 & 73 & Spaß, Brief \\
3 & 51 & 82 & Sproß, Strumpf \\
& & & & \\
\hline \multirow{3}{*}{ Konsonaten } & & & \\
& Konder Koda & & & \\
& in der & 77 & 43 & Schuh, Brei \\
& 0 & 753 & 63 & Schuß, Tür \\
& 1 & 503 & 74 & Schutz, Halt \\
& 2 & 73 & 77 & Schurz (surts/) \\
3 & 4 & - & Arzt (/artst/) \\
\hline
\end{tabular}


Neben diesem unabhängig von spezifischen Lautwerten wirkenden Prinzip gibt es eine Reihe spezifischer phonologischer Regelmäßigkeiten für die monosyllabischen Nomina, für die Korrelationen mit der Genuszuweisung nachgewiesen werden können.

(1) $[\mathrm{kn}$ \#] $\rightarrow$ Mask.

Distribution: m: 14, f: 0, n: 1; andere Prinzipien: 0, Total: 15.

(2) $\left[\breve{s}+K_{-} \#\right] \rightarrow$ Mask.

Distribution: $\mathrm{m}$ : 144, f: $2, \mathrm{n}: 8$; andere Prinzipien: 13; Total: 167.

(3) [\#_Nasal(m, n, $\eta)+\mathrm{K}] \rightarrow$ Mask.

Distribution: m: 75, f: 4, n: 11; andere Prinzipien: 17; Total: 107.

(4) [\#_(K) + Frikativ $(f, c, x)+t] \rightarrow$ Fem.

Distribution: $\mathrm{m}: 4, \mathrm{f}: 35, \mathrm{n}$ : 0; andere Prinzipien: 16; Total: 55.

Die unter (1) und (2) abgedruckten Prinzipien operieren über den Anlaut, die Prinzipien unter (3) und (4) über die Koda. Wie die Prinzipen zu lesen sind, soll exemplarisch an (4) vorgeführt werden: Es gilt mit großer Wahrscheinlichkeit die feminine Genuszuweisung, sofern die Koda eines monosyllabischen Nomens auf Frikativ plus VerschluB auslautet. Diesem Auslautcluster kann fakultativ ein weiterer Konsonant vorausgehen. Prinzip (4) trifft auf insgesamt 55 monosyllabische Nomina zu; darunter finden sich 35 Feminina, wie etwa Frucht, Luft, Kluft, Schicht, und 4 als Ausnahmen zu wertende Maskulina. 16 Nomina erhalten ihr Genus aufgrund anderer, insbesondere semantischer Prinzipien, etwa bei Bezeichnungen für Menschen wie der Knecht, der Wicht.

Die eigentlich interessante Frage lautet nun, ob und wie diese und ähnliche Prinzipien mental repräsentiert sind, ob ihnen also so etwas wie eine psychologische Realität zugeschrieben werden darf. Wir haben hierzu ein Experiment mit erwachsenen Sprechern des Deutschen durchgeführt, vgl. Köpcke/Zubin (1983). Die Sprecher hatten die Aufgabe, Kunstwörtern, die der deutschen Phonotaktik entsprachen, ein Genus zuzuweisen. Die Kunstwörter wurden mit jeweils zwei Genusalternativen vorgelesen, dabei wurde sowohl die Wahl der Genusalternativen selbst wie auch ihre Reihenfolge systematisch ausgetauscht. Für das Konsonantenhäufungsprinzip und die phonologischen Prinzipien (1) bis (4) gelten die in Tabelle 2 abgedruckten Ergebnisse. 
Tabelle 2: Ergebnisse des Kunstwortexperiments für das Konsonantenhäufungsprinzip und die phonologischen Prinzipien (1) bis (4)

\begin{tabular}{|c|c|c|c|c|c|c|c|}
\hline & Muster & $\begin{array}{l}\text { beteiligte } \\
\text { Muster }\end{array}$ & $\begin{array}{l}\text { Test- } \\
\text { wörter }\end{array}$ & $\overline{\text { Prognose }}$ & $\begin{array}{c}\text { Gen } \\
+\end{array}$ & zuw. & $\begin{array}{c}\text { \%-Anteile } \\
\text { der } \\
+F \text { ālle }\end{array}$ \\
\hline (1) & $\begin{array}{l}{\left[\mathrm{kn} \_\#\right]} \\
{\left[s+K_{-\#]}\right.}\end{array}$ & $\begin{array}{l}1 \\
1\end{array}$ & $\begin{array}{l}4 \\
4\end{array}$ & $\begin{array}{l}\mathbf{m} \\
\mathbf{m}\end{array}$ & $\begin{array}{l}29 \\
24\end{array}$ & $\begin{array}{l}11 \\
16\end{array}$ & $66 \%$ \\
\hline $\begin{array}{l}\text { (2) } \\
\text { (3) }\end{array}$ & $\begin{array}{l}\text { [KK_KK] } \\
{\left[\mathrm{kn \_ KK}\right]} \\
{\left[\xi+K \_K K\right]}\end{array}$ & $\begin{array}{l}1 \\
2 \\
2\end{array}$ & $\begin{array}{l}4 \\
2 \\
2\end{array}$ & $\begin{array}{l}\mathbf{m} \\
\mathbf{m} \\
\mathbf{m}\end{array}$ & $\begin{array}{l}27 \\
\\
15 \\
14\end{array}$ & $\begin{array}{r}13 \\
5 \\
6\end{array}$ & $68 \%$ \\
\hline (4) & $\begin{array}{l}{\left[\mathrm{kn} \_N a s+K\right]} \\
{\left[\xi+\mathrm{K} \_\mathrm{Nas}+\mathrm{K}\right]}\end{array}$ & $\begin{array}{l}3 \\
3\end{array}$ & $\begin{array}{l}2 \\
2\end{array}$ & $\begin{array}{l}\mathbf{m} \\
\mathbf{m}\end{array}$ & $\begin{array}{l}15 \\
17\end{array}$ & $\begin{array}{l}5 \\
3\end{array}$ & $80 \%$ \\
\hline (5) & $\begin{array}{l}{[\#-f t]} \\
{[\#-x t]}\end{array}$ & $\begin{array}{l}1 \\
1 \\
\end{array}$ & $\begin{array}{l}2 \\
2 \\
\end{array}$ & $\begin{array}{l}\mathrm{f} \\
\mathrm{f}\end{array}$ & $\begin{array}{l}14 \\
15 \\
\end{array}$ & $\begin{array}{l}6 \\
5 \\
\end{array}$ & $73 \%$ \\
\hline
\end{tabular}

Alle in der Tabelle abgedruckten Ergebnisse sind signifikant, die für die Zeilen (1) und (2) auf dem .05 Niveau und die für die Zeilen (3) bis (5) auf .01 Niveau. Die Prognosen werden also von den Versuchspersonen eingelöst. Am interessantesten an diesen Ergebnissen ist aber die Beobachtung, daß die Prinzipien offenbar kumulieren können. Während für die beiden ersten Zeilen, die jeweils die Anwendung nur einer Regel in (1) bzw. des Konsonantenhäufungsprinzips in (2) betreffen, nur Werte von $66 \%$ und $68 \%$ erzielt werden, steigt in Zeile (3) der prozentuale Anteil der entsprechend zur Prognose getroffenen Entscheidungen der Versuchspersonen auf $73 \%$ an. Bei den Kunstwörtern der Zeile (3) sind immer zwei Prinzipien beteiligt, nämlich die Anlautprinzipien aus Zeile (1) und das Konsonantenhäufungsprinzip aus Zeile (2). Die Testitems der vierten Zeile vereinigen drei Prinzipien auf sich, nämlich zusätzlich zu den eben genannten noch das Auslautprinzip 'Nasallaut + Konsonant'. Wiederum steigt der prozentuale Anteil der entsprechend zur Prognose getroffenen Entscheidungen an, und zwar auf nunmehr 80\%. Die Ergebnisse in Zeile (5) zeigen, daß das Auslautprinzip 'Frikativlaut + Ver- 
schluB', mit dem die feminine Genuszuweisung assoziiert wird, dieselbe Stärke aufweist, wie die Kumulation zweier Prinzipien in (3). Überhaupt gilt ganz generell, daB Auslautprinzipien insgesamt etwas bessere Ergebnisse erzielen als Anlautprinzipien, vgl. Köpcke/Zubin (1983). Für den Fall einer Konkurrenz zwischen einem Anlaut- und Auslautprinzip obsiegt im allgemeinen das Auslautprinzip, etwa bei Schrift, wo trotz des maskulinen Anlauts $\left(\left[\breve{s}+K_{-} \#\right] \rightarrow m\right)$ das Femininum gilt. Offensichtlich erscheint es vor dem Hintergrund dieser Ergebnisse gerechtfertigt, den Prinzipien psycholinguistische Realität zuzuschreiben.

\subsection{Semantische Prinzipien}

Nachfolgend soll es wieder um natürliche Nomina gehen, also solche, die nicht nur eine Ausdrucks- sondern auch eine Inhaltsseite haben. Wir kommen damit zu den semantischen Charakteristika der Nomina und einer damit einhergehenden Genuszuweisung. Die Klassifikation der Nomina auf der Grundlage semantischer Eigenschaften ist selbstverständlich nicht durch ausdrucksseitige Merkmale der Nomina beschränkt; die folgenden Prinzipien beziehen sich demzufolge nicht nur auf monosyllabische Nomina.

Es ist allgemein bekannt, daß mit einem auslautenden Schwa, sofern die obliquen Kasus nicht auf /n/gebildet werden, wie etwa bei der Junge des Jungen, fast immer das Femininum assoziiert wird. Allerdings ist es keineswegs immer der Fall, daB ein spezifisches auslautendes Segment, auch wenn es häufig auftritt, immer mit einer spezifischen Genuszuweisung zusammenfällt. Dies soll beispielhaft an den Nomina vorgeführt werden, die ausdrucksseitig mit unbetontem /i/ auslauten, etwa das Kali, der Chianti, das Maori und die Kiwi. Obwohl im Lexikon etwas mehr als 200 Nomina diesen Auslaut aufweisen, ist die Distribution der Nomina über die drei Genera weit davon entfernt, einheitlich zu sein. Es gilt: $m=97, f=27$ und $n=79$. Eine genauere Analyse der Nomina zeigt jedoch, daß fast alle durch semantische Prinzipien erklärt werden können. U.a. sind die folgenden semantischen Prinzipien hier von Bedeutung (ausführlicher hierzu Zubin/Köpcke (in Vorb.)):

(1) Prinzip des natürlichen Geschlechts $\rightarrow \mathrm{m} / \mathrm{f}$

Beispiele: Rabbi, Bubi, Kadi, Mutti, Omi, Lady, wie auch solche ohne unbetontes /i/ im Auslaut, etwa Knecht, Mann, Frau, Braut usw.

(2) Bezeichnungen für alkoholische Getränke $\rightarrow \mathrm{m}$

Beispiele: Martini, Chianti, Brandy, wie auch solche ohne unbetontes /i/ im Auslaut, etwa Schnaps, Wodka, Sekt usw. 
(3) Bezeichnungen für chemische Grundstoffe und Substanzen $\rightarrow \mathbf{n}$ Beispiele: Kali, Alkali, wie auch solche ohne unbetontes /i/ im Auslaut, etwa Brom, Eisen, Chlor usw.

(4) Bezeichnungen für Spiele $\rightarrow$ n

Beispiele:Hobby, Derby, Hockey, wie auch solche ohne unbetontes /i/ im Auslaut, etwa Schach, Halma, Whist usw.

(5) Bezeichnungen für kalendarische Angaben $\rightarrow \mathrm{m}$

Beispiele: Juni, Juli, wie auch solche ohne unbetontes /i/ im Auslaut, etwa Januar, Herbst, Winter, Mittwoch usw.

(6) Bezeichnungen für Farben $\rightarrow \mathrm{n}$

Beispiele: Khaki, Uni, wie auch solche ohne unbetontes /i/ im Auslaut, etwa Rot, Gelb, Ocker, Azur usw.

(7) Bezeichnungen für Früchte $\rightarrow f$

Beispiele: Kiwi, Peperoni, wie auch solche ohne unbetontes /i/ im Auslaut, etwa Birne, Mango, Melone usw.

(8) Bezeichnungen für Sprachen $\rightarrow \mathbf{n}$

Beispiele: Pali, Maori, Hindi, wie auch solche ohne unbetontes /i/ im Auslaut, etwa Deutsch, Schwedisch usw.

Wie eben gezeigt, muß eine spezifische Endung nicht notwendig mit einer einheitlichen Genuszuweisung einhergehen. Analog kann es sich auch für Nomina verhalten, die demselben semantischen Feld angehören. Intuitiv würde man in einem soichen Fall eine einheitliche Genusklassifikation erwarten. Auch dies triftt nicht immer zu: Nomina, die beispielsweise das semantische Merkmal „Körperteilbezeichnung” miteinander teilen, haben keineswegs alle ein übereinstimmendes Genus.

Tabelle 3: Genuszuweisung bei Körperteilbezeichnungen

\begin{tabular}{|l|l|l|}
\hline maskulin & feminin & neutral \\
\hline Arm, Finger, & Brust, Nase, & Auge, Haar, \\
Nerv, Knochen, & Faust, Wange, & Becken, Knie, \\
Zeh, Mund, & Hand, Scham, & Bein, Kinn, \\
Zahn, Schwanz usw. & Stirn, Schulter usw. & Ohr, Herz usw. \\
\hline
\end{tabular}

Bei den Nomina dieser Aufzählung handelt es sich ausnahmslos um Mitglieder des Kernwortschatzes. Interessanterweise verletzen viele der genannten Nomina formale Prinzipien. So gilt etwa für die Stirn sowohl das Konsonantenhäufungsprinzip wie auch das oben vorgestellte phonologische Prinzip (2). Aufgrund dieser beiden Prinzipien hätte hier statt des Femininums das Maskulinum gelten müssen. Für die Hand gilt das schon genannte phonologische Prinzip (3), demzufolge dieses Nomen eigentlich 
ebenfalls maskulin klassifiziert sein soltte und für das Auge schließlich gilt, daß Schwa-Auslauter feminin sein sollten. Wahrscheinlich können diese Nomina ihr spezifisches, in gewissem Sinne abweichendes Genus nur konservieren, weil sie sehr frequent sind, täglich verwendet und zudem im Spracherwerb früh erworben werden. In diesem Sinne handelt es sich bei diesen Nomina um Mitglieder des Kernwortschatzes. Zudem sollte nicht vergessen werden, daB es eine der wesentlichen Funktionen des Genus ist, Eindeutigkeit bei der pronominalen Referenz zu gewährleisten. Die textverweisende und Kohärenz sichernde und ermöglichende Funktion des Genus macht es gerade bei solchen Wortfeldern, für die man vermuten kann, daB in einer kommunikativen Situation im allgemeinen auf mehr als ein Mitglied verwiesen wird, sinnvoll, möglichst große Heterogenität anstatt Homogenität bei der Genuskategorisation zu haben. Erst so wird effektive pronominale Referenz ermöglicht, vgl. hierzu Köpcke/Zubin (1984).

Nachfolgend soll es um Bezeichnungen für Menschen gehen, wir greifen damit die eingangs vorgestellte Auffassung von Grimm über die Einheit von Sexus und Genus wieder auf, vgl. ausführlich hierzu Zubin/Köpcke (in Vorb.). Gerade die defektive Korrespondenz zwischen Sexus und Genus, wie etwa bei das Mädchen und das Weib, muB immer wieder als Evidenz für die vermeintliche semantische Arbitrarität bei der Genuszuweisung im Deutschen herhalten. Ausgangspunkt für unsere Überlegungen soll das Prinzip des perzipierten Geschlechts sein. Dieses Prinzip ist in zwei Teile untergliedert und besagt folgendes:

1. Wenn ein Nomen noch keine stabile Genuszuweisung erhalten hat, etwa bei spontanen Entlehnungen, der Referent aber als weiblich bzw. männlich wahrgenommen wird, dann wird das feminine bzw. maskuline Genus zugewiesen.

2. Wenn der Referent als Mensch perzipiert wird und gleichzeitig nicht hinsichtlich des natürlichen Geschlechts unterschieden wird, dann erfolgt die maskuline Genuszuweisung.

In dieses Prinzip des perzipierten Geschlechts sind auch Nomina mit abweichender Genuszuweisung eingebettet, die sich jedoch zu spezifischen semantischen Gruppen zusammenschlieBen. Bei der Diskussion von Abbildung 1 soll von der Verzweigung nach rechts zu den Verwandtschaftsbezeichnungen abgesehen werden; hier werden kategorisch das Femininum und das Maskulinum entsprechend zum natürlichen Geschlecht des Referenten zugewiesen. 
Abbildung 1: Genuszuweisung bei Bezeichnungen für Menschen

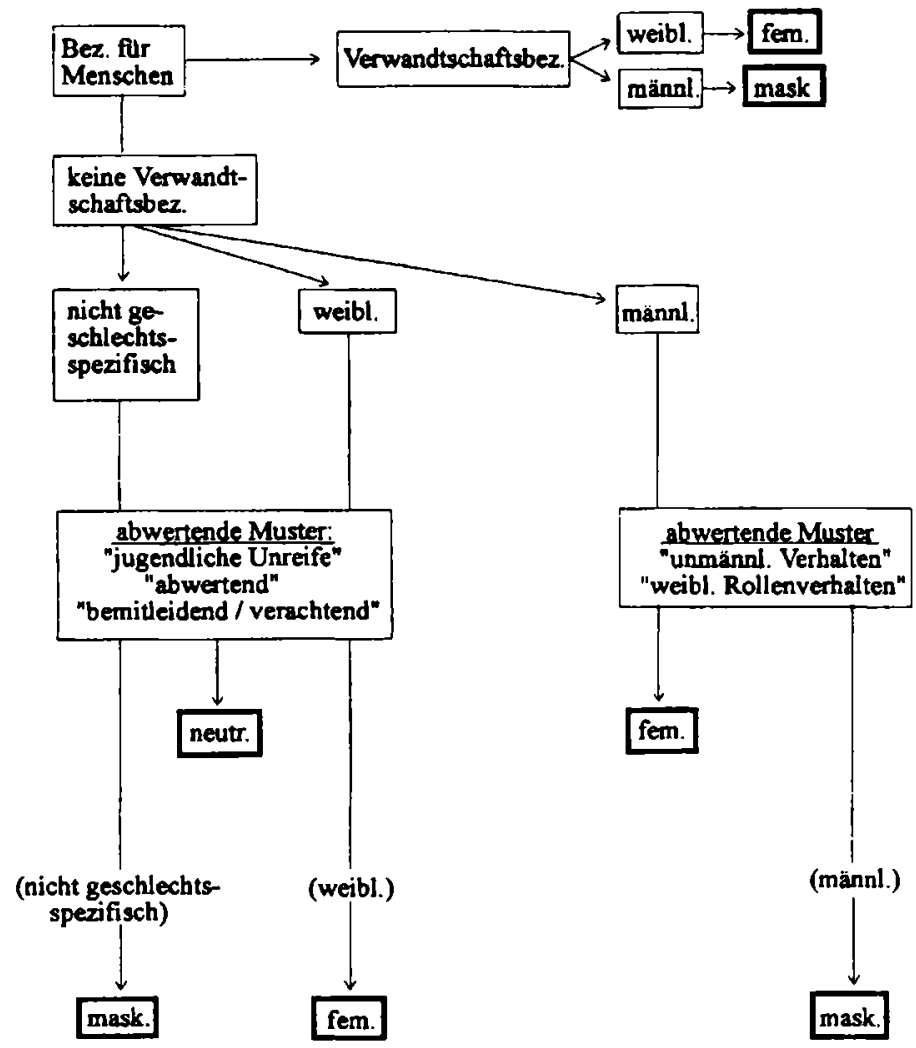

Für Nomina, bei denen es sich nicht um Verwandtschaftsbezeichnungen handelt und die auf Menschen referieren, ohne explizit das natürliche Geschlecht zu kennzeichnen, gilt das Maskulinum, etwa der Professor, Beamte, Spion, Nachbar, Gast, Feind. Solche Nomina, die gerade das natürliche Geschlecht des Referenten kennzeichnen sollen, werden entsprechend hierzu als Maskulinum oder Femininum klassifiziert, z.B. der Mann, Greis, Kerl bzw. die Frau, Dame, Braut. Dieses Prinzip findet ebenfalls Anwendung für Nomina, die auf Frauen in ihrer beruflichen Eigenschaft referieren. Hier kann, muß aber nicht in allen Fällen ein De- 
rivationssuffix auftreten: die Beamtin, Sekretärin, Ärztin aber Nonne, Magd, Krankenschwester.

Neben diesen sehr transparenten Prinzipien gibt es eine Reihe anderer, bei denen immer das Konzept der Abwertung auftritt, vgl. Mathiot (1979). Die neutralen Pejorativa für Frauen sind Nomina mit herabsetzender oder bemitleidender Bedeutung, etwa das Weib, das Mensch, das Frauenzimmer. Bedeutsam ist die Tatsache, daB Nomina, die auf Männer, Jungen, Verwandtschaftsverhältnisse und Frauen in ihrer sexuellen Funktion referieren, niemals eine Abwertung via Genuszuweisung erfahren. Darüber hinaus wird das Neutrum bei Bezeichnungen für Kinder gebraucht, um „Unreife” zu signalisieren, etwa das Kind, das Baby, das Wurm. Wenn spezifisch Männer einem abwertenden Muster unterworfen werden sollen, dann geschieht dies niemals durch das Neutrum; sehr wohl aber gibt es eine Reihe Feminina, die sich auf Männer beziehen, die „unmännliche" Verhaltensweisen zeigen: die Tunte, die Schwuchtel, die Memme.

Insgesamt sollte deutlich geworden sein, daB das Genus in spezifischen Kontexten Bedeutung transportiert, etwa wenn bei Bezeichnungen für Menschen abwertende Konnotationen impliziert sind. Es sei in diesem Zusammenhang noch einmal an das eingangs schon erwähnte Gedicht von Heinrich Heine erinnert.

Die These, daß die Kategorie Genus semantisch-pragmatisch dafür ausgenutzt wird, Bedeutungen zu transportieren, läßt sich auch bei der Klassifikation der belebten Welt in Relation zum Menschen bestätigen. Grundlage für die nachfolgende Diskussion ist das ethnozoologisch oder anthropozentrisch organisierte Kontinuum in Abbildung 2, vgl. ausführlicher Zubin/Köpcke (in Vorb.). 
Abbildung 2: Ethnozoologisches (anthropozentrisches) Kontinuum. $\left(\mathrm{m}^{*} / \mathrm{f}\right.$ zeigt an, daß das Mask. das Default-Genus ist. Das heiBt aber nicht, daß die Anzahl der Maskulina hier dominiert.)

maximal

menschenāhnlich

geringste Āhnlichkeit

menschenahnich

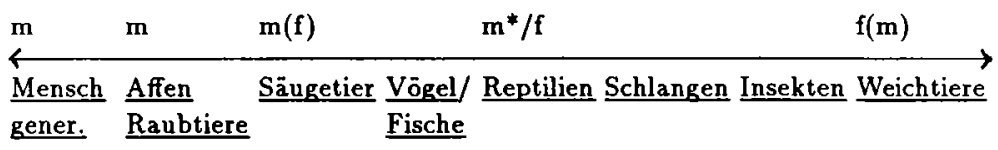

Zeuge Schimp. Elephant Fasan Alligator Viper Hummel Assel Nachbar Makak Hamster Specht Lurch Python Laus Schnecke Athlet Orang-U. Fuchs Barsch Frosch Kobra Fliege Krake

$(\mathrm{m} / \mathrm{f})$

$\begin{array}{llll}\text { Giraffe } & \begin{array}{l}\text { Lerche Unke } \\ \text { Taube Echse }\end{array} & \text { Käfer } & \text { Egel } \\ & & \end{array}$

Das Kontinuum zeigt einen allmählichen Wechsel von der dominant maskulinen Genuszuweisung hin zur dominant femininen, und zwar in dem Maße, wie bei der Bezeichnung von Tieren mit dem Menschen gemeinsame Charakteristika in den Hintergrund treten. Solange generische $\mathrm{Be}-$ zeichnungen für Menschen und Bezeichnungen für Affen und Raubtiere vorliegen, wird maskulin klassifiziert; bei Säugetieren überwiegt das Maskulinum, jedoch tritt gelegentlich das Femininum auf. Hierbei handelt es sich meist um Nomina auf Schwa im Auslaut. Sehr viel häufiger erscheint das Femininum bei Bezeichnungen für Vögel, Fische und Reptilien. Für diese Gruppen ist das Maskulinum das Default-Genus, da alle Nomina dieser Gruppen, die ein hiervon abweichendes Genus aufweisen, spezifisch phonologisch markiert sind, etwa durch Schwa, wie bei Unke und Echse oder durch -il, wie bei das Krokodil. Bei Bezeichnungen für Schlangen, Insekten und Weichtiere, also im Bereich der Peripherie des ethnozoologischen Kontinuums, ist das Femininum das dominante Genus. Nur vereinzelt finden sich hier noch Maskulina. Vor dem Hintergrund der allgemeinen Annahme, daß das Genus in spezifischen Kontexten als bedeutungstragende Kategorie ausgenutzt wird, kann nun als Generalisierung über einige hundert Nomina hinweg festgehalten werden, daß das Deutsche im Kontext der Klassifikation der belebten Welt das Femininum dafür ausnutzt, um Distanz zum Menschen auszudrücken. Kormplementär hierzu dient das Maskulinum dazu, Nähe zum Menschen auf einem anthropozentrischen Kontinuum zu signalisieren. 
Soviel zu den Prinzipien für die Genuszuweisung im Deutschen. Insgesamt meinen wir zeigen zu können, daB die Genuszuweisung keinesfalls arbiträr ist, allerdings ist sie auch nicht, wie Grimm glaubte, auf eine Grundopposition von männlich/weiblich zurückzuführen. Vielmehr ist davon auszugehen, daB im nominalen Lexikon so etwas wie ein semantischer Kern und eine Vielzahl formal oder semantisch motivierter Felder existieren. Für manche der semantisch motivierten Felder läßt sich nachweisen, daB die Kategorie Genus dafür ausgenutzt wird, Bedeutung zu transportieren.

\section{Zur Bestimmung des Motivierungsgrades für das Gesamtlexikon}

Nach diesen „Tiefbohrungen” in die motivationale Struktur der Genuszuweisung im Deutschen ist natürlich zu fragen, wie charakteristisch die beschriebenen motivationalen Eigenschaften für das Gesamtsystem sind. Manche Sprachen, wie etwa das Englische, haben ein nominales Klassifikationssystem, das semantisch in dem Sinne transparent ist, daß die Nomina auf der Grundlage ihrer zentralen Bedeutung der he-, sheoder it-Klasse zugewiesen werden. Andere Sprachen, wie etwa das Spanische, sind entlang eines morphologisch transparenten Systems organisiert, da hier die meisten Nomina auf der Basis phonologischer Merkmale des Stammes dem Maskulinum oder Femininum zugeordnet werden können. Im Deutschen gibt es für die nominale Klassifikation ein erheblich reduzier teres Motivationsniveau. Weder aber ist das Genus eines Nomens immer völlig vorhersagbar, noch ist die Genuszuweisung arbiträr. Das Verhältnis von Motiviertheit einerseits und Arbitrarität andererseits schwankt, je nachdem in welchem spezifischen Teil des nominalen Lexikons man sich gerade befindet. Benötigt wird also ein Maß für den Grad der Ungewißheit hinsichtlich der Genuszuweisung, und zwar nicht nur hinsichtlich spezifischer lexikalischer Felder, sondern über das gesamte nominale Lexikon hinweg betrachtet. Wir haben uns dazu entschlossen, in diesem Zusammenhang von "Entropie” zu sprechen.

Ein geringer Grad an Entropie, also keine Ungewißheit hinsichtlich der Klassifikation, liegt vor, wenn das Genus aufgrund produktiver Prinzipien zugewiesen wird, wie etwa im Spanischen. Wir wollen in einem solchen Fall den Wert "5" zuweisen. Auch im nominalen Lexikon des Deutschen gibt es solche Segmente, beispielsweise die Derivationssuffixe und die damit häufig einhergehende Genuszuweisung.

Etwas weniger gering ist der Entropie-Wert, wenn es sich um die Klassifikation großer semantischer Felder handelt, für die nur begrenzte Produktivität gilt und innerhalb derer auch einige Ausnahmen nachgewiesen 
werden können. Man denke etwa an die Klassifikation von Früchten, die zwar im allgemeinen feminin ist, zu der aber auch Ausnahmen existieren, nämlich $A p f e l$ und Pfirsich. In diesen Fällen soll der Wert "vier” gelten.

Höher ist der Entropie-Wert, wenn es sich um größere Cluster von Nomina handelt, etwa um Bezeichnungen für offene Wasserflächen, die zu femininer Klassifikation tendieren. Es gibt aber eine Reihe von Ausnahmen und der Produktivitätsgrad ist vergleichsweise gering. Der Grad der Ungewißheit hinsichtlich der Genusklassifikation nimmt zu. Wir vergeben hier den Wert "drei”.

Der Wert „zwei” wird zugewiesen, wenn es sich um kleinere Cluster handelt und ein Default-Genus in einem gemischtklassifizierten Feld zugewiesen wird, etwa das Maskulinum bei Vogelnamen. Die Unsicherheit bei der Genuszuweisung ist in solchen Fällen schon relativ groß.

Ein hohes $\mathrm{MaB}$ an Entropie, und damit Ungewißheit gilt, wenn die Genuszuweisung lediglich auf der Basis von Analogien vorgenommen wird, etwa der/das Juwel zu der Edelstein bzw. das Schmuckstück. In solchen Fällen soll der Wert „eins” gelten.

Der höchste Entropie-Wert, wir vergeben hier eine „null”, liegt schließlich vor, wenn für die Genuszuweisung eines Nomens überhaupt keine motivationale Basis mehr nachgewiesen werden kann. Hier herrschte dann das Chaos, die Genuszuweisung wäre arbiträr.

Das AusmaB der Entropie im Gesamtsystem haben wir durch die Analyse von zwei Querschnitten durch das gesamte nominale Lexikon bestimmt. In einem ersten Querschnitt, bei dem jeweils der erste nominale Eintrag auf jeder Seite des Duden-Universalwörterbuchs gezählt wurde, wurde die Bedeutung der Morphologie bestimmt. Ergebnis: In nahezu $65 \%$ aller Fälle reduziert sich das Problem der Genuszuweisung auf die genuszuweisenden Eigenschaften einer relativ kleinen Anzahl von Derivationsaffixen.

Der zweite Querschnitt setzte sich aus den zurückgebliebenen Simplizia des ersten Querschnitts zusammen. Hier wurden nun durch die Anwendung der oben vorgestellten und ähnlicher Zuweisungsprinzipien für jedes Nomen die Entropie-Werte ermittelt. Der Beitrag, den die einzelnen Nomina zur Gesamtentropie des Systems beitragen, ist sehr unterschiedlich. Das Genus mancher Nomina ist aufgrund eines Summeneffekts verschiedener genuszuweisender Prinzipien hochgradig determiniert, etwa der Knall durch die Addition des semantischen Merkmals „punktuell” mit dem oben vorgestellten Anlautprinzip / kn/. Beide Effekte sorgen für eine maskuline Genuszuweisung und in diesem Fall für sehr niedrige 
Entropie. Für manche Nomina konnten keine Prinzipien gefunden werden, und gelegentlich operierten die Prinzipien sogar entgegen der im Lexikon festgelegten Genuszuweisung. Andererseits jedoch, und dies ist weitere Evidenz für die Tragfähigkeit unserer Prinzipien, korrespondieren solche Fälle meistens mit einer Genusschwankung. Insgesamt können wir die Genuszuweisung von gut $90 \%$ des nominalen Wortschatzes mehr oder weniger verläßlich erklären. Hinsichtlich der Gesamtentropie für die Simplizia des Lexikons haben wir den Wert "4" ermitteln können. Dieser Wert rangiert auf dem zweiten der oben beschriebenen Niveaus. Mit anderen Worten, der Entropiewert für das Gesamtsystem ist niedrig, damit ist der Grad der Ungewißheit für die Genuszuweisung im Deutschen nur schwach ausgeprägt. Das System der Genuszuweisung im Deutschen ist somit, wenn wir uns ein Kontinuum mit den beiden Extrempunkten determiniert einerseits und chaotisch andererseits vorstellen, sehr viel näher am Determinismus als am Chaos.

\section{Bemerkungen zur typologischen Einordnung des Genus im Deutschen}

Welche typologischen Gemeinsamkeiten und Unterschiede gibt es nun $z$ wischen einem Genussystem und anderen nominalen Klassifikationssystemen? Eine mögliche Antwort auf diese Frage erhielte man sicherlich bei der Gegenüberstellung der jeweiligen morpho-syntaktischen Differenzen von nominalen Klassifikationssystemen. Dixon (1982) unterscheidet $z$ wischen nominalen Klassensystemen und numeralen Klassifizierersystemen. Während sich der erste Typ durch eine geschlossene Anzahl von Klassen und die obligatorische Klassifikation aller Nomina, die sich irgendwo außerhalb des Nomens selbst manifestiert, auszeichnet, gilt für den zweiten Typ eine offene - oder zumindest große - Zahl von Klassen und eine wenigstens in einigen grammatischen Kontexten optionale Kreuzklassifikation der Nomina.

Anstatt morphosyntaktische Differenzen weiterzuverfolgen, soll nachfolgend ein Vorschlag skizziert werden, der die verschiedenen Klassifikationssysteme hinsichtlich ihres kognitiven Organisationsgrades oder des Ausmaßes ihrer Motivierung zu typologisieren versucht. Wir wollen uns dabei ausschließlich auf die semantische Motivierung beschränken, von formalen Motivierungsprinzipien soll ausdrücklich abgesehen werden.

Die Unterscheidung von Dixon hat in bezug auf unsere Überlegungen für die kognitive Organisation der Klassifikation zumindest zwei Konsequenzen: 
1. Da die Genussysteme die Klassifikation der Nomina obligatorisch vorschreiben, muß jedes neue Nomen sofort klassifiziert werden, auch dann, wenn es den Klassifikationskriterien des Systems nicht entspricht. Das kann dazu führen, daB zusätzlich zu einer semantischen Basierung der Klassifikation phonetische und derivationelle Kriterien relevant werden, oder dab so etwas wie eine Restklasse entwickelt wird.

2. Genussysteme zeichnen sich typischerweise durch eine sehr kleine und fixierte Anzahl von Klassen aus. Das bedeutet, daß dieselben Klassenmarkierer für verschiedene und sehr unterschiedliche semantische Felder verwendet werden müssen. Mit anderen Worten: Genussysteme haben die Tendenz, viele verschiedene semantische Konzepte durch dieselbe formale Markierung abzubilden, während numerale Klassifikationssysteme, eben weil sie mit offenen Klassen operieren, dahin tendieren, eine 1:1-Korrespondenz $z$ wischen Klassifizierer und dem jeweiligen Konzept zu etablieren.

Vor dem Hintergrund dieser Überlegungen soll nun ein Kontinuum skizziert werden, das von hochgradig semantisch motiviert bis hin zum Chaos reicht. Die hierzu verwendeten Niveaus 1 bis 6 lassen sich als Grade der Entropie für die Klassifikationssysteme begreifen.

Niveau 1: Hier gilt geringe Entropie und damit eine hohe Wahrscheinlichkeit der korrekten Vorhersage. Die Klassenzuordnung erfolgt auf der Basis nur eines oder weniger Merkmale. Solche Systeme sind so transparent, daB sie kaum als Klassifikationssysteme verstanden werden. Im Englischen etwa werden die Pronomina auf der Basis des perzipierten Sexus der Entität, auf die sie referieren, ausgewählt. Von der rudimentär vorhandenen affektiven Klassifikation mit she von Autos, Maschinen und Booten durch spezifische Sprachbenutzergruppen sehen wir hier ab.

Niveau 2 betrifft die Einordnung der Nomina in Klassen auf der Grundlage prototypischer Eigenschaften. Alle Mitglieder einer spezifischen Klasse teilen eine gewisse Ähnlichkeit miteinander, gleichwohl sind die Ähnlichkeiten immer nur partiell. Dieses Muster ist charakteristisch für die Formklassifizierer im Mandarin. Ein- und zweidimensionale Objekte werden in Abhängigkeit von Form, Stärke, Funktion verschiedenen Klassen zugewiesen. In die chang-Klasse etwa werden zweidimensionale Objekte eingeordnet; das bedeutet aber nicht, daß beispielsweise die Konsistenz der Objekte identisch ist, noch daß es sich notwendig um sehr dünne oder flache Objekte handeln muß. Zudem gilt, daß nicht alle zweidimensionalen Objekte dieser Klasse zugeordnet werden, insofern ist die Mitgliedschaft in dieser Klasse nicht vollständig prognostizierbar. 
Niveau 3 zeichnet sich durch das Vorhandensein eines semantischen Kerns und radialer Strukturen aus, so daß die Klassenmitgliedschaft über die Beziehung zum Kern definiert wird. Dabei können die Klassenmitglieder an ganz unterschiedliche radiale Gelenkstücke der Gesamtstruktur angebunden sein. Das führt dazu, daB die Klassenmitglieder ohne den Rückgriff auf die zugrundeliegende radiale Struktur keine Ähnlichkeiten miteinander aufweisen. Der Japanische Numeralklassifizierer hon ist durch die Arbeiten von Downing (1986) und Lakoff (1987) ein bekanntes Beispiel für diesen Typ geworden. Zum Geltungsbereich von hon gehören primär eindimensionale in der Hand zu haltende Objekte. Die radiale Ausdehnung vollzieht sich folgendermaßen:

- durch die Nadel auf die Spritze;

- durch den Telefonhörer auf die Telefonleitung und von da auf den Telefonanruf,

- durch den Baseballschläger auf den home run usw. usf.

Spritzen, Telefonleitungen, Telefonanrufe und home runs weisen untereinander keine semantischen Ähnlichkeiten auf; sie werden jedoch mittels der radialen Pfade zu demselben semantischen Kern miteinander in Beziehung gesetzt.

Niveau 4: Auf diesem semantischen Organisationsniveau findet man viele Genussprachen, auch das Deutsche. Zwar gibt es, wie oben ausführlicher dargestellt, einen semantischen Kern, aber keine radialen Strukturen, die das Kernkonzept in das Lexikon hinein ausdehnen. Als Folge davon entstehen viele untereinander unverbundene semantisch basierte „Miniklassen”. Das ist nicht nur charakteristisch für das Deutsche, sondern übrigens auch für die Bantusprachen. Im Deutschen gibt es, wie oben gezeigt, einen auf das natürliche Geschlecht gegründeten semantischen Kern, aber um diesen Kern gibt es eine Vielzahl semantischer Strukturierungen, die mit dem Kern nichts zu tun haben.

Niveau 5 ist dadurch charakterisiert, daß auch der semantische Kern verloren gegangen ist. Die grammatisch definierten Klassen weisen eine Vielzahl semantischer Cluster auf, von denen aber keines dominiert, geschweige denn als Basis für die anderen identifiziert werden kann. Genau dies scheint für das Neutrum im Deutschen zu gelten. Es ist damit vergleichbar der sogenannten „Restklasse” im Dyirbal, einer Ureinwohnersprache Australiens, vgl. Dixon (1982).

Niveau 6 ist nur theoretisch anzunehmen, insofern handelt es sich um ein Gedankenexperiment. Nehmen wir einmal an, daß nicht nur der semantische Kern und die radialen Gelenkstücke verlorengegangen sind, sondern auch der Rest einer semantischen Substruktur. Wäre dies dann 
überhaupt noch eine für den Menschen lernbare und speicherbare kognitive Struktur? Wir behaupten, dab eine solche semantische Un-struktur nicht überdauern kann und prognostizieren drei Auswege:

1. Das System weist sehr starke phonologische Korrelate auf und wird als Deklinationssystem reinterpretiert; eine Vorstellung, die auf das Russische zuzutreffen scheint;

2. Klassenmarkierungen werden als phonologische Bestandteile des Nomens reinterpretiert, das grammatische Klassifikationssystem verschwindet vollständig; ein ProzeB, der für eine Reihe von BantuSprachen angenommen wird, vgl. Denny/Creider (1986); und schlieBlich

3. die Motivierung der Klassenmitgliedschaft der Nomina fält auf völlig transparente Klassifikationsprinzipien zurück, etwa auf das Prinzip des natürlichen Geschlechts. Genau das scheint beim Übergang vom Mittelenglischen zum frühen Neuenglischen der Fall gewesen zu sein.

\section{Literatur}

Brugmann, K. (1889): Das Nominalgeschlecht in den indogermanischen Sprachen. In: Internationale Zeitschrift für allgemeine Sprachwissenschaft 4, S. 100-109.

Carey, S. (1978): The child as word learner. In: Halle, M./Bresnan, J./Miller, G.A. (Hg.): Linguistic Theory and Psychological Reality. Cambridge, Mass.

Claudi, U. (1985): Zur Entstehung von Genussystemen. Überlegungen zu einigen theoretischen Aspekten, verbunden mit einer Fallstudie des Zande. Hamburg.

Corbett, G.G. (1988): Gender in Slavonic from the standpoint of a general typology of gender systems. In: Slavonic and East European Review 66, S. $1-20$.

Denny, J.P./Creider C.A. (1986): The semantics of noun classes in ProtoBantu. In: Craig, C. ( $\mathrm{Hg}$.): Noun Classification and Categorization. Philadelphia. S. 217-239.

Dixon, R.M.W. (1982): Where have all the adjectives gone? and other essays in semantics and syntax. Berlin.

Downing, P. (1986): The anaphoric use of classifiers in Japanese. In: Craig, C. (Hg.): Noun Classification and Categorization. Philadelphia. S. 345-375.

Fodor, I. (1959): The origin of grammatical gender. In: Lingua 8, S. 1-41 und S. 186-214.

Grimm, J. (1831): Deutsche Grammatik. 3. Teil. Gōttingen.

Hyman, L.M. (Hg.) (1980): Noun Classes in the Grassfields Bantu Borderland. Southern California Occasional Papers in Linguistics 8. Los Angeles: Department of Linguistics, University of Southern California. 
Köpcke, K.-M. (1982): Untersuchungen zum Genussystem der deutschen Gegenwartssprache. Tübingen.

Kōpcke, K.-M./Zubin, D. (1983): Die kognitive Organisation der Genuszuweisung zu den einsilbigen Nomen der deutschen Gegenwartssprache. In: Zeitschrift für germanistische Linguistik 11, S. 166-182.

Köpcke, K.-M./Zubin, D. (1984): Sechs Prinzipien für die Genuszuweisung im Deutschen: Ein Beitrag zur natūrlichen Klassifikation. In: Linguistische Berichte 93, S. 26-50.

Lakoff, G. (1987): Women, Fire, and Dangerous Things. What Categories reveal about the Mind. Chicago.

Leiss, E. (1994): Genus und Sexus. Kritische Anmerkungen zur Sexualisierung von Grammatik. In: Linguistische Berichte 152, S. 281-300.

Mathiot, M. (Hg.) (1979): Ethnolinguistics: Boas, Sapir and Whorf Revisited. The Hague. (Contributions to the Sociology of Language, 27).

Ronneberger-Sibold, E. (1994): Die Lautgestalt neuer Wurzeln. Kürzungen und Kunstwörter im Deutschen und Französischen. Habilitationsschrift (Albert-Ludwigs-Universität Freiburg im Breisgau).

Royen, G. (1929): Die nominalen Klassifikations-Systeme in den Sprachen der Erde. Historisch-kritische Studie, mit besonderer Berücksichtigung des Indogermanischen. Wien. (Linguistische Anthropos-Bibliothek; 4).

Werner, O. (1975): Zum Genus im Deutschen. In: Deutsche Sprache 3, S. 3558.

Wienold, G. (1967): Genus und Semantik. Meisenheim am Glan.

Zipf, G.K. (1949): Human Behavior and the Principle of Least Effort. Cambridge, Mass.

Zubin, D./Köpcke, K.-M. (1981): Gender: A less than arbitrary grammatical category. In: R. Hendrick et al. (Hg.): Proceedings of the Chicago Linguistics Society 17. S. 439-449.

Zubin, D./Köpcke, K.-M. (1984): Affect classification in the German gender system. In: Lingua 63, S. 41-96.

Zubin, D./Kōpcke, K.-M. (1986): Gender and folk taxonomy: The indexical relation between grammatical and lexical categorization. In: Craig, C. (Hg.): Noun Classification and Categorization. Philadelphia. S. 139-180.

Zubin, D./Köpcke, K.-M. (in Vorb.): The Irrgarden: Natural classification in the German gender system and the noun-classifying languages of the world. Chicago. 


\title{
Morphologischer Strukturwandel: Typologische Entwicklungen im Deutschen
}

\begin{abstract}
Der Aufsatz thematisiert die typologische Veränderung in der morphologischen Struktur des Deutschen vom frühen Althochdeutschen zum modernen Neuhochdeutschen. Das Althochdeutsche ist eine noch weitgehend fusionierend aufgebaute Sprache. Im Laufe der Sprachgeschichte entwickelt das Deutsche in starkem MaBe nichtfusionierende Strukturzüge. Ihre Herausbildung ist (im wesentlichen) durch das Zusammen wirken von phonologischem Wandel, morphologischem Wandel und Grammatikalisierung/Reanalyse bedingt. Die einzelnen Wandelprozesse sind höchst unterschiedlich motiviert und verlaufen in typologisch unterschiedliche Richtungen; auch eine 'Grundrichtung' der Veränderung (etwa von der Synthese zur Analyse oder von der Fusion zur Isolierung) ist nicht auszumachen. Das Ergebnis dieser Entwicklungen ist das typologisch stark inkohārente morphologische System des Neuhochdeutschen, das fusionierende, agglutinierende, introflexive, isolierende und polysynthetischinkorporierende Strukturzüge aufweist und insgesamt keinem der gängigen morphologischen Sprachtypen zugewiesen werden kann.
\end{abstract}

\section{o. Einleitung}

Sprachtypologie kann man bekanntlich auf sehr verschiedene Weise betreiben; wie in anderen Bereichen der Linguistik gibt es auch in der Typologie recht unterschiedliche Herangehensweisen. Doch ein wohl ziemlich durchgängiges Charakteristikum der modernen Typologieforschung ist, daß sie nicht primär die existierenden Sprachen insgesamt klassifizieren will und sie als mehr oder weniger konsequente Verkörperungen eines der angenommenen morphologischen Sprachtypen betrachtet. Vielmehr untersucht sie primär die einzelnen grammatischen Einheiten und Teilsysteme der Sprachen hinsichtlich ihrer typologischen Struktur und baut dann darauf ihre verallgemeinernden Aussagen auf.

Schon Humboldt hat festgestellt, daB die Sprachen nicht notwendigerweise typologisch einheitlich aufgebaut sind. Er verweist im Gegenteil darauf, daß alle Sprachen „eine oder mehrere dieser Formen”, gemeint sind seine drei morphologischen Typen flektierend, agglutinierend und isolierend, „in sich tragen” (1836, S. 317). In jüngerer Zeit hat dann vor allem Skalička immer wieder betont, daß jede gegebene Sprache Struk- 
tureigenschaften mehrerer Sprachtypen aufweist (so u.a. 1979, S. 23). Es soll hier nicht diskutiert werden, ob die Aussage in dieser strikten Form wirklich für sämtliche Sprachen gilt. Interessant für unseren Zusammenhang ist jedoch, daß Skalička als gut nachvollziehbares Beispiel für eine Sprache, in der alle fünf von ihm angenommenen morphologischen Typen zugleich realisiert sind, gerade das Deutsche, genauer das Neuhochdeutsche, anführt. Damit stellt sich das Neuhochdeutsche als eine Sprache dar, die zur detaillierten Untersuchung ihrer typologischen Struktur geradezu herausfordert. Hier ergibt sich unter anderem natürlich auch die Frage, wie sich eine solche, doch offenbar recht spezifische, stark uneinheitliche Struktur des Neuhochdeutschen sprachhistorisch überhaupt herausbilden konnte.

Der vorliegende Aufsatz will dieser Fragestellung nachgehen. Der Ausgangspunkt der Untersuchung ist die älteste überlieferte Form des Deutschen, das frühe Althochdeutsche. Es soll überprüft werden, wie sich die formalen Mittel der Flexion und partiell auch der Wortbildung, die den unterschiedlichen morphologischen Typen zuzuordnen sind, im Laufe der Geschichte des Deutschen entwickeln. Wenn wir hier in diesem Sinne von typologischen Entwicklungen sprechen, so bezieht sich das also auf die Veränderung der typologischen Struktur von Elementen des Systems und nicht auf den Übergang des Gesamtsystems von einem zu einem anderen Sprachtyp.

Den Untersuchungen sollen Skalička folgend (vgl. speziell Skalička (1979)) fünf morphologische Sprachtypen zugrundegelegt werden. Es sind dies:

- der isolierende Typ,

- der agglutinierende Typ,

- der fusionierende Typ (bei Skalička: flektierend),

- der introflexive Typ,

- der polysynthetisch-inkorporierende Typ (bei Skalička: polysynthetisch).

Natürlich ist diese typologische Klassifizierung (wie im Prinzip auch jede andere) nicht unproblematisch. Das betrifft speziell die Annahme eines eigenen introflexiven Typs, der sich auf morphologische Formen mit interner Flexion bezieht, wie sie vor allem für die semitischen Sprachen prägend und im Deutschen durch Umlaut- und Ablautformen vertreten sind. ${ }^{1}$ Da sich die Formen dieses Typs in ihrer Struktur grundsätz-

1 Das heißt natũrlich nicht, daß die introflexiven Formen des Deutschen und der semitischen Sprachen strukturell völlig gleichzusetzen sind; vgl. dazu Wurzel (1989, S. 287ff.). 
lich von fusionierenden (flektierenden) Formen mit Suffixen und/oder Präfixen unterscheiden und solche Formen gerade im Deutschen eine wichtige Rolle spielen, wollen wir auch in diesem Punkt Skalička folgen. Der polysynthetische Typ wurde zum polysynthetisch-inkorporierenden Typ erweitert, weil im Deutschen neben polysynthetischen ('vielfach zusammensetzenden') Konstruktionen (Kern-waffen-versuchs-stop) auch inkorporierende ('eingliedernde') Konstruktionen (teil-nehmen, gewährleisten) existieren, die eben nicht 'vielfach', sondern nur 'einfach' zusammengesetzt sind. SchlieBlich wurde der Terminus 'flektierend' durch 'fusionierend' ersetzt, weil erstens Flexion und Agglutination keine Gegensätze sind (auch typisch agglutinierende Sprachen wie Türkisch haben natürlich eine Flexion, d.h. Deklination und Konjugation) und zweitens auch in der Wortbildung fusionierende ('flektierende') Strukturen vorkommen.

\section{Zur typologischen Struktur des Althochdeutschen}

Das Althochdeutsche gilt im allgemeinen als eine typische ältere indoeuropäische Sprache und wird entsprechend als eine fusionierende Sprache klassifiziert, was durchaus angemessen ist. Doch es enthält daneben auch nichtfusionierende Strukturzüge. Wir wollen im folgenden im Detail, d.h. anhand der einzelnen Formen und Kategorienmarker, überprüfen, wie sich das fusionierende und das nichtfusionierende Potential im Flexionssystem des frühen Althochdeutschen verteilen.

\subsection{Das fusionierende Potential des Althochdeutschen}

Der Grundstock der althochdeutschen Flexionsmorphologie ist eindeutig fusionierend, d.h. die Symbolisierung der Kategorien erfolgt durch additive Kategorienmarker, genauer: durch Suffixe, die für mehrere Kategorien zugleich stehen. Das gilt sowohl für die Deklination der Substantive und Adjektive als auch für die Konjugation der Verben.

Bei den Substantiven werden durch die additiven Marker jeweils zwei Kategorien symbolisiert, eine Numeruskategorie und eine Kasuskategorie:

(1) tag 'Tag'
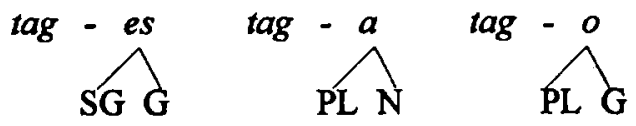

Dabei ist zu betonen, daß die substantivischen Kategorienmarker des frühen Althochdeutschen ausschließlich fusionierend sind. In bestimm- 
ten Paradigmen tritt zwar bereits Umlaut im Plural auf, doch ist der Umlaut noch strikt phonologisch (durch folgendes vokalisches oder konsonantisches $i$ ) bedingt, d.h. er ist noch kein morphologischer Marker, vgl. z.B. gast 'Gast' - N.PI. gesti. ${ }^{2}$

In der Deklination der Adjektive stehen die einzelnen Marker für jeweils vier Kategorien zugleich, was einen sehr hohen Grad an Fusion bedeutet. Meist werden nur drei Kategorien angeführt, eine Numerus-, eine Kasusund eine Genuskategorie. Doch die Flexionsformen der althochdeutschen Adjektive unterscheiden sich nicht nur hinsichtlich dieser Kategorien, sondern zusätzlich auch darin, ob sie 'schwach' oder 'stark' dekliniert werden. Es ist also eine weitere Flexionskategorie zu berücksichtigen. Wenn man davon ausgeht, dab etwas vereinfacht gesagt die 'schwache' Flexion des Adjektivs in Verbindung mit dem Demonstrativpronomen und später mit dem sich daraus entwickelnden bestimmten Artikel auftritt und die 'starke' Flexion sonst, vgl. der blinto man 'der blinde Mann' - blintêr man 'ein blinder Mann', so läßt sich hier am angemessensten ein Kategoriengefüge der Definitheit mit den Kategorien Definit und Indefinit annehmen. Damit sehen die Symbolisierungsverhältnisse beim althochdeutschen Adjektiv folgendermafen aus:
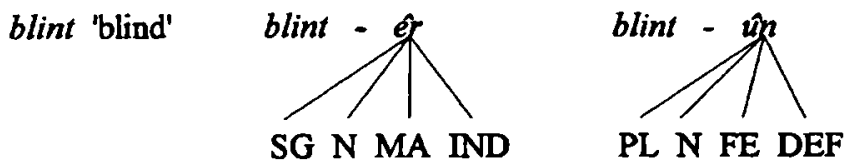

Noch wesentlich komplexer stellt sich das Verhältnis von Markern und Kategorien bei den althochdeutschen Verben dar, nicht zuletzt auch deshalb, weil neben den fusionierenden Markern auch Marker anderer Typen an der Kategoriensymbolisierung beteiligt sind. Bei den starken Verben symbolisiert das fusionierende Suffix zunächst Modus, Person und Numerus. Doch es ist zugleich auch der Hauptmarker für das Tempus; der Ablaut hat (noch) den Status eines Nebenmarkers. Bei den schwachen Verben steht der fusionierende Marker für drei Kategorien, je eine Modus-, Personal- und Numeruskategorie, als alleiniger Marker und zugleich für die Tempuskategorie, deren Hauptmarker das Dentalsuffix ist,

2 Genau genommen ist der Marker nicht der Umlautvokal als solcher, sondern die Umlautalteration; vgl. (die) Vögel zu (der) Vogel, aber (die) Bügel zu (der) Bügel. Entsprechendes gilt auch für den Ablaut; vgl. einerseits (sie) braten - (sie) brieten und andererseits (sie) hegen - (sie) lagen. 
als Nebenmarker. (Auf das Dentalsuffix und den Ablaut kommen wir gleich zurück.) Vgl. die folgenden beiden Beispiele (Hauptmarker sind durch durchgehende, Nebenmarker durch unterbrochene Linien gekennzeichnet):

swimman 'schwimmen'

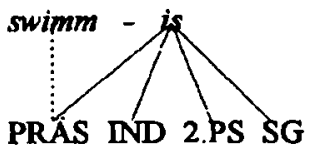

(b) suochen 'suchen'

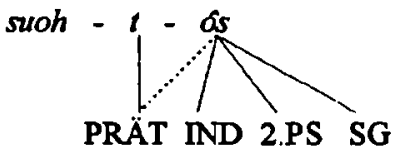

Soweit das fusionierende Potential der althochdeutschen Flexion, das wie leicht zu sehen - noch das gesamte System dieser Sprachstufe prägt.

\subsection{Das nichtfusionierende Potential des Althochdeutschen}

Es wurde gerade festgestellt, daB es in der Substantiv- und Adjektivdeklination des Althochdeutschen nur fusionierende Marker gibt. Dagegen treten in der Komparation der Adjektive (wenn man von den einzelnen suppletiven Bildungen einmal absieht) grundsätzlich nur agglutinierende Marker auf, also additive Marker, die jeweils genau eine Kategorie symbolisieren:

\section{(4) hôh 'hoch'}
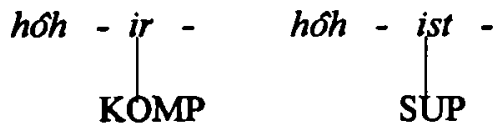

Diese agglutinierende Symbolisierung der Komparationskategorien ist keine deutsche oder germanische Neuerung; sie findet sich interessanterweise in allen alten indoeuropäischen Sprachen, auch wenn diese in ihrer Flexion sonst keine weiteren agglutinierenden Affixe aufweisen.

Es wurde bereits erwähnt, daß das Präteritum der schwachen Verben im Althochdeutschen mit Hilfe des Dentalsuffixes - $t$ - gebildet wird. Dieser Marker ist eine relativ junge, gemeingermanische Bildung, die ja bekanntlich mit großer Wahrscheinlichkeit auf die Grammatikalisierung einer analytischen Form mit dem Verb 'tun' zurückgeht. Er steht für eine einzige Kategorie, hat also eindeutig agglutinierenden Charakter. Dabei funktionieren die Suffixe, die auf fusionierende Weise Modus, Person und Numerus kombiniert anzeigen, zusätzlich auch als Nebenmarker des Tempus, denn sie sind jeweils tempusspezifisch. Man vgl. dazu beispielsweise die Formen der 2. Person Singular im Präsens und Präteritum: 


$$
\begin{array}{lll} 
& \text { Präsens } & \text { Präteritum } \\
\text { Indikativ } & \text { suoch-is } & \text { suoh-t-ôs } \\
\text { Optativ } & \text { suoch-ês } & \text { suoh-t-îs }
\end{array}
$$

In der Flexion der starken Verben tritt bekanntermaBen im Althochdeutschen wie im Neuhochdeutschen der Ablaut, also ein Vokalwechsel, auf. Sein Auftreten ist nicht (genauer: nicht mehr) phonologisch bedingt. Die Ablautalternation funktioniert also (bereits) morphologisch. Dennoch unterscheidet sich die Flexion der starken Verben im Althochdeutschen wesentlich von der im Neuhochdeutschen.

Erstens gilt für den Großteil der starken Verben (die der stark belegten Klassen I bis IV), daß kein einheitlicher Präteritalvokal in den Paradigmen existiert; vgl. die Indikativformen swam (1./3.Ps.Sg.), swummi (2.Ps.Sg.) und swummum, swummut, swummun (Plural). Das bedeutet, daB der Ablaut neben dem Tempus zugleich auch Modus, Numerus und sogar die Person mitsymbolisiert:
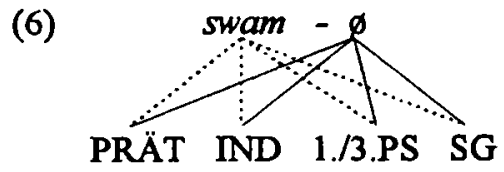

Zweitens erscheint im Präteritum der Verben aufgrund der in den Paradigmen variierenden Vokale und der vielen verschiedenen starken Klassen eine große Anzahl unterschiedlicher Vokale und Diphthonge, nämlich $e i, i, o u, u, \hat{o}, a, \hat{a}, u o, i a$ und $i o$, während im Neuhochdeutschen nur die vier Vokale $i, a, u$ und $o$ (deren Länge automatisch geregelt ist) als Präteritalmarker fungieren. ${ }^{3}$

Drittens schließlich sind die fusionierenden Suffixe der starken Verben (wie die der schwachen) voll distinktiv hinsichtlich Tempus und Modus; vgl. wiederum die Formen der 2. Person Singular:

$$
\text { Präsens Präteritum }
$$

Indikativ swimm-is swumm-i

Optativ swimm-ês swumm-î̀

Die Suffixe sind dabei anders als die Präteritalvokale für sämtliche Klassen der starken Verben einheitlich.

3 Vgl. dazu z.B. Wurzel (1970, S. 69ff.). 
Diese Befunde erweisen, daB die von uns vorgenommene Wertung der fusionierenden Suffixe als Hauptmarker und des introflexiven Ablauts als Nebenmarker des Tempus (und des Modus) im Althochdeutschen den gegebenen Verhältnissen entspricht. Der Ablaut ist noch recht schwach grammatikalisiert und insofern faktisch eine Art von 'unsystematischem Beiwerk' der Verbflexion. Dafür spricht im übrigen auch die Tatsache, $\mathrm{da} B$ es im Althochdeutschen noch keinerlei Tendenzen zur Vereinheitlichung der Präteritalvokale in den Paradigmen gibt.

Damit ist das Potential an nichtfusionierenden Kategorienmarkern in der althochdeutschen Flexion bereits erschöpft. Es läßt sich also konstatieren, daB das Flexionsystem im Althochdeutschen noch in ganz überwiegendem MaBe fusionierend aufgebaut ist. Abweichungen davon haben faktisch den Charakter von Ausnahmen. In diesem Sinne ist das Althochdeutsche insgesamt ohne Schwierigkeiten als fusionierende Sprache zu charakterisieren.

\section{Typologische Veränderungen vom frühen Althochdeut- schen zum Neuhochdeutschen}

\subsection{Die Herausbildung des agglutinierenden Potentials}

In der Substantivflexion entwickelt sich bereits relativ früh in der althochdeutschen Periode aus dem Stammbildungselement -ir- (das dem indoeuropäischen Element -es-/-os- entspricht) in einer Flexionsklasse ein Marker, der ausschließlich die Kategorie des Plurals symbolisiert, d.h. ein agglutinierender Pluralmarker. Er ist damit das erste agglutinierende Element in der deutschen Substantivflexion überhaupt. ${ }^{4}$ Dabei ist jedoch zu beachten, daß die Flexionsformen dieser Klasse insgesamt nicht konsequent agglutinierend aufgebaut sind, da Flexive wie -um noch als Nebenmarker des Numerus funktionieren; vgl. dazu auch die Verhältnisse in den anderen Flexionsklassen, wo diese Flexive noch fusionierende Numerus-Kasus-Marker sind:

(8) (a) hrind 'Rind'

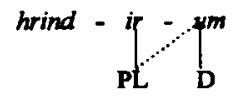

(b) lag

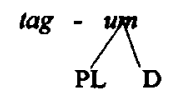

Im Mittelhochdeutschen (genauer: mit der Reduzierung der Endsilbenvokale) wird dann die gesamte Substantivdeklination in entsprechender

4 Eine detaillierte, die gesamte Substantivflexion einbeziehende Darstellung der Herausbildung einer eigenständigen Pluralsymbolisierung im Deutschen gibt Werner (1969). 
Weise umgestaltet. Anstelle der alten fusionierenden Marker erscheint jetzt im Plural der Paradigmen ein agglutinierender Numerusmarker, im Dativ z.T. kombiniert mit einem quasi-agglutinierenden Kasusmarker: ${ }^{5}$

$\begin{array}{lllll} & \text { ahd. } & \text { mhd. } & \text { ahd. } & \text { mhd. } \\ \text { N.Sg. } & \text { zung-a } & \text { zunge } & \text { tag } & \text { tac } \\ \text { N.Pl. } & \text { zung- } \hat{n} n & \text { zunge- } n & \text { tag-a } & \text { tag-e } \\ \text { D.Pl. } & \text { zung-ôm } & \text { zunge- } n & \text { tag-um } & \text { tag-e- } n\end{array}$

Mit diesem Wandel von fusionierenden zu agglutinierenden Markern in den Substantivparadigmen sind zwei weitere Veränderungen verbunden, die zu für agglutinierende Systeme charakteristischen Strukturzügen führen:

- erstens der Übergang von der Stammflexion, deren Basis der Stamm des Wortes ist (zung-a - zung-ûn, zur Grundformflexion, deren Basis die Grundform des Wortes ist (zunge - zunge-n);

- zweitens der Übergang von der formalen Kennzeichnung (im Prinzip) aller Kategorien zur formalen Kennzeichnung nur der abgeleiteten (markierten) Kategorien, d.h. der nichtnominativischen Kasus und des nichtsingularischen Numerus (in zung-a ist - $a$ der Marker des N.Sg., in zunge ist weder der Nominativ noch der Singular symbolisiert; in $z u n g-\hat{u} n$ ist das - $\hat{u}^{n}$ der Marker des N.Pl., in zunge-n ist $-n$ nur der Marker des Plurals).

Beides entspricht genau den Verhältnissen in agglutinierenden Sprachen wie Türkisch oder Ungarisch.

Auch im Verbsystem wird im Laufe der deutschen Sprachgeschichte das agglutinierende Potential verstärkt, wenn auch in völlig anderer Weise. Vom Mittelhochdeutschen angefangen treten nämlich starke Verben zur schwachen Flexion über. Das bedeutet in erster Linie, daß die introflexivische Tempusflexion mit Ablaut, die im Mittelhochdeutschen an die Stelle der althochdeutschen fusionierenden Tempusflexion getreten ist (vgl. den nächsten Abschnitt), bei den betroffenen Verben nun selbst durch die agglutinierende Tempusflexion mit Dentalsuffix abgelöst wird; vgl. dazu das Beispiel der 2.Ps.Pl.Prät.Ind.:

5 Der Marker $-n$ in mhd. tag-e-n und $n$ hd. Tag-e- $n$ symbolisiert anders als der entsprechende ahd. Marker -um in tag-um also nicht den D.Pl., sondern den Dativ im Plural. Von einem echt agglutinierenden Marker unterscheidet er sich durch diese Kontextbindung. 
(10) ahd.
mhd. smiogan
schmiegen schmieg - smug -

Zur neuhochdeutschen Form ist zu bemerken, daß bei Verben dieses Typs Indikativ und Konjunktiv nicht mehr unterschieden sind.

\subsection{Die Herausbildung des introflexiven Potentials}

Zunächst zur Deklination der Substantive. Bereits im späteren Althochdeutschen erhält der ursprünglich rein phonologisch bedingte Umlaut aufgrund des Unproduktivwerdens der phonologischen Umlautregel und der Verteilung der umgelauteten und nichtumgelauteten Formen in den Paradigmen bei den Neutra des Typs lamb 'Lamm' - N.Pl. lembir und bei den Maskulina des Typs gast 'Gast' - N.Pl. gesti den Status eines Nebenmarkers für den Plural. Beim Übergang zum Mittelhochdeutschen verschwindet mit der Reduzierung des $i$ zu [a] dann auch die Bindung des Umlauts an ein $i$ der folgenden Silbe vollständig. Damit wird der Umlaut frei als Kategorienmarker und kann auch auf Wörter übertragen werden, denen er 'lautgesetzlich' nicht zukommt. So wird der Umlaut als Pluralmarker auf neue Instanzen ausgedehnt: ${ }^{6}$

- durch den Übertritt von Neutra und Maskulina in die er-Pluralklasse, bei denen (wenn der Vokal umlautbar ist) generell Umlaut auftritt (Typ mhd. lamp - lember) speziell im späten Mittelhochdeutschen und im Frühneuhochdeutschen; hierher gehören z.B. Land - Länder und Mann - Männer,

6 Zur Entwicklung des Umlauts zum Pluralmarker vgl. Wurzel (1980) und (1992). 
- durch den Übertritt vieler Maskulina und einiger Neutra in die ePluralklasse mit Umlaut (Typ mhd. gast - geste); hierher gehören Wolf - Wölfe und Floß - Flöße;

- durch die Verallgemeinerung der unumgelauteten G./D.Sg.-Formen der femininen i-Stämme, d.h. den Abbau der entsprechenden umgelauteten Formen, im Frühneuhochdeutschen, so dab auch hier dann konsequent ein Plural mit Umlaut einem Singular ohne Umlaut gegenüberstand:

mhd.

N.Sg. kraft

$$
\text { N.Pl. krefte }
$$

G. krefte, kraft G. krefte

D. krefte, kraft

D. kreften

A. kraft

A. krefte

fnhd.

In all diesen Fällen ist der Umlaut Nebenmarker des Plurals, Hauptmarker ist das Suffix -er bzw. -e. Wichtig ist, daB der Umlaut aber auch auf Wörter übertragen wird, die ihr Suffix (aus unterschiedlichen Gründen) verloren hatten, vgl. bereits mhd. vater - N.Pl. veter, bruoder - N.PI. brüeder, später dann auch mutter - N.Pl. mütter und tochter - N.Pl. töchter. Diese Entwicklung erfaßt dann immer mehr Maskulina, was Pluralformen wie Nägel, Gärten und Kästen, in jüngster Zeit auch $\mathrm{Hämmel,}$ Hämmer und Wägen (sämtlich bereits vom „Duden" sanktioniert!) zeigen. Hier bildet der Pluralumlaut den Hauptmarker. Man kann also konstatieren, daß sich vom Althochdeutschen zum Neuhochdeutschen beim Substantiv ein durchaus beachtenswertes introflexives Potential herausbildet.

Bei den starken Verben wird der Ablaut, im Althochdeutschen wie herausgearbeitet noch Nebenmarker, trotz seiner aufgezeigten 'Defizite' durch die phonologische Neutralisierung der Suffixe im Mittelhochdeutschen zum einzigen Marker des Tempus; vgl. die jeweiligen Flexionsformen der 2. Person Plural:

$$
\text { ahd. mhd. }
$$

$\begin{array}{lll}\text { Präs.Ind. } & \text { swimm-et } & \text { swimm-et } \\ \text { Präs.Opt. } & \text { swimm-êt } & \text { swimm-et } \\ \text { Prät.Ind. } & \text { swumm-ut } & \text { swumm-et } \\ \text { Prät.Opt. } & \text { swumm-it } & \text { swümm-et }\end{array}$

Zugleich wird der Umlaut bei Verben mit umlautbarem Präteritalvokal zum Marker des Optativs im Präteritum, vgl. swümmet vs. swummet. Beide Entwicklungen werden weitergeführt. Die Präteritalvokale werden beginnend mit dem Frühneuhochdeutschen innerhalb des Paradigmas 
vereinheitlicht. Im modernen Neuhochdeutschen haben dann alle Verben durchgängige Präteritalvokale:

$$
\text { mhd. nhd. }
$$

1./3.Ps.Sg. swam schwamm

2.Ps.Sg. swümme schwammst

1./3.Ps.Pl. swummen schwammen

2.Ps.Sg. swummet schwammst

Auf diese Weise gewinnt der Ablaut im deutschen Verbsystem einen höheren Grammatikalisierungsgrad. Durch diese Entwicklung ergibt sich eine Entflechtung der Kategoriensymbolisierung bei den starken Verben. Während im Althochdeutschen ein Marker für vier Kategorien zugleich steht, symbolisieren im Neuhochdeutschen (ohne Berücksichtigung des Personalpronomens, s. weiter unten) zwei Marker je zwei Kategorien, was eine Reduktion des Fusionsgrades bedeutet:

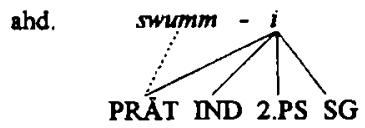

nhd.

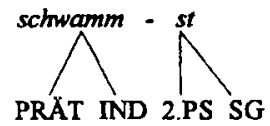

Auch der Umlaut als Optativ- bzw. Konjunktivmarker wird systematisiert, indem die entsprechenden Formen soweit möglich von den jeweiligen Indikativformen gebildet werden. So wird z.B. schwömme (das das ältere schwümme fortsetzt) durch schwämme ersetzt. Desweiteren wird der Konjunktivumlaut auf eine Reihe irregulärer schwacher Verben übertragen: er hätte, er dächte usw. So wird auch bei den Verben im Laufe der deutschen Sprachgeschichte das intoflexive Potential auf Kosten des fusionierenden Potential beträchtlich erweitert. Doch ist an dieser Stelle daran zu erinnern, daß erstens vom Mittelhochdeutschen an die starken Verben zur agglutinierenden schwachen Flexion tendieren und daB zweitens der Konjunktiv des Präteritums zur Ersetzung durch die isolierende würde-Konstruktion tendiert (vgl. dazu den folgenden Abschnitt).

\subsection{Die Herausbildung des isolierenden Potentials}

Beim Substantiv beginnt sich bereits im Althochdeutschen der Artikel als 'Definitheitsmarker' aus dem Demonstrativpronomen der/diu/da3 bzw. dem Numerale ein herauszubilden. Diese Entwicklung wird in der Ge schichte des Deutschen konsequent weitergeführt. Aufgrund des Abbaus bzw. der Neutralisierung der unterschiedlichen Kasusflexive des Substantivs übernimmt der Artikel zusätzlich die Funktion eines Kasusmarkers; vgl. nhd. die/der/der/die Frau und die/der/den/die Frauen. Wo die 
Singular- und Pluralformen der Substantive formal identisch sind, fungiert er weiterhin auch als Marker des Numerus, partiell schon mhd. wie bei der jeger(e) - die jeger(e), nhd. der Jäger - die Jäger. Im modernen Deutschen ist die Anzahl der hierher gehörigen Maskulina und Neutra sehr groß; vgl. Lehrer, Hebel bzw. Fenster, Segel usw. Kasus und partiell Numerus werden außerhalb der Wortgrenzen symbolisiert.

Beim Verb sind hier zwei Entwicklungen einschlägig, die Herausbildung des obligatorischen Personalpronomens und die Entstehung der analytischen Verbformen. Das Personalpronomen entwickelt sich im Laufe der Sprachgeschichte zum Hauptmarker von Person und Numerus, der auch dort funktioniert, wo keine anderen Mittel mehr zur Verfügung stehen; vgl. dazu nhd.:

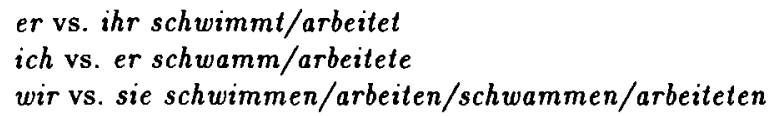

er vs. ihr schwimmt/arbeitet

ich vs. er schwamm/arbeitete

wir vs. sie schwimmen/arbeiten/schwammen/arbeiteten

Analytische Formen des Perfekts und Plusquamperfekts sowie des Passivs begegnen teilweise bereits im Althochdeutschen; vgl.

(16) (a) Denne der paltêt, der gipua33it hapêt

'Deshalb wird sich freuen, wer gebüßt hat.'

(b) Denne wirdit untar in uuic arhapan.

'Dann wird ein Kampf zwischen ihnen begonnen.'

Mit ihrer einigermaßen konsequenten Grammatikalisierung ist allerdings erst im 13. Jahrhundert zu rechnen. Von dieser Zeit an werden sie etwa so verwendet wie im modernen Neuhochdeutschen. Gewissermaßen in einem zweiten Schub beginnt dann die Herausbildung des analytischen Futurs seit dem 13./14. Jahrhundert sowie in seiner Folge des Konditionals, der heute bereits vielfach den alten introflexiven Optativ/Konjunktiv ersetzt hat. Was das Futur betrifft, so gibt es bereits frühe Ansätze der Umschreibung mit 'sollen' bzw. 'wollen'. Später setzen sich dann die 'werden'-Formen durch, zunächst mit dem Partizip Präsens, später mit dem Infinitiv gebildet, also z.B.

(17) (a) Diu werdent mîn stimme hcerend.

'Sie werden meine Stimme hören.'

(b) ... wan sie unser werden sehen.

'... wenn sie uns sehen werden.' 
Der Konditional ist dann etwa bei Luther voll grammatikalisiert:

(18) Wäre mein Reich von dieser Welt, meine Diener würden darob kämpfen.

Kurz zusammengefaBt: Wenn sich in einer Sprache mit der Struktur des Deutschen auch keine strikt isolierenden Konstruktionen ohne jede Flexion (wie sie beispielsweise im Chinesischen oder Vietnamesischen vorkommen) herausbilden können, so gelangt doch speziell im Mittel- und Frühneuhochdeutschen mit den analytischen Konstruktionen ein starkes isolierendes Potential in das grammatische System des Deutschen.

2.4 Die Herausbildung des polysynthetischen und inkorporierenden Potentials in der Wortbildung

Bisher wurde, was die Herausbildung von nichtfusionierenden Mitteln im Deutschen betrifft, ausschlieBlich die Flexion betrachtet. Doch das Deutsche hat seit dem Althochdeutschen auch interessante nichtfusionierende morphologische Konstruktionen entwickelt, die zwar nur in der Wortbildung auftreten, aber nichtsdestoweniger seine typologische Struktur insgesamt stark prägen und sie von vielen anderen Sprachen, speziell indoeuropäischen deutlich unterscheiden, nämlich polysynthetische und sogar inkorporierende Bildungen. In diesem Zusammenhang sollen drei Typen von bemerkenswerten Konstruktionen angeführt werden.

Erstens hat das Neuhochdeutsche bekanntlich eine echt polysynthetische Kompositastruktur herausgebildet. Demgegenüber unterliegt im Althochdeutschen die formale Struktur von Komposita noch starken Einschränkungen. So sind im Althochdeutschen (nach Henzen (1965, S. 47f.)) Komposita, deren zweite Glieder selbst „schwere Komposita” darstellen, „zunächst ungeläufig”. Entsprechend kommen Komposita mit einem Zweitglied, das mehr als zwei Stämme enthält, nicht (oder doch kaum) vor. Nicht allzu häufige Fälle wie ban=fiêr-tag 'gebotener Feiertag' und holz=werc-man 'Holzarbeiter' bilden hier faktisch das Maximum. Das Erstglied von Komposita ist „meist noch ein einsilbiger, unabgeleiteter Stamm". Bildungen mit einem ersten Glied, das aus zwei Stämmen besteht, wie wi-rouh=fa3 'Weihrauchgefäß' und hazal-nu $3=k e r n o$ 'Haselnußkern' treten dann erst im späteren Althochdeutschen auf. Komposita, die mehr als drei Stämme enthalten, sind offensichtlich nicht überliefert. Man vgl. dagegen neuhochdeutsche Komposita wie die folgenden, deren Bildungstyp ja keineswegs selten vorkommt:

(19) Bundes - ver-fassungs - gerichts - grund - satz - ur-teil

Heiz - öl - rück - stoß - dämpf-ungs - ver-ordn-ung

Fuß - ball - welt - meister-schafts - qualifikations - spiel 
Zweitens entsteht bereits im Althochdeutschen ein neuer Kompositionstyp, nominale Komposita mit verbalem Erstglied. Er nimmt seinen Ausgang von Zusammensetzungen mit nominalem Erstglied, das aber seiner Form nach auch ein Verbstamm sein konnte; vgl die Fälle unter (a). Dieses Erstglied wurde dann als Verbstamm aufgefaßt, und nach diesem Muster wurden dann Komposita mit (eindeutigen) Verbstämmen gebildet; vgl. die Fälle unter (b):

(20) (a) decki-lachan 'Tuch zur Bedeckung' (b) scepfi-faz 'Schöpfgefäß' slâf-hûs 'Haus für den Schlaf' stôz-isen 'Eisen für den Stoß' scer-sahs 'Schermesser' wezzi-stein 'Wetzstein'

Komposita mit Verbstämmen als erstem Glied nehmen in der Geschichte des Deutschen nahezu ununterbochen zu; gegenwärtig werden ständig neue Wörter dieses Typs gebildet. Vgl Beispiele wie Drohgebärde, Eßkultur, Fahrprüfung, Lesebuch, Merkmal, Rauchverbot, Schreibhemmung; Singakademie, Stinkstiefel und Turnhalle sowie Probierstube, Renommiergehabe, Schnupperpreis und Verwöhnaroma. Wenn man bei diesem Wortbildungstyp auch nicht im strengen Sinne von polysynthetischen, also 'vielfach zusammensetzenden' Konstruktionen sprechen kann, so gehören sie doch ohne Zweifel in den hier diskutierten Zusammenhang. Sie sind ein typisches Charakteristikum der deutschen Wortbildung, das in der Mehrzahl der europäischen Sprachen kein Pendant hat.

Drittens schließlich entwickelt das Deutsche, ebenfalls beginnend mit der althochdeutschen Periode, einen Strukturtyp, den man als inkorporierend bezeichnen kann, wenn die entsprechenden Konstruktionen auch nur zu einem Teil durch wirkliche Inkorporierungsprozesse, zum anderen Teil aber durch Wortbildungsprozesse anderer Art ('Rückbildungen') entstanden sind. Es handelt sich dabei um Verben mit inkorporierten Substantiven und Adjektiven. Wir wollen uns hier auf die Betrachtung von Verben mit inkorporierten Substantiven beschränken. Solche Bildungen treten vereinzelt bereits im Althochdeutschen auf; vgl. die Verben halswerfôn 'den Hals drehen' und muotbrechôn '(sich) vor Gram verzehren'. Die Anzahl solcher komplexen Verben, die teils untrennbar wie schlußfolgern, teils trennbar wie danksagen sind, wächst seit dem Althochdeutschen beständig an. Die deutschen Verben mit inkorporierten Substantiven speisen sich aus unterschiedlichen Quellen. Neben 'echten' Inkorporierungen von direkten Objekten in das Verb wie danksagen und schlußfolgern gehören hierher 'unechte' Inkorporierungen; diese entstehen durch

- Reverbalisierungen von komplexen substantivischen Infinitiven: bausparen, probesingen; 
- Reverbalisierungen von komplexen adjektivischen Perfektpartizipien: platinbeschichten, schalldämpfen;

- Reverbalisierungen von deverbalen Nomina actionis: ehebrechen (< Ehebruch), notlanden (< Notlandung);

- Ableitungen von Nomina agentis: heimwerken, testfahren.

Im gegenwärtigen Deutschen nehmen solche Konstruktionen geradezu sprunghaft zu. Man kann faktisch ständig entsprechende Neubildungen hören bzw. lesen. Man vgl. z.B. die folgende Auswahl:

(21) Chomsky-adjungieren, endchecken, ergänzungsausstatten, feldforschen, genmanipulieren, kollektivbestrafen, kuhhandeln, säbelrassen, schleimscheißen, strafverfolgen, spitzelberichten, testfahren, volkswandern, wortprasseln

Soviel zur Entwicklung des doch beachtlichen polysynthetisch-inkorporierenden Potentials in der deutschen Wortbildung. Es spricht alles dafür, daß dieses Potential auch in Zukunft weiter wachsen wird.

\section{Zur typologischen Struktur des Neuhochdeutschen}

Nachdem zu zeigen war, da $B$ die typologische Entwicklung der Morphologie vom frühen Althochdeutschen zum modernen Neuhochdeutschen im wesentlichen durch eine Zurückdrängung der fusionierenden durch nichtfusionierende Strukturelemente gekennzeichnet ist, soll jetzt kurz zusammenfassend die typologische Struktur des Neuhochdeutschen betrachtet werden. Wir gehen dabei nacheinander auf die einzelnen Gebiete der Morphologie ein.

\subsection{Die Substantivflexion}

Da sich Numerusflexion und Kasusflexion im Neuhochdeutschen typologisch nicht einheitlich darstellen, sollen sie hier getrennt behandelt werden.

Zunächst zur Numerusflexion. Diese funktioniert primär agglutinierend, d.h. sie geschieht durch Suffixe, die nur noch für den Plural stehen, also keine Kasus mehr mitsymbolisieren. Die Suffixe $-e,-(e) n,-e r$ und $-s$ wie in Hunde, Hasen, Rinder und Ponys sind eindeutig nur Numerusmarker. Es ist die Tendenz zu beobachten, bei Formengleichheit des Substantivs selbst in Singular und Plural neue, 'sekundäre' agglutinierende Suffixe einzuführen; vgl. (der) Onkel - (die) Onkel >(die) Onkels/Onkeln, (das) Mädel - (die) Mädel > (die) Mädels/Mädeln (Madeln) usw. Desweiteren erscheint in der Numerusflexion der Umlaut als introflexives Mittel, wie erwähnt ebenfalls mit der Tendenz der Ausdehung auf neue Instanzen: 
die Bogen > die Bögen, die Hammer > die Hämmer. Schließlich tritt bei den Nichtfeminina der flektierte Artikel als isolierender Pluralmarker auf: der/das - die. Es ist charakteristisch, daB diese Marker unterschiedlichen Typs auch kombiniert erscheinen; vgl. z.B. der Wolf - die Wölfe mit drei Pluralmarkern.

Die Kasusflexion erfolgt primär isolierend durch den Artikel und resthaft noch zusätzlich durch agglutinierende Suffixe:der Hund - des Hund-es den $H u n d-\epsilon-n$, wobei sämtliche noch vorhandenen Kasussuffixe am Substantiv deutliche Abbautendenzen zeigen; vgl. z.B. des Dollar, des Iltis; dem/den Bär, dem/den Präsident; ab zwölf Meter, Käse mit Kräuter usw. ${ }^{7}$ Interessant ist nun, daß der Artikel als isolierender Marker der Substantivflexion selbst wiederum stark fusionierend flektiert wird:
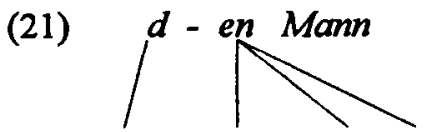

DEF MASK AKK SG

So ist mit dem isolierenden Marker des obligatorischen Artikels zugleich auch neues fusionierendes Potential in die Substantivflexion gelangt.

In der Flexion des neuhochdeutschen Substantivs wirken also fusionierende, aggluinierende und isolierende Marker zusammen. Eine solche Kombination von typologisch unterschiedlichen Strukturmerkmalen in einem Teilbereich der Flexion ist in den Sprachen der Welt sicher nicht häufig.

\subsection{Die Adjektivflexion}

Hier liegen die Verhältnisse wesentlich einfacher. Die Deklination der Adjektive ist wie im Althochdeutschen rein fusionierend und Tendenzen zur Einschränkung der Fusion sind nicht vorhanden. Die Komparation ist wie ebenfalls schon im Althochdeutschen agglutinierend.

\subsection{Die Verbflexion}

In der Tempusflexion ist die Präteritalbildung der schwachen Verben agglutinierend, partiell, nämlich in der 3.Ps.Sg., verbunden mit einem fusionierenden Suffix: er sagte vs. er sagt. Die Präteritalbildung der starken

7 Der Verlauf und die Bedingungen dieses Abbaus sind dargestellt in Wurzel (1980) und (1992). 
Verben funktioniert introflexiv, partiell, in der 1./3.Ps.Sg. ergänzt durch fusionierende Suffixdistinktionen; vgl. ich/er schrieb vs. ich schreibe/er schreibt. Die fortwirkende Tendenz zum Übergang von den introflexiven starken Verben zu den agglutinierenden schwachen Verben wurde bereits erwähnt. Die analytischen Tempusformen sind selbstredend isolierend, kombiniert mit fusionierenden Mitteln, beim Perfekt der starken Verben z.T. zusätzlich verbunden mit dem introflexiven Ablaut des Partizips Perfekt: schreiben - ich habe geschrieben.

Die Modusbildung erfolgt heute in Gestalt des 'würde-Ersatzkonjunktivs' schon weitgehend isolierend, verbunden mit fusionierenden Mitteln und bei einigen Gruppen von starken Verben im Präteritum noch introflexiv; vgl. wir kämen vs. wir kamen.

Für das Passiv gilt das gleiche wie für die analytischen Tempora.

Die Personal-Numerus-Flexion schlieBlich funktioniert im Neuhochdeutschen in Kombination der isolierenden Personalpronomen und der fusionierenden Suffixe.

\subsection{Zur Wortbildung}

Die neuhochdeutsche Kompositabildung zeigt (wie eben festgestellt) starke Tendenzen zur Polysynthese und es gibt eine ständig wachsende Zahl von Verben mit Inkorporierung. Die neuhochdeutsche Derivation, zu der bisher noch nichts gesagt wurde, ist wie die althochdeutsche im wesentlichen agglutinierend.

An dieser Stelle ergibt sich natürlich die Frage, welcher der fünf zugrundegelegten morphologischen Stukturtypen im System des Neuhochdeutschen am stärksten ausgeprägt ist, welchem dieser Typen die Sprache also insgesamt zuzuordnen wäre. Betrachtet man die diskutierten Fakten vorurteilsfrei, so ist wohl kaum eine begründete Antwort auf diese Frage möglich. Was man sagen kann, ist lediglich, daß das Neuhochdeutsche einen morphologischen 'Mischtyp' realisiert, der in dieser Form unter den Sprachen der Welt ziemlich rar, wenn nicht vielleicht sogar unikal ist.

4. Die Mechanismen der typologischen Veränderungen vom Althochdeutschen zum modernen Deutschen

Nachdem wir herausgearbeitet haben, welche Veränderungen in der typologischen Struktur vom frühen Althochdeutschen zum modernen Deutschen eingetreten sind, soll im folgenden untersucht werden, auf welche Weise sich diese Veränderungen vollzogen haben, was die Mechanismen 
dieser Veränderungen sind. Die Betrachtung der Ergebnisse des Wandels soll also durch eine Betrachtung der Wandelprozesse ergänzt werden. Wert soll vor allem auf die Beantwortung der Frage gelegt werden, welche Wandeltypen jeweils bei den einzelnen typologischen Veränderungen zusammenwirken.

\subsection{Die Mechanismen der Herausbildung des agglutinierenden Potentials}

Beginnen wir mit der Substantivflexion. Es war zu zeigen, daß die substantivischen Flexionsformen und damit auch die substantivischen $\mathrm{Pa}$ radigmen (wenn wir hier zunächst die Herausbildung des Artikels vernachlässigen) in der Geschichte des Deutschen von einer konsequent fusionierenden zu einer zumindest stark agglutinierenden Struktur übergehen. Diese Struktur ist (wie weiter oben festgestellt) charakterisiert durch Grundformflexion, durch Nichtbezeichnung der nichtabgeleiteten (unmarkierten) Kategorien Nominativ und Singular sowie durch agglutinierende Numerusmarker und, soweit noch vorhanden, quasiagglutinierende Kasusmarker (im übrigen symbolisiert auch der introflexive Pluralumlaut ausschlieBlich die Kategorie Plural).

Diese stark agglutinierende Struktur hat sich in fünf Schritten herausgebildet:

(i) Phonologischer Wandel: Bedingt durch den dynamischen Anfangsakzent wird die phonologischen Substanz der unbetonten Silben des Wortes stark reduziert (es wirken die sogenannten 'Auslautgesetze'). Von dieser Reduktion sind u.a. auch die Formen der Paradigmen vom Typ ahd. hrind betroffen, die nicht nur einen Teil ihrer Flexive, sondern im N./A.Sg. auch ihr Stammbildungselement -ireinbüßen.

(ii) Reanalyse und Grammatikalisierung: Die im Plural dieser Paradigmen durchgängig erhaltenen Instanzen des Stammbildungselements -ir- werden als Pluralmarker analysiert, was entsprechend auch eine Grammatikalisierung dieses Morphems darstellt. Damit erfolgt eine Trennung von Numerus- und Kasusflexion bei diesen Substantiven (vgl. D.Pl.hrind-ir-um).

(iii) Morphologischer Wandel: Die im Paradigma (aus phonologischen Gründen) verbliebenen Singularinstanzen des Morphems -ir- (G.Sg. und D.Sg.) werden abgebaut, so daß sich ein höheres MaB an morphosemantischer Transparenz im Paradigma ergibt. ${ }^{8}$

8 Der morphosemantischen Transparenz liegt das alte 'Form-Funktions- 
(iv) Phonologischer Wandel: Im Laufe der weiter fortschreitenden Reduktion der phonologischen Substanz der unbetonten Silben werden u.a. auch in den Flexionsformen sämtlicher Substantivparadigmen alle Vokale der Flexionssuffixe zu [ə] abgeschwächt.

(v) Reanalyse und 'Umgrammatikalisierung': Alle Flexionsformen des substantivischen Flexionssystems werden nach dem Muster der Substantive des Typs mhd. rint reanalysiert. Damit erfolgt eine durchgängige Trennung von Numerus- und Kasusflexion; vgl. tag$e-n$ wie rind-er-n. Zugleich werden die N.Sg.-Formen als flexivlos reanalysiert (so etwa zunge - G.Sg. zungen als zunge - zunge-n, nicht mehr dem Althochdeutschen entsprechend als zung-e - zungen).

Das agglutinierende Potential des deutschen Substantivs kommt also durch das Wirken von phonologischem Wandel, morphologischem Wandel und Reanalyse/Grammatikalisierung zustande, d.h. durch die Interaktion sehr unterschiedlicher Wandelprozesse.

Bei den Verben bildet sich zusätzliches agglutinierendes Potential durch den Übertritt starker Verben zu den schwachen heraus. Hier sind die folgenden Wandelprozesse relevant:

(i) Phonologischer Wandel: Durch die erwähnte Reduktion der phonologischen Substanz der unbetonten Silben werden auch die Vokale der verbalen Flexive zu [a], wodurch die starken und schwachen Verben nicht mehr anhand ihrer Grundform, des Infinitivs, zu unterscheiden sind; vgl, ahd. neman vs. suochen, salbôn, habên $>$ mhd. nemen, suochen, salben, haben.

(ii) Morphologischer Wandel: Aus der weit schwächer belegten, instabilen Flexionsklasse der starken Verben treten Wörter in die stärker belegte, stabile Flexionsklasse der schwachen Verben über, was sich noch heute fortsetzt. Unter dem hier zugrundegelegten Gesichtspunkt handelt es sich dabei um Übertritte von der introflexiven zur agglutinierenden Tempusflexion. ${ }^{9}$

Hier interagieren also phonologischer und morphologischer Wandel, in Pauls Terminologie 'Lautgesetz' und 'Analogie'.

Prinzip' zugrunde. Zum Konzept der morphosemantischen Transparenz vgl. Wurzel (1994, S. 57ff.).

9 Morphologische Wandelprozesse solcherart sind unter dem Stichwort 'Flexionsklassenstabilität' ausführlich behandelt in Wurzel (1984), S. 116ff. 
4.2 Die Mechanismen der Herausbildung des introflexiven Potentials

Wie zu zeigen war, spielen in der Flexion des Neuhochdeutschen anders als im Althochdeutschen Umlaut und Ablaut eine entscheidende Rolle.

Betrachten wir zunächst den Umlaut beim Substantiv. Auch in diesem Fall ist wieder eine ganze Reihe von Wandelprozessen einschlägig:

(i) Phonologischer Wandel: Betonte hintere Vokale werden an ein vokalisches oder konsonantisches $i$ der Folgesilbe assimiliert, also umgelautet. Aufgrund der Verteilung dieses Segments in den Paradigmen wird nur ein Teil der Flexionsformen vom Umlaut erfaBt.

(ii) Phonologischer Wandel: Durch die Reduktion der phonologischen Substanz der unbetonten Silben werden die umlautbewirkenden Segmente zu [ə] oder getilgt. Die Verteilung von nichtumgelauteten und umgelauteten Vokalen in den Paradigmen büBt ihre phonologische Motivation ein.

(iii) Reanalyse und Grammatikalisierung: Der Umlaut wird als grammatisch bedingt reanalysiert, d.h. an die grammatischen Kategorien gebunden. Damit findet eine Morphologisierung, d.h. eine Grammatikalisierung einer phonologischen Alternation statt. Bei den Substantiven mit erhaltenem Flexionssuffix wird der Umlaut zum Nebenmarker (gast - geste, lamp - lember), bei denen mit verlorenem Flexionssuffix zum einzigen und damit zum Hauptmarker (nagel negel).

(iv) Morphologischer Wandel: Im Sinne der Verstärkung der morphosemantischen Transparenz im Paradigma werden die störenden Umlautinstanzen im Singular beseitigt. Der Umlaut wird zum eindeutigen Pluralmarker.

(v) Morphologischer Wandel: Maskulina mit $\emptyset$ - und $e$-Pluralen treten in die Umlautpluralklasse über, bedingt im ersten Fall durch das Fehlen eines Pluralmarkers am Wort (so mhd. vater - vater $>$ veter, nhd. Bogen - Bogen> Bögen), im zweiten Fall dadurch, daB die Umlautklasse stärker belegt und stabil, die Nichtumlautklasse schwächer belegt und instabil ist (so frnhd. wolf - wolfe >wölfe, nhd. Strand - Strande >Strände).

Bei der Herausbildung des Pluralumlauts spielen also wiederum alle drei bisher registrierten Typen von Wandel, phonologischer und morphologischer Wandel sowie Reanalyse/Grammatikalisierung eine Rolle. 
Im Rahmen der Verbflexion äußert sich die Herausbildung eines introflexiven Potentials vor allem in der Entwicklung des Ablauts. Auch hier sind wieder mehrere Stufen dieser Entwicklung zu konstatieren:

(i) Phonologischer Wandel: Die Ablautalternation ist, nach allem was wir wissen, durch phonologischen Wandel entstanden und zwar bereits im Indoeuropäischen. Die Qualität und die Quantität der Vokale wurde bedingt durch bestimmte suprasegmentale Eigenschaften (wahrscheinlich Akzent und Ton) dahingehend verändert, daß sich eine qualitative 'Abtönung' (z.B. $e-o$ und $\hat{\boldsymbol{e}}-\hat{o}$ ) und eine quantitative 'Abstufung' (z.B. $e-\hat{e}-\boldsymbol{\partial}-\boldsymbol{\theta})$ u.a. auch der Stammvokale in den Verbparadigmen ergab. ${ }^{10}$

(ii) Phonologischer Wandel: Durch Veränderungen im suprasegmentalen System werden die phonologischen Bedingungen der Ablautalternationen abgebaut, die Verteilung der Alternanten in den Verbparadigmen wird phonologisch demotiviert. Dieser Stand ist (spätestens) im Gemeingermanischen erreicht.

(iii) Reanalyse und Grammatikalisierung: Die Vokalalternationen in den Verbparadigmen werden als grammatisch bedingt reanalysiert, d.h. an die entsprechenden Kategorien gebunden und damit morphologisiert. Der Ablaut wird damit zum kombinierten Nebenmarker für Tempus, Modus, Numerus und Person mit einer zumindest partiell stark unsystematischen Verteilung der Alternanten in den Paradigmen. Auf dieser Stufe steht das Althochdeutsche.

(iv) Phonologischer Wandel: Durch die Reduktion der phonologischen Substanz der unbetonten Silben werden u.a. auch die Vokale der verbalen Flexionssuffixe zu [ə]. Auf diese Weise werden diese Suf-

fixe hinsichtlich Tempus und Modus neutralisiert und als einziger Marker bleibt der Ablaut, der damit zum Hauptmarker wird.

(v) Morphologischer Wandel: Die morphosemantische Transparenz im Paradigma wird dadurch verstärkt, daß die Präteritalvokale im Paradigma jeweils vereinheitlicht werden.

An dieser Entwicklung sind wieder alle schon bisher relevanten Wandeltypen beteiligt.

Der Umlaut beim Verb, der speziell als einziger Marker des Konjunktivs im Präteritum Bedeutung hat (wir kämen vs. wir kamen), soll

$\overline{10}$ Vgl. dazu etwa Braune (1987, S. 53). 
nur kurz erwähnt werden. Auch hier haben wir nacheinander eine phonologische Entstehung, eine phonologische Demotivierung, eine Reanalyse mit Grammatikalisierung und schließlich eine Verstärkung der morphosemantischen Transparenz im Paradigma (durch Angleichung der Konjunktiv- an die Indikativvokale: wir sangen - wir süngen > wir sangen - wir sängen).

\subsection{Die Mechanismen der Herausbildung des isolierenden Potentials}

Während im frühen Althochdeutschen isolierende Mittel in der Flexion bestenfalls sporadisch vorkommen, sind sie für das Neuhochdeutsche in bestimmten Bereichen geradezu charakteristisch.

Im substantivischen Bereich ist in diesem Zusammenhang die Ausbildung des obligatorischen Artikels. Wir wollen uns hier auf den definiten Artikel beschränken; die Entwicklung des indefiniten Artikels verläuft jedoch weitgehend parallel. Es sind die folgenden Entwicklungsschritte zu verzeichnen:

(i) Grammatikalisierung und Reanalyse: Im Interesse einer deutlichen Symbolisierung von Definitheitsverhältnissen wird das Demonstrativpronomen der/diu/da3 zum obligatorischen Begleiter aller Substantive entwickelt, deren Definitheit nicht lexikalisch-semantisch oder syntaktisch gegeben ist (der hunt; aber sunna 'Sonne', ze naht 'zur Nacht', si sahen kampf der vor in was 'sie sahen den Kampf, der vor ihnen stattfand'). Semantisch gesehen erfolgt hier im wesentlichen ein Übergang von einer demonstrativen zu einer definiten Bedeutung des Pronomens. Das Demonstrativpronomen wird zum Artikel grammatikalisiert, was eine Reanalyse der Kategorie einschließt. ${ }^{11}$

(ii) Phonologischer Wandel: Durch die Reduktion der phonologischen Substanz der unbetonten Silben werden in den Substantivparadigmen vor allem Kasusmarker abgebaut bzw. reduziert (vgl. ahd. tag - N.Pl. taga- G.Pl. tago> mhd. tac - N.Pl. tage-G.Pl. tage). Die Distinktivität vieler Kasusformen und auch bestimmter Numerusformen in den Paradigmen ist gefährdet.

(iii) Reanalyse und Grammatikalisierung: Da der Artikel nicht nur nach dem Genus, sondern auch nach Numerus und Kasus flektiert wird und die Distinktivität seiner Formen wesentlich stärker als die der

11 Wahrscheinlich findet hier zugleich auch eine syntaktische Reanalyse substantivischer Phrasen von der NP zur DP statt. 
Substantivformen erhalten ist, wird er als Hauptmarker des Kasus und bei Formengleichheit von N.Sg. und N.Pl. auch als Marker des Numerus analysiert, wodurch er eine zweite Grammatikalisierung erfährt, die damit anders als die erste Grammatikalisierung motiviert ist.

(iv) Weiterführung der ersten Grammatikalisierung: Der obligatorische Artikel wird schrittweise auf weitere lexikalisch-semantisch bzw. syntaktisch bestimmte Gruppen von Substantiven übertragen (die Sonne; zur Nacht; sie sahen den Kampf, der ...; aber Gott), so daß heute der definite Artikel im Prinzip bei allen Substantiven außer Eigennamen und Prädikatsnomen steht und damit in allen diesen Fällen den Kasus bzw. den Numerus symbolisieren kann. ${ }^{12}$

(v) Morphologischer Wandel: Die verbliebenen (nicht durch phonologischen Wandel getilgten) Kasusflexive am Substantiv, die zu Nebenmarkern geworden sind, werden sukzessive abgebaut. Dieser Prozeß, der sich gegenwärtig vollzieht, wird aller Voraussicht nach schließlich zum Abbau sämtlicher Kasusflexive am Substantiv führen.

Auch in der Herausbildung des Artikels als Träger der Substantivflexion interagieren alle erwähnten Wandeltypen. Interessant ist hier nicht zuletzt das Zusammenwirken von zwei unterschiedlich motivierten Grammatikalisierungen.

Im verbalen Bereich entsteht ein bedeutendes isolierendes Potential durch die Herausbildung des obligatorischen Personalpronomens und der analytischen Verbformen. Zunächst zum Personalpronomen. Hier ist der Ablauf der involvierten einzelnen Wandelprozesse wie folgt:

(i) Phonologischer Wandel: Bereits im Voralthochdeutschen sind in den Flexionsparadigmen aller Verben die 1, und 3. Ps.Sg. im Präs.Opt., im Prät.Ind. und im Prät.Opt. formal zusammengefallen. Im Althochdeutschen werden dann durch die Reduzierung der phonologischen Substanz der unbetonten Silben zusätzlich die Flexive der 1. und 3. Ps.Pl. im Präs.Opt., Prät.Ind. und Prät.Opt. neutralisiert.

12 Diese Entwicklung setzt sich noch heute mit der Übertragung des bestimmten Artikels auf Personennamen auch in der Standardsprache fort der Ulli, der Meier), wodurch auch hier Kasusdistinktionen eindeutig symbolisiert werden können (... weil Ulli Gustav Willi empfohlen hat >... weil der Ulli dem Gustav den Willi empfohlen hat). 
(ii) Grammatikalisierung und Reanalyse: Das ursprünglich nicht obligatorische Personalpronomen, das ähnlich wie in anderen älteren indoeuropäischen Sprachen nur unter spezifischen Bedingungen auftritt, wird im Interesse einer eindeutigen Person-NumerusSymbolisierung grammatikalisiert, d.h. es erscheint in allen Fällen, in denen kein nominales Subjekt vorhanden ist. Dabei wird das Personalpronomen als obligatorischer Teil der Verbform reanalysiert. $^{13}$

(iii) Morphologischer Wandel: Die noch im Mittelhochdeutschen vorhandene formale Distinktion zwischen der 1. und der 3.Ps.Pl. im Präs.Ind. wird beseitigt (vgl, wir geben - sie gebent >wir geben - sie geben), wodurch die Flexive der 1. und 3.Ps.Pl. im System generell vereinheitlicht werden. Die entsprechenden Formen sind nur noch durch das Personalpronomen unterschieden.

Wie in allen anderen Fällen ist die skizzierte Entwicklung das Ergebnis des Zusammenwirkens unterschiedlicher Wandelprozesse.

Die Herausbildung der unterschiedlichen analytischen Verbformen, d.h. von Perfekt/Plusquamperfekt, Futur, Passiv und Konditional vollzieht sich zusammengefaßt auf folgende Weise:

(ia) Phonologischer und morphologischer Wandel: In der Entwicklung vom Indoeuropäischen zum Gemeingermanischen sind, offenbar durch die Interaktion von phonologischem und morphologischen Wandel, aber im einzelnen nur schwer zu rekonstruieren, eine Reihe von verbalen Tempuskategorien verlorengegangen. Ähnlich stellt sich der Abbau des Passivs (das im Gotischen noch vorhanden ist) in germanischer Zeit dar.

(ib) Phonologischer Wandel: Durch die starke Reduzierung der phonologischen Substanz der unbetonten Silben vom Alt- zum Mittelhochdeutschen ergibt sich ein weitgehender Zusammenfall der Formen des Indikativs und des Konjunktivs im Präsens bei allen Verben und im Präteritum bei allen schwachen und einem Teil der starken Verben (bei denen, deren Präteritalvokal nicht umlautbar ist). Man vgl. dazu die Formen der 2.Ps.Pl.; schwache Verben: Präsens ahd. Indikativ suochet - Optativ suochêt $>$ mhd. beides suocht, Präteritum ahd. Indikativ suochtut - Optativ suochtit $>$ mhd. beides suochtet; starke Verben: Präsens ahd. Indikativ râtet - Optativ râtêt $>$ mhd. beides râtet, Präteritum ahd. Indikativ rietut - Optativ rietît $>$ mhd.

13 Syntaktisch bedeutet das den Übergang des Deutschen von einer 'Pro-DropSprache' zu einer 'Nicht-Pro-Drop-Sprache'. 
beides rietet. Damit entfällt für diese Verben die Möglichkeit, den Optativ formal distinkt vom Indikativ zu symbolisieren.

(ii) Grammatikalisierung und Reanalyse: Es werden von ihrer Semantik her geeignete syntaktische Konstruktionen, die jeweils ein zweites Verb (habe, bin, werde, würde) enthalten, grammatikalisiert, um entsprechende temporale, diathetische bzw. modale Verhältnisse möglichst eindeutig zu symbolisieren. Die syntaktischen Konstruktionen werden als einheitliche grammatische Formen des (Haupt-) Verbs reanalysiert. ${ }^{14}$

Auch hier resultieren wie in allen anderen betrachteten Fällen die Veränderungen aus dem Ineinandergreifen unterschiedlicher Wandelphänomene.

4.4 Zu den Mechanismen der Herausbildung des polysynthetischinkorporierenden Potentials in der Wortbildung

In der Wortbildung stellen sich aufgrund ihrer Spezifik die Mechanismen der Entstehung typologisch neuer Strukturen zumindest partiell anders dar als in der Flexion. Speziell der Bildung neuer Komposita und damit auch der Bildung neuer Kompositamuster liegt stets ein außergrammatischer Faktor zugrunde, der im allgemeinen mit 'Benennungsbedarf' umschrieben wird. Während sich jedoch bei der Bildung einzelner neuer Komposita der 'Benennungsbedarf' unmittelbar, ohne daß ein grammatischer Wandel eintritt, durchsetzen kann, kommen neue Kompositamuster (wie neue Flexionsstrukturen) immer durch grammatischen Wandel ins Sprachsystem. Wir wollen im folgenden herausarbeiten, welche Typen von Wandel bei der Herausbildung der oben erwähnten drei Kompositamuster involviert sind.

14 Besonders deutlich wird die Reanalyse bei der Herausbildung der Perfektformen. Ausgangspunkt der Entwicklung sind hier transitive syntaktische Konstruktionen, in denen die Verben habên und eigan noch die ihre ursprüngliche Bedeutung 'besitzen' haben und das Partizip das Attribut zum Objekt ist; vgl.Si eigun mir ginommanan lioban druhtin min, wörtlich 'sie haben den mir genommenen meinen lieben Herrn', d.i. 'sie haben mir meinen lieben Herrn genommen'. Die Verben habên und eigan werden als Perfektmarker reanalysiert, die zusammen mit dem Partizip eine einheitliche Verbform bilden. Das Partizip verliert entsprechend seine Akkusativflexion. Damit kann diese Konstruktion dann auch auf nichttransitive Instanzen übertragen werden: Denne der paltêt, der gipuaz3it hapêt. Für eine ausführlichere Behandlung vgl. Moskalskaja (1965, S. 107ff. und S. 193ff.) sowie Wolf (1981, S. 80ft.). 
Die Herausbildung der charakteristischen polysynthetischen Kompositastruktur des Neuhochdeutschen vollzieht sich durch den schrittweisen Abbau von strukturellen Restriktionen der Kompositabildung. In den alten germanischen Sprachen (das ist auch der Stand im Gotischen) sind nur Komposita aus zwei Stämmen möglich. Es existiert also lediglich der Typ 'N = N'; Rekursivität in der Kompositabildung ist generell ausgeschlossen. In der Entwicklung des Althochdeutschen erscheinen dann die Typen 'N $=\mathbf{N}-\mathbf{N}$ ' und später auch 'N $-\mathbf{N}=\mathbf{N}$ '. Die Einschränkung, da $B$ Komposita nur aus zwei Stämmen bestehen können, ist aufgehoben. Es gilt nun also die weniger strenge Restriktion, daß Komposita aus mehr als drei Stämmen nicht zugelassen sind. Später wird auch diese Einschränkung durch eine weniger restriktive ersetzt usw. usf. Im modernen Neuhochdeutschen existiert schlieBlich keinerlei quantitative Restriktion für die substantivische Kompositabildung mehr. Anders gesagt: Im modernen Deutschen gibt es kein längstes Substantivkompositum; vgl. Donaudampfschiffahrtsgesellschaftskapitänswitwenschänder ... usw.

Die substantivischen Komposita mit verbalem Erstglied des Typs Eßzimmer entstehen aufgrund von Reanalyse: Ursprünglich existierten nur Komposita mit substantivischem Erstglied. Bereits im Althochdeutschen wurden dann substantische Erstglieder, die formal ambigue waren, d.h. ihrer Form nach sowohl Substantiv- als auch Verbstämme sein konnten, als Verbstämme reanalysiert; vgl. z.B. das Substantiv slâf-hûs, dessen erster Bestandteil der Stamm des Substantivs slâf oder des Verbs slâfan sein konnte. Nach diesem Muster werden dann Komposita mit 'echten' verbalen Erstgliedern gebildet; vgl. z.B. scer-sahs, dessen erster Bestandteil der Stamm des Verbs sceran 'scheren, schneiden' ist. Damit ist ein neues Kompositamuster entstanden. Hier wird eine qualitative strukturelle Restriktion der Kompositabildung durch Reanalyse beseitigt.

Die Herausbildung der deutschen Verben mit inkorporierten Substantiven vollzieht sich in zwei Schritten:

(i) Bildung einer neuen Kompositastruktur: Substantiva, die ihrem syntaktischen Status nach direkte Objekte entsprechender transitiver Verben sind und mit diesen zusammen 'institutionalisierte Tätigkeiten' bezeichnen, werden in die Verben inkorporiert, wodurch Komposita eines neuen Typs entstehen, so im Fall von ahd. hals-werfôn 'den Hals drehen' aus hals 'Hals' und werfôn 'hin und her werfen, drehen'. 
(ii) Reanalyse: Das Muster 'direktes Objekt + transitives Verb' wird generalisierend reanalysiert als 'Substantiv + Verb', was dann die Herleitung von Verbkomposita dieses Typs durch 'Rückbildung' aus den unterschiedlichsten Ausgangsformen, so substantivierten Infinitiven wie (das) Kopfrechnen, adjektivischen Perfektpartizipien wie goldbeschichtet, Nomina actionis wie Ehebruch, Nomina agentis wie Testfahrer, ermöglichte. Damit entstehen verbale Komposita, die zwar nicht ihrer Entstehung nach, aber ihrer Struktur nach Inkorporierungen sind; vgl. kopfrechnen, goldbeschichten, ehebrechen und testfahren. ${ }^{15}$

\subsection{Zusammenfassung: Wandeltypen und sprachhistorisches Ergebnis}

Wenn wir hier wegen ihrer eben erwähnten besonderen Spezifik die Mechanismen der Herausbildung neuer Wortbildungsstrukturen vernachlässigen, so sind es im wesentlichen drei Typen von Wandel, die für die vom frühen Althochdeutschen zum modernen Deutschen eingetretenen typologischen Veränderungen in der Morphologie verantwortlich sind, nämlich

- phonologischer Wandel,

- morphologischer Wandel,

- Grammatikalisierung und Reanalyse.

Wenn schon die Gesamtentwicklung des morphologischen Systems, wie deutlich belegt, nicht in eine typologisch einheitliche Richtung verläuft, so ist in diesem Zusammenhang doch zu fragen, ob nicht zumindest diese drei Wandeltypen jeweils in diesem Sinne einheitlich ausgerichtet sind. Wir wollen uns die einschlägigen Fakten daraufhin ansehen.

\subsubsection{Phonologischer Wandel}

Die für die Entwicklung der deutschen Morphologie relevanten phonologischen Wandelprozesse, d.h. die Reduktionen einerseits und der Umlaut andererseits, sind ihrem Wesen nach artikulatorische Vereinfachungen, d.h. phonetisch motiviert. Phonetisch motivierter Wandel ist im System

15 Es ist nicht uninteressant, daß man vielen solcher Verben ihre Herkunft nicht ansehen kann. So nimmt sich beispielsweise ehebrechen wie eine echte Inkorporierung aus (vgl. die parallele transitive Konstruktion die Ehe brechen, ist aber von Ehebruch abgeleitet. Andererseits stellt die heute verdunkelte Bildung stattfinden eine wirkliche Inkorporierung dar; vgl. eine stadt finden bei Luther mit der gleichen Bedeutung. Zur Problematik der Inkorporierungen im Deutschen vgl. Wurzel (1993). 
angelegt und insofern natürlicher phonologischer Wandel, der im Abbau von phonologischer Markiertheit besteht. ${ }^{16}$

Die beobachteten phonologischen Wandelprozesse stellen allesamt Schwächungsprozesse ('Entdeutlichungsprozesse') dar, die im Abbau phonologischer Substanz und/oder phonologischer Distinktivität bestehen. Der Abbau phonologischer Substanz bedeutet zugleich den Abbau morphologischer Substanz, die Tilgung und Neutralisation von Flexiven. In diesem Sinne führen sie, teils direkt, teils indirekt, in die Richtung isolierender Strukturen.

Doch sie haben zusätzlich noch andere Konsequenzen. Sie schaffen die strukturellen Voraussetzungen für die Reanalyse von fusionierenden Flexiven als agglutinierende Flexive, besonders deutlich beim Übergang vom Althochdeutschen zum Mittelhochdeutschen. Man vgl. dazu nochmals ahd. tag-N.Pl. tag-a - D.Pl. tag-um $>$ mhd. tac - N.Pl. tag-e - D.Pl. tag$e-n$, ahd. zung-a-N.Pl. zung-ûn >mhd. zunge - N.Pl. zunge-n. Die phonologischen Wandelprozesse bedingen also auch agglutinierende Strukturen.

Desweiteren schaffen sie die strukturellen Bedingungen für die Nutzung des Umlauts als Kategorienmarker; vgl. vorahd. gast - N.Pl. * gasti >ahd. gast - N.Pl. gesti >mhd. gast - N.Pl. geste. Sie führen damit auch zu introflexiven Strukturen.

Die phonologischen Veränderungen führen also nicht in eine einheitliche Richtung der Entwicklung des Flexionssystems, sondern in typologisch unterschiedliche Richtungen.

\subsubsection{Morphologischer Wandel}

Die in der Entwicklung zu beobachtenden morphologischen Wandelprozesse stellen allesamt Systematisierungen der morphologischen Struktur, genauer gesagt des Verhältnisses von morphologischen Kategorien einerseits und morphologischen Zeichen andererseits im Flexionssystem, dar. Sie sind entsprechend semiotisch motiviert. Auch diese Wandelerscheinungen sind im System angelegt und damit Instanzen von natürlichem morphologischem Wandel, dessen Wesen im Abbau morphologischer Markiertheit besteht. ${ }^{17}$

16 Zum phonologischen Wandel vgl. Bailey (1973, S. 36ff.), Vennemann (1988) und Wurzel (1994, S. 44ff.).

17 Zum morphologischen Wandel vgl. Wurzel (1994, S. 55ff.). 
Zum einen bedingen diese morphologischen Wandelprozesse die 'analogische' (nichtphonologische) Tilgung von Flexiven; vgl. dazu den Abbau der nach den phonologischen Reduktionsprozessen verbliebenen substantivischen Kasusflexive: nhd. dem Manne >dem Mann, dem/den Bären $>\mathrm{dem} / \mathrm{den} \mathrm{Bär}$ usw. Insofern weisen sie in Richtung isolierender Strukturen.

Zum anderen bewirken sie (im direkten Gegensatz dazu) die Erneuerung von phonologisch abgebauten Flexiven, so der substantivischen Pluralmarker am Wort; vgl. mhd. klage - N.Pl. klage >nhd.Klage - N.Pl. Klagen, nhd. Onkel - N.Pl. Onkel >Onkel - N.Pl. Onkels/Onkeln. Diese neuen Marker sind agglutinierend; in den Beispielen symbolisieren sie ausschlieBlich die Kategorie des Plurals. Hier verläuft der morphologische Wandel demnach in Richtung auf agglutinierende Strukturen.

Zum dritten vollzieht sich die Erneuerung phonologisch abgebauter Marker auch durch die Übertragung des Umlauts als Pluralmarker auf neue Instanzen, so z.B. im Fall von mhd. vater - N.Pl. vater >vater - N.Pl. veter und nhd. Bogen - N.Pl. Bogen >Bogen - N.Pl. Bögen. Es entstehen neue introflexive Strukturen im System.

Auch die morphologischen Wandelprozesse führen damit, je nach ihren spezifischen Voraussetzungen, in typologisch unterschiedliche Richtungen. ${ }^{18}$

\subsubsection{Grammatikalisierung und Reanalyse}

Grammatikalisierungen von lexikalischen Einheiten bestehen, stark verkürzt formuliert, in der Herausbildung neuer grammatischer Mittel zur Symbolisierung bisher nicht systematisch ausgedrückter Verhältnisse (d.h. in der Schaffung neuer grammatischer Kategorien, vgl. die Grammatikalisierung der analytischen Verbformen) bzw. zur möglichst eindeutigen Symbolisierung vorhandener, aber unzureichend symbolisierter Kategorien (d.h. in der Schaffung neuer formaler Mittel, vgl. die Grammatikalisierung der Personalpronomen).

Es ist natürlich evident, daß Grammatikalisierungen von lexikalischen Einheiten (die stets mit Reanalysen verbunden sind) in erster Linie Entwicklungen darstellen, die in Richtung isolierender Strukturen führen. Doch wenn lexikalische Einheiten grammatikalisiert werden, die selbst flektieren, so bringen sie auch wieder fusionierende, agglutinierende oder introflexive Marker in die Formenbildung ein, vgl. z.B. (ich) hab -e ge-

18 Vgl. dazu Wurzel (1984, S. 81ff., S. 116ff.), wo speziell die Determiniertheit morphologischer Wandelprozesse behandelt wird. 
arbeit-et, (er) wïrd-e arbeit-en oder den flektierten Artikel, der zusätzlich zur Determiniertheit auch Genus, Numerus und Kasus' des Substantivs symbolisiert. Solche Grammatikalisierungen führen aliso zu Strukturen, die fusionierende, agglutinierende und/oder introflexi vische Elemente enthalten. Es soll noch erwähnt werden, daß Grammatikialisierungen von phonologischen Alternationen (ebenfalls mit Reanaly.sen verbunden) natürlich in Richtung introflexiver Strukturen gehen; vgl. mhd. slagen - Prät. sluogen und nochmals gast - N.Pl. geste. Auch bei Grammatikalisierungen kann somit von einer einheitlichen Entwicklungsrichtung nicht die Rede sein.

Also: Keiner der drei betrachteten Typen von Wandelprozessen, die in der Geschichte des Deutschen eine Rolle spielen, bedingt eine einheitliche Entwicklungstendenz im Flexionssystem. Es liegt in ihrem Wesen, daß sie ein morphologisches System wie das des Deutschen nicht in Richtung auf eine bestimmte typologische Zielstruktur hin führen können.

\section{Fazit}

Wohl sind all die grammatischen Wandelprozesse unterschiedlicher Typen, die wir hier diskutiert haben, jeder für sich, motiviert und insofern auch gerichtet. So unterschiedlich sie im einzelnen auch seien mögen, sie 'dienen' alle der Beseitigung bestimmter Defizite im Sprachsystem, nämlich dem Abbau von phonologischer oder phonologischer Markiertheit im System bzw. der Schaffung neuer grammatischer Mittel. Doch sie folgen keinerlei irgendwie gearteten Gesamtstrategie für die Gestaltung des Systems, sind also auch durch keinen 'deutschen Sprachgeist' gesteuert. Im betrachteten Zeitraum der Geschichte des Deutschen erfolgt demgemäß keine Entwicklung in eine typologisch einheitliche Richtung. Zusammenfassend läßt sich damit das folgende Fazit der Entwicklung vom frühen Althochdeutschen zum modernen Deutschen ziehen:

(i) Es gibt keine einheitliche Entwicklungsrichtung von einem Sprachtyp, dem fusionierenden, zu einem bestimmten anderen Typ (auch nicht tendentiell) im Sinne von Gabelentz' 'Spirale' der Sprachentwicklung. Das Deutsche bewegt sich seit dem Althochdeutschen nicht eindeutig auf den in der 'Spirale' dem fusionierenden Typ folgenden isolierenden Typ zu. ${ }^{19}$

19 Nach Gabelentz' Modell der typologischen 'Spirale' entwickeln sich die Sprachen von der Isolation über die Agglutination und die Flexion (Fusion) zur Isolation zurück usw. usf., ohne freilich jemals wieder genau ihren alten Zustand zu erreichen. Vgl. von der Gabelentz (1901, S. 255ff.). 
(ii) Es gibt auch keine einheitliche Entwicklungsrichtung von einem Subty $\rho$ zum anderen, also vom fusionierend-synthetischen zum fusionierend-analytischen, wie sie von Germanisten häufig postuliert wurde. ${ }^{20}$ (Man vgl dazu speziell die Herausbildung neuer agglutinierender Strukturen.)

(iii) Es gibt nicht einmal eine einheitliche Entwicklungsrichtung der individuellen Marker, wie sie die Grammatikalisierungstheorie annimmt. Eine Reihe der zu beobachtenden Entwicklungen von Markern erfolgen zudem von der Fusion zur Agglutination, also gerade entgegen der von dieser Theorie angenommenen Richtung. ${ }^{21}$

(iv) Ebenso gibt es keine einheitliche Entwicklungssichtung bei der Ersetzung von Markern eines Typs durch Marker eines anderen Typs. So werden dis (phonologisch abgebauten) fusionierenden N.Pl.-Marker der Substantive durch agglutinierende Pluralmarker, durch introflexive Pluralmarker und durch isolierend-fusionierende N./A.Pl.- Marker (Artikel) ersetzt.

(v) Schließlich gibt es auch keine Tendenz zur Herstellung einer typologischen Adäquatheit der enzelnen Marker und Formen des Systems, d.h. zur typologischen Vereınheitlichung des Systems in Richtung auf den darin am stärksten verankerten Typ, whe es die von Dressler vertretene Variante der natürlichen Morphologie annimmt ${ }^{22}$ Die unterschiedlichen Typen von Markern und Formen im System 'vertragen' sich im Gegenteil sehr gut

Am ehesten könnte man die Gesamtentwicklung des morphologischen Systems vom frühen Althochdeutschen zum modernen Neuhochdeutschen noch negativ charakterisieren Sie führt im wesentlichen weg vom fusionierenden Typ, wenn eben auch bestımmte Gegenentwicklungen auszumachen sind.

Das alles heißt natürlich nicht, daß das morphologische System des Neuhochdeutschen eine unstrukturierte Anhäufung von Fakten darstellt. Zwar enthält es Formen, die alle fünf hier zugrundegelegten Sprachtypen repräsentieren. Dennoch ist es natürlich ein strukturiertes und funktionierendes System, das in seinen einzelnen Teilbereichen, beson-

20 So spricht z.B. Wolf $(1981$, S. 80$)$ bezogen auf das Deutsche recht undifferenziert vom „Ūbergang vom synthetischen zum analytischen Sprachbau, der sich im nominalen ... wie im verbalen Bereich bemerkbar macht"

21 Zur Grammatikalisierungstheorie vgl. Lehmann (1982)

22 Vgl. u.a. Dressler (1985). 
ders deutlich in der Kasusflexion und der Präteritalbildung, auch klare lokale Vereinheitlichungstendenzen zeigt. Doch darauf detaillierter einzugehen, wäre ein neues Thema. ${ }^{23}$

\section{Literatur}

Bailey, Charles-James N. (1973): Variation and Linguistic Theory. Arlington.

Braune, Wilhelm (1987): Althochdeutsche Grammatik. 14. Auflage, bearbeitet von H. Eggers. Tübingen.

Dressler, Wolfgang Ulrich (1985): Typological aspects of Natural Morphology. In: Acta Linguistica Academiae Scientiarum Hungaricae 35, 1-2, S. 5170.

Gabelentz, Georg von der (1901): Die Sprachwissenschaft. Leipzig.

Henzen, Walter (1965): Deutsche Wortbildung. 3. durchgesehene und ergänzte Auflage. Tübingen.

Humboldt, Wilhelm von (1836): Ūber die Verschiedenheit des menschlichen Sprachbaues und ihren EinfluB auf die geistige Entwicklung des Menschengeschlechts. Berlin.

Lehmann, Christian (1982): Thoughts on Grammaticalization. A Programmatic Sketch, vol. 1. Akup Nr. 48. Köln.

Moskalskaja, Olga Ivanovna (1965): Deutsche Sprachgeschichte. Moskva/Leningrad.

Paul, Hermann (1909): Prinzipien der Sprachgeschichte. 4. Auflage. Halle.

Paul, Hermann (1944): Mittelhochdeutsche Grammatik. 14. Auflage, bearb. von E. Gierach, Satzlehre von O. Behaghel. Halle.

Schützeichel, Rudolf (1969): Althochdeutsches Wörterbuch. Tübingen.

Skalǐ̌ka, Vladimir (1979): Das Erscheinungsbild der Sprachtypen. In: Skaliðka, Vladimir: Typologische Studien. Mit einem Beitrag von Petr Sgall. Herausgegeben von Peter Hartmann. Braunschweig/Wiesbaden, S. 21-58.

Vennemann, Theo (1988): Preference Laws for Syllable Structure and the Explanation of Sound Change. Berlin/New York/Amsterdam.

Werner, Otmar (1969): Das deutsche Pluralsystem. Strukturelle Diachronie. In: Sprache - Gegenwart und Geschichte. Sprache der Gegenwart, Jahrbuch 1968. Düsseldorf, S. 92-128.

Wolf, Norbert Richard (1981): Althochdeutsch - Mittelhochdeutsch. (= Moser, Hans/Wellmann, Hans/Wolf, Norbert Richard: Geschichte der deutschen Sprache, Bd. 1). Heidelberg.

Wurzel, Wolfgang Ullrich (1970): Studien zur deutschen Lautstruktur. Studia grammatica VIII. Berlin.

$\overline{23 \text { Vgl. dazu Wurzel (1984, S. 81ff.). }}$ 
Wurzel, Wolfgang Ullrich (1980): Ways of morphologizing phonological rules. In: Fisiak, Jacek (ed.): Historical Morphology. The Hague/Paris/New York, S. 443-462.

Wurzel, Wolfgang Ullrich (1984): Flexionsmorphologie und Natūrlichkeit. Ein Beitrag zur morphologischen Theoriebildung. Studia grammatica XXI. Berlin.

Wurzel, Wolfgang Ullrich (1989): Von der Inadāquatheit einer Affixmorphologie - Weshalb morphologische Marker nicht als eigene Einheiten im Lexikon reprāsentiert sein kōnnen. In: Motsch, Wolfgang (Hg.): Wortstruktur und Satzstruktur. Linguistische Studien, Reihe A, H. 194. Berlin, S. 277298.

Wurzel, Wolfgang Ullrich (1992): Morphologische Reanalysen in der Geschichte der deutschen Substantivflexion. In: Folia Linguistica Historica XIII/1-2, S. 279-307.

Wurzel, Wolfgang Ullrich (1993): Inkorporierung und 'Wortigkeit' im Deutschen. In: Tonelli, Livia/Dressler, Wolfgang Ulrich (eds.): Natural Morphology - Perspectives for the Nineties. Padova.

Wurzel, Wolfgang Ullrich (1994): Grammatisch initiierter Wandel. Unter Mitarbeit von Andreas und Dagmar Bittner. Projekt Prinzipien des Sprachwandels, Bd. 1. Bochum. 


\title{
NANNA FUHRHOP
}

\section{Fugenelemente}

\begin{abstract}
Die Sprecher des Deutschen haben eine klare Intuition darūber, wann und welche Fugenelemente in Komposita zu setzen sind. Dieser Intuition liegen Regeln unterschiedlicher Art zugrunde. Diese können in notwendigen Bedingungen und mitunter auch in hinreichenden formuliert werden. Zunächst werden in dieser Arbeit die einzelnen in der Literatur genannten Kriterien beschrieben (Abschnitt 1 und 2). Keines von diesen kann alleine die Systematik der Fugenelemente erfassen. An einzelnen Fugenelementen wird die Interaktion verschiedener Kriterien gezeigt (Abschnitt 4 und 5). So können Regularitäten erfaßt werden. Dabei erweist es sich insbesondere als sinnvoll, die Fugenelemente in ihrer phonologischen Substanz und nicht in ihrer ursprünglichen Funktion zu betrachten, die im allgemeinen dem Flexionssystem geschuldet ist."
\end{abstract}

\section{Einleitung}

Die Komposition mit Fugenelement ist im Deutschen weit verbreitet, das Wort selbst enthält schon ein Fugenelement: Fuge $+n+$ element. Fugenelemente haben keine eindeutige Funktion und keine klare Systematik. Immer wieder wurde versucht, Regeln $\mathrm{zu}$ formulieren. ${ }^{1}$ Zudem gibt es eine Reihe von Vorschlägen, die den Fugenelementen Funktionen im Sprachsystem zuordnen und ihre Existenz damit begründen. ${ }^{2}$ Sowohl die Erfassung in einheitliche Regeln als auch der Nachweis einheitlicher Funktionen ist bisher nicht gelungen.

In dieser Arbeit sollen Bedingungen dafür formuliert werden, wann Fugenelemente gesetzt werden. Mit Hilfe dieser Bedingungen wird die Möglichkeit geschaffen, auf die Funktion der Fugenelemente zu schließen. Die Analyse verschiedener Einzelfälle ist die Voraussetzung dafür, um die Fugenelemente ins Sprachsystem einordnen zu können.

* Ich danke Ulrike Demske, Peter Eisenberg, Jürgen Fuhrhop, Daniel Isele, Ewald Lang und Oliver Teuber für die freundliche Kommentierung.

1 z.B. Wellmann/Reindl/Fahrmaier (1974), Augst (1975), Dt. Wortbildung (1991); diachron: z.B. Gröger (1911).

2 Dressler (1984) und Wiese (1994, Ch.5: S. 40ff.), Abraham (1994), Gawlitzek-Maiwald (1994), diachron: Demske (1994) 
In den exemplarischen Analysen in den Abschnitten 4 und 5 werden die Fugenelemente in ihrer phonologischen Substanz einzeln beschrieben. Daraus ergibt sich eine kategorielle Aufteilung. Die einzelnen Fugenelemente sind durch die Interaktion verschiedener Kriterien zu systematisieren. Dabei handelt es sich um phonologische, morphologische, syntaktische und semantische Kriterien.

Von manchen Sprechern des Deutschen wurden die Fugenelemente mitunter als überflüssig empfunden und abgelehnt. Der Dichter Jean Paul ermutigte seine Kollegen, die Fugenelemente ganz auszulassen und das Problem so zu lösen:

„Das Erste, die Einführung der richtigen Doppelwörter, haben Schriftsteller zwar weniger gegen das Volk - aus dessen vielkehligem Munde schwer die Wörter Wirtshaus, Ḱriegskasse, Staatsrat werden nehmen zu sein, aber wohl gegen Schriftsteller selber in der Gewalt; und sind diese bekehrt, so wird die kleine s-Stürmerei auch bald die lesenden Sprechklassen ergreifen." (Jean Paul 1818-1820, S. 48)

Dieser Aufruf löste das Problem nicht.

Hundert Jahre später spielte der Kabarettist Karl Valentin mit der scheinbaren Regellosigkeit:

Er: „Du kannst nie aus einer Semmel Semmelnknödeln machen. [...] Das Wichtigste ist das $\mathbf{n} \mathbf{z}$ wischen Semmel und Knödeln.

[wie auch in ...] Kartoffel-n-knödeln [...], Schinkenknödeln [...], es gibt keine Knödeln ohne n."

Sie: „Doch die Leberknödeln.”

Er: „Ja, stimmt - Lebernknödeln kann man nicht sagen.” (Valentin 1985, S. 218)

Valentins Problem zeigt die Unklarheit der synchronen Systematik. Auf sie soll hier besonders eingegangen werden, auch wenn dabei die Gefahr unzulässiger Reanalysen heraufbeschworen wird (wie die Interpretation von Gänse in Gänsebraten als Pluralform, obwohl dies ursprünglich eine Genitivform war). Neben den synchronen Regularitäten spielt auch die Diachronie eine große Rolle, manche Fugen sind inzwischen schlichtweg als lexikalisiert anzunehmen, was die Suche nach Regularität erschwert bzw. manche Regularität unplausibel machen könnte. Mitunter werden sogar alle Fugenelemente als lexikalisiert betrachtet. Dem steht zum einen die Intuition der Sprecher gegenüber: Offenbar haben Sprecher eine klare Intuition über das Auftreten von Fugenelementen entwickelt. Zum anderen werden Fugenelemente produktiv verwendet - neue Komposita werden mit Fugenelementen gebildet. 


\section{Form}

\section{Phonologische Form}

Zunächst sollen die Fugenelemente phonologisch beschrieben werden. Am häufigsten sind dabei die additiven Fugenelemente, aber es finden sich auch substitutive und subtraktive. Additive Fugenelemente, die in deutschen Komposita auftreten, sind -e-, $-s-,-e s-,-n-,-e n-,-e r-,-e n s-$ (die Fugen werden der Einfachheit halber orthographisch wiedergegeben), von manchen Autoren werden auch -at- und -o- hinzugerechnet (Gymnasıallehrer, Elekt roakustik, Dt. Wortbildung 1991). St ammauslautendes Schwa wird bel Komposition manchmal getılgt (2. F3. -e- in Rebstock), seltener 'ersetzt' (durch -s- in Hilfsstellung).

Alle genanhten Fugenelemente auBer -s- und - $n$ - sind silbisch. Das - $n$ tritt dabel grundsätzlich nur in Schwa-Silben auf Da es sich bei den silbisehen Fugenelementen ausnahmslos um Schwa-Silben handelt, erscheinen die Fugenelemente auBer -s- nur in unbetonbaren Silben (im Sinne von Eisenberg 1991) Somit ist -s- das einzige Fugenelement, das - wenn es denn gesetzt wird - die Aufeinanderfolge zweier betonbarer Silben nicht verhindert Gemäß der Sonoritätshierarchie kann -s-allen Lauten (außer $s$ Lauten) in der gleichen Silbe folgen, insofern ist es als unsilbisches Fugenelement prädestiniert $\mathrm{Da}$ es sich ansonsten bei den Fugenelementen um unbetonbare silbische Elemente handelt, könnte man eıne prosodische Motivation der Fugenelemente vermuten, um zum Beispiel eine Folge mehrerer betonter Silben zu vermeiden so heißt es zwar $R_{\imath} n$ flessch, aber Rınderhackflessch. Während -n-, -r- (und Schwa sowieso) wegen ihrer hohen Sonorität nicht in die nachste Silbe gezogen werden können, kann -s-aufgrund anderer Prinzipien mit keinem anderen Konsonanten im Silbenanfangsrand im Standarddeutschen kombiniert werden (ledıglıch $s k$ ist in Skat möglich, wird aber an der Silbengrenze stets getrennt Muskat [mus kat]) - die Fugenelemente verbleiben also bereits aus phonotaktıschen Gründen im Silbenendrand.

Die Hauptdounäne des Fugen-s ist eine Position nach mehrsilbigen Wörtern, bel denen die vorangehenden Silben betonbar (also keine Schwa-Sılben), wenn auch häufig nicht betont sind, z B. Frühlıngstag, Hochzertsessen Mitunter folgt es auch geschlossenen Schwa-Silben: Verbrechensbekämpfung, Handelsvertreter, Lehrerstochter Offenen SchwaSılben folgt hingegen - $n$ - (Wtesenblume), Hier kann direkt eine negatıve prosodısche Regelmäßigkeit formuliert werden $-s$ - und $-\boldsymbol{n}$ - sind die Standard-Fugenelemente, die nach Schwa-Silben auftreten 
Mitunter wird ein phonologischer Zusammenhang $\mathrm{z}$ wischen Stamm und Fuger.element angenommen, so z.B. das häufige Auftreten des Fugen-s nach $/ t /$, was die Annahme nahelegt, daB eine Funktion der Fugenelemente die Markierung der Morphemgrenze ist (Dt. Wortbildung 1991, S. 51). Gerade / $t /$ könnte aufgrund seiner niedrigen Sonorität häufig in den Anfangsrand der nächsten Silbe gezogen werden. Da aber nicht jedem auf $/ \mathrm{t} /$ endenden Erstglied ein Fugen- $s$ folgt, dies also auch das Fugenelenent nicht systematisch bestimmt, kann die Funktion der Fugenelemente kaum in der Markierung der Morphemgrenze bestehen.

\subsection{Morptiologische Form: Flexionsendungen}

Normalerweise komponiert als Erstglied die Nominativ-Singular-Form bei Substantiven (Haustür), der Verbstamm bei Verben (Backform) und die einfache Form bei Adjektiven (Grünfink). Alle anderen Formen gelten als gefugt und sind Gegenstand dieser Untersuchung. Alle auftretenden Fugenelemente en tsprechen in ihrer phonologischen Substanz Flexionsendungen, d.h., der phonologische Bestand der Fugenelemente ist Teilmenge des phonologischen Bestandes von Flexionsendungen. Die 'fremden' Fugenelementen - o- und - al- sind auf Erstglieder fremder Herkunft beschränkt geblieben (Elektrokocher, Gymnasiallehrer) bzw. als 'Verbindungsvokal' zu fremden (betonbaren) Quasi-Suffixen: Kartothek (E. Lang, mündl. Mitteilung).

Wurzel (1970, S. 96) nimmt für jedes Wort einen Kompositionsstamm an. Allerdings kann man nicht strikt vorgehen, denn ein und dasselbe Erstglied tritt mitunter in unterschiedlichen Varianten auf, z.B. Eiweif - Eierschale, Männerbekanntschaft - Mannsbild - Mannesruhm-Mannweib, Kinderwagen - Kindesbeinen - Kindskopf - Kindbett, Rindfleisch - Rindsleder - Rinderbraten. Dabei können nicht alle Fugenelemente mit allen Stämmen kombiniert werden, sondern es treten Restriktionen auf, die zum Teil mit dem Flexionsparadigma bzw. mit der Flexionsklassenzugehörigkeit des entsprechenden Wortes zusammenhängen. Dieses 'morphologische' Kriterium unterscheidet das paradigmische von dem unparadigmischen Fugenelement (bei Wilmanns 'organisch' und 'unorganisch', bei Grimm 'unflexivisch', bei Briegleb 'Bindungs-s'). 'Paradigmisch' meint dabei, daB das Erstglied des Kompositums zusammen mit dem Fugenelement eine Wortform des Deutschen bildet - so sind z.B. Mann, Mannes und Männer Wortformen des Deutschen, während ${ }^{*} V e r$ sicherungs (Versicherungsvertreter) keine Wortform des Deutschen ist. Im letzten Fall ist also - $s$ - ein 'unparadigmisches' Fugenelement. 
Zusätzlich zu dieser rein formalen Unterteilung ist bei den paradigmischen Fugenelementen zu prüfen, welche Markierungen diese Wortformen haben, ob also Wortformen bestimmter Kategorien bevorzugt werden.

Fugenelemente treten insbesondere bei substantivischem und verbalem Erstglied auf; adjektivische Erstglieder erscheinen bis auf spezielle regionale Fälle (eisekalt, knallerot, vgl. Abschnitt 5.2) in Komposita stets in der einfachen Form (Grünfink). Verbale Erstglieder können in ihrer Stammform oder in einem mit Schwa erweiterten Stamm erscheinen: Badehose.

Die substantivischen Formen, die häufig bei dem paradigmischen Fugenelement auftreten, sind die Genitiv-Singular-Form (Herzenswunsch, Mordskerl, Freundeskreis) und die (Nicht-Dativ-) Plural-Form Hundeleine, Blumenvase, Rinderwahnsinn bzw. Bücherwurm, Gänsebraten, Müttergenesungswerk - hier ist es schon formal wegen des zusätzlich auftretenden Umlauts problematisch von einem Fugenelement zu sprechen, ohne den Zusammenhang zur Pluralform herzustellen. Die GenitivSingular-Form und die Pluralform sind neben der Grundform die stabilsten der deutschen Substantivflexion (Wurzel 1994, S. 41); hier kann ein Zusammenhang zu den Fugenelementen vermutet werden.

Im Gegensatz zum Singular bei Maskulina und Neutra ist bei den Pluralformen grundsätzlich der Genitiv und somit auch der Nicht-Genitiv nicht eindeutig, was bei Feminina auch für die Singularformen gilt, da sie für den Genitiv nicht flektieren. Komposita mit einem pluralischen Erstglied können also analog zu den (eindeutigen) singularischen Formen aus Konstruktionen mit vorangestelltem Genitiv entstanden sein.

Bei den unparadigmischen Fugenelementen ist interessant, welche Fugenelemente auftreten können. Produktiv tritt nur -s- auf (bereits - es- kann nur paradigmisch auftreten). Andere unparadigmische Fugenelemente wie -en- in Schwanenhals und -ens- in Schmerzensgeld sind diachron als paradigmisch zu werten: Schwan wurde ursprünglich schwach flektiert, von Schmerz hieB die Genitiv-Singular-Form Schmerzens (Paul/Betz 1981). Wörter wie Bräutigam und Nachtigall sind nicht mehr als Komposita zu analysieren, obwohl -i- ebenfalls ursprünglichen Flexionsendungen entsprach. Die unparadigmischen Fugenelemente außer $-s$ - sind nicht produktiv.

Die Einteilung 'paradigmisch - unparadigmisch' suggeriert, daB das Erstglied das Fugenelement bestimmt. Unbestritten gilt dies für die Form; allerdings hat das Zweitglied einen EinfluB darauf, ob überhaupt ein Fugenelement auftritt, wie in Abschnitt 5 gezeigt wird. Der EinfluB scheint insbesondere von der Wortart des Zweitgliedes und damit von der Wort- 
art des gesamten Wortes abhängig zu sein. Zunächst betrachten wir Substantivkomposita (4); in Abschnitt 5 die Besonderheiten von Adjektivund Verbkomposita.

\section{Funktion}

\subsection{Morphologische Funktion: Gliederung}

Den Fugenelementen wird häufig die Funktion der morphologischen Gliederung zugeschrieben, da eine Bevorzugung von Fugenelementen nach polymorphemischen ersten Konstituenten festgestellt wird: Werkzeug Handwerkszeug, Turmuhr - Kirchturmsuhr (van Dam 1940, S. 394f.). Durch das Fugenelement wird eine Hierarchisierung angegeben. Handwerkszeug soll also zunächst in Handwerk + Zeug und nicht in Hand + Werkzeug segmentiert werden, Kirchturmsuhr in Kirchturm + Uhr. Dies legt folgenden SchluB nahe: je komplexer das Wort, desto eher wird ein Fugenelement gesetzt. Hier ist das Fugenelement also von der Länge bzw. der Komplexität des sogenannten Erstgliedes ${ }^{3}$ bestimmt. Entsprechende Minimalpaare sind allerdings selten: Fleischer (1975, S. 126) nennt Triebkraft - Antriebskraft, Hofmauer - Friedhofsmatter.

In Schiffsanlegestelle steht zwischen Schiff + Anlegestelle ein Fugen-s. Fahrgastschiffanlegestelle ist ein komplexeres Kompositum, doch hier fehlt das Fugenelement zwischen Schiff und anlege(n). Also ist die Angabe der hierarchischen Ordnung weit davon entfernt, eine hinreichende Bedingung für die Setzung eines Fugenelements zu sein. Auch eine notwendige Bedingung kann sie nicht sein, wie Plank (1974, S. 144) feststellt.

Žepić (1970, S. 53) sucht allgemeiner nach dem Zusammenhang zwischen ein- und zweimorphemigen (also auch derivationell komplexen) Erstgliedern und ihren Fugenelementen. Er formuliert als wahrscheinlichste Kombination das zweimorphemige Erstglied mit Fugenelement und das entsprechende einmorphemige ohne ein solches. Die Kombination eines einmorphemigen Erstgliedes mit und eines zweimorphemigen ohne Fugenelement, wurde im Deutschen nicht gefunden.

Neben dieser Tendenz kann man festhalten, daß das Fugenelement, das zum Zwecke der Hierarchisierung gesetzt wird, in den meisten Fällen -sist.

3 'Erstglied' wird der Einfachheit halber statt 'vor dem Fugenelement' gebraucht. 


\subsection{Semantische Funktion: Plural}

Das paradigmische Fugenelement kann jeweils als Genitiv- oder Pluralform kategorisiert werden. Die Kategorie der Erstgliedform kann Hinweise auf die Funktion des Fugenelements liefern. So wird die Verwendung der Pluralform als Erstglied häufig rein semantisch begründet, was der Interpretation durch die Sprecher entspricht, wie das Beispiel Semmelnknödel zeigt. Trotz Valentins guter Begründung ( „Du kannst nie aus einer Semmel Semmelnknödeln machen") hat sich die Pluralform in diesem Beispiel nicht durchsetzen können. Dennoch tritt der Plural häufig als Erstglied auf, wie zum Beispiel in Bücherregal, Männerheim, Frauenarbeit, Quadratestadt, Mäusegift, Töchterschule, wobei ein Bücherregal sicher für mehrere Bücher bestimmt ist, die Quadratestadt (Mannheim) aus mehreren Quadraten besteht usw. Bei den tatsächlich auftretenden mag es sich oft wirklich um eine Vielzahl von Dingen handeln; wie das Beispiel der Semmelknödel zeigt, ist dies aber keine hinreichende Bedingung. Da auch der Schweinebraten nur Teil eines Schweines ist, ein Hühnerei nur von einem Huhn gelegt und ein Kinderwagen nur von einem Kind belegt wird, ist die Vielzahlbedeutung auch keine notwendige Bedingung für das Auftreten der Pluralform im Kompositum, so auch Plank (1974, S. 134).

\subsection{Syntaktische Funktion: Genitiv}

Wie zu Anfang behauptet, ist die Komposition im Deutschen kaum Restriktionen unterworfen. Häufig wird angenommen, da $B$ das Fugen- $s$, das seinen Ursprung im Genitiv hat, das Begriffsverhältnis des Genitivs verdeutlichen soll. So ist z.B. Schweinsleder das Leder eines Schweins, der Amtsdiener der Diener eines Amts. Die Genitivkomposita könnten also als Versuche der Verdeutlichung der Komposita gelten. In diesem Sinne unterscheidet Grimm die Typen der Komposita: eine 'eigentliche' Komposition, die „eine allgemeine, vielseitige, neue bedeutung hervor[bringt]”" und eine 'uneigentliche', die „auf dem engen und bestimmten sinn [beruht], den die construction enthält, aus welcher sie entwachsen sind." (Grimm 1878, S. 588)

Dabei haben uneigentliche Komposita notwendigerweise interne Flexion (Grimm 1878, S. 588) - also Fugenelemente. Doch diese Unterscheidung ist nach Grimm nicht gegen Wandel gefeit:

"Gleichwohl insofern das erste wort nach und nach der construction entzogen wird und die composition zustande kommt, kann sich auch sein begriff einigermaßen verändern und es gibt puncte, wo eigentliche und uneigentliche zusammensetzungen einander nahe treten, wo sie nach zeit und mundart sich gegenseitig vertreten." (Grimm 1878, S. 588) 
Für das heutige Deutsch sind nur bedingt Rückschlüsse auf die Systematik von Fugenelementen durch diese Unterscheidung zu ziehen.

Historisch ist der Bezug auch formal einleuchtend - war doch die Voranstellung des Genitivs in früheren Sprachstufen üblich: des Schwein(e)s Braten, des Amt(e)s Diener. So hält Grimm diese Art der Komposition für typisch deutsch.

"Liebte die deutsche sprache dieses vorausstellen nicht, setzte sie gleich der frz. [das abhängige nomen] immer nach, so würde es weit weniger oder gar keine deutsche uneigentliche composita geben." (Grimm 1878; S. 588)

Das Fugenelement kann Hinweis für uneigentliche Komposition sein, aber kein 'ausschlaggebendes' Kriterium. Das Begriffsverhältnis des Genitivs ist keine hinreichende Bedingung für das Fugen-s; in einigen Fällen müßte die Abwesenheit des Genitiv-s begründet werden: wieso heißt es Apfelkern und nicht Apfelskern (Briegleb 1935, S.7)? Briegleb nimmt hier eine notwendige Bedingung an:

"In der genitivischen Zusammensetzung herrscht also (bis auf spätere Ausnahmen) unbedingt das Begriffsverhältnis des Genitivs, wāhrend in der eigentlichen Zusammensetzung alle möglichen Begriffsverhältnisse, aber a u c h das des Genitivs vorliegen könnte." (Briegleb 1935, S. 8)

Sie ist auch nicht notwendig, wie Wurzel $(1970$, S. 95) an dem Beispiel Lieblingsgetränk erläutert, das nicht das Getränk des Lieblings ist. Außerdem sind feminine Erstglieder von dieser Unterscheidung ausgeschlossen. Allerdings wird das unparadigmische Fugen-s bei Feminina (wie in Versicherungsvertreter) häufig als Übertragung des genitivischen Begriffsverhältnisses interpretiert: es wäre dann ein analoge Übertragung eines 's-Suffixes' (Demske 1994, S. 18).

Es gibt einige Fälle, in denen Komposita mit und ohne Fugen- $s$ nebeneinander stehen. Manchmal bedeuten die Wörter mit und ohne Fugenelement etwas Unterschiedliches: Landmann - Landsmann; in anderen Fällen jedoch nicht, nach Blatz $(1900$, S. 751$)$ etwa Fälle wie: Bürgerkind - Bürgerskind, Heimatkunde - Heimatskunde.

Die unterschiedliche Bedeutung hat sich nach Blatz herausgebildet, weil es unterschiedliche Formen gab. Da es auch hier sehr wenige Fälle gibt, kann dies kaum eine allgemeine Funktion der Fugenelemente sein.

\section{Zwischenbilanz}

Weil die Mehrzahl der Komposita ohne Fugenelement gebildet wird, kann man kaum eine allgemeine Funktion der Fugenelemente für die Kompo- 
sition annehmen, obwohl die phonologische Eigenschaft der Elemente, nicht in die nächste Silbe gezogen werden zu können, eine Erklärung wie 'markiert die Morphemgrenze' nahelegt. Auch die Hilfe zur Interpretation der Komposita wie Markierung eines 'Genitivverhältnisses', Bezug auf Plural oder die Angabe der internen Struktur des Kompositums (Hierarchie) konnte nicht gezeigt werden. Wegen der klaren Sprecherintuition muB jedoch angenommen werden, daß Fugenelemente keineswegs willkürlich gesetzt werden und somit gewissen Regeln unterliegen.

Unser Ziel bleibt, hinreichende Bedingungen für die Setzung von Fugen zu nennen. Da die einzelnen Kriterien offenbar nicht ausreichen, andere nicht vorliegen, liegt die Interaktion verschiedener Kriterien nahe.

Die Fugenelemente werden zunächst nach ihrer phonologischen Form unterteilt. Während diese Einteilung in der Derivationsmorphologie üblich ist, steht in der Flexionsmorphologie im allgemeinen die Funktion im Vordergrund. Da die Funktion der Fugenelemente unklar ist, liegt eine erste Unterteilung aufgrund der Form nahe. Ohne Bezug auf das Erstglied können die Fugenelemente aufgrund der Form an sich, mit Bezug auf das Erstglied in 'paradigmisch-unparadigmisch' unterteilt werden, was (produktiv) nur das Fugen-s betrift. In der weiteren Unterteilung soll die Menge der auftretenen Fugenelemente möglichst adäquat beschrieben werden. Aus dieser Vorgehensweise ergibt sich, daß zunächst in den meisten Fällen nur notwendige Bedingungen formuliert werden können.

Von den auftretenden Fugenelementen sind hier jeweils über $90 \%$ der Fälle (nach Wellmann/Reindl/Fahrmaier 1974) beschrieben, außer beim paradigmischen -s-. Das Fugenelement - ens- ist hier nicht berücksichtigt, da es sehr selten auftritt. Der Untersuchung liegt eine mit Hilfe von CELEX erstellte Liste zugrunde, die manuell ergänzt wurde. Bei den exemplarischen Analysen werden unterschiedliche - morphologische und phonologische - Kriterien angewendet. Um die Bedingungen erfassen zu können, sind zunächst alle Kriterien zugelassen.

\section{Exemplarische Analysen}

\section{$4.1 \quad-s-$}

Das - $s$ - ist das häufigste und zugleich am wenigsten transparente Fugenelement. Als formale Besonderheiten des Fugen- $s$ halten wir fest, daB es unparadigmisch auftreten kann, und daß es nicht silbisch ist. Der $s-$ Plural wird in der Komposition regelmäßig ausgespart, d.h., ein Wort, das den $s$-Plural nimmt, tritt niemals mit diesem als Erstglied auf, auch 
wenn die Genitiv-Singularform homonym ist - des Autos - die Autos, aber nie ${ }^{*}$ Autosbahn. Einzige Ausnahmen sind Shrimpscocktail, Chipsfabrikant ( $H$. Wegener, mündliche Mitteilung), bei denen aber die Singularform die markierte Form sein dürfte, denn sowohl Kartoffelchips als auch Shrimps treten bevorzugt in der Mehrzahl auf. Ein 'Chipfabrikant' stellt Mikrochips her, während ein 'Chipsfabrikant' für Kartoffelchips verantwortlich ist. Für die Genitivform, die homonym zur Pluralform ist, hat K.-M. Köpcke (mündliche Mitteilung) eine Ausnahme gefunden: Leutnantsuniform.

\subsubsection{Unparadigmisches $-s$ -}

Das -s- tritt nur bei femininen Substantiven als unparadigmisches Fugenelement auf, weil diese gerade keine Genitivmarkierung aufweisen, die der Form mit -s- homonym sein könnte.

(1) a) Kindheitserinnerungen, Tapferkeitsmedaille, Wissenschafispolitik, Versicherungsvertreter, Religionszugehörigkeit, Identitätsbescheinigung

b) Abfahrtszeit, Absichtserklärung, Ansichtsexemplar, Aufsichtsverpflichtung, Auskunftstisch, Durchfahrtsstraße

c) Anstaltsleiter, Arbeitserlaubnis, Armutszeugnis, Geburtstag, Gegenwartssprache, Heiratsantrag, Vernunftsmensch

d) Hochzeitsfest.

In a) sind suffigierte feminine Substantive aufgelistet. Die hier vorhandenen Suffixe sind fast alle Suffixe des Deutschen, die feminine Substantive bilden (daneben - $e i,-e r e i,-i n$ ). Nach diesen treten Fugenelemente regelmäßig auf; bei ausdrücklicher Pluralbedeutung ist auch das entsprechende Pluralflexiv als Fugenelement möglich: Antiquitätenhandel, Minderheitenregelung. Die Erstglieder in b) sind implizite Ableitungen von Partikelverben, die in c) (synchron) Simplizia, und in d) ein formales Kompositum, das semantisch lexikalisiert ist. Die in b) - d) aufgelisteten Wörter haben auffallende Gemeinsamkeiten: die Erstglieder sind mehrsilbig und enden auf $-t$, was eine phonologische Restriktion sein könnte. Die Wörter in b) sind alte Ableitungen mit $-t$ aus Partikelverben. Die Mehrsilbigkeit scheint eine notwendige Bedingung für das unparadigmische Fugen-s zu sein. Bei den Wörtern, bei denen das zweite Glied des komplexen ersten Wortes alleine als Erstglied auftritt (also Fahrt als Erstglied im Gegensatz zu Durchfahrt, Abfahrt), taucht das Fugen-s nicht auf: Fahrtrichtung, Fahrtkosten, Fahrtunterbrechung, Sichtbehinderung, Sichtfenster, Zeitvertreib. 
Ausnahmen für das unparadigmische Fugen-s, die von solchen Einschränkungen nicht erfaßt werden können, sind: Liebesbrief, Mietshaus, Hilfsdienst. Die Ausnahmen sind bezüglich ihres alternativen Fugenelements markiert: bei Miete und Hilfe ist jeweils das Schwa durch -s- ersetzt, stammauslautendes Schwa nimmt in anderen Fällen - $n$ - als Fugenelement (vgl. Abschnitt 4.3.2).

\subsubsection{Paradigmisches -s- (Genitiv)}

Da ein Erstglied mit paradigmischem -s- niemals einer Pluralform entspricht, kann es nur der GenSg-Form homonym sein. Hier sollen nur wenige Fälle erläutert werden.

\subsubsection{Deverbale Substantive auf -en}

Für das Genitiv-s möchte ich exemplarisch deverbale Substantive auf -en analysieren. Hier seheint im allgemeinen ein -s- als Fugenelement aufzutreten.

(2) a) Essensmarke, Einkommensgrenze, Lebensversicherung, Leidensgestöhn, Mißtratensvotum, Unternehmensberater, Verbrechensbekämpfung, Vermögenslage, Vertrauensamt, Wissensdurst

b) Erdbebenvorsorge, Einschreibenbearbeitung, Guthabenzinsen

c) Bratensaft, Hustensaft, Nutzenrechnung.

In a) haben die Erstglieder neutrales Genus; sie nehmen ein Fugen-s. Die Wörter in b) sind durchweg komplex, haben neutrales Genus und nehmen kein Fugenelement, die in c) haben maskulines Genus und nehmen ebenfalls kein Fugenelement. Die zugrundeliegenden Verben in b) sind trennbar: er hat 1000 Mark gut. Die Erde bebt. ${ }^{*}$ Es erdbebt, während die in a) nicht trennbar sind: *er traut miß, *er nimmt unter. Die Erstglieder der Wörter in a) und c) sind homonym zu Verbinfinitiven.

Wir halten also fest, daß bei einfachen oder präfigierten (nichttrennbaren) deverbalen (neutralen) Substantiven auf -en das Fugen- $s$ steht.

Die Halbsuffixe -wert und -würdig folgen häufig deverbalen Substantiven auf -en:

(3) anerkennenswert, bemitleidenswert, beneidenswert, erklärenswert, kaufenswert, lebenswert, liebenswert, lobenswert, merkenswert, rügenswert, sehenswert, tadelnswert

(4) begehrenswürdig, bejammernswürdig, liebenswürdig, lobenswürdig, verabscheuenswürdig, vertrauenswürdig 
Das Fugenelement ist hier auf einen ursprünglichen Genitiv zurückzuführen (Paul/Betz 1981): Sie ist des Liebens wert/würdig. Steht als Erstglied eine zum Verbinfinitiv homonyme Form, so folgt bei diesen Halbsuffixen stets ein Fugenelement. Einzige Ausnahme sind ehrenwert und lobeswürdig, die aber auf die Substantive Ehre (4.3.2) bzw. Lob (4.1.3) zurückgeführt werden können.

\subsubsection{Implizite Ableitungen komplexer Verben}

Erstglieder, die implizite Ableitungen sind, komponieren manchmal mit Fugenelement und manchmal ohne.

(5) Abschiedsbrief, Anfangsgehalt, Antragsformular, Bestandsaufnahme, Gebrauchsanweisung, Unterhaltspflicht, Verfallsdatum, Verkaufspreis, (Verlagsanstalt), Versuchsperson, Vertragsabschluß, Vorkaufsrecht, Vorschlagsrecht, Widerspruchsgeist, Widerstandskraft

(6) (Schiedsgericht), Fangarm, Standbein, Brauchtum, Halt(e)griff, Fallbesprechung, Kaufpreis, Schlagball, Spruchband

In 5) sind als Erstglieder implizite Ableitungen komplexer Verben aufgelistet; in 6) die Ableitungen der entsprechenden einfachen Verben. Notwendige Bedingung für das Auftreten der Fugenelemente nach Substantiven, die durch implizite Ableitung entstanden sind, ist das Vorkommen eines Präfixes. Dieses entspricht der von Žepić (1970) angenommenen Tendenz, daß Fugenelemente bevorzugt nach polymorphemischen Erstgliedern auftreten (s. 2.1).

Sowohl die implizite Ableitung als auch die dem Infinitiv homonymen Formen sind formal auf Verben zu beziehen. Briegleb (1935, S. 19) ordnet dem Fugenelement die Funktion zu, die Substantivität des Erstgliedes zu zeigen. So begründet er z.B. die Fugenelemente in Handelsmann, Zweifelsfall, Wandersmann. Diese Erstglieder entsprechen prosodisch denen auf - en (4.1.2.1), könnten also auch mit diesen in Zusammenhang gebracht werden. Denn diese Unterscheidung entfällt gerade bei den meisten impliziten Ableitungen einfacher Verben. In diesen Fällen verhalten sich im Gegensatz zu den Fällen in 4.1.2.1 die präfigierten Verben anders als die einfachen Verben. Der grundlegende Unterschied, der hier zunächst festgehalten werden kann, ist die Einsilbigkeit von Erstgliedern wie Fall-, Kauf- usw., die kein Fugenelement nehmen. Der Bezug auf die Einsilbigkeit stimmt mit dem Gebrauch des unparadigmischen Fugenelements überein, das in keinem Fall einem einsilbigen Erstglied folgt.

Augst (1975, S. 113f.) spezifiziert Žepićs Aussage auf 'nach links erweiterte' Kernwörter und faßt damit die hier beschriebenen Fälle zusammen. 
Allerdings triftt diese Aussage nur die Fälle, in denen das Fugenelement direkt der akzenttragenden Silbe folgt, nicht bei den in 4.1.2.1 behandelten Substantiven auf -en.

\subsubsection{Paradigmisches -s- nach Ableitungssuffixen}

Das unparadigmische -s- tritt regelmäßig nach bestimmten Ableitungssuffixen auf. Von den produktiven Suffixen des heutigen Deutsch, die feminine Substantive bilden, nimmt die Mehrzahl ein Fugen-s; nämlich alle außer -ei (-erei, Eisenberg 1991) und -in (hier taucht häufig Plural auf: Lehrerinnenstreik, ${ }^{*}$ Lehrerinstreik). Von den maskulinen Suffixen -ling, -ler, -er, (-ian, -bold, -rich) nimmt nur -ling regelmäßig ein Fugen$s,-e r$ mitunter bei besitzanzeigenden Verbindungen Lehrerstochter (also im Falle des Genitivverhältnisses), in einigen lexikalisierten Fällen (Bauersfrau, Jägersmann) und in Ortsnamen (Spindlersfeld, Richterswil).

Das Fugenelement $-s$ - scheint im wesentlichen bei mehrsilbigen und damit häufig morphologisch komplexen Erstgliedern vorzukommen. Einsilbige Maskulina und Neutra, denen das Fugen-s folgt, sind:

(9) Amtsgericht, Bootsbau, Glücksklee, Heilslehre, Kalbsbrust, Kindskopf, Kriegsende, Lammsgeduld, Landsmann, Mannsperson, Mordskerl, Ortsname, Ratskeller, Rechtswissenschaft, Reichsmark, Rindsleder, Schiffsbau, Sportsmann, Staatsbetrieb, Stabsarzt, Stiftskirche, Volksarmee, Weibsbild, Wirtshaus, Wolfsgrube

Die Anzahl ist gering, und das Bildungsmuster scheint nicht produktiv zu sein. Außerdem gibt es für einige Erstglieder Varianten: Rinderleder, Rathaus, Lammkeule. Allerdings ist das Fugen-s bei dem Erstglied Mordin übertragender Bedeutung (Mordskerl) noch jung (Paul/Betz 1981).

Aus der Distinktivität der hier ausgewählten Fälle kann auf Folgendes geschlossen werden: Das Fugen-s tritt bevorzugt nach mehrsilbigen, derivationell komplexen Erstgliedern auf. Unparadigmisch tritt es regelmäßig nach Suffixen auf, die feminine Substantive bilden, und nach mehrsilbigen, die auf $-t$ enden. Paradigmisch kommt es nach einfachen oder präfigierten deverbalen neutralen Substantiven auf -en; bei impliziten Ableitungen komplexer Verben und nach dem Suffix -ling.

\section{1 .3 -es-}

-es- gehört zu den paradigmischen Fugen, d.h., -es- tritt nur an maskuline und neutrale Stämme. Es kann nur der Genitiv-Singular-Form entsprechen, da diese Variante von -s- keine mögliche Pluralmarkierung ist. Während die Genitivform zwischen dem Flexiv -es- und -s-variieren 
kann (des Diebes, des Diebs, des Mannes, des Manns, des Freundes, des Freunds), kann das Fugenelement in bestimmten Wörtern nur -esheißen.

(7) Armeslänge, Bundesrat, Eidesbelehrung, Eiseskälte, Fleischeslust, Geistesgegenwart, Gottesfurcht, Haaresbreite, Heeresbericht, Jahresbeginn, Kindesalter, Kreuzestod, Landesamt, Leibeskraft, Lobeshymne, Manneskraft, Meeresalge, Sangeslust, Siegesfeier, Sinnesänderung, Sohnespflicht, Stammesgeschichte, Standesamt, Tagesanbruch, Todesanzeige, Windeseile, Zinseszins, Zornesausbruch

(8) Verstandeskraft

Nur wenige Beispiele enden auf einen koronalen Frikativ, so daß Schwa nicht phonologisch begründet werden kann (Kreuzestod, Zinseszins).

Notwendige Bedingung für das Auftreten des Fugen-es ist die direkte Nachbarschaft zur akzenttragenden Silbe. Im allgemeinen meint dies ein einsilbiges Erstglied. Da -es- stets paradigmisch ist, kann es nur maskulinen und neutralen Substantiven folgen. Das Fugen-es ist nicht sehr verbreitet, die obige Aufzählung enthält alle in der CELEX-Liste vorhandenen; fehlen dürften nur wenige. Das Genitivverhältnis ist hier auch nicht durchgängig zu finden (Gottesfurcht ist nicht die Furcht Gottes) es ist also offenbar keine notwendige Bedingung.

Fast alle Erstglieder können auch ohne Fugenelement bzw. mit einem anderen als -es- vorkommen. Die Verteilung geschieht nach unterschiedlichen semantischen bzw. morphologischen Gesichtspunkten wie z.B. bei Armeslänge und Haaresbreite. Sie werden eher im übertragenen Sinne verwendet; ansonsten stehen die Bildungen Armlänge (Beinlänge, Armweite, Armband) und Haarbreite, Haarlänge zumindest in Konkurrenz.

Das Fugen-es ist notwendig in der Form bestimmt. Die Entscheidung kann entweder anhand der Morphologie des Zweitgliedes (Kindesalter, Kindesentziehung - Kinderwagen, Kindergarten) oder anhand der Semantik des Erstgliedes in dem speziellen Kompositum (Tagebuch - Tageszeitung; Tagelöhner - Tageslohn) getroffen werden. Es konkurriert mit anderen Fugenelementen, jedoch praktisch nicht mit dem Fugen-s (außer in Mannesruhm, Mannsbild, Kindesalter, Kindskopf), das in seinem Gebrauch nach einsilbigen Erstgliedern sowieso eingeschränkt ist (4.1.2.3). Eine allgemeine Tendenz ist weder aus den einzelnen semantischen Unterschieden noch aus der Morphologie des Zweitgliedes zu abstrahieren.

Einzige Ausnahme für ein zweisilbiges Erstglied ist Verstandes-; hier folgt -es- wie in den anderen Beispielen der betonten Silbe. Allerdings nimmt beispielsweise Bestand in Bestandsaufnahme nur -s-. 
Das Fugen-es ist vermutlich als lexikalisiert zu werten und wird deshalb hier nicht näher betrachtet.

\subsection{Schwa}

\subsubsection{Verbfuge}

Verbale Erstglieder treten entweder in ihrer Stammform auf (Backform, Glühwürmchen, Malkasten, Schreibtisch, Singspiel, Putzlappen) oder nehmen als Fugenelement ein Schwa.

(10) a) Ankleidekabine, Anlegestelle, Anzeigepflicht, Badeanstalt, Bindeglied, Einschreibebrief, Fragezeichen, Hängebauch, Hebebühne, Klagemauer, Ladefläche, Lebemann, Legehenne, Lesebuch, Liegestuhl, Meldestelle, Nagetier, Pflegefall, Redefreiheit, Reibelaut, Schiebedach, Schmiedeeisen, Schwebebalken, Schweigepflicht, Sendeanstalt, Siedepunkt, Sorgepflicht, Speisekarte, Sterbebett, Werbefernsehen, Zeigefinger

b) Haltestelle, Reifezeugnis, Stinkefuß, Wartesaal

Vorwiegend tritt Schwa nach Stammauslaut auf stimmhaften Obstruenten auf: Badehose, Hebebühne, Nagetier. Schwa verhindert hier die Gleichlautung der stimmhaften und stimmlosen Obstruenten im Auslaut. Außerdem folgt es manchmal dem velaren Nasal (Hängematte), dessen Stellung in der Phonotaxe ungeklärt ist. Mit bestimmten Voraussetzungen kann man hier ein / $g /$ annehmen, das aber auch auslautend nicht entstimmt wird. In b) sind die Fälle mit stimmlosen Obstruenten angeführt. Dies scheinen jedoch die einzigen Verben mit stimmlosem Obstruenten zu sein, die Schwa als Fugenelement nehmen. Das zeigt, daß stimmhafte Obstruenten keine notwendige Bedingung für das SchwaFugenelement sind. Es ist also lediglich eine Tendenz festzuhalten, daß ein Schwa-Fugenelement nach verbalem Erstglied bevorzugt nach auslautendem stimmhaften Obstruenten auftritt, zumindest im Standarddeutschen. Hier gibt es nämlich viele regionale Varianten; so wird das Schwa-Fugenelement im Schweizerdeutschen sehr viel seltener verwendet: Badzimmer, Siedfleisch, Traggriff, Wartgeld (Meyer 1989, S. 56).

$\mathrm{Da} B$ der stimmhafte Obstruent im Auslaut des Verbstammes keine hinreichende Bedingung ist, sieht man an Fällen wie

(11) Abblendlicht, Abzweigdose, Auffanglager, Ausreibtuch, Belegexemplar, Beweggrund, Bindfaden, Blendschutz, Bremslicht, Fangkorb, Einschreibbrief, K'lebstoff, Lebtag, Lesart, Reibeisen, Saugflasche, Schabeisen, Schlingpflanze, Schraubstock, Schreibblock, Schwind- 
sucht, Sendbote, Singstimme, Sprengstoff, Springbrunnen, Tob. sucht, Tragbahre, Treibmittel, Webfehler, Zündstoff

Einige dieser Verben nehmen in anderen Komposita Schwa:

(12) Bindfaden - Bindefaden, Einschreibbrief - Einschreibebrief, Lebtag - Lebemann, Lesart - Lesebuch, Reibeisen - Reibekuchen, Saugflasche - Säugetier, Schabeisen - Schabefleisch, Schneideisen - Schneidetisch, Siedfleisch - Siedetemperatur, Umhangtuch Umhängetuch, Würgengel - Würgegriff

Als These können wir festhalten, daB bei präfigierten Verben eher auf das Schwa verzichtet wird. Die Vokalqualität hat keinen EinfluB auf die Fuge.

\subsubsection{Schwa bei substantivischen Erstgliedern}

Das Schwa-Fugenelement gibt es auch in einzelnen Fällen bei substantivischen Erstgliedern.

(13) a) Hundeleine, Schweinebraten, Pferdestall, Tagebuch, Wegegeld

b) Gänsefeder, Mäusegifi

c) Ärztekammer, Räterepublik, Städtetag, Ständekammer

d) Mausefalle, Mauseloch

In einigen Fällen tritt der Schwa-Plural in der Fuge auf. Nur der SchwaPlural (also ohne Umlaut) wie in (a) kommt bei Tierbezeichnungen und bei den Wörtern Tag und Weg vor. Unparadigmisch (wegen des fehlenden Umlauts) kommt Schwa bei Maus (d) vor. Hier sind jedoch auch die jeweils paradigmischen Varianten möglich: Mäuseloch, Mäusefalle. Das Wort mausetot ist eine lexikalisierte Ausnahme: "mäusetot, " maustot. Bei vielen Wörtern mit diesem Erstglied ist nur das paradigmische Fugenelement möglich: Mäusebussard, Mäusekäfig, Mäusegift. Insofern sind die beiden in d) aufgelisteten Varianten als lexikalisiert zu werten. Den in c) aufgelisteten kann man positiv Pluralbedeutung zuweisen; ansonsten heißt es: Arztpraris, Stadtbesichtigung (vs. Städtetour), Rathaus, Standbein. Hier kann Pluralbedeutung also als notwendige Bedingung angenommen werden.

Auffällig ist das häufige Auftreten von Tierbezeichnungen in den Fällen, in denen nur Schwa auftritt, aber nicht alle Tierbezeichnungen mit Schwa-Flexiv treten mit diesem als Fugenelement auf:

Hirsch - Hirsche, Reh - Rehe: Hirschrücken - ${ }^{*}$ Hirscherücken, Rehrücken - *Reherücken 
Insofern ist zu vermuten, daß es sich genau um diese Fälle handelt und Schwa als 'reines' Fugenelement bei Substantiverstgliedern nicht produktiv ist. Es scheint aber bei positiver Mehrzahlbedeutung produktiv zu sein. Bei den gefundenen ist allerdings auffallig, daB sie alle auf dentalen Plosiv enden, und daß sie fast alle zusätzlich den Umlaut nehmen.

Für Schwa halten wir fest, daß es bei Substantiverstgliedern positiv die Mehrzahlbedeutung angibt. Für Verbstämme ist Schwa ein kategorielles Fugenelement, das heißt, es dient der Kennzeichnung des Verbseins.

\section{$4.3-e n-/-n-$}

\subsubsection{Schwache Flexion}

Substantive, die schwach flektieren, erscheinen im allgemeinen in der flektierten - also Nicht-NomSg - Form:

(14) Automatenschokolade, Bärenkäfig, Funkenregen, Heldentat, Menschensohn, Präsidentenwahl

Alle schwach flektierenden Maskulina treten in ihrer flektierten Form im Kompositum auf. Dies ist eine hinreichende Bedingung. Für schwache Maskulina kann damit eine Kompositionsstamm, der sich von der Nominativ-Singular-Form unterscheidet, angenommen werden. Bei Flexionsklassenübertritt bleibt mitunter die schwache Flexionsform in der Komposition erhalten (Schwanensee, Hahnenkamm). Die Erstglieder können analog auf andere Komposita übertragen werden; eine Übertragung des -en-alleine ist jedoch nicht möglich.

Das Fugenelement - en- ist in einer seiner produktiven Verwendungen hinreichend durch das Flexionssystem bedingt. Dies gilt auch für $-n$-bei auf Schwa auslautenden schwachen Maskulina (Franzose, Pole, Gedanke).

In seiner anderen produktiven Verwendung tritt - en- bei positiver Pluralmarkierung einiger femininer Substantive auf (Minderheitenregelung, Geburtenregelung, Antiquitätenhandel, Lehrerinnenstreik).

\subsection{2 - n-: Stammauslautendes Schwa}

Obwohl es der Normalfall zu sein scheint, daB Schwa in der Komposition - $n$ - nimmt (Blumenvase, Bienenstock, Silbenphonologie, Wiesenblume) gibt es auch Fälle, in denen Schwa anders behandelt wird: SchwaBeibehaltung (Stärkemehl, 15), Schwa-Tilgung (Eckfenster, 16), SchwaErsetzung (Hilfsverb, 17) und SchlieBung der offenen Schwa-Silbe durch -s (Liebesbrief, 18). 
(15) a) Ensemblemusiker, Erdkundelehrer, Hansestadt, Heiderōslein, Hirsebrei, Leuteschinder, Reservetank

b) Erntehelfer, Folgeschäden, Lagebericht (aber: Grundlagenforschung), Pflegefall, Pressevertreter, Pusteblume, Redepult

c) Frischebehälter, Gütesiegel, Schwächeanfall, Schwüleopfer, Stärkemehl

d) Beschwerdebrief (aber: Behördengang), Gebäudekunde, Geländemaschine, Gemäldegalerie, Gemeindevertretung, Gemüsesuppe, Geschmeideansammlung, Getreidemühle

f) Gebläsedruck, Gefälleweg, Gefügediskussion, Gelübdeschwur, Getriebegeräusch, Gewebekrankheit, Gewerbeaufsicht, Gewindemutter, Gewölbebiegung

Bei den Wörter in 15) wird Schwa beibehalten. Die Wörter in a) nehmen teils keinen Plural (Hanse), teils nicht auf $-n$ (Ensemble) und teils ist er ungewöhnlich (Heide, Erdkunde). So heißt es zwar Erdkundelehrer, aber Urkundenfälschung, Modemacher aber Modenschau. Bei manchen - namentlich denen fremder Herkunft - wird das Schwa nur in einigen Dialekten gesprochen (im Berlinischen): Avantgarde, Emaille usw. Die 'fremd' klingenden Wörter scheinen in ihrer 'Grundform' im Kompositum aufzutreten; häufig nehmen sie - wenn sie denn auf Schwa auslauten - auch keinen n-Plural. Wir klassifizieren sie hier als (lexikalisierte) Einzelfälle.

In b) (Erntehelfer, Folgeschäden, Pflegefall) sind Wörter aufgelistet, die auch auf Verben bezogen werden können, das heiBt, es sind (mit Schwa) abgeleitete Substantive, also sind sie derivationell komplex oder als verbale Erstglieder zu interpretieren (vgl. Abschnitt 4.2.1). Die Substantive in c) haben eine adjektivische Basis. Auch sie sind mit Schwa abgeleitet. Die abgeleiteten nehmen häufig gar keinen Plural (jedenfalls nicht ohne Bedeutungsänderung) oder keinen Plural mit $-n$. So sind Fälle wie ?Güten, ?Frischen fraglich. Möglicherweise sind abgeleitete Substantive resistenter gegen Tilgung und 'Schließung' der Silbe, wodurch die 'SchwaErhaltung' einigermaßen verständlich würde.

In c) wird noch eine semantische Deutung möglich, die durch Minimalpaare deutlich wird. So ist ?Stärkenmehl eher möglich als ${ }^{*}$ Stärkenbeweis. So auch Säurenkocher (insbesondere in der instrumentalen Verwendung) - *Säurengefühl, *Säurengeschmack. Lexikalisierung, also die zunehmende Undurchsichtigkeit der Bedeutung, ist nach der hier vertretenen Auffassung ein allmählicher ProzeB. So kann man annehmen, daß bei den Varianten mit - $n$ - die Lexikalisierung weiter vorangeschritten ist; der Bezug zur adjektivischen Basis wird indirekt. 
Die Stärke als Mehl ist lexikalisierter als die Stärke des Bodybuilders, die auf das Adjektiv stark bezogen werden kann; die chemische Saure lexikalisierter (oder abstrakter) als die Säure einer Zitrone; denn die Säure einer chemischen Säure ist abstrakter.

(16) a) Ascheimer, Eckfenster, Elbdampfer, Erdapfel, Farbeimer, Himbeermarmelade, Kirschbaum, Kontrollgang, Kronjuwelen, Kutschbock, Palmwedel, Pappschachtel, Pfannkuchen, Rebfrucht, Schulangst, Sprachwissenschaft, Stimmbruch

b) Bleichmittel, Brühwürfel, Duschvorhang, Erbmasse, Rutschbahn, Strafarbeit, Taufbecken, Tuschkasten, Wachposten

In 16) sind Schwa-Tilgungen aufgelistet. Die in a) aufgelisteten nehmen $n$-Plural, einige haben Varianten mit -en-jedoch nie nur mit Schwa: Farbeimer - Farbeneimer, Pappschachtel - Pappenstiel, Sprachschule Sprachenschule. Die Schwa-Tilgung bleibt hier aber weiterhin ungeklärt. In b) können auch verbale Basen angenommen werden; daher kein Schwa.

(17) Gebirgsurlaub, Geschichtsbuch (aber: Geschichtenbuch), Herbergs. papa, Hilfsverb

In 17) sind die Erstglieder keine 'reinen' Substantive. Hilfe kann auf ein Verb bezogen werden; Gebirge und Herberge sind als morphologisch komplex anzusehen. Allerdings gibt es auch Hilfestellung, hilfreich. Bei Hilfe gibt es also drei Möglichkeiten: Schwa-Beibehaltung, Schwa-Tilgung, Schwa-Ersetzung.

Liebesbrief

In 18) handelt es sich um ein unparadigmisches Fugenelement; Liebes- als Erstglied ist in dieser Form singulär; allerdings werden alle Komposita mit Liebe als Erstglied mit Liebes- gebildet.

Stammauslautende offene Schwa-Silben werden im unmarkierten Fall in der Komposition mit - $n$ - geschlossen (feminine morphologisch einfache Substantive, die einen $n$-Plural nehmen). Ist mit dem Plural eine Bedeutungsänderung verbunden, wird er vermieden (z.B. Hirse als mass noun vs. Hirsen als count noun), so auch Fleischer:

„Singulariatantum haben jedoch als erste Konstituente in der Regel kein - $n$-, vgl. hilfebedürftig (neben hilfsbedürfig), rachedurstig, wärmespeichernd." (Fleischer 1972, S. 241, auf Adjektive bezogen)

Je mehr die Ableitungen lexikalisiert werden, desto eher tendieren sie dazu, ein Fugenelement zu nehmen.

Nach dieser Betrachtung können wir festhalten, daB - $n$ - nur nach Schwa auftritt und bei Feminina auf -er: Asternstrauß, Elsternnest, Opernball, 
Schwesternliebe bzw. Schwesternhäubchen. Diese RegelmäBigkeit kann ein Grund dafür sein, daß sich Valentins Semmelnknödeln nicht durchgesetzt haben; gegen Lebernknödel spricht hier allerdings nichts.

\section{$4.4-e r-$}

Das Fugen-er folgt einsilbigen Stämmen und ist stets paradigmisch (auBer in Aschermittwoch)

(19) Aschermittwoch, Bilderstürmenei, Eierlikör, Eierschale, Geisterbahn, Götterspeise, Kinderarzt, Kleiderschrank, Lichterglanz, Liederabend, Räderwerk, Rinderpest, Schilderwald, Völkerkunde, Wörterbuch

Nach der hier vertretenen Ansicht entspricht das Fugen-er nicht nur stets der Pluralform, sondern es dient bei produktiver Verwendung auch stets dazu, auf eine Mehrzahl hinzuweisen.

(20) Länderspiel, Schilderwald, Liederabend, Wörterbuch.

Das einzige Wort, in dem das Fugenelement (synchron) nicht der Pluralform entspricht, ist Aschermittwoch. Da heute der Bezug auf Asche kaum noch klar ist, ist dieses Wort lexikalisiert. Außerdem entspricht Ascher der alten Pluralform (Pfeifer 1989). Nun gibt es noch einige Wörter, in denen der Bezug auf die Mehrzahl nicht bestätigt wird.

(21) Rinderbraten, Hühnerei, Eierschale, Kinderwagen

$\mathrm{Da} B$ Tierbezeichnungen sich in Komposita mitunter anders verhalten, war schon bei dem Schwa-Plural zu sehen. Bei $E i$ wie in Eiweiß gibt es auch andere Erstglieder, früher hieß es z.B. Eierweiß und Eiergelb (so Pfeifer 1989). Die ehemalige Pluralform ist also aus dem Kompositum verschwunden. Da die Wurzel von $E i$ sprachgeschichtlich zweisilbig war, entspricht das Erstglied in früheren Sprachstufen dem Stamm. Die Interpretation als Pluralform ist also eine Reanalyse. Der zunehmende Abbau dieser Form unterstützt die These, daß -er-als positive Pluralkennzeichnung in Komposita interpretiert wird, so auch Henzen (1957, S. 60).

Produktiv ist -er- bei expliziter Pluralbedeutung (Völkerkunde - Volkskunde). Dies ist eine notwendige und keine hinreichende Bedingung.

„Die er- Fuge bei der Zusammensetzung von Kardinalzahlen mit Substantiven in Fällen wie Drei-er-gespräch [...] schließt sich Mustern an, in denen eine -er-Ableitung aus Numeralia als Bestimmungswort fungiert: Achterrennen usw ...” (Dt. Wortbildung 1991, S. 60) 


\subsection{Zwischenbilanz: Nominale Komposition}

Die Fugenelemente, die nach einsilbigen Substantiven auftreten, sind -es-, -ens- und -s-. Sie sind in diesem Kontext als lexikalisiert zu werten. - en- tritt stets bei schwachen Maskulina auf und ist vom Flexionsparadigma bestimmt, schwache Maskulina können generell nicht in ihrer Nominativ-Singular-Form als Erstglieder auftreten. Die produktiven Fugenelemente bei substantivischen Erstgliedern sind somit -e-, -er-, - $n$ - und -s-. Ferner sind -e- und -er-sowohl vom Flexionsparadigma als auch von der Bedeutung determiniert - sie treten nur bei positiver Pluralbedeutung auf. Insofern sind $-s$ - und $-\boldsymbol{n}$ - am unabhängigsten vom Flexionssystem.

Man kann eine Abstufung feststellen: -ens-, -s-, -es-, die nach einsilbigen Substantiven auftreten, sind lexikalisiert. - en- ist bei schwacher Flexion nur durch das Flexionssystem bestimmt. -e-, -er- sind sowohl vom Flexionssystem als auch von der Bedeutung bestimmt. Damit sind alle produktiven silbischen Fugenelemente durch das Flexionssystem notwendig begründet; möglicherweise hängt die hinreichende Begründung mit der Prosodie zusammen. Das Fugenelement $\boldsymbol{n} \boldsymbol{n}$ - ist formal an das Flexionssystem gebunden, semantisch jedoch nicht. Obwohl es stets dem Pluralflexiv entspricht, bezeichnet es keine Pluralbedeutung. Dahingegen ist die Bindung von -s- an das Flexionssystem negativ zu bestimmen: es ist ausgeschlossen, wenn das Erstglied zusammen mit dem Fugenelement homonym zu einer Pluralform ist. Außerdem tritt es als einziges Fugenelement unparadigmisch auf. Diese beiden Fugenelemente konnten im wesentlichen durch 'derivationelle Komplexität' begründet werden. Für diese Begründung ist $Z$ weisilbigkeit eine notwendige Bedingung. Für - $s$ haben wir das gezeigt, für - $n$ - ergibt es sich aus der Tatsache, da $\beta$-nauf Schwa auslautenden Substantiven folgt. Beide verändern die Prosodie des Erstgliedes nicht. Bezüglich der morphologischen Komplexität treten sie allerdings komplementär auf: der unmarkierte Fall für auf Schwa auslautende Substantive ist das Auftreten des Fugen- $\boldsymbol{n}$, ansonsten die Fugenlosigkeit. Die morphologische Komplexität wird markiert ausgedrückt: durch das fehlende Fugen- $n$ beim Schwa-Auslaut und sonst durch das Auftreten des Fugen-s. Der Schwa-Plural drückt - wie gesagt - eine Mehrzahl aus. Insofern ist eine offene Schwa-Silbe stets zu interpretieren (als Kennzeichnung eines Verbstammes, als Pluralkennzeichnung oder als Derivationssuffix). Schwa bei Verberstgliedern ist ein kategorielles Fugenelement, das den verbalen Charakter des Erstgliedes betont. Wegen seiner phonologischen Restriktion ist es allerdings nicht sehr stark. 


\section{Nicht-substantivische Zweitglieder}

Im allgemeinen wird das Fugenelement durch das Erstglied bestimmt. Dieser These liegt die Tatsache zugrunde, daß die meisten Komposita Substantivkomposita sind.

\subsection{Zusammensetzung - Zusammenfügung}

Ähnlich Grimms Unterscheidung von eigentlicher und uneigentlicher Komposition wird heute häufig eine Unterscheidung zwischen Zusammensetzung und Zusammenfügung (so z.B. Augst 1975) gemacht. Augst unterscheidet lediglich danach, ob das Fugenelement vom Zweitglied bestimmt wird, d.h. ob sich das Erstglied von dem Erstglied eines Substantivkompositums unterscheidet. Weil das Zweitglied einer anderen Kategorie zugehört, erscheint das Erstglied in anderer Form als sonst. Dabei kann das Zweitglied ein Verb, ein deverbales Substantiv oder ein Adjektiv sein. Das gesamte Verb erscheint dabei stets in einer infiniten Form (Infinitiv, Partizip I und Partizip II), bei Flexion wird die Zusammenfügung getrennt oder ist so nicht möglich. Die Formen kommen hier mitunter so vor wie in dem entsprechenden Satz oder mit dem Fugenelement der entsprechenden Substantivkomposita:

kennenlernen, Zähneputzen, richtungweisend - richtungsweisend, verstandbegabt, aufsichtführend - geistesgestört.

Diese Art der Komposita ist historisch jünger, so daß die Herausbildung und die Verselbständigung des Fugenelements noch nicht weit vorangeschritten ist. Synchron müssen sie allerdings beachtet werden.

\subsection{Adjektivisches Zweitglied: Fugenelement der Emphase}

Bei adjektivischen Zweitgliedern tritt zur Verstärkung der Adjektivbedeutung manchmal ein Schwa als Fugenelement auf.

(22) eisekalt, heilefroh, knallerot, stinkesauer

In der Berliner Region sind dies Varianten der gleichen Komposita ohne Fugenelement. Dabei scheint charakteristisch zu sein, daß das Erstglied ohne Fugenelement einsilbig ist. Die Wortart des Erstgliedes ist zwar nicht determiniert (es können Substantive, Adjektive oder Verben sein), aber weitgehend bedeutungsleer (das Erstglied an sich dient nur zur Verstärkung). 


\subsection{Deverbale Substantive}

Deverbale Substantive verlangen mitunter ein anderes Fugenelement als 'primäre' Substantive.

Insbesondere Ableitungen der Verben geben und nehmen werden häufig als ungewöhnlich eingeordnet, da sie häufig die Nominativ-Singular-Form verlangen, obwohl in anderen Komposita mit dem gleichen Erstglied ein Fugenelement verlangt wird. So heiBt es zwar Arbeitswille aber Arbeitnehmer, Arbeitgeber und auch das sonst regelmäBige Fugen-s nach dem Suffix -ung wäre bei Stellungnahme ungrammatisch. Aber auch andere Nomina agentis verlangen das Fugenelement der syntaktischen Konstruktion: Augst (1975) nennt Plānemacher, Geschäflemacher.

Bei anderen deverbalen Substantiven bleibt mitunter auch die von der Syntax geforderte Form bestehen. So kann bei einem Wort wie Eiersuche auf das Erstglied nur mit einem pluralischen Pronomen referiert werden:

(23) a) Eiersuche - Die Kinder sind auf Eiersuche - wenn sie sie / welche / eines *es finden, kommen sie zurück.

b) Die Kinder sind auf Eisuche. Wenn sie es / eines / ?sie / ?welche finden, kommen sie zurück. (Dressler/Barbaresi 1991, S. 138)

Der Einfluß der Zweitglieder ist keineswegs einheitlich. Allerdings bieten sich nur die zwei 'vorhandenen', aber keine neue Möglichkeiten: entweder es wird das Fugenelement der Substantivkomposita genommen oder das der entsprechenden syntaktischen Konstruktion. Während die PartizipPerfekt-Komposita weitgehend das Fugenelement der substantivischen Zweitglieder nehmen, stehen die Komposita, die mit dem PartizipPräsens gebildet werden, näher an der entsprechenden ursprünglichen syntaktischen Konstruktion.

Bei Annäherung an die 'normale' Komposition ist auch eine Angleichung der Fugenelemente festzustellen (z.B. richtungweisend - richtungsweisend), was darauf hindeutet, daß die Komposition sich formal von der ursprünglichen syntaktischen Konstruktion wegbewegt und das Fugenelement sich zu einer selbständigen Einheit mit selbständigen Regeln entwickelt.

\section{Zusammenfassung}

Die Fugenelemente werden keineswegs willkürlich gesetzt. Eine einheitliche Begründung für alle gibt es nicht. Wann die hier exemplarisch vorgeführten Fugenelemente gesetzt werden, dafür konnten notwendige Bedingungen formuliert werden; in einigen Fällen sogar hinreichende. Dabei 
können die einzelnen phonologisch bestimmten Fugenelemente systematisiert werden. Diese Systematik zeigt auch ihre Funktion. Sie sind entweder nur durch das Flexionssystem bestimmt (-n-, -en- bei der schwachen Flexion), durch eine Pluralbedeutung (-er- und $-e-$ bei Substantiverstgliedern) oder durch die Markierung der derivationellen Komplexität der Erstglieder (-s-, - $n$ - bei stammauslautendem Schwa).

'Normale' Fugenelemente setzen sich durch. Wenn neue Kompositionstypen entstehen, wie bei den Verbkomposita gezeigt, ist deutlich ein Wandel festzustellen: Die Flexionsendungen der ursprünglichen syntaktischen Konstruktion verschwinden, an ihre Stelle treten die in dieser Arbeit untersuchten üblichen ('normalen') Fugenelemente. Deren Funktion wird durch diesen Wandel noch verstärkt.

Die Fugenelemente sind auf unterschiedliche Weise entstanden. Die meisten haben sich aus der Flexion entwickelt, weil sich das Sprachsystem verändert hat (z.B. wurde das Genitivattribut nachgestellt). Andere sind ursprünglich aus Stammbildungssuffixen entstanden (Rinderbraten). Sie konnten wegen synchroner Homonymie als Flexionsendung reinterpretiert werden.

Als es sprachgeschichtlich möglich wurde, zwei Wörter zu einem neuen zusammenzusetzen, entstanden sinnlose Segmente: Die Flexionsendung des ersten Wortes verlor ihre Funktion. Das Sprachsystem hat wenigstens drei Möglichkeiten, auf die 'Sinnlosigkeit' derartiger Segmente zu reagieren; erstens können sie getilgt werden, wie es bei Eiweiß, das ursprünglich Eierweiß hieß, geschehen ist; zweitens kann das Fugenelement gemäß seiner Form reinterpretiert werden - z.B. als Pluralflexiv wie bei -er- und -e-; oder es wird ihnen drittens eine (neue) Funktion gegeben, wie bei - $n$ - und -s-. Aus allen drei Möglichkeiten ergibt sich jeweils eine neue Systematik: das Sprachsystem ordnet sich neu und bestimmt, welche Fugenelemente produktiv sind. Der Stand dieser Neuordnung wurde hier dargestellt.

\section{Literatur}

Abraham, Werner (1994): The Focus Null Hypothesis and the Head-Direction Parameter: Word Compounding. In: de Boer, A./de Hoop, H./de Swart, H. (Hg.): Language and Cognition 4. Yearbook of the Research Group for Theoretical and Experimental Linguistics of the University of Groningen. Groningen. S. 1-12.

Augst, Gerhard (1975): Untersuchungen zum Morpheminventar der deutschen Gegenwartssprache. Tübingen. 
Blatz, Friedrich (1900): Neuhochdeutsche Grammatik mit Berücksichtigung der historischen Entwickelung der deutschen Sprache. Bd 1. 3., völlig neu bearbeitete Aufl. Karlsruhe.

Briegleb, Otto (1935): Das verfemte Zwischen-s bei Wortzusammensetzung. Leipzig.

Dam, Jan van (1940): Handbuch der deutschen Sprache. Bd. 2. Groningen.

Demske, Ulrike (1994): Wort- vs. Phrasenstruktur: Zur Entstehung von sog. 'Genitiv'-Komposita im Deutschen. Ms. Stuttgart.

Deutsche Wortbildung (1991): Fugen: Die formale Verbindung zwischen den Konstituenten. In: Vierter Hauptteil: Substantivkomposita. Berlin.

Dressler, Wolfgang Ulrich (1984): Zur Wertung der Interfixe in einer semiotischen Theorie der Natürlichen Morphologie. In: Wiener Slawistischer Almanach 13, S. 35-45.

Dressler, Wolfgang Ulrich/Barbaresi, Lavinia Merlini (1986): How to Fix Interfixes? In: Acta Linguistica Academiae Scientiarum Hungaricae 36, S. 53-67.

Dressler, Wolfgang Ulrich/Barbaresi, Lavinia Merlini (1991): Interradical Interfixes: Contact and Contrast. In: Ivir, Vladimir/Kalogjera, Damir (Hg.) Languages in Contact and Contrast. Berlin. S. 133-145.

Eisenberg, Peter (1991): Syllabische Struktur und Wortakzent: Prinzipien der Prosodik deutscher Wörter. In: Zeitschrift für Sprachwissenschaft 10/1, S. 37-64.

Erben, Johannes (1993): Einführung in die deutsche Wortbildungslehre. 3. Auflage. Berlin.

Fleischer, Wolfgang (1975): Wortbildung der deutschen Gegenwartssprache. Tübingen.

Fleischer, Wolfgang/Barz, Irmhild (1992): Wortbildung der deutschen Gegenwartssprache. Tübingen.

Gawlitzek-Maiwald, Ira (1994): How Do Children Cope with Variation in the Input? The Case of German Plurals and Compounding. In: Tracy, Rosemarie/Lattey, Elsa: How Tolerant Is Universal Grammar? Tübingen. S. 225-266.

Grimm, Jacob (1878): Deutsche Grammatik II. hrsg. von Wilhelm Scherer. Hildesheim. 1967.

Gröger, Otto (1911): Die althochdeutsche und altsächsische Kompositionsfuge. Zürich.

Grube, Henner (1976): Die Fugenelemente in neuhochdeutschen appellativischen Komposita. In: Sprachwissenschaft 1, S. 187-222.

Henzen, Walter (1957): Deutsche Wortbildung. Zweite, verbesserte Auflage. Tübingen.

Jean Paul (1818-1820): Über die deutschen Doppelwörter; eine grammatische Untersuchung in 2 wölf alten Briefen und 2 wölf neuen Postskripten. In: Sämtliche Werke. Abteilung 2. Bd. 3, hrsg. von Norbert Miller. München. S. 9-108. 
Meyer, Kurt (1989): Wie sagt man in der Schweiz? Mannheim.

Nitta, Haruo (1987): Zur Erforschung der 'uneigentlichen' Zusammensetzung im Frühneuhochdeutschen. In: Zeitschrift für deutsche Philologie 106, S. $400-416$.

Paul, Hermann (1981): Deutsches Wörterbuch. Bearb. von Werner Betz. 8. Aufl. Tübingen.

Pfeifer, Wolfgang (1989): Etymologisches Wörterbuch. Berlin.

Plank, Frans (1974): Die Kompositionsfuge in der nhd. Nominalkomposition. Magisterarbeit Universität Regensburg

Valentin, Karl (1985): Gesammelte Werke. Hrsg. von Michael Schulte. München.

Wellmann, Hans/Reindl, Nikolaus/Fahrmaier, Annemarie (1974): Zur morphologischen Regelung der Substantivkomposition im heutigen Deutsch. In: Zeitschrift fūr deutsche Philologie 93, S. 358-378.

Wiese, Richard (1994): The Phonology of German. Ms. Düsseldorf.

Wurzel, Wolfgang Ullrich (1970): Studien zur deutschen Lautstruktur. Berlin.

Wurzel, Wolfgang Ullrich (1994): Skizze der Natūrlichen Morphologie. In: Papiere zur Linguistik 50/1, S. 23-50.

Żepić, Stanko (1970): Morphologie und Semantik der deutschen Nominalkomposita. Zagreb. 


\section{Phonologie und Graphie}





\title{
Silben- und Morphemstruktur in der Phonologie des Deutschen*
}

\begin{abstract}
In diesem Aufsatz wird anhand von ūberwiegend deutschen Beispielen gezeigt, daß sich phonotaktische Beschränkungen sowohl auf die Silbe als auch auf das Morphem beziehen können. Es wird die Hypothese aufgestellt, daß nur die Beschränkungen, die das Morphem als Domäne haben, Ausnahmen zulassen können.
\end{abstract}

\section{Einleitung}

Seit Anfang der siebziger Jahre ist sehr viel über die Rolle der Silbe in der Phonologie geschrieben worden. Die Popularität diese Themas ist im großen und ganzen auf die Behauptung von Chomsky und Halle (1968) in Sound Pattern of English zurückzuführen, daß die Silbe keine phonologische Entität sei. Diese Ansicht hat sich als falsch erwiesen, wie zahlreiche Phonologen in den späten 70er und den $80 \mathrm{er}$ Jahren mit verschiedenen sprachspezifischen Studien gezeigt haben. ${ }^{1}$

Eine Grundannahme der Silbenphonologie ist, daß auch die Silbe - und nicht nur das Wort - Domäne für phonotaktische Regularitäten sein kann. Ein bekanntes Beispiel ist die Auslautverhärtung im Deutschen. Obstruenten, d.h. Plosive und Frikative, sind im Deutschen am Ende eines Wortes stimmlos, aber man kann nicht davon ausgehen, daß die Regel der Auslautverhärtung wortfinal operiert, weil sie auch wortintern Anwendung findet. Relevante Beispiele sind in (1a) angegeben: ${ }^{2}$

- Ich danke Peter Janker, Ursula Kleinhenz, Ewald Lang, und Sylvia Lōhken für viele nützliche Hinweise und Vorschläge

1 Einige dieser Studien sind Fudge (1969), Vennemann (1972), Kahn (1976), Hooper (1976), Steriade (1982), Clements/Keyser (1983), Levin (1985), Ito (1986), und Vennemann (1988). Die Silbe wurde auch von vielen Phonologen im Strukturalismus angenommen (z.B. Pike/Pike (1947), Hockett (1955) und Haugen (1956)).

In den letzten 15 bis 20 Jahren sind auch viele Arbeiten über die Rolle der Silbe speziell in der deutschen Phonologie entstanden. Vier bekannte Studien sind Giegerich (1985), Wiese (1988), Giegerich (1992), und Hall (1992).

2 Ein Punkt in der phonetischen Form entspricht einer Silbengrenze. „ $\sigma$ ” bezeichnet in (1b) und unten eine Silbe. 
(1a)

$\begin{array}{ll}\text { Freund } & \text { [.fRoYnt.] } \\ \text { freundlich } & \text { [.fRoYnt.lic.] } \\ \text { Freunde } & \text { [.fRoYn.də.] }\end{array}$

(1b) [+obstruent] $\rightarrow[$-stimmhaft $] / \ldots] \sigma$

Wenn die Silbe als phonologische Entität zugrunde gelegt wird, kann man die Auslautverhärtung als silbenbezogene Regel wie in (1b) analysieren. ${ }^{3}$

Dieses Beispiel zeigt, daB das Wort als Domäne für die phonologische Regularität der Auslautverhärtung nicht ausreicht, sondern daß hier auch die Silbe zu berücksichtigen ist. Viele Phonologen gehen davon aus, daß alle phonotaktischen Regularitäten silbenbezogen sind. Ein Beispiel ist der Artikel von Hooper (1975), in dem die Autorin behauptet, daB nur die Silbe und nicht das Wort oder das Morphem die Domäne für phonotaktische Beschränkungen ist. Zahlreiche Linguisten haben sich dieser Idee angeschlossen.

In diesem Artikel wird diese Auffassung in Frage gestellt. Selbstverständlich kann sich die Phonotaktik auf die Silbe beziehen - dafür gibt es genügend Beispiele. Der wichtige Punkt ist jedoch, daß für viele phonotaktische Regularitäten die Domäne das Morphem ist. Dieser Artikel soll dazu beitragen, zwei Arten von phonotaktischen Bedingungen, nämlich Silbenstrukturbedingungen und Morphemstrukturbedingungen auseinanderzuhalten. Die letzteren gab es $\mathbf{z w a r}$ auch schon in Sound Pattern of English, aber seit die Silbe in der Phonologie FuB gefaßt hat, werden sie vernachlässigt. ${ }^{4}$

Zwar ist Gegenstand der folgenden Untersuchung hauptsächlich die Phonotaktik des Deutschen, im Laufe des Artikels werden aber auch Silbenund Morphemstrukturbedingungen in anderen Sprachen berücksichtigt. Als erstes Beispiel werden einige phonotaktische Generalisierungen des Englischen diskutiert, die beide Arten von Bedingungen erläutern sollen.

$3 \mathrm{Daß}$ die Auslautverärtung silbenbezogen ist, ist relativ unumstritten. Seit einigen Jahren bespricht man eher die Frage, ob ein Obstruent im Deutschen am Ende einer Silbe auslautverhärtet wird, wie in (1b), oder in der subsilbischen Konstituente Koda (s. Vennemann (1972), (1978), Wiese (1988), Rubach (1990), und Hall (1992), (1993) für Diskussion).

4 Eine Ausnahme zu diesem Trend ist Davis (1991), der eine Morphemstrukturbedingung des Englischen behandelt. 
Im Englischen kann das Wort bzw. die Silbe - die Unterscheidung ist in diesem Fall nicht wichtig - auf zwei stimmhafte Obstruenten auslauten wie in (2):

$\begin{array}{lll}\text { kid+s } & {[\mathrm{kId}]} & \text { "Kinder" } \\ \text { bagts } & {[\mathrm{b} 2 \mathrm{gz}]} & \text { "Taschen" } \\ \text { rob+s } & {[\mathrm{rabz}]} & \text { "stiehlt" }\end{array}$

Beispiele wie die in (2) haben eine Gemeinsamkeit: Es gibt immer eine Morphemgrenze - in (2) und nachfolgend durch ein " + " gekennzeichnet - zwischen den zwei finalen Obstruenten. Mit anderen Worten, es gibt im Englischen keine finale Abfolge, die auf zwei stimmhafte Obstruenten auslautet, wenn diese Laute zum selben Morphem gehören. Diese Lücke kann man mit der negativen Morphemstrukturbedingung in (3) erfassen (s. Kahn 1976):

(3) Morphemstrukturbedingung für das Englische:

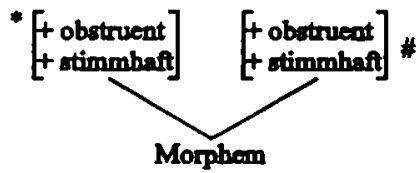

Diese Bedingung besagt, da $\beta$ zwei stimmhafte Obstruenten, die zu demselben Morphem gehören, in finaler Position (d.h. vor "\#") ausgeschlossen sind.

Die Lücke, die diese Bedingung erfaßt, ist nicht zufällig; Kahn (1976) hat gezeigt, daB erfundene englische Wörter wie [n£gz] und [libd] von Muttersprachlern immer als bimorphemisch interpretiert werden, d.h. als Plural- oder als Vergangenheitsformen.

Es gibt allerdings ein paar Ausnahmen zu der Bedingung in (3): Erstens gibt es idiosynkratische Ausnahmen, nämlich die zwei allerdings seltenen Wörter adze, und ides in (4):

(4) adze [ædz] „Breitbeil” ides [aidz] "Datum”

Zweitens gibt es viele (native) Eigennamen, die gegen die Bedingung in (3) verstoßen. Einige Beispiele sind in (5) aufgelistet:

(5) Boggs, Riggs, Gibbs, Hobbes, Ives 
Die Idee, daß Namen Ausnahmen zu phonologischen Generalisierungen bilden können, ist nicht neu (s. Raffelsiefen 1993). Man darf aber nicht außer acht lassen, daß Namen ohnehin anderen phonologischen Regularitäten unterliegen. In diesem Fall sind die Namen in (5) wohlgeformte englische Silben. Englische Silben können auf zwei Obstruenten auslauten, aber nicht jede Kombination ist möglich: Ein [p] und ein [k] zusammen kommen beispielsweise in finaler Position nicht vor, eine Generalisierung, die auch für das Deutsche zutrifft, wie unten gezeigt wird. Diese Generalisierungen $z u$ silbenfinalen Konsonantenverbindungen des Englischen sind in (6) in zwei Silbenstrukturbedingungen zusammengefaßt. Die letzteren unterscheiden sich von den Morphemstrukturbedingungen dadurch, daB die Abfolgen sowohl tautomorphemisch, als auch heteromorphemisch sein können.

(6) Silbenstrukturbedingungen für das Englische:

(6a) positiv: [+obstruent][+obstruent]] $]_{\sigma}$

(6b) negativ: * [+obstruent, -koronal] [+obstruent, -koronal] $\sigma$

(6a) ist eine positive Bedingung, die zwei Obstruenten in silbenfinaler Position zuläßt. (6b) besagt, daß zwei nichtkoronale ${ }^{5}$ Obstruenten in silbenfinaler Position nicht vorkommen, d.h., englische Silben, die auf ${ }^{*}[\mathrm{pk}]$, oder ${ }^{*}[\mathrm{kp}]$ usw. auslauten, sind ausgeschlossen.

Die Namen in (5) enthalten nach den Silbenstrukturbedingungen in (6) wohlgeformte silbenfinale Obstruentencluster. Es gibt ferner keine nativen Namen im Englischen, wie *[apk] oder ${ }^{*}[a k p]$, die gegen (6b) verstoßen würden, indem sie auf $\mathbf{z w e i}$ nichtkoronale Obstruenten auslauten.

Ich werde in diesem Artikel zeigen, daB die zwei Arten von phonotaktischen Bedingungen sich dadurch unterscheiden, daß nur die eine, nicht aber die andere Ausnahmen zuläßt. Diese Hypothese ist in (7) zusammengefaßt:

(7a) Silbenstrukturbedingungen haben keine Ausnahmen.

(7b) Morphemstrukturbedingungen können Ausnahmen haben.

Diese Ausnahmen sind idiosynkratisch wie adze und ides in dem englischen Beispiel oder native Eigennamen.

5 "Koronal” ist die Bezeichnung für Laute, die mit dem vorderen Zungenteil (d.h. Zungenspitze und/oder Zungenblatt) ausgesprochen werden. Das Merkmal [+koronal] umfaßt also alveolare Laute, wie $[t, d, s, z]$ und palatoalveolare Laute, wie $\left[\int, 3, \mathrm{t} \int, \mathrm{d} 3\right]$. Alle anderen Konsonanten, zum Beispiel die labialen (d.h. [p, b, f, v, m]), die palatalen (d.h. [c]) und die velaren (d.h. $[k, g, x]$ ), sind [-koronal]. 


\section{Obstruentenverbindungen im Deutschen}

In diesem Abschnitt geht es um mögliche und unmögliche Kombinationen von Obstruenten im Auslaut deutscher Wörter.

Eine deutsche Silbe kann auf eine Folge aus zwei Obstruenten auslauten. Ich zeige dies in (8) anhand von wortfinalen und einigen wortinternen Beispielen:

(8a) Plosiv plus Plosiv:

$\begin{array}{ll}{[\mathrm{kt}]} & A k t \\ \text { [pt] } & A b t\end{array}$

(8b) Plosiv plus Frikativ:

[ps] Gips

[ks] Lachs

[PS] hübsch

(8c) Frikativ plus Plosiv:

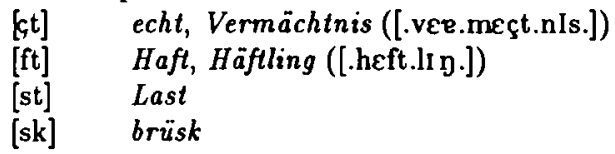

(8d) Frikativ plus Frikativ:

[xs] Dachs

[fs] Hofs

Die Sequenzen von zwei Obstruenten in (8) unterliegen starken Restriktionen hinsichtlich der Artikulationsstelle. Es gibt zum Beispiel keine Abfolgen von zwei finalen Obstruenten wie in (9):

(9a) ${ }^{*} \mathrm{pk}, \mathrm{kp}, \mathrm{fk}, \mathrm{kf}, \mathrm{fp}, \mathrm{p} \varsigma$, sp, kç, çk usw.

(9b) *tp, tk, tç, tf usw.

Die Sequenzen in (9a), die aus zwei nichtkoronalen Obstruenten bestehen, kommen in silbenfinaler Position niemals vor. ${ }^{6}$ Die Sequenzen in (9b), die aus einem koronalen Plosiv und einem nichtkoronalen Obstruenten bestehen, sind ebenfalls ausgeschlossen.

Die Fakten in (8) und (9) erfordern die Silbenstrukturbedingungen in (10):

6 Das [pf] in Wörtern wie Kopf ist von dieser Generalisierung nicht betroffen, weil [pf] eine Affrikate ist, d.h. ein einziges komplexes Segment, und keine Abfolge von [p] plus [f]. 
(10) Silbenstrukturbedingungen für das Deutsche

(10a) [+obstruent] [+obstruent] $]_{\sigma}$

(10b) ${ }^{*}[$ +obstruent, -koronal ] [+obstruent, -koronal $\left.]\right]_{\sigma}$

(10c) *[+obstruent, +koronal, +plosiv $]$

[+obstruent, -koronal $]_{\sigma}$

(10a) läBt eine Abfolge von zwei Obstruenten in silbenfinaler Position $\mathrm{zu}$, und durch $(10 \mathrm{~b})$ und $(10 \mathrm{c})$ werden die ungrammatischen Sequenzen in (9) ausgefiltert. Die Bedingungen in (10) beziehen sich auf die Silbe. Es gibt also keine Ausnahmen, was (7a) zu bestätigen scheint. Namen, die gegen (10a) und (10b) verstoßen, sind ebenfalls nicht wohlgeformt.

Die ungrammatischen Sequenzen in (9b) und (9c) kommen jedoch in anderen Positionen des Wortes vor, nämlich wortintern und zwar dann, wenn sie zu verschiedenen Morphemen gehören wie in (11):

(11a) [+obstruent, -koronal] + [+obstruent, -koronal] mach + bar, Öffentlich +keit, Päck+chen

(11b) [+koronal, +plosiv, +obstruent] + [-koronal, +obstruent] Brat+kartoffeln, Heft+klammern, furcht+bar, Gärt+chen

Die beiden adjazenten Obstruenten in den Beispielen in (11) gehören zu verschiedenen Morphemen, d.h., es gibt keine Monomorpheme im Deutschen wie *[akpa], oder *[apka]. Die oben besprochenen Lücken in (11) kann man mit den Morphemstrukturbedingungen in (12) zum Ausdruck bringen: ${ }^{7}$

(12) Morphemstrukturbedingungen für das Deutsche

7 Die umgekehrte Reihenfolge der Laute in (12b) (d.h. [-koronal, tobstruent] [+koronal, +plosiv, +obstruent]) ist dagegen morphemintern erlaubt: vgl. Faktor, Optik, Techtelmechtel. 
(a)
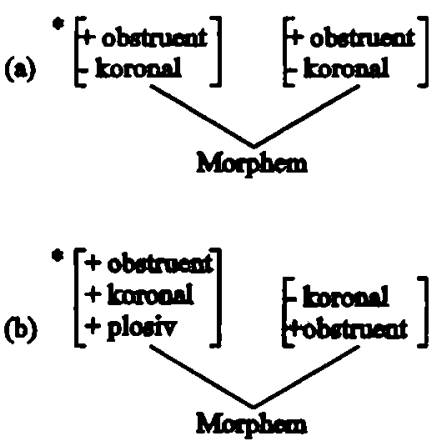

Die Silbenstrukturbedingungen in (10b) und (10c) kommen also auch in (12) als Morphemstrukturbedingungen vor, d.h., die entsprechenden Konsonantenverbindungen sind sowohl am Ende einer Silbe als auch morphemintern und morpheminitial ausgeschlossen. ${ }^{8}$

Zwei idiosynkratische Ausnahmen zu dieser Regularität sind in (13a) angegeben, und Namen, die gegen (12b) verstoßen, in (13b):

(13a) Frettchen, Wodka

(13b) Stuttgart, Cottbus, Oetker, Roentgen, Edgar, Lüdke, Haftka

Ähnliche Beispiele wie die in (14) unterliegen der Morphemstrukturbedingung in (12a) nicht:

(14a) Steppke

(14b) Kafka, Frankfurt, Köpcke

Das Interessante daran ist, daß nur die Morphemstrukturbedingungen in (12), nicht aber die Silbenstrukturbedingungen in (10) Ausnahmen haben. Dies bestätigt die Hypothese in (7).

Die Silben- und Morphemstrukturbedingungen in (10) und in (12) kommen auch in anderen Sprachen vor. Einige Studien haben gezeigt, daB Sequenzen von $[t]$ plus $[k]$ oder $[t]$ plus $[p]$ in vielen Sprachen nicht zugelassen sind, und zwar sowohl silbenfinal als auch zwischen zwei Vokalen. Beispiele hierfür finden sich u.a. bei Blust (1979) für einige austronesische Sprachen, bei Bailey (1970) für Griechisch, und bei Jacobs (1992) für Latein.

8 Ein scheinbares Gegenbeispiel zu (12a) ist [kv] (z.B. Quark). Es gibt jedoch Argumente, daß das [v] in solchen Wörtern kein Obstruent ist (s. Hall 1992, S. 162ff.) 
Es ist deshalb keine besondere Überraschung, daß in vielen Sprachen phonologische Prozesse wie Assimilation, Vokalepenthese und Metathese als Reparaturmechanismen üblich sind, die dazu beitragen, diese markierten Konsonantenverbindungen zu vermeiden. Im Englischen beispielswiese unterliegen in der Umgangssprache koronale Plosive der Ortsassimilation, $\mathbf{s .}$ (15a). Dies gilt sowohl morphemintern als auch über eine Morphemgrenze hinweg. Das altgriechische Beispiel in (15b) zeigt dagegen, daB dieselbe Abfolge von koronalem Plosiv plus nichtkoronalem Plosiv durch Metathese umgekehrt wurde.

(15a) Assimilationen im Englischen (Blust 1979)

$$
\begin{aligned}
& \text { Rutgers } \rightarrow \text { Ru[k]gers } \\
& \text { foot }+ \text { ball } \rightarrow \text { foo[p]ball }
\end{aligned}
$$

(15b) Metathese im Altgriechischen (Bailey 1970)

${ }^{*} k^{w} \underline{i} \underline{d}+\underline{p}$ e $\rightarrow$ típte

Diese und ähnliche phonologische Prozesse in anderen Sprachen deuten darauf hin, daB die Bedingungen in (10b) und (10c) und (14) nicht sprachspezifisch sind, sondern einen universalen Charakter haben. ${ }^{9}$

Das nächste Beispiel einer Morphemstrukturbedingung bezieht sich auf die Wörter in (8d) (s. (16)):

$$
\begin{gathered}
{[+ \text { frikativ }]+[+ \text { frikativ }] \#} \\
\text { Hof }+s, D a c h+s
\end{gathered}
$$

Diese Wörter zeigen, daß Silben im Deutschen auf zwei Frikative auslauten können. Es gibt jedoch in diesen Fällen immer eine Morphemgrenze zwischen diesen Segmenten. Mit anderen Worten: Es gibt kein monomorphemisches Wort, das auf zwei Frikative auslautet. Diese Einschränkung wird durch die Morphemstrukturbedingung in (17) erfaßt:

(17) Morphemstrukturbedingung für das Deutsche

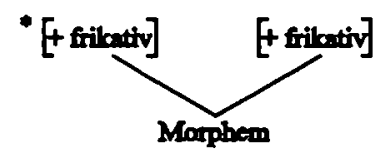

Eine idiosynkratische Ausnahme ist in (18a) angegeben, sowie zwei $\mathrm{Na}$ men, die gegen (17) verstoßen, in (18b):

9 Vgl. die Diskussion in Lamontagne (1993). 
(18a) Asphalt

(18b) Lauffs, Rohlfs

Die Morphemstrukturbedingung in (17) kann also verletzt werden und bestätigt damit die Hypothese in (7).

\section{Silbenfinale Sonorantencluster im Deutschen und die Verteilung von Schwa}

In diesem Abschnitt werden Kombinationen von sonorantischen Konsonanten und Obstruenten im Auslaut deutscher Wörter behandelt. Es wird außerdem gezeigt, daß ein Zusammenhang besteht $\mathrm{zwischen}$ silbenfinalen Konsonantenverbindungen und der Verteilung vom Schwa.

Im Standarddeutschen sind nur bestimmte Abfolgen von sonorantischen Konsonanten und Obstruenten am Ende einer Silbe erlaubt. Beispiele von zweigliedrigen Konsonantenverbindungen sind in (19) aufgelistet:

(19) Mögliche silbenfinale Konsonantenverbindungen:

(19a) Liquid plus Obstruent:

[lt] kalt, bellt

[Rk] karg, Arktis ([.ark.tIs.])

(19b) Nasal plus Obstruent:

[gk] krank

[mt] Amt

(19c) Liquid plus Nasal:

[Rm] Arm, ärmlich ([.eRm.lic, $])$

[lm] Helm

Die drei Gruppen in (19) kommen in silbenfinaler Position und nicht nur in wortfinaler Position vor, weil sie auch wortintern auftreten.

Die umgekehrten Reihenfolgen kommen in silbenfinaler Position nicht vor: ${ }^{10}$

(20) Unzulässige silbenfinale Konsonantenverbindungen:

(20a) Obstruent plus Liquid

$*^{*} \mathrm{tl}_{\sigma}$

$\left.{ }^{*} \mathbf{k R}\right]_{\sigma}$

10 Der letzte Konsonant in den Clustern in (20) ist nichtsilbisch. Während die Abfolge [t] plus [m] zum Beispiel in dem Wort Atem erlaubt ist, weil das [m] silbisch ist, gibt es jedoch keine deutsche Silbe, die auf [t] plus nichtsilbischem [m] auslautet. 
(20b) Obstruent plus Nasal

$\left.{ }^{*} \mathrm{k \eta}\right]_{\sigma}$

$\left.*_{\mathrm{tm}}\right]_{\sigma}$

(20c) Nasal plus Liquid

$\left.{ }^{*} \mathrm{mR}\right]_{\sigma}$

$\left.{ }^{*} \mathrm{ml}\right]_{\sigma}$

Die deutsche Silbe erlaubt also die finalen Sequenzen in (19), aber nicht diejenigen in (20). Man kann diese Diskrepanz mit einer Hierarchie wie der in (21) erfassen:

(21) Liquid > Nasal > Obstruent

Die Hierarchie in (21) nennt man manchmal „Sonoritätshierarchie”, wobei Liquidae sonorer als Nasale und Obstruenten sind, und Nasale sonorer als Obstruenten. Seit mindestens $100 \mathrm{Jahren}$ diskutiert man die Frage, was unter Sonorität eigentlich zu verstehen ist. ${ }^{11}$ Für meine Zwecke ist diese Frage nicht relevant, weil man (21) ohnehin in der Phonologie des Deutschen als Wohlgeformtheitsbedingung braucht.

Die Generalisierung in (22) erfaßt die Fakten in (19) und (20):

(22) Silbenstrukturbedingung für das Deutsche Wenn $\left.\mathrm{K}_{\mathrm{a}} \mathrm{K}_{\mathrm{b}}\right]_{\sigma}$ dann $\mathrm{a}>\mathrm{b}$.

(22) besagt folgendes: Wenn es zwei Konsonanten am Ende einer Silbe gibt, so hat der erste dieser Konsonanten in der Hierarchie in (21) eine Position, die links von der des zweiten Konsonanten ist. ${ }^{12}$ Die Silbenstrukturbedingung in (22) erklärt, warum die finalen Sequenzen in (19) wohlgeformt sind und die in (20) nicht. Diese Generalisierung ist nicht sprachspezifisch für das Deutsche. Viele Untersuchungen haben gezeigt, $\mathrm{da} B$ andere, typologisch verschiedene Sprachen diese oder ähnliche Restriktionen haben. ${ }^{13}$

Es gibt einen engen Zusammenhang zwischen der Distribution vom Schwa im Deutschen und der Hierarchie in (21). Viele deutsche Wörter lauten auf eine Abfolge von Konsonant plus Schwa plus Konsonant aus. Einige Beispiele sind in (23) angegeben: ${ }^{14}$

11 Vgl. Sievers (1901) sowie Jespersen (1926).

12 Die zwei Konsonanten in (22) kōnnen nicht beide Obstruenten sein, weil sie denselben Sonoritätswert haben (z.B. Akt, Hofs).

13 Eine bekannte Studie ist Clements (1991).

14 Die Aussprache in (24) mit silbischen Sonoranten ist auch mōglich (z.B. 


$\begin{array}{lll}\text { Obstruent plus Liquid: } & \text { Adel } & \text { [a:dəl] } \\ \text { Obstruent plus Nasal: } & \text { Atem } & \text { [a:təm] } \\ \text { Nasal plus Liquid: } & \text { Himmel } & \text { [hI mal] }\end{array}$

Die Daten in (24) zeigen, daß das Schwa in finaler Position zwischen zwei Konsonanten vorkommen kann. Es gibt Restriktionen hinsichtlich dieser Segmente, d.h., in (24) liegt der erste der zwei finalen Konsonanten in der Hierarchie in (21) nicht links, sondern rechts vom Folgekonsonanten. Mit anderen Worten: Eine finale Abfolge wie die in (24a) kommt vor, die in (24b) jedoch kaum:

$$
\begin{array}{ll}
\text { mal }]_{\sigma} & \text { (z.B. Himmel) } \\
\text { tam }]_{\sigma} & \text { (z.B. Atem) } \\
\operatorname{lam}_{\sigma} & - \\
\text { mət }]_{\sigma} & -
\end{array}
$$

(24b) ləm] $\sigma$

Es gibt viele Beispiele für die Sequenzen in (24b). Es gilt aber in allen Fällen, daß eine Morphemgrenze zwischen den beiden Konsonanten liegen muB:
Liquid plus Schwa plus Nasal:
teurten
Liquid plus Schwa plus Obstruent:
kühltes
Nasal plus Schwa plus Obstruent:
Manntes

Wenn keine Morphemgrenze zwischen den beiden Konsonanten liegt, kommen Sequenzen wie die in (24b) nur sehr selten vor. Diese Generalisierung bringt man mit der Morphemstrukturbedingung in (26) zum Ausdruck:

(26) Morphemstrukturbedingung für das Deutsche

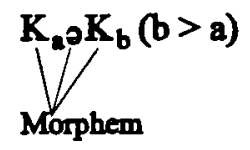

(26) besagt folgendes: Wenn Schwa zwischen zwei Konsonanten steht und es keine Morphemgrenze zwischen diesen Konsonanten gibt, dann muß der zweite Konsonant sonorer sein als der erste.

[a:d!̣], [a:tmi], [hI m! ]). 
Idiosynkratische Ausnahmen zu der Morphemstrukturbedingung in (26) finden sich in (27a) und Namen, die dagegen verstoßen, in (27b): ${ }^{15}$

(27a) Pommes, Tinnef, Kummet, Sammet (27b) Johannes, Ines, Dahlem, Golem, (Bad) Honnef

Die Morphemstrukturbedingung in (26) kann also verletzt werden und bestätigt damit die Hypothese in (7).

\section{Beschränkungen auf nichtadjazente Konsonanten}

In diesem Abschnitt wird eine Morphemstrukturbedingung behandelt, die sich auf Konsonanten bezieht, die nicht unmittelbar nebeneinanderstehen.

Es gibt im Deutschen und Englischen Beschränkungen zwischen $K_{b}$ und $K_{c}$ in Abfolgen wie in (28). Im allgemeinen kommen solche Sequenzen nicht vor, wenn $K_{b}$ und $K_{c}$ identisch oder fast identisch hinsichtlich der Artikulationsstelle sind.

(28) $\mathrm{K}_{\mathrm{a}} \mathrm{K}_{\mathrm{b}} \mathrm{V} \mathrm{K}_{\mathrm{c}}$

Im folgenden geht es um deutsche und englische Wortformen, in denen $K_{a}$ entweder [s] oder [ $\left.f\right]$ ist. ${ }^{16}$

Die vier Segmente in (28) können wortinitial sein, aber die Generalisierung, die hier Gegenstand ist, betrifft auch wortinterne Abfolgen der Laute in (28). Die Fakten beziehen sich auf das Morphem und nicht auf die Silbe, weil eine Silbengrenze zwischen den vier Segmenten in (28) vorkommen kann. Relevante Daten sind in (29):

(29a) $s / \int[-$ koronal] V [+koronal] deutsch: Skat, Skizze, Speise, Spaß, Spedition, englisch: spit, spin, scold, hospital

(29b) $s / \int[+$ koronal] V [-koronal] deutsch: stipulieren, Stich, stecken englisch: stake, stipulate

(29c) $\mathrm{s} / \int[+$ koronal] V [+koronal] deutsch: Stadt, Staat, still, Stand englisch: state, still, stone

15 Die vier Ausnahmen in (27a) sind nichtnativ. Das einzige native Wort, das gegen (26) verstößt, ist Kirmes.

16 Vgl. Davis (1991) für das Englische und Hall (1992) für das Deutsche. 


\author{
s/ $\int[-$ koronal] V [-koronal] \\ deutsch: skeptisch, Speck, Skrupel, Respekt \\ englisch: scope, speak
}

Es gibt viele Beispiele wie in (29a), in denen der Konsonant nach [s] nichtkoronal und der zweite koronal ist. Wörter wie die in (29b), in denen der erste Konsonant nach [s] koronal und der postvokalische Konsonant nichtkoronal ist, sind ebenfalls sehr häufig. Die Artikulationsstelle von $K_{b}$ und $K_{c}$ kann auch identisch sein, aber nur, wenn $K_{b}$ und $K_{c}$ beide koronal sind, wie in (29c). Zwei nichtkoronale Konsonanten können vorkommen, wie in (29d), aber nur, wenn sie zwei verschiedene Artikulationsstellen haben. In dem Wort skeptisch zum Beispiel sind das [k] und das [p] beide nicht koronal, aber das [p] ist labial und das [k] nicht labial.

Wortformen wie die in (30) sind hingegen in beiden Sprachen unzulässig:

$$
\text { *spap, skak, spim, smip, skacht }
$$

In diesen Wörtern sind $\mathrm{K}_{\mathrm{b}}$ und $\mathrm{K}_{\mathrm{c}}$ beide nichtkoronal und sie haben dieselbe Artikulationsstelle. Diese phonotaktische Beschränkung wird durch die Morphemstrukturbedingung in (31) erfaBt:

(31) Morphemstrukturbedingung

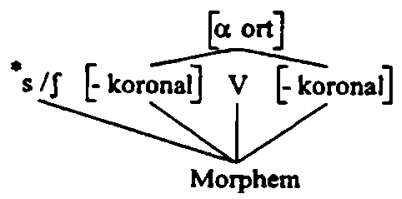

Das Beispiel in (32) soll verdeutlichen, daB (31) eine Morphemstrukturbedingung ist. Die Abfolge in (31) kann also nur vorkommen, wenn eine Morphemgrenze innerhalb der vier Segmente vorkommt:

(32) grasp+able

Ich habe nur ein englisches Beispiel in (32) angegeben, weil es wenige deutsche Morpheme gibt, die auf [sp] oder [sk] auslauten und die außerdem mit einem vokalinitialen Suffix kombiniert werden können.

Es gibt im Englischen eine Ausnahme zu (31), nämlich das seltene Wort skeg: „Teil eines Schiffes." Namen wie die in (33) unterliegen (31) ebenfalls nicht: 
Spamer, Speemann

Die Ausnahmen in (33) bestätigen also die Aussage in (7b).

\section{Diskussion}

In den Abschnitten 2 und 3 sollte gezeigt werden, daB nicht nur die Silbe, sondern auch das Morphem die Domäne von phonotaktischen Beschränkungen sein kann. Ich habe behauptet, daß nur die Morphemstrukturbedingungen Ausnahmen zulassen, die Silbenstrukturbedingungen dagegen nicht.

Eine Erklärung für diese Diskrepanz liegt vielleicht darin, daß die Silbenstrukturbedingungen und die Morphemstrukturbedingungen verschiedene Funktionen haben: Nur die Silbenstrukturbedingungen beziehen sich auf Abfolgen von Segmenten auf der phonetischen Oberfläche. Die Morphemstrukturbedingungen operieren dagegen auf einer abstrakteren Ebene der Grammatik, nämlich auf der Ebene der phonemischen Repräsentationen. Dies kann in (34) mit dem englischen Wort kids illustriert werden:

(34a) phonemisch $/ \mathrm{kId} / \mathrm{z} /$ Ebene der Morphemstrukturbedingun gen

(34b) phonetisch $[\mathrm{kIdz}] \quad$ Ebene der Silbenstrukturbedingungen

Die meisten Phonologen nehmen an, daß es diese zwei Ebenen in der Grammatik gibt, die phonemische und die phonetische.

Eine mögliche Erklärung des unterschiedlichen Verhaltens wäre, daß die beiden Ebenen (34a) und (34b) verschiedene Funktionen haben. (34a) bildet lediglich die zugrunde liegenden Formen der Morpheme ab. $\mathrm{Zu}$ gleich spiegelt sie die idiosynkratischen Eigenschaften dieser Formen wider. Daher müssen die Morphemstrukturbedingungen, die sozusagen der Input des Lexikons sind, relativ tolerant sein.

Im Vergleich dazu fungieren die Silbenstrukturbedingungen als Wohlgeformtheitsbedingungen in der synchronen Grammatik, d.h., sie können phonologische Regeln auslösen. Morphemstrukturbedingungen können das jedoch nicht. Die letzte Generalisierung kann den Beispielen in (15) entnommen werden: Hier finden Assimilationen und Metathesen sowohl morphemintern als auch zwischen zwei Morphemen statt.

Vor diesem Hintergrund wird die Tatsache verständlich, daß es Ausnahmen zu Morphemstrukturbedingungen geben kann: Die Kookkurrenzrestriktionen innerhalb von Morphemen werden auf einer abstrakteren 
Ebene festgelegt als Eigenschaften von Silbenstrukturen, die auf einer „konkreteren” Ebene der Grammatik gelten.

\section{Zusammenfassung und Ausblick}

In diesem Aufsatz wurde gezeigt, daß phonotaktische Beschränkungen sich sowohl auf die Silbe als auch auf das Morphem beziehen können. Es wurde anhand von Daten aus dem Deutschen und Englischen die Hypothese aufgestellt, daB nur Morphemstrukturbedingungen idiosynkratische Ausnahmen haben können.

Im Anschluß an diese Analyse stellen sich zwei weiterführende Fragen. In Abschnitt 2 wurden einige Studien zitiert, nach denen die Silben- und Morphemstrukturbedingungen in (10b), (10c), und (12) in typologisch verschiedenen Sprachen gelten. Erstens ist noch zu klären, ob es Sprachen gibt, in denen Cluster wie finale [tp] und [tk] doch vorkommen. Man könnte die Hypothese verfolgen, daß es einen Zusammenhang zwischen der Existenz von solchen Konsonantenverbindungen und anderen Faktoren in diesen Sprachen gibt. Die zweite Frage betrifft die Hypothesen in (7), die durch deutsche und englische Daten gestützt werden. Auch hier bleibt noch offen, ob diese Generalisierungen mit Daten aus anderen Sprachen belegt werden können.

\section{Literatur}

Bailey, C. J. (1970): Towards specifying constraints on phonological metathesis. In: Linguistic Inquiry 1, S. 347-349.

Blust, R. A. (1979): Coronal-noncoronal consonant clusters: New evidence for markedness. In: Lingua 47, S. 101-117.

Chomsky, N./Halle, M. (1968): The sound pattern of English. New York.

Clements, G. N. (1991): The role of the sonority cycle in core syllabification. In: Kingston, J./Beckman, M. (Hg.): S. 282-333. Papers in laboratory phonology I. Between the grammar and physics of speech. Cambridge.

Clements, G.N./Keyser, S.J. (1983): CV Phonology. A generative theory of the syllable. Cambridge.

Davis, S. (1991): Coronals and the phonotactics of nonadjacent consonants in English. In: Paradis, C./Prunet, J.-F. (Hg.): The special status of coronals. New York. S. 49-60.

Fudge, E. (1969): Syllables. In: Journal of Linguistics 5, S. 253-287.

Giegerich, H. (1985): Metrical phonology and phonological structure. German and English. Cambridge.

Giegerich, H. (1992): Onset maximisation in German: the case against resyllabification rules. In: Eisenberg, P./Ramers, K.H./Vater, H. (Hg.): Silbenphonologie des Deutschen. Tübingen. S. 134-171. 
Hall, T.A. (1992): Syllable structure and syllable related processes in German. Tübingen.

Hall, T.A. (1993): The phonology of German /R/. In: Phonology 10, S. 83-105.

Haugen, E. (1956): The syllable in linguistic description. In: Halle, M./Lunt, H.G./MacLean, H./van Schooneveld, C.H. (Hg.): For Roman Jakobson. Den Haag. S. 213-221.

Hockett, C. (1955): A manual of phonology. Baltimore.

Hooper, J. (1975): The archi-segment in natural generative phonology. In: Language 51, S. 536-560.

Hooper, J. (1976): An Introduction to Natural Generative Phonology. New York.

Ito, J. (1986): Syllable theory in prosodic phonology. Dissertation: University of Massachusetts/Amherst.

Jacobs, H. (1992): The interaction between syllable structure and foot structure in the evolution from Classical Latin to Old French. In: Laeufer, C./Morgan. T.A. (Hg.): S. 55-79. Theoretical analyses in Romance linguistics. Amsterdam.

Jespersen, O. (1926): Lehrbuch der Phonetik. Leipzig.

Kahn, D. (1976): Syllable-based generalizations in English phonology. Dissertation: MIT.

Lamontagne, G. (1993): Syllabification and consonant cooccurrence conditions. Dissertation: University of Massachusetts/Amherst.

Levin, J. (1985): A metrical theory of syllabicity. Dissertation: MIT.

Pike, K./Pike, E.V. (1947): Immediate constituents of Mazateco syllables. In: International Journal of American Linguistics 13, S. 78-91.

Raffelsiefen, R. (1993): Relating words. A model of base recognition. Part I. In: Linguistic Analysis 23, S. 3-159.

Rubach, J. (1990): Final devoicing and cyclic syllabification in German. In: Linguistic Inquiry 21, S. 79-94.

Sievers, E. (1901): Grundzüge der Phonetik. Leipzig.

Steriade, D. (1982): Greek prosodies and the nature of syllabification. Dissertation: MIT.

Vennemann, T. (1972): On the theory of syllabic phonology. In: Linguistische Berich te 18, S. 1-18.

Vennemann, T. (1978): Universal syllabic phonology. In: Theoretical Linguistics 5, S. 175-215.

Vennemann, T. (1988): Preference Laws for Syllable Structure and the Explanation of Sound Change. Berlin.

Wiese, R. (1988): Silbische und lexikalische Phonologie. Studien zum Chinesischen und Deutschen. Tübingen. 


\title{
URSULA KLEINHENZ
}

\section{Zur Typologie phonologischer Domänen*}

\begin{abstract}
Eine aktuelle Debatte in der Phonologie betrifft den Status phonologischer Konstituenten oberhalb des Wortes, insbesondere von kleineren phonologischen Einheiten innerhalb von Intonationsphrasen. In vielen Sprachen haben solche Phrasengrenzen eine phonologische Funktion. Offenbar bedienen sich andere Sprachen dieser Möglichkeit aber nicht.

Ich möchte hier zwei Fragen diskutieren: Erstens, ob man für die Sprachen der zweiten Gruppe annehmen soll, daB sie ebenfalls über diese Kategorie verfügen, diese also abstrakt in ihrem System vorhanden ist, und zweitens, welche Einsichten wir aus der Gruppe von Sprachen, in denen die phonologischen Phrase eine Funktion hat, gewinnen kōnnen. Besteht irgendeine Korrelation zwischen dieser Eigenschaft von Sprachen und anderen phonologischen Eigenschaften dieser auf den ersten Blick inkonsistenten Gruppe?

Ich argumentiere, daß es nicht sinnvoll ist zu behaupten, daß die phonologische Phrase eine universelle Kategorie ist, weil man dann eine typologische Generalisierung über Sprachen verlieren würde. Ich zeige in diesem Beitrag, daß die Tendenz von Sprachen, Phrasengrenzen eine phonologische Funktion zuzuweisen, mit rhythmischen Eigenschaften auf der Wortebene korreliert. Anschließend mache ich einen Vorschlag zur Revision der phonologischen Kriterien der Typologie des Sprachrhythmus.
\end{abstract}

\section{Die Funktion von Intonationseinheiten}

Alle Sprachen phrasieren, d.h., stets werden Sätze in der gesprochenen Sprache in kleinere Intonationseinheiten eingeteilt. Diese phonetische Phrasierung ist universell; Sprachen unterscheiden sich lediglich in der Art der akustischen Realisierung dieser Phrasierung (Pitch-Akzent, Längung etc.). Die Rolle dieser Phrasen in der Phonologie ist jedoch umstritten.

Generell müssen Konstituenten bestimmte Kriterien erfüllen, bevor man annimmt, daß sie eine phonologische „Funktion” haben. Man vergleiche die folgende Liste (1).

* Für Hinweise und Kommentare danke ich T.A. Hall, Ewald Lang, Sylvia Löhken, Christine Mooshammer und Iggy Roca. 
(1) Kriterien für phonologische Konstituenten (vgl. Selkirk 1980; Rice 1990)

Eine Konstituente muß eine Domäne eigener Art sein, d.h., sie darf nicht isomorph mit anderen Domänen sein (z.B. dürfen Phonologische Phrasen nicht immer identisch mit einer syntaktischen Phrase sein).

Sie muB aber (mit ihren eigenen Regeln) abgeleitet werden können: es darf keine zufällige oder willkürliche Domäne sein.

Regeln müssen sich systematisch auf sie beziehen, d.h. entweder ist die Konstituente selber die Domäne einer Regel oder die Grenzen der Konstituente blockieren eine Regel. Auf diese Weise kann man die Grenzen der Domäne nachweisen.

In vielen Sprachen korrelieren phonologische Domänen nicht mit den vergleichbaren syntaktischen Einheiten (z.B. Wort, Phrase). Die prosodische Hierarchie in (2) zeigt alle Konstituenten, die in der Phonologie eine Funktion haben können.

(2) Prosodische Hierarchie (vgl. Nespor/Vogel 1986)

Äußerung

Intonationsphrase

Phonologische Phrase

Klitikgruppe

Phonologisches Wort

FuB

Silbe

subsilbische Konstituenten

\subsection{Phonologische Phrasen}

Wie gesagt sind nicht alle diese Einheiten unumstritten. Während Phonologen z.B. implizit oder explizit davon ausgehen, da B es Intonationsphrasen oder Silben gibt, herrscht Uneinigkeit über die Rolle der Phonologischen Phrase. Die Phonologische Phrase hat offenbar nicht in allen Sprachen eine Funktion. Frota (1995) 2.B. hat alle in Frage kommenden Regeln des Portugiesischen untersucht und festgestellt, daB keine davon auf Domänen vom Format der phonologischen Phrase operiert.

Diese Feststellung allein läBt noch keine Aussage über die Relevanz der phonologischen Phrase zu. Zwar haben manche Autoren vorgeschlagen, $\mathrm{da} B$ nicht alle prosodischen Konstituenten universell sind (z.B. Auer 1994 für die Silbe), aber solange davon keine weiteren Argumente abhängen, 
könnte man ebensogut (oder besser) davon ausgehen, daB die prosodische Hierarchie universell ist, man aber in einigen Sprachen die Grenzen bestimmter Konstituenten in der Phonologie nicht sehen kann. Bevor ich näher auf diese Argumente eingehe, erläutere ich kurz, was man genau unter der Kategorie „phonologische Phrase” versteht.

Die phonologische Phrase ist ursprünglich in der einschlägigen Literatur eine rhythmische Einheit. Sie wurde zunächst nur verwendet, um rhythmisch bedingte Akzentverschiebungen zu beschreiben. Bekannte Beispiele habe ich in (3) aufgelistet. Hauptakzente sind mit Großbuchstaben markiert, Nebenakzente mit ' . Von der syntaktischen Struktur her handelt es sich bei den Beispielen in (3) jeweils um Nominalphrasen.

(3) Akzentverschiebung innerhalb „phonologischer Phrasen” (vgl. Giegerich 1985)
(a) thirTEEN
aber
thírteen BAbies
(b) PaderBORN
aber
Páderborner UNi
(c)
aber
die UNi von Pader BORN

Nur in (3 c) wird keiner der Hauptakzente reduziert. Als Grund hierfür wird häufig genannt, daß es eine rhythmische Einheit, eben die phonologische Phrase, gibt, innerhalb derer es nur einen Hauptakzent geben kann. Stoßen zwei Hauptakzente innerhalb einer phonologischen Phrase zusammen, so wird einer davon reduziert („Rhythm Rule”). [Paderborner $U n$ i] wäre in diesem Beispiel eine einzige Phrase, während [die Uni] [von Paderborn] aus zwei Phrasen bestünde. Der Akzent kann demnach in (3 c) auf Paderborn bleiben, weil zwischen den beiden Akzenten eine phonologische Phrasengrenze liegt, die die Rhythm Rule blockiert.

Phonologische Phrasen werden durch einen Algorithmus, den ich in (4) zitiert habe, abgeleitet. ${ }^{1}$

(4) (a) Ableitung phonologischer Phrasen

(Nespor/Vogel 1986, S. 168)

The domain of $\mathrm{PhP}$ consists of a CG [=Clitic Group] which contains a lexical head $(\mathrm{X})$ and all CGs on its nonrecursive side up to the CG that contains another [lexical] head outside the maximal projection of $\mathrm{X}$.

(b) Restrukturierung phonologischer Phrasen

(Nespor/Vogel 1986, S. 173)

1 Die in der Ableitung verwendete Kategorie der "Klitikgruppe” ist hier nicht von Bedeutung. Man kann stattdessen auch „Wort” einsetzen. 
A nonbranching $\mathrm{PhP}$ which is the first complement [or adjunct] of $\mathrm{X}$ on its recursive side is joined into the $\mathrm{PhP}$ that contains $\mathrm{X}$.

Phonologische Phrasen werden also im Prinzip aus maximalen syntaktischen Projektionen abgeleitet. In einer Zwischenstufe entsprechen sie den syntaktischen Phrasen. Durch die „Restrukturierung” werden die eigentlichen phonologischen Phrasen erzeugt. Dabei fallen die intermediären Phrasen teilweise zusammen. Die Restriktion hierüber betrifft die Länge der Konstituenten, also kein syntaktisches Kriterium.

Dies wird in (5) anhand des Italienischen demonstriert ( $\phi$ ist die Abkürzung für "phonologische Phrase").

(5) Anwendung von (4) auf das Italienische (vgl. Nespor/Vogel 1986, S. 171)
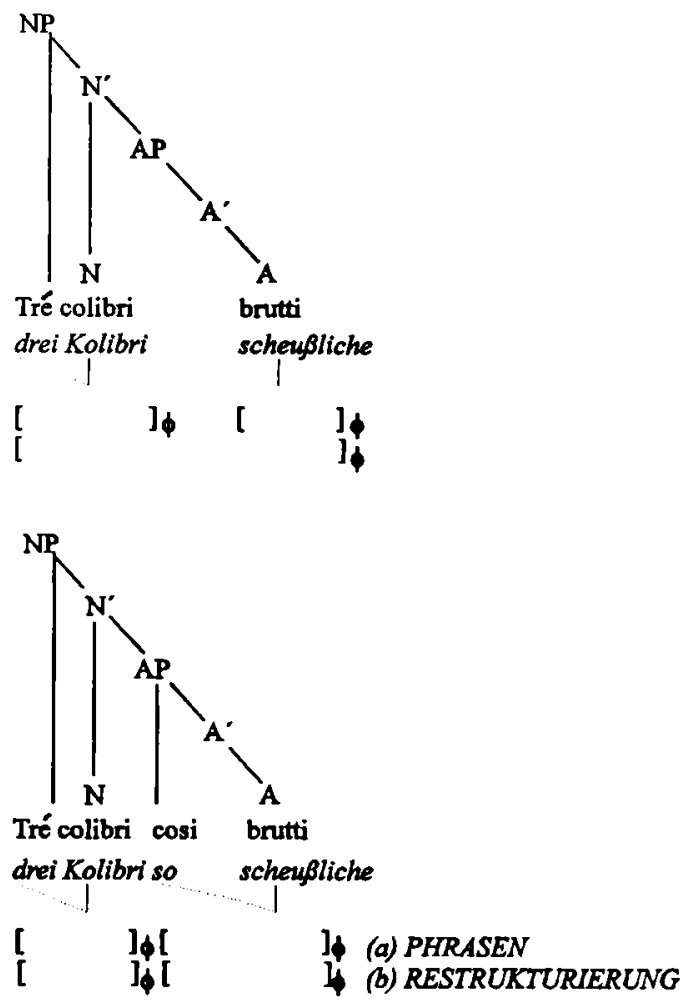
Zuerst werden vom am weitesten rechts stehenden lexikalischen Kopf aus nach links (da das Italienische eine rechtsverzweigende Sprache ist) Phrasen konstruiert. Anschließend werden diese "vorläufigen" Phrasen in die vorangehende Phrase inkorporiert, sofern sie nicht verzweigen. Diese Restriktion verhindert die Bildung überlanger Phrasen.

Die phonologische Phrase im Italienischen ist phonologisch relevant, d.h., sie entspricht den in (1) zusammengefaBten Kriterien. Es gibt z.B. eine segmentale Regel, das radoppiamento sintattico (kurz RS), die Konsonanten längt (Nespor/Vogel 1986, S. 38). RS längt wortinitiale Konsonanten, wenn bestimmte Bedingungen erfüllt sind. Diese Bedingungen sind regional unterschiedlich und spielen im vorliegenden Zusammenhang keine Rolle. Hier ist lediglich zu beachten, daB ein wortinitialer Konsonant nur dann gelängt wird, wenn das vorangehende Wort auf einen betonten Vokal auslautet und die beiden Wörter in derselben phonologischen Phrase sind. Aus (6) bis (8) wird deutlich, daB tatsächlich die phonologische, und nicht die syntaktische Phrasierung ausschlaggebend ist.

(6) Radoppiamento Sintattico (RS) im Italienischen (Region Toskana)

$\begin{array}{llllll}\text { (a) Ho } & \text { visto } & \text { tré } & {[\mathrm{k}: \text { ]olibri }} & \text { [b:]rutti } \\ & \text { Ich } & \text { habe gesehen } & \text { drei } & \text { Kolibri } & \text { scheußliche } \\ \text { (b) Ho } & \text { visto } & \text { tré } & {[\mathrm{k}: \text { ]olibri }} & \text { [k]osi } & \text { [b:]rutti } \\ & \text { Ich } & \text { habe gesehen } & \text { drei Kolibri so } & \text { scheußliche }\end{array}$

Wichtig ist der fettgedruckte Konsonant nach colibri. Er wird in (6b) nicht gelängt, obwohl die segmentale Umgebung (wortinitial, nach einem betonten Vokal) gegeben wäre. Auch die syntaktische Beziehung zwischen colibri/brutti bzw. colibri/cosi ist dieselbe, wie in (7) dargestellt.

(7) Syntaktische Phrasierung von (6)

(Nespor/Vogel 1986, S. 40)
a. [tré
b. [tré [colibri
[colibrí
$\left[\begin{array}{ll} & {[\text { brutti]]] }} \\ {[\text { cosi }} & \text { [brutti]]] }\end{array}\right.$

Relevant für die Anwendung der Regel ist nicht der syntaktische Kontext der $\ddot{A} u ß e r u n g$, sondern ihre phonologische Phrasierung. Diese hängt mit der einfachen Länge der Äußerung zusammen, wie man in (8) erkennen kann: durch die Hinzufügung von cosi in $(8 b)$ entsteht eine zweite verzweigende Phrase. Die beiden Phrasen können nun nicht mehr zusammenfallen. 
(8) Phonologische Phrasierung von (6)
a. [tré colibrí
brutti $]_{\phi}$
b. [tré colibri $]_{\phi}[\operatorname{cosi} \text { brutti }]_{\phi}$

RS betrifft also Konstituenten, die syntaktisch gesehen keine sind. Wenn man z.B. sagen würde, daB RS in der syntaktischen Domäne NP angewandt wird, wäre cosi in (8b) genau so betroffen wie brutti.

Aber nicht in allen Sprachen findet man so deutliche Evidenz für phonologische Phrasen als Kategorie in der Phonologie.

Ein solcher Fall ist das Deutsche. Wiese (1995) argumentiert $\mathrm{zwar}$, daß es phonologische Phrasen (PPh) im Deutschen gibt (wiedergegeben in (9)).

(9) Phonologische Phrasen im Deutschen (vgl. Wiese 1995, S. 71)

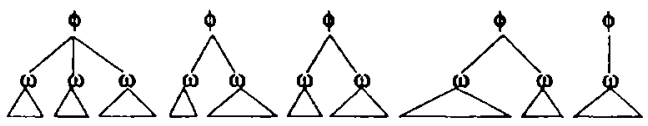

Phonologische Phrasen

Phonologische Wörter

Der alte Mann am Strand fing heute besonders viele Fische

Diese Repräsentation entspricht aber nicht dem Algorithmus von Nespor und Vogel, den ich in (4) wiedergegeben habe, da dort Präpositionalphrasen wie [am Strand] keine eigene phonologische Phrase bilden (im Modell von Nespor/Vogel lösen nur die lexikalischen Köpfe ${ }^{2}$ N, V, A, aber nicht $P$ die Bildung einer phonologischen Phrase aus). Intuitiv sind für den Satz in (9) auch andere Phrasierungen denkbar, vor allem die in $(10)$, in welcher die PP keine eigene Phrase ist: ${ }^{3}$

2 Nespor und Vogel nehmen an, daß nur $N, V$ und $A$ lexikalische Kōpfe sind. Für Leser, die diesem Argument nicht folgen, schlagen sie eine Revision ihres Algorithmus vor, der nur N, V und A-Kategorien einbezieht (Nespor/Vogel 1986, S. 169).

3 Wiese muß aus unabhāngigen Grūnden annehmen, daß der Algorithmus von Nespor/Vogel auch PPs einschließt: Als Evidenz für phonologische Phrasen verwendet er eine Regel, die Koordinationsreduktion, die aber auch für PPs gilt. Diese Regel kann hier nicht besprochen werden (vgl. aber Kleinhenz (1994) für eine Diskussion). In jedem Fall würde seine Kategorie der phonologischen Phrase im Deutschen nicht in das Schema von Nespor/Vogel passen. 
(10)

[der alte Mann am Strand][fing heute] [besonders viele] [Fische] oder [besonders viele Fische]

Die Tatsache, daB die Intuitionen der Muttersprachler über die Phrasierung im Deutschen offenbar auseinandergehen, mag als erster Hinweis auf eine mangelnde Evidenz für die $\mathrm{PPh}$ gelten. Entscheidend ist aber der Mangel an phonologischen Regeln, die sich auf die Konstituente PPh beziehen. Diese Eigenschaft teilt das Deutsche mit anderen Sprachen (vgl. (2.2). In (11) sind einige dieser Sprachen aufgeführt.

(11) Phonologische Phrasen als Regeldomäne

Sprache

(a)

Französisch

Mandarin

Bengali

Italienisch

(b)

Englisch

Portugiesisch

Niederländisch

Deutsch
Beispiel

Liaison (Nespor/Vogel 1986)

Dritter Ton Sandhi (Cheng 1970)

r-Assimilierung (Hayes/Lahiri 1991)

RS (Nespor/Vogel 1986)

nur Akzenttilgung

keine (Frota 1995)

nur Akzenttilgung

nur Akzenttilgung (phon. Phrasen = synt.

Phrasen)

Nur die Sprachen in (11a) haben phonologische Regeln, die systematisch die Grenzen phonologischer Phrasen markieren, wie z.B. das Radoppiamento Sintattico im Italienischen (vgl. (5)). Die Sprachen unter (11b) haben zwar die rhythmisch bedingte Akzenttilgung (vgl. (3)), der entscheidende Unterschied zu den Sprachen in (11a) ist jedoch, dab die Domäne der Akzenttilgung immer auch eine syntaktische Domäne ist (z.B. Kopf und Modifizierer). Damit sind die angenommenen "phonologischen Phrasen" noch keine eigenen Domänen.

Die Aufstellung unter (11) erscheint zunächst wie eine ziemlich willkürliche Ansammlung von Sprachen, von denen einige offenbar dazu neigen, phonologische Phrasen als Regeldomäne zu verwenden.

Die Frage bleibt, wie man dies bewerten soll. Dafür sind zwei Möglichkeiten denkbar. Man kann (wie 2.B. Auer (1991, S. 105)) sagen, daB sich Sprachen hinsichtlich der Anzahl ihrer prosodischen Kategorien unterscheiden können. Solange davon aber keine weiteren Argumente abhängen, ist es im Hinblick auf die Theorie angemessener zu sagen, daß 
alle Sprachen über alle prosodischen Kategorien verfügen, daß aber in manchen Sprachen nicht alle "aktiv" sind (vgl. Frota 1995, S. 17). In diesem Beitrag soll untersucht werden, ob die Kategorie der phonologischen Phrase tatsächlich universell ist, oder ob die Existenz phonologischer Phrasen als Regeldomäne weitere Eigenschaften der betreffenden Sprachen impliziert.

Meine Hypothese ist, daß die Neigung von Sprachen, den Rändern von phonologischen Phrasen eine Funktion zuzuweisen, mit anderen Eigenschaften dieser Sprachen korreliert, und zwar genau mit den Eigenschaften, die andere Autoren für die Wortakzenttypologie aufgestellt haben.

1.2 Typologische Eigenschaften auf der Wortebene: silbenzählende vs. akzentzählende Sprachen

Auf der Wortebene gibt es zahlreiche Bemühungen um eine typologische Einteilung der einzelsprachlichen Eigenschaften von Rhythmus. In der Phonetik unterschied man schon früh zwei Sprachrhythmustypen, die silben- und die akzentzählenden Sprachen. Diese Unterscheidung geht auf Pike (1945) zurück. In silbenzählenden Sprachen sollte demnach die Dauer der einzelnen Silben immer konstant sein, in akzentzählenden Sprachen dagegen der Abstand zwischen den betonten Silben.

Aus diesen unterschiedlichen rhythmischen Grundbestrebungen der Sprachen ergeben sich weitere Eigenschaften, die eine Einteilung in diese zwei Sprachtypen rechtfertigten. So neigen nur akzentzählende Sprachen dazu, Silben in unbetonter Stellung zu reduzieren, um so die Abstände zwischen den Akzenten gleich zu halten. Silbenzählende Sprachen dagegen tendieren dazu, ihre Silben zu vereinheitlichen. Sie unterliegen typischerweise phonologischen Prozessen, die in einem CV-Silbenschema resultieren.

Mit der Weiterentwicklung und Verfeinerung phonetischer Meßmethoden hat sich allerdings herausgestellt, daß diese Unterscheidung so nicht zu halten ist. ${ }^{4}$ In einer eher phonologisch basierten Arbeit schlägt Auer (1991) eine alternative Rhythmustypologie vor, wobei er weitere typologische Parameter hinzuzieht. Auer gelangt so zu einer Einteilung in silbenbetonte und wortbetonte Sprachen. Dabei verwendet er im wesentlichen die Einteilungskriterien, die schon aus den phonetischen $\mathrm{Ar}$ beiten bekannt sind, allerdings mit zwei wichtigen Unterschieden: Zum einen betont er, daß eine binäre Aufteilung aller Sprachen in diese Typen nicht möglich ist. Statt dessen sieht er einen graduellen Übergang vor

4 Für einen Ūberblick über die Kritik vgl. Auer (1991); Mooshammer (1994). 
(vgl. (13)). ${ }^{5}$ Außerdem hat Auer eine funktionale Erklärung für die Eigenschaften, die jeweils mit den Typen "silbenbetont" und "wortbetont" korrelieren. In Sprachen vom letzteren Typ (wie z.B. dem Englischen) ist das Wort die wichtigste Domäne, da sich diese Sprachen rhythmisch am Wortakzent orientieren. Wortgrenzen fallen in diesen Sprachen immer mit Silbengrenzen zusammen und sind daher einfach zu erkennen. Daraus resultieren die anderen Eigenschaften dieses Sprachtyps. Sprachen vom silbenbetonten Typ (wie z.B. das Französische) dagegen haben typischerweise Sandhiregeln (die Wortgrenzen ignorieren) um das CV-Silbenschema zu erfüllen. Diese Sprachen müssen ihre Wortgrenzen auf andere Weise markieren, nämlich durch segmentale Regeln, die sich zumeist auf Silben beziehen. Die Liste in (12) basiert auf Auers Einteilungen.

(12) Sprachrhythmustypologie (nach Auer 1991)

$\begin{array}{ll}\begin{array}{l}\text { Rhythmus silbenbetont } \\ \text { eher Tonsprache }\end{array} & \begin{array}{l}\text { Rhythmus wortbetont } \\ \text { eher keine Tonsprache } \\ \text { keine reduzierten Vokale }\end{array} \\ \begin{array}{l}\text { unbetonte Vokale werden reduziert } \\ \text { einfache Silben }\end{array} & \begin{array}{l}\text { komplexe Silben } \\ \text { keine Liaison }\end{array} \\ \text { Liaison } & \begin{array}{l}\text { Geminaten nicht möglich } \\ \text { Geminaten möglich }\end{array} \\ \text { keine wortbezogenen Regeln } & \text { wortbezogene Regeln } \\ \text { keine silbenbezogenen Regeln } & \text { silbenbezogene Regeln }\end{array}$

Anhand dieser (und ähnlicher) Kriterien hat Auer ein Korpus von 34 Sprachen auf einer Skala zwischen dem Silbentyp und dem Worttyp eingeteilt.

(13) Kontinuum vom „Silbenpol” zum „Wortpol” (nach Auer 1991)

Silbensprachen .......................Wortsprachen

$\begin{array}{lll}\text { Yoruba } & \text { Mandarin Französisch Uzbekisch } & \text { Englisch } \\ \text { Vietnamesisch } & \text { Japanisch Koreanisch } & \text { Russisch } \\ & \text { Hausa } & \text { Arabisch }\end{array}$

An Auers Vorschlag sind meiner Meinung nach einige Punkte problematisch. Sie betreffen die Behauptung, daB dem "Wortrhythmustyp" ein "Silbenrhythmustyp" entgegengesetzt ist, und daB sich nur der letztere regelhaft auf die Silbe beziehen kann. Es erscheint mir wenig sinnvoll,

5 In diese Richtung geht auch Nespor (1990), die gegen eine Parametrisierung von Sprachrhythmuseigenschaften in der Phonologie argumentiert. 
Sprachen anhand ihrer Silbenbezogenheit zu unterscheiden. Die Silbe ist eine Regeldomäne, auf die alle Sprachen in mehr oder weniger starkem Maße zurückgreifen. Die Kriterien von Auer, die sich auf Silbengrenzen beziehen, lassen sich nicht einmal auf alle Sprachen in seinem Korpus anwenden (so hat z.B. das Arabische Geminaten, obwohl es bei Auer dem extremen Gegenpol zum Silbenrhythmus zugeordnet ist). Eine andere Sprache, die man dem Wortrhythmustyp zuordnen würde, ist das Deutsche (es fehlt in Auers Korpus). Im Deutschen gibt es jedoch gleichzeitig eine Vielzahl von silbenbezogenen Regeln (vgl. Hall 1992) ${ }^{6}$

Im Gegensatz dazu ist Auers funktionale Motivation für den Sprachtyp "Wortrhythmus" überzeugend: Wortgrenzen fallen in diesen Sprachen immer mit Silbengrenzen zusammen. Regeln, die über Wortgrenzen hinausgehen, kommen (im Gegensatz zu dem Silbentyp, vgl. die französische Liaison in (14)) hier nicht vor. Daher ist zu erwarten, daß in den Worttypsprachen dem Wortende eine größere phonologische Bedeutung - im Sinne von Regeldomänen - zugewiesen wird.

Meiner Meinung nach ist jedoch der Gegenpol zu diesem Sprachtyp nicht ein Sprachtyp, der eine kleinere Regeldomäne (wie die Silbe) bevorzugt, sondern einer, der die phonologische Phrase als Domäne verwendet.

\subsection{Phrasenebene: typologische Korrelate}

In diesem Abschnitt möchte ich die Vermutung aufstellen, daß es eine Korrelation gibt zwischen dem Trend einer Sprache zum Silbentyp nach Auer und dem Trend, phonologische Phrasen mit Funktionen zu beladen. Hierzu vergleiche ich Sprachen vom Worttyp und vom Silbentyp.

In Sprachen vom Worttyp ist die Wortgrenze zugleich Barriere für phonologische Regeln, mit anderen Worten, Wortgrenzen werden markiert, indem phonologische Regeln an dieser Stelle unterbrochen werden. Weitere Mittel zur Markierung von Grenzen stehen in diesen Sprachen nicht zur Verfügung, weil unbetonte Silben zugleich reduziert werden, d.h., akustisch sind die Grenzen oft nicht wahrnehmbar. Aufgrund der Akzentverhältnisse wäre es in solchen Sprachen schwer, ein Phrasenende zu

6 Auer würde dieser Auffassung nicht zustimmen: Er hat argumentiert (z.B. in Auer (1994)), daß die Silbe keine Hauptkategorie im Deutschen ist, indem er zeigt, daß man die Auslautverhärtung ohne Bezug auf die Kategorie Silbe erklären kann. Er diskutiert aber nicht die kritischen Beispiele wie re/k/nen (Hall, persönliche Mitteilung). Ich möchte die Diskussion, ob die Silbe tatsächlich eine universale Kategorie ist, hier nicht vertiefen. Wichtig ist mir in diesem Zusammenhang, daß bei der Einteilung in „Wort-” und "Silbensprachen" die Kriterien, die auf der Einheit Silbe beruhen, nicht so nachvollziehbar sind wie die, die auf der Einheit Wort beruhen. 
markieren: falls der lexikalische Akzent nicht zufälig auf die letzte Silbe fällt, kann er nicht dorthin bewegt werden. Aufgrund dieser fehlenden Prominenz könnte die phrasenfinale Silbe nur schwer dazu dienen, in der Phonologie etwas zu markieren.

Wenn man annimmt, daB alle Sprachen in der einen oder anderen Form dem "Silbentyp” angehören, so stellt sich die Frage, welche Strategie die Sprachen verwenden, die nicht unter den Wortrhythmustyp fallen, also etwa Französisch, Italienisch, viele Tonsprachen. Das phonologische Wort kann in diesen Sprachen nur schwer als Regeldomäne dienen: Dessen Grenzen verschwimmen häufig zugunsten der Silbe. Charakteristisch für diese Sprachen sind Resilbifizierungen über Wortgrenzen hinweg, wie die französische Liaison. Als Resultat dieser Liaison entstehen größere artikulatorische Einheiten - vgl. (14). Daraus kann sich dann eine Tendenz in der Phonologie entwickeln, die Grenzen dieser Einheiten mit einer Funktion zu versehen. Das heißt, es wäre zu erwarten, daß Sprachen, die keine ausgeprägten phonologischen Wörter haben, eher dazu neigen, phonologische Phrasen als Regeldomäne zu entwickeln, als Sprachen, bei denen die entsprechenden Regeln bereits auf der Wortebene lokalisiert sind. Demzufolge könnten Sprachen solche phonologischen Phrasen als eigene Domäne entwickeln. In einem solchen Entwicklungsproze $B$ verwandeln sich die ursprünglichen Phrasen, die mit den syntaktischen Phrasen übereinstimmen und (wie in 1.1 beschrieben) die Domäne von Phrasenakzenten sind, in unabhängige Domänen. Dadurch sind sie nicht mehr isomorph mit syntaktischen Phrasen. Vermutlich können Sprachen solche Domänen ausbilden oder verlieren. Im nächsten Abschnitt illustriere ich dies anhand der romanischen Sprachen Italienisch, Französisch und Portugiesisch.

Danach zeige ich, wie diese Idee zu einer Sprachrhythmustypologie beitragen könnte.

\section{Beispiele}

In diesem Abschnitt soll die oben aufgestellte Hypothese anhand von Sprachen, die unterschiedlichen Sprachrhythmustypen entsprechen, überprüft werden. Die Frage lautet, ob man wirklich den „Silbentyp” zugunsten eines "Phrasentyps” abschaffen kann. Mit anderen Worten: Korrelieren Sprachen, die dem "Silbentyp" entsprechen, mit den Sprachen, die eigene phonologische Phrasen haben? 
2.1 Italienisch - Französisch - Portugiesisch

Laut Auer entspricht Italienisch (wie auch Latein) dem Prototyp einer Silbentypsprache (so hat es Geminaten, keine reduzierten Vokale, einfache Silben); Französisch hat laut Auer eine "Tendenz" zum Silbentyp, es weist aber weniger Eigenschaften dieses Typs auf und läßt sich daher nicht so gut zuordnen.

Das Portugiesische wurde von Auer nicht untersucht. Es bietet sich hier als Vergleich an, weil es sich nach Auers Kriterien zu einer Worttypsprache entwickelt haben müBte: Es hat keine Geminaten, alle unbetonten Vokale werden $\mathrm{zu}[u]$ reduziert und es hat komplexe Silben.

Die Frage lautet nun, wie sich diese Sprachen hinsichtlich größerer phonologischer Domänen verhalten. Im Italienischen sind phonologische Phrasen eigene Domänen (z.B. Radoppiamento Sintattico (6)). Im Französischen gibt es eine Resilbifizierungsregel, die über Wortgrenzen hinweg operiert, aber von Phrasengrenzen blockiert wird, die Liaison. Silbenfinale Konsonanten werden im Französischen nicht realisiert. Durch Liaison können sie zum Onset einer folgenden vokalinitialen Silbe werden. Wie (14) zeigt, operiert diese Regel aber nur innerhalb der Domäne der phonologischen Phrase, also [les enfants] [sont allés] etc., nicht zwischen diesen Domänen, auch wenn die segmentale Umgebung dafür gegeben wäre.

(14) Französische Liaison (vgl. Nespor/Vogel 1986)

\author{
les enfants sont allés à l'école \\ die Kinder sind gegangen in die Schule \\ [le:.zãfã.s5.ta.le: ?a] \\ aber nicht [s J.ta.le.za]
}

Im Portugiesischen gibt es überhaupt keine Evidenz für phonologische Phrasen, wie Frota (1995) gezeigt hat. Sie hat alle Regeln, die über Wortgrenzen hinweg operieren, untersucht und gezeigt, daß deren Domäne nicht die phonologische Phrase sein kann.

Diesen Beobachtungen zufolge korreliert also die "Silbentypsprache” Italienisch mit dem von mir hier postulierten „Phrasentyp”, die „Worttypsprache" Portugiesisch hat dagegen keine phonologischen Phrasen. Das Französische läßt sich mit dem neu hinzugekommenen Kriterium der Phrase nun deutlicher mit dem Italienischen zusammen gruppieren. In Abschnitt 3 erläutere ich den „Phrasentyp” ausführlicher. 


\subsection{In welche Kategorie gehört das Deutsche?}

Wie schon gesagt ist das Deutsche ein Beispiel für eine Sprache, die sich nicht einem von Auers Rhythmustypen zuweisen läBt. Es läßt sich aber nicht in die Mitte zwischen den Polen einordnen, weil es einerseits die Eigenschaften von wortbetonten Sprachen aufweist, andererseits aber viele silbenbezogene Regeln hat (vgl. Hall 1992). Es entspricht also beiden Typen. Meiner Meinung nach ist dies darauf zurückzuführen, dab die Silbe eine universelle Konstituente ist, deren Grenzen in allen Sprachen phonologisch relevant sind.

Wie läßt sich das Deutsche anhand einer Einteilung in Wort- und Phrasensprachen klassifizieren? Wenn man Auers Typologie hinsichtlich der Eigenschaften von Wortsprachen beibehält, ist das Deutsche klar eine Wortsprache. Das sagt auch Auer (1994). Allerdings muB er dann den Stellenwert der silbenbezogenen Regeln im Deutschen typologisch neu bewerten.

Eine Einteilung in wort- vs. phrasenbezogene Sprachen würde die Vorliersage machen, daß das Deutsche keine phonologischen Phrasen hat.

Nun hat das Deutsche aber eine Regel, die möglicherweise auf phonologischen Phrasen operiert, die "Rhythm Rule” (vgl. auch (3) oben).

(15) Akzentabschwächung (Rhythm Rule) im Deutschen

$\begin{array}{lll}\text { KONstanz } & \text { aber } & \text { Konstanzer ÚNi } \\ & \text { aber } & \text { [die ÚNi] [von KONstanz] }\end{array}$

Allerdings genügt dies allein noch nicht, um von einer unabhängigen $\mathrm{Ka}$ tegorie "phonologische Phrase” zu sprechen. Erstens ergeben sich Akzentuierung und Akzentreduktion direkt aus der syntaktischen Beziehung der Konstituenten.

Außerdem ist die Akzentuierung wie auch die Akzentverschiebung Teil der Prosodie, die einen anderen Stellenwert in der Grammatik hat als die eigentlichen phonologischen Regeln, auch die sog. "postlexikalischen” Regeln, d.h. phonologische Regeln, die erst nach dem Lexikon applizieren. In dem Modell von Selkirk (16), welches hinsichtlich der Rolle der Prosodie in der Grammatik als Standardmodell angesehen werden kann, sieht man, daß sich die Prosodie direkt auf die Syntax beziehen kann. Erst anschließend an den AkzentuierungsprozeB erfolgt die postzyklische Phonologie. Auf diese Regeln aber beziehen sich die Domänen der Phonologie (z.B. die französische Liaison, das Radoppiamento Sintattico im Italienischen). 
(16) Prosodie und Deakzentuierung in der Grammatik (nach Selkirk 1984, S. 34)

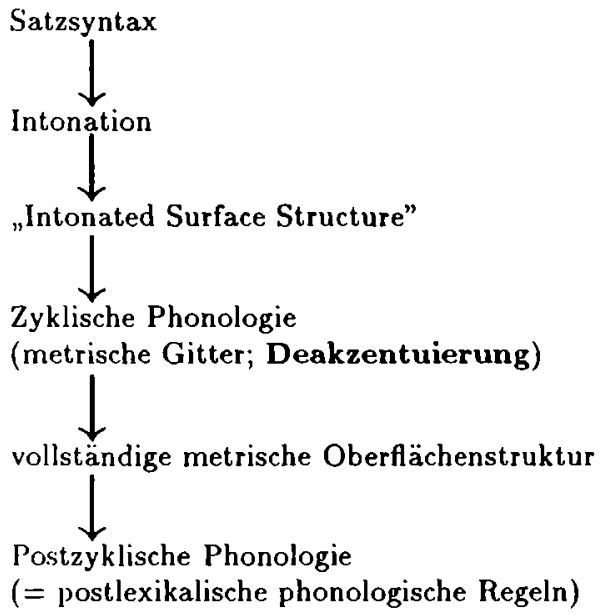

In der Literatur wird oft kein Unterschied zwischen Prosodie und postlexikalischer Phonologie gemacht, weil er normalerweise nicht relevant ist. Wenn man aber, wie im Rahmen der vorliegenden Problemstellung, $\mathbf{z w i}$ schen „Wort-” und „Phrasensprachen” unterscheiden will, so wird dieser Unterschied wichtig. Man findet in der Phonologie des Deutschen keine Evidenz für phonologische Konstituenten in Phrasengröße im eigentlichen Sinne, d.h. als von der Syntax abweichende Domänen postzyklischer Regeln (vgl. die Kriterien in (1)). Eine Regel, die sich auf das syntaktische Verhältnis zwischen den Konstituenten bezieht, wie die Akzentabschwächung, kann nicht als Evidenz für eine unabhängige phonologische Domäne gelten.

\section{Zusammenfassung: wort- vs. phrasenbezogene Sprachen}

In wortbetonten Sprachen spielen Phrasengrenzen als Regeldomäne keine Rolle. Phonologische Phrasen, wenn es sie überhaupt gibt, fallen stets mit syntaktischen Phrasen zusammen und erfüllen damit nicht das Kriterium einer unabhängigen Domäne gemäß (1). Andererseits ist aber die Silbe auch in vielen wortbetonten Sprachen (närnlich wohl allen NichtTonsprachen) eine wichtige Konstituente.

Ich habe daher für eine andere Unterscheidung argumentiert, nämlich für eine Differenzierung in wort-und phrasenbezogene Sprachen. Für diese 
Unterscheidung kann man viele von Auers Beobachtungen hinsichtlich der Worttypsprachen beibehalten, einige silbenbezogene Regularitäten allerdings nicht.

Umgekehrt möchte ich dem typologischen Raster ein wichtiges Einteilungskriterium hinzufügen, nämlich die Isomorphie mit morphosyntaktischen Einheiten.

(17) Erweiterung von Auers Typologie auf Phrasen

phrasenbezogen

eher Tonsprache

keine reduzierten Vokale

Liaison

phonologisches Wort $=$ morpho-

syntaktisches Wort

phonologische Phrase $\neq$ syn-

taktische Phrase

\section{wortbezogen}

eher keine Tonsprache

unbetonte Vokale werden

reduziert

keine Liaison

phonologisches Wort $\neq$ morphosyntaktisches Wort

wenn phonologische Phrase, dann $=$ syntaktische Phrase

Phrasenbezogene Sprachen haben der Domäne der Phrase und ihren Grenzen ein großes funktionales Gewicht verliehen. Daher sind die Wortgrenzen weniger relevant, sie können innerhalb der Phrase verschwimmen (z.B. Französisch bei der Liaison). In wortbetonten Sprachen (wie dem Deutschen) übernehmen die Wortgrenzen viele Funktionen der Phrasengrenzen. Daher können sie nicht noch mit weiteren Funktionen befrachtet werden. Die Silbe steht beiden Sprachtypen zur Verfügung, wird aber erwartungsgemäß von den phrasenbetonten Sprachen stärker genutzt, da viele Regeltypen kleine Domänen, wie Silbe oder Wort erfordern (z.B. lokale Assimilationen).

Es ist nicht sinnvoll, anzunehmen, daß Sprachen, die keine overte Markierung von phonologischen Phrasengrenzen haben, diese „unsichtbar” doch haben, weil man dann eine typologische Generalisierung verlieren würde. Allerdings können Sprachen phonologische Phrasen entwickeln. In der ersten Stufe werden syntaktische Phrasen verwendet, um phonologische Domänen zu markieren, wie die Akzentreduzierung im Deutschen oder Englischen. In der nächsten Stufe entwickeln diese Phrasen eigene GesetzmäBigkeiten, so daß sie nicht mehr mit den syntaktischen Phrasen zusammenfallen. Dies erfüllt dann ein Charakteristikum einer phrasenbetonten Sprache. Unabhängig von diesem graduellen Übergang ist aber anhand des Vorhandenseins unabhängiger phonologischer Phrasen als Regeldomäne eine eindeutige Klassifizierung der Sprachen möglich. 
Im Schema ist dieser graduelle Übergang dargestellt:

Wortsprachen

Deutsch

Portugiesisch
Phrasensprachen

Französisch Italienisch

\section{Literatur}

Auer, Peter (1991): Is a Rhythm-Based Typology Possible? A Study on the Role of Prosody in Phonological Typology. Universitāt Konstanz: KontRI Working Papers 21.

Auer, Peter (1994): Einige Argumente gegen die Silbe als universale prosodische Hauptkategorie. In: Ramers, Karl-Heinz et al. (Hg.): Universale phonologische Strukturen und Prozesse. Tübingen. S. 55-78.

Cheng, Chin-Chuan (1970): Domains of Phonological Rule Application. In: Saddock, J.M./Vanek, A.L. (Hg.): Studies presented to Robert B. Lees by his students. Edmonton: Linguistic Research, S. 39-59.

Frota, Sonia (1995): Prosodic Phrases and European Portuguese: in Search of Evidence. Erscheint in: Proceedings of ConSole III, Venedig.

Giegerich, Heinz (1985): Metrical Phonology and Phonological Structure. German and English. Cambridge.

Hall, T.A. (1992): Syllable Structure and Syllable-Related Processes in German. Tübingen.

Hayes, Bruce/Lahiri, Aditi (1991): Bengali Intonational Phonology. In: Natural Language and Linguistic Theory 9, S. 47-96.

Kleinhenz, Ursula (1994): Focus and Phrasing in German. Stuttgart/Tübingen: Arbeitspapiere des Sonderforschungsbereichs 340. Nr. 52.

Mooshammer, Christine (1994): Sprachrhy thmustypologie. Akzentzählende vs. silbenzählende Sprachen. MS. Berlin/München.

Nespor, Marina/Vogel, Irene (1986): Prosodic Phonology. Dordrecht.

Nespor, Marina (1990): On the Rhythm Parameter in Phonology. In: Roca, I. (Hg.): Logical Issues in Language Acquisition. Dordrecht. S. 157-173.

Pike, Kenneth (1945): The Intonation of American English. Ann Arbor.

Rice, Keren D. (1990): Predicting Rule Domains in the Phrasal Phonology. In: Inkelas, Sharon/Zec, D. (Hg.): The Phonology-Syntax Connection. Chicago. S. 289-312.

Selkirk, Elizabeth (1980): Prosodic Domains in Phonology: Sanskrit Revisited. In: Aronoff, Mark/Kean, M.L. (Hg.): Juncture. Saratoga. S. 107-129.

Selkirk, Elizabeth (1984): Phonology and Syntax: The Relation between Sound and Structure. Cambridge, Mass.

Wiese, Richard (1995): The Phonology of German. Oxford. 


\title{
KAI ALTER
}

\section{Der Zusammenhang von Akzentuierung und Phrasierung im Sprachvergleich*}

\begin{abstract}
Im allgemeinen ist man sich darüber einig, daß ein Zusammenhang zwischen Informationsstrukturierung (Fokus-Hintergrund-Gliederung, Topik-KommentarGliederung) sowie Akzentuierung und prosodischer Phrasierung besteht (vgl. Hayes/Lahiri 1991). Gut untersucht ist die Beziehung zwischen der Unterteilung von Sätzen in prosodische Phrasen und der Fokusstruktur (vgl. Nespor/Vogel 1986). Dies triftt ebenso auf die Analyse der Akzentpositionen in Verbindung mit der Informationsstruktur zu (Féry 1993). Bezüglich der Annahmen zur prosodischen Phrasierung und ihrem Zusammenhang mit der Akzentplazierung läßt sich ein solcher minimaler Konsens nur schwer feststellen. Übereinstimmung besteht lediglich darin, daf durch Grenzsignale (Pausen, GlottisverschluBinsertion, Grenztōne) die prosodische Phrasierung manifestiert wird.

Ich möchte hier zeigen, daB zwischen der Akzentplazierung und der prosodischen Phrasierung ebenfalls ein Zusammenhang besteht, und Möglichkeiten erörtern, diese Verbindung sprachübergreifend und experimentell nachzuweisen.

Ich beziehe mich dabei auf Beobachtungen zur Akzentplazierung im Deutschen und Französischen und schlage darauf aufbauend eine Methode zur Determinierung prosodischer Grenzen im Russischen vor.
\end{abstract}

\section{Problemstellung}

Hier soll gezeigt werden, wie mit unterschiedlichen Untersuchungsmethoden der Zusammenhang $\mathrm{zwischen} \mathrm{Akzentuierung} \mathrm{und} \mathrm{prosodischer} \mathrm{Phra-}$ sierung in verschiedenen Sprachen exemplifiziert werden kann. Intonatorische Phänomene wie Akzentplazierung und prosodische Phrasierung stehen in enger Beziehung zu informationsstrukturellen und phonologischen Eigenschaften auf der Satz- und Phrasenebene, ohne daß es immer eine eindeutige Korrelation zwischen linguistischen Kategorien und akustischen Signalparametern gibt. Das liegt am generellen Unterschied von abstrakten phonologischen Beschreibungseinheiten und konkreten signalphonetischen Daten.

* Ich danke Gerhard Jäger, Peter Janker, Ursula Kleinhenz und Ewald Lang für ihre kritischen Bemerkungen und Hinweise. 
Ich gehe davon aus, daß die akustische Realisierung von Akzenten über verschiedene Parameter wie z.B. Grundfrequenzverlauf, Intensität und Länge gesteuert werden kann. Aus dem Bündel der akustischen Parameter wird die Grundfrequenz ausgewählt und anhand des Grundfrequenzverlaufes nach Indizien für die prosodische Phrasierung gesucht.

Die Basis dieser Untersuchung ist in der unterschiedlichen Funktion von Akzenten angelegt: in Sprachen wie dem Französischen können Akzente auch eine demarkative Funktion übernehmen, in anderen Sprachen wie dem Deutschen übernehmen Akzente diese Funktion nur unter bestimmten Bedingungen. Diese Bedingungen werden durch bestimmte Faktoren determiniert, die sich aus der Informationsstrukturierung ergeben.

Im folgenden werden methodische Verfahrensweisen dargelegt, die eine effiziente Bearbeitung akustischer Parameter unter dem Blickwinkel funktional-phonologischer Überlegungen gestatten.

\subsection{Methodologische Vorüberlegungen}

Der beim Sprechvorgang an den Lippen abgestrahlte Schall ist das Resultat komplexer biomechanischer Artikulationsprozesse. Diese Prozesse werden ihrerseits durch neuronale Prozesse gesteuert. Ich beschränke mich hier auf diejenigen meBbaren Vorgänge in dem eigentlich nicht unterbrochenen physikalischen Bereich des signalphonetischen Bandes (Tillmann 1980), der den mittels Mikrophon aufgenommenen und im Oszillogramm sichtbaren Teil des phonetischen Signals betrifft. Damit kann eine Interpretation meBtechnisch ermittelter Daten gewährleistet werden, und, wenn auch in beschränktem Maße, eine Korrelierung dieser Daten mit linguistisch motivierten Beschreibungseinheiten erfolgen.

Zentrales Meßobjekt ist der zeitliche Verlauf des akustischen Signals unter Einbeziehung des Grundfrequenzverlaufes (Fo-Verlauf). Der Grundfrequenzverlauf im akustischen Signal reflektiert die Stimmlippenschwingungen pro Sekunde und hat auf der perzeptiven Seite sein Korrelat im Tonhöhen- bzw. Melodieverlauf (vgl. Abb. 2).

Es wird gezeigt, daß die Einteilung von Äußerungen in kleinere prosodische Gruppen nur bedingt über den Grundfrequenzparameter gesteuert wird, da $B$ auch andere Möglichkeiten existieren, Phrasengrenzen im akustischen Signal zu ermitteln.

Die Grundannahme besteht demnach darin, daß basierend auf der Überlegung von Kleinhenz (in diesem Band) Phrasengrenzen in verschiedenen Sprachen unterschiedlich realisiert werden und ihre Existenz an funktionale Eigenschaften gebunden ist. 
Weiterhin möchte ich annehmen, daß diese Phrasengrenzen akustisch unterschiedlich signalisiert werden und ihre Realisierungsform von den Eigenschaften der lexikalischen Wortakzentuierung abhängt.

\section{$1.2 \quad$ Untersuchungsmaterial}

Zunächst werden Beispielsätze aus dem Deutschen untersucht und die Schwierigkeiten gezeigt, die bei der Detektion von Phrasengrenzen mittels Fo-Verlauf auftreten. Die untersuchten Sequenzen sind dem von Jacobs (1994) analysierten Material entnommen. Weiterhin wird dafür argumentiert, daB es methodisch angebracht ist, Untersuchungen nicht nur innerhalb einer Einzelsprache vorzunehmen, sondern ähnlich gelagerte Phänomene auch in anderen Sprachen zu analysieren und aus dem Vergleich des möglicherweise unterschiedlichen Verhaltens der sprachtypischen Parameter AufschluB über das generelle Verhalten der Grundfrequenz bei Phrasierung zu erlangen.

Daher wird auch Material aus dem Französischen und Russischen vorgestellt und diskutiert. Alle drei Sprachen verhalten sich bereits bezüglich der Festlegung des lexikalischen bzw. Wortakzentes sehr verschieden: Russisch ist äußerst variabel bei der Positionierung des Wortakzentes (vgl. zavxóz „Verwalter” und závtrak „Frühstück”), die WortakzentPositionierung im Deutschen unterliegt starken morphologischen und phonologischen Restriktionen, während im Französischen der lexikalische Akzent an der rechten Peripherie von Syntagmen auftritt (vgl. beaucoup „viel”, mamán „Mama”).

In diesen drei Sprachen wird Prominenz als phonologische Funktion von Wortakzentuierung in unterschiedlichen Positionen realisiert.

Untersucht man Sätze bezüglich ihrer Akzentuierungsvariationen, hat man neben der lexikalischen Ebene für Wortakzentzuweisung die Ebene der Informationsstrukturierung zu berücksichtigen. Die informationsstrukturelle Gliederung eines Satzes wird im Diskurs festgelegt und beeinfluBt u.a. erheblich die Ausprägung der Intonationskontur. Es gibt die Möglichkeit, die Diskursvariabiltät relativ stabil zu halten, und, sieht man von der Untersuchung spontan gesprochener Sprache zunächst ab, durch Fokus-Hintergrund-Gliederung bedingte Effekte differenziert herauszustellen.

Die Frage-Antwort-Methode erlaubt es, die Informationsstruktur eines Satzes zu kontrollieren und Unterschiede in der Informationsgliederung zu analysieren. Durch entsprechende Frageformulierungen können unterschiedliche Fokusstrukturen evoziert werden. 
Hier möchte ich mich auf informationstrukturell unterschiedlich geartete Deklarativsätze beschränken, die als Antwortsequenzen auf Fragen produziert wurden. Die Fragen wurden bezüglich des zu erwartenden Fokustyps unterschiedlich angelegt.

Der Untersuchungsgegenstand ist somit der Grundfrequenzverlauf und die daran ablesbare prosodische Phrasierung von in ihrer Fokusstruktur differierenden Deklarativen im Deutschen, Französischen und Russischen.

Im folgenden möchte ich die theoretische Basis der hier angelegten Untersuchung spezifizieren und Möglichkeiten für die Berechnung der Fokusakzentpositionen darstellen.

\subsection{Theoretischer Rahmen}

Derzeit gibt es verschiedene Möglichkeiten, Akzentuierung und prosodische Phrasierung mit Eigenschaften der syntaktischen und informationsstrukturellen Strukturierung von Sätzen zu verbinden.

Algorithmen an der Schnittstelle zur Phonologie, die sich mit der Ableitung der Position von Satz- und Fokusakzenten befassen, sind bevorzugt im Rahmen der Metrischen Phonologie zu suchen. Sie beziehen sich auf den Übergang einer hierarchisch organisierten syntaktischen Struktur in eine metrische Baum- und/oder Gitterstruktur.

Die strukturelle Position von neutralem Satz- bzw. Fokusakzent ist die der syntaktisch am tiefsten eingebetteten Komponente (Cinque 1993; Abraham 1994; Alter 1994).

Ein ähnlich gelagerter Ansatz, der neben syntaktischen zugleich semantische Informationen berücksichtigt und ebenfalls die Position von Fokusakzenten voraussagt, wird von Jacobs (1994) vorgestellt. Dieses Konzept basiert im wesentlichen auf dem Phänomen der Integration, welches die syntaktischen und informationsstrukturellen Beziehungen $z$ wischen den einzelnen Schwester-Konstituenten im Satz regelt. So ist beispielsweise ein direktes Objekt in einem Satz mit finaler Verbstellung in das Verb integriert, wenn neben anderen semantischen Faktoren der Kontext ein neutraler ist bzw. Normalfokus vorliegt. Aus der Position des Fokusmerkmals läBt sich dann die Satzakzentposition über dem direkten Objekt berechnen:

Was ist passiert?

(1a) Hans hat einem Freund ein HAUS gebaut. 
Ausschlaggebend für die Determinierung der Satzakzentposition ist die Anzahl der errechneten Einträge ( $" *)$. Die Gesamtheit der Einträge bildet ein sog. metrisches Gitter. Die Einträge werden anhand der Spezifizierung der einzelnen Konstituenten für metrische Stärke und Fokus zugewiesen. Sind alle Konstituenten im Satz verarbeitet worden, erhält man eine unterschiedliche Staffelung der Einträge. Diejenige Konstituente, die die meisten Einträge bekommt, ist die prominenteste im Satz:

(1b).... [ einem Freund] [[ein Haus] gebaut $]_{F}$

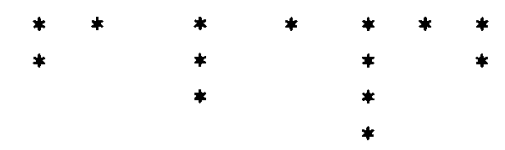

Ohne jetzt im einzelnen auf den exakten Algorithmus für die Ableitung metrischer Bäume und Gitter dieses Satzes bei unterschiedlicher Fokussierung einzugehen, soll hier auf das Phänomen der Fokusambiguität aufmerksam gemacht werden. Die gleiche Sequenz ohne Veränderung der Wortstellung ist auch in einem minimal fokussierten Kontext realisierbar, nämlich auf die Frage:

Was hat Hans einem Freund gebaut? (2a) Hans hat einem Freund ein HAUS gebaut.

(2b).... [ einem Freund] [[ein Haus] $]_{F}$ gebaut]

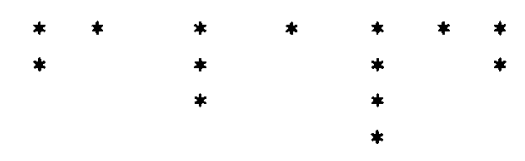

Bei der Ableitung der Prominenzverhältnisse in dieser Antwortsequenz stellt sich heraus, daß der Satzakzent ebenfalls auf dem direkten Objekt liegt und das metrische Gitter in (2b) dem in (1b) gleicht. Ein Unterschied besteht in der Position des Fokusmerkmals, welches in (2) nur das direkte Objekt umfaßt.

Umgekehrt ist eine Disambiguierung anhand der Prominenzverhältnisse dann gegeben, wenn eine andere Konstituente als direktes Objekt eng/minimal fokussiert wird:

Wem hat Hans ein Haus gebaut?

(3a) Hans hat einem FREUND ein Haus gebaut. 
(3b).... [ einem Freund $]_{F}[[$ ein Haus] gebaut]

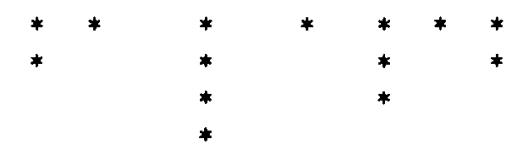

Bei dem durch die Frage vorgegeben Kontext rückt alles außer dem indirekten Objekt in den bekannten Hintergrund, und das Fokusmerkmal wird nur dem indirekten Objekt zugewiesen. Daraus wird dann die Position des prominentesten Akzentes berechnet.

Ein ähnlicher Effekt tritt bei multipler Fokussierung, ausgelöst durch multiple w-Fragen, auf: Sowohl dem indirekten als auch dem direkten Objekt wird ein separates Fokusmerkmal zugewiesen, und beide erhalten gegenüber den anderen Konstituenten entsprechend mehr Einträge im metrischen Gitter, wobei zu beachten ist, daB das direkte Objekt, ausgezeichnet als das designierte terminale Element, einen Eintrag zusätzlich im Vergleich zu seiner linksadjazenten Schwester bekommt.

Was hat Hans wem gebaut?

(4a) Hans hat einem FREUND ein HAUS gebaut.

(4b).... [ einem Freund $]_{F}\left[[\text { ein Haus }]_{F}\right.$ gebaut $]$

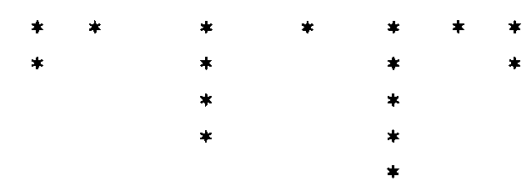

Dieser Ansatz gestattet es, eine syntaktische Struktur derart zu verarbeiten, da $B$ die Position des Satzakzentes voraussagbar wird. Diese Position ist diejenige, die die meisten Einträge in einem metrischen Gitter erhält.

Wird das direkte Objekt eng fokussiert oder kontrastiert, ergibt sich die gleiche metrische Gitterkonstellation wie bei neutraler Fokussierung. Der Satzakzent fallt wegen Integration und/oder syntaktischer Einbettungstiefe im deutschen Verb-letzt-Satz bei neutraler Fokussierung auf das direkte Objekt. Das Fokusmerkmal projiziert in diesen Fällen über einen maximalen Bereich, der nur durch Topikalisierung unterbrochen wird, während in anderen Kontexten die Projektion von Fokus eingeschränkt wird und sich u.U. nur auf das direkte Objekt bezieht. Die sog. Fokusprojektion kann aber durch Fokussierung anderer Konstituen- 
ten aufgebrochen werden, und genau das beeinfluBt auch die prosodische Phrasierung.

Jedoch sind die Voraussagen metrischer Transformationen bezüglich der prosodischen Phrasierung restringiert, da sie ausschlieBlich an die Position der metrisch stärksten Einheit gebunden sind.

Ein Modell, welches sich in der Nähe der Schnittstelle zur Phonetik/Akustik ansiedelt, ist das Tonsequenzmodell (vgl. Pierrehumbert 1980). Dieses Modell inkorporiert gleichsam eine metrische Komponente und transformiert die relevanten Informationen in eine tonale Komponente.

\subsubsection{Der Ton-Sequenz-Ansatz}

Dieser theoretische Ansatz erlaubt neben der Ableitung der Prominenzverhältnisse mittels Einträgen der metrischen Gitter zusätzlich eine Annäherung an den Grundfrequenzverlauf in einem Satz. Der Fo-Verlauf wird in einer tonalen Komponente aus den Informationen der metrischen Repräsentationsebene und der Spezifizierung des Fokustyps gewonnen und über Interpolationsregeln in eine akustische Form übergeleitet.

Damit ergibt sich die Möglichkeit, extrahierte Grundfrequenzverläufe zu interpretieren. Fo-Verläufe können reanalysiert werden, indem zwei interagierende Tonniveaus angenommen werden: Hoch- und Tieftöne. Die aus den Tönen kombinierten Tonsequenzen bilden eine zugrunde liegende Form im Sinne einer prosodischen Realisierung von Konturen bzw. Melodieverläufen und dienen als Eingabe für die Ableitung des Grundfrequenzverlaufes der Äußerung.

Eine Äußerung ist in kleinere prosodische Einheiten - in Intonationsphrasen und intermediäre Phrasen - zerlegbar. Jede Phrase enthält eine Sequenz von Hoch- und Tieftönen, die wiederum in 3 Typen klassifizierbar sind: Akzenttöne, Phrasentöne und Grenztöne. Akzenttöne können mono- oder bitonal auftreten. Sie werden über zentrale Assoziierung den minimalen tontragenden Einheiten zugewiesen. Über Merkmalsperkolation werden die als metrisch stark ausgewiesenen Silben mit Akzenttönen assoziiert.

Grenztöne werden der letzten Silbe der Phrase zugewiesen, Phrasentöne stehen zwischen Akzent- und Grenztönen. Die Zuweisung von Grenztönen an Phrasengrenzen erfolgt über periphere Assoziierung. Die folgende Graphik veranschaulicht den Aufbau des Tonsequenzmodells in Auszügen. Wie auch in der Autosegmentalen Phonologie wird von einem multidimensionalen Aufbau der einzelnen Ebenen ausgegangen. In 
Abb. (1) sind die prosodische, die tonale und die phonemische Ebene dargestellt. Die prosodische Ebene enthält die relevanten Informationen zur prosodischen Hierarchie und damit zum Aufbau der prosodischen Phrasen und der darunter liegenden Ebenen. Die tonale Ebene kodiert die Informationen über die Zuweisungsdomäne von Akzenttönen und Grenztönen. Im vorliegenden Fall werden Akzenttöne der Domäne „pitch accent” (PA) zugewiesen und Grenztöne mit den Grenzen intermediärer (ip) und Intonationsphrasen (IP) assoziiert. Die phonemische Ebene erhält zugleich Informationen aus der prosodischen Ebene, z.B. über den Aufbau der Silbenstruktur, und setzt die Informationen über die Tonstruktur der tonalen Ebenen um.

Dieses Informationspaket, insbesondere jedoch die Angaben über die tonale Struktur, kann dann mittels Interpolationsregeln in einen Grundfrequenzverlauf transformiert werden.

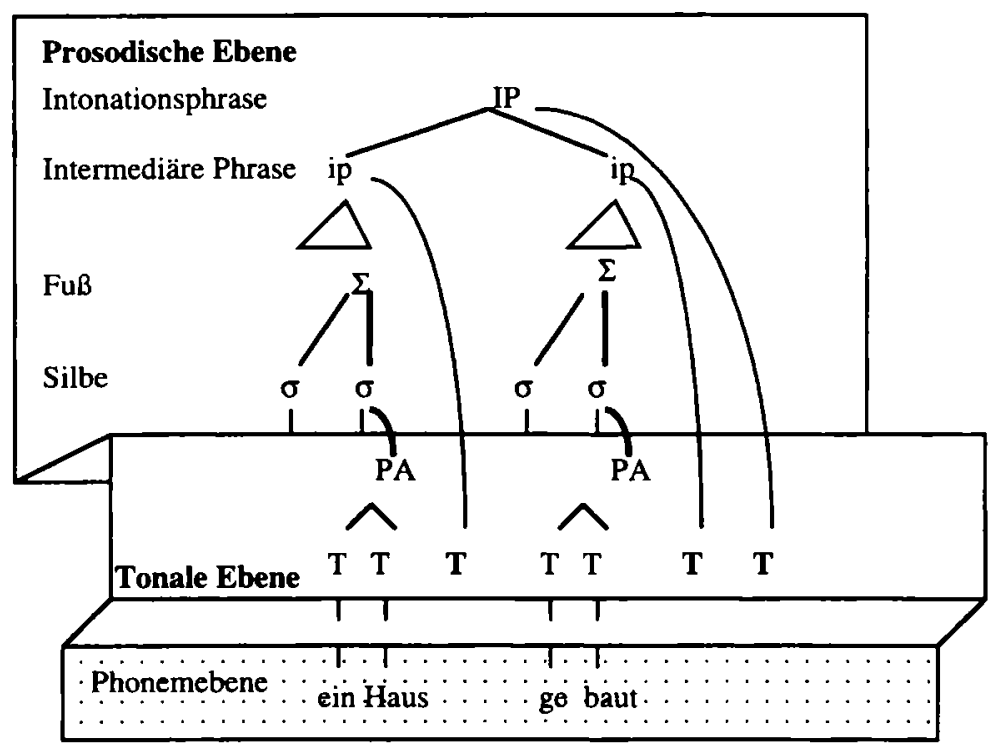

Abb.1: Der schematisierte Aufbau einzelner Ebenen im TonsequenzModell für den Abschnitt „...ein Haus gebaut”.

Nicht unumstritten ist allerdings die Zuweisungsdomäne für die verschiedenen Typen von Tönen. Erschwerend tritt hinzu, daß Akzenttöne und Grenztöne direkte funktionale Korrelate (Fokus resp. prosodische Phra- 
sierung) haben, diese aber akustisch nicht immer exakt determinierbar sind. Der Bezug zum Fo-Parameter genügt daher nicht immer, um alle Facetten einer globalen Kontur und diskursrelevante Varietäten zu erfassen. Anzeichen dafür gibt es aus aktuellen Untersuchungen von Dogil (1995) für das Deutsche, wo der Wortakzent (i.e. Akzent in neutraler Position) auch über den Zeitparameter und der Fokusakzent über den Grundfrequenzverlauf gesteuert werden kann. Selbiges gilt auch für die Detektion prosodischer Phrasengrenzen (s. Batliner 1994).

Damit ist der theoretische Rahmen für die folgenden experimentellen Untersuchungen vorgegeben: Die Informationsstruktur wird in eine syntaktische Struktur mittels Merkmalen implementiert. Mit diesen strukturellen Vorgaben lassen sich in einer metrischen Komponente die Prominenzverhältnisse im Satz berechnen. Eine tonale Komponente gibt zusätzlich dazu Informationen über die prosodische Phrasierung und die tonale Struktur, womit eine maximale Annäherung an die tatsächlich realisierte akustische Form erreicht werden kann. Auf diesem Hintergrund lassen sich nun die folgenden Arbeitshypothesen aufstellen, die experimentell verifiziert werden sollen.

\subsection{Arbeitshypothesen}

Es gibt, wie oben diskutiert, einen Zusammenhang zwischen Akzentplazierung, Akzenttyp und Informationsstrukturierung. Dieser Zusammenhang soll um die Kategorie "Phrasierung” erweitert und am Verhalten des Grundfrequenzparameters nachgewiesen werden. Dabei wird gezeigt, inwieweit dieser Parameter für den Nachweis informationsstruktureller Eigenschaften strapazierbar ist.

Die Grundfrequenzbewegung (Fo) hat (neben anderen Funktionen) die Aufgabe

a) die Position der Fokusakzente anzuzeigen,

b) die Art des Fokus zu signalisieren,

c) die Grenzen von prosodischen Einheiten zu markieren.

\subsubsection{Beobachtungen im Deutschen}

Diejenigen Silben, die Träger für lexikalischen Wortakzent sind, tragen auch den Fokusakzent. Das sagt allerdings weder etwas über die $\mathrm{Zu}$ weisungsdomäne für Fokusakzente aus, noch sind Voraussagen über die Phrasierung möglich.

Die oben genannten Schwierigkeiten für die Zuweisung von Akzentund Grenztönen und deren akustische Realisierung sollen im folgenden an ausgewählten Beispielen des Deutschen exemplifiziert werden. Dazu 
wurde ein Teststimulus nach der Frage-Antwort-Methode aufgebaut und die von Jacobs (1994) untersuchten Sätze wurden aufgezeichnet, digitalisiert und einer me日technischen Analyse unterzogen. Dies betrifft die folgenden Frage-Antwort-Paare:

(5) Was ist passiert?

Hans hat seinem Freund ein HAUS gebaut.

(=Normalfokus)

(6) Was hat Hans seinem Freund gebaut?

(=Fokus auf dem)

Hans hat seinem Freund ein HAUS gebaut. direkten Objekt)

(7) Hans hat wem was gebaut?

Hans hat seinem FREUND ein HAUS gebaut.

(=multiple Foki)

Anhand von Fo-Verläufen und Oszillogrammen soll nun nach der Fokusakzentposition, der durch den Fo-Verlauf induzierten Fokusart und der durch Fokussierung bedingten Phrasierung gesucht werden.

Die graphischen Darstellungen in Abb. (2) sind folgendermaßen zu interpretieren: Im oberen Teil des Gesamtdiagramms ist der oszillographische Verlauf, d.h. die Schalldruck-Zeit-Funktion als Resultat der Membranschwingung des Mikrophons abzulesen, im unteren Teil ist der aus dem Signal extrahierte Fo-Verlauf zu sehen. Auf der x-Achse ist der zeitliche Verlauf der Grundfrequenz in Millisekunden ablesbar, die $y$-Achse zeigt die Werte der Grundfrequenz in Hertz an. Das Gesamtdiagramm beinhaltet die digitalisierte und damit computerlesbare Information jeweils einer Antwortsequenz.

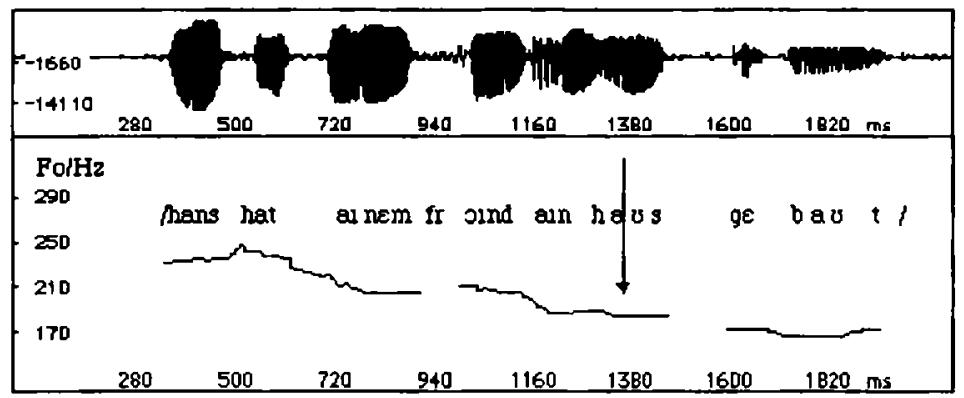

Abb. 2: Oszillogramm und Fo-Verlauf von Beispiel (5), die mit Pfeil markierte Stelle ist die Position des Fokusakzentes bei Normalfokussierung. 
Bevor die Position und die Form der einzelnen Akzente interpretiert werden kann, ist einem bio-mechanisch basierten Prozeß Rechnung zu tragen - dem der Deklination. Dieser Prozeß bewirkt das stetige Absinken der Grundfrequenz zum Satzende hin. Dies ist am gleichmäßig fallenden globalen Kurvenverlauf in Abb. (2) erkennbar.

Da Fokusakzente in dem hier untersuchten Material auf den Bereich des direkten und indirekten Objekts beschränkt sind, werden auch nur diese Sequenzen näher betrachtet.

Zunächst fällt auf, daß die Fokusposition anhand des Fo-Verlaufes nicht einfach zu bestimmen ist. Aufgrund der Voraussagen aus der Metrik kann davon ausgegangen werden, daB das direkte Objekt ein Haus Träger der Fokus- resp. Satzakzentposition ist. Der Fokustyp „Normalfokus” beeinflußt den tonalen Verlauf über dieser Position. Dieser Verlauf kann als, wenn auch schwach ausgeprägtes, Fallen beschrieben werden.

Eine Phrasierung sollte nach den Regeln der Fokusprojektion zwischen indirektem und direktem Objekt nicht existieren, da in diesem Satz ein maximaler Bereich fokussiert ist.

In Abb. (3) ist der Fo-Verlauf aus Beispielsatz (6) zu sehen. Hier wird das direkte Objekt minimal fokussiert, es ist auch Träger des Satzakzents (s.o.). Der Tonhöhenverlauf zeigt im Gegensatz zu (5) keine signifikanten Unterschiede. In diesem Beispielsatz gibt es ebenfalls keine Indizien für eine Phrasengrenze $\mathbf{z w i s c h e n ~ i n d i r e k t e m ~ u n d ~ d i r e k t e m ~ O b j e k t . ~}$

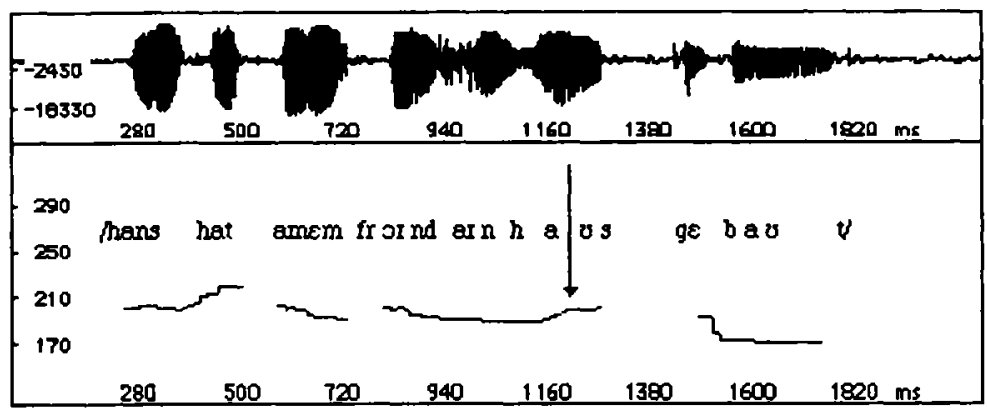

Abb. 3: Oszillogramm und Fo-Verlauf von Beispiel (6), die mit Pfeil markierte Stelle ist die Position des Fokusakzentes bei enger Fokussierung des direkten Objekts. 
Im Vergleich dazu ist der Fall der multiplen Fokussierung in Abb. (4) bezüglich der Akzenttypen und auch der Phrasierung eindeutig interpretierbar. Deutlich sind die zwei Fokusakzente als Fo-Anstieg über beiden Objekten realisiert. Damit ergibt sich auch die Möglichkeit, anhand des Fo-Verlaufs eine Phrasengrenze zu interpretieren.

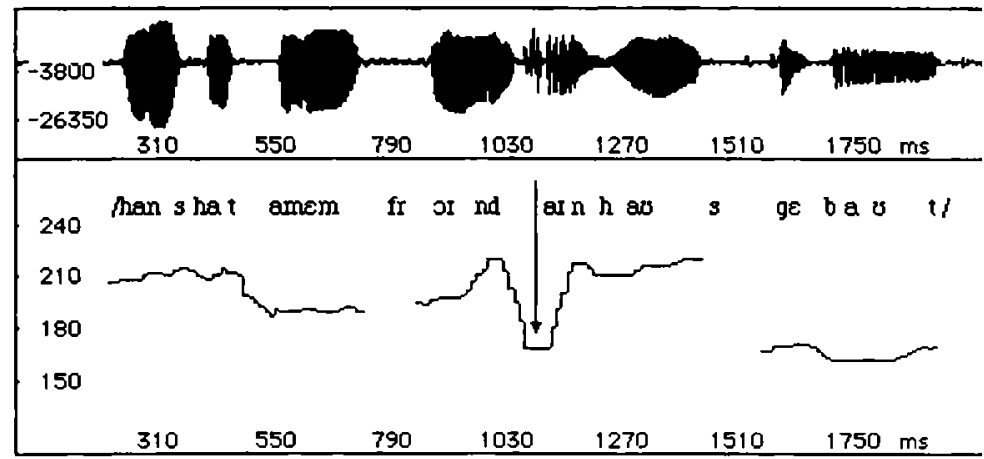

Abb. 4: Oszillogramm und Fo-Verlauf von Beispiel (7), die mit Pfeil mar kierte Stelle ist die Position der Grenze zwischen den beiden eng fokussierten Konstituenten.

\subsubsection{Interpretation der Daten im Tonsequenzansatz}

Die Beispiele zeigen, daB es charakteristische natürliche Tendenzen für die Realisierung unterschiedlicher Fokusstrukturen und der damit verbundenen Phrasierung gibt (vgl. Féry 1993 und Uhmann 1989).

Jede Ebene der prosodischen Hierarchie ist phonologisch motiviert und hat Verbindungen zu anderen Ebenen der Grammatik (Syntax, Informationsstruktur).

Sprachen können sich dadurch unterscheiden, welche der Ebenen die wichtigste für Akzentzuweisung und Grenzmarkierung ist. Dabei können verschiedene Domänen miteinander konkurrieren, genauso wie es möglich ist, daB in einer Sprache bestimmte Ebenen nicht relevant sind. Unter Berücksichtigung informationsstruktureller Gegebenheiten ist es wichtig, diejenige Domäne zu spezifizieren, die stärker an syntaktischinformationsstrukturelle Einheiten gebunden ist, um die prosodische Strukturierung angemessen ableiten zu können. 
Ohne auf die kontroverse Diskussion zum Inventar prosodischer Einheiten einzugehen, will ich zeigen, daß die zwei höchsten prosodischen Domänen relevant für Fokuseffekte sind: im vorgestellten Modell die Intonationsphrase und intermediäre Phrasen.

Jede intermediäre Phrase ist potentielle Trägerin eines separaten Akzenttons. Dies wird deutlich im Fall (7) mit multipler Fokussierung. Die weniger eindeutigen Fälle (5/6) bedürfen einer zusätzlichen Erläuterung.

Neutraler bzw. globaler Fokus induziert einen maximalen Fokusbereich und nur die integrierte Konstituente, das adjazent zum Verb stehende direkte Objekt sticht als prominent hervor.

Dies ist ebenso der Fall bei minimaler Fokussierung des direkten Objekts wie in (6). Vergleicht man beide Fälle, so zeigt sich Fokusambiguität, d.h., beide Sätze sind prosodisch nicht voneinander zu unterscheiden.

Im Rahmen des Tonsequenzansatzes findet sich eine Erklärung für diesen Effekt. Bei normalem Fokus dominiert das Fokusmerkmal eine Intonationsphrase, die indirektes und direktes Objekt umschließt. Bei minimalem Fokus (6) dominiert das Fokusmerkmal die tiefer eingebettete Konstituente des direkten Objekts, allerdings ändert sich an der prosodischen Phrasierung nichts (vgl. Nespor/Vogel 1986). Die eng fokussierte Objektphrase formt innerhalb der sie dominierenden Intonationsphrase eine eigene intermediäre Phrase (ip), die zugleich die Domäne für die Zuweisung des Fokusmerkmals ist.

(8) ... [seinem Freund [ein Haus] ip]IP gebaut

Das Fokusmerkmal perkoliert auf die höhere Ebene der Intonationsphrase und wiederum werden beide Objekte von diesem Merkmal dominiert. Damit ergibt sich keine zwingende Notwendigkeit, ein Grenzsignal vor dem direkten Objekt einzufügen.

Im Gegensatz dazu steht Beispiel (7) mit multipler Fokussierung, wo jeder Objektphrase ein Fokusmerkmal zugewiesen wird und beide dadurch eigene prosodische Phrasen bilden können.

(9) $\ldots[\text { [ [seinem Freund }]_{i p}$ [ein Haus $\left.]_{i p}\right]_{I P}$ gebaut

Damit ergibt sich, da $B$ jede fokussierte Konstituente eine eigene prosodische Phrase auf den unterschiedlichen Ebenen bilden kann und dann auch, wie im folgenden demonstriert, eine Domäne für die Fokusakzentzuweisung bietet.

Gussenhoven (1994) argumentiert für eine radikale Annahme der prosodischen Struktur für das Englische: Es gibt bei normalem Fokus, keine 
Indizien für Phrasierung bzw. Grenztonrealisierung sondern nur bei multiplem Fokus.

Zunächst wird jeder Konstituente ein bitonaler Akzentton der Form $\mathrm{H}^{*} \mathrm{~L}$ zugewiesen. ${ }^{1}$ Dieser Akzentton bedeutet, daB über der akzentuierten Silbe ein von einem hohen Niveau ( $\mathrm{H}$ für $h i g h$ ) auf ein niedrigeres Niveau (L für low) fallender tonaler Verlauf erzeugt wird.

Bei weiter Fokussierung wandert der zweite Ton (L) des präfinalen bitonalen Akzentes nach rechts und endet an der linken Seite des folgenden Akzentes (vgl. unten für das Deutsche). Die Verbindung zwischen beiden Akzenten wird durch Interpolationsregeln hergestellt. Bei Normalfokus gibt es prosodische Restrukturierung, bei multiplen Foki wird die ursprüngliche, d.h. die syntaktische Phrasierung weitestgehend beibehalten.
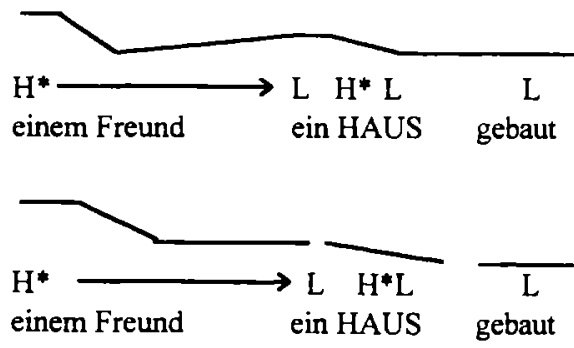

Man kann hier annehmen, daB im Fall (10) $(=(5))$ das Fokusmerkmal oberhalb der Domäne der intermediären Phrasen operiert und die gesamte Verbhülle dominiert. Die Tonverschiebung ist daher möglich, weil keine Eigenschaft die Insertion von Grenzmarkern zwingend erfordert. Ähnliches gilt auch im Beispiel (11) (=(6)). Das Fokusmerkmal dominiert zunächst die intermediäre Phrase, bestehend aus direktem Objekt, perkoliert dann aber an die Intonationsphrase, womit die Fokusdomäne erweitert wird. Dadurch werden Grenzmarker vermieden, der Akzentton erfährt die gleiche Realisierung wie in (5), woraus Fokusambiguität resultiert.

1 Es wird im allgemeinen davon ausgegangen, daß Fokusakzente im Englischen und Deutschen bitonal sind. 


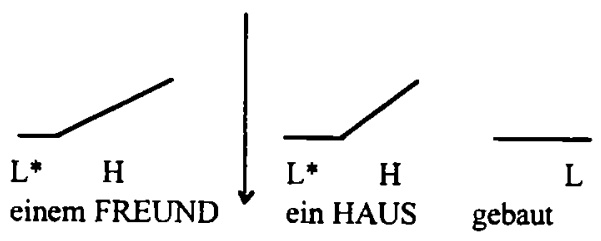

In (12) dominiert je ein Fokusmerkmal eine syntaktische Konstituente, beide Merkmale bewirken die Bildung zweier prosodischer Phrasen, über denen je ein bitonaler Akzentton realisiert wird. Die Tonhöhenbewegung weicht von der in den vorangegangenen Beispielen $a b$, da in (12) ein andere Fokustyp vorhanden ist und daher vom Sprecher eine andere Tonsequenz aus dem Toninventar ausgewählt wird.

\subsubsection{Zusammenfassung}

Die Hypothesen (a) und (b) aus Abschnitt 1.4 oben konnten anhand der akustischen Untersuchung der hier ausgewählten Beispiele bestätigt werden: Die Tonhöhenbewegung zeigt zugleich die Position und die Art der Fokusakzente an.

Weniger eindeutig ist die prosodische Phrasierung am Grundfrequenzverlauf ablesbar. Das hängt mit der Eigenschaft des Deutschen zusammen, Wortakzente nicht demarkativ zu verwenden, sondern ihnen eine lexikalische Funktion zuzuweisen.

Bildet man jedoch Extremfälle, wie bei multipler Fokussierung, und vergleicht zwei eng fokussierte, adjazent zueinander stehende, einsilbige Konstituenten miteinander, läßt sich am Tonhöhenverlauf die prosodische Strukturierung erkennen. Dies soll jedoch nicht ausschließen, daß es andere Möglichkeiten für die Signalisierung von prosodischen Grenzen gibt, z.B. die GlottisverschluBinsertion und Assimilationserscheinungen. Diese wurden im Rahmen der vorliegenden Untersuchungen nicht analysiert.

Bezüglich der akustischen Realisierung der mittels metrischer Algorithmen errechneten Prominenzverhältnisse in Sätzen muß die Untersuchung erweitert werden, was hier nicht geleistet werden soll. Der Verweis darauf, daß Prominenz ein ganzes Merkmalsbündel akustischer Parameter 
umfaßt (z.B. Umfang der Tonhöhenbewegung, Dauerverhältnisse, Intensität usw.) und sie im Deutschen nicht direkt am Fo-Verhalten über den relevanten Positionen erkennbar ist, soll hier genügen.

Im folgenden wird eine Sprache untersucht, die Akzente in fester Position hat und diesen eine demarkative Funktion zuweist - das Französische.

\section{Beobachtungen im Französischen}

Die aktuelle Diskussion zur Phonologie des Französischen betrifft den Zusammenhang zwischen Silbifizierungsregeln und Akzentuierung (vgl. Tranel 1987 und 1995), insbesondere die oft beschriebenen Phänomene der Liaison, Verkettung (enchainement) und Schwa-Tilgung.

Im weiteren möchte ich die eben genannten phonologischen Prozesse im Zusammenhang mit Akzentuierungsregeln exemplifizieren. Es zeigt sich, daß einige Silbifizierungseffekte nur bedingt unabhängig von Einflüssen der Akzentuierung im Französischen auftreten.

Erst dann möchte ich eine an die vorherige Analyse des Deutschen anschließende Beschreibung der Akzentuierungsphänomene im Zusammenhang mit Fokussierungsstrategien im Französischen geben.

\subsection{Die Liaison}

Zusätzlich zu den in Nespor/Vogel (1986; vgl. Kleinhenz in diesem Band) beschriebenen Daten bezüglich der durch die Phrasierung blockierten Liaison möchte ich weitere Daten aus der einschlägigen Literatur (z.B. Lyche/Girard 1995) und eigene Beobachtungen anführen. Liaison, Schwa-Tilgung und Resilbifizierung sind phonologisch eng zusammenhängende Prozesse: Der betroffene Konsonant kann in den Onset einer Silbe eines folgenden Wortes oder aber in die Coda der letzten (betonten) Silbe des vorangehenden Wortes verlagert werden. Diese Prozesse sind nur dann voneinander zu differenzieren, wenn die Position und damit zusammenhängend die Art des Akzentes korrekt berücksichtigt werden. Ich möchte zeigen, daß die Resilbifizierung und die Zuweisung von Fokusakzenten miteinander in Verbindung stehen.

Folgende zwei Typen der Liaison sind in Relation zur Verkettung im Französischen zu unterscheiden: nicht-verkettete (13) und verkettete (14) Liaison.

(13) J'avais ... un rêve /Zave ... zöere:v/ ich hatte einen Traum 
(14) J'avais ... un rêve

/3avez ... œ̃re:v (cf. Lyche/Girard 1995, S. 211)

ich hatte einen Traum

Die Liaison vom Typ (13) kann allerdings dann verhindert werden, wenn das folgende Wort initialen Akzent trägt:

(15) Il y a une incroyable pudeur (vgl. Lyche/Girard 1995, S. 216)

/i li ja yn ... Ẽkrwajablo pydœ:r/

*/i li ja y ... n Ẽkrwajabla pydœ:r/

es gibt eine unglaubliche Schamhaftigkeit

Dieses Phänomen ergibt sich aus der Tatsache, daB aufgrund der Betonung der ersten Silbe ein Glottisschlag eingesetzt wird und daher keine Position mehr frei ist für den Konsonanten der Coda des vorangehenden Wortes.

Hier liegt auch der fundamentale Unterschied $z$ wischen beiden Typen der Liaison (13/14). Die nicht-verkettete Liaison ist obligatorisch, die verkettete fakultativ. Sie wird daher in der einschlägigen Beschreibung auch unter der Bezeichnung "fakultative Liaison" geführt.

Die obligatorische Liaison tritt aber im Gegensatz zu (15) auch dann auf, wenn die initiale Silbe des nachfolgenden Wortes betont wird:

(16) Un appui

$$
\begin{aligned}
& \text { / ̃ ... napपi/ } \\
& \text { eine Unterstützung }
\end{aligned}
$$

Andere Beispiele verweisen darauf, daß es möglicherweise einen weiteren Zusammenhang zwischen der Plazierung des Akzentes, also initial vs. final, und der Liaison gibt.

$$
\begin{aligned}
& \text { Son imagination } \\
& \text { seine Vorstellungskraft }
\end{aligned}
$$

(a) /sñimaว3inasjj/ bei Endbetonung

(b) /s̃̃...nimazinasjõ/ bei initialer Betonung

Dennoch lassen sich systematische Unterschiede zwischen Akzentplazierung und dem Vorkommen der Liaison verschiedenen Typs feststellen, wenn längere Sequenzen untersucht werden.

Betrachtet man die folgenden Beispiele, läBt sich erkennen, daß bei initialer Betonung von (I) (vgl. 18c) der rechte Wortrand des Wortes (I) nicht von der Liaison betroffen wird, während bei finaler Betonung in (II) sowohl der linke Wortrand von (II) als auch der rechte Wortrand von (I) einer Resilbifizierung durch die Liaison unterzogen werden. 


$$
\begin{aligned}
& \text { I } \\
& \text { un chemin de campagne } \\
& \text { ein Weg des Feldes (= ein Feldweg) }
\end{aligned}
$$

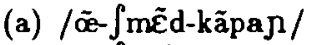

(b) / $\tilde{a}-\int \mathrm{m} \tilde{\varepsilon}$-dkäpan/

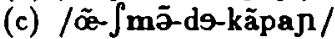

bei Endbetonung auf II

bei initialer Betonung auf II bei initialer Betonung auf I

Im Beispiel (18a) tritt die verkettete Liaison auf, der Konsonant der Präposition de wird in die Coda des vorangehenden Wortes (I) verschoben. In (18b) trifft man auf die nicht-verkettete Liaison, wobei der Konsonant der Präposition de nach der Tilgung des Schwa an den ersten Konsonanten der ersten Silbe des folgenden Wortes verschoben wird, jedoch die Konstituente I intakt bleibt. Bei Betonung des Wortes (I), also bei initialer Betonung der gesamten Kombination, wird weder das Schwa der Präposition getilgt, noch tritt eine Variante der Liaison auf, d.h. die Grenzen des folgenden Wortes bleiben intakt.

Die oben genannten Beispiele (16) und (17) sind, wie ich im folgenden ausführen möchte, nicht als Gegenbeispiele zu (15) oder (18c) zu interpretieren. Dazu schlage ich folgende Interpretation für (16/17) vor: In diesen Beispielen ist die Liaison obligatorisch, in (15) wird sie aber durch die Einsetzung des Glottisverschlusses blockiert. Man kann hier annehmen, daB in (15) durch die initiale Akzentuierung des Adjektivs dieses eine selbständige prosodische Phrase bildet, während in (16/17) trotz initialer Betonung der Nominalphrasen diese neben dem Indefinitartikel und dem Possessivum keine eigenständigen prosodischen Phrasen formen. Die Beispiele (16/17) sind dann lediglich ein Indiz dafür, daß die obligatorische, d.h. die nicht-verkettete, Liaison unabhängig von der Akzentplazierung stattfindet, wenn durch die initiale Akzentuierung kein besonderer Fokustyp ausgedrückt wird. Wären die Nominalphrasen in (16/17) eng fokussiert, würde sich der Akzent keinesfalls verlagern, sondern die Art des Akzentes würde sich verändern.

Die Beispiele unter (18) verweisen jedoch auf ein weiteres Phänomen. Der Vergleich 2wischen (18a) und (18b) zeigt, daß bei initialer Betonung der Konstituente II campagne die Konstituente I chemin am rechten Wortrand intakt bleibt und der Onset der betonten Silbe in Konstituente II ein selbst für das Französische ungewöhnliches Konsonantencluster bildet.

Die Beispiele (18b) und und (18c) haben gemeinsam, daß generell bei initialer Betonung rechte Wort- bzw. Phrasengrenzen nicht der Liaison 
unterzogen werden. Die Konstituente I chemin bleibt in beiden Fällen an ihrem rechten Rand im ursprünglichen Zustand.

Daraus läßt sich ableiten, daß drei Prozesse miteinander interagieren die Akzentverlagerung auf die erste Silbe einer Konstituente, die Konservierung des rechten Phrasenrandes dieser Konstituente sowie die der rechten Peripherie der vorangehenden Konstituente.

Im weiteren möchte ich zeigen, daB es externe Faktoren der Informationsstruktur sind, die eine Verlagerung des Akzentes bedingen können und dadurch die eigentliche prosodische Phrasierung aufbrechen. Diese Prozesse sind nicht nur eine Strategie zur Konservierung der Autonomie kleinerer prosodischer Einheiten wie z.B. Wort (vgl. die Argumentation von Lyche/Girard 1995). Sie können auch aus einer Sicht erklärt werden, die sich auf die Kategorie Fokus bezieht und das Erklärungspotential wesentlich erweitert.

Im folgenden möchte ich demonstrieren, daB initiale Akzentuierung von bestimmten Konstituenten dazu dient, Unterschiede in der Fokusstruktur von Sätzen zu signalisieren. Das Untersuchungsobjekt sind hierbei Adverbien, die über spezielle syntaktische Eigenschaften verfügen.

\subsection{Vorüberlegung zum Experiment}

Ähnlich der für das Deutsche demonstrierten Methode wurden Minimalpaare nach der Frage-Antwort-Methode gebildet, wobei jedoch im Französischen andere Konstituenten erfragt wurden.

Der Test bezieht sich hier auf Adverbien, die in ihrer Positionierung im Satz bestimmten syntaktischen Restriktionen unterliegen. Gradadverbien können im Französischen nicht an die Satzspitze bewegt oder linksdisloziiert werden.

(19) ${ }^{*}$ C'est énormément ce qu'il a fumé. es ist enorm viel was er geraucht hat

(20) *Enormément a-t-il fumé. enorm viel hat er geraucht

Anders verhalten sich dagegen Objekte. Sie können an die Satzspitze bewegt werden und signalisieren durch ihre veränderte Position im Satz einen bestimmten Fokustyp.

(21) C'est Wim que Anne aime. es ist Wim den Anne mag

Gradadverbien können jedoch sowohl vor als auch nach dem Partizip stehen: 
(22) Il a énormément fumé. er hat Adv. geraucht

(23) Il a fumé énormément. er hat geraucht Adv.

Das von Objekt-Phrasen verschiedene Verhalten der Adverbien bezüglich ihrer Positionierung im Satz soll in der folgenden Untersuchung dahingehend ausgenutzt werden, daß sie bei Verschiebung im Mittelfeld des Satzes die prosodische Phrasierung verändern können. Dies ist bedingt durch ihren kategoriellen Status - sie sind Maximalphrasen (vgl. Hirst 1993). Werden sie zudem eng bzw. kontrastfokussiert, verlagert sich der Akzent auf ihre erste Silbe. Hierbei wäre wie in (15) zu erwarten, daß ein Glottisschlag als Grenzsignal vor der betonten Silbe eingefügt wird. Nur in 60\% der untersuchten Fälle konnte jedoch ein Glottisschlag beobachtet werden (vgl. Tranel 1987, der auf die Optionalität der Glottisverschlußinsertion bei emphatischer Hervorhebung von Adverbien verweist). Damit stellt sich die Frage, wie bei bestimmten Fokusarten eine Veränderung in der prosodischen Phrasierung akustisch determinierbar ist. Im weiteren wird gezeigt, daB der bei der Phrasierung beteiligte relevante Parameter der Fo-Verlauf ist.

\subsubsection{Datenerfassung}

Es tritt der Effekt auf, daB bei kontrastiver Fokussierung des Adverbs die erste Silbe dieser Konstituente betont wird. Im Gegensatz dazu steht der Fall der Normalfokussierung, wobei die lexikalische Betonung beibehalten wird und die letzte Silbe des Adverbes betont bleibt.

(24) Qu'est-ce qui s'est passé?

Was ist passiert? (= Normalfokus)

(24a) Il a fumé énormément.

(24b) Il a énormément fumé.

Unter Normalfokussierung und bei Kontrastfokus sind beide Stellungsvarianten des Adverbes möglich.

A-t-il fumé beaucoup ou peu?

Hat er viel oder wenig geraucht? (= kontrastiver Fokus)

(25a) Il a fumé énormément.

(25b) Il a énormément fumé.

Bei Kontrastfokus wird hingegen die erste Silbe der erfragten Konstituente, hier des Adverbs, betont.

Aus dem Gesamtkorpus möchte ich an zwei ausgewählten Grundfrequenzverläufen belegen, daB tatsächlich Unterschiede in der prosodischen 
Strukturierung zwischen normal- und kontrast-fokussierten Sätzen auftreten.

Die Voraussetzung dafür ist, daB der Grundfrequenzparameter ein mögliches akustisches Korrelat für Akzentuierung im Französischen ist ${ }^{2}$ und $\mathrm{da} B$ aus phonologischer Sicht die Position und weniger die Art des Akzentes verschiedene Fokustypen anzuzeigen vermag.

Die folgende Abbildung zeigt das Oszillogramm und den dazugehörigen Grundfrequenzverlauf eines aufgezeichneten Satzes (24b). Der Kontext, hier die entsprechende Frageformulierung, verweist auf einen normalfokussierten Antwortsatz.

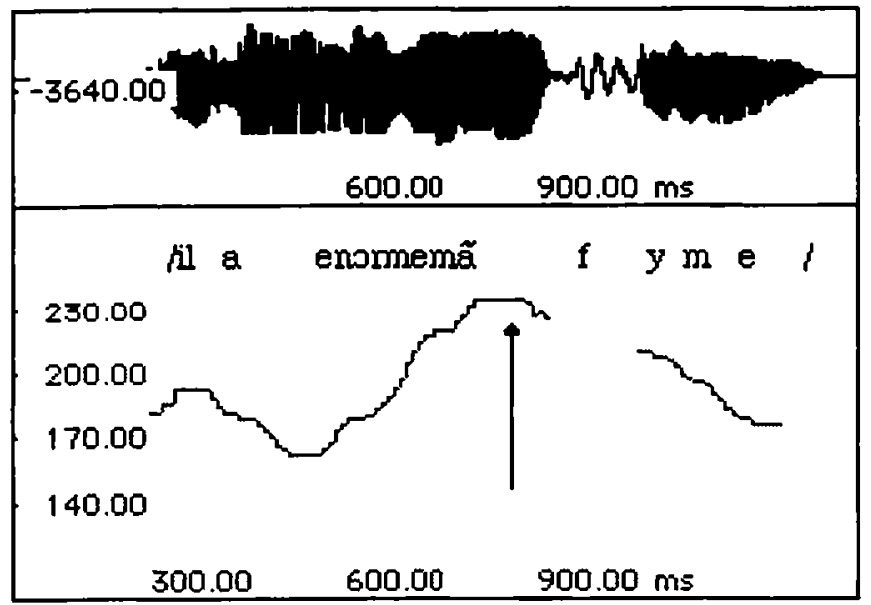

Abb. 5: Der Pfeil markiert die Stelle zwischen der rechtsseitigen Grenze des Adverbes und dem Frikativ, der linksseitigen Begrenzung des Partizips.

Wie der Abbildung zu entnehmen ist, zeigt der Gipfel des Grundfrequenzverlaufes über der letzten Silbe des Adverbs einen Akzent an; der Grundfrequenzfall über der letzten Silbe des Partizips ist durch den Satzmodus bedingt - hier ein Deklarativ, und markiert somit eine weitere Akzentposition und die rechte Satzgrenze.

2 Vgl. dazu Caelen-Haumont (1993) über die wichtigsten akustischen Korrelate von Akzentuierung im Französischen. 
Ein völlig abweichendes Verhalten des Fo-Verlaufs ergibt sich bei Kontrastfokussierung im Beispiel (25b). Obwohl die Wortfolge die gleiche wie in (24b) ist, ergibt sich ein anderes Bild: Anhand der Grundfrequenzbewegung über der ersten Silbe des Adverbs (s. Pfeil) kann davon gesprochen werden, daß sich an dieser Position der Phrasenakzent befindet.

Der finale Fall über dem Partizip verläuft ähnlich wie in Satz (24b).

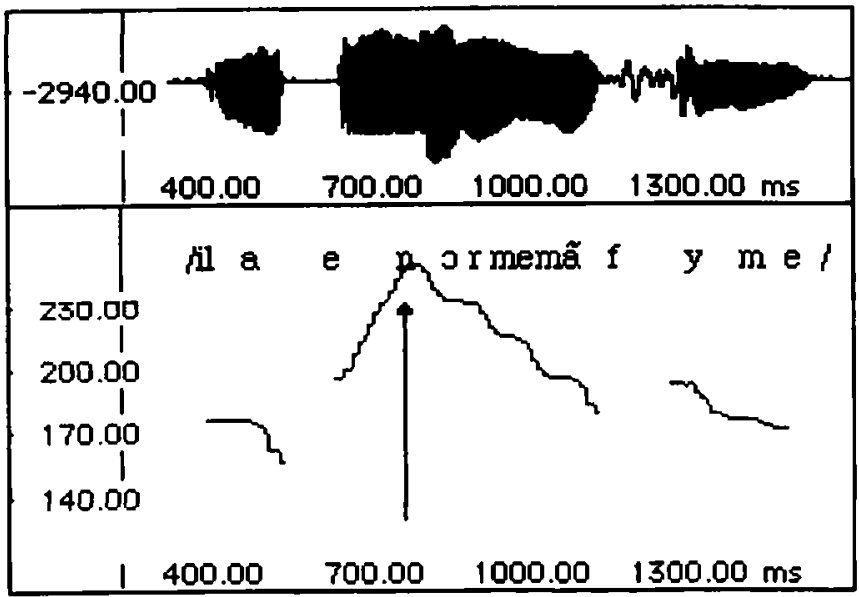

Abb. 6: Der Pfeil markiert die Fo-Gipfelposition auf der ersten, betonten Silbe des Adverbs.

Ähnliche Beobachtungen ergeben sich in den Beispielen (24a) und (25a). Im normalfokussierten Satz (24a) liegt der Fo-Gipfel zu Beginn der betonten Silbe am rechten Phrasenrand gefolgt von einem Grundfrequenzfall, wie in der folgenden Skizze dargestellt.

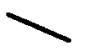

$\mathrm{H}^{*} \mathrm{~L}$

Il a

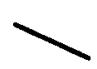

$\mathrm{H}^{*} \mathrm{~L}$

fumé

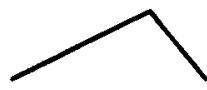

L $\quad \mathrm{H}^{*} \mathrm{~L}$

énormément 
Am rechten Satzrand fallen somit drei funktional-prosodische Eigenschaften zusammen: der Phrasenakzent des Adverbs, der Satzakzent und der für Deklarative typische finale tiefe Grenzton.

Eine weitere Beobachtung konnte bezüglich der Liaison getätigt werden. Bei Normalfokussierung trat keine Glottisverschlußinsertion vor dem Vokal der ersten Silbe des Adverbs auf.

Entsprechend den Voraussagen für das akzentuelle Verhalten unter den Bedingungen des Kontrastfokus verändert sich das Bild für (25a) dahingehend, daB der Phrasen- und somit Kontrastfokusakzent auf die erste Silbe des Adverbs fällt und auch durch eine angemessene Grundfrequenzbewegung angezeigt wird.

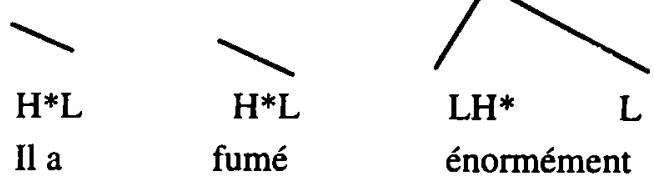

Bezüglich der GlottisverschluBinsertion konnte festgestellt werden, daß sie in $60 \%$ der aufgezeichneten Fälle auch tatsächlich eintrat. ${ }^{3}$

Untersuchungen zum Verhalten kontrastfokussierter Adverbien bezüglich der verketteten Liaison am rechten Phrasenrand stehen noch aus. ${ }^{4}$

\subsection{Auswertung und Zusammenfassung}

Das prosodische Verhalten des Französischen weicht vom Deutschen dahingehend $a b, d a ß$ das Französische eine Sprache mit festen, vorhersagbaren Akzentpositionen ist. Der Akzent tritt immer an der Peripherie von Wörtern oder Phrasen auf - sowohl bei Normal- als auch bei Kontrastfokussierung.

Bei Normalfokussierung befindet sich der Akzent an der rechten Peripherie von Phrasen, bei Kontrastfokussierung wird der Phrasenakzent an die linke Grenze von Phrasen verschoben. In beiden Fällen wird dadurch eine Veränderung der prosodischen Phrasierung signalisiert. Bei

3 Das Korpus besteht aus Aufnahmen von 4 französischsprachigen Sprecherinnen und enthält u.a. weitere Adverbien mit initialem Vokal wie immodérément "unmäßig”. Der Glottisverschluß wurde phonetisch auf verschiedene Weise realisiert, z.B. durch Laryngalisierung.

4 Das sind z.B. Sātze wie: $\Pi_{s}$ se sont trop aimés. (Sie haben sich zu sehr gemocht). 
Kontrastfokussierung wird eine prosodische Phrasierung erzeugt, die sich stark an der ursprünglichen syntaktischen Phrasierung orientiert. Die kontrastfokussierten Konstituenten konservieren damit ihre Autonomie, die Akzentverschiebung an den linken Phrasenrand bricht die normale Phrasierung auf und erlaubt zugleich eine Disambiguierung hinsichtlich der Informationsstruktur.

Der Zusammenhang zwischen Akzentplazierung und der damit einhergehenden Fokussierung sowie segmentalen phonologischen Regularitäten wie Liaison wird besonders bei initialer Betonung deutlich. Durch die GlottisverschluBeinfügung in den Onset einer vokalisch anlautenden betonten Silbe eines Adverbs wird diese Silbenposition gefült und eine Liaison unterbleibt.

Ist diese Silbe nicht betont, besteht auch keine Notwendigkeit, die Autonomie dieser Phrasengrenze aufrecht zu erhalten, da die prosodische Phrasierung in Sätzen mit konsequenter rechtsseitiger Phrasenbetonung normalfokussierten Sätzen entspricht.

Im nächsten Abschnitt möchte ich eine weitere Möglichkeit der akustischen Analyse unterschiedlich fokussierter Sätze andeuten. Ausgewählt wurde dazu ein kleines Korpus aus dem Russischen.

\section{Beobachtungen im Russischen}

Das Russische verfügt über äußerst variable Stellungseigenschaften für Akzente. Damit unterscheidet es sich vom Deutschen und vom Französischen, wobei das Russische einen Gegenpol zum Französischen bildet und das Deutsche zwischen diesen beiden Extremen liegt.

Die Schwierigkeiten, die mit der Erkennung von Phrasengrenzen anhand des Grundfrequenzverlaufes im Deutschen verbunden sind, können bei der Analyse des Russischen von vornherein durch ein anderes Vorgehen umgangen werden.

Das Ziel der Untersuchung besteht weiterhin darin, im akustischen Signal Indikatoren für die durch Fokussierung bedingte prosodische Phrasierung zu ermitteln. Wenn die Phrasierung nicht durch den Platz der Akzente angezeigt werden kann, bietet es sich an, nach Pausensignalen zu suchen und anhand derer Rückschlüsse auf die prosodische Phrasierung zu ziehen.

Die Verfahrensweise, die hier vorgestellt wird, orientiert sich an einer Beobachtung von Hayes/Lahiri (1991) im Bengali, wo durch bestimmte Assimilationsprozesse Phrasengrenzen determinierbar sind. Ähnliches ließ sich für bestimmte phonologische Prozesse im Russischen ermitteln. Dort 
kann innerhalb von phonologische Phrasen zwischen zwei Konsonanten Geminierung auftreten:

(28) $\mathbf{k}$ kasse

$/ \mathbf{k}:$ asje/

zur Kasse
(29)

$$
\begin{aligned}
& \text { ob bereg } \\
& \text { /ob: jerعg/ } \\
& \text { über das Ufer }
\end{aligned}
$$

Dieser ProzeB tritt auch mit regressiver Stimmassimilation auf, d.h. der im Auslaut verhärtete ursprüngliche stimmhafte Konsonant wird unter der Bedingung der Geminierung wieder stimmhaft.

(30) iz zala

/iz: ala/

aus dem Saal

Diese Beobachtung wird hier als Grundlage für ein gegenüber den vorangehenden Untersuchungen modifiziertes Analyseverfahren genommen.

\subsubsection{Testaufbau}

Zunächst wurde davon ausgegangen, daß der syntaktische Kontext, d.h. die Wortfolge in den untersuchten Sätzen, stabil gehalten wird und die Konstituenten zweisilbige Wörter sind. ${ }^{5}$

(31) Subjekt + Verb + Objekt

Weiterhin wurde angestrebt, für jede Konstituente an den linken und rechten Worträndern das gleiche segmentale Material zu haben ( $C=$ Konsonant, $\mathrm{V}=$ Vokal).

(32) Subjekt + Verb +Objekt

$\mathrm{C}_{1} \mathrm{VC}_{\mathrm{n}} \mathrm{VC}_{1}+\mathrm{C}_{1} \mathrm{VC}_{\mathrm{n}} \mathrm{VC}_{1}+\mathrm{C}_{1} \mathrm{VC}_{\mathrm{n}} \mathrm{VC}_{1}$

Der Konsonant $C_{n}$ in der Wortmitte bleibt unspezifiziert, der Konsonant $\mathrm{C}_{1}$ dagegen wurde für diesen Test auf den stimmhaften Frikativ $/ z /$ festgelegt. Daraus ergibt sich folgende Wortkombination:

$$
\begin{array}{ll}
\text { (33) zavxoz } & \text { zavjoz zakaz } \\
\text { /zavxoz/ } & \text { /zavjoz/ / zakaz/ } \\
\text { der Verwalter brachte die Bestellung }
\end{array}
$$

Die Voraussage betrifft die prosodische Phrasierung unter dem EinfluB verschiedener Fokustypen. Bei Normalfokussierung werden alle Konstituenten des Satzes fokussiert, die prosodische Phrasierung sollte daher

5 Dieses Korpus wurde in Zusammenarbeit mit Uwe Junghanns (FAS) und Gerhild Zybatow (U. Leipzig) aufgebaut. 
den gesamten Satz oder wenigstens das Verb und das Objekt umfassen. Das Objekt sollte bei Kontrastierung eine eigene prosodische Phrase bilden und es sollte ein Grenzsignal zwischen Verb und Objekt erkennbar sein.

\subsubsection{Durchführung des Experiments}

Zur Festlegung der Informationsstruktur wurde wiederum die FrageAntwort-Methode verwendet. Als Antwort auf die Fragen diente der in seiner Wortstellung unveränderte Antwortsatz (33). Vorgestellt werden hier nur die Sequenzen bei Normalfokussierung (34) und Kontrastfokussierung (35).

$V$ čjom delo?

Was ist passiert?

(34) Zavxoz zavjoz zakaz.

Zavxoz zavjoz zavtrak ili zakaz?

Brachte der Verwalter das Frühstück oder die Bestellung?

(35) Zavxoz zavjoz zakaz.

\subsubsection{Ermittlung der Daten}

Beide Sätze wurden aufgezeichnet und anhand des Oszillogramms analysiert. Ich gehe davon aus, daB sich die Geminierung stimmhafter Frikative im oszillographischen Bereich, d.h. anhand der Schalldruck-ZeitFunktion periodischer und aperiodischer Schwingungen ablesen läßt. Dieses Verfahren ist relativ einfach, wenn man berücksichtigt, daß stimmhafte Sequenzen einen periodischen Verlauf aufweisen, stimmlose Sequenzen dagegen keine periodischen Schwingungen haben. Das beruht auf der Tatsache, daß bei stimmlosen Lauten die Glottis nicht schwingt.

\subsubsection{Auswertung}

Das folgende Oszillogramm zeigt genau denjenigen Ausschnitt aus (34), der zwischen dem Verb und dem Objekt liegt. Es ist deutlich zu erkennen, $\mathrm{da} \beta$ die letzten periodischen Schwingungen des Konsonanten $/ z /$ des Verbs ohne Unterbrechung in die ersten periodischen Schwingungen des ersten Konsonanten des Objektes überführt werden. 


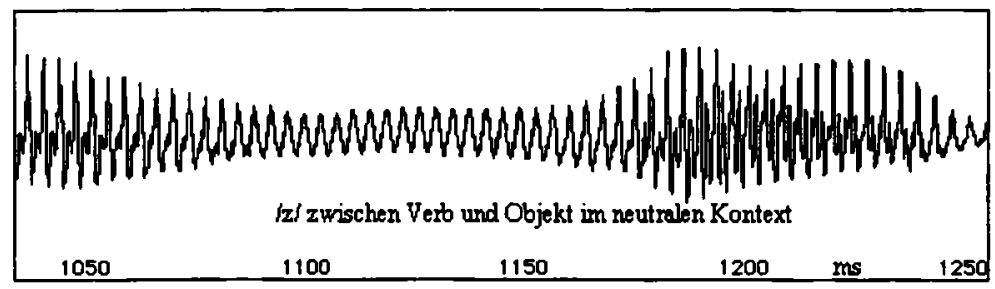

Abb. 7: Der nicht unterbrochene periodische Übergang von Verb zu Objekt für (34).

Völlig anders verhält sich das akustische Signal im gleichen Abschnitt $\mathrm{z}$ wischen dem Verb und dem Objekt in der Antwortsequenz (35). Hier ist deutlich zu erkennen, daß das periodische Signal durch eine aperiodische Sequenz unterbrochen wird.

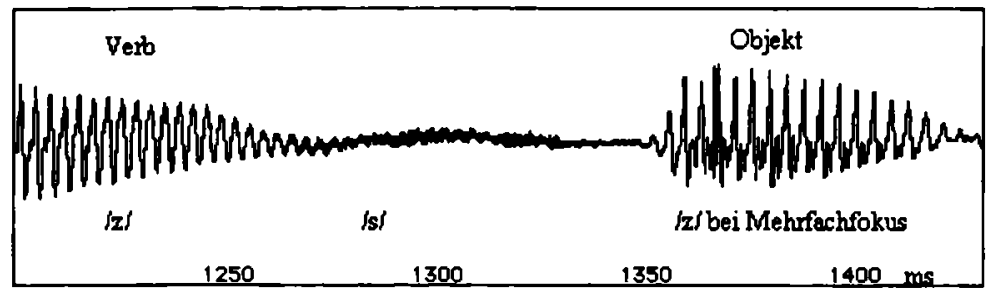

Abb. 8: Der entsonorisierte Übergang von Verb zu Objekt für (35).

Diese relativ lange aperiodische Sequenz, die in ihren spektralen Eigen-

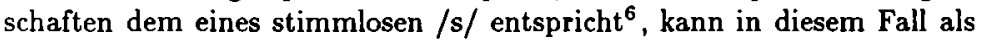
Grenzsignal interpretiert werden.

Obwohl die beiden untersuchten Sätze die gleiche syntaktische Strukturierung und die gleiche segmentale Umgebung an der Peripherie ihrer Konstituenten aufweisen, sind Unterschiede $\mathrm{zwischen}$ den verschiedenen Fokustypen und damit verbunden $z$ wischen den daraus induzierten unterschiedlichen prosodischen Phrasierungseigenschaften erkennbar. Die o.g. Voraussage, daB bei Kontrastierung des Objektes dieses eine eigene prosodische Phrase bildet, konnte verifiziert werden.

6 Das Spektrogramm des relevanten Signalabschnittes wird hier nicht gezeigt. 
Mithin ergibt sich ein dem Französischen ähnliches Bild: Die Insertion eines Grenzsignals bedeutet die Aufspaltung der unter Normalfokussierung bestehenden Phrasenverhältnisse. ${ }^{7}$ Ebenso wurde gezeigt, daß bei Normalfokussierung größere prosodische Einheiten gebildet werden, was darauf beruht, daB der fokussierte Bereich maximiert wird. Daraus folgt, daß zwischen den betroffenen Konstituenten keine solche Grenze signalisiert wird.

\section{$3.2 \quad$ Fazit}

Damit ergibt sich ein ähnliches Bild wie im Deutschen und Französischen. Werden innerhalb eines kontinuierlichen Signalverlaufs Grenzsignale eingefügt, verändert sich die prosodische Phrasierung, bedingt durch die Änderung der Zuweisungsdomänen für Merkmale der verschiedenen Fokustypen. Wird eng oder kontrastfokussiert, sind hierarchisch sehr hoch angesiedelte Domänen nicht mehr erkennbar und auch nicht mehr notwendig. Wird bei Normalfokussierung dagegen die vom Fokusmerkmal dominierte Domäne optimiert, sind die darunterliegenden prosodischen Domänen nicht mehr erkennbar.

An drei Sprachen, die sich syntaktisch, informationsstrukturell und phonologisch unterschiedlich verhalten, wurde gezeigt, daß es markante $\mathrm{Zu}$ sammenhänge $z$ wischen Akzentuierung und prosodischer Phrasierung geben kann. Das hängt damit zusammen, daß bereits in der Syntax operierende Fokusmerkmale auf der Phonologischen Ebene Einfluß auf die Positionierung und den tonalen Verlauf der Akzente nehmen können. Hinzukommt, daB je nach Fokusart der Einflußbereich dieses Merkmals unterschiedlich definiert ist.

Die Strategien zur Detektion von Phrasierungseinheiten im akustischen Signal müssen daher auf unterschiedliche Bedingungen im syntaktischen, informationsstrukturellen und phonologischen Bereich ausgerichtet werden. Es wurde gezeigt, daB anhand des Parameters der Grundfrequenz prosodische Phrasierung in Sätzen nur bedingt nachweisbar ist: im Deutschen im Fall der multiplen Fokussierung adjazent zueinander stehender Konstituenten, im Französischen eindeutig an der Grundfrequenzbewegung über der betonten Silbe. Für das Russische wurde von vornherein aufgrund phonologischer Vorüberlegungen ein anderer Weg gewählt. Es

7 Āhnlich dem Franzōsischen würde eine Phrasengrenze zwischen Verb und Objekt auch eine solche zwischen Subjekt und Verb verlangen. Dies trifft für den hier vorgestellten Typ der Kontrastierung auch zu. Weitere Untersuchungen dazu für die multiple Fokussierung sind in Vorbereitung. 
konnte belegt werden, daB im Russischen an Phrasengrenzen Assimilationserscheinungen auftreten.

Den Ausgangspunkt für die akustische Erkennung von Phrasierungseinheiten bildete die Beobachtung, daB das Französische über eine festgelegte Position des lexikalischen Akzentes an der rechten Wortperipherie verfügt und bei Kontrastfokussierung von Adverbien der Akzent an die linke Peripherie verlagert wird. Wird der Akzent durch eine deutliche Grundfrequenzveränderung angezeigt, ist damit die Phrasierung mittels dieses Parameters auch möglich.

Deutsch und Russisch dagegen verfügen über andere Eigenschaften bezüglich der Position lexikalischer Akzente. Sie fallen nicht immer an die Wortperipherie, was induziert, daB nur in bestimmten Fällen die prosodische Phrasierung über den Fo-Parameter realisiert wird. Im Russischen zeigen Assimilationen Phrasierungen an; bezüglich des Deutschen muß auf die derzeit noch existierende Lücke in der Untersuchung von informationsstrukturell gesteuerten Assimilationsregeln und Glottisverschlußeinfügungen auf phrasaler Ebene verwiesen werden.

\section{Literatur}

Abraham, W. (1994): The Focus Null Hypothesis and the head-direction parameter: word compounding, numerals, and proper names. In: de Boer, A./de Hoop, H./de Swart, H. (eds.): Language and Cognition 2. S. 1-15.

Alter, K. (1994): Die französischen Interrogative und Exklamative - zum modularen Zusammenhang von Syntax und Phonologie. Diss. Uni. Leipzig.

Batliner, A. (1994): Prosody, focus, and focal structure: some remarks on methodology. In: Bosch, P./van der Sandt, R. (eds.): Focus/Natural language Processing. Vol. 1. Intonation and Syntax, Working Paper 6. Dec. 1994. Heidelberg. S. 11-28.

Caelen-Haumont, G. (1993): Stratégies des locuteurs en réponse à des consignes de lecture d'un texte: Analyse des interactions entre modèles syntaxiques, sémantiques, pragmatiques et paramètres prosodiques. Grenoble.

Cinque, G. (1993): A null theory of phrase and compound stress. In: Linguistic Inquiry 24, S. 239-398.

Cruttenden, A. (1986): Intonation. Cambridge textbooks in linguistics. Cambridge.

Dogil, G. (1995): Word prosodic systems in Slavic Languages. In: v.d. Hulst, H. (ed.) (to app.): Chapt. $11 \& 12$.

Féry, C. (1993): German Intonational Patterns. Tübingen. (Linguistische Arbeiten 285).

Grice, M. (1995): The intonation of interrogation in Palermo Italian. Tübingen. (Linguistische Arbeiten 334). 
Gussenhoven, C. (1994): Focus and sentence accent in English. In: Bosch, P./van der Sandt, R. (eds.): Focus \& Natural language Processing. Vol. 1. Intonation and Syntax. Working Paper 6. Dec. 1994, Heidelberg. S. 83-92.

Hayes, B./Lahiri, A, (1991): Bengali Intonational Phonology. In: Natural Language and Linguistic Theory 9, S. 47-96.

Hirst, D. (1993): Detaching Intonational Phrases from Syntactic Structure. In: Linguistic Inquiry 23, S. 781-788.

Jacobs, J. (1994): Informational Autonomy. In: Bosch, P./van der Sandt, R. (eds.): Focus \& Natural language Processing. Vol. 1. Intonation and Syntax. Working Paper 6. Dec. 1994. Heidelberg. S. 113-132.

Lyche, C./Girard, F. (1995): Le mot retrouvé. In: Durand, J./Hintze M.-A. (eds.): French Phonology: Morae, syllables, words. S. 205-221. (Lingua, vol. 95).

Möbius, B. (1993): Ein quantitatives Modell der deutschen Intonation: Analyse und Synthese von Grundfrequenzverläufen. Tübingen. (Linguistische Arbeiten 305).

Nespor, M./Vogel, I. (1986): Prosodic Phonology. Dordrecht.

Pierrehumbert, J. (1980): The Phonetics and Phonology of English Intonation. Doctoral diss. MIT.

Rooth, M. (1992): A theory of focus interpretation. In: Natural Language Semantics 1, S. 75-116.

Tillmann, H.G. (mit Mansell, P.) (1980): Phonetik. Lautsprachliche Zeichen, Sprachsignale und lautsprachlicher KommunikationsprozeB. Stuttgart.

Tranel, B. (1987): The sounds of French. Cambridge.

Tranel, B. (1995): French final consonants and non-linear phonology. In: Durand, J./Hintze, M.-A. (eds.): French Phonology: Morae, syllables, words. S. 131-168. (Lingua, vol. 95).

Uhmann, S. (1987): Fokussierung und Intonation. Diss. Uni. Konstanz. 


\title{
Zur Typologie der Alphabetschriften: Das Deutsche und die Reform seiner Orthographie
}

\begin{abstract}
Alphabetschriften von altverschrifteten Sprachen weisen Charakteristika auf, die es erlauben, von einer Typologie der Alphabetschriften zu sprechen. Als typologischer Parameter gilt der einer phonologischen, prosodischen, morphologischen und historischen 'Tiefe'.

Die vorliegende Arbeit unternimmt es, typologische Eigenschaften des deutschen Schriftsystems zu benennen und an zwei Beispielen genauer zu explizieren. An der Umlautschreibung $\langle\mathbf{a}-\bar{a}\rangle$ sowie der Verdoppelung von Konsonantgraphemen in Anglizismen wird gezeigt, wie phonologische und morphologische Struktureigenschaften von Wörtern bei der Schreibung interagieren. Typisch für das Deutsche scheint insgesamt zu sein, daß sich die Tiefe der Einzelparameter gegenseitig auf transparente Weise begrenzen.

Eine erste Nutzanwendung besteht im Bezug auf Formulierungen des Reformvorschlages. Liegt die Orthographiereform typologisch richtig? Greift sie strukturelle Eigenschaften des Deutschen auf oder wird sie eher zu einer 'Deregulierung' beitragen? Der Beitrag möchte zeigen, wie Fragen dieser Art fundiert bearbeitet werden können.
\end{abstract}

\section{Schrifttypologie und Schriftsystemtypologie}

Schrift- und Schriftsystemtypologien unterscheiden sich in der Regel erheblich von Sprachtypologien allgemein. Sprachtypologische Untersuchungen gehen letztlich der Frage nach, welche strukturellen Charakteristika Sprachen haben, wenn man sie anhand vereinbarter Parameter vergleicht. Diese Parameter sind wie die je verwendeten kategorialen und funktionalen Begriffe, wie die Strukturformate und linguistischen Beschreibungsebenen in keiner Weise a priori fixiert.

Auch Schrifttypologien weisen eine erhebliche Vielfalt auf und unterscheiden sich in Abhängigkeit vom theoretischen Rahmen, in dem sie angesiedelt sind. Seitdem man 'Schrift' definitorisch auf solche visuellen Materialisierungen beschränkt, deren Einheiten sich systematisch auf sprachliche Einheiten beziehen lassen, beschäftigen sich Schrifttypologien aber eigentlich immer mit derselben - vergleichsweise engen und konkreten - Frage. Es ist die Frage danach, auf welcher Ebene sprachlicher Einheiten eine Schrift operiert, auf welchen Typ sprachlicher Ein- 
heiten sich die Einheiten einer Schrift als ihre Grundebene systematisch beziehen lassen.

Daß man auf diese Weise zu drei Haupttypen danach kommt, ob die Einheiten einer Schrift sich primär auf bedeutungstragende (logographisch), prosodische (silbisch) oder kleinste segmentale (alphabetisch) Einheiten bezieht, ist in der neueren Literatur weitgehend unkontrovers. Schwierigkeiten ergeben sich aber bei der genaueren Untersuchung jeder einzelnen Schrift daraus, daß sie sich als Mischtyp erweist oder sich der Bindung an eine der Ebenen überhaupt entzieht. So gilt das Chinesische als 'im Prinzip' logographisch, weist aber derart zahlreiche und strukturell bedeutsame prosodische und segmentale Bezüge auf, daß die Zuordnung $\mathrm{z}$ weifelhaft wird. Das Phönizische gilt als Konsonantschrift, schon weil man so seine Bedeutung für die Entstehung der Alphabetschrift des Griechischen versteht. Aber macht diese Einordnung Sinn, wenn man die lineare Abfolge von Konsonanten eigentlich wie Silben liest? Es wird folglich auch die Auffassung vertreten, das Phönizische habe eine Silbenschrift (zur Übersicht De Francis 1989; Faber 1992; Coulmas 1995).

Die Schrifttypen sind im Grunde nicht einmal Idealtypen, von denen die Schriften der Einzelsprachen mehr oder weniger stark abweichen. Viele Sprachen verwenden Schriften, die sich keinem der Typen als eindeutig dominant zuordnen lassen. Dies gilt umso mehr, je weniger man die auch in der Schriftforschung bis in die jüngste Vergangenheit hinein übermächtige diachrone Perspektive als einzige gelten läßt. Die Schrifttypologie der erwähnten Art ist dann eigentlich nur eine Typologie der Schriftzeichen. Um das Schriftsystem einer Einzelsprache angemessen zu beschreiben, hat man die Schriftzeichen kategorial und die Art ihrer Verwendung beim Aufbau sprachlicher Einheiten strukturell zu erfassen. Damit ist man bereits bei genuin linguistischen Fragestellungen. Für die Aufgabe, die sich die vorliegende Arbeit stellt, ist nun von Bedeutung, daB sich der Zusammenhang von Schrifttypologie und Schriftsystemtypologie nicht für alle Sprachen in derselben Weise stellt. Für Sprachen, deren Schrift einen erheblichen Anteil an logographischen und silbischen Zeichen aufweist, beginnt die Ebenenmischung bereits bei den Grundeinheiten. Wie das Schriftsystem einer solchen Sprache als Ganzes konsistent zu beschreiben ist, muß hier offen bleiben. Die Schwierigkeiten sind erheblich (ausführlich dazu Eisenberg 1995).

Weniger groß scheinen sie bei Sprachen zu sein, die eine Alphabetschrift in der Art verwenden, wie es das Deutsche und alle seine näheren und entfernteren Nachbarn tun. Logogramme und Silbenzeichen sind in diesen Sprachen selten und systematisch auf Abkürzungen, Zahlen u.ä. be- 
schränkt. Sie bleiben bei der Beschreibung des Schriftsystems als Teil der Kerngrammatik unberücksichtigt.

Das Gemeinsame solcher Systeme ist, daf sie mit Grundzeichen derselben Art operieren und Bezüge auf die verschiedenen Beschreibungsebenen deshalb prinzipiell auf dieselbe Weise realisieren. Die Grundzeichen sind Buchstaben und Buchstabenfolgen (Mehrgraphen) sowie in einigen Fällen Buchstaben mit Diakritika. Dazu kommen Interpunktionszeichen, deren Status und Funktion hier unberücksichtigt bleibt. Die Grundzeichen, in der neueren Literatur meist als Grapheme geführt, lassen sich regelhaft bestimmten Abschnitten des Lautkontinuums der gesprochenen Sprache zuordnen, eben den Sprachlauten. Eine solche mehr oder weniger eindeutige oder sogar eineindeutige Zuordnung ist bei allen genannten Sprachen möglich. Als Zuordnung von Graphemen zu Lauten stellt sie den alphabetischen Anteil eines Schriftsystems dar. Der Terminus 'alphabetisch' bezieht sich also einmal auf das Inventar an Grundzeichen, zum anderen aber auch auf eine Relation zwischen diesen Grundzeichen und einer Menge von Sprachlauten.

Ein Bezug auf größere sprachliche Einheiten wie Silben und Morpheme kann in Sprachen mit Alphabetschrift nur auf eine Weise realisiert werden, nämlich durch eine besondere, von der alphabetischen im genannten Sinne abweichende Verwendung der Grundzeichen. Diese besonderen Verwendungen sind immer wieder dieselben, sie lassen sich auf wenige Grundtypen reduzieren. Da eine systematische Darstellung dieser Mittel $\mathrm{m} . \mathrm{W}$. nicht vorliegt, sollen die wichtigsten anhand einfacher Beispiele aufgezählt werden.

Prosodische und insbesondere silbenstrukturelle Information wird enkodiert durch Diakritika oder durch besondere Graphemkombinationen. So kann ein betontes, gespanntes [æ] im Französischen als <ai> geschrieben werden, ein betontes gespanntes [i] im Deutschen als $\langle i e\rangle$, ein entsprechendes [e] als <ee> usw. Ein $<\mathrm{h}>\mathrm{kann}$ im Deutschen eine Silbengrenze markieren und eine Silbe entweder schließen (neh-men) oder öffnen (gehen). Die Verdoppelung von Konsonantbuchstaben wird auf vergleichbare Weise zur Markierung von Silbengrenzen verwendet, z.B. deutsch bit-te. Besondere Zuordnungen von Graphemen zu Lauten können silbische Information tragen, indem sie auf bestimmte Positionen in der Silbe beschränkt sind. So steht $<s>$ im Deutschen für $\left[\int\right]$ nur in bestimmten Anfangsrändern wie in Spiel. Auch das graphematische Überspringen echter Allophonie wie die Schreibung <ch> für [c], [x] und [k] kodiert silbenstrukturelle Information. 
Werden morphologische Bezüge realisiert, so meist mit der Funktion, morphologischen Einheiten eine stabile visuelle Gestalt zu verleihen. Das kann bedeuten, dab 'stumme' Konsonanten wie im Französischen geschrieben werden (tout-toute) oder daB ganze morphologische Einheiten wie das Plural- oder das Fem.-Morph gelegentlich wohl zu sehen, aber nicht zu hören sind (enfant-enfants; lingual-linguale). Das geht im Französischen so weit, daB manche Wörter eine Morphologie haben, die zum überwiegenden Teil 'stumm' ist ([gardé] = garder, gardez, gardé, gardés, gardée, gardées).

$\mathrm{Zu}$ ähnlichen Zwecken wird im Geschriebenen die Abbildung bestimmter Lautmerkmale neutralisiert, d.h., statt auf ein Phonem bezieht sich das Grundzeichen auf ein Morphophonem. Beispiele sind das Überspringen der Auslautverhärtung im Deutschen (Hunde-Hund) oder die Neutralisierung von Gespanntheit des Vokals in einem Suffix wie -ig (freudiges mit gespanntem, freudig mit ungespanntem Vokal). Der wichtigste logographische Zug alphabetischer Systeme besteht aber wohl in der Konservierung silbischer Schreibungen wie bei Gemination (Stam-mes-Stamm) oder beim silbenschließenden $<\mathrm{h}\rangle($ hoh-ler - hoh $)$.

Eine Graphematik für eine Einzelsprache kann man sich dann so vorstellen, daB jede zu beschreibende sprachliche Einheit, also etwa jede Wortform, in Hinsicht auf ihren alphabetischen, prosodischen und morphologischen Anteil gekennzeichnet wird. Wo das nicht systematisch möglich ist, hat man es in der Regel entweder mit Einheiten aus abgeschlossenen lexikalischen Klassen (funktionalen Einheiten), mit historisch obsoleten Schreibungen oder entlehnten Schreibungen zu tun. Ansätze für derartige Beschreibungen liegen für viele Sprachen vor (vgl. z.B. die entsprechenden Artikel in Günther/Ludwig 1995), wirklich ausführliche Darstellungen fehlen aber bisher.

Auf der Grundlage des damit auch für Alphabetschriften etablierten Ebenenbezugs ist nun eine typologische Charakterisierung von Alphabetschriftsystemen in Angriff genommen worden. Als typologisch relevanter Parameter gilt der der Tiefe. Am weitesten ausgearbeitet wurde er in den Arbeiten von Trudel Meisenburg (1994), (1994a). Anhand der in 1 vereinfacht und leicht abgewandelten Tiefenskala vergleicht Meisenburg die Schriftsysteme einer Reihe europäischer Sprachen, unter ihnen das Deutsche. Das Deutsche erweist sich als System mittlerer Tiefe. Es hat Bezüge zu allen Ebenen. Es weist sehr viel mehr synchronmorphologische Bezüge auf als etwa das Spanische, bleibt bei den historischen Bezügen weit hinter dem Englischen zurück und regelt sehr viel mehr Schreibungen über das Basissystem von Graphem-PhonemKorrespondenzen als das Französische. 
(1)

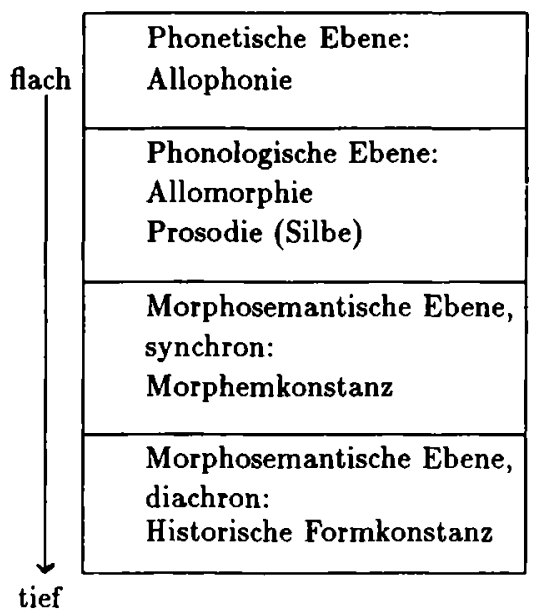

Die theoretisch interessante Frage ist, in welchem Sinne die in 1 aufgeführten Ebenen eine Ordnung bilden. Bezüge zu 'tieferen' Ebenen führen dazu, daß der alphabetische Anteil des Systems eingeschränkt wird. Das gilt für all diese Ebenen. Aber kann ein System beispielsweise eine ausgeprägte etymologische Komponente haben und im übrigen ganz alphabetisch orientiert sein? Ist ein synchron-morphologischer Zug ohne einen silbisch-prosodischen denkbar?

Für das Deutsche ist ein Bezug auf ein Ebenenschema wie in 1 unproblematisch. Seine systematische Beschreibung wird dann am einfachsten, wenn phonographische Schreibungen (z.B. menlich als phonographische Schreibung für männlich) zunächst nach silbenstrukturellen und dann nach morphologischen Regeln überformt werden. Im Beispiel ergibt sich die Geminate $n n$ aus dem Bezug auf eine Form wie Männer (dazu Abschnitt 3), während das < $\ddot{a}>$ sich aus einem Bezug auf Monn herleitet (dazu Abschnitt 2). Im Gesamtkonzept für eine Graphematik des Deutschen kann man in der Tat dem Phonographischen das Silbenstrukturelle und diesem das Morphologische im Sinne der sukzessiven Abarbeitung von Strukturbedingungen folgen lassen (dazu im Ansatz Eisenberg 1992; Duden 1995).

Wie weit das in der Logik der Sache liegt und damit 1 zumindest bis auf den historischen Aspekt generell und für alle alphabetischen Systeme rechtfertigt, kann nicht erörtert werden. Unabhängig von dieser 
die Globalstruktur alphabetischer Systeme betreffenden Frage ist jedoch zu klären, ob und gegebenenfalls in welchem Umfang ein bestimmtes System phonologische, silbische oder morphologische Tiefe aufweist. Welche Probleme dabei auftreten, wird im folgenden für die morphologische Komponente des deutschen Schriftsystems gezeigt.

Der morphologische Bezug alphabetischer Systeme wird in der Regel unter Stichworten wie Stammprinzip, Morphemkonstanz oder Schemakonstanz abgehandelt. Dabei wird kaum einmal gefragt, welche Form es denn ist, die konstant gehalten wird. Und ebenso wenig wird gefragt, was Abweichungen von der Morphemkonstanz eigentlich bedeuten. Meist werden sie einfach als Abweichungen vom morphologischen Prinzip, als Ausnahmen oder eben als Anzeichen dafür genommen, daB das Schriftsystem nicht die mögliche morphologische Tiefe erreiche.

Die beiden folgenden Abschnitte haben das Ziel, das morphologische Prinzip etwas genauer als üblich zu beschreiben. An zwei für das Deutsche typischen Erscheinungen wird gezeigt, wo das Prinzip seine Grenzen hat und was die Gründe dafür sein könnten. Was 'morphologische Tiefe' für dieses und vielleicht weitere Systeme heißt, wird damit einer genaueren Explikation zugänglich.

Die gewählten Bereiche $a$-Umlaut und Doppelkonsonantbuchstabe erörtern wir jeweils unter Bezug auf Regelformulierungen in den letzten Fassungen des Vorschlags zur Reform der deutschen Orthographie (Reformvorschlag 1994; 1995). Dies geschieht nicht mit der Absicht, einen Beitrag zur aktuellen Reformdiskussion zu leisten. Dafür ist der Rahmen der vorliegenden Arbeit denkbar ungeeignet. Das Ziel ist vielmehr, die in den vergangenen Jahren in Gang gekommene Debatte um einen möglichen linguistischen Beitrag zu einer längerfristigen Reformarbeit fortzusetzen.

\section{Grenzen des morphologischen Prinzips: \\ Markiertheit und phonologische Fundierung der Schreibung des $\ddot{a}$-Umlautes}

Die Unsicherheiten der $\vec{a}$-Schreibung lassen sich auf unterschiedliche Weise systematisch erfassen und deuten. Wir setzen für das folgende eine Grundklassifikation der betonbaren Vokale des Deutschen nach dem Merkmalspaar gespannt/ungespannt voraus. Unter synchroner Perspektive und Beschränkung auf Distinktivität als funktionalem Parameter ergibt sich dann ein System mit acht gespannten und sieben ungespannten Vokalen.

Die Asymmetrie entsteht bei den vorderen halbgeschlossenen bis halboffenen Vokalen. In diesem Bereich steht zwei gespannten Vokalen, dem [e] 
(nehme) und dem [æ] (nähme), ein ungespannter gegenüber, der meist in der Position des dritten primären Kardinalvokals angesiedelt und als [E] (renne) transkribiert wird. In allen anderen Fällen treten gespannte und ungespannte Vokale in eindeutiger Zuordnung paarweise auf.

Bei an der Schrift orientierter Aussprache lassen sich die Verhältnisse mit Minimalpaaren wie Beet - Bett und quälen - quellen illustrieren, wobei der ungespannte Stammvokal in der jeweils zuletzt genannten Form eben derselbe sein soll. Die Opposition [e] - [æ] spielt im nativen Wortschatz kaum eine Rolle. Selbst bei strikter Leseaussprache finden sich wenige echte Minimalpaare vom Schlage Ehre - $\bar{A} h r e$. Schon in Fällen wie Beeren - Bären ergibt sich eine Paarbildung nur für die Pluralformen und bei Zeh - zäh läBt sich von 'Minimalpaar' nicht mehr sprechen. Die funktionale Belastung der in Rede stehenden Opposition ist gering.

$\mathrm{Ob}$ sie bei realistischer Betrachtung und Absehung vom Geschriebenen überhaupt vorhanden ist, beurteilen die Phonologen unterschiedlich. Ein abschließendes Urteil, das überregionale Geltung beanspruchen und sich auf einen ausgewiesenen Begriff von Standardlautung berufen kann, der nicht identisch ist mit einer reinen Leseaussprache, wird es in dieser Frage kaum geben können. Es ist für unsere Zwecke auch nicht erforderlich. Eine Formulierung wie in der Dudengrammatik wird den Notwendigkeiten gerecht, indem sie darauf verweist, es bestehe „in der Standardlautung eine Konkurrenz zwischen [e] und [æ]. Sie führt dazu, daß sich ein halboffenes [ $\varepsilon$ ] als Standard durchsetzt. Man hört heute sowohl [fæ:təR] wie [f $\varepsilon: t \partial R$ ] und [fe:təR] (letztere Aussprache vorwiegend in Norddeutschland). In Wörtern wie A hre und $B a ̈ r$ ist der Vokal - anders als in Väter - kein Umlaut von [a]. Auch hier kommen mehrere Öffnungsgrade des Vokals vor." (Duden 1995, S.51).

Die Formulierung schließt nicht aus, daß die Opposition [e] - [æ] in besonderen Fällen funktional sein kann, und in der Tat ist das der Fall. Für Verben wie nehmen, geben, lesen, sehen, treten gibt es Stammformen mit gespanntem [a] und [æ], z.B. sehe-sah-sähe, gebe-gab-gäbe. Die Vokalreihe [e] [a] - [æ] ist in allen möglichen Paarbildungen funktional belastet. Insbesondere gilt das auch für den Vokal des Konjunktivs Präteritum im Verhältnis zu dem des Präsens (Ind oder Konj). Soll der Konj des Prät markiert werden, so ist das nur durch das gegenüber [e] deutlich offenere [æ] möglich. Die Umlautschreibung <ä> stellt direkt nur einen morphologischen Bezug zur Stammform mit $<a>$ her. Daß sie sich hält und tatsächlich verwendet wird, liegt aber offenbar auch am Bezug auf die Stammform mit <e>. 
Welche Rolle die morphologisch fundierte Distinktivität von [e] und [æ] insgesamt spielt, muß dahingestellt bleiben. Im Vergleich zur graphematischen Opposition im Standardfall Hahn - Hähne, Wahl - Wähler oder lahm - lähmen ist die phonologische Opposition von geringer Bedeutung, aber sie ist vorhanden und sie hat ein eindeutiges phonetisches Korrelat. Man kann dem <ä> immer sein Korrelat [æ] verschaffen.

In der neuesten Fassung des Reformvorschlags ist der Fall so geregelt: „Für langes [e:] und [ $\varepsilon$ :] (entspricht unserem [æ:], P.E.), die in der Aussprache oft nicht unterschieden werden, schreibt man $\vec{a}$, sofern es eine Grundform oder verwandte Form mit a gibt, z.B. quälen (wegen Qual). Wörter wie zum Beispiel sägen, $\bar{A} h r e$ ( $\neq$ Ehre), Bär sind Ausnahmen." (Reformvorschlag 1995, S. 23).

Diese Formulierung weist eine Reihe von Problemen auf, die für eine genauere Fassung des morphologischen Prinzips, wie es für das Deutsche gilt, von Interesse sind. Warum wird die 'Grundform' neben der 'verwandten Form' genannt? Jede Grundform zu einer gegebenen Form ist mit ihr verwandt. Mit 'verwandte Form' selbst ist offenbar 'morphologisch verwandte Form' gemeint. Die Art der Verwandtschaft ist ohne Belang. Nichts wird über Ableitungsrichtung, Flexion vs. Derivation, Regelhaftigkeit, phonologische Beziehbarkeit usw. gesagt. DaB Qualifizierungen dieser Art fehlen, hat nichts mit der gerade besprochenen Regel zu tun. Sie fehlen fast durchweg, d.h., ihr Fehlen zeigt, wie das morphologische Prinzip im Reformvorschlag verstanden wird: „Was verwandt ist, muß auch gleich geschrieben werden."

$\mathrm{Zu}$ fragen ist weiter, warum die Regel den postulierten Zusammenhang zwischen Schreibung und Lautung auch umkehrt und die Schreibungen mit $\langle\ddot{a}>$ ohne morphologischen Bezug auf $<a>$ als Ausnahmen bezeichnet. Die Liste solcher Schreibungen ist lang, zumindest wenn man sich auf die synchrone Perspektive beschränkt. Sie umfaßt außer den bereits genannten Wörter wie Krähe, Strähne, Häher, Märe, Mähre, Häme, Träne, fähig, träge, erzählen, gähnen, mähen, während und viele andere. Gerade weil morphologisch nicht fundierte Umlautschreibungen beim ungespannten [e] sehr viel seltener sind, spricht man beim gespannten Vokal im allgemeinen nicht von Ausnahmen. Ganz im Gegenteil. Es lassen sich zahlreiche auch neuere phonologische Arbeiten anführen, die dieses <ä> explizit oder implizit als Anzeichen für die Existenz eines Phonems [æ] ansehen (z.B. Wiese 1988; Vennemann 1991).

Die Unsicherheiten auf der phonologischen Seite machen es unmöglich, das < $\ddot{a}>$ für gespannten Vokal auf eine morphologische Funktion zu reduzieren. Nur umgekehrt ist die Regelhaftigkeit eindeutig: wann immer 
eine Wortform mit [e] oder [æ] morphologisch auf eine mit [a] bezogen ist, wird sie mit $\langle\ddot{a}\rangle$ geschrieben. Ausnahmen gibt es nicht, und so enthält der Reformvorschlag keinen einzigen Fall, in dem ein $\langle e\rangle$ zur weiteren Durchsetzung des Stammprinzips künftig durch ein $\langle\ddot{a}\rangle$ ersetzt werden sollte.

Ein erster Versuch, das Gesagte als Schlubfolgerung zu verallgemeinern, könnte so aussehen: Als markiertes Graphem für gespannten Vokal verhält sich <ä〉 dann systemkonform, wenn gilt: (1) Formen mit $\langle a ̈\rangle$ sind gegenüber Formen mit $<a>$ morphologisch markiert, (2) Formen mit dem markierten Graphem $\langle a ̈>$ kommen auch dann vor, wenn kein morphologischer Zusammenhang zu Formen mit $\langle a\rangle$ besteht. Formen mit dem unmarkierten Graphem $\langle\mathrm{e}\rangle$ kommen dagegen nicht vor, wenn ein morphologischer Zusammenhang zu Formen mit <a> besteht, (3) das Graphem <ä> hat ein eigenes phonologisches Korrelat, d.h., es gibt einen Laut [æ], der im Regelfall auf $\langle\ddot{a}\rangle$ abgebildet wird und auch umgekehrt kann jedes $\langle a ̈\rangle$, wenn es für einen gespannten Vokal steht, als [æ] gelesen werden.

Interessanter und in mancher Hinsicht auch kritischer ist das $\langle\ddot{a}\rangle$ für den

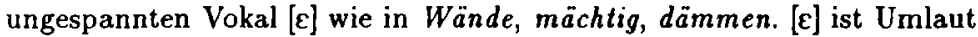
zu [a], kommt aber genau so und nur so auch als nicht umgelauteter Vokal vor. Die Möglichkeit, den umgelauteten Vokal zu öffnen wie beim [æ], besteht nicht. Damit haben wir hier einen der ganz seltenen Fälle vor uns, bei denen im Deutschen morphologische Information graphematisch enkodiert ist, die nicht hörbar gemacht werden kann.

Die letzte Fassung des Reformvorschlages formuliert so: „Für kurzes [ $\epsilon]$ schreibt man $a$ statt $e$, wenn es eine Grundform mit $a$ gibt. Dies betrifft flektierte und abgeleitete Wörter wie: Bänder, Bändel (wegen Band), Hälse (wegen Hals); Kälte, kälter (wegen kalt), überschwänglich (wegen Überschwang)." (Reformvorschlag 1995, S. 23).

Instruktiv ist ein Vergleich mit der Regelformulierung im Reformvorschlag von 1994. Dort heißt es: „Für das kurze e schreibt man $a$ statt $e$, wenn es eine Grundform oder verwandte Wörter auf a gibt." Und weiter hieß es dort: „Man schreibt ausnahmsweise $e$ in Eltern (trotz alt) und bei Wörtern wie rennen - rannte, hetzen - Hatz, schwenken - schwanken." (Reformvorschlag 1994, S. 19). Noch 1994 war man also der Auffassung, daB rennen eine irreguläre Schreibung sei. Man hat diese Fehlanalyse jetzt beseitigt, indem die Regel von "Grundform oder verwandte Wörter” auf "Grundform” eingeschränkt wurde. Der Fall bleibt aber weiter problematisch, wenn man ihn in einem größeren Kontext sieht. 
(2) a. renne - rannte - rennte; kenne - kannte - kennte

b. spreche - sprach - spräche; treffe - traf - träfe

c. sterbe - starb - stürbe; werfe - warf - würfe

d. berge - barg - ?; berste - barst - ?

e. lege - legte - legte; trenne - trennte - trennte

In den Beispielen sind jeweils die Formen der 1.Ps $\mathrm{Sg}$ des Präsens (Ind=Konj, wenn man für den Ind die Form mit Schwa wählt) sowie die entsprechenden Formen für den Ind des Prät und den Konj des Prät zusammengestellt. Nach der Formulierung im Regelwerk 1995 müßte der Konj Prät der Verben in $2 \mathrm{~b}$ mit $\langle\mathrm{e}\rangle$ geschrieben werden, also spreche und trefe. Ausschlaggebend ist offenbar nicht die Grundform, sondern eine geeignete Bezugsform. Für den Konj Prät ist das der zugehörige Ind, dessen Stammvokal in der Regel umgelautet wird. Dies ist an sich eine Kleinigkeit. Sie zeigt aber wieder, daß man eine ausgearbeitete Morphologie braucht, um die Graphematik angemessen zu formulieren. Auch bei den Verben der anderen Gruppen aus 2 hat der Vokal in der Stammform des Ind Präs zum Vokal der Stammform des Prät das Lautverhältnis des Umlauts. Morphologisch, d.h. richtungsbezogen, handelt es sich natürlich nicht um ein Umlautverhältnis, d.h., das Präsens wird nicht mit $<\ddot{a}>$ geschrieben. Bezüglich des Konj Prät ergeben sich unterschiedliche Konsequenzen.

Von den Verben, die nicht schwach flektieren, bilden nur die in $2 b$ einen regulären Konj Prät durch Umlautung des Stammvokals im Ind. Möglich ist das, weil der Stammvokal des Prät gespannt ist und damit Distinktivität im Verhältnis zum Präs besteht. Die insgesamt sieben oder acht Verben aus 2c haben diese Möglichkeit nicht, weil die Koda der Stammform starb, warf usw. komplex ist und deshalb den gespannten Vokal ausschließt. Es bleibt deshalb beim alten Konjunktiv mit Umlaut des alten Pluralvokals. Ist diese Möglichkeit blockiert oder verlorengegangen wie bei den Verben in 2d, dann gibt es keinen Konj Prät. Bei den schwachen Verben fällt der Konj mit dem Ind zusammen.

Die Verben in den Gruppen $2 b$ bis $2 e$ zeigen, daß das morphologisch relevante Oppositionsverhältnis des Konj Prät nicht zu seinem Ind, sondern zum Präsens besteht. Der Zusammenfall der Lautform mit dem Präsens blockiert die reguläre Konjunktivbildung im Prät oder verhindert sie ganz. Der Grund dafür liegt letztlich im Gebrauch der Konjunktivformen. Unter den synthetischen Konjunktivformen ist der Konj Prät unmarkiert. Er wird in der sog. indirekten Rede, der 'eigentlichen' Domäne des Konj Präs, genauso verwendet wie im Potentialis. In diesem Sinne haben auch die Formen des Prät der schwachen Verben konjunktivische 
Eigenschaften und werden als konjunktivisch verstanden (Näheres dazu in Wunderlich 1994; B. Wiese 1994; Eisenberg 1995a).

Damit wird verständlich, warum die Verben mit Rückumlaut wie in 2a den Konj Prät mit $\langle e>$ schreiben. Sie verhalten sich in diesem Punkt ganz wie die schwachen Verben. Das Umlautgraphem <ä> wäre sowohl phonologisch als auch morphologisch leer. Die Umlautung zum Vokal der Präsensstammform ist ausgeschlossen. In den Formen brennte und rennte liegt tatsächlich kein Umlaut vor, sondern der Stamm hat denselben Vokal wie das Präsens. Auch dieses Beispiel zeigt, mit welcher Konsequenz das morphologische Prinzip im Deutschen an die phonologische Oberfläche gebunden ist.

3. Grenzen des morphologischen Prinzips: Flexion vs. Derivation bei der Verdoppelung von Konsonantbuchstaben in Anglizismen

Die Gemination von Konsonantbuchstaben wird im Reformvorschlag mit 3 als Grundregel erfaßt und mit Beispielen wie denen in $4 a$ illustriert.

(3) Folgt im Wortstamm auf einen betonten kurzen Vokal nur ein einzelner Konsonant, so kennzeichnet man die Kürze des Vokals durch Verdoppelung des Konsonantbuchstabens.

(4) a. Affe, denn, dünn, gönnen, Hass, Paddel, schlimm, statt, wessen

b. Bus, Chip, fit, Gag, Grog, Jet, Job, Kap, Klub, Mob, Pop, Slip, top, Twen

c. Ananas, April, City, Hotel, Kamera, Kapitel, Limit, Mini, Relief, Roboter

Neben den regelhaften Fällen führt der Reformvorschlag acht Gruppen von Ausnahmen vor, $\mathrm{zu}$ denen die in $4 \mathrm{~b}$ und $4 \mathrm{c}$ vollständig wiedergegebenen Beispiellisten von Anglizismen und sonstigen Fremdwörtern gehören (Reformvorschlag 1995, S. 18f.). Im weiteren interessieren nur die Anglizismen und unter ihnen vor allem die Substantive.

Als Grundregel für die Beschreibung der Gemination von Konsonantbuchstaben wird in Eisenberg 1989 und anderen Arbeiten eine zu 3 alternative Regelformulierung vorgeschlagen, die nicht die Vokalkürze, sondern die silbenstrukturelle Position des Konsonanten selbst zum entscheidenden Gesichtspunkt macht. Angenommen wird, daß dann verdoppelt wird, wenn der entsprechende Konsonant allein zwischen betontem gespanntem und unbetontem Vokal steht wie in Balles, gönnen, schlimmer, wenn er also die Position eines Silbengelenkes hat. Alle ande- 
ren Verdoppelungen sind aus diesen nach dem morphologischen Prinzip abgeleitet, z.B. Ball, gönnst, schlimm.

Es sollen an dieser Stelle nicht die anderenorts ausführlich diskutierten Vor- und Nachteile der prosodisch orientierten gegenüber der segmentalphonologisch orientierten Lösung vorgeführt werden. Zur Demonstration der strukturellen Gegebenheiten, auf denen die Geminatenschreibung im Deutschen beruht, ist es aber instruktiv, das Verhalten von Anglizismen zu studieren. Dahinter steht die Auffassung, daB Eigenschaften des zentralen Systems einer Sprache besonders gut an peripheren Einheiten studiert werden können, sofern diese in hinreichend großer Zahl zur Verfügung stehen und den Eigenschaften der Einheiten des zentralen Systems gegenüber in einem zu explizierenden Sinne offen sind.

Beispielsweise ist dafür argumentiert worden, daß gewisse Prinzipien der Plazierung des Wortakzents im Deutschen besonders gut an Fremdwörtern untersucht werden können, weil nur in diesem Bereich des Lexikons eine große Zahl von mehrsilbigen und dennoch morphologisch einfachen Einheiten zur Verfügung steht (dazu z.B. Vennemann 1991; Eisenberg 1991; zur Fremdwortschreibung Meisenburg 1992). Allerdings bleibt dies ein methodisch riskanter Weg, weil nicht immer klar ist, ob man tatsächlich Eigenschaften des zentralen Systems entdeckt oder ob man sie ihm nicht eher zuschreibt. Noch komplizierter wird die Situation, wenn mit einem Wandel im zentralen System zu rechnen ist, der möglicherweise gerade durch die zu beschreibenden Einheiten mit verursacht wird. All dies wird im folgenden eine Rolle spielen. Unserem Eindruck nach lassen sich trotz der Schwierigkeiten einige interessante Aussagen über das Funktionieren der deutschen Orthographie machen. Man sollte auch nicht vergessen: Die Zahl der Anglizismen ist im gegenwärtigen Deutsch so groB, daB sie bei einer systematischen Beschreibung nicht unter den Tisch fallen können.

Die weiteren Ausführungen knüpfen an eine Diskussion zwischen Gerhard Augst und mir an, deren Stand anhand der Daten in 5 resümiert wird (vgl. zuletzt Eisenberg 1991a und die zum Teil bereits seit 1990 vorliegende Untersuchung in Augst 1995). Die Beispiele in 5 sind zum allergrößten Teil der Arbeit von Augst entnommen. Als Geminatenschreibung gilt dabei die im Deutschen übliche Schreibweise, also auch $\langle\beta\rangle$ und <ck> in entsprechenden Positionen.

(5) a. Bluff, Boß, Dock, Dreß, Drill, Grill, Jazz, Puck, Riff, Scheck, Skull, Stewardeß, Trimm, Truck

b. Chip, Cup, Fan, Gag, Gin, Hit, Mop, Pot, Pub, Shit, Slum, Smog, Snob, Trip, Twen 


$$
\begin{aligned}
& \text { c. Cut - cutten/Cutterin, Flip - Flipper/flippen, Flop - floppy, } \\
& \text { Hot - hotten, Jet - jetten, Job - jobben, Mob - Mobbing, } \\
& \text { Pep - peppig, Pin - pinnen, Pop - poppig, Shop - Shopping, } \\
& \text { Set - Setting, Step - steppen, Stop - stoppen }
\end{aligned}
$$

Die Wörter in 5 a sind nach unserer Analyse im Deutschen regelhaft geschrieben, wenn sie auf eine geeignete Langform mit Silbengelenk bezogen werden können. Das ist bei vielen dieser Formen der Fall, und zwar so, daß die Langform eine Form im selben Flexionsparadigma ist (z.B. Boß - Bosse, Dreß - Dresses, Riff - Riffe, Stewardeß - Stewardessen). Bei anderen ergibt sich ein solcher Bezug erst, wenn man als Langform auch derivativ bezogene Formen zuläBt ( Jazz - jazzen, Skull Skuller, Trimm - trimmen, Truck - Trucker). Einige der Wörter haben gar keinen Bezug zu einer geeigneten Langform (Puck, Scheck).

Die Wörter in 5b sind nach unserer Analyse regelhaft, soweit sie keinen Bezug auf eine Langform zulassen. Das ist bei allen der Fall. Sollte ein derartiger Bezug möglich werden, so geht das Wortpaar in die Liste von $5 c$ über. In $5 c$ finden sich Paare von Wörtern, die je für sich gesehen regelhaft geschrieben sind, die aber zusammengesehen gegen das morphologische Prinzip verstoBen.

Bei dieser Feststellung muB man es nicht bewenden lassen. In Eisenberg 1991 a wurde vorgeschlagen, das morphologische Prinzip so zu differenzieren, daß Flexions- und Derivationsmorphologie auch in der Orthographie getrennt zur Geltung gebracht werden können. 'Stammkonstanz' oder 'Schemakonstanz' muB dann auf jeden Fall innerhalb des Flexionsparadigmas gewahrt sein, soweit das morphologische Prinzip überhaupt reicht. Die Formen aus verschiedenen Flexionsparadigmen, die zueinander in einer Ableitungsbeziehung stehen, sind weniger eng aufeinander bezogen als die Formen aus demselben Paradigma. Das ist an sich ein morphologischer Allgemeinplatz. Daß er für eine Graphematik des Deutschen bisher nicht fruchtbar gemacht worden ist, liegt wohl daran, daß er im Kernwortschatz für Fälle wie die in $5 c$ aus kontingenten Gründen keine Rolle spielt.

Die für die Wörter in $5 c$ relevanten Ableitungsbeziehungen sind entweder mit vokalisch anlautenden, betonungsneutralen Suffixen realisiert oder es handelt sich um Fälle von Konversion. Bei Ableitungen mit vokalisch anlautendem Suffix ist die Geminationsbedingung im Derivat erfüllt, d.h., es wird unabhängig von der Basis geminiert. Etwas Ähnliches gilt im Kernbereich aber auch für Konversion. Wörter der offenen flektierenden Klassen weisen innerhalb des Paradigmas regelmäßig zweisilbige Flexionsformen auf. Beim Substantiv sind das mindestens die Pluralformen, 
beim Adjektiv sind es alle flektierten Formen. Auch in der Verbflexion spielen die zweisilbigen Flexionsformen als solche eine wichtige Rolle. Sie tauchen systematisch etwa als Formen der 1./3. Ps Pl und als Formen des synthetischen Konjunktivs auf. Damit stehen aber im Deutschen innerhalb eines jeden solchen Flexionsparadigmas Langformen zur Verfügung, die eine Gemination der Konsonantbuchstaben induzieren.

So schreiben wir beispielsweise eine Form wie knallt mit doppeltem $\langle\mathrm{l}\rangle$, weil sich im Verbparadigma Langformen wie knallen finden. Das zugehörige Substantiv Knall hat mit Knalles seine eigene Langform, muß also schon aus paradigmeninternen Gründen mit Geminate geschrieben werden. Das kann man verallgemeinern. Dem abgeleiteten Wort sieht man im allgemeinen nicht an, ob es eine Geminatenschreibung mit der Derivation übernommen hat oder nicht.

Gerade in dieser Hinsicht verhalten sich nun die Anglizismen anders als die Substantive im Kernber eich. Bei denen in 5b treten keine Langformen auf, weil sie, sofern sie überhaupt flektieren, der sog. $s$-Deklination folgen. Das einzige Flexionssuffix dieses Flexionstyps ist das $s$, das als Suffix im Gen $\mathrm{Sg}$ und im Pl auftritt. Wichtig dabei ist, daß dieses $s$ immer die Koda der letzten Stammsilbe verlängert, nie aber eine zusätzliche Silbe nach sich zieht. Das ist etwa beim Genitiv-s der starken Substantive im Kernbereich anders. Im unmarkierten Fall haben wir Balles neben Balls, d.h., die zusätzliche Silbe ist möglich. Nicht möglich ist dagegen *des Chipes, Fanes, Gages usw. Es wird konsequent an der Einsilbigkeit festgehalten, und genau deshalb kann es bei der Schreibung mit Einfachbuchstabe bleiben.

Einer anderen Regularität folgen, wie bereits in früheren Arbeiten festgestellt wurde, die Substantive mit koronalem Frikativ im Auslaut ( $B \circ \beta$, Dreß, Jazz, Stewardeß). Soweit sie einen Plural bilden, ist dieser zweisilbig (Bosse, Stewardessen). Im Gen Sg folgen sie der Regularität für die heimischen Substantive, die ja besagt, daB das Genitiv-s mit einer zweiten Silbe angeschlossen werden muß (Haus - Hauses genau so wie Boß - Bosses). Alle diese Substantive finden sich in 5a. Das Interessante ist, da $B$ offenbar rein phonologische $Z$ wänge dafür ausschlaggebend sind, ob ein Substantiv entsprechend $5 a$ in den Kernbereich integriert wird oder nicht.

Für das Deutsche sollte bei der Anwendung des morphologischen Prinzips zwischen Flexions- und Derivationsmorphologie unterschieden werden. Systematisch verankert ist eine graphematische Erscheinung wie die Gemination von Konsonantbuchstaben offenbar primär in der Flexions- 
morphologie. Wie weit dies auf andere graphematische Regularitäten zu verallgemeinern ist, bleibe vorerst dahingestellt.

Die zweite Frage bezüglich der Daten in 5c betrifft das Verhältnis des Deutschen zum Englischen. Ein Wechsel bei der Gemination wie in $5 c$ ist für das Englische ganz geläufig, und es ist vermutet worden, daB daran ein typologischer Unterschied zwischen beiden Sprachen deutlich wird. Das graphematische System des Englischen gilt als tiefer als das des Deutschen. Deshalb ist zunächst nicht zu erwarten, daB das Englische bei der Gemination sozusagen weniger Morphologie zeigt als das Deutsche (dazu ausführlicher wiederum Eisenberg 1991a; Augst 1995).

Mit den vorausgehenden Ausführungen zur Gemination ist die Frage im Grunde schon beantwortet. Das Deutsche schreibt im betrachteten Bereich nicht mehr oder weniger morphologisch als das Englische. Die Unterschiede liegen nicht im Schriftsystem, sondern sie liegen in der Morphologie selbst. Neuere Untersuchungen zur Flexionsmorphologie des Deutschen stellen insbesondere deren prosodische Charakteristika heraus, wozu auch der systematische Wechsel zwischen einsilbigen und zweisilbigen Formen gehört (vgl. z.B. Vennemann 1991, 1991a; Eisenberg 1991; Köpcke 1993; R.Wiese 1995). Dies begründet offenbar einen typologischen Unterschied zum Englischen, der Folgen für die Orthographie hat, der aber nicht in der Orthographie seine Quelle hat.

Gerhard Augst (1995, Teil II) schlägt nun vor, die in Eisenberg (1991a) formulierte und oben differenzierte Geminationsregel von ihrer einseitigen Bindung an den zweisilbigen FuB zu lösen und auch auf die Schreibung von einsilbigen Formen konsequent anzuwenden. Die Regel besagt ja bisher, daß Einsilber immer dann mit Geminate geschrieben werden, wenn eine geeignete Langform vorhanden ist. In ihrer verschärften Form würde sie besagen, da $\beta$ Gemination nur unter diesen Bedingungen auftritt und daB jede nicht so fundierte Gemination im Kernbereich des Vokabulars unakzeptabel wäre.

Bei Wörtern wie Scheck und Puck aus 5a, für die es keine verwandten Zweisilber gibt, würde Integration ins System des Deutschen bedeuten, daß sie die Geminate durch einen Einfachbuchstaben ersetzen. Dasselbe würde für $J a z z$, Truck und viele andere Wörter gelten, die keine Langform im Flexionsparadigma haben, obwohl es zweisilbige Derivate gibt.

Offenbar führt die Geminationsregel nicht zu dieser Konsequenz. Es gibt nicht nur unter den Anglizismen eine ganze Reihe von Wörtern, deren Schreibweise mit Geminate synchron nicht prosodisch motiviert ist. Entlehnung von Formen, historische Isolierung von Formen, Analogiebildung unterschiedlicher Art, Reanalyse usw. spielen in allen Bereichen des Le- 
xikons und für alle Strukturebenen eine bedeutende Rolle. DaB es sie auch in der Orthographie gibt, ist eigentlich selbstverständlich und besagt nichts über die Wirksamkeit des entscheidenden Strukturprinzips. Anders als sonst fallen sie uns aber in der Schrift besonders auf und veranlassen uns sogar, über eine Reform und damit ihre Beseitigung nachzudenken. Das liegt letztlich wohl wieder an dem besonderen Verhältnis, daß wir zur Orthographie haben. Ordnung muß sein.

\section{Zusammenfassung}

Die in Abschnitt 2 und 3 behandelten Beispiele bringen bezüglich der Frage, ob und gegebenenfalls wie typologische Aussagen über ein Alphabetschriftsystem wie das des Deutschen möglich und von Interesse sind, unterschiedliche Gesichtspunkte ins Spiel. Die $\vec{a}$-Schreibung zeigt, wie man innerhalb des isolierten Tiefenparameters Morphologie Unterschiede $\mathbf{z w i s c h e n ~ E i n z e l s p r a c h e n ~ f o r m u l i e r e n ~ k a n n . ~ D a s ~ S c h r i f t s y s t e m ~}$ des Deutschen morphologisiert konsequent, aber an die phonologische Oberfläche gebunden. Bei der Gemination von Konsonantbuchstaben zeigt sich, daß Unterschiede im Schriftsystem zweier Sprachen unter Umständen gar nicht als solche isoliert werden können, sondern sich aus davon unabhängigen typologischen Unterschieden ableiten lassen. Beide Arten von Gesichtspunkten sind für eine Typologie der Alphabetschriften von Interesse.

\section{Literatur}

Augst, Gerhard (1995): Einfacher und doppelter Konsonant in Anglizismen. In: Sommerfeldt, Karl-Ernst/Ewald, Petra (Hg.) (1995): Probleme der Schriftlinguistik. Frankfurt/M. Demnächst.

Coulmas, Florian (1995): Typology of Writing Systems. In: Gūnther/Ludwig (Hg.) (1995). Demnächst.

De Francis, John (1989): Visible Speech. The diverse oneness of writing systems. Honululu.

Duden (1995): Grammatik der deutschen Gegenwartssprache. 5. Aufl. Mannheim.

Eisenberg, Peter (1989): Die Schreibsilbe im Deutschen. In: Eisenberg, Peter/Günther, Hartmut (Hg.) (1989): Schriftsystem und Orthographie. Tübingen. S. 57-84. (= RGL 97).

Eisenberg, Peter (1991): Syllabische Struktur und Wortakzent. Prinzipien der Prosodik deutscher Wörter. In: Zeitschrift für Sprachwissenschaft 10, S. 37-64.

Eisenberg, Peter (1991a): Integration einer fremden Struktur. Die Gemination von Konsonantgraphemen in deutschen Anglizismen. In: Iwasaki, Eijiro (Hg.) (1991): Begegnung mit dem 'Fremden'. Grenzen - Traditionen Vergleiche. Band 4. München. S. 341-347. 
Eisenberg, Peter (1995): Sprachsystem und Schriftsystem. In: Günther/Ludwig (Hg.) (1995). Demnächst.

Eisenberg, Peter (1995a): Konjunktiv als verbale Flexionskategorie im Deutschen. In: Debus, Friedhelm/Leirbukt, Oddleif (Hg.): Aspekte der Modalitāt im Deutschen. Demnāchst.

Faber, Alice (1992): Phonemic segmentation epiphenomenon. In: Downing, Pamela u.a. (Hg.) (1992): The Linguistics of Literacy. Amsterdam. S. 111134.

Günther, Hartmut/Ludwig, Otto (Hg.) (1995): Schrift und Schriftlichkeit. Ein interdisziplinäres Handbuch internationaler Forschung. Band 2. Berlin demnächst.

Köpcke, Klaus-Michael (1993): Schemata bei der Pluralbildung im Deutschen. Tübingen (= SdG 47).

Meisenburg, Trudel (1992): Graphische und phonische Integration von Fremdwörtern am Beispiel des Spanischen. In: Zeitschrift für Sprachwissenschaft 11 , S. 47-67.

Meisenburg, Trudel (1994): Zur Typologie von Alphabetschriften anhand des Parameters der Tiefe. Ms.

Meisenburg, Trudel (1994a): Romanische Schriftsysteme im Vergleich. Habilitationsschrift Universitāt Freiburg.

Reformvorschlag (1994): Deutsche Rechtschreibung. Regelteil. Überarbeitete Fassung vom April 1994, vorgelegt von Mitgliedern des Internationalen Arbeitskreises für Orthographie im Auftrag der zustāndigen amtlichen Stellen in Deutschland, Österreich und der Schweiz. Ohne Ort.

Reformvorschlag (1995): Deutsche Rechtschreibung. Regeln und Wörterverzeichnis. Vorlage für die amtliche Regelung. Tübingen. März 1995. Ohne Ort.

Vennemann, Theo (1991): Syllable structure and syllable cut prosodies in Modern Standard German. In: Bertinetto, Piermarco/Kenstowicz, Michael/Loporcaro, Michele (Hg.) (1991): Certamen Phonologicum II. Turin. S. 211-243.

Vennemann, Theo (1991a): Skizze der deutschen Wortprosodie. In: Zeitschrift für Sprachwissenschaft 10, S. 86-111.

Wiese, Bernd (1994): Die Personal- und Numerusendungen der deutschen Verbformen. In: Kōpcke, Klaus-Michael (Hg.) (1994): Funktionale Untersuchungen zur deutschen Nominal- und Verbalmorphologie. Tübingen. S. 161-191. (= LA 319).

Wiese, Richard (1988): Silbische und lexikalische Phonologie. Studien zum Chinesischen und zum Deutschen. Tübingen. (= LA 211).

Wiese, Richard (1995): The Phonology of German. Oxford. Demnāchst.

Wunderlich, Dieter (1994): Minimalist Morphology: The Role of Paradigms. In: Proc. of the Sixth International Morphology Meeting Szombathely 1994. Demnächst. 



\section{Anschriften der Autoren}

Prof. Dr. Werner Abraham

Germanistisch Instituut, RUG

Oude Kijk in 't Jatstraat 26

NL-9712 EK GRONINGEN

e-mail: Abraham@let.rug.nl

Dr. Kai Alter

Austrian Research Institute for AI

Schottengasse 3

A-1010 WIEN

e-mail: Kai@ai.univie.ac.at

Prof. Dr. Ole Askedal

Universität Oslo

Germanistisches Institut

Postfach 1004 Blindern

$\mathrm{N}-0315$ OSLO 3

Prof. Dr. Bernard Comrie

University of Southern California

Department of Linguistics GFS-301

University Park

LOS ANGELES, CA 90089-1693, USA

e-mail: comrie@bcf.usc.edu

Prof. Dr. Östen Dahl

Inst. för lingvistik

Stockholms universitet

S-10691 STOCKHOLM, Schweden

Prof. Dr. Karin Donhauser

Humboldt-Universität zu Berlin

Institut für deutsche Sprache und Linguistik

Sitz: Glinkastr. 18-24

D-10099 Berlin

e-mail: Karin=Donhauser@german.hu-berlin.de 
Prof. Dr. Veronika Ehrich

Deutsches Seminar

der Universität Tübingen

Wilhelmstr. 50

D-72074 Tübingen

Prof. Dr. Peter Eisenberg

Universität Potsdam

Fachbereich Germanistik

Postfach 601555

D-14415 Potsdam

e-mail: eisenberg@rz.uni-potsdam.de

Prof. Dr. Ulrich Engel

Burgweg 20

D-64646 Heppenheim

Nanna Fuhrhop

Zentrum für Allgemeine Sprachwissenschaft

Jägerstr. 10/11

D-10117 Berlin

e-mail: fuhrhop@fas.ag-berlin.mpg.de

Dr. Joachim Grabowski

Lehrstuhl für Psychologie III

der Universität Mannheim

Schloß EO

D-68131 Mannheim

e-mail: psyIII@mailrum.uni-mannheim.de

Dr. Brigitta Haftka

Zentrum für Allgemeine Sprachwissenschaft Jägerstr. 10/11

D-10177 Berlin

e-mail: haftka@fas.ag-berlin.mpg.de

Dr. T. Alan Hall

Zentrum für Allgemeine Sprachwissenschaft

Jägerstr. 10/11

D-10117 Berlin

e-mail: hall@fas.ag-berlin.mpg.de 
Dr. Elke Hentschel

Freie Universität Berlin

Fachbereich Germanistik

Habelschwerdter Allee 45

D-14195 Berlin

Ursula Kleinhenz

Zentrum für Allgemeine Sprachwissenschaft

Jägerstr. 10/11

D-10117 Berlin

e-mail: ursula@fas.ag-berlin.mpg.de

Prof. Dr. Ekkehard König

Freie Universität Berlin

Institut für Engl. Philologie (WE 1)

GoBlerstr. 2-4

D-14195 Berlin

e-mail: koenig@zedat.fu-berlin.de

Prof. Dr. Klaus-Michael Köpcke

Universität Hannover

FB Erziehungswissenschaften I

Bismarckstr. 2

D-30173 Hannover

e-mail: Koepcke@fbez1.uni-hannover.de

Prof. Dr. Ewald Lang

a) Humboldt-Universität zu Berlin

Institut für $\mathrm{dt}$. Sprache und Linguistik

Sitz: Glinkastr. 18-24

D-10099 Berlin

e-mail: Ewald=Lang@german.hu-berlin.de

b) Zentrum für Allgemeine Sprachwissenschaft

Jägerstr. 10/11

D-10117 Berlin

e-mail: Lang@fas.ag-berlin.mpg.de

Dr. Barbara Lenz

Haspeler Str. 20

D-42285 Wuppertal 
Prof. Dr. Susan Olsen

Schillerstr. 4-5

D-10625 Berlin

Prof. Dr. Christer Platzack

Institut für Nordische Sprachen

der Universität Lund

Helgonabacken 14

S-22362 LUND

e-mail: Christer.Platzack@nordlund.lu.se

PD Dr. Beatrice Primus

Institut für Deutsche Philologie

Schellingstr. 3

D-80799 München

e-mail: ue801cj@sunmail.lrz-muenchen.de

Michal Starke

Université de Genève

Departement de Linguistique Générale

2 , rue de Candolle

CH-1211 GENF 4

e-mail: starke@uni2a.unige.ch

Dr. Christopher Wilder

MPG-Arbeitsgruppe Strukturelle Grammatik

Jägerstr. 10/11

D-10117 Berlin

e-mail: chriss@skyline.asg.ag-berlin.mpg.de

Prof. Dr. Wolfgang Ullrich Wurzel

Zentrum für Allgemeine Sprachwissenschaft

Jägerstr. 10/11

D-10117 Berlin

e-mail: wurzel@fas.ag-berlin.mpg.de

Prof. Dr. David A. Zubin

State University of New York at Buffalo

Department of Linguistics

685 Baldy Hall

BUFFALO, NY 14260 , USA

e-mail: Linzubin@ubwms.cc.Buffalo.edu 


\section{Das Institut für deutsche Sprache im Jahre 1995}

0. Allgemeines

1. Arbeiten und Mitarbeiter der Abteilungen und Arbeitsstellen

2. Tagungen, Kolloquien, Kommissionssitzungen und Vortrāge externer Wissenschaftler am IDS

3. Lehrauftrāge und Vortrāge von IDS-Mitarbeitern auBerhalb des Instituts

4. Publikationen von IDS-Mitarbeitern

5. Kontakte des IDS zu anderen Institutionen, Studienaufenthalte und Besuche in- und ausländischer Wissenschaftler am IDS, Besuchergruppen

6. Gremien des Instituts für deutsche Sprache

7. Besondere Nachrichten

8. Personalstärke, Anschriften, finanzielle Angaben

9. Veröffentlichungen im Jahre 1995

\section{Allgemeines}

Vom Institut für deutsche Sprache wird erwartet, daß es sich in seiner Forschungsarbeit in erster Linie auf größere Projekte konzentriert, die an den germanistischen Instituten der Universitäten nur schwer durchgeführt werden können. So heißt es in den nach wie vor geltenden "Richtlinien für die wissenschaftliche Arbeit” unter anderem: „Das IDS verfolgt längerfristige Vorhaben, die umfangreiche Datensammlungen, eine gröBere apparative Ausstattung und eine Arbeit in Forschergruppen erforderlich machen." Kleinere, befristete Projekte werden damit nicht ausgeschlossen. Sie sollen aber „den größeren Vorhaben zugeordnet" sein.

Was die größeren Projekte des IDS angeht, so war das Jahr 1995 bemerkenswert ertragreich. Von dem schon in den Vorjahren abgeschlossenen Vorhaben "Kommunikation in der Stadt” erschienen endlich die letzten Teile der insgesamt vierbändigen Ergebnispublikation. Die Ergebnisse des Projekts "Schlichtungsgespräche” gingen in Druck und werden demnächst in drei Bänden erscheinen. Weitgehend beendet wurden im Berichtsjahr die Abschlußarbeiten an der großen „Grammatik der deutschen Sprache". Die Diskettenversion des Gesamtmanuskripts im Umfang von über 3000 Seiten konnte Mitte des Jahres an den Verlag geschickt werden. Ebenfalls abgeschlossen wurden die beiden ersten 
Bände der auf insgesamt 10 bis 12 Bände geschätzten Neubearbeitung des "Deutschen Fremdwörterbuchs".

Zur Veröffentlichung der Ergebnisse von kleineren Untersuchungen und von Vorstudien und Ergänzungen zu größeren Projekten wurde eine schon seit langem bestehende Reihe umbenannt. Die Reihe „Forschungsberichte des Instituts für deutsche Sprache”, deren Titel nur zu einem Teil der ingesamt 75 erschienenen Bände paBt, wurde abgeschlossen. Die Nachfolgereihe beim selben Verlag (Narr, Tübingen) heiBt „Studien zur deutschen Sprache - Forschungen des Instituts für deutsche Sprache". Die ersten beiden Bände der neuen Reihe sind erschienen, mehrere weitere wurden für den Druck vorbereitet.

Nähere Angaben zu den Veröffentlichungen des IDS im abgelaufenen Jahr 1995 finden sich in den Kapiteln 4 und 9. Über die laufenden Arbeiten der Abteilungen und Forschungsstellen, die auf künftige Publikationen abzielen, wird im folgenden Kapitel 1 berichtet.

Neben den laufenden Forschungsarbeiten ist insbesondere die Beteiligung des Instituts an der bevorstehenden Reform der deutschen Rechtschreibung zu erwähnen. Nach der langjährigen Erarbeitung und wissenschaftlichen Begründung der Reformvorschläge, an denen die Rechtschreibkommission des IDS maßgeblichen Anteil hatte, galten die Aktivitäten 1995 der fachlichen Unterstützung der politischen und administrativen Instanzen bei der Beratung und Entscheidungsfindung. Neben Wissenschaftlern des IDS waren auch mehrere externe Mitglieder der Rechtschreibkommission mit derartigen Beratungsaufgaben nahezu ständig befaßt. Für das IDS zeichnet sich eine Daueraufgabe auf diesem Gebiet ab: Die Konferenz der Kultusminister der Länder (KMK) beschlo $B$, daß die einzurichtende $Z$ wischenstaatliche Kommission für die deutsche Rechtschreibung ihren Sitz am IDS haben soll. (Siehe hierzu auch Abschnitt 2.3.)

\section{Arbeiten und Mitarbeiter der Abteilungen und Arbeitsstellen}

\subsection{Abteilung Grammatik}

Die Arbeiten der Abteilung galten 1995

- der Endredaktion der Grammatik der deutschen Sprache

- dem Teilprojekt Validierung der Syntax

- dem Teilprojekt Modifikation im Deutschen

- dem Teilprojekt Grundlagen eines grammatischen Informationssystems (GRAMMIS)

- der Erarbeitung eines Handbuchs der Konnektoren. 
Die redaktionellen Arbeiten an der Grammatik der deutschen Sprache wurden Ende des Jahres mit der Erstellung eines Registers abgeschlossen. Nach Auskunft des Verlags ist bis Mitte 1996 mit der Fertigstellung der Druckfassung zu rechnen.

Die Teilprojekte „Validierung der Syntax” und „Modifikation im Deutschen" vertiefen Untersuchungen, die im Rahmen des Großprojekts "Grammatik der deutschen Sprache” begonnen wurden. Ziel der Validierung der Syntax ist die Erprobung der Leistungsfähigkeit einer erweiterten Kategorialgrammatik bei der Analyse notorisch problematischer Ausdrucksphänomene des Deutschen. Bearbeitet wurden 1995 die $\mathrm{Be}-$ reiche Wortstellung im Nebensatz, Distanzstellung von Quantifikatoren, Zusammenhang zwischen Determinativen und Protermen (u.a. Pronomen). Das Teilprojekt „Modifikation im Deutschen” beschreibt unter semantischem Aspekt die Verfahren der attributiven und adverbiellen Erweiterung von Ausdrücken verschiedener Kategorien.

Im Teilprojekt GRAMMIS wurde die Arbeit an einer 'elektronischen Grammatik' weitergeführt: Die Möglichkeit zur Wahl zwischen vier Zugriffen auf grammatische Informationen (über ein Inhaltsverzeichnis, über eine Datenbank grammatischer Termini, über sog. Funktionswörter und - aus dem Text heraus - über sog. Aktionswörter) ist eingerichtet. Die exemplarische Umsetzung des Kapitels Wortarten und interaktive Einheiten aus der Grammatik der deutschen Sprache in ein Hypertextdokument wurde Ende 1995 abgeschlossen. Eine vergleichende Erprobung von Buchtext und Hypertext ist für Frühjahr 1996 geplant. In zwei weiteren Bereichen (Grammatik aus funktionaler Sicht und Verbgrammatik) wurden Hypertext- und Datenbankstrukturen entwickelt, in denen bereits größere Texteinheiten als Hypermediadokumente realisiert wurden. Um technisch weniger versierten Benutzern die Handhabung des Systems zu erleichtern, werden zusätzlich kontextspezifische Hilfen entwickelt.

Im Teilprojekt Konnektoren (u.a. Konjunktionen) wurden im Berichtsjahr Kriterien für die Bestimmung der „Konnekte” bei verschiedenen Klassen von Konnektoren entwickelt und weitere Manuskripte zu übergreifenden Themen vorgelegt, die in den systematischen Teil des geplanten Handbuchs aufgenommen werden sollen.

Projektübergreifend befaßte sich die gesamte Abteilung zum Ende des Berichtsjahrs mit einer Aktualisierung der Arbeitsplanung mit dem Ziel, die Teilvorhaben im Anschluß an das Großprojekt "Grammatik der deutschen Sprache" im Rahmen eines längerfristig geltenden Gesamtkonzepts einander zuzuordnen. 
Mitarbeiter der Abteilung:

Abteilungsleitung: Priv.Doz. Dr. Gisela Zifonun (bis 31.07.95); Prof. Dr. Bruno Strecker (seit 1.08.95 komm.); Wissenschaftliche Mitarbeiter: Prof. Dr. Joachim Ballweg - Dr. Ursula BrauBe - Dr. Eva Breindl-Hiller (beurlaubt) - Helmut Frosch - Ursula Hoberg - Dr. Renate Pasch - Dr. Angelika Storrer - Klaus Vorderwülbecke (beurlaubt); Programmierer: Roman Schneider;

Sekretärinnen: Ulrike Bossert (bis 31.08.95) - Ruth Maurer

\subsection{Abteilung Lexikologie und Wortbildung}

In der Abteilung werden lexikologische und lexikographische Projekte zu ausgewählten Wortschatzbereichen und zur Wortbildung sowie Forschungen zur Graphie und Orthographie durchgeführt.

Im Projekt „Erklärende Synonymik kommunikativer Ausdrücke des Deutschen" (ESKA) wurden die Verbgruppen der Repräsentative und Direktive bearbeitet, wobei die semantische Feinstrukturierung (Wortfeldstrukturen) im Vordergrund stand. Die in Zusammenarbeit mit der Arbeitsstelle Linguistische Datenverarbeitung (LDV) entwickelte Datenbank wurde fortlaufend optimiert.

Für das Handbuch "Deutsche Wortbildung in Grundzügen” wurden die Kapitel „Allgemeine Grundlagen der Wortbildung” und „Wortbildung des Adjektivs” abgeschlossen; erste Vorarbeiten zum Kapitel "Wortbildung des Verbs" liegen vor.

Die Bearbeitung des neuen "Valenzlexikons deutscher Verben” wurde fortgesetzt.

Im Arbeitsbereich "Graphie und Orthographie" wurde im Zuge der Bemühungen um die Reform der deutschen Rechtschreibung die Vorlage der amtlichen Regelung, bestehend aus Regelteil und Wörterverzeichnis, fertiggestellt und den zuständigen staatlichen Stellen in Deutschland, Öster reich und der Schweiz übergeben. Dem großen Informationsbedürfnis der Bevölkerung entgegenkommend, wurde dieser zwischen Fachwissenschaftlern und Fachbeamten international abgestimmte Vorschlag im Gunter Narr Verlag, Tübingen veröffentlicht und eine breite Öffentlichkeitsarbeit geleistet.

Die Arbeit an dem von der Deutschen Forschungsgemeinschaft (DFG) geförderten Projekt "Orthographiedarstellungen im 19. Jahrhundert" wurde fortgesetzt. 
Mitarbeiter der Abteilung:

Abteilungsleiterin: Prof. Dr. Gisela Harras; Wissenschaftliche Mitarbeiter: Dr. Elke Donalies (seit 1.06.95) - Dr. Klaus Heller - Monika Kolvenbach, M.A. (bis 30.09.95) - Jacqueline Kubczak - Dr. Wolfgang Mentrup-Wenzel - Prof. Dr. Wolfgang Motsch - Vera de Ruiter - Renate Schmidt - Helmut Schumacher - Dr. Edeltraud Winkler;

Sekretärinnen: Susanne Bergmann (seit 22.9.1995) - Karin Laton - Renate Wegener (bis 31.08.95)

\subsection{Abteilung Historische Lexikologie und Lexikographie}

Die Arbeiten an der "historischen Datenbank" zur deutschen Wortschatzentwicklung seit $\mathbf{1 7 0 0}$ wurden fortgesetzt. Die Datenbank soll die Grundlage zur Behandlung wortgeschichtlicher und anderer Themen der jüngeren Sprachgeschichte bilden. Erste Ergebnisse gehen in Studien über Formulierungstraditionen seit dem 18. Jahrhundert ein.

Das Manuskript zu den ersten beiden Bänden der Neubearbeitung des historischen „Deutschen Fremdwörterbuchs” ist abgeschlossen. Der erste Band soll im Winter 1995/96 erscheinen, der zweite Band folgt in der ersten Jahreshälfte 1996. Drei Bände historischer Untersuchungen über die "Lehnwortbildung im Deutschen" sind fertiggestellt und werden zum Druck vorbereitet.

Im Rahmen der 1993 begonnenen Beteiligung am „Frühhochdeutschen Wörterbuch" (Anderson/Goebel/Reichmann) wurde das Manuskript der ersten Mannheimer Lieferung erarbeitet und in Druck gegeben. Die Lieferung erscheint im Frühjahr 1996.

Mitarbeiter der Abteilung:

Abteilungsleiter: Prof. Dr. Hartmut Schmidt; Wissenschaftliche Mitarbeiter: Dr. Elke Donalies (bis 31.05.95) - Gabriele Hoppe - Dr. Heidrun Kämper-Jensen - Isolde Nortmeyer - Dr. Elisabeth Link - Dr. Gerhard StrauB - Prof. Dr. Joachim Schildt - Dr. Rosemarie Schnerrer - Oda Vietze - Priv.Doz. Dr. Ulrike Hab-Zumkehr;

Sekretärinnen: Sabina Schuster (bis 15.11.95) - Sigrid Ziehr

\subsection{Abteilung Sprachentwicklung in der Gegenwart}

In dieser Abteilung werden Prozesse der Veränderung der deutschen Sprache in der Gegenwart untersucht.

Zentrales Vorhaben war in den letzten Jahren die Untersuchung von Sprachveränderungen im Zusammenhang mit der staatlichen Vereini- 
gung Deutschlands. Ein großes Textkorpus aus der Zeit von Mitte 1989 bis Ende 1990 wurde für die Untersuchung von Wortschatzveränderungen wie auch Bedeutungsveränderungen in Texten genutzt.

Das Projekt „Sprachwandel in der Wendezeit” war in drei Teilprojekte gegliedert:

(1) Wendebezogene Wortschatzveränderungen in der DDR 1989/90

(2) Lexikographische ErschlieBung des Wende-Korpus

(3) Bedeutungsvariation und -uminterpretation in Texten zur deutschen Einheit.

Die Teilprojekte (2) und (3) sind inzwischen mit der Vorlage der druckfertigen Manuskripte im wesentlichen abgeschlossen. Teilprojekt (1) wird in Kürze folgen.

Parallel zu diesem Projekt wurde seit Ende 1994 mit der Arbeit am neuen zentralen Vorhaben der Abteilung, der Neologieforschung, begonnen. Geplant sind die laufende Erfassung von 'Neuwörtern' (Neologismen) und die Erstellung korpusbasierter Neologismenwörterbücher in regelmäßigen Abständen.

Das von der Deutschen Forschungsgemeinschaft (DFG) geförderte Projekt „Eurotexte” wurde mit der Veröffentlichung der Untersuchungsergebnisse (Joachim Born/Wilfried Schütte: Eurotexte. Textarbeit in einer Institution der EG. Tübingen: Narr 1995) abgeschlossen.

Seit August 1994 läuft das von der Europäischen Kommission finanzierte britisch-deutsche Projekt "Ökologische Innovation und Unternehmenskommunikation". Partner sind das IDS und die Aston University, Birmingham. Das Projekt wurde Ende 1995 abgeschlossen.

Seit November 1994 läuft das von der Europäischen Kommission finanzierte Infrastrukturprojekt PAROLE, das der Schaffung eines Netzwerks von Sprachinstituten in Europa und dem Aufbau von Ressourcen für multilinguale Anwendungen dient. Beteiligt sind die zentralen Sprachinstitute in 13 EG-Ländern. Das IDS ist deutscher Partner. Die jetzige Bewilligungsphase reicht bis ins Frühjahr 1997.

Begonnen wurde die im COPERNICUS-Programm der Europäischen Kommission finanzierte konzertierte Aktion „Trans-European Language Resources Infrastructure" (TELRI, 1995 - 1997), in der 22 Institute in 17 Ländern zusammenarbeiten. Das IDS ist Koordinator. 
Mitarbelter der Abtellung:

Abtellungsleiter Dr Wolfgang Teubert, Wissenschaftliche Mitarbeiter Dr Claudia Fraas - Dr Manfred W Hellmann - Prof Dr Dieter Herberg - Dr Mıchael Kınne - Dipl rer pol Pantelis Nıkıtopoulos - Heıke Rettıg, M A - Dr Doris Steffens - Dr Kathrin Steyer - Deniz Tandogan, M A - Dr. Elke Tellenbach;

Sekretärin Joyce-Ann Thompson (selt 1 7.1995)

\subsection{Abteilung Verbale Interaktion}

Die Arbelt konzentrierte sich auf die Erarbeltung eines Handbuchs "Rhetorik der Problem- und Konfliktbearbeitung”, in dem verbale Muster und Verfahren in Problem- und Streitgesprächen dargestellt werden sollen Das Projekt schließt an die in den vergangenen Jahren durchgeführten Projekte zu Beratungs- und Schlichtungsgesprächen sowle zur Kommunkation in der Stadt an und soll die vorhandenen gesprächsanalytischen Ergebnisse unter rhetorischer Perspektive systematisieren und vertiefen

In das Rhetorikprojekt sind auch die beiden Projekte am Sonderforschungsbereich 245 „Sprache und Situation” integriert „Wissenschaftsinformation" und "Bedeutungskonstitution im Dialog"

Ein Sammelband mit Ergebmissen der ersten Arbeitsphase des Projekts hegt in Manuskriptfassung vor und wird zur Veröffentlichung in den "Studien zur deutschen Sprache” vorbereitet (Kallmeyer, Werner $(\mathrm{Hg})$ Gesprächsrhetorık Zur Analyse von rhetorıschen Verfahren in Gesprächsprozessen)

Im Zusammenhang mit der Arbeit an der „Rhetorı" wird eine DiskursDatenbank (DIDA) aufgebaut (siehe auch 17 ).

Zusammen mit der Arbeitsstelle Linguistische Datenverarbeltung wird ein drittmittelfinanziertes Projekt zur Entwicklung eines Arbeitsplatzes für computerunterstützte Transkriptıon und Analyse von Gesprächsdaten durchgeführt (SERGES - Schriftliche Erfassung gesprochener Sprache; vgl. auch 1 7)

Mitarbeiter der Abteilung

Abteilungsleiter- Prof Dr. Werner Kallmeyer, Wissenschaftliche Mitarbetter Priv Doz Dr Bernd-Ulrich Biere (seit 1 04.95) - Katrin Bischl, M A (selt 1 06.95) - Dr Inken Kelm-Zingelmann - Dr Wolfgang Klein, M A - Dr Andreas Liebert (bıs 31 05.95) - Priv. Doz Dr. Werner Nothdurft, M A (bıs 3101 95) - Dr Reinhold Schmitt, M A. - Dr Wilfried 
Schütte - Dr. Carmen Spiegel - Franc Wagner, M.A. (seit 1.07.95) - Dr. Ricarda Wolf;

Sekretärinnen: Hanni Kohlhase - Doris Richter

\subsection{Abteilung Gesprochene Sprache: Analyse und Dokumentation}

Die Arbeit der Abteilung zielt darauf ab, gesprochene Sprache auf den verschiedenen Beschreibungsebenen (durch den Vergleich mit anderen Kommunikationsformen) in ihren besonderen Eigenschaften zu charakterisieren und ihre funktionalen, arealen und sozialen Varianten zu beschreiben. Zu den Aufgaben der Abteilung gehört ferner, gesprochene Sprache in ihrer Vielfalt zu dokumentieren.

1995 wurde an drei Projekten gearbeitet:

Im Projekt "Sprachliche Integration von Aussiedlern" wird untersucht, wie sich Aussiedler aus der GUS und Polen in die Sprach- und Kommunikationsgemeinschaft integrieren, die sie in Deutschland vorfinden. Die Forschungsschwerpunkte sind im einzelnen: (a) Der AnpassungsprozeB der Sprache der Rußlanddeutschen in der Integrationsphase in Deutschland: Es werden mit variations- und kontaktlinguistischen Methoden phonologische, lexikalische und syntaktische Veränderungen analysiert. (b) Die Zweisprachigkeit in Aussiedlerfamilien und ihre Auswirkungen auf den Spracherwerb der Kinder: Hier geht es vor allem um die lebenslange, generationstypisch verlaufende Entwicklung der Zweisprachigkeit in rußlanddeutschen Familien einschließlich der Prozesse der sprachlichen Integration in Deutschland. (c) Die Kommunikationsbeziehungen zwischen Aussiedlern und Einheimischen: Im Mittelpunkt des Interesses steht hier die Identitätsarbeit von Aussiedlern im Kontakt mit Einheimischen.

Mit den Arbeiten am Projekt "Eigenschaften gesprochener Sprache" wurde begonnen. Gesichtet wurden die in der Literatur beschriebenen Besonderheiten mündlicher Kommunikation und die Modelle zu ihrer Erklärung. Angefangen wurde mit der korpusbasierten empirischen Untersuchung einer exemplarischen Besonderheit - der sogenannten Operator-Skopus-Struktur.

Die Pilotphase des Projekts "Wandel im gesprochenen Deutsch” wurde abgeschlossen. Im März fand dazu ein „Expertengespräch” im IDS mit auswärtigen Sprachwissenschaftlern statt.

Das „Deutsche Spracharchiv” (DSAv) hat die 1994 begonnene Digitalisierung seiner meistgefährdeten Tonaufnahmen fortgesetzt und daneben 
weitere externe Korpora von Tonaufnahmen des gesprochenen Deutsch integriert. In Zusammenarbeit mit der Abteilung Verbale Interaktion wurde die Dokumentation aller IDS-Korpora zur gesprochenen Sprache (einschlieBlich der Bestände aus laufenden Projekten) aktualisiert, und es wurden Vorarbeiten zur Einrichtung einer Informations-Datenbank geleistet, die die Bestände genauer dokumentieren und besser erschließen helfen soll. Als Band 42 der Reihe PHONAI ist der von Anne Betten herausgegebene Textband "Sprachbewahrung nach der Emigration. Das Deutsch der 20er Jahre in Israel" (mit einer im DSAv gefertigten CD) erschienen.

Mitarbeiter der Abteilung:

Abteilungsleiter: Prof. Dr. Reinhard Fiehler; Wissenschaftliche Mitarbeiter: Dr. Karl-Heinz Bausch - Dr. Nina Berend - Sylvia DickgieBer, M.A. - Dr. Mechthild Elstermann - Dr. Barbara Kraft - Dr. Katharina Meng - Dipl.-Soz. Ulrich Reitemeier - Dr. Peter Schröder - Dr. Peter Wagener; Toningenieur: Wolfgang Rathke,

Sekretärinnen: Ulrike Bossert (seit 1.09.95) - Vladimira Schroeder (bis 30.04.95) - Renate Wegener (seit 1.09.95)

\subsection{Zentrale Arbeitsstelle Linguistische Datenverarbeitung (LDV)}

Die Arbeitsstelle hat drei Aufgabenbereiche:

(1) Grunddienste der Datenverarbeitung im IDS,

(2) Neu- und Weiterentwicklung von Datenverarbeitungssystemen,

(3) Erfassung und Aufbereitung der Textkorpora des IDS und korpusbezogener Service.

Zu den Grunddiensten gehört das Betreiben der Computer, die Pflege der Betriebssysteme, der Benutzer-Software und die Sicherung der Daten. Betrieben werden fünf miteinander vernetzte Mehrplatz-UNIXComputer vom Typ mx300 (Siemens), ein Unix-Computer vom Typ AViion 6225 (Data General) und eine Reihe von PCs. Mit dieser Ausstattung stehen im IDS rund 130 Bildschirm-Arbeitsplätze zur Verfügung.

Folgende Datenverarbeitungs-Systeme wurden entwickelt bzw. weiterentwickelt:

Neben der Abteilung "Verbale Interaktion" transkribiert und bearbeitet jetzt auch die Abteilung "Gesprochene Sprache” ihre Gesprächsdaten mit dem System "Diskursdatenbank (DIDA)". Die Leistung dieses Systems wurde so erweitert, daß jetzt alle auf modernen graphischen Oberflächen zur Verfügung stehenden Zeichensätze genutzt werden können. 
In das Korpus-Recherche-System COSMAS wurden weitere Funktionen integriert; die Korpora wurden laufend erweitert. Im COSMASGesamtsystem können nun auch auswärtige Benutzer über Internet, DFN und andere Netzwerke on-line recherchieren. 1995 gab es 40 externe Dauerabonnenten u.a. in Basel, Rom, Trondheim, Oslo, Kopenhagen, Vaasa, New York, Tokio.

Das durch die Europäische Union finanzierte Projekt „Multilingual Environment for Corpusbased Lexicon Building", in dem COSMAS zu COSMAS-II weiterentwickelt wurde, fand seinen erfolgreichen AbschluB. Dieses System kann annotierte Textkorpora verwalten und erschließen.

Mit dem vom Bundesministerium für Verteidigung finanzierten Projekt SERGES (schriftliche Erfassung gesprochener Sprache) wurde begonnen. An diesem Projekt sind vom IDS die Abteilung Verbale Interaktion und die Arbeitsstelle LDV beteiligt. Einer der externen Projektpartner ist der Lehrstuhl für Mustererkennung der Universität Erlangen, welcher über die nötige Kompetenz im Bereich der Spracherkennung verfügt. SERGES ist in einer wissenschaftlichen Arbeitsgemeinschaft "Sprachstrukturen" eingebettet, die aus weiteren Forschungsstellen aus Industrie und Universitäten besteht und ihre Ergebnisse auf in regelmäßigen Abständen stattfindenden Kolloquien präsentiert. Die Dauer von SERGES, das für die IDS-Partner am 1. November 1995 angefangen hat, ist auf 2-4 Jahre angesetzt und verteilt sich auf drei Phasen, nach welchen jeweils über den Fortgang entschieden wird.

Projektziel ist ein Arbeitsplatz für die computerunterstützte Beschreibung und Analyse von Gesprächsdaten. Der Arbeitsplatz soll auf der Basis des COSMAS-II-Prototyps aufgebaut werden. COSMAS-II wird ausgebaut, um die Integration von gesprochenem Material in digitalisierter Form und die Zuordnung von gesprochenen und transkribierten Äußerungen zu ermöglichen. Außerdem wird COSMAS-II mit einer Schnittstelle versehen, die ein Spracherkennungsmodul aufnehmen kann.

Mitarbeiter der Arbeitsstelle:

Leiter: Robert Neumann; Wissenschaftliche Mitarbeiter: Dipl.-Ing. Cyril Belica - Franck Bodmer - Sylvie Costantino (bis 31.07.95) - Dr. Irmtraud Jüttner - Dr. Rudolf Schmidt - Dipl.-Inf. Eric Seubert - Doris al-Wadi; Mitarbeiter in der Datenverarbeitung: Siegmund Gruschka Rainer Krauß - Peter Mückenmüller - Ingrid Schellhammer - Uwe Sommer;

Sekretärin: Gerda Beck 


\subsection{Zentrale Arbeitsstelle Öffentlichkeitsarbeit und Dokumentation}

In der Arbeitsstelle sind die Bereiche 'Öffentlichkeitsarbeit und Presse', 'Publikationswesen', 'Dokumentation' und die Bibliothek organisatorisch zusammengefaßt.

Im Berichtsjahr wurden die laufenden Aufgaben wie Pressekontakte, Redaktion der Zeitschrift 'Sprachreport', Redaktion der Zeitschrift 'Deutsche Sprache', Gästebetreuung, Besucherprogramme, Betreuung des Vereins der Freunde des IDS, Tagungsorganisation, Druckvorlagenerstellung für die IDS-Publikationen, Zentrale Adreßverwaltung, Vertrieb der Eigenverlagspublikationen, Bearbeitung von Anfragen usw. wahrgenommen. Hinzu kommen Aktivitäten zur Verbesserung der internen Information und Kommunikation.

Neben diesen laufenden Aufgaben waren 1995 Schwerpunkte der Öffentlichkeitsarbeit:

die Jahrestagung zum Thema „Deutsch - typologisch”, eine Ausstellung mit dem Titel "Die Welten der Wörter" in Zusammenarbeit mit dem Klett-Verlag und eine Ausstellung zum Thema ,in-schrift” von Mannheimer, Wiener und tschechischen Künstlern in den Räumen des IDS. Außerdem wurde die Öffentlichkeitsarbeit auch in diesem Jahr stark von dem Interesse an der Rechtschreibreform dominiert.

Die „Dokumentation sprachwissenschaftlicher Forschungsvorhaben” ist im Mai 1995 erschienen. In Zusammenarbeit mit der Arbeitsstelle Linguistische Datenverarbeitung wurde das Informationsangebot des IDS im WWW (Internet) erheblich ausgebaut. Aktuelle Informationen über das IDS können unter http:/www.ids-mannheim.de abgerufen werden.

In der Bibliothek werden seit der Einführung des Katalogisierungssystems BISLOK (August 1993) sämtliche Neuerwerbungen und - soweit möglich - Altbestände mit diesem System erfaßt und verstichwortet. Durch die zunehmende Zahl von Gastwissenschaftlern und wegen der auf mehr als das Doppelte angewachsenen Zahl von Nutzern aus den umliegenden Hochschulen sind die Beratungsaufgaben der Bibliothek erheblich gestiegen. Die von der Bibliothek herausgegebenen Neuerwerbungslisten (Erscheinungsweise 3-4mal jährlich) dienen der in- und ausländischen Hochschulgermanistik als wichtige Informationsquelle.

Mitarbeiter der Arbeitsstelle:

Leiterin: Dr. Annette Trabold, M.A.; Wissenschaftliche Mitarbeiter: Franz Josef Berens - Monika Kolvenbach, M.A. (seit 1.10.95); Dokumentarin: Dipl.-Dok. Katrin Freese, M.A.; EDV-Mitarbeiter: Claus Hoff- 
mann; Erstellung von Druckvorlagen: Ursula Blum - Cornelia Kayser Ria Schiel;

Bibliothek: Lucia Berst - Birgit Günther - Dipl.-Bibl. Eva Teubert (Leitung);

Sekretärin: Iris Wohlfarth

\subsection{Verwaltung und Vorstandssekretariat}

Verwaltungsleiter: Harald Forschner; Verwaltungsangestellte: Monika Buchmüller (seit 25.8.95) - Gerhard Köck - Hildegard Magis - Gerd Piroth - Marianne Wardein - Hannelore Wittmann - Manfred Wondra (bis 31.05.95); Telefonist: Franz-Albert Werner; Hausmeister: Uwe Zipf; Vorstandssekretariat: Cornelia Pfützer-König - Barbara Stolz

\subsection{Doktoranden}

Andreas Müller - Sylvia Roderburg - Jarochna Dabrowska

\section{Tagungen, Kolloquien, Kommissionssitzungen und Vorträge externer Wissenschaftler am IDS}

2.1 Jahrestagung 1995 „Deutsch - typologisch”, 14.-16.3.1995

Das Deutsche ist ein Haus mit vielen Etagen. Ob ein und derselbe Architekt auch den französischen Bauernhof, das englische SchloB oder die russische Holzkirche konstruiert haben könnte und ob die Tapetenmuster nicht ähnliche Farben aufwiesen, das fragten sich vom 14.-16. März 1995 mehr als dreihundert Sprachwissenschaftler. Treffpunkt für die forschenden Neugierigen waren diesmal die Räume des Ostflügels des Mannheimer Schlosses. Germanisten aus der ganzen Welt stellten verschiedene Forschungsansätze und Erkenntnisse zum Thema „Deutsch - typologisch" vor. Referenten und Zuhörer versuchten in etwa zwanzig Vorträgen und anschließenden Diskussionen eine feinkörnige Analyse, in welchen Variationsbreiten sich die grammatischen Strukturen des Deutschen bewegen. Die typologische Zeichnung des Deutschen auf dem Reißbrett der Sprachen ist auch für die Vermittlung als Fremdsprache von Bedeutung. Daß nach der Aufforderung „Parke vor dem anderen Auto!” der Wagen des deutschen Fahrers auf einer anderen Stelle als der des Engländers zu stehen kommt, war nur eins der diskutierten Beispiele. Die Vortragstexte sind im Hauptteil dieses Jahrbuchs wiedergegeben.

Das Tagungsprogramm war gemeinsam vom IDS und dem Forschungsschwerpunkt Allgemeine Sprachwissenschaft, Typologie und Universalienforschung, Berlin, vorbereitet worden. Das Berliner Institut brachte zur Tagung durchaus praktische Neuerungen mit. Mit Utensilien aus dem 
Phonetiklabor bestückt konnten Tagungsteilnehmer ihre Aussprache am Computer nachverfolgen. Messungen an Gaumen, Zunge und Lippen erschienen am Bildschirm als verschiedene Berührungen der Sprechorgane miteinander. Auch dies könnte - weiterentwickelt - beim Erlernen einer Fremdsprache als elektronische Lehrhilfe dienen. Aussprachefehler werden so per Computer visuell und akustisch mitgeteilt.

Kein Haus ohne Hausmaus - eine Rolle bei der Tagung im Institut für deutsche Sprache spielte auch die grammatikalisch bewanderte Schwester des kleinen Nagetiers, die sich auf der Tagung von ihrer klügsten Seite zeigte. Sie offenbarte den wißbegierigen Gästen ein Computerprogramm, das Grammatikwissen sowohl ausführlich und beispielorientiert vermittelt als auch spielerisch überprüft. Die Multimediagrammatik GRAMMIS ist eine Pilotstudie, die seit einem Jahr am Institut für deutsche Sprache läuft. Sie wendet sich vor allem an Gymnasiallehrer der Oberstufe und Studenten sprachwissenschaftlicher Fakultäten. Inhaltliche Grundlage der elektronischen Ausführung ist die am IDS erarbeitete "Grammatik der deutschen Sprache", die mit einem Umfang von ca. zweitausendvierhundert Seiten voraussichtlich im Sommer 1996 erscheinen wird.

Im Rahmen der Tagung wurde Herrn Dr. Helmuth Feilke der HugoMoser-Preis 1995 verliehen (s. hierzu den Anhang).

\subsection{Kommission für Fragen der Sprachentwicklung}

Die Arbeit an der Rahmenthematik "Sprache und Sprachentwicklung unter dem Einfluß der (technischen) Medien" wurde am 23. und 24. Juni 1995 mit einem Kolloquium fortgesetzt, das den Titel trug: „Boulevardisierung in Zeitung und Fernsehen. Textsorten und Textsortenwandel".

Dabei wurde der Begriff der 'Boulevardisierung' von verschiedenen Seiten problematisiert und meist durch 'Modernisierung' ersetzt. U. Püschel (Trier) eröffnete eine historische Perspektive, indem er die verstärkt unterhaltsamen Züge einer profitorientierten Zeitungskommunikation nach der Reichsgründung aufzeigte. H.-J. Bucher (Tübingen) behandelte dann die neuesten Modernisierungstendenzen, die unter dem Stichwort "Textdesign” zu aufwendig gestalteten "Clustern” von Grafiken, Bildern und kürzeren Teiltexten führen. B.U. Biere (IDS) fand stilistische Mittel der Sensationspresse auch in der Wissenschaftsberichterstattung, aber hier eben zum Zwecke der Popularisierung komplexer Sachverhalte. In den Fernsehnachrichtensendungen kommerzieller Anstalten - so M. Muckenhaupt (Tübingen) - gibt es zwar gewisse reißerische Züge zur 
Aufmerksamkeitsheischung, aber Fiktionalität, Vermischung von Meinung und Nachricht und eindeutige Tendenzen fehlen; vieles sei einfach schlecht gemacht. J. Klein (Koblenz) untersuchte, wie Kulturmagazine im Fernsehen durch ein weniger elitäres Themenspektrum und zahlreiche unterhaltsame Züge eine Veränderung des zugrundeliegenden Kulturbegriffs, nicht aber "Boulevardisierung” spiegeln. J. Reichertz (Essen) entwickelte anhand der Sendung "Traumhochzeit" nicht wertend, aber verstehend die These, daB "Fernsehen als Sinnsystem” eine rituelle Überhöhung des Alltags und damit angesichts eines höheren Trennungsrisikos eine brauchbare Lösung anbieten könne. B. Sandig (Saarbrücken) riet dann in ihrer Zusammenfassung zum vorsichtigen Umgang mit dem Etikett „Boulevardisierung”; eine entsprechende Tendenz sei allenfalls im komplexen Zusammenspiel verschiedener Textmerkmale und dann auch nur graduell auszumachen.

In der internen Kommissionssitzung verständigte man sich darauf, neben einer eventuellen Publikation der Beiträge eine kurze und außenwirksame Darstellung der Ergebnisse in Thesenform zu versuchen.

Das nächste Kolloquium am 28./29. Juni 1996 wird sich mit dem Thema "Neue und neueste Medien und Kommunikationsformen” (Arbeitstitel) befassen.

\subsection{Kommission für Rechtschreibfragen}

Vom 22. bis 24. November 1994 hatten die „3. Wiener Gespräche zur Neuregelung der deutschen Rechtschreibung" stattgefunden; zwischen Fachwissenschaftlern und Vertretern der zuständigen staatlichen Stellen aller betroffenen Länder war es in allen Fragen zu einvernehmlichen Lösungen gekommen. In der Folge galt es, die Beschlüsse von Wien in das künftige amtliche Regelwerk einzuarbeiten und insbesondere das Wörterverzeichnis fertigzustellen. In Wien war hierzu eine Redaktionskommission benannt worden, der sowohl Fachbeamte als auch Sprachwissenschaftler angehörten. Zu letzteren gehörten vier Mitglieder der IDS-Kommission für Rechtschreibfragen: Prof. Dr. Gerhard Augst (Siegen), Prof. Dr. Günther Drosdowski (Mannheim), Dr. Klaus Heller (Mannheim) und Prof. Dr. Burkhard Schaeder (Siegen). Die redaktionellen Arbeiten am Regelwerk konnten Anfang April abgeschlossen werden. Eine letzte kritische Durchsicht wurde von mehreren Kommissionsmitgliedern vorgenommen. Am 13. April konnte die Vorlage für das künftige amtliche Regelwerk den zuständigen Behörden in Deutschland, Österreich und der Schweiz übergeben werden. 
Um allen Interessierten Einblick in das vollständige Regelwerk zu geben und besonders denen, die sich - wie viele Verlage - auf die neue Rechtschreibung einstellen müssen, eine längere Vorbereitungszeit zu ermöglichen, veröffentlichte der "Internationale Arbeitskreis für Orthographie" Anfang Juli die vollständige Vorlage für das amtliche Regelwerk im Gunter Narr Verlag, Tübingen. Die Herstellung des druckfertigen Manuskripts erfolgte im IDS. Am 3. Juli tagte die Kommission im IDS in Mannheim. In einer Reihe von Berichten informierten sich die Mitglieder der Kommission über bisherige und für die nächste Zeit geplante Schritte, die zum offiziellen Inkraftsetzen der Neuregelung der deutschen Orthographie in Deutschland, Österreich und der Schweiz zu beachten sind. Das habe insbesondere auch für eine Verteilung des schulisch zu vermittelnden rechtschreiblichen Stoffes auf eher zentrale und eher periphere Bereiche zu gelten.

Das Gremium war einvernehmlich der Auffassung, daß eine künftige Zwischenstaatliche Kommission für die deutsche Rechtschreibung ihren administrativen Sitz am IDS haben solle. Bis zur Einrichtung dieser Zwischenstaatlichen Kommission müsse die Kommission für Rechtschreibfragen des IDS in der vorhandenen personellen Zusammensetzung bestehen bleiben.

Im Verlaufe des politischen Beratungs- und Entscheidungsverfahrens waren Mitglieder der Kommission für Rechtschreibfragen mehrfach Ansprechpartner für die zuständigen staatlichen Behörden. So nahmen Prof. Dr. Augst, Dr. Heller und Prof. Dr. Munske an der Konferenz der Amtschefkommission am 18. Oktober in München teil.

\subsection{Vorträge externer Wissenschaftler im IDS 1995}

09.03.95 Olaf Jäkel, Universität Hamburg

Bilder von der Wissenschaft

Metaphorische Szenarien aus einer abstrakten Domäne

27.04.95 Dr. Matthias Jung, Universität Düsseldorf

Öffentliches Sprachbewußtsein und Fehlleistungen linguistischer Sprachkritik

12.06.95 Prof. Dr. Jovan Djukanović, Universität Belgrad Verben mit 'sich' im Deutschen und 'se' im Serbokroatischen 
25.07.95 Prof. Dr. Vladimir Pavlov, Akademie der Wissenschaften, St. Petersburg, RuBland Die Feldstruktur des Sprachsystems

19.09.95 Prof. Feng Zhiwei, Universität Peking, China Language Resources and Language Engineering in China

18.10.95 Yoshihisa Yamada, Gifu Keizai Universität, Japan Grimm-Database

26.10.95 Prof. Dr. Inger Rosengren, Universität Lund, Schweden Gibt es ein Subjekt im Imperativsatz?

08.11.95 Prof. Dr. Inger Rosengren, Universität Lund, Schweden Konzeptuelle Struktur und Grammatik.

Am Beispiel der Lokativalternation

23.11.95 Prof. Dr. Inger Rosengren, Universität Lund mit Prof. Dr. Marga Reis, Universität Tübingen Fokus, Skopus und Informationsstruktur

06.12.95 Prof. Dr. Inger Rosengren, Universität Lund mit Prof. Dr. Marga Reis, Universität Tübingen Die „freie" Wortstellung im Deutschen

3. Lehraufträge und Vorträge von IDS-Mitarbeitern außerhalb des Instituts

\subsection{Lehraufträge von IDS-Mitarbeitern}

Prof. Dr. Joachim Ballweg: SS 1995, Logik für Linguisten I, Proseminar, Universität Stuttgart

Wortfeldtheorie, Hauptseminar, Universität Stuttgart

WS 1995/96, Logik für Linguisten II: Tempus, Proseminar, Universität, Stuttgart

Determinative im Deutschen, Hauptseminar, Universität Stuttgart

Dr. Karl-Heinz Bausch: SS 1995, Dialekt und Schule, Seminar, Pädagogische Hochschule Heidelberg 
WS 1995/96, Dialekt und Schule, Seminar, Pädagogische Hochschule Heidelberg

Priv.Doz. Dr. Bernd Ulrich Biere: SS 1995, Textverstehen und Textverständlichkeit, Vorlesung, RWTH Aachen

Kolloquium für Examenskandidaten, RWTH Aachen

Jugendsprache, Hauptseminar, Pädagogische Hochschule Heidelberg

WS 1995/96, Jugendsprache, Hauptseminar, RWTH Aachen

Dr. Elke Donalies: SS 1995, Gebt die Wortbildung frei! - Einführung in die Wortbildung, Proseminar, Universität Mannheim

Prof. Dr. Reinhard Fiehler: SS 1995, Grammatische Besonderheiten gesprochener Sprache, Seminar, Universität Bielefeld

WS 1995/96, Kommunikation im Unternehmen, Seminar, Universität Mannheim

Prof. Dr. Gisela Harras: WS/SS 1995/96, Schrift und Schriftlichkeit, Kolloquium, Universität Mannheim

Priv. Doz. Dr. Ulrike Haß-Zumkehr: SS 1995, Wissenschaftsgeschichte der Germanistik im 19. Jahrhundert, Hauptseminar, Universität Heidelberg

WS 1995/96, Zeitung lesen - gestern und heute. Lexik, Syntax und Pragmatik von Zeitungen des 17. bis 20. Jahrhunderts, Hauptseminar, Universität Heidelberg

Prof. Dr. Werner Kallmeyer: SS 1995, Soziolinguistik und Ethnographie, Vorlesung, Universität Mannheim

WS 1995/96, Ethnographie der Kommunikation, Hauptseminar, Universität Mannheim

Dr. Heidrun Kämper-Jensen: SS 1995, Historische Semantik und Lexikographie, Proseminar II, Universität Mannheim, TH Darmstadt WS 1995/96, Linguistische Analyse literarischer Texte, Proseminar II, TH Darmstadt

Dr. Inken Keim-Zingelmann: WS 1994/95, Stereotyp und Vorurteil in der interkulturellen Kommunikation, Hauptseminar, PH Heidelberg

WS 1994/95, Kommunikative soziale Stile, Forschungsseminar, Universität Saarbrücken

WS 1995/96, Kulturell gebundene Höflichkeitskonzepte und ihre sprachliche Realisierung, Proseminar, Universität Mannheim

Priv.Doz. Dr. Katharina Meng: SS 1995, Kindersprache II: Fragen und Antworten im Erwachsenen-Kind-Diskurs, Hauptseminar, Universität Mannheim 
WS 1995/96, Sprachbiographie und Migration, Hauptseminar, Universität Mannheim

Dipl. rer. pol. Pantelis Nikitopoulos: SS 1995, Interkulturelle Kommunikation und Binnendifferenzierung im Unterricht der Regelklasse, Seminar, PH Heidelberg

WS 1995/96, Interkulturelle Kommunikation und Binnendifferenzierung im Unterricht der Regelklasse, Seminar, PH Heidelberg

Prof. Dr. Joachim Schildt: WS 1995/96, Historische Textsorten des Deutschen in frühneuhochdeutscher Zeit (1350-1650). Texttypologie und Sprachwandel, Seminar, Universität Mannheim

Dr. Rudolf Schmidt: SS 1995, Digitale Bild- und Sprachverarbeitung, Vorlesung, Berufsakademie Mannheim

WS 1995/96, Digitale Bildverarbeitung und Mustererkennung, Vorlesung, Universität Mannheim

Dr. Peter Schröder: SS 1995, Fri skriftlig produksjon, Seminar, Høyskolen i Østfold (Halden/Norwegen)

Dr. Wilfried Schütte: WS 1995/96, Gesprächsanalyse zur medienvermittelten Kommunikation, Seminar, Universität Koblenz-Landau, Abt. Landau

Dr. Carmen Spiegel: WS 95/96, Sprache und Sprechen in der Umweltdiskussion, Hauptseminar, PH Heidelberg

Prof. Dr. Gerhard Stickel: WS 1995/96, Deutsch im Vergleich, Hauptseminar, Universität Mannheim

Dr. Angelika Storrer: SS 1995, Die Wortarten des Deutschen, Proseminar, Universität Heidelberg

WS 1995/96, Text und Hypertext, Proseminar, Universität Hejdelberg

Theoretische und angewandte Valenzforschung, Hauptseminar, Institut für Deutsch als Fremdsprachenphilologie, Universität Heidelberg

Prof. Dr. Bruno Strecker: WS 1995/96, Deutsche Grammatik für Sprecher, Hauptseminar, Universität Augsburg

\subsection{Kurse und Kurzseminare von IDS-Mitarbeitern}

Katrin Bischl, M.A.: 26.10--19.12.1995, Journalistisches Schreiben, Kurs im Bereich Erwachsenenbildung, Volkshochschule Heidelberg

Helmut Frosch: 15.-26.5.1995, Kompaktseminar „Intensionale Logik” am germanistischen Institut der Lajos-Kossuth-Universität Debrecen, Ungarn (Pro renovanda cultura Hungariae-Stiftung)

Prof. Dr. Gisela Harras: 1.1.-30.4.1995, Gastprofessur University of Florida, Gainesville/Fl., USA 
Dr. Klaus Heller: 23.11.1995, 2 Workshops auf dem 3. Berliner Sekretärinnen-Tag

Dr. Manfred W. Hellmann: 18.09.1995, Sprache und Verständigung in Deutschland nach der Vereinigung - Brücke oder Hindernis?, Kurzseminar: Internationaler Sommerkurs für deutsche Sprache und Kultur, Universität Mannheim

Prof. Dr. Werner Kallmeyer: 18.-26.8.1995, Abteilung Linguistik der Wirtschaftsuniversität Helsinki, Finnland (Wirtschaftsuniversität Helsinki)

Dr. Inken Keim: 15.9.-15.10.1995, Gastdozentur an der Universität Jerewan, Armenien (DAAD)

Prof. Dr. Wolfgang Motsch: 24.4.-24.5.1995, Germanistisches Institut der Universität Belgrad, Jugoslawien (DAAD)

Ulrich Reitemeier: 5/95-12/95, Soziologie für Logopäden, Deuser-Schule, Ludwigshafen

Dr. Reinhold Schmitt: 23.6.1995, Kommunikationstraining für Sekretärinnen, GKW-INGENIEURE, Mannheim

Dr. Peter Schröder: 10.-13.10.95, Einführung in die gesprochene Sprache, Gastseminar im Rahmen der Unterrichtsveranstaltung „Muntlig forretningskommunikasjon" Hoyskolen i Østfold (Halden/Norwegen)

Dr. Angelika Storrer mit Roman Schneider: 5.-7.4.1995 Poster und Systemdemonstration des Prototypen GRAMMIS-1 auf der HIM 95 (Conference Hypertext - Information Retrieval - Multimedia), Universität Konstanz

26.6.1995, Kurzseminar zu: Grammatiklernen mit Hypermedia, Studentische Sommeruniversität der Erziehungswissenschaftlichen Hochschule Koblenz-Landau

Helmut Schumacher: 22.-24.6.1995, Internationales Symposium Lexikalische Analyse romanischer Sprachen: Methodische Neuansätze, Universität Heidelberg (Gastgeber-Universität)

Dr. Edeltraut Winkler mit Prof. Dr. Gisela Harras: 29.11.95, Semantik von Sprechaktverben aus unterschiedlichen Perspektiven, Workshop, IDS Mannheim

\subsection{Vorträge von IDS-Mitarbeitern}

Dr. Joachim Ballweg: 7.2.1995, Kategorialgrammatik und Wortstellung, IDS-Kolloquium, Mannheim

18.5.1995, Quantorenfloating - Nein Danke!!, Stuttgart 
4.11.1995, Determinative und gleichlautende Proterme, Lyon (im Rahmen der Tagung „Proformen” zur Vorbereitung der Agregation, 3./4.11.)

Karl-Heinz Bausch: 17.3.1995, Zur Auswertung von DSAv-Aufnahmen unter dem Aspekt „Sprachwandel”, IDS Mannheim

23.9.1995, Variation eines Themas - oder: wie erzählt man wem eine Story?, Sprachliche Varianz als Ergebnis von Handlungswahl, Sonderforschungsbereich 245, Universität Heidelberg

Cyril Belica: 7.6.1995, Statistische Analyse zeitrelevanter Sprachstrukturen in Korpora, Tagung des Arbeitskreises „Korpora” der GLDV, Universität Stuttgart

26.7.1995, Statistische Kollokationsanalyse, Kolloquium „Entwicklungen in der Korpuslinguistik: Ein neuer Korpusbegriff und seine Methoden", Mannheim

Dr. Nina Berend: 4.2.1995, Varietätenwandel in der Integrationsphase, Graduiertenkolleg Dynamik von Substandardvarietäten, Universität Heidelberg

Priv. Doz. Dr. Bernd-Ulrich Biere: 24.6.1995, Boulevardisierung von Wissenschaft 2, Kolloquium der Kommission für Fragen der Sprachentwicklung, IDS Mannheim

13.9.1995 Textverstehen - Vom hermeneutischen zum kognitivistischen Paradigma, 30. Linguistisches Kolloquium Universität Gdansk/ Danzig (Polen)

Jarochna Dabrowska: 10.-12.4.1995, Sprachliche Stereotype über Polen in einem deutschen Zeitungstext (1980), eine Textanalyse, Universität Bielefeld

Dr. Mechthild Elstermann: 10.-12.4.1995, Vorstellung des IDS-Projekts "Deutsche und Polen im Kontakt" und Leitung eines Work-shops zum Thema "Asymmetrien im deutsch-polnischen Verhältnis” im Rahmen des Kolloquiums „Polnisch-deutsche interkulturelle Kommunikation" am Zentrum für interdisziplinäre Forschung Bielefeld

Dr. Claudia Fraas: 29.9.95, Bedeutungskonstitution im Diskurs - Intertextualität über variierende Wiederaufnahme diskursiv zentraler Konzepte, Jahrestagung der Gesellschaft für Angewandte Linguistik, Kassel

IJelrnut Frosch: 22.5.1995, Appositive und restriktive Relativsätze im Deutschen, Germanistisches Institut der Lajos-Kossut-Universität Debrecen (Ungarn)

18.7.1995, Der Relativsatz im Deutschen, IDS-Kolloquium

Priv. Doz. Dr. Hartmut Günther: 8.6.1995, Von A bis Z - Zu Geschichte und Funktionsweise alphabetischen Sortierens, Germanistisches Institut der Universität Innsbruck 
13.6.1995, Von A bis Z - Zu Geschichte und Funktionsweise alphabetischen Sortierens, IDS Mannheim

Prof. Dr. Gisela Harras: 2.2.1995, Sinn und Unsinn einer Reform der deutschen Rechtschreibung, University of Florida, Gainesville, FI./USA

18.3.1995, Informationsstrukturen deutscher und englischer Sätze, Goethe-Institut Atlanta, Ga./USA

4.7.1995, Meinen wir, was wir sagen oder sagen wir, was wir meinen?, Technische Hochschule Darmstadt

3.11.1995: Bedeutung 2 wischen Intention und Konvention. Symposium: Bedeutung - Konzepte - Bedeutungskonzepte. WernerReimers-Stiftung, Bad Homburg

29.11.1995, zusammen mit Edeltraut Winkler: Sprechakte und Sprechaktverben, Workshop: Semantik von Sprechaktverben aus unterschiedlichen Perspektiven, IDS Mannheim

Priv. Doz. Dr. Ulrike Haß-Zumkehr: 28.6.1995, „alle Welt erwartet hier eine Erklärung von mir", Jacob Grimms Vorrede zum Deutschen Wörterbuch zwischen Apologie und Programm. Zur Historiographie der germanistischen Sprachwissenschaft, Antrittsvorlesung vor der Neuphilologischen Fakultät der Universität Heidelberg 21.-22.9.1995, Aufgeklärte Germanistik im 19. Jahrhundert, Vortrag auf dem IX. Internationalen Kolloquium des Studienkreises 'Geschichte der Sprachwissenschaft', Universität Trier

Dr. Klaus Heller: 1.2.1995, Die geplante Rechtschreibreform, Wo liegen die Probleme?, Goethe-Institut Mannheim

2.2.1995, Der Schikoree im Frigidär, Die Neuregelung der deutschen Rechtschreibung, Interschul: Schulbuch Forum 95 Hannover (gemeinsam mit H. Zimmermann, Saarbrücken)

9.3.1995, Die Reform der deutschen Rechtschreibung und ihre informationstechnischen Auswirkungen, Cebit 95 Hannover

29.3.1995, Die Reform der deutschen Orthographie, Hintergründe und Auswirkungen, Berufsbildende Schule "Wirtschaft II", Ludwigshafen

19.5.1995, Deutsch für Inländer - Konsequenzen der Rechtschreibreform, PR-Treff 95 des Trurnit-Verlages München

1.6.1995, Das Känguru frißt Schikoree. Müssen wir neu schreiben lernen? (Eröffnungsveranstaltung des Zweiges Göttingen der Gesellschaft für deutsche Sprache), Göttingen

10.6.1995, Das Känguru frißt Schikoree. Die Neuregelung der deutschen Rechtschreibung (Polenzer Gesprächskreis), Polenz/Sachsen 14.6.1995, Reform der Fremdwortorthographie oder Linguistik ist nicht alles, Institut für Germanistik der Universität Leipzig 
13.7.1995, Die Reform der deutschen Orthographie, Hintergründe und Auswirkungen, Lektorensommertreffen des DAAD, Bonn 4.09.1995, Zur geplanten Rechtschreibreform im Deutschen, Hintergründe, Stand und Auswirkungen, (Zentrales Seminar des Goethe-Instituts München), Mannheim

6.11.1995, Rechtschreibreform - Sprachfrevel oder Sprachpflege (Treffpunkt Klett), Frankfurt/M.

11.11.1995, Rechtschreibreform - Chance oder Katastrophe, Jahrestagung Verein Hochdeutsch in der Schweiz (VHS), Olten/Schweiz

15.11.1995, Rechtschreibreform - Sprachfrevel oder Sprachpflege, (Treffpunkt Klett), Düsseldorf

23.11.1995, Rechtschreibreform - Änderungen, die Sie kennen müssen, (3. Berliner Sekretärinnen-Tag), Berlin

27.11.1995, Zur geplanten Rechtschreibreform des Deutschen Frißt das Känguru Schikoree?, Brüssel

30.11.1995, Rechtschreibreform - Bruch mit der Schreibkultur oder recht verstandene Sprachpflege? (Festvortrag zum 20jährigen Bestehen der DSV-Arbeitsgemeinschaft), Frankfurt/M.

12.12.1995, Rechtschreibreform, Müssen wir neu schreiben lernen?, Walldorf

Dr. Manfred W. Hellmann: 27.1.1995, Lexikographische Erschließung des Wendekorpus - Ein Werkstattbericht, Arbeitskreis Lexikographie der GLDV: Theorie der Semantik und Theorie der Lexikographie - Angewandte Semantik und Praxis der Lexikographie, Institut für Kommunikationsforschung und Phonetik, Universität Bonn 14.2.1995, Trennung und Vereinigung - Folgen der Wende für Sprache und Verständigung der Deutschen, Hermann-EhlersAkademie, Kiel

15.2.1995, Lexikographische Erschließung des Wendekorpus Ziele, Methoden, Probleme (Werkstattbericht), Universität Kiel, 25.6.1995, „Falsche Wörter”? Wortschatz, Vorurteile und Verständigungsprobleme in der deutsch-deutschen Kommunikation nach der Wende, Twenty-first New Hampshire Symposium, World Fellowhip Center, Conway: „Who's 'We'? The Identity Dispute in the New German States Five Years after Unification", Conway, N.H., USA

Dr. Irmtraud Jüttner: 3.5.1995, Das Computersystem COSMAS und seine praktische Anwendung, Forschungsschwerpunkt Allgemeine Sprachwissenschaft, Typologie und Universalienforschung, Berlin 
7.11.1995, Kollokationsanalyse mit COSMAS, 5. Workshop: Studie Sprachstrukturen, MEDAV Digitale Signalverarbeitung GmbH, IDS Mannheim

Prof. Dr. Werner Kallmeyer: 23.9.95, Sprachvariation, soziostilistische Divergenz und Konfliktdynamik. Dargestellt am Material aus dem Mannheimer Projekt „Kommunikation in der Stadt”, Kolloquium „Sprachliche Varianz als Ergebnis von Handlungswahl”, SFB 245 "Sprechen und Situation", Oberflockenbach.

14.12.95, Was bedeutet Ethnographie des Sprechens für die neuere Soziolinguistik?, Germanistisches Seminar. Universität Würzburg 18.12.95, Perspektivität im Diskurs, Fachbereich Germanistik, Freie Universität Berlin

Dr. Heidrun Kämper-Jensen: 29.6.1995, Sprachwandel nach 1945, Heinrich Heine Universität, Düsseldorf

25.11.1995, Die frühere Nachkriegszeit - Texte und Wörter 1945 bis 1955, TU Braunschweig

Dr. Barbara Kraft: 08.12.1995, "sicher das is n ziemlich wichtiger punkt” - Zur grammatischen und interaktionellen Funktion topologisch nicht integrierter „Adverbiale”, Satz- und textgrammatische Kategorien und die Beschreibung mündlicher Kommunikation. Übernahme - Rekonstruktion - Erweiterung, IDS Mannheim, Abt. Gesprochene Sprache

Dr. Wolf-Andreas Liebert: 24.1.1995, Sprachreflexion und Innovation, Universität Hamburg

5.-7.4.1995, Hypermedia als mentale Werkzeuge, HIM '95, Konstanz

18.7.1995, Principles of Expansion and Adaption in Metaphorical Reasoning. A Model of Source-to-Target and Target-to-Source Dynamics in Creative Thinking. 4th International Cognitive Linguistics Conference, 16.-21.7.1995, Albuquerque

Priv. Doz. Dr. Katharina Meng: 5.9.1995, Thematische Akte, deutsch und russisch, Tagung: Sprachliche Integration von deutschen Aussiedlern aus Ost- und Ostmitteleuropa in der Bundesrepublik Deutschland, Europa-Universität Viadrina, Fakultät für Kulturwissenschaften, Arbeitsstelle Deutsch als Minderheitensprache, Angelenhof bei Frankfurt/Oder

Prof. Dr. Wolfgang Motsch: 16.6.1995, Sprachliche und kommunikative Aspekte von Sprechakten, Germanistische Seminar der Universität Hamburg

13.11.1995, Was muß man wissen, um Wortbildungen zu verstehen?, Philologische Fakultät der Universität Belgrad 
13.11.1995, Der Streit um die deutsche Orthographie, GoetheInstitut Belgrad

Robert Neumann: 7.3.1995, Konzept zu einer computativen, korpusbasierten Lexikographie, Paris 7 LADL

3.5.1995, COSMAS - Theorie und Praxis, FU Berlin

1.6.1995, Linguistik mit COSMAS, Universität Tromsö

6.6.1995, Linguistik mit COSMAS, Universität Trondheim

Prof. Dr. Hartmut Schmidt: 27.6.1995, Das Fremdwortproblem in der historischen Lexikographie, Universität Frankfurt/M.

Dr. Rudolf Schmidt: 24.10.1995, Anwendung formaler Sprachen in der maschinellen Spracherkennung, FH Worms

Dr. Reinhold Schmitt: 12.4.1995, „Ich werde Sie sehen lassen” oder Über die Möglichkeiten interaktiver Kulturvermittlung, Zentrum für interdisziplinäre Forschung, Universität Bielefeld

29.5.1995, Probleme interkultureller Kommunikation, Am Beispiel des polnisch-deutschen Kontaktes, Universität GieBen

27.6.1995, Vorsicht Hilfe! Unterstützende Verfahren im Gespräch, Universität Bielefeld

Roman Schneider (zusammen mit Dr. Angelika Storrer): 12.7. 1995: Die Grammatik mit der Maus. Konzeption und Realisierung eines grammatischen Informationssystems mit dem Autorensystem "Toolbook", Fachbereich Informationswissenschaft der Universität Konstanz

Dr. Peter Schröder: 27./28.2.1995, Vortrag und Kolloquium „zunächst mal- * die sache ist noch sehr komplex - 'Operator-Skopus'Strukturen in mündlicher Kommunikation im heutigen Deutsch", Halden/Norwegen

15.5.1995, Vortrag und Kolloquium „Zur linken und rechten Grenze deutscher Sätze. Oder: Überlegungen zur Segmentierung des Äußerungskontinuums in gesprochener Sprache", Halden/Norwegen

Dr. Carmen Spiegel: 23.2.1995, Gesprächsanalystisches Arbeiten unter der Lupe, Arbeitstagung Neuere Entwicklungen in der Gesprächsforschung, Graduiertenkolleg „Mündlichkeit und Schriftlichkeit”, Freiburg

3.11.95, „Bedeutungskonstitution im Dialog - die Geschichte eines Ledersofas", Bedeutung - Konzept - Bedeutungskonzepte, Werner-Reimers-Stiftung, Bad Homburg

Prof. Dr. Gerhard Stickel: 3.3.1995, Tendenzen der deutschen Gegenwartssprache, Deutsches Institut für Normung (DIN) (Innovationenmesse Leipzig) 
23.5.1995, Meinungen zur deutschen Gegenwartssprache, Universität Leipzig

23.5.1995, Was steht uns orthographisch bevor?, Universität Leipzig/Gesellschaft für dt. Sprache

25.5.1995, Tendenzen in der Entwicklung der deutschen Gegenwartssprache, Universität Danzig

Dr. Angelika Storrer: 31.3.1995, Das grammatische Informationssystem GRAMMIS, GLDV-Tagung, Regensburg

(zusammen mit Roman Schneider) 26.6.1995, Grundlagen eines grammatischen Informationssystems, Studentische Sommeruni Koblenz

(zusammen mit Roman Schneider) 12.7.1995, Entwicklung eines grammatischen Informationssystems - das Projekt GRAMMIS, Fachbereich Informationswissenschaft an der Universität Konstanz

3.11.1995, Verbbedeutung und Argumentstruktur, Symposium, Bedeutung - Konzepte - Bedeutungskonzepte; 2.-4. November 1995, Werner-Reimers-Stiftung, Bad Homburg

27.11.1995, Die Grammatik mit der Maus, Anglistisches Seminar der Universität Tübingen

Dr. Gerhard StrauB: 2.11.1995, Thema: Wort - Bedeutung - Begriff: Relationen und ihre Geschichte, Werner-Reimers-Stiftung, Bad Homburg

Dr. Wolfgang Teubert: 4.4.1995, Language Resources: The European Scenario, State Language Commission, Peking, China

5.4.1995, The Challenge of Parallel Corpora, Department of Computer Science, Universität Peking (Beida), China

6.4.1995, Terminology Work and the Corpus, Chinese Encyclopedia, Peking

14.4.1995, (1) Language Resources - The European Scenario, (2) The Challenge of Parallel Corpora, (3) Neologisms and the Corpus, Dept. of Computer Science and Engineering, Jiao Tong Universität Shanghai

15.09.1995, TELRI and the European Language Resources Market, TELRI European Seminar: Language Resources for Language Technology, Tihany, Ungarn

10.11.1995, Language Resources for Language Technology, Workshop: Integration and Speech, 9.-11. November 1995, Moskau, Rußland

8.12.1995, Post-Socialist Language, Conference: Political Linguistics, 7.-9. Dezember 1995, Antwerpen, Belgien 
Doris al-Wadi mit Cyril Belica: 10.8.1995, Documentation of Corpora, im Rahmen des Abschlußtreffens zum EU-Projekt MECOLB (Multilingual Environment for Corpus-Based Lexicon Building), IDS Mannheim

15.9.1995, Statistischer Zugriff auf Korpora: Ein Arbeitsumfeld, im Rahmen der GLDV-Herbstschule '95 mit dem Thema: Moderne Methoden der Corpusanalyse, Institut für Kommunikationsforschung und Phonetik der Universität Bonn

Dr. Peter Wagener: 29.1.1995, Digital Instead of Analogue. Experiences with the Modernization of the "Deutsches Spracharchiv". Joint Technical Symposium 95, London

17.3.1995, Die Pilotstudie zum Projekt „Sprach- und Sprachgebrauchswandel im gesprochenen Deutsch", 2. Expertengespräch des Deutschen Spracharchivs, Mannheim

15.8.1995, Sprach- und Sprachgebrauchswandel im gesprochenen Gegenwartsdeutsch, IVG-Kongreß, Vancouver

21.1.1993, Zur Konzeption einer erklärenden Synonymik kommunikativer Ausdrücke des Deutschen (gemeinsam mit Prof. G. Harras), Heidelberger Kolloquium zur Lexikographie und Lexikologie 18.3.1993, Die Darstellbarkeit lexikalischen Wissens - am Beispiel kommunikativer Ausdrücke des Deutschen, IDS-Jahrestagung Mannheim

3.9.1994, A Model for Describing Speech Act Verbs. The Semantic Base of a Polyfunctional Dictionary (zusammen mit Prof. G. Harras), 6. EURALEX Jahrestagung Amsterdam

3.11.95: Kommunikationskonzepte und Kommunikationsverben, Tagung: Bedeutung - Konzepte - Bedeutungskonzepte, WernerReimers-Stiftung, Bad Homburg

Dr. Ricarda Wolf: 17.2.1995, Zum Zusammenhang von Kategorisierungsund Interaktionsdynamik in einem Gespräch zwischen ost- und westdeutschen Frauen, Freie Universität Berlin

5.4.1995, Interaktive Fallen auf dem Weg zur deutschen Einheit, 27. KongreB der Deutschen Gesellschaft für Soziologie, Sektion Sprachsoziologie, Halle 10.-12.4.1995, Zur unvermeidlichen Präsenz stereotyper Orientierungen im interkulturellen Kontakt, olloquium „Polnisch-deutsche interkulturelle Kommunikation”, Zentrum für interdisziplinäre Forschung der Universität Bielefeld (ZIF)

18.4.1995, Zur Rolle von Intonationsmustern beim Formulieren im Gespräch, Technische Universität Berlin

11.7.1995, Zu einigen Asymmetrien in Gesprächen zwischen Ostund Westdeutschen, Universität Würzburg 


\section{Publikationen von IDS-Mitarbeitern}

\section{Ballweg, Joachim}

Ballweg, Joachim (1995): Allgemeingültige Sätze - eine Herausforderung an die Prototypensemantik. In: Harras, Gisela (Hg.): Die Ordnung der Wörter. Kognitive und lexikalische Strukturen. Berlin/New York. S. 271-288. (Jahrbuch 1993 des Instituts für deutsche Sprache).

Ballweg, Joachim (1995): Was sind „zugelassene Antworten”? Notizen aus dem Bermuda-Dreieck zwischen Semantik, Pragmatik und Interaktion. In: Schecker, Michael ( $\mathrm{Hg}$.): Fragen und Fragesätze im Deutschen. Tübingen. S. 63-70.

\section{Bausch, Karl-Heinz}

Bausch, Karl-Heinz (1995): Auskünfte über Mannheim. Textausschnitte aus ethnographischen Interviews. In: Kallmeyer, Werner (Hg.): Kommunikation in der Stadt. Teil 2. Ethnographien von Mannheimer Stadtteilen. Berlin/New York. S. 344-511. (Schriften des Instituts für deutsche Sprache 4.2).

Bausch, Karl-Heinz (1995): Das Herstellen lokaler Identität in der Kommunikation - am Beispiel eines Stadtteils in einer Großstadt. In: Werlen, Iwar ( $\mathrm{Hg}$.): Verbale Kommunikation in der Stadt. Tübingen. S. 39-65. (Tübinger Beiträge zur Linguistik 407).

\section{Berend, Nina}

Berend, Nina (1995): „Des is arich intresting”. Deutsch im Kontakt mit anderen Sprachen. In: Sprachreport 2/95, S. 1-3.

Berend, Nina und Autorenkollektiv (1995): Gegen den Abbau von Sprachforderungsmaßnahmen - Mannheimer Appell. In: Deutsch lernen 1 , S. 78-81.

\section{Biere, Bernd Ulrich}

Biere, Bernd Ulrich (1995): Die Bedeutung der Mündlichkeit in Verstehenstheorie und Verständlichkeitsforschung. In: Spillner, Bernd (Hg.): Sprache: Verstehen und Verständlichkeit. Kongreßbeiträge der 25. Jahrestagung der Gesellschaft für Angewandte Linguistik (GAL e.V.), Trier 1994. Bern/Berlin/Frankfurt. S. 83-85.

Biere, Bernd Ulrich/Hoberg, Rudolf (Hg.) (1995): Bewertungskriterien in der Sprachberatung. Tübingen. (Studien zur deutschen Sprache 2). 
Biere, Bernd Ulrich (1995): Germanistik und Öffentlichkeit. In: Jäger, Ludwig (Hg.): Germanistik. Disziplinäre Einheit und kulturelle Identität. Vorträge des Aachener Germanistentags 1994. Weinheim. S. 105-120.

Biere, Bernd Ulrich (1995): Verständlichkeitsforschung und Angewandte Linguistik. In: Bulletin suisse de linguistique appliquée, S. 155170.

\section{Bischl, Katrin}

Bischl, Katrin (1995): Boulevardisierung: Gesucht und kaum gefunden. Experten-Kolloquium. In: Sprachreport 3/95, S. 19.

\section{Dabrowska, Jarochna}

Dabrowska, Jarochna (1995): Polen in der deutschen Presse. In: Sprachreport 3/95, S. 1-4.

\section{Danilejko, Sabine}

Danilejko, Sabine (1995): Typologisches Porträt des Deutschen. Tagungsbericht. In: Sprachreport 2/95, S. 11.

\section{Donalies, Elke}

Deutsches Fremdwörterbuch (1995): Begonnen von Hans Schulz, fortgeführt von Otto Basler, völlig neu bearbeitet im Institut für deutsche Sprache von Gerhard Strauß, Elke Donalies, Heidrun Kämper-Jensen, Isolde Nortmeyer, Joachim Schildt, Rosemarie Schnerrer, Oda Vietze. Bd. I: a-Präfix - Antike. Berlin/New York. XVII, 52*, $615 \mathrm{~S}$.

\section{Fiehler, Reinhard}

Fiehler, Reinhard: Implizite und explizite Bewertungsgrundlagen für kommunikatives Verhalten in betrieblichen Kommunikationstrainings. In: Biere, Bernd Ulrich/Hoberg, Rudolf (Hg.): Bewertungskriterien in der Sprachberatung. Tübingen. S. 110-131. (Studien zur deutschen Sprache 2).

Fiehler, Reinhard (1995): Kann man Kommunikation lehren? Zur Veränderbarkeit von Kommunikationsverhalten durch Kommunikationstraining. In: Finlance. A Finnish Journal of Applied Linguistics XV, S. 137-156.

Fiehler, Reinhard (1995): Kommunikationsanalyse an der Fakultät für Linguistik und Literaturwissenschaft der Universität Bielefeld. In: 
Fiehler, Reinhard/Metzing, D. (Hg.): Untersuchungen zur Kommunikationsstruktur. Bielefeld. S. 9-20. (Bielefelder Schriften zu Linguistik und Literaturwissenschaft 5).

Fiehler, Reinhard (1995): Perspektiven und Grenzen der Anwendung von Kommunikationsanalyse. In: Fiehler, Reinhard/Metzing, D. (Hg.): Untersuchungen zur Kommunikationsstruktur. Bielefeld. S. 119138. (Bielefelder Schriften zu Linguistik und Literaturwissenschaft $5)$.

Fiehler, Reinhard/Metzing, D. (Hg.) (1995): Untersuchungen zur Kommunikationsstruktur. Bielefeld. (Bielefelder Schriften zu Linguistik und Literaturwissenschaft 5).

Fiehler, Reinhard (1995): Wandel der Kommunikationsgemeinschaft? Medienrevolution! In: Ethik und Sozialwissenschaften 5/4, S. 524526.

Fiehler, Reinhard (1995): Weichenstellungen der Sprachwissenschaft und ihre Folgen oder: Zum Verhältnis von Grammatik und Pragmatik. In: Kertész, A. (Hg.): Sprache als Kognition - Sprache als Interaktion. Studien zum Grammatik-Pragmatik-Verhältnis. Frankfurt a.M. S. 19-58.

Fiehler, Reinhard (1995): Die Wiedervereinigung als Kulturberührung. Ausarbeitung von wechselseitigen Kategorisierungen und von Beziehungsmodellen im massenmedialen deutsch-deutschen Diskurs. In: Czyzewsky, Marek/Gülich, Elisabeth/Hausendorf, Heiko/ Kastner, Mary (Hg.): Nationale Selbst- und Fremdbilder im Gespräch. Kommunikative Prozesse nach der Wiedervereinigung Deutschlands und dem Systemwandel in Ostmitteleuropa. Opladen. S. 328-347.

Fiehler, Reinhard (1995): Zur allmählichen Verfertigung der Aneignung beim Sprechen. Der deutsch-deutsche Diskurs in Publikumssendungen des Fernsehens zu Zeiten der Wiedervereinigung. In: Wodak, R./Kirsch, P. (Hg.); Totalitäre Sprache - Langue de bois Language of Dictatorship. Wien. S. 151-171.

\section{Fraas, Claudia}

Fraas, Claudia (1995): Communication Conflicts against the Background of Contrasting Experiences. Beitrag für die Datenbank "Linguistics and Language Behavior Abstracts", San Diego (USA) (verfügbar als CD-ROM, gedruckt und online).

Fraas, Claudia (1995): Die Deutschen nach der Vereinigung. Begriffsgeschichte und Gebrauchswandel eines Reizwortes. In: Sprachreport $4 / 95$, S. $7-11$. 
Fraas, Claudia (1995): Sprache und Kommunikation nach der Wende Konflikte und Tendenzen. In: Mitteldeutsches Jahrbuch für Kultur und Geschichte 2/1995 (Stiftung Mitteldeutscher Kulturrat). S. 221-229.

\section{Freese, Katrin}

Freese, Katrin (Bearb.) (1995): Dokumentation zur Germanistischen Sprachwissenschaft. Sprachwissenschaftliche Forschungsvorhaben 1993/1994. Hg. vom Institut für deutsche Sprache. Mannheim. $615 \mathrm{~S}$.

\section{Frosch, Helmut}

Frosch, Helmut (1995): Montague and Categorial Grammar. In: Verschueren, Jef/Östman, Jan-Ola/Blommaert, Jan (Hg.): Handbook of Pragmatics: Manual. Amsterdam/Philadelphia. S. 384-390.

\section{Günther, Hartmut}

Günther, Hartmut (1995): Die Grammatik der Schrift und die Schrift der Grammatik - Einige Thesen. In: Die Grundschulzeitschrift $4 / 1995$.

Günther, Hartmut (1995): IDS - was ist das? In: Sprachreport 3/95, S. 20.

Günther, Hartmut (1995): Die Schrift als Modell der Lautsprache. In: Ossner, Jakob (Hg.): Schriftaneignung und Schreiben. S. 15-32. (Osnabrücker Beiträge zur Sprachtheorie 51).

\section{Harras, Gisela}

Harras, Gisela (1995): Eine Möglichkeit der kontrastiven Analyse von Kommunikationsverben. In: Kaer, A. (Hg.): Aspekte der kontrastiven Lexikologie. Tübingen.

Harras, Gisela (Hg.) (1995): Die Ordnung der Wörter. Kognitive und lexikalische Strukturen. Berlin/New York. (Jahrbuch 1993 des Instituts für deutsche Sprache.)

\section{Haß-Zumkehr, Ulrike}

Haß-Zumkehr, Ulrike (1995): Daniel Sanders. Aufgeklärte Germanistik im 19. Jahrhundert. Berlin/New York. (Studia Linguistica Germanica 35).

Haß-Zumkehr, Ulrike (1995): Daniel Sanders - Dimensionen demokratischen Wirkens vor und nach 1848. In: Modernisierung und 
Freiheit. Beiträge zur Demokratiegeschichte in MecklenburgVorpommern. Hg. vom Innenministerium des Landes MecklenburgVorpommern. Red. Michael Heinrichs und Klaus Lüders. Schwerin. S. 340-357.

Haß-Zumkehr, Ulrike (1995): Daniel Sanders und die Historiographie der Germanistik. In: Gardt, Andreas/Mattheier, Klaus J./Reichmann, Oskar (Hg.): Sprachgeschichte des Neuhochdeutschen. Gegenstände, Methoden, Theorien. Tübingen. S. 199-225. (Germanistische Linguistik).

\section{Heller, Klaus}

Heller, Klaus (1995): Brief an die Herausgeber zu den vorgelegten Neuregelungsvorschlägen zur deutschen Rechtschreibung. In: Zeitschrift für germanistische Linguistik 3, S. 324-325.

Heller, Klaus (1995): [Redaktion und Koordination; Mitautor: Regelteil, A: Laut-Buchstaben-Zuordnungen; Wörterverzeichnis (Ausarbeitung über mehrere Fassungen auf der Grundlage einer Materialliste von W. Mentrup)]. Deutsche Rechtschreibung. Regeln und Wörterverzeichnis. Vorlage für die amtliche Regelung. Hg. vom Internationalen Arbeitskreis für Orthographie. Tübingen.

Heller, Klaus (1995): Müssen wir neu schreiben lernen? Die Rechtschreibreform auf einen Blick. In: Jur-PC 3, S. 3036-3045.

Heller, Klaus (1995): Orthographie - Empfehlungen zu behutsamer Reform. In: Spektrum der Wissenschaft 1, S. 106-108.

Heller, Klaus (1995): Portemonnaie oder Portmonee. Rechtschreibreform: Die wichtigsten Änderungen. In: Schule aktuell 2, S. 8-11.

Heller, Klaus (1995): Rechtschreibreform. In: Anhaltspunkte 4, S. 117 119.

Heller, Klaus (1995): Rechtschreibreform. In: Ehlert, Anke (Hg.): Das Wort. Germanistisches Jahrbuch '95. Deutscher Akademischer Austauschdienst. (Bonn/Moskau). S. 218-232.

Heller, Klaus (1995): Rechtschreibreform. Beilage zum Neuen Bertelsmann Taschenlexikon März 1995. (Geleitwort von Dr. Franz Allemann).

Heller, Klaus (1995): Rechtschreibreform. Die wichtigsten Änderungen. In: Journalist 4, S. 65-76.

Heller, Klaus (1995): Rechtschreibung 2000. Die Reform auf einen Blick: Wörterliste der geänderten Schreibungen. Stuttgart/Düsseldorf/ Berlin/Leipzig.

Heller, Klaus (1995): Die Rechtschreibreform auf einen Blick. In: Alfa Rundbrief 10/28 (Frühjahr 1995), S. 15-17. (Kommentar Prof. Dr. Carl Ludwig Neumann). 
Heller, Klaus (1995): Reform der deutschen Rechtschreibung. Die Neuregelung auf einen Blick. Gütersloh. 2. Aufl. 1995.

Heller, Klaus (1995): Statement zum Vortrag auf dem „Schulbuch-Forum '95” in Hannover: „Der Schikoree im Frigidär - Die Neuregelung der deutschen Rechtschreibung". In: Zur pädagogischen Gegenwart \& zur Zukunft des Bildungswesens. Probleme, Divergenzen und Lösungsvorschläge. Eine Dokumentation zum „SchulbuchForum '95'. Hannover, 30.1.-3.2.1995.

Heller, Klaus (1995): Die Vereinfachung war überfällig. Veraltete Rechtschreibung muB den heutigen Erfordernissen angepaßt werden. In: Erziehung und Wissenschaft 2 (16.2.1995), S. 10-11.

Heller, Klaus (1995): Was ändert sich an der deutschen Rechtschreibung? In: Deutsch als Fremdsprache 3, S. 168-176.

Hellmann, Manfred W.

Hellmann, Manfred W. (1995): Wörter der Wendezeit - Dokumentarischlexikographische Erschließung des Wendekorpus. In: Sprachreport $3 / 95$, S. 14-16.

\section{Herberg, Dieter}

Herberg, Dieter (1995): Lexikalischer Wandel 1989/90. Zur Analyse von Schlüsselwörtern der Wendezeit. In: Müller, Oskar/Nerius, Dieter/Schmidt-Radefeld, Jürgen (Hg.): Sprachnormen und Sprachnormwandel in gegenwärtigen europäischen Sprachen. Rostock. (Rostocker Beiträge zur Sprachwissenschaft 1), S. 109-114.

Herberg, Dieter (1995): Rechtsschreibangaben im allgemeinen einsprachigen Wörterbuch. In: Ewald, Petra/Sommerfeldt, Karl-Ernst (Hg.): Beiträge zur Schriftlinguistik. Festschrift zum 60. Geburtstag von Prof. Dr. phil. habil. Dieter Nerius. Frankfurt a. M. S. 147-155 (Sprache - System und Tätigkeit 15).

Herberg, Dieter (1995): Schlüsselwörter der Wendezeit. Ein lexikologischlexikographisches Projekt zur Auswertung des IDS-Wendekorpus. In: Jordanova, Ljubima/Mattheier, Klaus J. (Hg.): Brennpunkte der Soziolinguistik: Deutschland. Sofia. S. 188-197 (in bulgarischer Sprache). (Sociolinguistics 2).

Herberg, Dieter (1995): Der Sprachreport im Urteil der Leserinnen und Leser. In: Sprachreport 1/95, S. 1-2. 


\section{Jüttner, Irmtraud}

Jüttner, Irmtraud (1995): Die deutsche Sprache in der Verfolgung und im Widerstand gegen den Nationalsozialismus 1933 - 1945. In: Sprachreport 3/95, S. 16-18.

Jüttner, Irmtraud (1995): Treffen des Arbeitskreises KORPORA am 21.2.1995 im Institut für deutsche Sprache (IDS), Mannheim Tagungsbericht. In: LDV-Forum, Forum der Gesellschaft für Linguistische Datenverarbeitung GLDV 12/1, S. 88-90.

\section{Kämper-Jensen, Heidrun}

Kämper-Jensen, Heidrun (1995): Auschwitzmythos bedeutet nicht Auschwitzlüge? In: Sprachreport 2/95, S. 4.

Deutsches Fremdwörterbuch (1995): Begonnen von Hans Schulz, fortgeführt von Otto Basler, völlig neu bearbeitet im Institut für deutsche Sprache von Gerhard StrauB, Elke Donalies, Heidrun Kämper-Jensen, Isolde Nortmeyer, Joachim Schildt, Rosemarie Schnerrer, Oda Vietze. Bd. I: a-Präfix - Antike. Berlin/New York. XVII, 52*, $615 \mathrm{~S}$.

Kämper-Jensen, Heidrun (1995): Deutsches Fremdwörterbuch - Bericht aus der Werkstatt II. MiBbrauchte Wörter und ihre Darstellung im allgemeinsprachlichen Wörterbuch. In: Sprachreport 1/95, S. 10-12.

\section{Kallmeyer, Werner}

Kallmeyer, Werner (1995): Ethnographie städtischen Lebens. Zur Einführung in die Stadtteilbeschreibungen. In: Kallmeyer, Werner (Hg.) (1995): Kommunikation in der Stadt. Teil 2: Ethnographien von Mannheimer Stadtteilen. Berlin/New York. S. 1-41. (Schriften des Instituts für deutsche Sprache 4.2).

Kallmeyer, Werner (Hg.) (1995): Kommunikation in der Stadt. Teil 2: Ethnographien von Mannheimer Stadtteilen. Berlin/New York. (Schriften des Instituts für deutsche Sprache 4.2).

Kallmeyer, Werner (1995): Der kommunikative soziale Stil der „kleinen Leute" in der Filsbach. In: Keim, Inken (1995): Kommunikation in der Stadt. Teil 3: Kommunikative Stilistik einer sozialen Welt "kleiner Leute" in der Mannheimer Innenstadt. Mit zwei Beiträgen von Werner Kallmeyer. Berlin/New York. S. 506-523 (Schriften des Instituts für deutsche Sprache. Bd. 4.3).

Kallmeyer, Werner (1995): Vorwort. In: Schwitalla, Johannes: Kommunikation in der Stadt. Teil 4: Kommunikative Stilistik von zwei Sozialwelten in Mannheim-Vogelstang. Berlin. S. XI-XIII. 
Kallmeyer, Werner (1995): Zur Darstellung von kommunikativem sozialem Stil in soziolinguistischen Gruppenporträts. In: Keim, Inken (1995): Kommunikation in der Stadt. Teil 3: Kommunikative Stilistik einer sozialen Welt "kleiner Leute” in der Mannheimer Innenstadt. Mit zwei Beiträgen von Werner Kallmeyer. Berlin/New York. S. 1-25 (Schriften des Instituts für deutsche Sprache. Bd. 4.3).

Kallmeyer, Werner (1995): Zur Kontextualisierung von sozialen Kategorien und Stereotypen in der sprachlichen Interaktion. In: Czyzewsky, Marek/Gülich, Elisabeth/Hausendorf, Heiko/Kastner, Mary (Hg.): Nationale Selbst- und Fremdbilder im Gespräch. Kommunikative Prozesse nach der Wiedervereinigung Deutschlands und dem Systemwandel in Ostmitteleuropa. Opladen. S. 396-401.

\section{Keim, Inken}

Keim, Inken (1995): Kommunikation in der Stadt. Teil 3: Kommunikative Stilistik einer sozialen Welt "kleiner Leute" in der Mannheimer Innenstadt. Mit zwei Beiträgen von Werner Kallmeyer. Berlin/New York. (Schriften des Instituts für deutsche Sprache. Bd. 4.3).

Keim, Inken (1995): Die kultur- und sozialspezifische Verwendung satzwertiger Formeln. In: Hiyoshi-Studien zur Germanistik (Tokyo) 2/1995, S. 66-94.

Keim, Inken (1995): Sprachvariation und soziale Kategorisierung. In: Werlen, Iwar (Hg.): Verbale Kommunikation in der Stadt. Tübingen. S. 159-174. (Tübinger Beiträge zur Linguistik 407).

Keim, Inken (1995): Die westliche Unterstadt. In: Kallmeyer, Werner (Hg.): Kommunikation in der Stadt. Teil 2. Ethnographien von Mannheimer Stadtteilen. Berlin/New York. S. 42-188. (Schriften des Instituts für deutsche Sprache 4.2).

Kinne, Michael

Kinne, Michael (1995): Wir Schnupperkinder. In: Sprachreport 4/95, S. 6 .

\section{Klein, Wolfgang}

Klein, Wolfgang (1995): Schliff durch Rhetorik? Rezension: Rudolf Neumann: Zielwirksam reden. 6. Aufl. Expert-Verlag 1995. 238 S. In: Sprachreport 3/95, S. 11.

Klein, Wolfgang (1995): Schlichten in der Vergleichsbehörde. Die Herbeiführung von Einigung. In: Nothdurft, Werner (Hg.): Schlich- 
tung. Bd. 1. Streit schlichten. Gesprächsanalytische Untersuchungen zu institutionellen Formen konsensueller Konfliktbearbeitung. Berlin/New York. S. 29-133. (Schriften des Instituts für deutsche Sprache 5.1).

\section{Kraft, Barbara}

Kraft, Barbara (1995): Beobachtungen zum Erwerb kooperationsorganisierender Sprechhandlungen bei drei- bis sechsjährigen Vorschulkindern. In: Wagner, Klaus R. (Hg.): Sprechhandlungserwerb. Essen. S. 38-63. (Kindersprache 10).

Kraft, Barbara (1995): Das Konzept der Sprechhandlung als Analysekategorie in entwicklungspragmatischen Untersuchungen. In: Ehlich, Konrad (Hg.): Kindliche Sprachentwicklung. Konzepte und Empirie. Opladen.

Kraft, Barbara/Vollhardt, Constanze (1995): Opposition und Widersprechen bei Fünfjährigen. In: Wagner, Klaus R. (Hg.): Sprechhandlungserwerb. Essen. S. 64-84. (Kindersprache 10).

Kraft, Barbara/Lanzen, Christina (1995): Zur Entwicklung des Widersprechens bei Vorschulkindern. Formen der Etablierung von Opposition. In: Der Deutschunterricht 47/1, S. 94-99.

\section{Liebert, Andreas}

Liebert, Andreas (1995): The Lexicon of Metaphor Models as a Mental Tool for Analogical Problem Solving in Science. In: Dirven, René/Vanparys, Johan ( $\mathrm{Hg}$.): Current Approaches to the Lexicon. Frankfurt a.M. u.a. S. 433-448.

Link, Elisabeth

Link, Elisabeth (1995): Rezension: „Sprich reines Deutsch!” Von einem Kapitel der Sprachpflege in Deutschland. In: Der Deutschunterricht 47 , S. 96-98.

\section{Meng, Katharina}

Meng, Katharina (1995): Bericht über „Sprachfähigkeiten, Sprachentwicklung und sprachliches Handeln bei Aussiedlern in Deutschland - empirische Zugänge", Workshop am Institut für deutsche Sprache (IDS) in Mannheim vom 27.9.-29.9.1994. In: Deutsch lernen 1, S. 68-78.

Meng, Katharina (und Autorenkollektiv) (1995): Gegen den Abbau von Sprachförderungsmaßnahmen für Aussiedler - Mannheimer Appell. In: Deutsch lernen 1, S. 78-81. 
Meng, Katharina (1995): Narrative Sozialisationen. In: Deutschunterricht 1, S. 100-107.

Meng, Katharina (1995): Sprachbiographien in einer rußlanddeutschen Aussiedlerfamilie. In: Deutsch lernen 1, S. 30-51.

\section{Mentrup, Wolfgang}

Mentrup, Wolfgang (Mitarbeit) (1995): Deutsche Rechtschreibung. Regeln und Wörterverzeichnis. Vorlage für die amtliche Regelung. Herausgegeben vom Internationalen Arbeitskreis für Orthographie. Tübingen. (Wörterverzeichnis: Erstellung der einspaltigen „Basisliste” A bis Z als Grundlage für die weitere Bearbeitung).

\section{Motsch, Wolfgang}

Motsch, Wolfgang (1995): Illokutionstypen, Implikaturen, sprachliche ÄuBerungen. In: Liedtke, F. (Hg.): Implikaturen: grammatische und pragmatische Analysen. Tübingen. S. 143-163.

Motsch, Wolfgang (1995): Rezension: M. Matussek, Wortneubildung im Text. In: Deutsch als Fremdsprache 3/32, S. 184-185.

Motsch, Wolfgang (1995): Semantische Grundlagen der Wortbildung. In: Harras, Gisela (Hg.): Die Ordnung der Wörter. Kognitive und lexikalische Strukturen. Berlin/New York. S. 193-226. (Jahrbuch 1993 des Instituts für deutsche Sprache).

Motsch, Wolfgang (1995): Semantische und pragmatische Aspekte der Wortbildung. In: Popp, H. (Hg.): Deutsch als Fremdsprache. An den Quellen eines Faches. Festschrift für G. Helbig zum 65. Geburtstag. München. S. 513-532.

Motsch, Wolfgang (1995): Wortbildungsfakten, Wortbildungstheorien. In: Agel, Vilmos/Brdar-Szabó, Rita (Hg.): Grammatik und deutsche Grammatiken. Tübingen, S. 61-67. (Linguistische Arbeiten 330 ).

\section{Neumann, Robert}

Neumann, Robert (1995): The Computerisation of the Language and Culture Atlas of Ashkenazic Jewry. In: LCAAJ Vol. 2. Tübingen. Neumann, Robert (1995): Korpora - Eine Herausforderung an die Informationserschließung. In: Feldweg, Helmut/Hinrichs, Erhard (Hg.): Lexikon und Text. S. 15-25. (Lexikographica Series Maior). Baviskar, Vera/Herzog, Marvin/Kiefer, Ulrike/Neumann, Robert/ Putschke, Wolfgang/ Sunshine Andrew/Weinreich, Uriel (1995): The Language and Culture Atlas of Ashkenazic Jewry (LCAAJ). Vol. 2, Research Tools. Tübingen. 


\section{Nortmeyer, Isolde}

Deutsches Fremdwörterbuch (1995): Begonnen von Hans Schulz, fortgeführt von Otto Basler, völlig neu bearbeitet im Institut für deutsche Sprache von Gerhard StrauB, Elke Donalies, Heidrun Kämper-Jensen, Isolde Nortmeyer, Joachim Schildt, Rosemarie Schnerrer, Oda Vietze. Bd. I: a-Präfix - Antike. Berlin/New York. XVII, 52*, S. 615.

\section{Nothdurft, Werner}

Nothdurft, Werner (1995): Environmental Mediation. Some insights and outlooks for political implications. In: Renn, $O$. et al. (Hg.): Fairness and Competence in Citizen Participation. Amsterdam/Boston.

Nothdurft, Werner (1995): Gesprächsanalyse von Schlichtung. Die Geschichte eines Forschungsprojekts und die Entwicklung seiner Ergebnisse. In: Nothdurft, Werner (Hg.): Schlichtung. Bd. 1. Streit schlichten. Gesprächsanalytische Untersuchungen zu institutionellen Formen konsensueller Konfliktbearbeitung. Berlin/New York. S. 1-26. (Schriften des Instituts für deutsche Sprache 5.1).

Nothdurft, Werner (Hg.) (1995): Schlichtung. Bd. 1. Streit schlichten. Gesprächsanalytische Untersuchungen zu institutionellen Formen konsensueller Konfliktbearbeitung. Berlin/New York. (Schriften des Instituts für deutsche Sprache 5.1).

Nothdurft, Werner (1995): ... und wie is es mit kulanz? Schlichtung in einer Schiedsstelle für den Gebrauchtwagenhandel. In: Nothdurft, Werner (Hg.): Schlichtung. Bd. 1. Streit schlichten. Gesprächsanalytische Untersuchungen zu institutionellen Formen konsensueller Konfliktbearbeitung. Berlin/New York. S. 364-421. (Schriften des Instituts für deutsche Sprache 5.1).

\section{Pasch, Renate}

Pasch, Renate (1995): Implikaturen im Bereich lexikalisch induzierter Präsuppositionen. In: Liedtke, Frank (Hg.): Implikaturen: Grammatische und pragmatische Analysen. Tübingen. S. 75-85. (Linguistische Arbeiten 343).

\section{Reitemeier, Ulrich}

Reitemeyer, Ulrich (1995) (und Autorenkollektiv): Gegen den Abbau von Sprachfördermaßnahmen für Aussiedler - Mannheimer Appell. In:

Deutsch lernen 1, S. 78-81. 
Reitemeyer, Ulrich (1995): „Hat jeder zu wissen, wo die Heimat ist”. Einheimische im Gespräch mit Aussiedlern. In: Neues Leben. Die erste deutsch-russische Monatszeitschrift in Deutschland. 2/10, S. 15-17.

Reitemeyer, Ulrich (1995): Rezension: Barbara Dietz/Peter Hilkes: Integriert oder isoliert? Zur Situation rußlanddeutscher Aussiedler in der Bundesrepublik Deutschland. München 1994. In: Deutsch lernen 1/1995 (auch in: Sprachreport 3/95, S. 4).

Reitemeyer, Ulrich (1995): Der Streit mit dem Handwerker. Zur Mikrosoziologie der Güteverhandlung vor der Handwerkskammer. In: Nothdurft, Werner (Hg.): Schlichtung. Bd. 1. Streit schlichten. Gesprächsanalytische Untersuchungen zu institutionellen Formen konsensueller Konfliktbearbeitung. Berlin. S. 268-363. (Schriften des Instituts für deutsche Sprache 5.1).

\section{Schildt, Joachim}

Deutsches Fremdwörterbuch (1995): Begonnen von Hans Schulz, fortgeführt von Otto Basler, völlig neu bearbeitet im Institut für deutsche Sprache von Gerhard Strauß, Elke Donalies, Heidrun Kämper-Jensen, Isolde Nortmeyer, Joachim Schildt, Rosemarie Schnerrer, Oda Vietze. Bd. I: a-Präfix - Antike. Berlin/New York. XVII, 52*, S. 615.

\section{Schmidt, Hartmut}

Schmidt, Hartmut (1995): Jacob Grimm über Akademie und Universität. Ein Text aus dem Berliner Akademiearchiv. In: Reiher, Ruth/Friemel, Berthold (Hg.): Brüder Grimm Gedenken. Bd. 11. Stuttgart/Leipzig. S. 51-54.

Schmidt, Hartmut (1995): Karl Philipp Moritz über Sprache, Hochdeutsch, Berliner Umgangssprache und märkischen Dialekt. In: Klingenberg, Anneliese/Fontius, Martin (Hg.): Karl Philipp Moritz und das 18. Jahrhundert. Internationale Fachtagung vom 23.25. September 1993 in Berlin. Tübingen. S. 61-73.

Schmidt, Hartmut (1995): Wörter im Kontakt. Plädoyer für historische Kollokationsuntersuchungen. In: Gardt, Andreas/Mattheier, Klaus J./Reichmann, Oskar (Hg.): Sprachgeschichte des Neuhochdeutschen. Gegenstände, Methoden, Theorien. Tübingen. S. 127143 (Reihe Germanistische Linguistik 156). 


\section{Schmitt, Reinhold}

Keim, Inken/Schmitt, Reinhold (1995): Das Problem der subsumtionslogischen Konstitution von Interkulturalität. In: Czyzewski, Marek/Gülich, Elisabeth/Hausendorf, Heiko/Kastner, Mary (Hg.): Selbst- und Fremdbilder im Gespräch. Wiesbaden. S. 413-429.

\section{Schnerrer, Rosemarie}

Deutsches Fremdwörterbuch (1995): Begonnen von Hans Schulz, fortgeführt von Otto Basler, völlig neu bearbeitet im Institut für deutsche Sprache von Gerhard StrauB, Elke Donalies, Heidrun Kämper-Jensen, Isolde Nortmeyer, Joachim Schildt, Rosemarie Schnerrer, Oda Vietze. Bd. I: a-Präfix - Antike. Berlin/New York. XVII, 52*, $615 \mathrm{~S}$.

Schnerrer, Rosemarie (1995): Einige Vorüberlegungen zu den Anfängen der Wörter „kommunizieren”, „Kommunikation” im Deutschen. In: Lerchner, Gotthard/Schröder, Marianne/Fix, Ulla (Hg.) (1995): Chronologische, areale und situative Varietäten des Deutschen in der Sprachhistoriographie. Festschrift für Rudolf Große. Frankfurt a.M. S. 403-412. (Leipziger Arbeiten zur Sprach- und Kommunikationsgeschichte 2).

\section{Schröder, Peter}

Schröder, Peter (1995): Besser ein magerer Vergleich als ein fetter Prozeß. Zur Güteverhandlung im Arbeitsgericht. In: Nothdurft, Werner (Hg.): Schlichtung. Bd. 1. Streit schlichten. Gesprächsanalytische Untersuchungen zu institutionellen Formen konsensueller Konfliktbearbeitung. S. 134-267. (Schriften des Instituts für deutsche Sprache 5.1).

\section{Schütte, Wilfried}

Born, Joachim/Schütte, Wilfried: Eurotexte. Textarbeit in einer Institution der EG. Tübingen. (Studien zur deutschen Sprache 1).

\section{Schumacher, Helmut}

Schumacher, Helmut (1995): Kontrastive Valenzlexikographie. In: Popp, Heidrun (Hg.): Deutsch als Fremdsprache. An den Quellen eines Faches. Festschrift für Gerhard Helbig zum 65. Geburtstag. München. S. 287-315. 


\section{Schwitalla, Johannes}

Schwitalla, Johannes/Holly, Werner (1995): „Explosiv - Der heiße Stuhl". Zur Inszenierung von "Streitkultur" im kommerziellen Fernsehen. In: Müller-Doohm, Stefan/Neumann-Braun, Klaus (Hg.): Kulturinszenierungen. Frankfurt/Main. S. 59-88.

Schwitalla, Johannes (1995): Kommunikation in der Stadt. Teil 4. Kommunikative Stilistik zweier sozialer Welten in MannheimVogelstang. Berlin/New York. (Schriften des Instituts für deutsche Sprache 4.4).

Schwitalla, Johannes (1995): Namen in Gesprächen. In: Eichler, Ernst/ Hilty, Gerold/Löffler, Heinrich/Steger, Hugo/Zgusta, Ladislav (Hg.): Namenforschung. Ein internationales Handbuch zur Onomastik. Berlin/New York. S. 498-504.

Schwitalla, Johannes (1995): Die narrative Struktur der ursprünglichen Josefserzählung. In: Schweizer, Harald (Hg.): Computerunterstützte Textinterpretation: Die Josefsgeschichte beschrieben und interpretiert im Dreischritt: Syntax - Semantik - Pragmatik. Tübingen/Basel. S. 240-283.

Schwitalla, Johannes (1995): Vogelstang. In: Kallmeyer, Werner (Hg.): Kommunikation in der Stadt. Teil 2. Ethnographien von Mannheimer Stadtteilen. Berlin/New York. S. 189-343. (Schriften des Instituts für deutsche Sprache 4.2).

Schwitalla, Johannes (1995): Vom Sektenprediger - zum Plauderton. Beobachtungen zur Prosodie von Politikreden vor und nach 1945. In: Löffler, Heinrich/Jakob, Karlheinz/Kelle, Bernhard (Hg.): Texttyp, Sprechergruppe, Kommunikationsbereich. Studien zur deutschen Sprache in Geschichte und Gegenwart. Festschrift für Hugo Steger zum 65. Geburtstag. Berlin/New York. S. 208-224.

\section{Spiegel, Carmen}

Spiegel, Carmen (1995): Streit. Eine linguistische Untersuchung verbaler Interaktionen in alltäglichen Zusammenhängen. Tübingen. (Forschungsberichte des Instituts für deutsche Sprache 75).

Stickel, Gerhard

Stickel, Gerhard (Hg.) (1995): Stilfragen. Berlin/New York. (Jahrbuch 1994 des Instituts für deutsche Sprache). 
Storrer, Angelika

Storrer, Angelika/Schwall, Ulrike (1995): Description and Acquisition of Multiword Lexemes. In: Steffens, P. (Hg.): Machine Translation and the Lexicon. Third International EAMT Workshop, Heidelberg, Germany, 26.-28.04.1993. Proceedings. Berlin/Heidelberg. S. 35-50.

Storrer, Angelika (1995): Wörterbücher zum Anklicken - Ein kleiner Rundgang durch die PC-Bibliothek. In: Sprachreport 2/95, S. 910.

\section{StrauB, Gerhard}

Deutsches Fremdwörterbuch (1995): Begonnen von Hans Schulz, fortgeführt von Otto Basler, völlig neu bearbeitet im Institut für deutsche Sprache von Gerhard StrauB, Elke Donalies, Heidrun Kämper-Jensen, Isolde Nortmeyer, Joachim Schildt, Rosemarie Schnerrer, Oda Vietze. Bd. I: a-Präfix - Antike. Berlin/New York. XVII, 52*, $615 \mathrm{~S}$.

\section{Strecker, Bruno}

Strecker, Bruno (1995): Sprachliches Handeln, Grammatik und Lexikon. In: Der Deutschunterricht 47, S. 14-22.

\section{Teubert, Eva}

Teubert, Eva (1995): Die Bibliothek des Instituts für deutsche Sprache (Juli 1995). In: Sprachreport 3/95, S. 5-6.

\section{Teubert, Wolfgang}

Teubert, Wolfgang (1995): Vorwort. In: Born, Joachim/Schütte, Wilfried: Eurotexte. Textarbeit in einer Institution der EG. Tübingen. S. 11-15 (Studien zur deutschen Sprache 1).

\section{Trabold, Annette}

Trabold, Annette (1995): Das Handbuch zur „Förderung der sprachlichen Kultur in der Bundesrepublik Deutschland". Bericht und Ausblick. In: Scharnhorst, Jürgen (Hg.): Sprachsituation und Sprachkultur im internationalen Vergleich. Aktuelle Sprachprobleme in Europa. Frankfurt a.M. S. 197-206.

Trabold, Annette (1995): Rechtschreibung und mehr. Das Institut für deutsche Sprache, Mannheim. In: Journal Blaue Liste 2/95, S. 4-5. 


\section{Vietze, Oda}

Deutsches Fremdwörterbuch (1995): Begonnen von Hans Schulz, fortgeführt von Otto Basler, völlig neu bearbeitet im Institut für deutsche Sprache von Gerhard StrauB, Elke Donalies, Heidrun Kämper-Jensen, Isolde Nortmeyer, Joachim Schildt, Rosemarie Schnerrer, Oda Vietze. Bd. I: a-Präfix - Antike. Berlin/New York. XVII, 52*, S. 615.

\section{Wimmer, Rainer}

Wimmer, Rainer (1995): Eigennamen im Rahmen einer allgemeinen Sprach- und Zeichentheorie. In: Eichler, Ernst/Hilty, Gerold/Löffler, Heinrich/Steger, Hugo/Zgusta, Ladislav (Hg.): Namenforschung. Ein internationales Handbuch zur Onomastik. Berlin/New York. 1. Teilband, S. 372-379.

\section{Winkler, Edeltraud}

Winkler, Edeltraud (1995): Die Darstellbarkeit lexikalischen Wissens am Beispiel kommunikativer Ausdrücke des Deutschen. In: Harras, Gisela (Hg.): Die Ordnung der Wörter. Kognitive und lexikalische Strukturen. Berlin/New York. S. 328-354. (Jahrbuch 1993 des Instituts für deutsche Sprache).

Wolf, Ricarda

Wolf, Ricarda (1995): Interaktive Fallen auf dem Weg zum vorurteilsfreien Dialog. Ein deutsch-deutscher Versuch. In: Czyzewski, Marek/Gülich, Elisabeth/Hausendorf, Heiko/Kastner, Maria (Hg.): Nationale Selbst- und Fremdbilder im Gespräch. Kommunikative Prozesse nach der Wiedervereinigung Deutschlands und dem Systemwandel in Ostmitteleuropa. Opladen. S. 203-231.

Wolf, Ricarda: Selbstverortung und Ost-Ost-Kontrolle: Zwei strukturelle Paradoxien im Ost-West-Diskurs. In: Sahner, Heinz/Schwendtner, Stefan (Hg.): Gesellschaften im Umbruch. Beiträge zum 27. KongreB der Deutschen Gesellschaft für Soziologie. Band II. Opladen. S. 530-534.

\section{Zifonun, Gisela}

Zifonun, Gisela (1995): Beitrag zur Podiumsdiskussion: Grammatik ja, aber meine. In: Agel, Vilmos/Brdar-Szabó, Rita (Hg.): Grammatik und deutsche Grammatiken. Budapester Grammatiktagung 1993. Tübingen. S. 253-260 (Linguistische Arbeiten 330). 
Zifonun, Gisela (1995): Der meiste Mensch ist die Frau. Sprachglosse. In: Sprachreport 3/95, S. 7 .

Zifonun, Gisela (1995): Minimalia grammaticalia: Das nicht-phorische es als Prüfstein grammatischer Theoriebildung. In: Deutsche Sprache 23, S. 39-60.

5. Kontakte des IDS zu anderen Institutionen, Studienaufenthalte und Besuche in- und ausländischer Wissenschaftler am IDS, Besuchergruppen

\subsection{Kontakte $z u$ anderen Institutionen}

- Alexander-von-Humboldt-Stiftung, Bonn

- Arbeitskreis der Sprachzentren, Sprachlehrinstitute und Fremdspracheninstitute

- Arbeitskreis für siebenbürgische Landeskunde, Gundelsheim

- Arbeitsstelle Deutsches Wörterbuch, Berlin

- Arbeitsstelle Deutsches Wörterbuch, Göttingen

- Arbeitsstelle „Sprache in Südwestdeutschland”, Tübingen

- DANTE. Deutschsprachige Anwendervereinigung TEX e.V., Heidelberg

- Deutsche Forschungsgemeinschaft (DFG), Bonn

- Deutsche Gesellschaft für Sprachwissenschaft (DGfS)

- Deutsche Gesellschaft für Dokumentation (DGD), Frankfurt a.M.

- Deutscher Akademischer Austauschdienst (DAAD), Bonn

- Deutscher Germanistenverband

- Deutscher Sprachatlas, Marburg

- DIN-NormenausschuB Terminologie, Berlin

- Dudenredaktion des Bibliographischen Instituts, Mannheim

- EURALEX, European Association for Lexicography, Exeter

- Fachverband Deutsch als Fremdsprache

- Fachverband Moderne Fremdsprachen

- Fremdsprachenhochschule Tianjin, VR China

- Fritz-Thyssen-Stiftung, Köln

- GLDV, Verein zur Förderung der wissenschaftlichen Datenverarbeitung e.V., Frankfurt

- Geisteswissenschaftliches Zentrum, Allgemeine Sprachwissenschaft, Berlin; früher: Forschungsschwerpunkt Allgemeine Sprachwissenschaft, Typologie und Universalienforschung der Förderungsgesellschaft Wissenschaftliche Neuvorhaben mbH, Berlin

- Gesellschaft für angewandte Linguistik e.V. (GAL)

- Gesellschaft für deutsche Sprache (GfdS), Wiesbaden

- Gesellschaft für Mathematik und Datenverarbeitung mbH, Bonn 
- Goethe-Institut, München

- Hugo-Moser-Stiftung im Stifterverband für die Deutsche Wissenschaft, Essen

- Institut für Auslandsbeziehungen, Stuttgart

- Inter Nationes, Bonn

- International Association of Sound Archives (IASA)

- Institut für niederdeutsche Sprache (INS), Bremen

- Laboratoire d'Automatique Documentaire et Linguistique (LADL), Paris

- Max-Planck-Institut für Psycholinguistik, Nimwegen

- Österreichische Akademie der Wissenschaften, Wien

- Robert-Bosch-Stiftung, Stuttgart

- Russische Akademie der Wissenschaften, Institut für russische Sprache, Moskau

- Stiftung Volkswagenwerk, Hannover

- Universitäten Mannheim und Heidelberg sowie zahlreiche weitere germanistische Institute an Universitäten und Hochschulen im Inund Ausland

- Verein zur Förderung sprachwissenschaftlicher Studien, Berlin

- Wissenschaftsgemeinschaft Blaue Liste (WBL)

5.2 Studienaufenthalte und Besuche in- und ausländischer Wissenschaftler am IDS

Prof. Dr. Werner Abraham, Universität Groningen, Niederlande, 13.17.3.1995 (IDS)

Anne Arold, Universität Tartu, Estland, 14.11.-14.12.1995

Prof. John Ole Askedal, Universität Oslo, Norwegen, 13.-17.3.1995(IDS)

Prof. Dr. Peter Bassola, József-Attila-Universität, Szeged, Ungarn 22.28.5.1995 (DAAD)

Dr. Csilla Bernáth, József-Attila-Universität, Lehrstuhl für Germanistische Linguistik, Szeged, Ungarn 23.-27.1.1995 und 24.10.4.11.1995 (DAAD)

Dr. Indu Bhave, Banares Hindu University, Varanasi, Indien, 15.5.15.8.1995 (DAAD)

Dr. Maria Teresa Bianco, Instituto Universitario Orientale, Neapel, Italien, 8.-29.8.1995 (Heimatuniversität)

Dr. Evelyn Breiteneder, Österreichische Akademie der Wissenschaften, Wien, Österreich 20.-28.9.1995

Arkadiusz Brycht, Universität Lódz, Polen, 13.-17.3.1995 (Robert Bosch Stiftung)

Prof. Dr. Bernard Comrie, Universität Los Angeles, USA, 13.-17.3.1995 (IDS) 
Prof. Jenny Cook-Gumperz, Santa Barbara, USA 12.-16.12.1995

Tomasz Czarnecki, Uniwersytet Gdanski, Polen, 4.-9.9.1995

Prof. Dr. Jan Czochralski, Warschau, Polen, 13.-17.3.1995 (Robert Bosch Stiftung)

Dr. Marek Czyzewski, Universität Lódz, Polen, 19.-26.2.1995 (IDS)

Prof. Dr. Östen Dahl, 13.-17.3.1995 (IDS)

Prof. Dr. Antoni Debski, Universität Krakau, Polen, 13.-17.3.1995 (Robert Bosch Stiftung)

Marina Denissowa, Samara, Rußland, 1.10.1995-31.7.1996

Prof. Dr. Valentin Devkin, Staatl. Pädagogische Universität Moskau, RuBland, 3.-17.11.1995

Dr. Ljubima Jordanova Dimitrova, Bulgarische Akademie der Wissenschaften, Sofia, Bulgarien, 1.7.-31.8.1995

Prof. Dr. Jovan Djukanovic, Germanistisches Institut der Universität Belgrad, Jugoslawien, 1.10.-15.12.1995

Prof. Dr. Csaba Földes, Pädagogische Hochschule „Gyula Juhasz”, Szeged, Ungarn, 3.9.1995-31.7.1996

Prof. Dr. Alicja Gaca, Universität Posen, Polen, 13.-17.3.1995 (Robert Bosch Stiftung)

Dr. Ewa Geller, Universität Warschau, Polen, 13.-17.3.1995 (IDS)

Yrd. Doc. Dr. Mehmet Gündogdu, C.Ü. Egitim Fakültesi Balcali/Adana, Türkei, 1.7.-31.8.1995 (DAAD)

Prof. John Gumperz, Santa Barbara, USA, 2.-16.12.1995

Piklu Gautam Gupta, University of Manchester, GroBbritannien, 9.20.1.1995 (British Council)

Prof. Rainer Hamel, Mexico, 27.11.-15.12.1995

Prof. Dr. Marja Järventausta, Universität Joensuu, Institut für interkulturelle Kommunikation in Savonlinna, Finnland, 14.-21.8.1995

Dr. Alina Jurasz, Universität Breslau, Polen, 13.-17.3.1995 (Robert Bosch Stiftung)

Aino Kärnä, Germanistisches Institut der Universität Helsinki, Schweden, 12.-20.2.1995

Dr. Andrzej Katny, Rzeszow, Polen, 13.-17.3.1995 (Robert Bosch Stiftung)

Gabriella Kiss, Kossuth Lajos Universität, Debrecen, Ungarn, 10.14.7.1995

Doz. Dr. Gerhard Konnerth, Universität Hermannstadt, Sibiu, Rumänien, 1.7.-31.8.1995 (KAAD)

Prof. Elena S. Kubrjakowa, Institut für Sprachwissenschaft, Russische Akademie der Wissenschaften, Moskau, RuBland, 15.9.-15.10.1995

Dr. Sarolta László, Loránd-Eötvös-Universität, Germanistisches Seminar, Budapest, Ungarn, 23.-27.1.1995 
Dr. Ole Letnes, Høgskolen i Agder, Institutt for Fremmedsprak, Kristiansand, Norwegen 4.-15.12.1995

Prof. Dr. Kwang-Sook Lie, Seoul National University, German Department, Korea, 1.7.-31.8.1995 (DAAD)

Sara Lines, Aston University, Department of Languages and European Studies, Birmingham, Großbritannien, 3.-31.7.95

Prof. Hongshen Liu, Universität Nanjing, Seminar für Germanistik, China, 12.-20.6.1995 (DAAD)

Dr. Pawel Mecner, Bedzin, Polen, 13.-17.3.1995 (Robert Bosch Stiftung)

Martina Möllering, Institut für Migrationsforschung, Ausländerpädagogik und Zweitsprachendidaktik, Essen, 27.2.-8.3.1995 (IDS)

Dr. Lorelies Ortner, Universität Innsbruck, Institut für Germanistik, Österreich, 17.-21.7.1995 (IDS)

Aicha Ouaret, Algier, Algerien, 2.7.-2.9.1995 (DAAD)

Dr. Andrzej Piotrowski, Universität Lódz, Polen, 19.-26.2.1995 (IDS)

Prof. Dr. Krystyna Pisarkowa, Krakau, Polen, 13.-17.3.1995 (Robert Bosch Stiftung)

Prof. Dr. Christer Platzack, Universität Lund, Schweden, 13.-17.3.1995 (IDS)

Carmen Pop, Cluj-Napoca, Rumänien, 1.11.1994-31.7.1995

Dr. Izabela Prokop, Universität Posen, Polen, 13.-17.3.1995 (Robert Bosch Stiftung)

Dr. Ekaterina Protassova, Helsinki, Finnland und Moskau, Rußland 1.10.-15.11.1995 (DFG)

Prof. Dr. Inger Rosengren, Lund, Schweden 18.10.-15.12.1995

Prof. Dr. Danuta Rytel-Kuc, Warschau, Polen 13.-17.3.1995 (Robert Bosch Stiftung)

Prof. Dr. Roman Sadzinski, Universität Lódz, Polen, 13.-17.3.1995 (Robert Bosch Stiftung)

Prof. Dr. Christoph Schatte, Sosnowiec, Polen, 13.-17.3.1995 (Robert Bosch Stiftung)

Prof. Dr. Czeslawa Schatte, Sosnowiec, Polen, 13.-17.3.1995 (Robert Bosch Stiftung)

Dr. Margret Selting, Universität Potsdam, Institut für Germanistik, 6.10.2.1995 (IDS)

Prof. Dr. Pawan Surana, University of Rajasthan, Jaipur, Indien, 7.6.9/1995 (DAAD)

Dr. Elzbieta Szwejkowska-Olsson, Stockholms Universitet, Schweden, 15.5.-14.7.1995 (DAAD)

Dr. Magda Tamássy-Biró, Loránd-Eötvös-Universität Budapest, Germanistisches Seminar, Ungarn 27.3.-1.4.1995 und 8.-17.11.1995 
Marja-Liisa Tommola, Universität Vaasa, Institut für deutsche Sprache und Literatur, Finnland, 15.9.-14.11.1995

Prof. Dr. Vural Ülkü, Universität Mersin, Türkei, 13.-17.3.1995 (Humboldt-Stiftung)

Mário Eduardo Viaro, Sao Paulo, Brasilien, 1.7.-31.12.1995 (DAAD)

Prof. Zhiyou Wang, Beijing, China

Hu Weishan, Nankai-Universität, Tianjin, China, 3.11.1995-3.4.96

Prof. Dr. Jozef Wiktorowicz, Universität Warschau, Polen, 13.-17.3.1995 (Humboldt-Stiftung)

Yoshihisa Yamada, Gifu Keizai University, Ogaki Gifu, Japan, 19.6.199531.3.1996

Prof. Zhang Shiguang, Fremdsprachenhochschule Xi'an, China, 20.9.31.12.1995

Prof. Feng Zhinei, Institute of Applied Linguistics, State Language Commission, Beijing, China, 11.-17.9.1995

\subsection{Besuchergruppen}

Im Jahr 1995 waren 14 Besuchergruppen - zusammen rund 270 Personen - Gäste im IDS (die Gastwissenschaftlerinnen und Gastwissenschaftler nicht mitgezählt). Viele Gruppen kamen aus Rußland, es gab jeweils eine Gruppe aus Brasilien und Bulgarien und eine gemischte Gruppe aus Südamerika. Zu Gast waren Deutschlehrerinnen aus 14 Nationen im Rahmen eines Kurses des Goethe-Instituts, die Mannheimer Wirtschafts"Senioren" (Kreis 58) sowie Deutsch-Fachberater und Deutschlehrerinnen der beruflichen Abteilung des Oberschulamtes Stuttgart. Darüber hinaus informierten sich in- und ausländische Germanistik-Studierende von deutschen Universitäten im Rahmen ihrer Seminare über die Arbeit des IDS. Die Besuchergruppen erwartet ein möglichst auf ihre Interessen und Forschungsschwerpunkte zugeschnittenes Programm, das von einer allgemeinen Einführung in die Arbeit des IDS und von einer Bibliotheksführung eingerahmt wird.

6. Gremien des Instituts fïr deutsche Sprache (Stand 1.12.1995)

\subsection{Kuratorium}

Vorsitzender: Prof. Dr. Friedhelm Debus, Universität Kiel Stellvertreter: Prof. Dr. Wolfgang Klein, Institut für Psycholinguistik, Nijmegen

Prof. Dr. Walther Dieckmann, Freie Universität Berlin - Prof. Dr. Hans-Werner Eroms, Universität Passau - Prof. Dr. Cathrine Fabricius- 
Hansen, Universität Oslo - Dr. Claudia Fraas, IDS Mannheim - Helmut Frosch, IDS Mannheim - Prof. Dr. Gerhard Helbig, Universität Leipzig - Dr. Wolfgang Klein, IDS Mannheim - Prof. Dr. Heinrich Löffler, Universität Basel - Lothar Mark als Vertreter der Stadt Mannheim LS Kantorczyk, Auswärtiges Amt Bonn - Dir. Peter Roschy, als Vertreter des Vereins der Freunde des Instituts für deutsche Sprache Mannheim - Prof. Dr. Barbara Sandig, Saarbrücken - Reg. Dir. Schrade, Ministerium für Wissenschaft und Forschung Baden-Württemberg, Stuttgart - OReg.Rätin Schwer, Ministerium für Wissenschaft und Forschung Baden-Württemberg, Stuttgart - Reg.Rätin Vera Stercken, als Vertreterin des Bundesministeriums für Bildung, Wissenschaft, Forschung und Technologie, Bonn - Prof. Dr. Peter Wiesinger, Universität Wien - Dr. Edeltraud Winkler, IDS Mannheim

\subsection{Direktion}

Prof. Dr. Gerhard Stickel (Vorstand) - Priv. Doz. Dr. Hartmut Günther (stellvertretender Direktor)

\subsection{Institutsrat}

Direktoren: Prof. Dr. Gerhard Stickel, Priv. Doz. Dr. Hartmut Günther - Abteilungsleiter: Prof. Dr. Reinhard Fiehler (Gesprochene Sprache) Prof. Dr. Gisela Harras (Lexikologie und Wortbildung) - Prof. Dr. Werner Kallmeyer (Verbale Interaktion) - Prof. Dr. Hartmut Schmidt (Historische Lexikologie und Lexikographie) - Dr. Wolfgang Teubert (Sprachentwicklung in der Gegenwart) - Prof. Dr. Gisela Zifonun (Grammatik, bis zum 1.8.) - Mitarbeitervertreter: Dr. Mechthild Elstermann - Prof. Dr. Dieter Herberg - Prof. Dr. Bruno Strecker - Wolfgang Rathke

\subsection{Wissenschaftlicher Rat}

Ehrenmitglieder

Prof. Dr. Johannes Erben, Bonn - Prof. Dr. Hans Glinz, Wädenswil Prof. Dr. Siegfried Grosse, Bochum - Prof. Dr. Peter von Polenz, Korlingen;

Ordentliche Mitglieder

Prof. Dr. Hans Altmann, München - Prof. Dr. Gerhard Augst, Siegen - Prof. Dr. Karl-Richard Bausch, Bochum - Prof. Dr. Anne Betten, Salzburg - Prof. Dr. Klaus Brinker, Hamburg - Prof. Dr. Karl-Dieter Bünting, Essen - Prof. Dr. Harald Burger, Zürich - Prof. Dr. Dieter Cherubim, Göttingen - Prof. Dr. Konrad Ehlich, München - Prof. Dr. 
Peter Eisenberg, Potsdam - Prof. Dr. Ulla Fix, Leipzig - Prof. Dr. Elisabeth Gülich, Bielefeld - Prof. Dr. Walter Haas, Freiburg/Schweiz Prof. Dr. Franz Josef Hausmann, Erlangen - Prof. Dr. Helmut Henne, Braunschweig - Prof. Dr. Hans Jürgen Heringer, Augsburg - Prof. Dr. Rudolf Hoberg, Darmstadt - Prof. Dr. Werner Hoffmann, Mannheim Prof. Dr. Werner Holly, Chemnitz - Prof. Dr. Ludwig Jäger, Aachen Prof. Dr. Rudi Keller, Düsseldorf - Prof. Dr. Dieter Krallmann, Essen - Prof. Dr. Gotthard Lerchner, Leipzig - Prof. Dr. Hans Moser, Innsbruck - Prof. Dr. Horst Haider Munske, Erlangen - Prof. Dr. Gerhard Nickel, Stuttgart - Prof. Dr. Uwe Pörksen, Freiburg - Prof. Dr. Rainer Rath, Saarbrücken - Prof. Dr. Oskar Reichmann, Heidelberg - Prof. Dr. Marga Reis, Tübingen - Prof. Dr. Gert Rickheit, Bielefeld - Prof. Dr. Lutz Röhrich, Freiburg - Prof. Dr. Horst Sitta, Herrliberg - Prof. Dr. Helmut Schnelle, Bochum - Prof. Dr. Stefan Sonderegger, Uetikon Prof. Dr. Hugo Steger, Freiburg - Prof. Dr. Dieter Stellmacher, Göttingen - Prof. Dr. Georg Stötzel, Düsseldorf - Prof. Dr. Erich Straßner, Tübingen - Prof. Dr. Heinz Vater, Köln - Prof. Dr. Hans Wellmann, Augsburg - Prof. Dr. Otmar Werner, Freiburg - Prof. Dr. Sigurd Wichter, Münster - Prof. Dr. Herbert Ernst Wiegand, Heidelberg - Prof. Dr. Norbert Richard Wolf, Würzburg - Prof. Dr. Dieter Wunderlich, Düsseldorf

Korrespondierende Mitglieder in Europa

Prof. Dr. Werner Abraham, Groningen, Niederlande - Prof. Dr. Pierre Bange, Lyon, Frankreich - Prof. Dr. Daniel Bresson, Aix-en-Provence, Frankreich - Prof. Dr. Andrzej Z. Bzdega, Posen, Polen - Prof. Dr. Jovan Djukanović, Belgrad, Jugoslawien - Prof. Dr. Martin Durrell, Manchester, Großbritannien - Prof. Dr. Gertrud Gréciano, Straßburg, Frankreich - Prof. Dr. Franciszek Grucza, Warschau, Polen - Prof. Dr. Regina Hessky, Budapest, Ungarn - Prof. Dr. Fernand Hoffmann, Luxemburg Prof. Dr. William Jones, London, Großbritannien - Prof. Dr. Gottfried Kolde, Genf, Schweiz - Prof. Dr. Jarmo Korhonen, Helsinki, Finnland - Prof. Dr. Oddleif Leirbukt, Troms $\varnothing$, Norwegen - Prof. Dr. Jacques Lerot, Louvain-la-Neuve, Belgien - Prof. Dr. Zdeněk Massařik, Brünn, Tschechische Republik - Prof. Dr. Norbert Morciniec, Breslau, Polen - Prof. Dr. Henrik Nikula, Vaasa, Finnland - Prof. Dr. Kurt Nyholm, Abo, Finnland - Prof. Dr. Pavel Petkov, Sofia, Bulgarien - Prof. Dr. Inger Rosengren, Lund, Schweden - Prof. Dr. Carlo Serra-Borneto, Rom, Italien - Prof. Dr. Emil Skála, Prag, Tschechische Republik - Prof. Dr. Anthony William Stanforth, Edinburg, Großbritannien - Prof. Dr. Vural Ülkü, Mersin, Türkei - Prof. Dr. Paul Valentin, Paris, Frankreich - Prof. Dr. R.A. Wisbey, London, Großbritannien - Prof. Dr. Jean-Marie Zemb, 
Paris, Frankreich - Prof. Dr. Stanislav Žepić, Zagreb, Kroatien - Prof. Dr. Zoran Žiletić, Belgrad, Jugoslawien

Korrespondierende Mitglieder in Übersee

Prof. Dr. Elmer H. Antonsen, Urbana, Ill., USA - Prof. Dr. Michael Clyne, Clayton, Victoria, Australien - Prof. Dr. F. van Coetsem, Ithaca, N.Y., USA - Prof. Dr. Jürgen Eichhoff, University Park, Pennsylvania, USA - Prof. Tozo Hayakawa, Tokyo, Japan - Prof. Dr. Robert D. King, Austin, Texas, USA - Prof. Dr. Alan Kirkness, Auckland, Neuseeland Prof. Dr. Byron J. Koekkoek, Buffalo, N.Y., USA - Prof. Dr. Herbert Kufner, Ithaca, N.Y., USA - Prof. Dr. Hans Kuhn, Canberra, Australien - Prof. Dr. Albert L. Lloyd, Philadelphia, Pennsylvania, USA - Prof. Dr. Stanley Starosta, Honolulu, Hawai

\subsection{Kommissionen}

Kommission für Rechtschreibfragen

Prof. Dr. Gerhard Augst, Siegen (Vorsitzender) - Prof. Dr. Dieter Nerius, Rostock (Stellvertr. Vorsitzender) - Prof. Dr. Günther Drosdowski, Mannheim - Prof. Dr. Peter Eisenberg, Berlin - Dr. Klaus Heller, IDS - Prof. Dr. Dieter Herberg, IDS - Prof. Dr. Manfred Kohrt, Bonn (bis zum 1.8.1995) - Prof. Dr. Horst Haider Munske, Erlangen - Prof. Dr. Burkhard Schaeder, Siegen - Prof. Dr. Eberhard Stock, Halle - Prof. Dr. Hermann Zabel, Dortmund

Kommission für Fragen der Sprachentwicklung

Prof. Dr. Werner Holly, Chemnitz-Zwickau (Vorsitzender) - Priv.Doz. Dr. Bernd Ulrich Biere, IDS (Stellvertr. Vorsitzender) - Prof. Dr. Dieter Cherubim, Göttingen - Prof. Dr. Walther Dieckmann, Berlin - Prof. Dr. Helmut Henne, Braunschweig - Prof. Dr. Rudolf Hoberg, Darmstadt - Prof. Dr. Heinrich Löfler, Basel - Ltd. Reg. Dir. a.D. Dr. Walter Otto, Würzburg - Prof. Dr. Barbara Sandig, Saarbrücken - Dr. Werner Scholze-Stubenrecht, Mannheim - Prof. Dr. Hugo Steger, Freiburg - Priv.Doz. Dr. Gisela Zifonun, IDS (bis zum 1.8.1995)

\subsection{Beiräte}

Beirat "Lexikon der Lehnwortbildung”

Prof. Dr. Johannes Erben, Bonn - Prof. Dr. Horst Haider Munske, Erlangen - Prof. Dr. Peter von Polenz, Korlingen 
Beirat „Deutsches Fremdwörterbuch”

Prof. Dr. Oskar Reichmann, Heidelberg - Prof. Dr. Michael Schlaefer, Göttingen - Dr. Heino Speer, Heidelberg

Beirat „Erklärende Synonymik”

Prof. Dr. Herbert Ernst Wiegand, Heidelberg - Prof. Dr. Peter Rolf Lutzeier, London - Prof. Dr. Georg Meggle, Leipzig

Beirat „Rhetorik”

Prof. Dr. Barbara Sandig, Saarbrücken (Vorsitzende) - Prof. Dr. Walter Dieckmann, Berlin - Prof. Dr. Carl Friedrich Graumann, Heidelberg Prof. Dr. Elisabeth Gülich, Bielefeld - Prof. Dr. Werner Holly, ChemnitzZwickau

\section{Besondere Nachrichten}

\subsection{Personalia}

- PD Dr. Hartmut Günther wurde zum 1.5.1995 auf vier Jahre zum stellvertretenden Direktor des IDS bestellt.

- Prof. Dr. Gisela Zifonun, langjährige Leiterin der Abteilung Grammatik, hat zum 1.8.1995 einen Ruf auf eine C-3 Professur an der FU Berlin angenommen.

- Die Arbeitsstelle Öffentlichkeitsarbeit und Dokumentation wird seit dem 1.4.1995 von Dr. Annette Trabold geleitet.

- Zum neuen Vorsitzenden des Kuratoriums (Aufsichtsgremium des IDS) wurde am 27.9.1995 Prof. Dr. Friedhelm Debus von der Universität Kiel gewählt. Er tritt die Nachfolge von Prof. Dr. Horst Sitta (Universität Zürich) an, der dem Kuratorium zwölf Jahre lang angehörte.

- Als neues Mitglied der Gruppe der externen Wissenschaftler im Kuratorium wurde Prof. Dr. Cathrine Fabricius-Hansen, Universität Oslo, am 27.9.1995 gewählt.

- Prof. Dr. Gerhard Stickel, Direktor des IDS, wurde bei der Versammlung der Institute der Blauen Liste am 30./31. März 1995 in Göttingen (da noch AG-BL) zum Sprecher der Sektion A (Geisteswissenschaften und Bildungsforschung) der Wissenschaftsgemeinschaft Blaue Liste (WBL) gewählt.

- Prof. Dr. Hartmut Schmidt, Leiter der Abteilung Historische Lexikologie und Lexikographie, wurde durch die Berlin-Brandenburgische Akademie der Wissenschaften nebenamtlich mit der Projektleitung der Berliner Arbeitsstelle des Deutschen Wörterbuchs und des Goethe-Wörterbuchs beauftragt. 
- Im Jahre 1995 sind verstorben: Prof. Dr. Mogens Dyhr, Kopenhagen - Prof. Dr. Manfred Höfler, Düsseldorf - Prof. Dr. Wladimir Admoni, RuBland - Prof. Dr. Kai Hyldgard-Jensen, Göteborg

\subsection{Vermischtes}

- Auf dem 2. Workshop zur sprachlichen Integration von Aussiedlern vom 3. bis 6.9.1995 in Frankfurt/Oder wurde beschlossen, den sogenannten „Mannheimer Appell - Gegen den Abbau von SprachförderungsmaBnahmen für Aussiedler" an verantwortliche politische $\mathrm{Or}$ ganisationen und Institutionen weiterzuleiten.

Dieser Appell war auf dem ersten vom IDS in Mannheim organisierten Workshop zur sprachlichen Integration von Aussiedlern auf den Weg gebracht worden. Er richtet sich u.a. gegen eine Verkürzung von Sprachkursen für Aussiedler von acht auf sechs Monate sowie gegen die Kürzung der Mittel für Integrationsmaßnahmen für Kinder und Jugendliche.

- Während eines Sommerkurses für deutsche Sprache und Landeskunde hielt sich vom 10.7. bis 10.8 .1995 eine Gruppe von Germanistik-Studenten der University of Florida, Gainesville/Fl. am IDS auf. Zahlreiche IDS-Mitarbeiterinnen und Mitarbeiter waren mit Vorträgen am Programm beteiligt.

- Internationales Seminar zur deutschen Gegenwartssprache Vom 27.8. bis zum 9.9.1995 nahmen Deutschlehrer und Deutschlehrerinnen aus Belgien, Bulgarien, Georgien, GroBbritannien, Israel, Italien, Luxemburg, Makedonien, den Niederlanden, Schweden, der Slowakei, Spanien, der Tschechischen Republik, der Ukraine und Ungarn an einem Fortbildungsseminar des Goethe-Instituts in Mannheim teil. Das Seminar behandelte Tendenzen der deutschen Gegenwartssprache und war nicht zuletzt aus diesem Grunde zu Gast im Institut für deutsche Sprache.

Auch das Seminarprogramm wurde in enger Zusammenarbeit mit dem Institut für deutsche Sprache entwickelt: für die Dauer von 2 Wochen lernten die Teilnehmer und Teilnehmerinnen u.a. konkrete Aufgaben und laufende Projekte des Instituts für deutsche Sprache kennen.

Neben den zahlreichen Vorträgen und Diskussionen recherchierten die Teilnehmer und Teilnehmerinnen auch selbst ausgewählte Aspekte der deutschen Gegenwartsprache und frischten in Gesprächen mit Fachleuten ihre Sprachkenntnisse auf.

Während eines Hospitationstags am Mannheimer Goethe-Institut und am Geschwister-Scholl-Gymnasium in Ludwigshafen gewannen 
die ausländischen Linguisten, Ausbilder von Deutschlehrerstudenten und Sekundarschullehrer auch Einblicke, wie in Deutschland unterrichtet wird.

Ergänzt wurde der Seminarplan durch ein kulturelles Rahmenprogramm, das die ausländischen Gäste mit Mannheim und seiner Umgebung vertraut machen sollte.

- In einer Arbeitsgruppe unter Leitung von Prof. Dr. Werner Kallmeyer wurde das Sprachverhalten von Bewohnergruppen in mehreren Mannheimer Stadtteilen zehn Jahre lang untersucht. Dieses umfangreiche sprachwissenschaftliche IDS-Projekt „Kommunikation in der Stadt" wurde mit Erscheinen des letzten Ergebnisbandes abgeschlossen. Da Mannheim nicht nur Ort, sondern auch Ziel und Gegenstand der Forschung gewesen war, wurde das vierbändige Werk, das beim Verlag de Gruyter erschienen ist, im Dezember in einer kleinen Feierstunde im IDS Herrn Oberbürgermeister Widder überreicht. Mannheim dürfte so wohl zu den von Sprachwissenschaftlern am besten erforschten Städten zählen.

\section{Personalstärke, Anschriften, finanzielle Angaben}

\subsection{Personalstärke (Stand: 1 12.1995)}

Mitarbeiter (einschl. Teilzeit- und Projektmitarbeiter):

wissenschaftliche Angestellte

(davon beurlaubt: 2)

Verwaltungs-/technische Angestellte

Projekt-Mitarbeiter

Doktoranden 3

Studentische Hilfskräfte

\subsection{Anschrift}

Institut für deutsche Sprache

Postanschrift:

R5, 6-13

Postfach 101621

D-68161 Mannheim

D-68016 Mannheim

Telefon (0621) 1581-0

Telefax (0621) 1581-200

e-mail: vorstand@ids-mannheim.de 


\subsection{Haushalt des Instituts im Berichtsjahr}

Einnahmen:

Ministerium für Wissenschaft und Forschung Baden-Württemberg

DM 6.653.000,-

Bundesministerium für Forschung

und Technologie

Stadt Mannheim

DM 6.653.000,-

eigene Einnahmen

DM 12.000,-

DM 131.000,-

DM 13.449.000,-

Ausgaben:

Personalausgaben

DM 10.749.000,-

Sachausgaben

DM 2.608.000,-

Zuwendungen, Zuschüsse

DM $\quad 6.000$,-

Investitionen

DM 86.000 ,-

DM 13.449.000,-

Projektmittel:

Deutsche Forschungsgemeinschaft

(DFG), Bonn

Projekt "Rußlanddeutsch"

Personalmittel

Sachmittel

\begin{tabular}{lr} 
DM & $108.600,-$ \\
DM & $2.800,-$ \\
\hline DM & $111.400,-$
\end{tabular}

Deutsche Forschungsgemeinschaft

(DFG), Bonn

Projekt „Wissenschaftlicher Austausch

mit RuBland"

Personalmittel

\begin{tabular}{lr} 
DM & $10.500,-$ \\
DM & $4.000,-$ \\
\hline DM & $14.500,-$
\end{tabular}

Sachmittel 
Projekt "Initiative Reaktionen" (SFB 245)

Personalmittel

\begin{tabular}{lr} 
DM & $113.600,-$ \\
DM & $2.100,-$ \\
\hline DM & $115.700,-$
\end{tabular}

Projekt „Bedeutungskonstitution” (SFB 245)

Personalmittel

\begin{tabular}{lr} 
DM & $113.600,-$ \\
DM & $800,-$ \\
\hline DM & $114.400,-$
\end{tabular}

Projekt "Orthographie, bis 1901" Personalmittel

\begin{tabular}{ll} 
DM & $35.900,-$ \\
\hline DM & $35.900,-$
\end{tabular}

Stiftung Volkswagenwerk "Deutsch-Zentrum Tianjin/China" Personalmittel

\begin{tabular}{ll} 
DM & $18.300,-$ \\
\hline DM & $18.300,-$
\end{tabular}

Kommission der EG

Projekt „Multilingual Environment for Corpus-Based Lexicon Building" Personalmittel

\begin{tabular}{lr} 
DM & $\begin{array}{r}103.900,- \\
19.400,-\end{array}$ \\
DM & \\
\hline DM & $123.300,-$
\end{tabular}

Projekt „Environmental Innovation” Personalmittel

\begin{tabular}{lr} 
DM & $59.300,-$ \\
DM & $45.000,-$ \\
\hline DM & $104.300,-$
\end{tabular}


Parole

Sachmittel

\begin{tabular}{ll}
$\mathrm{DM}$ & $47.300,-$ \\
\hline $\mathrm{DM}$ & $47.300,-$
\end{tabular}

\section{TELRI}

Personalmittel

\begin{tabular}{lr} 
DM & $60.000,-$ \\
DM & $129.500,-$ \\
\hline DM & $189.500,-$
\end{tabular}

\section{SERGES}

Personalmittel

\begin{tabular}{lr} 
DM & $\begin{array}{r}16.400,- \\
\text { DM }\end{array}$ \\
\hline DM & $22.300,-$ \\
\hline
\end{tabular}

Sachmittel

\begin{tabular}{lr} 
DM & $897.300,-$ \\
DM & $13.449 .000,-$ \\
\hline DM & $14.346 .300,-$
\end{tabular}

Summe der Projektmittel

Ordentlicher Haushalt

DM 14.346.300,-

\section{Veröffentlichungen im Jahre 1995}

\section{SCHRIFTEN DES INSTITUTS FÜR DEUTSCHE SPRACHE}

Verlag Walter de Gruyter, Berlin/New York

Band 4: Friedhelm Debus/Werner Kallmeyer/Gerhard Stickel (Hg.): Kommunikation in der Stadt

Teil 4.2: Werner Kallmeyer $(\mathrm{Hg}$.$) :$

Ethnographien von Mannheimer Stadtteilen. V/525 S.

Teil 4.3: Inken Keim:

Kommunikative Stilistik einer sozialen Welt "kleiner Leute" in der Mannheimer Innenstadt. X/536 S.

Teil 4.4: Johannes Schwitalla:

Kommunikative Stilistik zweier sozialer Welten in Mannheim-Vogelstang. XIII/558 S. 
Band 5: Werner Nothdurft/Gerhard Stickel (Hg.): Schlichtung

Teil 5.1: Werner Nothdurft (Hg.):

Streit schlichten - Gesprächsanalytische Untersuchungen zu institutionellen Formen konsensueller Konfliktregelung. $431 \mathrm{~S}$.

\section{JAHRBÜCHER DES INSTITUTS FÜR DEUTSCHE SPRACHE}

Verlag Walter de Gruyter, Berlin/New York

Redaktion: Franz Josef Berens

Gisela Harras (Hg.):

Die Ordnung der Wörter. Jahrbuch 1993 des Instituts für deutsche Sprache. $403 \mathrm{~S}$.

Gerhard Stickel (Hg.):

Stilfragen. Jahrbuch 1994 des Instituts für deutsche Sprache. V/455 S.

FORSCHUNGSBERICHTE DES INSTITUTS FÜR DEUTSCHE SPRACHE

Herausgegeben von Rainer Wimmer, Bruno Strecker und Gisela Zifonun Gunter Narr Verlag, Tübingen

Band 75: Carmen Spiegel: Streit. Eine linguistische Untersuchung verbaler Interaktionen in alltäglichen Zusammenhängen. $289 \mathrm{~S}$.

(Die Reihe wird hiermit abgeschlossen und durch die folgende Reihe ersetzt:)

\section{STUDIEN ZUR DEUTSCHEN SPRACHE}

Forschungen des Instituts für deutsche Sprache

Herausgegeben im Auftrag des Instituts für deutsche Sprache von Hartmut Günther, Bruno Strecker, Reinhard Fiehler

Gunter Narr Verlag, Tübingen

Band 1: Joachim Born/Wilfried Schütte: Eurotexte. Textarbeit in einer Institution der EG. $456 \mathrm{~S}$.

Band 2: Bernd Ulrich Biere/Rudolf Hoberg (Hg.): Bewertungskriterien für die Sprachberatung. $160 \mathrm{~S}$. 


\section{PHONAI}

Texte und Untersuchungen zum gesprochenen Deutsch

Herausgegeben von Walter Haas und Peter Wagener Max Niemeyer Verlag, Tübingen

Band 42: Anne Betten (Hg.): Sprachbewahrung nach der EmigrationDas Deutsch der 20er Jahre in Israel. Teil I:

Transkripte und Tondokumente. VIII/449 S./CD.

\section{DEUTSCHES FREMDWÖRTERBUCH}

Deutsches Fremdwörterbuch. Begonnen von Hans Schulz, fortgeführt von Otto Basler, völlig neu bearbeitet im Institut für deutsche Sprache von Gerhard Strauß/Elke Donalies/Heidrun Kämper-Jensen/Isolde Nortmeyer/Joachim Schildt/Rosemarie Schnerrer

Band 1: a-Präfix bis Antike. XVII, 52*, $615 \mathrm{~S}$.

\section{STUDIENBIBLIOGRAPHIEN SPRACHWISSENSCHAFT}

Im Auftrag des Instituts für deutsche Sprache hg. von Ludger Hoffmann (bis Bd. 9); Manfred W. Hellmann (ab Bd. 10)

Julius Groos Verlag, Heidelberg

Band 12: Markus Nussbaumer:

Argumentation und Argumentationstheorie. IV/44 S./

Diskette.

Band 13: Willy Sanders:

Stil und Stilistik. 52 S./ Diskette.

Band 14: Gerd Antons/Karl-Heinz Pogner:

Schreiben. 43 S./Diskette.

\section{DEUTSCHE SPRACHE}

Zeitschrift für Theorie, Praxis, Dokumentation

Im Auftrag des Instituts für deutsche Sprache hg. von Siegfried Grosse (Geschäftsführer), Hans Werner Eroms, Gisela Harras, Gerhard Stickel Erich Schmidt Verlag, Berlin

Redaktion: Franz Josef Berens

Jahrgang 1995: 4 Hefte 
SPRACHREPORT

Informationen und Meinungen zur deutschen Sprache

Hg. vom Institut für deutsche Sprache

Jahrgang 1995: 4 Hefte

VERÖFFENTLICHUNGEN IM EIGENVERLAG DES INSTITUTS

Katrin Freese (Bearb.):

Dokumentation zur germanistischen Sprachwissenschaft. Sprachwissenschaftliche Forschungsvorhaben 1993/94. Herausgegeben vom Institut für deutsche Sprache. $615 \mathrm{~S}$. 



\section{Anhang}

\section{Ansprache des Hugo-Moser-Preisträgers Helmuth Feilke (Siegen)}

Zu Beginn der Jahrestagung des IDS am 14. Mărz 1995 erhielt Herr Dr. Helmuth Feilke von der Universitāt Siegen den zweijährlich vergebenen Förderpreis der Hugo-Moser-Stiftung. Herr Feilke bedankte sich mit folgender Ansprache:

\section{Danksagung und Kurzvorstellung des Projektes „Schrift und Muster”}

Sehr geehrter Herr Präsident, sehr geehrte Damen und Herren,

Die Zuerkennung und Verleihung des Hugo-Moser-Preises ist für mich eine große Freude, und ich danke dem wissenschaftlichen Beirat der Hugo-Moser-Stiftung für die damit verbundene Anerkennung. In sehr großzügiger Weise haben Sie mich mit einer Auszeichnung bedacht, die ich mir eigentlich erst zu verdienen habe. Ausgezeichnet haben Sie den Entwurf für ein Projekt, für das eigentlich Arbeit zu tun bleibt. Für dieses Vertrauen in meine künftige Arbeit möchte ich Ihnen danken. Daran, daß man sich Ziele setzen und sie umsetzen kann, sind stets viele beteiligt. Wenn mit dem Projektentwurf heute auch die bisherige wissenschaftliche Arbeit ausgezeichnet wird, dann verdanke ich dies insbesondere der Zusammenarbeit mit Gerhard Augst in Siegen sowie seiner stets tatkräftigen und uneigennützigen Förderung meiner Arbeit. Auch dafür möchte ich mich an dieser Stelle bedanken.

Es ist üblich, und ich möchte die verbleibende kurze Zeit gerne nutzen, um noch etwas zu dem geplanten Forschungsprojekt selbst zu sagen. Thema in diesem Projekt sind Prozesse der Musterbildung in Schrift und Schreiben, die ich am Beispiel der Entwicklung von Schreibfähigkeiten untersuchen möchte. Musterbildung ist eine allgemeinsprachliche Erscheinung, von großer sprachtheoretischer, aber auch praktischer Bedeutung. Ich definiere das Muster als pragmatisch typisiertes, syntagmatisches Ausdrucksgefüge.

Auf die besondere Bedeutung des Musters weist schon Hugo Moser in seiner Rede zur Verleihung des Konrad Duden-Preises 1964 hin:

„Es gibt ein Empfinden für Sprachbrauch und Sprachnorm im Bereich der Schreibweise und der Lautung, der Satzschemata und der Wortstrukturen (...). Die Reaktion des Sprachempfindens beruht auf dem in der Regel unbewußten Wissen um sprachliche Muster (patterns). Man kann auch von ihm sagen es realisiere eine geistige Geltung, die innerhalb einer Sprachgemeinschaft am Werk ist." (Moser 1967, S. 42; Herv. H.F.). 
Worauf beruht diese geistige Geltung, von der Hugo Moser spricht? Sie beruht darauf, daß Muster im Unterschied zu Regeln und kleinsten Einheiten in der Sprache sehr komplexe Erwartungen zu organisieren vermögen. Es handelt sich um ausdruckseitig gebundene, sprachkulturell vermittelte, obligatorische Orientierungen eines sprachlichen "Common sense" (vgl. Feilke 1994). Wer z.B. ein 'einerseits' liest, der erwartet auch ein 'andererseits', wer ein 'zwar' liest, der erwartet aber ein 'aber', und wer eine Überschrift wie 'Schrift und Muster' liest, der erwartet einen expositorischen Text zu diesem Thema.

Wo Muster Brüche zeigen oder bewußt durchbrochen werden, wird die scheinbare Selbstverständlichkeit von Erwartungen problematisch. Wenn Bertold Brecht in der Mutter Courage schreibt: „Der Mensch denkt: Gott lenkt", durchbricht er bewuft durch seine Interpunktion die mit dem syntaktischen Parallelismus verbundene semantische Erwartungsstruktur. Brüche und Inkonsistenzen von Mustern sei es der Orthographie und Interpunktion, sei es der Syntax und Textstruktur markieren in umgekehrter Perspektive aber auch den Weg schreibenlernender Kinder in die Schrift. Sie zeigen, wie die Lerner in medialer Schriftlichkeit, langsam aber sicher fortschreitend, die musterbasierten Ordnungen konzeptioneller Schriftlichkeit konstruieren.

Dabei besteht das Spezifische des Schreibenlernens darin, daß die Lerner hier auf völlig veränderte Bedingungen der Kommunikation reagieren. Vergrößert wie in einem Brennglas, mit dem man den Umgang erst mühsam erlernen muß, nehmen Lerner beim Schreiben ihre eigene Sprachtätigkeit wahr. Sie konstruieren damit auch vom Schreiben her bestimmte Sprachstrukturen und einen von der Schreiberfahrung bestimmten Sprachbegriff. Im Unterschied zu Mustern des Sprechens, die sehr stark auf kommunikative Routinen bezogen sind, reflektieren Muster des Schreibens Prozesse sprach- und textorientierter Metakognitio nen. Ich möchte dies in je einer empirischen Studie für die Bereiche der Interpunktion, der Syntax und Formulierung und der Textstruktur untersuchen.

An die Seite, ja vielleicht sogar an die Stelle des sogenannten 'logischen Problems' des Spracherwerbs, der Diskrepanz von Kenntnis und Erfahrung, tritt bei der Schreibentwicklung in exemplarischer Weise das sogenannte 'Entwicklungsproblem' des Spracherwerbs (z.B. Bamberg/Budwig 1989), d.h., die Frage danach, warum dieser Prozeß Zeit braucht. Die Frage ist beim Schreiberwerb besonders brisant, weil hier die Entwicklung vordergründig homologer Strukturen der gesprochenen und geschriebenen Sprache um drei bis zu acht Jahren verzögert erfolgt. Entsprechend wird in der entwicklungspsychologischen Forschung bereits bei 
Piaget und Wygotski von einer sogenannten 'Verschiebung' gesprochen. Die Verschiebung ist ein ungelöstes Problem für die Theorie der sprachlichen Kompetenz. Daß und wie wir mit Sprache etwas tun, und daß dieses Tun seinerseits auf die sprachliche Kompetenz zurückwirkt und sie strukturiert, ist ein wichtiger Zeitfaktor. Er kommt aber etwa im Kontext rationalistischer Kompetenzbegriffe nicht in den Blick. Für Noam Chomsky z.B. sind Schrift und Schreiben nicht mehr als ein „Papier- und Bleistift-Verfahren" (Chomsky 1981, S. 222) zur Entlastung des Gedächtnisses. Das Entwicklungsprogramm erscheint hier, wenn überhaupt als bloßes Datenproblem für den 'Input'. David Barton dagegen kommt mit seiner Formulierung der Lösung des Entwicklungsproblems schon näher, wenn er formuliert: "Learning to write ist not just learning to bring units into awareness, it is also a case of learning the units of written language." (Barton 1985, S. 198/199).

Das Entwicklungsproblem ist damit unmittelbar gekoppelt an die Frage, warum die Lernenden für den Prozeß nachweisbar eben nicht bloB $\mathrm{Da}$ ten, sondern spezifische, aber durch das Medium bestimmte Kontexte eigenen Handelns brauchen. Der bloß scheinbar tautologische schreibdidaktische Erfahrungssatz 'Schreiben lernt man nur durch Schreiben' reflektiert in seiner Formulierung einer Rückwirkung der Praxis auf die Kompetenz eine sprachtheoretisch zentrale Dimension des Kompetenzbegriffs. Auch für die schriftsprachliche Kompetenz gilt deshalb Philipp Wegeners sprachtheoretischer Basissatz aus den 'Grundfragen des Sprachlebens' von 1885, wo er im Blick auf die Sprachkenntnis feststellt: „Mittel wird .. Alles das, dessen Wirkung wir an uns erfahren haben und eben nur das." (Wegener 1885, S. 71)

Die wichtigste Form der Vergegenständlichung dieses Strukturgewinns ist auch in der geschriebenen Sprache das Muster, sei es als orthographisches Muster, als syntaktisches Formulierungsmuster oder als textuelles Ordnungsmuster.

\section{Literatur}

Bamberg, Michael/Budwig, Nancy (1989): Entwicklungstheoretische Überlegungen zum Spracherwerb. In: Zeitschrift für Literaturwissenschaft und Linguistik 19, Heft 73, S. 33-52.

Barton, David (1985): Awareness of language units in children and adults. In: Ellis, A.W. (ed.): Progress in the Psychology of Language. Hillsdale N.J.: S. 187-205.

Chomsky, Noam (1981): Regeln und Reprāsentationen. Frankfurt a.M. 
Feilke, Helmuth (1994): Common sense-Kompetenz. Überlegungen zu einer Theorie des 'sympathischen' und 'natürlichen' Meinens und Verstehens. Frankfurt a.M.

Moser, H. (1967): Sprache - Freiheit oder Lenkung? Zum Verhältnis von Sprachnorm, Sprachwandel, Sprachpflege. Mannheim.

Wegener, Philipp (1885/1991): Untersuchungen über die Grundfragen des Sprachlebens. Amsterdam. 


\section{Jahrbücher des \\ Instituts für deutsche Sprache}

\section{Das 19. Jahrhundert}

Sprachgeschichtliche Wurzeln des heutigen Deutsch Herausgegeben von Rainer Wimmer

509 Seiten. Mit 7 Abbildungen. 1991. Broschur. ISBN 3110129604 (Jahrbuch 1990)

\section{Deutsche Syntax}

Ansichten und Aussichten

Herausgegeben von Ludger Hoffmann

VI, 613 Seiten. 1992. Broschur. ISBN 3110137062

(Jahrbuch 1991)

\section{Deutsch als Verkehrssprache in Europa} Herausgegeben von Joachim Born und Gerhard Stickel VI, 342 Seiten. 1993. Broschur. ISBN 3110140063 (Jahrbuch 1992)

\section{Die Ordnung der Wörter}

Kognitive und Iexikalische Strukturen

Herausgegeben von Gisela Harras

V, 403 Seiten. Mit 26 Abbildungen und 7 Tabellen. 1995.

Gebunden. ISBN 3110144387

(Jahrbuch 1993)

\section{Stilfragen}

Herausgegeben von Gerhard Stickel

V, 455 Seiten. Mit zahlreichen Abbildungen. 1995.

Gebunden. ISBN 3110147483

(Jahrbuch 1994) 


\section{Schlichtung}

Band 1: Streit schlichten Gesprächsanalytische Untersuchungen zu institutionellen Formen konsensueller Konfliktregelung

Herausgegeben von Werner Nothdurft

VIII, 431 Seiten. Mit 4 Abbildungen und 4 Tabellen. 1995 Ganzleinen ISBN 3110135086 (Schriften des Instituts für deutsche Sprache, Band 5.1)

Für wichtige Institutionen des Streit Schlichtens (Schiedsmann, Arbeitsgericht, Handwerkskammer, GebrauchtwagenSchlichtung) wird gezeigt, welche Schlichtungsmuster sich in ihnen herausbilden, welche Strategien die Beteiligten verfolgen und welche Kommunikationsprobleme bestehen.

\section{Walter de Gruyter $\cdot$ Berlin $\cdot$ New York}



